
Digitized by the Internet Archive in 2017 with funding from Getty Research Institute 




\title{
MITTEILUNGEN
}

\author{
AUS DEN
}

\section{Deutschen Schutzgebieten}

MIT BENUTZUNG AMTLICHER QUELLEN HERAUSGEGEBEN VON

\author{
D. FREIHERR VON DANCKELMAN
}

ZWANZIGSTER BAND

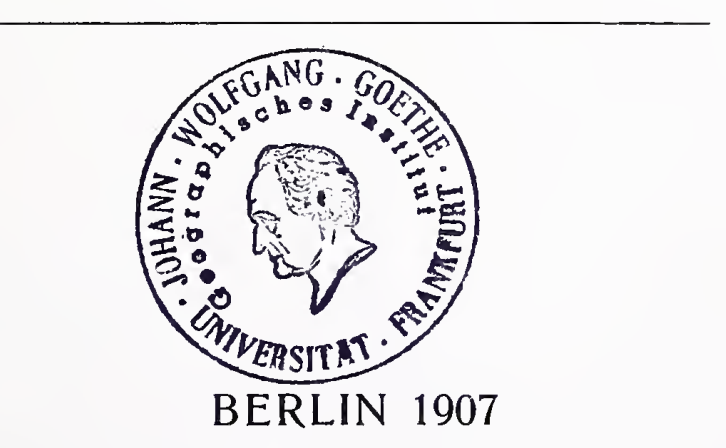

ERNST SIEGFRIED MITTLER UND SOHN, KÖNIGLICHE HOFBUCHHANDLUNG KOCHSTRASSE $68-71$ 


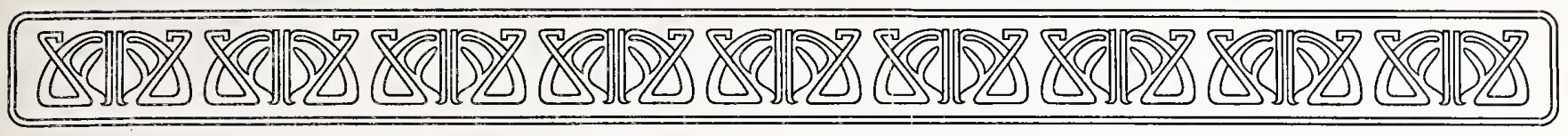

\section{Inhaltsverzeichnis.}

Aus dem Schutzgebiete Togo.

Das Klima von Togo. Von Dr. H. Maurer . . 115

Ergebnisse der Regenmessungen in Togo im Jahre I9o6 118

Togo während des letzten Erdbebens von Accra. Nach einem Bericht des Bezirksgeologen Dr. Koert

\section{Aus dem Schutzgebiete Kamerun.}

Der Handel der Duala. Von Dr. jur. et phil. Asm is Ergebnisse der Regenmessungen in Kamerun in den Jahren 1905 und 1906 (hierzu Tafel VIl). . . 12

\section{Aus dem deutsch-südwestafrikanischen} Schutzgebiete.

Die Niederschlagsverhältnisse von Deutsch-Südwestafrika mit einer Niederschlagskarte von DeutschSüdwestafrika, 2 Kartons der Verteilung der Regentage nebst 24 Tabellen, 54 Diagrammen und einer Profilkarte der Regenhöhen von West nach Ost auf 6 Tafeln. Von Dr. Emil Ottweiler, Münster i. W.

Ergebnisse der meteorologischen Beobachtungen in Deutsch-Südwestafrika im Jahre Juli 1905 bis Juni 1906. Nach dem Bericht des Katastersekretärs Thomas. . . . . . . . . . .

Täglicher Gang des Luftdruckś und der Temperatur zu Windhuk vom Juli 1904 bis Juni 1905 wie seine harmonischen Konstituenten. Von Dr. P. Heidke . . . . . . . . . . . . . 100

Das Klima von Swakopmund. Von A. Gülland (hierzu Tafel VIII bis X) . . . . . . . 131

\section{Aus dem deutsch-ostafrikanischen Schutz- gebiete.}

Zweiter Bericht über die landeskundlichen Expeditionen der Herren Dr. Fritz Jäger und Prof. Dr. Karl Weule in Deutsch-Ostafrika . . . . . . .

Dritter Bericht über die landeskundliche Expedition des Herrn Dr. Fritz Jäger in Deutsch-Ostafrika
Bericht über die astronomischen und geodätischen Arbeiten, welche zur Festlegung der Grenze Deutsch-Ostafrikas gegenüber dem Kongostaat und Britisch-Ostafrika von seiten der deutschen Kommissare in den Jahren 1902 bis 1905 ausgeführt worden sind. Bearbeitet und zusammengestellt nach der Berichten der Expeditionsführer von Professor Dr. L. Ambronn . . . . . 16

Aus den Schutzgebieten der Südsee.

Lava vom neuesten Ausbruch des Sawaii-Vulkans (Samoa-Archipel) . . . . . . . . . . . 11

Wanderungen im Gebiete der Kai (Deutsch-Neuguinea). Von Dr. Rudolf Pöch (hierzu Karte Nr. 8 und Tafel XI) . . . . . . . . . . 22

Resultate der Regenmessungen im Jahre igo6. . . 231

Die Regenverhältnisse Samoas im Jahre 1906. Bericht des Samoa-Observatoriums, erstattet von Dr. F. Linke . . . . . . . . . . . . 239

\section{Karten.}

Karte Nr. I. Niederschlagskarte von Deutsch-Südwestafrika. Mit 2 Kartons:

Gesamtzahl der jährlichen Regentage mit einem Niederschlag von mindestens $0,2 \mathrm{~mm}$.

Anzahl der jährlichen Regentage mit einem Niederschlag von I $\mathrm{mm}$ und darüber.

Karte Nr. 2. Karte von Togo in I : 20000o, bearbeitet von P. Sprigade. Blatt $C_{I}$ : Bismarckburg.

Karte Nr. 3. Karte von Togo in I : 2000oo, bearbeitet von P. Sprigade. Blatt A 2: Tamberma. 
Karte Mr. 4. Das untere Panganital. Trigonometrisch und polygonometrisch aufgenommen, berechnet und gezeichnet durch E. Kayses. I : 30000.

Karte Nr. 5. Die deutsch-englische Grenze zwischen dem 30. Längengrad und dem Djipe-See nach den Aufnahmen der deutsch-englischen Grenzexpedition unter Leitung von Hauptmann Schlobach und Colonel Delmé Radcliffe bar. Colonel Smith. I: 1000000 .

Karte Nr. 6. Triargulationsnetz der Herrmannschen Kiwu- und der Schlobachschen Uganda-Grenzexpedition. I:927 500.

Karte Nr. 7. Triangulationsnetz der Schlobachschen Grenzexpedition zwischen dem Victoria-See und Zanzibar. I:927500.

Karte Nr. 8. Der Sattelberg und Umgebung. (Kaise1Wilhelmsland). Unter Benutzung neuer Aufnahmen Dr.R. Poech s bearbeitet von M. Mo is el. r: I 00000 .
Karte Nr. 9. Die Umgebung des Hansemann-Berges. (Kaiser-(Vilhelmsland) nach den Vermessungen der Rheinischen Mission. I :20000.

Karte Nr. ıo. Provisorische Karte von Teilen der Bezirke Ossidinge, Bamenda und Dschang. Konstruiert und gezeichnet auf Grundlage der Aufnahmen des Hauptmanns Glauning etc. von C. Jurisch, H. Wehlmann und H. Nobiling unter Leitung von M. Moisel. 1:500000.

\section{Tafeln.}

Tafel I-VI. Die Niederschlags-Verhältnisse von DeutschSüdwestafrika.

Tafel VII. Wasserstände des Mungo und Wuri im Jahre 1906.

Tafel VllI-X. Das Klima von Swakopmund,

Tafel X1. Wanderungen im Gebiete der Kai. 


\title{
Die
}

\section{Niederschlags-Verhältnisse}

\author{
von
}

\section{Deutsch-Südwestafrika}

mit einer Niederschlagskarte von Deutsch-Südwestafrika, 2 Kartons der Verteilung der Regentage nebst 24 Tabellen, 54 Diagrammen und einer Profilkarte der Regenhöhen von West nach Ost auf 6 Tafeln.

\section{Dr. Emil Ottweiler}

(Münster i. W.) 



\section{Inhaltsverzeichnis.}

Vorbemerkungen

\section{A. Das Beobachtungsmaterial und seine Verarbeitung.}

I. Überblick über die bisherige Literatur zur Kenntnis der Niederschlagsverhä'tnisse Dentsch-Südwestafrikas . . . . . . . 5

2. Stand des Beobachtungsmaterials. - Übersicht und Herkunft desselben . . . . . . . . . . . . . . . . . . .

3. Zusammenstellung des bisher vorliegenden Regenmebmateria's von Südwestafrika, soweit dasselbe zur Untersuchung der Niederschlagsverhältnisse Deutsch-Südwestafrikas in Betracht kam . . . . . . . . . . . . . . . . . . . . . 9

4. Verzeichuis der Regenmefstationen . . . . . . . . . . . . . . . . . . . . . . . . . . . . . . . . 22

5. Prüfung des Beobachtungsmaterials auf seine Brauchbarkeit . . . . . . . . . . . . . . . . . . . . . . . . 27

6. Die Verarbeitung des Beobachtungsmaterials. - Berechnung der Normalmittel . . . . . . . . . . . . . . . . 29

7. Verzeichnis des Regenmebstationen mit den berechneten und reduzierten Mittelwerten unter Augabe der benutzten Reduktionsstationeu

\section{B. Die Verteilung der Niederschlagsmengen in Deutsch-Südwestafrika.}

(Hierzu die NiederschTagskarte: Karte r.)

I. Die Anlage der Regenkarte .

2. Die Niederschlagsverhältnisse des Küstengebietes . . . . . . . . . . . . . . . . . . . . . . . . . . . 4 I

3. Die Niederschlagsverhältnisse dex Gras- ınd Buschsteppe des Binnenlandes. . . . . . . . . . . . . . . . . . . 44

a) Der Norden von Gr. Namaland . . . . . . . . . . . . . . . . . . . . . . . . . . . . . . . . . 44

b) Damaraland . . . . . . . . . . . . . . . . . . . . . . . . . . . . . . . . . . . . . . 46

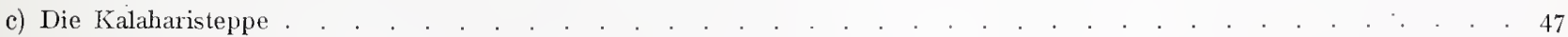

d) Die Niederschlagsverhäitnisse des nördlichen Teils ron Deutsch-Sïdwestafrika . . . . . . . . . . . . . . . . . . 48

\section{Speziellere Untersuchungen.}

I. Tau'all und Nebelbildung

2. Schneefall

3. Hagelfall

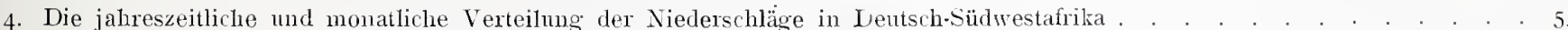

5. Jähriche Schwankungen des Niederschlags . . . . . . . . . . . . . . . . . . . . . . . . . . . . 59

a) Allgemeine Schwankung von Jahr zu Jahr . . . . . . . . . . . . . . . . . . . . . . . . . . . . . . . . . . . . 59

b) Zur Frage einer etwaigen Periodizität in den Schwankungen des jährlichen Niederschlags. . . . . . . . . . . 65

c) Zur Frage der sogenamnten Austrocknung Südafrikas . . . . . . . . . . . . . . . . . . . . . . . . . . . 68

6. Die jährliclıe Anzahı der Regentage in Dentsch-Südwestafrika (hierzı 2 Kártons auf Karte I) . . . . . . . . . . . 70

7. Die Beziehung der Niederschläge zu den Windrichtungen und die dadurch bedingten Grundzüge der altgemeinen V'erteilmug des Regens in Deutsch-Südwestafrika . . . . . . . . . . . . . . . . . . . . . . . . . . . . . . . 75

a) Im Küstenland . . . . . . . . . . . . . . . . . . . . . . . . . . . . . . . 77

b) Im Binnenland . . . . . . . . . . . . . . . . . . . . . . . . . . . . . 78

Nachtrag . . . . . . . . . . . 80

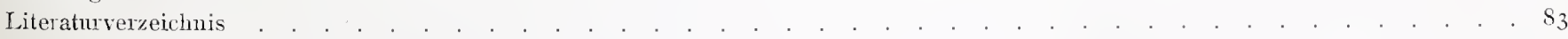





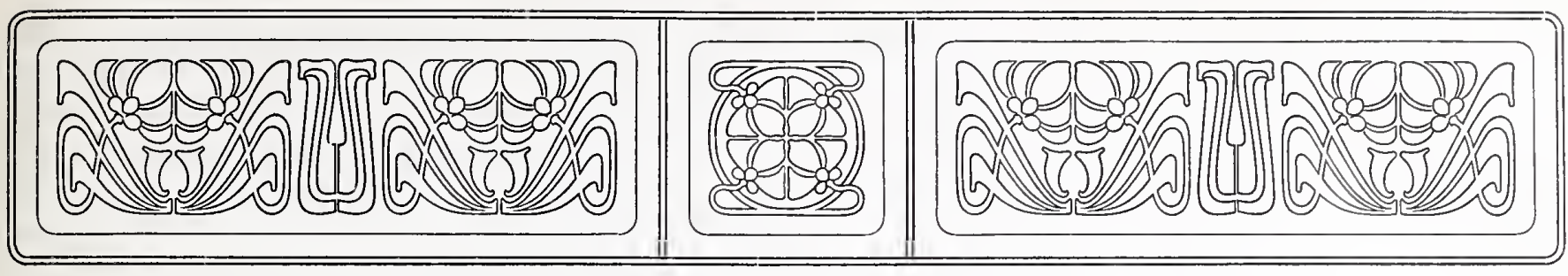

\section{Vorbemerkungen.}

Es bedarf nicht vieler Erörterungen, welche ungeheuere und geradezu grundlegende Bedeutung für die gesamten Lebensbedingungen die Wasserfrage in unserem größtenteils so regenarmen Schutzgebiete Deutsch-Südwestafrika besitzt.

Für alle Angelegenheiten der praktischen Nutzbarmachung, ob es sich dabei nun handelt um die örtliche Möglichkeit des Ackerbaues und von Baumkulturen oder die Viehzucht, oder seien es speziellere Fragen der Anlage von Staudämmen und Wasserreservoirs, von Bahn- und Brückenbauten, dann bei allen bergmännischen Unternehmungen, überall spielt die Wasserfrage die Hauptrolle.
In dieser Beziehung muß deshalb eine eingehende Untersuchung der Niederschlagsverhältnisse des Landes von größter Wichtigkeit für seine wirtschaftliche Zukunft sein. Besonders wird sie dabei die Frage nach der Menge und Verteilung der jährlich fallenden Regen, dann der Zahl der Regentage und vor allem die Schwankungen des jährlichen Niederschlags $z u$ behandeln haben. Von besonderem Nutzen dürfte auch eine aufzustellende Regenkarte sein.

\section{A. Das Beobachtungsmaterial und seine Verarbeitung.}

\section{Überblick über die bisherige Literatur zur Kenntnis der Niederschlagsverhältnisse Deutsch-Südwestafrikas.}

Schon bald nach der Erwerbung des Schutzgebietes erkannte man allgemein die große Bedeutung der meteorologischen Beobachtungen und speziell der dortigen Regenmessungen für alle Lebensbedingungen im Lande. So kann es denn auch nicht wundernehmen, daß uns bisher schon eine ganze Reihe von Veröffentlichungen über seine mutmaßlichen klimatischen Verhältnisse vorliegt. Man suchte eben möglichst bald, und daher meistens verfrüht, die geringen schon vorliegenden MeBresultate praktisch $\mathrm{zu}$ verwerten.

Die meisten dieser Abhandlungen sind allerdings mehr Schriften populären Charakters und kommen eben über Mutmaßungen und Andeutungen nicht hinaus. So muß ich mich denn in folgender Mitteilungen von Forschungsreisenden, XX. Band. I.
Abhandlung darauf beschränken, sie nur am Schlusse in einem Literatur-Verzeichnis anzugeben oder gelegentlich an passender Stelle in der Arbeit zu erwähnen.1)

An vorliegender Stelle sind nur einige Autoren anzuführen, deren Arbeiten in streng wissenschaftlichem Sinne für nachfolgende Abhandlung brauchbar erschienen und die mir auch, wie aus manchen Ausführungen $\mathrm{zu}$ ersehen, oft gute Dienste leisteten.

Der älteste wissenschaftliche Aufsatz über klimatologische und meteorologische Bedingungen in Deutsch-Südwestafrila liegt uns in einer kleineren Arbeit von A. v. Danckelman in den Jahresberichten des Vereins für Erdkunde zu Leipzig

1) Ebendort sind die Verweisungen auf bestimmte Autoren unter dem Zeichen L.V. (Literatur-Verzeichnis) mit der entsprechenden laufenden Nummer und Seitenangabe geschehen. 
I 883 bis I 885 vor mit „Bemerkungen zu den RegenmeBresultaten von Rehoboth 47), Omaruru (I9) und Otjizeva 28 .

Diese wie auch alle anderen nicht einzeln aufgeführten Arbeiten anderer Gelehrten und Forscher, z. B. Wie folgende von C. Kaßner, Die Klimate der deutschen Schutzgebiete" ${ }^{\prime 1}$ ) dam eine andere klimatologische von $\mathrm{K}$. Dove,2) beschränken sich jedoch samt und sonders noch auf die allgemeine Andeutung, daß die Niederschlagshöhe von der Küste aus nach Osten und rom Orange aus nach Norden ständig zunimmt.

Die ersten in zusammenfassender Weise auf Grund gröberen exakten Zahlenmaterials uber die Nieclerschldgsverhältnisse Sïdwestafrikas handelnden Arbeiten wurden erst Witte der goer Jahre vorigen Jahrhunderts vou K. Dove, Th. Rehbock, A. Supan und A. Buchan veröffentlicht. K. Dove ${ }^{3}$ gibt in seiner Arbeit eine ziemlich ausfihrliche Schilderung von den Niederschlagsverhältnissen, besonders des Hererolandes, auf Grund eines Beobachtungsmaterials von 15 Stationen. ${ }^{\frac{1}{*}}$ ) Da das zugrunde selegte Beobachtungsmaterial jedoch zu kurz war und besonders zum größten Teile der regenreichen Periode I892/93 entnommen ist, so konnten seine Darlegungen wie auch die Th. Rehbocks') eben nur eine vorläufige Bedeutung besitzen.

Beide liommen riemlich übercinstimmend auf Grund ihrer in Deutsch-Sidwestafrika, wo sie sich studienhalber längere Zeit aufhielten, selbst gesammelten Regenmeßresultate ungefähr zu folgendem Eryebnis:

Die jährliche Niederschlagsmenge im äußersten Norden des Hererolandes und im Kaokogebiete beläuft sich, ähnlich wie im Ambolande, auf etwa foo $\mathrm{mm}$ und darüber. Im nördlichen und mittleren Teile des Tererolandes beträgt sie etwa 300 bis $400 \mathrm{~mm}$. Die Lone von Otjimbingue nach W'esten hat schon eine bedeutend niedrigere und stetig nach dem Atlantischen Ozean zu abnehmende jährliche Niederschlagsmenge. Was das zentrale Hochland angeht, so fallen in den Talweitungen und auf den Flächen von weniger als $1800 \mathrm{~m}$ Meereshöhe (z. B. in der Gegend von Windlutk und am oberen Schaffluß) etwa $400 \mathrm{~mm}$, dagegen in den Awas- und Khomasbergen, wie aus dem reicheren Naturleben zu schliefen ist, wohl noch über $400 \mathrm{~mm}$; östlich davon wird eine Regenhöhe riemlich gleich der

1) Vexöffentlicht in dei met. Zeitschrift ,Das Wetter", X, Jahrgang. Berlin I893. S. 103 bis I10, I21 bis 132 .

2) K. Dove, L. V. I 5 .

3) K. Dove, I. V. I7.

4) K. Dove, a. a. O. S. 3I, L. V. I7.

5) Th. Rehbock, Deutsch-Südwestafrika, Berlin I 898 . von Windhuk angenommen, wobei jedoch eine gewisse stetige Zunahme nicht ausgeschlossen ist.

Nach Süden nimmt die Regenmenge zunächst schnell ab. Sie beträgt auf den Ebenen des südlichen Bastardlandes weniger als $300 \mathrm{~mm}$, im mittleren Namalande etwa $200 \mathrm{~mm}$, im südlichsten Hottentottengebiete nur noch 100 bis $200 \mathrm{~mm}$.

Gleichzeitig fügt Dove seiner Abhandlung sogar schon ein Regenlärtchen bei mit IOO: I00 mmIsohyeten. Das darin dargestellte Gebiet zieht von der $K$ üste aus zwischen $2 \mathrm{I}^{1} / 2$ und $24^{\circ} /^{\circ}$ s. Br. nach Osten in das Binnenland bis etwa $18^{\circ} \ddot{0}$. L. Bei dem bis heute erfolgten großen Zuwachs von Regenmeßmaterial war es dem Verfasser möglich, nicht nur für dieses Gebiet die Isohyeten bei weitem differenzierter und genauer auszuführen, sondern auch für das ganze Land mit mehr oder minder beträchtlicher Wahrscheinlichkeit zu entwerfen.

Auch Supan erwähnt in seiner Schrift über die Niederschlagsverteilung auf der festen Erdoberfläche ${ }^{1}$ ) die des Nama- und Damaralandes; jedoch fußt er zum größten Teile noch auf den Berechnungen K. Doves.

In besonders zusammenfassender Weise hat weiterhin A. Bucha $n^{2}$ ) die Niederschlaysverhältnisse des Kaplandes und gleichzeitig auch des südlichen Grenzstriches Deutsch-Südwestafrikas unter Beifügung von Karten der monatlichen, jahreszeitlichen und jährlichen Regenhöhen behandelt. Diese Abhandlung leidet jedoch an einem großen Mangel, indem Buchan nur die rohen Beobachtungsmittel zur Herstellung seiner Regenkarten verwendet und dabei alle als gleichwertig behandelt, mögen sie nun aus einer langen oder noch so kurzen Beobachtungsreihe gewonnen sein. Jedeufalls blieb das Erfordernis der Gleichzeitigkeit der Beobachtungen bei der Anlage seiner synoptischen Darstellungen des Regenfalls in keiner Weise gewahrt. Ebenso bringt er nicht dás wichtige Hilfsmittel der Reduktion kiirzerer Reihen auf längere Perioden zur Anwendung.

Infolgedessen mußten für vorliegende Abhandlung zwecks Herstellung der Normalmittel der Ieutsch-Südwestafrika benachbarten kapländischen Stationen alle Berechnungen noch einmal ausgeführt werden.

Die mannigfach aus der Zeit 1898 bis jetzt (1905) sonst erschienenen Veröffentlichungen über Deutsch-Südwestafrika sind, soweit sie klimatologische Dinge berühren, zu populären Charakters,

1) A. Supan, L. V. 46.

2) A. Buchan, L. V. Io. 
um als exakte wissenschaftliche Abhandlungen gelten zu können.

Das Bedürfnis einer neuen uud spezielleren Untersuchung der Niederschlagsverhältnisse von Deutsch-Südwestafrika dürfte, somit auf der Hand liegen.

\section{Stand des Beobachtungsmaterials. Übersicht und Herkunft desselben.}

Die ersten exakten Beobachtungsdaten verdanken wir mehreren Missionaren der Rheinischen Missionsgesellschaft zu Barmen, welche mit den von dem Verein für Erdkunde zu Leipzig zur Verfügung gestellten meteorologischen Instrumenten ihre Beobachtungen und insonderheit auch Regenmessungen mit großem Eifer und Verständnis angestellt haben.

So liegen aus Omaruru (I9) im Damaraland ${ }^{\text {l) }}$ von Missionar Viehe RegenmeBresultate von Dezember 1882 bis Dezember I 885 vor; späterhin unterbrochen, sind die Beobachtungen dort auf Veranlassung der deutschen Regierung Oktober I899 wieder aufgenommen worden.

Sodann ist besonders Rehoboth (47) zu erwähnen, wo von Missionar Heidtmann seit August I 883 bis zum Endtermin, also etwa 22 Jahre hindurch, fast ununterbrochen beobachtet worden ist. Leider fehlen uns die Monatssummen der Jahre 1886 bis I 890 einschließlich, da das Manuskript in Rehoboth laut einer eigenhändigen Randbemerkung des Beobachters, welche mir selbst zugängig wurde, in den goer Jahren durch Termiten vernichtet wurde.

Die Jahressummen dieser Jahre konnten jedoch glücklicherweise noch einer Veröffentlichung von C. Kaßner in der Zeitschrift „Das Wetter" Jahrgang I893, „Die Klimate der deutschen Schutzgebiete", entnommen werden.

In Otjiseva (28), nördlich von Gr. Windhuk, stellte Missionar W. Eich von Februar I 884 bis 23. Dezember I 885 Regenbeobachtungen an.

Veröffentlicht ist das Material dieser drei Stationen aus den 8oer Jahren durch A. v. Danckelman in den Jahresberichten des Vereins für Erdkunde zu Leipzig. ${ }^{2}$ ) Die Regenmeßergebnisse

1) Die hier und im späteren Text öfters stehenden eingeklammerten Zahlen beziehen sich auf die entsprechenden fortlaufenden Nummern dex einzelnen Stationen in Tab. 2.

2) Mitteilungen des Vereins für Exdkunde zu Leipzig; Jahrgang 1883, I. Abt. A. v. Danckelman, Bemerkungen zu den meteorolog. Beobachtungen aus Omaruru und Rehoboth. Mit Tabelle, II. Abt. A. v. Danckelman, Bemerkungen zu dex klimatolog. Tafel der meteorolog. Station Omaruru (Damaraland). Jahrgang i884. A. v. Danckelman, Bemerkungen zu deu Resultaten der meteorolog. Stationen im Herero- und Namalande.
Rehoboths wurden mir als authentisches Manuskript von Windhuk aus, und zwar bis einschließlich I898, freundlichst durch Herrn Katastersekretär Thomas zur Verfügung gestellt. Von diesem Jahre ab finden sie sich wie auch die von Omaruru in den ,,Mitteilungen von Forschungsreisenden und Gelehrten aus den deutschen Schutzgebieten" fortlaufend veröffentlicht. ${ }^{1}$ )

Im Norden nahe der Etoscha-Salzpfanne liegen aus Olukonda (5) aus folgenden Zeitabschnitten Regenmebdaten vor: Beobachter Missionar Rautanen: März I 886 bis Dezember I 890; Beobachter Missionar Pettinen: Juli I89 I bis Oktober I 892 ; Beobachter Missionar Rautanen: Regenperiode I $893 / 94$.

Herr Prof. Dove hat die dortigen Regenmengen, welche von den Beobachtern gewogen worden waren, nach einer gefl. Mitteilung an mich in entsprechender Weise umgerechnet und ihre Höhe in Millimeter ausgedriickt. Das gesamte Material ist mir von ihm freundlichst zugestellt worden.

In Otjosazu (26) stellte Missionar Irle von Januar I 884 bis zur Regenperiode I902/O3 Regenmessungen an; jedoch sind seine eigenen Berichte 2 ) hierüber, denen ich die Resultate entnahm, wenig zusammenhängend.

Als letzte von diesen Stationen mit älteren Beobachtungen wäre noch $\mathrm{zu}$ erwähnen Kanas (70), am Löwenfluß, nahe den Kharasbergen gelegen, wo Farmer F. Haybittel während der Regenperioden I 886/87, I 887/88, I888/89 Regenmessungen angestellt hat. Veröffentlicht ist dieses Material in den kapländischen ,Reports of the Meteorological Commission" for the year I 887, i 888, i 889. Capetown.

Seit Beginn der goer Jahre wurde das Stationsnetz in Deutsch-Südwestafrika immer mehr vergrößert. In den Jahren I 890 bzw. I89 I wurden 5 neue Stationen eingerichtet: Tsaobis (34), Okahandja (25), Waterberg (oder Otjosondjupa) (I 7), Schaprivier (42) (Kubabub) und Gr. Windhuk (35). Von ihnen liegen fast ununterbrochene

1) Berlin. Herausgegeben durch Dr. A. v. Dauckelman. Regenmefergebnisse aus Deutsch-Südwestafrika finden sich dort Band V, S. $74 \mathrm{ff.}$; Band VI, S. $298 \mathrm{ff}$.; VIII. Jahrgang I895, S. I2I bis I 29 ; IX. Jahrgang I896, S. Ioo; XII. Jahrgang I 899 , S. 225; XIII. Jahrgang I 900, S. I09; XIV. Jahrgang I90I, S. I4, I67; XV. Jahrgang 1902, S. I4, 90; XVI. Jahrgang I903, S. 9, 2I6; XVII. Jahrgang I904, S. 29, 93; XVIII. Jahrgang I 905 , S. 293,303 .

2) Es sind dies zwei Briefe mit einer Zusammenstellung dex in Otjosazu gemachten Regenmessungen, gerichtet an Herru Prof. Rehbock in Karlsruhe und an das Gouvernement in Windhuk. Beide wurden mir von zuständiger Seite freundlichst zur Auswertung überlassen. 
Beobachtungsreihen von bzw. 3, ro, I I, I 4 Jahre langer Dauer vor.

Besonders aber brachte das Jahr I892 eine bemerkenswerte weitere Vergröberung des Beobachtungsnetzes, indem K. Dove während einer Studienreise in das Schutzgebiet eine ganze Reihe neuer Stationen errichtete: Heusis (39), Otjimbingue (29), Luderitzbucht (65), Kubub (66), Bethanien (62), Otjosondjupa ( 17 ).

Die Regenmefergebnisse aller dieser neueren Stationen sind mir, soweit sie bis zur Regenperiode I 897/98 überhaupt vorlagen, gütigst als handschriftliches Material durch Herrn Prof. Dove bzw. Herrn Katasterseliretär G. Thomas zu Windhuk zur Verwertung überlassen worlen.

Th. Rehbock konnte 1896/97 bei seiner behufs agrikulturtechnischer Studien unternommenen Bereisung des Schutzgebietes ebenfalls 15 Regenmesser abgeben. Nach einer Notiz seines dort geführten Tagebuches, welches Herr Prof. Rehbock den Zwecken vorliegender Abhandlung nebst einer ganzen Reihe von ihm während der Zeit seines dortigen Aufenthalts gemachter Regenmessungen gütigst überlieb, kamen sie in folgender Weise zur Terteilung: im Lugust 1897 an

r. Leutnant Held - Gobabis (31)

2. Missionar Judt - Hoachanas (5 I)

3. Bez. Hauptmann v. Burgdorff - Gibeon (58)

4. Dr. Golinelli - Keetmanshoop $(63)$

5. Farmer Welser - Ukamas (72)

6. Leutnant v. Bunsen - Warmbad (75)

7. - - Orangeflub

8. Farmer Gessert - Inachab (69)

9. - - Grootfontein (IO)

IO. - - Hoornkranz,

schon vorher 1896 abgegeben an:

I I. Leutnant Franke - Otjimbingue (29)

I 2. Leutnant v. Zülow - Okahandja (25)

I3. Leutnant Volkmann-Outjo (I4)

I4. Farmer Wheeler — Seeheim (68)

I 5. Oberfeuerwerker Donnewert -

Gr. Windhuk (35a).

Von Hoornkranz und Orangeflub liegen mir keine Notizen über Beobachter bzw. gewonnene Regenmebresultate vor; von allen übrigen Stationen jedoch sind sie mehr oder weniger durchgeführt bis zur Regenperiode 1903/04. Das aus dem Regenjahr I896/97 stammende Material erhielt ich, wie schon angegeben, guitigst von Herrn Prof. Rehbock zugestellt.

In den der Regenperiode I $896 / 97$ folgenden Jahren errichtete die Regierung von Windhuk aus, nachdem hier eine meteorologische Zentralstelle
II. Ordnung geschaffen war, Jahr für Jahr immer mehr Regenmebstationen, so dab wir jetzt innerhalb der Grenzen Deutsch-Südwestafrikas, nachdem acht im Laufe der Zeit leider wieder eingegangen sind, deren 65 rählen.

Seit der Regenperiode I898/99 werden die RegenmeBergebnisse der einzelnen Stationen fortlaufend in den ,Mitteilungen aus den Deutschen Schutzgebieten" veröffentlicht.

Dic Leitung der meteorologischen Zentralstelle in Windhuk lat jetzt nach leider melurmaligem Wechsel Herr Katastersekretär Thomas in Händen.

Zum Vergleich und zur Ergänzung des vorliegenden Materiais und weiterhin, um die betreffenden Verhältnisse Südwestafrikas überhaupt noch in einem etwas weiteren Ausblick verfolgen zu können, erschien es nützlich, noch dasjenige einer Reihe britischer Regenmeßstationen im nördlichen Kaplande mit zur Untersuchung heranzuziehen. Zur Verwendung in vorliegender Abhandlung sind so noch die Beobachtungen von 22 Stationen gekommen, welche bei ihrer langen Beobachtungsdauer von durchschnittlich I 885 bis I 90 I gleichzeitig noch eine gute Unterlage boten zu der noch später zu besprechenden Reduktion der deutschen Stationen in suidlichsten Namalande. Gerade ilnnen ist es auch zuzuschreiben, daß im äuBersten Süden die Niederschlagskarte ein besonders genaues Bild zu bieten vermag.

Die Beobachtungen der englischen RegenmeBstationen finden sich in den jährlich erscheinenden kapländischen , Reports of the Meteorological Commission for the year .... Capetown" veröffentlicht. Letztere wurden mir freundlichst teils von der Deutschen Seewarte gelegentlich einer zu diesem Zwecke unternommenen Reise nach Hamburg, teils auch von dem Meteorologischen Zentralinstitut zu Berlin zur Verfügung gestellt. Ebenso fand ich manches bezügliche Material in A. Buchans, ,Rainfall of South-Afrika 1885 bis I894", dann in dem Werlie von A. R. E. Burton "Cape Colony for the Settler, London I903“. Jahresmengen des Regens an 57 typischen Stationen.

Zu erwähnen ist hier ferner noch das Material einer anderen britischen Station, welches besonders für das regenarme Küstengebiet typisch ist, Walfischbai (46). Die dortigen über den Zeitraum Januar I 886 bis Dezember I 894 sich erstreckenden und von Missionar Böhm angestellten Regenmessungen wurden in den ,Deutschen überseeischen meteorologischen Beobachtungen" von der Deutschen Seewarte in Hamburg veröffentlicht. 1) Aus

1) Meteorolg. Beobachtungen in Walfischbai: I. Dezember I 885 bis 3 I. Dezember I 896 . Heft I bis 9. - VIII. Jahrgang. 
späterer Zeit dagegen fand ich von dieser Station nur noch die Mebresultate einiger Jahre in den kapstädtischen Reports ${ }^{1}$ ) und der ,Meteorologischen 'Zeitschrift". ${ }^{2}$ )

Um auch im Norden zu dem benachbarten portugiesischen Gebiete gewissermaßen cinen Übergang zu gewinnen, wurden ferner noch die Regenmessungen der beiden einzigen Stationen in Angola mit dem Gesamtmaterial vercinigt, nämlich von Loanda (I) und Caconda (2).

Das Matcrial von Loanda wurde mir auf der Deutschen Secwarte zu Hamburg zugänglich, nämlich die Monatssummen von 1879 bis I 89 I. $\left.^{3}\right)$ Die späteren Monatssummen von I 894 bis 1903 crhielt ich freundlichst direlit zugesandt durch das Kaiserl. Konsulat 7 São Paulo de Loanda.

In Caconda (2), im Hochland des Inneren gelegen, wurde beobachtet von Januar I 889 bis Juni I890. Die von dort stammenden Meßresultate veröffentlichté Hann in der ,Meteorolog. Zeitschrift" I 893.4 )

Es ist demnach vorliegender Abhandlung über die ,Niederschlagsverhältnisse von Deutsch-Süidwestafrika" ein Beobachtungsmaterial zugrunde gelegt, welches sich über einen Zeitraum von etwa 20 Jahren erstreckt, nämlich Anfang der Socr Jahre bis Juni roo4 als SchluBtermin. Dasselbe gehört 85 Regenmeßstationen an, welche auf der beigegebenen Regenkarte verzeichnet sind, außerclem noch I I weitercn, die außcrhalb des Rahmens der

1) ... for the year r $897-$ r 90 I

2) Jahrgang i 898

3) Die täglichen meteorologischen Beobachtungen von Loanda in: ,Observatorio Meteorologico de Loanda. Observaçòes meteorologicas 1879 bis r 89 I. Lisboa. Imprensa Nacional I 892 ".

4) Entuommen dem ,Boletin da Sociedade de Geographia de Lisboa r89i (roe Ser. No. 4 e 5 pg. 209 etc.).
Karte liegen, teils in Portugiesisch-Angola teils in der nördlichen Kapkolonie, deren Beobachtungen aber zur Beurteilung der gesamten Niederschlagsverhältnisse Südwestafrikas ebenfalls Verwendurg fanden.

\section{Zusammenstellung des bisher vorliegenden Regen- meßmaterials von Südwestafrika, soweit dasselbe zur Untersuchung der Niederschlagsverhältnisse Deutsch- Südwestafrikas in Betracht kam.}

Zwecks besserer Handhabung und leichterer Kontrolle der ganzen Abhandlung und besonders ihrer Zahlenwerte habe ich mich entschlossen, das gesamte zur Verwendung gekommene Material in Tabellenform folgen zu lassen (Tab. 1). Ebenso kann diese Zusammenstellung die Grundlage für cine nochmalige spätere Überarbeitung des vorliegenden Stoffes bieten, da manches Zahlenmaterial, besonders, soweit es handschriftlich mir zur Verfügung stand, in Zukunft wohl schwer zu beschaffen sein wird.

Die Tabellen geben die Monatsbeträge der Niederschläge der einzelnen Regenperioden und deren jeweilige Summe an. Hicrbei schien es zweckmäBig, die Jahre jedesmal vom I. Juli bis 30. Juni zu nehmen, weil so die jedesmalige Regenperiode, welche in unserem Schutzgebict fast allgemein in das Sommerhalbjahr der südlichen Halbkugel fällt, unzerstückelt in den mittleren Teil der Monatsreihen zu liegen kommt.

In der Tabelle sind die einzelnen Stationen geographisch in der Weise geordnet, daß sie von Norden nach Süden aufgezählt und mit einer fortlaufenden Nummer versehen sind, mittels deren sic bei spätcrer Erwähnung stets leicht nachgeschlagen werden können. 
Tabelle 1. Zusammenstellung des zur Verwendung gekommenen Regenmeßmaterials.

Anmerkung: Die Regenmengen sind in Millimetern angegeben. o.o bedentet eine "unmeßbar" kleine Menge. Die Monate ohne Niederschlag sind durch (-) gekennzeichnet. Die Zahlen in Kursivdruck geben die durch Berechnung (auf dem Wege der Reduktion) und nicht durch direkte Beobachtung gelieferten Regenmengen an. Die Zahlen in Klammern bedeuten eine für den betr. Zeitraum (z. B. eine Regenperiode) nicht vollständig gegebene Summe.

Die Jahresmaxima sind durch Fettluck, die Minimat durch ein stemchen gekennzeichnet.

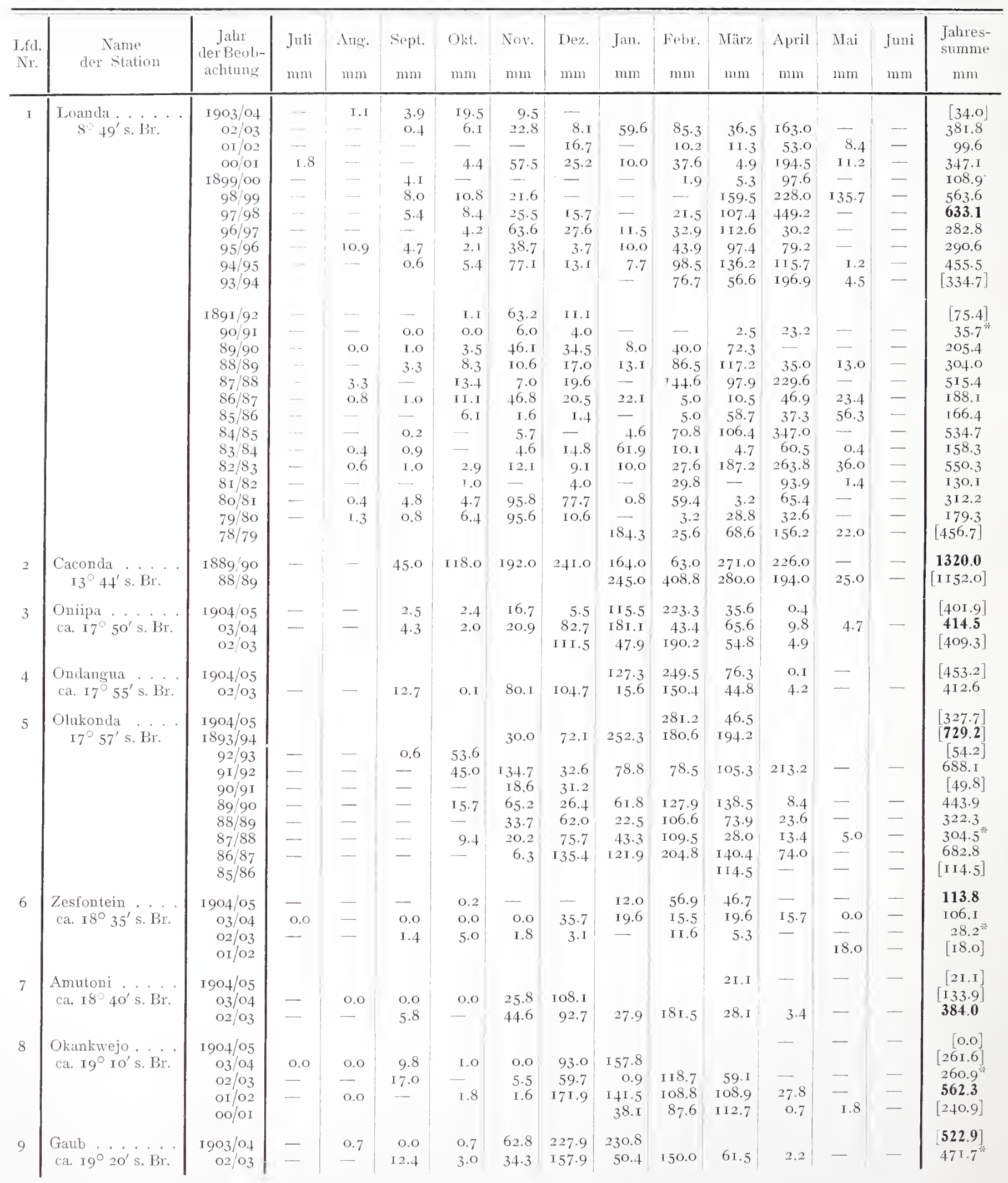




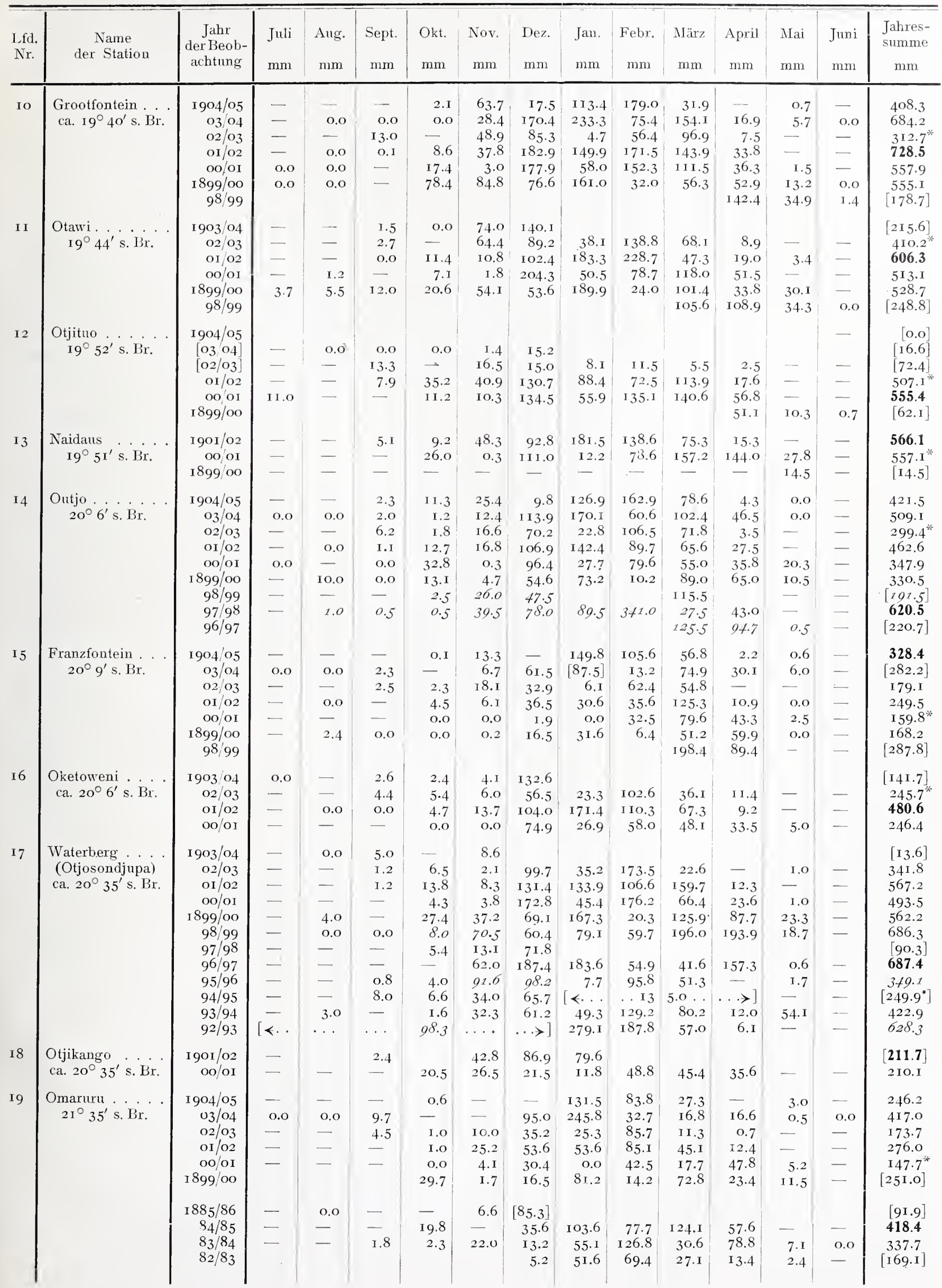




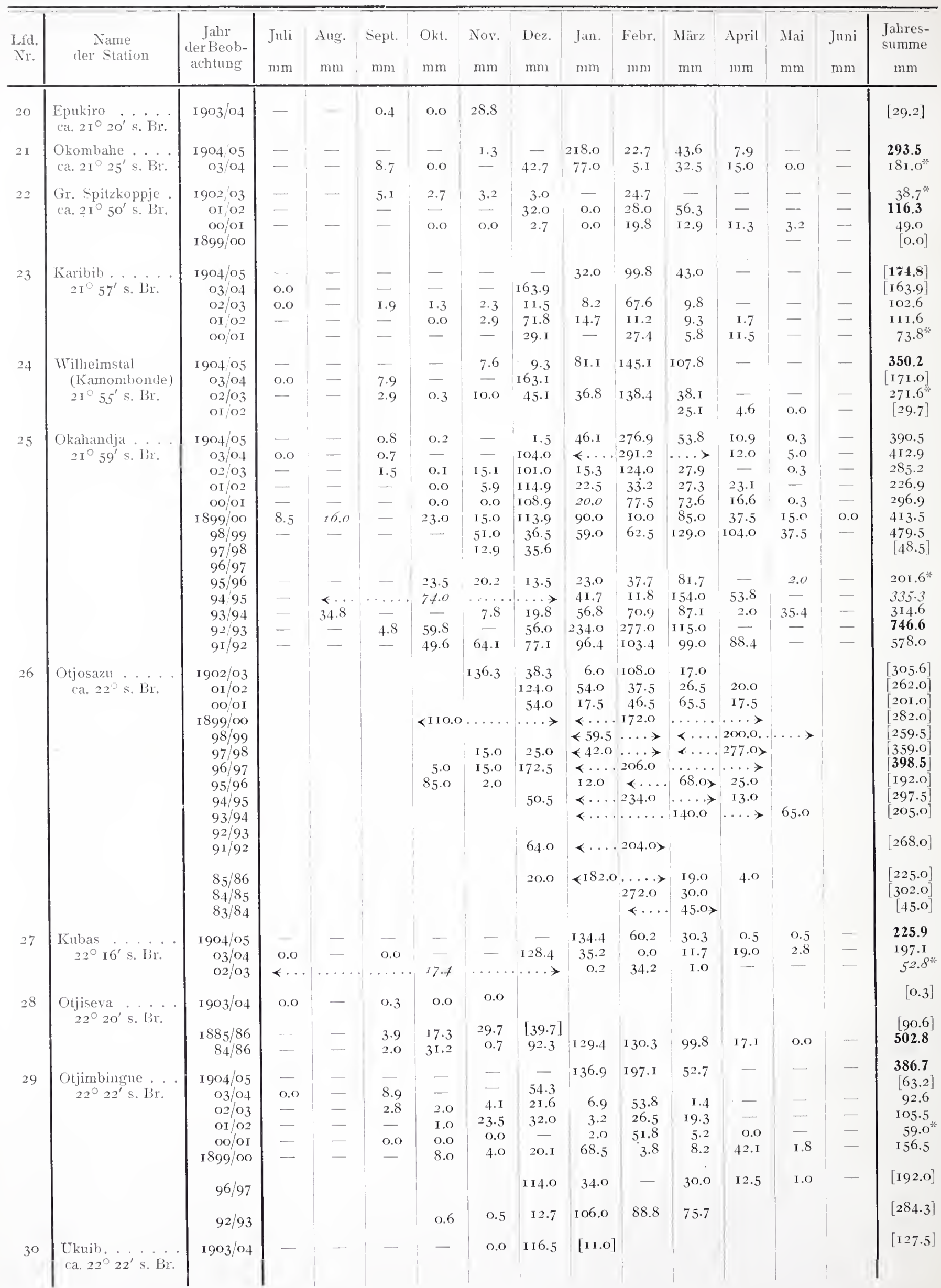




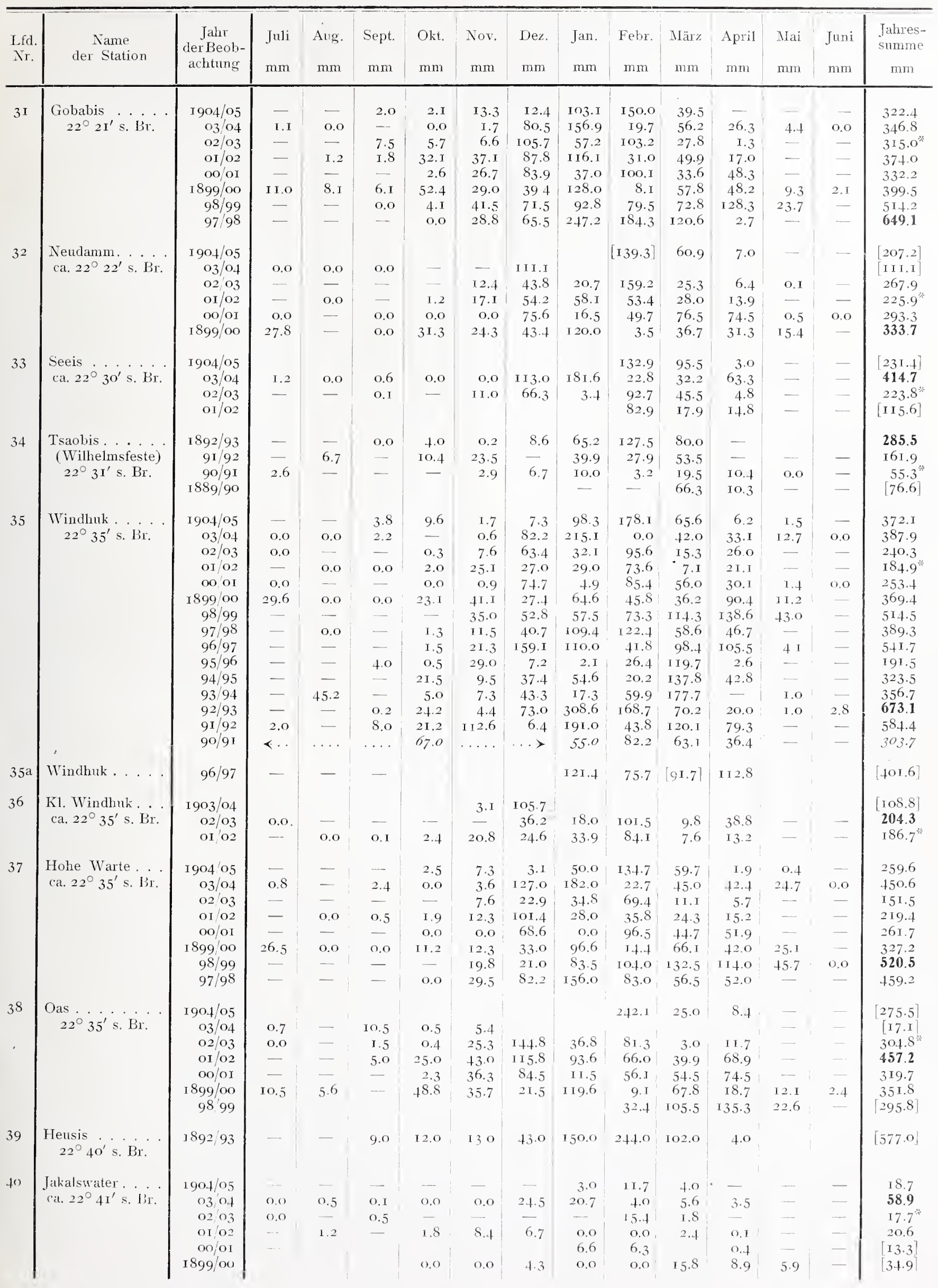




\begin{tabular}{|c|c|c|c|c|c|c|c|c|c|c|c|c|c|c|c|}
\hline $\begin{array}{l}\text { Lfd. } \\
\mathrm{Ni}\end{array}$ & $\begin{array}{c}\text { Niame } \\
\text { der Station }\end{array}$ & $\begin{array}{c}\text { Jalur } \\
\text { derBeob- } \\
\text { achtumg }\end{array}$ & $\begin{array}{l}\text { Jnli } \\
\mathrm{mm}\end{array}$ & $\begin{array}{l}\text { Aug: } \\
\text { min }\end{array}$ & Sept. & $\begin{array}{l}\text { Okt. } \\
\min \end{array}$ & Nov: & me\% & $\begin{array}{l}\text { Jim. } \\
\text { nim }\end{array}$ & Feln. & Mä̀\% & April & Mai & Jumi & $\begin{array}{l}\text { Jahles- } \\
\text { stumme } \\
\text { mnl }\end{array}$ \\
\hline $4 \mathrm{I}$ & $\begin{array}{l}\text { Swakopmund } \\
22^{\circ}+2^{\prime} \text { s. Br. }\end{array}$ & \begin{tabular}{r:r|}
1904 & 05 \\
$03 / 04$ \\
$02 / 03$ \\
01 & 02 \\
$00 / 01$ \\
I $899 / 00$ \\
$98 / 99$
\end{tabular} & $\begin{array}{l}\text { I.O } \\
\text { O. I } \\
\text { I. I } \\
0.0 \\
--\end{array}$ & $\begin{array}{l}0.0 \\
1.2 \\
1.9 \\
0.0 \\
-\end{array}$ & $\begin{array}{l}0.0 \\
1.3 \\
1.1 \\
0.7 \\
0.0 \\
0.0\end{array}$ & $\begin{array}{l}0.0 \\
3.0 \\
0.5 \\
0.0 \\
1.2 \\
8.7\end{array}$ & $\begin{array}{l}0.0 \\
0.1 \\
-- \\
0.0 \\
0.6 \\
-\end{array}$ & $\begin{array}{r}0.0 \\
10.3 \\
2.6 \\
8.6 \\
15.1\end{array}$ & $\begin{array}{l}5 \cdot 3 \\
-6 \\
-6\end{array}$ & $\begin{array}{r}- \\
0.0 \\
13.3 \\
1.4 \\
0.7 \\
0.0\end{array}$ & $\begin{array}{r}16.0 \\
3.4 \\
0.3 \\
15.2 \\
0.1 \\
-. \\
2.7\end{array}$ & $\begin{array}{l}- \\
0.0 \\
0.2 \\
0.1 \\
0.0 \\
6.4 \\
0.0\end{array}$ & $\begin{array}{r}0.0 \\
\text { I I. } 2 \\
\text { I. } 8\end{array}$ & $\begin{array}{l}- \\
0.0 \\
1.4 \\
0.3 \\
0.2 \\
-\end{array}$ & $\begin{array}{l}17.0 . \\
23.4 \\
20.7 \\
29.3 \\
20.5 \\
26.3 \\
|4.5|\end{array}$ \\
\hline+2 & $\begin{array}{l}\text { Schataprivier } \\
\text { (Kubalmal) } \\
22+5^{\prime} \text { s. Br. }\end{array}$ & $\begin{array}{r}1904 / 05 \\
03 / 04 \\
02 / 03 \\
01 / 02 \\
00 / 01 \\
1899 / 00 \\
98,99 \\
97 / 98 \\
96 / 97 \\
95 / 96 \\
94,95 \\
93 / 94 \\
92 / 93\end{array}$ & $\begin{array}{c}\cdots \\
\cdots \\
27.2 \\
- \\
- \\
- \\
- \\
-1\end{array}$ & $\begin{array}{c} \\
\cdots \\
0.0 \\
- \\
0.0 \\
- \\
- \\
\cdots \\
5+.5 \\
-\end{array}$ & $\begin{array}{l}\overline{-} \\
2.7 \\
\overline{-} \\
0.0 \\
-- \\
- \\
- \\
- \\
- \\
- \\
- \\
-\end{array}$ & $\begin{array}{l}5.0 \\
- \\
0.2 \\
1.2 \\
9.6 \\
0.8 \\
3.0 \\
25.0 \\
18.7\end{array}$ & $\begin{array}{r}1.0 \\
15.0 \\
10.5 \\
34.3 \\
2.4 \\
24.4 \\
27.9 \\
15.7 \\
16.3 \\
21.7 \\
8.5 \\
19.9 \\
13.3\end{array}$ & $\begin{array}{r}20.2 \\
48.6 \\
103.5 \\
69.0 \\
38.3 \\
27.5 \\
167.0 \\
48.4 \\
28.2 \\
43.7 \\
4.3\end{array}$ & $\begin{array}{r}240.1 \\
20.5 \\
35.9 \\
6.8 \\
85.0 \\
42.9 \\
182.8 \\
55.4 \\
1.8 \\
72.3 \\
22.4 \\
324.4\end{array}$ & $\begin{array}{r}60.0 \\
24.8 \\
90.7 \\
24.1 \\
77.6 \\
68.9 \\
31.8 \\
28.1 \\
25.9 \\
132.4 \\
157.4\end{array}$ & $\begin{array}{r}21.1 \\
7.0 \\
12.0 \\
61.6 \\
66.5 \\
160.9 \\
38.6 \\
95.0 \\
38.9 \\
124.4 \\
128.4 \\
103.6\end{array}$ & $\begin{array}{r}4.5 \\
35.9 \\
69.7 \\
40.7 \\
103.2 \\
10.3 \\
82.2 \\
\\
19.1 \\
\\
\text { II.7 }\end{array}$ & $\begin{array}{c}\text { II.0 } \\
- \\
10.4 \\
10.5 \\
29.4 \\
2.6 \\
1.1 \\
8.9\end{array}$ & $\begin{array}{l}- \\
2.3 \\
0.0 \\
0.0 \\
- \\
6.4 \\
- \\
-\end{array}$ & $\begin{array}{c}{[6.0]} \\
{[289.9]} \\
122.7 \\
197.0 \\
3+6.3 \\
357.0 \\
+77.2 \\
3+4.6 \\
403.3 \\
1+5.3 \\
304.5 \\
+10.2 \\
674.4\end{array}$ \\
\hline+3 & Haris $22-5 \mathrm{O}^{\prime}$ s Br. & 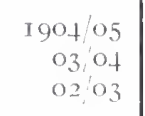 & $\overline{-}$ & - & $\begin{array}{l}0.2 \\
2.0\end{array}$ & $\begin{array}{l}-- \\
- \\
--\end{array}$ & $\begin{array}{l}- \\
0.0 \\
3.6\end{array}$ & $\begin{array}{r}5.0 \\
\text { I } 18.3 \\
29.7\end{array}$ & $\begin{array}{r}\text { IOI.O } \\
291.5 \\
28.3\end{array}$ & $\begin{array}{l}\text { I } 81.0 \\
\leftarrow \ldots \\
96.0\end{array}$ & $\begin{array}{c}53.5 \\
104.5\rangle \\
11.6\end{array}$ & $\frac{\mathrm{I} 2.5}{2 \mathrm{I} .2}$ & & & 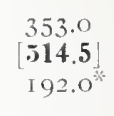 \\
\hline 44 & Kowas .a. $22^{6} 55^{\prime}$ s. Br. & $\begin{array}{r}1903,04 \\
02 / 03\end{array}$ & 0.0 & $\begin{array}{c}0.0 \\
-\end{array}$ & 0.0 & & $\begin{array}{l}0.0 \\
3.3\end{array}$ & $24 . I$ & II.3 & $50 . \mathrm{I}$ & 9.8 & - & & & $\begin{array}{l}{[0.0]} \\
98.6\end{array}$ \\
\hline 45 & $\begin{array}{l}\text { Watsamas } \\
2257^{\prime} \text { s. Br. }\end{array}$ & $\begin{array}{r}\text { I } 904 / 05 \\
03 / 04 \\
02 / 03 \\
01 / 02 \\
00 / 01 \\
\text { I } 899 / 00 \\
98 / 99 \\
96 / 97\end{array}$ & $\frac{0.0}{-}$ & $\begin{array}{l}-\bar{c} \\
\overline{-} \\
0.0 \\
\overline{0} \\
0.5\end{array}$ & $\begin{array}{l}- \\
- \\
-0.0 \\
-\end{array}$ & $\begin{array}{r}10.2 \\
0.0 \\
12.8 \\
2.3 .2\end{array}$ & $\begin{array}{r}0.0 \\
12.5 \\
27.5 \\
7.1 \\
12.3\end{array}$ & $\begin{array}{r}10.7 \\
90.3 \\
25.4 \\
92.6 \\
139.0 \\
31.6\end{array}$ & $\begin{array}{r}169.4 \\
9.2 \\
13.5 \\
5.0 \\
82.2\end{array}$ & $\begin{array}{r}82.3 \\
0.0 \\
88.9 \\
22.6 \\
51.1 \\
6.4\end{array}$ & $\begin{array}{r}49.8 \\
26.3 \\
12.6 \\
2.9 \\
64.0 \\
107.7\end{array}$ & \begin{tabular}{|r|}
1.1 \\
67.3 \\
- \\
29.3 \\
50.6 \\
35.8 \\
III.5 \\
98.4
\end{tabular} & $\begin{array}{l}1+.0 \\
- \\
- \\
\text { I } 5.7 \\
32.4\end{array}$ & $\begin{array}{c} \\
\ldots \\
- \\
- \\
-\end{array}$ & $\begin{array}{l}{\left[\begin{array}{c}I \\
5\end{array}+.1\right]} \\
367.3 \\
I+8.6^{*} \\
201.2 \\
316.8 \\
3+3.2 \\
{\left[\begin{array}{l}1+3.9 \\
{[98.4}\end{array}\right.}\end{array}$ \\
\hline+6 & $\begin{array}{l}\text { Walfischibai } \\
22^{\circ} 56^{\prime} 30^{\prime \prime} \therefore \text { Br. }\end{array}$ & $\begin{array}{r}\text { I } 901 / 02 \\
00 / 01 \\
\text { I } 899 / 00 \\
98 / 99 \\
97 / 98 \\
96 / 97 \\
95 / 96 \\
94 / 95 \\
93 / 94 \\
92 / 93 \\
91 / 92 \\
90 / 91 \\
\text { I } 889 / 90 \\
88 / 89 \\
87 / 88 \\
86 / 87 \\
85 / 86\end{array}$ & $\begin{array}{l}- \\
- \\
- \\
- \\
- \\
- \\
-\end{array}$ & $\begin{array}{l}0.0 \\
-- \\
-- \\
-- \\
5.6 \\
-- \\
-- \\
--\end{array}$ & $\begin{array}{l}0.0 \\
0.0 \\
0.0 \\
0 \\
\\
+1.0 \\
1.0 \\
- \\
- \\
1.0\end{array}$ & $\begin{array}{r}2.5 \\
2.5 \\
10.2 \\
\\
0.0 \\
- \\
\cdots \\
- \\
2.0 \\
- \\
-\end{array}$ & $\begin{array}{c}- \\
0.0 \\
0.0 \\
0.0 \\
0 \\
-- \\
2.0 \\
- \\
+0\end{array}$ & $\begin{array}{c}0.0 \\
0.3 \\
0.0 \\
- \\
- \\
- \\
- \\
- \\
- \\
-\end{array}$ & $\begin{array}{l}-\overline{0.0} \\
\ldots \\
- \\
- \\
5.0 \\
- \\
- \\
0.5 \\
1.8\end{array}$ & $\begin{array}{l}0.0 \\
0.6 \\
6.6 \\
0.1 \\
0.0 \\
1.4 \\
2.2\end{array}$ & $\begin{array}{r}- \\
1+7 \\
1.6 \\
-- \\
- \\
1.7\end{array}$ & $\begin{array}{l}0.2 \\
2.0 \\
0.0 \\
\\
+ \\
- \\
- \\
13.0 \\
-0.0 \\
- \\
- \\
-\end{array}$ & $\begin{array}{l}0.3 \\
0.3 \\
0.0 \\
0.0 \\
- \\
-- \\
- \\
0.0 \\
- \\
6.6 \\
-\end{array}$ & $\begin{array}{l}0.0 \\
0.0 \\
- \\
- \\
- \\
- \\
- \\
- \\
-\end{array}$ & $\begin{array}{c}{[2.5]} \\
3.0 \\
12.8 \\
{[0.0]} \\
\\
|0.0| \\
|0.0| \\
0.0] \\
0.0 \\
21.3 \\
33.3 \\
1.0 \\
0.0 \% \\
0.0 \\
5.9 \\
14.4 \\
|2.2|\end{array}$ \\
\hline 47 & $\begin{array}{l}\text { Rehobutl } \\
23^{\circ} 19^{\prime} \& \text { Br. }\end{array}$ & $\begin{array}{r}\text { I } 90+05 \\
03 / 04 \\
02 / 03 \\
01 / 02 \\
00 \% 101 \\
\text { I } 899 \text { Oo } \\
98 / 99 \\
97 / 98 \\
96 / 97 \\
95 / 96 \\
94 / 95 \\
93 / 94 \\
92 / 93 \\
91 / 92 \\
90 / 91 \\
\text { I } 889 / 90 \\
88 / 89\end{array}$ & $\begin{array}{l}- \\
0.5 \\
- \\
- \\
1.0 \\
- \\
- \\
\cdots \\
- \\
- \\
- \\
0.3 \\
<\cdots\end{array}$ & $\begin{array}{c}- \\
- \\
- \\
- \\
- \\
\\
- \\
5 \\
5.8 \\
\ldots \\
\ldots \\
\ldots\end{array}$ & $\begin{array}{c}0.0 \\
- \\
- \\
- \\
- \\
- \\
- \\
0.1 \\
- \\
- \\
0.7 \\
\ldots . . \\
3.5\end{array}$ & $\begin{array}{r}1.5 \\
-- \\
1.3 .5 \\
0.0 \\
16.9 \\
- \\
0.8 \\
8.6 \\
-\overline{1}+6 \\
0.4 \\
21.9 \\
14.1 \\
+0.3 \\
-\end{array}$ & \begin{tabular}{r}
\multicolumn{1}{c}{2.6} \\
- \\
34.0 \\
0.4 \\
20.7 \\
18.3 \\
6.9 \\
8.2 \\
15.4 \\
6.2 \\
10.8 \\
18.3 \\
86.2 \\
$\ldots .$.
\end{tabular} & $\begin{array}{l}19.8 \\
56.8 \\
14.6 \\
38.8 \\
46.0 \\
17.3 \\
13.5 \\
- \\
87.5 \\
16.5 \\
22.6 \\
+2.3 \\
35.7 \\
11.2 \\
\ldots .>\end{array}$ & $\begin{array}{r}22.2 \\
228.0 \\
1.8 \\
4.5 \\
21.3 \\
49.4 \\
57.3 \\
139.5 \\
37.6 \\
0.8 \\
29.5 \\
22.5 \\
248.1 \\
185.8 \\
+5.1\end{array}$ & $\begin{array}{r}116.5 \\
1.0 \\
80.0 \\
13.0 \\
40.8 \\
14.1 \\
67.1 \\
95.4 \\
+7.1 \\
26.2 \\
29.7 \\
103.3 \\
207.5 \\
30.9 \\
17.7\end{array}$ & $\begin{array}{r}14.8 \\
40.6 \\
14.8 \\
5.9 \\
7.6 \\
38.5 \\
96.5 \\
12.7 \\
48.6 \\
47.2 \\
102.7 \\
126.7 \\
60.8 \\
92.9 \\
70.4\end{array}$ & $\begin{array}{r}4.2 \\
+3.3 \\
- \\
12.6 \\
49.8 \\
32.0 \\
55.4 \\
38.3 \\
71.2 \\
0.1 \\
26.1 \\
0.7 \\
4.1 \\
78.4 \\
29.0\end{array}$ & $\begin{array}{c}27.6 \\
- \\
0.3 \\
0.5 \\
49.7 \\
0.6 \\
1.2 \\
- \\
7.7 \\
3.7 \\
0.0 \\
1.0\end{array}$ & $\begin{array}{c}- \\
- \\
- \\
- \\
- \\
\\
9.6 \\
- \\
- \\
-\end{array}$ & $\begin{array}{l}\text { I } 81.6 \\
397.8 \\
\text { II } 1.2 \\
\text { I } 22.6 \\
167.2 \\
193.4 \\
347.8 \\
294.2 \\
310.0 \\
115.9 \\
239.1 \\
369.2 \\
598.9 \\
501.5 \\
18.5 \\
217.9 \\
146.4\end{array}$ \\
\hline
\end{tabular}




\begin{tabular}{|c|c|c|c|c|c|c|c|c|c|c|c|c|c|c|c|}
\hline Lfill. & $\begin{array}{l}\text { Tame } \\
\text { let Station }\end{array}$ & $\begin{array}{c}\text { Jalur } \\
\text { ler Beob- } \\
\text { açhtung }\end{array}$ & $\begin{array}{l}\text { Juli } \\
\text { mm }\end{array}$ & Ame. & -ept. & rikt. & Vigr. & $\begin{array}{l}\text { Dez. } \\
\mathrm{mm}\end{array}$ & Jan. & $\begin{array}{l}\text { Fehr. } \\
\text { mm }\end{array}$ & $\begin{array}{l}. \text { Mằr } \\
\text { mm }\end{array}$ & April & Mlai & Irmi & $\begin{array}{c}\text { Jahre:- } \\
\text { summe } \\
\text { nm }\end{array}$ \\
\hline & $\begin{array}{l}\text { Rehoboth } \\
23^{2} 19^{\prime} \text { s. Pir. }\end{array}$ & $\begin{array}{l}s_{7}-88 \\
86,87 \\
8_{5}, 86 \\
s_{4} s_{5} \\
s_{3} s_{4}\end{array}$ & $\underline{-}$ & $\underline{-}$ & $\frac{0.3}{3.3}$ & $\begin{array}{r}4.5 \\
0.7 \\
19.7\end{array}$ & I0. & $\frac{19.2}{0.6}$ & $\begin{array}{l}50.7 \\
13.6\end{array}$ & $\begin{aligned} \text { I } 10.6 \\
\text { I } 3.5\end{aligned}$ & $\begin{array}{r}137.5 \\
14.5\end{array}$ & $\begin{array}{l}29.4 \\
36.5\end{array}$ & $\begin{array}{c}\cdot \\
\frac{-}{5.6}\end{array}$ & & $\begin{array}{r}213.2 \\
2+6.5 \\
5.1 \\
3+8.0 \\
115.3\end{array}$ \\
\hline ts & $\begin{array}{l}\text { Hopemine } . . . \\
\text { ra. } 23^{\prime} 25^{\prime} \therefore \text { Br. }\end{array}$ & I $88_{5} \$ \mathrm{S6}$ & & & & & & & $<$ & 35.6 & $\ldots>$ & & & & 3.5 .5 \\
\hline+9 & $\begin{array}{l}\text { Nauchas } \\
\text { 'a. } 23^{2}+5^{\prime} \text { B. Br. }\end{array}$ & $\begin{array}{r}\text { I904 } 05 \\
03 / 04 \\
02,03 \\
0102 \\
0001 \\
\text { I } 89900\end{array}$ & $\begin{array}{l}0.3 \\
0.0 \\
\frac{-}{-} \\
0.5\end{array}$ & $\begin{array}{l}- \\
0.0 \\
2.7 \\
0.0 \\
-\end{array}$ & $\begin{array}{l}-- \\
0.0 \\
2.5 \\
-\end{array}$ & $\begin{array}{l}\bar{c} \\
\overline{0.0} \\
\overline{0.2} \\
0.0\end{array}$ & $\begin{array}{c}-\overline{-} \\
\overline{-} \\
\overline{16 . \overline{7}} \\
0.0\end{array}$ & $\begin{array}{l}10.5 \\
89.4 \\
22.1 \\
46.2 \\
25.2\end{array}$ & $\begin{array}{r}3+.9 \\
22+.9 \\
0.3 \\
12.4 \\
6.5\end{array}$ & $\begin{array}{r}129.7 \\
0.0 \\
36.1 \\
\text { IS. } \\
52.7 \\
2.6\end{array}$ & $\begin{array}{r}16.7 \\
3+.9 \\
- \\
19.3 \\
3.7 \\
29.1\end{array}$ & $\begin{array}{r}\text { I } 5.8 \\
23 . \mathrm{I} \\
\text { I. I } \\
1.0 \\
27.9 \\
59.9\end{array}$ & $\begin{array}{l}\dot{-} \\
5.3 \\
- \\
0.2 \\
4.0\end{array}$ & $\begin{array}{l}5.6 \\
- \\
- \\
-\end{array}$ & $\begin{array}{r}216.5 \\
377.6 \\
64.5 \\
\text { I } 14.2 \\
\text { I } 16.7 \\
125.6\end{array}$ \\
\hline 50 & $\begin{array}{c}\text { Aminuis } \\
23^{2}+5^{\prime}\end{array}$ & $\begin{array}{r}1904,05 \\
0304 \\
0203 \\
0102 \\
00,01 \\
159900 \\
98,99\end{array}$ & $\begin{array}{c}-- \\
2.0 \\
0.1 \\
- \\
\overline{1} \overline{7} .2\end{array}$ & $\begin{array}{l}- \\
0.1 \\
- \\
- \\
I_{-5}\end{array}$ & $\begin{array}{l}4.5 \\
1.2 \\
2 . I \\
5.5 \\
-\end{array}$ & $\begin{array}{c}- \\
5.0 \\
\overline{7.7} \\
0.0 \\
19.2\end{array}$ & $\begin{array}{r}1.5 \\
4.0 \\
49.4 \\
9.2 \\
10.0\end{array}$ & $\begin{array}{l}+3.3 \\
72.8 \\
30.4 \\
+4.4 \\
28.6 \\
57.0\end{array}$ & $\begin{array}{r}70.5 \\
106.4 \\
20.5 \\
40.5 \\
7.8 \\
49.0\end{array}$ & $\begin{array}{r}130.5 \\
19.2 \\
95.4 \\
14.8 \\
35.0 \\
0.0 \\
\text { I } 1.0\end{array}$ & $\begin{array}{r}18.5 \\
\text { I } 27.3 \\
3.2 \\
0.6 \\
76.3 \\
63.5 \\
72.6\end{array}$ & $\begin{array}{r}+.5 \\
8.3 \\
2.7 \\
+1.0 \\
+3.1 \\
+3.2 \\
99.9\end{array}$ & $\begin{array}{l}\frac{5}{1.6} \\
- \\
- \\
-6.0\end{array}$ & $\begin{array}{l}- \\
- \\
-7 \cdot+ \\
0.5 \\
2.7 \\
-\end{array}$ & $\begin{array}{l}273.6 \\
343.9 \\
163.7 \\
219.6 \\
200.5 \\
263.3 \\
259.5 .\end{array}$ \\
\hline 51 & $\begin{array}{l}\text { Hoachanas . } \\
23^{2} 57^{\prime} \leq \text { Pir. }\end{array}$ & $\begin{array}{r}190405 \\
03 \text { O4 } \\
02,03 \\
0102 \\
00 / 01 \\
1899.00 \\
9599\end{array}$ & $\begin{array}{l}- \\
0.0 \\
- \\
- \\
2.8 \\
-\end{array}$ & $\begin{array}{l}- \\
- \\
- \\
0.0 \\
-\end{array}$ & $\begin{array}{l}- \\
0.0 \\
- \\
0.0 \\
- \\
-\end{array}$ & $\begin{array}{l}\text { I.O } \\
0.0 \\
- \\
0.3 \\
\overline{6.0} \\
-\end{array}$ & $\begin{array}{r}- \\
0.0 \\
\\
15.4 \\
4.0 \\
0.6 \\
7.5\end{array}$ & $\begin{array}{r}3.3 \\
83.8 \\
4.9 \\
9.6 \\
11.0 \\
0.2 \\
-\end{array}$ & $\begin{array}{r}21.3 \\
199.0 \\
4.2 \\
20.9 \\
- \\
4.0 \\
18.9\end{array}$ & $\begin{array}{r}\text { I I I.3 } \\
3.2 \\
\text { I } 33.9 \\
3.8 \\
5.5 \\
6.6 \\
\text { I } 3 \text { I.S }\end{array}$ & $\begin{array}{r}27.3 \\
76.7 \\
14.8 \\
22.2 \\
1.0 \\
61.9 \\
50.9\end{array}$ & $\begin{array}{r}23.2 \\
17.9 \\
- \\
2.0 \\
31.7 \\
125.2 \\
75.5\end{array}$ & $\begin{array}{c}9.2 \\
- \\
- \\
5.0 \\
15.0\end{array}$ & $\begin{array}{l}- \\
- \\
- \\
-3 \\
-\end{array}$ & $\begin{array}{l}\text { I } 8-.4 \\
389.8 \\
\text { I } 57.8 \\
32.5 \\
53.2 \\
215.3 \\
299.9\end{array}$ \\
\hline 52 & Kuis $2+$ Is's Br. & 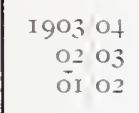 & $\begin{array}{l}0.0 \\
1 .+\end{array}$ & I.O & $\begin{array}{l}1.0 \\
0 . \bar{\jmath}\end{array}$ & $\begin{array}{l}0.0 \\
0.2\end{array}$ & $\overline{0.3}$ & $\begin{array}{l}6-.1 \\
23.9\end{array}$ & $\begin{array}{r}197.3 \\
3.0\end{array}$ & $\begin{array}{l}\text { II.I } \\
\text { SI.I }\end{array}$ & $\begin{array}{l}3 \mathrm{I} .6 \\
\mathrm{I} 3.3\end{array}$ & $\begin{array}{r}23.8 \\
0.2 \\
13.5\end{array}$ & - & $\frac{-}{-.2}$ & $\begin{array}{l}332.9 \\
\text { I24.1 } \\
{[21.0]}\end{array}$ \\
\hline 53 & $\begin{array}{c}\text { Jomtsas } \\
\text { ca. } 2 t^{2}{ }_{2} S^{\prime} \text { s. Br. }\end{array}$ & $\begin{array}{r}1904 / 05 \\
03 \text { O4 } \\
02 / 03 \\
01,02 \\
0001 \\
\text { I } 89900 \\
90.99\end{array}$ & $\begin{array}{l}- \\
0.0 \\
2.0 \\
- \\
- \\
-\end{array}$ & $\begin{array}{l}- \\
- \\
- \\
- \\
-\end{array}$ & $\begin{array}{l}0.0 \\
- \\
0.0 \\
- \\
-\end{array}$ & $\begin{array}{c}0.0 \\
\overline{2.4} \\
\overline{1} \\
\overline{-} . \overline{7}\end{array}$ & $\begin{array}{l}- \\
2.6 \\
6.6 \\
9.6 \\
1.0\end{array}$ & $\begin{array}{r}17.0 \\
57.6 \\
15.3 \\
24.5 \\
17.0 \\
1.4 \\
0.9\end{array}$ & $\begin{array}{r}30.0 \\
\text { I }+4.1 \\
- \\
\text { II.5 } \\
1.0 \\
19.7 \\
7+.0\end{array}$ & $\begin{array}{r}93.5 \\
1.5 \\
52.5 \\
8.0 \\
27.9 \\
7.0 \\
92.9\end{array}$ & $\begin{array}{r}22.2 \\
56.8 \\
8.0 \\
19.6 \\
19.0 \\
23.4 \\
107.6\end{array}$ & $\begin{array}{r}9.0 \\
53.6 \\
2.0 \\
14.0 \\
15.0 \\
+5.4 \\
71.5\end{array}$ & $\begin{array}{l}-\bar{c} \\
0.6 \\
- \\
- \\
0.5 \\
i .7 \\
8.6\end{array}$ & $\begin{array}{l}- \\
\frac{1.5}{-} \\
0.0\end{array}$ & $\begin{array}{c}171.7 \\
314.5 \\
79.5^{2} \\
84.3 \\
97.0 \\
128.9 \\
356.5\end{array}$ \\
\hline $5+$ & $\begin{array}{l}\text { Mariental } \\
\text { ca. } 2 t^{2}+0^{\prime} \text { s. Br. }\end{array}$ & $\begin{array}{r}\text { I } 904 \text { O5 } \\
03 \text { O4 } \\
02,03 \\
01 \text { O2 } \\
00 \text { OI } \\
\text { I } 399,00\end{array}$ & $\begin{array}{l}0.0 \\
0.6 \\
- \\
-\end{array}$ & $\begin{array}{l}- \\
- \\
-\end{array}$ & $\frac{0.0}{-}$ & $\frac{0.0}{-}$ & $\begin{array}{l}13.5 \\
11.3 \\
-\end{array}$ & $\begin{array}{l}+9.7 \\
36.6 \\
20.6 \\
19.0\end{array}$ & $\begin{array}{r}\text { I I } 1.7 \\
3.4 \\
25.5 \\
3.1\end{array}$ & $\begin{array}{r}26.6 \\
76.5 \\
3.1 \\
40.6\end{array}$ & $\begin{array}{r}78.0 \\
0.8 \\
10.6 \\
20.4 \\
52.3\end{array}$ & $\begin{array}{r}20.5 \\
0.3 \\
4.6 \\
19.0 \\
47.7\end{array}$ & $\begin{array}{l}- \\
- \\
-\end{array}$ & $\begin{array}{l}- \\
-.5 \\
0.0 \\
-\end{array}$ & $\begin{array}{c}0.0] \\
286.5 \\
132.0 \\
85.7 \\
102.1 \\
100.0\end{array}$ \\
\hline 55 & $\begin{array}{l}\text { Gochas } \\
\text { ca. } 2 t^{\circ} t^{\prime} \text { s. Br. }\end{array}$ & $\begin{array}{r}190405 \\
0304 \\
0203 \\
0102 \\
00 \% 1 \\
\text { IS99, } 00\end{array}$ & $\begin{array}{l}- \\
0.0 \\
2.3 \\
- \\
- \\
-\end{array}$ & $\begin{array}{l}- \\
0.0 \\
- \\
- \\
-\end{array}$ & $\begin{array}{l}- \\
0.0 \\
0.8 \\
3.2 \\
-\end{array}$ & $\begin{array}{l}- \\
0.0 \\
-\overline{3.3} \\
0.0 \\
-\end{array}$ & $\begin{array}{l}- \\
- \\
2.0 \\
6.4 \\
8.2 \\
-\end{array}$ & $\begin{array}{l}- \\
54.3 \\
29.5 \\
19.0 \\
60.7\end{array}$ & $\begin{array}{r}- \\
194.1 \\
31.9 \\
34.2 \\
2.0 \\
-\end{array}$ & $\begin{array}{r}- \\
5.6 \\
28.0 \\
7.8 \\
39.1 \\
-\end{array}$ & $\begin{array}{l}-\overline{53.6} \\
\frac{7.6}{7.6} \\
56.1 \\
65.0\end{array}$ & $\begin{array}{l}- \\
17.0 \\
- \\
\overline{53.2} \\
67.7\end{array}$ & $\begin{array}{r}- \\
2.3 \\
1.2 \\
- \\
\text { I.O } \\
\text { II } 6\end{array}$ & $\begin{array}{l}- \\
- \\
+.8 \\
2.1 \\
-\end{array}$ & $\begin{array}{c}0.0] \\
326.9 \\
95.7 \\
56.3 \\
222.4 \\
{[1+4.3]}\end{array}$ \\
\hline 56 & $\begin{array}{l}\text { Naltahöhe } \\
\text { ca. } 24^{\circ} 50^{\prime} \text { s. Br. }\end{array}$ & $\begin{array}{r}1904,05 \\
03,04 \\
0203 \\
01 / 02 \\
00,01 \\
\text { I } 99900\end{array}$ & $\begin{array}{l}- \\
0.0 \\
2 . I \\
-\end{array}$ & $\begin{array}{l}\overline{0.0} \\
\overline{0.0} \\
-\end{array}$ & $\begin{array}{l}\overline{-} \\
0.4 \\
\overline{0.0} \\
-\end{array}$ & $\begin{array}{r}- \\
- \\
\text { II. } 6 \\
0.0\end{array}$ & $\begin{array}{l}- \\
- \\
.5 \\
0.7\end{array}$ & $\begin{array}{l}- \\
24.1 \\
28.8 \\
\text { II. } \\
\text { I0.4 }\end{array}$ & $\begin{array}{r}10.0 \\
169.1 \\
1.6 \\
0.3 \\
2.3\end{array}$ & $\begin{array}{r}63.7 \\
1.6 \\
62.5 \\
6.5 \\
22.3\end{array}$ & $\begin{array}{r}20.0 \\
60.4 \\
10.9 \\
25.0 \\
3.3 \\
11.2\end{array}$ & $\begin{array}{r}9.0 \\
- \\
I .5 \\
28.1 \\
104.5\end{array}$ & $\begin{array}{l}\overline{-} \\
0.0 \\
- \\
- \\
-\end{array}$ & $\begin{array}{c}\frac{}{0.0} \\
- \\
0.0 \\
--\end{array}$ & $\begin{array}{c}102.7 \\
{[255.6]} \\
105.9 \\
55.7 \\
67.1 \\
115.7]\end{array}$ \\
\hline 57 & $\begin{array}{l}\text { Gibeon } \\
25^{\circ} 7^{\prime} \text { s. Br. }\end{array}$ & $\begin{array}{r}1904 / 05 \\
0304 \\
0203 \\
01 / 02 \\
00 / 01 \\
1999 / 00 \\
98 / 99\end{array}$ & $\begin{array}{l}- \\
0.0 \\
2.1 \\
- \\
- \\
-\end{array}$ & $\begin{array}{l}- \\
- \\
- \\
- \\
-\end{array}$ & $\begin{array}{l}- \\
\mathrm{I.2} \\
- \\
- \\
- \\
-\end{array}$ & $\begin{array}{c}- \\
- \\
2.0 \\
17.2 \\
- \\
22.1 \\
-\end{array}$ & $\begin{array}{r}0.0 \\
- \\
22.2 \\
1.5 \\
9.0 \\
9.0\end{array}$ & $\begin{array}{r}3.4 \\
32.1 \\
5.1 \\
16.9 \\
7.1 \\
0.2 \\
17.0\end{array}$ & $\begin{array}{r}3.2 \\
\text { I S1.S } \\
5.2 \\
27.9 \\
4.3 \\
19.4 \\
116.0\end{array}$ & $\begin{array}{r}7+.7 \\
\text { II.2 } \\
3.5 .0 \\
19.8 \\
3.8 \\
0.2 \\
67.8\end{array}$ & $\begin{array}{l}35.4 \\
32.2 \\
8.3 \\
18.9 \\
23.8 \\
35.3 \\
66.0\end{array}$ & $\begin{array}{l}\text { I0.8 } \\
\text { I } 3.5 \\
5.2 \\
- \\
\text { II.2 } \\
21.8 \\
63.8\end{array}$ & $\begin{array}{l}- \\
- \\
- \\
- \\
3.0 \\
-\end{array}$ & $\begin{array}{l}- \\
- \\
- \\
\text { I.9 } \\
0.0 \\
3.0\end{array}$ & $\begin{array}{r}\text { I } 27.5 \\
272.0 \\
65.9 \\
\text { I } 24.5 \\
51.7 \\
\text { II } 4.0 \\
339.6\end{array}$ \\
\hline
\end{tabular}




\begin{tabular}{|c|c|c|c|c|c|c|c|c|c|c|c|c|c|c|c|}
\hline $\begin{array}{l}\text { Lfu. } \\
\text { Nr. }\end{array}$ & $\begin{array}{l}\text { Name } \\
\text { der Stattion }\end{array}$ & $\begin{array}{c}\text { Jahr } \\
\text { der Beob- } \\
\text { achtumg }\end{array}$ & $\begin{array}{l}\text { Juli } \\
\mathrm{mm}\end{array}$ & $\begin{array}{l}\text { Aug. } \\
\text { mmx }\end{array}$ & sept. & Okt. & $\begin{array}{l}\text { Nor. } \\
\text { mum }\end{array}$ & $\begin{array}{l}\mathrm{Dez} \\
\mathrm{mm}\end{array}$ & Jan. & $\begin{array}{l}\text { Febt. } \\
\text { min }\end{array}$ & März & April & Mlai & $\begin{array}{l}\text { Juni } \\
\mathrm{mm}\end{array}$ & $\begin{array}{c}\text { Jalures- } \\
\text { slumme } \\
\text { mm }\end{array}$ \\
\hline 59 & $\begin{array}{l}\text { Föraliorabes } \\
\text { cal. } 25^{\prime} 3^{\prime} \text { s. Br. }\end{array}$ & 190203 & -- & & & & 6.2 & & & & & & & & {$[6.2]$} \\
\hline 59 & $\begin{array}{l}\text { Dentsche Erde. } \\
\text { cat. } 25^{\prime \prime} 20^{\prime} \text { s. Bir. }\end{array}$ & $1903,0.4$ & 0.0 & $0 . .1$ & & & & & & & & & & & $\lfloor 0.4 \mid$ \\
\hline \multirow[t]{4}{*}{60} & Kulits 2 'at. 25 s5 Bir. & $\begin{array}{r}1904,05 \\
030^{\prime}\end{array}$ & $\overline{0.0}$ & - & I. I & 0.0 & - & 35.2 & I 69.2 & - & 21.5 & I 8.2 & - & - & $\begin{array}{r}|0.0| \\
245.2\end{array}$ \\
\hline & & $02 / 03$ & 6.8 & - & - & - & & 23.8 & & 81.9 & 3.9 & I.I & - & & I 17.7 \\
\hline & & $01 / 02$ & - & - & & & 8.3 & 31.4 & & 3.0 & 23.6 & $7 \cdot 4$ & 一 & - & $73.7^{*}$ \\
\hline & & $\begin{array}{r}00 / 01 \\
\text { I } 899 / 00\end{array}$ & - & & - & - & - & 60.6 & $3 \cdot 4$ & 39.1 & 34.5 & I0.3 & 2.5 & 0.6 & $\begin{array}{r}\mathrm{I} 47.9 \\
{[3 . \mathrm{I} \mid}\end{array}$ \\
\hline \multirow[t]{4}{*}{61} & $\begin{array}{l}\text { Bersebla } \\
\text { ca. } 25 \quad 59^{\prime} \text { s. Iir. }\end{array}$ & $\begin{array}{r}1904 / 05 \\
0304\end{array}$ & & - & 0.0 & - & & & $3^{0.1}$ & 37.3 & 78.3 & 4.2 & 3.8 & - & $\begin{array}{r}{\left[\begin{array}{c}153.7 \\
{[0.0]}\end{array}\right.} \\
\end{array}$ \\
\hline & & 0203 & & - & - & - & & 0.5 & - & 32.7 & 9.0 & $\cdots$ & - & -. & 42.2 \\
\hline & & $01 / 02$ & & & 0.0 & 0.0 & 0.2 & 0.2 & - & 0.7 & 8.0 & - & - & - & 9. I \\
\hline & & $\begin{array}{r}00 \text { OI } \\
\text { I } 899 / 00\end{array}$ & - & & - & & & 3.9 & 46.0 & 0.0 & & 20.9 & - & & $\begin{array}{l}70.8 \\
{[0.0]}\end{array}$ \\
\hline \multirow[t]{8}{*}{62} & Bethanien & $1904 / 05$ & $\mathrm{r} .4$ & & & 2.6 & - & 17.3 & - & 49.6 & 38.2 & I 2.5 & 5.2 & & I 26.8 \\
\hline & $26 \quad 30^{\prime} \mathrm{s}$. Br. & $\mathrm{O}_{3} \mathrm{O}_{4}$ & 0.0 & & 2.9 & $\cdots$ & & 30.I & 70.7 & $4 . I$ & 66.6 & 53.1 & 3.2 & 0.0 & 230.7 \\
\hline & & $02 / 03$ & - & 0.9 & I. 5 & - & & 4.2 & -- & 50.7 & 8.0 & - & - & - & 65.3 \\
\hline & & $\mathrm{O} 1 \mathrm{O} 2$ & - & & 0.0 & - & 14.2 & 2.5 & 0.0 & - & I0.9 & I6.8 & & 0.3 & $44.7^{*}$ \\
\hline & & $\begin{array}{r}\text { OO/OI } \\
1899 \% 00\end{array}$ & & - & - & 202 & + & 44.2 & 0.2 & $\begin{array}{r}20.6 \\
7.5\end{array}$ & I9. I & 4.4 & $\overline{1.2}$ & $\overline{4.2}$ & 88.5 \\
\hline & & 9899 & & & & 29.2 & 0.4 & 1.3 & 0.1 & 7.5 & 2.0 & 70.2 & 1.2 & 4.- & {$[0.0]$} \\
\hline & & $\begin{array}{l}9495 \\
9394\end{array}$ & & I 3.2 & & & 0.6 & & & 4.6 & I 93. I & & & & $\begin{array}{l}{[93.1]} \\
{[18.4]}\end{array}$ \\
\hline & & 92,93 & 0.7 & - & & [1 4.0] & 0.0 & & 76.8 & 61.8 & $6_{3} .6$ & - & - & 23.7 & {$[240.6]$} \\
\hline \multirow[t]{7}{*}{$6_{3}$} & Keetminshoop. & 190405 & & & & & & 6.4 & 22.5 & $24: I$ & 30.5 & 12.0 & 6.9 & 3.5 & 105.9 \\
\hline & $26^{\prime} 32^{\prime}$ s. 13 t. & $03 / 04$ & 0.0 & 0.0 & 0.0 & -- & - & $37 \cdot 3$ & I I 5.5 & 8.0 & 63.0 & 26.1 & 9.2 & - & 259.1 \\
\hline & & 02,03 & - & & - & - & 4.0 & 8.0 & - & 63.8 & I 7.5 & 2.0 & - & - & 95.3 \\
\hline & & $\begin{array}{l}\mathrm{OI} / \mathrm{O}_{2} \\
00 / 0 \mathrm{I}\end{array}$ & $\overline{0.0}$ & o.o & 0.0 & 3.0 & 163 & 0.0 & 2.5 & I.2 & iI.O & 2.0 & - & $\begin{array}{l}3.5 \\
0.0\end{array}$ & $39.5^{*}$ \\
\hline & & $\begin{array}{r}00 / 01 \\
\text { I 899/00 }\end{array}$ & $\begin{array}{r}0.0 \\
19.5\end{array}$ & - & $\overline{0.0}$ & $\begin{array}{r}0.0 \\
29.5\end{array}$ & $\begin{array}{l}0.0 \\
5.5\end{array}$ & $\begin{array}{r}8.0 \\
\text { I I.O }\end{array}$ & $\begin{array}{r}7.0 \\
24.5\end{array}$ & $\begin{array}{l}\text { I0.0 } \\
15.5\end{array}$ & $\begin{array}{l}51.0 \\
57.0\end{array}$ & $\begin{array}{r}19.5 \\
62.5\end{array}$ & $\cdots$ & 3.0 & $\begin{array}{r}95.5 \\
228.0\end{array}$ \\
\hline & & $98 / 99$ & & & & & 7.0 & & 24.3 & 64.5 & 64.5 & 49.5 & 2.5 & - & {$\left[\begin{array}{llllll}2 & 1 & 2 & 3\end{array}\right]$} \\
\hline & & 97.98 & & & & & & & & 48.0 & 31.4 & 36.4 & & & [ I I 5.8 .8$]$ \\
\hline \multirow[t]{5}{*}{64} & HastuII ...... & $1904 / 05$ & - & - & 0.2 & & & & & & & & & & {$[0.2]$} \\
\hline & (at. $26^{\circ} 36^{\prime}$ s. Isr. & $03 / 04$ & 5.0 & 0.0 & 0.0 & 0.0 & & 41.7 & I 20.9 & 24.5 & 152.5 & 0.0 & 3.0 & I.O & {$[348.6]$} \\
\hline & & $02 / 03$ & - & 0.5 & 0.5 & - & 28.5 & I 3.2 & I0.5 & 71.7 & - & I. 5 & & - & I 26.4 \\
\hline & & $\mathrm{OI} \mathrm{O} 2$ & & 0.0 & 4.1 & 9.0 & II.7 & 22.0 & 0.8 & 30 & 5.0 & 21.7 & - & 0.3 & $77.6^{*}$ \\
\hline & & $\begin{array}{r}00 / 0 \text { I } \\
\text { I } 899 / 00\end{array}$ & 0.5 & 0.0 & - & - & 19.0 & 21.4 & $9 \cdot 3$ & 34.0 & 50.8 & 6.2 & 0.3 & $\begin{array}{r}0.2 \\
14.2\end{array}$ & $\begin{array}{l}\text { I } 41.4 \\
{[14.5]}\end{array}$ \\
\hline \multirow[t]{5}{*}{65} & I.üderitzbuht. & $1904 / 05$ & 2.7 & & 4.0 & & - & & & - & 2.0 & 2.5 & 20.4 & 5.0 & 36.6 \\
\hline & $26^{\circ} 36^{\prime} \mathrm{s}$ Iir. & $03 / 04$ & & 1.6 & 5.5 & - & 0.0 & - & 0.0 & - & 0.4 & 0.9 & 0.8 & 0.0 & $9.2^{*}$ \\
\hline & & $02 / 03$ & & & & & 0.9 & - & 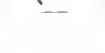 & O. I & 0.4 & 0.5 & 4.0 & 0.9 & {$[6.8]$} \\
\hline & & 1893,94 & & 8.5 & 0.0 & & & & & & & & & & {$[8.5]$} \\
\hline & & $92 / 93$ & & & & & $\ldots$ & 4.8 & - & 16.6 & 0.1 & $\mathrm{I} .5$ & 6.7 & $5 \cdot 3$ & {$[35.0]$} \\
\hline \multirow[t]{3}{*}{66} & Kulbuls & $1904 / 05$ & O.I & 0.4 & O.I & I. 5 & & $\begin{array}{r}4.5 \\
378\end{array}$ & I 8.4 & 18.3 & 47.6 & 2.8 & 22.4 & 0.2 & II $6.3 *$ \\
\hline & $2642^{\prime}$ s. B. & $03 / 04$ & & & - & 0.0 & & 37.8 & 5.7 & $\ldots$ & 20.2 & 16.6 & - & 0.0 & $80.3^{*}$ \\
\hline & & $\begin{array}{r}\text { I } 893 / 94 \\
92 / 93\end{array}$ & - - & $\begin{array}{l}7.3 \\
3.1\end{array}$ & $\begin{array}{l}0.4 \\
9.9\end{array}$ & 0.7 & 0.0 & $5 \cdot 9$ & 39.2 & 40.6 & 54.5 & I 5.0 & 22.1 & 29.6 & $\begin{array}{r}{[7.7]} \\
220.6\end{array}$ \\
\hline \multirow[t]{2}{*}{67} & Sandverhaar ... & $1904 / 05$ & 3.0 & - & $\cdots$ & & & & 7.0 & 30.0 & 65.0 & - & - & - & {$[105.0]$} \\
\hline & ca. 26 & $\begin{array}{l}03 / 04 \\
02 / 03\end{array}$ & - & - & 0.0 & - & & 26.1 & I 6.0 & 44.0 & - & 35.0 & - & 0.0 & $\begin{array}{l}\text { I } 2 \text { I.I } \\
\quad[0.0]\end{array}$ \\
\hline 68 & $\begin{array}{l}\text { Seeheim } \\
\text { ca. } 26^{\circ} 50^{\prime} \text { s. Br. }\end{array}$ & I $897 / 9^{8}$ & $<$. & & & 13.8 & & $\cdots>$ & {$[18.0]$} & 23.0 & 6.0 & 47.0 & - & 一 & 107.8 \\
\hline \multirow[t]{5}{*}{69} & Inachab. . . . . & I $902 / 03$ & - & & I. 4 & - & O.I & 2.0 & - & 40.0 & 0.9 & - & & & 44.4 \\
\hline & ca. $26^{\circ} 59^{\prime}$ s. Br. & $\mathrm{O} 1 / \mathrm{O} 2$ & - & - & $2 . I$ & I.O & 30.0 & 2.0 & - & O.I & 3.0 & 4.2 & - & - & 42.4 \\
\hline & & $\begin{array}{r}\text { OO O I } \\
\text { I } 809 / 00\end{array}$ & $\begin{array}{l}0.0 \\
5.8\end{array}$ & - & $\overline{0.0}$ & $\begin{array}{r}0.0 \\
16.1\end{array}$ & - & 5.7 & $\begin{array}{l}\text { O.O } \\
9.1\end{array}$ & $\begin{array}{l}0.5 \\
0.0\end{array}$ & I 5.5 & $\begin{array}{l}15.1 \\
35.0\end{array}$ & - & $\overline{4.6}$ & $\begin{array}{l}36.8^{*} \\
75.1\end{array}$ \\
\hline & & $\begin{array}{r}1899 / 00 \\
98 / 99\end{array}$ & $\begin{array}{l}5.0 \\
0.6\end{array}$ & - & - & + & 0.0 & $\begin{array}{l}3.1 \\
0.0\end{array}$ & $\begin{array}{r}9.1 \\
15.9\end{array}$ & $\begin{array}{r}0.0 \\
43.1\end{array}$ & $\begin{array}{r}1.4 \\
47.6\end{array}$ & $\begin{array}{l}35.0 \\
35.8\end{array}$ & I 3.3 & - & $\begin{array}{r}75.1 \\
156.3\end{array}$ \\
\hline & & $97 / 9^{8}$ & & & & & & & & & 3.6 & 40.4 & 0.0 & 0.0 & {$[44.0]$} \\
\hline
\end{tabular}




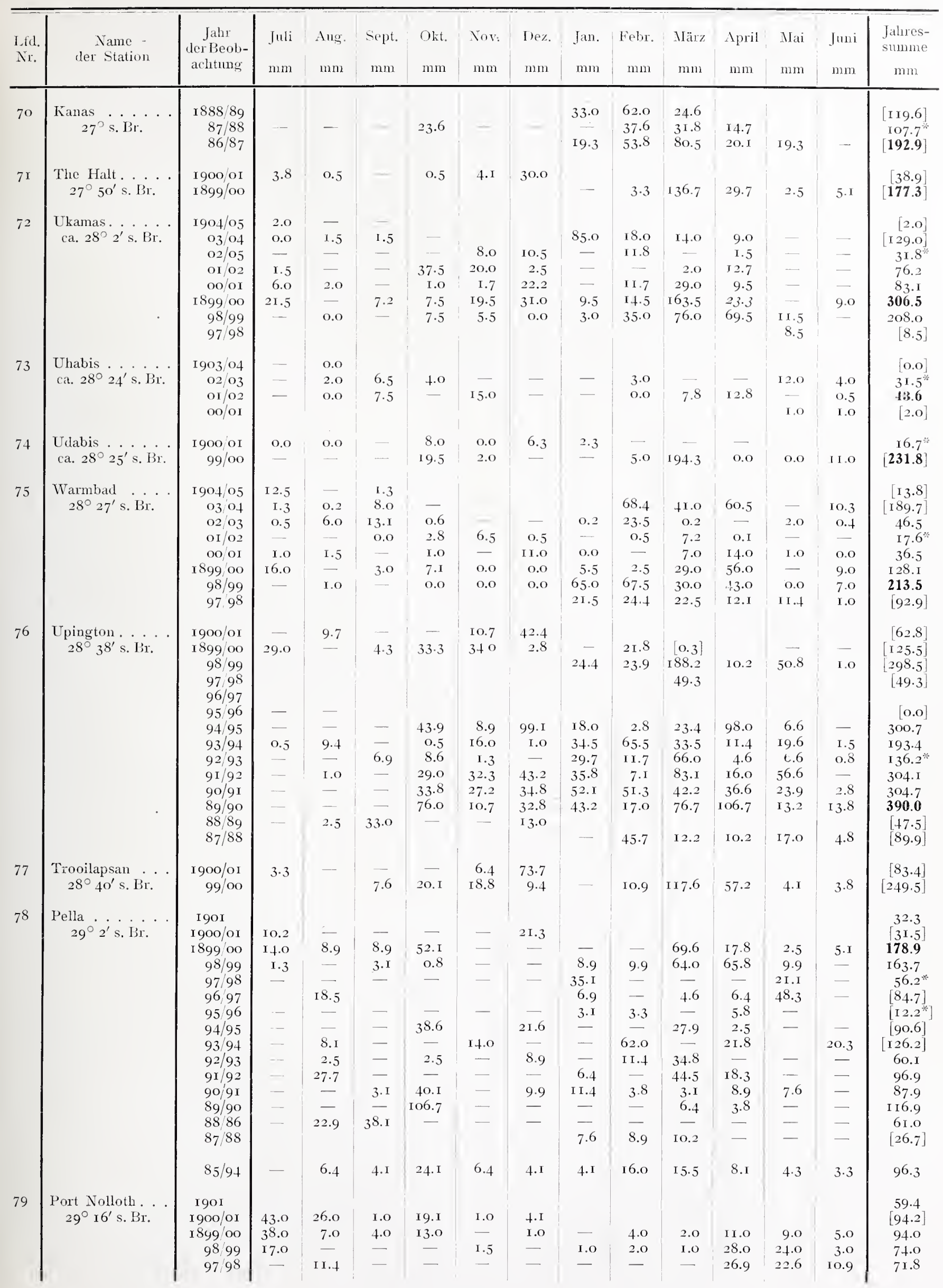




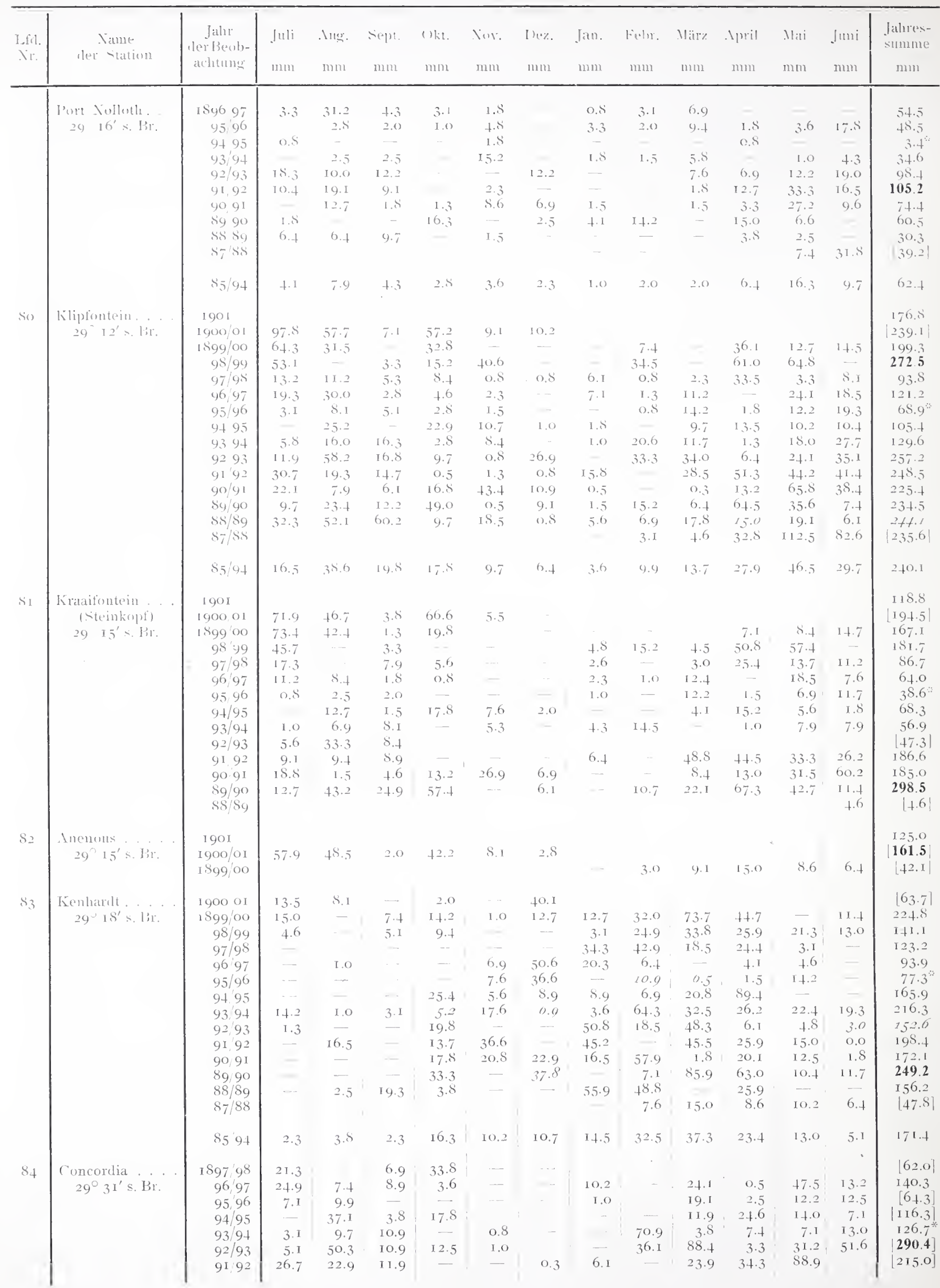




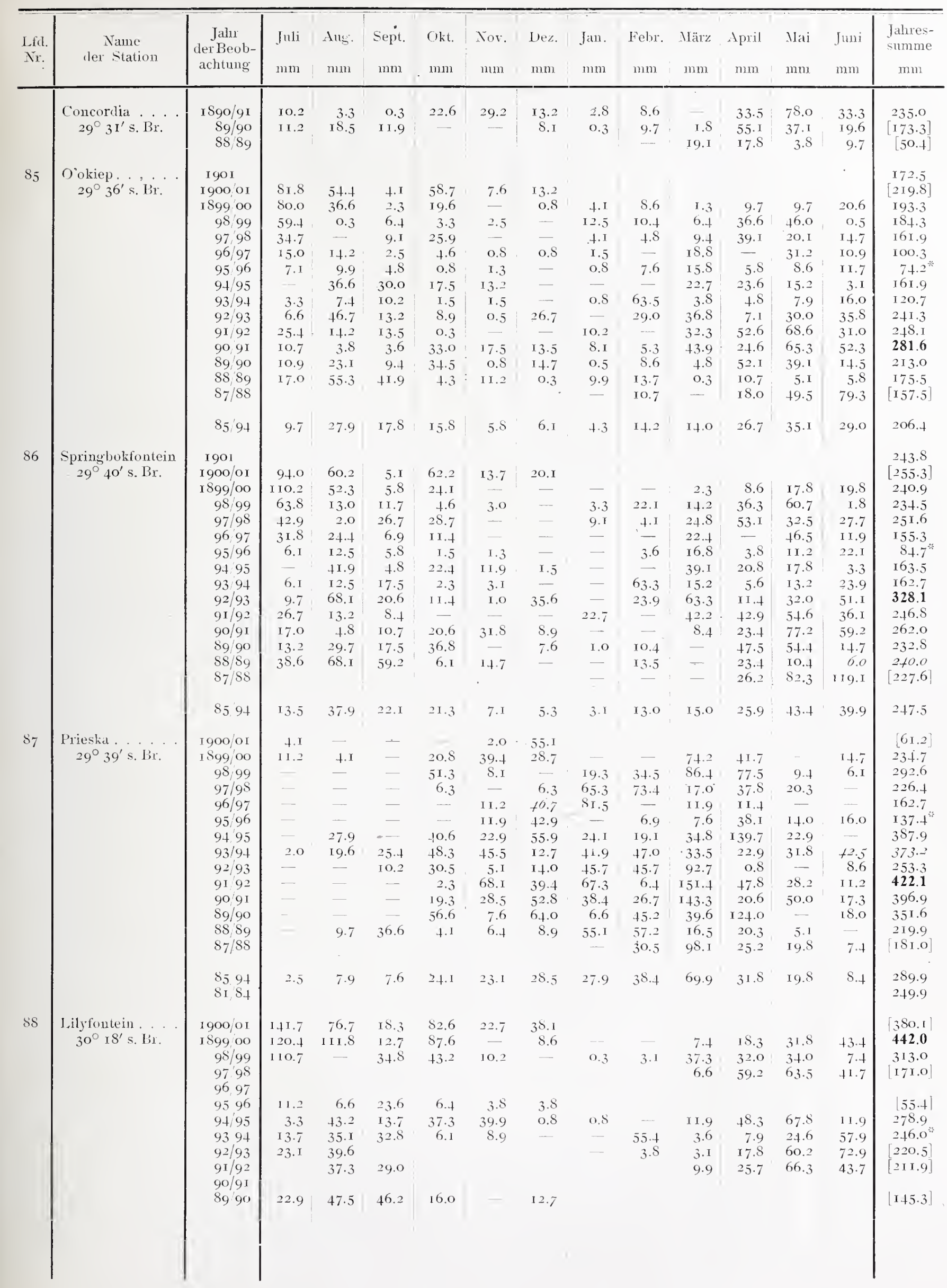




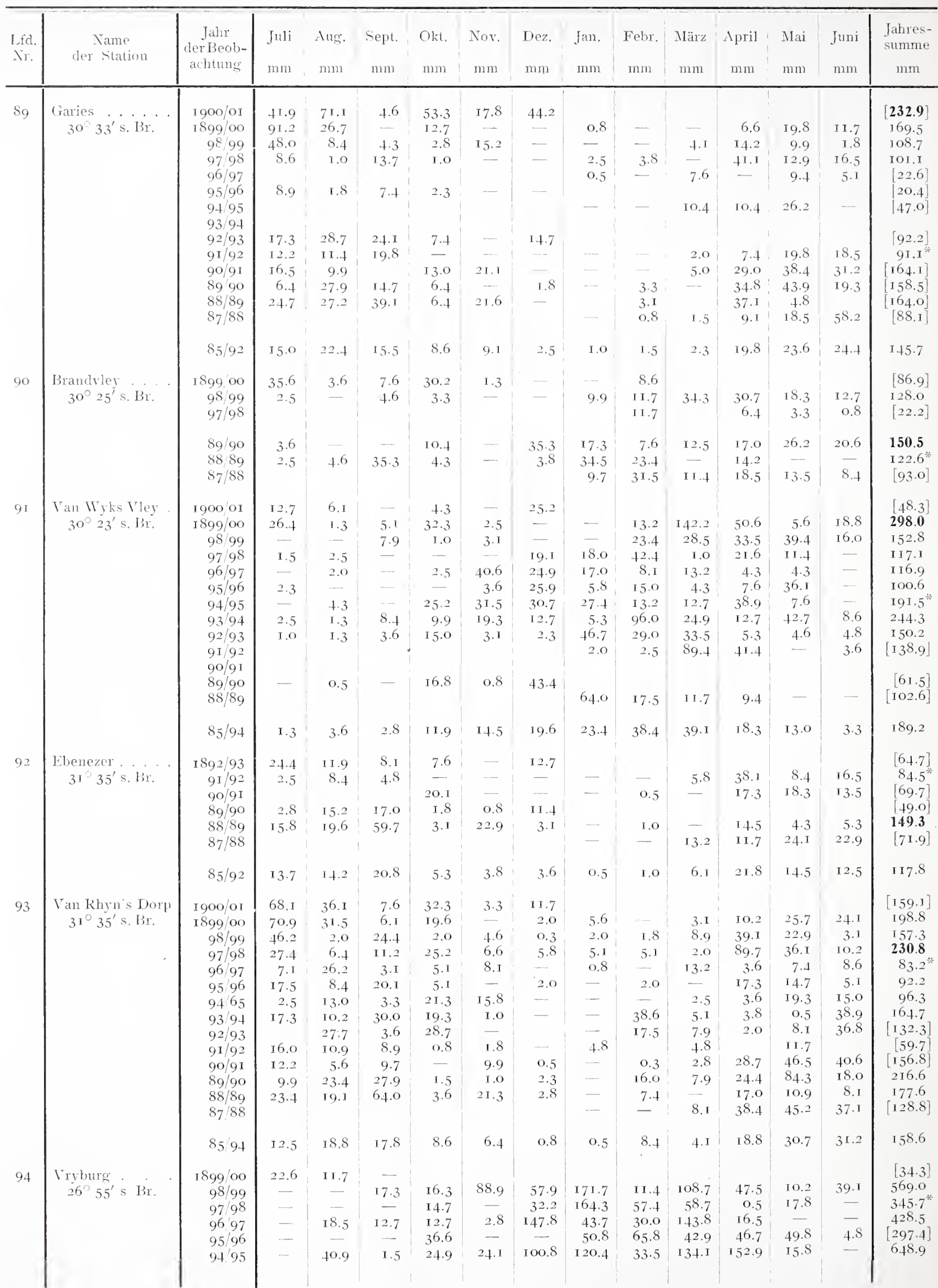




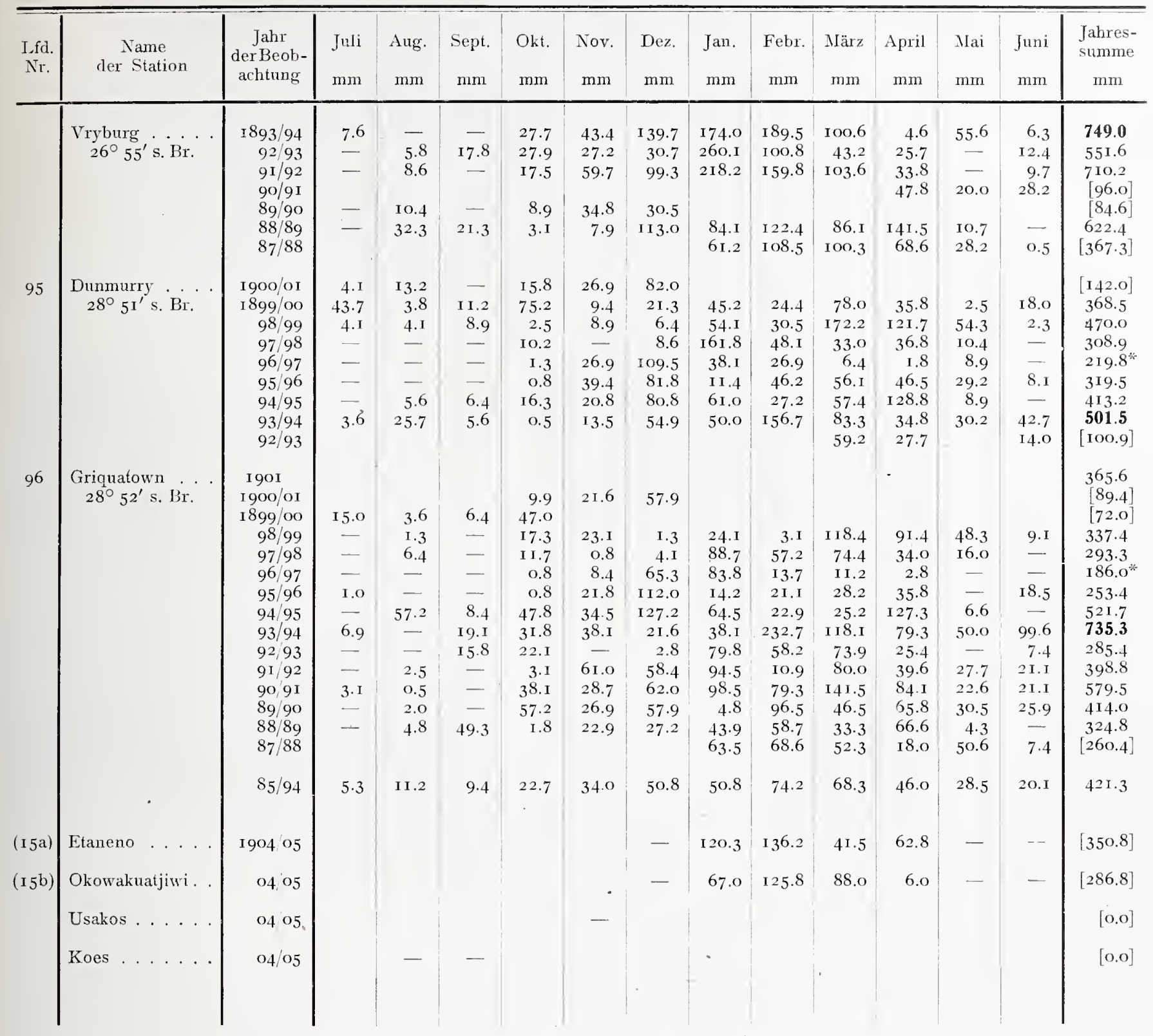




\section{Verzeichnis der Regenmeßstationen.}

Im folgenden soll ein zusammenfassendes Verzeichnis aller bezüglichen Regenmebstationen nebst Angabe ihrer geographischen Lage, Sechöhe, Beschaffenheit der ïrtichen V'crhältnisse und dgl. scgeben werden.

Die betreffenden Notizen sind teils den Quellen für das Material, teils Reiseberichten von Forschcrn, welche sclbst in Deutsch-Südwestafrika waren, teils auch Fitzners ${ }^{1}$ ) Kolonialhandbuch entnommen.

Die Aufzählung ist wieder die von Nord nach Süd mit den gleichen laufcnden Nummern wie in Tabelle $I$.

1) Rud. Fit\%er, Deutsclues Kolonialhandbuch, 2 Bde., Berlin IgoI, 2. Aittl.

Tabelle 2.

\begin{tabular}{|c|c|c|c|c|c|}
\hline Lfid. & Name der Station & $\begin{array}{c}\text { Geogr. Breite } \\
- \text { if }\end{array}$ & $\begin{array}{l}\text { o. geogr. } \\
\text { Lüinge } \\
\lambda\end{array}$ & $\begin{array}{l}\text { Seeliöhe der } \\
\text { Station in } \\
\mathrm{m}\end{array}$ & $\begin{array}{l}\text { Bescliaffenlieit der ötlichen Verhältnisse } \\
\text { und allgemeine Bemerkungen }\end{array}$ \\
\hline I. & Loanclal & $8^{\prime}+8^{\prime}+5^{\prime \prime}$ & $13^{\prime} 13^{\prime} 15^{\prime \prime}$ & 59.2 & I87 11 vom Neere abgelegen; Küstenstation in Angola. \\
\hline 2. & Cacondia & $13^{\circ}+4^{\prime}$ & $15^{\circ} \quad 2^{\prime}$ & 1642 & Im Quellgebiet des Kunene; inneres Hochland von Angola. \\
\hline $\begin{array}{l}3 . \\
4 .\end{array}$ & $\begin{array}{l}\text { Oniipa } \\
\text { Ondangua }\end{array}$ & $\begin{array}{l}\text { (a. } 17^{\circ} 50^{\prime} \\
\text { ca. } 17^{\circ} 55^{\prime}\end{array}$ & $\begin{array}{lll}\text { ca. } & 16 & \text { I } \\
\text { cal. } & 16 & 14^{\prime}\end{array}$ & & $\begin{array}{l}\text { Bei der Berechung und Verwertung des Materials wurden } \\
\text { diese beiden Stationen mit Olukonda zu einer einzigen } \\
\text { zusammengefabt. Bei ungefäln gleicher Meereshöhe liegen } \\
\text { diese } 3 \text { Stationen in der Ebene nur mehrere Wegestunden } \\
\text { voneinander entfernt. }\end{array}$ \\
\hline 5 . & Olukonda & $17^{\circ} 57^{\prime}$ & 16 I $8^{\prime}$ & 1070 & $\begin{array}{l}\text { In der Nähe reicher Palmenhain, im Osten vou Omulonga } \\
\text { hört das fruclitbare Knltuland auf; alsdam folgt Busch- } \\
\text { steppe. Umgegend mit Bämmen reich bestanden; flaches } \\
\text { Jand: Mangel an Abflutrimen und infolgedessen währent } \\
\text { der Regenzejt seeartiges Aussehen des Gebietes. }\end{array}$ \\
\hline 6. & Zesfonteil & cat. $1835^{\prime}$ & (al. $13^{\circ} 36^{\prime}$ & & $\begin{array}{l}\text { Nördlich von Franzfontein im Gebirge; Klima von Novem- } \\
\text { ber his Februar tropisch heis; sonst gemäBigt. }\end{array}$ \\
\hline 7 & Amutoni & (a. $18^{\circ} 4 \mathrm{O}^{\prime}$ & ca. $17^{\circ} 9^{\prime}$ & & \\
\hline 8. & Okankwejo & ('il. $19^{\circ} 10^{\prime}$ & ca. $16^{\circ} 7^{\prime}$ & & \\
\hline 9. & Gatub & Cal. $\quad 1920^{\prime}$ & ca. $17^{\circ} 47^{\prime}$ & & \\
\hline IO. & Grootfontein & $19.40^{\prime}$ & I $82^{\prime}$ & $\begin{array}{l}\text { I } 530 \\
\text { (rach Stieler } \\
\text { Nr. } 75)\end{array}$ & $\begin{array}{l}\text { Nach Nordwest Kalksteinlingel. I'mgegend fruchtharster } \\
\text { Landstrich Deutsch-Sïdwestafrikas; Ackerbau (fast) ohne } \\
\text { künstliche Bewässerung möglich. }\end{array}$ \\
\hline II. & Otawi & $19^{\prime} 44^{\prime}$ & $17^{\circ} 26^{\prime}$ & I 100 & \\
\hline I 2. & Otjituo & $19^{\prime} 52^{\prime}$ & $1855^{\prime}$ & & $\begin{array}{l}\text { I Jahr } 6 \text { Monate der Beobachtungen sind nicht verwertet } \\
\text { worden (I902/03 und 1903/04). Siehe hierzu die Bemer- } \\
\text { kungen anf Seite } 27 \text {. }\end{array}$ \\
\hline I 3. & Naidans & $19^{\circ} 5 \mathrm{I}^{\prime}$ & $x 7^{\circ} 5^{\prime}$ & & \\
\hline I4. & Outjo & $20^{\circ} 6^{\prime}$ & $16^{\prime} 10^{\prime}$ & & $\begin{array}{l}\text { Die Beobachtumgen von März bis Juni } 1897 \text { stammen vou } \\
\text { Mr. Langfeld, gleich der halben Menge, welche gleich- } \\
\text { zeitig von Leutnant A. Volkmann dort notiert wurden. Die } \\
\text { von Juli r } 897 \text { bis Dezember } 1898 \text { sind die halben Summen } \\
\text { der von Leutnant A. Volkmann beobachteten. }\end{array}$ \\
\hline 15 & Franzfontein & $20^{\circ} 9^{\prime}$ & $15^{\circ} 16^{\prime}$ & 1105 & $\begin{array}{l}\text { Hart an mäclitigen Gebirgsrücken (westost streichend) ge- } \\
\text { legen; Umgegend nach Süden, Osten und Westen busch- } \\
\text { und baumreich. }\end{array}$ \\
\hline I6. & Oketoweni & cal. $20^{\circ} 6^{\prime}$ & ca. $16^{\circ} 30^{\prime}$ & & \\
\hline 17 & $\begin{array}{l}\text { Waterberg } \\
\text { (Otjosondjupa) }\end{array}$ & ca. $20^{\circ} 35^{\prime}$ & & & $\begin{array}{l}\text { In flacher Einbuchtung des Waterberges, an dessen Südost- } \\
\text { abhang. Lage nach Art eines Amṕhitheaters. Nach Süden } \\
\text { und Osten ist das Terrain leicht gewellt und gut bewaldet. }\end{array}$ \\
\hline 18. & Otjikango & ca. $20^{\circ} 35^{\prime}$ & ca. $16^{\circ}$ I $2^{\prime}$ & & \\
\hline
\end{tabular}




\begin{tabular}{|c|c|c|c|c|c|}
\hline $\begin{array}{c}\mathrm{Lfd} . \\
\mathrm{Nr}\end{array}$ & Name der Station & $\begin{array}{c}\text { Geogr. Breite } \\
-\varphi\end{array}$ & $\begin{array}{c}\text { o. geogr. } \\
\text { Länge } \\
\lambda\end{array}$ & $\begin{array}{l}\text { Seehöhe der } \\
\text { Station in } \\
\text { m }\end{array}$ & $\begin{array}{l}\text { Beschaffenheit der örtlichen Verlıälnisse } \\
\text { und allgemeine Bemerkungen }\end{array}$ \\
\hline I9. & Omaruru & $21^{\circ} 35^{\prime}$ & $16^{\circ} 13^{\prime}$ & I 160 & $\begin{array}{l}\text { Im breiten Flubbett des Omaruruflusses. Flubufer sanft an- } \\
\text { steigend; Station auf dem rechten. Ufer des periodischen } \\
\text { Flusses. Die Ufer sind besonders hier mit vielen groben } \\
\text { Dornbäumen bestanden. Ungegend: Ebene und Steppe; } \\
\text { bei genügendem Regen üppiger Blumen- und Grasteppich. } \\
\text { Westlich in großer Nähe das Erongomassiv, dessen Aus- } \\
\text { läufer bis auf } 3 \text { bis } 4 \text { engl. Meilen herankommen; seine } \\
\text { höchsten Punkte etwa } 30 \text { engl. Neilen von Ontaruru bis } \\
\text { zu etwa mehreren tausend FuB relativer Höhe. Oktober } \\
\text { oder November einige Frühregen; Januar bis April eigent- } \\
\text { liche Regenzeit. - Omaruru gewäht mit seinen großen } \\
\text { Akazienbäumen den Anblick eines thüringisclien Dorfes. }\end{array}$ \\
\hline 20. & Epukiro & ca. $2 \mathrm{I}^{\circ} 2 \mathrm{O}^{\prime}$ & ca. $19^{\circ}$ & & \\
\hline $2 \mathrm{I}$. & Okombahe & ca. $21^{\circ} 25^{\prime}$ & ca. $15^{\circ} 25^{\prime}$ & 945 & Regen beginnen selten in Oktober. \\
\hline 22. & Gr. Spitzkoppje & ca. $2 \mathrm{I}^{\circ} 5 \mathrm{O}^{\prime}$ & ca. $15^{\circ} 7^{\prime}$ & & Im Quellgebiet des Karubflusses. \\
\hline 23. & Karibib & $2 \mathrm{I}^{\circ} 57^{\prime}$ & $15^{\circ} 53^{\prime}$ & & $\begin{array}{l}\text { Am Südwestende einex großen Fläche, die in weiter Ferue } \\
\text { von Gebirgszügen umrahmt wird. Am nächsten treten } \\
\text { die Nordauslänfer des Khousgebirges heran; im Osten } \\
\text { trennen die Otjimakajoberge die Fläche von Karibib von } \\
\text { der Niederung des Swakop, während sich im Westen } \\
\text { der massige Erongo zwischen das Flufigebiet des Omarum } \\
\text { und die Ebene drängt. Die Wasserstelle Karibib liegt } \\
\text { malerisch in einem lichten Hain von Giraffenakazien, den } \\
\text { einzigen in der Gegend. }\end{array}$ \\
\hline
\end{tabular}

\begin{tabular}{|c|c|c|c|c|c|}
\hline 24 & $\begin{array}{l}\text { Wilhelmstal } \\
\text { (Kamombonde) }\end{array}$ & $2 \mathrm{I}^{\circ} 55^{\prime}$ & $16^{\circ} 22^{\prime}$ & & \\
\hline 25 & Okahandja & $2 \mathrm{I}^{\circ} 59^{\prime}$ & $16^{\circ} 57^{\prime}$ & 1330 & $\begin{array}{l}\text { Weite Talebene; im Osten der I6I5 m hohe Kaiser Wil- } \\
\text { helms-Berg; iu Südosten die Otjihavera- und Onjatiberge; } \\
\text { allmählicher Anstieg zum Awasgebirge. }\end{array}$ \\
\hline 26. & Otjosazu & ca. $22^{\circ}$ & ca. $17^{\circ} 7^{\prime}$ & I 500 & $\begin{array}{l}\text { Auf einer Hochebene, begrenzt im Westen und Süden } \\
\text { von Bergen. }\end{array}$ \\
\hline 27. & Kubas & $22^{\circ} I 6^{\prime}$ & $15^{\circ} 4 \mathrm{O}^{\prime}$ & & \\
\hline 28. & Otjisewa & $22^{\circ} 2 \mathrm{O}^{\prime}$ & $16^{\circ} 5^{8^{\prime}}$ & I $55^{\circ}$ & 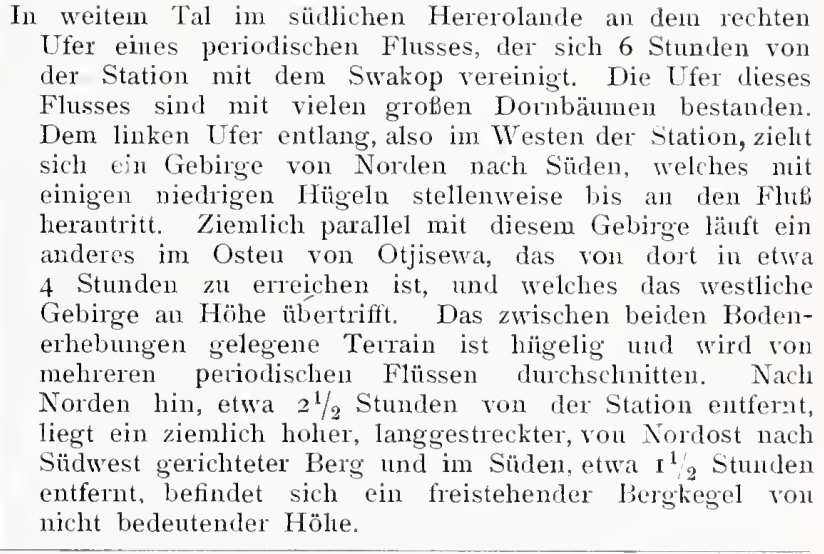 \\
\hline 29. & Otjimbingue & $22^{\circ} 22^{\prime}$ & $16^{\circ} 10^{\prime}$ & 940 & $\begin{array}{l}\text { In einem Talkessel des Swakop, auf einer aus der Ebene } \\
\text { sich erhebenden Plattform; Sandfäche; nur in der Regen- } \\
\text { zeit blumige Wiese. Lage gegen Winde von Ost und } \\
\text { West geschïtzt; Flußbett rechts durch ein steiles Ufer und } \\
\text { links durch ein sich sanft nach dem Gebirge zu crheben- } \\
\text { des Gelände eingeschlossen. - Äuferste Station mit er- } \\
\text { kemnbarer Einwirkung des Küstenklimas. }\end{array}$ \\
\hline 30. & Ukuib & ca. $22^{\circ} 22^{\prime}$ & ca. $15^{\circ} 48^{\prime}$ & . & \\
\hline $3 \mathrm{I}$. & Gobabis & $22^{\circ} 2 \mathrm{I}^{\prime}$ & $19^{\circ} I^{\prime}$ & $\begin{array}{c}\text { I } 4 \text { I } 7 \\
\text { (nach Stieler) }\end{array}$ & $\begin{array}{l}\text { Auf dem östlichen Talabhange des } 50 \mathrm{~m} \text { tief eingeschnitteneu } \\
\text { Nosob; } 40 \mathrm{~m} \text { iber der Talsohle; auf dem Rücken einer } \\
\text { mäPig ansteigenden Erhebung; 80o m rom Nosob entfernt, } \\
\text { Wassenceicher Ort; Bau- und Brennholz reichlich vorhanden. }\end{array}$ \\
\hline
\end{tabular}




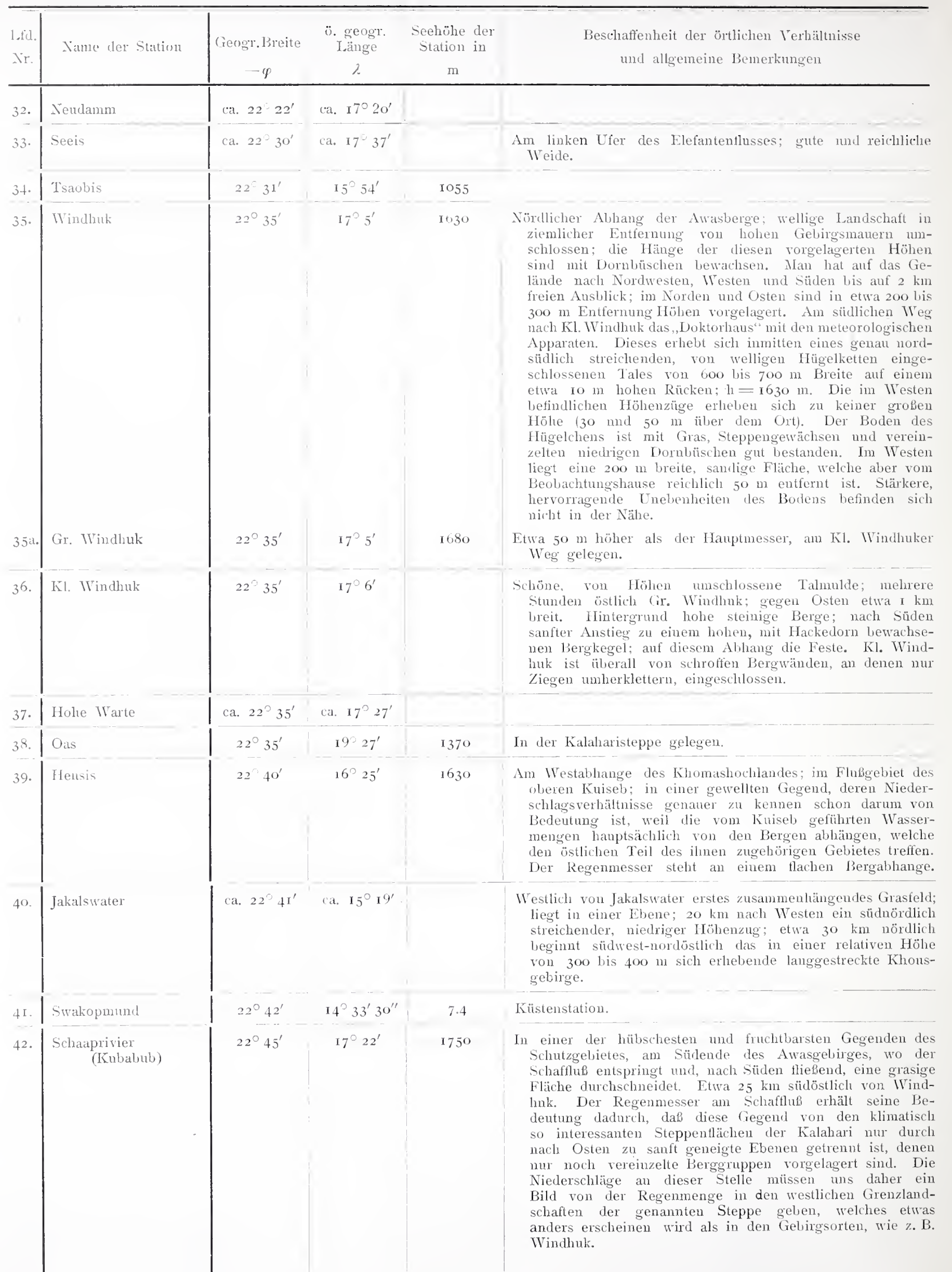




\begin{tabular}{|c|c|c|c|c|c|}
\hline $\begin{array}{c}\text { Lfd. } \\
\text { Nr. }\end{array}$ & Name der Station & $\begin{array}{c}\text { Geogr. Breite } \\
-\varphi\end{array}$ & $\begin{array}{l}\text { o. geogr. } \\
\text { Iä̈nge } \\
\lambda\end{array}$ & $\begin{array}{l}\text { Seehöhe der } \\
\text { Station in } \\
\mathrm{m}\end{array}$ & $\begin{array}{l}\text { Bescliaffenheit der örtlichen Verhältnisse } \\
\text { und allgemeine Bemerkungen }\end{array}$ \\
\hline 43. & Haris & ca. $22^{\circ} 5 \mathrm{o}^{\prime}$ & ca. $16^{\circ} 48^{\prime}$ & 1920 & Leicht wellige Gegend; durch gutes Weideland berühmt. \\
\hline 44. & Kowas & ca. $22^{\circ} 55^{\prime}$ & ca. $17^{\circ} 59^{\prime}$ & & $\begin{array}{l}\text { Im Osten der Koeibniederung; Baumsavanne; ausgedehnte } \\
\text { Grastlächen. }\end{array}$ \\
\hline 45. & Hatsamas & ca. $22^{\circ} 57^{\prime}$ & ca. $17^{\circ} 34^{\prime}$ & & \\
\hline 46. & Walfisclibai & $22^{\circ} 56^{\prime} 30^{\prime \prime}$ & $14^{\circ} 26^{\prime} 30^{\prime \prime}$ & 3 & Küstenstation; in flacher Bucht; östlich hohe Dünen. \\
\hline 47 & Rehoboth & $23^{\circ}$ I $9^{\prime}$ & $17^{\circ} 3^{\prime}$ & I 460 & $\begin{array}{l}\text { In einer ebenen Fläche; nach Westen ein Gebirgsstock, kurz } \\
\text { znsammenhäugend; nach Osten Fläche mit einigen kleinen } \\
\text { Kuppen; im Norden und Süden des Ortes befindet sich } \\
\text { ein lichter Akazienwald. }\end{array}$ \\
\hline 48. & Hopemine & ca. $23^{\circ} 25^{\prime}$ & ca. $15^{\circ} 14^{\prime}$ & & $\begin{array}{l}\text { Auf der Namieb; weiter ost- und nordostwärts finden schon } \\
\text { häufiger Gewitter und Regengüsse statt, deren Gebiet am } \\
\text { Narramashügel zu enden pflegt, weshalb auch der Gras- } \\
\text { reiclitum der Namieb vou da landeinwärts zu erklären ist. }\end{array}$ \\
\hline $49 \cdot$ & Nauchas & ca. $23^{\circ} 45^{\prime}$ & ca. $16^{\circ} \mathrm{I} 2^{\prime}$ & $\begin{array}{c}1647 \\
\left(\begin{array}{c}\text { nach An- } \\
\text { drees H. Atl.) }\end{array}\right.\end{array}$ & \\
\hline 50. & Aminuis & $23^{\circ} 45^{\prime}$ & $19^{\circ} \mathrm{I}^{\prime} 2 \mathrm{I}^{\prime \prime}$ & & Im Südwesten der Kalahari. \\
\hline $5 \mathrm{I}$ & Hoachanas & $23^{\circ} 57^{\prime}$ & ${ }^{1} 7^{\circ} 58^{\prime}$ & 1260 & $\begin{array}{l}\text { In weiter Ebene; tageweit Gras- und Buschland; die Fern- } \\
\text { sicht von der. Station nach Norden beträgt } 1 / 2 \text { bis } 3 / 4 \text { Stunde, } \\
\text { nach Nordosten I Stunde, nach Osten } I^{1 / 2} \text {, Südosteı I } 1 / 2, \\
\text { Süden } 3 / 4 \text {, Westen } 3 / 4 \text { Stunden. Die ganze Gegend ist } \\
\text { nur mit Dorn und anderen Sträuchern bewachsen. Einige } \\
\text { verkrüppelte Laublölzer, kaum I5 bis } 20 \text { Fub loch auf } \\
\text { der Fläche, erscheinen aus der Ferne als hohe Bätume. }\end{array}$ \\
\hline 52. & Kuis & ca. $24^{\circ} 18^{\prime}$ & ca. $17^{\circ} 29^{\prime}$ & & \\
\hline 53 . & Nomtsas & ca. $24^{\circ} 28^{\prime}$ & ca. $16^{\circ} 46^{\prime}$ & & \\
\hline 54. & Mariental & ca. $24^{\circ} 4 \mathrm{o}^{\prime}$ & ca. $18^{\circ} 6^{\prime}$ & & \\
\hline $55 \cdot$ & Gochas & ca. $24^{\circ} 48^{\prime}$ & ca. $18^{\circ} 46^{\prime}$ & & $\begin{array}{l}\text { In einem Talkessel des Aobflusses, hart am Rande der Ka- } \\
\text { lalıari; stärkere Regen selten; Aobflub fülnt stets Wasser. }\end{array}$ \\
\hline 56. & Maltahöhe & ca. $24^{\circ} 50^{\prime}$ & ca. $16^{\circ} 52^{\prime}$ & & \\
\hline 57 & Körakorabes & ca. $25^{\circ} 3^{\prime}$ & ca. $18^{\circ} \mathrm{I}^{\prime}$ & & - \\
\hline 58. & Gibeon & $25^{\circ} 7^{\prime} 23^{\prime \prime}$ & $17^{\circ} 45^{\prime} 43^{\prime \prime}$ & II 30 & $\begin{array}{l}\text { Linkes Ufer des großen Fischflusses oberhalb seines Durch- } \\
\text { bruches durch die Nunanibberge. Während der letzten } \\
\text { beiden Monate des Jahres sind die Weiden jederzeit noch } \\
\text { düre und wasserlos. }\end{array}$ \\
\hline 59. & Deutsche Erde & ca. $25^{\circ} 2 \mathrm{O}^{\prime}$ & ca. $17^{\circ} 4 \mathrm{o}^{\prime}$ & & \\
\hline 60. & Kuias & ca. $25^{\circ} 55^{\prime}$ & ca. $16^{\circ} 3 \mathrm{I}^{\prime}$ & I 390 & Südostabfall der Homs-Hochebene. \\
\hline $6 \mathrm{I}$ & Berseba & ca. $25^{\circ} 59^{\prime}$ & ca. $17^{\circ} 4 I^{\prime}$ & $\begin{array}{l}\text { Io64? } \\
\text { (nach Stieler } \\
\text { Nr. } 74 \text { ) }\end{array}$ & $\begin{array}{l}\text { In einer sich ostwärts dehmenden Ebene; die im Westen } \\
\text { durch einen niedrigen Höhenzug abgeschlossen wird; im } \\
\text { Norden der Geitsigubib. }\end{array}$ \\
\hline 62. & Bethanien & $26^{\circ} 30^{\prime}$ & $16^{\circ} 52^{\prime}$ & $\begin{array}{r}935 \\
\text { (nach Andrees } \\
\text { H. Atl. S. I75) }\end{array}$ & $\begin{array}{l}\text { Große Ebene; im Osten hohe Reihe von Tafelbergen; nach } \\
\text { Süden bis Inachab Ebene; Grasland iiberall im betha- } \\
\text { nischen Gebiete. }\end{array}$ \\
\hline 63. & Keetmanshoop & $26^{\circ} 32^{\prime}$ & $18^{\circ} 2^{\prime}$ & 1028 & $\begin{array}{l}\text { Talmulde von Norden nach Sïden abflachend; in } 2 \text { Stunden } \\
\text { Entfernung durch ein vorgelagertes Gebirge begrenzt. } \\
\text { Buschform und Steppe. }\end{array}$ \\
\hline 64. & Hasuur & ca. $26^{\circ} 36^{\prime}$ & ca. $19^{\circ} 5 I^{\prime}$ & & \\
\hline 65. & Lüderitzbucht & $26^{\circ} 36^{\prime}$ & $15^{\circ} \mathrm{I} 5^{\prime}$ & 4 & $\begin{array}{l}\text { Küistenstation auf breitem Landvorsprung; Klima gut; ein } \\
\text { fast beständig welıender Südwestwind lindert die Hitze. } \\
\text { Uferland kahl. }\end{array}$ \\
\hline 66. & Kubub & $26^{\circ} 42^{\prime}$ & $16^{\circ} 10^{\prime}$ & $\left|\begin{array}{c}\text { I } 430 \\
\text { (nach Andrees } \\
\text { H. Atl.) }\end{array}\right|$ & Westabhang der Huib-Hochebene. \\
\hline
\end{tabular}




\begin{tabular}{|c|c|c|c|c|c|}
\hline $\begin{array}{l}\text { Lfel. } \\
\text { Nre. }\end{array}$ & Name der Station & \begin{tabular}{|} 
Geogr. Breite \\
$-\varphi$
\end{tabular} & $\begin{array}{c}\text { ö. geogr: } \\
\text { Länge } \\
\lambda\end{array}$ & $\begin{array}{l}\text { Seeliöle der } \\
\text { Station in } \\
m\end{array}$ & $\begin{array}{l}\text { IBeschaffenheit der örtlichen Verhältnisse } \\
\text { und allgemeine Bemerkungen }\end{array}$ \\
\hline 67. & Sandrerhatar & ca. $26^{\circ}+8^{\prime}$ & ca. $17^{\circ} 16^{\prime}$ & & \\
\hline 68. & Seeheim & ca. $26^{\circ} 50^{\prime}$ & ca. $17^{\circ} 36^{\prime}$ & & \\
\hline 69. & Inachab & ca. $26^{\circ} 59^{\prime}$ & cal. $17^{\circ} 19^{\prime}$ & & \\
\hline 70 & Kanas & $27^{\circ} \mathrm{o}^{\prime}$ & I $80^{\prime}$ & & \\
\hline $7 \mathrm{I}$ & The Halt & $27^{\circ} 50^{\prime}$ & $20^{\circ} 20^{\prime}$ & 1525 & \\
\hline 72. & Urkamas & ca. $28^{\circ} 2^{\prime}$ & $19^{\circ} 42^{\prime}$ & & \\
\hline 73. & Uhab is & ca. $28^{\circ} 24^{\prime}$ & (a). $18^{\circ} 6^{\prime}$ & & \\
\hline 74. & Udabis & ca. $28^{\circ}=5^{\prime}$ & (ial. $19^{\circ} 8^{\prime}$ & & . \\
\hline 75 & Warmbad & $28^{\circ} 27^{\prime} 23^{\prime \prime}$ & $18^{\circ}+2^{\prime}$ & 720 & Sandige Grastläclien; Tabakbau. \\
\hline 76 & Upington & $28^{\circ} 38^{\prime}$ & $21^{\circ} 20^{\prime}$ & 854 & \\
\hline 77. & Trooilapsin & $28^{\circ}+0^{\prime}$ & $2 I^{\circ} 3 I^{\prime}$ & & \\
\hline 78. & Pellit & $29^{\circ} 2^{\prime}$ & $19^{2} 9^{\prime}$ & $55^{\circ}$ & \\
\hline 79. & Port Nolloth & $29^{\circ} \mathrm{I} 6^{\prime}$ & $16^{\circ} 52^{\prime}$ & 12.2 & $\begin{array}{l}\text { Altes Regenmess. Modell Negretti und Zambra; auf dem } \\
\text { Dach des Gefängnisses mehr als } 4^{1 / 2} \text { miber dem Boden } \\
\text { aufgestellt; demnach unbehindert, aber unbequem. Seit i } 895 \\
\text { iuf dem nenen Dach des Gefängnisses; sehr gute Auf- } \\
\text { stellung. }\end{array}$ \\
\hline 8o. & Klipfontein & $29^{\circ} \mathrm{I} 2^{\prime}$ & $17^{\circ} 39^{\prime}$ & 947 & Nenes Modell Negretti und Zambra; ziemlich hoch aufgestellt. \\
\hline $8 \mathrm{I}$ & $\begin{array}{l}\text { Kraaifontein } \\
\text { (Steinkopf) }\end{array}$ & $29^{\circ} 15^{\prime}$ & $17^{\circ}+t^{\prime}$ & 825 & $\begin{array}{l}\text { Neues Modell aus Kapstadt; ohne imeres Meßgefäb. Um- } \\
\text { friedigung vorhanden. }\end{array}$ \\
\hline 82. & Anenous & $29^{\prime} 15^{\prime}$ & I $734^{\prime}$ & 541 & \\
\hline 83. & Kenhardt & $29^{\circ} 18^{\prime}$ & $2 I^{\circ} 9^{\prime}$ & 824 & \\
\hline 84. & Concordia & $29^{\circ} 3 I^{\prime}$ & $18^{\circ} \mathrm{o}^{\prime}$ & 1020 & Nenes Modell, aus Kapstadt: I m hoch anfgestellt. \\
\hline $8_{5}$ & Ookiep & $29^{\prime} 36^{\prime}$ & $17^{\circ} 52^{\prime}$ & 926 & $\begin{array}{l}\text { Neues Modell Negretti und Zambra; } 1.22 \text { m hoch. MeB- } \\
\text { geräß aus Knpfer. }\end{array}$ \\
\hline 86. & Springbockfoutein & $29^{\circ} 40^{\prime}$ & I $7^{\prime} 53^{\prime}$ & 976 & $\begin{array}{l}\text { Altes Modell Negretti und Zambra; sehr gute Stellung; Mebr } \\
\text { gerät ans Kupfer, in Ordnumg. }\end{array}$ \\
\hline 87. & I'rieska & $29^{\circ} 39^{\prime}$ & $22^{\circ} 45^{\prime}$ & IOOO & \\
\hline 88. & Lilyfontein & $30^{\circ} 18^{\prime}$ & $18^{\circ} 5^{\prime}$ & 1525 & $\begin{array}{l}\text { Neues Hodell Negretti und Zambra: unversehnt: mit einer } \\
\text { Umfriedigung versehen. }\end{array}$ \\
\hline 89. & Garries & $30^{\circ} 33^{\prime}$ & ${ }^{1} 8 \mathrm{I}^{\prime}$ & 253 & $\begin{array}{l}\text { Nenes Modell Negretti und Zambra, in sehr guter Auf- } \\
\text { stellung. }\end{array}$ \\
\hline 90. & Srandvley & $30^{\circ}-25^{\prime}$ & $20^{\circ} 30^{\prime}$ & 930 & \\
\hline yi. & Van Wyks Vleyr & $30^{\prime} \quad 23^{\prime}$ & $2 \mathrm{I}^{\circ} 5 \mathrm{O}^{\prime}$ & 1000 & $\begin{array}{l}\text { Altes Modell Negretti und Zambra, vollständig und gut er- } \\
\text { halten; in guter Aufstellung und richtiger Höhe. }\end{array}$ \\
\hline 92. & Ebenezer & $31^{\prime} 35^{\prime}$ & $18^{\circ} 2 \mathrm{O}^{\prime}$ & 31 & $\begin{array}{l}\text { Neues Modell; seit I } 893 \text { wurde wicht mehr beobachtet. } \\
\text { Kiistenstation. }\end{array}$ \\
\hline 93. & Van Rliyns Dorp & $3 I^{\prime} 35^{\prime}$ & $18^{\circ}+4^{\prime}$ & I 22 & $\begin{array}{l}\text { Nenes Modell; vollständig und gut erlalten; auf einem } \\
\text { Steinpfeiler in gnter Aufstellung. }\end{array}$ \\
\hline 94. & Vryburg & $26^{\circ} 55^{\prime}$ & $2+43^{\prime}$ & I3I 2 & $\begin{array}{l}\text { Altes Modell; gut erlalten; in guter Anfstellung. "Nyburg } \\
\text { ist a healthy township, and has got a good water supply. } \\
\text { The rainfall is about twenty-five inches a year, most of } \\
\text { the rain falling between Dezember and the following } \\
\text { March." }\end{array}$ \\
\hline
\end{tabular}

\begin{tabular}{l|l|l|l|l} 
95. & Dunmurry & $28^{\circ} 51^{\prime}$ & $23^{\circ} 16^{\prime}$ & I300 \\
\hline 96. & Griquatown & $28^{\circ} 52^{\prime}$ & $23^{\circ} 17^{\prime}$ & I085
\end{tabular}

Altes Modell Negretti und Zambra; gut aufgestellt. 
Prüfung des Beobachtungsmaterials auf seine Brauchbarkeit.

Nachdem im vorstehenden eine Zusammenstellung des gesamten bisher vorliegenden Reģenmaterials Deutsch-Südwestafrikas sowie der hier hinzugenommenen Nachbarlandschaften gegeben worden ist, kommen wir nunmehr zu der Frage seiner Verwertung und Brauchbarkeit für die Berechnung der durchschnitlich im Jahre fallenden Niederschlagsmengen.

Außerdem wird es noch erubrigen; einiges über die Regenmeßapparate selbst und die Art und Weise der Beobachtung zu sagen.

$\mathrm{Da}$ zunächst bei der Frage nach der Verwendbarkeit von meteorologischem Beobachtungsmaterial die Homogeneität desselben eine Hauptvorbedingung bildet, so dürfte das Folgende zur Beurteilung der jüngsten RegenmeBresultate vielleicht von Bedeutung erscheinen.

Weiter ist es von großer Wichtigkeit, ob während der ganzen Dauer der Beobachtungen nicht nur keine Unterbrechungen derselben, sondern auch kein Wechsel in der Person des Beobachters, in der Aufstellung des betreffenden MeBinstrumentes, dann vor allem in dem Modell des Instrumentes selbst vorgekommen ist.

In der Behandlung eines Ombrometers kann nun allerdings durch einen eventuellen Wechsel in der Person des Beobachters nicht so leicht cine Störung durch subjektive Ablesung vorkommen, wie z. B. bei Thermo- und Barometerbeobachtungen. Dagegen würde eine veränderte Aufstellung, wie Wechsel des Ortes oder Wahl eines höheren oder niedrigeren Standpunktes für den Regenmesser eine konstante größere oder kleinere Veränderung in den Meßresultaten hervorrufen. Jedoch auch dieser Faktor mußte in vorliegendem Falle bei der Beobachtung der Homogeneität ausgeschaltet bleiben, da sich in den Quellen für das deutsche Material eine darauf bezügliche Bemerkung nie fand, für das kapländische nur an ganz vereinzelten Stellen darüber etwas gesagt war. Bei der Betrachtung des folgenden Punktes, nämlich der Gleichwertigkeit des zeitlich aufeinanderfolgenden Materials, stellten sich mehrere Unregelmäßigkeiten heraus.

Das Material der Station Otjituo (12) aus den Regenperioden 1902/03 und 1903/04 erscheint im Vergleich mit dem gleichzeitigen der benachbarten Stationen so gering in der Angabe der Höhe der gefallenen Niederschlagsmengen, daß die Vermutung von Fehlern in der Beobachtung oder Messung nahe liegt. Über die Ursache der ofienbar falschen Notierungen habe ich nichts in Erfahrung bringen können. In der Berechnung können die Fehler nicht liegen, da die angegebenen Monatsbeobachtungen nicht mit konstantem, d. h. proportionalem Fehler behaftet sind. Es mußten daher die Jahre $1902 / 03$ und $1903 / 04$ von der Berechnung ausgeschlossen werden.

$\mathrm{Zu}$ kritischen Einwürfen berechtigten in einem anderen Falle noch die Aufzeichnungen einer zweiten Station: Outjo (I4), und zwar die von März I 897 bis Dezember I898. Der Umstand, daß hier zufällig zeitweise, nämlich März bis Mai I 897, zwei Beobachter, deren tägliche Aufzeichnungen mir durch Giite des Herrn Prof. Rehbock zur Verfügung standen, tätig waren, versetzte mich in die Lage, den Fehler in den Aufzeichnungen des einen Beobachters entdecken und wegschaffen zu können.

Die Beobachtungsreihen Dr. Langfelds sind zwar kürzer (März bis Mai I 897), aber nach Vergleichung mit den gleichzeitigen Beobachturfgen mehrerer Stationen der Nordhälfte des Schutzgebietes augenscheinlich richtig, während diejenigen des zweiten Beobachters (Leutnant Volkmann), obwohl von längerer Dauer, März I 897 bis Dezember 1898, so doch zweifellos viel zu hoch erschienen. Eine Vergleichung der täglichen Aufzeichnungen von beiden ergáb nun, daß die Mehrresultate von Leutnant Volkmann bis auf das Resultat eines einzigen Tages ständig doppelt so groß waren wie die von Dr. Langfeld. Mit Rücksicht auf dieses Ergebnis gelang es mir, die längeren Beobachtungen des zweiten Regenmessers nach Division durch den Falitor 2 ebenfalls der Bearbeitung nutzbar zu machen. Die Ursache der falschen Aufzeichnungen könnte vielleicht darin zu suchen sein, daß hier ein Meßglas verwandt wurde, welches die doppelte Menge des gefallenen Niederschlags anzeigte und nicht zu dem Ombrometer paßte.

Was die in Deutsch-Südwestafrika für die Regenmessungen verwendeten Apparate angeht, so möge noch angegeben werden, daß während der I880er und goer Jahre auf den älteren Stationen Regenmesser mit dem Durchmesser $240 \mathrm{~mm}$ in Gebrauch waren, ${ }^{1}$ ) gestiftet von dem Verein für Erdkunde zu Leipzig, während alle von der deutschen Regierung späterhin eingerichteten Regenmeßstationen mit dem Ombrometer "Modell Hellmann", Durchmesser I I $2,8 \mathrm{~mm}$ und Auffangefläche $100 \mathrm{qcm}$, ausgerüstet wurden, also einem wesentlich kleineren Modell. Letzteres ist seit der Regenperiode I902/03 auf allen Stationen des Schutzgebietes gebräuchlich.

Ein von dem langjährigen Förderer meteorologischer Beobachtungen, Missionar Heidtmann in

1) Es sind dies die im Königreich Sachsen gebränchlichen Ombrometer. 
Rehoboth, zwischen beiden Modellen rg02/03 unternommener Vergleich ergab, daß das ältere, größere Modell in der Jahressumme I24.I 1mm, der Hellmanusche II I.2 $\mathrm{mm}$ aufwies. Während der Regenzeit I904/05 stellten sich die entsprechenden Zahlen auf I96.4 mm bzw. I $81.6 \mathrm{~mm}$. Das ältere Modell hatte also II.6 bzw. 7.5 v.H. mehr Regenmenge aufgefangen als das neue. Hinsichtlieh der Einzelheiten sei auf die entsprechenden Angaben auf S. 5 ff. des Jahrganges 1904 und auf S. 154 des Jahrganges Igo6 d. Z. hingewiesen.

Der Prozentsatz der auf cler Auffangefläche verdunstenden und daher nicht mehr zur Messung gelangenden Niederschlagsmenge $111 \mathrm{~B}$ sich $11 \mathrm{~m}$ so größer und daher ungünstiger gestalten, je klemer die Auffangefläche und je värmer und trockener das Klima ist. Bei sehr geringen Niederschlägen kann in dieser Weise der Fall eintreten, daß ein Hellmannscher Ombrometer line Messung gestattet, während der größere alte Regenmesser noch $0 . t$ bis sogar $0.5 \mathrm{~mm}$ angeben kann.

Die erwähnten Vergleichungen zeigen also eine faktisch bestehende Inhomogeneität des betreffenden Beobachtungsmaterials von Rehoboth und demnach auch der ïbrigen Regenmeßstationen, welche frïher größere Ombrometer besaßen.

Jedoch ist eine Korrektur der neueren Resultate gegenuiber den mit den größeren Messern gewonnenen vorlerhand untunlich, da die Messungsergebnisse noch zu starke Schwankungen aufweisen. Un einen konstanten Reduktionsfaktor zu erhalten, müßten die vergleichenden Messungen Jahre hindurch und an verschiedenen Stationen ausgeführt werden. Da nun auch noch dic Aufstellung der beiden Ombrometer im Missionshofe, der ältere I.OO m, der kleinere $1.45 \mathrm{~m}$ über dem Boden, welcher Umstand von vornherein ein geringeres Ergebnis für den Hellmannschen Messer erwarten ließ, keine einwandsfreie war, ${ }^{1}$ ) so dürfte man bisher in jener Hinsicht keine endgültigen Schlüsse ziehen können. Da fernerhin das Gesamt ergebnis des Vergleiches nicht so bedeutende Unterschiede der Messungen zeigte, dab sie ihre praktische Verwertung in Frage stellen würden, so habe ich mich entschlossen, das gesamte Material so, wie es vorlag, zu den einzelnen Berechnungen heranzuziehen.

Betreffs der Auswahl und Einrichtung der Regenmeßstationen Deutsch-Südwestafrikas ist noch einiges zu bemerken. Bei den älteren Stationen ist sie erfolgt teils nach Anweisung des Leipziger Vereins für Erdkunde, teils persönlich durch Dove und

1) Erst seit Februal I 903 erhielten beide Messer die gleiche Aufstellung: I.oo $\mathrm{m}$ hoch auf freiem Felde.
Rehbock, bei den neueren nach Angaben der Zentralstelle zu Windhuk.

Die Aufstellung der einzelnen Ombrometer geschah in $\mathrm{I} .00$ bis $1.10 \mathrm{~m}$ Höhe iiber dem Erdboden. Leider muß noch festgestellt werden, daß keine regelmäBigen Revisionen der einzelnen Stationen vorgenommen wurden, was entschieden das Vertrauen $z u$ den erhaltenen Regenmebergebnissen erhöht haben würde.

K. Dove erwähnt a. a. O. in einer Abhandlung über die klimatischen Verhältnisse und ebenso in einer brieflichen Mitteilung an mich, dab offenbar manche Regenmesser mangels fachmännischer Leitung des meteorologischen Dienstes nicht in einer VVeise aufgestellt sind, dab ihre Ergebnisse als für die Landschaft charakteristisch angesehen werden können. Allerdings muß man sich diesem Urteile in mancher Bezichung auch heute noch anschließen; jedoch ist gerade in den letzten Jahren eine ganze Reihe neuer Stationen angelegt worden, so daß jetzt das Beobachtungsnetz, wenn auch im nördlichsten und südlichsten Teile weniger dicht, über das ganze Gebiet ausgedehnt ist. Während Dove I 896 nur die Resultate von I 5 Stationen zur Verfügung standen, sind es deren bis heute etwa 70 geworden.

Die Ungunst der gegebenen Verhältnisse in dem bisher nur wenig ersehlossenen Lande machte sich auch in anderer Beziehung, z. B. in der Auswahl der Beobachter, welche meistens Unteroffiziere der Schutztruppe oder Farmer waren, geltend. Jedoch wird der Eifer und das dem Werte der Niederschlagsmessungen entgegengebrachte Verständnis aller Beobachter allenthalben gerühmt. Die Ansiedler wissen ja auch selbst am besten, wie sehr das ganze Leben in dem Schutzgebiete von den jeweiligen Regenfällen abhängig ist.

Leider wurden durch Kriegsereignisse oder andere Umstände auch öfters Störungen der fortlaufenden Beobachtungen veranlaßt. So z. B. mußte Heusis (39), das sehr günstig auf freier offener Fläche des Khomashochlandes gelegen ist, wegen der Kriegswirren zwischen Hottentotten und Hereros Ende der Regenperiode I 892/93 als Regenmeßstation aufgehoben werden. Die Beobachtungen wurden dort auch späterhiri leider nicht wieder aufgenommen. Auch noch viele andere Stationen lieferten nur wenig zusammenhängende Beobachtungsresultate.

Wollen wir nummehr die gefundenen und auf der Regenkarte zur Darstellung gebrachten Ergebnisse rler Regenmessungen nach ihrem bleibenden Werte beurteilen, so dürften sie wohl für den südlichen und mittleren Teil des Schutzgebietes zum mindesten genügend und ausreichend sichergestellt 
sein. Dahingegen wird die Bearbeitung der Niederschlagsverhältnisse des äuBersten Nordens immerhin nur eine grundlegende und vorläufige zu nennen sein.

Es erübrigt sich, nunmehr noch einige allgemeine Bemerkungen über das Material der zu Reduktionszwecken für den südlichsten Teil von Gr. Namaland herangezogenen britischen Stationen des nördlichen Kaplandes zu machen.

Die zu den Beobachtungen dort verwendeten Regenmesser sind solche vom Modell »Negretti und Zambra«, aus Kapstadt bezogen. Der Durchmesser der Auffangefläche beträgt $20 \mathrm{~cm}$. Das Meßgefäß ist ein Kupferbehälter mit zwei parallelen Glasstreifen, von denen der eine glatt ist, der andere graduiert in o.OI inch.

Es herrscht die Bestimmung, daf nach jedem Regenfall nachgesehen wird, ob das Meßglas noch intakt ist. Jährliche Inspektionsreisen durch einen kapstädtischen Fachmann sorgen für gewissenhafte Aufstellung - nämlich $1.20 \mathrm{~m}$ über dem Erdboden — und Behandlung.

Mit der englischen Messung auf o.OI inch ist nun allerdings ein kleiner Übelstand verbunden, indem Regenmengen unter $0.254 \mathrm{~mm}$ nicht mehr zur Beobachtung und Aufzeichnung gelangen können. Vielleicht hebt aber die größere Auffangefläche der Ombrometer gegenuber derjenigen der in DeutschSüdwestafrika jetzt gebräuchlichen diesen Übelstand wieder auf, indem, wie oben gezeigt wurde, gerade die kleinsten Messungen der deutschen Stationen von 0.0 bis $0.3 \mathrm{~mm}$ bei Anwendung eines größeren Messers ja auch etwas größer ausgefallen wären; hier würde also eine Kompensation eintreten.

\section{Die Verarbeitung des Beobachtungsmaterials. Berechnung der Normalmittel.}

Um einen möglichst sicheren Mittelwert der jährlich niedergehenden Regenmengen für die einzelnen Beobachtungsstationen bilden zu können, ist natürlich zunächst das Vorhandensein einer möglichst langen und ununterbrochenen Beobachtungsreihe erforderlich. Es liegt auf der Hand, daß, je größer die jährliche Schwankung des Niederschlags in einem bestimmten Klimagebiete ist, um so größer auch dicse Jahresreihe sein muß, wenn das daraus $z u$ ziehende Mittel den ungefähren wirklichen Durchschnittswert ergeben soll. Allerdings ist die Schwankung der jährlichen Regenmengen in Deutsch-Südwestafrika, wie in allen regenärmeren Ländern, ziemlich groß. Trotzdem kommt aber auch hier schon der einer ro-bis 20jährigen Periode entnommene Mittelwert dem wahren ziemlich nahe, und er würde unter den obwaltenden Verhältnissen Mitt. von Forschungsreisenden, XX. Band. I. ein genügend sicheres Bild der betreffenden Niederschlagsverhältnisse eines Ortes und seiner Umgebung liefern können.

Sobald es sich jedoch um eine synoptische Darstellung der Niederschlagsverhältnisse eines größeren Bezirkes, wie in vorliegender Abhandlung, handelt, tritt ein weiteres Moment für die Berechnung der Mittelwerte auf: die Beobachtungsreihen sollen denselben Perioden entstammen. Die Gleichzeitigkeit der Beobachtungen mußdurchausgewahrt bleiben, da alle meteorologischen und besonders auch die Regenverhältnisse in den aufeinanderfolgenden Zeitabschnitten nicht gleichmäßig verlaufen, sondern gewissen Schwankungen unterworfen sind.

Ohne hier von einer periodischen Änderung als gegebener Tatsache reden $z u$ wollen, wie z. B. einer I jährigen Periode mit regelmäßigem Fallen und Steigen der einzelnen klimatologischen Elemente oder einer etwa 35 jährigen nach Ed. Brückner, dürfen wir trotzdem auch in Südafrika gewisse Zeitabschnitte unterscheiden, die ausgezeichnet sind durch besonderen Regenreichtum oder besondere, vielleicht mehrere Jahre hindurch anhaltende Trockenheit.

So erhalten wir z. B. als Mittel der 54 jährigen Beobachtungsreihe 184r bis 1895 von Kapstadt: $655 \mathrm{~mm}$ jährlichen Niederschlag, während Supan aus einer 43jährigen Periode als Mittel $632 \mathrm{~mm}$ berechnet. ${ }^{1}$ ) Selbst diese doch relativ langen Perioden entnommenen Mittel stimmen noch nicht genau überein.

Allerdings haben wir es bei der Behandlung der Niederschlagsverhältnisse Deutsch-Südwestafrilias mit anderen Verhältnissen zu tun, da es sich hier um ein noch wenig erschlossenes Gebiet handelí; und selbstverständlich gestattet das Material da nicht die gleiche Behandlung und Verwertung wie in Ländern mit regelrechtem und seit lange vorhandenem Beobachtungswesen. Man muß eben in unserem Schutzgebiete mit den gegebenen und häufig wenig genügenden Daten rechnen.

Zunächst muf Loanda (r), Beobachtungsdauer 23 Jahre, als zu weit nördlich an der Küste von Angola liegend, so daß seine Ergebnisse wenig für das ubrige Gebiet maßgebend sein dürften, ausgeschaltet werden. Es bleibt dann nur noch in Rehoboth (47) eine Station, die mit dem vorliegenden Material von 20 Beobachtungsjahren in etwa unseren Ansprüchen zur Bildung eines Normalmittels genügen würde.

Weitere längere Beobachtungsreihen von etwa ro bis $\mathrm{I}_{5}$ Jahren liefern Olukonda-OndanguaOniipa (5, 4, 3), Waterberg (I7), Windhuk (35),

1) A. Supan, L.V. 46, S. 78 . 
Schaaprivier (42), Walfischbai (46), dann im nördlichen Teile des Kaplandes auBer anderen besonders noch Pella $(78)$, Klipfontein (80) und Port Nolloth (79). Ob jedoch die einzelnen Mittelwerte aus ihrem Material schon als Normalmittel gelten dürfen, muß vorderhand dahingestellt bleiben und wird sich dies aus den späteren Berechnungen ergeben.

An allen ibrigen Orten ist die Dauer der Beobachtungen eine weit kürzere, nämlich 5 bis 8 Jahre, bei den meisten nur 2 bis 5 Jahre. Die Rohmittel dieser letzteren Stationen sind also nicht hinreichend zur Beurteilung der dort herrschenden Regenverhältnisse. ${ }^{1}$ )

Glüiclicherweise ist jedoch der wissenschaftlichen Bearbeitung ein Hilfsmittel zur Hand gegeben, welches gestattet, auch aus kürzeren Reihen ein dem wabren Durchschnitte möglichst naheliommendes Mittel zu gewinnen.

Dies geschieht in der Weise, daf man das aus einer liurzen Beobachtungsreihe gewonnene Mittel einer Station A auf dieselbe Zeitperiode einer mit I vergleichbaren Nachbarstation B, welche schon ein aus einer genuigend langen Beobachtungsreihe gebildetes Normalmittel besitzt, reduziert. Betreffs einer näheren Begründung dieses bereits vielfach angewendeten Verfahrens darf hier wohl nur auf die nähere Erörterung desselben durch J. Hann²) und Meyer ${ }^{3}$ ) verwiesen werden. Die Vergleichbarkeit zweier Stationen setzt dabei immer eine nicht $z u$ weite Entfernung und ungefähr ähnliche oder doch nicht zu sehr verschiedene Verhältnisse des Reliefs, der Lage usw. voraus. Erforderlich wäre jedoch, darzutun, ob auch in einem Gebiete wie das hier vorliegende das Verfahren der mannigfach anderwärts bewährten Reduktion anwendbar ist. Diesen Beweis hoffe ich in folgendem in befriedisender Weise führen zu können. In ihrer schließlichen Anwendung wäre dann auch einer Hauptbedingung zur synoptischen Darstellung von meteorologischen Normalmitteln, nämlich der Gleichzeitigkeit der Beobachtungen Rechnung getragen.

Nach Hann²) bilden die Quotienten der korrespondierenden Regenmengen zweier Orte ein sehr bequemes Mittel, die Ergebnisse kürzerer Reihen von Niederschlagsmessungen einer Station A auf die Normalwerte einer benachbarten und mit $A$

1) [nter $\gg$ Rohmittel" ist ras ans den von einer Station vorhandenen and mit dem Ombrometer gemessenen Jahreshzw. Jlonatsregensummen gohillete arithmetische Mittel verstanden.

2) J. II tan 1h, L. I. 27, s. 328 if.

3) Ur. H. Meyer, Anleitung zur Bearbeitung metrorologischer Beobachtungen. Berlin r89 I. S. $45 \mathrm{ff}$. in limatischer und orographischer Beziehung vergleichbaren Station $B$ zu reduzieren.

Dicse Quotienten sind viel weniger veränderlich als die Regenmengen selbst. .... Dies ist der Erfahrungssat\% von der genäherten Konstanz der Verhältniszahlen der gleichzeitig gefallenen jährlichen Niederschlagsmengen zwcier benachbarten Orte."

Gesetzt daher den Fall, wir haben eine sogenannte Hauptstation A mit einer besonders langen Reihe von Beobachtungen und dem bereits daraus gebildeten Normalmittel $N$, und ferner von einer nicht zu weit davon entfernten und ähnliche Verhältnisse des Reliefs und der sonstigen Lage aufweisenden Station B eine weit kiirzere Reihe von Bcobachtungen, deren Zeit jedoch in die Reihe der anderen fällt, mit dem rohen Mittel $M_{b}$. Das aus den Ergebnissen derselben Periode gebildete Mittel der Station A möge heißen $M_{\text {a. }}$. Nunmehr wird nach Hann folgende Proportion bestehen:

$$
M_{a}: N=M_{b}: N_{x}
$$

wobei $N_{x}$ das gesuchte Normalmittel der Station B bedeutet. Wir erhalten also durch diese Berechnung ein wirkliches Normalmittel:

$$
N_{x}=\frac{N^{\top}}{M_{a}} \cdot M_{b}
$$

der Station B mit kïrzerer Beobachtungsdauer.

Die Anwendbarkeit dieses Verfahrens vorausgesetzt, müßte daher die positive oder negative Abweichung der jährlich niedergegangenen Regenmengen vom beiderseitig gefundenen Normalmittel bei den beiden Stationen stets angenähert dieselbe bleiben, sobald man sie z. B. fortlaufend in Prozenten des Normalmittels ausdrüclit. Weiterhin wird auch während eines kürzeren Zeitabschnittes, etwa innerhalb derselben Regenzeit, eine durchgreifende Witterungsänderung in gleichem Sinne und mit mehr oder minder derselben Intensität sich auf weitere Strecken hin geltend machen, eine Tatsache, welche allerdings selbst von langeingesessenen Kennern des Landes von manchen Strichen DeutschSüdwestafrikas bestritten worden ist.

Zur besseren Veranschaulichung und besonderen Untersuchung, ob diese Vorausset»ungen auch für die Regenverhältnisse in Deutsch-Südwestafrika gegeben sind und gelten können, mögen mehrere Tabellen nebst graphischen Darstellungen beigefügt werden:

I. Graphische Darstellung der prozentmäßigen Abweichung der Jahresmittel einzelner Stationen von ihren Normalmitteln während der Dauer ihrer Beobaclitungen;

2. Tabellen zur Veranschaulichung der Gleichzeitigkeit des Eintritts, der gleichen Dauer und 
Intensität des Niederschlags einer beschränkten Anzahl benachbarter RegenneBstationen.

Bei der graphischen Darstellung in den Diagrammen I bis 10 sind die jährlichen Niederschlagsmengen in Prozenten des gefundenen Normalmittels der betreffenden Station ausgedrückt und als Ordinaten 1) eingetragen. Die FuBpunkte sind durch die Nullinie verbunden; die Verbindung der oberen Endpunkte stelit dann eine Kurve dar, die teils oberhalb, teils unterhaib der Iooprozentigen oder Normallinie verläuft und so auf den ersten Blick die einzelnen Jahrgänge als feuchte bzw. trockene kennzeichnet. Bei einem einigermaßen parallelen Verlauf einzelner Kurven untereinander ersibt sich also, daß einer trockenen Periode bei einer bestimmten Station auch eine ebensolche bei der zweiten oder vielleicht dritten betrachteten entspricht.

Eine flüchtige Betrachtung zeigt in unserem Falle schon eine gewisse Ahnlichkeit im Verlaufe fast aller Prozentlinien; jedoch tritt dies bei einzelnen ganz evident hervor.

Tabelle 3. Jährliche Niederschlagsmengen in Prozenten des Normalmittels. $\mathrm{N}=100 \mathrm{v} . \mathrm{H}$.

\begin{tabular}{|c|c|c|c|c|c|c|c|c|c|c|c|c|c|c|c|c|c|}
\hline $\begin{array}{c}\text { geogr: } \mathrm{Br} . \\
\text { (siidi.) }\end{array}$ & Station & $83 / 84$ & $84 / 85$ & $90 / 9 I$ & $91 / 92$ & $92 / 93$ & $93 / 94$ & $94 / 95$ & $95 / 96$ & $96 / 97$ & $97 / 9^{8}$ & $98 / 99$ & $99 / 00$ & OO/OI & $01 / 02$ & $02 / 03$ & $03 / 04$ \\
\hline ca. $24^{\circ} 28^{\prime}$ & $\begin{array}{l}\text { Nomtsas }(53) \\
\text { Ioov.H. }=208.4 \mathrm{~mm}\end{array}$ & & & & & & & & & & & I 7 I.I & $6 I .9$ & 41.8 & 40.5 & $3^{8} \cdot 3$ & I 50.9 \\
\hline $23^{\circ} \mathrm{Ig}^{\prime}$ & $\begin{array}{c}\text { Rehoboth }(47) \\
100 \mathrm{v} \cdot \mathrm{H}=265.6 \mathrm{~mm}\end{array}$ & 44.5 & I 31.0 & {$[68.7]$} & I 88.0 & & I 39.0 & 90.0 & 43.6 & I 16.7 & I I 0.8 & I 3 I.O & 72.8 & 63.0 & 46.2 & $4 I .9$ & I 49.8 \\
\hline $22^{\circ} 45^{\prime}$ & $\begin{array}{l}\text { Schaaprivier }(42) \\
\text { Ioo v.H. }=350.1 \mathrm{~mm}\end{array}$ & & & & & I92.6 & II 7.2 & 87.0 & $4 I .5$ & I I 5.2 & 98.4 & 136.3 & 102.0 & 99.0 & 56.3 & $35 . \mathrm{I}$ & \\
\hline $22^{\circ} 34^{\prime}$ & $\begin{array}{l}\text { Windhuk (35) } \\
\text { Ioo v.H. }=357.3 \mathrm{~mm}\end{array}$ & & & {$[85.0]$} & 163.6 & I88.4 & 98.8 & 90.5 & 53.7 & I 62.8 & 109.0 & I 44.I & IO3.4 & 70.9 & 5 I. 8 & $67 \cdot 3$ & I06. I \\
\hline $22^{\circ} 20^{\prime}$ & $\begin{array}{l}\text { Otjimbingue (29) } \\
\text { roov.H. }=136.2 \mathrm{~mm}\end{array}$ & & & & & 208.7 & & & & 141.3 & & & I I 4.9 & $43 \cdot 3$ & $77 \cdot 5$ & 68.0 & \\
\hline $2 \mathrm{I}^{\circ} 35^{\prime}$ & $\begin{array}{c}\text { Omaruru }(19) \\
\text { Ioo v. } \mathrm{H}=273.7 \mathrm{~mm}\end{array}$ & I 22.5 & I 53.2 & & & & & & & & & & 91.2 & 53.6 & IOO.I & 63.0 & I 55.3 \\
\hline $2 I^{\circ} 59^{\prime}$ & $\begin{array}{c}\text { Okahandja }(25) \\
\text { Ioo v.H. }=377.4 \mathrm{~mm}\end{array}$ & & & & 53.2 & 197.8 & $83 \cdot 4$ & 88.8 & 53.4 & & & I $27 . \mathrm{I}$ & I09.6 & 78.7 & 6o.I & 75.6 & I09. 4 \\
\hline $22^{\circ} 2 x^{\prime}$ & $\begin{array}{c}\text { Gobabis ( } 3 \mathrm{I}) \\
\text { Ioo v.H. }=470.6 \mathrm{~mm}\end{array}$ & & & & & & & & & & I 37.9 & 109.3 & 84.9 & 70.6 & 79.5 & 66.9 & 73.7 \\
\hline $\operatorname{ca} .20^{\circ} 35^{\prime}$ & $\begin{array}{c}\text { Waterberg (I7) } \\
\text { Ioov.H. }=564.4 \mathrm{~mm}\end{array}$ & & & & & I I I. 3 & 74.9 & {$[44 \cdot 3]$} & $6 I .9$ & I 21.8 & & I 21.6 & 99.6 & 87.4 & 100.5 & 60.6 & \\
\hline $8^{\circ} 49^{\prime}$ & $\begin{array}{c}\text { Loanda }(\mathrm{I}) \\
\text { Ioo v. } \mathrm{H} .=315.0 \mathrm{~mm}\end{array}$ & 50.3 & I69.7 & I I. 3 & & & & 144.6 & 92.3 & 89.7 & 201.0 & 178.9 & 34.6 & I 10.2 & 31.6 & I 21.2 & \\
\hline
\end{tabular}

So zeigen z. B. die Kurven von Nomtsas, Rehoboth, Schaaprivier, Gr. Windhul, dann Omaruru, Otjimbingue, eine fast auffallende Übereinstimmung, wie eine Vergleichung der jährlichen Prozentzahlen ergibt; ebenso wieder die Kurven von Windhuk, Omaruru, Okahandja, Gobabis, Waterberg.

Bei der Redultion irgend einer Station mit kurzer Beobachtungsreihe auf die längere Periode einer benachbarten mit gegebenem Normalmittel bin ich in der Weise vorgegangen, daß ich die Quotienten der einzelnen entsprechenden Jahressummen herstellte; sobald diese andauernd genähert konstant blieben, durfte das Verfahren der Reduition in dem vorliegenden Falle als anwendbar betrachtet werden. Ich glaube, dais in dieser Beziehung die Vergleichbarkeit so sorgfältig wie eben möglich in jedem einzelnen Falle geprüft worden ist.

Im folgenden möge noch an einem Beispiele die Berechtigung der Reduktion einer Station

1) Der senkrechte Maßstab dieser Diagramme beträgt: I $\mathrm{cm}=50 \mathrm{v} \cdot \mathrm{H}$. mit einer kürzeren Beobachtungsdauer auf die längere Periode einer anderen, welche sofort in ihrem rohen Mittel das Normalmittel lieferte, dargelegt werden. Hierzu nehmen wir beispielsweise die Stationen Rehoboth (47) und Schaaprivier (42).

Von der Station Rehoboth, derjenigen, welche am längsten itınerhalb des Schutzgebietes beobachtet hat, auf relativ freier Fläche, wie auch Schaaprivier am Südabhang der Awasberge gelegen und unter ähnlichen klimatischen Bedingungen, stehen uns die Jahresbeobachtungen von $1883 / 84$ bis $1903 / 04$ (außer I885/86), also von 20 Jahren, zur Verfügung. Schaaprivier weist eine Beobachtungsdauer von I892/93 bis 1902/03 auf. Das rohe Mittel von Rehoboth wurde gleichzeitig als Normalmittel angesehen ind beträgt $265.6 \mathrm{~mm}$. Als rohes Mittel von Schaaprivier erhalten wir aus seiner I I jährigen Beobachtungsperiode $343.9 \mathrm{~mm}$. Bei der großen Schwankung der jährlich fallenden Regenmengen in vorliegenden Gebiete dürfen wir dies nicht ohne weiteres als Normalmittel annehmen, sondern greifen zu dem Hilfsmittel der Redultion. 
N bezeichne das Nommalmittel von Reloboll, $\mathrm{M}_{\mathrm{i}}$ sein rohes Mittel, aus der Periode $1892193 \mathrm{bis}$ I902/03 gewonnen, $\mathrm{I}_{\mathrm{b}}$ sei das rohe Mittel ron Schaaprivier aus derselben Periole IS92/93 bis 1902/03, so ist anzunchmen, lab das reduierte Normalmittel $N_{x}$ von Schaprivier wleich ist:

$$
N_{x}=\frac{N}{M_{a}} \cdot M_{b}=\frac{265.6}{260.9} \cdot 343.9=350.1 \text {. }
$$

350. I mm wäre demnach das reduzierte Jahresmittel von Schaiprivier, welches allerdings ja auch kaum von dem rohen abweicht. Cberhaupt war die Ibweichung des gefundenen Normalmittels bei den Stationen mit längerer, 8 - bis 15 jähriger Beobachtungsdamer gegenüber dem gegebenen rohen Mittel eine liaum nennenswerte.

Um num noch zu zeigen, daß auch bei einem geringeren Beobachtungsmaterial eine Reclulition berechtight und möglich gevesen wäre, wollen wir annehmen, ron Schaaprivicr wäre nur dic Periode I896/99 vorhanden; diese ist fur beicle Stationen, wic im allgemeinen in Deutsch-Südwestafrika, eine besonders regenreiche gewesen. Das rohe Mittcl dieser Periode beträgt für Rehoboth $317.3 \mathrm{~mm}$, für Schaprivier 408,4 mm. Ních entsprechender Berechnung und Einsetzung der rohen Mittel beider Stationen wirden wir damn erhalten:

$$
\mathrm{N}_{\mathrm{X} \text { (3. Jahre) }}=\frac{265.6 \cdot 408.4}{317.3}=34 \mathrm{r} .9 \text {. }
$$

Wir erhalten also diesmal als Normalmittel von Schaprivier $34 \mathrm{I} .9 \mathrm{~mm}$; gegen $350.1 \mathrm{~mm}=\mathrm{N}_{x}$ ist also cine uiberaus kleine Differenz zu konstatieren.

Allerdings wird mit geringerer Dauer (ler Beobachtungen atch dic Unsicherheit der Reduktion immer größer. Jedoch habe ich in allen Fällen dann, sobald Jahres- und Monatskurven der geemessenen Regensummen nicht vollständig übereinstimmten, d. h. wenn die Quotienten der lorrespondicrenden Regenmengen der betreffenden Jahrgänge nicht konstant blieben, was ja spontan durch auBergewöhnliche gröBere oder kleinere Regenfälle in lokal begrenztem Gebiete verursacht sein lionnte, dic Reduktion auf zwei oder vielleicht auch drei Stationen, die im selben Regengebiete lagen, ausgeführt. Es darf angenommen werden, daß hicrdurch nach Möglichkeit ein etwaiger Fehler wieder ausgeglichen wurde.

Auch noch in anderer Weise glaubte ich die Ausfülnbarkeit der Redultion auf längere Zeitperioden crhärten zu können. In Anbetracht der Wichtigkeit dieser Darlegungen, ohne welche ja besonders die Aufstellung einer detailierten Regenkate direkt ein Ding der Unmöglichlicit wäre, seicn hier noch die beiden folgenden Darstellungen in Tabellenform aufgeführt.
Schon K. I)ove stelle in einer Hbhindlung über das Klinal von Deutsch-Sürlwestafrikal) fest, dab cin Zusammenhang im zeitlichen Eintritt und (ter 1)auer des Nicderschlags in lokal begrenztem Gebiete auch in unserem Schut\%gebicte bestehe. Die von ihm aufgeführten Daten sind den Regenperioden I 892, I 892/93 entnommen. Während Dove jedoch nur einen ähnlichen Charakter der Regenverhältnisse bei den Stationen Crr. Windhuk (35), Heusis (39), Rehoboth (47) und Kubabub (42), also für cin Gebiet von dem Flächenraum von etwa rOOO( ) gkm, feststellen lionnte, ist mir dies für cine weit gröbere Landschaft möglich gewesen.

Auf Grund des mir freundlichst von Herrn Prof. Rehbock ïberwiesenen Materials bringe ich im folgenden dic gleichzeitige Ausdehnung der Regenfälle über ein Gebiet, welches die Stationen Rehoboth, Hatsamas (45), Windhuk, Otjimbingue (29), Outjo (It), Waterberg (I 7 ) und Gobabis (3I) umfaBt, tabellarisch zur Darstellung

\begin{tabular}{|c|c|c|c|c|}
\hline \multirow{2}{*}{1897} & \multicolumn{2}{|c|}{ Gobabis } & \multicolumn{2}{|c|}{ Waterberg } \\
\hline & Tage & $\mathrm{mm}$ & Tage & $\mathrm{mm}$ \\
\hline \multirow{4}{*}{$\begin{array}{l}\dot{-} \\
0 \\
\Xi \\
a \\
0 \\
\dot{0} \\
\vdots \\
\dot{1}\end{array}$} & $\begin{array}{l}12 . \\
23 .\end{array}$ & $\begin{array}{l}\text { I. I } \\
0.5\end{array}$ & 11. & 0.6 \\
\hline & 28. & 8.7 & 28. & 5.5 \\
\hline & 29. & I 8.5 & 29. & I. 6 \\
\hline & & & 30. & 5.4 \\
\hline \multirow{5}{*}{$\begin{array}{l}a \\
0 \\
己 \\
\text { a } \\
0 \\
\text { N } \\
0 \\
0\end{array}$} & 2. & 5.8 & 2. & I .O \\
\hline & 8. 9. & 11.0 & 8. -9. & 11.2 \\
\hline & & & 12. & 0.7 \\
\hline & 17. & 4.8 & $17 . "$ & 6.2 \\
\hline & 19. 22 . & 43.9 & $19 .-22$ & 52.7 \\
\hline
\end{tabular}

Tabelle $4 \mathrm{a}$.

Die Tabelle, welche neben Eintritt und Daucr der meBbaren Niederschläge ciniger Monate aus dem Jahre 1897 auch dic in den betreffenden Zeiten gefallene Niederschligsmenge in Millimetern angibt, zeigt deutlich dic gleichzeitige Ausbreitung über cin etwa + bis 5 mal gröBeres Gebiet als dasjenige, von dem K. Dove den bezüglichen Nachweis führte.

Wir ersehen hieraus also, daB der ,Eintritt des Regens auch in Deutsch-Südwestafrika über ziemlich weite Gebiete hin cinigermaßen gleichmäßig erfolst und nur die zu Boden gelangenden Mengen verschicklen sind".

1) Dr. K. Dore, I. V. I7, S. 30,31 . 
Tabelle 4. Vergleich des zeitlichen Eintritts sowie der Dauer und Menge von Niederschlägen über größeren Gebieten in Deutsch-Südwestafrika.

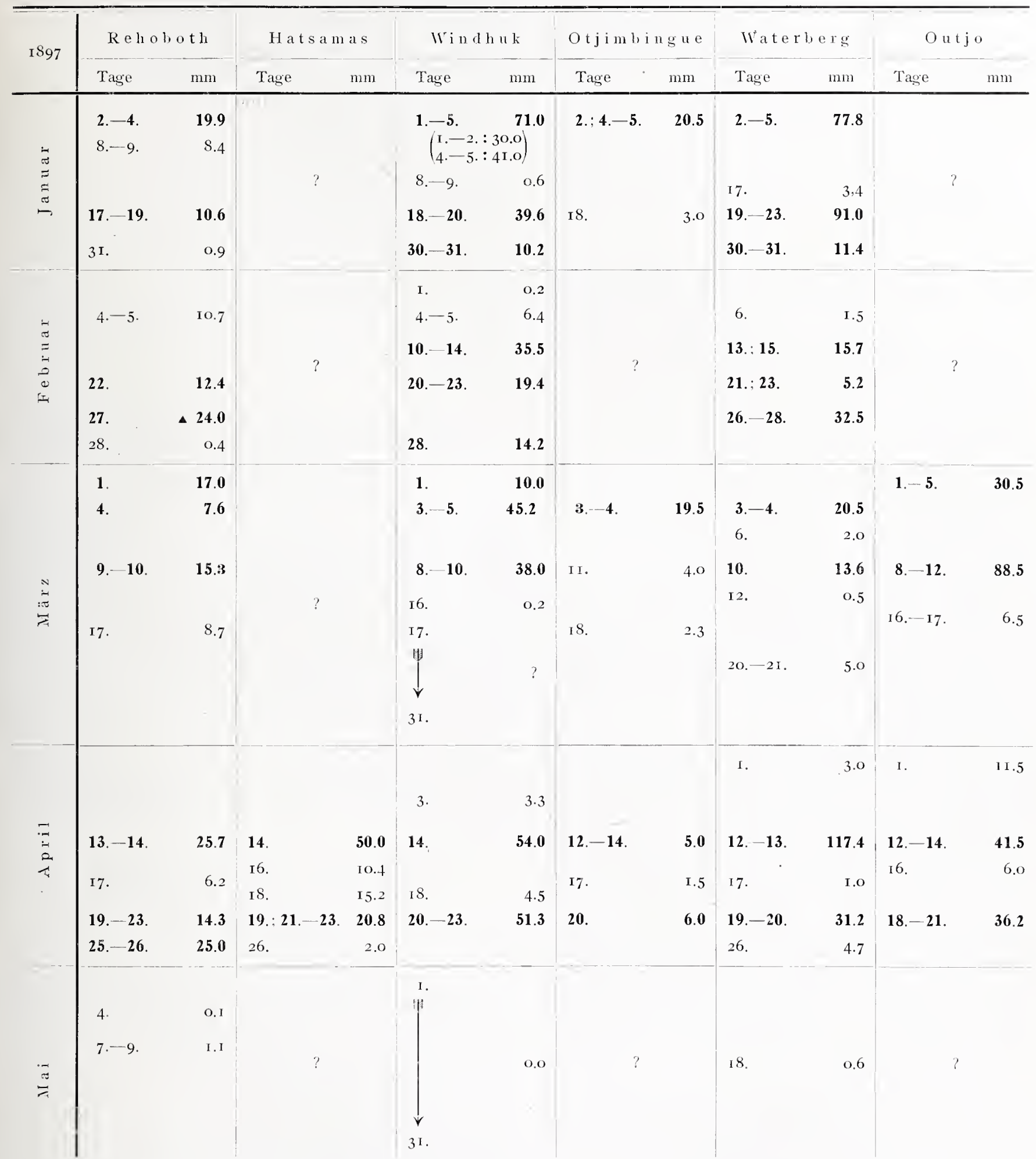

Die vielfach auch im Schutzgebiet vertretene Meinung, daß dort die Niederschläge häufig nur strichweise eintreten und fallen, hat sich daher nach obigen Darlegungen nicht bestätigt. Besonders die stärkeren Regenfälle, auf welche es bei der kulturellen Nut\%barmachung des Landes hauptsächlich ankommt, erstrecken sich wie auch in unseren Breiten als wirkliche ,Landregen", allerdings nicht so lange andauernd, über größere Länderstrecken hin.

Auch die zu ungewölnnlicher Zeit, im Winter, niedergehenden Regen- und Schneefälle finden eine weitere Verbreitung und zeigen so cbenfalls, dab 
im algemeinen, ,ieinc örtiche Regellosigkeit der Niederschläge in Deutsch-Sïdwestafrilá herrscht".

Noch deutlicher tritt dies durch die in den folgenden Tabellen (5 u. 6) angeführten Daten in die Erscheinung. Letztere zeigen die in DeutschSuidwestafrika während zweier willkürlich gewählten Monate August und Olitober IS99 registricrten Regenfälle und ergeben eine auffallende Übereinstimmung des Eintritts, der Dauer und Verbreitung des Niederschlags im ganzen Binnenlande des Schutzgebietes.

Diese hier dargelegten Tatsachen erlaubten auch, die Inzahl der Beobachtungsjahre mancher Stationen, welche neben wenigen Jahressummen nur noch Teile von solchen, nänlich die Summenangaben einzehner Monate besaben, künstlich durch Redultion auf die vollständige betreffende Jahresregensumme einer Nachbarstation zu erhöhen. Das Verhälnis der monatlichen zur Gesamtjahresregenmenge bleibt nämlich für ziemlich weite Kreise nahezu konstant. Als Beleg hierfür können auch die späteren Tabellen und Diagramme mit der monatlichen und jahreszeitlichen Regenverteilung gelten. Vgl. Tab. IO, I I. Diagr. I I bis 33 .

Selbstverständlich blieb zu jeder auszuführenden Reduktion ständige Voraussetzung, daß die Entfernung und der Höhenunterschied der beiden Stationen möglichst unbedeutend waren, wie ja auch anderseits ,Kammlagen nicht mit Tallagen verglichen werden duirfen".

Als cin sogenannter Hauptreduktionsort für den mittleren Teil des Landes lonnte, wie schon gesagt, Rehoboth (47) mit einer Beobachtungsdauer von 20 Jahren angesehen werden; als solche zweiter Ordnung die RegenmeBstationen Klipfontein (80), Pella (78), Bethanien(62), Gibeon(58), Schaaprivier(42), Gr. Windhuk (35), Waterberg (17), Omaruru (19), Okahandja (25), Olukonda-Oniipa-Ondangua (3 bis 5) und Loanda (I). Es wurde so bei allen Stationen eine Reduktion erzielt, die sich mindestens auf den Zeitraum der Regenperioden I890/9I (bzw. I89I/92) bis $1903 / 04$ erstrcckt, also auf etwa I 4 Jahre.

Erforderlichenfalls wurden jedoch außerdem noch, wie aus der folgenden Übersicht hervorgeht, andere Hilfsreduktionsorte mit hinzugezogen.

„Die Eigenart Deutsch - Südwestafrikas in cler plateauartigen Entwicklung der Gebirge, das Fehlen ausgedehnter, hoch iiber das umliegende Land emporsteigender Gebirgsketten und geschlossener Kammlinien läßt von vornherein annehmen, daß eigentliche Klimascheiden (abgesehen natürlich von dem Gegensatz zwischen Binnen- und Küistenland) dem Lande fehlen"; dies erleichterte denn auch die Iuswahl greeigneter Reduktionsorte.

Nach K. Dove (a. a. O.) sind besonders Kubabub (Schaaprivier), Heusis (39) und Rehoboth durch ihre Lage in ziemlich freien Hochländern für ausgedehntere Landschaften des mittleren Teiles des Schutzgebietes typische und zu Reduktionszwecken verwendbare Stationen.

Bei anderen, wie \%. B. Windhuk, mußte allerdings diese Erwägung etwas hinter die andere Ruichicht der langen Dauer und der Gewissenhaftigkeit der gemachten Beobachtungen zurücktreten.

In folgenden gebe ich nummehr eine Zusammenstellung aller Stationen mit Angabe ihrer rohen und ihrer durch Reduktion gefundenén wahrscheinlichen Normalmittelwerte der jährlich fallenden Niederschlagsmengen. (Tab. 7.)

\section{Verzeichnis der Regenmeßstationen mit den berechneten und reduzierten Mittelwerten unter Angabe der benutzten Reduktionsstationen.}

Anmerkung: Die mit : bezeichneten Orte sind portugicsische RegenmeBstationen aus Angola, die mit : bezeichneten britische aus dem nördlichen Kapland bzw. Walfischbai.

Bei der Angabe der Dauer der vorliegenden Beobachtungen durch die Anzahl der Jahre und Monate ist außerdem noch diejenige der ununterbrochenen Regenperioden verzeichnet worden.

[] bedeutet eine unvollständige Anzahl oder eine Anzahl unvollständiger Summen.

Bei einer Reduktion auf mehrere Orte liefert das arithmetische Mittel den Normalmittelwert der durchschnittlich im Jahre fallenden Regenmenge.

\section{Beispiele einer ausgeführten Reduktion.}

I. Berechnung des Normalmittels von Okahandja (25).

Nls Reduktionsort ist Gr. Windhuk gewählt (35).

Als rohe Mittel von Okahandja ergeben sich für den Zeitraum der Regenperioden

I 898/I903 (5 Jahre): 340.4 mm jährlicher Niederschlag I 89 I/ I 896 (5 Jahre): 435.2 "

Gr. Windhuk:

I 898/I903: 3 I $2.5 \mathrm{~mm}$ | auBerdem schon gegebenes I 89I/I 896: $425.8 \mathrm{~mm}$ / Normalmittel: $357.3 \mathrm{~mm}$.

Nach der Reduktionsmethode erhalten wir also zunächst folgende Normalmittel von Okahandja:

$$
\begin{aligned}
& \mathrm{x}_{1}=\frac{357.3}{3 \mathrm{I} 2.5} \cdot 340.4=389.6 \mathrm{~mm} \\
& \mathrm{x}_{2}=\frac{357.3}{425.8} \cdot 435.2=365.2 \mathrm{~mm} .
\end{aligned}
$$




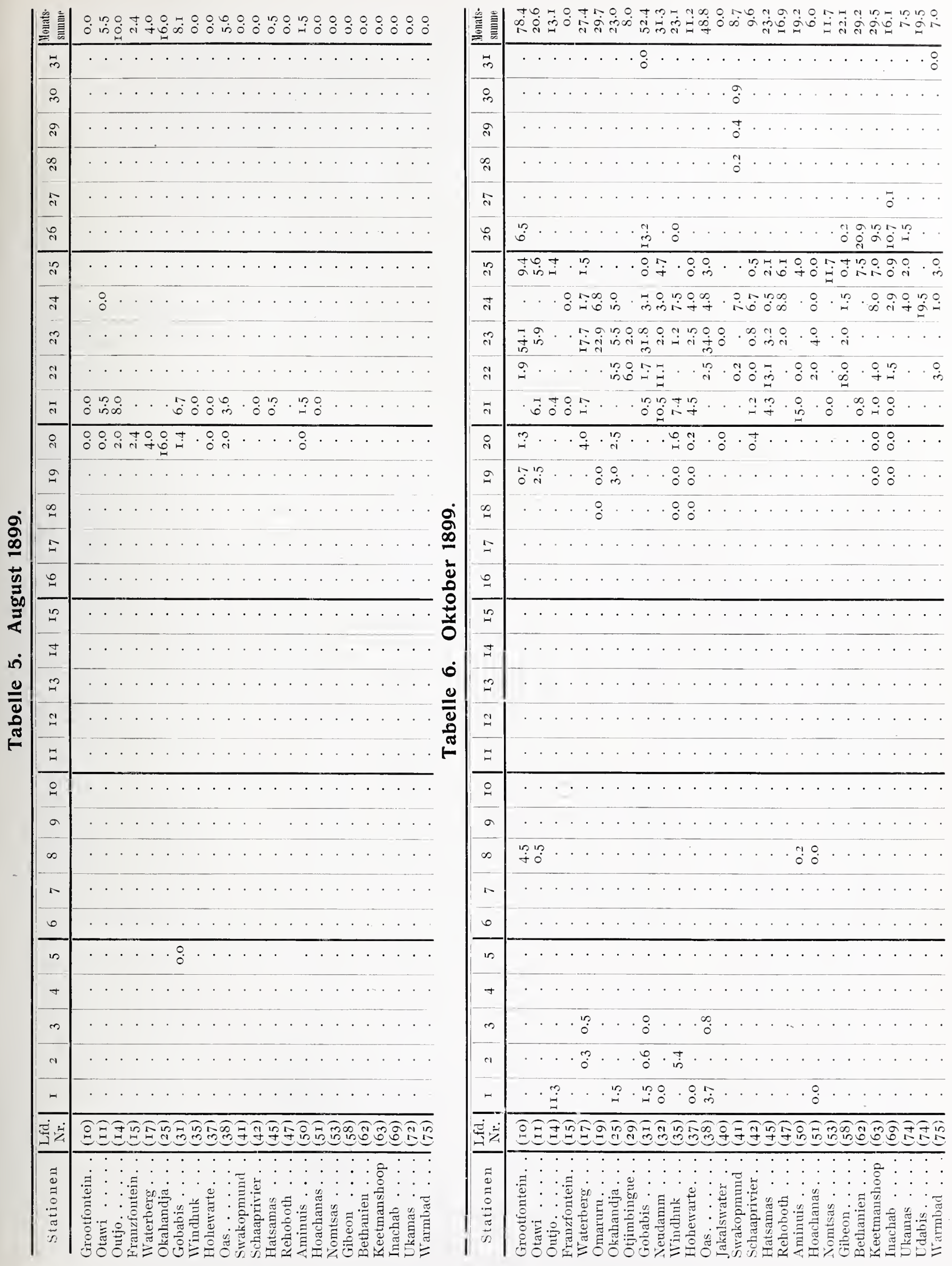


Das arithmetische Mittel liefert uns clas Normalmittel von Okahandja: $\mathrm{N}=377.4 \mathrm{~mm}$. Das rohe Mittel aus den zehn gegebenen Beobachtungsreihen (I\$9I bis I 896 , I $\$ 98$ bis 1903) würde uns eine nur wenig rom Normalmittel abweichende Gröbe geben: $M=387.8 \mathrm{~mm}$.

\section{Berechnung des Normalmittels von Omaruru (19).}

I)as vorhandene Naterial liefert ein rohes Mittel: $M=272.3 \mathrm{~mm}$. Nls. Redultionsorte sind Gr. Windhuk (35) und Okahandja (25) gewählt, welche cine gleichzcitige Beobachtungseihe von + Jahren mit Omaruru yeneinsam haben: I\$99 bis 1903.

Dic rohen Mittel, aus diesem Zcitraum gewonnen, betragen für: Omaruru 2I2.I 1mm, Gr. Winclhuk 262,0 mm, Okahandja $305.6 \mathrm{~mm}$; die Normalmittel: von $\mathrm{Gr}$. Windhuk $\mathrm{N}_{1}=357.3 \mathrm{~mm}$, Okahandja $\mathrm{N}_{2}=$ $377 \cdot+$ mm. Für Omaruru erhalten wir also je nach Wahl des Reduktionsortes als vorläufige reduzierte Jahresmittel cles Niederschlags:

$\mathrm{x}_{1}=\frac{357.3 \cdot 212.1}{262.0}=289.3 \mathrm{~mm}($ Red. Ort: Gr. Windhuli) $\mathrm{x}_{2}=\frac{377.4 \cdot 2 \mathrm{I} 2 . \mathrm{I}}{305.6}=262.0 \mathrm{~mm}$ (Rel. Ort: Okiahandja) Mls Normalmittel von Omaruru ergibt sich daher: $\mathrm{N}=1 / 2(289.3+262.0)=275.7 \mathrm{~mm}$.

Anmerknng: Die näheren Zahlenangaben und sonstigen bemerkungen zu den ausgefïhrten Reduktionen liefern die Tabliellen I und 2.

Tabelle 7.

\begin{tabular}{|c|c|c|c|c|c|c|c|c|c|c|c|c|}
\hline \multirow{3}{*}{$\begin{array}{l}\text { I. firl. } \\
\mathrm{N} \text {. } \\
\mathrm{I} .\end{array}$} & \multirow{2}{*}{\multicolumn{2}{|c|}{$\begin{array}{l}\text { Name der Station } \\
\text { mund ihre geographische Breite } \\
\text { (siidl.) }\end{array}$}} & \multicolumn{3}{|c|}{$\begin{array}{c}\text { Daner der Beob- } \\
\text { achtungen. }\end{array}$} & \multirow{2}{*}{$\begin{array}{l}\text { Kohes Mittel } \\
\text { in } \mathrm{nm}\end{array}$} & \multicolumn{4}{|c|}{ Rerluktionsstationen } & \multirow{2}{*}{$\begin{array}{l}\text { Reduzierte } \\
\text { Mittel } \\
\text { iu mm }\end{array}$} & \multirow{2}{*}{$\begin{array}{l}\text { Normal- } \\
\text { nittel }\end{array}$} \\
\hline & & & Jahre & Mon. & $\begin{array}{c}\text { Regen- } \\
\text { zeiten }\end{array}$ & & $\begin{array}{l}\text { Lfil. } \\
\mathrm{Nr}_{\mathrm{r}}\end{array}$ & $\mathrm{Nam}$ & & & & \\
\hline & Loandia $\quad \dot{s}^{2} \dot{4}^{\prime} \cdot$ & & 23 & - & 21 & 315.0 & & - & & & - & 315.0 \\
\hline 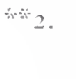 & Cacontial $13^{\circ} 44^{\prime}$ & . & I & 6 & I & I 534.0 & & & & & - & - \\
\hline 3. & Oniipa . & . . & I & 5 & [2] & 427.9 & IO. & Grootfontein & & & 545.0 & \\
\hline 4. & $\begin{array}{c}\text { Ondangila } \\
\text { (cil. I } 77^{\prime} 55^{\prime}\end{array}$ & . . & I & - & I & 412.6 & $\begin{array}{l}9 . \\
7\end{array}$ & Amul & . & $\dot{ }$ & $\begin{array}{l}604.5 \\
599.7\end{array}$ & 570.3 \\
\hline 5. & Onkonda ${ }_{\mathbf{1} 7} 57^{\prime}$ & . . & 6 & 7 & {$[6]$} & 528.5 & 25 . & Okahandjil. & . & . & $599.7 / 563.9$ & \\
\hline 6. & Zesfontein & . . & 2 & 2 & 2 & 67.2 & $\begin{array}{l}14 . \\
19 .\end{array}$ & $\begin{array}{l}\text { Ontjo } \\
\text { Omarurnil }\end{array}$ & . & $\dot{.}$ & $\begin{array}{l}67.2 \\
71.5\end{array}$ & 69.4 \\
\hline 7. & Amutoni (a. I $8{ }^{\prime} \mathrm{o}^{\prime}$ & . & I & 6 & I & 384.0 & $\begin{array}{r}\text { II. } \\
9 .\end{array}$ & $\begin{array}{l}\text { Otawi } \\
\text { Ganb }\end{array}$ & . & . & $\begin{array}{l}553.5 \\
562.6\end{array}$ & $55^{8.1}$ \\
\hline 8. & $\begin{array}{r}\text { Okankwejo } \\
\text { ca. I9 } 10^{\prime}\end{array}$ & . . & 3 & I & 2 & 441.9 & $\begin{array}{l}\text { I } 4 . \\
\text { II. }\end{array}$ & $\begin{array}{l}\text { Outjo } \\
\text { Otawi }\end{array}$ & . & . & $\begin{array}{l}494.5 \\
484.0\end{array}$ & 489.3 \\
\hline 9. & Gaub ca. $19^{\circ} 20^{\prime}$ & . . & 1 & 7 & I & $604 \cdot 3$ & 11. & Otawi. & . & . & 691.0 & 691.0 \\
\hline Io. & $\begin{array}{l}\text { Grootfontein. } 19^{\circ} 40^{\prime} \\
\text { "ad. }\end{array}$ & . . & 5 & 3 & 5 & $567 \cdot 7$ & 17. & Waterberg & . & . & 618.9 & 6 I 8.9 \\
\hline II. & Otawi ${ }_{19^{\circ}} 4^{\prime}$ & . . . & 4 & 10 & 4 & $5 I 4.6$ & 10. & Grootfontein & . & . & 591.3 & $591 \cdot 3$ \\
\hline 12. & Otjituo & . . & $\underset{2}{|3|}$ & $\begin{array}{c}|9| \\
3\end{array}$ & $\begin{array}{c}\lfloor 3\rfloor \\
2\end{array}$ & $531 \cdot 3$ & $\begin{array}{l}17 . \\
10 .\end{array}$ & $\begin{array}{l}\text { Waterberg } \\
\text { Grootfontein }\end{array}$ & $\dot{\cdot}$ & $\cdot$ & $\begin{array}{l}565.4 \\
511.2\end{array}$ & 538.3 \\
\hline 13. & Naidans $\quad \dot{19}^{\circ} 5^{\mathrm{I}^{\prime}}$ & . . & 2 & 2 & 2 & 561.6 & $\begin{array}{l}11 . \\
17 .\end{array}$ & Otawi & . & $\dot{.}$ & $\begin{array}{l}572.7 \\
597.6\end{array}$ & 585.2 \\
\hline 14. & Outjo $\quad{ }_{20^{\circ}} 6^{\prime}$ & . . & 7 & I & 6 & 428.3 & $\begin{array}{l}17 . \\
19 .\end{array}$ & $\begin{array}{l}\text { Waterberg } \\
\text { Omaruru }\end{array}$ & $\dot{.}$ & . & $\begin{array}{l}413.8 \\
468.8\end{array}$ & 441.3 \\
\hline 15. & Franzfontein $20^{\prime} 9^{\prime}$ & $\cdot \cdot$ & 4 & IO & 4 & I 89.2 & $\begin{array}{l}\text { I } 4 . \\
19 .\end{array}$ & $\begin{array}{l}\text { Ontjo } \\
\text { Omarurui : }\end{array}$ & . & . & $\begin{array}{l}213.3 \\
239.4\end{array}$ & 226.4 \\
\hline I6. & Oketoweni ca. $20^{\circ} \dot{6}^{\prime}$ & . . & 3 & 6 & 3 & 324.2 & $\begin{array}{l}17 . \\
14 . \\
25\end{array}$ & $\begin{array}{l}\text { Waterberg . } \\
\text { Outjo } \\
\text { Okahandja. }\end{array}$ & · & . & $\begin{array}{l}391.4 \\
442.8 \\
551.8\end{array}$ & 417.1 \\
\hline 17 & Waterberg $20^{\circ} 35^{\prime}$ & $\cdot$ & 10 & II & 9 & 526.5 & $\begin{array}{l}25 . \\
35 . \\
19 .\end{array}$ & $\begin{array}{l}\text { Wiudhuk } \\
\text { Omaturu }\end{array}$ & i. & $\dot{.}$ & $\begin{array}{l}51.0 \\
515.5 \\
638.5\end{array}$ & 564.4 \\
\hline
\end{tabular}




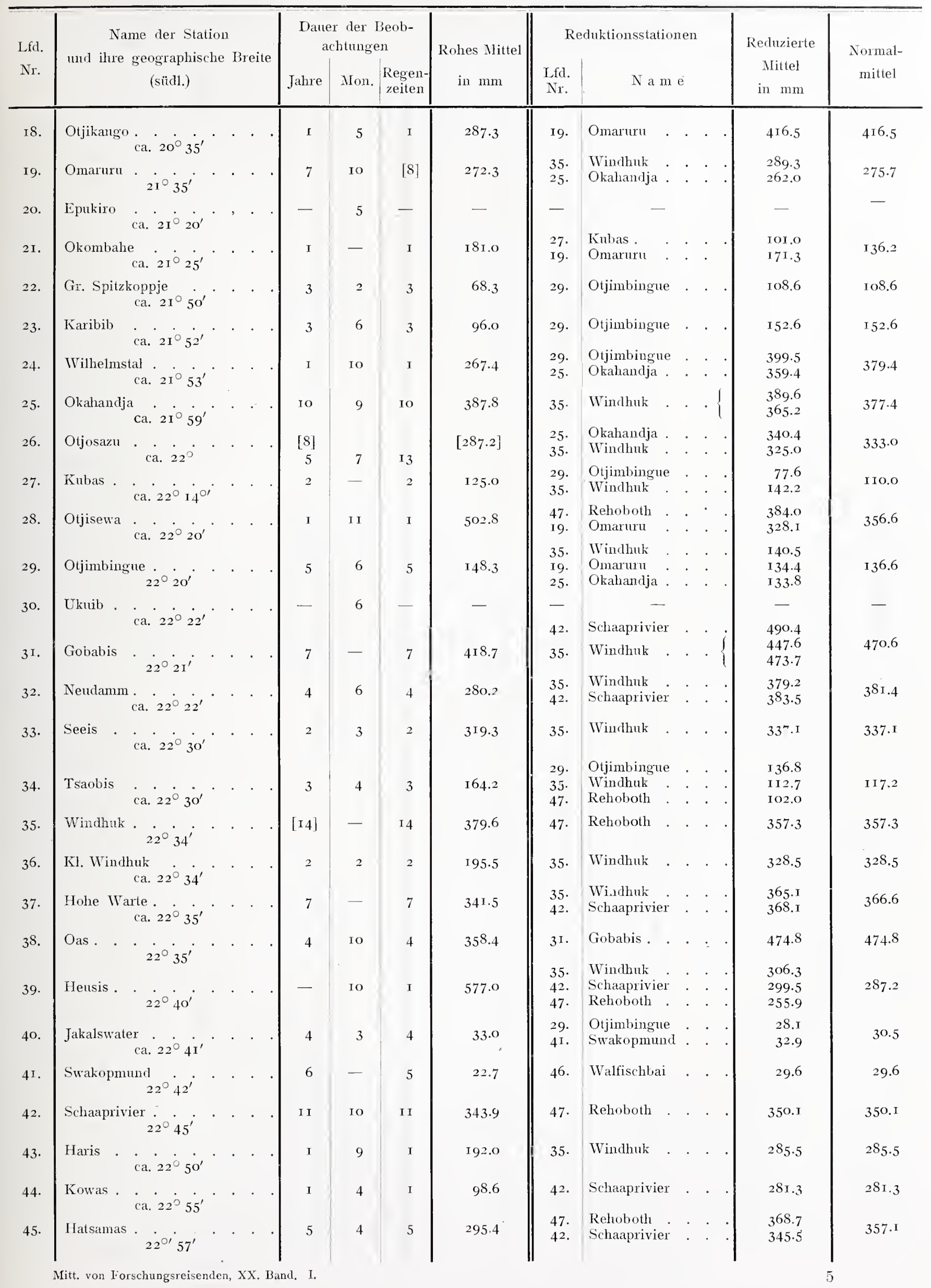




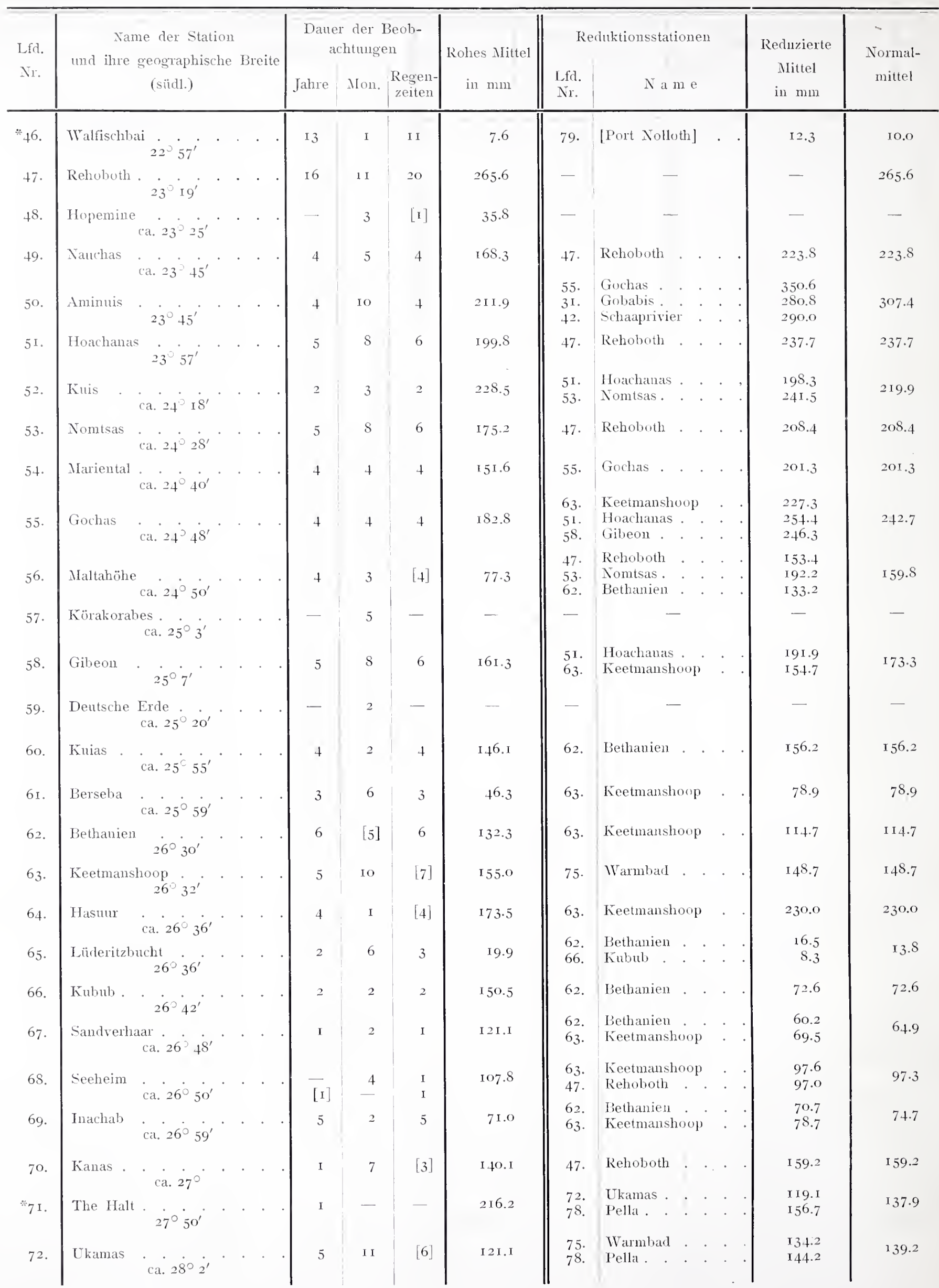




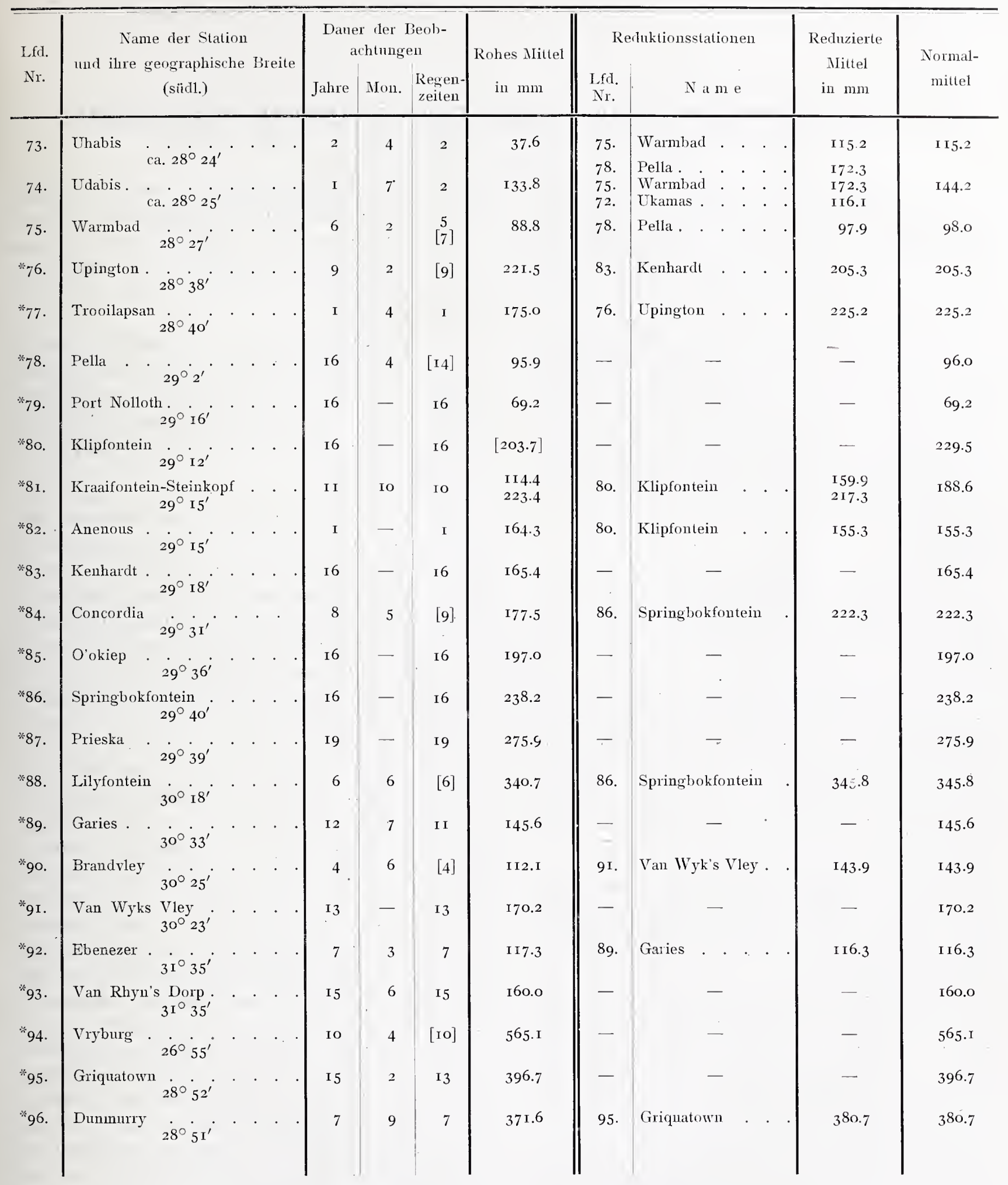




\section{B. Die Verteilung der Niederschlagsmengen in Deutsch -Südwestafrika.}

(Siehe hierzu die beigegebene Niederschligskarte.)

Einen Hauptzweck vorliegender Abhandlung bildete die Herstellung einer Regenkarte von DeutschSüdwestafrika. Auf Grund der Normalmittelwerte der einzelnen Regenmeßstationen, welche nach oben angegebener Redultionsmethode erhalten wurden, ist dieselbe aufgestellt.

Zunächst enthält sie neben den einzelnen Orten die jeweiligen Normahmittel in liegrenden verstärkten Zahlen $(\mathrm{mm})$; ferner in mit Klammern versehenen unverstärliten liegenden Zahlen die rohen Mittelwerte des jährlichen Regenfalls in mm. Diese Werte sind der Tabelle 7 entnommen. Nit stehenden Zahlen ist die Meereshöhe der betreffenden Örtlichlieit (m), gefunden durch barometrische Höhenmessung, angegeben.

Bei der Einzelanlegung des Verlaufes der Isohyeten wurden nach Möglichkeit die Reliefgestaltungen und zum Teil auch die in den Vegetationsverhältnissen liegenden Fingerzeige berüicksichtigt.

So spielt bei der Anlage der einzelnen Zonen neben der Meereshöhe der verschiedenen Gegrenden vor allem auch die Streichrichtung der Gebirge eine große Rolle. Die Luvseite in Deutsch-Südwestafrilia, wie wir später noch sehen werden, fast durchgängigs die östliche, ist bei weitem regenreicher als die Leeseite.

Natürlich hängt in jedem Teile der Karte die Sicherheit des Verlaufes der Isohyeten vor allen Dingen von der Anzahl und Verteilung der dortigen Regenmeßstationen und dem dadurch gegebenen exakten Anhalt ab.

Mit Rücksicht auf die vorhandene Literatur über Relief- und Vegetationsverhältnisse wurden daraufhin die Linien gleichen jährlichen Niederschlags, und zwar in Abstufungen von $50 \mathrm{zu} 50 \mathrm{~mm}$, gezogen. Ebenso ist der besseren Übersicht halber außerdem noch eine dreifarbige Abstufung gelb-grün-blau vorgenommen worden.

Zum Vergleiche mit den eingetragenen Normalmitteln sollen die in Klammern beigefügten rohen Mittelwerte, die sich aus dem vorliegenden Materiale sofort ergeben, dienen.

Bei der nachfolgenden Erörterung der aus der Regenkarte ersichtlichen Niederschlagsverteilung Deutsch-Südwestafrikas werde ich mich mehr zusammenfassend auf größere Landschaftsgebiete ein- lassen, während eine speziellere Behandlung kleinerer Gebiete nur in einzelnen Fällen angebracht erschien.

VIie bereits erwähnt, mußten für Einzelheiten in der Anlegung der Isohyeten auch öfters die Vegetationsverhältnisse mit als ein gewisser Anhalt benutyt werden.

In pflanzengeographischer Beziehung können wir in Deutsch-Südwestafrika drei Zonen unterscheiden: die der Wüstenvegetation, der Steppenvegetation und der durch häufigeren Baumwuchs schon an tropische Verhältnisse erinnernden Buschund Baumsavanne.

Die Sandwüste erstreclit sich in mehr oder weniger schmalem Streifen, abgesehen von lokalem Vorkommen im Binnenland, zientich parallel der Küste entlang; östlich an sie schlieft sich überall die sogenannte Namieb oder Steinwüste an, die sich in breiter Zone im Süden auf der Nordseite des Orangeflusses bis tief ins Binnenland hineinzieht. Das Kennzeichen der Sand- und Steinwüste ist das fast völlige Fehlen jeglicher Pflanzendecke; höchstens gedeihen neben der charakteristischen Narapflanze, auf die wir später noch «u sprechen kommen, spärliche Dünen- und Steppengräser in etwas regenreicheren Jahren auf dem unfruchtbaren Boden und vermitteln dann den Übergang zu dem Steppengebiete des Inneren. Letzteres umfaßt den nördlichen Teil von Gr. Namaland, die Kalahari und den größten Teil des Damaralandes. Es ist charakterisiert durch seine oft bis $1 \frac{1}{2} m$ hohen Steppengräser und die dornbewehrten Akazienarten und bewohnt von Viehzucht treibenden Völkerschaften. Weiterhin im Norlen und Nordosten schließt sich dann endlich die Busch- und Baumsavanne an.

Mit geringen Ausnahmen, wie bei dem schon häufigeren Auftreten von rein tropischen Gewächsen im äußersten Norden, ist der Wechsel des Pflanzenlebens im allgemeinen nicht so sehr von der Temperaturverteilung in unserem Schutzgebiete als vor allem von der des Niederschlags bzw. der Bodenfeuchtigkeit abhängig.

Ein Blick auf die Regenkarte von Deutsch-Südwestafrika wird dies in unserem Falle sofort bestätigen, fallen doch die drei soeben bezeichneten pflanzengeographischen Zonen bzw. mit den drei besonderen Abstufungen der jährlichen Niederschlagsmenge, gelb-grün-blau, ziemlich sicher zusammen. 


\section{Die Niederschlagsverhältnisse des Küstengebietes.}

Wenden wir uns zunächst der Küstenregion als der regenärmsten Zone zu. Wir sehen hier die $50 \mathrm{~mm}$-Isohyete, einen schmalcn Streifen abgrenzend, ler Küste entlang hinstreichen. Aus verschiedenen Rücksichten wurde ihr Anfang im Norden in die Gegend der Kunenemündung verlegt. Nördlich der letzteren beginnt nach cinem Expeditionsbericht auf portugiesischem Boden längs der Küste wieder eine spärliche Vegetation. Als einziger Anhalt auf deutschem Gebiete dienten die Beobachtungen von Zesfontein mit einem jährlichen Mittel von $69 \mathrm{~mm}$. Dabei liegt Zesfontein (6) unter $181 \%^{\circ} \mathrm{s}$. Br. schon ziemlich weit, etwa $120 \mathrm{~km}$, ins Land hinein.

Weiter nach Süden sieht das Auge, soweit ein Europäer je diesen Küstenstrich besucht hat, nichts als öde, sonnerhitzte Dünen und Sandwüsten, die nur in der Nacht und in den frühen Morgenstunden vielfach in dichten Nebel gehüllt und von reichlichem Tau benetzt sind. In der mittleren Küstengegend bei Swakopmund und Walfischbai (mit einer jährlichen mittleren Regenhöhe von $30 \mathrm{bzw}$. IO $\mathrm{mm}$ ) wurde mit Rücksicht auf die Regenmeßergebnissc von Jakalswater (40), dessen Normalmittel gleich 3 I $\mathrm{mm}$ ist, die $50 \mathrm{~mm}$-Kurve mehr ins Landinnere gezogen; erst hier zeigt sich auch wieder etwas mehr eine beginnende Vegetation.

Ein Regenfall ist in diesen Gegenden etwas Seltenes; zeigen doch die langjährigen Beobachtungen von Walfischbai (46) Perioden von uber zwei Jahren, in denen kein Tropfen meßbaren Niederschlags gefallen ist. Die Existenz von Mensch und Tier ist dort fast allein an das Vorhandensein von Grundwasser gebunden. Kennzeichnend für die Wasserarmut dieser Striche ist, daß z. B. in Walnischbai Trinkwasser aus der Kapstadt bis vor nicht langer Zeit per Schiff eingeführt und literweise teuer verkauft wurde. Jetzt sind hier und in Lüderit $\%$ bucht Kondensatoren zur Trinkwasserbereitung aus Meerwasser aufgestellt. Die geringe Vegetation besteht, soweit man von einer solchen ïberhaupt reden kann, hauptsächlich in der sogenannten Narapflanze mit einer gurkenähnlichen Frucht, welche vermöge ihrer IO bis $15 \mathrm{~m}$ langen Wurzeln imstande ist, aus tieferen, Grundwasser fuihrenden Schichten die zu ihrer Nahrung notwendige Feuchtigkeit cmporzusaugen. Dann sieht man wohl noch kleine Dünengräser, welche von dem hier ziemlich oft und reich'ich fallenden Tau ihren Wasserbedarf beziehen.

Zur Beurteilung der Niederschlagsverhältnisse des Küstenstriches von Gr. Namaland steht uns allein das Beobachtungsmaterial von Luideritzbucht (65), jährlich I4 mm, zur Verfügung. Hier ist die Landschaft, wenn überhaupt möglich, fast noch öder und kahler. Eine ungehcuere Steinwüste, die sich an die sandige Küstenregion anschliebt, zieht sich bis tief ins Innere längs des Orange bis südlich der Huib-Hochebene, Von dieser Gegend gilt ja auch der bekannte Ausspruch Nachtigals: ${ }^{1}$ ) "Ich will lieber durch die Wüste reisen, da finde ich doch wenigstens Oascn, als noch einmal durch dieses Land! «

Diese Betrachtungen und dann noch die Regenmeßbeobachtungen von Kubub (66) unter $262 /{ }^{\circ}$ s. Br., etwa I Io km von der Küistc entfernt, mit cinem Jahresmittel von $73 \mathrm{~mm}$, lassen erkennen, daß sich hier die regenärmste Zone von der Küste aus weit ins Innere des Landes zieht. Südlich des Orange scheinen dann wieder allmählich die Niederschläge an der Küste zuzunehmen. Port Nolloth (79), $29^{\circ}$ I $6^{\prime}$ s. Br., hat schon einen mittleren jährlichen Regenfall von $69 \mathrm{~mm}$, dann das noch südlicher ebenfalls an der Küste unter $3 \mathrm{I}^{\circ} 35^{\prime} \mathrm{s}$. Br. gelegene Ebenczer (92) einen solchen von I $6 \mathrm{~mm}$.

Wir sehen also, dab gerade der deutsche Anteil an der regenarmen Südwestküste Afrikas der trockenste und vegetationsloseste ist.

Auch nach Norden zu, an der Küste von Portugiesisch-Angola, wird der Niederschlag ein reichlicherer; trotzdem hat Loanda (I), unter $8^{\circ}$ $49^{\prime}$ s. Br., also etwa $81 / 2$ Breitengrade nördlich der Nordgrenze des Schutzgebietes (d. 1. der Kunenemündung), immerhin erst ein jährliches Mittel von $315 \mathrm{~mm}$, ein in Anbetracht der nicderen Breitenlage gewiß außerordentlich geringer Betrag. Dagegen steht die Armut der Küste Deutsch-Südwestafrikas an meßbarem Niederschlag fast beispiellos da. Höchstens könnte diejenige des Küstenstriches Perus und des nördlichen Chile als Analogon dienen. ${ }^{2}$ )

Der ziemlich gänzliche Mangel an meßbaren atmosphärischen Niederschlägen und die Geringfügigkeit des nur an wenigen Stellen, besonders in den Flußbetten vorkommenden bzw. in yeringcr Tiefe erreichbaren Grundwassers hindert jeden Vcrsuch zu Kolonisationszwecken.

Das Minimum des jährlichen Niederschlags, welches beinahe gleich Null zu setzen ist, dürfte bei Walfischbai und südlich von hier bis Lüderitzbucht zu suchen sein. Jedenfalls darf man sagen, daß der Küstenstrich Deutsch-Südwestafrikas eincr der regenärmsten Striche, wenn nicht überhaupt

1) Pohle, Pet. Mitt. I 886, S. 238 . Bericht ïber die ron Lüderitz ausgerüstete Expedition nach Südwestafrika I884/85.

2) Ygl. hierzu: A. Supan: "Die Verteilung des Niederschlags auf dex festen Erdoberfläche«, in J'etermanns Mitteilungen, Erg. Heft I 24, I 898 , S. I3. 
der regcnärmste der gan\%en festen Frdober fläclıe ist.

Kommen wir zu den mehr im Inneren gelegenen Stationen der Küstentegion, so sehen wir, dab mit der steigenden Meereshöhe auch die Niederschläge allmählich zunchmen. Auf eins möge hier noch besonders hingewiesen werden, daß ein einheitlicher Zug die Niederschlagsverhältnisse der Küustenregion beherrscht. Überall läßt sich von der Küiste landeinwärts eine gleichmäbige Steigerung der jährlichen Niederschlagsmenge lonstatieren, wogegen die Verhältnisse vou Süd mach Nord ziemlich konstant bleiben: Zesfontein, I $81 / 2$ s. Br., ctwa I $20 \mathrm{~km}$ von cler Küiste entfernt, 69.4 mm, gegenüber Kubub, $262 / 3$ s. Br. und etwa I IO $\mathrm{km}$ von der Küiste entfernt, $72.6 \mathrm{~mm}$. Im Binnenland werden wir in letzterer Beziehung anderen Verhältnissen begegnen.

Mit Ruicksicht auf die Tatsache, daß im äußjersten Süden des Gr. Namalandes und in der unteren Orangegegend ähnlich greringe Regenmengen wie in dem eigentlichen Küistenland fallen, dab ferner hier wic dort die jahreszeitliche Verteilung der Niederschläge, wie wir später sehen werden, keine mehr so ausschließlich sommerliche wie im nördlicheren Binnenlande ist, mögen deren Niederschlagsverhältnisse der Einfachheit halber gleichzeitig mit denen des Küistenlandes behandelt werden.
In Süden macht sich in der Steinwïste von (ler Küiste aus allmählich cine Übergangszone bemerkbar, gekennmeichnet durch das vereinzelte Vorkommen des Milchbusches; es ist dies alie Euphorbienzone nach Schin\%.

Hier möge nochmals besonders darauf bingewiesen werden, daß gerade in der Küstengegend besonders pflanzengeographische Gesichtspunkte bei lem dort so geringfüigigen Beobachtungsmaterial zur Inlage der Isohyeten maßgebend waren.

Die für das Küstengebiet so charakteristischen Tau- und Nebelpflanzen und diejenigen, die nur an das V'orhandensein und die Erreichbarkeit von Grundwasser gebunden sind, verschwinden allmählich nach Osten hin. »Der von der See landeinwärts wandernde Nebel wird von der über der erhitzten Vüste lagernden Luft nicht mehr so regelmäßig zu Tau verdichtet; vielmehr löst $\mathrm{cr}$ sich hier wieder auf. « Erst am Westabhang des höheren Tsirubgebirges und auf der Huib-Hochebene vermag er sich wicder vielleicht sogar $z u$ regelrechtem Niederschlag zu verdichten. Hier finden wir denn auch die Station Kubub (66) mit $73 \mathrm{~mm}$ jährlicher Regenmenge.

Weiter ostwärts haben wir hier im Süden zwei besonders erwähnenswerte Depressionsgebiete des jährlichen Niederschlags zu unterscheiden.

Tabelle 8.

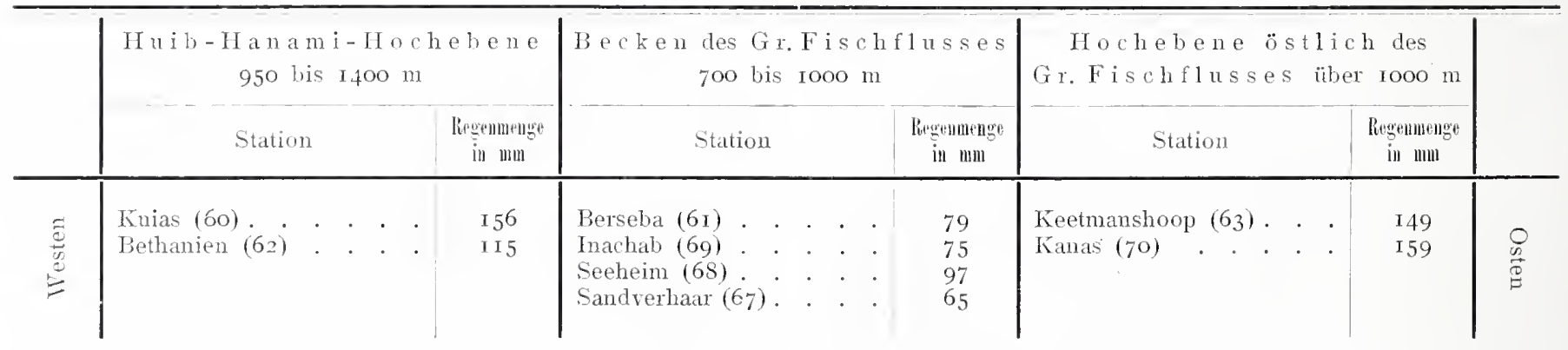

Auf Grund der Bcobachtungen von Sceheim (68), Inachab (69), Sandverhaar (67) und Berscba (6I) ergibt sich fur die von Nord nach Süd weit ausgedehnte Mulde des Gr. Fischflusses ein deutliches Sinken der jährlichen Regenmenge gegenüber den höher gelegenen westlichen und östlichen Gegenden. Diese Senke schafft also anscheinend ein lokales Regenschattengebiet gegenüber den die Niederschläge bringenden Ost- und vielleicht auch. westlichen Winden. Wie die beigegebene Regenkarte und Tab. 8 zeigen, ist die Verminderung augenscheinlich.

Ein weiteres Regenschattengebiet und dadurch eine gewisse Vcrminderung der jährlich fallenden Regenmengen gegenüber denen der umliegenden Landschaften wird dann noch durch die ostwärts vom Unterlauf des Gr. Fischflusses zwischen dem etwa 900 bis $1000 \mathrm{~m}$ hohen Westrande des Kl. Namalandes und den bis $\mathrm{zu} 2000 \mathrm{~m}$ hohen Kharasbergen sich ausdehnende Niederung des Orange geschaffen. Hier, tief im Landinneren, haben wir auf Grund der Regcnmessungen verschiedener Stationen, z. B. Pella mit $96 \mathrm{~mm}$, dann auch Warmbad mit $98 \mathrm{~mm}$, eine jährliche Niederschlagshöhe von nur IOO bis $150 \mathrm{~mm}$. Diese Zone verminderten Niederschlags zieht sich noch wcit südlich bis etwa $3 \mathrm{O}^{1} / 2^{\circ}$ s. Br. ins Kapland hinein. Diese Abnahme der Niederschläge hier in Siiden, die sich so auffallenderweise bis tief ins Land hinein kundgibt, liegt wohl an der allgemeinen Senkung und beiderseitigen Neigung nach dem Orangefluß zu, dessen Meereshöhe im mittleren Gebiete der Südgrenze durchschnittlich nur 400 bis $500 \mathrm{~m}$ beträgt. 
$\mathrm{Ob}$ die Regenarmut dieser südlichen Landschaften Deutsch-Südwestafrikas sowie der südlich und südöstlich davon gelegenen Bezirke des Kaplandes als eine durch den besonders in dieser geographischen Breite erhöhten. Ostrand Südafrikas verursachte Regenschattenwirkung, welche sich bis in diese westlichen Gegenden geltend macht, angesehen werden kann, darf vorläufig nur als Vermutung hingestellt werden.

Sobald von eben behatidelter Niederung aus das Land nach Norden zu wieder ansteigt, nehmen auch die Niederschläge wieder zu. So schreibt der Ansiedler R. Haybittel an Herrn Prof. Rehbock (Karisruhe) als Anlage zu einer RegenmeBtabelle von Seeheim, daß es in dem (höheren) nördlichen Bondelswartsgebiet und in der Nähe der Kharasberge bei weitem mehr regnet als in seinem Ansiedlungsgebiete (hier etwa $97 \mathrm{~mm}$ jährlicher Niederschlagsmenge).

Dieselbe Erscheinung finden wir südlich des unteren Orange in dem Hochlande der nördlichen Kapkolonie (K1. Namaland), welches der tieferen östlichen Landschaft auch die mit den westlichen Winden kommenden Niederschläge (Winterregen, wie wir später sehen werden) vorenthält.

Dagegen tritt auf dem Hochlande selbst eine durch seine größere Seehöhe verursachte Steigerung der Niederschlagsmengen auf der Karte deutlich hervor. In Längenzonen von West nach Ost finden wir:

Port Nolloth (79) • mit $69.2 \mathrm{~mm}$ Niederschlag

Garies (89) . . . " 145.6 ",

Ebenezer (92) . . , , I I6.3,

Klipfontein (80) . . mit $229.5 \mathrm{~mm}$ Niederschlag

Kraaifontein (8I) • , I88.6 ,

Concordia $(84)$. , 222.3 ,

O'okiep (85)..., , 197.0 ,

Springbokfnt. (86). ,, 238.2 ,

Lilyfontein (88) . , 345.8 ,

Pella $(78)$. . . mit $96.0 \mathrm{~mm}$ Niederschlag

Kenhardt (83) . . " I65.4 ,"

Brandvley (90) . , , I43.9 "

Van Wyks Vley (9I) , 170.2 ,"

VanRhynsDorp(93) ", 160.0 "

Interessant ist innerhalb dieses Hochlandes auch ein Gebiet geringerer Ausdehnung mit verminderter jährlicher Regenmenge, welches auch nur durch die Senkung und durch den dadurch bewirkten Höhenunterschied im Gebirge verursacht sein kann. So finden wir von Nordwest nach Südost für die Stationen:

Tabelle 9.

\begin{tabular}{|c|c|c|c|c|c|c|}
\hline Bei einer & Anenous (82) & Klipfontein (3o) & Steinkopf (8r) & O'okiep $\left(8_{5}\right)$ & Concordia $(84)$ & $\begin{array}{c}\text { Springbokfontein } \\
\qquad(86)\end{array}$ \\
\hline ron: & $\begin{array}{l}54 \mathrm{Im} \\
\text { I } 55 \mathrm{~mm}\end{array}$ & $\begin{array}{c}947 \mathrm{~m} \\
230 \mathrm{~mm}\end{array}$ & $\begin{array}{l}825 \mathrm{~m} \\
\mathrm{I} 89 \mathrm{~mm}\end{array}$ & $\begin{array}{l}926 \mathrm{~m} \\
\mathrm{I} 97 \mathrm{~mm}\end{array}$ & $\begin{array}{l}1020 \mathrm{~m} \\
222 \mathrm{~mm}\end{array}$ & $\begin{array}{c}976 \mathrm{~m} \\
238 \mathrm{~mm}\end{array}$ \\
\hline
\end{tabular}

jährlicher Regenmenge. Trotz des nicht sehr bedeutenden Unterschiedes in der Seehöhe ist die lokale Verminderung des jährlichen Regenfalles bei O'okiep und Steinkopf doch offenkundig und durch die 12 - bis I 5 jährige Beobachtungsdauer der einzelnen Stationen verbürgt.

Uberhaupt kamen der Genauigkeit der Isohyeten im südlichsten Teil unseres Gebietes die langjährigen Regenmessungen in der nördlichen Kapkolonie sehr zugute, indem durch entsprechende Reduktion auf britische Stationen, wie Pella (78), Rlipfontein (80), Upington (76), die Werte der deutschen Stationen ziemlich sichergestellt werden konnten.

Im übrigen zeigt der ganze Küstenstreifen, wie schon vorher erwähnt, eine ganz allmähliche Steigerung der Niederschläge nach Osten zu.

Im allgemeinen muBte die Anlage der Isohyeten hier wieder von pflanzengeographischen Gesichtspunkten aus geschehen. So \%. B. erwähnt v. Bülowl) von Nadab in der Nähe von Hope-

1) v. Bïlow, L. V. I2, S. I 86. mine (48) auf der Namieb gelegen: »In der Höhe von Nadab hörte die vollkommene Wüste auf und es begann jene Steppenregion ganz dünnen Toagrases ohne Buschbestand. Nach der besonders reichen Regenperiode .891/92 prangte hier die Ebene schon in üppigem Graswuchs. «

Weit besseren Anhalt und selbst exaktes Beobachtungsmaterial haben wir zur Beurteilung der Niederschlagsverhältnisse der mittleren Kuistengegend ostwärts Swakopmund.

Quer in den soeben behandelten Strich schiebt sich bei Jakalswater (40) ein Gebiet mit reichlicherem Niederschlag, das schmale, etwa $400 \mathrm{~m}$ iiber der umliegenden Landschaft hoch aufragende Khousgebirge, welches hier noch zu erwähnen ist.

Auch Dove schreibt im selben Sinne von dem Einfluß dieser Höhen auf die Niederschläge. Immerhin genuigt ihre Höhe, um das Zustandekommen reicherer Niederschläge zu begünstigen, als sie sonst in dieser Länge fallen. Darauf deuten tiefe Wasserrisse an den Abhängen, das beweisen 
die unterirdischen VTasserschätze in einzelnen von hier herabliommenden FluBadern, welche die Hochebenen durchziehen, schon von weitem durch das dunkle Grïn der Giraffenaliazien ihr Dasein verkiïden(1. «1)

Daß trotz der relativ reichen Niederschlagsmengen keine reichere Flora diese Höhenzuige bekleidet, selbst an geschüitzten Stellen nicht, erklärt Dove mit der reinen und klaren Höhenluft und ihren bedeutenden, der Vegetation schädlichen Temperaturgegensätzen zwischen Tag und Nacht.

Vielleicht dürfte das schnelle Abrinnen des Nassers von den Höhen hier wohl auch erheblich mitwirken. Dagegen findet man oft in tiefen zerkiüfteten FluBtilern und Gebirsskesseln eine viel üppigere V'egetation, selbst kleine Galeriewaldungen; eben nur, weil sie vielleicht neben der größeren Nahrung, die sie aus dem unterirdisch fließenden Wasser schöpfen, auch mehr geschuitzt sind gegen die sroßen Temperaturgegensätze zwischen Tag und Nacht. Dabei erreicht der Niederschlag hier wohl bei weitem nicht dieselbe Höhe wie der der umliegenden öden Hochländer.

Diesen Fall sehen wir z. B. bei Otjimbingue (29) besonders ausgeprägt. Letzteres liegt mit jährlich I $36 \mathrm{~mm}$ schon außerhalb des Küstengebietes, in der Übergangszone zu dem Steppen- und Buschland des Inneren.

So ist denn auch, wie schon K. Dove zeigte, die geringe Regenmenge von Otjimbingue nicht so sehr aus seiner geographischen, sondern aus seiner örtlichen Lage in dem allseitig umschlossenen Swakoptal zu erklären. Östlich von Otjimbingue bei Uitdrai ninmmt bei Verengung des Tales und mit dem ansteigenden Hochlande nach verschiedenen Reiseberichten auch sofort wieder die jährliche Regenmenge zu. Ebenso wird gleichzeitig die Vegetation, die ja überall von der zugeführten Feuchtigkeit abhängt, dichter.

Der Regenfall bei Otjimbingue selbst ist ein äuberst geringer und erzeugte nach meinen Beobachtungen nur im Frïljahr 1893 eine Vegetation, die in einem dichten Felde gelber, blatuer und roter Blumen bestand. «2) Der Regen, welcher reichlich auf dem Khomas-Hochland, den Ausläufern des Livenberges, bis I $\mathrm{km}$ vor Otjimbingue fällt, erreicht diesen Ort selbst nur selten und auch dann noch in bei weitem geringeren Quantitäten. ${ }^{3}$ )

Bei solcher für den Zweck einer synoptischen Darstellung ihrer Mebresultate gewissermaßen unsünstigen Lage so mancher Regenmeßstationen in

\footnotetext{
i) Dr. K. Dove, L. V. I7, S. 5 .

2) V. B 3 ïlow, L. V. I2, S. 103.

$\left.{ }^{3}\right) \mathrm{Vgl}$. in dieser Beziehung anch Pet. Mitt. I894, S. Iooff.
}

Talkesseln und eingeschlossenen Flußbetten mußte in vorliegender Abhandlung besonders darauf geachtet werden, daß die Meßresultate der Stationen nicht ohne weiteres für das ganze umliegende Gebiet verallgemeinert wurden. Es wurde daher auf der Regenkarte nach Möglichkeit zur Darstellung gebracht, daß Niederschlagsmengen der Höhen größer angenommen werden müssen als diejenigen solcher in Talbecken gelegener Stationen.

Un einen kurzen Uberblick über die bisher besprochenen Niederschlagsverhältnisse des Küstengebietes und des äußersten Südens von DeutschSiidwestafrika, zweier Gebiete, die sich also durch große Regenarmut auszeichnen, zu geben, so sind sie dạdurch charakterisiert, dab man hier noch nicht mit aller Bestimmtheit schon Hauptregenmonate angeben kann, und daB nur selten, selbst in den mit Regenfällen besser bedachten Strichen, ein »Landregen« vorkommt.

\section{Die Niederschlagsverhältnisse der Gras- und Busclisteppe des Binnenlandes.}

Die nach Osten $z u$ von dem Küstenland allmählich zahlreicher auftretenden Buschbestände nebst der sommerlichen Grassteppe künden uns das Herannahen einer regenreicheren Zone an, der Hochlandsteppen des Inneren Deutsch-Südwestafrilias.

Dieser Übergang aus der nur spärlich bewachsenen Fläche nahe der Küste in die mit dichterer Vegretation bedeckten Binnensteppen geht so allmählich vor sich, daf man deutlich sieht, wie nur der Regen und nicht etwa blof vermehrte unterirdische Wasserzufuhr die Ursache dieser Veränderung sein kann.

Die Beschreibung der Niederschlagsverhältnisse der inneren Hochebene unseres Schutzgebietes soll im folgenden ebenfalls im Hinblick auf die einzelnen Landschaften versucht werden, wodurch manche Eigentümlichkeit in der örtlichen Verteilung der jährlichen Regenmengen viel eher zur Anschauung gebracht werden kann.

Geographisch können wir hierbei hauptsächlich drei Landschaften unterscheiden und auch in der Behandlung der Regenverhältnisse einzeln betrachten : den nördlichen Teil Gr. Namalandes, Damaraland und Amboland. Diesen wiirden sich sodann noch zwei weitere Gebiete anschließen: die Kalaharisteppe und das Kaokoveld.

\section{Der Norden von Gr. Namaland.}

Die Regenmenge in Gr. Namaland ist im allgemeinen eine kontinuierlich nach Nord und Nordost mit der allmählichen Erhebung des Landes von etwa r I 00 auf I $400 \mathrm{~m}$ zunehmende. Die Karte zeigt 
uns drei ziemlich breite Bänder steigender jährlicher Regenhöhen von $23^{\circ} \mathrm{s}$. Br. ab, der Gegend der Großen Kharasberge, bis zu dem Südabhange des zentralen Hochgebietes der Awasberge mit Niederschlagsmengen von $\mathrm{I} 5 \mathrm{O}$ bis $300 \mathrm{~mm}$.

Die Großen Kharasberge, welche bis über $2000 \mathrm{~m}$ Höhe über dem Meeresspiegel erreichen, dürften dabei in noch stärkerem Maße als die Kleinen Kharasberge gegenüber der Ungegend eine Steigerung der Regenmengen verursachen.

Für größere Landschaften im nördlichen Teile können die Regenmeßergebnisse von zwei Stationen, nämlich Hoachanas (5 I) mit $238 \mathrm{~mm}$ und Rehoboth (47) mit $266 \mathrm{~mm}$ jährlicher Regenhöhe als charakteristisch gelten. Zur Redultion der südöstlichsten Stationen kam wieder eine britische des Kaplandes, Upington (76), am Orange mit $205 \mathrm{~mm}$ sehr zustatten.

Supan glaubte $\left.{ }^{1}\right)$ a. u. a. O. annehmen zu müssen, daß ein Jahresmittel von $200 \mathrm{~mm}$ für diese Gegend und speziell für Upington viel zu hoch sein würde; jedoch dürfte die angegebene Zahl von $205 \mathrm{~mm}$ auf Grund des in vorliegender Abhandlung gegebenen, weit größeren, nämlich ı Jahre umfassenden Beobachtungsmaterials jetzt ziemlich sicher festgestellt sein. Von hier aus steigt in dem Nordrand der Kapkolonie nach Osten zu andauernd die jährliche Regenmenge: das in der Nähe Upingtons gelegene Trooilapsan (77) hat ein Jahresmittel von $225 \mathrm{~mm}$, Griquatown (96) und Dunmurry (95) etwa $2^{\circ}$ weiter östlich unter gleicher südlicher Breite gelegen, schon $397 \mathrm{~mm}$ bzw. $38 \mathrm{I} \mathrm{mm}$. Die Beobachtungen in Trooilapsan umfassen allerilings nur $\mathrm{I}^{1 / 3}$ Jahre.

Die Niederschlagsverhältnisse im nördlichen Teil des Gr. Namalandes mit seinen weitausgedehnten Hochflächen sind also ziemlich gleichmäßige zu nennen, wie auch die Vegetation sehr eintönig bleibt. Wir haben hier ein Steppengebiet vor uns, durchsetzt mit nach Norden immer dichter werdendem Buschbestand, welches zur Kleinviehzucht besonders geeignet ist. Bald treten nach Norden hin auch schon einzelne Akazienarten auf, wie ja die dornbewehrten Sträucher und Bäume als Anpassungsform an die noch ziemlich geringen, jährlich niedergehenden Regenmengen gerade Gr. Namaland kennzeichnen.

Sobald jedoch nur einigermaßen gute Regen fallen, ist das Weidefeld ein gutes zu nennen. Bei den großen Schwankungen des jährlichen Regenfalls, die in einem regenarmen Gebiete in ihrer Wirkung auf die Vegetation viel empfindliclier gespürt werden, genügen aber die in manchen Jahren niedergehenden Niederschläge nicht, den Bedarf an Futter durch

1) Met. Z. I 896, S. 478 .

Mitt. von Forschungsreisenden, XX. Band. I.
Wiederbelebung der Vegetation decken zu können. So hört man denn in vielen Jahren noch Klagen über zu große Trockenheit und dadurch verursachte Hungersnot, besonders aus dem westlicheren und südlichen Teile Gr. Namalandes. Als Beispiel möge ein Auszug aus dem amtlichen »Jahres. bericht I $895 / 96$ ïber Deutsch-Südwestafrika « folgen.

"Besonders gering waren auch die Niederschläge im südlichen Teile; Notstand auf einzelnen Strecken; im englischen Kl. Namaland Hungersnot. Die Eingeborenen haben Mangel an Feldkost, ihrer eigentlichen Nahrung, während die Weißen große Verluste an Vieh infolge des Wasser- und Weidenmangels zu verzeichnen haben ... Im südlichsten, regenärmsten Strich sind damals Menschen und Vieh durch Hunger infolge der Dürre zugrunde gegangen; von diesem schreibt Andersson: „Zwei bis drei Tagereisen südlich von Rehoboth verwandelt sich die Steppenvegetation in eine elende W üstenvegetation. «1)

Je weiter man aber nach Norden kommt, um so günstiger werden auch die Regenverhältnisse, und Hungersnöte infolge von Dürre kennt man in der Rehobother und der Gegend von Hoachanas kaum noch.

Ein Gebiet vermehrten Niederschlags, jedoch lokal begrenzt, wird noch in der Gegend des Wendelireises bei Nauchas (49), der Naukluft und dem Hoornkranzgebirge infolge ihrer relativ weit größeren Seehöhe zu vermuten sein. Infolgedessen wurden jene Gebirge auch auf der Regenkarte vermutungsweise mit einer größeren Niederschlagsmenge angelegt.

Nördlich und östlich von Rehoboth treten nunmehr mit schnell ansteigender Meereshöhe auf der Steppe schon vereinzelte Exemplare von Laubhölzern auf, als Zeichen, daß wir uns dem zentralen Hochgebiete im südlichen Hererolande, einer der regenreicheren und fruchtbarsten Landschaften DeutschSuidwestafrikas, nähern.

$\mathrm{Zu}$ erwähnen wäre noch, daß, wenn auch von der Rehobother Ebene aus die jährliche Regenmenge nach den Gegenden südlich der Awasberge schnell stark zunimmt, doch die Vegetation sich bis dorthin nur wenig verändert. Diese Tatsache ist aus dem Vorhandensein der breiten Flußalluvien und ihren unterirdischen Wasservorräten in den südlicheren Landschaften bei Rehoboth zu erlilären. Das Gefälle der Flußbetten ist hier bei weitem geringer als in den nördlichen Gegenden, so daß die niedergehenden, wenn auch absolut geringeren Regenmassen der Vegetation des Landes trotzdem einen relativ größeren Nutzen bringen können.

\footnotetext{
1) Andersson, Lake Ngami, S. 323, 324.
} 


\section{Damaraland.}

Zwischen $2 \mathrm{I}^{\circ}$ und $23^{\circ} \mathrm{s}$. Br. erhebt sich in einzelnen hochaufragenden schmalen Gebirgsmauern und ausgedehnten Hochländern Deutsch - Südwestafrika zu einer mittleren Meereshöhe von I600 bis I $800 \mathrm{~m}$, während einzelne Gebirgszüge, wie \%. B. das Iwasgebirge südlich Windhuk, bis über $2000 \mathrm{~m}$ ansteigen.

Inselartig zeigt sich uns hier auf der Regenkarte ein begrenztes Gebiet, welches ungefähr der Flächenausdehnung IVürttembergs gleich. lommt, mit einer yroben und sofort auffallenden Steigerung der jährlich fallenden Regenmengen, selbstgegenüber mehr östlich selegenen Landstrichen.

Rings umschlossen ist diese Landschaft von einer Zone mit einem jährlichen Regenfall von 300 bis $350 \mathrm{~mm}$; z. B. ostwärts Seeis (33) mit $337 \mathrm{~mm}$, dann Otjosazu (25), I $500 \mathrm{~m}$ hoch, mit $333 \mathrm{~mm}$.

Mit Annäherung an dic uber $2000 \mathrm{~m}$ hohen Gebirgszüge tritt auf Grund der Regenmełbeobachtungen einer ganzen Reihe von Stationen eine weitere Vermehrung der Niederschläge bis beinahe $400 \mathrm{~mm}$ jährlich auf, während für die Gebirgsmauern selbst eine Regenhöhe von mindestens über $400 \mathrm{~mm}$ bis vielleicht $500 \mathrm{~mm}$ anzunehmen sein dürfte.

Dove schreibt a. a. O., ${ }^{1}$ ) daß es im Gebirge bei weitem mehr regnete als in dem nahegelegenen Windhuk (hier bei einer Meereshöhe von I650 m $357 \mathrm{~mm}$ ). Die Hochlandschaften von mehr als I $800 \mathrm{~m}$ haben jedenfalls Regenmengen von $500 \mathrm{~mm}$ und darüber, denn selbst in mäBigen Regenjahren sieht man von fern über diesen Landschaften schwere Regen niedergehen; dies zeigt auch das Aubere dieser Gegenden, die Pflanzenwelt und der Wasserreichtum der natürlichen Becken und selbst kleinerer Flußläufe.

Dagegen scheint mir Dove, dessen Anwesenheit in Deutsch-Südwestafrika in eine besonders regenreiche Periode fiel, auf Grund des zum größten Teile (lieser letzteren entnommenen Materials die Menge des jährlich dort fallenden Niederschlags etwas zu überschätzen, so Windhuk mit foo mm und die Hochlandschaften mit $500 \mathrm{~mm}$ und darüber. Allerdings sind die Ingaben im einzelnen ähnlich und relativ dieselben wie die in vorliegender Abhandlung gemachten.

Demgegenüber dürften wohl bei der langen Dauer der Beobachtungen von etwa 7 bis i 5 Jahren, welche bis zur Regenperiode $1903 / 04$, und zwar von einem gerade dort verhältnismäßig dichten Stationsnetze vorliegen, die hier auf der Regenkarte ange-

1) Dr. K. Dove, L. V. I7, S. 32 ff. gebenen Daten ziemlich sicher stehen, ja vielleicht definitive Gültigkeit besitzen: so z. B. Okahandja (25), I $330 \mathrm{~m}$ hoch gelegen, mit $377 \mathrm{~mm}$, Windhuk (35), $1650 \mathrm{~m}$ hoch, mit $357 \mathrm{~mm}$, Neudamm (32) mit $38 \mathrm{~s} \mathrm{mm,}$ Hohe Varte (37) mit $367 \mathrm{~mm}$ und Schaaprivier (42) mit $350 \mathrm{~mm}$ jährlichem Regenfall.

Auf dem Khomashochlande bemerken wir eine verhältnismäßig schnelle Verminderung der Niederschläge analog der ebenso rapiden Abnahme der Sechöhe der einzelnen Orte bis zur Küste hin: Heusis (39) und Haris (43) erreichen schon $300 \mathrm{~mm}$ jährlicher Niederschlagshöhe nicht mehr.

Infolge der relativ reichlichen Regenfälle gehört dieses zentrale Hochland auch zu den verhältnismäßig fruchtbarsten und günstigsten Gegenden des ganzen Schutzgebietes: Baumsavannen wechseln allenthalben mit üppigem Neideland ab. Besonders werden in dieser Hinsicht immer Haris (43), Schaaprivier (42), Kl. Windhuk (36) und die mehr östlich und nördlich gelegenen Ortschaften lobend hervorsehoben. Im nördlichen Hererolande trifft man soyar schon Laubwälder.

Ebenso deuten die uppige Vegetation, Moose und Flechten, starke Quellen an den Abhängen die noch reichlicheren Niederschläge in den Gebirgen selbst an. Der Elephantenfluß kommt aus so regenreichem Quellgebiete, daß er, nach Dove, als der einzige Flub innerhalb des Schutzgebietes seinen Namen in unserem Sinne für die Strecke seines perennierenden Oberlaufes verdient.

Regenärmere Jahre treten in dem zentralen Hochlande wohl auch noch auf, z. B. die Regenperioden I 895/96, dann I90I/02, I902/03 (vgl. hierzu die Diagramme 35 und 36 ). Jedoch sind in solchen Notjahren die Verhältnisse schon ganz andere und bei weitem günstigere als in Gr. Namaland. Z. B. ist auch das Ausbleiben der fuir die Saat besonders wichtigen Frühregen im Oktober etwas Seltenes und Auffallendes. Getreidebau ist in den FluBbetten und -alluvien möglich.

Auch der Reichtum an Quellen und die große Anzahl der von diesen nach den verschiedensten Richtungen ausgehenden Flufbetten deuten die mindestens zeitweilig besondere Ergiebigkeit der Regen in diesem zentralen Hochlande an. Wir haben hier das Quellgebiet der bedeutendsten Flubsysteme des ganzen Schutzgebietes vor uns, nach Westen: Kuiseb und Swakop, nach Norden bis Nordwesten: Omuramba, Uamatako und Eiseb, nach Osten: Nosob und Elephantenfluß, nach Süden: Gr. Fischfluß.

Zur besseren Veranschaulichung sei hier noch eine graphische Darstellung der Niederschlagsverteilung zwischen dem 22. und 23. Parallel von West nach Ost quer durch den mittleren Teil 
Deutsch-Südwestafrikas hinzugefügt. Die betreflenden jährlichen Regenhöhen sind einem von Rehbock entnommenen schematischen Gcbirgsprofil aufgesetzt. $\left.{ }^{1}\right)$ Die festen, auf Beobachtung und Berechnung gestützten Punkte sind durch geradeStrichchlinien verbunden. Darauf ist dann auf Grund der durch die Regenkarte gegebenen Daten eine den orographischen Verhältnissen angepaßte Kurvc der wahrscheinlichen jährlichen Regenhöhen eingezeichnet worden. Sehr deutlich zeigt sich hier die schnelle Verminderung gegen die Meeresküste hin, der lokale Reichtum an Niederschlägen in dem zentralen Hochlande und schließlich das allmähliche Anwachsen nach Osten bis in die Kalaharisteppe hinein. Alle weiteren Einzelheiten ergeben sich aus dem Diagramm und bedürfen keiner weiteren Erörterung. ${ }^{2}$ )

\section{Die Kalaharisteppe.}

Ehewir zur Behandlung derRegenverhältnisse des Nordens von Deutsch-Sidwestafrika übergehen, seien noch einige Bemerkungen bzw. Andeutungen über die mutmaßliche Niederschlagsmenge eines Gebietes hinzugefügt, von dem bisher nur verhältnismäßig wenig genauere Mitteilungen und äußerst spärlichc Beobachtungen vorliegen, der Kalaharisteppe.

Auf die Niederschlagsverhältnisse gerade dieser Region etwas näher einzugehen, wird schon wegen der Beurteilung der Verhältnisse des Ostens von Deutsch-Südwestafrika erwünscht sein; um so interessanter aber wird diese Untersuchung, als gerade dieser Teil Südafrikas früher so oft fälschlicherweise als öde, wohl auch fast regenlose Gegend von beinahe wüstenhaftem Charakter verschrieen wurde. Ganz auffallend nämlich ist es, wie vom mittleren Nosob aus ostwärts des soeben behandelten zentralen Hochlandes die jährlich fallenden Regenmengen eine allmähliche und starke Zunahme erfahren, die sich bei Gobabis und Oas auf über $450 \mathrm{~mm}$ steigert. In dieser Gegend wird also erst wieder (jenscit der Depression) die Niederschlagshöhe des zentralen Berglandes im Damaragebiete auf seinen höchsten Erhebungen erreicht.

In der Kalahari selbst besitzen wir leider bisher besonders auf englischem Gebiete keine Regcnmeßstationen. Die Behandlung ihrer Regenverhältnisse wird daher auch nur vermutungsweise gelten können, und müssen wir sie in Beziehung bringen zu der-

1) Letzteres »Deutsch-Südwestafrika«, 1898, von Th. Rehbock entnommen.

2) Die Kreuze $(\times)$ kennzeichnen die Mittelwerte der tatsächlich durch Beobachtung und Berechnung gefundenen Regenmengen einzelner Stationen. jenigen der Randstationen. Anderseits muf sie sich auf allgemeine kimatologische Berichte und sonstige Mitteilungen stuitzen.

Am Ostrand der Kalahari stehen uns die Beobachtungsresultate von hauptsächlich zwei Stationen Vryburg (94) und davon südlich Molopolole, erstere mit einer jährlichen Regenmenge von $565 \mathrm{~mm}$ $\left(26^{\circ} 55^{\prime}\right.$ s. Br.; $24^{\circ} 43^{\prime}$ ö. L.), Molopolole ( $24^{\circ}$ s. Br.; $25^{\circ}$ ö. Lg.), nach Hann, mit etwa $500 \mathrm{~mm} .{ }^{1}$ ) Auf deutschem Gebiete, also dem Westrand der Kalahari, fand ich für Gobabis (3I), welches nach Passarge noch inncrhalb der Kalahari liegt, ${ }^{2}$ ) und Oas (38) etwas über $450 \mathrm{~mm}$, und für Aminuis etwa $300 \mathrm{~mm}$. Es scheint demnach, daß von Südwest nach Nordost über die Steppe hinweg ziemlich breite Zonen zunehmender jährlicher Regenhöhe von 300 bis über $500 \mathrm{~mm}$ anzunehmen seien, weil ja doch auf der Steppe, die sich durch keinc besonderen Gebirgszüge auszeichnet, der Übergang ein ziemlich kontinuierlicher sein dürfte.

Da demgegenüber Supan in seiner Schrift über Die Niederschlagsverteilung auf der festen Erdoberfläche « die Zone von nur $250 \mathrm{~mm}$ noch weit in dic Kalahari sich hineinziehen läßt, und auch noch manche andcre Forscher, wie Passarge, sich dieser Ansicht von der großen Regenarmut der Kalahari anschließen, so wird ein näheres Eingehen auf diese Verhältnisse angebracht sein.

Vorliegender Abhandlung steht zur Beurteilung der Regenverhältnisse dieses Grenzgebiets DeutschSudwestafrikas heute ein weit reicheres Beobachtungsmaterial, auf welches sie sich stützen kann, als je einer früheren, zur Verfügung.

Auch K. Dove glaubte a. a. O. $\left.{ }^{3}\right)$ schon annehmen $z u$ dürfen, daß die Kalaharisteppe weit reichlicherc Niederschläge habe, als gemeinhin geglaubt würde. »Man darf sich die Kalahari nicht als eine in höchsten Grade regenarme Steppe oder gar fast als regenlose Wüste vorstellen. Höchstens im Südwesten beträgt die Niederschlagsmenge weniger als $100 \mathrm{~mm}$. In der Mitte und besonders im Nordosten sind wir genötigt, größere Regenmengen anzunehmen.«

Es möge hier noch auf die verschiedensten Reiseberichte vorzüglicher Kenncr der Kalahari verwiesen werden, welche die, stellenweise fast üppig zu nennendc Vegetationskraft der Kalahari nicht allein ihrem hohen Grundwasserstande, sondern vor

1) Dr. K. Dove, Das Klima des außertropischen Südafrika. S. II5: »Ist auch das aus etwa drei vollen Jahrgängen gebildete Mittel fïr Molopolole mit 522,0 mm vielleicht zu hoch.....

2) S. Passarge, Die Kalahari, 1904, S. 353.

3) Dr. K. Dove, 1. r. I5, S. I I9. 
allem den relativ reichen Regenfällen im Sommer zuschreiben. ${ }^{1}$ )

Auf alle diese Schilderungen der Kalahari als einer relativ reich mit Niederschlägen gesegneten Gegend kann sich eine Abhandlung über die Niederschlagsverteilung bei ihren Darlegungen doch höchstens nur allgemein stiitzen, ihnen jedoch keine exakten Tatsachen, d. h. in Zahlen ausdrückbare W'erte, entnehmen.

Demgegenüber bin ich in der Lage, für die auf dem V'estrande der Kalaharisteppe gelegenen Stationen folgende feststehende Werte, welche allerdings meist durch Redultion gewonnen wurlen, bieten zu können: Gobabis (31) $470 \mathrm{~mm}$, Oas (38) $475 \mathrm{~mm}$, Aminuis (50) $307 \mathrm{~mm}$, Gochas (55) $243 \mathrm{~mm}$, Hasuur (64) $230 \mathrm{~mm}$ Niederschlagshöhe im Jahre; desgleichen ganz im Süden der Steppe von West nach Ost: The Halt (7I) $157 \mathrm{~mm}$, Upington $205 \mathrm{~mm}$, Trooilapsan $225 \mathrm{~mm}$, Dunmurry und Griquatown (95, 96) etwa $400 \mathrm{~mm}$. Nach Norden hin in der Gegend des Ngamisee-Sumptlandes nehmen die Niederschläge nach vielen Reiseberichten, wie von Schinz, Passarge u. a. m., immer mehr zu.

Die Tatsache nun vorausgesetzt, daß auf der flachen Mulde die Niederschläge sich kontinuierlich in positivem oder negativem Sinne, und zwar nach Norden und Nordosten hin zunehmend, verändern, so dürfen wir mit großer Sicherheit auf Grund der Regenmeßresultate der Randstationen für den äußersten Südwesten eine mutmaßliche jährliche Niederschlagshöhe von mindestens $250 \mathrm{~mm}$ annelumen; sich andauernd steigernd, wird sie im Nordosten nit aller Wahrscheinlichkeit $550 \mathrm{~mm}$ erreichen, während sie im Norden, der Niederung des Okavango und des Ngamisees, bis zum Sambesi, vielleicht sogar 600 bis $700 \mathrm{~mm}$ und dariiber betragen wird.

Daß diese relativ großien Mengen jährlichen Niederschlags sich in ihrer Wirkung auf die Vegetation und das Naturleben, welches allerdings zur Sommerzeit weit reicher ist als unter der gleichen Breite in Deutsch-Südwestafrika, nicht lebhafter geltend machen, liegt wohl an der Tatsache, daß wir in der Kalaharisteppe ein abflußloses Gebiet vor uns sehen mit verivittertem und noch verwitterndem, losem Kalk- und Sandboden, welcher den gefallenen Regen sofort aufsaugt und in die Tiefe entführt.

1) Es sind hier vor allem zu erwähnen: Schinz, „DeutschSüdwestafrika«; Missionar Büttner in C. Ka l ner, „Die Klimate der deutschen Schutzgebiete«. r893, S. ro4; C. v. Franç̧o is, »Bereisung der Kalahari«, Verhandhungen der Gesellschaft für Erdkunde zn Berlin. r893. Bd. XX, S. 475; Livingstone, "Missionary Travels and Researches in South Africa". London I 857, S. 47, 48, 49, 95, 96; Grisebach, „Die Vegetation der Erde«. Bd. II. Leipzig 1872 , S. I53.
Anmerkung: Nach Abschlus rorliegender Abhandlung erschieu von Dr. Siegfried Passarge: ,Die Kalahari. Versuch einer physikalisch-geographischen Darstellung der Sanclfelder des südafrikanischen Beckens." Auf Grund ron ï̈ser zwei Jahre langen meleorologischen beobachtungen kommt I'assarge auf Seite 94, 95 zu einem Ergebnis, betreffend die Regenverhältnisse der Kallhari, rrelches sich im wesentlichen mit den obigen Darlegungen deckt. Es heiBt dort:

„Die Sommerregen begannen im Jahre I896 und I897 Ende November; Vorboten zeigten sich schon früher. Die Hauptregen fielen im darauf folgenden Dezember und Jamiar. Februar, März und April hatten weniger Regentage. Die Niederschläge sind an Gewitter gebunden und fallen oft strichweise und inregelmäbig. Infolgedessen mußte man an vielen stellen längere Zeit hindurch beobachten, um auch nur annähernd den durchschnittlichen Regenfall berechnen zu kömnen. Auch die einzehen Jahre sollen sehr schrrankende Verhältnisse anfweisen. Es gab Jahre, wo erst im Februar, selbst im März die ersten Regen fielen und die Vegetation anfs schwerste litt.

Die Sommerregen fallen bei östlichen Winden, und zwar sowohl bei südost- wie bei Nortost-Winden. Es scheint also dieser Teil Siidafrikas im Übergangsgebiet des Südost-Passats und Nordost-Mousuns zu liegen.

Für die Beurteilung der Höhe der Niederschläge fehlt jeder Anhalt. I'h möchte aber mit Rücksicht anf die Wassermenge, die manche Salzpfannen halten, glauben, daß Regenmengen von 400 bis $500 \mathrm{~mm}$ nicht zu den Seltenheiteu gehören. Ich halte es wenigstens für sehr fraglich, ob das Ngamiland noch innerhalb der Zone mit weniger ats $250 \mathrm{~mm}$ Regen liegt, wie die Regenkarte Supans es darstellt.

Die Trockenzeit beginnt im Laufe des April. Der Mai gehört jedenfalls schon ganz jener an. Regelmäbige östliche Winde am Tage, kühle bis kalte, oft taureiche Nächte, mäBige Tageswäme claarakterisieren den Mai, Juni und Juli. Mit Beginn der Regen nimmt die Hitze entschieden ab.

Ton Mai bis zum Juli nun macht sich der Südwestwind mit Winterregen, wie schon früher von Schinz und anderen beobachtet wurde, hänfig geltend, meist in jedem Monat einmal. Der Südwestwind hricht oft mit Gewitter und schwachem Regen herein, kühlt die Luft empfindlich ab, und in seine Zeit fallen die Frosträchte. Häufig tritt er als eisiger Südwind und selbst Südostwind - dann ohne Regen - auf.

Die Winterregen sind meteorologisch sehr interessant, und ich möchte die Erklärung Schencks bezüglich dex sie begleiteulen Regen für zutreffend latten. Von Bedeutung für die Vegetation und die Tierwelt sind sie nicht, da sie sehr schwach sind."

\section{Die Niederschlagsverhältnisse des nördlichen Teils von Deutsch-Suidwestafrika.}

Nördlich von dem 22. Parallellkreise s. Br. etwa kommen wir nunmehr in den hinsichtlich seiner Regenverhältnisse, soweit man von den auch hier regenarmen küstennahen Strichen absieht, am günstigsten gestellten Teil Deutsch-Südwestafrikas.

Das Kaokoveld.

Den westlichen, der Küste nahen und ihr entlang ziehenden Streifen des hier zu behandelnden Gebictes bildet das sogenannte Kaokoveld.

Im Verhältnis zu dem relativ reichlichen Material des schon besprochenen Teils unseres Schutzgebietes 
liegt von hier wie überhaupt aus dem Norden des Landes ein nur geringes Regenmeßmaterial vor.

Trotzdem setzt es uns einigermaßen in den Stand, den für das Kaokoveld besonders charakteristischen Zug der jährlichen Regenverteilung zu gewinnen. Für die'Anlegung der Isohyeten waren als Anhalt $\mathrm{zu}$ benutzen die Beobachtungsergebnisse von: Zesfontein $(6)$, welches noch zu dem eigentlichen Küstenland gehört, mit $69 \mathrm{~mm}$, dann Franzfontein (I5) mit $227 \mathrm{~mm}$, Okombahe (2 I) mit I36 mm, Omaruru (I9) mit $276 \mathrm{~mm}$, Gr. Spitzkoppje (22) mit $109 \mathrm{~mm}$ und Karibib (23) mit I $53 \mathrm{~mm}$ jährlicher Niederschlagshöhe.

Im Anfang unserer Erörterungen erwähnten wir schon den einheitlichen Zug, welcher die jährliche Regenverteilung gerade des Küstengebietes von Deutsch-Südwestafrika kennzeichnet, indem wir nur eine Zunahme der jährlichen Regenmenge nach Osten hin konstatieren konnten, während nach der verschiedenen geographischen Breitenlage keine besonderen Unterschiede in den Niederschlagshöhen der einzelnen Stationen sich zeigten.

Dieselben Verhältnisse treten uns im Kaokoveld entgegen. Auch hier können wir auf Grund der vorliegenden Beobachtungen etwa vom 2I. bis 22. Parallelkreise s. Br. aus nach Norden im Gegensatz zu dem ganzen übrigen Binnenland des Schutzgebietes keine besondere Zunahme der jährlich niedergehenden Regenmengen feststellen, sondern nur eine solche nach Osten, und zwar eine verhältnismäßig schnelle.

Diese interessante Tatsacheläßt sich ostwärts, leider gibt es im nordwestlichen Teile des besprochenen Gebietes fast gar keine RegenmeBstationen, ungefähr bis in die Gegend zwischen $\mathrm{I} 6^{\circ}$ ö. Lg. und $17^{\circ}$ ö. Lg. verfolgen. Überhaupt haben wir es im Kaokoveld mit relativ günstigeren Niederschlagsverhältnissen als in den ihm geographisch analog gelegenen Gebieten des südlichen Teils DeutschSüdwestafrikas zu tun. Nach verschiedenen Reiseberichten sollen dort die Sanddünen im Küstenland seltener sein als im Süden, und Gras soll im nördlichen Kaokogebiet bis ziemlich an die Küste wachsen.

Auf alle diese Momente darf sich unsere Annahme der schnelleren Zunahme der jährlich niedergehenden Regenmengen nach Osten zu im Kaokoveld gründen. $\mathrm{Zu}$ vorstehenden Darlegungen muß noch erwähnt werden, daß das Kaokoveld wie auch das anliegende Küstengebiet noch wenig durchforscht ist.

Nördliches Damaraland.

Nördlich des zentralen Hochlandes kommen wir in ein verhältnismäßig regenreiches Gebiet, das nördliche Damaraland, welches bis vor dem letzten Aufstande der Hauptsitz des damals noch reichen und Viehzucht treibenden Volkes der Herero war.
Die Vegetation ist üppig, aber ziemlich eintönig: iiberall dasselbe hohe Gras, ïberall dieselbe Buschund Baumart. Hier und da sollen an günstig gelegenen Plätzen auch schon Laubhölzer auftreten.

In diesem Gebiete werden, je weiter wir nach Norden gelien, die jährlichen Regenfälle auch immer reichlicher. So hat $\mathrm{Z}$. B.

Windhuk (35) unter $22^{\circ} 34^{\prime}$ s. Br. $357 \mathrm{~mm}$,

Neudamm (32) unter $22^{\circ} 22^{\prime} \mathrm{s}$. Br. 38 r mm,

Okahandja (25) unter $2 \mathrm{I}^{\circ} 59^{\prime}$ s. Br. $379 \mathrm{~mm}$,

Otjikango (I8) unter $20^{\circ} 35^{\prime} \mathrm{s}$. Br. $416 \mathrm{~mm}$,

Waterberg (I7) unter $20^{\circ} 35^{\prime} \mathrm{s}$. Br. $564 \mathrm{~mm}$ durchschnittlichen jährlichen Niederschlag.

Es ist vielleicht nicht ohne Interesse, einige Vergleiche anzustellen zwischen den jährlichen Regenhöhen von Stationen dieser Teile Deutsch-Südwestafrikas und solchen in Mitteleuropa. Doch darf dabei allerdings nicht vergessen werden, daß die gleiche oder ähnliche Regenmenge dort und bei uns durchaus nicht auch den gleichen Wert für die Vegetationsverhältnisse und die Kulturfähigkeit der betreffenden Gebiete besitzt. Denn einerseits verursacht die bei weitem größere Insolation eine erheblich größere Verdunstungsfähigkeit der Luft und trägt damit die Schuld an dem relativ geringeren Werte der im Schutzgebiete niedergehenden Regenmengen; anderseits ist auch die jahreszeitliche Verteilung und die Intensität der Regenfälle eine z. B. für Feldkulturen hier bei weitem ungünstigere als in Mitteleuropa.

Was die Menge des jährlich niedergehenden Regens angeht, könnte man im nördlichen Damaralande Okahandja (25) mit $377 \mathrm{~mm}$, Prag mit $416 \mathrm{~mm}$ und Otjosondjupa ( $\mathrm{r} 7$ ) mit $564 \mathrm{~mm}$ schon Berlin mit $540 \mathrm{~mm}^{-}$an die Seite stellen.

Namentlich das Plateaugebirge des Waterbergs zeichnet sich nach verschiedenen gleichlautenden Beriehten durch besonderen Regenreichtum aus. Infolgedessen wurde für dasselbe eine höhere Regenmenge angenommen und auf der Karte angelegt. Die Bewachsung seiner Hochebenen ist eine so reiche, wie man sie in südlicheren Gegenden des Schutzgebietes nur äußerst selten findet: "gute Viehweiden sind reichlich vorhanden «. Den Fuß des Gebirges umsäumen bis in die östlichen Tiefebenen weitausgedehnte und dichte Dornbuschwälder.

Trotz dieser günstigen Niederschlagsverhältnisse ist jedoch bei der relativ großen Schwankung der jährlich fallenden Mengen selbst in diesen Strichen auf einen lohnenden Ackerbau ohne künstliche Bcwässerung durchweg nicht zu rechnen.

Amboland.

Nördlich des Waterberges sehen wir uns in jeder Beziehung schon tropischen Verhältnissen 
gesenuber. Maisbau ist auch hier schon allein auf Regenfall hin möglich. ${ }^{1}$

Auf Grund meiner Berechnungen der Regenmefergebnisse der dortigen Stationen beträgt das jährliche Normalmittel von:

$\begin{array}{lrr}\text { Naidaus } & \text { (I3) } & 585 \mathrm{~mm}, \\ \text { Otawi } & \text { (I I } & 591 \mathrm{~mm}, \\ \text { Grootfontein } & \text { (IO) } & 6 \mathrm{I} 9 \mathrm{~mm}, \\ \text { Gaub } & (9) & 69 \mathrm{Imm}, \\ \text { Amutoni } & (7) & 558 \mathrm{~mm}, \\ \text { Olukonda } & (3-5) & 570 \mathrm{~mm} .\end{array}$

Wir funden hier eine mittlere jährliche Niederschlagshöhe von etwa $600 \mathrm{~mm}$ und darüber, während die Vermutung berechtigt erscheint, daß sie im äußersten Nordosten, also in der Okavangogegend, vielleicht noch bis über $700 \mathrm{~mm}$ steigt. Sie würde also ungefährim Ambolandeschon derjenigen des norlwestlichen deutschen Flachlandes entsprechen.

In Grootfontein (IO) mit etwa $600 \mathrm{~mm}$ jährlicher Regenmenge kann schon, nach Dr. Rohrbach und verschiedenen Berichten der dortigen Ansiedler, ganz ohne liünstliche Bewässerung Ackerbau getrieben werden. Ersterer berichtet hierüber: »Was die wirtschaftliche Ausnutzung des vorstehend skizzierten zur Besiedlung in Aussicht genommenen Gebietes betrifft, so ist zunächst von grundlegender Bedeutung die Tatsache, daß sich - im Gegensatz zu den mittleren und suidlichen Teilen des Schutzgebietes - im Grootfonteiner Distrikt der Ackerbau ohne Zuhilfenahme künstlicher Bewässerung, allein auf den Regenfall hin, als möglich und lohnend erwiesen hat. 2 )

Kennzeichnend ist weiterhin, daB die Amboneger schon einen regelmäBigen Ackerbaubetrieb kennen, während die Herero noch reine Viehzüchter sind.

Eins darf hier allerdings nicht unerwähnt bleiben, was viclleicht gerade bei diesen nördlichsten Stationen Deutsch-Südwestafrikas am auffälligsten hervortreten dürfte, nämlich der relativ große Unterschied zwischen den rohen und den reduzierten Mitteln der jährlichen Regenhöhe. Jedoch darf diese Tatsache uns nicht so sehr in Erstaunen setzen, da eben bei den betreffenden Regenmeßstationen des Ambolandes der Umstand die Berechnung der reduzierten Jahresmittel sehr beeinflußte, daß sic sämtlich nur in einer nachweisbar trockenen Periode ihre Beobachtungen angestellt haben, so daß von vorn-

1) Jahresbericht iiber die Entwichlung der deutschen Schutzgebiete. I903/04. Anlage D.IV. S. 265, nach Dr. Rohrbach.

2) Anlage D. IV., S. $2 \epsilon_{5}$. Jahresbericht über die Entwicklung der deutschen Schutzgebiete in Afrika nnd der Südsee im Jalre I903/04. (Wericht ïber Deutsch-Sïdwestafrika von Dr. Rolrubach.) herein kleincre Rohmittel crwartet werden mußten. Allerdings wird mit den kürzeren Beobachtungsreihen auch die Reduktion unsicherer. Sobald jedoch die Beobachtungsreihen größer sind und regenreichere Jahre in ihren Bereich fallen, reduziert sich auch der Unterschied in einer IVeise, daß er dann niemals ïber vielleicht den zehnten Teil des absoluten Betrages des rohen Mittels hinausgeht.

Es tritt diese Erscheinung vor allem dadurch hervor, weil wir hier absolut viel höheren W' Werten der jährlich fallenden Regenmengen begegnen als in den mittleren und suidlichen Gegenden unseres Schutzgebietes.

Ein besonders eigentümlicher Zug cler Verteilung des Nicderschlags im nordöstlichen Ambolande verdient hier noch erwähnt zu werden. Während in ganzen übrigen Lande der Verlauf der.lsohyeten, abgesehen von lokalen Abweichungen, im allgemeinen ein von Nordwest nach Siidost gerichteter ist, berechtigen die Beobachtungsresultate aus dem Ambolande 'su der Annahme, daß ein ebensolcher Verlauf nur bis ungefähr in die Gegend der Outjo-Sandsteinterrasse und des Waterbergs für sic gelten liann, daf sie dann aber in ziemlich scharfem Bogen nach Nordosten sicl wenden. Bei A. Supan ${ }^{1}$ ) ist dieser Sachverhalt ebenfalls schon angedeutet und auf seiner Niederschlagsliarte der festen Erdoberfläche auch zur Darstellung gekommen. Nur nach Nordosten ist also eine starke Zunahme der jährlichen Regenhöhen zu'konstatieren. Eine gerade Linie von Nordwest nach Südost wird demnach ungefähır in der Mitte ein Maximum der jährlich fallenden Regenmenge treffen: Oniipi-Ondangua-Olukonda (3-5) $570 \mathrm{~mm}$, Amutoni $558 \mathrm{~mm}$, Gaub $69 \mathrm{I} \mathrm{mm,} \mathrm{Groot-}$ fontein $6 \mathrm{rg} \mathrm{mm}$, Otjituo $538 \mathrm{~mm}$.

Für die Annahme, daß îm äußersten Nordosten Deutsch-Sülwestafrilias die Regenfälle noch günstiger werden und so eine wahrscheinliche Höhe von melr als 700 mm ergeben, sprechen die einzelnen Berichte über Reisen nach dem Okavango und dem Ngamisee, welche die dort und im sogenannten Caprivizipfel herrschende tropische Vegetation und den dortigen Viehreichtum rühmen. So heißt es z. B. in einem Reisebericht ${ }^{2}$ ) des Leutnants Eggers von Grootfontein nach dem Okavango:

Trotzdem ich in der trockensten Jahreszeit $z o g$, fand ich iuberall reichliches griines Gras, für dessen Wert wohl der Umstand am besten spricht, daß die mitgenommenen Ochsen und Pferde trotz großer Anstrengungen in besserem Zustande zurückkamen als zu Anfang der Reise.

\footnotetext{
1) A. Supan, L. V. 46, S. I3.

$\left.{ }^{2}\right)$ Mitieilungen a. d. Sch. Geb. XIII. I900. S. I 88.
} 
Auch Schinz rühmt in seinem oft angeführten Werke den überaus reichlichen Regenfall des Nordostens, durch dën während der Regenzeit die Landschaft infolge ihrer Abflußlosigkeit auf weite Strecken hin ein seenartiges Aussehen gewönne. Dabei haben im Ambolande die Niederschläge schon oft den Charakter der Landregen, die oft die kommende Nacht hindurch und selbst den folgenden Tag anhalten.

Ebenso nehmen im Binnenlande von PortugiesischAngola die Niederschläge andauernd und ziemlich schnell von Süden nach Norden an Menge zu; gleichzeitig tragen sie hier schon den Charakter der tropischen Zenitalregen.

Nördlich der Gegend des Kubango sind nach H. Baum ${ }^{1}$ ) in der Regenperiode Gewitter sehr häufig, oftmals in kurzen Zwischenräumen aufeinanderfolgend. Landregen dauern selten länger als zwei bis drei Tage.

Leider besitzen wir zur Schätzung der Niederschlagsverteilung im hohen Berglande Inner-Angolas nur von einer einzigen Regenmeßstation exalstes Beobachtungsmaterial. In Caconda (2), im Quellgebiet des Kunene, fielen von Januar I 889 bis Juni I 890 $2472 \mathrm{~mm}$, was einer durchschnittlichen Regenmenge von etwa 1200 bis $1400 \mathrm{~mm}$ im Jahre gleichläme. Caconda liegt $1640 \mathrm{~m}$ hoch. Da einerseits die Beobachtungsdauer ( $\mathrm{I} \frac{1}{2}$ Jahre) nur sehr kurz ist, anderseits eine Redultion nicht möglich war, so dürfte das Mab der Sicherheit der angegebenen Regenhöhe nur wenig groß sein. Jedenfalls aber können wir daraus auf ein weiteres und beträchtiches Steigen der jährlichen Regenmengen im hohen Binnenlande Angolas nach Norden hin schließen. Ebenso mehren sich, wenn auch nur alimählich, an der Küste nordwärts die Regenfälle, wie schon früher dargelegt, von der Kunenemündung mit vielleicht $50 \mathrm{~mm}$ bis Loando (I) mit $315 \mathrm{~mm}$ jährlicher Niederschlagshöhe.

Erscheint demnach einerseits das Amboland als der durch seine Niederschlagsmengen günstigste Teil Deutsch-Südwestafrikas, so darf für Kolonisationszwecke freilich auch nicht unberücksichtigt bleiben, $\mathrm{da} \mathrm{B}$ sich hier anderseits auch schon die ständige Begleiterscheinung feuchter, tropischer Gegenden, dasFieber, einstellt (nach Stabsarzt Dr. Richter). ${ }^{1}$ )

\section{Speziellere Untersuchungen.}

\section{Taufall und Nebelbildung.}

Bereits bei der Darlegung der Niederschlagsverhältnisse des Küstenlandes von Deutsch-Südwestafrika mußte auch des für diese so iberaus regenarme Küstenzone höchst wichtigen Faktors, des Taufalls, gedacht werden.

Es möge hier nun eine kurze zusammenfassende Beschreibung dieser Erscheinung und der mit ihr eng verbundenen Nebelbildungen folgen. Diese Darlegung, welche sich möglichst über das ganze Schutzgebiet erstrecken soll, kann sich allerdings nicht auf exakte Messungen stützen, da wir es hier eben mit einem unmeßbaren 2) Niederschlag zu tun haben. Dagegen dürften uns allgemeine Angaben der meteorologischen Stationen über Taufall und Nebelbildung, die allerdings nur äußerst spärlich vorliegen, und dann auch die wohl in jeder Reisebeschreibung aus Deutsch-Südwestafrika gemachten Aufzeichnungen das Material über diesen Gegenstand an die Hand geben.

1) H. Baum, L. V. I, S. I47.

2) Das heiBt vorderhand! Allerdings sind schon verschiedentlich Versuche angesteilt worden, so anch in Port Nolloth, den für diese südwestafrikanischen Küstenstriche so wichtigen und reichlich fallenden Tau einer Messung zu unterziehen und seinen jährichen Duxchschnittswert zu berechnex. Jedoch haben diese Versuche, welche mit Hilfe eines kompliziert gebauten Apparats die Wägung bzw. Messung der auf einer Glasplatte niedergeschlagenen Taumenge gestatten sollten, vorläufig noch nicht zu befriedigenden Ergebnissen geführt.
Auf die auffallenden Nebelbildungen, besonders desKüstenlandes, machen alle Beobachter aufmerksam.

Besonders während der Winterzeit liegt die Küstenregion während der Nacht- und frühen Morgenstunden in dichten Nebel gehüllt, so ständig, daß z. B. korrespondierende Sternbeobachtungen in Walfischbai mit Kapstadt nur ganz äu3erst selten gelangen.

Bei der überaus geringen meßbaren Regenmenge von Walfischbai (46) von etwa IO $\mathrm{mm}$, dabei verteilt auf durchschnittlich (1886 bis 1894) 9 Regentage, wird es sehr ins Gewicht fallen, daß dort 1886 bis 1892 durchschnittlich 156 mal im Jahre am Morgen Nebel mit Tau beobachtet worden ist. Auch die Seeschiffahrt wird durch diese widrigen Nebel hier andauernd behindert.

Die Nebel lagern manchmal noch den ganzen Tag über der Küste, gar oft aber verdichten sie sich des Morgens zu einem so starken Tauniederschlag, daß das Wasser geradezu von den Dächern

1) In Kurd Schwabe, Deutsch - Südwestafrika, S. 385: "Nur in dem nördlichen Teile des Schutzgebietes, welcher durchreg tropischen Charakter aufweist, kommen bösartige Formen der Malariafiebex, wie auch echte Ruhr, vor, und werden anch nach völiger Unterwerfung der dort wohnenden OvamboStämme, trotz der gröberen Fruchtbarkeit des Bodens, der besseren Wasserverhältnisse und der Möglichkeit, Ackerbau zu treiben, einer größeren Einwanderung und Ansiedelung stets eiren Riegel vorschieben. 
träufelt und man Süßwasser sammeln liönnte. Der Bollen wird oft bis $\mathrm{r}$ cm tief durchfeuchtet.

Daß eine solche regelmäßig fallende Taumenge praktisch cinen nicht unerheblichen Einfluß auf die V'egetation ausüben kann, besonders wo an der Küiste der Niederschlag so gering ist, daß oft jahrelang kein Tropfen mebbaren Regens fällt, liegt auf de1 Hand.

In seinem oft angeführten Werke erwähnt ein berufener Kenner auf diesem Gebiete, Schinz,1) sogar eine trt Nebel- und Tauphlanzen, die allein dem Tauniederschlay ihre zur Nahrung notwendige Feuchtigkeit entnehmen. Überhaupt scheint an der Küste die Nutzbarmachung des Regens durch die Pflanzenwelt hinter die der regelmäßigen, wenn auch unmeBbaren Tauniederschläge ziemlich zurückzutreten.

So schreibt Schinz:2) betreffs der Wirkung jener geringen Niclerschläge: . Die Bedeutung dieser Art von Wasserspendung lommt daher füir die Vegetation liaum in Betracht; denn wenn auch der Regen tiefer in den Sand einzudringen vermag als die vom Nebel gespendete Feuchtigkeit, so ist jener doch zu selten und unregelmäßig, als daf die Pflanzen und Tiere erheblichen Nutzen daraus ziehen könnten.

Bis in die Gegend von Tsaobis und Otjimbingue, etwa s fo km von der Küiste entfernt, ziehen sich diese regelmäßigen winterlichen Nebelniederschläge; häufig erstrecken sie sich noch tief ins Bimnenland Deutsch-Südwestafrikas, meist ohne mebbaren Niederschlag, an hochgelegenen Punkten wie das Awasgebirge, der Geitse-gubib, als Schnee.

Im ïbrigen liann im ganzen Schutzgebiet und in jedem Nonat Nebel auftreten, wie die verschiedensten Beobachter iibereinstimmend berichten.

So beobachtete Schinz am 15. Februar IS85 zwischen Guos und Aus in Gr. Namaland Nebel von auBergewöhnlicher Dichtigkeit, dann am I 4., I5. und I6. Februar I886 in Olukonda im Norden, am 6. August unterhalb Witvley. Missionar Irle aus Otjosazu (26), nördlich von Windhuk gelegen, bezeichnet seradezu das Jahr I 884 als »Nebeljahr ".3)

Starker Tau ist namentlich in Gr. Namaland und auch im Hererolande häufig; z. B. berichtet Schinz, daß zrvischen Aus und Keetmanshoop von November 1884 bis April 1885 die Zeltleinen seines Wagens fast jeden Morgen triefend naß waren. $\left.{ }^{4}\right)$ Ebenso erzählt er dort: "Als ich einst, auf einer Reise von Aus nach Angra Pequena begriffen, durch den Nebel gezwungen wurde, zwischen den Dünen zu kampicren, waren unsere Kleider am anderen Morgen ganz durch-

\footnotetext{
1) Schinz, a. a. O., S. 475 .

2) Schinz, a. a. O., S. 441 .

3) V'g1. hierzu S. 67 in vorliegender Abhandlung.

4) Schinz, a. a. O., S. 440 .
}

näBt; die kalten Wagenräder trieften, und der lockere Sand war $4 \mathrm{~cm}$ tief vollkommen durchfeuchtet.

Von Inachab (69) erwähnt FarmerFerd. Gessert ${ }^{1}$ ) aus dem Winter nachts stärkere Bewölkung und ausnahmsweise ausgiebigen Taufall. Ebenso berichtet aus Lüderitzbucht z. B. H. Pohle 2 ) vom I I. Dezember 1885 und 3I. Januar I 886 von fast täglichem Nebel mit ziemlich starkem Tauniederschlag bei eintretendem Nordwind. Ebenso finden wir bei Schinz $3^{3}$ iber seine Ergiebigkeit: „Die wenigen der Flord dieses Litoralsürtels zukommenden Gewächse sind in ihrer Entwicklung vollständig auf die Luftfeuchtigkeit angewiesen; zur Winterszeit, wenn der Nordwestwind die dichten Nebel iber Angra wirft, dann ist auch hier der Sand dermaßen durchfeuchtet, daß er an den Wagenrädern haften bleibt, und dies ist dann für die im Boden ruhenden Keime der Moment zum Erwachen, um in möglichst kurzem Zeitraum den ganzen Entwicklungsgang zu durcheilen."

In Swakopmund erfolgen die Niederschläge häufig in Gestalt von Nebel des Nachts und morgens bis 9 Uhr. $\left.{ }^{4}\right)$

Ohne Bedeutung für die Vegetation und mit den eben besprochenen Nebel- und Tauniederschlägen nicht zu verwechseln ist eine Art Bergnebel. Dieser lagert sich in den Gebirgen des Binnenlandes nach stärkeren Regen um die Kuppen und Hänge der Höhen, während die ersteren nur durch die nächtliche Wärmeausstrahlung des Bodens und die damit verbundene Abkühlung der mit großer relativer Feuchtigkeit beladenen unteren Luftschichten unter den Taupunkt hervorgerufen werden.

Kurz Zusammengefaßt, läßt sich eine starke $\mathrm{Zu}$ nahme der besonders winterlichen Nebelbildungen und Taunicderschläge von Nord nach Süd im Schutzgebiete und ebenso vom Osten zur Küste hin konstatieren, so sehr, dab man an letzterer fast ständig auf solche rechnen kann. Genügt doch z. B. an manchen Orten, wie Sandwichhafen und Walfischbai, der tägliche Taufall, um eine wenn auch kümmerliche Vegetation ständig zu erquicken und sogar zu unterhalten, die dem auf der Reise durch die trockene Namieb erschlafften Zugvieh oft zum Labsal wird.

\section{Schneefall.}

Nach H. Fischeró) zieht dic äußerste Grenze des regelmäßigen Schneefalls im Westen von Süd-

1) Mitt. XIII. I900, S. 3 .

2) Pet. Mitt. 1886, S. 229. Expedition nach Deutsch-Südwestafrika.

3) Schinz, a. a. O., S. I5.

4) Jahresbericht der deutschen Schutzgehiete I898/99.

5) H. Fischer, L. Y. 2 I. 
afrika auf dem Meere dem 35. Parallelkreise s. Br. etwa entlang, auf dem Festlande dringt sie nördlich bis zum Orangefluß vor.

Nach diesen Darlegungen hätten wir also in Deutsch-Südwestafrika selbst keine winterlichen Schneefälle oder doch solche nur äußerst selten und vielleicht nur auf den höchsten Erhebungen des Landes zu erwarten. So hält z. B. Th. Rehbock 1 ) nur die Tatsache eines einzigen Schneefalls in Gr. Namaland für erwiesen.

Wenn auch Schneefälle ein seltenes Schauspiel für unser Schutzgebiet sind, so haben wir doch neben manchen älteren Berichten ${ }^{2}$ ) von Missionaren und Reisenden heute darüber exakte Beobachtungen zur Hand aus den verschiedensten Gegenden des mittleren und besonders südlichen Teiles DeutschSüdwestafrikas.

Abgesehen von einigen in Reiseberichten erwähnten Fällen - so z. B. beobachtete Dr. Schenck nach Schinz am Himmelfahrtstage ${ }^{8} 85$ einen Schneefall, "welcher die Gneißkuppen bei Kubub vorübergehend deckte "; weiterhin kam am 7. August I 89 I in Windhuk, Tsaobis und Rehoboth ein Schneefall, der sich also iiber ein ziemlich ausgedehntes Gebiet erstreckte, vor; ebenso im Juli I892 in Schaaprivier und Windhuk, desgleichen am ersteren Orte am 7. August I $899-\ldots$ abgesehen von diesen und manchen anderen, mehr unbestimmten Fällen sei hier nur kurz auf die im Jahrgang I903 S. IO gुegebene Zusammenstellung über einen am IO. und II. Juni 1902 erfolgten ausgedehnten Schneefall, der sich bis Gobabis nach Norden erstreckte, hingewiesen.

Nimmt man noch die verschiedenen allgemeinen Berichte über stattgefundene Schneefälle hinzu so sehen wir, daß dieselben doch immerhin trotz der niedrigen Breitenlage des Schutzgebietes sogar noch einige Grad "nördlich des Wendekreises im Winter vorkommen können.

Die unter den Eingeborenen und Ansiedlern anscheinend verbreitete Annahme, daß ein reichlicher Schneefall eine ergiebige Regrenzeit erwarten lasse, wurde freilich, wie das so häufig auch in Deutschland bei volkstümlichen Wetterregeln der Fall ist, durch den oben erwähnten ausgedehnten Schneefall des Juni I9O2 ad absurdum geführt, denn die Regenzeit I9O2/03 war vielfach die unergiebigste von allen seit dem Bestehen der Beobachtungen.

Ebenso fällt in Deutsch-Südwestafrika in Winter auch öfters Reif, und zwar erstreckt sich sein Herrschaftsgebiet nach mehreren Reiseberichten noch weiter nach Norden als das des Schnees.

1) Th. Rehbock, Dentsch-Südwestafrika, S. 45.

$\left.{ }^{2}\right)$ Pet. Mitt. 1858 , S. 198 . Zeitschrift für Met. XIII, S. 420 Mitt. von Forschungsreisenden, XX. Band. I.
Selbst bis ins Amboland hinein kann nach Schinz $z^{1}$ ) während der Nacht im Winter eine Ab kühlung unter den Gefrierpunkt noch vorkommen. Häufiger tritt diese Erscheinung und mit ihr die Verwandlung der winterlichen Tauniederschläge in Schnee oder Reif im zentralen Hochlande und besonders im Süden auf, während von der Küstenregion daruber keine Berichte vorliegen.

$$
\text { Hagelfall. }
$$

Über Hagclfälle liegen neben gelegentlichen Notizen von Reisenden auch exakte Beobachtungen der meteorologischen Regenmeßstationen, wcnigstens für die Dauer der Regenperioden I 899/ I g00, I 900/OI, I9OI/O2 und I9O2/03, vor.

Danach wurde diese Art des Niederschlags im Norden wie im Süden Deutsch-Südwestafrikas besonders in den Sommermonaten September bis Mai beobachtet.

Aus den erwähnten vier Regenperioden meldeten nach den »Mitteilungen aus deutschen Schutzgebieten « 30 Stationen im ganzen 82 Hagelfälle; danach können sie also mit Ausnahme der küstennahen Striche im ganzen Binnenlande Deutsch-Südwestafrikas auftreten.

\section{Die jahreszeitliche und monatliche Verteilung der Nieder- schläge in Deutsch-Südwestafrika.}

Nächst der jährlichen Menge der Niederschläge ist naturgemä $B$ auch die jahreszeitliche Verteilung derselben für die gesamten Vegetationsverhältnisse und alle Fragen einer kolonisatorischen Nutzbarmacinung Deutsch-Südwestafrikas von sehr großer und allgemeiner Bedeutung. ${ }^{2}$ )

Zur deutlicheren Veranschaulichung der monatlichen und jahreszeitlichen Regenverteilung in unserem Schutzgrebiete mögen die Tabellen IO und I I sowie die Diagramme I I bis 39 dienen, welche in Zahlen und Kurvendarstellung den absoluten und relativen (prozentmäBigen) Anteil der durchschnittlich gefallenen monatlichen Regenmengen an der jährlichen Nieder schlagshöhe einer Anzahl von Stationen zeigen.

Um ein möglichst sicheres und übersichtliches Bild geben $z u$ können, wurde zwar nur eine beschränkte Anzahl, nämlich 29 Stationen, jedoch nur solcher mit längerer Beobachtungsdauer ausgewählt. Die Stationen verteilen sich von Nord nach Süd über das ganze Gebiet.

]) $\mathrm{S} \operatorname{chinz}$, a. a. O., S. $442 \mathrm{ff}$.

2) Den Aufstellungen dieses Kapitels sind auch die Regenmebergebnisse der Periode I904/05 zugrunde gelegt, welche mir kurz, vor der Drucklegung noch zugingen und so mitbenutzt werden kounten. Für die ganze übrige Abhandlung gilt sonst als Endtermin der zur Verwendung gekommenen Beobachtungsresultate die Regenperiode I903/04, also 30. Juni I904. 
Tabelle 10. Monatliche und jahreszeitliche Verteilung der Niederschläge (absolute) in Millimetern mit Angabe des rohen Jahresmittels.

\begin{tabular}{|c|c|c|c|c|c|c|c|c|c|c|c|c|c|c|c|c|c|c|c|c|}
\hline $\begin{array}{l}\text { Sïdl. } \\
\text { geonr. } \\
\text { Breite }\end{array}$ & $\begin{array}{l}\text { I.fd. } \\
\mathrm{Nr} .\end{array}$ & $\begin{array}{l}\text { Name } \\
\text { der } \\
\text { Station }\end{array}$ & $\begin{array}{c}\text { Damer } \\
\text { cler } \\
\text { Beob. } \\
\text { Jahie }\end{array}$ & Juli & Aug & Sept. & Okt. & Nor. & Dez. & Jan. & Felor. & Mäız & April & Mrai & Juni & 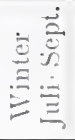 & 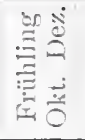 & 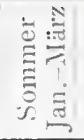 & 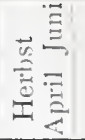 & 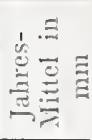 \\
\hline $1757^{\prime}$ & $(3-5)$ & lukonda & 9 - Io & 0.0 & 0.0 & 3.1 & I 4.0 & 45.5 & 73.4 & 8.2 & .5 & 5.8 & 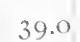 & 1.2 & 0.0 & $3 . I$ & 132.9 & 317.5 & 40.2 & 493.7 \\
\hline $19-70^{\prime}$ & (IO) & ntein. . & $5^{1}+$ & 0.0 & 0.0 & 2.8 & 20.9 & 40.6 & I to. 6 & I 2 I.4 & 97.5 & I 12.5 & +8.3 & 9.2 & 0.2 & 2.8 & 202.1 & 331.4 & 57.7 & $59+.0$ \\
\hline $20-35^{\prime}$ & (I 7$)$ & Wraterberg . . . & ro & 0.0 & 0.8 & I. 2 & 7.8 & 35.5 & IOI.S & I09.0 & I I I.O & 89.0 & $5+.8$ & 10.0 & 0.0 & 2.0 & $\mathrm{I}+5 . \mathrm{I}$ & 309.0 & $6+.8$ & 520.9 \\
\hline $21059^{\prime}$ & $(25)$ & Okalıamilja . . & $9^{3}+$ & I.I & 6.3 & 0.8 & 19.5 & 19.2 & 67.7 & 74.9 & So. 8 & 88.0 & 36.2 & 9.8 & 0.0 & 8.2 & 106.4 & 243.7 & 46.0 & 404.3 \\
\hline $222^{\prime} 2 I^{\prime}$ & $(3 I)$ & Gobalbis. & 7 & 1.7 & 1.3 & 2.2 & 13.8 & 24.5 & 76.3 & I I 9.4 & 75.2 & 59.8 & 38.9 & 5.3 & 0.3 & 5.2 & I I 4.6 & $25+4$ & +4.5 & +18.7 \\
\hline $2220^{\prime}$ & $(29)$ & Otjimbingue. & 6 & 0.0 & 0.0 & 2.3 & 1.9 & $5 \cdot 4$ & 35.0 & 36.9 & 37.5 & $23 \cdot 3$ & 10.5 & 0.5 & 0.0 & 2.3 & +2.3 & 97.7 & I I.O & I 53.3 \\
\hline $22^{\circ} 34^{\prime}$ & $(35)$ & Gr. Winthuk. & I $3^{1}:$ & 2.4 & 3.5 & I. I & 7.7 & 23.5 & 53.4 & 89.4 & 67.1 & 79.8 & +5.4 & $5 \cdot 3$ & 0.2 & 7.0 & $8+6$ & 236.3 & 53.9 & 381.8 \\
\hline $22=45^{\prime}$ & $(42)$ & Schatprivier . . & I I $^{5}$ & 2. I & $4 . \mathrm{I}$ & 0.2 & 5.0 & 17.3 & 58.6 & 93.3 & 60.1 & 71.5 & $3+6^{\prime}$ & 6. I & 0.8 & 6.8 & So.9 & $22+9$ & +1.5 & 353.7 \\
\hline $23^{\circ} 19^{\prime}$ & $(47)$ & Kehoboth . . & $I 5^{11 / 12}$ & O. I & 3.5 & 0.5 & 6.8 & 13.9 & 24.9 & 71.0 & 56.1 & $5 \mathrm{I} . \mathrm{I}$ & 30.5 & 5.8 & 0.7 & 4.1 & 45.6 & 178.2 & 37.0 & $26+9$ \\
\hline $23-57^{\prime}$ & $(5 \mathrm{I})$ & lioachimas. & 6 & 0.5 & 0.0 & 0.0 & I. I & 4.6 & I $\$ .3$ & +1.2 & +7.5 & 37.9 & 42.1 & 5.4 & 1.4 & 0.5 & 24.0 & 126.6 & +8.9 & 0.0 \\
\hline $242 S^{\prime}$ & $(53)$ & Nomtsas .. & 6 & 0.3 & 0.0 & 0.0 & 2.4 & 3.3 & 19.4 & +1. & 31.7 & 39. I & 34.1 & 2.9 & 0.3 & 0.3 & 25.1 & I 12.5 & 37.3 & 5.2 \\
\hline $25-7^{\prime}$ & $(58)$ & Gibeon ... & 6 & 0.4 & 0.0 & 0.2 & 6.9 & 6.9 & I3.I & 59.6 & 23.0 & 30.8 & 19.3 & 0.5 & 0.8 & 0.6 & 26.9 & 113.4 & 20.6 & 61.5 \\
\hline $26^{3} 32^{\prime}$ & $(63)$ & ushoop. & 6 & $3 \cdot 3$ & 0.0 & 0.0 & 6.5 & 5.5 & 12.9 & 29.0 & 30.1 & +2.2 & 28.3 & 2.0 & I.I & $3 \cdot 3$ & 24.9 & 101.3 & 32.4 & 161.9 \\
\hline $26^{3} 30^{\prime}$ & $(62)$ & Bethanien . . . & $6^{1}$ & O.I & 2.0 & 0.9 & 7.2 & 2.2 & 13.7 & 26.0 & $2 I .3$ & 36.8 & $24 . I$ & 0.6 & 4.0 & 3.0 & 23.1 & $S_{4} . \mathrm{I}$ & $2 \mathrm{~S} .7$ & 138.9 \\
\hline $26+2^{\prime}$ & $(66)$ & Kubub ... & 246 & 0.0 & 3.5 & 3.4 & 0.4 & 0.0 & 21.9 & 22.4 & 20.3 & $37 \cdot 4$ & I 5.8 & I I. I & 14.8 & 6.9 & 22.3 & So.I & +1.7 & I 5 I .O \\
\hline $28 \cdot 27$ & $(75)$ & Walmbar. & $6^{16}$ & 3.1 & $\mathrm{I} .5$ & 4.0 & 2.3 & 1.3 & 2.3 & 15.4 & 26.7 & 19.6 & 26.5 & I.9 & 4.0 & $\$ .6$ & 5.9 & 61.7 & 32.4 & I 08.6 \\
\hline $8+49^{\prime}$ & (I) & Loanda & $(23)$ & O.I & 0.8 & & 5.2 & 30.9 & & I 7.6 & 39.8 & $6+6$ & I30.t & I 3.6 & 0.0 & 1.7 & 50.6 & 122.0 & I 44.0 & 318.3 \\
\hline I $8=35^{\prime}$ & (6) & Zesfontein... & (2) & 0.0 & 0.0 & 0.7 & 2.5 & 0.9 & 19.4 & 9.8 & I3.6 & I 3.0 & 7.9 & 6.0 & 0.0 & 0.7 & 22.8 & 36.4 & 13.9 & 73.8 \\
\hline $22 \cdot 42^{\prime}$ & $(f I)$ & mund. & (6) & 0.4 & 0.5 & 0.5 & 2.2 & O.I & 6.1 & 1.3 & 2.6 & 3.6 & I. I & 2.2 & 0.3 & I.t & 8.4 & 7.5 & 3.6 & 20.9 \\
\hline $2257^{\prime}$ & $(46)$ & Wraltischbai. & $\left.(13)^{1 / 6}\right)$ & 0.0 & 0.43 & 0.4 & I. 23 & 0.4 & 0.04 & 0.8 & 0.96 & 1.5 & I. 2 & 0.6 & 0.0 & 0.83 & I.67 & 3.26 & 1.8 & 7.6 \\
\hline $26^{\circ} 36^{\prime}$ & $(65)$ & Linderitzburcht & $\left(2_{2}^{1}\right)$ & 0.0 & 5.1 & 2.8 & 0.0 & 0.3 & I. 6 & 0.0 & 5.6 & 0.3 & I.O & 3.8 & I.t & 7.9 & 1.9 & 5.8 & 6.2 & 21.9 \\
\hline $29^{-} 2^{\prime}$ & $(78)$ & Pella. & $(x+1)$ & I. 7 & 5.7 & 3.5 & I 9.5 & +.3 & 4.I & 5.9 & I 0.8 & 20.1 & I I .2 & 7.8 & 2.4 & 10.9 & 27.9 & 36.8 & 21.4 & 97.0 \\
\hline $29^{\circ}$ I $2^{\prime}$ & (So) & Ǩlip fon & (I 5 ) & 26.0 & 32.5 & 13.9 & I 8.7 & 9.4 & 4.7 & 3.2 & 9.0 & I0.9 & 26.5 & 37.0 & 23.0 & 72.7 & 32.8 & 23.1 & 86.5 & $2 \mathrm{I} 5 . \mathrm{I}$ \\
\hline $29^{\circ}+6^{\prime}$ & $(79)$ & Port Nolloth. . & (I 5$)$ & 8.9 & 9.8 & +.5 & $5 \cdot 4$ & 2.6 & 2.3 & $\mathrm{I} .3$ & $2 .+$ & $3 \cdot 3$ & 8.3 & 13.9 & 8.4 & 23.2 & 10.3 & 7.0 & 30.6 & $7 \mathrm{I} . \mathrm{I}$ \\
\hline
\end{tabular}

Bei der Anlegung der Diagramme bin ich nicht dem Vorsang Th. Rehbocks gefolgt, der in seinem Werle auch schon eine Kurvendarstellung der durchschnittlichen Verteilung der Nicelerschläge nach ihren tatsächlichen Beträgen auf die einzelnen Monate von 3 Stationen (Olukonda, Windhuk und Rehoboth) gibt; vielmehr habe ich, da es sich hier mehr um die Tergleichung des relativen Anteils der einzelnen Monate und Jahreszeiten handelt, die betr. Regenmengen in Prozenten des rohen Jahresmittels ausgedruickt und als Ordinaten der Kurven eingetragen. In Form einer Tabelle soll allerdings neben dieser letzteren Darstellung Tabelle I I nach Prozenten des rohen Jahresmittels eine solche nach den absoluten ITerten gegeben werden. Tabelle io zeigt demnach die durchschnittliche absolute Regenhöhe der einzelnen Monate und Jahresteiten in Millimeter-Angabe.

Gewählt sind hier im ganzen 16 Stationen des Binnenlandes und 8 aus dem Küistengebicte.

Aus den nun folgenden Zusammenstellungen (Tab. I I) ergibt sich, daf das Innere von DeutschSüdwestafrika, allgemein genommen, ein Gebiet mit deutlich ausgesprochenem Sommerregen ist; denn es fällt dort fast überall im Sommervierteljahr (Januar bis März) mehr als die Hälfte, ja großenteils mehr als $3 / 5$ des Jahresniederschlages.

Das hiervon sehr abwcichende Verhalten der Küstengebiete möge erst weiter unten erörtert werden.

An der Hand der erwähnten Tabellen und besonders veranschaulicht durch die Kurvendarstellung zeigen sich jedoch gewisse Verschiedenheiten der einzelnen Landschaften betreffs der V'erteilung auf dic cinzelnen Mnnate. Die Stationen sind in den Aufstellungen von Nord nach Süd der geographischen Breite nach, und zwar in zwei Rubriken geordnet, zunächst die des Binnenlandes und dann die der Küstenregion und des äußersten Südens im betrachteten Gebiete.

Um nummelyr zuvor einen allgemeinen Überblick zu gewinnen, so tritt uns bei ihnen ein gewisser Übergang klar vor Augen. Dic Sommerregen (Januar bis März, rote Farbe) überwiegen im Landinnern andiutuernd; im äußersten Süden und Südwesten nehmen sie allmählich ab, bis schließlich Herbstund Vinterregen (April bis Juni, violett; Juli bis September, blau) ihre Stelle cinnelnmen und glie Winterregen des Kaplandes so anküundigen. W'Teiterhin nehmen die Frühlingsregen (braun) nach Süden und der Küste zu allmählich ab, während der Anteil der Herbstregen (violett) in demselben Maße andauernd wächst.

Die jahreszeitliche Regenverteilung in DeutschSüdwestafrika ist verwandt derjenigen der nördlicher gelegenen Gebicte der tropischen Zenitalregen mit einem doppelten Regenmaximum im Sommer, für welche noch Portugiesisch-Benguela typisch ist, und leitet über, wic dic beigegebenen Diagramme deutlich zeigen, zu dem im südlichen und südwestlichen Kaplande herrschenden ausschließlichen Winterregengebiete. 


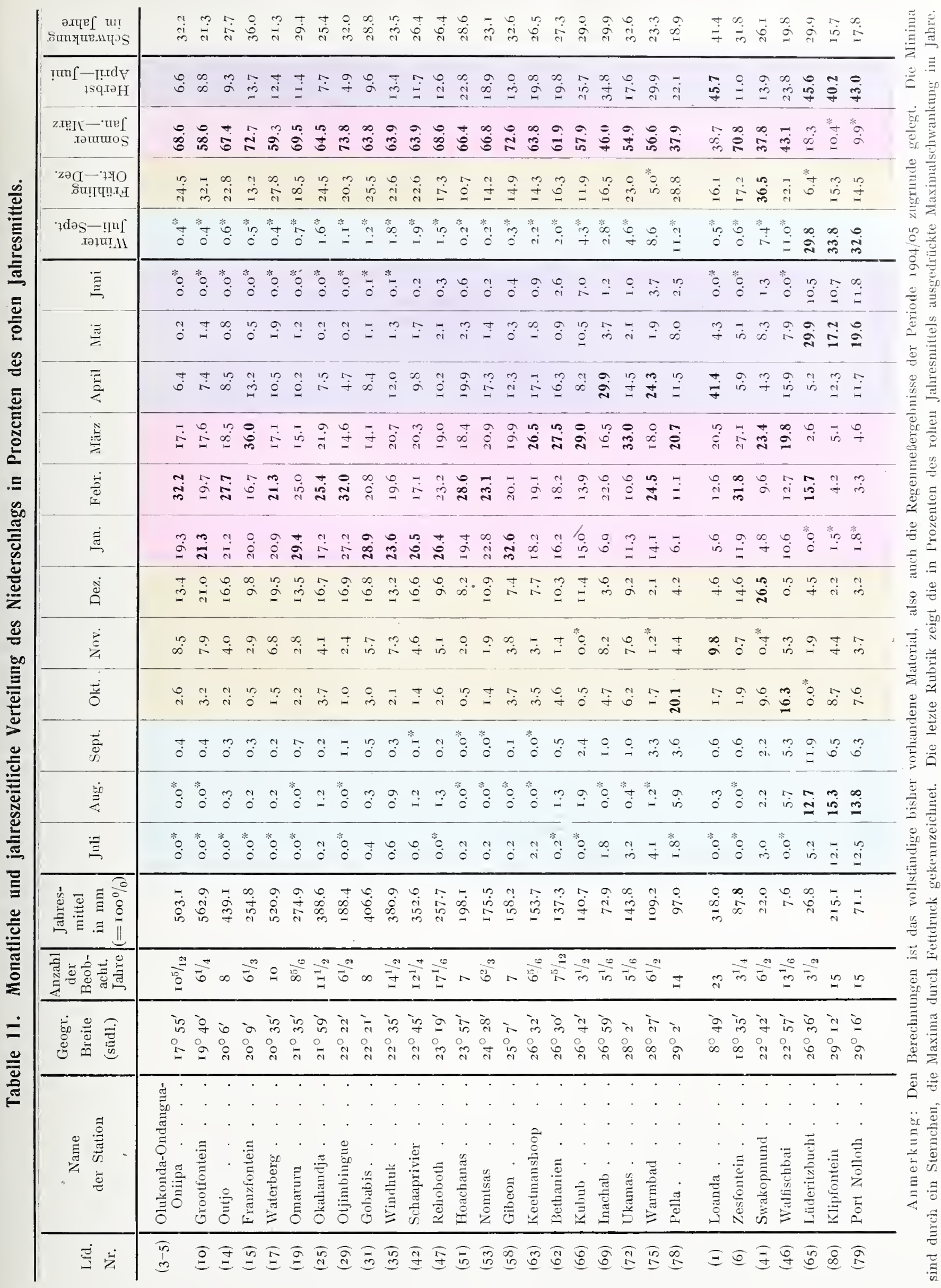


Für Loanda (1) wie auch Caconda (2) prägt sich der Typus der Zenitalregen des inneren tropischen Gürtels noch ziemlich deutlich aus: 2 Hauptmaxima des jährlichen Regenfalls um die Zeit der Zenitdurchgänge der Sonne. Allerdings tritt das erste Naximum bei Loanda (I) weniger gut, aber immer noch erkennbar, im November hervor. Dagegen lann sich bei Caconda (2), im suidlichen Hochlande Angolas gelegen, die Behauptung des zweimaligen Anwachsens der Regen während der sommerlichen Niederschlagsperiode leider nur auf die Ergebnisse der einen vorliegenden vollständigen Regenzeit I $889 / 90$ stuitzen. ${ }^{1}$ ) Hier geben sich aber die beiden sommerlichen Maxima deutlich zu erkennen (vgl. Tab. I).

Treten wir nunmehr südlich auf deutsches Gebiet über, so sehen wir diese beiden Maxima sich zu einem einzigen im Sommer zusammenziehen, welches ohne besonders erkennbare Bevorzugung auf einen der Monate Januar bis März entfällt. Dieses Gebiet erstreclit sich, das Küstenland ausgenommen (dessen Regenverteilung später noch bcsonders besprochen wird), iiber den ganzen Norden, Ambo- und Damaraland, bis ungefähr $22^{\circ} \mathrm{s}$. Br., auf den Tafeln gekennzeichnet durch dic Stationen: (3 bis 5), (10), (17), (25), (3 I).

Der Anteil der Regenmengen, welcher auf den Sommer (Januar bis März) allein entfällt, beträgt etwa 60 bis 65 v. H., derjenige der Frühlingsregen (braun) 25 bis $30 \mathrm{v}$. H., während die Herbstregen (violett) noch stark zurücktreten. Der Winter (Juli bis September) ist fast absolut trocken zu nennen. Besonders das relativ starke Auftreten der Frühlingsregen ist für dieses Gebiet charakteristisch. Allerdings ist es nicht so selır aus den Tabellen zu erkennen, da sie nur ihre relative bzw. absolute Menge zeigen, sondern aus den täglichen Aufzeichnungen und der Zahl der Regentage der einzelnen Stationen. Mit großer Sicherheit treten nämlich im nördlichen Teil Deutsch-Südwestafrikas im Oktober oder November Frühregen in ziemlicher Stärle ein, um einige Zeit anzudauern und dann wieder einer liurzen Trockenzeit von vielleicht 4 bis 5 Wochen Platz zu machen. Diese erste kleine Frühregenzcit, welche vielleicht noch ein Anklang an das in den nördlicheren tropischen Landschaften zur Zeit des ersten Zenitdurchganges der Sonne auftretende erste Regenmaximum ist, spielt bei der Aussaat einzelner Feldkulturen im nördlichen und mittleren Teile DeutschSüdwestafrikas eine große Rolle. Im November sprießt schon netues, frisches Gras empor, und diese

1) Vgl. hierzu: Georg Wa11häuser, „Die Verteilung der Jalureszeiten in südäquatorialen tropischen Afrika”. Diss. I larmstadt I904. erwähnten Frühregenschater kommen diesem und manchen jungen Frühliulturen sehr zugute. Die Hauptregen fallen jedoch erst kurz nach der bzw. um die Zeit des zweiten Zenitdurchgangs der Sonne. $\left.{ }^{1}\right)$

Diese Verhältnisse betreffs des sicheren und relativ starken Einsetzens der Frühregen werden, wie die Prozentzahlen zeigen, mehr nach Süden im Schutzgebiete wesentlich andere und bei weitem ungünstigere.

Jedenfalls stimmen alle Berichte von Reisenden und Kennern des Landes dahin überein, daß der Farmer im nördlichen Damara- und im Ambolande ziemlich bestimmt mit dem Eintreten der Frühregenzeit für seine Kulturen rechnen kann. Setzt dagegen in einem Jahre die Hauptregenzeit ungewöhnlich früh und stark ein, so kann ihn allerdings das Mißgeschick treffén, daß seine ganzen Kulturen, die besonders im Damaraland oft nur in Flußbetten oder doch Flußniederungen angepflanzt werden können, von dem abliommenden Flusse mit weggeschwemmt und so vernichtet werden. Von solchen Fällen berichten z. B. v. Bülow und Missionar Irle.

Verfolgen wir nummehr den Verlauf der Kurven der monatliclien und jahreszeitlichen Regenverteilung für das Innere des mittleren und südlichen Teiles unseres Schutzgebietes, so können wir hier einen beträchtlichen Unterschied gegenüber denjenigen für die nördlicheren Bezirke feststellen. Typisch für diesen Teil sind hier die Stationen: ( I 5$),(29),(35)$, $(42),(47),(51),(53),(68),(63),(62),(66),(69),(72),(75)$.

Im zentralen Hochlande und in den zunächst südlich davon gelegenen Landschaften haben wir allerdings noch das durchschnittliche Maximum der sommerlichen Regenperiode meist im. Januar zu suchen. Gegenüber den Frühlingsregen, die vorher ganz im Übergewicht waren, treten jetzt allmählich auch die Herbstregen etwas in der Menge hervor, und wir finden im März²) bzw. April ein zweites

1) Es diufte am Platze sein, zum besseren Verständnis der Tabellen eine kurze Übersicht der Zenitdurchgänge der Sonne für den hier in Rede stehenden Teil Südafrikaś zu geben:

\begin{tabular}{|c|c|c|c|c|c|}
\hline süd1. Br. & Zenitdu & $\begin{array}{l}\text { irchg } \\
\text { in }\end{array}$ & $\begin{array}{l}\text { nge d } \\
\text { littage }\end{array}$ & Sonne & \\
\hline 15 & November & 3. & und & Februar & 9 \\
\hline $\pm 6^{\circ}$ & $"$ & 7. & " & $"$ & 5 . \\
\hline$I 7^{\circ}$ & . & IO. &, & $n$ & 2. \\
\hline I 8 & , & I4. & , & Januar & 29. \\
\hline $19^{\circ}$ & $n$ & I 8. & $"$ & $"$ & 25 \\
\hline 20 & , & 22. & " & $"$ & 21 \\
\hline $2 I^{\circ}$ & $"$ & 27 & $"$ & $"$ & 16. \\
\hline 22 & Dezember & 3. & " & $"$ & xo. \\
\hline $23^{\circ}$ & $"$ & 12. & $"$ & $"$ & 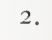 \\
\hline $23^{\circ} 27^{\prime}$ & $"$ & 22. & bis & ember & \\
\hline
\end{tabular}

2) Eigentlich »Ende März und im April«. Dies ist jedoch nur aus den täglichen Aufzeichnungen zu ersehen. Hier ist also der Herbstanfang gemeint. 
oder Teilmaximum mit großer Deutlichkeit ausgeprägt, während der Februar eine gewisse Verminderung der Niederschläge zwischen beiden Schwellen zeigt. Diese Verhältnisse sind auch für das Kaokoveld maßgebend.

Der Anteil derFrühiingsregen (braun)an der ganzen Jahresmenge beträgt durchschnittlich nur noch etwa 20 v.H., bis zu den südlichsten Strichen fällt er sogar bis auf 15 v.H. und darunter, der der Sommerregen (Januar bis März) etwa 60 v.H., im Süden nur mehr etwa $50 \mathrm{v} . \mathrm{H}$; ; dagegen steigt die relative Menge der Herbstregen (violette Farbe) von IO v.H. bis uiber 30 v. H., nach Süden bis zur Orangeflubgegend.

Besonders in den südlicheren Landschaften, in Groß-Namaland, befinden wir uns in einem Gebiete, wo durchaus nicht mehr mit Sicherheit das Eintreten der Fruhlingsregen erwartet und damit bei einer event. Frihaussaat gerechnet werden kann. Einen solchen, wenn auch vereinzelten Fall, daB die erste kleinere Frühregenzeit im Oktober-November nicht eintrat, erwähnt Dove sogar aus Damaraland und versucht dafür im folgenden eine Erklärung zu geben: »Womit übrigens das seltene Ausbleiben der Frühregen 1893 zusammenhing, ist schwer festzustellen; vielleicht aber stand der im Olitober 1893 in Windhuk fast immer wehende SO in engstem Zusammenhang mit der außergewöhnlichen Stärke und abnormen Häufigkeit desselben Windes am Kap während der diesjährigen warmen Zeit.«1)

Jedoch auch der Eintritt der Hauptregenzeit ist sehr schwankend, und es kann dies, sobald die Hauptregen ungewöhnlich spät einsetzen, den Kulturanlagen $z u$ besonders großem Nachteil gereichen. Manchmal setzen vor allem in Gr. Namaland die Hauptregen erst gegen Ende Januar oder vielleicht noch später ein. Die Bestellung mancher Früchte, wie Mais, Melonen, Kürbisse, kann dann auch erst sehr spät erfolgen. Da nun die ersten Fröste schon Ende April eintreten, so ist dann die Vegetationsperiode bis zur völligen Reife zu kurz.

Von besonderer Wichtigkeit dürfte auch eine kurze Betrachtung der durchschnittlichen Dauer und Schwankung der winterlichen Trockenzeit sein.

Im allgemeinen werden wir wohl annehmen dürfen, daß mit der abnehmenden Regenmenge nach Süden die Dauer der Trockenzeit, also der Zeit mit keinem oder doch fast gar keinem Regenfall, zu-

1) Jahresbericht über die Entwicklung der deutschen Schutzgebiete 1893: „Diese eigentümliche Verteilung des Regens gegen Ende des Jahres ist bei der Aussaat von Getreide und uberhaupt bei der Bodenbewirtschaftmng genügend zu berücksiclitigen, wenn nicht eine schlechte Ente die Folge der Nichtheachtung dieses Umstandes sein sol1. Bei einigen kleineren Kulturen in K1. Windhıtk hat man jetzt (I893) die Erfahrung gemacht, dab ein Einbeziehen der Frühregen in die Rechnimg fehlerhaft ist." nehmen wird. Jedoch gilt dies nur für die Landschaften mit weit überwiegenden Sommerregen.

In den südlichsten Landstrichen Deutsch-Südwestafrikas und über der Küstenregion erstreckt sich der jährliche Regenfall allmählich immer gleichmäßiger auf alle Monate des Jahres, so daß wir schließlich überhaupt keine ausdrückliche Trockenzeit mehr konstatieren können bzw. eher das ganze Jahr bei den geringen monatlichen Niederschlagsmengen als solche annehmen müssen. Jedenfalls tritt bei den außerordentlich geringen Niederschlagsmengen der Küstenstationen Deutsch-Südwestafrikas wenig Regelmäßigkeit hinsichtlich ihrer jahreszeitlichen Verteilung hervor. Es möge hier auch auf die Tabelle XXI in der Arbeit von Sandmann hingewiesen werden.

In dieser Beziehung wollen wir also eine bestimmte Grenze ansetzen, wann wir einen Monat als »trocken« bezeichnen, nämlich sobald seine Gesamtmenge kleiner als o.I mm bleibt, außerdem soll in Tabelle I2 auch die durchschnittliche Anzahl der Monate mit einem Regenfall unter IO $\mathrm{mm}$ angegeben werden. Weiterhin, um die Gröbe der Schwankung kennzeichnen zu können, wird sie gleichzeitig das Minimum wie auch das Maximum der Dauer der Trockenzeit während der beobachteten Zeit geben. Da die soeben besprochenen Verhältnisse über größere Flächen hin ziemlich dieselben bleiben, so möge hierbei nur eine beschränkte Anzahl von Stationen als Beispiele herangezogen werden.

Die folgende Tabelle I 2 möge nun genügen, Dauer und Schwankung der Trockenzeî́in Südwestafrika ersichtlich zu machen.

Den größten Wert hat jedenfalls die Angabe der durchschnittlichen Anzahl von Monaten mit einer Niederschlagsmenge von weniger als I $\mathrm{cm}$, da diesc der Vegetation wenig zugute kommen dürfte. Diesc Aufstellung zeigt denn auch deutlich die Zunahme der zeitlichen Dauer der Trockenzeit, je weiter wir im Binnenland von Norden nach Süden und anderseits zur Küste vorschreiten. Allerdings ändert sich dieses Verhältnis, wie wir aus dem Beispiel von Klipfontein ersehen, im Kaplande mit dem hier beginnenden Gebiete mit Niederschlägen zu allen Jahreszeiten.

Wir sahen schon an den für Gr. Namaland und besonders für seinen Süden charakteristischen Kurven der jährlichen Regenverteilung, wie das allerdings immer noch sommerliche Regenmaximum (Januar bis März) sich allmählich verbreitert und auf die Herbstmonate (violett) in cinem Teilmaximum übergreift (vgl. Diagramm 20 bis 26).

Diese Anzeichen einer gleichmäßigen Verteilung der Regen auf die einzelnen Monate des Jahres sind, wie die betreffenden Kurven bzw. Tabellenwerte 
Tabelle 12.

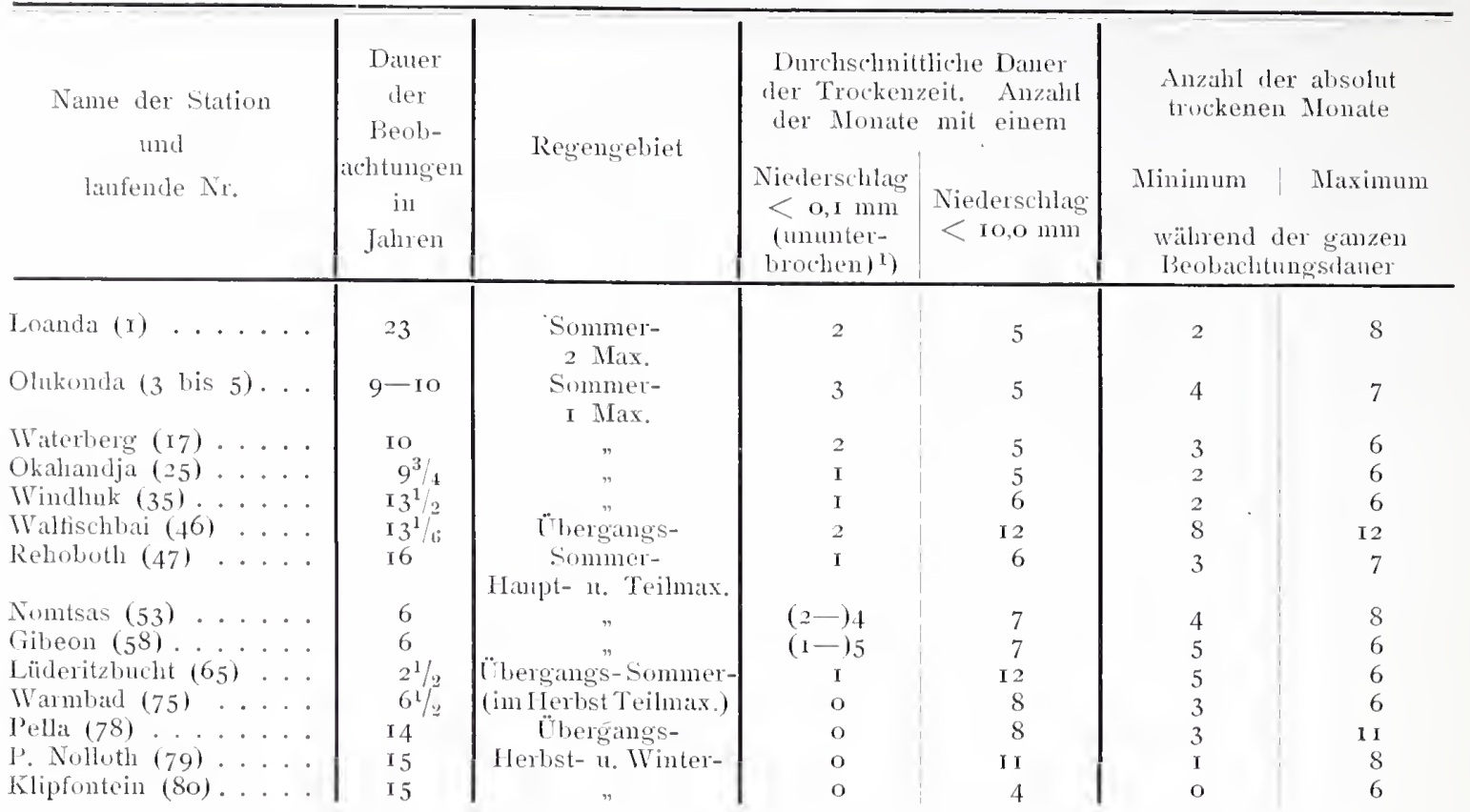

1) Diese Spalte gibt die Anzahl der Nonate mit andanernder absolnter Trockenheit (Niederschlag < o, r mm) an.

zeigen, bei weitem deutlicher ausgedrïckt bei den Stationen der Orangeflub-Landschaften und des südkichen für die vorliegende Abhandlung in Betracht konmenden Küistenlandes. Letztere Gebiete leiten in dieser Beziehung über zu den Landschaften des südwestlichen Kaplandes mit ausgesprochenem WVinterregentypus.

\section{Regenverteilung im äubersten Süden Deutsch-Südwestafrikas.}

Tabelle 13.

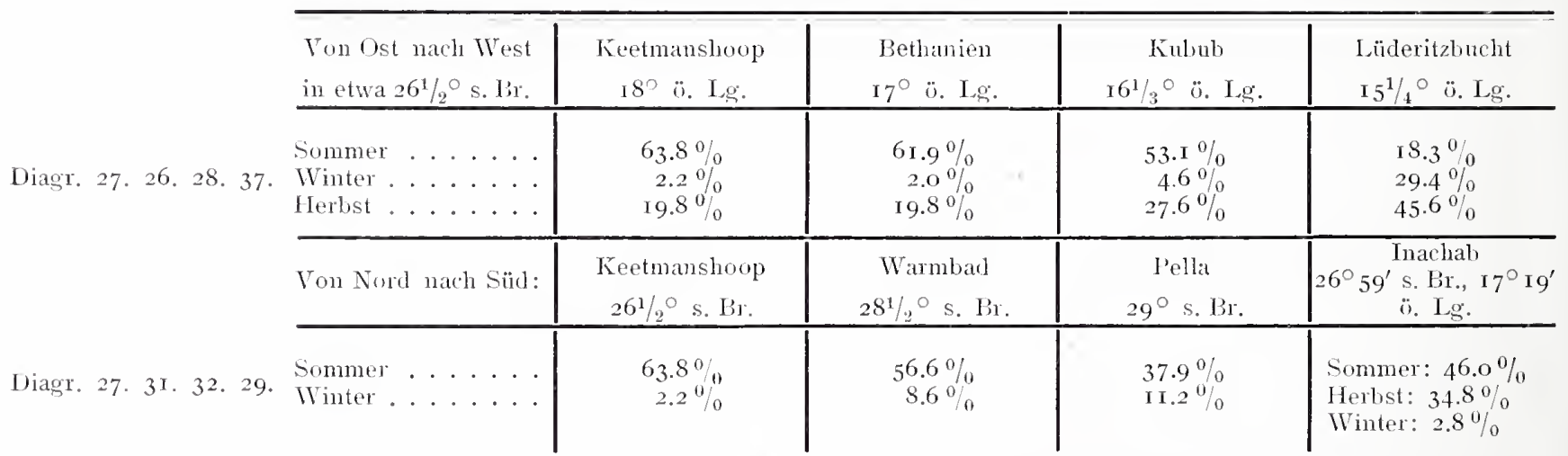

Die RegenmeBstationen des Kl. Namalandes, welches nach $\operatorname{Hann}^{1}$ ) im Winter schon regelmäßige Seeregen bei Westwinden erhält, empfangen bereits ïberwiegend Herbst- und Winterregen, was in klarer Weise an den Kurven von Klipfontein (8O) und Port Nolloth (79) hervortritt. In Prozenten der gesamten Jahressumme ausgedrïckt, hat

Klipfontein Port Nolloth

$\begin{array}{llr}\text { Sommerregen nur noch } & \text { I0.4\% } & 9.9 \% \\ \text { dagegen Winterregen } & 33.8 \% & 32.6 \% \\ \text { und Herbstregen } & 40.2 \% & 43.0 \%\end{array}$

1) J. Hann, L. V. 28, S. $6 x_{7}$
Folgende Beispiele machen es noch ersichtlicher, wie die Frühlings- (braun) und Sommerregen (rot) allmählich abnchmen, während der Anteil der Herbstund Winterregen (April bis September) an der Gesamtjahressumme nach Sïlen und Westen $\mathrm{zu}$ im südlichen Gr. Namaland immer größer wird.
Sïdlich dieser zuletzt behandelten Gebiete beginnt schon dic Region der Winterregen, für die 2. B. auch Kapstadt typisch ist; nach Supan stellt sich die monatliche Regenverteilung in MillimeterAngabe für letzteren Ort auf Grund der Beobachtungsreihe von I $84 \mathrm{I}$ bis 1894 in folgender Weise:

$$
\begin{array}{cccccc}
\text { Januar } & \text { Februar } & \text { März } & \text { April } & \text { Mai } & \text { Juni } \\
\text { I6 } & \text { I } 7 & 25 & 49 & \text { IOI } & \mathbf{1 1 8}
\end{array}
$$

Juli August Septbr. Olitbr. Novbr. Dezbr.

$\begin{array}{llllll}92 & 88 & 56 & 42 & 28 & 2 \mathrm{I}\end{array}$

Anmerkung. Auch in den verschiedenen Vegetationsperioden der Pllanzenwelt zeigt sich der Süden ron Gr. Namaland 
als ein Übergangsgebiet mit Regen zu allen Jahreszeiten. So erwähut $\mathrm{Scheuck}{ }^{1}$ ) dab in der Gegend von Aus, Tsirub (also nahe bei Kubıb [66]) "jährlich ein zweimaliges Maximum in der Entwicklung der Vegetation « zu bemerken sei, »das eine während der sommerlichen Regenzeit, in welcher die Steppenvegetation des Innern ihre Blïten entfaltet; das andere im Mai und Jıni, entsprechend der Vegetationsentwicklung der zir Kap-Flora in Beziehung stehenden Pflanzen«.

Ähulich berichtet $\operatorname{Schin} z^{2}$ ) von einer immergrünen Vegetation des Südens ınd des Küstengebietes.

Im übrigen macht im Binnenlande das sogenannte Übergangsgebiet seinen Einfluß auch nach Norden weithin geltend. - Als Beweis können hier die gelegentlichen abnormen Winterregen und Schneefälle des Binnenlandes dienen. So fielen z. B. zu Okahandja (25), Windhuk (35) und besonders Kubabub (Schaaprivier) (42) im August 1893 ganz abnorme Regengüsse. Demgegenüber führen in manchen Jahren gelegentliche Sommerregen mit östlichen Winden der Küste mehr meßbaren Niederschlag zu, als die viel öfter vorkommenden Taufälle und Nebelregen im Winter. Selbst in der Kalahari noch werden gelegentliche, wenn auch schwache Winterregen beobachtet. Zuerst hat Schinz auf sie aufmerksam gemacht.3) »Die Buschleute, die ich darüber befragte, waren keineswegs über den (Winter-) Regen als vielmehr über mich verwundert, daß mich das ihnen bekannte Ereignis in Erstaunen setzen konnte." Im selben Sinne erwähnt Passarge, $\left.{ }^{4}\right)$ daß sich im Winter (Mai bis Juli) der Südwestwind mit Winterregen in der Kalahari bemerkbar macht.

Wie weit sich dies Gebiet mit stärkeren Herbstund Winterregen, welches soeben behandelt wurde, der Küste entlang nach Norden erstreckt, kann heute bei dem geringen Beobachtungsmaterial aus dem äußersten Nordwesten Deutsch-Südwestafrikas und überhaupt des nördlicheren Küstengebietes noch nicht festgestellt werden. Ob die betreffenden Werte der jahreszeitlichen Regenverteilung von Zesfontein (6), nahe der Küiste gelegen, dann besonders Walfischbai und Swakopmund (4I) schon Anklänge an das Übergangsgebiet mit Regen zu allen Jahreszeiten geben, möge vorläufig noch dahingestellt bleiben (vgl. auch Diagr. 35 bis 37). Nach einer früheren Berechnung, welche die Meßresultate nur bis 1903/04 einschl. ausnutzen konnte, erhalten wir folgende jahreszeitliche Verteilung des Regens in Prozenten der Gesamtsumme:

1) Schenck, Dentsch-Südwestafrika; Verhandhnngen des 13. Deutschen Geographentages zu Breslan rgor, S. I64.

2) Schinz, a. a. O., S. 459 .

3) Schinz, a. a. O., S. 447.

4) S. Passarge, Die Kalahari 1904. S. 95 .
Tabelle 14.

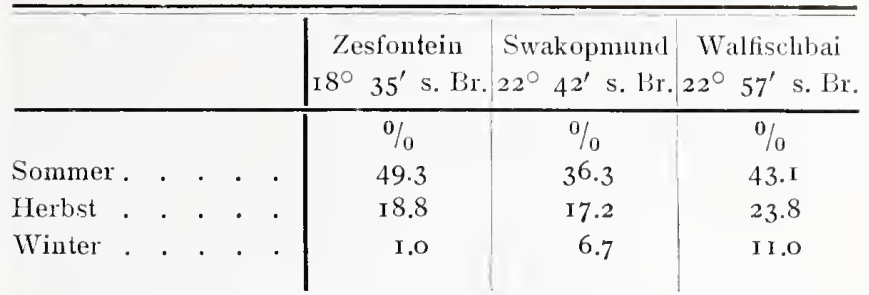

Im übrigen haben, wie schon oben bemerkt, die Prozentualwerte dieser Küstenstationen umsoweniger Bedeutung, als hier die absoluten Werte der einzelnen Jahreszeiten, ja sogar die Jahresmittel selbst so außerordentlich gering sind. Anderseits ist auch bei der großen Unregelmäßigkeit und Seltenheit, in der hier die meßbaren Niederschläge fallen, die Beobachtungsdauer der Stationen teilweise cine zu kurze, um aus den vorliegenden Werten allein bereits mit Bestimmtheit eine Zugehörigkeit zu dem Übergangsgebiete folgern zu können. Nach den neuesten Werten müßte jedoch Zesfontein unbedingt noch zu dem Sommerregengebiet gerechnet werden.

Man gewinnt iibrigens, wenn man die betreffenden Werte von Swakopmund, Walfischbai und Lüderitzbucht vergleicht, den Eindruck eines allmählich von Norden nach Süden sich vollziehenden Überganges zu immer stärker hervortretenden Winterregen: Swakopmund $\left(222 / 3^{\circ}\right.$ s. Br. $) 7,4$ v.H.; Walfischbai $(23$ s. Br.) I I,O v. H.; Lüderitzbucht $(262 / 3$ s. Br.) 29,8 v. H. Winterregen!

\section{Jährliche Schwankungen des Niederschlags.}

Allgemeine Schwankung von Jahr zu Jahr.

Für alle Fragen wirtschaftlicher Nutzbarmachung Deutsch-Südwestafrikas ist natürlich auch die Größe der jährlichen Schwankungen im Niederschlag von hoher Wichtigkeit, und eine Aufstellung, welche die Grenzwerte der Schwankungen in der von Jahr zu Jahr fallenden Regenmenge angeben könnte, würde allein schon aus praktischen Rücksichten sehr willkommen sein. Leider steht uns vorderhand im allgemeinen nicht das Beobachtungsmaterial von genügend langer Dauer zur Verfügung, um gerade in dieser Beziehung exakte und endgültige Werte berechnen zu können.

Die Schwankung der Niederschläge von Jahr zu Jahr kann sich auf drei Gesichtspunkte beziehen und dementsprechend erörtert werden: Zunächst a) auf die Veränderlichkeit betreffs Anfang und Ende der Regenzeit bzw. ihre Dauer, dann b) auf die Schwankung in der durchschnittlichen jährlichen Anzahl der Regentage und der Ergiebigkeit der einzelnen Niederschläge und c) vor allem auf die Schwankung der jährlichen Gesamtmenge des Regens. 
a) Über die durchschnittliche Dauer der Regenperioden und ihre Schwankung ist schon oben, bei der Erörterung der monatlichen und jalıreszeitlichen Regenverteilung in Deutsch-Südwestafrilia, kur\% gesprochen worden. Im allgemeinen setzen die cinzelnen Regenperioden des Binnenlandes im Norden fruiher und regelnäßiger ein, wobei die Hauptregen in den Frühsommer fallen, während sie sich im Süden weiter in den Herbst (April bis Juni) zu erstrecken pflegen. Im übrigen wird es eine schwierige Sache sein, ganz bestimmt jedesmal Anfang und Ente, also die Daner der Regenperiode feststellen zu wollen, dir auch die sonst trockene Zeit oft durch abnorme Regenfälle ausgezeichnet ist. Überhaupt ergibt diese zeitliche Abgrenzung nur geringe Unterschiede zwischen den Landschaften des Nordens und Süidens. Eine kleine Tabelle 161) möge dies zeigen:

\begin{tabular}{|c|c|c|c|c|}
\hline \multirow[t]{2}{*}{$\begin{array}{l}\text { Regen- } \\
\text { periole: }\end{array}$} & \multicolumn{2}{|c|}{$\begin{array}{l}\text { Waterbers } \\
\left.20^{\circ} \text { fo' }^{\prime} \mathrm{s} \cdot \mathrm{Br} .\right)\end{array}$} & \multicolumn{2}{|c|}{$\begin{array}{l}\text { Rehoboth } \\
\left(23^{\prime \prime} 19^{\prime} \text { s. Br.) }\right.\end{array}$} \\
\hline & nfang & Encle & Infang & Ende \\
\hline 107 & - & - & - & I千. \\
\hline & & 6. April & - Okit. & oril \\
\hline 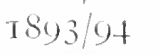 & Olit. & 6. Mai & 28. Okt. & 5. \\
\hline & 16. Okt. & 27. Apri & 17. Olit. & 2. Mai \\
\hline & 30. Olit. & 21. Mili & 4. Nov. & 21. Apri \\
\hline & 4. $\mathrm{Nc}$ & IS. Mai & 7. Olit. & 9. Мai \\
\hline $307 / 98$ & I 5. Olit. & - & 26. Nov. & I. Мai \\
\hline 590 (99 & im Okt. & 12. Mai & If. Nov. & - \\
\hline
\end{tabular}

Die groißten Schwankungen reigt hier allerdings der Anfangstermin für die Regenperioden von Rehoboth; deren Maximalwert allein für diese relativ kurze Reihe beträgt schon etwa 2 Monate: 2. Oktober I 892/26. November 1897. Auf die Dauer der Trockenzeit und ihre Schwanlinung ist schon oben²) näher eingegangen worden.

b) Die Schwankung in der Zahl der jährlichen Regentage darf wohl, soweit die Verlältnisse des Binnenlandes von Deutsch-Sëdwestafrika nur in Betracht kommen, als analog der Veränderlichlieit der jährlich fallenden Regenmengen angenommen werden. Da in einem besonderen späteren Kapitel die durchschnittliche jährliche Anzahl der Regentage sowie die Ergiebigkeit und die Art der einzelnen Niederschläge etwas eingehender besprochen werden sollen, so möge dann auch die Frage nach der Schwankung der Zahl der Niederschlagstage miterörtert und daher hier einstweilen übergangen werden. Leider besitzen

1) Die täglichen Aufzeichnumgen der Regenbeobachtmngen, anf Grund deren diese Tabelle aufgestellt werden konnte, wwilen mir fremdliclsst im Mlantskript überlassen, nnd zwar die von Waterberg durch Herm Prof. Dove (Jena), die ron Rehoboth durch das Gouvernement in Windhuk.

2) S. oben: S. 58 . Tab. 12 . wir auch hier bisher das genügende exalte Beobachtungsmaterial in allgemeincn noch nicht in der Vollständigkeit, um «u cinem definitiven Schluß kommen zu können.

c) Von weit größerer praktischer Bedeutung als alle diese letzten Erörterungen ist die Frage nach der jährlichen Schwankung in der Menge der fallenden Regen.

Gerade in einem regenarmen Lande machen sich diese Schwankungen im jährlichen Niederschlag natiurlich schon von vornherein weit bemerlibarer und, sobald es sich um negative (unterhalb des Mittels) handelt, in ihrer Wirliung auf die Vegetation und das gesamte Leben viel cmpfindlicher fühlbar als in unseren Breiten. Je crheblicher sie sind, um so unsicherer werden natiirlich auch alle landwirtschaftlichen Unternehmungen. Die Wichtigkeit der Aufstellung von exaliten Zahlenwerten über die Größe der jährlichen Schwankung, besonders im Minblick auf den Ackerbau und die Viehzucht, liegt daher auf der lland.

Eine graphische Darstellung der Prozentzahlen des jährlichen Regenfalls auf eincr Reihe leutschsüdwestafrikanischer RegenmeBstationen (s. Diagr. I bis Io) führt uns diese Schwankungen, allerdings meist nur für einen ziemlich beschränliten Zeitraum (die meisten der betreffenden Diagramme erstrecken sich nur auf einen Zeitraum von 6 bis ro Jahren, nur wenige auf noch längere Perioden), in ihrem Verhältnis zum Normalmittel vor Augen. - Zunächst sehen wir allgemein nasse ${ }^{1}$ ) mit trockenen Jahren abwechseln; jedoch scheint die Anzahl der trockeneren Jahre in der Zeit der betreffenden Beobachtungsreihen gegenüber der der feuchteren überall zu überwiegren. Die positive Schwankung vom Normalmittel der wenigeren feuchten Jahre muf also durchschnittlich größer als dic negative der trockeneren Jahre sein.

Deutlicher wird diese Tatsache durch eine Tabelle gezeigt werden können. (Tab. 15.)

Die einzelnen Zahlen stellen hier nicht die Prozentualwerte der von Jahr zu Jahr gefallenen Regenmengen vom Normalmittel $(\mathrm{N}=100 \mathrm{v} . \mathrm{H}$.) dar, sondern die jeweilige ( + oder --) Schwankungsgröße vom Normalmittel. Die positiven Schwankungen, welche also feuchtere Jahre kennzeichnen, sind zur Unterscheidung von den negativen fett gedruckt. Außerdem ist gleichzeitig das Maximum der Schwankung während der beobachteten Periode angegeben. Es wird gefunden durch Addition des

1) Unter einem »nassen « Jahre ist ein solches verstanden, dessen Niederschlagsmenge größer oder gleich dem Normalmittel der betreffenden Regenmebstation ist. Alle anderen sollen »trockene" Jahre heifen. 
größten Wertes der positiven und des der negativen Schwankungen. - Die jeweiligen Prozentualwerte, welche auf den Diagrammen I bis Io zur Darstellung gebracht werden, würde man also wieder erhalten, sobald man die einzelnen Zahlenwerte zu IOO addiert.

Erstrecken sich diese Prozentzahlen der einzelnen Beobachtungsjahre mit vollständigen Summen allerdings meist auch nur auf verhältnismäßig liurze Perioden, so sehen wir doch schon die absoluten Schwankungsdifferenzen mit ausdrücklicher Tendenz der Küste und dem Süden unseres Schutzgebietes zu steigen, während sie mit der jährlich zunehmenden Regenmenge nach Norden und Nordosten hin kontinuierlich abnimmt. Außerdem ist zu berücksichtigen, wie sich ja auch aus den soeben gefundenen Tatsachen ergibt, daß die in vorliegender Abhandlung allenthalben angeführten und $z u$ Berechnungen herangezogenen Normalmittelwerte der jährlichen Regenmengen eben nur als »Mittel werte, nicht aber als die durchschnittlich bzw. häufigst vorkommenden sogenannten Scheitelwerte betrachtet werden dürfen.

Die Scheitelwerte ${ }^{1}$ ) liegen, wie wir soeben sahen, unterhalb der betreffenden Normalmittel.

Von größtem Werte, besonders für landwirtschaftliche Interessen, ist jedoch eine exalite Angabe des Grenzwertes der in der Menge der jährlich fallenden Niederschläge vorkommenden Schwankungen.

Da die einzelnen Stationen Südwestafrikas teilweise in oft ganz verschiedenen Perioden, teilweise aber auch gleichzeitig Regenbeobachtungen angestellt haben, ließ es sich ermöglichen, längere fortlaufende Reihen der jährlichen Prozentzaillen aufzustellen, indem ich immer mehrere Stationen eines Landstriches mit ihren Werten zu einer für einen größeren Bezirk typischen Idealstation bzw. zur Gewinnung eines Durchschnittsbildes der Verhältnisse einer solchen zusammenfaßte.

Das arithmetische Mittel aus der Summe der Normalmittelwerte der zu diesem Zwecke jedesmal vereinigten Stationen bildet demnach offenbar einen Idealwert der durchschnittlich jährrlich über einen größeren Bezirk fallenden Regenmengen. Setzt man letzteren Idealmittelwert gleich IOO v. H., so können die ähnlich gebildeten, fortlaufenden jährlichen Prozentualwerte durch eine Umrechnung schnell die von Jahr zu Jahr gefallene absolute Niederschlagshöhe liefern.

Wie schon oben (s. S. 29ff.) bei der Untersuchung der Möglichkeit der Redultionen gezeigt

1) Über »Scheitelwerte« vgl. H. Meyer, Anleitung zur Bearbeitung meteorolog. Beobachtungen. Berlin is9i.

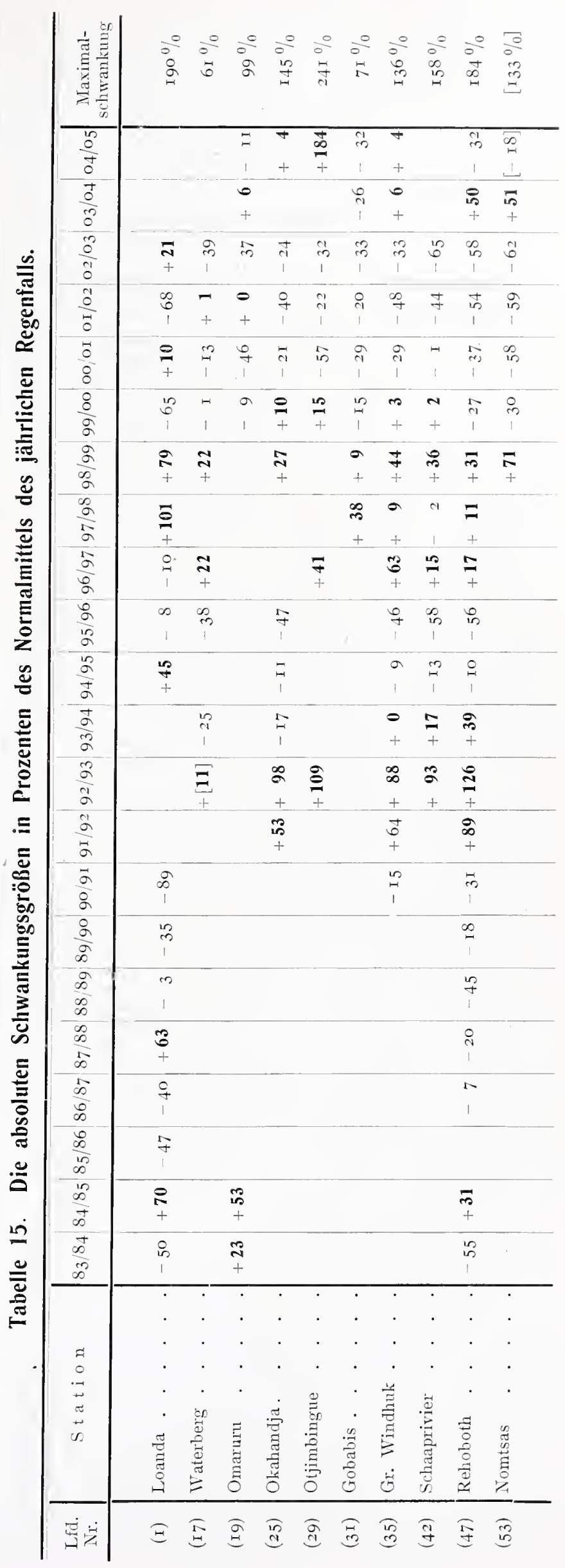


wurde, bleiben sich diese Prozentualwerte für nicht allzuweit voneinander entfernte Orte mit klimatisch ähnlichen Verhältnissen in den einzelnen aufeinander folgenden Jahren relativ ziemlich gleich.

In Tabelle 17 habe ich nummehr in solchem Sinne cine Zusammenstellung der einzelnen Stationen der gcographischen Breite nach versucht (s. w. u.), und zwar immer für. Streifen von je zwei Breitengraden.

Es wurden dabei dic Beobachtungsergebnisse der sämtlichen in einem solchen Streifen gelegenen Stationen zusammengefaBt und aus den für jedes Jahr vorliegenden Werten jedesmal das Mittel genommen. Schlieblich erhalten wir in dieser Weise Reihen mit den jährlichen Ideal-Prozentualwerten, dic sich über eine durchschnittlich schon relativ große Inzahl von Jahren erstrecken und uns die jährliche Schwankungsgröbe wie gleichzeitig auch das Maximum, also einen vorläufigen Grenzwert, der Schwankung angeben.

Die Stationen des deutschen Küstengebietes sind von diesen Zusammenstellungen aus besonderen Gründen ausgeschlossen worden, hauptsächlich wegen des geringeren Wertes ihrer Prozentzahlen (infolge der auBerordentlich geringen durchschnittlichen jährlichen Regenmengen).

Nachdem wir noch die cinzehnen Zonen mit den ungefähr zutreffenden typischen Landschaftsnamen belegt haben, erhalten wir somit folgende Zusammenstellungen von 8 Zonen.

1. Zone: $17 \frac{1}{2}$ bis 20 s. Br.: Amboland. Onipa (3) - Ondangua (4) - Olukonda (5), Amutoni (7), Okankwejo (8), Gaub (9), Grootfontein (IO), Otawi (II), Otjituo (12).

II. Zone: 20 bis 22 s. Br.: Nördliches Damaraland.

Naidaus (I 3), Outjo (I4), Franzfontein (I5), Oketoweni (16), Otjikango (IS), Waterberg (I7), Omaruru (I9), Oliombahe (2I), Gr. Spitzkoppje (22), Karibib (23), Wihhelmstal (24), Olkahandja (25).

III. Zone: 22 bis 24 s. Br.: Südliches Damaraund nördliches Gr. Namaland.

Kubas (27), Otjiscuva (28), Otjimbingue (29), Gobabis (31), Neudamm (32), Seeis (33), Tsaobis (34), Windhuk (35), Kl. Windhuk (36), Hohe Warte (37), Oas (38), Heusis (39), Jakalswater (40), Schaaprivier (42), Haris (43), Kowas (44), Hatsamas (45), Rehoboth (47), Nauchas (49), Aminuis (50), Hoachanas (5I).

IV. Zone: 24 bis $26^{\circ} \mathrm{s}$. Br.: Mittlerer Teil von Gr. Namaland.

Kuis (52), Nomtsas (53), Mariental (54), Gochas (55), Maltahöhe (56), Gibeon (58), Kujas (60), Berseba $(6 \mathrm{I})$.
V. Zone: 26 bis $28^{\circ}$ s. Br.: Süden von Gr. Namaland.

Bethanien (62), Keetmanshoop (63), Hasuur (64), Kubub (66), Sandverhaar (67)-Seeheim (68), Inachab (69), Kanas (70).

VI. Zone: 28 bis $30^{\circ}$ s. Br.: Das Orangeflußgebiet nach Osten bis etwa $2 \mathrm{I}^{1} /_{2}^{\circ} \ddot{0}$. L.

Ukamas (72), The Halt (71), Uhabis (73), Udabis (74), Narmbad (75), Pella (78), Upington (76), Trooilapsan (77).

VII. Zone: 27 bis $3012^{\circ}$ s. Br.: Das Orangeflußgebiet von etwa 2 I bis $24 \frac{1}{2}{ }^{\circ}$ ö. L.

Vrybury (94), Griquatown (96), Dummurry (95), Kenhardt (83), Prieslia (87), Brandvley (90), Van Wyks Vley (9I).

VIII. Zone: 29 bis $311^{\circ}$ s. Br.: Das Küstengebiet des nordwestlichen Kaplandes.

Port Nolloth (79), Klipfontein (80), Kraaifontein (Steinkopf) (8I), O'oliep (85), Concordia (84), Springbokfontein (86), Lilyfontein (88), Garies (89), Ebenezer (92), Van Rhyns Dorp (93).

Als Idealmittel der jährlich über diesen Zonen fallenden Regrenmengen wurden gefunden:

\begin{tabular}{|c|c|c|c|c|}
\hline I. & Zone: & $N=585$ & $m m$ & Niederschlag \\
\hline II. &, & $\mathrm{N}=340$ & , & , \\
\hline III. & , & $N=294$ & , & , \\
\hline IV. & , & $\mathrm{N}=\mathrm{I} 8 \mathrm{O}$ & , & , \\
\hline $\mathrm{V}$. & , & $\mathrm{N}=\mathrm{I} 20$ & , & " \\
\hline VI. & , & $N=14^{6}$ & , & ", \\
\hline VII. & ", & $N=300$ & , & ", \\
\hline V1II. & , & $\mathrm{N}=\mathrm{I} 9 \mathrm{I}$ & ," & , \\
\hline
\end{tabular}

In den nummelnr folgenden Aufstellungen über die Schwankungen im jährlichen Regentall ist das jedesmalige Normalmittel für die einzelnen Zonen $\mathrm{N}$ gleich IOO v. H. gesetzt.

Bilden wir nun die Prozentualwerte der von Jahr zu Jahr über den einzelnen Zonen gefallenen Regenmengen, so läßt sich aus ihnen die jährliche Schwankung wie auch das Maximum der Schwankungen, d. i. die Differenz des größten und kileinsten Prozentualwertes während der ganzen Beobachtungsdater, sofort ersehen.

In der nun folgenden Tabelle 17 über diese Werte sind dicjenigen über IOO v. H., welche also feuchte Jahre kennzeichnen, in gewöhnlichen Ziffern. Der Maximalwert jeder Zone ist durch fette Ziffern, der Minimalwert jedesmal durch fette Kursivziffern gekennzeichnet. Die Werte unter IOO v. H. sind in gewöhnlichen Kursivziffern. Außerdem ist der Grenzwert der Schwankung (Differenz zwischen Maximum und Minimum) gegeben. 


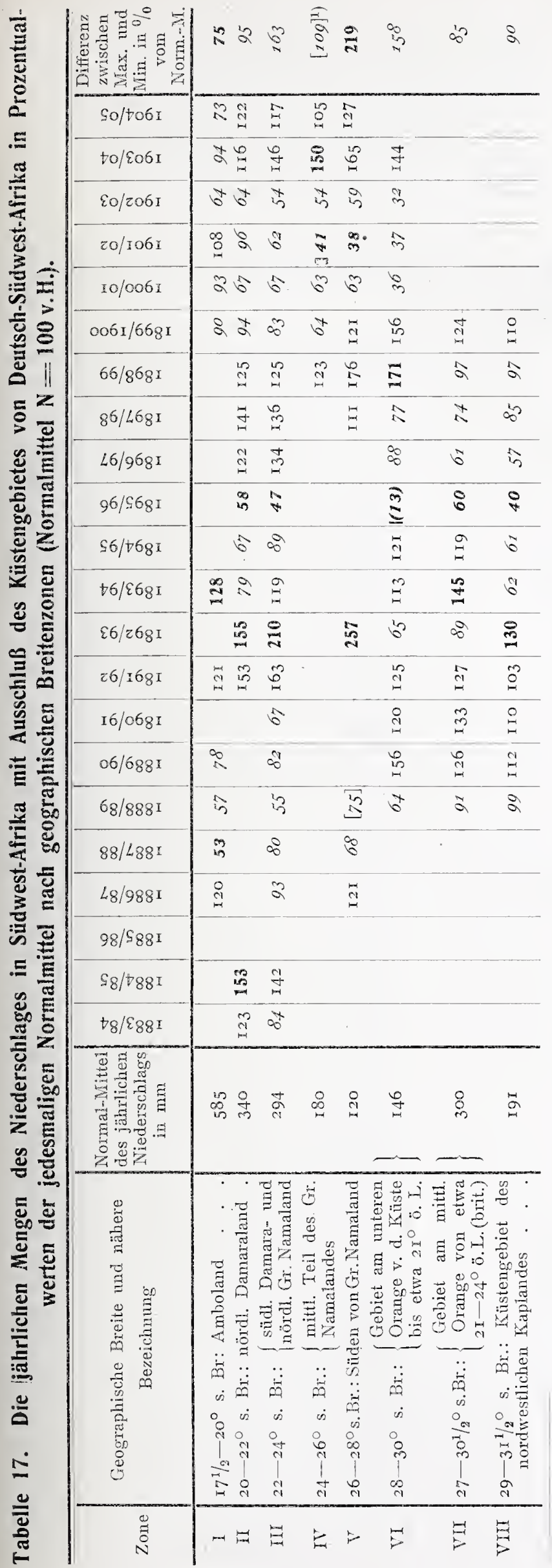

Mitt. von Forschungsreisenden, XX. Band I.
Ehe wir an die Verwertung vorstehender Auf stellungen der Tabelle it gehen, darf allerdings nicht unerwähnt bleiben, daß die einzelnen Prozentualjahreswerte untereinander nicht immer den gleichen Wert besitzen, da sie ja auch stets aus ungleicher Anzahl von Beobachtungssummen gebildet wurden. Auch der jedesmalige Grenzwert der Schwankung gewinnt naturgemäß mit steigender Beobachtungs dauer eine immer größere Bedeutung. Trotzdem darf wohl vorliegende Tabelle, deren Daten zur besseren Veranschaulichung auch graphisch dargestellt sind (Diagramm 40 bis 46), einen wenn auch nur vorläufigen Wert beanspruchen.

Der Minimalwert der Zone VI für I 895/96 mit I 3 v. H. des Normalmittels ist nur auf die vorliegenden Ergebnisse von Pella (78) gestützt. Doch dürfte auch ihm nach den auf Seite 45 gemachten Bemerkungen eine volle Bedeutung zugemessen werden.

Betrachten wir nunmehr die durch Tabelle I7 gegebenen absoluten Maxima der Schwankungen im jährlichen Regenfall, so erkennen wir in der Richtung von Norden nach Süden eine deutliche stetige Zunahme der Schwankungsgrenzwerte, d.h. der Differenz zwischen dem höchsten und niedrigsten Prozentualwerte der jährlich gefallenen Niederschlagsmengen; und zwar erstreckt sich diese Zunahme bis in die Zone $V$, südliches Gr. Namaland.

Allerdings finden wir eine zunächst scheinbare sprunghafte Abnahme der Schwankung im mittleren Teile des Gr. Namalandes (Zone IV). Wie wir sofort sehen werden, ist sie jedoch keine tatsächliche, sondern wohl nur durch die geringere Dauer der Beobachtungen bedingt. Nehmen wir nämlich ein relativ gleiches Verhalten in den jährlichen Schwankungen des Regenfalls für größere engbenachbarte Gebiete, welche durch ähnliche oder sogar gleiche orographische und klimatische Verhältnisse ausgezeichnet sind, an - und auf der Richtigkeit dieser Annahme beruht ja das in vorliegender Abhandlung allerorten zur Anwendung gekommene Reduktionsverfahren -, so dürfen wir auch hier wohl wieder die Ermittlung eines Normalwertes durch Redultion walten lassen.

Die Prozentualwerte 'der Zone IV erstrecken sich über die Regenperioden $1898 / 99$ bis $1903 / 04$ und ergeben eine absolute Schwankungsgröße von ro9 v. H. Läge für Zone III (südliches Damaraund nördliches Namaland) auch nur dieselbe kurze Beobachtungsdauer vor, so erhielten wir hier als Grenzwert oder Maximalschwankung nur 92 v. H. vom Normalnittel dieser Zone. Die weit längere Reihe ihrer Beobachtungsjahre liefert jedoch eine solche von $16_{3}$ v. H. Setzen wir nunmehr in Pro- 
portion 92: $163=109: x$, so erhalten wir als Grenzwert der Schwankungen in den jährlich fallenden Regenmengen 193 v.H.

Entsprechend der Abnahme der durchschnittlich jährlich niedergehenden Regenmengen nelumen also von Amboland nach Sirlen bis zum südlichen Gr. Namaland ihre absoluten Schwankungs- grenzwerte $z u$, von 75 bis 210 v. H. des Jahres. mittels. Von hier aus werden sie wieder kleiner, und zwar einerseits nach dem britischen Landinnern \%u mit wachsender jährlicher Regenhöhe, anderseits im Kiistengebiet gemildert durch den in jeder meteorologischen Beziehung ausgrleichenden Einfluß des Seelilimas.

Tabelle 18. Die Extreme der tatsächlich beobachteten Jahresregenmengeı einer größeren Anzahl Stationen in Südwestafrika.

( $M$ axim $11 \mathrm{~m}$ und $M$ in in $u m$ in $m m$.)

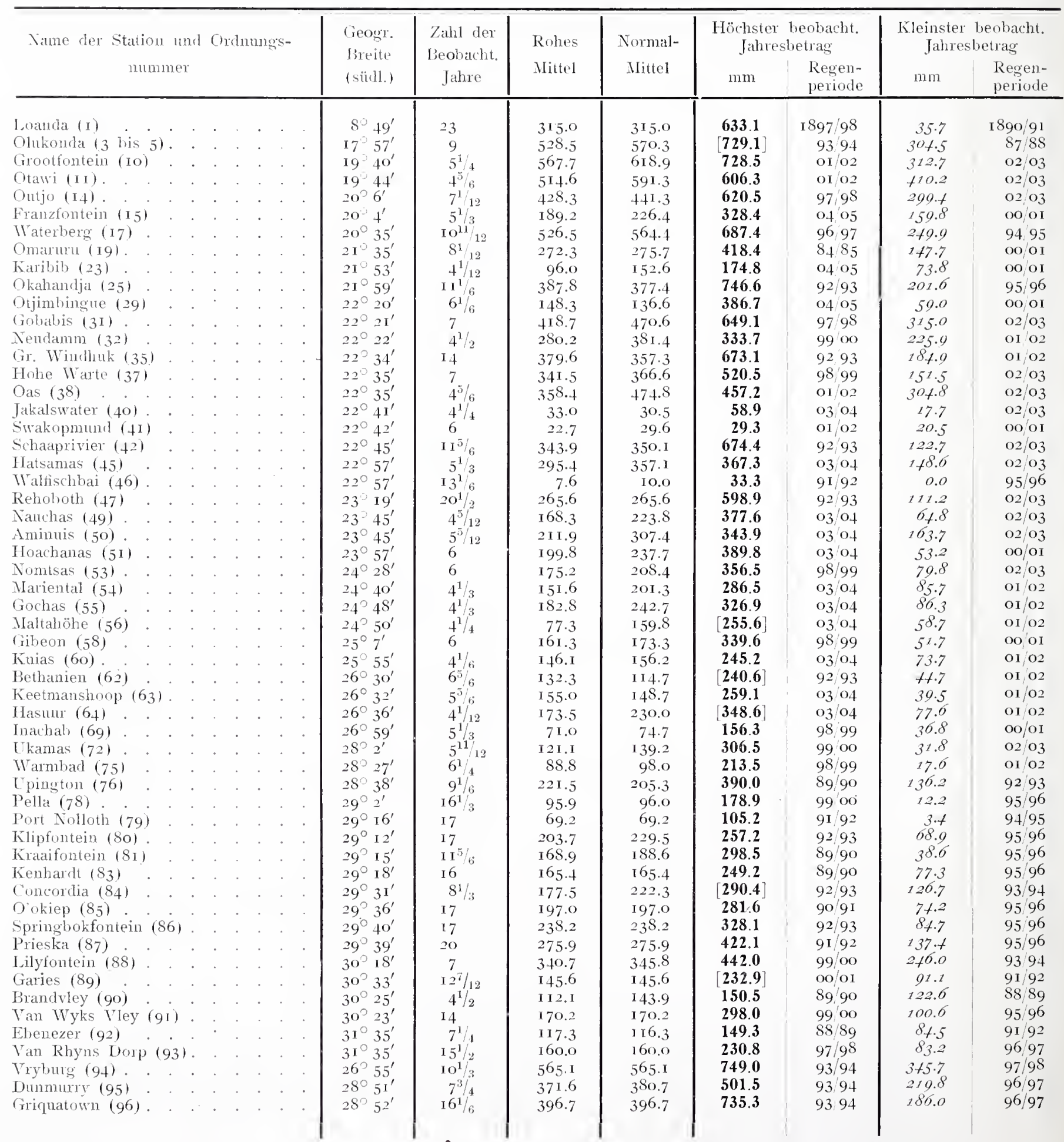


Während die Differenz von Maximal- und Minimalprozentualwert in dem westichen Orangeflußgebiet noch i $5 \mathrm{~S}$ v. H. vom Jahresmittel beträgt, ist sie in Binnenlancle weiter östlich (Betschuanaund Griqualand) schon auf 85 v. H. und im Küstengebiet auf 90 v. H. gefallen.

Für die kulturelle Nutzbarmachung DeutschSüdwestafrikas würde es wolıl auch von einigem Interesse sein, die Grenzwerte der jährlichen Schwankung in der Regenmenge bei den einzelnen Stationen selbst zu kennen. Allerdings haben diese Daten bei der durchschnittlich nur kurzen Dauer der Beobachtungen auch nur einen vorläufig genügenden Wert. Ailein Rehoboth (47) und Loanda (I), letzteres nur zur Ergänzung des Bildes mit herangezogen, dürften vielleicht eine Ausnahme machen. Für Rehoboth (47), in oben erwähnter ZoneIII gelegen, finden sich die Grenzwerte: Regenperiode I892/93: $599 \mathrm{~mm}=226$ v. H. gegenüber 1902/03: I I $\mathrm{mm}=42 \mathrm{v}$. H. des Normalmittels $\mathrm{N}=265.6 \mathrm{~mm}$ $=\mathrm{I} 00 \mathrm{v} . \mathrm{H}$. Diese Werte würden also eine Maximalschwankung von I 84 v. H. für die 20 jährige Beobachtungsdauer Rehoboths ergeben. - Für Loanda (I) mit 23jähriger Beobachtungsdauer und dem Normalmittel: $\mathrm{N}=315.0 \mathrm{~mm}=\mathrm{IOO}$ v. H. ergeben sich die Grenzwerte: Regenperiode 1890/91: $36 \mathrm{~mm}=1 \mathrm{I}$ v. H. gegenüber $633 \mathrm{~mm}=201 \mathrm{v}$. H. für I $897 / 98$. Wir erhalten hier also eine Maximalschwankung von I9O v. $\mathrm{H}$.

Bei der großen Bedeutung, welche die Kenntnis dieser Schwankungen für alle landwirtschaftlichen Unternehmungen und noch dazu in einem relativ regenarmen Lande besitzt, wird jedoch auch schon eine Aufstellung willkommen sein, die sich auf Beobachtungsergebnisse kürzerer Perioden stützen kann. Als untere Grenze, ein vorläufig genügendes Bild bieten zu können, habe ich eine Mindestbeobachtungsdauer von 4 Jahren angenommen.

Zur klaren Übersicht möge daher noch eine Tabelle von allen Regenmeßstationen mit mindestens 4jähriger Beobachtungsdauer folgen, welche in $\mathrm{mm}$ Angabe die Extreme der tatsächlich beobachteten Jahresmengen zeigt (s. Tab. I8).

Es ist hier nicht der geeignete Ort, aus den soeben gegebenen Tatsachen weitere Schlüsse zu ziehen betreffend ihre Wirkung auf die Vegetationsfähigkeit des Landes oder überhaupt seinen Kulturwert. Wohl aber muß auf die so außerordentlich beträchtlichen Schwankungen im jährlichen Regenfall im südlichen Teile des Schutzgebietes hingewiesen werden. Stehen sie doch, soweit die Beobachtungsdaten einen Schluß zu ziehen gestatten, fast beispiellos da und müssen so für alle Zeiten bei allen landwirtschaftlichen Unternehmungen ein gewichtiges Wort mitreden.

\section{Zur Frage einer etwaigen Periodizität} in den Schwankungen des jährlichen Niederschlags.

Wir liommen nunmelır $\%$ der pralitisch wie theoretisch ebenfalls sehr wichtigen Frage, ob vielleicht auf Grund unseres Regenmeßmaterials eine bestimmte Periodizität in der Schwankung der Niederschlagsverhältnisse in Deutsch-Südwestafrika sich erkennen läßt, oder ob die Schwankungen von Jahr zu Jahr sich vollständig regellos folgen.

Leider erstrecken sich die hier vorliegenden längsten Beobachtungsreihen nur auf eine Periode von etwa 20 Jahren.

Trotzdem erkennen wir schon in unseren kurzen Reihen (s. die graphische Darstellung [Diagr. I bis IO] mit den jährlichen Prozentzahlen der fortlaufend gefallenen Regenmengen) ein ziemlich gleichmäbiges und gleichzeitiges Auf- und Abschwellen der einzelnen Werte. In diesen wie auch an den soeben behandelten zusammenfassenden Kurven bestimmter Breitenzonen Deutsch-Südwestafrikas (s. Seite 63, Diagramme 40 bis 46 ) können wir mit verhältnismäßiger Bestimmtheit zunächst drei ziemlich gleichzeitig fallende Maxima des Regenfalls konstatieren. Dieselben fallen auf Anfang der I880er sowic I $890 e r$ Jahre und 1903/04 bzw. 1904/05.

Nach verschiedenen Berichten, wie z. B. von A. v. Danckelman, Irle u. a., waren die gefallenen Regenmengen in den Regenperioden I 883/84, I 882/83 abnorm groß für ganz Südwestafrika. Das zweite Maximum fällt, wie fast alle Kurven zeigen, auf die Regenperiode 1892/93; dann sind wieder 1903/O4 und 1904/05 große Nengen Regen gefallen. Zwischen die beiden letzten Maxima schiebt sich noch ein kleineres viertes etwa um I897/98 ein. Es ist zu beachten, daß dasselbe nach Süden zu etwas später auftritt als in Norden. Depressionen sind, und zwar ebenso für alle Zonen annähernd gleichzeitig und gleichmäßig, für die Jahre um die Regenperioden I887/88, I895/96, I901/02 festzustellen. Aus dem dreimaligen besonderen Anschwellen der jährlichen Niederschlagsmengen innerhalb der angegebenen Zeitdauer könnte man nun vielleicht, analog den I I jährigen Klimaschwankungen in anderen Breiten, auf eine etwa I I jährige Periodizität in den Schwankungen des jährlichen Niederschlages schließen. Jedoch dürfte in dieser Hinsicht in Anbetracht der meist erst relativ kurzen Beobachtungsreihen, die bisher vorliegen, vorderhand noch große Vorsicht geboten sein. Aus dem jetzigen Zahlenmaterial allein dürfte vorläufig eine besondere Tendenz in dieser Beziehung wohl nicht zu konstatieren sein. Auch auf die rein aus der Erinnerung und ohne Grundlage wirklicher Messungen oder doch genauerer Aufzeichnungen stammenden Angaben 
von Eingeborenen und langeingesessenen Europäern, welche ebenfalls auf eine Periodizität der Niederschlagsverhältnisse von etwa Io bzw. 30 Jahren hinzudeuten scheinen, kann in dieser Richtung nicht allzuviel gegeben werden.

Doch möge der Bedeutung der Sache halber in folgendem eine Zusammenstellung aus zwei Berichten des Missionars Irle aus Otjosazu (26) folgen, da sie vielleicht sonst für die Wissenschaft verloren gehen wiirden. Diese Aufstellung ist zwei ziemlich gleichlautenden Schreiben des betreffenden Missionars entnommen, von denen das eine an Herrn Prof. Th. Réhbock in Karlsruhe, das andere an das Gouvernement in Gr. Windhuk gerichtet ist; beide wurden mir von zuständiger Seite freundlichst zur Verfügung gestellt. Von Bedeutung erscheint mir auch die eigene Notiz des Missionars, der selbst schon etwa 4o Jahre in Deutsch-Siidwestafrika tätig ist und daher als ein guter Kenner der clortigen Verhältnisse angesehen werlen darf, welche sich am Schlusse seiner alten Missionsberichten teilweise entnommenen Aufzeichnungen findet.

Im übrigen möge noch bemerlit sein, dałs ich im folgenden diese Aufzeichnungen möglichst wortgetreu wiedergebe.

Ferner sind der lilareren Übersicht halber in lrles Bericht hier die Jahre mit stärkeren Regenfällen durch fette Ziffern, die mit geringeren durch Kursivziffern gekennzeichnet.

Regenbeobachtungen in Otjosazu (26) mit

Vorbemerkungen aus alten Zeiten"von Mlissionar Irle.

1761, 1792, 1833 duirre, fast regenlose Jahre (nach O. Dappers's WVerk iiber Suiclafrika, holländisch).

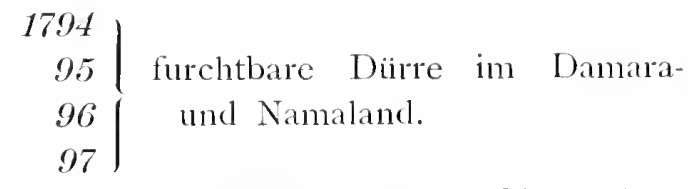

große Wasserfluten. Nach Aussagen alter hundertjähriger Herero mußten die Bewohner Oka31 handjas auf die Berge flüchten; 32 das ganze Tal eine Wasserflut. 33 Die Quelle von Omburo floB aus 34 bis Omaruru, bis Okombahe und weiter. Damals wurden dort im Omaruru noch Scekühe gefunden.

36

37 (nach Schinz floß der Kuisib bis ins Meer) s. u. S. 68.

38

39

1840

44 Generalılüre, Missionare Hahn und Rath muBten wegen Wassermangel Okahandja verlassen und nach Otjikango flüchten.

45

46 Fürchterliche Dürre in Kl. Nama47 land, Steinkopf und Umgegend, und hier.

48 (nach Schinz flob der Kuisib

49 bis ins Meer) s. u. S. 68.

I 850

$5 \mathrm{I}$

52 (nach Schinz flob der Kuisib bis ins Meer) s. u. S. 68.

53

Fluten; der jetzige Regierungsgarten auf Otjimbingue war

54

55

56

57

58

8

59

1860

1861 allgemeine große Ausnahme mit Regen im ganzen Landle.

62

63

64 (nach Schinz Kuisib bis ins Meer abgekommen) s. u. S. 68.

65 Große Dürre, besonders im

66 Westen, Otjimbingue. Der

67 Swakop hatte drei Jahre nicht 68 geflossen.

69 im Mär\% find Irle das Wasser erst in 7 Fuß tiefen Löchern im Missionsgarten. Gegen Ende des Jahres gute Regen.

1870

71 die Regen blieben aus bis i8. III., sie setyten dann stark ein bis Nai, so daß der Swakop in Otjimbingue im Mai + Wochen lang floB; der Verkehr der Baiwagen (durch den Swakop) stockte 3 Wochen.
72 
1880 (nach Schinz Kuisib bis ins Meer

[302.0] $\mathrm{mm}$

[225.0] $\mathrm{mm}$ begonnen; im April Hagelstürme;

I 890 kein Regenmesser.

$[268.0]$
74 Jahr der Fluten.

75 sämtliche Gärten bis Otjimbingue wurden samt Dattel- und Maulbeerbäumen weggefegt.

$76 \quad$ r $874 / 75$ Flutenjahr (ich hatte damals leider keinen Regenmesser [Irle]; I 875 nahm die Flut alles Korn mit weg.

77

78

79 wenig Regen und Dürre. abgekommen) s. u. S. 68.

81 große Fluten hier und in Okahandja. Dort floß der Fluß hinter Missionar Diels Schule vorbei, und im Store, Voigts Haus und jetzigen Schlaf- und Wohnräumen stand das Wasser 3 Fuß hoch. Der Kuisib kam seit 25 Jahren das erste Mal herunter und setzte alle Stranddiinen und Walfischbai unter Wasser. Man fuhr mit Kähnen vom Strand bis zu den Sanddünen. In Swakopmund stand dieSee weit hinter dem Steinbruch hoch oben auf der Fläche, also die jetzige Stadt tief unter dem Meer.

82 keine Flüsse; viel Hagelwetter und Kälte.

83 kalter Regen; viel Kälte und keine Flüsse.

84 schwacher Regen, nur Februar und März 8 Tage mit $45 \mathrm{~mm}$; ein Nebeljahr; Anfang Olitober setzte der Fluß ein und nahm schließlich alles Korn mit weg.

85 Dezember in 2 Tagen $20 \mathrm{~mm}$ (nach Schinz s. u. S. 68 Kuisib bis ins Meer). Regen hatte Ende Januar keine Flüsse, viel Kälte; im Dezember I885 Regen.

86 Februar und Januar $182 \mathrm{~mm}$.

Irle am Kap, daher keine

87 Messungen; jedoch soll große

88 Dürre gewesen sein; I 888

89 begann die Regenzeit erst nach Ostern.

$[205.0]$

$[297.5]$

[192.0]

$[398.5]$

[359.0]

$[259.5]$

[282.0]

[201.0]

[262.0]

$[305.6]$

91 1891/92 starke Regen.

92. viel Regen.
93 viel Regen (I4. Jan. 93 Kuisib bis Walfischbay abgekommen, nach v. Biilow a. a. O. S. 280).

94 Jan. bis Mai $(25 \mathrm{~T})$ I $47 \mathrm{~mm}$, Dez. (4 T) $50.5 \mathrm{~mm}$.

95 Jan. bis April (24 T) 234 mm, Okt. bis Nov. (4 T) $87 \mathrm{~mm}$.

96 Jan. bis März (I 4 T) $88 \mathrm{~mm}$; tiefer Wasserstand, wenig Gras, viel Verlust an Großvieh. Wegen Wassermangel konnte nicht gesät werden, es war überhaupt das einzige Jahr seit I 872 aufOtjosazu, wo Irle es so geseher hat.

97 Jan. bis Mitte April (2 I T) $206 \mathrm{~mm}$; Nov. (4 T) und Dez. (9 T) zus. $40 \mathrm{~mm}$. Kuisib bis ins Meer (s. S. 68).

98 Jan. bis Febr. 42 mm; Ende April starker Regen; $319 \mathrm{~mm}$, in einer Nacht $44 \mathrm{~mm}$, dann in einer Stunde $40 \mathrm{~mm}$.

99 Jan. bis Febr. ( 5 T) 59.5 mm; Reise nach dem Cap; März bis Mai mehr als $200 \mathrm{~mm}$, Regenmesser übergelaufen. Okt. bis Dez. (5 T) I IO $\mathrm{mm}$.

1900 Jan. bis Ende April(I4 T) I72 mm; Dez. $(5 \mathrm{~T}) 54 \mathrm{~mm}$.

O1 Jan. (2 T) I $7.5 \mathrm{~mm}$; Febr. 4. bis 27. (5 T) $46.5 \mathrm{~mm}$; März $(8 \mathrm{~T})$ $65.5 \mathrm{~mm}$; April (4 T) I7,5 mm; bisherige Summe I $46.5 \mathrm{~mm}$; daher starke Flüsse; Dez. (IO T) I24 $\mathrm{mm}$. Tiefer Wasserstand, 8 bis ro Fuis tief.

O2 Jan. (7 T) $54 \mathrm{~mm}$; Febr. (6 T) $37.5 \mathrm{~mm}$; März (4 T) $26.5 \mathrm{~mm}$; April (I T) $20 \mathrm{~mm}$, zus. $143 \mathrm{~mm}$. Nov. 23., 26., 27. (4 Stunden) I $36.3 \mathrm{~mm}$; Dez. (5 T bis I 3.$)$ $38.3 \mathrm{~mm}$, zus. $174.5 \mathrm{~mm}$.

o3 Jan. 6.0 mm, Febr. $107.5 \mathrm{~mm}$, März $17.0 \mathrm{~mm}$ (nach Schinz Kuisib bis ins Meer abgekommen, s. u. S. 68).

$\mathrm{O}_{4}$ ziemlich günstige Regenzeit (nach

05 den neuesten Berichten aus

5 Deutsch-Südwestafrika).

Eine Generaldurre scheint hier bis Kl. Namaland jede 30 Jahre, eine mittlere Dürre etwa jede IO Jahre einzutreten. I86I, I874, I88 I, I892 waren Flutjahre, I869/70, I878/79, 
I888/89, I896, I902/03 duirre Jahre; I77, I792, $1833,184+, 1867,1902 / 03$ Generaldüre.

Soweit dic Berichte von Missionar Irle. Hieraus ohne weiteres, die 35 jährige, sogenannte Brücknersche Periode bzw. die I jährige Periode der Klimaschwankungen konstatieren zu wollen, wäre aber wohl ebenso durchaus verfrüht.

Auch Schinz glaubt an eine gevisse Periodizität in diesen Verhältnissen. So z. B. teilt er mit (a. a. O. S. 454), dâ das Wasser der gröBeren Omiramba des Hererolandes durchschnittlich etwa alle IO Jahre einmal clas Meer erreicht; so soll z. B. der Kuisib nur I 837, I 848, I 849, I 852, I 864, I 880 und I $885^{1}$ ) bis nach Walfischbai gelangt sein.

- Wohl also können wir aus dem vorliegenden Beobachtungsmaterial von Südwestafrika und den ïbrigen Aufzeichnumgen und Berichten bestimmte, miteinander abwechselnde Perioden mit Jahren bald stärkeren, bald geringeren Niederschlags im Laufe des vorigen Jahrhunderts erkennen; jedoch aus ihnen ein bestimntes Gesetz für diese Periodizität zu lesen sind wir vorläufig nicht imstande.

\section{Zur Frage der sogenannten Austrocknung Südafrikas.}

Zum Schlusse vorstehender Erörterungen sei es mir vergönnt, kur\% noch die vielfach umstrittene und immer wicker angeregte Frage einer allgemeinen Verschlechterung des sidafrikanischen Klimas bzw. der Austrocknung Suidafrikas zu berihren. Hierbei kann es sich für uns nur um die Frage handeln: Ist in historischer Leit eine Abnalnme der jährlichen Niederschlagsmengen $\approx u$ konstatieren?

Passarge kommt in seinemunlängst erschienenen Werke über die Kalahari²) - unter der Überschrift Die Abnahme der Niederschläge in Südafrika auf Grund eigener Beobachtungen und gesammelter Materialien zu dem Schlub, dab in Südafrika eine stete Verringerung, der jährlich fallenden Regenmengen, selbst in historischer Zeit, zu bemerken sei, und in dieser Tatsache müsse die Ursache der allmählichen Austrocknung Südafrikas gesucht verden.

Die zunächst liegende Frage, ob tatsächlich eine noch in historischer Zeit andauernde Austrocknung Suidafrikas und damit auch unseres Schutzgebietes bestehc, ist in neuerer Zeit oft erörtert worden.

Es ist hier nicht der Ort, auf diese Dinge näher einzugehen; jedenfalls wird von den meisten andern Forschern und Kennern Sidafrikas, wie

1) Später noch 1897 und I903.

2) S. Passarge, Die Kalahari. Versuch einer phys.geograph. Darstellung der Sandfelder des südafrikanischen Beckens. Berlin 1904.
Livingstone, Dove, Pechü̈l-Lösche, Schinz u. a., die Austrocknungsfrage bejaht. Dove1, erklärt sogar entschieden, dab eine Terschlechterung des Klimas Südafrikas unleugbar iste. Auf Grund vicher Erscheinungen kommt nun S. Passarge zu derselben Ansicht. Letzterer, welcher ziemlich die sesamte Literatur iber diesen Gegenstand in dem erwähnten Werke zusammengestellt hat, sicht dic Austrocknung Südafrikas in dem Rückgang und der vollständigen Austrocknung von Flüssen und Seen, in dem allmählichen Versiegen von Quellen und ibberhaupt in der allgemeinen Abnahme des Wasservorrates des Landes, damn in der allmählich zunehmenden Ausdehnung der öderen Landstriche und Sandflächen, in dem heute nur vereinzelten Auftreten sewisser anspruchsvollerer Baumarten. Für alles dieses glaubt Passarge in der Hauptsache eine Verminderung der jährlichen Niederschläge als Ursache annehmen zu müssen. Der Unterschied zwischen den einzelnen Darstellungen der Austrocknungsfrage beruht nun in den verschiedenen Gründen, welche man für dic unheilvolle Austrocknung verantwortlich machen will. Passarge, Livingstone u. a. suchen sie in meteorologischen Ursachen, also z. B. direliter Verminderung der Regen, dagegen K. Dove, Fox Wilson, ${ }^{2}$ ) Pechuël-Lösche und ganz besonders Schinz ${ }^{3}$ ) in der zunehmenden Schwankung der klimatischen Verhältnisse und vor allem den von Menschenhand verursachten lokalen Veränderungen des südaf rikanischen Bodens mit ihren Folgen. Vor allen Dingen wird hier die allerdings in großem Maßstabe ausgeführte Entwaldung durch Eingeborene und Europäer angeführt. Dementgegen glaubt Passarge wieder für besondere Fälle ${ }^{4}$ ) den Beweis erbringen zu können, z. B. für das Kalaharibecken selbst, dab dort niemals die Entwaldung Endursache der Austrocknung gewesen sein könne. Der ungeheuere Rückgang des Ngamisees und des Flubsystems des Botletle liönne nur auf die Abnahme des jährlichen Niederschlags in historischer Zeit zurïickgeführt werden.

Es ergibt sich daher hier für uns die Frage, ob die bis heute in unserem Schutzgebiete und überhaupt in Südafrika gemachten exakten Regenmessungen die Annahme Passarges von der Verminderung des Niederschlags zu unterstützen vermögen.

Um diese Frage zu beantworten, seien hier zunächst einige längere Beobachtungsreihen aus dem

1) K. Dove, L. Y. 15, S. I52.

2) Fox Wilson, Water supply in the hasin of the Orange River; Journal of the Royal Geograph. Society, l.ondon. 1865. S. $106 \mathrm{ff}$.

3) Schinz, Dr., H., L. V. 43 , S. 482 if.

$\left.{ }^{4}\right)$ Vg1. S. Passarge, Die Kalahari, S. 100, 66I, 684. 
Kaplande herangezogen. ${ }^{1}$ ) Die längste derselben ist die von Kapstadt selbst.

Die durchischnittliche jährliche Regenmenge betrug in den einzelnen Perioden ( $z u ;$ Jahren) für Kapstadt:

\begin{tabular}{|c|c|c|}
\hline+6 & $\begin{array}{l}. \quad 50 \\
. \quad 50\end{array}$ & 63 1.2 \\
\hline $5 \mathrm{I}$ & " $\quad 55$ & 557.0 \\
\hline 56 &,, 60 & 661.9 \\
\hline $6 \mathrm{I}$ & " 65 & 6 II.4 \\
\hline 66 &,,$\quad 70$ & 624.8 \\
\hline $7 \mathrm{I}$ &,$" 75$ & 635.8 \\
\hline 76 & , $\quad 80$ & 709.4 \\
\hline 8 I &,, 85 & 730.3 \\
\hline 86 &,$\quad 90$ & 732.2 \\
\hline 9I &,$\quad 95$ & 740.2 \\
\hline 96 & , $\quad 00$ & 579.6 \\
\hline
\end{tabular}

für die ganze 60jährige Periode

1841 bis 1900 . . 647.9 ,

Aus dieser Aufstellung, besonders aber auch deutlich aus der graphischen Darstellung des jährlichen Regenfalls zu Kapstadt I 84 I bis I900 (Diagr.48) ergibt sich durchaus keine tendenziöse Abnahme, viel eher schon ein Anwachsen der jährlichen Niederschlagshöhe gerade in den letzten Jahrzehnten. Wie die meistens korrespondierenden Ordinaten der regenreicheren (ausgezogen) und trockenen (gestrichelt) Jahre, soweit aus Deutsch-Südwestafrika darüber Mitteilungen vorliegen, anzeigen, dürfte man geneigt sein, diese Tatsache auch für das übrige Südwestafrika als wahrscheinlich anzunehmen.

Zunächst mögen aber noch einige Beispiele aus dem Innern Südafrikas folgen.

Für Kimberley $\left(28^{\circ} 23^{\prime}\right.$ s. Br.; $24^{\circ} 46^{\prime}$ e. L.; Höhe $=1230$ ) ergibt sich als Mittel der gesanten 24 jährigen Beobachtungsreihe I 877 bis I $900: 442 \mathrm{~mm}$ und nach vierjährigen Mittelwerten:

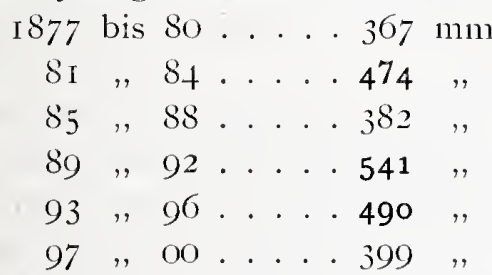

Für Goliads Kraal $\left(32^{\circ} 8^{\prime} \mathrm{s}\right.$. Br.; $24^{\circ}$ fo e. L.; $h=1070 \mathrm{~m})$ in der Karroo gibt K. Dove a. a. O.2)

S. I 52 noch eine kleine Tabelle an:

I 863 bis 67 (5j.) . . . $345 \mathrm{~mm}$

$$
\begin{aligned}
& 68,73, \ldots 322, \quad \text { (I872 fellit) } \\
& 74,78, \ldots 388, \\
& 79,83 \quad, \quad \ldots 367 \quad,
\end{aligned}
$$

1) Sämtliches Material zu den folgenden Aufsteilungen findet sich in den kapländischen Reports. - Reports of the Meteorological Commission of Cape of Good-Hope.

2) K. Dove, L. V. I5, S. I 52 . außerdem kann ich noch hinzufügen:

I 888 bis $92(5 \mathrm{j}.) \ldots 454 \mathrm{~mm}^{1}$ )

Alle diese Zahlenangaben bestätigen für die betreffenden Perioden und die betreffende Gegend in keiner Weise die Richtigkeit der Annahme Passarges.

Es zeigen sich da in den Niederschlagsmengen wohl zeitweilige Verminderungen, aber den letzteren folgten auch wieder Vermehrungen. Eher schon zeigen die angeführten Beispiele eine gewisse gleichmäßige Periodizität des Niederschlagss, wobei ein besonderes Anschwellen desselben sogar noch in die jüngste Zeit, Anfang der 8oer und goer Jahre vorigen Jahrhunderts, fällt. Ebenso ist meinen eigenen Berechnungen und Darlegungen der jährlichen Schwankungen der Niederschlagsverhältnisse einer Reihe deutsch-südwestafrikanischer Stationen, wie sie graphisch auf den Diagrammen I bis IO, s. o. S. 3 I ff., zur Anschauung gebracht sind, keine Tendenz zur allmählichen Abnahme für die betreffenden Jahresreihen $z u$ entnehmen.

Dagegen zeigen sie, ebenso wie die Aufstellungen über die Schwankungen im jährlichen Regenfall, Diagramm 40 bis 46 , gerade in den allerletzten Perioden 03/O4 und 04/05 vielmehr ein drittes Anschwellen der Niederschlagsmenge.

Aus der vollständigsten und längsten Reihe, zusammengestellt aus den Beobachtungsergebnissen von 2 I Stationen des südlichen Damara- und nördlichen Namalandes (s. Diagramm +2 ), entnehme ich außerdem noch folgende Werte:

Beobachtungsdauer: 2 I Jahre; Jahresmittel des Niederschlages über diesem Getiete (Zone III): $\mathrm{N}=294 \mathrm{~mm}$. Davon fielen durchschnittlich:

1883 bis 87 . . I06 v.H. Also auch hier ist nur I 887,90 . . 72, ein gewisses $\mathrm{An}$ - und AbI $890,, 93$. . I 47, , schwellen der jährlichen I 893 , 96 . . 85 , Niederschlagshöhe von 3 $1896,99 \ldots$ 132 , 2 zu 3 Jahren zu erkennen. I899 " $02 \ldots 7 \mathrm{I}$, $1902,05 \ldots 1+16$,

$(\mathrm{N}=294 \mathrm{~mm}=\mathrm{I} 00 \mathrm{v} . \mathrm{H}$.

Wenigstens für diese Periode und diesen Landstrich ist also auch nicht die Annahme Passarges bestätigt gefunden.

Die von Passarge zusammengestellten Mitteilungen und Tatsachen erstrecken sich rückwärts auf einen Zeitraum von höchstens etwa I 50 Jahren. Demgegenüber steht nun, wie wir sahen, ein exalites Beobachtungsmaterial, welches sich ibber mindestens die letzten 6o Jahre ausdehnt, und das durchaus keine Neigung der jährlichen Niederschlagsmengen zur allmählichen Abnahme ergibt. Allerdings

1) Den kapläud. Reports entnommen 1888 bis 1892. 
steht uns lcider zur Erbringung dieses Beweises für die Karroo und Deutsch-Südwest. afrika nur ein geringeres Material zur Ver. fïgung, nämlich auf die Dauer der Perioden I 863 bis I 900 bzw. 1883 bis I904. WTeiterhin dürften hier nochmals die alten Missionsberichten, also einer ziemlich vertrauenswerten Quelle, entnommenen Aufzeichnungen des Missionars Lrle ${ }^{1}$ ) angeführt werden. Juch dort sehen wir in einem Zeitraum von etwa ioo Jahren nur andauernde Schwanliungen der jährlichen Regcnfälle, jedoch, soweit sich dies aus (ler nicht zahlenmäßigen Darstellung erlicnnen läßt, durchaus keine Tendenz zur allmählichen Ibnahme in dieser fuir Südafrika historischen Zeit.

Jene Inschaumes $S$. Passarges von einer fortschreitenden Verminderung der Niederschläge in Sülafrika findet also, soweit es die hier behandelten Gebicte betrifft, in dem vorliegenden exaliten Beobachtungsmaterial für dic angegebene Zeit keine Stiitze.

Zu demselben Schlub kam auch schon K. Dove,2) wenn er sagt: : Wir liönnen uns nach alledem dem Trteil Gambles anschlieben, der im Cape-Government-Bluebook sich folgendermaßen äußert: ,,Man hört oft behaupten, dab Südafrika austrocknet. Wenn damit gesagt sein soll, dab weniger Regen fällt als in früherer Zeit, so ist die Behauptung nicht erwiesen und wahrscheinlich auch unrichtig." "3)

Doch wird ein genaucres Urteil hierüber sich natürlich erst gewimnen lassen, wenn bedeutend längere Reihen brauchbarer Niederschlagsmessungen vorliegen werden. Deswegen wird es auch vorderhand vorteilhafter sein, die angeführten Einzelfälle nicht allzusehr zu verallgemeinern.

\section{Die jährliche Anzahl der Regentage in Deutsch- Südwestafrika.}

Neben der Menge des jährlich fallenden Regens ist naturgemäß auch die Anzahl der Tage, auf welche er sich verteilt, von grober Bedeutung.

Hierbei muß jedoch zuvor festgestellt werden, welche Tage überhaupt als »Regentage werden sollen.

Es scheint zunächst nahe zu liegen, alle Tage, an denen überhaupt irgend ein Niederschlay fällt, sei er nun meßbar oder auch, wie so viele Nebelregen, im Ombrometer unmeßbar, bei einer speziellen Darstellung ohne Unterschied mitzurechnen. Da aber hierbei die subjektive Auffassung des Beobachters zu sehr zur Geltung kommen würde, wann

1) Vgl. hierzu dieselben auf S. 66 ff

2) K. Dove, Das Klima ... I 888 ; S. I 55 ff

3) Tgl. Meteorolog. Zeitschxift. I 885 ; S. 397. cin Tag mit starkem Nebel b\%w. Taufall schon als Niederschlagstag gerechnet werden sollte, so dürfte es ratsam sein, für die Inrechnung eines Regentages eine bestimmte untere Grenze anzusetzen.

Es schien daher eine Beschränliung auf den wirklich meßbaren Niederschlag, und zwar mindestens $0.2 \mathrm{~mm}$, allein eine ausreichend sichere Grundlage zur Behandlung der angeregten Frage geben zu können.

Auch K. Dove bezeichnet in mehreren Manuskripten mit Regenmessungen, welche mir freundlichst zur Verfügung gestellt wurden, erst die Tage mit wenigstens $0.2 \mathrm{~mm}$ Niederschlag als Regentage.

Ahnlich werden auf den britischen Stationen Suidafrikas erst die Tage mit mindestens $0.0 \mathrm{I}$ inch $=0.25+\mathrm{mm}$ als Regentage gezählt

Selbst dieses Verfahren kann oft noch ungenau werden. So schreibt J. Hann: ${ }^{1}$ Die Zahl der Tage mit Niederschlägen unter I $m m$ variiert oft erheblich mit der Sorgfalt der Beobachter, Art und Größe des Regenmessers, dessen Aufstellung usw. Daher ist es zu genauen Vergleichungen sehr erwiinscht, die Zahl der Tage mit Niederschlägen von I.O $\mathrm{mm}$ und daruber daneben mit anzugeben.

Im übrigen dürfte $z u$ berücksichtigen sein, daß in Gebieten mit solchen Temperatur- und Luftfeuchtigkeitsverhältnissen ein Niederschlag von weniger als $0.2 \mathrm{~mm}$ praktisch kaum eine nennenswerte Bedeutung besitzen wird.

Im allgemeinen würde auch die Zählung der Niederschlagstage ohne untere feste Grenze der gefallenen Niederschlagsmenge für das gesamte hier zu behandelnde Gebiet ein schiefes Bild geben. Beispielsweise wurden für die Regenperiode I903/04 in Swakopmund (4I) I32, in Zesfontein (6) I64 „Regentage" mit Niederschlag $\left.{ }^{2}\right)$,,im allgemeinen" gezählt, welche Anzahl diejenige der Binnenstationen bei weitem übertraf und auf Rechnung der häufigen Nebelregen mit unmeBbarem Niederschlag gesetzt werden muß.

Aus ähnlichen Grïnden, wie die oben angegebenen, soll in folgenden jedoch auch noch die Anzahl der Regentage mit einem Niederschlag von mindestens I.O $\mathrm{mm}$ berechnet und beigefügt werden.

Das Material für die folgenden Darlegungen ist denselben Quellen wie dasjenige der gefallenen Regenmengen selbst entnommen. Von über 20 Stationen lay mir ein solches von mindestens vierjähriger und teilweise erheblich längerer Dauer vor.

Zunächst sei nun in den Tabellen ig und 20 das vorliegende und zu den folgenden Berechnungen und Darlegungen benutzte Beobachtungsmaterial beigefügt.

1) J. Hann, I. V. 28, I. Bd., Seite 66.

2) Vährend der Regenperiode I903/04 wurden gemessen: in Zesfontein (6) Io6.I mm, in Swakopmund (4I) $23.4 \mathrm{~mm}$ Niederschlag. 


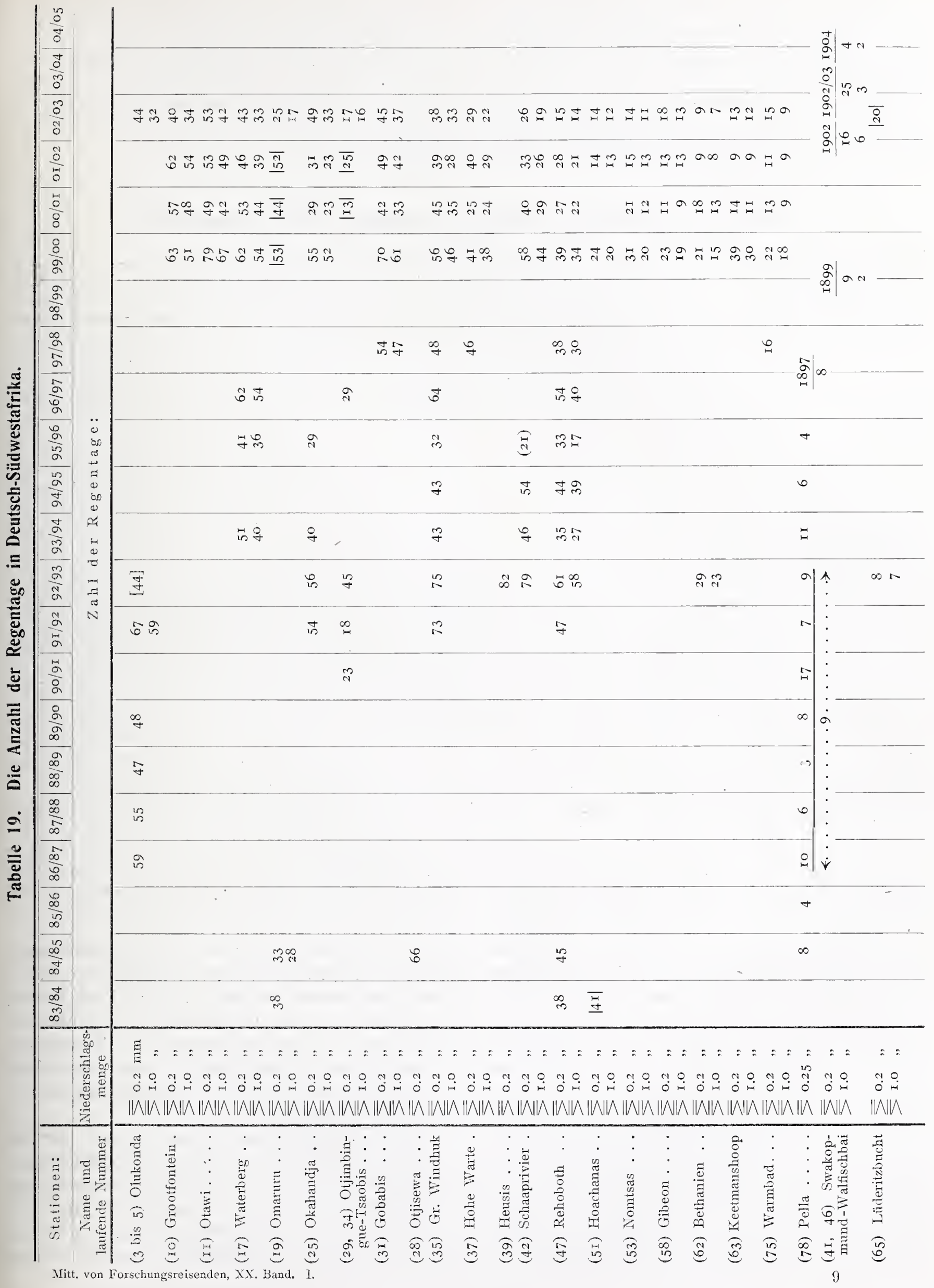


Tabelle 10 goibt die jährliche Anzahl der Regrentage, soweit exalite Beobachtungen vorlagen, mit cinem Niederschlage von mindestens $0.2 \mathrm{~mm}$ sowie die von mindestens I.O $\mathrm{mm}$.

Dabei bedeuten die Zahlenangaben in $[\mathrm{x}]$ durch mangellafte Bcobachtung unvollständige Summen, während dic $\mathrm{x}$ ungenau im allgemeinen, vielleicht auch $z u$ groß sind, da sic Regentage mit ,Niederschlag iiberhaupt" kennzeichnen.

Diese Angaben wurden nach Möglichlieit nicht mit zur Verwertung horangezogen. - Zur Herstellung der Tabelle 20 wurden nur die Regentage mit einem Niederschlag von mindestens $0.2 \mathrm{~mm}$ berïclisichtigt.

Tabelle 20. Die monatliche Verteilung der Regentage in Deutsch-Sïdwestafrika.

(Niederscllag $\equiv 0.2 \mathrm{~mm}$.)

\begin{tabular}{|c|c|c|c|c|c|c|c|c|c|c|c|c|c|c|}
\hline $\begin{array}{l}\text { Name der Station } \\
\text { und lanfende Nummer }\end{array}$ & & Juli & Aug. & Sept. & Okt. & Nov. & De $\%$ & Jan. & Febr. & Mä̀z & April & Mai & Juni & $\begin{array}{l}\text { Jahres- } \\
\text { mittel }\end{array}$ \\
\hline ( 3 his 5) Olukonda & $\begin{array}{l}\text { ahsol. Anzahl } \\
\% \text { des } \\
\text { Jahresmittels }\end{array}$ & $\begin{array}{l}0.0 \\
0.0\end{array}$ & $\begin{array}{l}0.0 \\
0.0\end{array}$ & $\begin{array}{l}0.2 \\
0.4\end{array}$ & $\begin{array}{l}4.6 \\
8.0\end{array}$ & $\begin{array}{r}6.7 \\
11.6\end{array}$ & $\begin{array}{r}8.7 \\
15.1\end{array}$ & $\begin{array}{r}9.3 \\
\mathbf{1} 6.1\end{array}$ & $\begin{array}{l}\text { I } 2.0 \\
20.8\end{array}$ & $\begin{array}{l}\text { II. } 4 \\
\text { I } 9.8\end{array}$ & $\begin{array}{l}4.5 \\
7.8\end{array}$ & $\begin{array}{l}0.3 \\
0.5\end{array}$ & $\begin{array}{l}0.0 \\
0.0\end{array}$ & 57.7 \\
\hline (I7) Waterherg ... & $\begin{array}{l}\text { absol. Anzahl } \\
\% \text { des } \\
\text { Jahresmittels }\end{array}$ & $\begin{array}{l}0.0 \\
0.0\end{array}$ & $\begin{array}{l}0.2 \\
0.4\end{array}$ & $\begin{array}{l}0.4 \\
0.8\end{array}$ & $\begin{array}{l}3.0 \\
5.9\end{array}$ & $\begin{array}{l}5.0 \\
9.8\end{array}$ & $\begin{array}{l}10.7 \\
20.9\end{array}$ & $\begin{array}{l}10.9 \\
21.3\end{array}$ & $\begin{array}{r}9.4 \\
18.4\end{array}$ & $\begin{array}{r}9.0 \\
17.6\end{array}$ & $\begin{array}{l}4.0 \\
7.8\end{array}$ & $\begin{array}{l}\text { I. } 6 \\
3 . \mathrm{I}\end{array}$ & $\begin{array}{l}0.0 \\
0.0\end{array}$ & 51.2 \\
\hline (19) Omaruru. & alisol. & $\begin{array}{l}0.0 \\
0.0\end{array}$ & $\begin{array}{l}0.0 \\
0.0\end{array}$ & $\begin{array}{l}0.2 \\
0.5\end{array}$ & $\begin{array}{l}1.2 \\
3.0\end{array}$ & $\begin{array}{l}2.7 \\
6.8\end{array}$ & $\begin{array}{r}7.1 \\
17.8\end{array}$ & $\begin{array}{r}6.3 \\
15.8\end{array}$ & $\begin{array}{r}9.5 \\
23.9\end{array}$ & $\begin{array}{r}7.2 \\
18.1\end{array}$ & $\begin{aligned} 4.6 \\
\text { II } .6\end{aligned}$ & $\begin{array}{l}1.0 \\
2.5\end{array}$ & $\begin{array}{l}0.0 \\
0.0\end{array}$ & 39.8 \\
\hline (25) Okahandja . & absol. & $\begin{array}{l}0.3 \\
0.7\end{array}$ & $\begin{array}{l}0.4 \\
0.9\end{array}$ & $\begin{array}{l}0.4 \\
0.9\end{array}$ & $\begin{array}{l}2.4 \\
5.5\end{array}$ & $\begin{array}{l}3 . \mathrm{I} \\
7 . \mathrm{I}\end{array}$ & $\begin{array}{r}7.6 \\
17.5\end{array}$ & $\begin{array}{r}6.4 \\
14.7\end{array}$ & $\begin{array}{r}8.3 \\
19.1\end{array}$ & $\begin{array}{l}10.0 \\
23.0\end{array}$ & $\begin{array}{l}3.0 \\
6.9\end{array}$ & $\begin{array}{l}1.6 \\
3.7\end{array}$ & $\begin{array}{l}0.0 \\
0.0\end{array}$ & 43.5 \\
\hline $\begin{array}{c}(29,34) \text { Otjimbingue- } \\
\text { Tsaobis....... }\end{array}$ & $\underset{0 / 1}{a b s o l}$ & $\begin{array}{l}0.0 \\
0.0\end{array}$ & $\begin{array}{l}0.6 \\
2.2\end{array}$ & $\begin{array}{l}0.0 \\
0.0\end{array}$ & $\begin{array}{l}1.3 \\
4.7\end{array}$ & $\begin{array}{l}1.3 \\
4.7\end{array}$ & $\begin{array}{r}4.7 \\
16.9\end{array}$ & $\begin{array}{r}4.8 \\
17 \cdot 3\end{array}$ & $\begin{array}{r}5.3 \\
19.1\end{array}$ & $\begin{array}{r}8.0 \\
28.8\end{array}$ & $\begin{array}{l}2.0 \\
7.2\end{array}$ & $\begin{array}{l}0.2 \\
0.7\end{array}$ & $\begin{array}{l}0.0 \\
0.0\end{array}$ & 27.8 \\
\hline (35) Gir. Windlutk. . & alosol. & $\begin{array}{l}0.3 \\
0.6\end{array}$ & $\begin{array}{l}0 . \mathrm{O} \\
0.0\end{array}$ & $\begin{array}{l}0.3 \\
0.6\end{array}$ & $\begin{array}{l}2.0 \\
3.9\end{array}$ & $\begin{array}{l}5.0 \\
9.7\end{array}$ & $\begin{array}{r}8.3 \\
\text { I } 6.1\end{array}$ & $\begin{array}{r}8.1 \\
15.7\end{array}$ & $\begin{array}{r}9.0 \\
\text { I } 7.4\end{array}$ & $\begin{array}{l}12.5 \\
24.2\end{array}$ & $\begin{array}{l}5.0 \\
9.7\end{array}$ & $\begin{array}{l}1.2 \\
2.3\end{array}$ & $\begin{array}{l}0.0 \\
0.0\end{array}$ & $5 \mathrm{I} \cdot 7$ \\
\hline (47) Rehoboth .... & $\begin{array}{l}\text { absol. } \\
\%\end{array}$ & $\begin{array}{l}0.1 \\
0.3\end{array}$ & $\begin{array}{l}0.1 \\
0.3\end{array}$ & $\begin{array}{l}0.2 \\
5.0\end{array}$ & $\begin{array}{l}2.1 \\
5 \cdot 3\end{array}$ & $\begin{array}{l}3.8 \\
9.6\end{array}$ & $\begin{array}{r}5.0 \\
12.6\end{array}$ & $\begin{array}{r}8.3 \\
20.9\end{array}$ & $\begin{array}{r}6.5 \\
16.3\end{array}$ & $\begin{array}{r}7.4 \\
\text { I } 8.6\end{array}$ & $\begin{array}{r}5.0 \\
12.6\end{array}$ & $\begin{array}{l}\text { I.I } \\
2.8\end{array}$ & $\begin{array}{l}0.2 \\
5.0\end{array}$ & 39.8 \\
\hline (5I) Hoachanas ... & $\underset{\%}{\text { absol. }}$ & $\begin{array}{l}0.1 \\
0.5\end{array}$ & $\begin{array}{l}0.0 \\
0.0\end{array}$ & $\begin{array}{l}0.7 \\
3.3\end{array}$ & $\begin{array}{l}1.0 \\
4.7\end{array}$ & $\begin{array}{r}2.6 \\
12.2\end{array}$ & $\begin{array}{l}\text { I. } 8 \\
8.5\end{array}$ & $\begin{array}{r}3.2 \\
15.0\end{array}$ & $\begin{array}{r}4.0 \\
18.8\end{array}$ & $\begin{array}{r}3.8 \\
17.8\end{array}$ & $\begin{array}{r}3.2 \\
15.0\end{array}$ & $\begin{array}{l}0.7 \\
3.3\end{array}$ & $\begin{array}{l}0.1 \\
0.5\end{array}$ & 21.3 \\
\hline (62) Bethanien.... & $\begin{array}{c}\text { absol. } \\
\%\end{array}$ & $\begin{array}{l}0.2 \\
\mathrm{I} .2\end{array}$ & $\begin{array}{l}0.2 \\
1.2\end{array}$ & $\begin{array}{l}0.3 \\
1.8\end{array}$ & $\begin{array}{l}\text { I.O } \\
5.9\end{array}$ & $\begin{array}{l}0.8 \\
4.7\end{array}$ & $\begin{array}{r}2.2 \\
\mathrm{I} 2.9\end{array}$ & $\begin{array}{l}\mathrm{I} .4 \\
8.2\end{array}$ & $\begin{array}{r}3.2 \\
18.7\end{array}$ & $\begin{array}{r}4.8 \\
28 . I\end{array}$ & $\begin{array}{r}2.0 \\
11.7\end{array}$ & $\begin{array}{l}0.2 \\
1.2\end{array}$ & $\begin{array}{l}0.8 \\
4.7\end{array}$ & I 7.I \\
\hline (75) Warmbad.... & $\underset{0}{a}=$ & $\begin{array}{l}0.8 \\
5.6\end{array}$ & $\begin{array}{l}0.8 \\
5.6\end{array}$ & $\begin{array}{l}1.0 \\
6.9\end{array}$ & $\begin{aligned} 1.6 \\
11.1\end{aligned}$ & $\begin{array}{l}0.4 \\
2.8\end{array}$ & $\begin{array}{l}0.8 \\
5.6\end{array}$ & $\begin{array}{l}1.4 \\
9.7\end{array}$ & $\begin{array}{r}\text { I } .8 \\
\text { I } 2.5\end{array}$ & $\begin{array}{r}2.8 \\
19.4\end{array}$ & $\begin{array}{l}1.2 \\
8.3\end{array}$ & $\begin{array}{l}1.0 \\
6.9\end{array}$ & $\begin{array}{l}0.8 \\
5.6\end{array}$ & I 4.4 \\
\hline (8) Pella ...... & $\underset{0 / 0}{\operatorname{absol.}}$ & $\begin{array}{l}0.3 \\
3.4\end{array}$ & $\begin{array}{l}0.7 \\
7.9\end{array}$ & $\begin{array}{l}0.3 \\
3.4\end{array}$ & $\begin{array}{r}1.3 \\
14.6\end{array}$ & $\begin{array}{l}0.3 \\
3.4\end{array}$ & $\begin{array}{l}0.6 \\
6.7\end{array}$ & $\begin{array}{l}0.8 \\
9.0\end{array}$ & $\begin{array}{l}0.8 \\
9.0\end{array}$ & $\begin{array}{r}\mathrm{I} .7 \\
\mathrm{I} 9 . \mathrm{I}\end{array}$ & $\begin{array}{r}\text { I.I } \\
\text { I } 2.4\end{array}$ & $\begin{array}{l}0.8 \\
9.0\end{array}$ & $\begin{array}{l}0.2 \\
2.3\end{array}$ & 8.9 \\
\hline (79) Port Nolloth.. & $\underset{0}{a b s o l .}$ & $\begin{array}{r}2.3 \\
10.7\end{array}$ & $\begin{array}{r}2.9 \\
13.4\end{array}$ & $\begin{array}{l}I .3 \\
6.0\end{array}$ & $\begin{array}{l}2.0 \\
9.3\end{array}$ & $\begin{array}{l}\text { I. I } \\
5 . I\end{array}$ & $\begin{array}{l}0.4 \\
1.9\end{array}$ & $\begin{array}{l}0.6 \\
2.8\end{array}$ & $\begin{array}{l}1.0 \\
4.6\end{array}$ & $\begin{array}{l}\text { I. } 7 \\
7.9\end{array}$ & $\begin{array}{r}2.4 \\
\text { II.I }\end{array}$ & $\begin{array}{r}3.0 \\
13.9\end{array}$ & $\begin{array}{r}2.9 \\
\mathrm{I} 3.4\end{array}$ & 21.6 \\
\hline
\end{tabular}

Anmerknng: Die Darstellung der monatlichen Verteilnng der Regentage giht zunächst die absolute Anzahl, das aus dem vorliegenden Material gewonnene Mittel, damn die relative an. Letztere ist in Prozenten der rohen Jahresmittel ausgedrückt. Die durchschnittliche (rohe) Jahressumme ist gleich roo \% gesetzt.

Eine Vergleichung dieser letzten Darstellungen, nämlich der monatlichen und jährlichen Verteilung der Regentage in Deutsch-Südwestafrika, mit derjenigen der Regenmengen ergibt uns nun cine ganz auffallende und fast gleichmäßig proportionale Änderung bzw. Schwankung von Jahr zu Jahr und ebenfalls von Monat zu Monat. (Vgl. hierzu die Tabellen I9 und 20 mit 4 und IO, II.). Besonders klar wird diese Tatsache durch die Diagramme 47 bis 53 zur Anschauung gebracht. Diese Kurvendarstellung zeigt ein ziemlich stetiges Verhalten der monatlichen und jährlichen Verteiiung der Regentage und Regenmengen zu Olukonda (5), Gr. Windhuk (35), Rehoboth (47) und Port Nolloth (79), also von Stationen mit relativ langen Beobachtungsreihen, die gleichzeitig über das ganze hier zu behandelnde Gebiet verstreut liegen. Dies brachte mich daher zu dem Gedanken, die Verteilung der Regentage in Deutsch-Südwestafrika in analoger Wcise wie die der Regenmengen, unter Anwendung einer Redultionsberechnung, liartographisch zur Anschauung zu bringen.

Die Hauptbedingung zur Berechtigung der Redulition der Stationen mit kürzeren Beobachtungsreihen auf die längeren von Nachbarstationen war ja gleichfalls gegeben (s. o. Seite 29 bis 35).

Zu Haupt- bzw. Reduktionsstationen, welche in ihrem Rohmittel der jährlichen Anzahl der Regen- 
tage gleichzeitig schon das Normalmittel bieten konnten, wurden Rehoboth (47), [Olukonda (3 bis 5), Grootfontein (IO)], Waterberg (I 7$)$, Gr. Windhuk (35), Pella (78), außerdem noch Loanda (I), Wal-
fischbai-Swakopmund $(46,41)$, Port Nolloth (79) angenommen.

Auf Grund der wie oben Seite 3off. ausgeführten Redultionsmethode erhalten wir nunmehr folgende Werte (Tabelle 2I):

Tabelle 21. Anzahl der jährlichen Regentage in Deutsch-Südwestafrika.

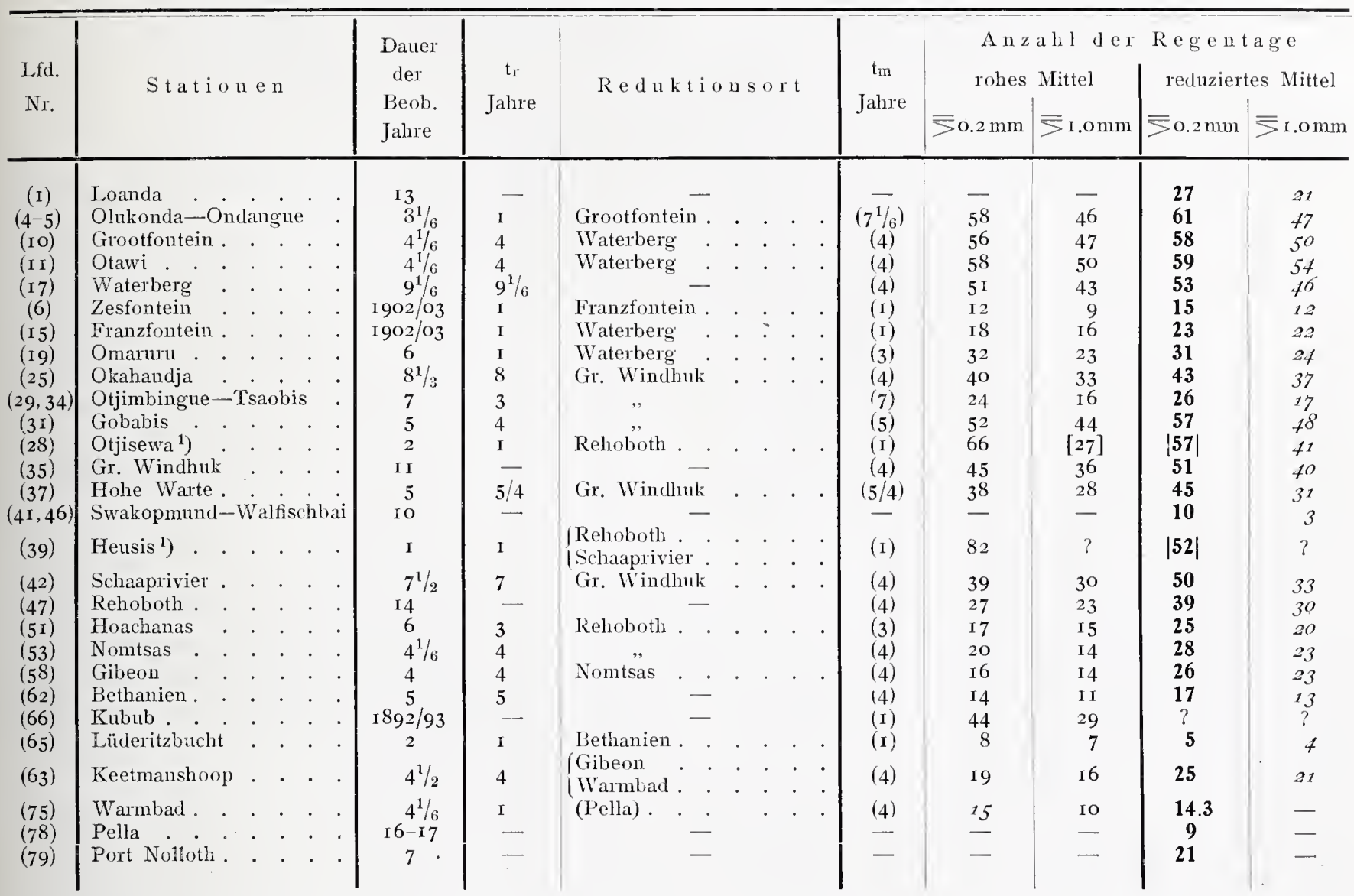

Anmerkung: tr bedeutet die Anzahl der Jahe, auf Grund deren (wegen der Gleichzeitigkeit der Beobachtung mit dem Reduktionsort) die Reduktion ausgeführt wurde. $t_{\mathrm{m}}$ : Anzahl der Jahre, aus denen das rohe Mittel gebildet ist; dabei bedeutet (4) die vier letzten Beobachtungs-Jahre 1899/03.

1) Die gefundenen Werte von Otjisewa und Heusis dürften wenig genau sein, da sie nur anf der Beobachtung eines Jahres beruhen.

Vergleichen wir in Tabelle $2 \mathrm{I}$ die reduzierten (Normal-) Mittel der einzelnen Stationen mit den aus den tatsächlichen Beobachtungen gewonnenen Rohmitteln der jährlichen Anzahl der Regentage, so ergeben sich meist nur geringe Unterschiede in den beiderseitigen, Zahlenangaben. Um so eher durfte daher daran gedacht werden, die durch Reduktion erhaltenen Werte zu einer synoptischen Darstellung, welche ein ziemliches Maß von Zuverlässigkeit beanspruchen darf, zu verwenden. Dies geschah durch Anlegung zweier Karten, auf denen bei den einzelnen Stationen Deutsch-Südwestafrikas die Anzahl der Regentage eingetragen ist und außerdem die Anlegung von Linien gleicher mittlerer Anzahl der jährlichen Regentage versucht wurde.

Die erste dieser beiden Karten zeigt die Gesamt- zahl der jährlichen Regentage mit einem Niederschlage von mindestens $0.2 \mathrm{~mm}$ in entsprechend kolorierten Abstufungen von IO zu IO Regentagen. Gleichzeitig ist den einzelnen Beobachtungsorten noch die Zahl der Regentage mit einem Niederschlag von mindestens $\mathrm{I} . \mathrm{O} \mathrm{mm}$ in Klammern beigefügt.

Um aber noch etwas näher die Verteilung der ergiebigeren Regen zu veranschaulichen, gibt die zweite Karte lediglich die Anzahl der jährlichen Regentage mit einem Niederschlage von mindestens I.0 mm, ebenfalls mit Linien gleicher mittlerer Anzahl der Tage mit einem Niederschlage von mindestens I.Omm und farbigen Abstufungen von IO zu Io Tagen.

Vergleicht man diese beiden Karten mit der Karte der Niederschlagsmengen von Deutsch-Südwestafrika (Karte Nr. I), so \%eigen sich deutlich zwei 
gemeinsame Züge im Verlaufe ihrer Isohyeten, näm. lich im Binnenlande die Zunahme von Zahl der Regentage und Menge der Niederschläge von Siid nach Nord und Vest nach Ost, im Küistenstrich aber, soweit bei der geringen Zahl der dortigen Stationen ein Urteil uiberhaupt möglich ist, ein mehr einheitlicher Charakter, der zwischen Norden und Süden nur geringere Unterschiede aufweist.

In ïbrigen verlaufen die einzelnen Isohyeten der beiden Darstellungen (Karte 2 und 3) auffallend ähnlich. Besonders bevorzugt erscheint uns wieder der Nordosten des Schutzgebietes mit einem durchschnittlichen Jahresmittel von 60 (bzw. 50) Regentagen mit einem Niederschlag von 0.2 (bzw. I.o) mm.

Ebenso tritt wieder die relativ günstige Stellung des zentralen Hochlandes bei Windhuk klar hervor. Eine ganz außerordentlich geringe jährliche Zahl der Tage mit mebbarem Niederschlag finden wir bei den Küistenstationen: für Swakopmund-Walfischbai Io (3) und Liideritzbucht sogar nur 5 (4) mit einer Intensität von $0.2(\mathrm{I} .0) \mathrm{mm}$. Nach Sürlen, im Küistengebiet des Kaplandes, scheint dann wieder eine Zunahme einzutreten: Port Nolloth hat in siebenjährigem Mittel 2I Regentage mit mindestens $0.25 \mathrm{~mm}$.

Zur Vergleichung mit der im allgemeinen außerordentlich geringen jährlichen Anzahl der Regentage in unserem Schutzgebiete mögen zwei Beispiele aus Deutschland herangezogen werden: Münster i. IV. hat durchschnittlich jährlich etwa I 70, Kiel I 53 Regentage mit meßbarem Niederschlag.

Wenn auch nicht zu übersehen ist, dak nach Suiden die Zahl der Tage mit meßbarem Niederschlag weit weniger abnimmt als die Menge des Niederschlags, so zeigt sich doch auch weiterhin, wie aus den täglichen Aufzeichnungen hervorgeht, bisweilen hier eine besondere Konzentration auf größere Regenmengen während einer geringeren Dauer von Tagen. So 7. B. fielen im äußersten Suiden des Schutzgebietes ${ }^{1}$ ) auf den beiden Stationen

$$
\text { Ukamas (72) }
$$

Udabis $(74)$

$$
\begin{aligned}
& \text { am 23. Mär\% } 1900 \quad 35.5 \mathrm{~mm} \\
& \text { am 24. März I9o0 } 23.5 \mathrm{~mm} \\
& \text { an 25. Mär» } 1900 \quad 92.0 \mathrm{~mm} \quad \mathbf{1 0 8 . 5} \mathrm{mm}
\end{aligned}
$$

bei anhaltenden Gewittererscheinungen, also nahezu die gesamte Regenmenge des Jahres innerhalb zweier Tage. Es trat infolgedessen ein Dammbruch bei Arriam ein und die Wasserhöhe erreichte 29 bis $30 \mathrm{FuB}$.

Im allgemeinen nimmt sonst die Zahl der Tage mit stäikeren Niederschlägen im Binnenland nach Norden ebenfalls zu. Im äußersten Norden kommen während der Hauptregenzeit schon öfters Regentage mit einem Niederschlag von über $100 \mathrm{~mm}$ vor, wie

\footnotetext{
1) Vgl. "Meteorologische Zeitsclurift 1902 , S. 43.
}

die in den Mitteilungen aus deutschen Schut\%gebieten veroffentlichten Tabellen zeigen.

Aber auch im mittleren Teile des Schutygebictes fallen of währent eines Tages uiber 50 und $60 \mathrm{~mm}$. K. Dove') und Th. Rehbock' ${ }^{2}$ ) führen eine ganze Reihe solcher auf, aul welche deshalb hier verwiesen werden soll.

Überhaupt liefern nur die bei weitem selteneren Regentage mit besonders stärkeren Güssen, etwa von IO bis $15 \mathrm{~mm}$ an, den größten Beitrag zu der Gesamtjahressumme.

Lus der jüngsten Regenperiode I904/05 seien von einzelnen starken Regengüssen folgende Messungen erwähnt: Olukonda am IO. und 11 . Februar $=63.7 \mathrm{~mm}$; Oniipa am 12. Februar $=43.5 \mathrm{~mm}$; Ondangua am I5. Februar $=48.5 \mathrm{~mm}$; Franzfontein am 28. Februar $=52.2 \mathrm{~mm}$; Grootfontein am 6. Februar $=66 . \mathrm{I} \mathrm{mm}$; Outjo am I9. Februar $=72.6 \mathrm{~mm}$; Okowakuatjiwi am 26. März $=50.0 \mathrm{~mm}$; Omaruru am 3I. Januar $=42.4 \mathrm{~mm}$; Olombahe vom 27. bis 30. Januar $=218.0 \mathrm{~mm}$, davon allein am 28. Januar $=128.0 \mathrm{~mm}$; Otjimbingue am 30 . Januar $=41.7 \mathrm{~mm}$; Windhuk am 9. Februar $=45.0 \mathrm{~mm}$; Kubas am 31. Januar $=83.7 \mathrm{~mm}$; Oas vom 4. bis 6. Februar $=\mathrm{I} 78.0 \mathrm{~mm}$; Seeis an 26. und 27. März $=73.0 \mathrm{~mm}$; I laris am 9. Februar $=45.0 \mathrm{~mm}$; Rehoboth am I. Februar $=34.3 \mathrm{~mm}$; Gibeon an 9. Februar $=$ 40.8 $\mathrm{mm}$; Kubub am 21. 11 är $=35.6 \mathrm{~mm}$; Sandverhar an 29. Мär\% $=40.0 \mathrm{~mm}$; Bersaba am 28. Mär\% $=42.5 \mathrm{~mm}$.

Ein weiterer starker, wolkenbruchartiger Regen ist in der Gegend der Eisenbahnstation Pforte $84.5 \mathrm{~km}$ von Swakopmund - Ende März gefallen. Der Regen kam in solchen Mengen, daß sich in dem Wüstensande große Wasserlachen bildeten. Leider waren nähere Angaben über diesen sehr interessanten, in der völlig vegetationslosen Wüstenregion niedergekommenen Regen nicht zu erhalten, weil Pforte keine Mebstation ist. Es soll demnächst in der Wüstenregion etwa in der Mitte zwischen Swakopmund und Jakalswater auf dem Platze Welwitsch noch eine Station eingerichtet werden. Die oben erwähnten einzelnen starken Güsse enthalten einen erheblichen Teil der auf den betreffenden Plätzen im ganzen Jahr zusammen gemessenen Regenmengen. Z. B. sind in Okombahe in den vier Tagen zwei Drittel, in Kubas und Kubub an dem cinen Tage etwa ein Drittel der Jahressumme gefallen. ${ }^{3}$ )

1) K. Dove, L. V. I7.

${ }^{2}$ ) Th. Rehbock, L. V. 37 , S. 43 ff.

$\left.{ }^{3}\right)$ Diese Notiz ist den Mitteilungen aus dentschen Schutzgebieten entnommen. Jahrgang r 906 \# Ergebnisse der meteorolog. Ieobachtungen in Deutsch-Siidwestafrika im Jahre 1904/05". 
Wie wir schon oben sahen, 1) sind die Regentage ungleich auf die einzelnen Monate verteilt, und zwar im allgemeinen, wie die monatlichen Prozentzahlen ergeben, proportional den relativen Regenmengen. In übrigen folgen sie sich innerhaib der eigentlichen Regenzeit ganz unregelmäßig.

Ein richtiger, mehrere Tage vielleicht anhaltender Landregen ist selbst im Norden Deutsch-Südwestafrikas und ebenso der Kalahari noch selten, während er im Süden fast unbekannt ist.

Im folgenden möge zum Schlusse noch eine Aufstellung gegcben werden, welche auf Grund eines siebenjährigen Mittels für Rehoboth (47) I 892 bis I 898 die monatliche Verteilung der Regentage ihrer Niederschlagsstärke nach bringt.

Von Januar I 892 bis Dezember I 898 wurden folgende Regentage zu Rehoboth (47) gezählt.

Tabelle 22.

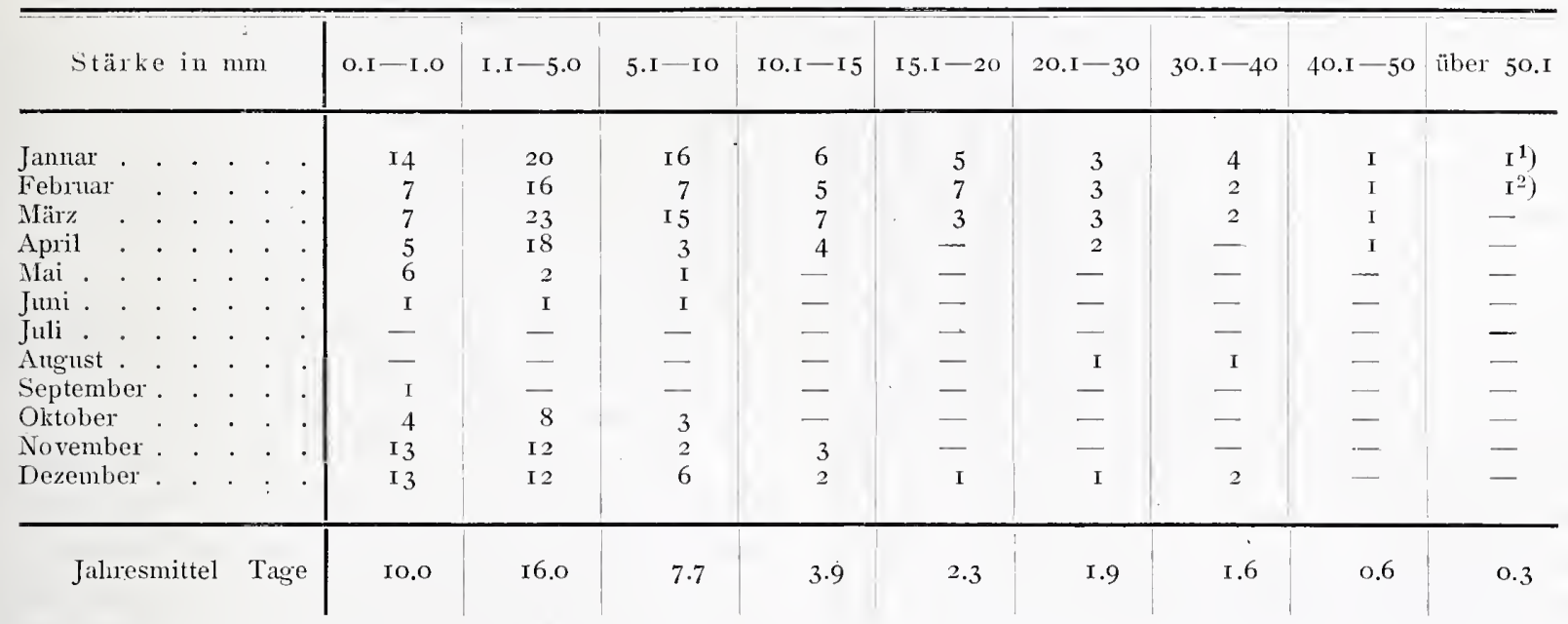

Das Zusammendrängen gerade der stärkeren Regen auf die Monate der eigentlichen Regenzeit Januar bis März tritt in dieser Tabelle deutlich hervor.

Bezeichnend für die Wirkungen der kurzen und heftigen Regengüsse ist, daß die Ansiedler mit Rücksicht auf dieselben groBe, bis mehrere Fuß tiefe Abzugsgräben durch ihre Feldanlagen ziehen müssen.

Eine Tatsache möge schließlich hier noch im allgemeinen erwähnt werden, daß nämlich fast alle Regen in den Nachmittagsstunden - das Maximum fällt von $2^{\mathrm{h}} \mathrm{p} . \mathrm{m}$ bis $5^{\mathrm{h}} \mathrm{p} . \mathrm{m}$-- niedergehen, und zwar beinahe ausschließlich unter Gewittererscheinungen. Nur die von den sommerlichen Niederschlägen betreffs ihrer Herkunft und Stärke ganz verschiedenen Nebelregen der Küstenlandschaften sind nicht von Gewittern begleitet.

Die Gewitterhäufigkeit nimmt nach Norden und Nordosten mit der wachsenden jährlichen Regenmenge gleichzeitig zu.

\section{Die Beziehung der Niederschläge zu den Windrichtungen und die dadurch bedingten Grundzüge der allgemeinen Verteilung des Regens in Deutsch-Südwestafrika.}

Eigentlich ist es nicht Aufgabe vorliegender Abhandlung, die in Deutsch-Südwestafrika herrschenden Vindverhältnisse einer eingehenden Untersuchung zu unterziehen. Trotzdem erschien es ratsam, die

1) Vgl, Tabelle 20, S. 72 .
Frage der Beziehung der Nicderschläge zu den Windrichtungen nicht ganz unberührt zu lassen, um so gleichzeitig in die Ursachen der eigentümlichen Regenverteilung des Schutzgebietes einigen Einblick zu gewähren. ")

Wenn auch im Norden besser bewässert, so muß der größte Teil Deutsch-Südwcstafrikas nach den vorausgegangenen Darlegungen doch im allgemeinen als ein regenarmes, im äußersten Süden sogar als ein höchst regenarmes Land, im Küstengebiet, abgesehen von Nebel und Tau, als fast niederschlagslos gelten.

Bei dieser so ungleichmäßigen Verteilung des Niederschlags fragt es sich nun, inwieweit und in welcher Weise dabei neben dem selbstverständlichen Einfluß der geographischen Lage sowie der Bodengestaltung und der räumlichen Ausdehnung des Landes auch die Windvcrhältnisse und besonders die herrschenden Windrichtungen mit bestimmend sind.

1) $56.1 \mathrm{~mm}$.

2) $50.7 \mathrm{~mm}$

3) Über dieses Thena liegt eine Reihe von Erörtermngen vor, vor allen vou J. Han $\mathrm{n}$, K. Dove, A. v. Danckelmau, A.schenck, S. Passarge u. a. m. Die in Sïdwestafrika während der einzehnen Jahreszeiten vorherrschenden Windrichtungen sind durch A. v. Danckelman, C. Kabner, K. Dove, A. Sandmann auf Grund von allerdings meist nur kurzen Beobachtungsreihen berechnet worden. Auf die einzeluen V'eröffentlichnngen hierüber, welche schon oben angegeben wurden, nöge in Interesse des folgenden hier nochnals rerwiesen werden. 


\section{Die Abhängigkeit der Niederschlagsverteilung von all- gemeinen Faktoren.}

Die eigenartige Bodengestaltungr Südafrikas mit seinen erhöhten Küistenrändern läßt ron vornherein niederschlagsreiche Küsten- und regenarme Binnenländer roraussehen. Dies trifft auch ${ }^{1}$ für den Ostund Südrand wie für die Binnensteppen Südafrikas zu, dagegen für Deutsch-Südwestafrika und sein Küstenland, wie wir oben sahen, nicht.

Gleichzeitig sei noch ein anderer Falitor erwähnt, der ebenfalls eine große Bedeutung im Zusammenhang ron Wind und Wetter gewinnt. In der Nähe der Ostküste zieht eine warme (20 bis $24^{\circ} \mathrm{C}$ ), die sogenannte Mosambil-Meeresströmung entlang: die über sie herstreichenden, dem Lande zustrebenden östlichen Winde werden demgemäB feucht und warm sein. Im Westen ron Sülafrika bemerken wir dagegen den kalten Benguelastrom ( $\mathrm{IO}$ bis $15^{\circ} \mathrm{C}$.), zu dem noch die bekannten kalten Auftriebwässer dicht an der Westliuste treten, deren Wirkungen auf die klimatischen Verhältnisse im Küistengebiete Deutsch-Südwestafrilas vor allem durch A. Sand. mann untersucht $\left.{ }^{2}\right)$ sind. Die westlichen Winde werden also nach schon rorangegangener Kondensation ihres Wassergehaltes relativ trocken und kalt das Land erreichen.

Um nun auf clie allgemeinen Luftdruck- und die dadurch gegebenen Windverhältnisse einzugehen, so wird Südafrika, ohne ein selbständiges barometrisches Gebiet zu schaffen, im großen und ganzen nach Hann, K. Dove, Passarge u. a. m. von den auf dem Meere west- und ostwärts ständig lagernden hohen Luitdruckgebieten beherrscht. ${ }^{3}$ )

Bedenken wir nummehr, daB fast das ganze Jahr hindurch in Südwestafrika vorwiegend suidwestliche, also Seewinde, über das Land hinwehen, die doch sonst allgemein Regen zu bringen pflegen, und daß diese Winde dabei noch, wenn sie von der Küste landeinwärts ziehen, eine bedeutende Steigung zu iiberwinden haben, so fragen wir uns erstaunt nach den Ursachen der großen Regenarmut und der auf beigegebener Regenkarte vor Augen geführten ganz eigentümlichen Niederschlagsverteilung des Landes.

Den gesuchten Aufschluß über diese Erscheinungen wird uns eine »Darlegung der jahreszeitlichen Verteilung der Windrichtungen und ihre Beziehung zum Niederschlag " geben.

Analog der Sonderstellung, welche das Küstenland Deutsch-Südwestafrikas gegenüber dessen Binnenlandschaften in der allgemeinen Verteilung der

1) Vgl. hierzu A. Supan, L. V. 46. K. Dove, I. Y. I5.

2) A. Sandmann, L. V. 40.

3) Tgl. hierzu und zum folgenden anch: J. Hann, "Atlas der Meteorologie", Gotha I887, Tafeln VI, III, VIII.
Niederschläge einnahm, wird es auch bei der jet»igen Untersuchung angebracht sein, cine Tremnung der Verhältnisse im Küstengrebict gegenüber denen des Binnenlandes vorzunehmen und beide Teile sesondert zu behandein.

Zunächst mögen jedoch die Grundzüge der allgemeinen Verteilung des Luftdrucks, die allerdings nur wenig durch exalkte Barometerbeobachtungen gestïtzt werden, folgen.

\section{Südwinter (April bis September).}

Nach früheren Darlegungen fanden wir in fast ganz Deutsch-Südwestafrika einen durchaus trockenen Winter. Übergangsgebiete mit geringen Winterregen sind nur der Süden und das Küstenland des Schutzgebietes, ebenso Britisch-Kl. Namaland. Für den Südwesten des Kaplandes dagegen wurden fast ausschlieBlich Winterregen konstatiert.

Über die Windverteilung im ITinterhalbjahr führt J. Hann auf Grund ron, wenn auch nur spärlichen, Beobachtungsdaten folgendes $\left.{ }^{1}\right)$ aus:

- Im Vinter liegt eine Antizyklone ïber Südafrika (eine ebensolche in gleicher Breite ost- und weit ins Meer hinein westwärts der Küsten).

Die Winde an der Ost- und Südseite des Kaplandes sind Landwinde und deshalb trocken. Auf der Westseite dagegen hat sich nun (gegenüber dem Sommerhalbjahr) das barometrische Maximum weiter von der Küste entfernt; die vorherrschenden Winde sind südlich und westlich und kommen weit her über das Meer; sie sind deshalb feuchter und bedingen die Winterregenzeit des Kaplandes an seiner Südwestliüste.

Sommerregenzeiten reichen westwärts bis $26.3^{\circ}$ ö. Lg., weiter westwärts regnet es (im Sommer) nur an vereinzelten Örtlichkeiten.

Die im Südwinter in Deutsch-Südwestafrika vorherrschenden Winde sind südlich bis westlich.

Anders liegen die Verhältnisse im

\section{Südsommer (Oktober bis März).}

Das Sommerregengebiet erstreckt sich beinahe über ganz Südafrika. Eine Ausnahme bildet allein das südwestliche Kapland. Regen zu allen Jahreszeiten, wenn auch nur sehr geringe, haben die deutsch-südwestafrikanische Küste und das Land der Orangeniederung.

Die Ursachen der im nördlichen und östlichen Teile Südafrikas niedergehenden relativ reichlichen Sommerregen sind in der Änderung der vorherrschenden Windrichtungen zu suchen.

Die drei durchschnittlich wärmsten Monate sind Januar bis März. Das Land wird jetzt in viel stär-

1) Meteorologische Zeitschrift I898《, S. 3 ff. 
kerem Maße als im Winter erhitzt, besonders die längs der Küste in einiger Entfernung von derselben herziehende etwa $100 \mathrm{~km}$ breite erhöhte Randzone, deren typischesBeispiel dieSteinwüste derNamieb ist. ${ }^{1}$ )

Es bildẹt sich hier nach K. Dove2) ein Gebiet höherer Temperatur und dadurch bedingten niederen Luftdruckes, »auf welches nun infolge der Auflockerung der schwebenden Luftmassen von allen Seiten die Winde zuwehen «.

Kommen wir nunmehr zur spezie:leren Behandlung der Frage: was ist bekannt über die $\mathrm{Ab}$ hängigkeit der Regen von den Winden?

Wenn auch bei dieser Erörterung bisweilen ein näheres Eingehen auf die Kausalität versucht werden muß, so darf doch nicht vergessen bleiben, daß der wahre innere Zusammenhang mangels exakteren Beobachtungsmaterials oft noch wenig klar ist. Es kann sich in folgenden daher nur um die Darstellung der wahrscheinlichen Tatsachen handeln.

Werden die im Winter fallenden Niederschlagsmengen an der Westküste des Kaplandes nach Norden zu schon immer geringer, so reduzieren sie sich, wie oben gezeigt wurde, für den Küistenstreifen Deutsch-Suidwestafrikas zu äußerst geringen Beträgen, und dies aus verschiedenen Gründen.

Die im Winter wie auch im Sommer an der Küste Deutsch-Südwestafrikas bei weitem vorherrschenden Winde sind südwestliche ${ }^{3}$ ) und westliche.

Einmal kommen nun diese den winterlichen Regen bringenden Winde aus höheren Breiten in niedere, also wärmere, und je weiter sie nordwärts auftreten, um so größer ist auch der Temperaturunterschied zwischen dem dortigen und dem kälteren Ursprungsgebiet, um so geringer wird also die Möglichkeit, sich weiterhin abkühlen und durch Kondensation Feuchtigkeit abgeben zu können.

Sodann kommt hier noch ein Unterschied hinzu, der das Spenden größerer Niederschlagsmengen

1) Vgl. F. MI. Stapff, »Bodentemperatur-Beobachtungen in Hinterlande der Walfischbai« in dem Sitzungsbericht der Kaiserlichen Akademie der Wissenschaften, Wien; Mathem.-Naturw. Klasse; Bd. XCVII, Abt. IIa.

2) K. Dove, L. V. I7, S. I9.

3) A. Sandmann gibt in seiner oben angefïhrten Abhandlung eine Aufstellung hierüber:

Neunjährige Tagesmittel dex Windrichtungen in Prozenten der Häufigkeit zu Waifischbai 1886 bis 1894 . des Winters. (April bis September). verbindert, nämlich das Vorhandensein der oben erwähnten, aus den südlichen kühleren Meeresgebieten stammenden kalten Meeresströmung, des Benguelastromes. Dieser streicht der Westküste Südafrikas nordwärts entlang, wie die verschiedensten Messungen des Meerwassers ergeben haben, und tritt dabei beträchtlich abkühlend auf; an der Küste unseres Schutzgebietes herrscht eine sogenannte negative Temperaturanomalie von etwa $4^{\circ} \mathrm{C}$.

Endlich aber tritt gerade hier noch cin anderer Faktor hinzu, der hier gleichfalls von erheblichem Einfluß sein muß, nämlich das kalte Auftriebwasser an der Küste von Deutsch-Südwestafrika. ')

Über diesem verhältnismäßig kalten Meeresgebiete, nämlich erstens dem nordwärts ziehenden relativ kühlen Benguelastrom, sodann aber nahe der Küste dem noch kälteren Auftriebwasser, kühlen sich die Winde immer mehr ab und verdichten schlieBlich einen beträchtlichen Teil ihres Feuchtigkeitsgehalts zu den ständigen starken Nebeln, die neben den ziemlich ergiebigen Taufällen den einzigen regelmäßigen Niederschlag jener Landstriche bilden. Nur selten werden winterliche Niederschlägc gemeldet, die als meßbare Nebelregen notiert werden können. Ja, Sommerregen aus dem Innern, die glücklich ihren Weg noch über den hohen Westrand bis zur Küste gefunden haben, bringen manchmal absolut größere Regenmengen, als die gewöhnlichen Nebel- und Tauniederschläge

Im Sommerhalbjahr sind diese Verhältnisse für das Küstenland von Deutsch-Südwestafrika noch ungünstiger. Das westliche barometrische Maximum ist jetzt, wie wir oben sahen (nach Hann), mehr nach Süden und näher an die Küste gerüclit. So bietet sich denn den Seewinden noch weniger Gelegenheit, sich mit Wasserdampf zu beladen und diesen auf der Küste abzusetzen, als im Winter

Einiger Regen fällt wohl noch im Sommer auf dem Nordwestrand des Kaplandes, welches sich da-

1) Näheres hierüber bringt Sandmann, L. V. 40.

\begin{tabular}{|c|c|c|c|c|c|c|c|c|c|}
\hline Windrichtung & $\mathrm{N}$ & NO & $\mathrm{O}$ & so & $\mathrm{S}$ & $s W$ & $\mathrm{~W}$ & NW & Stille \\
\hline $\begin{array}{l}\text { Frühling (Oktober bis Dezember). } \\
\text { Sommer (Januar bis März) . . . } \\
\text { Herbst (April bis Juni) . . . . . } \\
\text { Winter (Juli bis September). . . }\end{array}$ & $\begin{array}{r}23 \\
19 \\
7 \\
18\end{array}$ & $\begin{array}{l}2 \\
2 \\
2 \\
3\end{array}$ & $\begin{array}{l}3 \\
2 \\
8 \\
9\end{array}$ & $\frac{\mathrm{I}}{2}$ & $\begin{array}{l}2 \\
2 \\
9 \\
6\end{array}$ & $\begin{array}{l}39 \\
39 \\
38 \\
35\end{array}$ & $\begin{array}{r}9 \\
\text { I } 8 \\
\text { Io } \\
8\end{array}$ & $\begin{array}{l}4 \\
6 \\
2 \\
3\end{array}$ & $\begin{array}{l}\text { I6 } \\
\text { I } \\
23 \\
\text { I6 }\end{array}$ \\
\hline $\mathrm{Jahr}$ & I 7 & 3 & 5 & I & 5 & 36 & II & 4 & I 8 \\
\hline
\end{tabular}


durch als ein Übergangsgebiet mit Regen zu allen Jahreszeiten erweist.

Dagegen können die nach Passieren des kalten Küstenmeeres mit nur geringem WTasserdampf beladenen Seewinde dem Kü̈stenland, welches hier auf der Namiebzone besonders erhitzt ist, im allgemeinen überhaupt lieine Niederschläge mehr bringen; vielmehr müssen sie sich dort wieder in erhöhtem Maße erwärmen und ausdehnen.

Die Nebelregen sind selbst an der Küste im Sommer seltener. Nur Tauniederschlag, mit dem überhaupt immer gerechnet werden kann, ist noch ziemlich reichlich.

Die Folge aller dieser Erscheinungen ist die ungeheure Regenarmut und im besonderen die Armut an meßbaren Niederschlägen der ganzen Küstenregion unseres Schutzgebietes im Sommer und Winter, welche vielleicht von keinem Gebiete der festen Erdoberfläche ïbertroffen wircl. $\left.{ }^{1}\right)$

Hierzu möge man die Regenmeßergebnisse von Zesfontein (6), Jakalswater (40), Swakopmund (41), Walfischbai (46), Luideritzbucht (65) und anderer im Küstenland Deutsch-Südwestafrikas gelegener Stationen vergleichen.

Die vorherschenden Winde im Binnenland Deutsch-Südwestafrikas während des Winterhalbjahrs sind dieselben wie im Küistengebiet zu dieser Jahreszeit, nämlich südwestliche und westliche.

Die mit ihnen kommenden winterlichen Niederschläge verirren sich, wie wir bei der allgemeinen Erörterung darlegten, nur in ganz vereinzelten und außergewöhnlichen Fällen bis ins Innere des Schutzgebietes. Denn, sobald die auf dem kühlen Meere schon eines beträchtlichen Teiles ihres Wassergehaltes beraubten Seewinde auf das wärmere Land übertreten, muß natürlich ihre Kondensationsfähigkeit sofort wieder abnehmen; und selbst das Ansteigen zum höheren Binnenlande scheint dann wenig neue Kondensation erzeugen zu können.

Anders jedoch die Verhältnisse im Sommerhalbjahr.

,Über der kalten Meeresregion lagert beständig ein höherer Luftdruck als im Innern, welcher auch die andauernden Sül- und Suidwest-IVinde veranlaßt. Sobald im Sommer ein Minimum nahe der Küste auf dem Festland sich bildet, wird das Herrschaftsgebiet der Südrestwinde nur noch ein beschränlites sein können, und östlich der Namieb müssen Winde aus dem östlichen Quadranten auftreten" (nach Dove a. a. O.).

1) A. Supan erwälnt a. a. O. S. I3. „Von allen Stationen, die unsere Tabellen anführen, haben nur zwci einen mittleren Xiederschlag von weniger als to $\mathrm{mm}$ : die Walfischbai und Copiapo an der Suidgrenze der Atacama."
Je weiter wir ostwärts der Namieb ${ }^{1}$ ) und überhaupt der küistennahen Sand- und Steinwüsten kommen, umsomehr überwiegen in Sommer die östlichen Winde, welche aller Wahrscheinlichkeit nach in einem Gebiete höchsten Luftdruckes über wärmeren Zonen des Indischen Ozeans ihren Ursprung haben dürften, und die sich über dem warmen Neeresstrom an der Ostküste Südafrikas vielleicht nochmals mit Feuchtigkeit beladen konnten.

Jedenfalls dürfte demnach für das Binnenland Deutsch-Südwestafrikas ein Ost- bis Nordostmonsun als der regenbringende Vind gelten.

Überaus reich mit Wassergehalt beladen gelangen die östlichen Seewinde zur Ostküste der südafrikanischen Landzunge und entladen von hier ab ihren Feuchtiglieitsreichtum in solch erheblicher Menge, daß die östlichen Teile Südafrilias, von etwa $10^{\circ}$ s. Br. nach Süden zu, besonders seine Randgebirge, $x u$ den regenreicheren Strichen der ganzen Erdoberfläche zählen können.

Mit weiterem Vorschreiten in das Landinnere und weiter nach dem über dem Küistenland DeutschSüdwestafrikias lagenden barometrischen Minimum 7.u werden (nach K. Dove und a.) die regenbringenden Ostwinde 2) - wenn auch teilweise immer wieder der Wassergehalt durch die große Verdunstung der ïber dem warmen Lande niedergegangenen Regenmassen ersetzt wird - immer trockener.

Es reiht sich demgemäß im allgemeinen von Nordost nach Südwest fortlaufend eine Zone mit geringerem sommerlichen Niederschlag an die vorangegangene regenreichere an, bis die Regenwinde ihren Rest an Wassergehalt uiber der Kalaharisteppe und nach einer geringen letzten Steigerung dann schließlich auf der Ostseite der Hochfächen DeutschSüdwestafrikas abgegeben haben (vgl. hierzu das Profil der Regenhöhen auf Seite 46-47).

Auch die Mitteilungen von Eingeborenen und der in Deutsch-Süiwestafrika ansässigen Farmer sowie aller übrigen Kenner des Landes stimmen mit dieser Annahme iiberein. Überall: bei K. Dove, Schin\%, Gürich, Hahn,";) v. Bülow, Rehbock, v. Danckelman, ${ }^{4}$ ) Schenck u. a. finden wir die Winde aus dem östlichen Quadranten als die im ganzen Binnenland Deutsch-Sidwestafrikas regenbringenden verzeichnet. - Ganz

1) Vg1. K. Dove, I. V. I7. - A. v. Danckelman, L. V. I4.

2) Nach S. Passarge, "Die Kalahari", Seite 87 , sollen es Südostwinde sein, die sich in der Nähe des Wendekreises ïber dem Binnenlande in einen Nordostmonsum umwandeln.

3) Pet. Mitt. 1878 , Seite 311.

4) Mitt. aus den Deutschen Schutzgebieten Band VIII, IS95. Mitt. des Vereins für Erdkunde zu Leipzig, Jahrgang 1884. 
besonders wichtig scheint mir auch zu sein, was mir Herr Missionar Irle freundlichst mitteilte, daß das ,Hereroland nie von Westen, sondern nur von Osten, und auch nur Gewitterregen empfängt." - J. Irle war 34 Jahre lang im Schutzgebict und lebte als Missionar in Otjosazu (26), letzteres im nördlichen Damaraland etwa unter $22^{\circ} \mathrm{s}$. Br. gelegen.

Selbst die Eingeborenen bringen diesen, für sie so wichtigen „Dingen eine große Aufmerksamkeit entgegen, die sich bis zum Aberglauben steigern kann". So halten sie die im Frühling, also vor der eigentlichen Regenzeit, auch von Osten kommenden Sandwehen und Wirbelstürme für Vorboten und "Regenbitter" (otukumbambura).

Eine besonders ausfuihrliche Schilderung dieser eben behandelten Verhältnisse gab mir in einer mündlichen Besprechung Herr Missionar Iudt für Hoachanas (5I). Letzterer war volle 30 Jahre in mittleren Teile Deutsch-Südwestafrikas als Missionar tätig und ist, da er auch selbst lange Jahre hindurch zu Hoachanas und Gobabis meteorologische Beobachtungen angestellt hat, ein zuverlässigcr Kenner der dortigen klimatischen Verhältnisse.

Iudt stellt als allgemeinen Zug der Witterungsverhältnisse fest:

Im Winterhalbjahr fast nur Süd- bis Westwinde mit großer Lufttrockenheit. Die nur äußerst selten auftretenden geringen Nebelregen dieser Jahreszeit kommen mit südwestlichen Winden und wären demnach mit den kapländischen Winterregen in Zusammenhang $\mathrm{zu}$ bringen.

Die in manchen Jahren schon in den letzten Wintermonaten häufiger auftretenden östlichen Winde künden nach der Ansicht Iudts eine günstige Regenzeit an. Sobaid der Sommer herannaht, schiägt der Wind allmählich um, und schon ziehen Wolken aus Norden und Osten herauf. Oft erwartet man jedoch noch zu Hoachanas vergebens den Regen, der schon in nördlicheren und östlicheren Gegenden im Frühling stark einsetzt (z. B. im Damaraland und der Kalaharisteppe). Im übrigen kommen die sommerlichen Niederschläge fast ganz ausschließlich mit nördlichen und östlichen Winden. Auch herrschen sonst im Sommer die aus dem Landinnern Südafrikas stammenden Ostwinde vor. Die Regen fallen im Sommer gewöhnlich unter Gewittererscheinungen, und zwar nachmittags und abends, selten vor io Uhr morgens. Besonders starken Gewittergüssen folgt hin und wicder einmal ein Landregen von ein bis drei Tage langer Dauer.

Da meines Wissens bisher weiter keine meteorologischen Beobachtungen, welche näher erkennen lassen, aus welcher Richtung die jedesmaligen Mitt. von Forschungsreisenden, XX. Band. I.
Nicderschläge kommen, veröffentlicht vorliegen, so wird vielleicht in dieser Beżiehung noch folgender Auszug aus den meteorologischen Beobachtungen des Missionars Iudt zu Hoachanas willkommen sein. Herr Katastersekretär G. Thomas aus Gr. Windhuk stellte mir unter anderem Material freundlichst ein Manuskript des ersteren zur Verfügung, worin neben Tag und Stunde des Regens auch dessen Heraufziehen mit der betreffenden Windrichtung angegeben ist. Die Beobachtungen stammen aus der Zeit Januar I 883 bis Oktober I 884 mit geringen Unterbrechungen.

Während dieses Zeitabschnittes wurden $z u$ Hoachanas (5r), im nördlichen Teile von Gr. Namaland gelegen, an 44 Tagen 50 Regenfälle und mit ihnen gleichzeitig die Windrichtung $\left.{ }^{1}\right)$ notiert.

Der prozentmäßige Anteil der gleichzeitigen Windrichtungen - also die Angabe, aus welcher Richtung die Niederschläge heraufgezogen kamen beträgt für:

Regenwindrichtung: S. SW. W. NW. N. NE. E. SE. v.H. d. Gesamtsumme: 2 I 2 I 4 I6 I4 36 I4 oder graphisch dargestellt durch die

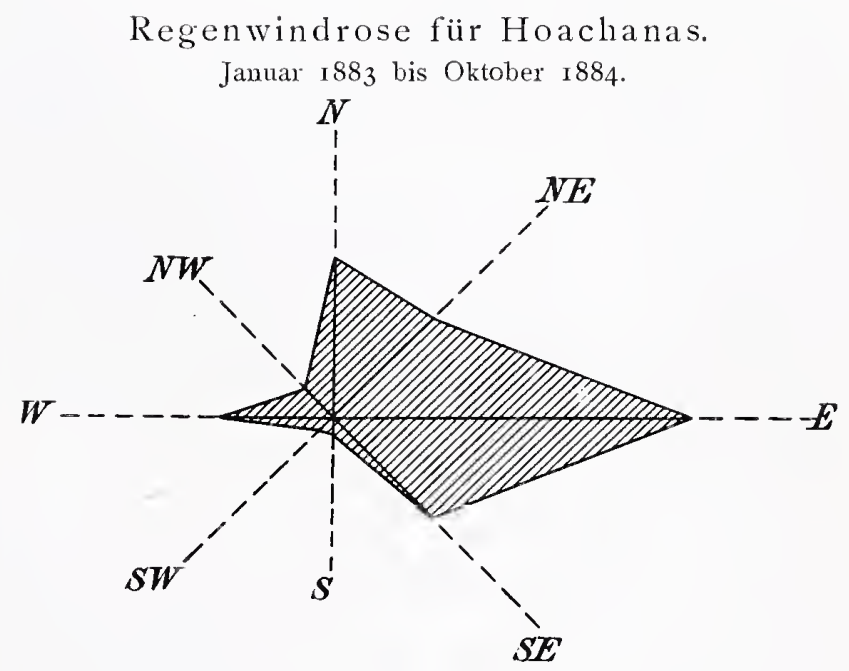

Die Abhängigkeit der Niederschläge von der Windrichtung kennzeichnet sich hier ganz deutlich in der Weise, daß bei weitem am häufigsten die aus dem östlichen Quadranten stammenden und jedenfalls aus dem Landinnern herkommenden Winde den Regen bringen.

Infolge der Lage von Hoachanas auf freiem Hochlande darf seine Regenwindrose als typisches Beispiel für das Binnenland von Gr. Namaland und vielleicht überhaupt den mittleren Teil von Deutsch. Südwestafrika gelten.

1) Es wurden dreimal täglich Windbeobachtungen angestellt: $7^{\text {h }}$ a. m., $2^{\text {h }}$ p.m., $9^{\text {h }}$ p. m.; auBerdem viele, spezielle Nebenbemerkungen ïber das Heranfziehen der mit Ts (Gewitter) meist verbundenen Wetter. 
Eine ziemlich eingehende Erörterung von A. Schenck ${ }^{1}$ ) iiber die Herkunft der Regen in Gr. Namaland bzw, ihren Zusammenhang mit den Winden glaube ich zum Schlusse noch erwähnen zu müssen.

A. Schenck, welcher persönlich längere Zeit in Deutsch-Südwestafrika war, kommt dabei auf Grund verschiedentlicher Regenbeobachtungen (so in Bethanien, Aus, Keetmanshoop) zu dem allerdings zunächst nur vorläufigen Schluß, daß in Gr. Namaland, abgesehen von den bisweilen auftretenden winterlichen Nebelregen, auch im Sommer die Niederschläge aus dem Westen kommen. Jedoch glaubt er schließlich annehmen zu müssen, daß auf den Hochebenen von Gr. Namaland es nur dann zu Niederschlägen kommen könne, wenn den feuchten und wärmeren Ostwinden die kalten trockenen Westwinde in den Weg treten, indem ihnen nur so die Gelegenheit zur Kondensation geboten werden könne.

Als Beleg für die größere Feuchtigkeit der östlichen Winde führte er schon früher einmal ${ }^{2}$ ) folgendes an: In bezug auf die Winde ist zu bemerken, daß hier (Bethanien) wie in Aus auch noch sehr häufig südliche und südwestliche Winde wehen, aber bei weitem nicht mit der Heftigkeit wie in Angra Pequena; sie sind auch hier stets trocken und bewirken einen heiteren, wenn auch immerhin meist nicht ganz wolkenlosen Himmel. Häufig aber treten auch nordöstliche Winde auf; sie sind feuchter als die Südwestwinde, was sich physiologisch dadurch äußert, daß man bei Nord- bis Ostwind schwitzt, während bei Südwest die Haut trocken bleibt. Die östlichen und nordöstlichen IVinde sind es auch, welche den Regen bringen, der fast stets von Gewittern begleitet wird.

Diese letzte Behauptung glaubte nun A. Schenck eben in seinen späteren Bemerkungen (von I9OI) über die Herkunft des Regens in der angegebenen Weise modiffzieren zu müssen. Danach fiele also nach Schenck den südwestlichen Winden in Gr. Namaland die Funlition $z u$, den Wassergehalt des viel wärmeren und feuchteren Nordostwindes zur Kondensation zu bringen.

Nach den vorangegangenen Darlegungen steht also im allgemeinen die Tatsache fest, daß die fast ausschließlichen Sommerregen im Innern Deutsch-Südwestafrikas fast nur mit Winden aus Nord bis Ost kommen, d. h. also einem Nordostmonsun als regenbringendem Wind zu verdanken sind.

1) Verhandlungen des r3. Deutschen Geagraphentages zu Breslau I901: S. 162 ff.: A. Schenck, Deutsch-Südwestafrika".

2) A. Schenck, „Das Gebiet zwischen Angra Pequena und Bethanien", Peterm. Mitt. I885, S. I35.
Damit erklären sich auch manche lokale Abweichungen in der Niederschlagsverteilung im Schutzgebiete, wie sie uns auf der Regenkarte entgegengetreten und dort in dieser Weise schon erörtert sind.

So z. B. dürfte die Vergrößerung der jährlichen Niederschlagsmengen im zentralen Hochlande beeinflußt sein durch das Aufsteigen der Ostwinde an dem hohen Gebirgsmassiv des Damaralandes; dagegen gibt sich auf der Westseite deutlich das Regenschattengebiet kund.

Auch in dem unregelmäßigen Einsetzen der Früllingsregen glaubt K. Dove (a. a. O.) eine Abhängigkeit von den vorherrschenden Winden zu erliennen, »indem eine schlechte Entwicklung der Zylilone auf der Namieb ein Vorwalten der (trockeneren) Südost- und Südwinde bedingen würde".

Zum Schlusse möge noch bemerkt werden, daß A. Schenck auch die große Gewitterhäufigkeit Deutsch-Südwestafrikas durch seine oben dargelegte Theorie zu erklären sucht. Danach würde sie, soweit man von eigentlichen Wärmegewittern nicht sprechen kann, wohl bedingt sein durch die durch Reibung der beiden entgegentirkenden Windrichtungen erzeugte große Luftelektrizität.

" Wegen der bedeutenden Unterschiede in Temperatur und Feuchtigkeit bewirkt der Zusammenstoß beider Winde, den wir uns so vorzustellen haben, daß der Südwest den Nordost veranlaßt, nach oben auszuweichen, die heftigsten elektrischen Entladungen, verbunden mit gewaltigen Regengüssen. «

Eine nähere Erörterung dieser mannigfachen die Windverhältnisse und ihren Einfluß auf die Niederschläge im Schutzgebiete betreffenden Fragen muß weiteren Studien vorbehalten bleiben.

\section{Nachtrag.}

Kurz vor Drucklegung vorliegender Abhandlung ging dem Verfasser noch das Regenmeßmaterial der Periode $1904 / 05$ zu. 28 Stationen lieferten vollständige Beobachtungsreihen; alle iubrigen waren durch den Herero- und Hottentottenaufstand vernichtet oder doch so in der Ausübung ihrer Funlition behindert worden, daß sie keine oder nur sehr lückenhafte Beobachtungsreihen einsenden konnten.

Die Regenzeit I904/05 war, was die Ergiebigkeit der Niederschläge angeht, eine im allgemeinen befriedigende. Über dem küstennäheren, sonst so regenarmen Westrand des Schutzgebietes, besonders in der näheren und weiteren Umgegend von Otjimbingue sind geradezu abnorm große Regenmengen gefallen.

Beifolgende Tabelle gibt die Niederschlagsmengen 1904/05 in Prozenten der in vorliegender Abhandlung 
berechneten bezüglichen Normalmittel an. So fielen 1904/05 in Prozenten

(3 bis 5) Olukonda

79.4 (43) Haris

I 23.7

(IO) Grootfontein

(I4) Outjo

66.0 (47) Rehoboth

68.4

95.5 (49) Nauchas

96.9

(I 5) Franzfontein

145.1 (5O) Aminuis

89.0

89.3 (5 I) Hoachanas 78.8

(I9) Omaruru

215.5 (53) Nomtsas

I I 4.6 (56) Maltahöhe

[82.0]

(2I) Okombahe

(23) Karibib

92.3 (58) Gibeon

(24) Wilhelmstal

(25) Okahandja

(27) Kubas

(29) Otjimbingue

IO3. 5

(6I) Berseba

64.3

73.6

205.3 (62) Bethanien

[199.3]

283.7 (63) Keetmanshoop 7 г.2

68.5 (66) Kubub

160.2

I04.2

(35) Windhuk

(37) Hohe Warte

70.8

(40) Jakalswater
$6 \mathrm{x} \cdot 3$
Im übrigen zeigt sich, daß die aus dem bisher einschl. I903/O4 vorliegendën Material gebildeten rohen Durchschnit tsmittel durch Hinzunahme des letzten von I904/O5 bei den allermeisten Stationen keine auffallende Veränderung mehr erleiden. Zu diesem Zwecke habe ich noch die umstehende Tabelle 23 aufgestellt. In Anbetracht dieses Umstandes sind denn auch die Normalmittel nicht von neuem berechnet worden.

Wohl aber fußen die Betrachtungen über die jahreszeitliche und monatliche Verteilung der Niederschläge schon mit auf dem Beobachtungsmaterial aus 1904/05. Für die ganze übrige Arbeit bleibt als Endtermin der Beobachtungen, welche das Material zu den einzelnen Berechnungen lieferten, der 3O. Juni rgo4 bestehen. 
Tabelle 23.

\begin{tabular}{|c|c|c|c|c|c|c|c|c|c|c|c|}
\hline & $\begin{array}{l}\text { Lfd. } \\
\text { Nr. }\end{array}$ & $\begin{array}{r}\mathrm{Name} \\
\text { der S t a t }\end{array}$ & i o & & $\begin{array}{c}\text { Anzaht } \\
\text { der Beob. } \\
\text { Jahre } \\
\text { (aussch1. } \\
\text { r904 05) }\end{array}$ & $\begin{array}{c}\text { Rohes Mittel } \\
\text { (ausschl. } \\
\text { I904/05) } \\
\mathrm{mm}\end{array}$ & $\begin{array}{c}\text { Rechniertes } \\
\text { (Normal-) } \\
\text { Wittel } \\
\text { mm }\end{array}$ & $\begin{array}{l}\text { Nieder- } \\
\text { schlagsmenge } \\
\qquad(\mathrm{mm}) \\
\text { während der } \\
\text { Regenperiode } \\
\text { 1904/05 }\end{array}$ & $\begin{array}{c}\text { Rohes Mittel } \\
\text { (einschl. } \\
\text { 1904/05) } \\
\text { mm }\end{array}$ & $\begin{array}{l}\text { Abweichung } \\
\text { Mittels (eins } \\
\text { gege } \\
\text { frïhere } \\
\text { rohe Mittel } \\
\text { (aussch1. } \\
\text { r } 904 / 05 \text { ) } \\
\text { in mm }\end{array}$ & $\begin{array}{l}\text { des rohen } \\
\text { chl. I 904/05) } \\
\text { n das } \\
\text { reduzierte } \\
\text { Nittel } \\
\text { in Prozent } \\
(\text { Normalmittel } \\
\text { N. }=100 \% \text { ) }\end{array}$ \\
\hline & (3) & Oniipa & . & . & $I^{5} / 12$ & 427.9 & 545.0 & 401.9 & $+19.8^{*}$ & 8.I & -23.0 \\
\hline & (4) & Ondangina & & & I & +12.6 & 602.1 & {$[453.2\}$} & $531.9^{*}$ & $+\operatorname{II} 9.3$ & $-\mathrm{II} .7$ \\
\hline & (5) & Olukonda. . & & & $67 / 12$ & 528.5 & 581.8 & $\lceil 327.7\rceil$ & $497.9^{*}$ & -30.6 & - I 4.4 \\
\hline$\dot{\overbrace{}}$ & (IO) & Grootfontein . & . & & $5^{3 / 12}$ & 567.7 & 618.9 & 408.3 & $562.9^{\%}$ & -4.8 & -9.0 \\
\hline$\Xi$ & $(I+4)$ & Ontjo & . & & $7^{1 / 12}$ & +28.3 & 441.3 & $42 \mathrm{I} .5$ & $+39 . I^{*}$ & $+\quad 10.8$ & -0.5 \\
\hline$\infty$ & (19) & Omarturt . & . & & $7^{10 / 12}$ & 272.3 & 275.7 & $2+6.2$ & $274.9^{*}$ & $+\quad 2.6$ & -0.3 \\
\hline 点 & $(25)$ & Okahanclja . & . & & $\mathrm{IO}^{9} / 12$ & 387.8 & 377.4 & 390.5 & $388.6^{*}$ & $+\quad 0.8$ & +3.0 \\
\hline in & (3I) & Gobabis. & • & & 7 & 418.7 & 470.6 & 322.4 & $406.6^{*}$ & $-\quad \mathrm{I} 2 . \mathrm{I}$ & $-\mathrm{I} 3.6$ \\
\hline $\begin{array}{l}\overrightarrow{0} \\
0 \\
n\end{array}$ & 1321 & Neudamm. & & & $4^{6} / 12$ & 280.2 & 381.4 & {$[207.2]$} & $258.6 \%$ & -21.6 & -32.2 \\
\hline$\tilde{u}$ & (33) & Seeis . . & & & $2^{3} / 12$ & 319.3 & 337.1 & {$[23 \mathrm{I} .4]$} & $340.8^{*}$ & $+2 \mathrm{I} .5$ & $+\quad I . I$ \\
\hline$=$ & $(35)$ & Windhuk . & & & It & 379.6 & 357.3 & 372.1 & $380.9^{*}$ & $+\quad 1.3$ & +6.6 \\
\hline$\stackrel{\Perp}{\Xi}$ & $(38)$ & Oas. . . & . & • & $4^{10} / 12$ & $35^{8.4}$ & 474.8 & {$[275.5]$} & $397.9^{*}$ & $+\quad 39.5$ & -16.2 \\
\hline$ت_{\pi}^{*}$ & $(37)$ & Hohewarte. & . & & 7 & 341.5 & 366.6 & 259.6 & $331.3^{*}$ & $\begin{array}{l}-\quad 10.2 \\
-1\end{array}$ & -9.6 \\
\hline 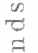 & $(45)$ & Hatsamas . & & & $5^{4} / 12$ & 295.4 & 357.1 & {$[\mathbf{I} 54 . \mathrm{I}]$} & $287.2^{*}$ & -8.2 & -19.6 \\
\hline$\stackrel{\infty}{=}$ & $(47)$ & Rehoboth. . & & & I $6^{11} / 12$ & 265.6 & 265.6 & I 8 I 6 & $257.7^{3 *}$ & $-\quad 7.9$ & -3.0 \\
\hline$\approx$ & $(50)$ & Aminuis . & & & $4^{10 / 12}$ & 211.9 & 307.4 & 273.6 & $263.6 \%$ & $+5 \mathrm{I} .7$ & $-\mathrm{I} 4.2$ \\
\hline $\bar{n}$ & $(5 I)$ & Hoachanas . & & & $5^{8 / 12}$ & I 99.8 & 237.7 & I 87.4 & $198 . I^{*}$ & $\begin{array}{ll}- & \mathrm{I} .7\end{array}$ & $-\mathrm{I} 6.7$ \\
\hline & $(53)$ & Nomtsas . & . & . & $58 / 12$ & I 75.2 & 208.4 & {$[\mathbf{I} 7 \mathrm{I} .7]$} & I $75.5^{*}$ & $+\quad 0.3$ & $-\mathrm{I} 3.8$ \\
\hline & $(56)$ & Maltahöhe & & . & $4^{3 / 12}$ & {$[77.3]$} & 159.8 & 102.7 & I $36.8 \%$ & +59.5 & - I 4.4 \\
\hline & $\left(5^{8}\right)$ & Gibeon & . & . & $5^{8 / 12}$ & 161.3 & 173.3 & I 27.5 & I $58.2^{* *}$ & $-\quad 3.1$ & -8.7 \\
\hline & $(6)$ & Zesfontein & & . & $2^{2} / 12$ & 67.2 & 69.4 & I I 3.8 & $87.8^{*}$ & +20.6 & +26.5 \\
\hline & (I 5) & Franzfontein . & & & $4^{10 / 12}$ & I 89.2 & 226.4 & 328.4 & $254.8^{*}$ & +65.6 & $+\mathrm{I} 2.6$ \\
\hline & $(2 \mathrm{I})$ & Okombahe & & & I & I 8 I .O & 136.2 & 293.5 & $237.5^{*}$ & +56.5 & +74.4 \\
\hline & (23) & Karibib . & . & & $3^{6 / 12}$ & 96.0 & 152.6 & I 74.8 & I $44.5^{5 \%}$ & +48.5 & $-5 \cdot 3$ \\
\hline 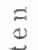 & (24) & Wilhelmstal . & . & & $\mathrm{I}^{10 / 12}$ & 267.4 & 379.4 & 350.9 & $341.4^{*}$ & +74.0 & -10.0 \\
\hline$\infty$ & $(27)$ & Knbas . . & . & & 2 & I 25.0 & 110.0 & 225.9 & I $74.6^{*}$ & +49.6 & $+5^{8.7}$ \\
\hline$=$ & $(29)$ & Otjimbingue . & & & $5^{6} / 12$ & I 48.3 & 136.6 & 386.7 & $188.4^{*}$ & +40.1 & +37.7 \\
\hline 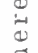 & $(40)$ & Jakalswater & . & & $4^{3} / 12$ & $33 \cdot 0$ & 30.5 & I 8.7 & $30.3^{*}$ & $\begin{array}{l}-\quad 2.7 \\
\end{array}$ & -0.6 \\
\hline : & (4I) & Swakopmind & . & & 6 & 22.7 & 29.6 & I 7.0 & $22.0^{*}$ & $\begin{array}{ll}- & 0.7\end{array}$ & $-25 \cdot 7$ \\
\hline \pm & (43) & Haris . . & . & & $I^{9} / 12$ & [I92.0] & 285.5 & 353.0 & $381.2^{*}$ & $+\mathbf{I} 89.2$ & +33.5 \\
\hline 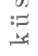 & (49) & Nauchas. & . & & $4^{5} / 12$ & I 68.3 & 223.8 & 216.8 & $172.8^{*}$ & $+\quad 4.5$ & -22.8 \\
\hline$\infty$ & (6I) & Berseba & . & & $3^{6} / 12$ & 46.3 & 78.9 & {$[\mathrm{I} 53.7]$} & $69.2^{*}$ & +22.9 & $-\mathbf{I} 2.3$ \\
\hline$\approx$ & $(62)$ & Bethanien. & . & & $6^{5} / 12$ & [ 132.3$]$ & 114.7 & I 26.8 & I $37 \cdot 3^{*}$ & $+\quad 5.0$ & +19.7 \\
\hline$\because$ & $(63)$ & Keetmanshoop & . & & $5^{10 / 12}$ & I 55.0 & 148.7 & 105.9 & I $53.7^{\%}$ & - $\quad \mathrm{I} \cdot 3$ & +3.4 \\
\hline 崩 & $(66)$ & Kubirb. . & . & & $2^{2} / 12$ & I 50.5 & 72.6 & I I 6.3 & $140.7^{*}$ & $\begin{array}{l}-\quad 9.8 \\
-\quad 1\end{array}$ & +93.8 \\
\hline$\sigma_{2}$ & $(65)$ & Lüderitzbucht & . & & $2^{6} / 12$ & I9.9 & 13.8 & 36.6 & $26.8^{*}$ & $+\quad 16.9$ & +94.2 \\
\hline & $(67)$ & Sandverhaar. & . & & $\mathrm{I}^{2} / 12$ & I $2 \mathrm{I} . \mathrm{I}$ & 64.9 & {$[105.0]$} & I $26 . I^{*}$ & $+\quad 5.0$ & $+94 \cdot 3$ \\
\hline
\end{tabular}




\section{Literatur-Verzeichnis.}

\section{Kartenwerke.}

I. Dr. Georg Hartmann, Karte von Dentsch-Sïdwestafrika, I : 300000 , I904.

2. Paul Langhans, Deutscher Kolonial-Atlas, Verlag von Justus Perthes, Gotha.

3. P. Sprigade und Max Moisel, Kriegskarte von Deutsch-Südwestafrika. Berlin I904, I: 8ooooo.

4. Wirtschafts- und Verkehrskarte von Deutsch-Südwestafrika. Verlag von D. Reimer, Berlin,

5. J. Han 11, Atlas der Meteorologie. Gotha I887.

6. A. Supan, Karte der Verteilung der Niederschläge auf der festen Erdoberfläche. Pet. Mitt.; Erg. Heft I24; Gotha I898.

\section{Allgemeine und spezielle meteorologische Literatur.}

7. H. Baum, Kunene-Sambesi-Expedition sowie Reisewerke über Südwestafrika, Berlin igo3. Herausgegeben von O. Warburg im Auftrag des Kolonial-Wirtschaftlichen Komitees.

8. C. G. Büttner. Die Missionsstation Otjimbingue, I 885 .

9. - Das Hinterland der Walfischbai und Angra Pequena. Heidelberg 1884.

10. A. Buchan, Rainfall of South Africa I885 bis I894. Cape Town 1897.

II. A. R. E. Burto n, Cape Colony for the Settler. London igoz.

12. J. J. v. Bülow, Deutsch-Südwestafrika; Drei Jahre im Lande Hendrik Witboois.

13. A. v. Danckelman, Über das Klima von Mossamedes (Deutsche Kolonial-Zeitung i 887, S. Ir6 ff.).

I4. - Bemerkungen zu den Regenmebresultaten von Rehoboth, Omaruru, Otjizeva (in den Jahresbericliteu des Vereius für Erdkunde zu Leipzig $188_{3}$ bis $188_{4}$ ).

15. K. Dove, Das Kilinıa des außertropischen Südafrika. Göttingen I 888 .

I6. - Über meteorologische Beobachtungen in Südwestafrika. Berlin I893.

17. - Deutsch-Sïdwestafrika, 1896, Gotha (Pet. Mitt. I898. Erg. I20).

18. G. Th. Fritsch, Drei Jahre in Siidafrika. I868.

19. - Klima von Südafrika, Zeitschrift der Gesellschaft für Erdkunde. Berlin r868.

20. R. Fitzuer, Deutsches Kolonialhandbuch, Berlin I901. 2. Aufl. 2 Bde.

21. H. Fischer, Die Äquatorialgrenze des Schneefalls. Inang. Diss. Leipzig 1888.

22. H. v. François, Deutsch-Südwestafrika; Nama und Damara. Magdeburg.

23. - Bereisung der Kalahari, 1893 .

24. Grisebach, Die Vegetation der Erde. Leipzig 1872. Band II.

25. G. Gürich, Deutsch-Sïdwestafrika. Reisebilder und Skizzen aus den Jahren I888 bis I889. Hamburg I89I. (Mitteilungen der Geographischen Gesellschaft zu Hamburg r891 bis I892.)

26. G. Frauenberger, Studien über die jährlichen Niederschlagsmengen des afrikanischen Koutinents. Pet. Mitt. 52. Band, Heft IV. I 906.

27. J. Hann, Lehrbuch der Meteorologie. Leipzig i gor.

28. - Handbuch der Klimatologie, 3 Bde., 2. Aufl. Stuttgart I897.

29. Hindorf, Der landwirtschaftliche Wert und die Besiedelıngsfähigkeit Deutsch-Südwestafrikas. I902.

30. G. A. Kannengieber, Deutsch-Südwestafrika im Jahre I9oo (Globus I90r).

3I. Lichtenstein, Reisen im südlichen Afrika. Berlin I8II.

32. Livingstone, Missionary Travels and Researches in South Africa. London 1857.

33. C. Kaßner, Die Klimate der deutschen Schutzgebiete (Das Wetter, I893).

34. S. Passarge, Die Hydrographie des nördlichen Kalahari-Beckens, I9or.

35. - Skizzen aus der Kalahari und vom Okavango. Frankfurt rgor.

36. - Die Kalahari. Berlin 1904.

37: Th. Rehbock, Deutsch-Südwestafrika. Berlin 1898 .

38. Der wirtschaftliche Wert der Subtropen in seiner Abhängigkeit von der Wasserfrage. Berlin I9or. 
39. Pecluül-L̈̈sche, Zur Fenntnis des Hererolandes (I886 Ansland«).

40. Sandmann, Klima der Waltischbai, Inamg. Diss. Münster i. Wr. r 901

4. A. Schenck, Deutsch-Südwestatrika (Verhandlungen des 13. Deutschen Geographentages zu Breslau, S. I62 ff. I9or).

42. - Gebiet zwischen Angra Pequena und Bethanien. Pet. Mitt, I885, S. I35 ff.

43. Il. Schinz, Deutsch-Südwestafrika, Reiseskizzen ans Nama- und I)amaraland. Oldenburg-Leipzig I89I.

44. Fr. Hahn, Afrika, 2. Autl. Leipzig-Wien rgor.

45. F. Il. Stapff, Bodentemperatux-Beobachtungen in Flinterlande der Wallischbai.

46. A. Supan, Verteilung der Xiederschläge auf der festen Erdobertläche. Pet. Mitt. rógs. Erg. Heft I24.

47. G. Wallhäuser, Verteilung der Jahreszeiten im sïdäquatorialen tropischen Afrika. GieBen-Darmstadt. Diss. 1904.

48. Fox Wilson, Water supply in the basin of the Orange River. London r 865.

49. E. v. Weber, Vier Jahre in Afrika. Leipzig 1878 .

50. E. Hahn, Die Ovalıerero. I869. (Zeitschrift für ạllgemeine Erdkunde, Berlin.)

5r. Woeikof. Die Kimate der Erde. Jena 1887.

52. Chapman, Travels in the Interior of South Atrica. London i 868 .

\section{Quellen der Regenmeßresultate der meteorologischen Stationen in Südwestafrika.}

53. Holetin da Sociedade de Geographid de Lisboa I89I. ro. Ser. Nir. + e 5, pg. 209 etc.

54. »Eentsches Kolonialblatt" I893, I 899. 1900.

55. Deutsche Kolonialzeitung « 1887 , I 893 bis 1905 .

56. Deutsche überseeische meteorologische Beol,achtungen《 I893 bis. rgor. Vrul. Jalneshericht der Dentschen Seewarte zu Limburg.

57. Globus" I 897, Heft 12, 19; r898, Heft 5. Brannschweig.

58. Wagners 》Geographisches Jahrbuch 1896 bis I 899 , I900 bis 1903.

59. Zeitschrift der "(resellschaft für Erdkunde zu Berlin«. IS93, 1905.

6o. Jahresberichte ïber die Entwicklung der deutschen Schntzgebiete in Afrika und der südsee.

6r. Nitteilungen des Leipziger Vereins für Erlkunde. I883, I884.

62. Neteorologische Zeitschrift. I883, I884, I888, 1890 , I 896, I 903.

63. Mitteilungen von Forschnngreisenden und Gelehrten aus den dentschen sihutagebieten.« Lerlin I893 bis r905.

64. Observatorio do Infanto D. Luiz, Lisboa". I88I. Observatorio Net. de Loandld, I879 bis I885, 1886 bis I89I, I89o bis I89I.

65. Petermanns Geographische Mitteilungen. I886, 1887, I 894, I 898 , 1900.

66. Report of the British Association . Glasgow I90r.

67. Report of the Meteorological Commission of Cape of Good Hopeu for the year r 888 .... Igor.

68. Das Wetter I893. Braunschweig.

\section{Berichtigung.}

Auf seite 69. linke Spalte, auf Zeile 22 ron oben lies I hagr. 53 statt Diagr. 48.

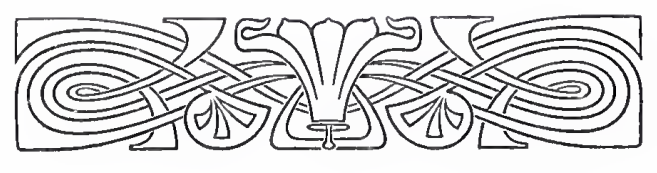




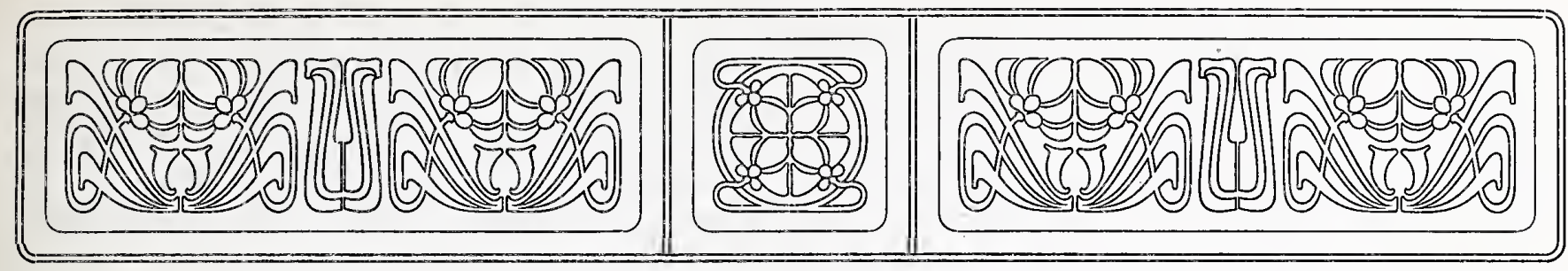

\section{Aus dem Schutzgebiete Kamerun.}

\section{Der Handel der Duala.}

Von Dr. jur. et phil. Asmis.

Unter den Küstenstämmen des Schutzgebietes Kamerun nehmen die Duala an der Kamerunmündung eine ganz besondere Stellung ein. Der ausgezeichnete Hafen erleichterte es den europäischen Kaufleuten, mit ihnen in enge Handelsbeziehungen $z u$ treten; sie selbst verstanden es, sich in einem weiten Gebiet um das Kamerunbecken herum bei den Eingebornenstämmen èin streng durchgeführtes Handelsmonopol $z u$ erwerben und bis in die neueste Zeit $\mathrm{zu}$ erhalten. Gerade die Gefährdung dieser privilegierten Stellung durch das Vordringen der europäischen Firmen war einer der Hauptgründe, die im Jahre I905 die Duala zu der Einreichung der bekannten Beschwerdeschrift veranlaßten. In dieser beschwerten sich die Akwa, einer der Hauptstämme der Duala, unter anderem darüber, daß die Regierung des Schutzgebietes ihr Handelsmonopol ničlt geschützt und die Anlegung von Buschfaktoreien durch die europäischen Firmen nicht verboten habe. Sie behaupteten ausdrücklich - allerdings ohne jede Grundlage -, daß in dem Vertrage vom I2. Juli I 884, in dem die Dualahäuptlinge ihre Hoheitsrechte an die Firmen C. Woermann und Jantzen und Thormählen abtraten, und dessen Verpflichtungen später von dem Deutschen Reich übernommen wurden, eine derartige Bedingung aufgestellt gewesen sei.

Art und Umfang des Handels der Duala verdienen daher - ganz abgesehen davon, daß diese Verhältnisse vom volkswirtschaftlichen Standpunkt aus recht interessant sind - bei deren weitgehendem Einfluß auf die Nachbarstämme auch in politischer Beziehung Beachtung.

Veröffentlichungen hierüber sind mir außer der Einleitung des Handbuches der Woermann-Linie von 1906 nicht bekannt geworden. Die großen Werke über Afrika und das Schutzgebiet Kamerun Mitteilungen a, d, D. Schutzgebieten, XX, Band. II, berühren, wenn überhaupt, diese spezielle Frage nur ganz flüchtig. Auch die nachfolgenden Zeilen machen keinen Anspruch auf absolute Vollständigkeit, immerhin mögen sie schon einigen Anhalt für etwaige weitere Untersuchungen geben. Die Grundlagen bilden vornehmlich mündliche Mitteilungen von Eingeborenen, Kaufleuten und Missionaren. Das subjektive Moment in diesen Erzählungen ist nach Möglichkeit ausgeschaltet.

Etwa um das Jahr I 706 zogen die Duala, damals noch ein reines Fischervolk, von Pity am Dibamba an die Mündung des Kamerunflusses. Der Fischreichtum des Kamerunbeckens hatte sie angelockt. Sie drängten die dort wohnenden Bassa zurück und siedelten sich zunächst auf den beiden Ufern des Kamerunflusses in der Höhe des jetzigen Hickory (Bonaberi) und der Akwastadt (Bonaku) an. Erst später entstanden die jetzigen Stadtteile Bonanjo (die Bellstadt) und Bonebela (die Deidostadt). Die ersten Europäer, mit denen sie hier in Berührung kamen, waren die Portugiesen. Diese besuchten bei ihren Fahrten an die Westküste Afrikas und die vorgelagerten Inseln auch die Niederlassung der Duala. Der erste portugiesische Händler soll im Jahre I786 nach Duala gekommen sein. Es ist aber nicht ausgeschlossen, daß bereits um die Mitte des I8. Jahrhunderts Portugiesen Duala fiüchtig beriihrt haben."*)

Die Portugiesen verfolgten hierbei lediglich den Zweck, Sklaven zu erhandeln. Die Duala fungierten hierbei von vornherein als Zwischenhändler. Sie selbst waren jeder ernsten kriegerischen Tätigkeit

*) Nach ınkontrollierbaren portugiesischen Angaben sollen portugiesische Händler bereits $\mathrm{I} 640$ in Duala gelebt und soll damals bereits der Versuch zu einer liesteigung des Kámerunberges gemacht worden sein. Sie scheinen dann infolge eines groBen Sterbens Duala wieder verlassen zu haben. Anm. d. Red. 
abgeneigt und machten daher selbst lieine Sklaven. Auch kam es wohl niemals vor, daß die Oberhäuptlinge der Duala Angehörige des Stanmes in die Sklaverei verkauften. Allerdings behaupten die Akwa dies von dem frühheren Oberhäuptling der Bellleute. Die Belleute selbst bestreiten es entschieden, und es dürfte jene Erzählung der Akwa lediglich als Ausflub der augenblicklichen Stammesfeindschaft anzusehen sein. Dic Duala erwarben vielmehr die Sklaven in IVege des Kaufes von den Nachbarstämmen, besonders von den am Mungo sitzenden Völliern.

Die Portugiesen hatten damals als Preis für einen Sklaven zu zahlen: ein Faß Rum (etwa 80 l), mehrere Fässer Pulver, ein oder mehrere Gewehre, einen Sack Salz und eine Anzahl Zeuge. Die Zahl der Zeuge bestimmte sich nach der Körpergröße des Sklaven. Es mußten so viel Stücke aufeinandergelegt werden, bis der Stapel die Höhe des Mannes hitte. Die Qualität des Stoffes war bei dieser Art der Preisbestimmung natürlich die denkbar schlechteste. Der Käufer des Sklaven suchte ein möglichst billiges und dennoch raumfuillendes Fabrikat zu verwenden. Der damals am meisten gebrauchte Stoff hieß Croydon, ein dünnes, lose liegendes Gewebe. Von diesem gehörten etwa I 5 bis 20 Stücke dazu, um, aufeinandergelegt, die Höhe eines Durchschnittssklaven zu erreichen. Das Stück enthielt ungefähr 60 Yards (I Yard $=9 \mathrm{I}, 4 \mathrm{~cm}$ ). Wie viel die Duala selbst als Einkaufspreis für einen Sklaven zu zahlen hatten, habe ich nicht genau ermitteln können. Jedoch wird es laum mehr als $1 / 3$ bis $1 / 2$ des Verkiaufspreises gewesen sein.

Eine Folge der mit dem Sklavenhandel verbundenen Aufhäufung von Pulvervorräten war uibrigens, daf in den allgemein anerkannten Kaufpreis für ein Weib eine bestimmte Menge Pulver mitaufyenommen wurde.

Die Unterdrückung des Sklavenhandels zu Beginn des 19. Jahrhunderts machte die Küste Kameruns zunächst für den europäischen Handel bedeutungslos. Erst um I 820 begannen englische Firmen, denen um die Mitte des Jahrhunderts deutsche - in erster Linie C. Woermann, Hamburg - folgten, wieder mit den Duala Handelsbeziehungen anzulnuipfen. Der Handel an der Westkuiste Afrikas wickelte sich damals in der Weise $\mathrm{ab}$, daß die heimische Firma ein Schiff mit Tauschwaren hinausschickte, um Landesprodukte, hauptsächlich Palmöl, und Elfenbein einzutauschen. Hatte der Kapitän seine Ladung umgesetzt, so segelte er nach Hause, um vielleicht erst nach Jahren die Küste Afrikas wieder zu besuchen. Irgendwelche ständigen Niederlassungen der Europäer gab es am
Kamerunbecken nicht. Die Duala-Häuptlinge verboten jeden Versuch der Kaufleute, sich auf dem Lande festzusetzen. Einmal hatten sie an dem Küstensaum nur verhältnismäßig wenig Platz für die eigenen Niederlassungen, sodann wollten sic vor allen jede Berührung der Europäer mit den Hinterlandstämmen verhindern, um nicht etwa direkte Handelsbeziehungen zu diesen entstehen zu lassen. Zugute kam ihnen hierbei die Scheu der Europäer, sich in jenen Fiebergegenden anzusiedeln.

Hatte ein Kapitän volle Ladung an Landeserzeugnissen erhalten, ohne seine Tauschwaren vollständig verbraucht zu haben, so ließ er wohl den Rest den Häuptlingen dort mit der Verpflichtung, bis zu seiner Wiederkehr hierfür Palmöl und Elfenbein von den Nachbarstämmen einzutauschen. Er überließ ihnen die Waren auf Kredit, ohne eine besondere Sicherheit dafür zu verlangen. Es war dies der Anfang des sogenannten Trustsystems, das 1 neuerer Zeit bekanutlich einen dem kulturellen Fortschritt direkt hinderlichen Umfang angenommen hat.

Im übrigen vollzog sich der Handel in den Formen des reinen Tauschverkehrs. Getauscht wurden an europäischen WVaren: Tuche, Buschmesser (englisch-cutlas), Salz, Pulver, Gewehre, Tabak in heads, d. h. kleine Bündel aus fünf mit einem sechsten Blatt zusammengebundenen Tabakblättern im Werte von ungefähı 0,20 M., Rum in demijohns, d. h. Korbflaschen, deren Inhalt einen Wert von etwa 5 M. hatte, und Perlen. Seit Mitte der 6oer Jahre des 19. Jahrhunderts traten zu dem bisher hierfür gewünschten Palmöl und Elfenbein die Palmkerne, die ba'd Haupthandelsartikel wurden. Vereinzelt wurden auch Kokosniisse und Ebenholz gehandelt. Die Produkte der Farmwirtschaft: Kassada, Mais, Erbsen, Bohnen, Jams und Kolio waren nur Gegenstand des Kleinhandels, und auch das nur in ganz unbedeutendem Umfang. Sie baute im wesentlichen jeder Duala für den eigenen Bedarf.

Bei diesem Tauschverkehr bildeten sich im Laufe der Zeit feste Preise für die einzelnen europäischen Waren und ein bestimmter Wertsatz für eine gewisse Menge derselben heraus, die als Preis für eine bestimmte Quantität von Rohstoffen galten.

roo $\mathrm{kg}$ Palmkerne, meist nur ganz ungenau und nicht zum Nachteil des weißen Händlers in einer abgeschnittenen Tonne gemessen, bildeten ein kroo (spr. Kru). Der Preis hierfür waren in erster Zeit Waren im Verkaufswerte von 20 M., die sich der Duala nach eigener Wahl aus den Beständen des weißen Kaufmanns wählen konnte. Der Name des Hohlmaßes wurde später die Bezeichnung des 
dafür gezahlten Preises, und so entstand nach und nach eine ganz eigenartige Warenwährung, bei der das kroo die Einheit bildete. Ursprünglich deckten sich noch die Unterteile dieser Währungseinheit mit de11 entsprechenden Hohlmaßen. So waren

I $\mathrm{keg}$ (wohl vom engl. keg $=$ Fäßchen) $=5 \mathrm{M}$. in Waren $=25 \mathrm{~kg}$ Palmkerne,

I piggin $=2,50 \mathrm{M} .=\mathrm{I} 2,5 \mathrm{~kg}$ Palmkerne,

I bar = I,25 M. = 6,25,

Später geriet die Entlehnung dieser Werte von den Hohlmaßen in Vergessenheit, und sie bezeichneten nur noch bestimmte Warenmengen, in denen die Preise berechnet und gezahlt wurden. Die Waren, die Mitte der 7oer Jahre ein kroo ausmachten, hatten im Einkauf vielleicht 6 M. gekostet. Das Geschäft war dahcr recht lukrativ. Die zunehmende Konkurrenz verteuerte jedoch durch die Vermehrung der Nachfrage den ursprünglichen Preis, so daß bald bis zu 2 kroo für $100 \mathrm{~kg}$ Palm. kerne gezahlt wurden. Auf diese Preissteigerung ist weiter unten noch ausführlicher einzugehen. Jedenfalls veranlaßte die Unsicherheit in der Bestimmung des Wertes eines kroo nach der Besitzergreifung Kameruns durch das Deutsche Reich die Regierung, hier einzuschreiten. Sie setzte die Werte, wie folgt, fest:

I $\mathrm{kroo}=\mathrm{I} 2 \quad$ M. in
I $\mathrm{keg}=3 \quad, \quad, \quad$,
I piggin $=$ I,50 ", ",
I bar $=0,50, "$,

d. h. der in Duala gangbarsten Münze, dem sixpence, entsprechend.

Die Zunahme des Handels zwischen den Duala und den europäischen Firmen machte es für diese wünschenswert, ständige Handelssitze an der Küste zu haben. Da ihnen eine Niederlassung auf dem Lande noch immer nicht gestattet wurde, so verankerten sie jetzt abgetakelte Schiffe in der Flußmündung und benutzten' diese als ständige Faktoreien. Diese „Hulks" sind schon so häufig beschrieben worden, daß sich eine genauere Beschreibung erübrigt. Sie ergänzten ihre Warenbestände mit Hilfe anderer, nur dem Transport dienender Schiffe, die eine regelmäßige Verbindung mit dem Heimatlande aufrecht erhielten. Aber auch jetzt blieb der Handel der Firmen ausschließlich Küstenhandel. Die Verteilung der von den Firmen angelieferten Waren an die eigentlichen Konsumenten und umgekehrt das Sammeln der Landeserzeugnisse besorgten nach wie vor die. Duala. Nur eine wesentliche Veränderung trat ein: War bisher der Kauf Zug um Zug das Übliche und der Kreditkauf die Ausnahme gewesen, so wurde er jetzt zur Regel. Die Firmen pflegten nunmehr den Häuptlingen zu
Beginn der Saison, d. h. mit Bcginn der Trockenzeit, große Mengen Waren auf Kredit zu geben, mit der Verpflichtung, am Schluß der Saison, mit dem Einsetzen der Regenzeit, entsprechende Massen Palmkerne u. dgl. abzuliefern. Es kam wohl vor, daß die einzelnen Firmen einem Häuptlinge einen Kredit bis zu 5000 kroo gewährten. Die Verbindlichkeiten der Oberhäuptlinge mochten sich hiernach, entsprechend der Anzahl der Handel treibenden Firmen, auf mehrere roo ooo M. in Waren belaufen. Über dieses Gcschäft stellte die Firma dem Häuptling einen Schein, ein ,Bcol" aus und vermerkte gleichzeitig den Betrag in ihren Büchern. Hatte der Häuptling die erhaltenen Waren umgesetzt, so kehrte er mit vollen Kanus zurück, um den Trust zu "waschen“. Er wollte seine Verbindlichkeit tilgen, den Vermerk auf der früher üblichen Tafel durch die Bezahlung seiner Schuld gewissermaßen abwaschen. Für die Familie des Häuptlings gab dessen Rückkehr von der Handelsreise Anlaß zu großen Festlichkeiten, dem sogenannten Nduta. Zu 15 und mehr lagen dann die beladenen Kanus in Parade quer über den Fluß, und unter lärmenden Spielen und reichlichem Palmweingenuß feierte die beteiligte Bevölkerung das Fest. Oder dic zurückkehrenden Dualahän dler umfuhren unter lautem Trommeln dieHulks, und dieFirmen suchten ihrerseits durch Geschenke allcr Art den betreffenden Häuptling zu veranlassen, zuerst das eigene Konto zu begleichen. Auch hier überboten sich bald die Konkurrenten, da die Häuptlinge nach der Art der Geschenke sich zu entscheiden pflegten, welches Konto und welchen Betrag sie bezahlen wollten, und verteuerten so die Unkosten des Geschäfts nicht unerheblich. Im allgemeinen kann man annelımen, daß bis in die Mitte der Soer Jahre des vergangenen Jahrhunderts die Schulden regelmäßig getilgt wurden.

Auf seiten der Duala besorgten nämlich in erster Linie die Oberhäuptlinge, die Kings, von Bell-, Akwa- und Deido-Stadt das Handelsgeschäft. Sie waren die eigentlichen Kontrahenten. Die Firmen hatten dafür, daß sie an der Küste Handel treiben durften, an sie gewisse jährliche Abgaben, das kumi, zu zahlen. Hierfür garantierten ihnen die Kings Sicherheit vor Überfällen und Erfüllung der Verbindlichkeiten. Später erlaubten die Oberhäuptlinge auch einzelnen Unterhäuptlingen und anderen Duala, selbständig mit den Firmen Handel zu treiben. Zur Erhöhung der Sicherheit für die weißen Kaufieute pflegten sich dann die Oberhäuptlinge für ihre Untertanen ausdrücklich zu verbürgen, sie beanspruchten aber hierfür von diesen einen gewissen Prozentsatz des Gewinns für sich. Kein Wundcr, daß bei einer derartigen doppelten 
Gewinnbeteiligung, den kumi von dem Gewinn des Europäers und jenem Prozentsitz von dem Verdienst des Duala, die Einnahmen der Oberhäuptlinge damals recht bedeutend waren. Betrug doch schon der Gewinn eines Duala aus einer cinzigen Handelsreise in den Busch, deren Dauer zwischen $1 / 2$ und $11 / 2$ Jahren schwankte, 300 bis 400 kroo. Das Trustsystem gab hicrbei aucl dem unbemittelten Duala die Möglichkeit, sich an dem gewinnbringenden Erwerbszweig zu beteiligen, sofern es nur der Oberhäuptling gestattete. Zahlte der Duala-Händler aber danach seine Schulden nicht, so war die Firma berechtigt, jedes Mitglied der Familie des Schuldners, dessen sie habhaft werden konnte, festzunehmen und so lange in Ketten zu legen, bis durch die Familie die Schuld getilgt war. Diese Berechtigung beruhte auf dem alten Grundsatz des Duala-Rechtes, nach dem die Familic als solche, in ältester Zeit sogar der ganze Stamm, für die Schulden der Mitglieder aufzukommen hatte. Wiederholt machten die Firmen hiervon Gebrauch, selbst gegenüber Angehörigen der Häuptlingsfamilien. Jedoch blieb bis zur Besitzergreifung durch die Deutschen der selbständige Handel mit den Firmen nur verhältnismäßig wenigen Duala gestattet.

An dem Absatz an die Hinterlandstämme beteiligte sich dagegen fast die gesamte männliche Bevölkerung. In der ersten Zeit bestand irgend eine Abgrenzung von Handelsgebieten für die einzelnen Duala-Stämme noch nicht. Jeder handelte dort, wo ihm Stammesfreundschaft und persönliche Beziehungen den Absatz möglichst erleichterten. Häufig kam es vor, daß die Stammesoberhäupter der Käufer und der Verkäufer durch Vereinbarung die Preise der Waren festsetzten. Noch häufiger war es aber, daß die an einem Ort im Hinterland ansässigen Duala-Händler sich zusammentaten und durch gemeinsamen Beschluß Maße und Preise für Landesprodulite festsetzten. Diese Vereinbarungen wurden dank des geschlossenen Zusammenhaltens der Duala und dank des Mangels jeder Konkurrenz durch andere Stämme für die ganze Gegend verbindlich. Dabei wurden von seiten der Stämme, in deren Gebiet die Duala handelten, Abgaben nicht erhoben. Wurden ihnen Schwierigkeiten in den Weg gelegt, so mieden sie lieber diese Gebiete und lieben sich jedenfalls nie auf einen kriegerischen Ausgleich ein. In der Regel hatten aber die entfernter wohnenden Stämme als Produzenten ein ureigenstes Interesse an der Vermittlung des Absatzes ihrer Produkte durch die Duala.

Als Eifersüchteleien und Konkurrenzneid erhebliche Reibereien zwischen den einzelnen DualaStämmen entstehen ließen, besonders zwischen den
Bell- und den Akwa-Leuten, grenzten die Oberhäuptlinge clurch mündliche Vereinbarung für den Bellund den Akwa-Stamm besondere Gebiete ab. Die Bell-Leute erhielten das Mungo-, die Akwa das WuriGebict. Die Deido-Leute handelten hauptsächlich ebenfalls im Mungo-Gebiet.

Vor der Berïhrung mit den europäischen Firmen waren bei den Handelsgeschäften von Angehörigen versclicdener Stämme und auch desselben Stammes, deren Hauptgegenstand der Weiberkauf bildete, Hunde und Ziegen Zahlungsmittel gewesen. Noch heute ist dies bei einzelnen von der Küste entfernter wohnenden Stämmen der Fall. Durch die größere Einfuhr von europäischen Waren wurde jedoch dies Geld « verdrängt, und an seine Stelle trat die bereits geschilderte Warenwährung, allerdings in etwas modifizierter Form.

Vährungseinheit wurde das bar. I 2 bar bildeten cin nbom, das also einem halben kroo entsprach. Der wirkliche Wert des »Geldes" wurde verschlechtert. Die Duala rechneten bei kleincren Beträgen bis zu cinem nbom nach bar. Wurden mehrere nbom gezahit, so wurde das nbom nur noch zu lo bar gerechnet. In nbom wurde aber nur bis zum Höchstbetrage von 9 nbom und 9 bar gezahlt, bei höheren Beträgen wurde wieder nur nach bar gerechnet, so daß also 100 oder 200 bar, nicht aber $\mathrm{I} O$ oder 20 bar gezahlt wurden.

Die Duala schafften die Waren teils auf den vielen Wasserläufen des Kamerun-Ästuars, mittels Kanus, teils mittels Trägerkarawanen in das Hinterland. Bestimmte Märlte zum Umsatz der europäischen Waren fanden dort nicht statt. In Duala selbst fand seit I 896 jeden dritten Tag Markt, hauptsächlich Lebensmittelmarkt, statt. Ihren Verdienst legten die Duala in Weibern an. Die nötigen Mittel zu erwerben, um sich eine möglichst große Anzahl von Weibern anschaffen zu können, war das Streben jedes einzelnen, und so war der gesamte übrige Handel eigentlich nur Mittel zur Erreichung dieses Zweclies. Der nicdrigste Händler hatte acht bis zehn, ein Häuptling 15 bis 2O, die Oberhäuptlinge bis zu 60 und mehr Weiber. Bei dem Weiberkauf haben sich daher auch allein bestimmte Handelsgebräuche herausgebildet. Wenn der Gewalthaber das Mädchen dem Käufer übergab, so ergriff er wohl dessen Hand und schlug ihm mit dem Rücken seiner eigenen Hand neunmal in die innere Handfäche. Auch wurde es üblich, daß, abgesehen von dem eigentlichen Kaufpreise, ganz bestimmte Geschenke an den Gewalthaber des Mädchens und an deren Mutter gemacht wurden. Der Käufer mußte nämlich 2 Ziegen - besonders große, sogenannte Heiratsziegen, von denen ein 
Tier einen Wert von etwa $40 \mathrm{Mk}$. hatte - , mindestens I ngaki $(=4$ Liter) Rum, ein Faß Pulver, einen Sack Salz und eine Kiste mit Tüchern für die Mutter abliefern. Erst dann wurde ihm das Weib übergeben.

Im Jahre I88I gelang es der Firma C. Woermann als erste auf dem Lande selbst festen Fuß zu fassen. Sie erwarb ein Grundstück in Deidostadt und errichtete dort eine Faktorei. Eine Änderung im Handelsverkehr trat hierdurch nur insofern ein, als nunmelir die Anlieferung der Landesprodukte auch am Nachmittage erfolgen konnte. Die Kanus hatten sich nämlich nur bis zum Einsetzen der Seebrise längsseit der Hulks halten können. Sobald diese aufkam, bestand die Gefahr, daß die Kanus vollschlugen, und der Handel an den Hulks hatte sich daher bisher nur in der Zeit von morgens 6 Uhr bis ungefähr nachmittags 2 Uhr abgewickelt. Zu Beginn der achtziger Jahre handelten außer C. Woermann noch die deutsche Firma Jantzen und Thormählen und die englischen Firmen John Holt, R. u. W. King, David Jones u. Comp., Herrschell und Rider son u. Andrew am Kamerunbecken. Nach und nach legten auch diese Faktoreien auf dem Lande an, und noch weitere Firmen eröffneten Geschäfte in Duala.

Die Erschwerung des Handels der Firmen infolge der zunehmenden Konkurrenz und die Änderung der gesamten Verhältnisse infolge der Besitzergreifung Kameruns durch das Deutsche Reich führten zusammen mit der Unfähigkeit der Duala, ihren Handel den veränderten Verhältnissen anzupassen, zur Vernichtung ihres Handelsmonopols.

Bei der Ablieferung der Landesprodukte hatte der Häuptling ursprünglich als „dash“ (= Geschenk) ein Glas Rum von den Firmen erhalten. Irgend eine Verpflichtung hierzu bestand jedoch für die Firmen nicht. Später wurde das dash allgemeiner Usus; bald verlangten ihn die Häuptlinge sogar. Die Firmen überboten sich gegenseitig; aus dem Glase Rum wurden bestimmte Mengen Waren, so daß I88 I bereits I keg als dash für I kroo Palmkerne gegeben wurde. Mitte der goer Jahre kam das dash bereits dem ursprünglichen Preis der Produkte gleich. Dabei hatte das dash den Charakter des Geschenkes, der freiwilligen Zugabe, verloren. Es war jetzt zum festen Bestandteil des Kaufpreises geworden, und nur noch die Bezeichnung erinnerte an den ursprünglichen Charakter. 1898 wurde schon I kroo und I keg als dash gegeben, so daß für IOO kg Palmkerne in Wirklichkeit $2 \mathbf{1} / 4$ kroo gezahlt wurden. Nach den von der Regierung festgesetzten Werten waren dies $27 \mathrm{M}$. in Waren. Ein kroo Waren kostete den Firmen im Einstand im
Durchschnitt ungefähr 8 M. . Der Einstandswert eines kroo schwankte jedoch damals sebr, da, wie erwähnt, der Duala sich aus den Beständen der Faktorei wällen konnte, was er wollte. Nahm er z. B. überwiegend billige Seife, so kam das kroo im Einkauf auf etwa 5 M., nahm er Pulver oder Gewehre - ein Gewehr wurde als I kroo gerechnet und kostete der Firma selbst ungefähr $9 \mathrm{M}$. - so war der Anschaffungspreis ungefähr $9 \mathrm{M}$. Wurden also $2 \frac{1}{4}$ kroo für IOO $\mathrm{kg}$ Palmkerne gezahlt, so hatten die Firmen - abgesehen von ihren Unkosten - bereits I 8 M. dafür aufgewandt. Dem entsprach aber der Palmkernpreis des Weltmarktes nicht.

Dazu kam, daß das Risiko der Firmen bei dem Trustsystem erheblich größer geworden war. Als Kamerun deutsch wurde und die Oberhoheitsrechte der Häuptlinge auf das Reich übergingen, fiel ihr Privilegium, den Handel allein zu betreiben und den Handelsbetrieb anderer Duala von ihrer Erlaubnis abhängig zu machen. Der Handel wurde für sämtliche Duala frei. Die Firmen konnten jetzt mit jedem beliebigen Duala in Geschäftsbeziehungen treten, und sie machten, gedrängt von derKonkurrenz, in weitestem Maße hiervon Gebrauch. An Leute, die selbst über kein Vermögen verfügten, wurden Waren in Beträgen gegeben, für die in Deutschland jeder Geschäftsmann weitgehendste Sicherheit verlangt. Daß ein einfacher Duala für mehrere ıooo Mark Kredit erhielt, war nichts Außergewöhnliches. Naturgemäß übernahmen jetzt die Oberhäuptlinge keineswegs mehr allgemein die Bürgschaft, und das Eindringen europäischer Rechtsanschauungen beseitigte mehr und mehr die alte Familienhaftung. Es kam daher jetzt häufiger vor, daß Duala ihre Schuld nicht mehr ,wuschen". Ein Versuch der Firmen, auf gerichtlichem Wege wieder zu ihrem Gelde zu kommen, war bei der Vermögenslosigkeit der Duala meist ergebnislos. Versuche der Regierung, mit Rücksicht auf die Gefährlichkeit des Trustsystems das Kreditgeben ganz $\mathrm{zu}$ verbieten, scheiterten an dem Widerstand der Kautleute, die trotz allem ohne Trust nicht auskommen zu können glaubten. Ebenso hatten die Bemühungen einer einzelnen Firma, den Bargeldverkehr einzuführen, infolge der Nichtbeteiligung der Konkurrenzfirmen keinen wesentlichen Erfolg. Dabei würden übrigens die Duala selbst sehr gern den Barverkehr eingeführt sehen. Die Lebensmittel werden auch schon fast nur noch mit barem Gelde bezahlt, so daß die Nachfrage hiernach bereits recht. lebhaft ist. Gerade bei dem Lebensmittelhandel findet auch schon das ro-Pfennigstück - von den Eingeborenen "kapa" nach den englischen Kupfer-(copper) münzen so genannt - 
und das 5-Pfennigstïck, das ,Habbapa“, Eingang, während sonst noch allgemein das 50-Pfennigstïck, das ,six pence", die eigentliche Münze des Kleinverkehrs ist.

Die Unsicherheit des Trusts und die Weigerung der Duala, in ihren Preisforderungen für Palmkerne der Weltmarktlage entsprechend herunter zu gehen, die so weit ging, daß sie sogar die gesamte Palmkernlieferung sperrten, ließ bei den Firmen den Entschluß entstehen, unter Umgehung des Zwischenhandels direkt mit den Produzenten in Geschäftsverbindungen $\mathrm{zu}$ treten, indem sie selbst Binnenlandoder Buschfaktoreien errichteten. Im Jahre is98 gingen alle Firmen, nachdem vorher schon cinzelne Faktoreien in Nkum, Mundame usw. errichtet worden waren, gemeinsam nach Jabassi und gründeten dort die ersten Buschfalitoreien. Die Duala hatten nicht mehr die Macht, dics zu verhindern. Nachdem eimmal der Infang gemacht war, mehrten sich die Buschfaktoreien in kurzer Zeit. Naturgemäß konnte dadurch der Zwischenhandel nicht vollständig beseitigt werden. Er wurde nur auf weiter entfernte Gebiete zurücligedrängt. Sache der Duala wärc es jetzt gewesen, von diesen vorgeschobenen Posten den Zwischenhandel mit diesen entfernteren Gegenden zu besorgen, wie es zum Teil die Wurileute taten. Das Fortschreiten der Befriedigung des Schutzgebictes gab ihnen die Möglichkeit, unter dem Schutze der Weißen mit diesen Stämmen in Verbindung zu treten. Sie taten es aber nicht: möglich, daß ihnen das Fchlen von Bcziehungen oder alte Stammesfeindschaften das Anknipfen des Handelsverkehrs erschwerte; möglich auch, dab ihnen dic jetzt in direkte Berührung mit den Firmen tretenden Stämme, unter denen sie bisher den größten Absatz für ihre Waren gehabt hatten, zuvorgckommen waren. Jedenfalls befreiten sich diese Stämme schr bald von der bisherigen Abhängigkeit von den Duala, sobald sie nur gemerlit hatten, daB ihnen in der Faktorei der Weißen bedeutend höhere Preise gezahlt wurden, als sie bisher von den Duala crhalten hatten.

So muBte denn der Zwischenhandel der Duala mehr und mehr ausgeschaltet werden. Nur wenige von ihnen besaßen genügend Energie und Intelligenz, um neue Handelswege $z$ u betreten oder sich anderen Erwerbszweigen zuzuwenden. Die Mehrzahl der Duala, in erster Linie aber auch der Oberhäuptling der Akwa, der es sich verscherzt hatte, durch die Ausübung der Elcfantenjagd sich neue Einnahmen verschaffen zu dürfen, und die angeseheneren Familien, in deren Händen vornehmlich der Handel gelegen hatte, kamen in ihrem Wohlstande zurück. Der Kleinhandel mit Schnitzereien und Gegenständen aus Flechtwerk, der sich bei der Zunahme der weißen Bevölkerung allmählich entwickelte, vermochte naturgemäß bei seinem immerhin beschränkten Umfang keinen Ersatz zu liefern.

Die Vernichtung des Zwischenhandelmonopols der Duala war hiernach eine notwendige Folge der politischen und wirtschaftlichen Verhältnisse, ihre Verarmung die Folge der Indolenz und Schwerfälligkeit des mit verhältnismäßig wenigen Ausnahmen zu ernster, zielbewußter Arbeit unfähigen Volkes 


\title{
Aus dem deutsch-südwestafrikanischen Schutzgebiete.
}

\section{Ergebnisse der meteorologischen Beobachtungen in Deutsch-Südwestafrika im Jahre Juli 1905 bis Juni 1906.}

\author{
Nach dem Bericht des Katastersekretärs Thomas.
}

Die Niederschlagsverhältnisse waren in der letzten Regenzeit im allgemeinen befriedigende. Die gemessenen Regenmengen zeigen, wenn man die Ergebnisse aller Stationen zusammennimmt, im Durchschnitt einen etwas geringeren Ertrag als in vorletzter Regenzeit; diese ist wiederum erheblich hinter dem Ergebnisse der guten Regenzeit 1903/04 zurückgeblieben. Zahlenmäßig stellen sich die Ergebnisse von I9 Stationen, für welche aus den letzten drei Jahren volle Beobachtungsergebnisse vorliegen, für diese Periode wie folgt:

$\begin{array}{ccc}1903 / 04 & 1904 / 05 & 1905 / 06 \\ 10.0 & 7.2 & 6.7\end{array}$

Die I9 Stationen verteilen sich über das ganze Land, so daß die Zahlen ein leidlich zuverlässiges Verhältnis der in den drei Kriegsjahren niedergekommenen Regen zueinander darstellen. Die genaue Beurteilung der Niederschlagsverhältnisse der letzten Regenzeit kann aus den Messungen von 39 Stationen erfolgen, für welche volle Beobachtungsergebnisse vorliegen.

Von den zur Zeit bestehenden 67 Stationen waren $2 / 3$ durch den Aufstand zerstört oder muBten auf Zeit aufgegeben werden. Von vornherein wurde angestrebt, die entstandenen Schäden sobald als möglich wett zu machen und die noch vorhandenen Stationen auch während der Zeit der Unruhen im Gange zu erhalten. Diese Bemühungen hatten einen guten Erfolg, so daß heute schon wieder 56 Stationen die Beobachtungen regelmäBig wahrnehmen. Es wird versucht werden, auch die anderen Stationen, sobald es die Verhältnisse gestatten, wieder in Gang zu bringen. In erstea Kriegsjahre wurden von 30, im zweiten von 28 Stationen volle Beobachtungsergebnisse erzielt. Diese Zahl ist im letzten Jahre auf 39 gestiegen.

Neu eingerichtet wurde die Station Otjomaware, eine Militärstation am Omuramba-omatako im Be- zirk Grootfontein und Witvley am weißen Nosob im Bezirk Gobabis. Weiter sind noch bisher drei neue Stationen eingerichtet, welche aber die Beobachtungen erst nach dem $\mathrm{I}$. Juli aufgenommen haben, so daß jetzt die Zahl der Stationen im Schutzgebiet 70 beträgt.

Die Regenzeit setzte frühzeitig mit teils sehr ausgiebigen Regen ein. Der Anfang ließ ein recht gutes Regenjahr erhoffen, der Verlauf der Regenzeit erfüllte aber nicht überall die gesteliten $\mathrm{Er}$ wartungen.

Im nördlichen Teil brachten der Oktober und November schon gute Regen; die Hauptniederschläge kamen im Dezember bis Februar, auch im März und April waren noch gute Anfeuchtungen zu verzeichnen. Der Januar brachte bei fast allen Stationen etwa die Hälfte des ganzen niedergekommenen Regens.

Im Owambolande ist das Ergebnis wieder recht günstig, die Messungsergebnisse auf den einzelnen Stationen weichen nur unerheblich voneinander $a b$ und ergaben etwa $620 \mathrm{~mm}$.

Grootfontein hat $27 \mathrm{~mm}$ mehr als $1 \mathrm{~m}$ Vorjahre und kommt mit $679.6 \mathrm{~mm}$ etwa der guten Regenzeit I903/04 gleich. Gaub zeigt mit $697.6 \mathrm{~mm}$ ein gleich gutes Ergebnis. Die Messungen in Okombahe zeigen eigenartige Ergebnisse, deren Richtigkeit anzuzweifeln kein AnlaB vorliegt. $1903 / 04=181.0,1904 / 05=$ $293.5,1905 / 06=87.7 \mathrm{~mm}$. Von letzterem sind am 29./30. Oktober 63.2 gefalien, so daB der kleine Rest von 24.5 sich auf die ganzen anderen Monate der Regenzeit verteilt.

Im mittleren Teile war der Beginn der Regenzeit wie im Norden, der Verlauf aber dann weniger günstig. Nach dem guten Regen des Januar blieb der Februar mit Ausnahme der östlichen Stationen Seeis, Gobabis und Oas fast ganz regenfrei; auch in den anderen Monaten ist dieser Ausfall nicht wettgemacht worden. 
Die Station Windhuk, von welcher jetzt für neun Jahre Beobachtungen vorliegen, blieb mit 279.6 um $53.0 \mathrm{~mm}$ hinter dem neunjährigen Durchschnitt zurück.

Otjimbingwe hat nur $165.5 \mathrm{~mm}$, gegen 386.7 im Vorjahre, welches allerdings für Otjimbingwe ein sehr gutes Ergebnis war.

Nauchas hat I $29.5 \mathrm{~mm}$ gegen $216.8 \mathrm{~mm}$ 1904/05 unel 377.6 in $1903 / 0+$.

Im südlichen Teil hat auch der Januar die lıauptsächlichsten Niederschläge gebracht, sonst sind solche vom September bis März in allen Monaten vorgekommen, die mehr oder weniger ergiebig waren.

Maltahöhe zeigt mit I70.7 eine Besserung um $70 \mathrm{~mm}$ gegen das Vorjahr; Bethanien hat nur 30.1 gegen $126.8 \mathrm{~mm}$ im Vorjahre; Kubub hat nur im September, Oktober, Nai und Juni meßbare Niederschläge gehabt, mit zusammen $43.8 \mathrm{~mm}$; in Vorjahre zusammen I I $6.3 \mathrm{~mm}$.

Von einzelnen besonders ergiebigen Regen seien folgende erwähnt:

Nördlicher Teil. Oniipa am 6. Januar $70.2 \mathrm{~mm}$; Ondangua am 20. Februar $73.4 \mathrm{~mm}$; Olukonda am 8. Januar 80.1 mm; am 2I. Februar $66.9 \mathrm{~mm}$; Otawi am 29./30. Januar 98.6, am 22. April $99.7 \mathrm{~mm}$; Omaruru an I. Januar $60.4 \mathrm{~mm}$.

Mittlerer Teil. Neudamm am 29. Januar $84.2 \mathrm{~mm}$; Seeis am 3. Januar 48.6, am 30. Januar II $3.3 \mathrm{~mm}$.

Sïdlicher Teil. Maltahöhe am I5/r6. Januar $66.2 \mathrm{~mm}$.

Diese oft in wenigen Stunden herabkommenden starken Güsse stellen einen erheblichen Teil des auf den einzelnen Stationen im ganzen Jahre gemessenen Regens dar. Haben solche Güsse für die Vegetation, Garten- und Ackerbau nicht den Wert wie länger anhaltender Landregen, weil das Wasser schnell abfließt und nicht genuigend in den Boden eindringt, so sind sie doch auch besonders wichtig in den Gebieten, wo Dämme in der Regenzeit gefüillt werden sollen. Durch den starken Guß am 29. Januar wurden z. B. dem Neudamm so viele Wassermengen zugeführt, $\mathrm{da} B$ er sich etwa zur Hälfte der Stauhöhe füllte und das ganze Jahr über die große Menge Vieh getränkt werden kann, welche das Gouvernement dort weiden läßt; gegenwärtig 750 Stück Großvieh und 2700 Stiick Kleinviel.

Die Wirkung der Niederschläge auf Wasser-und Weideverhältnisse, Garten-und Ackerbau läßt sich, wie folgt, zusammenfassen: Wenn auch die Regenzeit nicht zii den besonders guten gerechnet verden kann, so war sie doch immerhin im großen und ganzen befriedigend, und dementsprechend sind auch die Wasser- und Weide- verhältnisse. Günstig beeinflußt sind diese immer noch durch die gute Regenzeit I903/O4 und die letzte 1904/05, die ebenfalls befriedigend ausgefallen war. Weiter kommt als günstiger Umstand hinzu, da $B$ infolge der immer noch unruhigen Verhältnisse wenig Vieh im Felde ist und deshalb Veide und Vasser im Verhältnis zu den normalen Verhältnissen wenig in Anspruch genommen wird.

Eine Ausnahme hiervon machen die Etappenund sonstigen Verkehrsstraßen, auf denen des großen Verkehrs wegen Mangel an Weide und an Wasser vorhanden ist. Im allgemeinen sind die jetzigen Wasser- und Weideverhältnisse im Lande als gute für den Norden, für den mittleren Teil als befriedigend und für den Süden als auskömmlich zu bezeichnen, wobei natürlich für das WVasser der Maßstab anzulegen ist, welcher für dieses wasserarme Land überhaupt in Frage lommt.

Im mittleren Teile hat der regenfreie Februar den Garten- und Ackerbau ungünstig beeinflußt. Viele Anpflanzungen (Mais, Kartoffeln usw.), zu welchen die Besitzer durch den guten Regen im Januar ermutigt waren und die sie auf Ländereien bewirkten, bei denen küunstliche Bewässerung ausgeschlossen war, gingen in der bald folgenden Trockenheit ein oder brachten nur geringen Ertrag.

Auch Spätfröste brachten im Olitober, wie schon in so manchem Jahre, den Anpflanzungen Schaden.

Zessfontein notierte am i9. Juni I806 Reif.

In Omaruru wurde im Mai 1906 zweimal Reif, am 25. Juni eine Temperatur von $-5^{\circ} \mathrm{C}$. beobachtet, ebenso in Okombahe am 27. u. 28. Juli I905 Reif. In Wilhelmstal kam im Mai 1906 viermal Frost vor, im Juni dreimal, in Okahandja wurde am I7. Mai $1906-2^{\circ} .5$, am 20. Juni $-5^{\circ}$ gemessen, in Gobabis trat am 23. und 24. Juni 1906 Nachtfrost ein, Seeis zählte im Mai 19069 Frostnächte, im Juni 20, Oas im Juli 1905 II, im Juni 1906 3, Hohe Warte im Juni 1906 II.

Erdbeben sind von fünf Stationen beobachtet.

Zessfontein notierte am I5. Juni 1906 um 8 Uhr 7 Min. (a. m.? p. m.?) ein Erdbeben.

Franzfontein me!dete am 3. Januar 8 Uhr 6 Min. a. m. ein heftiges Erdbeben von NW. nach SO., 20 Sek. andauernd. Am 17 . Februar 4 Uhr 47 Min. p. m. ein weniger heftiges Beben von $N$. nach SW., I2 Sek. andauernd. Am I8. April to Uhr 50 Min. p. m. ein Erdbeben von N. nach S., I 8 Sek. andauernd.

Karibib meldet am I. Juli 19053 Uhr p. m. vier Stöße, 7 Uhr 30 Min. 2 Stöße, 9 Uhr I 5 Min. I Stoß, auch in der Nacht noch weitere Stöße, deren Zeit nicht genau festgestellt wurde. Am 2. Juli 6 Uhr 35 Min., 8 Uhr 20 Min. und 8 Uhr 45 Min. p.m. 
je ein Stoß; am 3. Juli 3 Uhr und 7 Uhr 55 Min. p. m. je ein Stoß; am I2. Juli 9 Uhr 55 Min. p. m. ein Beben.

Otjimbingwe meldet Erdbeben am 19. Juli I905 1 I Uhr 5 Min. p. m.; am 27. Juli I Uhr Io Min. p. m., am 23. September 6 Uhr 25 Min. p. m., am II. Februar io Uhr 50 Min. p. m., am 9. April I I Uhr p. m., am 8. Juni I906 4 Uhr und I I $1 / 2$ Uhr p. 1 .

Outjo meldet am 28. Juni 1906 einen leichten Stoß von 5 Sek. Dauer.

Da keines dieser von der einen Station gemeldeten Beben zeitlich mit den an den anderen Orten beobachteten zusammenfällt, kann es sich nur um engbegrenzte, lokale Erscheinungen handeln.

In Otjimbingwe sind schon in früheren Jahren Erdbeben berichtet, in Franzfontein auch im Vorjahre.

Das erste nächtliche Wetterleuchten bzw. die ersten Gewitter als Vorboten der herannahenden Regenzeit machten sich in einem großen Teil des
Schutzgebietes von Norden bis in die Breite von Aminuis am 27. bis 29. August 1905, weiter im Süden erst am I. September bemerkbar. Die letzten Gewitter bzw. nur Wetterleuchten wurden von Zessfontein im Norden bis Warmbad im Süden zwischen dem 23. und 27. April notiert. Von Seeis bzw. Hoachanas nach Süden hin traten noch einzetne Wintergewitter im Mai und im Juni auf, ohne eine gleichzeitige größere Verbreitung zu zeigen.

Hagel wird gemeldet aus: Epukiro (I. November), Karibib (30. August 1905, 26. April 1906), Okahandja (2I. Dezember), Gobabis (3. September, 2. Januar), Neudamm (27. Dezember, I2. März), Hasuur (17. Mai).

Weitere meteorologische Beobachtungen, wie Wind-, Temperatur-, Luftdruck- und Luftfeuchtigkeitsmessungen usw., sind in Windhuk und Swakopmund ${ }^{*}$ gleich wie in früheren Jahren ausgeführt.

*) Da die meteorologischen Beobachtungen von Swakopmund für das Jahr Igo6 erhebliche Mängel aufweisen, können dieselben nicht, wie ïblich, veröffentlicht werden. Die Red. 
Regenmenge

Für die Monate September bis April

\begin{tabular}{|c|c|c|c|c|c|c|c|c|c|c|c|c|c|}
\hline \multirow{2}{*}{\multicolumn{4}{|c|}{$1905 / 06$}} & \multirow{2}{*}{$\begin{array}{c}\text { Regen- } \\
\text { summe } \\
\text { Juli }\end{array}$} & \multirow{2}{*}{$\begin{array}{l}\text { Regen } \\
\text { summe } \\
\text { August }\end{array}$} & $\begin{array}{l}\text { Regen- } \\
\text { summe }\end{array}$ & $\left|\begin{array}{c}\operatorname{Max} \\
\text { in } \\
\mathrm{I} \\
\text { Tag }\end{array}\right|$ & $\begin{array}{l}\text { Regen- } \\
\text { summe }\end{array}$ & $\begin{array}{c}\operatorname{Max} . \\
\text { in } \\
\mathrm{I} \\
\mathrm{Tag}\end{array}$ & $\begin{array}{l}\text { Regen- } \\
\text { summe }\end{array}$ & $\begin{array}{l}\text { Max. } \\
\text { in } \\
\text { I Tag }\end{array}$ & $\begin{array}{l}\text { Regen- } \\
\text { summe }\end{array}$ & $\begin{array}{l}\text { Max. } \\
\text { in } \\
\text { I Tag }\end{array}$ \\
\hline & & & & & & \multicolumn{2}{|c|}{ September } & \multicolumn{2}{|c|}{ Oktober } & \multicolumn{2}{|c|}{ November } & \multicolumn{2}{|c|}{ Dezember } \\
\hline I. & Oniipa & & & 0.0 & 0.0 & 0.0 & 0.0 & 4.0 & 2.0 & 32.2 & I 3.6 & I 8.6 & 7.6 \\
\hline 2. & Ondangtlat & & & 0.0 & 0.2 & U.I & O.I & 2.7 & $2 . I$ & 57.1 & 34.1 & 23.4 & I0.9 \\
\hline 3. & Onajena & & . & - & - & - & - & & & - & - & 28.4 & I 5.4 \\
\hline 4. & Olukonda & & 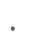 & 0.0 & 0.0 & 0.0 & 0.0 & 0.0 & 0.0 & 75.0 & $45 . I$ & 34.7 & I 2.4 \\
\hline 5. & Zessfontein & & & 0.0 & 0.0 & 0.0 & 0.0 & 26.6 & 20.6 & 0.0 & 0.0 & 0.0 & 0.0 \\
\hline 6. & Amutoni & & & 0.0 & 0.0 & 0.0 & 0.0 & 0.0 & 0.0 & 0.0 & 0.0 & 39.9 & 10.4 \\
\hline 7. & Okankwejo & & & 0.0 & 0.0 & 0.0 & 0.0 & $4 \cdot 4$ & $3 \cdot 4$ & 7.9 & 6.3 & II.3 & $3 \cdot 4$ \\
\hline 8. & Gaub & & . & 0.0 & 0.0 & 0.0 & 0.0 & 6.3 & 4.7 & 4.4 .8 & I 8.6 & 1.40 .7 & 37.8 \\
\hline 9. & Grootfontein & & & 0.0 & 0.0 & 0.0 & 0.0 & $4 \cdot 4$ & $4 \cdot 4$ & 22.5 & 17.9 & 91.4 & 36.5 \\
\hline IO. & Otjituo & & 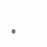 & 0.0 & 0.0 & 0.0 & 0.0 & 6.5 & 6.5 & 32.3 & 24.6 & 107.5 & 23.8 \\
\hline I I. & Otaw & & . & - & - & - . & - & 1.6 & 1.6 & +4.0 & 33.5 & 58.5 & 12.6 \\
\hline I 2. & Otjomaware & . & 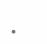 & - & - & 0.0 & 0.0 & 4.0 & 4.0 & $(17.8)$ & II .0 & - & - \\
\hline I 3. & Franzfontein & & & 0.0 & 0.2 & 0.7 & 0.7 & 37.0 & 22.0 & 0.6 & 0.6 & 0.0 & 0.0 \\
\hline 14. & Outjo & 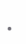 & 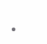 & 0.0 & 0.5 & 0.6 & 0.3 & 27.4 & 27.4 & 9.9 & 6.2 & I 2.9 & 8.3 \\
\hline I 5. & Waterberg & & & - & - & - & - & & - & - & - & - & 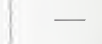 \\
\hline 16. & Etaneno & & & 0.0 & 0.0 & 5.2 & 5.2 & 0.0 & 0.0 & 0.0 & 0.0 & $45 \cdot 3$ & +5.0 \\
\hline 17. & Olowalinatjiwi & & & 0.0 & 0.0 & 0.0 & 0.0 & I 7.0 & 7.0 & 42.0 & 24.9 & 22.6 & I 5.4 \\
\hline I 8. & Omarurus. & & & 0.0 & 0.0 & 0.0 & 0.0 & 32.4 & 24.9 & I0.9 & 6.8 & 0.0 & 0.0 \\
\hline 19. & Epukiro & . & & - & - & - & - & - & - & 56.7 & 47.5 & 58.4 & I 3.6 \\
\hline 20. & Oliombahe & & & 0.0 & 0.0 & 0.0 & 0.0 & 63.2 & 38.0 & 0.2 & 0.2 & 0.0 & 0.0 \\
\hline $2 \mathrm{I}$ & Karibib & & & 0.0 & 8.4 & 0.0 & 0.0 & 30.7 & 27.3 & 0.0 & 0.0 & 0.0 & 0.0 \\
\hline 22. & Wilhelmstal & & & 0.0 & 2. I & 1.7 & I.7 & 37.0 & 29.5 & I6.7 & II.3 & 4.6 & 3.2 \\
\hline 23. & Olkahandja & & 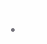 & 0.0 & 2.0 & 0.0 & 0.0 & 31.6 & 24.0 & 2.0 & I. 2 & I I.9 & $5 \cdot 5$ \\
\hline 24. & Usakos & & & - & - & - & - & - & r & - & - & 0.0 & 0.0 \\
\hline 25. & Kubas & & 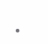 & 0.0 & 0.0 & 0.0 & 0.0 & 59.7 & 58.5 & 0.0 & 0.0 & 0.0 & 0.0 \\
\hline 26. & Otjimbingwe & 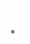 & & 0.0 & 0.0 & 0.0 & 0.0 & 23.8 & 23.8 & 0.0 & 0.0 & 0.0 & 0.0 \\
\hline 27. & Ckuib & & & - & - & - & - & - & - & - & - & - & - \\
\hline 28. & Gobabis & & & 0.0 & 0.2 & $5 \cdot 4$ & 3.7 & I.9 & $1 \cdot 3$ & 24.7 & $7 \cdot 4$ & 40.8 & I6.9 \\
\hline 29. & Witvley & & & - & -. & - & - & - & - & 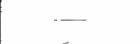 & - & - & - \\
\hline 30. & Neudamm & & 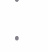 & 0.0 & I.O & 1.7 & I.O & 29.7 & 19.6 & 6. I & 2.5 & 8.3 & 6.3 \\
\hline $3 \mathrm{I}$. & Seeis & & 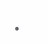 & -- & - & - & - & & & - & - & $\overline{-}$ & - \\
\hline 32. & Windhuk & & & 0.0 & 0.3 & 0.0 & 0.0 & 26.6 & 23.2 & 17.3 & 7.0 & 6.9 & 3.7 \\
\hline 33. & Das & $\cdot$ & & 0.0 & 0.7 & 6.I & 4.2 & 6.9 & 4. I & 32.5 & I6.I & 52.6 & 8.9 \\
\hline 34. & Jakalswater & & & 0.0 & 0.2 & 0.6 & 0.3 & I 7.5 & $9 \cdot 3$ & 0.0 & 0.0 & 0.0 & 0.0 \\
\hline 35. & Swakopmund & & & 0.0 & 3.0 & 1.5 & I & 0.0 & 0.0 & 0.0 & 0.0 & 0.0 & 0.0 \\
\hline 36. & Hohe Warte & & & 0.0 & 0.0 & 0.0 & 0.0 & 9. I & 8.3 & IO.I & 6.9 & 29.2 & I 4.8 \\
\hline 37. & Haris . & & & 0.0 & 3.4 & 3.0 & 3.0 & 40.5 & 350 & $29 . I$ & 16.5 & 22.4 & I 2.5 \\
\hline 38. & Hatsamas & & & 0.0 & 0.0 & 0.0 & o. & t:O & 4.0 & 46.0 & 35.9 & 3.7 & 1.8 \\
\hline 39. & Rehoboth & & & 0.0 & 0.0 & 0.0 & 0.0 & $1+6$ & I 4.6 & 6.3 & $3 \cdot 3$ & 10.2 & I0.2 \\
\hline 40. & Nauchas & & & 0.0 & 0.0 & 9. 2. & 6.0 & $35 . \circ$ & 35.0 & 0.0 & 0.0 & 0.0 & 0.0 \\
\hline $4 \mathrm{I}$ & Aminuis & & & o. & 0.0 & 0.5 & o. & 0.0 & 0.0 & 9.5 & 2.5 & 59.9 & 51.2 \\
\hline 42. & Hoachanas & & & 0.0 & 0.0 & 3.2 & 3.2 & 0.3 & 0.3 & 15.3 & 6.5 & 0.2 & 0.2 \\
\hline 43 & Nomtsas & & & - & 0.0 & - & $\ldots$ & 17.2 & 17.2 & 0.0 & 0.0 & 0.0 & 0.0 \\
\hline 44 & Maltahöhe & & & 0.0 & 0.0 & I 5.5 & IO. I & 5.2 & 5.2 & 0.0 & 0.0 & 0.0 & 0.0 \\
\hline 45 & Gibeon & & 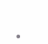 & 0.0 & 0.0 & I 1.4 & 8.0 & 2.0 & 2.0 & 0.0 & 0.0 & 0.0 & 0.0 \\
\hline 46. & Bersaba & & & 0.0 & 0.0 & 3.7 & 3. & 0.0 & 0.0 & 2.5 & 2.5 & I4.I & I4. I \\
\hline 47. & Bethanien & & & 0.0 & 0.0 & 4.6 & 3. & 0.0 & 0.0 & 0.0 & 0.0 & 0.0 & 0.0 \\
\hline 48. & Keetmanshoop & & & 0.0 & 0.0 & 6.4 & 3.0 & 4.0 & 4.0 & 12.0 & 7.0 & C.O & 0.0 \\
\hline 49. & Hasuur. & & & - & -- & - & - & - & & - & - & - & - \\
\hline $5 \%$ & Kubub & & & 0.0 & 0.0 & 5.7 & 5.7 & 8.4 & 8.4 & 0.0 & 0.0 & 0.0 & 0.0 \\
\hline $5 \mathrm{I}$. & Lüderitzbucht & & & 0.0 & 0.0 & 2. I & 2.I & 0.0 & 0.0 & 0.0 & 0.0 & 0.0 & 0.0 \\
\hline 52. & Sandverhaar & & & 0.0 & 0.0 & 4.0 & 4.0 & 0.0 & 0.0 & 0.0 & 0.0 & 0.0 & 0.0 \\
\hline 53. & Warmbad. & & . & - & - & -. & - & $14 \cdot 3$ & I 4.3 & I I.8 & I I. 8 & 8.4 & 6.2 \\
\hline
\end{tabular}

*) Beob. vom 6. bis I5. Jan. ausgefallen. - **) Beob. vom I4. bis 21. Olst. ausgefallen. 
in Millimeter.

auch Maxima des Regenfalles an einem Tage.

\begin{tabular}{|c|c|c|c|c|c|c|c|c|c|c|c|c|}
\hline $\begin{array}{l}\text { Regen- } \\
\text { summe }\end{array}$ & $\begin{array}{c}\text { Max. } \\
\text { in } \\
\text { I Tag }\end{array}$ & $\begin{array}{l}\text { Regen- } \\
\text { summe }\end{array}$ & $\begin{array}{l}\text { Max. } \\
\text { in } \\
\text { I Tag }\end{array}$ & $\begin{array}{l}\text { Regen- } \\
\text { summe }\end{array}$ & $\begin{array}{l}\text { Max. } \\
\text { in } \\
\text { I Tag }\end{array}$ & $\begin{array}{l}\text { Regen- } \\
\text { summe }\end{array}$ & $\begin{array}{l}\text { Max. } \\
\text { in } \\
\text { I Tag }\end{array}$ & $\begin{array}{l}\text { Regen- } \\
\text { summe }\end{array}$ & $\begin{array}{l}\text { Regen- } \\
\text { summe }\end{array}$ & \multirow{2}{*}{\multicolumn{2}{|c|}{ Jahr I905/06 }} & Jahr \\
\hline \multicolumn{2}{|c|}{ Januar } & \multicolumn{2}{|c|}{ Februar } & \multicolumn{2}{|c|}{ März } & \multicolumn{2}{|c|}{ April } & Mai & Juni & & & \\
\hline 286.6 & 70.2 & I 83.5 & 55.6 & 61.8 & 28.0 & $24 \cdot 5$ & 24.5 & 0.0 & 0.0 & $6 \mathrm{II} .2$ & 70.2 & 401.9 \\
\hline 290.2 & 59.7 & I 78.5 & 73.4 & 61.3 & $24 \cdot 3$ & 7.6 & 7.6 & 0.0 & 0.0 & $62 \mathrm{I} . \mathrm{I}$ & $73 \cdot 4$ & - \\
\hline 310.2 & 55.0 & I62.I & 42.5 & 56.3 & 36.4 & - & - & - & - & $(557.0)$ & $(55.0)$ & - \\
\hline 281.9 & 80. I & I 77.6 & 66.9 & 14. I & 8.2 & I 2.3 & I 2.3 & 0.0 & 0.0 & 595.6 & $80 . \mathrm{I}$ & - \\
\hline 4I.I & $2 \mathrm{I} . \mathrm{O}$ & 14.7 & I I.O & I. 3 & I. 3 & 8.0 & 8.0 & 0.0 & 0.0 & $9 \mathrm{I} .7$ & $2 \mathrm{I} . \mathrm{O}$ & I I 3.8 \\
\hline 224.9 & 36.3 & $57 \cdot 4$ & I0.7 & 56.6 & 42.6 & I 5.8 & I0.8 & 0.0 & 0.0 & 394.6 & 42.6 & - \\
\hline I 72.4 & 26.6 & I 33.6 & $45 \cdot 5$ & 41.8 & 38.2 & 0.8 & 0.8 & 0.0 & 0.0 & 372.2 & $45 \cdot 5$ & - \\
\hline 288.8 & 36.8 & 67.6 & $37 \cdot 3$ & I 27.3 & 48.8 & $22 . I$ & 22.0 & 0.0 & 0.0 & 697.6 & 48.8 & - \\
\hline 362.2 & $64 \cdot 5$ & 144.6 & 30.7 & 38.2 & I 2.5 & I 6.3 & I I. 3 & 0.0 & 0.0 & 679.6 & $64 \cdot 5$ & 408.3 \\
\hline 179.6 & 28.4 & I $39 \cdot 4$ & $59 \cdot 3$ & 59.2 & 36.0 & $\mathrm{I} .2$ & I. 2 & 0.0 & 0.0 & 525.7 & $59 \cdot 3$ & - \\
\hline$(177.6)$ & 66.3 & 41.6 & $\mathrm{I} 4.0$ & 65.6 & $34 \cdot 5$ & 112.6 & 99.7 & 0.0 & 0.0 & 501.5 & $99 \cdot 7$ & - \\
\hline$\overline{48}$ & - & 4I. 3 & 178 & $\overline{\mathrm{I} 0.6}$ & 68 & $\overline{27.1}$ & 220 & - & - & $\overline{2660}$ & $=$ & $\overline{328}$ \\
\hline $\begin{array}{l}\text { I } 48.5 \\
241.3\end{array}$ & $\begin{array}{l}53.7 \\
35.7\end{array}$ & $\begin{array}{l}4 I \cdot 3 \\
44 \cdot 9\end{array}$ & $\begin{array}{l}17.8 \\
13.4\end{array}$ & $\begin{array}{l}\text { I0.6 } \\
33.4\end{array}$ & $\begin{array}{l}0.8 \\
9.5\end{array}$ & $\begin{array}{r}27.1 \\
9.9\end{array}$ & $\begin{array}{r}22.0 \\
6.7\end{array}$ & $\begin{array}{r}0.0 \\
1.4\end{array}$ & $\begin{array}{l}0.0 \\
0.0\end{array}$ & $\begin{array}{l}200.0 \\
382.2\end{array}$ & $\begin{array}{l}53.7 \\
35.7\end{array}$ & $\begin{array}{l}320.4 \\
421.5\end{array}$ \\
\hline 3 OI. 5 & $54 \cdot 5$ & 29.3 & I 1.3 & 74.4 & 22.1 & 10.8 & 5.8 & 0.5 & 0.0 & - & - & - \\
\hline I 3.0 & 2.0 & 22.8 & I9.8 & 25.2 & 10.9 & 4.6 & $4 \cdot 3$ & 0.0 & 0.0 & I I 6. I & 45.0 & - \\
\hline 244.1 & $4 \mathrm{I} . \mathrm{O}$ & $34 \cdot 7$ & I 5.2 & 24.2 & 7.2 & 7.6 & 6.3 & 0.7 & 0.0 & 392.9 & $4 I .0$ & - \\
\hline $205 . I$ & 60.4 & I $7 \cdot 3$ & 10.5 & 33.6 & 29.4 & 22.0 & I I. 8 & 0.0 & 0.0 & $32 \mathrm{I} \cdot 3$ & 60.4 & 246.2 \\
\hline 140.0 & 48.2 & $74 \cdot 3$ & $4 \mathrm{I} .2$ & 30.3 & I 2.7 & 6.5 & $5 \cdot 5$ & 0.0 & 0.0 & $(366.2)$ & 48.2 & - \\
\hline 9.7 & I. 5 & I. 5 & 0.9 & 4.9 & 3.2 & 8.2 & 5.8 & 0.0 & 0.0 & 87.7 & 38.0 & $293 \cdot 5$ \\
\hline $94 \cdot 4$ & 20.8 & I $3 . I$ & $5 \cdot 4$ & 0.0 & 0.0 & I 6.2 & 7.0 & 0.0 & 0.0 & 162.8 & 27.3 & I 74.8 \\
\hline 145.7 & 33.6 & $4 \mathrm{I} \cdot 3$ & 22.4 & IO.4 & 4.8 & I0.7 & 4.0 & 0.0 & 0.0 & 270.2 & 33.6 & 350.9 \\
\hline $229 . \mathrm{I}$ & 32.0 & 46.5 & $2 \mathrm{I} .5$ & $9 \cdot 3$ & 5.0 & 7.7 & 7.2 & 0.0 & 0.0 & $340 . \mathrm{I}$ & 32.0 & 390.5 \\
\hline 78.9 & $45 \cdot 5$ & 4.8 & 1.6 & I. 2 & 0.8 & $23 \cdot 5$ & I 6.7 & 0.0 & 0.0 & - & - & - \\
\hline 72.3 & 49.6 & 0.8 & 0.8 & 0.0 & 0.0 & 29.3 & I9.3 & 0.0 & 0.0 & I 62. I & 58.5 & 225.9 \\
\hline I 27.8 & 50.3 & 0.4 & 0.4 & 3.2 & 3.2 & IO. 3 & 6.6 & 0.0 & 0.0 & 165.5 & 50.3 & 386.7 \\
\hline- & - & - & - & - & - & 17.7 & $9 \cdot 5$ & 0.2 & 0.0 & - & - & - \\
\hline I99.2 & $49 \cdot 4$ & I06.7 & 35.4 & 43.6 & I 5.9 & 0.2 & 0.2 & I.7 & 0.0 & 424.2 & $49 \cdot 4$ & 322.4 \\
\hline - & - & - & - & - & - & 一 & - & - & 0.0 & - & - & - \\
\hline 260.1 & 84.2 & $2 \mathrm{I} .5$ & 12.7 & I 3.6 & 8.5 & 0.0 & 0.0 & 0.0 & 0.0 & 342.0 & 84.2 & - \\
\hline 259.2 & I I $3 \cdot 3$ & I 31.5 & 80.5 & 30.5 & I 5.0 & 0.0 & 0.0 & 0.0 & 0.0 & - & - & - \\
\hline I 81.9 & 35.0 & $5 \cdot 5$ & 2.6 & 38.8 & 26.8 & 2.3 & 1.6 & 0.0 & 0.0 & 279.6 & 35.0 & $372 . \mathrm{I}$ \\
\hline I 65.4 & 34.6 & I I 5.2 & 57.2 & I 8.6 & 4.2 & 0.0 & 0.0 & 0.0 & 0.0 & 398.0 & 57.2 & 一 \\
\hline 20.4 & 5.0 & 0.0 & 0.0 & 0.0 & 0.0 & 39. I & 28.2 & 0.0 & I. 5 & 79.3 & 28.2 & I 8.7 \\
\hline 0.8 & 0.8 & 0.0 & 0.0 & 0.0 & 0.0 & I. I & I. I & 0.0 & 3.9 & $7 \cdot 3$ & 3.9 & 17.0 \\
\hline $\mathrm{I} 55.2$ & 38.5 & I I.7 & 6.3 & I 6.6 & 9.8 & 3.9 & 3.9 & 0.0 & 0.0 & 235.8 & 38.5 & 259.6 \\
\hline I 82.6 & 40.0 & 20.7 & IO.O & 17.0 & $7 \cdot 5$ & 5.6 & 2.8 & 0.0 & 0.0 & $324 \cdot 3$ & 40.0 & 353.0 \\
\hline I 49.0 & 31.9 & 23.0 & I 4.2 & 10.0 & 4.6 & 0.0 & 0.0 & 0.6 & 0.0 & 236.3 & 35.9 & 一 \\
\hline I 49.8 & $33 \cdot 5$ & $29 \cdot 3$ & 23.6 & 2.0 & I. 7 & 0.0 & 0.0 & 0.0 & 0.8 & 213.0 & 33.5 & I 8 I. 6 \\
\hline 75.9 & $43 \cdot 4$ & 0.0 & 0.0 & 0.0 & 0.0 & $9 \cdot 4$ & $7 \cdot 5$ & 0.0 & 0.0 & I 29.5 & $43 \cdot 4$ & 216.8 \\
\hline 94.8 & $3 \mathrm{I} .2$ & 46. I & 24.0 & 6.3 & 2.0 & 6.0 & 6.0 & 0.0 & 0.0 & $223 . \mathrm{I}$ & $5 \mathrm{I} .2$ & 273.6 \\
\hline 102.0 & 34.0 & I 2.6 & 10.0 & 0.0 & 0.0 & 0.0 & 0.0 & 0.0 & 0.0 & I 33.6 & 34.0 & I 87.4 \\
\hline 73.2 & - & 0.0 & 0.0 & 2.8 & 2.2 & 0.0 & 0.0 & 0.0 & 0.0 & $>93.2$ & - & - \\
\hline 146.3 & 34.9 & 2.3 & $2 \cdot 3$ & I. 4 & I. 4 & 0.0 & 0.0 & 0.0 & 0.0 & I 70.7 & 34.9 & 102.7 \\
\hline 93.8 & $25 \cdot 5$ & 3.0 & 3.0 & 0.2 & 0.2 & 0.0 & 0.0 & $4 \cdot 5$ & 0.0 & I I 4.9 & $25 \cdot 5$ & I 27.5 \\
\hline $37 \cdot 3$ & 22.5 & $\mathrm{O} . \mathrm{O}$ & 0.0 & 17.7 & I 7.2 & 0.0 & 0.0 & 0.0 & 0.0 & $75 \cdot 3$ & 22.5 & - \\
\hline I6.I & I 3.7 & $0 . \mathrm{O}$ & 0.0 & 8.8 & 7.5 & 0.6 & 0.3 & 0.0 & 0.2 & 30.3 & I 3.7 & I 26.8 \\
\hline 56.5 & 28.2 & 0.0 & 0.0 & $\mathrm{I} 4.4$ & 8.0 & 0.0 & 0.0 & 0.6 & 0.0 & 93.9 & 28.2 & 105.9 \\
\hline- & - & I0.6 & 5.2 & 70.0 & 28.0 & 0.0 & 0.0 & 20.2 & 0.0 & - & - & - \\
\hline O. I & O.I & 0.0 & 0.0 & 0.0 & 0.0 & 0.0 & 0.0 & I. 8 & 27.8 & 43.8 & I 8.2 & I I 6.3 \\
\hline - & - & 0.0 & 0.0 & 0.0 & 0.0 & I.O & I.O & 2.5 & I 5.0 & $>20.6$ & 6.0 & 36.6 \\
\hline 21.0 & I 2.0 & 0.0 & 0.0 & I I.O & 7.0 & 7.0 & 6.0 & 0.0 & 4.0 & 47.0 & 12.0 & - \\
\hline 0.0 & 0.0 & O.I & O. I & $7 \cdot 3$ & 6.1 & 0.5 & 0.3 & 0.0 & 2.0 & $(44.4)$ & (I 4.3) & - \\
\hline
\end{tabular}


$\mathrm{a}=$ Regentage im allgemeinen, $\mathrm{b}=$ Regentage mit mehr als $0.2 \mathrm{~mm}$,

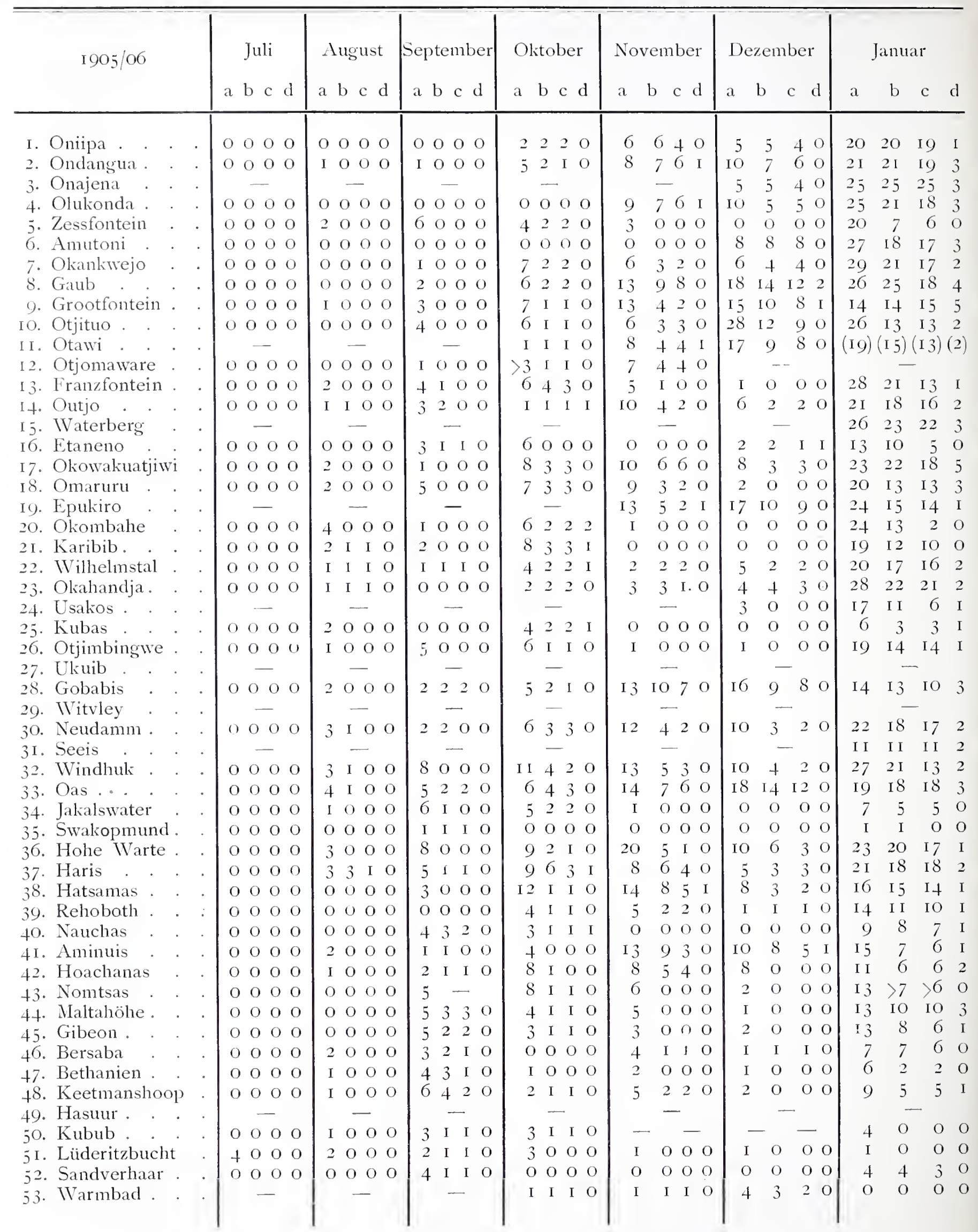


und Gewittertage.

$\mathrm{c}=$ mit mehr als $1.0 \mathrm{~mm}, \mathrm{~d}=$ mit mehr als $25.0 \mathrm{~mm}$.

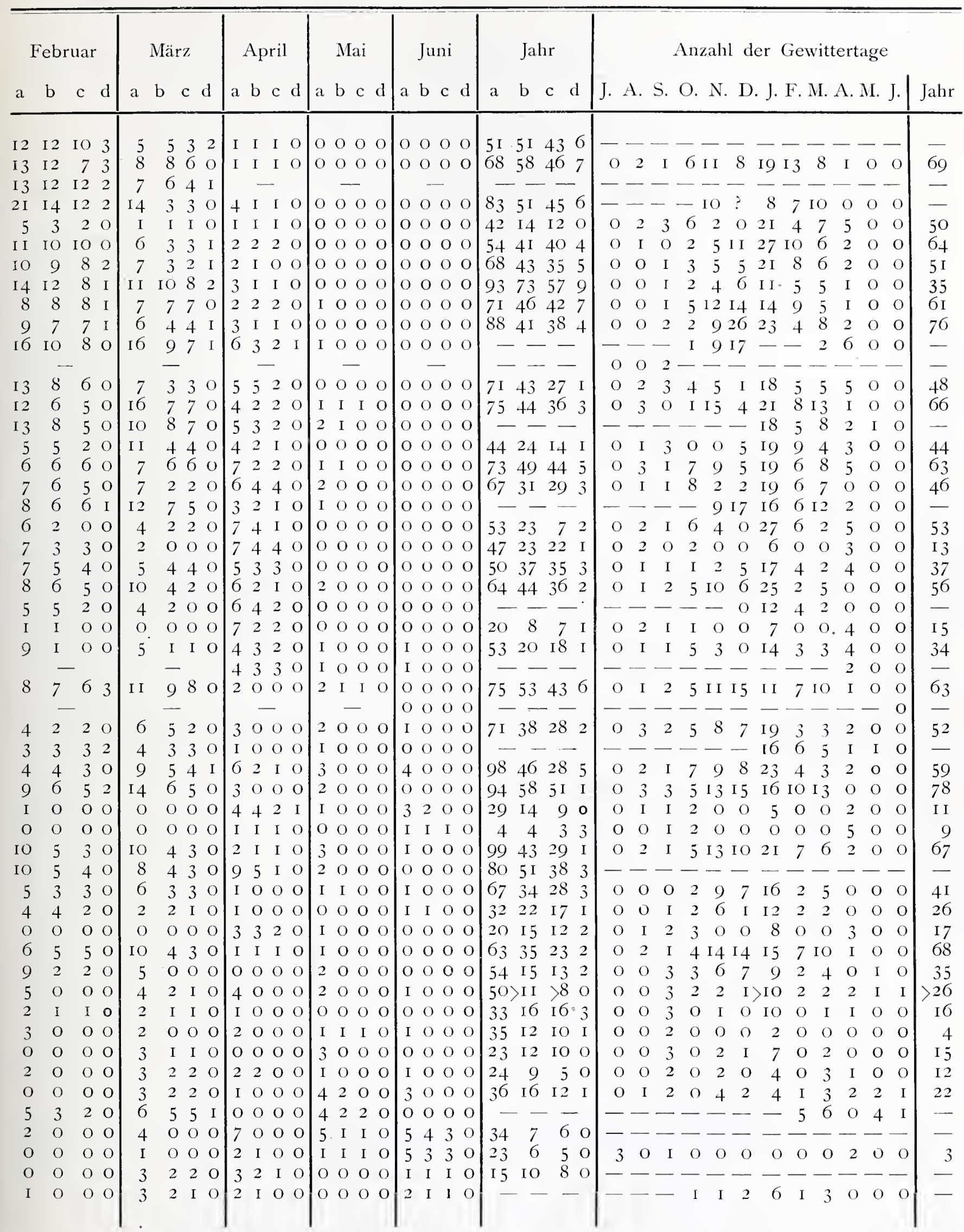


W i n d h u k.

$$
p=-22^{\circ} 34^{\prime} . \quad \lambda=\mathrm{I} 7^{\prime \prime} 6^{\prime} \ddot{\partial} . \mathrm{Gr} . \quad \mathrm{h}=\mathrm{I} 664 \mathrm{~m} \text {. }
$$

Beobachter: Katastersekretär Thomas.

Die Barometerablesungen: Generalkommissions-Zeichner Trümper, Kataster-Zeichner Löwenberg und Prechel.

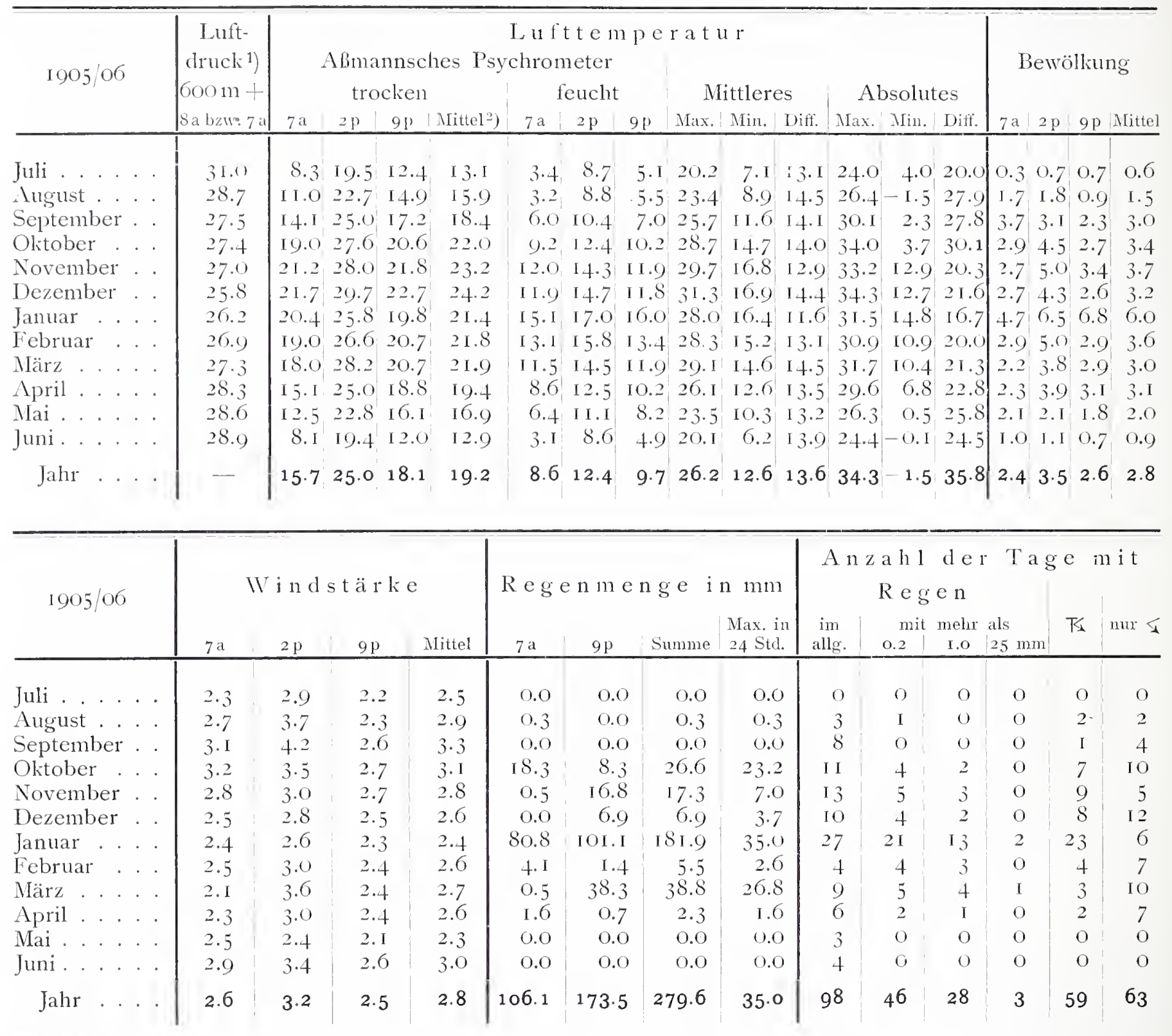

1) Barometer vom I. Oktober um 7 a abgelesen, reduziert anf $o^{\circ}$ und mit Schwerekorrektion versehen.

2) Mittel $\frac{7 a+2 p+9 p+9 p}{4}$.

Das Quecksilberbarometer kounte nur an einem Termin (bis 3o. September 1905 um 8 a, später um 7 a) abgelesen werden, da dasselbe im Hause der Landesverwaltung aufgestellt ist und dieses etwa $\mathrm{I} \mathrm{km}$ vom Standort der übrigen Instrumente entfernt liegt. 
Windhuk. Windrichtungen, beobachtet im Jahre 1905/06.

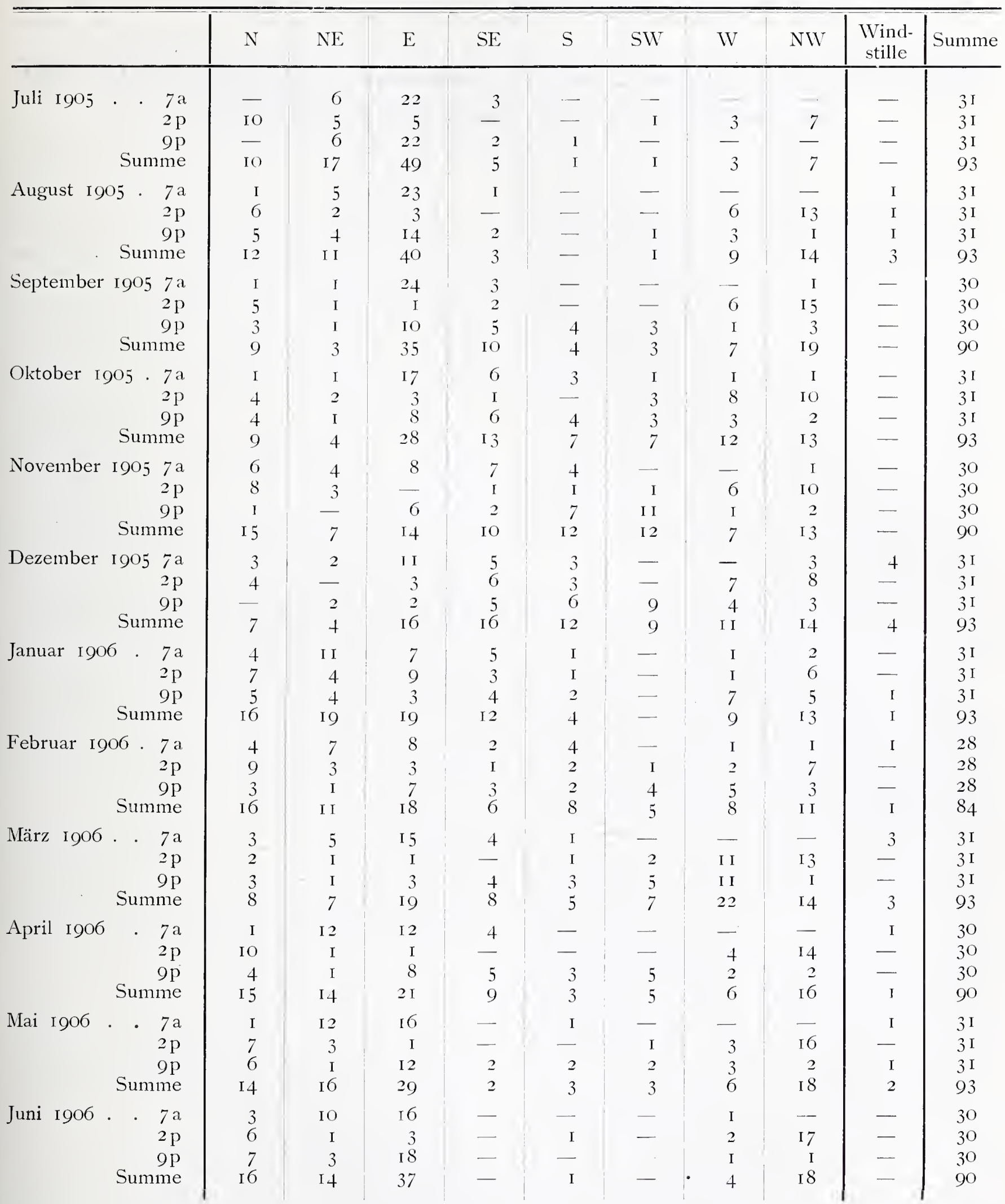




\title{
Täglicher Gang des Luftdrucks und der Temperatur zu Windhuk vom Juli 1904 bis Juni 1905 wie seine harmonischen Konstituenten.
}

\author{
Vou Dr. P. Heidke.
}

Auber den Terminbeobachtungen des Luftdrucks, der Temperatur, wie cler ibrigen meteorologischen Elemente $\left.{ }^{*}\right)$ sind von Herrn Katastersekretär Thomas und Herrn Trimper vom Juli I904 bis Juni 1905 luickenlose Aufzeichnungen des Luftdricks und der Temperatur gewonnen worden. Benutzt wurden der Barograph Richard Nr. I27 und der Thermograph Richard Nr. I9I. Hervorgehoben zu werden verdient, daB die Aufzeichnungen beider Instrumente frei von Treppen sind, die durch ein zu festes Aufliegen der Feder auf dem Papier entstehen und den Wert der Aufzeichnungen wesentlich herabzusetzen vermögen.

Die Registrierstreifen sind auf ganze Millimeter bzw. Grade genau, der Zeit nach von zwei zu zwei Stunden eingeteilt. Jeder Streifen enthält dic Iufzeichnungen einer Woche.

Die Auswertung der Autogramme erfolgte durch Herrn Julius Gilcher, Hamburg, der bereits zahlreiche Autogramme berechnet hat.

Die Streifenkorrektion wurde durch Vergleichı mit den Terminbeobachtungen bestimmt und im Gegensatz zu der Bearbeitung von den Registrierungen der Jahre Igor bis Juni 1904 für jede Terminablesung an die Ablesungen von den Autogrammen angebracht. Bei beiden Instrumenten hält sich die Änderung der Streifenkorrektion innerhalb sehr geringer Grenzen.

Die Berechnung der harmonischen Konstituenten erfolgte unter Zugrundelegung der Summenwerte der Monate bzw. des Jahres für die einzelnen Tagesstunden, wodurch die Feliler vermieden werden, welche bei der Benutzung der Mittelwerte durch die Abkürzung auf eine gewisse Stellenzahl entstehen, während die Schwierigkeit der Rechnung hicrdurch in keiner Weise erhöht wird. Als Rechenschema wurde das von Börgen in den snnalen der Hydrographie und maritimen Meteorologie« I884, S. 506 , gegebene benutzt, von dem eine abgekürzte Darstellung von Kassner auch in der » Meteorologischen Zeitschrift « I90I, S. 8I, veröffentlicht ist.

-) „Ergebnisse der meteorologischen Beobachtungen in Deutsch-Südwestafrika" im Jahre $1904 / 05$ in Band XIX, S. I5I, dieser Zeitschrift.

**) Siehe Hann: Der tägliche Gang der Temperatur und des Luftlucks zu Windhuk. Band XIX, S. 3I und 37 dieser Zeitschrift.
Zwecks Berechnung der mittleren Fehler I füir die Abweichungen der einzelnen Stundenwerte vom Mittelwert wurden die harmonischen Konstituenten bis zum vierten Gliede berechnet; wenn auch nicht verhehlt werden darf, daß namentlich beim Luftdruck bereits das dritte Glied keinen reellen Wert mehr besitzt, das dritte und vierte Glied also eigentlich nur noch rechnerische Größen sind.

Trotzdem nur auf den Thermographenstreifen Zeitmarken angebracht sind, hat sich auch die Auswertung der Barographenstreifen, ebenso wie in früheren Jahren, als durchaus lohnend erwiesen, da der Barogratph keinen in Betracht kommenden Gang liat, und die Beobachtungszeiten offenbar sehr genau innegehalten sind. Beweis hierfür ist die geringe Schwankung in der Streifenkorrelition des Barographen, deren Werte hier allerdings nicht wiedergegeben werden können.

Die Größe der Werte $\delta$, die zwischen 9 und I9 Einheiten der zweiten Dezimale beträgt, hat dazu geführt, die Werte $a_{1}$ und $a_{2}$ nur auf zwei Stellen genau wiederzugeben, da die dritte Stelle nur rein rechnerischen Wert besitzt, während im übrigen mit drei Stellen gerechnet ist.

Sowohl $A$, als der aus 1 durch Division mit $\sqrt{6}$ erhaltene Wert $\delta$ sind nicht erheblich größer als theoretisch zu erwarten ist. Sieht man nämlich von clem theoretisch nicht ohne weiteres zu ermittelnden Einflub der Störungen im normalen Gange des Luftdrucks zunächst ab, so ergibt sich für einen Monat von 30 Tagen $A=\frac{\sqrt{0.1^{2}+0.04^{2}}}{130}=0,02 \mathrm{~mm}$, wobei als mittlerer Fehler bei der Ablesung vom Barographenstreifen O.I $\mathrm{mm}$ angenommen ist, während der mittlere Fehler der auf $0^{\circ}$ reduzierten Barometerablesung wegen der Ablürzung auf Zehntel Millimeter $0.04 \mathrm{~mm}$ beträgt.

Die Barometerkurve von Windhuk ist auch in diesem Jahr, wie schon Hann für die früheren Jahre nachgewiesen hat, völlig normal für die geographische Breite. Auch im Jahre I904/05 ist dem kontinentalen Klima entsprechend das nächtliche Minimum und das Abend-Maximum nur gering, das VormittagsMaximum und das Nachmittags-Minimum grob. Regel- 
mäßig zeigt ferner das Nachmittags-Minimum eine größere Abweichung vom Mittel als das VormittagsMaximum. Die ganz- und halbtägige Barometerschwankung bleiben mit 0.59 und $0.60 \mathrm{im}$ Jahreswert etwas gegen die entsprechenden von $0.6 \mathrm{I}$ und $0.62 \mathrm{~mm}$ früherer Jahre zurück. Das Maximum der ganz- resp. halbtägigen Schwankung trat im Jahreswert um $5^{\mathrm{h}} \mathrm{O}^{\mathrm{m}}$ vormittags resp. $9^{\mathrm{h}} 42^{\mathrm{m}}$ vor- und nachmittags gegen $4^{\mathrm{h}} 5^{2^{\mathrm{m}}}$ vormittags resp. $9^{\mathrm{h}} 4 \mathrm{O}^{\mathrm{m}}$ vor- und nachmittags der früheren Jahre ein, also für beide um I $2^{\mathrm{m}}$ später.

Gleichzeitig mit der täglichen periodischen und unperiodischen Luftdruckschwankung erreichen auch die Amplituden der ganz- und halbtägigen Welle ihren größten Wert im Dezember, ihren kleinsten im Juni. Des weiteren zeigt sich, wie bei den meisten tropischen Stationen, daß die halbtägige Welle in ihren Werten viel konstanter ist als die ganztägige. Während bei dieser die Größe der Amplitude von 0.42 bis 0.84 schwankt - also der größte Betrag das Doppelte des kleinsten beträgt und die Zeit des Eintritts des Maximums von $4^{36} \mathrm{a}$ bis $5^{29} \mathrm{a}$ - also um 53 Minuten - schwankt, bewegt sich bei jener die Größe der Amplitude innerhalb der Grenzen 0.56 und 0.67 - die größte Amplitude beträgt also nur das I, 2 fache der klcinsten - und die Eintrittszeit des Maximums liegt zwischen $9^{39}$ und IO $^{13}$ - schwankt also nur um 34 Minuten.

Die Korrektionen des Mittels $(7 a+2 p+9 p): 3$ auf das 24 stündige sind

Juli August Sept. Okt. Nor. Dez. Jan. Febr. März April Mai Juni Jahr $+0.08+0.05-0.04-0.03-0.09-0.07-0.02+0.090 .00+0.01+0.05+0.05-0.01$ also fast gleich Null.

Windhuk.

Täglicher Gang des Luftdrucks.

\begin{tabular}{|c|c|c|c|c|c|c|c|c|c|c|c|c|c|}
\hline \multirow{2}{*}{ - } & \multicolumn{6}{|c|}{ I904 } & \multicolumn{6}{|c|}{1905} & \multirow{2}{*}{ Jahr } \\
\hline & Juli & August & Sept. & Okt. & Nov. & Dez & Jan. & Febr. & März & April & Mai & Juni & \\
\hline I a & 628.63 & 628.95 & 628.23 & 626.00 & $626.5^{\circ}$ & 625.84 & 625.88 & $625.8_{I}$ & 626.85 & $628.3^{8}$ & 628.34 & 627.37 & 627.22 \\
\hline 2 & $8.5 \mathrm{I}$ & 8.83 & 8.08 & 5.82 & 6.40 & $5 \cdot 74$ & $5 \cdot 72$ & 5.65 & 6.73 & 8.28 & 8.24 & 7.28 & 7.10 \\
\hline 3 & 8.49 & 8.70 & 7.93 & 5.69 & $6.3 \mathrm{I}$ & 5.69 & 5.57 & $5 \cdot 45$ & 6.56 & 8.10 & 8.10 & $7 \cdot 17$ & 6.97 \\
\hline 4 & 8.45 & 8.63 & 7.88 & 5.70 & $6.3^{8}$ & $5 \cdot 7^{\circ}$ & $5 \cdot 55$ & $5 \cdot 39$ & $6.5^{2}$ & 8.03 & 8.05 & 7.10 & 6.94 \\
\hline 5 & 8.45 & 8.69 & 8.05 & 5.83 & 6.55 & 5.87 & 5.68 & $5 \cdot 45$ & 6.59 & 8.12 & 8.06 & 7.05 & 7.02 \\
\hline 6 & $8.6 \mathrm{I}$ & 8.93 & 8.35 & 6.08 & 6.84 & 6.16 & $5 \cdot 9 \mathrm{I}$ & 5.63 & 6.75 & $8.3 \mathrm{I}$ & 8.23 & 7.16 & 7.23 \\
\hline 7 & 8.87 & 9.27 & 8.68 & 6.32 & 7.05 & 6.33 & 6.08 & 5.88 & 7.06 & $8.6 \mathrm{I}$ & 8.53 & $7 \cdot 44$ & $7 \cdot 5^{\circ}$ \\
\hline 8 & $9 \cdot 3^{2}$ & $9.5 \mathrm{I}$ & 8.91 & 6.50 & 7.15 & 6.39 & 6.18 & 6.12 & $7 \cdot 35$ & 8.89 & 8.83 & 7.74 & $7 \cdot 73$ \\
\hline 9 & $9 \cdot 37$ & 9.69 & 8.97 & 6.53 & 7.09 & 6.37 & 6.22 & 6.18 & 7.47 & 9.08 & 9.05 & 7.95 & 7.82 \\
\hline IO & 9.42 & 9.66 & 8.90 & 6.42 & 6.93 & 6.26 & 6.19 & 6.18 & $7 \cdot 46$ & 9.11 & 9.07 & 7.95 & $7 \cdot 78$ \\
\hline II & 9.08 & $9 \cdot 30$ & $8.5 \mathrm{I}$ & $6 . \mathrm{II}$ & 6.54 & 5.97 & 6.00 & 6.04 & 7.22 & 8.84 & 8.75 & 7.66 & 7.49 \\
\hline Mittag & $8.7 \mathrm{I}$ & 8.86 & 8.01 & $5 \cdot 74$ & 6.23 & 5.60 & 5.69 & 5.82 & 6.93 & $8.5^{\circ}$ & 8.35 & $7 \cdot 3 \mathrm{I}$ & 7.13 \\
\hline I p & 8.03 & 8.28 & $7 \cdot 48$ & 5.25 & 5.68 & 5.07 & $5.2 \mathrm{I}$ & 5.40 & $6.4^{8}$ & 7.98 & $7 \cdot 79$ & 6.74 & 6.60 \\
\hline 2 & 7.64 & 7.81 & 7.10 & 4.85 & $5 \cdot 3 I$ & 4.64 & 4.72 & 5.06 & 6.15 & $7 \cdot 5^{8}$ & $7 \cdot 43$ & 6.44 & $6.2 \mathrm{I}$ \\
\hline 3 & $7.4 \Upsilon$ & 7.61 & 6.77 & $4 \cdot 54$ & 4.95 & 4.22 & $4 \cdot 30$ & 4.64 & $5 \cdot 79$ & $7 \cdot 30$ & 7.22 & 6.25 & 5.90 \\
\hline 4 & 7.39 & 7.60 & 6.74 & 4.49 & 4.84 & 4.02 & 4.09 & $4 \cdot 44$ & 5.70 & 7.21 & 7.21 & 6.21 & 5.82 \\
\hline 5 & 7.47 & $7 \cdot 73$ & 6.80 & $4 \cdot 57$ & 4.89 & 3.94 & 4.12 & 4.41 & $5 \cdot 75$ & 7.27 & $7 \cdot 34$ & 6.34 & 5.87 \\
\hline 6 & $7.7 \mathrm{I}$ & $7 \cdot 98$ & 7.06 & 4.85 & 5.15 & $4 \cdot 30$ & 4.45 & 4.68 & $5 \cdot 9 \mathrm{I}$ & $7 \cdot 43$ & $7 \cdot 36$ & $6.5^{8}$ & 6.13 \\
\hline 7 & 8.10 & 8.31 & $7 \cdot 5 \mathrm{I}$ & $5 \cdot 3 I$ & $5 \cdot 72$ & 4.92 & $4 \cdot 93$ & 5.09 & 6.19 & $7 \cdot 77$ & 7.96 & 6.93 & 6.55 \\
\hline 8 & 8.42 & 8.64 & 7.88 & $5 \cdot 73$ & 6.17 & 5.43 & $5 \cdot 32$ & $5 \cdot 54$ & 6.54 & 8.05 & 8.25 & 7.19 & 6.92 \\
\hline 9 & 8.62 & 8.85 & S.2I & $5 \cdot 99$ & 6.64 & 5.84 & $5 \cdot 75$ & $5 \cdot 95$ & 6.79 & 8.32 & 8.43 & $7 \cdot 4 \mathrm{I}$ & 7.22 \\
\hline IO & 8.72 & 8.95 & 8.30 & 6.11 & 6.84 & 6.14 & 6.13 & $6.1 \mathrm{I}$ & 7.07 & 8.40 & $8.5^{\circ}$ & $7 \cdot 48$ & $7 \cdot 3^{8}$ \\
\hline I I & 8.77 & 8.99 & 8.30 & 6.10 & 6.83 & $6.2 \mathrm{I}$ & $6.2 \mathrm{I}$ & 6.14 & 7.11 & 8.42 & $8.5 \mathrm{I}$ & $7 \cdot 4^{8}$ & $7 \cdot 4 \mathrm{I}$ \\
\hline Mitternacht & 8.73 & 8.95 & 8.29 & 6.00 & 6.70 & 6.10 & 6.17 & 6.00 & 7.08 & 8.35 & 8.45 & $7 \cdot 43$ & $7 \cdot 34$ \\
\hline Mittel & 8.46 & 8.69 & 7.96 & 5.69 & 6.24 & $5 \cdot 53$ & $5 \cdot 5^{\circ}$ & $5 \cdot 54$ & 6.67 & 8.18 & 8.18 & 7.15 & 6.97 \\
\hline Höchster & 32.4 & 32.0 & 34.4 & 28.9 & 28.8 & 28.7 & 28.5 & 28.6 & 30.8 & $3 I \cdot 5$ & $32 . \mathrm{I}$ & 30.1 & 34.4 \\
\hline Niedrigster & 24.5 & 24.2 & 22.4 & 22.3 & 23.0 & 20.3 & 21.6 & $23 . I$ & 22.4 & 25.0 & 23.5 & 23.2 & 20.3 \\
\hline$\left.I^{1}\right)$ & $2.2 \mathrm{I}$ & 2.26 & 2.47 & 2.35 & 2.56 & 2.77 & 2.55 & 2.27 & 2.02 & $2 . \mathrm{OI}$ & 2.06 & I .84 & 2.28 \\
\hline $\left.\mathrm{II}^{2}\right)$ & 2.03 & 2.09 & 2.23 & 2.04 & $2.3 \mathrm{I}$ & 2.45 & 2.13 & 1.74 & I. 77 & 1.90 & I.86 & I. 74 & 2.00 \\
\hline
\end{tabular}

1) $\mathrm{I}=$ Mittlere unperiodische Tagesschwankung.

2) $\mathrm{II}=, \quad$ periodische

Mitteilungen a. d. D. Schutzgebieten, XX. Band. II. 
Windhuk.

Abweichungen der Stundenmittel des Luftdrucks vom Tagesmittel.

\begin{tabular}{|c|c|c|c|c|c|c|c|c|c|c|c|c|c|}
\hline & \multicolumn{6}{|c|}{1904} & \multicolumn{6}{|c|}{1905} & \multirow{2}{*}{ Jahr } \\
\hline & Juli & August & Sept. & Okt. & Nov. & Dez. & Jan. & Febr. & März & April & Mai & Juni & \\
\hline Ia & O.I 7 & 0.26 & 0.27 & $0.3 I$ & 0.26 & $0.3 \mathrm{I}$ & 0.38 & 0.27 & O.I 8 & 0.20 & 0.16 & 0.22 & 0.25 \\
\hline 2 & O.IO & 0.14 & 0.12 & 0.13 & 0.16 & $0.2 \mathrm{I}$ & 0.22 & O.I I & 0.06 & 0.10 & 0.06 & 0.13 & O.I 3 \\
\hline 3 & 0.03 & 0.01 & -0.03 & 0.00 & 0.07 & 0.16 & 0.07 & -0.09 & $-0 . \mathrm{I} I$ & -0.08 & -0.08 & 0.02 & 0.00 \\
\hline 4 & -0.01 & -0.06 & -0.08 & $0.0 \mathrm{I}$ & O.I 4 & 0.17 & 0.05 & - O.I 5 & - O.I 5 & -0.15 & -0.13 & -0.05 & -0.03 \\
\hline 5 & - $0.0 \mathrm{I}$ & 0.00 & 0.09 & O.I 4 & $0.3 \mathrm{I}$ & 0.34 & 0.18 & -0.09 & -0.08 & -0.06 & -0.12 & -0.10 & 0.05 \\
\hline 6 & O.I 5 & 0.24 & 0.39 & 0.39 & 0.60 & 0.63 & $0.4 \mathrm{I}$ & 0.09 & 0.08 & o.I 3 & 0.05 & $0.0 \mathrm{I}$ & 0.26 \\
\hline 7 & $0.4 \mathrm{I}$ & 0.58 & 0.72 & 0.63 & 0.8 I & 0.80 & $0.5^{8}$ & 0.34 & 0.39 & 0.43 & 0.35 & 0.29 & 0.53 \\
\hline 8 & 0.86 & 0.82 & 0.95 & $0.8 \mathrm{I}$ & 0.91 & 0.86 & 0.68 & 0.58 & 0.68 & $0.7 \mathrm{I}$ & 0.65 & 0.59 & 0.76 \\
\hline 9 & 0.91 & 1.00 & 1.01 & 0.84 & 0.85 & 0.84 & 0.72 & 0.64 & 0.80 & 0.90 & 0.87 & 0.80 & 0.85 \\
\hline Io & 0.96 & 0.97 & 0.94 & 0.73 & 0.69 & 0.73 & 0.69 & 0.64 & 0.79 & 0.93 & 0.89 & 0.80 & $0.8 \mathrm{I}$ \\
\hline I I & 0.62 & $0.6 \mathrm{I}$ & 0.55 & 0.42 & 0.30 & 0.44 & 0.50 & 0.50 & 0.55 & 0.66 & 0.57 & $0.5 \mathrm{I}$ & 0.52 \\
\hline Mittag & 0.25 & O.I 7 & 0.05 & 0.05 & $-0.0 \mathrm{I}$ & 0.07 & O.I9 & 0.28 & 0.26 & 0.32 & O.I 7 & o.I 6 & o.I 6 \\
\hline Ip & -0.43 & $-0.4 \mathrm{I}$ & -0.48 & -0.44 & $-0.5^{6}$ & -0.46 & -0.29 & -0.14 & -0.19 & -0.20 & -0.39 & $-0.4 \mathrm{I}$ & -0.37 \\
\hline 2 & -0.82 & -0.88 & -0.86 & -0.84 & -0.93 & -0.89 & -0.78 & -0.48 & -0.52 & -0.60 & -0.75 & $-0.7 \mathrm{I}$ & $-0.7^{6}$ \\
\hline 3 & $-\mathrm{I} .05$ & - $\mathbf{I} .08$ & - I.I 9 & - I.I 5 & $-\mathrm{I} .29$ & $-\mathrm{I} .3 \mathrm{I}$ & $-\mathrm{I} .20$ & -0.90 & -0.88 & -0.88 & -0.96 & -0.90 & - I.07 \\
\hline 4 & -1.07 & -1.09 & -1.22 & -1.20 & -1.40 & $-\mathrm{I} .5 \mathrm{I}$ & -1.41 & - I.IO & -0.97 & -0.97 & -0.97 & -0.94 & -1.15 \\
\hline 5 & -0.99 & -0.96 & - I.I 6 & - I.I 2 & $-\mathbf{I} .35$ & -1.59 & $-\mathbf{I} .38$ & -1.13 & -0.92 & $-0.9 \mathrm{I}$ & -0.84 & $-0.8 \mathrm{I}$ & - I.IO \\
\hline 6 & -0.75 & $-0.7 \mathrm{I}$ & -0.90 & -0.84 & $-\mathbf{I} .09$ & -1.23 & $-\mathrm{I} .05$ & -0.86 & -0.76 & -0.75 & -0.62 & -0.57 & -0.84 \\
\hline 7 & -0.36 & -0.38 & -0.45 & -0.38 & -0.52 & $-0.6 \mathrm{I}$ & -0.57 & -0.45 & $-0.4^{8}$ & $-0.4 \mathrm{I}$ & -0.22 & -0.22 & -0.42 \\
\hline 8 & -0.04 & -0.05 & -0.08 & 0.04 & -0.07 & - O.IO & -0.18 & 0.00 & -0.13 & -0.13 & 0.07 & 0.04 & -0.05 \\
\hline 9 & O.I 6 & o.I 6 & 0.25 & 0.30 & 0.40 & $0.3 \mathrm{I}$ & 0.25 & $0.4 \mathrm{I}$ & O.I 2 & O.I 4 & 0.25 & 0.26 & 0.25 \\
\hline 10 & 0.26 & 0.26 & 0.34 & 0.42 & 0.60 & $0.6 \mathrm{I}$ & 0.63 & 0,57 & 0.40 & 0.22 & 0.32 & 0.33 & $0.4 \mathrm{I}$ \\
\hline I I & $0.3 \mathrm{I}$ & 0.30 & 0.34 & $0.4 \mathrm{I}$ & 0.59 & 0.68 & $0.7 \mathrm{I}$ & 0.60 & 0.44 & 0.24 & 0.33 & 0.33 & 0.44 \\
\hline itternacht & 0.27 & 0.26 & 0.33 & $0.3 \mathrm{I}$ & 0.46 & 0.57 & 0.67 & 0.46 & $0.4 \mathrm{I}$ & 0.17 & 0.27 & 0.28 & 0.37 \\
\hline
\end{tabular}

Harmonische Konstituenten der täglichen Barometerschwankung db zu Windhuk im Jahre 1904/05 nach der Formel:

$\mathrm{db}=\mathrm{a}_{1} \sin \left(\mathrm{x}+\mathrm{A}_{1}\right)+\mathrm{a}_{2} \sin \left(2 \mathrm{x}+\mathrm{A}_{2}\right)$.

$a_{1}$ und $a_{2}$ in Millimetern,

$\mathrm{x}=$ Zeit nach Mitternacht, eine Stunde gleich $15^{\circ}$ gesetzt,

$\Delta=$ mittlerer Fehler der Abweichung des Stundenmittels vom täglichen in Millimetern,

$\delta=\quad, \quad, \quad$ "Werte $\mathrm{a}_{1}$ und $\mathrm{a}_{2}$ in Millimetern,

$\mathrm{T}_{1}$ und $\mathrm{T}_{2}=$ Eintrittszeit des Maximums der ganz- bzw. halbtägigen Werte.

Juli Aug. Sept. Okt. Nov. Dez. Jan. Febr. März April Mai Juni Jahr

$\begin{array}{lllllllllllllll}\mathrm{a}_{1} & 0.56 & 0.59 & 0.67 & 0.63 & 0.79 & \mathbf{0 . 8 4} & 0.70 & 0.46 & 0.45 & 0.50 & 0.43 & \mathbf{0 . 4 2} & 0.59\end{array}$

$\begin{array}{llllllllllllll}\mathrm{A}_{1} & 9^{\circ} .3 & 7^{\circ} .8 & \mathrm{IO}^{\circ} .7 & 17^{\circ} .3 & 2 \mathrm{I}^{\circ} . \mathrm{I} & 20^{\circ} .0 & 20^{\circ} .6 & \mathrm{I} 8^{\circ} .8 & 7^{\circ} .4 & -\mathrm{I}^{\circ} .3 & \mathrm{IO} 0^{\circ} .4 & \mathrm{I} 5^{\circ} .6 & \mathrm{I} 4^{\circ} .0\end{array}$

$\mathrm{T}_{1} \quad 5^{23} \mathrm{a} \quad 5^{29} \mathrm{a} \quad 5^{17} \mathrm{a} \quad 5^{08} \mathrm{a} \quad 4^{36} \mathrm{a} \quad 4^{40} \mathrm{a} \quad 4^{38} \mathrm{a} \quad 4^{45} \mathrm{a} \quad 5^{30} \mathrm{a} \quad 6^{05} \mathrm{a} \quad 5^{18} \mathrm{a} \quad 4^{58} \mathrm{a} \quad 5^{04} \mathrm{a}$

$\begin{array}{llllllllllllll}\mathrm{a}_{2} & 0.58 & 0.6 \mathrm{I} & 0.65 & 0.58 & 0.65 & \mathbf{0 . 6 7} & 0.66 & 0.63 & 0.58 & \mathbf{0 . 5 6} & 0.59 & \mathbf{0 . 5 6} & 0.60\end{array}$

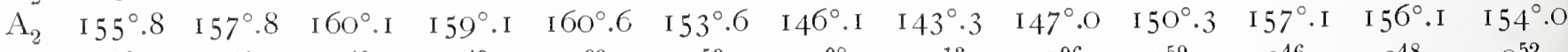

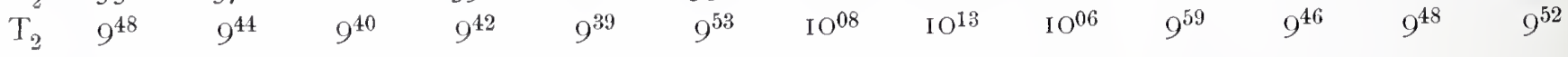

\begin{tabular}{lllllllllllllll}
\hline & 0.029 & 0.032 & $\mathbf{0 . 0 4 6}$ & $0.04 \mathrm{I}$ & 0.034 & 0.039 & $0.03 \mathrm{I}$ & $\mathbf{0 . 0 2 1}$ & 0.032 & 0.033 & 0.025 & 0.034 & 0.026
\end{tabular}

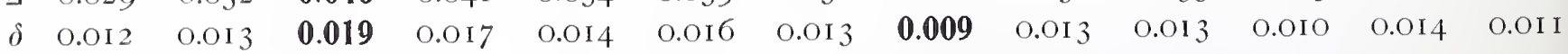


Nicht annähernd mit der gleichen Genauigkeit wie der tägliche Gang des Luftdrucks läßt sich derjenige der Temperatur durch die Besselsche Formel darstellen, da auf ihn die durch Wind, Bewölkung, Niederschlag etc. erzeugten Abweichungen vom normalen Verlauf beträchtlich größer sind. Selbst wenn man mit einem mittleren Fehler von $\mathrm{O}^{\circ} .5$ der Einzelablesung vom Thermographen rechnen wollte, so würde sich doch nur ein mittlerer Fehler von $\frac{0^{\circ} .5}{\sqrt{30}}=0^{\circ} .09$ für die Abweichung $\Lambda$ des einzelnen Stundenmittels im Monat von dem Monatsmittel erwarten lassen, während sie innerhalb der Grenzen $\mathrm{O}^{\circ} .2 \mathrm{I}$ und $\mathrm{O}^{\circ} .33$ liegt.

Der mittlere Fehler der Einzelablesung am Thermographen kann nicht entsprechend dem am
Barographen $z \mathbf{u ~} O^{\circ}$. I angenommen werden, sondern ist beträchtlich höher $\mathrm{zu}$ veranschlagen, da die Thermographenkurve einen viel unruhigeren und gezackteren Verlauf als die Barographenkurve zeigt. Infolgedessen ist auch bei den ungeraden Stunden, für welche keine Ordinaten gezogen sind, der Einfluß des Interpolationsfehlers in der Zeit, der 5 bis IO Minuten betragen kann, von viel größerem Einfluß als beim Barographen, wo kaum jemals hierdurch eine Änderung von mehr als O.I mm eintritt, während sie beim Thermographen zuweilen über $\mathrm{I}^{\circ}$ betragen kann. Aus demselben Grunde sind auch Ungenauigkeiten im Gange des Thermographen von größerem Einfluß auf den mittleren Fehler $\Lambda$ als beim Barographen.

Es betragen die Korrektionen I des Mittels $(7 a+2 p+9 p): 3$ auf das 24 stündige,

II des Mittels $(7 \mathrm{a}+2 \mathrm{p}+9 \mathrm{p}): 4$ auf das 24 stündige,

III des Mittels (Maximum + Minimum) 2 auf das 24 stündige.

$\begin{array}{rcrrrrrrrrrrrr} & \text { Juii } & \text { August } & \text { Sept. } & \text { Okt. } & \text { Nov. } & \text { Dez. } & \text { Jan. } & \text { Febr. } & \text { März } & \text { April } & \text { Mai } & \text { Juni } & \text { Jahr } \\ \mathrm{I} & +0.2 & 0.0 & -0.3 & -0.7 & -0.8 & -0.8 & -0.6 & -0.2 & -0.4 & -0 . \mathrm{I} & 0.0 & +0.2 & -0.3 \\ \mathrm{II} & +0.5 & +0.4 & 0.0 & -0.2 & -0.3 & -0.4 & -0 . \mathrm{I} & +0.2 & -0 . \mathrm{I} & +0.2 & +0.7 & +0.6 & +0 . \mathrm{I} \\ \mathrm{III} & -0 . \mathrm{I} & +0.5 & +0.5 & +0.9 & +\mathrm{I} .0 & +0.9 & +0.2 & -0 . \mathrm{I} & +0.4 & -0 . \mathrm{I} & -0.5 & +0.3 & +0.5\end{array}$

Windhuk.

Täglicher Gang der Temperatur.

\begin{tabular}{|c|c|c|c|c|c|c|c|c|c|c|c|c|c|}
\hline & \multicolumn{6}{|c|}{ I9O4 } & \multicolumn{6}{|c|}{1905} & \multirow{2}{*}{ Jahı } \\
\hline & Juli & Aug. & Sept. & Okt. & Nov. & Dez. & Jan. & Febx. & März & April & Mai & Juni & \\
\hline Ia & I0.6 & I I. 7 & I3. I & I 5.9 & I9.6 & I 9.8 & I9. 8 & I 7.2 & 17.5 & I 6.7 & I 2.0 & 8.I & I 5.2 \\
\hline 2 & I0.0 & I I. 2 & I 2.5 & I 5.7 & I9.I & I9.4 & 19.6 & I6.9 & $\mathrm{I} 7.2$ & I6. 5 & I I.9 & 7.6 & I 4.8 \\
\hline 3 & 9.6 & 10.9 & I 2.2 & 15.0 & I 8.4 & I 8.9 & I9.I & I6.7 & 17.0 & 16.3 & I I.5 & $7 \cdot I$ & I 4.4 \\
\hline 4 & 9.3 & I0. 6 & I I. 8 & I 4.7 & I8.0 & I 8.5 & I 8.7 & I6.5 & 16.5 & I 5.9 & II.I & 7.0 & I $4 . \mathrm{I}$ \\
\hline 5 & 9. I & I0.0 & I I. 3 & 14.2 & 17.5 & 18.0 & 18.3 & I 6.4 & 16.2 & I 5.8 & I 0.7 & 6.5 & 13.7 \\
\hline 6 & 8.8 & 9.9 & 11.0 & I 5.3 & I 8.9 & I9.I & I 8.8 & 16.2 & 16.2 & 15.7 & 10.6 & 6.1 & I 3.9 \\
\hline 7 & 9.2 & I0.8 & I 2.7 & I 8.0 & 21.8 & 21.7 & 21.2 & I 8.0 & I 7.8 & I6.9 & I I.5 & 6.5 & I 5.6 \\
\hline 8 & II.5 & I I.O & I6.I & $20 . \mathrm{I}$ & 23.5 & $23 \cdot 3$ & 22.8 & I9.6 & I9.9 & I 9.4 & I 4.5 & 9.7 & I 7.9 \\
\hline 9 & I 4.9 & 17.0 & I 8.2 & 22.0 & 25.4 & 25.2 & $24 \cdot 7$ & $2 \mathrm{I} .4$ & $2 \mathrm{I} .7$ & 21.9 & I 7.9 & I 3.3 & 20.4 \\
\hline IO & I6.7 & 19.0 & I9.8 & 23.4 & 26.6 & 26.4 & 25.8 & 22.4 & 22.9 & 23.2 & I9.6 & I 5.5 & 21.8 \\
\hline I I & 17.9 & 20.3 & $2 \mathrm{I} .4$ & 24.6 & $27 \cdot 7$ & 27.8 & 27.0 & 23.3 & 23.7 & $24 . I$ & 20.9 & 17.2 & 23.0 \\
\hline Mittag & I 8.9 & 21.4 & 22.4 & 25.6 & 28.3 & 28.7 & 27.8 & 23.9 & 24.4 & $24 \cdot 9$ & 21.8 & I8.4 & 23.9 \\
\hline Ip & I9.5 & 22.2 & 23.5 & 26.3 & 28.9 & 29.5 & 28.0 & 24.2 & 25.0 & 25.5 & 22.4 & I9.4 & 24.6 \\
\hline 2 & I9.8 & 22.7 & 23.9 & 26.5 & 29.3 & 29.9 & 28.6 & 23.9 & 25.4 & 25.6 & 22.8 & 20.0 & $\begin{array}{l}4.9 \\
\end{array}$ \\
\hline 3 & 19.9 & 22.9 & 24.1 & 26.7 & $29 . \mathrm{I}$ & 30.0 & 28.6 & 23.6 & $25 . \mathrm{I}$ & 25.7 & 22.8 & 20.3 & 25.0 \\
\hline 4 & 19.6 & 22.7 & 23.8 & 26.3 & 28.9 & 29.7 & 27.6 & 23.6 & $24 \cdot 7$ & 25.0 & 22.7 & 20.1 & 24.6 \\
\hline 5 & I 8.7 & 22.0 & 22.7 & 25.4 & 27.8 & 29.1 & 27.4 & 22.9 & 23.8 & 24.2 & 21.8 & I9.I & 23.8 \\
\hline 6 & I6.4 & I9.4 & 20.9 & 23.6 & 26.8 & 27.8 & 26. I & 22.0 & $23 . I$ & 22.5 & I9. I & I6.2 & 22.0 \\
\hline 7 & I 4.6 & I7.I & I9. I & 21.8 & 24.8 & 25.5 & 24.4 & 20.7 & 21.7 & 20.8 & I6.9 & I3.7 & $20 . I$ \\
\hline 8 & I 3.7 & I 5.7 & I 7.8 & 20.4 & 23.6 & 24.4 & $23 \mathrm{I}$ & I 9.7 & 20.7 & I9. 8 & I 5.6 & I 2.5 & 19.0 \\
\hline 9 & I 2.7 & I 4.7 & I6.5 & I9.4 & 22.4 & 23.2 & 22.2 & I 8.9 & 19.9 & I9.0 & I 4.6 & I I.O & 17.9 \\
\hline IO & I 2.0 & 13.9 & I 5.4 & I 8.3 & 21.6 & 22.2 & 21.6 & I 8.6 & I 9.3 & I 8.4 & I 4.0 & IO. 2 & 17.2 \\
\hline II & I I. 5 & 12.9 & 14.4 & 17.6 & 20.8 & $2 \mathrm{I} .3$ & 20.9 & I8.0 & I 8.7 & I 7.7 & 13.0 & 9.3 & I6.4 \\
\hline Mitternacht & I I. 3 & I 2.4 & I 3.7 & I 6.8 & 20.1 & 20.6 & 20.4 & I 7.5 & I 8. I & I 7.4 & I 2.2 & 8.9 & $\mathrm{I}_{5} .8$ \\
\hline Mittel & I 4.0 & I6.I & I 7.4 & 20.6 & 23.7 & 24.2 & 23.4 & 20.1 & 20.7 & 20.4 & I6. 3 & I 2.7 & 19.2 \\
\hline
\end{tabular}


Windhuk.

Abreichungen der Stundenmittel der Temperatur vom Tagesmittel.

\begin{tabular}{|c|c|c|c|c|c|c|c|c|c|c|c|c|c|}
\hline & \multicolumn{6}{|c|}{1901} & \multicolumn{6}{|c|}{ I 905} & \multirow{2}{*}{ Jahr } \\
\hline & Iuli & Ang. & Sept. & Okt, & Nor. & Dez. & Jan. & Febr. & Mārz & April & Mai & Juni & \\
\hline I & -3.4 & -4.3 & -13 & -4.6 & -4.2 & -4.4 & -3.7 & $\rightarrow 2.8$ & -3.2 & -3.6 & -4.3 & -4.5 & -3.9 \\
\hline 2 & -40 & -4.8 & -4.9 & -4.9 & -4.6 & -4.5 & -3.9 & -3.2 & -3.5 & -3.9 & -4.5 & -5.1 & -4.3 \\
\hline 3 & $-\div 4$ & $-5 . I$ & -5.2 & -5.6 & -5.3 & -5.2 & $-4 \cdot 3$ & -3.4 & $-3 . \bar{i}$ & -4.0 & -4.8 & $-\mathbf{5 . 6}$ & -4.7 \\
\hline 4 & -1.7 & -5.5 & -5.7 & -5.9 & -5.3 & -5.7 & $-\div-7$ & -3.5 & -1.2 & -4.4 & -5.2 & -5.7 & -5.1 \\
\hline 5 & $\div .9$ & -6.0 & $-6 . I$ & -6.3 & -6.2 & -6.2 & -5.1 & -3.7 & -4.5 & -4.6 & -5.6 & $-6 . I$ & -5.4 \\
\hline 6 & -5.1 & -6.2 & -64 & -5.2 & -4.5 & -5.1 & -4.6 & -3.9 & -4.5 & -4.7 & -5.7 & -6.6 & -5.2 \\
\hline$\overline{4}$ & -4.5 & -5.3 & $-\div-7$ & -2.6 & - I.9 & -2.4 & -2.3 & $-2 . I$ & -2.9 & -3.4 & -4.8 & $-6 . I$ & -3.6 \\
\hline$s$ & -2.5 & $-2 . I$ & - I.f & -0.5 & -0.2 & -0.9 & -0.6 & -0.5 & -0.8 & - I.O & - I.S & -2.9 & -1.3 \\
\hline $\bar{y}$ & 0.9 & I.O & 0.5 & I. 4 & 1.7 & I.I & I.2 & I. 3 & I.O & I.5 & I. 6 & 0.6 & 1.2 \\
\hline IO & 2.7 & 3.0 & 2.4 & 2.5 & 2.9 & 2.2 & 2.4 & 2.4 & 2.2 & 2.8 & $3 \cdot 3$ & 2.9 & 2.7 \\
\hline II & 3.9 & $\div 3$ & 3.9 & 4.0 & 40 & 3.6 & $3 \cdot 5$ & $3 \cdot 3$ & 3.0 & 3.7 & 4.5 & 4.5 & 3.8 \\
\hline MA: & 4.8 & 5.3 & 5.1 & 5.0 & 4.6 & 4.6 & 4.3 & 3.8 & 3.5 & 4.5 & $5 \cdot 4$ & 5.8 & 4.8 \\
\hline in & $5 \vdots$ & $0 . . I$ & 6.0 & 5.7 & 5.2 & 5.4 & 4.6 & 4.1 & $4 \cdot 3$ & 5.2 & 6.0 & 6.8 & $5 \cdot 4$ \\
\hline 2 & 58 & 6.6 & 6.5 & 6.0 & 5.6 & 5.5 & 5.2 & 3.5 & 4.7 & 5.3 & 6.5 & $7 \cdot 3$ & 5.8 \\
\hline$\Xi$ & 59 & 6.5 & 6.6 & 6.2 & 54 & 5.5 & $5 \cdot I$ & 3.6 & 4.4 & 5.3 & 6.5 & 7.6 & 5.8 \\
\hline$\div$ & 5.6 & 6.6 & 6.3 & 5.7 & 5.2 & 5.5 & $4 \cdot 5$ & $3 \cdot 5$ & 4.0 & 4.6 & 6.4 & $7 \cdot 4$ & $5 \cdot 4$ \\
\hline$\Sigma$ & 1.7 & 5.9 & 5.2 & 49 & $\therefore \cdot I$ & 4.9 & 3.9 & 2.8 & $3 \cdot I$ & 3.8 & 5.5 & 6.4 & 4.6 \\
\hline 6 & 2.1 & $3 \cdot 3$ & 3.5 & 3.1 & $3 \cdot I$ & 3.7 & 2.7 & 1.9 & 2.4 & $2 . I$ & 2.8 & $3 \cdot 5$ & $3 \cdot 7$ \\
\hline$\overline{3}$ & 0.6 & I.I & 1.6 & 1.2 & I. I & 1.3 & I.O & 0.6 & I.O & 0.4 & 0.6 & I.O & I.O \\
\hline 5 & -0.3 & -. o 3 & 0.4 & -0.2 & - O.I & 0.2 & -0.3 & -0.7 & 0.0 & -0.6 & -0.7 & -0.2 & -0.2 \\
\hline 9 & -1.3 & -1.4 & -0.9 & -I.2 & - I.3 & - I.O & - I.2 & - I.2 & -0.8 & - I.4 & -1.7 & $-I .7$ & -1.3 \\
\hline IO & -2.0 & -2.2 & -2.0 & -2.2 & $-2 . I$ & -2.0 & - I.S & -1.5 & 一 I.4 & -2.0 & -2.4 & -2.4 & -2.0 \\
\hline II & -2.5 & -3.2 & -3.0 & -3.0 & -2.9 & -2.8 & -2.5 & -2.0 & -2.0 & -2.7 & -3.3 & -3.4 & -2.6 \\
\hline Ma:zernauzi & -2.7 & -3.6 & -3.5 & -3.5 & -3.6 & -3.6 & -3.0 & -2.6 & -2.6 & -3.0 & -4.2 & -3.8 & -3.4 \\
\hline Perizdistze & & & & & & & & & & & & & \\
\hline $\begin{array}{l}\text { Sinmangung } \\
\text { Tiperio isise }\end{array}$ & I I.O & I 3.0 & I 3.0 & 12.5 & II.S & I 2.0 & 10.3 & 8.0 & 9.2 & IO.O & I 2.2 & I 3.9 & I I. 2 \\
\hline Shxarkms & $I \uparrow \cdot I$ & 15.5 & . 16.0 & $I 5.5$ & 14.5 & I $5 \cdot 3$ & I 4.0 & I 0.3 & I I. 3 & I 2.7 & I 5.6 & I6.0 & $\mathrm{I}_{4} \cdot 3$ \\
\hline Minel" & 3.6 & 4.2 & 4.0 & 3.5 & 3.6 & 3.7 & 3.2 & 2.6 & 2.8 & $3 \cdot 3$ & 4.I & 4.5 & 3.6 \\
\hline
\end{tabular}

Windhuk.

Harmonische Fonstituenten der täglichen Temperaturschwankung dt zu Windhuk im Jahre 190405 nach der Formel:

$$
\left.d t=a_{1} \sin \left(x-A_{1}\right)+a_{2} \sin \left(x+A_{2}\right)+a_{3} \sin x+A_{3}\right)+a_{4} \sin \left(x-A_{4}\right) .
$$

$a_{1} \cdot a_{2}: a_{3}, a_{4}$ in Celsiusgraden.

$\mathrm{I}$ die Zeit nach Mitternacht, eine Stunde $=15^{\circ}$ gesetzt,

1 mitrlerer Fehler der Abreichung des Stundenmittels rom täglichen in Celsiusgraden,

$\delta$ der mittlere Fehler der T'erte $a_{1}$ : $a_{2}, a_{3} . a_{4}$ in Celsiusgraden.

Iuli Ang. Sept. Okt. Tor. Dez. Jan. Febr. Närz April Mai Juni Jahr $\begin{array}{llllllllllllllll}a_{1} & \vdots .36 & 6.35 & 6.24 & 5.98 & 5.35 & 5.74 & 4.89 & 3.88 & 4.35 & 4.94 & 6.14 & 6.86 & 5.53\end{array}$ $\begin{array}{llllllllllllll}A_{1} & 229^{\circ} .1 & 229^{\circ} .0 & 227^{\circ} .6 & 232^{\circ} .8 & 234^{\circ} .3 & 230^{\circ} .0 & 233^{\circ} .2 & 236^{\circ} .1 & 230^{\circ} .6 & 234^{\circ} .9 & 232^{\circ} .8 & 228^{\circ} .0 & 231^{\circ} \cdot 3\end{array}$ $\mathrm{I}_{1}+2^{42} \mathrm{p} \quad 2^{44} \mathrm{p} \quad 2^{50} \mathrm{p} \quad 2^{29} \mathrm{p} \quad 2^{23} \mathrm{p} \quad 2^{40} \mathrm{p} \quad 2^{27} \mathrm{p} \quad 2^{16} \mathrm{p} \quad 2^{88} \mathrm{p} \quad 2^{20} \mathrm{p} \quad 2^{29} \mathrm{p} \quad 2^{48} \mathrm{p} \quad 2^{35} \mathrm{p}$ $\begin{array}{llllllllllllll}\mathrm{a}_{2} & 1.36 & 1.02 & 1.06 & 0.75 & 0.71 & 0.60 & 0.74 & 0.73 & 0.77 & 1.03 & 1.27 & 1.56 & 0.95\end{array}$ $\begin{array}{llllllllllllll}A_{2} & 50.5 & 36^{\circ} .5 & 64^{\circ} .3 & 82^{\circ} .2 & 97^{\circ} .4 & 77^{\circ} .9 & 78^{\circ} .3 & 84^{\circ} .1 & 79^{\circ} .0 & 68^{\circ} .2 & 56^{\circ} .8 & 49^{\circ} \cdot 4 & 67^{\circ} .2\end{array}$

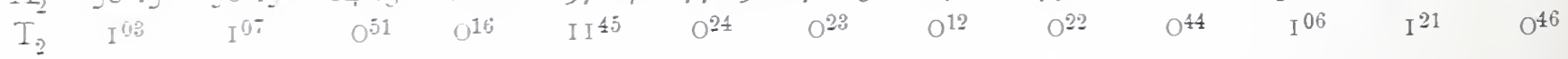

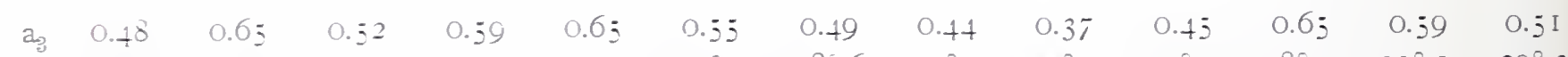
$\begin{array}{llllllllllllll}-t_{3} & I 5^{\circ} .9 & 20^{\circ} .9 & 2 I^{\circ} .1 & 53^{\circ} .0 & 50^{\circ} .2 & 49^{\circ} .4 & 38^{\circ} .6 & 13^{\circ} .9 & 24^{\circ} .2 & 24^{\circ} .2 & 18^{\circ} .5 & 15^{\circ} .5 & 29^{\circ} .3\end{array}$

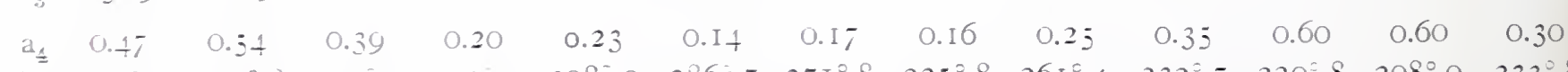

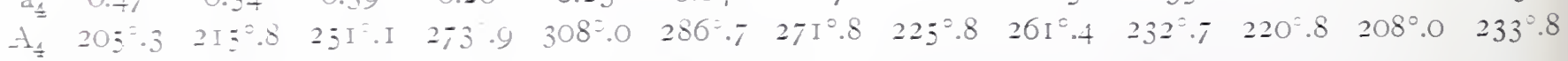
$\begin{array}{llllllllllllll}j & 0.25 & 0.25 & 0.28 & 0.25 & 0.27 & 0.33 & 0.27 & 0.27 & 0.23 & 0.21 & 0.28 & \mathbf{0 . 3 3} & 0.19 \\ \delta & 0.1 \mathrm{II} & 0.10 & \text { O.II } & \text { 0.IO } & 0.1 \mathrm{II} & \mathbf{0 . 1 3} & 0 . \mathrm{II} & 0 . \mathrm{II} & \mathbf{0 . 0 9} & 0.09 & 0 . \mathrm{II} & \mathbf{0 . 1 3} & 0.08\end{array}$

*) Die Relle Mitiel iš als Mittel der absoluten Terte der Abreichungen gebildet und gerăhrt ein Bild über die tăgliche Teränderlichei: der Temperatur. 
Diese Zahlen bestätigen wiederum die Ansicht, daß nur im äuBersten Notfall das Tagesmittel der Temperatur als Mittel aus den Mitteln der täglichen (unperiodischen) Extreme ${ }^{\text {y }}$ zu berechnen ist. Besonders aber dann ist dies zu beachten, wenn, wie auch bei Windhuk, kein regelmäfsiger Tergleich der Angaben der Extrem-Thermometer mit dem trockenen stattgefunden hat, da die Korrektionen der ExtremThermometer unregelmäbigen Änderungen unterworfen sind. Es kann deshalb nur immer wieder darauf hingewiesen werden, daß dieser Vergleich unter allen Lmständen rorzunehmen ist. Am besten eignet sich hierzu im allgemeinen die Zeit zwischen
9 und I I Thr vormittags, also eine Zeit, zu der die Temperatur meist im Steigen ist

TTährend also das. Wittel $; a-2 p+9 p-g p: \div$ für das Jahr sich nur um $O . I^{*}$ ron dem 24 stündigen unterscheidet und auch in den einzelnen Nonaten sich meist um weniger als $0.5^{\circ}$ ron ihm unterscheidet, zeigt das Mittel $7 \mathrm{a}-2 \mathrm{p}-\mathrm{gp}: 3$ bereits beträchtlich grölere Abreichungen. und das Mrittel der Extrem.Thermometer gib: in einem Monat sogar einen um einen rollen Grad verkehrten Wer.

Die Eintritiszeiten der Maximal- und MinimalTemperaturen wie der Tagesmittel sind:

\begin{tabular}{|c|c|c|c|c|c|c|c|c|c|c|c|c|c|}
\hline & Juli & Augusi & Sep: & ott. & Sor. & Dez. & Jan. & Febr. & Mearz & Aturil & Yai & $I==i$ & JEtr \\
\hline Minimum & $\begin{array}{l}5.8 \\
16.4\end{array}$ & $\begin{array}{l}5 \cdot 4 \\
(4 \cdot 3 !\end{array}$ & $\begin{array}{l}5.3 \\
(6.0)\end{array}$ & $\begin{array}{l}4.3 \\
15.2\end{array}$ & $\begin{array}{l}+.3 \\
5.2\end{array}$ & $\begin{array}{l}4 \cdot 4 \\
5.2\end{array}$ & $\begin{array}{l}4.5 \\
5.4\end{array}$ & $\begin{array}{l}4 \cdot \div \\
(6 . I)\end{array}$ & 5.0 & $\begin{array}{l}5.3 \\
5.2\end{array}$ & $\begin{array}{l}5 \cdot 5 \\
5.6\end{array}$ & $\begin{array}{l}5.6 \\
5.0\end{array}$ & $\begin{array}{l}5.0 \mathrm{a} \\
\vdots .3 \mathrm{a}\end{array}$ \\
\hline Maximum & 3.0 & $3 \cdot 3$ & 3.0 & 2.8 & 2.8 & 3.8 & 2.7 & 1.9 & 2.7 & 2.6 & $3 \cdot 3$ & $3 \cdot$ & $2.8 \mathrm{p}$ \\
\hline$"$ & (2.6) & $(3.0)$ & $3.0)$ & (3.I) & 1.9 & $2.8)$ & 12.5 & I.O) & I. 3 ) & 2.7 & 2.1 ) & i & 2.6 \\
\hline Mittel & 8.9 & 8.8 & 8.7 & 8.3 & 8.1 & 8.4 & 8.1 & 8.4 & 8.5 & 8.5 & 8.6 & 8.9 & 3.6 a \\
\hline , & $(8.7)$ & $(8.7)$ & $(8.4)$ & 8.31 & $(8 . I)$ & 18.4 & 8.3 & 8.3 & 8.3 & 8.4 & 8.5 & & $8.5 \mathrm{a}$ \\
\hline ", & 7.6 & 7.8 & 8.3 & 7.9 & 8.0 & 8.2 & 7.9 & -.6 & 3.2 & 7.7 & $\pi \vdots$ & & 7.8 \\
\hline , & $(7.6)$ & $(\bar{\gamma} \cdot \bar{j})$ & $(8.3)$ & 7.9 & 7.9 & $3.2\}$ & $1, .8$ & -.6 & 8.0 & 7.7 & 7.る1 & -0 & -.8 \\
\hline
\end{tabular}

Die Werte der ersten Reihen geben die Zeit an, welche man aus der durch die harmonischen Konstituenten dargestellten Kurre erhält, die eingeklammerten Zahlen sind als die Zeit erhalten. welche man durch die graphische Darsteliung aus den Stundenwerten erhält, die der gesuchten Zeit benachbart sind.

\begin{tabular}{|c|c|c|c|c|c|c|c|c|c|c|c|c|c|}
\hline & Juli & Angust & Sept. & Ot. & Tor. & Dez. & Jan. & Fetr. $^{2}$ & Yrazz & sprii & $\mathrm{M} a$ & $J=n i$ & Take \\
\hline$a_{2}: a_{1}$ & 0.25 & 0.16 & O.I & 0.13 & 0.13 & 0.10 & O.I & 0.19 & 0.18 & $0.2 \mathrm{I}$ & 0.21 & 0.25 & O.IT \\
\hline$a_{3}: a_{1}$ & 0.09 & O.IO & 0.05 & O.IO & O. I I & O.IO & O.IO & O.I I & 0.09 & 0.09 & C.II & 0.009 & og \\
\hline $4: a_{1}$ & 0.09 & 0.08 & 0.06 & 0.03 & 0.04 & 0.02 & 0.03 & $0.0 \div$ & 0.05 & 0.07 & O.IO & 0.09 & \\
\hline
\end{tabular}

Anderseits zeigt diese Tabelle aber auch. daf man ebenfalls die vierteltägige Amplitude in Rech-

*) Siehe Hann: Der täglicke Gang der Temperasur in der inneren Tropenzone. Band 53. S. 249 der Denkschrifen der mathematisch-naturwissenscharlicken Klasse der Kaiserlicken Akademie der Wissenschaften 2u Tien.
Maßgebend für den Verlaü des täglichen Temperaturganges ist in bei weitem überwiegenden Mabe die ganztägige Amplizude, ron sehr geringem Einflub ist die drittel- und vierteltägige: wie deutlich aus den folgenden Quotienten der halb-. drittel- und vierteltägigen Amplitude durch die ganztägige herrorgeht.

nung ziehen muB, wenn man die dritteltägige berücksichtigt, da in manchen Monaten die vierte.tägige etma $\epsilon$ benso groB ist mie die dritteltägige. Sehr honstant bleibt das Terhältnis $a_{3}: a_{1}$. Welches nur innerhalb der Grenzen 0.05 und 0.1 I schwankt. 


\title{
Aus dem deutsch-ostafrikanischen Schutzgebiete.
}

\author{
Zweiter Bericht ïber die landeskundlichen Expeditionen der Herren Dr. Fritz Jäger und \\ Prof. Dr. Karl Weule in Deutsch-Ostafrika.
}

I.

Von Herrn Dr. Fritz Jäger, über dessen Untersuchung der Westgletscher des Kilimandjaro wir im vorigen Heft dieser Zeitschrift berichtet haben, sind inzwischen weitere Nachrichten über die Fortsetzung seiner Forschungsreise zum Vulkan- und Seengebiet des großen "Ostafrikanischen Grabens" eingetroffen, aus denen wir im folgenden das Wesentliche mitteilen.

Herr Dr. Jäger schreibt aus Mkalama in Issansu, den 9. Olstober I906:

„Am I. September marschierten wir von Moschi $\mathrm{ab}$ und über Aruscha an Meru nach Umbugwe und Iraku. Diesem interessanten Lande widmeten wir einige Tage und stiegen dann wieder über den $500 \mathrm{~m}$ hohen Grabenrand an den Nordfuß des Gurui hinab. Nachdem wir uns in der Landschaft Mangati verproviantiert hatten, bestiegen wir den Gurui von Norden, umgingen ihn dann, widmeten einen Tag der Erforschung des Balangdasees und kehrten zum Akida Maussa in Süd-Iraku zurück. Von da wollten wir über den Hohenlohesee nach Mkalama. Wir hatten vom Oberleutnant Abel in Moschi, der gerade vom Kriege in Iraku zurïckgekehrt war, erfahren, daß die Eingeborenen hier zwei Seen Basotu und Masodisch kannten, die jedenfalls der Hohenlohesee seien. Deshalb ließen wir uns Führer nach diesen Seen geben und waren nicht wenig erstaunt, als wir statt an den Hohenlohesee in ein Gebiet zahlreicher Kraterseen auf dem Hochland westlich des Balangdasees kamen. Entdeckt haben wir dieses kleine Vulkangebiet mitten auf der altkristallinen Rumpffäche nicht, obwohl es noch auf keiner Karte steht. Hauptmann v. Prittwitz, ein anerkannt vorzüglicher Routenaufnehmer, an dessen Aufnahmen anzuschließen ja meine Aufgabe ist, soll dieses Gebiet aufgenommen haben, indessen dürften alle unsere nicht rein topographischen $\mathrm{Er}$ gebnisse aus dieser Gegend neu sein. Von diesen
Seen marschierten wir direkt ïber Igambi nach Mkalama, wo wir am 6. Oktober eintrafen.

Von Umbugwe (Anschluß an Uhligs und meine Routenaufnahmen 1904) habe ich eine ununterbrochene Routenaufnahme und einige Abzweiger davon angefertigt bis hierher. Oehlers botanische und photographische Sammlung ist stark angewachsen, in geringerem Maße bisher die geologische (I 20 Nummern) und dieethnographische(60 Nummern). Doch haben wir in Umbugwe, bei den Tatoga und namentlich in Iiaku hübsche Resultate erhalten.

Von den besuchten Ländern erschien uns Iraku besonders interessant, und da dieses Ländchen jetzt nach Beendigung des Aufstandes auch noch ein gewisses alituelles Interesse besitzt, will ich Ihnen etwas Ausführlicheres davon berichten.

Von der sonnendurchglühten Ebene Umbugwe steigt man über den $500 \mathrm{~m}$ hohen, aus Gneisen bestehenden Westrand des großen ostafrikanischen Grabens hinauf in ein Hochland von ganz anderer Beschaffenheit. Unbehindert schweift der Blick über zahlreiche Hügelrücken, die von wenigen höheren und mehr oder weniger bewaldeten Bergzügen überragt sind. Eine dem Afrikareisenden ungewohnte, an unsere deutschen Mittelgebirge erinnernde Frische zeigt hier die Natur. Frisch bläst der Ostwind und jagt häufig feuchte Nebel über die Landschaft, munter plätschern Bäche in jedem Tal und Tälchen, in üppigem Grün sprießen Máas und Bohnen empor, die gelben Grashänge der Hügel in rechteckigen Feldern unterbrechend. Wie die Äcker, so sind die Häuser unregelmäßig über die Fläche zerstreut, und die zahlreichen Buckelrinder-, Ziegen- und Schafherden weiden bald an trockeneren Grashängen, bald im feuchteren, oftmals sumpfigen Grunde der Täler. Die Häuser sind Temben, deren Wände aus starken Knüppeln gebaut und deren flache Dächer mit dem lehmigen, rötlichen oder weißen Sand des aus den altkristallinen Gesteinen hervorgegangenen Verwitterungsbodens dick bedeckt sind. 
Auf geneigten Hängen ist der hintere Teil des Hauses etwas eingegraben, um Boden und Dach, zwischen denen man gerade oder kaum stehen kann, horizontal zu halten. Die Wairaku sind ein hübscher, nicht negerhalter Menschenschlag. Durch sorgfältigen Ackerbau und ziemlich ausgedehnte Viehzucht erhaiten sie sich und das Land im Wohlstand. Ein anderes Aussehen hat in den letzten Monaten der Mittelpunkt des Landes angenommen. Dort, in der Landschaft des regierungstreuen Mangi Isara, der von den Aufständigen vertrieben und so seines großen Viehstandes beraubt worden war, nun aber wieder eingesetzt und $\mathrm{zu}$ seinem Eigentum gelangt ist, dort ist nun eine Boma errichtet und ein großes Feldlager einer Kompagnie Askaris, die einstweilen dort verbleiben soll. Damit ist der Kultur sehr plötzlich in einem vorher unberührten Lande Eingang verschafft worden, denn an das Heerlager schließen sich Händler und regelmäßige Märkte, und das Land wird in den Handel der Kolonie einbezogen.

Der Gurui ist ein aus Laven bestehender Vulkankegel, der durch eine Explosionscaldera in Nordosten, durch eine zentrale, hauptsächlich durch Erosion gebildete Caldera und durch große Schluchten an den Hängen wesentlich zerstört ist. Die flachen sanft geneigten Landschaften des Bergfußes sind mit ansehnlichen parasitischen Kratern besetzt. Es sind Gras- oder lichte Baumgrassteppen, in denen Tatoga mit ihren Viehherden hausen.

Der Balangdasee an seinem Westfuß ist $1 n$ der Trockenzeit nur $1 / 2 \mathrm{~m}$ tief, so daß die Wellen seinen schlammigen Boden aufwühlen und seine Salzflut trüben.

Die Vulkane des erwähnten Kraterseengebietes auf der Hochfläche westlich des Balangdasees sind sehr unbedeutende Hügel. Bestehen doch die Kraterwälle fast mehr aus Trümmern der durchbrochenen Gesteine (Granit u. a.) als aus vulkanischem Material, so dafs sie moränenartig aussehen. Die Seen sind teils süß, teils salzig.

In den nächsten Tagen gedenken wir nun an die eingehendere Erforschung des Ejassisees zu gehen und von dort auch einen Abstecher nach dem Hohenlohesee zu machen. So dürften wir wohl Anfang Dezember nach Muansa kommen."

In dem nächsten Bericht des Herrn Dr. Jäger aus Mkalama, 3 I. Oktober I906, heißt es unter anderm folgendermaßen:

„Die Erforschung des Ejassisees hat früher ein vorläufiges Ende gefunden, als ich gedacht hatte. Der Wassermangel erlaubte uns nicht, länger dort $z u$ verweilen. Ich bin zwar der Überzeugung, daß es im Ejassi- und Hohenlohe-Seegebiet Wasser- stellen genug gibt, um mit einer Karawane von 80 Mann, wie die unsrige ist, hindurchziehen zu können, wenn man Führer hat, die die Wasserstellen kennen. Die zu bekommen, ist aber so gut wie unmöglich in diesen unbewohnten Gebieten. Das scheue Jägervölkchen der Wakindiga, das dort haust und dessen verlassene Lagerplätze und Wildfallen wir öfters sahen, bekommt kaum ein Eingeborener zu Gesicht, der auf Jagd hierherzieht (ein solcher war unser „Führer"); eine große Karawane niemals. So waren wir denn meist darauf angewiesen, die Wasserstellen selbst zu suchen, was günstigsten Falls sehr viel Zeit kostet, während im ungïnstigen Falle die Karawane verdurstet.

Zwci Stunden östlich vom Südende des Ejassisees fanden wir reichlich Wasser und ließen dort das Hauptlager, während wir mit den allernötigsten Lasten und einigen Wasserträgern zwei Abstecher machten: einen am Südostufer des Sees nordwärts, einen nach der Mündung des Sibiti- oder Vembäreflusses. An das Nordufer des Sees und die hohen Berge daselbst, anscheinend Vulkane, konnten wir leider nicht gelangen. Die Tour hat uns immerhin über die Natur des Ejassisees und seines Grabens einen Überblick verschafft. Dann unternahmen wir eine Tour nach dem HohenloheGraben. Sie lehrte uns, daß der Hohenloheoder Jaida-Sumpf süßes Wasser hat, sogar jetzt in der trockensten Zeit. Auch in der Regenzeit dürfte. die Gegend mehr Sumpf als See sein. Nur ein Sumpf befindet sich im Hohenlohe-Graben, den die Bewohner der Nachbarlandschaften Jaida nennen. Er liegt übrigens viel näher am Cjassisee, als auf Werthers Karte angegeben. Wir marschierten in 5 Stunden vom Ejassi-Graben in den Hohenlohe= Graben. Nach Besteigung des Kinjangiruberges, eines guten Übersichtspunlites über die in den letzten $\mathrm{I}^{1} / 2$ Monaten bereisten Gegenden, kehrten wir vorgestern nach Mkalama zurück.

Morgen wollen wir nach Iramba aufbrechen, um mit einem langjährigen Ansiedler und Kenner der Gegend, namens Lieblinger, zusammenzutreffen, der uns vielleicht einen Führer in die Ejassigegend verschaffen kann. Ist dies nicht der Fall, werden wir von da direkt nach Muansa ziehen und die weitere Erforschung des Ejassigebietes in der Regenzeit von Norden her unternehmen. Namentlich von den Vulkanen (Lerobi) am Nordende des Sees verspreche ich mir viel."

Weiter schreibt Herr Dr. Jäger aus Muansa, den I7. November I906:

,,Seit meinem Bericht aus Mkalama ist nicht viel vorgefallen, worüber ich Ihnen schreiben sollte. Wir marschierten nach Iramba, um uns von 
einem dortigen Ansiedler, Herrn Lieblinger, das dortige Goldfeld des Irangi-Syndikats, das nicht abgebaut wird, zeigen und dariber Auskunft geben zu lassen. Dann marschierten wir möglichst rasch über die Wembäre-Steppe und durch die Ussukumalandschaften Uduhe, Seke, Nera, Urima nach Muansa. Die Routenaufnahme setzte ich fort bis zum Anschluß an die Telegraphen. linie Tabora-Muansa.

Muansa ist ja ron unserm eigentlichen Forschungsgebiete, dem abflublosen Gebiet, etwas abgelegen, und der lange Marsch durch das gut bekannte Ussukuma dahin war mehr Studien-als Forschungsreise, die ich deswegen auch möglichst beschleunigte. Indessen ist der Marsch nach Muansa kein müßiger Spaziergang und der Aufenthalt daselbst durchaus nicht eine Vergnügungsreise. IVir haben einen mindestens I 4 tägigen Aufenthalt hier dringend nötig, um allerlei aufzuarbeiten (z. B. Photographien entwickeln) und um unsere Ausrïstung wieder instandzusetzen, wie es für die Reise in der Regenzeit erforderlich ist. Ich hatte nicht damit gerechnet, wie sehr durch eine solche Reise alles aufgebraucht wird und erneuert werden muß.

Abgesehen davon denke ich aber, daß es auch den Forschungen in unserm speziellen Gebiet nur zugute kommen kann, wenn wir unsere Studien auch auf Nachbargebiete ausdehnen kïnnen, besonders auch auf die wirtschaftlich so hoch interessante Gegend des Sees. Das allein wïrde auch ohne den äußeren Zwang der Verhältnisse den Abstecher nach Muansa rechtfertigen, wenn auch direkt 1 ichts Neues dabei herausliommt."

Einem Bericht Herrn Dr. Jägers aus Muansa, den I 4. Dezember I906, entnehmen wir folgendes:

, $\mathrm{Zu}$ meinem Eedauern sitzen wir immer noch hier, da ich seit 24. November drei Anfälle von Rückfallfieber und zwei von Malaria gehabt habe. Doch hoffe ich, ïbermorgen kräftig genug zu sein, um in anfangs kleinen Märschen nach Ikoma und dann in die gesunde Gegend von Ngoróngoro zu marschieren.

Wir trafen hier einen Herrn Siedentopf, Ansiedler in Ngoróngoro, der uns seine weitgehende Unterstuitzung in Aussicht stellte und sehr viel Interessantes von jenen Gegenden wußte. Da mir ohnehin schon der Schwerpunkt der tektonisch-vulkanologischen Untersuchungen dort zu liegen schien und, nach Siedentopfs Bericht zu schließen, auch sonstige geographische Probleme reichlich sich bieten werden, so gedenke ich mich auf Ngoróngoro, den nördlichen Hohenlohe- und Ejassigraben und den zunächst nördlich anstoßenden Landstrich zu bescinänken, nebst AnschluB nach $\mathrm{N}$ u. $\mathrm{S}$ und an den Grabenrand. Die eingehendere Erforschung dieses beschränkten Gebietes verspricht den meisten Erfolg. Wenn dann noch Mittel übrig sind, werde ich mit Vergnügen auch noch die Nebenprojekte (Doenje Ngai, Gelai, Meru) ausführen. Ich freue mich sehr auf dieses interessante Gebiet."

Der zuletzt eingetroffene Bericht des Reisenden, datiert Ngoróngoro, den 16. Januar 1907, meldet des weiteren:

,Endlich sind wir wieder eifrig und freudig beim Forschen in einem Gebiet, welches hübsche Ergebnisse verspricht.

Am i6. Dezember brachen wir von Muansa auf. Da ich indessen am folgenden Tage einen ziemlich starken Fieberanfall bekam und auch die nächste Zeit nie ganz fieberfrei war, so kamen wir nur langsam vorwärts und blieben über Weihnachten einige Tage in Gasamo, wo zur Zeit in größerem Maßstabe Versuche über die Abbauwürdigkeit des Goldes gemacht werden. Dort wurde ich das Fieber los, muBte mich aber noch sehr schonen.

Von Ikoma brachen wir am I. Januar auf. Ikoma ist durch die Grenzaufnahme genau festgelegt, hier begann ich mit der Routenaufnahme, die zunächst in unübersichtlicher flacher Baumsteppe wenig befriedigend war. Nachdem wir dann mit vieler Mühe einen Ndorobboführer gefunden hatten, zogen wir durch das Bergland von Ndassekera (im weiteren Sinne, den eigentlichen Namen des Berglandes konnte ich noch nicht erfahren) nach Osten, dann am östlichen Steilabfall dieses Berglandes entlang durch die Salehsteppe südwärts, bis wir (der Führer war inzwischen entflohen) in eine abflußlose Senke kamen, die ich zunächst für Ngoróngoro hielt. Auf der Suche nach der Ansiedelung von Siedentopf, die für unsere weiteren Unternehmungen Stützpunkt werden sollte, stieß ich indessen östlich davon auf den mächtigen Ngoróngorokrater, in dem ich das Gehöft Siedentopfs liegen sah. Gestern sind wir mit der Karawane hier angekommen.

Das Bergland von Ndassekera ist im Westen, Süden und Osten von Steilrändern begrenzt. Der westliche Steilrand fällt gegen die flachwelligen Baumsteppen der weiteren Umgebung von Ikoma und im Süden gegen die ausgedehnte Grassteppe Serengeti ab, der östliche Steilrand - es ist der westlichste der drei Bruchränder, in denen der Westrand des großen Grabens zum Natronsee abfällt begrenzt Ndassekera gegen die Grassteppe Saleh. Der südliche Teil von Ndassekera, den wir durchzogen, besteht aus Quarziten und einem Quarzglimmergestein, das meist etwa senkrecht $z u$ den begrenzenden Brüchen, also West-Ost, streicht. 
Im Westen ist das Bergland stark in einzelne Berge aufgelöst, zwischen denen weite flachwellige Grassteppen sich ausdehnen. Im Osten, nahe dem Steilrand, ist es geschlossener, aber von tiefen Tälern durchschnitten. Hier gibt es einige dauernd fließende Bäche, während der Westen sehr wasserarm ist. Das Bergland erreicht nahe dem östlichen Steilrand Höhen von etwa $2500 \mathrm{~m}$, die zum Teil mit Ur. wald spärlich bedeckt sind. Das ganze südliche Bergland scheint unbewohnt zu sein.

Südlich vom Ndassekerabergland liegt eine Bergkette mit gleichfalls östlichem Streichen der Quarzitschichten, von Ndassekera durch einen etwa eine Stunde breiten Quergraben getrennt. Vulkanische Laven und darüber Tuffe (!) (ich halte es für das Wahrscheinlichste, daß die merkwürdige Ablagerung Tuffe sind) erfüllen das Bruchgebiet und sind den beiden alten Gebirgen angelagert.

Südlich dieses Tuffgebiets folgt die bisher unbekannte abflußlose Senke Balbal (die ich, wie erwähnt, zuerst für Ngorongoro hielt). Im Süden und Osten ist sie von hohen Vulkanen umgeben, dem Magrut (Lmagro der Karten), Lóirobi, Ngorongoro, Olmoti und Laneirobi. Im Westen begrenzt sie ein etwa $\mathrm{I}_{5} \mathrm{O} \mathrm{m}$ hoher Steilrand gegen die Serengetisteppe, ein ebensolcher Steilrand im Norden gegen das vulkanische Tuffgebiet an der Südostecke von Ndassekera. Der Boden der Senke hat eine Meereshöhe von gegen I 300 m. Die Senke ist sehr wasserarm, da sie im Wind- und Regenschatten der hohen Vulkane liegt. Deshalb enthält sie auch keinen See. An den Rändern ist sie mit Akazien bestanden, die Mitte ist offene, äußerst wildreiche Grassteppe.

Ngoróngoro hält uns nicht entfernt, was Siedentopf in Muansa uns in Aussicht stellte. Die Verpflegung der Karawane ist hier äußerst schwierig, da alles Getreide usw. etliche Tage weit hergeholt werden muB. Die Verpflegung durch Wildfleisch hat seit Ikoma unsere Leute schon sehr mitgenommen, so daß wir sehr nach vegetarischer Kost suchen müssen, damit sie uns hier oben in der Kälte und bei den Bergtouren, die wir vorhaben, nicht völlig versagen.

Das Gebiet um Ngoróngoro verspricht reichen Lohn der Forschung. Hier findet eine dichte Häufung der mächtigsten Vulkane statt. Wir wollen zunächst den Loirobi und Le Magrut besteigen und den Anschluß an unsere Untersuchungen am Ejassisee herstellen. Dann die drei großen Vulkane Elaneirobi, Ossirwa und Olmoti im Norden von Ngorongoro, die Uhlig und ich vor zwei Jahren wissenschaftlich entdeckten, näher untersuchen und dann den Anschluß nach dem Hohenlohegraben, Mitteilungen a. A. D. Schutzgebieten, XX. Band. II.
Iraku und dem Grabenrand östlich von Ngoróngoro herstellen. Vulkanologisch "und tektonisch bietet das Gebiet eine Fülle interessanten Stoffes."

\section{II.}

Seit seinem ausführlichen, im 4. Heft der «Mitteilungen» 1906 abgedruckten Bericht aus Newala vom 7. Oktober 1906 hat Herr Prof. Karl Weule seine ethnologischen Forschungen im äußersten Süden des Schutzgebietes erfolgreich zu Ende geführt. Er schreibt aus Lindi, 30. November 1906:

»Von Newala bin ich in der zweiten Oktoberwoche in das auf dem Südrande des Makondeplateaus gelegene Wangoni-Gebiet von Nchichira marschiert. Mein Standquartier habe ich dort beim alten Madjaliwa aufgeschlagen. Die I4 Tage meines Aufenthaltes unter diesem etwa 5000-6000 Seelen zählenden Völkchen haben mir eine Überraschung nach der anderen gebracht. Der ganz allgemein geteilten Überzeugung entgegen, nach der jene Wangoni ein vor Jahrzehnten abgesprengter Teil der $z u$ den Kaffern gehörigen Wangoni auf dem Ostufer des nördlichen Njassa seien, fand ich auf Grund der sprachlichen und der ethnologischen Aufnahme, der Tradition und des Habitus, daß die Nchichira-Wangoni in Wirklichkeit nichts als den Namen mit jenen Kaffern-Wangoni gemein haben. Freilich haben auch sie noch zu Lebzeiten der jetzigen Stammesältesten an den linken Zuflüssen des oberen Rowuma gesessen; diese Ältesten wußten sich auch noch sehr gut der anderen "von weither gekommenen» Wangoni zu erinnern, doch sind die Berührungen mit diesen Eindringlingen stets nur feindlicher Natur gewesen: von dem neuen Element ist das alte immer mehr den Rowuma abwärts gedrängt worden. Sprachlich bestehen zwischen dem Kingoni vom Nchichira, das ich selbst aufgenommen habe, und dem von Ssongea, das ich aus der Arbeit von SpieB einsehen konnte, gar keine Zusammenhänge; jenes gehört, soweit ich das jetzt schon beurteilen kann, vielmehr der Kijao-KimakondeKimuera-Gruppe an und scheint besonders dem letzteren nahe $\mathrm{zu}$ stehen. Auch in Farbe und Habitus sind die hiesigen Wangoni typische Ostbantu.

Eine hübsche Entdeckung machte ich beim Abstieg in das Rowumatal. Dort am Fuß des auch hier sehr steil abstürzenden Plateaurandes haben die Wangoni seit einiger Zeit angefangen, Schamben und Siedelungen anzulegen. Der üppige Humusboden verlockt ja auch förmlich dazu. Die Lichtungen nun, die die Eingeborenen hier in den prachtvollen Waldbestand eingeschlagen haben, sind 
durch zweierlei charakterisiert: die ungeheure Menge des zwecklos zu Boden gestreckten, halb und ganz verkohlten Nutzholzes und die auf hohen Pfählen stehenden Wohnhiutten der Menschen. In der Tat ist der ganze Landstrich mit typischen Pfahlbauten bedeckt. Hanche Häuser sind sogar in drei Stockwerken ibereinander bewohnt, dem Erdgeschoß, wo das Herdfeuer brennt, dem darüber liegenden eigentlichen Hausraum und dem Dachgeschoß, das neben Schlafmatten stets auch Vorratskörbe für Mtama und andere Nahrungsmittel enthielt. Nach dem Beweggrunde für diese angesichts des hoch und trocken liegenden Hügellandes doch nur schwer zu verstehende Bauweise befragt, gaben mir die Bewohner in allen Fällen die Furcht vor den Elefanten an. Diese sind tatsächlich sehr zahlreich und auch sefährlich. Den Schutz selbst verleilht indessen wohl weniger das Pfahlsystem an sich als eine aus starken Pfählen gefertigte Boma, die das Ganze umschließt.

Die letzten drei Wochen meiner Expedition habe ich in Mahuta verlebt. Mahuta ist keine eigentliche Ortschaft, sondern lediglich der Sitz eines Wali, der mit einer kleinen Schutztruppe in einer großen Boma haust. Eigentliche Ortschaften gibt es auf dem Makondeplateau überhaupt nicht. Man kann dort tage- und wochenlang marschieren, ohne eine Siedelung zu sehen. Verriete nicht das Krähen der zahlreichen Hähne oder der Schlag der Axt die Anwesenheit menschlicher Siedelungen, so könnte man meinen, das Land sei völlig unbewohnt; so versteckt liegen die kleinen Weiler in dem dichten Busch. Und dabei zählen die Makonde mehr als 80000 Seelen. Was Mahuta Bedeutung verleiht, und warum es auch der Sitz der höchsten Beamten auf dem Plateau ist, ist seine Lage am Treffpunlt der großen Straßen , die je von Lindi und Mikindani über Mahuta und Newala zum mittleren Rowuma und ins Portugiesische führen. Für mich war Mahuta der gegebene Standort schon wegen der ausgedehnten Machtbefugnisse des Wali; dieser Beamte hat denn auch Tag für Tag für neues Beobachtungsmaterial gesorgt. In der ersten Zeit strömte dies Material sogar zu reichlich herbei: allmorgendlich füllte sich der große Bomaplatz mit Hunderten von Makonde: Männern mit oft prachtvoller Tätowierung und Weibern mit schneeweif gefärbten Oberlippenscheiben von meist ganz ungeheuren Abmessungen. Pflöcke oder richtiger Klötze von 6 bis $7.5 \mathrm{~cm}$ Dicke waren nicht selten.

Das Kimakonde habe ich in der gleichen Ausdehnung aufgenommen wie das Kijao und das Makuan. Es steht jenem und noch mehr dem Kisuaheli recht nahe. Ein Versuch, dem Kimuera näher zu treten, gelang nicht recht. Da im mittleren Lukuledital sehr wenig Nahrungsmittel vorhanden sind, habe ich, wenn auch schweren Herzens, von der geplanten Rückkehr in jenes Wamueragebiet Abstand nehmen müssen. Dafür ließ ich mir ein paar «gelchrte» Stammesälteste nach Mahuta kommen, um wenigstens sprachliches Vergleichsmaterial zu erlangen. Für das Kimuera bin ich nun auf die etwaigen Vorarbeiten der Mission angewiesen.

Gegen die Mitte des November mußte ich an den Autbruch zur Küste denken. In Mahuta waren die ersten Regen schon am Anfang des Monats gefallen. Die mit der Feldbestellung beschäftigten Eingeborenen blieben infolgedessen mehr und mehr aus. Zudem war ich mit meinen I $3 \times$ I 8 Platten, den Kinematographen-Films und den PhonographenWalzen zu Ende. Schlieblich hatte ich auch alle mir gesteckten Ziele im großen und ganzen erreicht. Am I3. November bin ich daher von Mahuta abmarschiert und in fünf anstrengenden Tagesmärschen habe ich am 17 . November Lindi wieder erreicht.

Inzwischen ist Herr Prof. Weule Ende Januar glücklich in die Heimat zurïckgekehrt und hat der Landeskundlichen Kommission in der Sitzung vom I8. Februar iiber die wichtigsten Resultate seiner Reise berichtet. Die Hauptpunkte sciner Ausführungen sind folgende:

\section{Kurze Übersicht über meine Forschungsergebnisse.}

Forschungsobjekt waren die Völkerschaften der Wamuera, Makua, Wanjassa, Wajao, Makonde, Wangoni und Wamatambwe. Als Leitfaden für meine Arbeit habe ich v. Laschans "Anleitung für ethnographische Beobachtungen und Sammlungen in Afrika und Ozeanien" benutzt. Im Anschluß an deren Disposition lassen sich meine Ergebnisse in folgende Stichworte zusammenfassen.

\section{A. Geographie und Statistik.}

Für die Statistik mußte ich mich auf die Nachprüfung der amtlichen Daten, Nachzählung der Hüttenzahlen und ihrer Bewohner u. dgl. beschränken. Geschlossene Ortschaften kommen in meinem Forschungsgebiet fast nirgends vor; vorherrschend ist vielmehr das Einzelgehöft inmitten der eignen Schambe, auf dem Makondeplateau der im dichten Busch versteckte, aus nur wenigen Hütten bestehende Weiler. Geographisch und geologisch ist der Südbezirk eines der interessantesten Gebiete Deutsch-Ostafrikas. Welche Probleme bergen allein die westlich vom Makonde- und Rondoplateau gelegenen Inselberglandschaften von Massassi bis zum mittleren Rowuma, und welche Zeitperspeltive 
eröffnet sich für die Besiedlungäsdauer des Makondeplateaus, wenn wir sehen, wie dessen gesamte heutige Vegetationsform lediglich eine Folge der dortigen primitiven Agrikultur ist! Und wie stark prägen sich erst die anthropogeographischen Wirkungen des Bodens aus! Die Beschränkung der Siedlungsmöglichkeit auf die Verwitterungsgebiete anstehenden Gneises oder angeschwemmter Lehmhalden, die Bedingtheit eines weiträumigen IVander- und Handelsverkehrs durch das Vorkommen pflanzensalzhaltiger Erde um Massassi sind nur ein par solcher Momente.

\section{B. Den Wohnstätten und ihrer Einrichtung} habe ich große Aufmerksamkeit zugewendet, da gerade sie beide für Lebenshaltung und Charakter der Eingebornen sehr bezeichnend sind. Ein einheitlicher Hof- oder Hausgrundriß besteht bei den Einzelvölkern nicht, oder vielleicht nicht mehr; neben dem Quadrat und dem Rechteck steht vielmehr ebenso häufig der Kreis oder das Oval. Jene tragen ganz allgemein das Satteldach, diese das Spitz- oder Kegeldach. Große Unterschiede bestehen auch in der Größe und der Ausstattung der Wohnungen; um Massassi mit seinem reichen Boden, bei Matola und Susa gab es grobc, schön gebaute Häuser mit 4, 5 und mehr Zimmern und breiten Veranden; um Newala und in Nchichira, vor allen Dingen aber bei den vom soeben beendeten Aufstand hart mitgenommenen Wamuera wohnten die Leute dagegen oft in ganz elenden, winzigen Hütten, die kaum den notwendigsten Schutz gewährten. Interessant warcn die Pfahlbauten der Wangoni im untern Rowumatal, die vor den dort häufigen Elefanten schützen sollten; desgleichen die in vielen Schamben des ganzen Südbezirkes aufgestellten hohen Wart- oder Wachthäuschen zum Schutz der Pflanzungen vor Raubzeug. Mehr oder minder stattliche Beratungshäuser gab es in fast allen größeren Siedlungskomplexen. Ganz außerordentlich waren schließlich Zahl und Formenreichtum der Vorratsbehälter und Vorratshäuser für das Getreide. Ich habe alles irgendwie Bemerkenswerte mit Stift und photographischem Apparat festgehalten, die Grundrisse aufgezeichnet, alle tragbaren Einrichtungsgegenstände gesammelt.

\section{Die Ernährung}

ist im ganzen Gebiet ziemlich gleichartig; Hirse, Mais, Mhogo und Reis sind die Hauptnahrungsmittel. Die Feldbaumethoden habe ich aufgezeichnet, Samenproben gesammelt. Die Zubereitungsmethoden für die Nahrung, das Enthülsen, Worfeln und Reiben der Körner habe ich sogar mehrfach in wohlgelungenen kinematographischen Aufnahmen mit nach Hause nehmen können. Desgleichen auch die Technik des Feuererzeugens, der ich, wie der ganzen Frage nach der Nutzbarmachung und Herstellung des Feuers durch den Menschen, seit Jahren eine rege Aufmerksamkeit zugewendet habe. Alle Wirtschaftsgeräte sind gesammelt worden.

\section{Schmuck und Haartracht.}

Diese ist bei den Inlandstämmen einfach im Gegensatz zur Küstenbevölkerung; sie ist lediglich durch das Tragen zahlreicher, schön gearbeiteter kleiner Kämme, von denen ich sehr zahlreiche Muster gesammelt habe, charakterisiert. Um so reicher und mannigfaltiger ist der übrige Körperschmuck, von dem ich ebenfalls alles Erreichbare zusammengetragen habe.

\section{E. Künstliche Verunstaltungen.}

Sie kann man mit Fug und Recht als das Wahrzeichen jener Völker des Südbezirkes bezeichnen. Zwar spielt die Bemalung keine große Rolle; aber wie mannigfaltig und umfangreich sind dafür Tätowierung und Ziernarben! Und wie unsagbar abenteuerlich wirkt auf uns die Verunstaltung der Oberlippe durch das Einfügen von Holzpflöcken von oft ganz riesigen Abmessungen bei den Frauen der Makonde, Wamatambwe und Wamuera! Dic ganz allgemeine Ohrläppchenscheibe und der anscheinend mehr auf die Jao-Frau beschränkte Holz- oder Metallpflock in linken Nasenflügel fallen jenem Lippenschmuck gegenüber, so eindrucksvoll auch sie an sich sind, kaum noch ins Auge. Für den Portrait-Photographen ist hier das gegebene $\mathrm{Ar}$ beitsfeld.

Bei don Matambwe und Makua tritt $\mathrm{zu}$ alledem noch hier und da Zahnverstümmelung: das Zuschärfen einiger oder auch aller Schneidezähne. Bemerkenswert für die Verbreitung aller dieser Verunstaltungen ist der Umstand, daß heute keine als ein Stammeswahrzeichen bezeichnet werden darf; die Wahl der einen oder andern ist heute vielmehr Geschmack- oder Modesache, ihre Anbringung oder Unterlassung Sache des freien IVillens. Nur die schroffe Unterscheidung besteht noch, daß die weißgefärbte Lippenscheibe auf Makonde und Matambwe, die schwarze vorwiegend auf die Wamuera beschränkt ist, während der Nasenpflock ursprünglich den Jao zukommt.

Eine große Rolle im Leben des Stammes wie des Einzelnen spielt die Beschneidung. Sie ist auf die Knaben beschränkt, doch werden auch zu Ehren der mannbar werdenden Mädchen langandauernde Feste gefeiert. Ich habe an manchen teilgenommen und eine reiche Ausbeute an Auf- 
zeichnungen, an Phonos, Photos und Kinos, an Liedern, Reden und Skizzen heimgebracht. Das Studium dieser Feste war unstreitig mit das Wichtigste und Interessanteste in meiner Forschertätigkeit.

Kopfdeformation habe ich nicht feststellen können; dagegen war eine künstliche, von den ersten Tagen der beginnenden Mannbarkeit an andauernd geibte Verlängerung der Labiora minora bei den Angehörigen des weiblichen Geschlechts entlegener Walddörfer ganz allgemein. Auf die Makuafrauen beschränkt schien jedoch eine andere Sitte zu sein: das Tragen von 2 bis 8 bohnengroßen, klaren, vom Rowuma und anderen Flubläufen rund und glatt geschliffenen Quarziten unter der Zunge. Dies Tragen geschieht zu Ehren des Mannes oder des Geliebten, der allein auch diese Steine je zu sehen bekommt. Etwa ein Dutzend habe ich zu erwerben vermocht.

\section{F. Kleidung.}

Sie bietet heute nichts Bemerkenswertes mehr, dit alle Kleidungsstoffe von der Küste kommen. Höchstens die Festlieidung bietet noch manches Originale. Interessant war eine gewisse Verlagerung des Schamgefühls: die großen Lippenscheiben von ihren Trägerinnen direkt zu bekommen, war ganz unmöglich; die Ohrscheiben nur sehr selten; häufiger schon die Nasenpflöcke. Aber auch hier deckten die Frauen die hohlgewordene Stelle in dem Moment der Herausnahme des Pflocks ganz schnell mit der Hand zu. So mußten diese Stücke fast durchweg durch die Vermittlung der Männer erworben werden, die sie ihren Frauen zu Hause abnahmen.

$$
\text { G. Waffen. }
$$

Heute herrscht der Vorderlader jedes älteren Systems vor; doch findet sich daneben fast stets auch noch viel SpieB, Bogen und Pfeil. Eine wirkliche Meisterschaft in der Handhabung der Waffen habe ich nirgends feststellen können; eher das Gegenteil. Eine einheitliche Bogenspannweise besteht nicht, selbst nicht einmal bei ein und demselben Schützen, der vielmehr von einem SchuB zum anderen je eine andere zu wählen imstande ist. Schilde waren nirgends üblich; bei den Wangoni habe ich gerade einen, von ihren Namensgenossen und alten Gegnern zurïckgelassenen, erwerben können. Interessant war das Vorkommen von Wurfstock und Wurfschlinge bei einzelnen Individuen. Prähistorische Steingeräte und -Waffen waren gänzlich unbekannt.

\section{H. Jagd, Fischfang und Ackerbau.}

Alle Stämme stellen ausgezeichnete Jäger; die Matambwe dagegen sind das ausgezeichnetste Fischer- volk des Ostens, das ein fast amphibisches Dasein am und auf dem Rowuma führt. Zahlreich sind die Arten und Prinzipien der Wildfallen, von denen ich eine wohl vollständige Sammlung von Originalen und Modellen, oder doch in der Zeichnung habe mitbringen können. Auch Stellnetze, Reusen, Fischgifte usw. habe ich in ziemlicher Anzahl zusammentragen können.

\section{J. GenuBmittel.}

Nur Tabak, der meist geschnupft wird, und Bier. aus Hirse oder Mais.

\section{K. Spielzeug, Spiele.}

Auf den ersten Blick fand ich wenig oder nichts; fragte ich aber nach, so lam eine große Mannigfaltigkeit von Kreiseln, Lärminstrumenten, Schießwaffen u. dgl. zu Tage. Auch Fadenspiele wurden geübt. Spiele der Erwachsenen sind die mit dem Gesamtnamen Ngona bezeichneten Tänze ohne oder mit Masken (Makonde), ohne oder mit Stelzen. An Maslien habe ich natürlich soviel zusammengetragen, wie nur möglich war; von den Tänzen besitze ich viele Photos und Kinos.

\section{Musik.}

Die Instrumente sind primitiv und wenig mannigfaltig; es kommen hauptsächlich nur die Trommel, eine Klimper, ein Monochord und ein Xylophon in Frage. Dabei sind alle Völker Musikliebhaber, und Berufsspieler, die zugleich tanzen, spielen und singen, ziehen unausgesetzt im Lande umher. Viele von den Liedern habe ich phonographisch und textlich gesammelt und auch ibersetzt. Im Gegensatz zu dem feierlichen, melodiösen Gesang meiner WanjamwesiTräger war der Gesang jener Südvölker ein unglaublich rauhes, polterndes Parlando. Ihr stets improvisierter Inhalt waren bestimmte Stammesereignisse oder persönliche Erlebnisse des Sängers selbst.

\section{Transportmittel.}

Lediglich eineSammlung von Körben, Netzen usw.

\section{N. Handel, Geldsurrogate, Maße und Gewichte.}

Ich bin glatt mit Rupie und Heller durchgekommen, die sehr gern genommen wurden. Allgemein gültige Wertmesser scheint es hier unten nie in größerem Maßstabe gegeben zu haben, außer dem Sklaven oder der Sklavin.

\section{O. Technik.}

Sie war ein ganz bevorzugter Gegenstand meines Studiums und meiner Sammeltätigkeit. Über den Hergang der Töpferei und des Flechtens, der Rindenstoffherstellung, des Schmiedens, des Metall- 
gusses u. dgl. habe ich mich genau unterrichtet; in Kino und Photo, in Skizze und Wort ist alles Wesentliche festgehalten worden, wo es nötig erschien in langen Reihen von Serienbildern.

\section{P. Politische Verhältnisse.}

Seit der Errichtung der deutschen Kolonialherrschaft sind die ursprünglichen Verhältnisse sehr verwischt worden; hier mußte der Forscherblick vielfach weit nach rückwärts schauen. Am interessantesten war wohl die Feststellung der mutterrechtlichen Erbfolge auch für die Häuptlingswürde.

\section{Q. Rechtspflege und soziale Verhältnisse.}

Das von den politischen Verhältnissen Gesagte gilt zumeist auch hier.

\section{R. Ehe, Stellung der Frau; Kinder.}

Dies Kapitel war eins der anziehendsten und ergebnisreichsten Forschungsgebiete: eine weitverzweigte exogamische, mutterrechtliche Sippeneinteilung der Völkerschaften, viele Gebräuche bei der Eheschließung, bei den außerordentlich komplizierten Pubertätsfeiern mit ihren Frauen- und Männertänzen mit und ohne Masken, die Namen von vielen Sippen und Einzelpersonen mit ihrer für den Negercharakter so bezeichnenden Bedeutung, alles dies und vieles zur Zeit für mich noch unübersehbares Andere habe ich in heißer, schwerer, aber doch genußreicher Arbeit feststellen und verfolgen können.

\section{S. Geburt und Tod.}

Die Gebräuche bei jener fallen für den Eingebornen mit in den Rahmen der Pubertätsfeiern, wenigstens wurde sie, von allen meinen Gewährsleuten ganz unabhängig voneinander $m i t$ in den Zyklus: erster Unterricht des Mädchens über die geschlechtlichen Verhältnisse, erste Menstruation, Schwangerschaft, Geburt eingereiht.

\section{T. Religion, Kultus, Mythologie.}

Ein sehr schwieriges Gebiet. Als positive Tatsache eines eigentlichen Kults war lediglich der Verkehr mit den Seelen der Verstorbenen mit Hilfe des Mzollo-Baumes festzustellen, an dessen Stamm Lappen befestigt, an dessen FuB Opfer von Speise und Trank niedergelegt wurden, um jene Seelen günstig zu stimmen, sie zur Hilfe in Not und Gefahr zu veranlassen. Amulette und Medizinen sind gesammelt worden, soweit es möglich war. Besonders als Jagdamulette spielen sie eine große Rolle.

\section{U. Totemismus}

im eigentlichen Sinne war nicht (oder nicht mehr?) erkennbar; die häufigen Benennungen der Sippen nach bestimmten Tieren und Pflanzen wurden auf rein äußerliche Beziehungen zwischen dem Menschen und seiner Umwelt zurückgeführt, sei es, daß das betr. Tier oder die betr. Pflanze den Vorfahren zur ausschließlichen Nahrung gedient hatte, daß sie in einer Umgebung der betreffenden Pflanze gewohnt hatten usw.

\section{V. Über die Medizin}

meiner Völkerschaften habe ich, besonders aus Zeitmangel, nicht sehr viel in Erfahrung zu bringen vermocht.

W. Zeitrechnung, Astronomie, Geschichte.

Über die ersten beiden bestehen nur sehr verworrene Vorstellungen, die aber gleichwohl sehr interessant sind, so z. B. das Verhalten bei Finsternissen, bei Neumond; Meteoriten gregenüber. Knotenkalender habe ich in einigen Exemplaren mitbringen können. Alles Geschichtliche habe ich sorgsam mit Angabe der Gewährsleute aufgezeichnet, die Stammbäume des Herrschergeschlechts mühsam festgestellt.

\section{Zählen und Rechnen. Y. Linguistik.}

Vom Kijao, Kimakonde und Kimakua habe ich sehr umfangreiche und gründliche Sprachaufnahmen unter Zugrundelegung der Veltenschen Suaheligrammatik gemacht; auch das Kingoni von Nchichira habe ich soweit verfolgt, wie es mir möglich war. Vom Kimuera habe ich dagegen nur ein mäßig umfangreiches Vokabular anlegen können. Den in langer Vergleichsarbeit erst noch festzustellenden Endergebnissen möchte ich hier noch nicht vorgreifen, doch scheint mir das Kimakua stark aus dem Rahmen der östlichen Bantu-Idiome herauszugehen. Alle übrigen Sprachen scheinen mehr oder weniger nahe verwandt $\mathrm{zu}$ sein; in jedem Fall aber gehören die so viel umstrittenen Jao diesem ostafrikanischen Völkerkreise und nicht etwa der Kafferngruppe an.

\section{Z. Der physischen Anthropologie}

hatte ich ursprünglich einen breiten Raum angewiesen; auf Anraten meines Kollegen v. Luschan habe ich sie indes sehr bald vom Arbeitsprogramm abgesetzt. Ich habe sicher recht daran getan. Zunächst gehört $z u$ solchen Untersuchungen eine volle Vertrautheit mit den Methoden, sodann viel Zeit. Beides fehlte mir aber. Immerhin habe ich immer wieder wenigstens die Körperfarben untersucht und, wo es ging, die Leute in den von der Anthropologie vorgeschriebenen Stellungen photographiert. Zuerst glaubte ich feststellen zu können, daß die Wamuera sich durch einen besonders hellen, fast kupferroten 
Ton von ihren Nachbarn unterschieden; später sah ich indes, daß gleich hell oder ähnlich gefärbte Individuen bei allen Völkern vorkamen. Auch die Körpergröße bildete kein Kriterium; neben mittelgroßen Leuten gab es ïberschlanken und sehr kleinen Wuchs in jeder Ortschaft. Eine Erkennungsund Unterscheidungsmöglichkeit scheint lediglich die Physiognomik bieten zu können, vor allen den Yao gegenüber, die man mit einiger Sicherheit an den Gesichtszügen zu erkennen vermochte. Meine überaus zahlreichen Porträtaufnahmen werden ja das Nähere ergeben.

Einen großen Wert habe ich auf Eingebornenzeichnungen gelegt; wer immer mit mir zu tun hatte, bekam Bleistift, Slizzenbuch oder Papier zur Hand. Manchmal zeichneten ganze Bezirke. Die Ergebnisse sind außerordentlich umfangreich; sie sind aber auch, da ich zu jeder Zeich- nung genatue Kommentare besitze, für die Denkweise des Negers bezeichnender als so manche andere Aufzeichnung. Bemerkenswert in der Beriehung sind vor allen die kartographisch niedergelegten geographischen Kenntnisse meiner Träger und Soldaten von den ihnen bekannten Teilen DeutschOstafrikas.

K. Weule.

Eine ausführliche Zusammenstellung seiner Forschungsergebnisse wird Herr Prof. Weule in einem der nächsten Hefte dieser Zeitschrift verïfentlichen.

Berlin, den 20. Februar 1907.

Die Konmission für die landeskundliche Erforschung der Schutzgebiete.

\section{I. $\Lambda$.:}

Hans Meyer, Vorsitzender.

\section{ancise}

\section{Aus den Schutzgebieten der Südsee.}

\section{Mineralogisches Museum und Institut der Universität Leipzig.}

\section{Lava vom neuesten Ausbruch des Sawaii-Vulkans (Samoa-Archipel).}

Die dunkelschwarze, stark pechglänzende, völlig kompakte Lava, in welcher dem bloBen Auge keine Ausscheidung hervortritt, ist ein sehr glasreicher Plagioklasbasalt: Unter dem Mikroskop im Dünschliff zeigt sich die Glasmasse bräunlich-gelb. Die schmalen farblosen gestreiften Plagioklase haben zufolge ihrer Auslöschungsschiefe eine Mittelstellung zwischen Labradorit und Antesin. Sie sind sehr häufig zunächst umsäumt von einem nach außen verblassenden Rand viel dunkleren Glases, in welchem spitzrhombische kristallistische Aggregate in großer Menge ausgeschieden liegen. Die blassen Pyroxene gehören dem gewöhnlichen monoklinen Augit an, Auffallend ist die außerordentliche Beteiligung von Olivin, meist in sehr scharfen Kristallen, auch in korrodierten oder zerbrochenen Individuen mit Glaseinschlïssen oder sich hinein erstreckenden Glasarmen; sie enthalten viele kleine Spinell-Oktaederchen interponiert. Zwillinge wurden nicht beobachtet. Um die Pyroxene und Olivine fehlt jene dunklere Glaszone. Magnetit oder ein anderes Eisenerz scheint ganz zu fehlen.

Bei der Einwirkung von heißer Chlorwasserstoffsäure auf die gepulverte Lava erfolgt eine reichliche Abscheidung von gelatinöser Kieselsäure, welche aber nur von der sehr großen Menge des Olivins herrührt: denn der mit Kalilauge behandelte Rückstand zeigt unter dem Mikroskop die Glaspartikel völlig unangegriffen.

Leipzig, 16. November 1906.

(gez.) F. Zirkel.

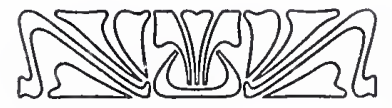




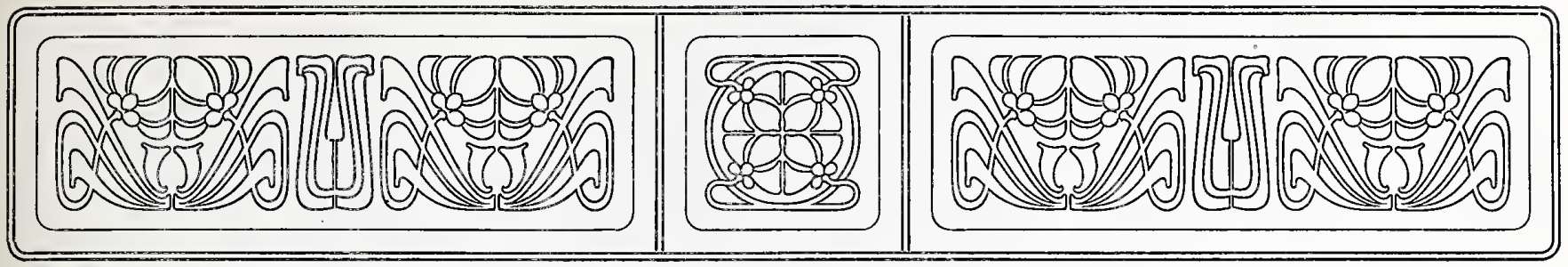

\title{
Aus dem Schutzgebiete Togo.
}

\section{Das Klima von Togo.}

\author{
Von Dr. H. Maurer.
}

Togo erstreckt sich als ein schmaler Landstreifen in einer Größe von etwa 87000 qkm Fläche in südnördlicher Richtung ungefähr von $6^{\circ}$ bis I I ${ }^{\circ}$ Nordbreite, ausgehend von einer kaum $50 \mathrm{~km}$ langen Küstenlinie am Golf von Guinea. Wenn so das ganze Land nördlich vom Äquator liegt, so reicht es doch nicht weit genug, um auch den Wärmeäquator nordwärts $z u$ überschreiten. Sucht man nämlich auf jedem Meridian den Punkt auf, der die höchste mittlerere Jahrestemperatur aufweist, und verbindet alle diese Punkte durch eine Linie, so verläuft der so erhaltene Wärmeäquator infolge der gewaltigen Landanhäufung Nordafrikas so weit nördlich, daß in Togo die mittlere Jahrestemperatur (gleiche Seehöhen der Stationen vorausgesetzt) von der Küste polwärts zunimmt. Von den beiden Stationen Bismarckburg und Amedschowe, die sich in ihrer rund $750 \mathrm{~m}$ betragenden Erhebung übers Meer nur um $60 \mathrm{~m}$ unterscheiden, zeigt das $11^{1}{ }^{\circ}$ nördlicher gelegene Bismarckburg eine um $2^{\circ} \mathrm{C}$. höhere mittlere Jahrestemperatur. Bei nahezu demselben Breitenunterschied ist Kete-Kratschi im Binnenland, obwohl es etwa IOO $\mathrm{m}$ über dem Meer liegt, im Mittel $\mathrm{I}^{1} / 2^{\circ} \mathrm{C}$. wärmer als Sebe an der Küste. Ebenso entspricht der jährliche Temperaturgang in Togo noch vollständig den Verhältnissen auf der südlichen Halbkugel. Sind doch Juli und August, die im allgemeinen auf der Nordhalbkugel die wärmsten Monate sind, in Togo die kältesten, während der Februar und in manchen Teilen der Kolonie der März die höchsten Mitteltemperaturen bringen. Die jährliche Temperaturschwankung ist, der Äquatornähe entsprechend, klein; sie überschreitet wohl nirgends $6^{\circ}$. (Vgl. Tabelle I.)

Zur Erklärung des abnormen jährlichen Temperaturverlaufs muß man die Wind- und Luftdruckverhältnisse des Gebiets näher ins Auge fassen. Über dem Äquatorialgürtel dehnt sich die stärker erwärmte Luft nach oben hin aus und fließt in den höheren Luftschichten von den Auflockerungs. gebieten polwärts zu beiden Seiten ab. Dadurch sinkt der Luftdruck über der heißen Zone, in der sich ein Band eines Luftdrucks unter $760 \mathrm{~mm}$ um die Erde schlingt, das nur im Nordsommer im Atlantischen Ozean unterbrochen erscheint. Nach diesem Auflockerungsgebiet blasen daher in den tieferen Schichten der Lufthülle jahraus jahrein von höheren Breiten herkommende Winde, die Passate. Sie erhalten unter dem Einfluß der Erddrehung eine westwärts gerichtete Komponente, so daß sie auf der Nordhalbkugel als Nordost-, auf der andern als Südostwinde entwickelt sind. Die Zone erwärmter, aufgelockerter Luft im Äquatorialgebiet bewegt sich nun im Laufe des Jahres mit dem Sonnen-

Tabelle I.

Mitteltemperaturen in Togo (Celsius ${ }^{\circ}$ ).

\begin{tabular}{|c|c|c|c|c|c|c|c|c|c|c|c|c|c|c|c|}
\hline Station & $\begin{array}{l}\text { Geogr. } \\
\text { Breite }\end{array}$ & $\begin{array}{c}\text { Seehöhe } \\
\text { m }\end{array}$ & Jan. & Febr. & März & April & Mai & Juni & juli & August & Sept. & Okt. & Nov. & Dez. & Jahr \\
\hline Sebe. & $6^{\circ}$ I $5^{\prime} \mathrm{N}$. & 5 & 27.5 & 27.9 & 28.1 & 26.8 & 26.8 & 25.4 & $24.0^{*}$ & 24. I & 24.5 & 26.6 & 27.7 & 28.1 & 26.5 \\
\hline Amedschowe . & 650 & 770 & 22.8 & 23,2 & 23.3 & 22.6 & $22 . \mathrm{I}$ & 20.6 & 19.9 & $19.6^{*}$ & 20.4 & $21 \cdot 3$ & 22.4 & 22.3 & 21.7 \\
\hline Misahöhe . & 656 & 590 & 24.6 & 25.5 & 25.4 & 24.9 & 24.7 & $23 \cdot 3$ & 21.9 & $21.7^{*}$ & 22.3 & $23 \cdot 3$ & $24 \cdot 5$ & 24.7 & 23.9 \\
\hline Bismarckburg & 8 I2 & 710 & 25.2 & 26.3 & 25.8 & $24 \cdot 7$ & 24.0 & 22.5 & 21.2 & $2 \mathrm{I} .2^{*}$ & $2 x .9$ & 23.0 & $24 \cdot 7$ & 24.8 & 23.8 \\
\hline
\end{tabular}

Mitteilungen a. d. D. Schutzgebieten, XX. Band. III. 
stande, so daß sie im Nordsommer weiter nach Norden, im Nordwinter weiter nach Siiden verlagert erscheint. Infolge der Landkonzentration im Norden wandert diese Zone aber im Nordsommer viel weiter nach Norden als im Südsommer nach Suiden; und so kommt es, daß über Togo den bei weitem größeren Teil des Jahres die südlichen IVinde, die von der Siidhalbkugel hier ïber den geographischen Äquator hinaustreten, vorwiegen, während nur in einem kleinen Teil des Jahres, mitten im Südsommer, nördliche Winde reichlicher auftreten können. Der Siidostpassat wirl an der westafrikanischen Küste von dem ansaugenden heißen Kontinent abgelenkt, und in demselben Sinne wirkt nach dem Überschreiten des Aqquators auch die Erddrehung ein, so daß in Togo den größten Tcil des Jahres Südwestwinde wehen. Da nun diese Südwestwinde, von einem relativ besonders kühlen Teile des Atlantischen Ozeans kommend, in das sonst wärmere Land blasen, so sind sie selbst verhältnismäBig kiihl, und der Nordsommer wird für Togo die kühlc Jahreszeit. An der Küste ist sie reich an Nebeln, und im Innern bildet die Mitte des Jahres die regenreichste Periode. Da sich in der Nacht das Land stärker als das Meer abkühlt, entsteht nachts an der Küiste ein (schwächerer) Wind vom Land zur See, während untertags die südlichen Winde dominieren. Nur im Südsommer kommen auch bei Tage Landwinde aus nördlichen Richtungen reichlicher auf. Sie beginnen ungefähr im November sich einzustellen und reichen etwa bis gegen den März hin. Das Nachlassen der küihlen Seewinde in dieser Zeit mindert die bisherige Abkïhlung, und der Südsommer wird Togos heißere Jahreszeit.

Zur Zeit dieser sehr trockenen Landwinde finden wir die interessante Erscheinung der Harmattantage. Man dachte sich früher unter dem Harmattan einen heißen Wüstenwind und verglich ihn mit dem Samum. Heute weiß man, daß nicht hohe Temperatur, sondern große Lufttrockenheit und der daraus folgende hohe Staubgehalt in der Luft die Kennzeichen des Harmattans sind. Wohl steigt bei Harmattan die Lufttemperatur bei Tage etwas, weil in der trockenen Luft, die mitunter nur Io v. H. relative Feuchtigkeit enthält, alle schützende Wolken bildung aufhört; dafür werden aber bei der starken Ausstrahlung in den Nächten diese so kalt, daß man bei geschlossenen Fenstern sich in wollene Decken hüllen mub, und daß trotz des geringen absoluten Feuchtigkeitsgehalts der Luft in den frühen Morgenstunden Tau keine Seltenheit ist. Auch bei Tage kann der Wind wegen seiner starken Trockenheit auf der Haut ein leichtes Kältegefühl erzeugen:";) Die An-

*) Näheres über den Harmattan sowie über die später zu erwähnenden Tornados geben Danckelmans Beiträge zur Kenntnis des Klimas des deutschen Togolandes. Diese Zeitschrift Bd. III, I 890. nahme, daß aller Staub dieser Vinde aus der Sahara stamme, ist ungerechtfertigt, denn seine Farbe und Beschaffenheit entsprechen dem jeweiligen Untergrund der Gegend. In den Waldgebieten ist die Staubmenge viel geringer als in offenen Vegetationsformen. Auch daß der Staub im südlichen Togo spätcr erscheint, liegt nicht an der größeren Entfernung von der Sahara, sondern daran, daf dort die Trockenzeit später einsetzt, entsprechend dem späteren Zenitdurchgang der Somne. Allerdings wird der leichte Staub von der aufsteigenden warmen Luft in große Höhen geführt und dort weit transportiert, so daß man wohl zugeben muB, daß sich in dem Staub in Togo auch solcher aus der Sahara befinden wird - besonders da die vorwiegenden Windrichtungen in den Harmattantagen im Quadranten NNW bis ENE liegen - ebensogut, wie man Saharastaub auf dem Atlantic über $2000 \mathrm{~km}$ von der afrikanischen Küste, wie ja sogar an unserer Nordseeküste gefunden hat. Man hat das Harmattanphänomen auch mit den großen Grasbränden in Verbindung bringen wollen; diese Brände beginnen aber nicht vor Ende November, während Harmattan schon merklich früher beobachtet worden ist.

Die Harmattanzeit um die Jahreswende ist in der ganzen Kolonie eine intensive Trockenzeit, an deren Ende im Februar oder März die Mitteltemperatur den höchsten Betrag erreicht. Bei der äußerst geringen Bewölkung (in Kete-Kratschi war z. B. im Januar durchschnittlich nur $1 / 10$ des Himmels bewölkt) ist die tägliche Temperaturschwankung in dieser Zeit am gröBten, sie hat an einzelnen Tagen mehr als $20^{c} \mathrm{C}$. betragen.

In Bismarckburg schwankt das mittlere Temperaturminimum im Jahre von $18^{\circ} .0$ bis $20^{\circ} .4$, das mittlere Temperaturmaximum dagegen von $26^{\circ} .2$ bis $33^{\circ} .6$, ein Beweis für die viel größere tägliche Temperaturschwankung in der warmen Jahreszeit.

Im Innern von Togo steht dieser Trockenzeit der ganze Nordsommer von April bis Oktober als eine große Regenzeit gegenüber. Sie ist besonders zu Beginn und Ende reich an Gewittern und heftigen Stürmen, den Tornados. In Bismarckburg z. B. zeigen im Mittel März und April je 22, der September 20 Tage mit Gcwittern, während Juli und August nur 9 oder Io aufweisen. Das Jahr hat hier I64 Gewittertage, an der Küste nicht halb so viel.

Von den Stürmen der gemäßigten Zone unterscheiden sich die Tornados durch den Barometerverlauf sehr wesentlich. Mit dem Einsetzen des Tornados, das einen rapiden Temperatursturz mit sich bringt, pflegt das Barometer ein wenig $z u$ steigen. Die großen Barometerschwankungen, die wir bei unseren Stürmen gewohnt sind, fehlen aber ganz. Die Gesamtschwankung des Luftdrucks im 
Laufe eines Jahres erreicht kaum $9 \mathrm{~mm}$. Die maximalen Regenmengen in 24 Stunden überschreiten in Togo selten $100 \mathrm{~mm}$. Hagel ist bei den Gewittern wiederholt beobachtet worden.

Die Tabelle II der mittleren Regenmengen zeigt, daB, wie in der Gewitterhäufigkeit, auch in der Niederschlagsmenge der August vielfach ein Nachlassen erkennen läßt (abgesehen von den Stationen im äußersten Norden). Wir finden um diese Zeit die allerkräftigste Ausbildung der südwestlichen Luftströmung, die weniger andere Winde wie die Tornado bringenden Oststürme neben sich aufkommen läßt und so $z u$ einer Verminderung der Regenmengen führt.
Plätzen kaum $2000 \mathrm{~mm}$ erreichen, für ein tropisches Küstenland nicht zu hoch; die Küste selbst aber, die mit 600 bis $800 \mathrm{~mm}$ kaum über die Jahresmengen Deutschlands hinausgeht, muß direkt regenarm genannt werden. Eine Erklärung dieser merkwürdigen Regenarmut an der Küste kann man aus dem Umstande herleiten, daB das Meerwasser in diesem Teil der Guineabucht in der Nähe der Küste durch aus der Tiefe aufquellende Wassermengen 5 bis $6^{\circ} \mathrm{C}$. kälter als in größerer Entfernung vom Lande ist. Der über diese kalte Zone hinstreichende Südwestwind kommt daher stark abgekühlt und, absolut genommen, arm an Feuchtigkeit an, so daß er auf dem wärmeren Festlande, besonders ehe

Tabelle II.

Mittlere Regenmengen in Togo (Millimeter).

(Unter Benutzung der vorhandenen Angaben bis eiaschlieblich Igo6).

\begin{tabular}{|c|c|c|c|c|c|c|c|c|c|c|c|c|c|c|c|}
\hline Station & $\begin{array}{l}\text { Geogr. } \\
\text { Breite }\end{array}$ & $\begin{array}{c}\text { Anzahl der } \\
\text { Beob- } \\
\text { achtungs- } \\
\text { jahre }\end{array}$ & Jan. & Febr. & März & April & Mai & Juni & Juli & August & Sept. & Okt. & Nov. & Dez. & Jahr \\
\hline Lome & $607^{\prime}$ & $7-9$ & 7 & 27 & 38 & IO4 & 152 & I 43 & 30 & 4 & 32 & 59 & $2 I$ & 7 & 624 \\
\hline Kpeme . & $6 \mathrm{I} 3$ & 6 & I 4 & I I & 37 & 66 & I 7 I & 129 & $6 I$ & IO & 45 & $5^{8}$ & 26 & 4 & 632 \\
\hline Sebe..... & $6 \times 5$ & $7-\mathrm{II}$ & 18 & I6 & 63 & I IO & 188 & $20 \mathrm{I}$ & 45 & 9 & 24 & $8_{5}$ & 44 & II & $8 I_{4}$ \\
\hline Amedschowe & 650 & $6-7$ & $x_{2}$ & 87 & 88 & 164 & I 7 I & 229 & 222 & 172 & 222 & I93 & 49 & 49 & 1658 \\
\hline Misahöhe . . & 656 & $9-\mathrm{I} 2$ & 24 & 49 & $9 I$ & 123 & 165 & 242 & $2 \mathrm{I} 4$ & $\mathrm{r} 43$ & I 54 & 376 & 79 & 48 & I 508 \\
\hline Atakpame . & $7 \quad 32$ & $4-7$ & I0 & 67 & 52 & 133 & 197 & I95 & 230 & 166 & 157 & 134 & 27 & $2 x$ & I389 \\
\hline Kete-Kratschi & 748 & 8 -10 & I4 & 28 & 52 & 129 & 174 & 182 & 162 & $\mathrm{I} 42$ & 2 II & 168 & 30 & 12 & 1304 \\
\hline Bismarckburg & $8 x_{2}$ & 7 & 35 & 48 & 84 & 137 & I 7 I & 177 & $\mathrm{I}_{55}$ & I I 3 & 272 & 146 & 20 & $3 I$ & I 389 \\
\hline Sokodé .. . & 859 & 6 & I & o & 47 & IOI & 194 & $15^{8}$ & I65 & 280 & 234 & $\mathrm{I} 23$ & I I & 4 & 1318 \\
\hline Bassari . . & $9 \times 5$ & 6 & 5 & 2 & 23 & 92 & 173 & 163 & 160 & 192 & 242 & I9I & 27 & 8 & 1278 \\
\hline
\end{tabular}

Erst die Übergangszeit im September von den Südwestwinden zu den immer häufiger auftretenden Landwinden derTrockenzeit läßt aufs neue schwächere Winde aus wechselnden Richtungen, aufsteigende Luftströme und kräftigere Regenbildung aufkommen. Die Wechsel zwischen beiden Windregimen im Frühjahr und Herbst folgen den Zenitdurchgängen der Sonne im Laufe des Jahres, und übereinstimmend damit, daß weiter im Norden die beiden Zenitdurchgänge zeitlich näher aneinanderrücken, finden wir die beiden Maxima der Regenzeit im Innern näher zusammengeschoben und die Regenpause zwischen beiden kaum merklich ausgebildet. An der Küste dagegen kommt nicht nur ein Nachlassen der Regen, sondern eine zweite intensive Trockenperiode in den Monaten Juli und August zustande, die mitunter ganz regenlos sind. Zugleich zeigt die Regentabelle, daß in allen Monaten und somit besonders in der Jahressumme die Regenmenge an der Küste weit hinter der des Innern zurücksteht. Wohl sind auch die jährlichen Regenmengen des Innern, die durchschnittlich zwischen 1200 und $1700 \mathrm{~mm}$ liegen und auch in regenreichen Jahren an feuchten ihn die Bodenerhebung zum Steigen zwingt, kein Wasser abgeben kann. Für die Richtigkeit dieser Erklärung spricht die geringe Ausdehnung des Phänomens von der Küste in das Innere, sein Aufhören an den Gebirgen und die stärkste Entfaltung zur Zeit der kräftigsten Entwicklung der Südwestwinde.

Die Zahlen der Tabelle III charakterisieren die Regenverteilung im Jahre besonders deutlich; sie geben für vier Abschnitte des Jahres an, wieviel Prozente von demjenigen Betrag, der bei gleichmäßiger Verteilung des Regens über das ganze Jahr im betreffenden Jahresteil fallen würde, tatsächlich in ihm fallen. Die Perioden mit Prozentzahlen unter IOO sind also relativ trockener als der Jahresdurchschnitt, die Perioden mit Zahlen über Ioo feuchter.

Man erkennt die kolossale Konzentration der Regen an der Küste (Lome) auf die Monate April bis Juni, in denen $21 / 2$ mal so viel Regen fällt, wie bei gleichmäßiger Verteilung auf das Jahr zu erwarten wäre, während das Monatspaar Juli-August relativ noch trockener als die große Trockenzeit von 
Tabelle III.

Regenverteilung auf vier Abschnitte des Jahres, absolut in Millimetern und in Prozenten der gleichmäßig verteilten Mengen.

\begin{tabular}{|c|c|c|c|c|c|c|c|c|c|c|}
\hline \multirow[t]{2}{*}{ Station } & \multirow[t]{2}{*}{$\begin{array}{l}\text { Geogr. } \\
\text { Breite }\end{array}$} & \multirow{2}{*}{$\begin{array}{c}\text { Seehöhe } \\
\text { m }\end{array}$} & \multicolumn{2}{|c|}{ November bis März } & \multicolumn{2}{|c|}{ April bis Juni } & \multicolumn{2}{|c|}{ Juli und August } & \multicolumn{2}{|c|}{ September u. Oktober } \\
\hline & & & Absolut & Prozente & Absolut & Prozente & Absolut & Prozente & Absolut & Prozente \\
\hline Lome . . . . . . . . & $6^{\circ} 7^{\prime}$ & 5 & IOO & 38 & 399 & 256 & 34 & 33 & 9I & 87 \\
\hline 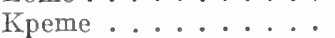 & 613 & 5 & 92 & 35 & 366 & 232 & 71 & 67 & IO3 & 98 \\
\hline 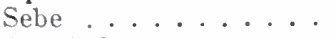 & $6 \quad 15$ & 5 & I 52 & 45 & 499 & 195 & 54 & 40 & IO9 & 8o \\
\hline Amedschowe...... & 650 & 770 & 285 & $4 I$ & 564 & 136 & 394 & I 43 & 4 I 5 & I 50 \\
\hline Misahöhe. . . . . & 656 & 590 & $29 I$ & 46 & 530 & I $4 \mathrm{I}$ & 357 & I 42 & 330 & I 31 \\
\hline Atakpame . . . . & 732 & 330 & 177 & $3 I$ & 525 & I $5 \mathrm{I}$ & 396 & I 7 I & $29 I$ & 126 \\
\hline Kete-Kratschi ..... & 748 & IIO & 136 & 25 & 485 & 149 & 304 & 140 & 379 & 174 \\
\hline Bismarckburg ..... & 812 & 710 & 218 & $3^{8}$ & 485 & 140 & 268 & I 6 & 418 & 181 \\
\hline Sokodé ........ & 859 & 410 & 63 & I I & 453 & 137 & 445 & 203 & 357 & 163 \\
\hline Bassari . . . . . & 9 I5 & 300 & 65 & I 2 & 428 & I 34 & 352 & $\Upsilon 65$ & 433 & 203 \\
\hline
\end{tabular}

November bis, März ist; auch das Paar SeptemberOktober erreicht nicht den Monatsdurchschnitt. Das ändert sich nach dem Innern hin sehr wesentlich. Abgesehen von Bismarckburg und Kete-Kratschi, sind Juli und August überall relativ regenreicher noch als das Vierteljahr April bis Juni, und im Gebirgsgürtel (Misahöhe, Atakpame) meist auch regenreicher als die Gruppe September-Oktober. Für die niedriger gelegenen Teile des Innern (KeteKratschi und besonders Sokodé und Bassari) wird die Trockenheit der fünf Monate November bis März noch viel intensiver als an der Küste, und da diese Trockenzeit dabei fünf Monate währt, wird diese ungünstige Regenverteilung für die Vegetation von entscheidender Bedeutung; sie setzt Steppencharakter im Norden an die Stelle der Wälder der mittleren Region, obwohl die Jahresmenge des Regens nicht wesentlich hinter der des Gebirgsgebietes zurückbleibt. Absolut genommen, variiert die Regenmenge im Vierteljahr April bis Juni durch die ganze Kolonie nur äußerst wenig; sie bleibt aber hinter den Mengen der Gebirgszone erheblich zurück an der Küste im ganzen Rest des Jahres, besonders im Juli und August, und im äußersten Norden der Kolonie in der Periode von November bis März.

So sind es drei klimatisch verschiedene Gebiete in der Kolonie, die auch in der Vegetation wesentliche Unterschiede voneinander aufweisen:

I. Die regenarme Küstenebene mit zwei ausgesprochenen Trockenzeiten von November bis März und Juli bis August.

II. Die mittlere Gebirgszone mit kräftigem Regen und günstiger Verteilung desselben im Jahr, in dem die Trockenzeit in der Jahresmitte wegfällt und auch die um die Jahreswende lange nicht so ausgedehnt und intensiv wie an der Küste ist.
III. Das Binnenplateau des Westsudan mit etwas geringerer Jahresregenmenge als die Gebirgszone, ebenfalls mit nur einer, aber sehr lang dauernden und sehr intensiven Trockenzeit.

\section{Ergebnisse der Regenmessungen in Togo im Jahre 1906.}

Das volle Jahr hindurch beobachteten ig Stationen gegen 7 im Vorjahr. Das Stationsnetz hat inzwischen aber noch eine Erweiterung erfahren.

Der Regenfall im Schutzgebiet war ungefähr wie auch im Vorjahre ein normaler. Nur das Gebiet von Atakpame und an Volta war um Ioo bis $200 \mathrm{~mm} \mathrm{zu}$ trocken, während in den Gebirgsgegenden, in Misahöhe und am Adaklu I 50 bis $350 \mathrm{~mm}$ mehr als im Jahre 1905 gemessen wurden.

Die von Beamten des Kaiserlichen Zollamtes in Lome zwischen 6 bis 8 Uhr morgens am Kopf der Landungsbrücke täglich gemessenen Meerestemperaturen ergeben folgende Resultate:

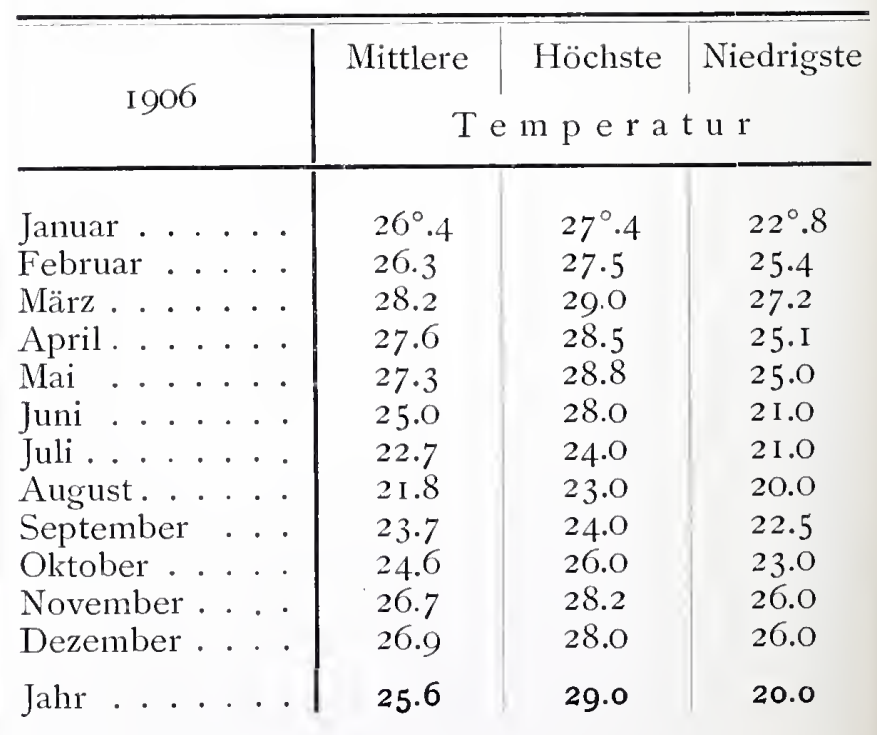


Lome. Beobachter: Poetzsch.

Kpeme. Beob.: Schleinitz u. Bernoully.

\begin{tabular}{|c|c|c|c|c|c|c|c|c|c|c|c|c|c|c|c|c|c|c|}
\hline \multirow[b]{2}{*}{1906} & \multicolumn{4}{|c|}{ Regenmenge in $\mathrm{mm}$} & \multicolumn{4}{|c|}{$\begin{array}{c}\text { Anzahl der Tage } \\
\text { mit Regen } \\
\text {. }\end{array}$} & \multicolumn{4}{|c|}{ Regenmenge in $\mathrm{mm}$} & \multicolumn{6}{|c|}{$\begin{array}{l}\text { Anzahl der Tage mit } \\
\text { Regen }\end{array}$} \\
\hline & $6 a$ & $6 \mathrm{p}$ & Summe & $\begin{array}{l}\text { Max. } \\
\text { in } \\
24 \text { St. }\end{array}$ & \begin{tabular}{|l} 
im \\
allg.
\end{tabular} & \begin{tabular}{|c|}
$\mathrm{mit}$ \\
0.2 \\
$\mathrm{~mm}$
\end{tabular} & $\begin{array}{r}\text { melhr } \\
\begin{array}{r}\mathrm{r} .0 \\
\mathrm{~mm}\end{array}\end{array}$ & $\begin{array}{r}r \text { als } \\
25.0 \\
\mathrm{~mm}\end{array}$ & $6 a$ & $6 p$ & Summe & $\begin{array}{l}\text { Max. } \\
\text { in } \\
24 \text { St. }\end{array}$ & \begin{tabular}{|l} 
im \\
allg.
\end{tabular} & \begin{tabular}{|c|}
$\mathrm{mit}$ \\
0.2 \\
$\mathrm{~mm}$
\end{tabular} & \begin{tabular}{|c|} 
mehr \\
1.0 \\
$\mathrm{~mm}$
\end{tabular} & $\begin{array}{r}\mathrm{r} \text { als } \\
25.0 \\
\mathrm{~mm}\end{array}$ & & $\begin{array}{l}\text { nur } \\
\longleftarrow\end{array}$ \\
\hline Januar & I 2.5 & 0.0 & 12.5 & 8.8 & 2 & 2 & 2 & o & I 8.0 & 0.0 & I 8.0 & I 8.0 & 4 & I & I & $\mathrm{O}$ & I & 0 \\
\hline Februar & 0.0 & I 6.4 & I 6.4 & I 6.4 & I & I & I & o & 0.0 & I. 4 & I. 4 & I. 4 & 2 & I & I & o & 2 & I \\
\hline März & 4.4 & 0.8 & 5.2 & 4.4 & 3 & 2 & I & o & 6.9 & 7.0 & I 3.9 & 7.0 & 3 & 3 & 3 & o & I & 3 \\
\hline April & 49.0 & $27 . I$ & 76.1 & 26.8 & 7 & 7 & 7 & I & 5.4 & 4 I. 8 & 47.2 & 21.0 & 8 & 7 & 7 & $\mathrm{O}$ & 3 & 6 \\
\hline Mai & $28 \mathrm{I} .5$ & I0.4 & 291.9 & I09. 5 & I 4 & I 3 & I 3 & 4 & 319.0 & I06.I & $425 . \mathrm{I}$ & 88. I & I6 & I6 & I 4 & 7 & 8 & 3 \\
\hline Juni. & I7.I & $2 \mathrm{I} \cdot 5$ & 38.6 & I 3.5 & 8 & 6 & 6 & $\mathrm{O}$ & 67.8 & 16.0 & 83.8 & $59 \cdot 3$ & IO & 9 & 6 & I & 2. & 4 \\
\hline Juli & 6.5 & 4.0 & 10.5 & 2.0 & 6 & 6 & 6 & $\mathrm{O}$ & I 4.4 & I 3.5 & 27.9 & 8.8 & IO & 6 & 4 & 0 & $\mathrm{O}$ & $\mathrm{O}$ \\
\hline August. & I 2.2 & 4.9 & 17.1 & 12.2 & 3 & 3 & 3 & o & 3.2 & 0.6 & 3.8 & I. 5 & 7 & 4 & 2 & $\mathrm{o}$ & o & o \\
\hline September & 5.0 & 0.0 & 5.0 & $2 . \mathrm{I}$ & 9 & 5 & 2 & 0 & 0.6 & I. 5 & $2 . \mathrm{I}$ & I. 3 & 7 & 2 & I & o & o & o \\
\hline Oktober & I 6.7 & I 5.3 & 32.0 & I 5.3 & 5 & 4 & 3 & $\mathrm{o}$ & 9.2 & 37.9 & $47 . \mathrm{I}$ & $3 \mathrm{I} . \mathrm{O}$ & 6 & 6 & 3 & I & I & I \\
\hline November & I 2.3 & 0.0 & I 2.3 & 10.5 & 2 & 2 & 2 & I & 2.8 & 4.2 & 7.0 & 2.3 & 7 & 4 & 3 & 0 & 5 & 3 \\
\hline Dezember & 0.8 & $\mathrm{O} . \mathrm{O}$ & 0.8 & 0.8 & 2 & I & $\mathrm{O}$ & $\mathrm{O}$ & 4.2 & 0.3 & $4 \cdot 5$ & 4.2 & 2 & 2 & I & o & 6 & o \\
\hline Jahr & 418.0 & 100.4 & 518.4 & 109.5 & 62 & 52 & 46 & 6 & 451.5 & 230.3 & 681.8 & 88.1 & 82 & 61 & 46 & 9 & 292 & 21 \\
\hline
\end{tabular}

Sebe. Beob.: Basch u. Madretzke.

Noëpe. Beob.: C. Bruce.

\begin{tabular}{|c|c|c|c|c|c|c|c|c|c|c|c|c|c|c|c|c|}
\hline \multirow{3}{*}{ I906 } & \multicolumn{4}{|c|}{ Regenmenge in $\mathrm{mm}$} & \multicolumn{4}{|c|}{$\begin{array}{c}\text { Anzahl der Tage } \\
\text { mit Regen }\end{array}$} & \multicolumn{4}{|c|}{ Regenmenge in $\mathrm{mm}$} & \multicolumn{4}{|c|}{$\begin{array}{l}\text { Anzahl der Tage } \\
\text { mit Regen }\end{array}$} \\
\hline & & & & Max. & & mit & mehr & $\mathrm{r}$ als & & & & Max. & & & mehn & \\
\hline & $6 a$ & $6 \mathrm{p}$ & Summe & $\begin{array}{c}\text { in } \\
24 \text { St. }\end{array}$ & $\begin{array}{l}\text { im } \\
\text { allg. }\end{array}$ & $\begin{array}{r}0.2 \\
\mathrm{~mm}\end{array}$ & $\begin{array}{r}\mathrm{I} . \mathrm{o} \\
\mathrm{mm}\end{array}$ & \begin{tabular}{|}
25.0 \\
$\mathrm{~mm}$
\end{tabular} \mid & $6 a$ & $6 \mathrm{p}$ & Summe & $\begin{array}{c}\text { in } \\
24 \mathrm{St} .\end{array}$ & im allg. & $\begin{array}{l}0.2 \\
\mathrm{~mm}\end{array}$ & $\begin{array}{l}\mathrm{r.o} \\
\mathrm{mm}\end{array}$ & $\begin{array}{l}25.0 \\
\mathrm{~mm}\end{array}$ \\
\hline anuar & 61.7 & 0.0 & $6 \mathrm{I} .7$ & $6 \mathrm{I} .7$ & I & I & I & I & 0.0 & 0.0 & 0.0 & 0.0 & o & o & o & o \\
\hline Februar & 0.0 & IO.O & IO.O & 10.0 & I & I & I & I & 0.0 & 9.0 & 9.0 & 9.0 & I & I & I & o \\
\hline März & 5.5 & 0.0 & 5.5 & 5.5 & 5 & I & I & o & IO. 3 & 85.8 & 96.1 & 30.6 & 8 & 8 & 8 & I \\
\hline April & 48.0 & 60.0 & 108.0 & 36.5 & IO & 8 & 8 & I & I. 7 & 46.5 & 48.2 & 20.5 & 5 & 5 & 5 & o \\
\hline Mai & 250.1 & I $3 \mathrm{I} .2$ & 381.3 & I06.2 & I 4 & I 2 & I 2 & 5 & I 37.5 & I 66.3 & 303.8 & 57.9 & 18 & I 8 & I 8 & 3 \\
\hline Juni. & 4.0 & 83.9 & 87.9 & 40.1 & 5 & 5 & 5 & 2 & 23.7 & 55.7 & 79.4 & 37.5 & 9 & 9 & 9 & 2 \\
\hline Juli & 31.4 & 0.0 & $3 \mathrm{I} .4$ & I 4.5 & 3 & 3 & 3 & $\mathrm{O}$ & 8.2 & $23 \cdot 3$ & $3 \mathrm{I} .5$ & 8. I & 9 & 9 & 9 & o \\
\hline August . . & 12.5 & I 4.5 & 27.0 & I 4.5 & 4 & 3 & 3 & $\mathrm{o}$ & 0.0 & 2.6 & 2.6 & 2.6 & I & I & I & 0 \\
\hline September & I0. 4 & 0.0 & I 0.4 & I0.4 & I & I & I & o & $7 . \mathrm{I}$ & I. 5 & 8.6 & 3.2 & 5 & 5 & 5 & o \\
\hline Oktober & 25.0 & 34.8 & 59.8 & 34.8 & 5 & 5 & 5 & I & I. 6 & 78.8 & 80.4 & I 7.6 & IO & IO & IO & o \\
\hline November & 7.5 & 25.3 & 32.8 & I 2.4 & 4 & 4 & 4 & $\mathrm{o}$ & 3.2 & 44.5 & 47.7 & 10.5 & 9 & 9 & 9 & o \\
\hline Dezember & 22.5 & 0.0 & 22.5 & I 5.0 & 2 & 2 & 2 & $\mathrm{O}$ & 30.5 & 66.0 & 96.5 & 50.4 & 7 & 7 & 5 & 2 \\
\hline Jahr & 478.6 & 359.7 & 838.3 & 106.2 & 55 & 46 & 46 & 11 & 223.8 & 580.0 & 803.8 & 57.9 & 82 & 82 & 80 & 8 \\
\hline
\end{tabular}

Solo. Beob.: W. Afanyinu.

Ho. Beob.: Voss u. Hahndorf.

\begin{tabular}{|c|c|c|c|c|c|c|c|c|c|c|c|c|c|c|c|c|c|}
\hline \multirow[t]{2}{*}{1906} & \multicolumn{4}{|c|}{ Regenmenge in $\mathrm{mm}$} & \multicolumn{4}{|c|}{$\begin{array}{c}\text { Anzahl der Tage } \\
\text { mit Regen }\end{array}$} & \multicolumn{4}{|c|}{ Regenmenge in $\mathrm{mm}$} & \multicolumn{5}{|c|}{$\begin{array}{l}\text { Anzahl der Tage mit } \\
\text { Regen }\end{array}$} \\
\hline & $6 a$ & $6 \mathrm{p}$ & Summe & $\begin{array}{l}\text { in } \\
24 \mathrm{St} .\end{array}$ & $\begin{array}{l}\mathrm{im} \\
\text { allg. }\end{array}$ & $\begin{array}{r}0.2 \\
\mathrm{~mm} \\
\end{array}$ & $\begin{array}{r}\mathrm{r} . \mathrm{o} \\
\mathrm{mm}\end{array}$ & $\begin{array}{l}25.0 \\
\mathrm{~mm}\end{array}$ & $6^{1 / 4 a}$ & $61 / 4 \mathrm{p}$ & Summe & $\begin{array}{l}\text { in } \\
24 \text { St. }\end{array}$ & $\begin{array}{l}1 \mathrm{~m} \\
\text { allg. }\end{array}$ & $\begin{array}{r}0.2 \\
\mathrm{~mm} \\
\end{array}$ & $\begin{array}{r}\mathbf{1 . 0} \\
\mathrm{mm} \\
\end{array}$ & \begin{tabular}{|c|}
25.0 \\
$\mathrm{~mm}$
\end{tabular} & 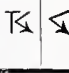 \\
\hline nu & 5.5 & $7 \cdot I$ & I 2.6 & 6.8 & 4 & 4 & 2 & o & $2 \mathrm{I} . \mathrm{O}$ & 8. I & $29 . \mathrm{I}$ & $2 \mathrm{I} . \mathrm{O}$ & 4 & 3 & 3 & $\mathrm{o}$ & 50 \\
\hline Hebru & 0.0 & 47.2 & 47.2 & I 8.9 & 3 & 3 & 3 & $\mathrm{o}$ & 0.0 & 33.0 & 33.0 & 33.0 & I & I & I & I & 4 \\
\hline März & 30.0 & 46.9 & 76.9 & 25.7 & 6 & 6 & 6 & I & 5.I & 44.9 & 50.0 & $2 \mathrm{I} . \mathrm{O}$ & I I & 6 & 6 & \begin{tabular}{l|l}
$\mathrm{O}$ & $\mathrm{I}$ \\
$\mathrm{C}$
\end{tabular} & 14 \\
\hline April & 4.9 & 81.9 & 86.8 & 27.0 & IO & 9 & 7 & I & 26.8 & 47.8 & 74.6 & 26.8 & 4 & 4 & 4 & I & \\
\hline Mai & 176.1 & I 26.6 & 302.7 & 53.2 & 22 & $2 \mathrm{I}$ & $2 \mathrm{I}$ & 2 & 212.5 & 57.8 & 270.3 & 63.8 & I 4 & I 4 & $\mathrm{I} 2$ & 5 & \\
\hline Juni & 42.5 & 62.4 & 104.9 & 47.2 & I 2 & I 2 & IO & I & 90.3 & 96.8 & I $87 . \mathrm{I}$ & $75 \cdot 5$ & 8 & 8 & 7 & 3 & \\
\hline Juli & I6.6 & 37.6 & 5 & I7.0 & IO & IO & 6 & $\mathrm{O}$ & 55.0 & I 35.2 & 190.2 & 55.0 & I I & II & I I & 3 & - \\
\hline August & 0.8 & I 2.8 & I 3.6 & 12.2 & 3 & 3 & I & $\mathrm{O}$ & 0.0 & 0.0 & 0.0 & 0.0 & $\mathrm{O}$ & $\mathrm{O}$ & $\mathrm{O}$ & $\mathrm{O}$ & \\
\hline Septe & I I.9 & 4.3 & 16.2 & $9 \cdot 3$ & 6 & 5 & 3 & $\mathrm{O}$ & $9 \cdot 5$ & IOI.5 & I I I.O & 70.5 & 7 & 7 & 7 & I & \\
\hline Oktober & 8.6 & 81.2 & 89.8 & 35.4 & 9 & 9 & 8 & 2 & 28.8 & I 7 I.I & I 99.9 & $99 . \mathrm{I}$ & IO & IO & IO & 2 & \\
\hline November & 3.8 & $55 \cdot 3$ & 59. I & 20.2 & IO & IO & 9 & $\mathrm{O}$ & 0.0 & 28.0 & 28.0 & 9.4 & 6 & 6 & 6 & $\mathrm{O}$ & \\
\hline Dezem & 3.7 & 28.2 & 31.9 & 8.2 & 8 & 8 & 7 & 0 & 0.0 & 19.8 & I9.8 & I 8.0 & 2 & 2 & 2 & $\mathrm{o}$ & \\
\hline Jahr & 304.4 & 591.5 & 895.9 & 53.2 & 103 & 100 & 83 & 7 & 449.0 & 744.0 & 1193.0 & 99.1 & 78 & 72 & 69 & 16 & - \\
\hline
\end{tabular}


Topli. Beobachter: Gedza.

Nuatjä. Beob.: Schneider.

\begin{tabular}{|c|c|c|c|c|c|c|c|c|c|c|c|c|c|c|c|c|}
\hline \multirow[t]{2}{*}{1906} & \multicolumn{4}{|c|}{ Regenmenge in $\mathrm{mm}$} & \multicolumn{4}{|c|}{$\begin{array}{c}\text { Anzahl der Tage } \\
\text { mit Regen } \\
\text { mit mehr als }\end{array}$} & \multicolumn{4}{|c|}{ Regenmenge in $\mathrm{mm}$} & \multicolumn{4}{|c|}{$\begin{array}{c}\text { Anzah1 der Tage } \\
\text { mit Regen }\end{array}$} \\
\hline & $6 a$ & $6 \mathrm{p}$ & Summe & $\begin{array}{c}\text { in } \\
24 \mathrm{St}\end{array}$ & allg. & $\begin{array}{r}0.2 \\
\mathrm{~mm} \\
\end{array}$ & $\begin{array}{r}\mathrm{I} . \mathrm{O} \\
\mathrm{mm} \\
\end{array}$ & $\begin{array}{l}25.0 \\
\mathrm{~mm} \\
\end{array}$ & $6 a$ & $6 \mathrm{p}$ & Summe & $\begin{array}{c}\text { in } \\
24 \text { St. }\end{array}$ & $\begin{array}{l}\text { im } \\
\text { allg. }\end{array}$ & $\begin{array}{r}0.2 \\
\mathrm{~mm}\end{array}$ & $\begin{array}{r}\mathrm{I} . \mathrm{O} \\
\mathrm{mm}\end{array}$ & $\begin{array}{l}25.0 \\
\mathrm{~mm} \\
\end{array}$ \\
\hline Januar . . & 0.0 & $25 . \mathrm{I}$ & 25.1 & 25.1 & I & I & I & I & 9.8 & I I .2 & $2 \mathrm{I} . \mathrm{O}$ & 9.6 & 5 & 3 & 3 & $\mathrm{O}$ \\
\hline Februar. & 0.0 & 32.3 & 32.3 & 32.3 & I & I & I & I & 0.3 & 56.9 & 57.2 & 56.9 & 2 & 2 & I & I \\
\hline März . · . & 51.2 & I 2.8 & 64.0 & 40.3 & 6 & 6 & 6 & I & 92.4 & 0.0 & 92.4 & 69.1 & 4 & 4 & 3 & I \\
\hline April . . & 42.1 & 71.0 & I I 3.1 & 40.5 & 6 & 6 & 6 & 2 & I. 4 & $75 . \mathrm{I}$ & 76.5 & 25.5 & 8 & 7 & 5 & I \\
\hline Mai . . . & 一 & - & 227.1 & 69.3 & I 5 & 15 & I 5 & I & I 56.1 & 88.3 & 244.4 & 51.2 & I 5 & I4 & I 3 & 5 \\
\hline Juni. . . . & - & - & 82.5 & 30.8 & 8 & 8 & 8 & I & 88.9 & 37.2 & I $26 . \mathrm{I}$ & 61.9 & I 2 & I 2 & 9 & I \\
\hline Juli . . . & - & 一 & $19 \cdot 3$ & 10.2 & 6 & 6 & 5 & $\mathrm{O}$ & 32.9 & 30.4 & $63 \cdot 3$ & I 2.8 & I I & I I & 8 & $\mathrm{O}$ \\
\hline August . . & - & - & 0.6 & 0.6 & 1 & I & $O$ & $\mathrm{O}$ & - & $-1)$ & 22.0 & 6.4 & $>5$ & $>5$ & $>5$ & $\mathrm{O}$ \\
\hline September & - & - & $3 I . I$ & 20.7 & 3 & 3 & 3 & $\mathrm{O}$ & $5 \cdot 5$ & 91.2 & 96.7 & 29.0 & I I & IO & 8 & 2 \\
\hline Oktober . & +2.2 & 57.6 & 99.8 & 50.4 & 5 & 5 & 5 & I & 29.1 & I 2O. I & 149.2 & $49 \cdot 3$ & I 4 & 12 & 9 & I \\
\hline November & I 0.5 & 56.9 & $67 \cdot 4$ & 30.2 & 5 & 5 & 5 & I & 3.6 & 29.8 & 33.4 & 17.0 & 7 & 6 & 4 & $\mathrm{O}$ \\
\hline Dezember & - & 59.2 & 59.2 & $43 \cdot 5$ & 3 & 3 & 3 & I & $23 \cdot 3$ & IO. 5 & 33.8 & 22.6 & 4 & 3 & 2 & $\mathrm{O}$ \\
\hline Jahr & - & - & 821.5 & $69 \cdot 3$ & 60 & 60 & 58 & 10 & $(443 \cdot 3)$ & $(550.7)$ & 1016.0 & 61.9 & $>98$ & $>89$ & $>70$ & 12 \\
\hline
\end{tabular}

1) Die Beobachtungen fielen vom $\mathbf{I}$. bis $\mathbf{1} 3$. August aus. In dieser Zeit sammelten sich $4.2 \mathrm{~mm}$ an.

Tafie. Beob.: Holverscheit u. Feubel. \| Vorwerk Njambo. Beob.: Ndanu.

\begin{tabular}{|c|c|c|c|c|c|c|c|c|c|c|c|c|c|c|c|c|}
\hline \multirow[t]{2}{*}{ I906 } & \multicolumn{4}{|c|}{ Regenmenge in $\mathrm{mm}$} & \multicolumn{4}{|c|}{$\begin{array}{c}\text { Anzahl der Tage } \\
\text { mit Regen } \\
\text { mit mehr als }\end{array}$} & \multicolumn{4}{|c|}{ Regenmenge in $\mathrm{mm}$} & \multicolumn{4}{|c|}{$\begin{array}{l}\text { Anzahl der Tage } \\
\text { mit Regen }\end{array}$} \\
\hline & $6 \mathrm{a}$ & $6 \mathrm{p}$ & Summe & $\begin{array}{c}\text { in } \\
24 \mathrm{St} .\end{array}$ & \begin{tabular}{|c|c}
$\mathrm{im}$ \\
allg.
\end{tabular} & $\begin{array}{r}0.2 \\
\mathrm{~mm} \\
\end{array}$ & \begin{tabular}{|r|}
$\mathrm{I} . \mathrm{o}$ \\
$\mathrm{mm}$ \\
\end{tabular} & \begin{tabular}{|c|}
25.0 \\
$\mathrm{~mm}$
\end{tabular} \mid & $6 \mathrm{a}$ & $6 \mathrm{p}$ & Summe & $\begin{array}{l}\text { in } \\
24 \mathrm{St} .\end{array}$ & allg. & $\begin{array}{c}0.2 \\
\mathrm{~mm}\end{array}$ & $\begin{array}{r}\mathrm{I} . \mathrm{O} \\
\mathrm{mm}\end{array}$ & $\begin{array}{r}25.0 \\
\mathrm{~mm} \\
\end{array}$ \\
\hline Januar & 2.7 & I I .O & 13.7 & 5.0 & 6 & 6 & 5 & $\mathrm{O}$ & 5.1 & $39 \cdot 4$ & $44 \cdot 5$ & 27.4 & 6 & 6 & 5 & I \\
\hline Februar & 1.5 & 71.6 & 73.1 & 64.5 & 4 & 4 & 4 & I & I. 5 & 78.3 & 79.8 & 78.3 & 2 & 2 & 2 & I \\
\hline März . . & 50.8 & 109.7 & 160.5 & 66.9 & 8 & 8 & 7 & 2 & 45.5 & $6 \mathrm{I} . \mathrm{I}$ & 106.6 & 45.7 & 9 & 9 & 8 & I \\
\hline April. . & 29.5 & 61.7 & $9 \mathrm{I} .2$ & 49.0 & 7 & 5 & 5 & 2 & 4.2 & 50.2 & $54 \cdot 4$ & 22.3 & IO & $\mathrm{IO}$ & 6 & $\mathrm{O}$ \\
\hline Mai . . & $244 \cdot 5$ & I 62.6 & 407.1 & 80.9 & 24 & 22 & 17 & 5 & 83.7 & 271.2 & $354 \cdot 9$ & 58.0 & 22 & 22 & $2 \mathrm{I}$ & 6 \\
\hline Juni. . & 227.7 & 44.4 & 272.1 & 83.9 & 23 & 22 & I 5 & 3 & 227.8 & 94. I & 321.9 & 109.2 & I 8 & I 8 & I I & 3 \\
\hline Juli . . . & 106.9 & 60.0 & 166.9 & $54 \cdot 4$ & 23 & $2 \mathrm{I}$ & I 3 & I & $23 \cdot 5$ & 38.0 & $6 \mathrm{I} \cdot 5$ & 15.5 & I 5 & I 5 & I 2 & $\mathrm{O}$ \\
\hline August . . & 21.8 & 10.7 & 32.5 & 9.9 & 17 & I 4 & 8 & O & 17.8 & I I. 2 & 29.0 & I I .3 & 9 & 9 & 4 & $\mathrm{O}$ \\
\hline September & I I.O & 50.6 & 61.6 & 22.0 & 19 & I 5 & 9 & $\mathrm{O}$ & $9 \cdot 4$ & $6 \mathrm{I} \cdot \mathrm{I}$ & 70.5 & I 8.6 & 13 & I 3 & 9 & $\mathrm{O}$ \\
\hline Oktober & 40.5 & 80.8 & I 2 I. I & 34.8 & 16 & 14 & 12 & I & $15 \cdot 3$ & 78.5 & 93.8 & 26.8 & I 3 & 12 & 8 & I \\
\hline Novemb. ${ }^{1}$ ) & 8.3 & 147.2 & 155.5 & 42.7 & I 5 & I 4 & 12 & 2 & I.O & 117.3 & I I 8.3 & 34.0 & I I & I I & 9 & I \\
\hline Dezember & 38.6 & $45 \cdot 3$ & 83.9 & 38.5 & 5 & 5 & 5 & I & $3 \cdot 3$ & 7.7 & I I .O & 6.6 & 4 & 3 & 2 & $\mathrm{O}$ \\
\hline Jahr & 783.8 & 855.6 & 1639.4 & $83 \cdot 9$ & 167 & 150 & 112 & 18 & 438.1 & 908.1 & 1346.2 & 109.2 & 132 & 130 & 97 & 14 \\
\hline
\end{tabular}

Misahöhe. Beob.: De Komla.

Kpandu. Beob.: Dovi.

\begin{tabular}{|c|c|c|c|c|c|c|c|c|c|c|c|c|c|c|c|c|c|}
\hline \multirow[t]{2}{*}{1906} & \multicolumn{4}{|c|}{ Regenmenge in $\mathrm{mm}$} & \multicolumn{4}{|c|}{$\begin{array}{l}\text { Anzah1 der Tage } \\
\text { mit Regen } \\
\text { mit mehx als }\end{array}$} & \multicolumn{4}{|c|}{ Regenmenge in $\mathrm{mm}$} & \multicolumn{5}{|c|}{$\begin{array}{l}\text { Anzahl der Tage } \\
\text { mit Regen } \\
\text { mit mehr als }\end{array}$} \\
\hline & $6 \mathrm{a}$ & $6 \mathrm{p}$ & Summe & $\begin{array}{c}\text { in } \\
24 \mathrm{St} .\end{array}$ & $\begin{array}{c}\operatorname{lm} 2 \\
\text { allg. }\end{array}$ & $\begin{array}{l}0.2 \\
\mathrm{~mm}\end{array}$ & $\begin{array}{c}\mathrm{I} . \mathrm{O} \\
\mathrm{mm}\end{array}$ & $\begin{array}{l}25.0 \\
\mathrm{~mm}\end{array}$ & $6 a$ & $6 \mathrm{p}$ & Summe & $\begin{array}{c}\text { in } \\
24 \mathrm{St} .\end{array}$ & $\begin{array}{c}1 \mathrm{~m} \\
\text { allg. }\end{array}$ & $\begin{array}{c}0.2 \\
\mathrm{~mm}\end{array}$ & $\begin{array}{c}\mathbf{I} .0 \\
\mathrm{~mm}\end{array} \mid$ & $\begin{array}{l}25.0 \\
\mathrm{~mm} \\
\end{array}$ & Ts \\
\hline Januar . . & 10.6 & $4 \cdot 3$ & I 4.9 & 9.6 & 4 & 3 & 2 & $\mathrm{O}$ & O.O & 9.1 & 9.1 & 8.5 & 2 & 2 & I & $\mathrm{O}$ & $\mathrm{O}$ \\
\hline Februar & I. 7 & 8.5 & 10.2 & $4 \cdot 5$ & 3 & 3 & 3 & $\mathrm{O}$ & 6.5 & 8.7 & I 5.2 & 8.5 & 3 & 2 & 2 & $\mathrm{O}$ & 6 \\
\hline März . . & 79.1 & 0.0 & 79.1 & 51.9 & 5 & 4 & 3 & I & 30.2 & 66.6 & 96.8 & 32.5 & I 3 & IO & IO & I & I3 \\
\hline April . & 17.5 & 65.1 & 82.6 & 28.6 & 8 & 5 & 5 & 2 & 52.2 & I I 4.2 & I 66.4 & 29.7 & 8 & 8 & 8 & 3 & I 4 \\
\hline Mai . . . & I $27 . \mathrm{I}$ & 179.8 & 306.9 & I06.5 & 20 & 16 & I 5 & 3 & $57 \cdot I$ & I 38.3 & I 95.4 & 41.0 & I 5 & I 5 & I 4 & 4 & $2 \mathrm{O}$ \\
\hline Juni. . & $2 \mathrm{I} \mathrm{I} .4$ & I 87.7 & 399. I & I 36.2 & 20 & I 8 & I 5 & 5 & 129.9 & $74 \cdot 5$ & $204 \cdot 4$ & 78.1 & I 7 & I 7 & 17 & 2 & 17 \\
\hline Juli . . . . & $\left(\begin{array}{lll}\text { I I } & 2.2\end{array}\right)$ & $(\mathrm{I} 2 \mathrm{I} . \mathrm{I})$ & 2) 233.3 & $(27 \cdot 3)$ & $>25$ & 25 & 22 & $>\mathrm{I}$ & 90.6 & 56.1 & I 46.7 & 4I.I & I 3 & I 3 & I 3 & 2 & 16 \\
\hline August. . & 35.0 & $3 \mathrm{I} . \mathrm{I}$ & 66.1 & 28.5 & I9 & I 4 & 7 & I & 26.5 & 9.0 & $35 \cdot 5$ & 22.0 & 4 & 4 & 4 & $\mathrm{O}$ & 7 \\
\hline September & 29. I & IOI.5 & I 30.6 & 30.9 & $2 \mathrm{I}$ & 16 & I 2 & I & 66.8 & 72.5 & I 39.3 & 38.0 & I 2 & I 2 & I I & 2 & I 2 \\
\hline Oktober . & 74.6 & 48.3 & I 22.9 & 36.5 & I9 & I7 & I 5 & I & IOO.O & 78.0 & I 78.0 & 67.0 & I 4 & I 4 & I 3 & 2 & I 7 \\
\hline November & 17.2 & 103.7 & I 20.9 & 24.7 & I 2 & I 2 & I 2 & $\mathrm{O}$ & $59 \cdot 4$ & 83.6 & I 43.0 & 26.2 & I I & I I & I I & I & I 3 \\
\hline Dezember & 36.5 & I 3.4 & 49.9 & I 6.0 & 7 & 7 & 5 & $\mathrm{O}$ & $9 \cdot 5$ & 0.0 & $9 \cdot 5$ & 5.0 & 2 & 2 & 2 & $\mathrm{O}$ & 4 \\
\hline Jahr . & 752.0 & 864.5 & 1616.5 & 136.2 & $>163$ & 140 & 11 & 15 & 628.7 & 710.6 & 1339.3 & 78.1 & 114 & 110 & 106 & 17 & 139 \\
\hline
\end{tabular}


Tetetu. Beob.: Dovi.

Gjeasekang. Beob.: E. Kwaku.

\begin{tabular}{|c|c|c|c|c|c|c|c|c|c|c|c|c|c|c|c|c|}
\hline \multirow{2}{*}{1906} & \multicolumn{4}{|c|}{ Regenmenge in $\mathrm{mm}$} & \multicolumn{4}{|c|}{$\begin{array}{c}\text { Anzahl der Tage } \\
\text { mit Regen } \\
\text { mit mehr als }\end{array}$} & & genmet & ge in $n$ & & \multicolumn{4}{|c|}{$\begin{array}{l}\text { Anzahl der Tage } \\
\text { mit Regen }\end{array}$} \\
\hline & $6 a$ & $6 \mathrm{p}$ & Summe & $\begin{array}{c}\text { Max. } \\
\text { in } \\
24 \mathrm{St} . \\
\end{array}$ & $\mathrm{im}_{\text {allg. }}$ & \begin{tabular}{|c|} 
mit \\
0.2 \\
$\mathrm{~mm}$ \\
\end{tabular} & $\begin{array}{r}\text { meh } \\
\mathrm{I.o} \\
\mathrm{mm} \\
\end{array}$ & $\begin{array}{l}25 \\
25.0 \\
\mathrm{~mm}\end{array}$ & $6 а$ & $6 p$ & Summe & $\begin{array}{r}\text { Max. } \\
\text { in } \\
24 \text { St. }\end{array}$ & $\begin{array}{l}\text { im } \\
\text { allg. }\end{array}$ & $\begin{array}{c}\mathrm{mi} \\
0.2 \\
\mathrm{~mm} \\
\end{array}$ & $\begin{array}{l}\text { mehr } \\
\text { I.o } \\
\mathrm{mm}\end{array}$ & $\begin{array}{l}\text { als } \\
25.0 \\
\mathrm{~mm} \\
\end{array}$ \\
\hline nua & $J$ & & 6.0 & 6.0 & I & I & I & 0 & I. 4 & O & I. 4 & I. 4 & I & I & I & \\
\hline & & I 5 & & I 5.4 & 3 & 2 & I & o & 0.0 & $\mathrm{O}$ & 5.0 & & 2 & 2 & 2 & \\
\hline àı & 0. & & 4 & I 3.6 & 6 & 6 & 5 & o & I 5.8 & 36.7 & 52.5 & 34.7 & 4 & 4 & 4 & \\
\hline pril. & 28.3 & 165.4 & 193.7 & 58.5 & I I & I I & I I & 3 & $55 . \mathrm{I}$ & 120.2 & 175.3 & 35.2 & IO & IO & 9 & \\
\hline & - & - & & 47.9 & I 2 & IO & IO & 2 & 59.2 & 95.9 & & 38.0 & I 3 & I 3 & I 2 & \\
\hline & - & - & .9 & 40.6 & 9 & 7 & 7 & 2 & - & $-1)$ & 5 & 50.6 & $>16$ & $>16$ & $>16$ & \\
\hline & 2.6 & 161.5 & I $64 . \mathrm{I}$ & I 20.7 & 9 & 9 & 8 & I & I 3 I. 4 & I I 8.2 & .6 & 46.3 & I 4 & I 4 & I 4 & \\
\hline & o. & & & 8.9 & 3 & 3 & 3 & o & - & $-2)$ & & & $>5$ & $>5$ & $>5$ & \\
\hline iber & 8. I & I I I I . 7 & I I 9.8 & 48.5 & 8 & 8 & 8 & I & 8.8 & I 31.8 & 6 & 38.0 & IO & IO & 9 & \\
\hline & 21.9 & 76 & 98.7 & 24.2 & 9 & 9 & 9 & o & 60.0 & I 53.5 & .5 & 32.8 & 20 & 20 & I9 & \\
\hline Nov & I 4 & & & 23.2 & 7 & 7 & 7 & $\mathrm{O}$ & $34 \cdot 3$ & 33.8 & $68 . \mathrm{I}$ & 22.9 & 7 & 7 & 7 & \\
\hline Dez & 0.0 & 27.2 & 27.2 & 27.2 & I & I & I & $\mathrm{I}$ & 8 & $-3)$ & - & - & 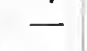 & 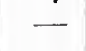 & - & - \\
\hline Jahr & - & - & 1021.1 & 120.7 & 79 & 74 & 71 & 10 & - & - & $(1451.8)$ & - & - & - & - & - \\
\hline
\end{tabular}

1) Die Beobachtungen vom 22. bis 26. Juni fielen aus; während dieser Zeit fielen $65.4 \mathrm{~mm} .{ }^{2}$ ) Desgl. vom 23. bis 27 . August; während dieser Zeit fielen $45.6 \mathrm{~mm} .{ }^{3}$ ) Dezember-Beobachtungen ansgefallen.

Atakpame. Beob.: Dehn.

Kete-Kratschi. Beob.: Kolberg.

\begin{tabular}{|c|c|c|c|c|c|c|c|c|c|c|c|c|c|c|c|c|}
\hline \multirow[b]{2}{*}{ I 906} & \multicolumn{4}{|c|}{ Regenmenge in $\mathrm{mm}$} & \multicolumn{4}{|c|}{$\begin{array}{c}\text { Anzahl der Tage } \\
\text { mit Regen } \\
\text { mit mehr als }\end{array}$} & \multicolumn{4}{|c|}{ Regenmenge in $\mathrm{mm}$} & \multicolumn{4}{|c|}{$\begin{array}{l}\text { Anzah1 der Tage } \\
\text { mit Regen }\end{array}$} \\
\hline & $6 \mathrm{a}$ & $6 \mathrm{p}$ & Summe & $\begin{array}{l}\text { Max. } \\
\text { in } \\
24 \text { St. }\end{array}$ & im & $\left|\begin{array}{c}\text { mit } \\
0.2 \\
\mathrm{~mm}\end{array}\right|$ & $\begin{array}{l}\text { meh } \\
\text { I.o } \\
\mathrm{mm}\end{array}$ & $\begin{array}{l}\text { als } \\
25.0 \\
\mathrm{~mm}\end{array}$ & $6 \mathrm{a}$ & $6 \mathrm{p}$ & Summe & $\begin{array}{l}\text { Max. } \\
\text { in } \\
24 \text { St. }\end{array}$ & $\begin{array}{l}\text { im } \\
\text { allg. }\end{array}$ & $\begin{array}{l}\mathrm{mi} \\
0.2 \\
\mathrm{~mm}\end{array}$ & $\begin{array}{l}\text { mehr } \\
\text { I.o } \\
\text { mm }\end{array}$ & $\begin{array}{l}\text { als } \\
25.0 \\
\mathrm{~mm}\end{array}$ \\
\hline anuar & 8.5 & 0.0 & 8.5 & 8.5 & I & I & I & o & $5 \mathrm{I} . \mathrm{O}$ & 0.0 & 5 I.O & 46.0 & 3 & 2 & I & I \\
\hline Februar & 0.5 & 30.2 & 30.7 & 30.7 & I & I & I & $\|$ & I 6.0 & 8.5 & 5 & I I .O & 4 & 4 & 3 & $\mathrm{O}$ \\
\hline [ärz & $2 \mathrm{I} .4$ & 6.5 & 27.9 & 19.7 & 6 & 4 & 3 & 0 & 42.8 & 22.0 & 64.8 & 29.0 & 4 & 4 & 4 & I \\
\hline April & 34.7 & 97.6 & I 32.3 & 37.5 & I 3 & IO & IO & 2 & IO9. 3 & 71.5 & I 80.8 & 5 I.9 & I 4 & I 2 & II & 2 \\
\hline Mai & 88.3 & I 4 O. I & 228.4 & 59.8 & 16 & I 2 & I 2 & 3 & 42.2 & 56.6 & 98.8 & 26.5 & I4 & I 3 & I 3 & 2 \\
\hline Jur & I 53.8 & I6.6 & 170.4 & 33.4 & I 4 & 12 & IO & 3 & I 5 I.9 & 52.9 & 204.8 & 39.0 & I 4 & I3 & IO & 3 \\
\hline Jul & 167.9 & 6.0 & I 73.9 & 62.5 & 24 & I9 & I I & 2 & $2 \mathrm{I} . \mathrm{I}$ & $74 . \mathrm{I}$ & 95.2 & 29.8 & I 8 & I 7 & I4 & I \\
\hline Aug & 72.2 & 20.7 & 92.9 & 39.5 & 16 & I 2 & IO & I & 34.8 & 13.7 & 48.5 & $23 \cdot 5$ & IO & 7 & 4 & $\mathrm{O}$ \\
\hline September & 35.0 & 63.4 & 98.4 & 57.6 & I 8 & I 5 & IO & I & I 26.3 & $83 \cdot 3$ & 209.6 & 36.3 & 22 & 20 & 19 & 3 \\
\hline & 76.7 & 33.5 & I 10.2 & I 8.3 & I 8 & I 3 & I 2 & $\mathrm{o}$ & I 79.8 & I00.9 & 280.7 & $34 \cdot 3$ & $2 \mathrm{I}$ & $2 \mathrm{I}$ & 20 & 4 \\
\hline November & 43.2 & 3 & 43.2 & 17.6 & 6 & 5 & 3 & 0 & 28.0 & I. 3 & 29.3 & 17.4 & 7 & 7 & 3 & $\mathrm{O}$ \\
\hline Dezember & 83.6 & - & 83.6 & 52.2 & 4 & 2 & 2 & 2 & 6.3 & 0.0 & 6.3 & $6 . \mathrm{I}$ & 2 & I & 1 & 0 \\
\hline Jahr & 785.8 & $(414.6)$ & 1200.4 & 62.5 & 137 & 106 & 85 & 15 & 809.5 & 484.8 & $1294 \cdot 3$ & 51.9 & 133 & 121 & 103 & 17 \\
\hline
\end{tabular}

Sokode. Beob.: Hoffbauer u. Jacobi.

Basari. Beob.: Mucke.

\begin{tabular}{|c|c|c|c|c|c|c|c|c|c|c|c|c|c|c|c|c|c|}
\hline \multirow{2}{*}{ I906 } & \multicolumn{4}{|c|}{ Regenmenge in $\mathrm{mm}$} & \multicolumn{5}{|c|}{$\begin{array}{l}\text { Anzahl der Tage } \\
\text { mit Regen } \\
\text { mit mehr als }\end{array}$} & \multicolumn{4}{|c|}{ Regenmenge in $\mathrm{mm}$} & \multicolumn{4}{|c|}{$\begin{array}{l}\text { Anzahl der Tage } \\
\text { mit Regen }\end{array}$} \\
\hline & $6 a$ & $6 \mathrm{p}$ & Summe & $\begin{array}{l}\text { Max. } \\
\text { in } \\
24 \text { St. }\end{array}$ & im & $\begin{array}{l}\text { mit } \\
0.2 \\
\mathrm{~mm}\end{array}$ & $\begin{array}{l}\mathrm{meh} \\
\mathrm{r} . \mathrm{O} \\
\mathrm{mm}\end{array}$ & $\left|\begin{array}{l}25.0 \\
\mathrm{~mm}\end{array}\right|$ & Ts & $6 a$ & $6 \mathrm{p}$ & Summe & $\begin{array}{l}\text { Max. } \\
\text { in } \\
24 \text { St. }\end{array}$ & $\begin{array}{l}\text { im } \\
\text { allg. }\end{array}$ & $\begin{array}{c}\mathrm{mit} \\
0.2 \\
\mathrm{~mm}\end{array}$ & \begin{tabular}{|l} 
mehr \\
I.o \\
mm
\end{tabular} & $\begin{array}{l}25.0 \\
\mathrm{~mm}\end{array}$ \\
\hline Tanua & 0.0 & 0.0 & 0.0 & 0.0 & o & O & $\mathrm{O}$ & $\mathrm{O}$ & 0 & 22.0 & 0.0 & 22.0 & 22.0 & I & I & I & $\mathrm{O}$ \\
\hline Feh & 0.0 & 0.0 & 0.0 & 0.0 & o & O & 0 & o & O & 0.0 & 0.0 & 0.0 & 0.0 & o & o & o & 0 \\
\hline Mär & 0.0 & 23.5 & 23.5 & I 8.0 & 3 & 3 & 2 & $\mathrm{O}$ & $?$ & I 4.5 & 0.0 & I 4.5 & I 4.5 & I & I & I & $\mathrm{O}$ \\
\hline Apri & 37.3 & 32. & 69.7 & 28.6 & 7 & 7 & 6 & 2 & 9 & 29.2 & 41.9 & $7 \mathrm{I} . \mathrm{I}$ & 2 I. 6 & 8 & 8 & 8 & 7 \\
\hline Mai & $15 \mathrm{I} .4$ & 78.2 & 229.6 & 54.8 & I 4 & I 3 & 13 & 4 & I 4 & 82.6 & I I 7.1 & I99.7 & 34.3 & I 8 & I6 & 5 I 6 & $5 \quad 2$ \\
\hline Jun & 98.4 & 59.9 & I 58.3 & 43.8 & I 7 & I 7 & 15 & 3 & 16 & I $53 . \mathrm{I}$ & 98.7 & 251.8 & 43.0 & I 5 & I 5 & I 5 & 3 \\
\hline Jul & 225.3 & I I 4.4 & 339.7 & 52.5 & 24 & 22 & 20 & 7 & 24 & 67.2 & 68.0 & I 35.2 & 9 & I 3 & 12 & I I & 2 \\
\hline $\mathrm{Au}$ & $42 . \mathrm{I}$ & $28 . \mathrm{I}$ & 70.2 & 32.4 & I 5 & I 3 & 8 & I & I 5 & 24.8 & 61.0 & 85.8 & 38.0 & I I & 9 & 8 & I \\
\hline Sep & I 40.7 & I $43 \cdot 3$ & 284.0 & $5 \mathrm{I} .8$ & 22 & 18 & I 6 & 4 & 22 & 67.6 & 2 II. 4 & 279.0 & & 19 & 19 & 19 & 5 \\
\hline Oktober & 58.9 & 89. I & I 48.0 & 3 I.9 & 19 & 17 & I 2 & 3 & I9 & 85.4 & I 56.3 & $24 \mathrm{I} .7$ & 64.6 & 19 & I9 & I 8 & I \\
\hline & 22.5 & 3.7 & 26.2 & 22.5 & 3 & 2 & 2 & $\mathrm{O}$ & 2 & 29. I & 22.0 & $5 \mathrm{I} . \mathrm{I}$ & $29 . \mathrm{I}$ & 3 & 3 & 3 & I \\
\hline Dez & 0.0 & 0.0 & 0.0 & 0.0 & $\mathrm{O}$ & $\mathrm{o}$ & 0 & $\mathrm{O}$ & $\mathrm{O}$ & $9 \cdot 5$ & 0.0 & 9.5 & 9.5 & I & I & I & 0 \\
\hline Jahr & 776.6 & 572.6 & 1349.2 & 54.8 & 124 & 112 & 94 & 24 & (121) & 585.0 & 776.4 & 1361.4 & 64.6 & 109 & 104 & +101 & 22 \\
\hline
\end{tabular}


Sansane Mangu. Beob.: Mellin.

\begin{tabular}{|c|c|c|c|c|c|c|c|c|}
\hline \multirow[t]{2}{*}{1906} & \multicolumn{4}{|c|}{ Regenmenge in $\mathrm{mm}$} & \multicolumn{4}{|c|}{$\begin{array}{c}\text { Anzahl der Tage } \\
\text { mit Regen }\end{array}$} \\
\hline & $6 a$ & $6 \mathrm{p}$ & Summe & 24 St. & ${ }_{\text {allg. }}^{1 \mathrm{~m}}$ & $\begin{array}{r}1.2 \\
\mathrm{~mm}\end{array}$ & $\begin{array}{r}\mathrm{I} . \mathrm{O} \\
\mathrm{mm}\end{array}$ & $\begin{array}{l}25 \\
111\end{array}$ \\
\hline an. & 0.0 & O.C & 0.0 & 0.0 & $\mathrm{O}$ & $\mathrm{O}$ & $\mathrm{O}$ & \\
\hline br. & $\mathrm{O}$ & $\mathrm{O}$ & $c$ & 0.0 & $\mathrm{O}$ & $\mathrm{O}$ & $\mathrm{O}$ & \\
\hline $\operatorname{irz}$ & O. & 0.0 & $c$ & 0.2 & I & $\mathrm{O}$ & $\mathrm{O}$ & \\
\hline oril . & I I 4 & 6.5 & I 20.8 & 99.0 & 6 & 6 & 5 & \\
\hline $\mathrm{i}$ & .6 & +2.2 & 99.8 & $2 \mathrm{I} . \mathrm{O}$ & I I & I I & $\mathrm{IO}$ & \\
\hline ii & I I 6. I & I 34.8 & 0.9 & 42.0 & 12 & I 2 & IO & \\
\hline Juli & 17.1 & & $\cdot 3$ & 34.0 & IO & IO & 9 & \\
\hline $5^{\circ}$ & 246.0 & 83 & 329.5 & 79.2 & I 7 & 17 & I 5 & \\
\hline t. . & I I 8.0 & 94.9 & 212.9 & 39.0 & I 8 & 17 & 15 & \\
\hline Dkt. & 87.1 & 26.4 & I I 3.5 & 22.3 & I 3 & I 2 & I 2 & \\
\hline . & I I.O & $5 \cdot 5$ & I 6.5 & I 5.0 & 2 & 2 & 2 & \\
\hline Dez. & 0.0 & 0.0 & 0.0 & 0.0 & $\mathrm{O}$ & $\mathrm{O}$ & $\mathrm{O}$ & \\
\hline ant & $767 \cdot 4$ & 477.0 & 1244.4 & 99.0 & 90 & 87 & 78 & \\
\hline
\end{tabular}

\section{Togo während des letzten Erdbebens von Accra.}

Nach einem Bericht des Bezirksgeologen Dr. Koert im Amtsblatt für Togo 1907, Nr. 5.)

Von den zahlreichen Erdbeben der jüngsten Zeit ist auch die westafrikanische Küste nicht verschont geblieben, die im allgemeinen als ruhig hinsichtlich des Auftretens von Erdbeben gilt. Am 20. November 1906 wurden gegen 9 Uhr nachmittags die Bewohner von Accra durch einen heftigen Erdstoß erschreckt, welcher etwa 30 Sekunden gedauert habcn soll. Manche Häuser von Kaufleuten trugen große Risse davon. Die Erdstöße hielten, allerdings in geringerer Stärke, nach den vorliegenden Nachrichten noch einige Tage an; angeblich wurden bis zum I I. November I 5 solche gezählt. Seit I862, wo Accra durch ein Erdbeben beinahe ganz zerstört wurde, soll dort kein so heftiges Erdbeben gespürt sein. Auch in Sekondi (in Luftlinie etwa $175 \mathrm{~km}$ südwestlich Accra) wurden mehrerc Stöße bemerkt.

In Togo wurde das letzte Erdbeben ebenfalls wahrgenommen, wobei sich freilich sehr empfindlich bei der Zeitbestimmung des Stoßmomentes an den verschiedenen Orten der Mangel an genau gehenden Uhren bemerkbar machte.

In Lome begann das Erdbeben am 20. November gegen 9 Uhr I 5 Minuten nachmittags mit einer etwa 5 Sekunden anhaltenden Erschütterung, der nach 2 I Minuten eine zweite, aber schwächere und von geringerer Dauer folgte.

In ganz auffallender Weise war im Westen von Togo die Bebenwirkung im Innern eine stärkere als an der Küste. Das erklärt sich leicht aus dem geologischen Bau. Während nämlich die Togoküiste und der ihr benachbarte Landstrich in einer Breite von 30 bis $45 \mathrm{~km}$ sich aufbaut aus mächtigen lockeren, sandigen und tonigen Bildungen, die den Stoß natürlich schlecht fortleiten, beginnt nach dem Innern $\mathrm{zu}$ überall der felsige Untergrund, der die Erdbebenwellen besser fortpflanzt. So war z. B. schon in Assahun die Erdbebenwirkung eine stärkere, demn ein Beobachter meldet von dort heftiges Zittern des ganzen Hauses.

In Palime und auf Misahöhe wurde ein ungefähr 10 bis I5 Sekunden anhaltendes gleichmäßiges Schwanken beobachtet. Der zweite Stoß folgte dort 2I.5 Minuten später und soll schwächer und von kürzerer Dauer gewesen sein. Die größte Intensität scheint das Beben in Ho erreicht zu• haben, also an dem Accra verhältnismäßig am nächsten gelegenen Beobachtungsort, dessen Untergrund ebenfalls felsig ist. Das Beben äußerte sich dort in einem zweimaligen starken Erzittern des Bodens und war mit starkem Donner und brausendem Geräusch verbunden. Merkwürdigerweise soll hier der zweite Stoß der stärkere gewesen sein.

Jenseit des Togogebirges wurde das Beben noch deutlich auf der Missionsstation Akpafu wahrgenommen.

Merklich schwächer waren die Äußerungen des Erdbebens im Osten von Togo. In Anecho wurde dasselbe nur von einzelnen Personen als leichte Erschütterung gespürt, in Tokpli am Monu erzitterte das Stationsgebäude und Teller und Gläser klirrten. In Atakpame ist ebenfalls ein Beben von kurzer Dauer wahrgenommen worden, dagegen ist im SokodéBezirk und in Mangu keine Spur eines Bebens bemerkt worden.

Das Erdbeben von Accra ist also über einen Küstenstreifen von mindestens $350 \mathrm{~km}$ Länge, zwischen Sekondi und Anecho, und etwa $200 \mathrm{~km}$ Breite beobachtet. Die Erscheinung gehört unzweifelhaft zu den tektonischen Beben, d. h. solchen, die durch Verschiebungen in der Erdkruste zustande kommen.

Bei Accra tritt nämlich die Verlängerung des Togogebirges, das Akwapingebirge, nahe an die Küste heran und wird hier zweifellos von mächtigen, ungefähr ost-westlichen Verwerfungen gegen die ozeanischen Tiefen hin abgeschnitten. Derartige ost-westliche Verwerfungen spielen auch im Gebirgsbau des südlichen Togo eine große Rolle und geben sich überall als recht junge Störungen zu erkennen. An solchen jungen Bruchlinien pflegen sich aber von Erdbeben begleitete Verschiebungen ganz gewöhnlich zu vollziehen. 


\section{Aus dem Schutzgebiete Kamerun.}

\section{Ergebnisse der Regenmessungen in Kamerun in den Jahren 1905 und 1906.}

Obwohl im vergangenen Jahre von der leitenden Stelle des Schutzgebiets ein erneuter Versuch unternommen wurde, die für die wirtschaftlichen Unternehmen in erster Linie bedeutungsvollen regelmäBigen Messungen des Regenfalls an allen Regierungs- und tunlichst auch an allen Pflanzungsstationen zur Durchführung $z u$ bringen, und obwohl eine große Anzahl von Regenmessern zur Verteilung gelangte, sind die während des Jahres 1906 erzielten Resultate leider noch nicht überall vollwertig, namentlich die Messungen an einem Teil der Pflanzungsstationen liegen nicht lückenlos vor; für eine Reihe derselben fehlen die Daten für den Monat Februar ganz. An vielen Pflanzungsstationen sind die Regenmessungen überhaupt nur auf ganze Millimeter abgerundet notiert worden.

Dic in Duala wenige Hundert Meter voneinander entferntcn Stationen am Doktorhaus und im Hafenamt weisen auch für das Berichtsjahr 1906 erhebliche Differenzen auf, die nicht allein aus den verschiedenen Beobachtungsterminen (am Doktorhaus vielfach $7 \mathrm{a}$, 2p, 9p, zuweilen auch nur an einem dieser Termine, am Hafenamt um $6 \mathrm{a}$ und $6 \mathrm{p}$ ) zu erklären sind.

Wir lassen zunächst der Raumersparnis halber die Daten von einigen ganz lückenhaften Stationen folgen, von denen nur einen oder wenige Monate umfassende Beobachtungen vorliegen.

\section{Regenmenge in $\mathrm{mm}$} morgens abends Summe
Anzahl der Tage mit Regen

Max. in im allge- mit mehr als 24 St. meinen $0.2 \mathrm{~mm}$ I.O mm $25.0 \mathrm{~mm}$ Joko

\begin{tabular}{|c|c|c|c|c|c|c|c|c|c|}
\hline Oktober I9́ & 206. & 160.7 & I 7.2 & 277.9 & 35.4 & 25 & 22 & I 8 & 4 \\
\hline November & . & I9.6 & 2.5 & 22. I & I 5.4 & 7 & 5 & 4 & $\mathrm{O}$ \\
\hline Dezember & . & 0.0 & $3 \cdot 4$ & 3.4 & $3 \cdot 4$ & I & I & I & $\mathrm{O}$ \\
\hline \multicolumn{10}{|c|}{ Garua } \\
\hline Juli 1906 & . & - & - & $97 \cdot 5$ & 22.0 & IO & IO & IO & $\mathrm{O}$ \\
\hline \multicolumn{10}{|c|}{ Molundu } \\
\hline Dezember & 1906 & - & - & 147.0 & 59.0 & 8 & 8 & 8 & 2 \\
\hline & & \multicolumn{8}{|c|}{ Kribi } \\
\hline November & 1906 & - & 一 & 239.5 & 40.6 & 17 & 17 & 6 & 3 \\
\hline Dezember & . . & - & - & 59.5 & 22.0 & 8 & 8 & 6 & $\mathrm{O}$ \\
\hline
\end{tabular}

Von der Missionsstation Groß-Batanga sind die des Jahres 1905 nachgeliefert, so daß sich für diese Station (s. diese Zeitschr., Jahrg. 1906, S. 147) ergibt:

GroB-Batanga

Regenmenge in $\mathrm{mm}$

Anzahl der Tage mit Regen Max. in im allge- mit mehr als morgens abends Summe

Oktober 1905. . 510.5

November . . . 100.9

$217.7 \quad 728.2$

$24 \mathrm{St}$.

I 68.6

Dezember . . . 99.7

I IO.I 211.0

$2.2 \quad$ I OI.9

Für die Station Banjo liegen für die Monate August I905 bis Februar 1906 allgemeine WetterMitteilungen a. d. D. Schutzgebieten, XX. Band. III.
31.2

meinen $0.2 \mathrm{~mm} \quad 1.0 \mathrm{~mm} \quad 25.0 \mathrm{~mm}$

$\begin{array}{llll}28 & 28 & 26 & 6\end{array}$

$\begin{array}{llll}24 & 24 & 19 & 3\end{array}$

$\begin{array}{lllll}57.2 & 8 & 7 & 7 & 1\end{array}$

aufzeichnungen ohne Regenmesserablesungen vor. Hiernach kamen auf die Monate 
Regentage Gewittertage

$\begin{array}{lrr}\text { August I905 . } & 22 & \text { IO } \\ \text { September . } & \text { 2 I } & 8 \\ \text { Olitober . } & 22 & \text { I I } \\ \text { November . . } & 9 & 7 \\ \text { Dezember . . } & 0 & 0 \\ \text { Januar I906 . } & 0 & 0 \\ \text { Februar . . } & 3 & 2\end{array}$

Vom I 7. November bis 5. Februar wurden 8 I vollständig trockene und gewitterfreie Tage notiert

Rohe Thermometerablesungen auf ganze Grade (über die Aufstellung und Qualität des Thermometers ist nichts bekannt) ergaben folgende Mittelwerte:

\begin{tabular}{|c|c|c|c|c|}
\hline I $905 / 06$ & & $6 a$ & Mittags & $6 \mathrm{p}$ \\
\hline August & . & $18^{\circ} .0$ & $23^{\circ} .0$ & $2 \mathrm{I}^{\circ} . \mathrm{O}$ \\
\hline September & & I 9.0 & 24.0 & $2 \mathrm{I} . \mathrm{O}$ \\
\hline Oktober & . & 19.5 & 25.0 & 22.0 \\
\hline November & . & 19.0 & 27.5 & 22.5 \\
\hline Dezember & . & 18.0 & 29.0 & 24.0 \\
\hline Januar & . & I 6.0 & 29.0 & $22 . \mathrm{O}$ \\
\hline Februar & . & 20.0 & 30.0 & 26.0 \\
\hline
\end{tabular}

Auf der Pflanzung Dipikar am Kampo sind regelmäBige Ablesungen von Indexthermometern meist allerdings nur auf ganze Grade angestellt worden, die folgende Resultate ergaben:

Mittleres Absolutes

\begin{tabular}{|c|c|c|c|c|c|c|}
\hline \multicolumn{3}{|l|}{1906} & Max. & Min. & Max. & Min. \\
\hline Januar & 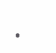 & & $30^{\circ} .0$ & $23^{\circ} .0$ & $34^{\circ} \cdot 5$ & $2 \mathrm{I}^{\circ} . \mathrm{O}$ \\
\hline Februar & & & 31.0 & 23.0 & 33.0 & 2 I.O \\
\hline März & . & & $3 \mathrm{I} . \mathrm{O}$ & 23.0 & 32.5 & 22.0 \\
\hline April & - & & 31.0 & 24.0 & 32.5 & 21.0 \\
\hline Mai. & & & 30.0 & 23.0 & $3 I .5$ & 21.0 \\
\hline Juni & 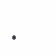 & & 28.5 & 22.0 & $3 I \cdot 5$ & 20.0 \\
\hline Juli & . & & 27.0 & 21.0 & 28.5 & 20.0 \\
\hline August & & & 27.0 & $2 \mathrm{I} . \mathrm{O}$ & 28.5 & I9. 5 \\
\hline Septeml & ber & & 27.0 & 22.0 & 29.0 & 21.0 \\
\hline Oktober & & & 28.0 & 22.0 & 29.0 & 20.5 \\
\hline Novem & per & & 29.0 & 22.0 & $29 \cdot 5$ & 21.0 \\
\hline Dezemb & er & & 29.0 & 23.0 & 31.0 & $2 \mathrm{I} .5$ \\
\hline Jahr & & & 29.0 & 22.4 & 34.5 & 19.5 \\
\hline
\end{tabular}

In Mundame am Mungo sind in den Jahren I 905 und I906, in Jabassi am Wuri I906 regelmäBige Pegelablesungen vorgenommen worden.

Die gleichzeitigen Pegelablesungen bezüglich der Wasserstände des Mungo und des Wuri um I 2 Uhr mittags für das Jahr I 906 sind auf Tafel VII graphisch zur Darstellung gebracht. Sie zeigt eine recht erhebliche Parallelität des Steigens und Fallens der Wasserstände beider Flüsse, ein Beweis dafür, daß die eine Flutwelle erzeugenden Regenfälle in den Einzugsgebieten beider Flüsse vielfach gleichzeitig eintreten. Der Mungo, welcher bei Mundame noch mehr den Charakter eines Gebirgsstromes besitzt als der WVuri bei Jabassi, weist dementsprechend auch gröBere Schwankungen seines Spiegels auf als der IVuri bei Jabassi, das bereits in der Ebene liegt. Beim Mungo betrug die Jahresschwankung der Pegelablesung 7.OI m (I9O5 $7.28 \mathrm{~m}$ ), beim Wuri nur $5.76 \mathrm{~m}$. Das sind naturgemäß nur Annäherungswerte, da bei den täglich nur einmal bzw. dreimal vorgenommenen Pegelablesungen die wirklichen Maxima der Flutwellen sich der Beobachtung oft entzogen haben werden. Denn das Fallen und Steigen des Spiegels vollzieht sich namentlich bei dem Mungo äußerst rapid; so stieg er vom I9. zum 20. September um $2.48 \mathrm{~m}$, vom 6. zum 7. Oktober um $2.86 \mathrm{~m}$ in 24 Stunden.

Leider fehlen in den oberen Einzugsgebieten beider Flüsse RegenmeBstationen, so daß sich der nähere Zusammenhang zwischen Regenfall und Pegelständen nicht nachweisen läßt. Die in Duala und Jabassi angestellten Regenmessungen lassen eine Parallelität zwischen Pegelständen und Regenmengen nicht immer erkennen.

Die absolut niedrigsten Pegelstände wưrden an beiden Flüssen im März, die höchsten im September beobachtet; in letzterem Monat erreichten beide Flüsse auch im Mittel die höchsten Pegelstände. Die mittleren niedrigsten Pegelstände traten im Mungo im Februar, im Wuri erst im März ein.

Wasserstände des Mungo-Flusses, beobachtet am Pegel zu Mundame.

\begin{tabular}{|c|c|c|c|c|c|c|c|c|c|c|c|c|}
\hline & \multicolumn{6}{|c|}{ Pegelstände 1905} & \multicolumn{6}{|c|}{ Pegelstände I906, I 2 Uhr mittags } \\
\hline & Mittel & Max. & Dat. & Min. & Dat. & Diff. & Mittel & Max. & Dat. & Min. & Dat. & Diff. \\
\hline & $\mathrm{m}$ & $m$ & & $\mathrm{~m}$ & & $\bar{m}$ & $\mathrm{~m}$ & $\mathrm{~m}$ & & $\mathrm{~m}$ & & $\mathrm{~m}$ \\
\hline Januar. . & I. 30 & I. 44 & $\mathrm{I}$. & 0.97 & $3 \mathrm{I}$. & 0.47 & 0.92 & I. I 2 & I. & 0.86 & $3 \mathrm{I}$. & 0.26 \\
\hline Februar. . & 0.79 & 0.96 & I. & 0.07 & 24. & 0.89 & 0.86 & 0.90 & I 2. & 0.83 & I I. & 0.07 \\
\hline März . . & 0.95 & I. 32 & 9. & 0.73 & 17. & 0.59 & I. 24 & 1.23 & 2O. $2 \mathrm{I}$. & $0.8 \mathrm{I}$ & I6. & 0.42 \\
\hline April .. & 1.16 & 2. IO & 7. & 0.79 & I 2. & I.3 I & I. 28 & 1.50 & 24 & I.06 & I. & 0.44 \\
\hline Mai ... & I. 00 & I. 57 & 7. & 0.73 & I 2. & 0.84 & I. 36 & I. 48 & I9. & I. 25 & I 4. & 0.23 \\
\hline Juni . . . & I.35 & 3.25 & I9. & 0.70 & I 8 . & 2.55 & 2.06 & 4.60 & 28 & 1.37 & I. & 3.23 \\
\hline Juli . & $3 \cdot 34$ & 5.53 & 5. $3 \mathrm{I}$. & I.53 & 4. & 4.00 & 4.70 & 6.29 & I I. & 2.45 & 2. & 3.84 \\
\hline August & 5.02 & $7 \cdot 35$ & 2O. $2 \mathrm{I}$. & 3.42 & I I. & 3.93 & 4.98 & $7 \cdot 32$ & I 5. & 3.15 & 5. & 4.17 \\
\hline September. & 5.18 & 7.05 & 9. & 3.43 & 28. & 3.62 & 6.08 & 7.82 & 4. & 4.37 & 29. & 3.45 \\
\hline Oktober... & 4.07 & 5.07 & 2. & 3.65 & 17. & I. 42 & 5.19 & 6.89 & 7 & 3.97 & $3 \mathrm{I}$ & 2.92 \\
\hline November. & 2.79 & 4.35 & I 4. & I. 78 & 30. & 2.57 & $3.4 \mathrm{I}$ & 4.56 & I 3. & 2.03 & 30. & 2.53 \\
\hline Dezember . & I. 38 & I. 74 & 3. & I. I 4 & $3 \mathrm{I}$ & 0.60 & I. 68 & 2.09 & I 4. & $\mathrm{I} .2 \mathrm{O}$ & $3 \mathrm{I}$ & 0.89 \\
\hline Mittel ... & 2.36 & $7 \cdot 35$ & $20 \cdot 21 \cdot /$ VIII. & 0.07 & $24 \cdot /$ II. & 7.28 & 2.81 & 7.82 & $4 \cdot / I X$ & 0.81 & 16./III. & 7.01 \\
\hline
\end{tabular}




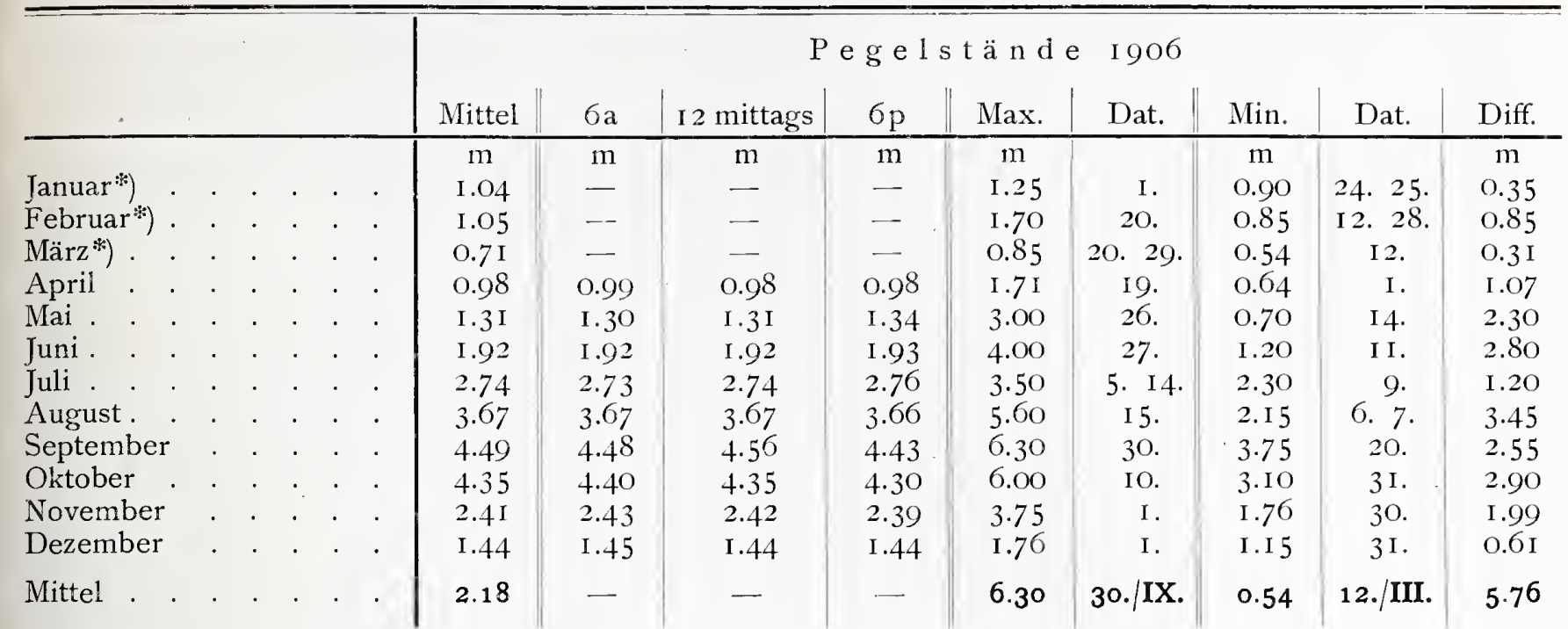

*) Von Januar bis März nur um 2 p gemessen.

Buea. Gouvernement.

Bamenda. Militärstation. 1905.

\begin{tabular}{|c|c|c|c|c|c|c|c|c|c|c|c|c|c|c|}
\hline \multirow[b]{2}{*}{ I906 } & \multicolumn{4}{|c|}{ Regenmenge in $\mathrm{mm}$} & \multicolumn{4}{|c|}{ Anzahl der Regentage } & \multicolumn{2}{|c|}{$\begin{array}{c}\text { Regenmenge } \\
\text { in } \mathrm{mm}\end{array}$} & \multicolumn{4}{|c|}{$\begin{array}{l}\text { Anzahl der Regentage } \\
\text { mit mehr als }\end{array}$} \\
\hline & $8 a$ & $6 \mathrm{p}$ & Summe & $\begin{array}{l}\text { Max. } \\
\text { in } \\
24 \text { St. }\end{array}$ & $\begin{array}{l}\text { im } \\
\text { allg. }\end{array}$ & $\begin{array}{c}\text { mit } \\
0.2 \\
\mathrm{~mm} \\
\end{array}$ & $\begin{array}{c}\text { mehr } \\
\text { I.o } \\
\mathrm{mm} \\
\end{array}$ & $\begin{array}{l}\text { ls } \\
25.0 \\
\mathrm{~mm} \\
\end{array}$ & Summe & $\begin{array}{c}\text { Max. } \\
\text { in } \\
24 \text { St. }\end{array}$ & $\operatorname{im}_{\text {allg. }}$ & $\begin{array}{r}\text { mit } \\
0.2 \\
\mathrm{~mm} \\
\end{array}$ & $\begin{array}{c}\text { mehr } \\
\mathrm{I} . \mathrm{o} \\
\mathrm{mm}\end{array}$ & $\begin{array}{l}25.0 \\
\mathrm{~mm} \\
\end{array}$ \\
\hline Januar & 4.0 & 24.8 & 28.8 & 24.8 & 3 & 3 & 2 & $\mathrm{o}$ & 0.0 & 0.0 & o & o & o & $\mathrm{o}$ \\
\hline Februar & 10.9 & 5.5 & I 6.4 & 7.0 & 7 & 6 & 4 & o & 0.0 & 0.0 & o & o & o & $\mathrm{o}$ \\
\hline März. & 3.0 & 8.3 & I I. 3 & 3.2 & 4 & 4 & 4 & o & 80.2 & 47.5 & 8 & 8 & 7 & I \\
\hline April & $(46.7)$ & $(\mathrm{I} 6.4)$ & 63.1 & $(20.4)$ & $\mathrm{I} 2$ & I 2 & 8 & o & I I 7.1 & $2 \mathrm{I} .5$ & 14 & I4 & I 4 & o \\
\hline Mai & 76.0 & 97.4 & 173.4 & 39.0 & 20 & I 7 & I 5 & I & 161.5 & 42.4 & 19 & 19 & 19 & I \\
\hline Juni & 69.6 & 82.4 & I 52.0 & 33.6 & 27 & 20 & I 7 & I & 295.5 & 54.6 & $2 \mathrm{I}$ & $2 \mathrm{I}$ & $2 \mathrm{I}$ & 2 \\
\hline Juli & 93.2 & 225.2 & $3 \mathrm{I} 8.4$ & $55 . \mathrm{I}$ & 31 & 29 & 27 & 4 & 505.1 & 53.5 & 28 & 28 & 28 & 7 \\
\hline August & I I I. 5 & 236.9 & 348.4 & 29.6 & $3 I$ & $3 I$ & 31 & 3 & 5 I 5.9 & 50.3 & 29 & 29 & 29 & 7 \\
\hline September & 89.3 & I69.0 & 258.3 & 35.8 & 29 & 28 & 24 & 4 & 477.3 & 54.0 & 29 & 29 & 28 & 6 \\
\hline Oktober & 76.0 & I 37.5 & 213.5 & 23.0 & 22 & $2 \mathrm{I}$ & I9 & o & 281.2 & 49.7 & 20 & 20 & 19 & 3 \\
\hline November & 52.6 & $5 . \mathrm{I}$ & 57.7 & 19.7 & I 2 & 9 & 8 & $\mathrm{o}$ & 76.1 & 22.0 & I I & I I & 10 & o \\
\hline Dezember . & 0.1 & I 4.9 & I 5.0 & 13.5 & 9 & 2 & 2 & $\mathrm{o}$ & 47.0 & 14.3 & 4 & 4 & 4 & o \\
\hline Jahır . & 632.9 & 1023.4 & 1656.3 & 55.1 & 207 & 182 & 161 & 13 & 2556.9 & 54.6 & 183 & 183 & 181 & 27 \\
\hline
\end{tabular}

Duala. Hafenamt.

Meanja. Pflanzung.

\begin{tabular}{|c|c|c|c|c|c|c|c|c|c|c|c|c|c|c|}
\hline \multirow[b]{2}{*}{1906} & \multicolumn{4}{|c|}{ Regenmenge in $\mathrm{mm}$} & \multicolumn{4}{|c|}{ Anzahl der Regentage } & \multicolumn{2}{|c|}{$\begin{array}{l}\text { Regenmenge } \\
\text { in } \mathrm{mm}\end{array}$} & \multicolumn{4}{|c|}{ Anzah1 der Regentage } \\
\hline & $6 \mathrm{a}$ & $6 \mathrm{p}$ & Summe & $\begin{array}{l}\text { Max. } \\
\text { in } \\
24 \text { St. }\end{array}$ & im & $\begin{array}{c}\mathrm{mi} \\
0.2 \\
\mathrm{~mm} \\
\end{array}$ & $\begin{array}{c}\text { mehr } \\
\text { I.o } \\
\text { mm }\end{array}$ & $\begin{array}{l}1 \mathrm{~s} \\
25.0 \\
\mathrm{~mm} \\
\end{array}$ & Stumme & $\begin{array}{c}\text { Max. } \\
\text { in } \\
24 \text { St. }\end{array}$ & $\begin{array}{l}\text { im } \\
\text { allg. }\end{array}$ & $\begin{array}{c}\begin{array}{c}\text { mit } \\
0.2 \\
\mathrm{~mm}\end{array} \\
\end{array}$ & $\begin{array}{c}\text { mehr } \\
\mathrm{I.o} \\
\mathrm{mm}\end{array}$ & $\begin{array}{l}\text { als } \\
25.0 \\
\mathrm{~mm} \\
\end{array}$ \\
\hline anuar & 2.4 & $23 \cdot 5$ & 25.9 & $24 \cdot 3$ & 3 & 3 & I & $\mathrm{O}$ & I 7.0 & I 7.0 & I & I & I & \\
\hline Febr & I66. I & & I 86.6 & 4 & 8 & 8 & 8 & 2 & 39.0 & I 8.0 & 5 & 5 & 4 & \\
\hline März & (I I I O. 3) & (I35.7) & 246.0 & $(80.0)$ & 9 & 9 & 9 & 6 & 36.5 & 21.0 & 4 & 4 & 3 & $\mathrm{O}$ \\
\hline April & 180.6 & 81.9 & 262.5 & 35.4 & 19 & I9 & I9 & 3 & 173.0 & 28.0 & 13 & I 3 & I3 & I \\
\hline Mai & 227.8 & 176.3 & 404. I & 99.2 & 24 & 24 & 20 & 7 & 240.0 & 74.0 & I 3 & I 3 & I 2 & \\
\hline Jun & 407.6 & 70.6 & 478.2 & 82.5 & 23 & 22 & 22 & 7 & I98.5 & 52.0 & I7 & I 7 & I 7 & \\
\hline Jul & 473.4 & 390.4 & 863.8 & 204.9 & 29 & 29 & 28 & I I & 43 I.O & 77.0 & 24 & 24 & 24 & \\
\hline Aug & 339.9 & I7 & 518.6 & 69.4 & 29 & 29 & 27 & 7 & |1) 379.5 & 38.0 & $>25$ & $(25)$ & (25) & \\
\hline ber & 350.7 & 203.6 & 554.3 & I I 2.5 & 29 & 29 & 26 & 7 & 317.5 & $4 \mathrm{I} . \mathrm{O}$ & $\mid>20$ & (20) & (20) & \\
\hline Okto & IO9.I & 149.5 & 258.6 & 38.3 & 24 & $2 \mathrm{I}$ & I 7 & 5 & 297.0 & 99.0 & I 4 & I 4 & I3 & \\
\hline Nove & I 45.8 & 40 & 186.7 & 67.8 & 20 & I4 & I 3 & 2 & 107.0 & 34.0 & 7 & 7 & 7 & \\
\hline Dezember & 145.3 & 23.1 & I 68.4 & 52.1 & 14 & I 3 & I I & 3 & 42.0 & 28.0 & 2 & 2 & 2 & \\
\hline Jahr . & 2659.0 & 1494.7 & 1453.7 & 204.9 & 231 & 220 & 201 & 60 & 2278.0 & 99.0 & $\mid>145$ & $(145$ & $(141)$ & $(2$ \\
\hline
\end{tabular}


Groß-Batanga. Kathol. Mission.

Ekona. Pflanzung.

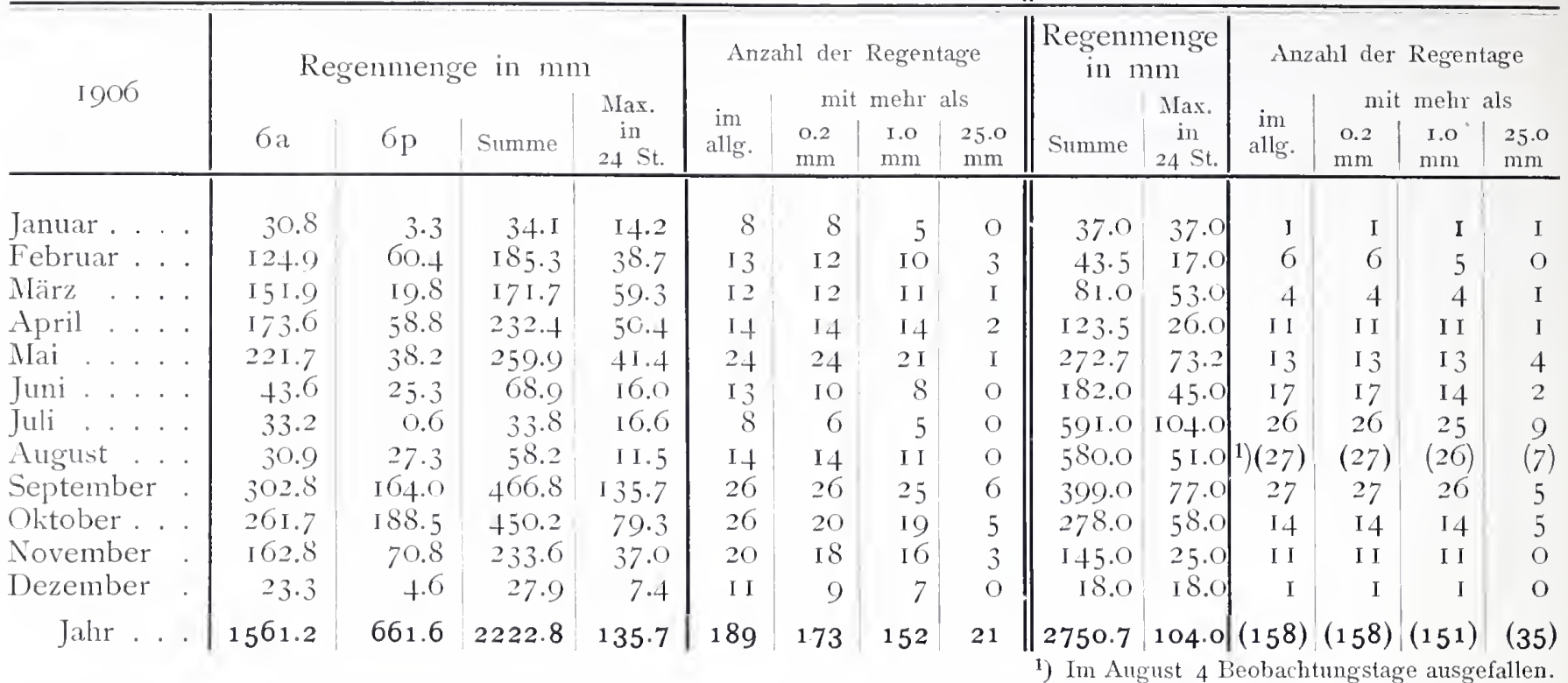

Debundscha. Pflanzung.

Hermannshöhe (Koke). Pflanzung.

\begin{tabular}{|c|c|c|c|c|c|c|c|c|c|c|c|c|c|c|}
\hline \multirow{3}{*}{1906} & \multicolumn{4}{|c|}{ Regenmenge in $\mathrm{mm}$} & \multicolumn{4}{|c|}{ Anzahl der Regentage } & \multicolumn{2}{|c|}{$\begin{array}{c}\text { Regenmenge } \\
\text { in } \mathrm{mm}\end{array}$} & \multicolumn{4}{|c|}{ Anzah1 der Regentage } \\
\hline & & & & Max. & & & mehr & & & Max. & & mit & mehr a & \\
\hline & $6 \mathrm{a}$ & $6 \mathrm{p}$ & Summe & $\begin{array}{c}\text { in } \\
24 \mathrm{St} .\end{array}$ & allg. & $\begin{array}{l}0.2 \\
\mathrm{~mm} \\
\end{array}$ & $\begin{array}{r}\mathrm{I} . \mathrm{O} \\
\mathrm{mm} \\
\end{array}$ & $\begin{array}{l}25.0 \\
\mathrm{~mm}\end{array}$ & Summe & $\begin{array}{c}\text { in } \\
24 \mathrm{St} .\end{array}$ & allg. & $\begin{array}{l}0.2 \\
\mathrm{~mm}\end{array}$ & $\begin{array}{r}\mathrm{I} . \mathrm{O} \\
\mathrm{mm} \\
\end{array}$ & $\begin{array}{l}25.0 \\
\mathrm{~mm} \\
\end{array}$ \\
\hline Januar . . & 139.0 & 45.0 & 184.0 & 86.0 & IO & IO & 8 & 2 & 25.0 & 25.0 & I & I & $\mathrm{I}$ & $\mathrm{O}$ \\
\hline Februar. & 393.5 & $3 \mathrm{I} . \mathrm{O}$ & 424.5 & 76.0 & 20 & 20 & 17 & 6 & 一 & - & 一 & - & 一 & - \\
\hline März . . . & +46.5 & 27.0 & 473.5 & 134.0 & I9 & 19 & 16 & 6 & 29.0 & I I.O & 6 & 6 & 6 & $\mathrm{O}$ \\
\hline April. . . & 160.0 & 417.0 & 577.0 & 128.5 & 24 & 24 & 22 & 5 & 129.5 & 29.0 & It & I 4 & I 3 & I \\
\hline Mai . . . & $604 \cdot 5$ & 132.0 & 736.5 & I 24.0 & 27 & 27 & 25 & IO & 314.7 & 85.2 & I 4 & I 3 & I 3 & 4 \\
\hline Juni . . & I I I 6.5 & 488.5 & 1605.0 & 283.5 & 26 & 26 & 25 & I 2 & I 86.7 & 55.0 & I 5 & I 5 & I 3 & I \\
\hline Juli . . . & 1070.0 & 527.5 & I 597.5 & 295.0 & $3^{\circ}$ & 30 & 30 & I 5 & 476.0 & 84.6 & 29 & 29 & 28 & 6 \\
\hline August . . & IOOO. 5 & 295.5 & I 296.0 & I 61.5 & 27 & 27 & 27 & I 4 & 460.0 & $47 \cdot 5$ & $3 \mathrm{I}$ & 29 & 29 & 5 \\
\hline September & 1218.5 & 391.0 & I 609.5 & I 86.0 & 29 & 29 & 29 & 23 & 544.7 & I I 4.9 & 29 & 28 & 28 & 8 \\
\hline Oktober & 982.0 & 258.0 & 1240.0 & I I I.O & 29 & 27 & 27 & I 8 & 357.6 & 59.2 & 22 & 20 & 20 & 7 \\
\hline November & 305.0 & I 1.7 & 316.7 & 59.0 & 25 & 22 & $2 \mathrm{I}$ & 4 & 153.3 & 29.0 & I I & I I & I I & I \\
\hline Dezember & 265.8 & 82.5 & 348.3 & 43.5 & 25 & 20 & I 8 & 8 & 25.0 & I 8.0 & 2 & 2 & 2 & $\mathrm{O}$ \\
\hline Jahr & 7701.8 & 2706.7 & 10408.5 & 295.0 & 291 & 281 & 265 & 123 & )$(2701.5$ & $(114.9)$ & $(174)$ & $(168)$ & $(164)$ & (33) \\
\hline
\end{tabular}

Jabassi. Bezirlisamt.

Logobaba bei Duala. Bergwerksstation.

\begin{tabular}{|c|c|c|c|c|c|c|c|c|c|c|c|c|c|c|c|c|}
\hline \multirow[b]{2}{*}{1906} & \multicolumn{4}{|c|}{ Regenmenge in $\mathrm{mm}$} & \multicolumn{6}{|c|}{ Anzahl der Regentage } & \multicolumn{2}{|c|}{$\begin{array}{l}\text { Regenmenge } \\
\text { in } \mathrm{mm}\end{array}$} & \multicolumn{4}{|c|}{ Anzahl der Regentage } \\
\hline & $6 \mathrm{a}$ & $6 \mathrm{p}$ & Summe & $\left|\begin{array}{c}\text { Max. } \\
\text { in } \\
24 \mathrm{St}\end{array}\right|$ & $\begin{array}{l}\mathrm{im} \\
\text { allg. }\end{array}$ & $\begin{array}{c}\text { mit } \\
0.2 \\
\mathrm{~mm}\end{array}$ & $\begin{array}{l}\text { mehr } \\
\left|\begin{array}{c}\mathbf{1} .0 \\
\mathrm{~mm}\end{array}\right|\end{array}$ & $\begin{array}{l}\text { a1s } \\
25 \cdot 0 \\
\mathrm{~mm}\end{array}$ & K & 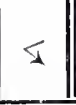 & Summe & $\begin{array}{c}\text { Max. } \\
\text { in } \\
24 \text { St. }\end{array}$ & $\begin{array}{l}\operatorname{lm} \\
\text { allg. }\end{array}$ & $\begin{array}{l}\quad \mathrm{mi} \\
0.2 \\
\mathrm{~mm} \\
\end{array}$ & $\begin{array}{c}\text { mehr } \\
\mathbf{I} . o \\
\mathrm{mmm}\end{array}$ & $\begin{array}{l}\text { als } \\
25.0 \\
\mathrm{~mm}\end{array}$ \\
\hline Januar & - & & I 5.9 & I I.9 & 2 & 2 & 2 & $\mathrm{O}$ & - & - & 30.5 & 24.7 & 3 & 2 & 2 & $\mathrm{O}$ \\
\hline Februar . & $\ldots$ & & 93.8 & 32.8 & 9 & 9 & 8 & I & $\ldots$ & 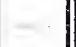 & $1+6.2$ & $35 . \mathrm{I}$ & IO & IO & 9 & 2 \\
\hline März . . . & 26.5 & 46.5 & 73.0 & 49.0 & 6 & 4 & 4 & I & 6 & 2 & 189.3 & 124.0 & 9 & 4 & 4 & 2 \\
\hline April. . . & 108.2 & 76.4 & 184.6 & 54.9 & 20 & I 5 & I 3 & 2 & I I & 6 & 215.1 & 58.8 & $2 \mathrm{I}$ & 15 & I 4 & 4 \\
\hline Mai ... . & 147.7 & 102.3 & 250.0 & 65.2 & I 5 & I 5 & I 2 & 3 & 9 & 3 & 206.6 & 27.6 & $2 \mathrm{I}$ & $2 \mathrm{I}$ & I 8 & 2 \\
\hline Juni . . & $3 \mathrm{I} 4 . \mathrm{I}$ & 163.0 & 477.1 & 92.9 & 23 & 22 & 20 & 5 & 4 & I & 475.3 & I09.8 & 27 & 26 & 23 & 5 \\
\hline Juli . . . & I 17.8 & I 80.5 & 298.3 & 38.3 & 29 & 26 & 24 & 5 & 2 & $\mathrm{O}$ & 1) $(684.0)$ & 107.0 & 25 & 25 & 25 & I I \\
\hline August. . & $2 \mathrm{I} 8 . \mathrm{I}$ & I 38.3 & 356.4 & 44.2 & $3 x$ & 29 & 28 & 5 & + & $\mathrm{O}$ & 384.8 & 40.8 & 28 & 27 & 27 & 3 \\
\hline September & $393 \cdot 3$ & I 25.8 & 519.1 & IO2.I & 29 & 29 & 28 & 6 & 4 & 4 & $647 \cdot 5$ & 96.9 & 30 & 28 & 26 & 8 \\
\hline Oktober. & 266.5 & 3 I 5.1 & 581.6 & 96.7 & 27 & 26 & 23 & 8 & I I & I & 2) 408.3 & 57.9 & $(22)$ & $(20)$ & (I 8$)$ & (5) \\
\hline November & 103.2 & 36.6 & I 39.8 & 31.7 & I I & I I & 9 & I & 8 & 2 & 3) (195.0) & 39.0 & (I4) & (I 3$)$ & (I 2) & (3) \\
\hline Dezember & 6.2 & I 5.6 & $2 \mathrm{I} .8$ & I 0.5 & 5 & 3 & 3 & $\mathrm{O}$ & 2 & $\mathrm{O}$ & - & - & - & - & 一 & - \\
\hline Jahr & $(1701.6)$ & $(1200.1)$ & 3011.4 & 102.1 & 207 & 191 & $|174|$ & 37 & $(61$ & 19)\| & $\left(35^{8} 3.0\right)$ & 124.0 & $(210)$ & (191) & $(178)$ & (45) \\
\hline
\end{tabular}


Kampo. Reg. Station.

Duala. Doktorhaus.

\begin{tabular}{|c|c|c|c|c|c|c|c|c|c|c|c|c|c|c|c|c|}
\hline \multirow[b]{2}{*}{1906} & \multicolumn{4}{|c|}{ Regenmenge in $\mathrm{mm}$} & \multicolumn{4}{|c|}{ Anzah1 dex Regentage } & \multicolumn{2}{|c|}{$\begin{array}{l}\text { Regenmenge } \\
\text { in } \mathrm{mm}\end{array}$} & \multicolumn{6}{|c|}{ Anzahl der Regentage } \\
\hline & $6 a$ & $6 \mathrm{p}$ & Summe & $\begin{array}{c}\text { Max. } \\
\text { in } \\
24 \text { St. }\end{array}$ & $\begin{array}{l}\text { im } \\
\text { allg. }\end{array}$ & $\begin{array}{r}\mathrm{m} \\
0.2 \\
\mathrm{~mm} \\
\end{array}$ & $\begin{array}{c}\mathrm{mehx} \\
\mathrm{I.0} \\
\mathrm{mm} \\
\end{array}$ & $\begin{array}{l}1 \mathrm{~s} \\
25.0 \\
\mathrm{~mm} \\
\end{array}$ & Summe & $\begin{array}{c}\text { Max. } \\
\text { in } \\
24 \text { St. }\end{array}$ & im & \begin{tabular}{|c|} 
mit \\
0.2 \\
$\mathrm{~mm}$
\end{tabular} & $\begin{array}{l}\text { mehr } \\
\mid \begin{array}{l}\mathrm{I} . \mathrm{o} \\
\mathrm{mm}\end{array} \\
\end{array}$ & $\begin{array}{r}2 \text { als } \\
25.0 \\
\mathrm{~mm} \\
\end{array}$ & 原 & $\underset{s}{\operatorname{nim}}$ \\
\hline us & - & 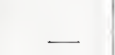 & $\ldots$ & - & - & - & - & - & 44.7 & 35.8 & 5 & 3 & 2 & I & 6 & $\mathrm{O}$ \\
\hline ebro & - & _ & - & - & $\ldots$ & - & - & - & 238.7 & 78.7 & I I & I I & IO & 2 & I 3 & I \\
\hline Tär: & 一 & - & 一 & 一 & - & - & - & - & 359.8 & 72.5 & I6 & 8 & 8 & 7 & I I & 2 \\
\hline pri & - & - & - & - & & - & - & - & 289.8 & 50.0 & $2 \mathrm{I}$ & I9 & 19 & 3 & IO & 2 \\
\hline (iai $\left.{ }^{1}\right)$ & $(87.8)$ & $(48.0)$ & $(35.8)$ & $(67.6)$ & (I 3$)$ & (1 3$)$ & (IO) & (2) & $529 \cdot 3$ & $\mathrm{r} 25.8$ & 27 & 24 & 22 & 9 & I I & o \\
\hline fut & 66.7 & $4.8^{\prime}$ & 71.5 & 24.0 & I I & I I & 9 & o & 700.0 & 232.1 & 28 & 24 & 20 & 9 & 5 & o \\
\hline ju & 16.6 & o. & 166 & & 3 & 3 & 3 & 0 & IO 43.0 & 243.5 & 29 & 29 & 28 & I I & I & o \\
\hline Augu & 30.7 & 9.2 & 39.9 & 18.9 & 8 & 7 & 7 & 0 & 850.0 & 81.7 & $3 \mathrm{I}$ & 29 & 28 & I 4 & 3 & 0 \\
\hline & 163.2 & 89.6 & 252.8 & 74.6 & 24 & 23 & $2 \mathrm{I}$ & 3 & 793.6 & I 49.3 & 29 & 29 & 27 & I I & 4 & I \\
\hline $\mathrm{lt}^{2} \mathrm{~b}$ & 141.0 & 315.2 & 456.2 & 87.0 & 29 & 28 & 25 & 6 & - & - & - & - & - & - & - & - \\
\hline Nove & 267.7 & 68.7 & 336.4 & 87.5 & 16 & I 6 & I 6 & 4 & - & - & 一 & - & - & - & - & - \\
\hline Dezer & 22.6 & 50.4 & 73.0 & 50.0 & 5 & 5 & 4 & I & - & 一 & - & - & - & - & - & - \\
\hline Jahr & - & - & - & - & - & - & - & - & $\ldots$ & - & - & - & - & - & - & - \\
\hline
\end{tabular}

1) Die Beobachtungen begannen am 7. Mai.

Pflanzung Dipikar (Nassovia) am Kampo.

\begin{tabular}{|c|c|c|c|c|c|c|c|c|c|}
\hline \multirow{2}{*}{1906} & \multicolumn{4}{|c|}{ Regenmenge in $\mathrm{mm}$} & \multicolumn{4}{|c|}{ Anzabl der Regentage } & \\
\hline & $6 a$ & $6 \mathrm{p}$ & Summe & $\begin{array}{c}\text { Max. } \\
\text { in } \\
24 \text { St. } \\
\end{array}$ & $\begin{array}{l}\text { im } \\
\text { allg. }\end{array}$ & $\begin{array}{c}\mathrm{mi} \\
0.2 \\
\mathrm{~mm} \\
\end{array}$ & $\begin{array}{c}\text { mehr } \\
\text { r.o } \\
\mathrm{mm} \\
\end{array}$ & $\begin{array}{l}1 \mathrm{~s} \\
25.0 \\
\mathrm{~mm}\end{array}$ & \\
\hline Januar & 133.3 & 0.0 & I 33.3 & 46.0 & I I & IO & 9 & 2 & Vom 23. Juni bis I0. August \\
\hline Februar & $\mathrm{IO} 3.4$ & 75.8 & 179.2 & 39.6 & I I & I I & I I & I & wurden nur zwei un \\
\hline März & 269.6 & 14.2 & 283.8 & 58.0 & I 2 & I 2 & I I & 4 & bedeutende Regenfälle unter \\
\hline April & 244.9 & 88.8 & 333.7 & 135.0 & 17 & I7 & I4 & 4 & I mm notiert, die Trocken \\
\hline Mai & 56.3 & 42.2 & 98.5 & 23.7 & 12 & 12 & IO & $\mathrm{o}$ & zeit dauerte also 49 Tage \\
\hline Juni & 16.2 & 9.9 & 26. I & 6.4 & I I & 9 & 7 & 0 & oder, da nach dem I I. August, \\
\hline Juli & 1.7 & 0.0 & I.7 & 0.9 & 3 & 2 & $\mathrm{O}$ & o & an dem nur ein schwacher \\
\hline August & II.I & 0.3 & I I.4 & 6.9 & б́ & 5 & 3 & 0 & Regenfall von $1.6 \mathrm{~mm}$ vor \\
\hline September & II 5.9 & 95.4 & $2 \mathrm{II} .3$ & 63.4 & 23 & 23 & $2 \mathrm{I}$ & 3 & kam, wieder absolute \\
\hline Oktober & $2 \pi 4.2$ & 318.8 & 533.0 & I I 7.5 & 27 & 27 & 26 & 7 & Trockenheit bis inkl. den \\
\hline November & I 50.4 & I06.8 & 257.2 & 61.0 & I 5 & I 5 & I3 & I & 23. August herrschte, \\
\hline Dezember. & 75.6 & 35.2 & I IO 0.8 & 43.0 & 9 & 9 & 9 & I & 62 Tage. \\
\hline Jahr & 1392.6 & 787.4 & 2180.0 & 135.0 & 157 & 152 & 134 & $23 \mid$ & \\
\hline
\end{tabular}

Regenmengen in $\mathrm{mm}$ an den Pflanzungsstationen am Kamerunberg.

\begin{tabular}{|c|c|c|c|c|c|c|c|c|c|c|c|}
\hline 1906 & Victoria & $\begin{array}{l}\text { Krater- } \\
\text { vorwerk }\end{array}$ & Ngeme & $\begin{array}{l}\text { Mittel- } \\
\text { vorwerk }\end{array}$ & Limbe & Bussumbu & $\begin{array}{l}\text { Neu-- } \\
\text { Buana }\end{array}$ & Ebongo & $\begin{array}{l}\text { Bombe } \\
\text { Bakundu }\end{array}$ & Bolifamba & Soppo \\
\hline Januar & 105 & I 25 & I 55 & 125 & 146 & I 50 & I 43 & 148 & - & - & - \\
\hline Februar & - & - & - & - & - & - & - & - & - & - & - \\
\hline März & 53 & 26 & 25 & 26 & 30 & 40 & 54 & 77 & - & - & - \\
\hline April & 109 & 93 & 147 & I 28 & I 48 & I I 8 & I 66 & I 37 & - & - & - \\
\hline Mai. & 363 & $29 \mathrm{I}$ & 416 & 297 & 348 & 300 & 242 & I 99 & - & - & - \\
\hline Juni & 946 & IO44 & 1082 & IIIO & 1000 & $87 \mathrm{I}$ & 985 & 524 & 234 & - & - \\
\hline Juli & I I65 & 1474 & I 285 & I380 & I 545 & I 492 & I594 & I08 I & 437 & 605 & IOI 5 \\
\hline August & ro68 & 1069 & $127 \mathrm{I}$ & 1136 & 1024 & 979 & I 232 & 842 & 473 & 501 & $7 \mathrm{OI}$ \\
\hline September & 676 & $8 \mathrm{I} 5$ & 865 & 600 & 708 & 601 & 782 & 619 & 455 & 494 & - \\
\hline Oktober & 432 & 462 & 544 & 427 & 445 & 397 & 332 & 344 & 354 & 372 & 415 \\
\hline November & 130 & 120 & 167 & 128 & I 29 & 97 & I 12 & 95 & I 39 & I 35 & I 2 I \\
\hline Dezember & 44 & 55 & 42 & $4 \mathrm{I}$ & 22 & 22 & 22 & 28 & 8 & - & 37 \\
\hline Jahr & 5091 & $>5574$ & $>5999$ & $>5398$ & $>5545$ & $>5067$ & $>5664$ & $>4094$ & - & - & - \\
\hline
\end{tabular}




\section{Aus dem deutsch-ostafrikanischen Schutzgebiete.}

\section{Dritter Bericht über die landeskundliche Expedition des Herrn Dr. Fritz Jäger in Deutsch-0stafrika.}

Herr Dr. Fritz Jäger, über dessen Reise wir zuletzt im 2. Heft dieser Zeitschrift, S. $106 \mathrm{ff}$, berichtet haben, hat seitdem seine Forschungen im Vulkan- und Seengebiet des großen , Ostafrikanischen Grabens" fortgesetzt und darüber Berichte eingesandt, aus denen wir das Nachstehende mitteilen.

Er schreibt aus Ngoróngoro, nördlich des Manjarasees, den 7. Februar 1907:

»Von unserer ersten Reise von Ngoróngoro aus sind wir befriedigt zurückgekehrt. Die Reise war der Untersuchung der beiden großen Vulkane Déani und Lemagrut (Lerobi und Lmagro der Karten) und des nordöstlichen Ejassisees gewidmet. Leider hat uns das Wetter nicht alle die erhofften topographischen und geographischen Resultate gewinnen lassen. Hätten vvir auf dem Déani und Lemagrut klares Wetter gehabt, so hätte dieser Umstand uns eine genaue Karte vom Ejassisee verschafft. Aber Nebel und Regen gestatteten uns nur beschränkte Übersicht. Auch als ich zuletzt noch auf den Gipfel des zwischen Déani und Lemagrut liegenden Malanjakraters stieg, der ein vorzüglicher Ubersichtspunkt ist, geriet ich in Nebel und kounte absolut nichts machen. Trotzdem hoffe ich, daß ich die Karte des nördlichen Ejassisees einigermaßen herausgearbeitet habe.

Leider mußte ich dieses wichtige Gebiet in der Regenzeit aufsuchen, wo so leicht Nebel die Aussicht benehmen. In der Trockenzeit ist es einfach unmöglich, sich länger in diesem Landstrich aufzuhalten, außer vielleicht mit ganz kolossalen Geldmitteln, die es ermöglichen, eine zweite große Karawane mit der Herbeischaffung von Wasser zu beschäftigen, sonst verdurstet man. Wir muBten uns deshalb im Oktober mit einem kleinen Vorstoß begnügen.

Der Déani, dessen höchsten Gipfel Baumann als Lerobi auf der Karte verzeichnet, ist ein mäch- tiger, $3200 \mathrm{~m}$ hoher Vulkan, der sich aus dem Ejassigraben erhebt und ihn zusammen mit dem Lemagrut fast ganz abschlieft. Er hat eine gewaltige Caldera von vielleicht $4 \mathrm{~km}$ Durchmesser. Der Krater und die Außenhänge des Vulkans sind großenteils mit Urwald, in den höchsten Teilen meist mit Bambus bedeckt.

Der Lemagrut besteht aus einer Somma und einem stark zerschluchteten Zentralkegel, jedoch ohne Krater. Er sitzt auf der Hochfläche nordwestlich des nordöstlichen Ejassigrabenrandes auf, aber seine Laven sind über den Grabenrand hinabgeflossen und vereinigen sich mit denen des Déani $\mathrm{zu}$ einem $2500 \mathrm{~m}$ hohen Hochland. Auf diesem Hochland sitzt der Malanjakrater (etwa $4 \mathrm{~km}$ Durchmesser) auf, der jedoch nur $\mathrm{zu} 2 / 3$ von einem Kraterwall umgeben ist.

Wir folgten dem nordwestlichen Ejassigrabenrand vom Lemagrut an etwa $30 \mathrm{~km}$ nach SW, und ich konnte hier außer topographischen Ergebnissen hübsche Aufschlüsse über die Telktonik des alten Rumpfgebirges erhalten, das durch den Grabenrand verworfen ist.

Vor Antritt dieser Tour nahm ich den Ngoróngorokessel auf, durch Meßtischpeilungen von drei Punkten aus. Der Ngoróngoro mit $20 \mathrm{~km}$ Durchmesser dürfte wohl der größte Krater der Erde sein. Vom Ngoróngorokraterrand erhielt ich eine vorläufige Übersicht über das Verhältnis des Ejassiund des Hohenlohegrabens zum großen ostafrikanischen Graben. Das ist ja ein Hauptproblem der Expedition, dessen weitere genauere Untersuchung einer Reise von hier nach Iraku und zurück vorbehalten bleibt.

Sobald die nächste Proviantkarawane eintrifft, hoffentlich heute, ziehen wir wieder los nach den großen Vulkanen Elaneirobi, Olmoti, Ossirwa und Lomalasin im $\mathrm{N}$ und $\mathrm{NO}$ von hier. Wir brauchen für unsere Reisen kaum 30 Träger, aber die übrigen 
30 sind ständig unterwegs, um aus Nachbarlandschaften Proviant für diese zu holen.

Nach dieser Vulkantour kommt noch die Reise nach Iraku und dann eine Basismessung hier im Ngoróngoro als Grundlage für die Karten. Sollten dann die Mittel noch reichen, so wollen wir noch dèn Gelei und Doenye Ngai besteigen und dann etwa über Sonjo-Olgoß_-Ikoma nach Muansa zurückkehren.«

Dem nächsten Bericht des Herrn Dr. Jäger aus Iraku, den 15. März 1907, entnehmen wir folgendes:

"Denken Sie sich die phlegräischen Felder bei Neapel, aber im zehnfachen Maßstabe, dann erhalten Sie einen Begriff davon, wie es um Ngoróngoro, im Lande der Riesenkrater, aussieht. Dort bei Neapel Hügel von 300 bis $400 \mathrm{~m}$, Krater von 300 bis 500 und mehr Meter Durchmesser; einer erreicht sogar $2 \mathrm{~km}$ Durchmesser. Hier Berge zwischen 3000 bis $4000 \mathrm{~m}$ Höhe, Krater von drei bis fünf und mehr Kilometer Durchmesser, und der Ngoróngorokrater sogar mit $20 \mathrm{~km}$ Durchmesser.

Vom IO. bis 27. Februar zogen wir in den hohen Vulkanbergen im NO des Ngoróngoro herum, bestiegen den Olmoti, den Elaneirobi, den Lomalasin und den Ossirwa und machten zuletzt noch eine Tour in den gewaltigen Elaneirobikrater (7 $\mathrm{km}$ Durchmesser), dem der Urwald seiner steilen Kraterwände und der Salzsee in seiner Tiefe einen ernsten, romantischen Charakter verleiht. Das Hauptergebnis ist ein Meftischblatt, auf dem diese Vulkane ziemiich eingehend dargestellt sind.

Die Basismessung in Ngoróngoro hatte ich schon vor dieser Reise ausgefuhrt. An sie bin ich im Begriff, eine Triangulation der ganzen Gegend (Land der Riesenkrater, nordöstlicher Ejassi- und Hohenlohegraben bis einschlieflich Iraku) anzuschließen. Natürlich kann ich allein hier keine so genaue Vermessung ausfuhren wie etwa die Grenzkommission, so sehr mir auch Herr Oehler die Sorge um die Verpflegung der Karawane abnimmt, was hier in diesen unbewohnten Gegenden keine einfache Sache ist. Dazu wäre namentlich eine vorherige Begehung des ganzen Gebietes und die Aufstellung von Sig. nalen erforderlich. Ersteres ist bei der uns zur Verfügung stehenden Zeit natürlich ausgeschlossen, letzteres nur in Ausnahmefällen möglich. Trotzdem glaube ich, daß auch eine so rohe Triangulation, wie ich sie mit meinen Mitteln nur ausführen kann, von bedeutendem Nutzen ist. Die Hauptpunkte werden immerhin mit einer für lange Zeit ausreichenden Genauigkeit festgelegt, und durch die Meßtischaufnahme von guten Übersichtspunkten aus wird das ganze Land erschlossen, nicht nur einzelne
Linien, wie bei der Routenaufnahme, und dazu noch mit viel größerer Genauigkeit als durch diese.

Unsere jetzige Reise am Nordostrande des Ejassisees vorbei hierher nach Iraku diente dem Zweck, den Anschluß an die früheren Aufnahmen in dieser Landschaft und am Hohenlohegraben herzustellen. Unliebsam gestört wird sie dadurch, daß Herr Oehler seit etwa zehn Tagen Fieber hat, das nicht weichen will. Ich gedenke nun auf die etwas eingehendere Aufnahme des Ländchens Iraku selbst 8 bis 14 Tage $z u$ verwenden. Wegen der wirtschaftlichen Interessen, die sich daran knüpfen, ist Iraku einer genaueren Aufnahme wert. Den Rückweg nach Ngoróngoro gedenken wir über Semdjukas Land zu nehmen, so daß dann die ganze Gegend bis zum Grabenrand bekannt sein wird. Von Ngoróngoro wollen wir womöglich einen Abstecher nach dem Geleivulkan machen und dann durch die Serengetisteppe nach Muansa marschieren. Wenn alles glatt geht, werden wir etwa Mitte Mai in Muansa eintreffen.«

Die letzte Nachricht von Herrn Dr. Jäger lautet folgendermaßen:

Auf dem Rückmarsch nach Muansa, den 2. Mai 1907.

"Mit Befriedigung kann ich Thnen jetzt den AbschluB der Expedition mitteilen. Nachdem mein Vetter Oehler wegen chronischer Malaria auf die weitere Mitarbeit verzichten mußte und von Iraku nach dem Sanatorium Wugire in West-Usambara abmarschiert war, trat auch ich am Io. April den Rückmarsch nach Ngoróngoro an. Ich ging diesmal diber das Mutiekplateau, das zwischen dem Grabenrand und dem SO-Abfall der Vulkane Déani, Ngoróngoro und Lomalasin liegt, und habe damit die letzte Lücke in den Aufnahmen der Gegend ausgefüllt. Mutiek scheint mir ein für europäische Besiedlung geeignetes Land zu sein, allerdings einstweilen nur für Viehzüchter; für Ackerbauer erst, wenn eine Bahn in die Nähe führt, die einen Absatz der Produkte ermöglicht. Außerdem besitzen wir am Abfall der genannten Vulkane sowie auf dem Plateau zwischen Iraku und Mutiek zwei Urwaldgebiete von zusammen, schätze ich, 90000 ha, die auch recht wertvoll werden können.

In Ngoróngoro vollendete ich meine Triangulation des Gebiets. Leider verhinderte die fast andauernde Bewölkung in der endlich eingetretenen Regenzeit die Ausführung einiger wünschenswerter Peilungen. Doch wird das gewonnene Material zur Berechnung der Punkte ausreichen. Am 23. April marschierte ich von Ngoróngoro ab in Eilmärschen, die nur durch eine geologische Untersuchung am NW-Rand der Balbalsenke unterbrochen wurden, 
über die Grassteppe Serengeti nach Meatu und bin nun auf dem Wege nach Muansa, wo ich am 7. Mai einzutreffen gedenke.

Ich bin recht befriedigt von der Expedition und ihren Ergebnissen, obwohl es natürlich von vornherein klar ist, daß nicht gerade auf alle damals aufgeworfenen Fragen die Antwort jetzt bereit sein kann. Die Erforschung des Landes war die Hauptaufgabe, und auf deren Lösung darf ich mit Genugtuung zurïckblicken. Im Gegensatz zu der mehr extensiven Forschungsarbeit älterer Expeditionen, wie Baumanns und Werthers, handelte es sich jetzt schon un eine eingehendere Erforschung des Gebiets, vor allem darum, nicht nur einzelne Routen, sondern zusammenhängend das ganze Gebict kennen zu lernen. In dieser Hinsicht bin ich über die ursprünglichen Ziele hinausgegangen durch die Triangulation und die MleBtischaufnahmen des größten Teiles meines Forschungsgebietes. So werden wir eine Karte gewinnen, wie sie außer den nach allen Regeln der Kunst vermessenen Grenzgebieten und in Usambara ihresgleichen in den Kolonien noch nicht hat. Ich habe mich natürlich nicht auf die rein topouraphische Arbeit beschränkt; das hätte ja auch cin Landmesser tun können. Stets habe ich die geographische Aufgabe, die Erkenntnis der Landesnatur, ihrer verschiedenen Falitoren und ihrer Wechselwirkung und Verbreitung im Auge behalten. Und wie das topographische Material, welches die, wie ich hoffe, solide Grundlage dieser Erkenntnis bildet, in den Meßtischblättern, so habe ich die geographischen Verhältnisse in den Beschreibungen meines Tagebuches niedergelegt.

Was den äuBeren Verlauf der Expedition be trifft, so kann man nicht sagen, daß sie vom Glück begünstigt war. Anfänglich erschwerte die Aufstandsgefahr in Iraku und Unyamwesi die Dispositionen sehr. Die in Daressalam zurückgelassenen Lasten konnten nicht rechtzeitig nach Muansa geschickt werden, so daß wir dort zu manchen Neuanschaffungen genötigt waren. Erst spät und auf sehr umständliche Weise konnten wir die Lasten erhalten. Ferner hatten wir wenig Glüick mit Fuihrern. Meist hatten wir gar keine, was das Reisen recht erschwerte. Man verlor viel Zeit mit
Wassersuchen und muBte auch manches Projelit aufgeben wegen der Gefahr, kein WVasser zu finden. Hatten wir Führer, so wußten sie günstigstenfalls den WTeg und die Wasserstellen, aber über Namen und dergleichen konnten sie in den seltensten Fällen einigermaßen zuverlässige Auskunft geben.

Unser Gesundheitszustand war recht wenig befriedigend. Erst hatte Oehler acht Wochen lang mit einer Fußverletzung zu tun. Dann mußten wir beide dem Fiebernest Muansa unseren Tribut reichlich zollen. Zuletzt bekam Oehler noch eine so hartnäckige chronische Malaria, daß er von Iraku aus nach Usambara marschieren mußte, um im Sanatorium Wugire Genesung zu suchen.

Ich will indes nicht unterlassen, einen für die Expedition recht glücklichen Umstand zu nennen: das ausnahmsweise späte Einsetzen der großen Regenzeit (8. April in Iraku). Eine heftige Regenzeit hätte unsere Arbeiten äußerst beeinträchtigen können. So aber hat uns das Wetter nur in wenigen Fällen einen Strich durch die Rechnung gemacht.

Das finanzielle Ergebnis ist recht günstig. Es dürften wohl noch 3000 bis 4000 Mark übrig bleiben. Ich hoffe, daß diese der Veröffentlichung meiner Forschungen zugute kommen werden.

Diesem Brief ist eine Nachschrift angefügt aus Muansa, den 7. Mai 1907.

"Soeben kurz vorPostschlußangekommen. Besten Dank für thren Brief vom 27. März 1907. Von Oehler erhielt ich ein Telegramm aus Tanga, daß er seit Moschi wieder gesund ist. Da ich hier mit Auflösung der Karawane, Verkauf usw. drei bis vier Tage zu tun habe, so kann ich leider nicht den morgen früh abgehenden Dampfer nach Port Florence benutzen, sondern erst den nächsten, am I7. Mai. VVerde also zweite Hälfte Juni in Deutschland ankommen.

Dies ist denn auch geschehen. Beide Herren sind gegen Ende Juni in guter Gesundheit wieder in der Heimat eingetroffen.

Die Kommission für die landeskundliche Erforschung der Schutzgebiete.

I. A.

Hans Meyer, Vorsitzender. 


\title{
Aus dem deutsch-südwestafrikanischen Schutzgebiete.
}

\section{Das Klima von Swakopmund.}

\author{
Von A. Guiland.
}

\section{Die geographische Lage.}

Swakopmund liegt $14^{\circ} 32^{\prime}$ östlich Greenwich und unter $22^{\circ} 42^{\prime}$ südlicher Breite, an der Westküste des südwestafrikanischen Schutzgebiets fast genau in der Mitte zwischen dem nördlichen und südlichen Grenzflusse, dem Kunene und dem Oranje. Ungefähr I $\mathrm{km}$ südlich von Swakopmund mündet der Swakop in den Atlantischen Ozean; derselbe fuhrt jedoch nur Wasser ins Meer, wenn im Innern des Schutzgebiets außerordentlich große Regengüsse erfolgt sind. Die Küste wird bespuilt vom Atlantischen Ozear mit einer von Suiden nach Norden gerichteten auffallend kalten Strömung, dem Benguelastrom.

Das Küstengebiet selbst ist fast regen- und vegetationslos und wird von mehreren FluBbetten durchzogen, die aber ähnlich wie der Swakop mit Ausnahme des Oranje und Kunene - nur selten Wasser fuhren. Dieser Küstenstreifen führt daher mit Recht den Namen "Namib«, d. h. Steinwüste; sie steigt nach Osten ziemlich gleichmäBig an, ist durchsetzt von zahlreichen Sanddunen und Felskuppen und erreicht an der Ostgrenze in einer Entfernung von etwa $60 \mathrm{~km}$ von der Küste eine ungefähre Höhe von 500 bis $600 \mathrm{~m}$.

Die meteorologischen Beobachtungen von Swakopmund fur die Jahre 1899 bis 1905 erstrecken sich auf Luftdruck, Luftemperatur, ihre Maximalund Minimalwerte, Bewölkung, Windrichtung und -Stärke, Gewitter, Wetterleuchten, Nebel, Regen und Brandung, und 2 war für die Termine $7 \mathrm{a}, 2 \mathrm{p}$ und $9 \mathrm{p}$.

Die monatlichen Mittelwerte sind alljährlich in den Mitteilungen aus den deutschen Schutzgebieten durch v. Danckelman veröffentlicht worden.

Der Leiter der meteorologischen Station Swakopmund, Wasserbauinspektor Ortloff, hat die Ergebnisse der Beobachtungen vom I. März I899 bis I. März 1902 zu einer kurzen Darstellung ${ }^{1}$ ) der klimatischen Verhältnisse dieses Ortes verwertet; dieselben erstrecken sich nur auf die Monatsmittel der absoluten und mittleren Temperaturmaxima und -Minima, eine graphische Darstellung der Windhäufigkeit und -Stärke sowie ihre Resultante nach Richtung und Stärke.

1) Ortloff, Der Bau des Hafens von Swakopmund. Zeitschrift für Bauwesen, 1904, S. 346 u. 670

Mitteilungen a. d. D. Schutzgebieten, XX. Band. III.
Die Darstellung ist aber mehr vom bautechnischen Standpunkt aus erfolgt; hier handelt es sich besonders um die extremen Werte; die Mittelwerte der Temperatur, welche aus dem arithmetischen Mittel vom mittleren Maximum und Minimum gebildet sind, geben zu hohe Werte; so beträgt zum Beispiel die mittlere Jahrestemperatur nach Ortloff $160^{\circ} 4$, während dieselbe nach den Beobachtungen von r 899 bis 1905 aus $1 / 3(7 a+2 p+9 p) ~ I 5 .{ }^{\circ} 2$ beträgt.

Es düfte daher nicht uninteressant sein, die jetzt vorliegenden Beobachtungen von 1899 bis 1905 zu einer Darstellung des Klimas von Swakopmund zu verwerten; zwar besitzen wir schon eine ähnliche Darstellung für die nur $23 \mathrm{~km}$ südlich gelegene Walfischbai von Sandmann, ${ }^{1}$ ) aber für die vorliegende Arbeit sind einmal exaktere Beobachtungen mit besseren Instrumenten (Aspirationsthermometer, Wildsche Windfahne und Stärketafel usw.) vorhanden, und dann ist die Abhandiung auch teilweise von anderen Gesichtspunkten (interdiurne Veränderlichkeit der Temperatur, Windrosen, mittlere Windrichtung, Föhnwinde) aus erfolgt.

Die vorliegende Arbeit beruht auf den in den "Mitteilungen aus den deutschen Schutzgebieten ", Jahrgang I 900 bis I906, veröffentlichten monatlichen Mittelwerten, die für die Jahre 1899 bis $1905 \mathrm{zu}$ einer Klimatabelle vereinigt wurden; die weiteren Untersuchungen wurden ermöglicht durch die gütige Überlassung der ausführlichen meteorologischen Beobachtungsjournale von Swakopmund.

Uber die Gründung und den Zweck der meteorologischen Station Swakopmund entnehmen wir einem Berichte von Ortloff 2 ) folgendes:

»Um über die klimatischen Verhältnisse der Westküste des Schutzgebiets an der Hand zuverlässiger Beobachtungen genauere Aufklärung zu erlangen, wurde vom Kaiserlichen Hafenbauamte eine meteorologische Station eingerichtet. Sie war zu Beginn des Jahres 1899 fertiggestellt; die Beobachtungen wurden seit dem 5. Januar desselben Jahres geführt. Sie finden täglich dreimal statt, um 7 Uhr morgens, 2 Uhr nachmittags und 9 Uhr abends mittlerer Ortszeit. Der Niederschlag wird nur am

1) Sandmann, Das Klima von Walfischbai. Paderborn Igor.

2) Zeitschrift für Bawwesen I904, S. 346 u. 670 . 
Morgen gemessen. Auf pünktliche Innehaltung dieser Zeitpunkte wird besonders geachtet, ebenso darauf, daß Luftwärme und Luftdruck möglichst gleichzeitig abgelesen werden. Außerdem werden noch die Luftfeuchtigkeit sowie Richtung und Stärke des Windes bestimmt. . . . . D Die Temperaturen des Meerwassers vor Swakopmund wurden täglich dreimal, morgens, mittags und abends, I m unter der Oberfläche gemessen; die Tagesunterschiede waren nur geringe. Dagegen zeigten sich durchweg Schwankungen der Meerestemperatur in den Jahreszeiten; es betrug die durchschnittliche Wärme im Sommer I $4 .{ }^{\circ} \mathrm{I}$, während sie in den Wintermonaten April bis September auf II. ${ }^{\circ} 5$ sank. Die durchschnittliche Jahrestemperatur betrug demnach 12. ${ }^{\circ} 8$. Die niedrigste Temperatur wurde im September I903 mit $9 .^{\circ} 3$, die höchste im März desselben Jahres mit I $4 .{ }^{\circ} 9$ beobachtet. "

Das als meteorologische Station dienende Bureaugebäude liegt $70 \mathrm{~m}$ vom Strande entfernt und 7 bis $8 \mathrm{~m}$ über Mittelwasser, $40 \mathrm{~m}$ südwestlich und $20 \mathrm{~m}$ nördlich befindet sich je ein ebenfalls einstöckiges Wohngebäude, sonst hat die Station eine freie Lage.

An den Beobachtungen selbst waren zehn Herren nacheinander beteiligt.

Es ist einleuchtend, daß bei dem oftmaligen Wechsel der Beobachter die Messungen selbst mit verschiedenem Interesse und Sachkenntnis ausgeführt worden sind; das geringste Vertrauen verdienen nach v. Danckelman ${ }^{1}$ ) die Beobachtungen vom Februar bis Oktober I905. Im allgemeinen kann man aber sagen, daß das vorliegende meteorologische Beobachtungsmaterial von Swakopmund das beste und vollständigste ist, welches wir überhaupt von Deutsch-Südwestafrika besitzen; es sind in der Beobachtungsperiode vom 5. Januar 1899 bis 3I. Dezember I905 nur an zwei Tagen die Beobachtungen eingestellt gewesen; auch die einzelnen Terminbeobachtungen zeigen geringe Lücken, die Jahrgänge I90I und 1902 sind vollständig lückenlos. Im ganzen sind die Temperaturbeobachtungen an 56 Terminen $=0.72 \mathrm{v}$. $\mathrm{H}$. ausgefallen.

Für die Zeit vom 5. Januar I 899 bis 3I. Dezember I905 liegen folgende ausführliche Beobachtungsergebnisse vor.

Für die Termine $7 \mathrm{a}, 2 \mathrm{p}$ und $9 \mathrm{p}$ :

I. Barometerablesungen auf $\mathrm{O}^{\circ}$ reduziert.

2. Ablesung des trockenen und feuchten Thermometers des Aspirations-Psychrometers.

3. Schätzung der Bewölkung (o wolkenlos, IO trüb). Skala.

4. Windrichtung und -Stärke nach zehnteiliger

1) Mitteil. I906, Heft 2, S. I 49.
Ferner wurden noch Maximum- und Minimumthermometer abgelesen, sowie die Erscheinung von Gewittern, Wetterleuchten, Regen, Nebel, starkem Ostwind mit Sandtreiben und Brandung notiert.

Die Messungen der Lufteuchtigkeit sind vom 29. September I 899 bis I2. Mai I 900 ausgefallen; die Berechnung der absoluten und relativen Luftfeuchtigkeit erfolgte nur für das Monatsmittel.

Seit dem Jahre 1903 sind auch Temperaturbeobachtungen des Meerwassers mit aufgenommen worden; es liegen jedoch nur Monatsmittel vor. Diese zeigen erhebliche Schwankungen in den einzelnen Monaten; im November und Dezember I 903 ergaben sie sogar höhere Werte als die Lufttemperatur, auch weichen sie von den Angaben Ortloffs für I 899 bis 1902 erheblich ab. Da nicht ersichtlich ist, wo die Temperaturmessung erfolgt ist und ob immer an derselben Stelle, so verdienen die Angaben vorläufig kein großes Vertrauen.

Die Nebelbeobachtungen scheinen von Oktober bis Dezember I 899 ausgefallen zu sein.

Der Zustand der Brandung wurde seit 1900 notiert, jedoch sind die Bezeichnungen in den einzelnen Jahren nicht gleichmäßig.

Über die meteorologischen Instrumente, ihre Aufstellung und Handhabung enthalten die Beobachtungsjournale leider keine Angaben.

\section{Die Lufttemperatur.}

Die Temperaturverhältnisse eines Ortes werden charakterisiert durch:

I. die Mittelwerte des Jahres, der Jahreszeiten, Monateund der einzelnen Beobachtungstermine;

2. die Wärmeschwankungen innerhalb dieser Zeitabschnitte (Amplituden);

3. die Abweichungen von den Normalmitteln (Anomalien);

4. die mittleren und absoluten Extreme;

5. ihre Veränderlichkeit.

Den kürzesten Ausdruck für die thermischen Verhältnisse eines Ortes bildet die mittlere Jahrestemperatur; sie beträgt für Swakopmund von I 899 bis I $90515.2^{\circ}$, eine im Vergleich zur geographischen Lage sehr niedrige Temperatur. Nach Spitaler ${ }^{1}$ ) beträgt dieselbe entsprechend den geographischen Positionen:

\begin{tabular}{lrrr} 
& Jahr & Januar & Juli \\
& $18.7^{\circ}$ & $24.0^{\circ}$ & $16.4^{\circ}$ \\
Beobachtet: & 15.2 & 17.0 & 13.2 \\
\hline Differenz & $-3.5^{\circ}$ & $-7.0^{\circ}$ & $-3.2^{\circ}$.
\end{tabular}

Die mittlere Jahrestemperatur von Swakopmund besitzt also eine negative thermische Anomalie von 1) Spitaler. Die Wärmeverteilung äber die Erdoberfläche. 
$3.5^{\circ}$, diejenige im Januar von $7.0^{\circ}$ und im Juli eine solche von $3.2^{\circ}$.

Dagegen hat Windhuk eine positive thermische Anomalie. Wenn man den jährlichen Gang der Temperatur nach $\operatorname{Hann}^{1}$ ) und den Reduktionsfaktor nach Dove $\left.{ }^{2}\right)-0.45^{\circ}$ pro $100 \mathrm{~m}-$ sowie eine Höhe von $\left.1660 \mathrm{~m}^{3}\right)$ zugrunde legt, so ergibt sich:

\begin{tabular}{lccc} 
& Jahr & Januar & Juli \\
Beobachtet & $27.3^{\circ}$ & $32 . \mathrm{I}^{\circ}$ & $22.3^{\circ}$ \\
Spitaler: & $2 \mathrm{I} .4$ & 26.5 & 19.2 \\
\hline
\end{tabular}

Differenz: $+5.9^{\circ}+5.6^{\circ}+3.1^{\circ}$.

Wenn man in der Spitalerschen Formel

$\mathrm{T} \varphi=-2.43+\mathrm{I} 7.6 \mathrm{I} \cos \varphi+7.05 \cos 2 \varphi+\mathrm{I} 9.29 \mathrm{n} \cos 2 \varphi$ $\mathrm{n}=\mathrm{o}$, also eine Wasserhemisphäre zugrunde legt, so findet man die mittlere Jahrestemperatur des Meeres $\left(14.3^{\circ}-18.6^{\circ}\right.$ ) um $4.3^{\circ}$ zu kalt. Würde man nach der Jahrestemperatur von $14.3^{\circ}$ auf die Herkunft des Wassers schließen, so würde dieser Ort $35^{\circ}$ südlicher Breite, also in der Gegend der Roßbreiten, zu suchen sein, vorausgesetzt, daß das Wasser dieselbe Temperatur beibehält, was nicht genau zutreffend ist.

Orte mit gleicher Jahrestemperatur wie Swakopmund sind Bahia Blanca (Argentinien) $38^{\circ} 45^{\prime}$ südl. Br. mit I $5.2^{\circ}$ Jahrestemperatur, aber $16.7^{\circ}$ Jahresschwankung, und Serena (Chile) $29^{\circ} 54^{\prime}$ südl. Br. mit einer Jahrestemperatur von $15.1^{\circ}$ und einer Jahresschwankung von $6.7^{\circ}$. Selbst Kapstadt, I I Breitengrade südlicher als Swakopmund, hat noch eine um I.I ${ }^{\circ}$ höhere Jahrestemperatur. Auffallend ist die Jahrestemperatur von Walfischbai, $23 \mathrm{~km}$ südlich von Swakopmund, mit $\left.16.9^{\circ},{ }^{4}\right)$ also um I. $7^{\circ}$ wärmer; auch der jährliche Gang zeigt hier durchweg eine um I.O bis $2.9^{\circ}$ höhere Temperatur.

Zwar beziehen sich die Beobachtungen hier auf die Jahre I886 bis I894, aber die geringe Abweichung der einzelnen Jahresmittel vom Normalmittel - das Maximum beträgt $+0.6^{\circ}$ und $-0.7^{\circ}$ gestatten einen Vergleich.

Die Temperaturdifferenz zwischen Swakopmund und Walfischbai könnte einmal darin zu suchen sein, daß letzteres durch die $8 \mathrm{~km}$ lange Pelikanhalbinsel ${ }^{5}$ ) von der kaiten Meeresströmung abgeschnitten ist. Das Wasser in der Bai erwärmt sich leichter und mildert den Einfluß der kalten Strömung.

Stapff ${ }^{6}$ ) fand am 8. Dezember I 885 nördlich der Pelikan-Spitze $14.9^{\circ}$, in der Bai dagegen $15.7^{\circ}$.

1) Hann. Der tägliche Gang der Temperatur von Windhuk. Mitteil. I906. I. Heft, S. 34 .

2) Dove. Das Klima des außertropischen Südafrikas. S. 23 S. 163 .

3) Mitteil. aus den deutschen Schutzgebieten 1906. Heft 2,

4) Sandmann. Das Klima von Walfischbai. Paderborn I9or.

5) Sandmann. S. 3 .

6) Annalen der Hydrographie I887, S. 68 u, 355 .
Derselbe Autor stellte bei einer Fahrt am 3. Januar I 886 von der Küste zur Pelikan-Spitze und wieder zurück folgende Meerestemperaturen fest.

Abstand von der Küste:

$\begin{array}{rr}50 \mathrm{~m} & \text { I } 7.8^{\circ} \\ \text { I } 550, & \text { I } 6.3 \\ 4600 ", & \text { I } 5.4 \\ 5900 " & \text { I } 5.7 \\ 2450 ", & \text { I } 6.5 \\ \text { I OOO , } & \text { I } 6.8 \\ \text { am Ufer } & 2 \text { I } . O .\end{array}$

Stapff bemerkt dazu: "Der kalte Strom setzt um Pelikan Point herum in die Bai hinein und folgt dem westlichen Ufer. Dann bewegt sich das Wasser in der Lagune erwärmt entlang dem östlichen Ufer wieder zur Bai hinaus«.

Ein anderer Grund muß in der zu sehr geschützten Aufstellung des Thermometers zu Walfischbai gesucht werden.

Dove fand bei seiner Anwesenheit an dieser Station, »daß die Ablesungswerte keinen Anspruch auf besondere Zuverlässigkeit machen können. Besonders gegen den herrschenden SW ist der Kasten mit den Thermometern so vollständig gedeckt, daß man an dem Schleuderthermometer am kaum $\mathrm{IOO} \mathrm{m}$ entfernten Strande erheblich niedrigere Temperaturen ablesen kann, als dies in der durch zwei Häuser gebildeten Verandaecke der Mission der Fall ist $\ll \cdot$ )

Als Hauptgrund müssen wir aber die Verschiedenheit der Thermometer selbst annehmen; in Swakopmund erfolgte die Messung, soweit bekannt, meist mit dem Aspirationsthermometer, sie besitzt daher eine größere Genauigkeit als diejenige von Walfischbai.

Der Einfluß des erwärmten Wassers in der Bai läßt sich erst feststellen, wenn korrespondierende Beobachtungen von beiden Orten mit dem Aspirationsthermometer vorliegen.

Nachdem wir uns durch eine Vergleichung der mittleren Jahrestemperatur von Swakopmund mit der den geographischen Positionen entsprechenden einen allgemeinen Einblick in die thermischen Verhältnisse Swakopmunds verschafft haben, wollen wir jetzt den jährlichen Verlauf der Lufttemperatur oder die jährlichen periodischen Änderungen betrachten.

Eine Zusammenfassung der einzelnen Monate nach Jahreszeiten, wie sie Sandmann bei der Beschreibung des Klimas von Walfischbai ausführt, hat bei der geringen Jahresschwankung und dem Fehlen an sonstigen charakteristischen Merkmalen, z. B. Regen- und Trockenzeiten, wenig Wert, ebenso wäre

1) Dove. Deutsch - Südwestafrika. Peterm. Mitteil. Ergänzungsheft Nr. 120, 1896 S. 22. 
eine Darstellung nach Dekaden oder Pentaden nur nach einer vieljährigen — nach H. Meyer ${ }^{1}$ ) min. destens 2ojährigen — Beobachtung am Platze.

Die Lufttemperatur zu Swakopmund erreicht in ihrem jährlichen Gange ihr Maximum mit $17.4^{\circ} \mathrm{im}$ März und ihr Minimum mit I2.7 ${ }^{\circ}$ im August; die mittlere Jahresschwankung beträgt mithin nur $4.7^{\circ}$, dagegen hat Windhuk eine solche von $10.7^{\circ}$ aufzuweisen. Der Einfluß der kontinentalen und maritimen Lage ist unverkennbar.

Eine gleiche Jahresschwankung wie die Lufttemperatur von Swakopmund zeigt auch die Meerestemperatur mit $4.7^{\circ}$; nur fällt hier das Maximum einen Monat früher, nämlich in den Februar, während das Minimum mit demjenigen der Luftemperatur zusammenfällt. Diese Erscheinung ist insofern auffallend, weil unter normalen Verhältnissen das Wasser sich langsamer erwärmt als die Luft und daher die Extreme später eintreten. Für in Bewegung befindliches Wasser wie der Benguelastrom kann aber der Gang der Temperatur zu Swakopmund allein nicht in Betracht kommen, sondern auch derjenige des Ursprungsortes und des zurückgelegten Weges. Wenn man nun den Wendepunkt des zurückkehrenden Zweiges der südlichen Äquatorialströmung in der Gegend des 35. Grad südlicher Brcite annimmt, so erreicht hier die Sonne am 2 I. Dezember ihre größte Höhe mit $78.5^{\circ}$, während sie in Swakopmund anfangs Januar noch im Zenit steht. Die Dauer sowohl wie die Intensität der Sonnenstrahlung ist in Swakopmund erheblich gröber als wie am 35. Grad südlicher Breite, und hierin dürfte neben der schweren Erwärmbarkeit des Wassers der Grund des früheren Eintritts des Maximums der Meerestemperatur zu suchen sein.

Das Temperatur-Maximum trat ein:

\begin{tabular}{|c|c|c|c|c|}
\hline & & & Luft & Meer \\
\hline I 899 & . & & März & - \\
\hline I 900 & . & & . Jan. u. Febr. & - \\
\hline I9OI & . & & Januar & 一 \\
\hline 1902 & . & & März & - \\
\hline 1903 & . & & Januar & Dezember \\
\hline I9O4 & . & & Februar & Jan. u. Febr. \\
\hline 1905 & . & . & Februar & Februar. \\
\hline
\end{tabular}

Das Maximum der Luftemperatur scheint demjenigen der Mecrestemperatur zu folgen; seine Lage schwankt zwischen Januar und März. Das Minimum der Luft- und Meerestemperatur fällt in den August.

Verfolgt man den Verlauf der jährlichen Temperaturkurve von Swakopmund, so findet man eine erhebliche Störung im April und Mai in Tagesmittel und besonders im 2 p Termin. Diese Störung finclet

1) H. Meyer. Anleitung zur Bearbeitung meteorologischer Beobachtungen für die Klimatologie. Berlin 1891, S. 78 . sich im Tagesmittel von I 899 bis 1902 und in dem $2 \mathrm{p}$ Termin von I 899 bis I904.

Was ist nun die Ursache einer derartigen Störung?

Der Temperaturfall im April dïrfte verursacht sein durch die abnehmende Intensität der Sonnenstrahlung und den starken Rückgang der Meercswärme vom Februar bis April; schon im März beträgt die Differenz zwischen Luft- und Meerestemperatur $1.6^{\circ}$. Diese hat eine stärkere Nebelbildung - im Mittel Februar 5.4, März 9.I, April 20.2 sowie Schwächung der Sonnenstrahlung und weiteres Sinken der Luftemperatur zur Folge. Den Anstieg der Lufttcmperatur im Mai wird man wohl den warmen Ostwinden - die hier ihr Maximum erreichen - zuschreiben können, wie bei der Darstellung der Windverhältnisse gezeigt werden wird.

Der jährliche Gang der Meerestemperatur zeigt ein geringes sekundäres Maximum im Juli, und zwar im Tagesmittel und in den Bcobachtungstcrminen. Dasselbe zeigt sich nur im Jahre 1905 , während in den beiden vorhergehenden Jahren der Temperaturgang gleichmäBig verläuft. Die klcine Temperaturschwankung zeigt sich bedeutend verstärlkt in der Lufttemperatur. Der Grund des sekundären Maximums der Tcmperatur im Juli 1905 liegt darin, daB in diesem Monat die warmen Ostwinde I 8 mal vorkommen, während sie durchschnittlich im Juli nur 7 mal auftreten.

Der tägliche Gang der Lufttempcratur in den drei Beobachtungsterminen gestaltet sich so, dab die Temperatur von 7 a bis $2 \mathrm{p}$ um durchschnittlich $3 . \mathrm{I}^{\circ}$ steigt und gegen den $9 \mathrm{p}$ 'Termin um $2.5^{\circ}$ fällt. Die Morgentemperatur ist also durchschnittlich um $0.6^{\circ}$ niedriger als die Abendtemperatur.

In den einzelnen Monaten sind die Diffcrenzen folgende:

$$
\begin{aligned}
& \text { I II III IV } \mathrm{V} \text { VI VII VIII IX } \mathrm{X} \text { XI XII Jahr } \\
& 2 \mathrm{p}-7 \mathrm{a} \\
& \begin{array}{lllllllllllll}
2.0 & 2.3 & 2.3 & 3.0 & 4.5 & 5.0 & 4.4 & 4.1 & 2.8 & 2.3 & 2.4 & \text { I.9 } & 3.1
\end{array} \\
& 2 \mathrm{p}-9 \mathrm{p} \\
& \begin{array}{lllllllllllll}
\text { I.8 } & \text { I.9 } & 1.8 & \text { I.9 } & 2.3 & 3.8 & 3.2 & 2.5 & 2.0 & 2.1 & 2.0 & \text { I.8 } & 2.4
\end{array} \\
& 9 \mathrm{P}-7 \mathrm{a}
\end{aligned}
$$

$\begin{array}{llllllllllllllll}0.2 & 0.4 & 0.5 & \text { I.I } & \text { I.2 } & \text { I.2 } & 1.2 & \text { I.6 } & 0.8 & 0.2 & 0.4 & 0.1 & 0.7\end{array}$

Die größten Differenzen fallen in die Monate Mai bis August. Die Differenzen zwischen 9p und 7 a sind geringer und regelmäßigcr. Die großen Unterschiede zwischen $7 \mathrm{a}$ und $2 \mathrm{p}$ einerseits und $2 \mathrm{p}$ und $9 \mathrm{p}$ andrerseits werden durch die hohen Temperaturen am $2 \mathrm{p}$ Termin verursacht. Wie wir später sehen werden, erreichen während der Monate Mai bis August die Maxima der Lufttemperatur ihre größten Werte.

Bedcutend geringer sind die Differenzen in der täglichen Periode der Meerestemperatur; sie steigt 
von morgens bis mittags nur um $0.8^{\circ}$ und fällt bis abends $\mathrm{um}$ 0. $\mathrm{I}^{\circ}$. Die Meerestemperatur ist also abends um $0.7^{\circ}$ höher als morgens. In den einzelnen Monaten zeigen sich folgende Differenzen:

\section{II III IV $\mathrm{V}$ VI VII VIII IX $\mathrm{X}$ XI XII Jahr morgens bis mittags}

$\begin{array}{lllllllllllllllll}0.9 & 0.9 & 0.9 & 0.6 & 0.7 & 0.7 & 0.6 & 0.9 & \text { I.O } & 0.9 & \text { I.O } & \text { I.O } & 0.8\end{array}$ mittags bis abends

$\begin{array}{lllllllllllll}\text { O.I } & \text { O.I } & \text { O.I } & \text { O.O } & \text { O.I } & \text { O.I } & \text { O.I } & 0.2 & 0.3 & 0.2 & 0.0 & 0.3 & \text { O.I }\end{array}$ morgens bis abends

$\begin{array}{lllllllllllllllll}0.8 & 0.8 & 0.8 & 0.6 & 0.6 & 0.6 & 0.5 & 0.7 & 0.7 & 0.7 & \text { I.O } & 0.7 & 0.7\end{array}$

Die Differenzen sind sehr gering und gleichmäßig; der Temperaturgang von mittags und abends zeigt die geringste Oszillation.

Die mittleren Abweichungen der einzelnen Jahrgänge vom Normalwert beträgt $0.5^{\circ}$; ihre Extreme sind $+\mathrm{I} .4^{\circ}$ und $-\mathrm{I} .2^{\circ}$. Am wärmsten war das Jahr 1899 mit einer Jahrestemperatur von $16.6^{\circ}$, es hat 9 positive und 3 negative Abweichungen; noch extremer war das Jahr I903 mit nur I4.0 ${ }^{\circ}$ Jahrestemperatur, es hat nur negative Abweichungen.

Von den einzelnen Monaten zeigt der März I 899 die größte Abweichung mit $+3.0^{\circ}$, er war zugleich der wärmste Monat der ganzen Beobachtungsperiode; ihm gegenüber steht als kältester Monat der Juli I903 mit $-2.9^{\circ}$. Die mittleren Abweichungen der einzelnen Monate sind in Tafel I Spalte I 7 enthalten; sie erreichen in den Monaten Mai-Juli ihren größten und von August-Februar ihren kleinsten Wert. Die Ursache liegt wohl darin, dab im Mai-Juli die Sonnenstrahlung ihr Minimum erreicht und der Temperaturgang nun durch lokale Erscheinungen (Land- und Seewinde, kalte Nebel usw.) beeinflußt wird.

Tafel I Spalte I I bis I 6 zeigt die mittleren und absoluten Extreme der einzelnen Jahre und Monate. Während die Kurve für das mittlere und absolute Minimum einen normalen Gang zeigt, findet man bei der Darstellung des mittleren Maximums eine Störung im April und Mai. Das Maximum liegt im Mai und ein sekundäres Minimum im April analog dem jährlichen Gange der Luftemperatur. Noch stärkere Abweichungen zeigt die Darstellung des absoluten Maximums; der höchste Wert fällt in den Juli, ein sekundäres Maximum zeigt der Monat Mai, im ganzen zeigen die Monate März bis Oktober die höchsten Temperaturen. Während also die Minima mit dem tiefsten Sonnenstande ihre kleinsten Werte erreichen und dadurch auf ihre Entstehung durch Abnahme der Insolation hinweisen, zeigen die Maxima einen der Insolation entgegengesetzten Gang und deuten damit schon auf ihren dynamischen Ursprung hin.

Von den absoluten Maxima und Minima entfallen:
4 Maxima auf Mai; 3 Minima auf Juni;

$2 \ll \quad$ « Juni; 2 « $«$ Juli;

I « « Juli; 2 " $\quad$ " August.

Als eine ganz auffallende Erscheinung muB es bezeichnet werden, da $B$ in Swakop. mund die höchsten Lufttemperaturen in die kalte Jahreszeit fallen, und zwar in die Monate Mai bis August.

Unter der unperiodischen absoluten Jahresschwankung versteht man die Differenz zwischen der höchsten und niedrigsten Temperatur eines jeden Jahres. Das Mittel aus diesen Differenzen ergibt die mittlere absolute Jahresschwankung; dieselbe beträgt $34 . \mathrm{I}^{\circ}$, ihre größten und kleinsten Werte sind: $37.6^{\circ}$ (1905) und $30.6^{\circ}$ (1900).

Bildet man die Differenz zwischen der höchsten und tiefsten Temperatur jeden Monats, so erhält man die unperiodische Monatsschwankung, nimmt man jedoch die Differenz zwischen dem absoluten Maximum und Minimum der einzelnen Monate innerhalb der Beobachtungsperiode, so findet man die absolute Monatsschwankung; die letztere ist größer als erstere. Beide erreichen im Mai-Juli ihre größten Werte, wie Tafel I Spalte I6 und I8 zeigt. Die höchste Temperatur während der ganzen Beobachtungsperiode beträgt 40.6 (Juli I905), die niedrigste $2.5^{\circ}$ (August I 899); die absolute Wärmeschwankung beträgt mithin $38 . \mathrm{I}^{\circ}$.

Frost scheint in Swakopmund nicht vorzukommen, während derselbe im Innern in den Monaten Mai-August sehr häufig ist; als Grund karn man die häufigen Nebel während der kühlen Jahreszeit annehmen, die gegen die nächtliche Ausstrahlung schützen. In klaren, windstillen Nächten tritt bei der hohen Lufteuchtigkeit oft Taubildung ein, indem durch die Ausstrahlung des Bodens die benachbarte Luft unter den Taupunkt abgekühlt und Kondensation hervorgerufen wird. Die hierbei freiwerdende Wärme verhindert ein weiteres Sinken der Temperatur.

Da die mittleren Extreme der Temperatur in den Monaten Mai-August ihre größten Werte erreichen, so muß natürlich auch in diesen Monaten die unperiodische tägliche Wärmeschwankung am größten sein. Wie aus Tafel I Spalte I 3 zu ersehen ist, erreichen die Maxima im Mai bis August fast den doppelten Wert als wie in den Monaten Dezember bis Februar.

$\mathrm{Zu}$ einer erschöpfenden Charakteristik der thermischen Verhältnisse eines Ortes sind die bisher ermittelten Ergebnisse nicht ausreichend; denn sie waren einerseits Mittelwerte oder aus mittleren Extremen abgeleitet und daher ebenfalls Durchschnittswerte, oder sie stellen die Differenz zwischen den 
absoluten Extremen dar und beziehen sich somit auf größere Zeitintervalle. Es ist aber für den Klimatologen und besonders für den Hygieniker und Biologen von großer Wichtigkeit, zu wissen, welche Temperaturschwankung an einem Orte innerhalb 24 Stunden zu erwarten ist, und diese Untersuchungen dürfen daher in einer klimatologischen Beschreibung eines Ortes nicht fehlen. Während H. IV. Dove ${ }^{1}$ ) unter der Veränderlichkeit der Temperatur die mittlere Abweichung vom Normalwert verstand, bezeichnet man jetzt nach $\mathrm{Hann}^{2}$ ) damit alle jene Wärmeunterschiede zweier sich unmittelbar folgenden Zeitabschnitte, welche nicht der täglichen und jährlichen Periode angehören «. Hann hat als erster die Veränderlichkeit der Lufttemperatur als klimatische Konstante eines Ortes eingeführt, indem er dieselbe von 90 Orten ermittelte. Weitere Untersuchungen haben Kremser, Wahlen, Knipping u. a. m. angestellt.

Um den Einfluß des normalen täglichen Wärmeganges zu eliminieren, wählte Hann die Temperaturdifferenz zwischen den Tagesmitteln zweier sich folgenden Tage; dieser Unterschied ist aber ebenfalls wieder cin Mittelwert und kleiner als die tatsächlichen Wärmeschwankungen. Wählen wir daher die Temperaturdifferenz zwischen $7 \mathrm{a}$ und 7 a Termin der einander folgenden Tage, wie sie in Wirklichkeit auf die Bewohner von Swakopmund einwirkt. Allerclings enthalten diese Differenzen noch den normalen jährlichen Wärmegang, aber dieser ist bei der geringen Jahresschwankung so unbedeutend - er beträgt pro Tag 0.02 bis $0.03^{\circ}$-, daß man ihn unberücksichtigt lassen kann.

Betrachten wir zunächst die mittlere interdiurne Veränderlichkeit der Temperatur für das Jahr und die einzelnen Monate.

Das Jahresmittel beträgt $1.49^{\circ}$; im jährlichen Gang wird das Maximum im Mai-Juni erreicht, hier sind die Beträge 2 bis 3 mal so groß als wie in den Monaten November-Februar. Auffallend ist das sekundäre Minimum im Juni; zunächst könnte man an ein rein zufälliges Ergebnis denken aus der nur kurzen Beobachtungszeit, aber ein Vergleich mit anderen Orten zeigt dieselbe Erscheinung, wenn auch für andere Monate. So haben z. B. Kapstadt ${ }^{3}$ ) und Maritzburg ${ }^{3}$, Orte mit maritimer und kontinentaler Lage, ebenfalls im Mai ein sekundäres Minimum, dasselbe zeigen auch mehrere andere Orte wie Kiel, Stettin, Cleve, Wien usw. Zum Ver-

1) Dove. Über d. täglich. Veränderungen d. Temperatur der Atmosphäre. Abhandlung der Kgl. Akad. der Wissensch. zu Berlin 1856 .

$\left.{ }^{2}\right)$ Hann. Untersıchung über die Veränderlichkeit der Temp. Akad. d. Wissensch. Bd. LXXI, Wien 1875.

3) $\operatorname{Hann}$ a. a. O. S. 578 , gleiche stehen nur die Orte Klausen ${ }^{1}$ ), Schneekoppe und Emden zur Verfügung, da bei den anderen zahlreichen Orten stets die Tagesmittel angewandt sind, die, wie bereits bemerkt, geringere Differenzen ergeben müssen. Klausen unı Schneekoppe zeigen durchweg eine größere Veränderlichkeit, dagegen Emden nur im Jahresmittel und im Sommer, im Winter ist in Swakopmund die interdiurne Veränderlichkeit größer als in Emden, das $53^{\circ} 22^{\prime}$ nördl. Br. liegt, wie folgende Zusammenstellung zeigt: $\begin{array}{lllllll}\text { I } & \text { II III IV } & \text { V } & \text { VI } & \text { VII }\end{array}$

$\begin{array}{llllllll}\text { Swakopmund * } 0.9 \text { I } & 0.87 & \text { I.I6 } & \text { I.09 } & 2.66 & 2.49 & 2.68\end{array}$ Emden . . $\begin{array}{llllllll}2.0 & 2.4 & \text { I.8 } & \text { I.7 } & \text { I.4 } & \text { I.8 } & \text { 1.5 }\end{array}$ VIII IX X XI XII Jahr $\begin{array}{lllllll}\text { Swakopmund . } & \text { I.72 } & \text { I.49 } & \text { I.I } 4 & 0.93 & 0.72 & \text { I.49 }\end{array}$ Emden . . I.4 I.8 $2.0 \quad 2.1 \quad 2.2 \quad$ I.84

Wenn auch die Werte von Kapstadt aus Tagesmitteln gewonnen sind und daher mit denjenigen von Swakopmund nicht direkt verglichen werden können, so läßt sich doch feststellen, daß der jährliche Gang demjenigen von Swakopmund sehr ähnlich ist, da auch hier die größten Werte zugleich mit dem niedrigsten Sonnenstande eintreten. Maritzburg als Repräsentant der kontinentalen Lage zeigt einen umgekehrten Gang, dasselbe würde bei Windhuk - aus dem Gang der unperiodischen Schwankungen zu schließen - der Fall sein. Im Kontinent beherrscht die Sonne den Wärmegang, während an der Küste mit dem Rückgange der Sonnenstralılung dic lokalen Störungen - namentlich Land- und Seewinde - ihren Einfluß geltend machen.

Wenn man in Tafel II die interdiurne Veränderlichkeit von Swakopmund mit derjenigen von Kapstadt und Maritzburg vergleicht, so wird man finden, daß diejenige von Swakopmund in der warmen Jahreszeit gering, dagegen in der kalten auffallend groß ist, größer als die von Kapstadt, unter 33.9" südl. Br., ja wahrscheinlich auch noch größer als diejenige von Maritzburg unter $29.6^{\circ}$ südl. Br. und $639 \mathrm{~m}$ Seehöhe.

Stellt man die mittlere Häufigkeit der Erwärmungen und Erkaltungen im Jahr und den einzelnen Monaten fest, so findet man keinen ausgeprägten Gang, wie man eigentlich entsprechend dem jährlichen Gang der Temperatur erwarten sollte, daß nämlich von Februar bis August die Erkaltungen und von August bis Februar dic Erwärmungen überwiegen; daß dies aber nicht der Fall ist, zeigt Tafel $\mathrm{II}_{2}$. Die Häufigkeit der Erwärmungen und Erkaltungen sind also keine reine Funktion der Sonnenstrahlung, sondern von mehreren anderen

1) Kremser. Die Veränderlichkeit der Lufttemp. in Norddeutschland. Abhandl. d. Preub. Met. Inst. I, I 888 bis r 901 S. I $5 / 16$. 
Einflüssen abhängig. In den Monaten Februar, April, August, September, Oktober und November überwiegen die Erwärmungen, in den übrigen mit Ausnahme des Juli, wo beide gleich häufig sind, die Erkaltungen. Im ganzen Jahr überwiegen ebenso wie an den von Hann und Kremser untersuchten Orten die Erwärmungen mit 178.7 gegenüber den Erkaltungen mit 169.4. Noch ubersichtlicher kann man das Verhältnis der Erwärmungen zu den Erkaltungen darstellen, wenn man berechnet, wieviel Erkaltungen auf eine Erwärmung fallen, wie aus Tafel II, 3 zu ersehen ist.

Um auch die seltener vorkommenden hohen Temperatursprünge mit zur Darstellung zu bringen, sind in Tafel $\mathrm{I}_{4}$, die Temperaturänderungen von bestimmter Größe je nach ihrer Häufigkeit geordnet; denn gerade die größeren Temperaturschwankungen sind es, die den Organismen schädlich werden können und daher den Arzt und Biologen interessieren.

Weitaus am häufigsten sind die Erwärmungen und Erkaltungen bis $1.9^{\circ}$, hier treten besonders die Monate September bis April hervor, während Mai-August zurücktreten, aber schon bei 2.0 bis $3.9^{\circ}$ überwiegen letztere, um die Führung bis zu den größten Werten von 14.0 bis $15.9^{\circ}$ zu übernehmen, nur September und Oktober sind bis zur Grenze ro.o bis II.9 , wenn auch schwach, vertreten; je größer die Schwankungen werden, umsomehr konzentrieren sich dieselben auf Mai--August.

Wodurch werden nun die großen Temperatur schwankungen hervorgerufen?

Beschreiben wir zunächst kurz die Wetterlage während der drei größten Temperatursprünge.

Vom I5. zum I6. Mai I89I beträgt die Erwärmung von 7 a bis 7 a $15.5^{\circ}$. Das Barometer ist um $0.7 \mathrm{~mm}$ gestiegen, der Himmel wolkenlos; es weht $E_{3}$, abends tritt Windstille ein; die nächtliche Strahlung kann nun ungehindert vor sich gehen und die Temperatur sinkt bis $7 \mathrm{a}$ um $\mathrm{I} 3 . \mathrm{I}^{\circ}$.

Vom 8. bis 9. Juni rgor betrug die Erwärmung I4. $5^{\circ}$, tags zuvor und am Morgen bis gegen Mittag weht $\mathrm{E}$, der Himmel ist heiter, das Barometer steigt um $0.8 \mathrm{~mm}$, trotzdem der E-Wind noch sechs Tage weiter weht, kühlt sich die Temperatur allmählich ab. Die Periode schlieBt mit Windstille und $3.5^{\circ}$ Erkaltung.

Am 27. bis 28. August 1902 trat eine Erwärmung um $14.8^{\circ}$ ein. Das Barometer fiel um $3.7 \mathrm{~mm}$, es weht bei heiterem Himmel ein starker E-Wind (Stärke 4) mit heftigem Sandtreiben.

Wir sehen also, die großen Erwärmungen und Erkaltungen sind stets eine Begleit- oder Folgeerscheinung der E-Winde; bei ihrem Eintritt steigt die Temperatur, infolge ihrer Wärme und Trockenheit nimmt die Bewölkung ab, und es tritt eine weitere Steigerung der Temperatur ein, beim Aufhören des E-Windes erfolgt bei dem heiteren Himmel während der Nacht eine starke Wärmeausstrahlung, und diese erzeugt eine große Erkaltung.

Die mittlere Größe einer Erwärmung und einer Erkaltung sowie ihre absoluten monatlichen Extreme zeigen nur den Unterschied, daß letztere erheblich größer sind, sonst ist der jährliche Gang derselbe wie bei der mittleren monatlichen Veränderlichkeit, indem auch hier vom Mai bis August dieselbe Tendenz zur Vergrößerung der Temperaturschwankung herrscht.

\section{Luftfeuchtigkeit.}

$\mathrm{Zu}$ Swakopmund wurde die Luftfeuchtigkeit mit einem Aspirations-Psychrometer bestimmt, indem die Ablesungen an dem trockenen und feuchten Thermometer täglich dreimal an den Beobachtungsterminen notiert wurden; aus dem Monatsmittel dieser Werte wurden die entsprechenden für absolute und relative Feuchtigkeit berechnet.

Vom I2. September I 899 bis I2. Mai r 900 fehlen die Feuchtigkeitsbestimmungen; die Beobachtungen in den Monaten Februar bis Oktober des Jahres 1905 sind weniger zuverlässig. $\left.{ }^{1}\right)$

Die Messung mit dem Psychrometer erfordert an der Küste Deutsch-Südwestafrikas eine sehr sorgfältige Behandlung, da durch die dortigen heftigen Ostwinde und durch die hierdurch hervorgerufenen Sandstürme die feuchte Hülle des Thermometers mit einer dichten Sandkruste bedeckt wird. Stapff ${ }^{2}$ ) schreibt hierüber: „Bei meiner Rückkehr nach Walfischbai fand ich die Baumwollhülle des nassen Thermometers von Sand inkrustiert und ihr unteres Ende abgefault. A Auch werden nach Angabe des selben Autors die Ablesungen an dem trockenen Thermometer durch Beschlagen mit Dunstbläschen und feinem Sand leicht ungenau.

Tafel I Spalte 23 bis 26 zeigt uns den mittleren Gang der absoluten Lufteuchtigkeit in den drei Beobachtungsterminen und im Tagesmittel; das Mittel aus den fünf Beobachtungsjahren beträgt IO.I $\mathrm{mm}$. Die Schwankung in den einzelnen Jahren ist gering, der kleinste Wert wurde 1903 erreicht mit $9.6 \mathrm{~mm}$, der größte 1902 und $1905 \mathrm{mit} 10.4 \mathrm{~mm}$. Der jährliche Gang ist ein außerordentlich gleichmäßiger; das Maximum tritt zugleich mit demjenigen der Temperatur im Februar-März, das Minimum dagegen 2 Monate früher, im Juni, ein, die Amplitude beträgt mithin nur $4.3 \mathrm{~mm}$. Abweichend von der

1) Mitteil. I906, S. I49.

$\left.{ }^{2}\right)$ Deutsche überseẹische Beobacht. I. I887, S. 63 . 
Temperaturkurve zeigt der Monat April einen regelmäßigen Verlauf; auch die warmen Ostwinde im Mai bis August mit ihrer abnormen Lufttrockenheit üben keinen merklichen Einfluß auf den mittleren Gang der absoluten Luftfeuchtigkeit aus, wohl weil ihre Häufigkeit eine zu geringe ist; dagegen ist der Einfluß der trockenen Landwinde unverkennbar, ihnen ist es zuzuschreiben, daß die absolute Feuchtigkeit ihren kleinsten Wert nicht zugleich mit demjenigen der Temperatur im Monat August, sondern im Juni erreicht, wo die Landwinde ihre größte Häufigkeit aufweisen.

Der jährliche Gang für die einzelnen Termine ist demjenigen für das Tagesmittel im großen und ganzen analog; nur derjenige für den $2 \mathrm{p}$-Termin zeigt im Juli ein sekundäres Maximum im Mittel und in den Jahren 1899, I900, 1902 und besonders stark 1905; für letzteres Jahr zeigt auch die Meerestemperatur ein sekundäres Maximum, und zwar in allen drei Terminen.

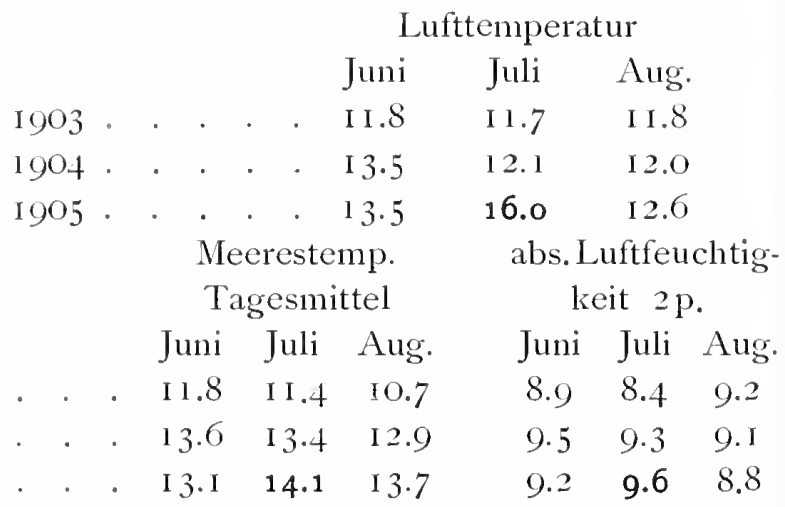

Bei der Luft- und Meerestemperatur wie bei der absoluten Luftfeuchtigkeit fehlt das sekundäre Maximum in den Jahren 1903 und 1904; leider ist die Beobachtungsperiode der Meerestemperatur zu kurz, um einen sicheren Anhaltspunkt zwischen beiden zu finden; da $\mathrm{im}$ allgemeinen nach $\operatorname{Hann}^{1}$ ) mit steigender Temperatur auch der absolute Wassergehalt der Luft zunimmt, so ist das sekundäre Maximum in der absoluten Luftfeuchtigkeit im Juli 1905 eine Folge analoger Störungen im Gange der Luft- und Meerestemperatur, und diese ist ihrerseits verursacht durch die im Juli 1905 außerordentlich stark auftretenden heißen Ostwinde (I 8 mal, das Mittel beträgt 7); v. Danckelman') sagt im Jahresbericht: "Durch die große Häufigkeit der warmen Ostwinde im Juli des Berichtsjahres (1905) erfuhr der jährliche regelmäßige Temperaturgang in diesem Monat eine auffällige Unterbrechung."

Im täglichen Gang steigt die absolute Feuchtigkeit von 7 a bis $2 \mathrm{p}$ im Mittel um $0.8 \mathrm{~mm}$ und fällt bis $9 \mathrm{p}$ um $0.3 \mathrm{~mm}$, so daß dieselbe $9 \mathrm{p}$ im Mittel

1) Meteor. I $906, \mathrm{~S} . \mathbf{1} 74$

2) Mitteil. I906, 2. Heft, S. 149. um $0.5 \mathrm{~mm}$ höher ist als 7 a; größere Schwankungen kommen nur in den Monaten Mai bis August vor, veranlaßt durch die enormen Schwankungen in der Lufttemperatur und durch die warmen Ostwinde.

I. II. III. IV. V. VI. VII.VIII. IX. X. XI. XII. Jahr $\begin{array}{llllllllllllllll}2 \mathrm{p} & \text { bis } & 7 \mathrm{a} & 0.4 & 0.1 & 0.3 & 0.6 & \text { I.3 } & 1.5 & 1.6 & \text { I.I } & 0.7 & 0.6 & 0.3 & 0.2 & 0.8\end{array}$ $\begin{array}{lllllllllllllll}2 p & \text { bis } 9 p & 0.2 & 0.2 & 0.1 & 0.3 & 0.6 & 0.4 & 0.8 & 0.3 & 0.2 & 0.2 & 0.2 & 0.1 & 0.3\end{array}$

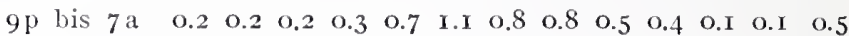

Der jährliche Gang der absoluten Luftfeuchtigkeit zu Swakopmund ist also ein außerordentlich gleichmäßiger, er schließt sich demjenigen der Temperatur eng an.

Zu einem ähnlichen Resultat gelangt Meyer in seinen Untersuchungen über den Gang der Luftfeuchtigkeit in Norddeutschland. ${ }^{1)}$

So wichtig die Angabe der absoluten Luftfeuchtigkeit auch für die Meteorologie ist, für den Klimatologen und Hygieniker kommt mehr die relative Luftfeuchtigkeit in Betracht; sie allein beeinflußt das Wohlbefinden des Menschen, indem sie in gewisser Beziehung steht zu dem Wasserverlust, den der Mensch durch Atmung und Verdunstung durch die Haut erleidet; daher ist mit Recht die relative Feuchtigkeit mit in die klimatischen Tabellen aufgenommen worden.

Da die relative Feuchtigkeit aus der absoluten berechnet wird, so weist erstere dieselben Lücken in der Beobachtungsperiode auf wie letztere (vom 12. September 1899 bis 12. Mai I900).

Das Jahresmittel der relativen Feuchtigkeit für die Jahre 190I bis 1905 beträgt $80 \mathrm{v}$. H., der höchste Wert 8r v. H. (I904) und der kleinste 78 v. H. (I9Or), die Schwankung in den einzelnen Jahren mithin 3 v. H.

Im jährlichen Gang erreicht die relative Feuchtigkeit im Februar ihr Maximum mit 84 v. H. und im Juni ilır Minimum mit 66 v. H., ein zweites Maximum im April mit 84 v. H., ein drittes geringeres im August mit 82 v. H.; im Gegensatz zur absoluten Feuchtigkeit ist der jährliche Gang der relativen ein sehr unruhiger.

Die Amplitude im jährlichen Gang beträgt I 8 v.H. Das zweite Maximum im April dürfte veranlaßt sein durch das starke Sinken der Luft- und Meerestemperatur in diesem Monat; da diese sich dem Taupunkte nähert, muß die relative Feuchtigkeit wachsen. Während vom März zum April die relative Feuchtigkeit den entgegengesetzten Gang der Temperatur zeigt, nehmen in den Monaten Mai und Juni beide Elemente ab, vom Juni bis August zeigen beide wieder einen entgegengesetzten Gang. Die relative Feuchtigkeit zeigt sich also nicht als eine reine Funktion der Temperatur, der Gang der ersteren

1) Meteor. Zeitschr. I 885 , S. I 53 
ist viel unregelmäßiger als derjenige der letzteren; es sind hier die trockenen Landwinde und besonders die warmen und trockenen Ostwinde, welche die Schwankungen im jährlichen Gang der relativen Feuchtigkeit herbeiführen; die charakteristischen Winde traten zuerst im März auf (12), hier finden wir eine Abnahme der relativen Feuchtigkeit, ihre kleinsten Werte im Mai und Juni sind eine Folge davon, daß hier die Ostwinde ihre größte Häufigkeit haben ( 96 und 8x), von hier folgt eine starke Abnahme bis zum Minimum im August. Dieses fällt mit dem sekundären Maximum der relativen Feuchtigkeit zusammen, ein sekundäres Maximum der Ostwinde im September erzeugt ein gleiches Minimum in der relativen Feuchtigkeit; auch die Werte in denseiben Monaten, z. B. Mai, Juni usw. während der verschiedenen Jahre, zeigen bei beiden Elementen einen entgegengesetzten Gang, wie bei der Erörterung der Windverhältnisse noch gezeigt werden wird. Den kleinsten Wert zeigt Juni 1899 mit 50 v. H., den gröBten April Igor mit 88 v. H., die absolute Monatsschwankung beträgt mithin $38 \mathrm{v}$. H.

In täglichen Gange zeigt sich die relative Feuchtigkeit mehr von der Temperatur beeinfluBt, das Mittel beträgt $7 \mathrm{a}: 83$ v. H., $2 \mathrm{p}: 74$ v. H., 9p: 82 v. H. Die Maxima liegen stets im Februar und April, die Minima meist im Juni, bisweilen im Mai.

Im allgemeinen ist das Klima von Swakopmund ein feuchtes $z u$ nennen; eine Folgeerscheinung der großen Lufteuchtigkeit ist die zerstörende Wirkung des Rostes.

Allgemein bekannt ist, daß feuchte Hitze. wie feuchte Kälte für den Menschen viel unangenehmer sind als wie dieselben Temperaturen bei trockener Luft; bei feuchter Hitze ist es die Verhinderung der wärmeentziehenden, normalen Verdunstung auf unserer Haut, welche in uns das unangenehme Gefühl der Schwüle erzeugt; bei der naßkalten Luft empfinden wir eine stärkere Wärmeentziehung infolge der gröBeren Wärmeaufnahmefähigkeit der in der Luft und in unserer Kleidung enthaltenen Feuchtigkeit. Diese NaBkälte fällt besonders demjenigen auf, der nach einem mehrjährigen Aufenthalt im Inneren des Landes mit seinem wolkenfreien Himmel und seiner reinen, klaren, trockenen Luft mit etwa $30 \mathrm{v}$. H. relativer Feuchtigkeit plötzlich an der Küste Aufenthalt nimmt. Die feuchte, kalte, neblige Luft wirkt dann doppelt unangenehm, sie belästigt die Atmungsorgane und erzeugt ein Gefühl des Fröstelns.

Fleis cher ${ }^{1}$ ) stellt folgende Bedingungen in bezug auf die Luftfeuchtigkeit eines kimatischen Kurortes:

I. daß der Taupunkt niemals die Temperatur von $15^{\circ}$ R. $\left(=18.8^{\circ} \mathrm{C}\right.$.) erreiche,

1) Fleischer, Gesunde Luft. Göttingen r888. S. 19. Mitt. a. d. D. Schutzgebieten, XX. Band. III.
2. daß die mittlere relative Feuchtigkeit zwischen 60 und 75 v. H. liege und höchstens bei vorherrschend bewegter Luft dieses Mittel den Wert von 75 v. H. ein wenig iberschreite,

3. dab das Minimum der relativen Feuchtigkeit in seltenen Fällen und auf kurze Zeit unter $40 \mathrm{v}$. H. herabsinke und dies auch nur bei Windstille.

Nach den vorstehenden Bedingungen Dr. Fleischers ist das Klima von Swakopmund nicht als sehr günstig zu bezeichnen, dagegen sind im Inneren des Landes wiederholt von Ärzten Heilstätten für Lungenkranke geplant worden.

Welche enormen Anforderungen die großen Schwankungen der Lufteuchtigkeit an die Lunge stellen, möge folgendes Beispiel zeigen: Am I5. Mai r 899 2p betrug die absolute Luftfeuchtigkeit $20.6 \mathrm{~mm}$, die relative $=89 \mathrm{v} . \mathrm{H} . \mathrm{t}=24.7$, am 26. Mai desselben Jahres dieselben Werte $=3.7 \mathrm{~mm}$, 9 v. H., 34.2 ${ }^{\circ}$ Unter der Annahme, daB nach Fleischer der Mensch pro Tag 9000 Liter Luft einatmet und daß dieselbe, gesättigt mit der Temperatur des Körpers $\left(=37^{\circ} \mathrm{C}\right.$. und $44 \mathrm{~g}$ Wasserdampf pro Kubikmeter) denselben verläßt, gestalten sich die Wasserverluste der Lunge, wie folgt:

$$
\begin{array}{cc}
\text { I } 5 . \text { Mai } & \text { 26. Mai } \\
t=24.7-\frac{20.6}{23.4} \text { pro cbm } & -\frac{3.7}{40.3} \text { pro cbm } \\
\text { oder } & \\
\text { 2r.I g pro Tag } & 36.3 \mathrm{~g} \text { pro Tag. }
\end{array}
$$

Am 26. Mai mußte also die Lunge fast die doppelte Feuchtigkeit an die Luft abgeben als wie am I5. Mai.

Derartige Schwankungen der Luftfeuchtigkeit während der kühlen Jahreszeit sind keine Seltenheit. So berechnete v. Danckelman für 2I. Mai rgor $2 \mathrm{p}$ die relative Feuchtigkeit $=1 \mathrm{v} . \mathrm{H}$., am 24. Mai $9 \mathrm{p}=83 \mathrm{v} . \mathrm{H} . ;$ gleichzeitig mit diesen enormen Schwankungen der Lufteuchtigkeit stellen sich große Temperatursprïnge - am 2x. Mai rgol von $2 \mathrm{p}$ bis $9 \mathrm{p}=14.7^{\circ}$ - ein; werden diese Schwankungen noch durch kräftige Winde - Ostwinde mit Sandtreiben, kalte neblige Seewinde - unterstützt, so läßt sich leicht denken, daß ihre Gesamtwirkung der Gesundheit des Menschen leicht schädlich werden kann. Nach Ortloffl) traten bei den Hafenarbeitern shauptsächlich Erkrankungen des Darmes und der Atmungsorgane, und zwar besonders in den Wintermonaten, auf.»

\section{Nebel und Bewölkung.}

Nachdem wir im vorigen Abschnitt die Feuchtigkeitsverhältnisse Swakopmunds in ihrer unsichtbaren,

1) Zeitschr. f. Bauwesen, 1904, S. 692 . 
dampfförmigen Gestalt kennen gelernt haben, wollen wir jetzt dieselben in ihrer sichtbaren, zu Nebel und Wolken kondensierten Form betrachten.

Der Grad der Bewölkung und die Häufigkeit der Nebel sind deshalb für einen Ort ron großer Wichtigkeit, weil sie die Intensität der Insolation sowohl wie auch die Värmeausstrahlung abschwächen, sie vermindern mithin die Temperaturschwankung und bilden einen natürlichen, mächtigen VIärmeregulator. Die Nebel bilden aber auch für die fast regenlose $\mathrm{K}$ iiste die Hauptquelle der Luftfeuchtigkeit und der nicht meBbaren Niederschläge, die immerhin noch einigen Wüstenpflanzen ilı Fort kommen gestattet.

StapffI) berichtet hierüber folgendes: "Dic große Feuchtigkeit des Morgens und Abends hängt mit den nächtlichen Nebeln eng zusammen, welche nach Mitternacht so regelmäBig einsetzen, daß korrespondicrende Sternbeobachtungen zu Walfischbai nur selten gelingen.

Das allnächtlich aus dem Nebel auf dem Sandboden abgesetzte Wasser ist für die Vegetation nicht gleichwertig mit Regenwasser, denn es dringt nie so tief in den platten Boden ein, dab andere als kriechende Wurzeln von ihm befeuchtet werden könnten; ein paar Zoll unter der klatschnassen Oberfläche ist der Sand staubtrocken.

Die Nebelbeobachtungen des Jahres I 899 sind unvollständig, sie scheinen von September ab cingestellt zu sein. In den Jahren 1900 bis I905 sind zusammen $892 \mathrm{mal}$ Nebel beobachtet worden, und zwar 7a: 496, 2p und 9p: I98 mal; der Durchschnitt betrug 7a: 83 , mittags und abends: 33 Nebel. Die Häufigkeit ist in den einzelnen Jahren schr schwankend, so betrug die Anzahl im Jahre I905: 2 I 5, im Jahre 1903: nur 94. In der jährlichen Periode sind dic Nebel in der kühleren Jahreszeit am häufigsten, und zwar liegt das Maximum im April mit I35, cin zweites sckundäres Maximum im Juli mit I2I; die geringste Anzahl weist der Januar auf mit 2 I Nebeln. Das sekundäre Minimum im Mai und Juni wird veranlaßt durch die trocknen und heißen Ostwinde, welche in diesen Monaten am häufigsten sind.

In der täglichen Periode sind die Nebel in Durchschnitt morgens mchr als doppelt so häufig als mittags und abends; morgens sind sie am häufigsten im August und April, mittags im Juli und abends im April; die Minima liegen an allen drei Terminen im Januar.

Im Mittel sind die Nebel 2p und $9 \mathrm{p}$ gleich häufig; jedoch überwiegen in den Monaten Januar, April bis Juni und September die Abendnebel. In der warmen Jahreszeit sind die Nebel mittags am

1) Kol. Zeit. Berlin 1887 S. $648 / 650$. seltensten, da sie von der starken Sonnenstrahlung aufgelïst werden, in der kühleren Jahreszeit dagegen, wo die Insolation bedeutend geringer ist, sind die Nebel häufiger.

Auffallend wenig Nebel herrschten ron Olitober 1903 bis März 1904, nämlich nur 14 mal Nebel in fünf Mlonaten an den drei Beobachtungsterminen; auffallend ist ferner die geringere Nebelhäufiglieit Swakopmunds im Vergleich zu Walfischbai; dort war die Häufigkeit von I 886 bis I $89+$ in Durchschnitt:

$\begin{array}{ccc}7 \text { a: I } 56 & \text { I P: I I } & 9 \text { P: } 58 \\ \text { Max. . } 187 & 2 \text { I } & 72 \\ \text { Min... . I I I } & + & 39\end{array}$

I) emgegenüber hat Swakopmund von 1900 bis 1905:

$\begin{array}{cccc} & \text { 7a: } 83 & \text { 2p: } 33 & 91: 33 \\ \text { Max. . } & \text { I } 21 & 49 & 53 \\ \text { Min. . . } & 52 & \text { I6 } & 20\end{array}$

Morgens und abends sind die Nebel zu Swakopmund bedeutend seltener, aber mittags häufiger in Valfischbai.

Ob dieser Unterschied in der bercits erwähnten von Stapfï gefundenen höheren Mecrestemperatur zu Walfischbai von 2 I.O (am 3. Januar i 886) gegeniber derjenigen von Swakopmund von I6.8 (Januar 2p) zu suchen ist oder in weniger sorgfältigen Notierungen an letzterer Station, bleibt noch aufzuklären.

Auf dic Temperaturschwankung scheinen die Nebel von geringem Einflub zu sein; in den Jahren I 903 bis I g05 stieg die Häufigkeit der Nebel von 94 auf 14 I und 215, die monatlichen periodischen Temperaturschwankungen in denselben Jahren waren $31.3,33.9^{\circ}$ und $37.6^{\circ}$. Nebelhäufigkeit wie Tenperaturschwankung nehmen von I903 bis $1905 \mathrm{zu}$, ferner findet bei beiden eine Zunahme während der kühleren Jahreszeit statt; allerdings mag der Nebel verhindern, daß die absoluten Minima der Temperatur größere Beträge erreichen, indem durch die Abkühlung seitens des Erdbodens die darüberlagernden Luftschichten zur Kondensation gebracht werden und die hierdurch frei werdende Wärme einer weiteren Abkühlung entgegenwirkt, aber die absoluten Maxima der Temperatur sind, wic wir gesehen haben, dynamischen Ursprungs und haben nichts mit der Insolation zu tun; daher ist die Nebelbildung auf die Wärmeschwankung nur von geringem Einfluß.

Während unter normalen Verhältnissen der Nebel die Insolation sowohl wie die Wärmeausstrahlung und infolgedessen die Temperaturschwankung vermindert, ist dies in Swakopmund nicht der Fall; sowohl Temperaturschwankungen wic Nebelhäufigkeit erreichen in der kühlen Jahreszeit ihr Maximum. 
Wenn wir nun nach der Ursache der häufigen Nebelerscheinungen zu Swakopmund fragen, so müssen wir zunächst feststellen, welche Vorgänge überhaupt eine Kondensation des Wasserdampfes in der Atmosphäre zur Folge haben können; nach v. Bezoldi) gibt es deren drei, nämlich:

1) direkte Abkühlung, sei es durch Beriihrung mit kalten Körpern oder durch Strahlung;

2) adiabatische Expansion oder wenigstens Expansion bei ungenügender Wärmezufuhr;

3) Mischung feuchter Luftmengen von verschiedener Temperatur.

Der ad 2) genannte Vorgang kommt bei der Bildung der Bodennebel nicht in Frage.

Nebelbildung durch Mischung feuchter Luftmengen erfordert einen großen Temperaturunterschied der beiden Komponenten; so ergibt z. B. nach v. Bezold) gesättigte Luft bei $700 \mathrm{~m}$ Druck von $\mathrm{O}^{\circ}$ und $20^{\circ}$ durch Mischung höchstens $0.75 \mathrm{~g}$ Niederschlag pro Kilogramm Luftmischung; die gleiche Wassermenge erhält man aber durch direkte Abkühlung von $20^{\circ}$ auf $19.2^{\circ}$, also um $0.8^{\circ}$.

$\mathrm{Da}$ nun eine Mischung von Luftmengen mit $20^{\circ}$ Temperaturunterschied nur zur Zeit der heiBen Ostwinde möglich ist und diese nicht feucht, sondern heiB und trocken sind und daher, wie die Beobachtung zeigt, vorhandene Nebel auflöst, so kann die Nebelbildung zu Swakopmund nur darin ihren Grund haben, daß die feuchten Seewinde durch den, durch Wärmeausstrahlung erkalteten Sandboden und über der kalten Meeresströmung unter ihren Taupunkt abgekühlt und so zur Kondensation gezwungen werden. Diese Annahme wird noch dadurch bestätigt, daß einmal die Secwinde den Nebel nicht verdrängen, und daß die Kondensation und Abkühlung in der Nähe des Erdbodens am stärksten ist.

Außer dem Nebel gibt es noch eine zweite Form der sichtbaren Wasserdämpfe, nämlich die Wolken; auch sie bestehen in gleicher Weise wie die Nebel aus feinen Wassertröpfchen von durchschnittlich $0.02 \mathrm{~mm}$ Durchmesser, ${ }^{2}$ ) nur ist ihre Gestalt von einer größeren Mannigfaltigkeit. Der Grad der Bewölkung wurde geschätzt nach der Ioteiligen Skala, indem o den heiteren und ro den trüben Himmel bezeichnet.

Der Hinmel ist in Swakopmund im siebenjährigen Tagesmittel durchschnittlich etwas mehr als zur Hälfte bewölkt (5.6), die Schwankung in den einzelnen Jahren ist gering, sie liegt zwischen 6.6 und 4.7; auch der jährliche Gang zeigt nur geringe Unterschiede; die größten Werte weisen die Monate

1) v. Bezold, Thermodynamik.

2) Hain, Lehrb. d. Met. I906 S. 200.
November bis März auf mit dem Maximum im Dezember. Die übrigen Monate zeigen eine Abnahme der Bewölkung; das Minimum weist der Juni auf mit 3.9.

Im täglichen Gang betragen die Bewölkungsgrade $7 \mathrm{a}: 7.6,2 \mathrm{p}: 4.4,9 \mathrm{p}: 4.8$; auch in den einzelnen Monaten zeigen sich nur geringe Schwankungen.

Termin Jahresschwankung Max. Min.

$\begin{array}{cccc}7 \mathrm{a} & 3.7 & \text { Febr. } & \text { Mai bis Juni } \\ 2 \mathrm{p} & 2.4 & \text { Febr. } & \text { Mai bis Juni } \\ 9 \mathrm{p} & 3.6 & \text { Dez. } & \text { Juni }\end{array}$

Da konstante Seewinde das ganze Jahr vorherrschen, so muß auch die Bewölkung in ihrem jährlichen Gange eine große Regelmäßigkeit zeigen; dieselbe würde noch bedeutender sein, wenn nicht in den Monaten Mai bis Juli die heißen, trockenen Ostwinde den feuchten Seewinden entgegenwirken würden.

Weitaus am häufigsten sind die Bewölkungsgrade $O$ und $x O$.

Sehr wünschenswert für eine Vorstellung von der Bewegung der oberen Luftströmungen und der Ursache der Bewölkung wäre eine Angabe im Beobachtungsjournal über die Wolkenform (cumulus oder stratus) und die Richtung des Wolkenzuges gewesen.

Wie wir gesehen haben, erreicht der Nebel sein Maximum in der kühlen, die Bewölkung dagegen in der warmen Jahreszeit; obwohl beide in ihrer "Struk. tur « sich sehr ähnlich sind, so ist doch ihre Entstehungsweise eine sehrverschiedene. NachKöppen ${ }^{1}$ ) setzt die Nebelbildung das Fehlen einer vertikalen Komponente in der Luftbewegung voraus; ein starker vertikaler Luftaustausch bewirkt einen Temperaturuberschuß der unteren Luftschichten, eine stete Entfernung von ihrem Sättigungspunkte und daher eine nebelfreie Luft, dagegen in den oberen Luftschichten Wolkenbildung. Nebelbildung wird begünstigt durch Windstille oder durch übereinander hinfließende Luftströmungen, die Wolkenbildung vorwiegend durch den aufsteigenden Luftstrom. Über dem Nebel und Wolken findet sich meist eine Temperaturzunahme. (Lamp2), Köppen $\left.{ }^{1}\right)$.) Nach dem jährlichen Gange der Nebelhäufigkeit und dem Grad der Bewölkung kann man schließen, daB in Swakopmund in der warmen Jahreszeit die vertikalen, in der kühlen die horizontalen Luftströmungen überwiegen.

\section{Der Niederschlag.}

Nach seiner Lage zum Meere, nach den konstanten Seewinden, häufigen Nebeln und hoher Luft-

1) Met. Z. I 885, S. 30 .

2) Met. Z. 1884, S. 474 . 
feuchtigkeit zu urteilen, sollte man in Swakopmund auch reichliche Niederschläge erwarten, leider ist gerade das Gegenteil der Fall. Die Küiste gehört mit zu den regenärmsten Strichen der Erde.

Während im Innern der Regen in der warmen Jahreszeit fällt und nur in der äußersten Süilwestecke Winterregen vorwiegen, hat Swakopmund keine ausgesprochene Regenzeit, nach der kurzen Beobachtungsperiode scheint mehr Neigung zu Sommerregen vorhanden zu sein; dasselbe fand Dove ${ }^{l}$ ) für Waltischbai.

Dic Jahressumme beträgt im Mittel $18.5 \mathrm{~mm}$; die Schwankungen sind bedeutend, die größte betrug 34.5 (I900), die kleinste 6.5 (1905); die beiden letzten Beobachtungsjahre I904 (6.7) und 1905 (6.5) lieferten die kileinsten Niederschläge.

Dieser geringe Niederschlag, der auBerdem über das ganze Jahr verteilt ist, vermag keinerlei Vegetation hervorzurufen.

Die größte Regenmenge innerhalb $2+$ Stunden fiel im Dezember I 900 , nämlich $14.7 \mathrm{~mm}$; die beiden letzten Jahre 1904 und 1905 zeigen auch die kleinsten Maxima innerhalb 24 Stunden, nämlich IgO4: 3.5 und Ig05: $5.0 \mathrm{~mm}$.

Die Zahl der Regentage im Jahre beträgt im Mittel 42.3; sie schwankt zwischen 73 (I903) und 4 (I905) Tagen. Das Maximum an Regentagen liefert der Monat Ausust I 90 I mit I 4, der Niederschlag beträgt aber nur I.9 mm. Regenlose Monate kommen häufig vor; während der ganzen Beobachtungsperiode waren 24 Monate $=30 \mathrm{v} . \mathrm{H}$. olne jeden Niederschlag; die Zahl der Regentage mit $>1.0 \mathrm{~mm}$ ist sehr gering, sie betragen im Mittel nur 3 Tage im Jahre und im Maximum 6 Tage; ungefähr dreimal so groß ist die Zahl der Tage mit $>0.2$ bis $1.0 \mathrm{~mm}$, nämlich 8.8. Das Maxinum weist i6 Tage im Jahre auf. Zieht man die Regentage mit $>0.2$ und $\mathrm{I} .0 \mathrm{~mm}=3.0-8.8=\mathrm{I}$ I. 8 von der Zahl der Regentage iiberhaupt ab, so erhält man die Zahl der Tage mit nicht mebbarem Niederschlag $=30.5$ Tage, also die weitaus gröbte Zahl der Regentage, etwa 7o v. H., liefern keinen mebbaren Niederschlag.

Worin ist nun der Grund fuir die geringen Niederschläge zu suchen?

Im Innern bringen bekanntlich $\mathrm{N}$-NE-Winde den Regen, sie verlieren ilure Feuchtigkeit immer mehr, je weiter sie nach SW vordringen; ${ }^{2}$ ) dieselben erreichen die Küste überhaupt nicht, wie aus dem geringen Prozentsatz der Landwinde in der warmen Leit hervorgeht; aber selbst wenn diese bis an die Kiiste gelangten, so würde durch das Herabsteigen und Kompression die Luft bedeutend erwärmt, und

1) Dove, Das auBertiopische Südafrika, S. 133.

2) Dove, Deutsch-Südwestafrika. Petermanns Mitteil. Ergänzungsband ז $20,1896$. somit würden die ohnehin ihrer Feuchtigleit beraubten Winde nicht ihrer Kondensation entgegengeführt, sondern würden sich vielmehr von derselben immer mehr entfernen, je näher sie der Küste gelangen.

Stapff ${ }^{1}$ ) berichtet hierüber: „Die zur Regen\%eit aus dem Innern lommenden Gewitterwolken entladen sich rorher oder verdampfen auf ihrem Vege uiber die Stein- und Sandwüiste."

Ähnlich ist es mit den Seewinden; dieselben wehen aus einer höheren Breite nach einer niederen, also wärmeren. Die Seewinde haben eine niedere Temperatur, sie können daher auch wenig Feuchtigkeit aufnehmen; bei Passieren der kalten Strömung werden sie abgekïhlt und zur Kondensation gezwungen, beim Erreichen des Landes und Weitervordringen in das Innere durch den erhitzten Sandboden aber erwärmt, entternt sich ihre Temperatur immer mehr vom Taupunkte; daher die auffallende Erscheinung, daß ein am Meere gelegener Ort, welcher das ganze Jahr hindurch konstanten Seewinden ausgesetzt ist, fast regenlos ist. Die kalte Meeresströmung übernimmt also dieselbe Rolle wie in anderen Gegenden die hohen Gebirgskämme.

Swakopmund liegt im Regenschatten der kalten Meeresströmung.

Dab die Küste nördlich von Swakopmund reichlichere Niederschläge empfängt, ist sehr unwahrscheinlich; denn das kalte Meereswasser erwärmt sich viel langsamer als die Luft; die negativ-thermische Anomalic wird also nach Norden immer zrößBer, mithin die Regenwahrscheinlichleit geringer. Aus dem Innern ist auch kein Regen zu erwarten, denn die Küste fällt ziemlich steil und terrassenförmig nach dem Meere $z u$ ab und begünstigt daher die Bildung von Fallwinden, die bekanntlich mehr geeignet sind, Wollien aufzulösen, als Kondensation herbeizufülıren.

Der Dunst, welcher nach Stapff²) oft uiber dem Meere lagert, ist nichts anderes als eine (lurch $\mathrm{Ab}$ kiullung hervorgerufene Kondensation der Seewinde, ähnlich dem »Tafeltuche« über dem Tafelberge bei Kapstadt, der seine Entstehung den Südwinden verdankt; auch hier werden die Winde abgekiihlt, und zwar durch das Emporsteigen am Tafelberge, und zur Kondensation gezwungen. Beim Herabsteigen werden die Winde durch Kompression wärmer, und sobald die Temperatur über den Taupunkt gelangt, findet die Kondensation ihr Ende. Dieselbe Rolle wie der Tafelberg bei den Südwinden übernimmt die kalte Meeresströmung bei den SW-Winden. Der Dunst auf der Landseite, besonders während der Nacht, dürfte sich erklären durch die Mischung der

1) Kol. Zeit. Berlin I 887 , S. 650.

2) Deutsch. Kol. Zeit. I 887 , S. 649. 
kalten, feuchten Seewinde mit den warmen, trockencn Landwinden, die wohl Trübung, aber keine Niederschläge liefern können. (v. Bezold. ${ }^{1}$ )

Im Innern selbst ist die Luft das ganze Jahr hindurch sehr klar und von einer wunderbaren Durchsichtigkeit, die nur im nördlichen Gebiete am Ende der Trockenzeit durch Grasbrändc gestört wird, so daß Triangulationsarbeiten im Gegensatz zu andern Ländern, z. B. Deutschland, das ganze Jahr hindurch ausgeführt werden können.

Die Zahl der Gewitter und Wctterleuchten ist eine außerordentlich geringe; sie betrug:

\begin{tabular}{|c|c|c|}
\hline $\begin{array}{l}\text { in den } \\
7 \text { Beob. } \\
\text { jahren }\end{array}$ & $\operatorname{im}_{\text {Mittel }}$ & Ma: \\
\hline I6 & 2.3 & 1902 \\
\hline \multirow[t]{3}{*}{ I8 } & 2.6 & I 900 \\
\hline & & 1902 \\
\hline & & 1904 \\
\hline
\end{tabular}

Min.

Gewitter ...... I6 $2.3 \quad$ I902: 5 I903:0

Wetterleuchten . . I $8 \quad 2.6 \quad$ I 900

s. Tafel III.

1904

I903:O

Im Innern des Landes dagegen sind Gewitter eine recht häufige Erscheinung, so wurden von Juli 1902 bis Juni 1903 in Otavi 93 Gewittertage ${ }^{2}$ ) notiert.

Seit dem Jahre 1900 wurden auch die für Swakopmund so wichtigen Brandungsverhältnisse beobachtet; die Resultate sind jedoch in den einzelnen Jahren nicht miteinander vergleichbar, da die Prädikate mit den Beobachtern oft wcchselten. Im Jahre I900schätzte man nach: sehr gut, gut, mäBig, schlecht, sehr schlecht, I901 bis 1904: gut, mittel, schlecht, sehr schlecht, 1905: sehr gut, gut, mittel, schlecht, sehr schlecht; läßt man das Jahr I 900 fort und faßt für I905 »sehr gut « und »gut « zusammen in »gut", so erhält man folgendes Resultat (Tabelle VIIIc).

Im allgemeinen ist die Brandung am günstigsten im Januar und Oktober und am schlechtesten von Mai bis August mit einem Maximum im Juli.

\section{Luftdruck und Windverhältnisse.}

Von allen klimatologischen Elementen ist derLuftdruck dasjenige, welches die größte Konstanz besitzt, und das in praktischer Hinsicht eine sehr untergeordnete Rolle spielt. Der höchste zu Swakopmund beobachtete Luftdruck betrug $770.5 \mathrm{~mm}$, der niedrigstc $753.7 \mathrm{~mm}$, die Differenz mithin $16.8 \mathrm{~mm}$; diese Druckdifferenz entspricht einem Höhenunterschiede von rund $175 \mathrm{~m}$. Ein jeder, der einen Hügel von ähnlicher Höhe bestiegen hat, weiß aus Erfahrung, $\mathrm{daß}$ eine derartige Verminderung des Luftdrucks überhaupt nicht zu verspüren ist. Trotzdem ist die Messung des Luftdrucks auf den meteorologischen Stationen mit aufgenommen worden, wcil von ihm

1) v. Bezold, Zur Thermodynamik der Atmosphäre. Sitz. Bericht der König1. preuß. Akademie. 1889.

2) Mitteil. a. d. Deutsch. Schutzgebieten. 1904 S. 33. die ganze Zirkulation der Atmosphäre abhängt. Die Luftdruckdifferenz oder der Gradient, d. h. ihre Größe pro Äquatorgrad (I I $\mathrm{km}$ ), ist die Ursache der Winde; diese sind die eigentlichen Träger des Klimas, ${ }^{1}$ ) und ganz besonders ist dies bei einem Küstenorte der Fall, der den Land- und den Seewinden mit ihren meist ganz entgegengesetzten Charaktereigcnschaften ausgesetzt ist.

Um die Ergebnisse der Luftdruckbeobachtungen an den verschiedenen Orten miteinander vergleichen zu können, werden die Barometerständc auf Normalbreite, auf das Meeresniveau und $o^{\circ}$ reduzicrt; die so erhaltenen Resultate nennt man »wahre Werte ${ }^{2}{ }^{2}$ )

Bei dem vorliegenden Material ist als Höhe über dem Meere bis März $1902 \mathrm{~h}=5.0 \mathrm{~m}$, vom April $\mathrm{I} 902$ an aber $\mathrm{h}=7.4 \mathrm{~m}$ angegeben worden, da nicht ersichtlich ist, ob die verschiedenen Angaben ihren Grund haben in einer Veränderung der Barometeraufhängung oder in einer Verlegung des Nullpunktes infolge neuer Pegelbeobachtungen oder schließlich in einer verbesserten Höhenbestimmung durch ein genaueres Nivellcment, sind obige Korrektionen - mit Ausnahme der Reduktion auf $0^{\circ}-$ an dem vorliegenden Material nicht angebracht worden.

Das Jahresmittel des Luftdrucks beträgt $762.2 \mathrm{~mm}$; die Schwankung in den einzelnen Jahren ist sehr gering; sie beträgt durchschnittlich $0.27 \mathrm{~mm}$ und im Maximum $0.4 \mathrm{~mm}$. Das Jahr I 899 hat entsprechend seiner höchsten Temperatur den niedrigsten $(761.8 \mathrm{~mm})$, das Jahr 1903 als das kälteste den höchsten Luftdruck $(762.6 \mathrm{~mm})$. Bringt man an dem Jahresmittel von $762.2 \mathrm{~mm}$ noch die Schwerekorrektion von - $1.4 \mathrm{~mm}$ und unter Annahme von $7.4 \mathrm{~m}$ Seehöhe die Redultion auf das Meeresniveau von $+0.6 \mathrm{~mm}$ an, so erhält man das wahre Jahresmittel von $761.6 \mathrm{~mm}$, dasselbe ist um $1.6 \mathrm{~mm}$ höhcr als der sogenannte $»$ Normaldruck von $760.0 \mathrm{~mm}$ im Meeresniveau. Diese Abweichung hat wohl weniger in der negativen thermischen Anomalie ihren Grund als vielmehr in der Lagc Swakopmunds zu den Roßbreiten, ist also mehr dynamischen Ursprungs; daß die Verteilung des Luftdrucks auf dcr Erdoberfläche keine reine Funktion der Temperatur ist, zeigt schon die Tatsache, daß vom Äquator bis zu den Roßbreiten der Luftdruck zu-, die Temperatur abnimmt, von den Roßbreiten nach den höheren südlichen Breiten dagegen nehmen beide, sowohl Luftdruck wie Temperatur, ab. ${ }^{3}$ )

Die jährliche Schwankung ist sehr gering; sie beträgt nur $4.4 \mathrm{~mm}$. Die höchsten Werte erreichen

1) Supan, Statistik der unteren Luftströmungen, r88I, S. I.

2) H. Meyer, Anleitung, S. 59.

3) Hann, Lehrbuch der Met., 1906, S. I37. 
Juni bis August, die niedrigsten Januar bis März, also die Monate nach dem tiefsten und höchsten Sonnenstande. Im allgemeinen ist der jährliche Gang des Luftdrucks demjenigen der Temperatur entgegengesetzt; das Minimum fällt in den wärmsten Monat (März) und das Maximum in den kältesten (August); denselben Gang zeigen die absoluten Maxima und Minima; ihre Differenzen zeigen im jährlichen Gang keine ausgeprägte Periode, sie schwanken zwischen 8.3 und $12.3 \mathrm{~mm}$. Das absolute Maximum beträgt $770.5 \mathrm{~mm}$, das entsprechende Minimum $753.7 \mathrm{~mm}$, die absolute Schwankung mithin I $6.8 \mathrm{~mm}$.

Der tägliche Gang zeigt gegen Mittag regelmäßig ein Fallen um $1.8 \mathrm{~mm}$ und zum $9 \mathrm{p}$ Termin ein Steigen um I.I $\mathrm{mm}$, so dab am Abend das Barometer um $0.7 \mathrm{~mm}$ niedriger steht als am Morgen.

Selbst eingehende Erörterungen über die Luftdruckverhältnisse eines einzelnen Ortes liefern direkt für die Darstellung seines Klimas so gut wie kein Material, erst durch Vergleichen wahrer Luftdruckangaben von mehreren Orten gewinnt man einen Einblick in die Verteilung des Luftdrucks, der hieraus resultierenden Winde und der anderen limatischen Faktoren.

Da aber derartige Angaben für das in Frage kommende Gebiet nicht vorhanden sind, so wollen wir kurz die Luftzirlulation zwischen Äquator und Pol auf der südlichen Halbkugel sowie die aus den Temperaturdifterenzen zwischen Land und Meer sich ergebenden Komponenten der WVindrichtungen für Swakopmund unter Benutzung der Theorie von Ferrel und der Isobarenkarten von Hann und Buchan betrachten.

Die moderne, physikalische Windtheorie sieht in der durch die ständige, hohe Erwärmung und die dadurch hervorgerufene Hebung der Temperaturflächen am Äquator eine Verstärkung der sphäroidischen Gestalt der Erde, und diese bildet den Anstoß zum Aquatorialstrom, der auf der suidlichen Halbkugel durch die Rotation der Erde eine westöstliche Komponente erhält und daher nicht auf dem geraden Wege, dem Druckgefälle folgend, zum Pol gelangt, sondern in einem großen Wirbel mit westöstlicher Richtung den Südpol umkreist; jedoch gelangt nur der Rest des Äquatorialstroms bis in den Polarwirbel; der übrige Teil sinkt schon zwischen dem 30. und $40 .^{\circ}$ zur Erde - und zwar nach Supan ${ }^{1}$ ) infolge Konvergenz der Meridiane gegen den Pol, nach Ferrel2) durch die äquatorwärts stauende Wirkung des Polarwirbels — und bildet hier einen

1) Supan, Statistik der unteren Luftströnungen, I88I, S. 17.

2) Met. Zeitschrift i 906, S. 354.
Gürtel hohen Luftdruclis; von hier neigen sich die Niveaufächen nach Norden bis zum Äquator und erzeugen den Passatwind so wie nach Süden und bilden dort mit dem polaren Wirbelring ein barometrisches Tal.

Während nun die Neigung der Niveauflächen von den Roßbreiten nach dem Südpol zu sich auf den Isobarenkarten durch den parallelen Verlauf der Linien gleichen Niveaus deutlich zeigt, findet man auf der Nordseite eine Störung; besonders in der Nähe des Kontinents treten erhebliche Unregelmäßigkeiten der Isobaren hervor. Wir wollen daher die Störungen der Niveauflächen und die Verteilung des Luftrucks iiber Südafrika und dem angrenzenden Meere in seinem jährlichen Verlaufe näher betrachten.

Nach Buchan befinden sich im Januar zwei Hochdrucligebiete zu beiden Seiten Südafrikas, das westliche mit $76+\mathrm{mm}$ etwas näher, das östliche mit $766 \mathrm{~mm}$ etwas weiter von der Küste; das Innere bedeckt in seiner östlichen Hälfte eine ausgedehnte Depression mit $757 \mathrm{~mm}$; letztere wandert mit der Sonne nach Norden und lagert im März bereits nördlich vom Äquator, währenddessen folgen die beiden Hochdrucligebiete ebenfalls etwas nach Norden und nähern sich, besonders das westliche, der Küste. Im Mai entsteht noch ein drittes Maximum im Innern mit $764 \mathrm{~mm}$. Von jetzt an weichen die Hochdruckgebiete von der Küste zurück und verstärken sich westlich auf $767 \mathrm{~mm}$, östlich auf $770 \mathrm{~mm}$; vom Monat August ab verschwindet das Luftdruck. maximum im Innern; diejenigen auf dem Meere schwächen sich ab und nähern sich der Küste. Im November erscheint die Depression wieder im Seengebiet Ostafrikas und folgt der Sonne nach Süden, wo sie im Januar mit $30^{\circ}$ sudlicher Breite ihre Grenze erreicht, um dann wieder nach Norden zu wandern.

Diese regelmäbigen Verschiebungen der Luftdruckmaxima und-Minima zueinander haben an der Küste Winde von monsunartigem Charakter zur Folge, und zwar haben wir infolge der Depression im Innern während des südhemisphärischen Sommers an der Westkïste nach dem Windgesetz von Buys Ballot für die südliche Halbkugel SW- und im Winter NE-Winde zu erwarten.

Der Güitel hohen Luftdrucks zwischen dem 3o. und 40. Grad südlicher Breite wird also während des südhemisplärischen Sommers durch die über Südafrika lagernde tiefe Depression durchbrochen, und es erhalten dadurch die nach $\mathrm{N}$ geneigten Niveaufächen ein starkes Gefälle nach E, und da nach dieser Richtung hin der Gradient bedeutend größer ist als nach $\mathrm{N}$, so wird der nach dem Äquator 
zurückkehrende SE-Passat als SW-Wind nach der südwestafrikanischen Küste abgelenkt.

Die aus SW bis $S$ vorherrschenden, polaren Winde sind also nichts anderes als der nach dem erhitzten Kontinent abgelenkte SE-Passat.

Über den SW- bis S-Wind sagt Supan:1)

"Wie eine Garbe teilt sich der Passat, um als SW bis $\mathrm{S}$ gegen Afrika, als $\mathrm{E}$ bis NE gegen Südamerika abzufließen, und diese Zweigströme gewinnen im Sommer bedeutend an Mächtigkeit, weil dann die erhitzten Nachbarkontinente eine besonders intensive Anziehungskraft ausüben.«

Wenn auch in der kühlen Jahreszeit die heransaugende Depression fehlt, so ist doch während dieser 'Zeit die Küste, besonders mittags, stets wärmer als das Meer, wie folgende Tabelle zeigt, und infolgedessen wehen in der kühlen Jahreszeit die SW-bis S-Winde als Küstenwind. ${ }^{2}$ ) Der ständige SW-bis S-Wind an der südwestafrikanischen Küste ist daher nicht bloß eine Folge der verschiedenen Erwärmung zwischen Land und Meer, wie Ortloff 3 ) annimmt, sondern auch des ständigen Barometermaximums im Südatlantischen Ozean.

Lufttemperatur - Meerestemperatur.

$$
\text { I. II. III. IV. V. }
$$

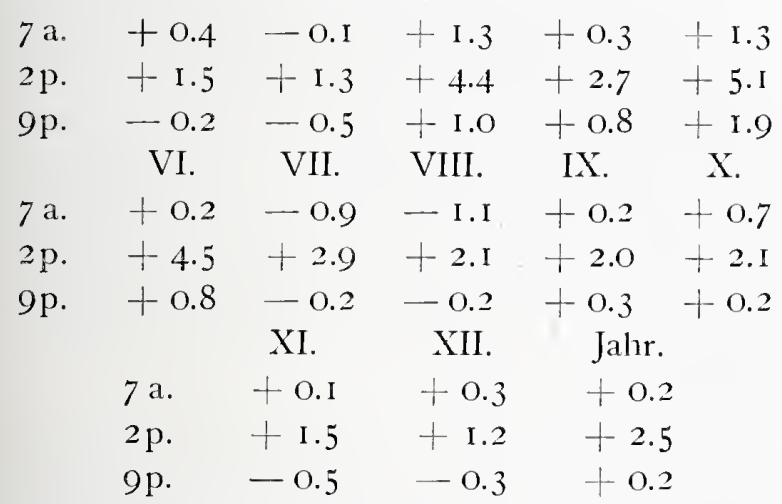

Die Abschwächung der SW-Winde am Morgen ist eine Folge der stärkeren nächtlichen Abkühlung des Landes gegenüber dem Meere, die besonders in der kühlen Jahreszeit häufige Landwinde zur Folge hat.

Nach einer Notiz seitens der Redalition der "Mitteilungen aus den Deutschen Schutzgebieten « ist durch den Zoologen Dr. Schulze festgestellt worden, daß die Windrichtungen in Swakopmund mißweisend notiert und so in obiger Zeitschrift veröffentlicht worden sind; da die Mißweisung $24.6^{\circ} \mathrm{W}^{4}$ ) beträgt, wurden die Bezeichnungen der I6teiligen Windrose

1) Supan, a. a. O., S. 216.

2) Supan, a. a. O., S. I30.

3) Zeitschrift fïr Bauwesen, r904, S. 357.

4) Atlas zum Segelhandbuch für den Atlantischen Ozean, 1902, Tafel 34 . um 22 $\frac{1}{2}$ im Sinne des Uhrzeigers gedreht, so daß an die Stelle des ursprünglichen $\mathrm{N}$ - jetzt NNW-Wind gesetzt wurde.

Die Beobachtungen sind nicht gleichmäßig, der eine Beobachter hat nach der I 6 teiligen, der andere nach der 8 teiligen Windrose beobachtet; vom Januar I9O2 bis I5. Juli I904 wurde ausschließlich nach der 8 teiligen Windrose geschätzt, aber auch während der übrigen Zeit scheint dies öfter der Fall zu sein. Bei der Darstellung der Häufigkeit der Winde wurde daher die I 6 teilige Windrose in eine 8 teilige zusammengezogen, indem die Nebenrichtungen je zur Hälfte zu den benachbarten Richtungen addliert wurden.

In der Tafel IV sind die Winde für die einzelnen Beobachtungstermine und das Tagesmittel inProzenten für jeden einzelnen Monat enthalten.

Wie Tafel IV und graphische Darstellung zeigen, herrschen morgens die Winde aus dem nördlichen Quadranten vor N, NW und NE, dann folgen nach ihrer Häufigkeit W, C, E, SW, SE, S. Während der N-Wind einen mehr schwankenden Gang aufweist und dadurch zugleich zeigt, daß er seine Entstehung wechselnden Ursachen verdankt, wahrscheinlich den von $W$ nach $E$ über Südafrika hinwegziehenden Depressionen, zeigen die übrigen Winde einen regelmäßigen Gang. Die Landwinde (NE, E und SE) erreichen während der kalten Jahreszeit, und zwar im Juni, ihre größte Häufigkeit, zugleich erreicht auch das zu dieser Jahreszeit im Innern ausgebreitete Hochdruckgebiet mit $768 \mathrm{~mm}$ seine größte Stärke. Die Landwinde sind also eine Folge der über dem Lande ausgedehnten Antizyklone, sie werden noch verstärkt durch den Temperaturunterschied zwischen dem Meere und dem Innnern des Landes, wo gerade in dieser Zeit Temperaturen $<0^{\circ}$ häufig sind. Die Landwinde haben in der kühlen Jahreszeit in gleicher Weise wie die SW-S-Winde in der wärmeren Jahreszeit eine dynamische und thermische Ursache.

Man hat sich den Gang der Luftzirkulation so zu denken, daß in der kühlen Jahreszeit über dem Atlantischen Ozean in der Nähe der Roßbreiten der Äquatorialstrom aus der Höhe auf das Meer herabsinkt; dieser Luftdruck wird noch verstärkt dadurch, daß durch die Erhitzung des Landes im Innern die Niveauflächen sich heben und infolgedessen die Luft nach dem Meere hin abfließt, hierdurch entsteht eine Gefälle vom Meere zum Lande; bei ihrer Annäherung an die Küste wird die Windgeschwindigkeit durch die Temperaturdifferenz zwischen Meer und Land noch vermehrt, daher die größte Windstärke zur Zeit des größten Temperaturunterschiedes. Im Innern steigt die Luft in der Depression in die 
Höhe und flebt nach dem Meere hin ab, wird in die Antizylione hineingezogen, um so den Kreislauf zu wiederholen. In der kïhlen Jahreszeit hat man sich den Kreislauf während der Nacht und am Morgen umgekehrt zu denken. Daher weht der SW-Wind um 7 a-Termin sehr schwach, aber bereits $2 \mathrm{p}$ hat er die 7 . Stelle mit der ersten vertauschıt und behält dieselbe auch während des Abendtermins; da mittags der Temperaturunterschied zwischen Meer und Land am größten ist, so wehen hier die Seewinde mit großer Kraft. Während der SIV das ganze Jahr hindurch fast gleich häufig weht, zeigen S- und IVWind einen deutlichen, aber umgelichrten Gang, nämlich der $\mathbb{V}^{\top}$-Wind ein Maximum im Dezember und ein Minimum im Mai, beim S-Mind sind die Extreme vertauscht, beide ergänzen sich fast zu gleicher Stärke. Im 2p-Termin folgen nach ihrer Häufigkeit SWT, IV, S, NV, N, NE, SE, E, C. Dic Landwinde sind an die letzte Stelle getreten, da mittags das ganze Jahr hindurch das Land bedeutend wärmer als das Meer ist; Windstillen lommen mittags so gut wic gar nicht ror.

An $9 \mathrm{p}$-Termin nelmen die Iandwinde ein wenig zu; bei weitem dominieren jedoch die Scewinde SIV, S, NW, W. S- und SW-Wind zeigen keinen ausgeprägten jährlichen Gang; dies duirfte sich daher erklären, daß mit dem Abnehmen des Temperaturunterschiedes zwischen Meer und Land in der küullen Jahreszeit der Gradient durch die Annäherung der atlantischen Antiziklone an die Kiiste verstärkt wird.

So lösen die dynamischen die thermischen Gegensätze ab. Im Tagesmittel treten ebenfalls dic Seewinde stark hervor; ein Zeichen, daß der Luftdruck über dem Meere durchschnittlich höher ist als auf dem Lande.

In täglichen Gang iiberwiegen also morgens die Winde aus dem $\mathrm{N}$-, mittags aus dem $\mathrm{S}$ - bis $\mathrm{W}$ - und abends aus dem S- bis SW-Quadranten.

Fs duirfte nicht uninteressant sein, bei den charakteristischen Windverhältnissen von Swakopmund den Gang der mittleren Windrichtung ${ }^{1}$ ) während des Jahres festzustellen.

$\mathrm{Zu}$ diesem Zwecke wurde die Häufigkeit jeder Windrichtung mit ihrer mittleren Windstärke multipliziert und so die verschiedenen Windwege erhalten, aus diesen wurde nach der Formel ${ }^{2}$ ) für das Kräfteparallelogramm die Resultierende nach Rich-

1) M. Lambext, Nouveaux mémoires de lacadémie roy. des sciences et belles lettres, Berlin I 777, Classe de math. pag. 36 . Sur les observations du vent.

2) Die Formel lantet füx die I6 teilige Windrose: $\operatorname{tang} \varphi=\frac{\mathrm{E}-\mathrm{W}+\cos 22 \frac{1}{2}(\mathrm{ESE}+\mathrm{ENE}-\mathrm{WNW}-\mathrm{WSW})+\cos 45(\mathrm{SE}+\mathrm{NE}-\mathrm{NW}-\mathrm{SW})+\cos 67 \frac{1}{2}(\mathrm{SSE}+\mathrm{NNE}-\mathrm{NNW}-\mathrm{SSW})}{\mathrm{N}-\mathrm{S}+\cos 22 \frac{1}{2}(\mathrm{NNE}+\mathrm{NNW}-\mathrm{SSW}+\mathrm{SSE})+\cos 45(\mathrm{NE}+\mathrm{NW}-\mathrm{SW}-\mathrm{SE})+\cos 67 \frac{1}{2}(\mathrm{ENE}+\mathrm{WNW}-\mathrm{WSW}-\mathrm{ESE})} \cdot$ Die Größe der Resultierenden $\mathrm{R}=\sqrt{\mathrm{A}^{2}+\mathrm{B}^{2}}$. tung und Größe berechnet, nachdem zuvor die S. von der $\mathrm{N}$ - und die $\mathrm{IV}^{\mathrm{r}}$ - von der E-Komponente subtrahiert worden waren.

Die Richtung und Größe der Resultierenden für die einzelnen Monate und das Jahr in den drei Beobachtungsterminen sind in Tafel $\mathrm{V}$ enthalten.

Die mittlere Richtung ist in ihrem jährlichen Gange durch die Angabe der Wendepunlite geliennzeichnet worden.

Aus der graphischen Darstellung ist folgendes zu ersehen:

Im 7 a-Termin schwankt die mittlere Richtung zwischen $\mathrm{IV}+7.5^{\circ} \mathrm{N}$ im Dezember und $\mathrm{N} 65.0^{\circ} \mathrm{E}$ im Juni; die Größe der Schwankung beträgt mithin I07 $1 \%{ }^{\circ}$, im 2p- und $9 \mathrm{p}-$ Termin ist die Schwankung bedentend geringer, die Werte für 2p sind:

$\mathrm{S} 58.7^{\circ} \mathrm{W}$ im Februar und $\mathrm{S} 30.5^{\circ} \mathrm{W}$ im Mai, die Schwankung $=28.2^{\circ}$, für 9p: $\mathrm{S} 54.7 \mathrm{~W}$ im Dezember und S 28.5 W im August, die Schwanliung beträgt $26,2^{\circ}$; sie erreicht mithin $9 \mathrm{p}$ ihren kleinsten Wert, d. h. die mittlere Windrichtung ist $\mathrm{zu}$ dieser Zeit am konstantesten; wenn man ferner aus der mittleren Windrichtung auf die Lage des barometrischen Minimums schließen wollce, so wäre dasselbe morgens in der warmen Zeit südöstlich von Swakopmund zu suchen; dic Depression wandert - nach dem Gang der mittleren Windrichtung zu schließen - iiber S und W nach NV; hier liegt sie im Juni and wandert bis Dezember wieder iber $W$ und $S$ nach SW zuriick; mittags und abends liegt die Depression in der warmen Zeit östlich von Swakopmund und wandert mit der Sonne in der kalten Jahreszeit nach Norden analog der Isobarenkarte von Buchan.

Es iiberwiegt also:

im 7 a-Termin der thermische Gradient, welcher sich durch die stärliere Ausstrahlung des Landes während der Nacht zwischen diescm und dem Meere gebildet hat,

im $2 \mathrm{p}^{-}$und $9 \mathrm{p}$-Termin der dynamische Gradient, hervorgerufen durch das Luftedruckmaximum der Roßbreiten und der Depression im Innern; mit der Verschiebung dieser nach Norden drehen sich die SW-Winde etwas nach Suiden.

Wenn Windstärken nicht vorliegen, kann man nach Lambert die mittlere Windrichtung auch aus der Windhäufigkeit berechnen; diese Rechnung wurde für den 7 a-Termin ausgeführt.

Die Resultate in Tafel $\mathrm{V}$ zeigen gegen die strengere Rechnung Differenzen zwischen $0.2^{\circ}$ (Juni) und $16.5^{\circ}$ (Dezember) und im Jahr $10.8^{\circ}$. 
Wir sehen also, daß in Swakopmund trotz der kurzen, aber stürmischen E-Winde im allgemeinen doch die Stärke der Winde ihrer Häufigkeit ziemlich proportional ist, und die relativ geringen Unterschiede zwischen beiden Rechnungsmethoden zeigen, $\mathrm{da}$ ß es erlaubt ist, die Richtung der Resultierenden - trotz der eigenartigen Windverhältnisse in Swakopmund - aus der Häufigkeit zu berechnen, wie es bereits Coffin ${ }^{1}$ ) für die Niederungen und Pernter ${ }^{2}$ ) für die Berggipfel nachgewiesen haben.

Nachdem wir die mittlere Richtung der Winde zu Swakopmund kennen gelernt haben, wollen wir jetzt ihre Charaktereigenschaften näher betrachten.

Um den Einfluß der Windströmungen auf das Klima von Swakopmund festzustellen, sind die Windrosen für Temperatur, Windstärke und Bewölkung berechnet worden.

Die Windrosen wurden zuerst von Lambert im Jahre I77I vorgeschlagen und daraufhin von v. Buch, Dove, Kämtz u. a. angewandt; man erkannte jedoch bald, daß dieselbe Windrichtung in bezug auf Temperatur und Feuchtigkeit einen ganz verschiedenen Charakter hat, je nachdem sie einer Zyklone oder Antizyklone entstammt; schon Dove sagte: "Die Winde sind Lügner, welche ihren Ursprung verleugnen".

Wenn z. B. in Swakopmund ein S-Wind weht, so kommt er aus südöstlich gelegenen Gebieten, wenn er einer Zyklone, dagegen aus nordwestlichen Gegenden, wenn er einer Antizyklone angehört; im ersteren Fall ist er Landwind, im zweiten Seewind.

Köppen ${ }^{3}$ ) macht bei seiner Untersuchung: UUber die Abhängigkeit des klimatischen Charakters der Winde von ihrem Ursprunge u unter Benutzung von synoptischen Wetterkarten den Unterschied, ob der Ort (Petersburg) im Gebiete einer Zyklone oder Antizyklone lag, und fand so sehr markante Unterschiede.

Am wenigsten scheint der Barometerstand von der Windrichtung beeinflußt zu werden, so gelangte z. B. Schreiber ${ }^{4}$ ) zu folgendem Resultate: »Windrichtung und Barometerstand stehen in keiner ausgeprägten Abhängigkeit erster Ordnung. Die Windrichtung kann den Barometerstand weder erhöhen noch herabdrücken, es können alle Barometerstände bei allen Windrichtungen vorkommen «.

Tafel VI zeigt uns die den einzelnen Windrichtungen während des Jahres in den drei Beob-

1) Coffin. Winds of the Globe. Washington 1875 .

$\left.{ }^{2}\right)$ Pernter. Die Windverhältnisse auf dem Sonnenblick. Wien I89I.

3) Rep. f. Met. Bd. IV, Nr. 4. I874.

4) Schreiber. Die Bedeutung der Windrosen für theoretische und praktische Meteorologie und Klimatologie. Peterm. Mitteil., Ergänzungsband XV. I88I/82, S. 3 I.

Mitt, a, d, D, Schutzgebieten, XX, Band, III, achtungsterminen zukommenden Mittelwerte der Temperatur.

Im 7 a-Termin bringen die höchste Temperatur: im Januar der S, Februar bis Juli die Landwinde, in August SW, September bis Dezember die Landwinde; die niedrigste Temperatur haben: im Januar SW, Februar bis April NW bis NE, Mai S, Juni bis Juli E, August bis Dezember NE.

Im $2 \mathrm{p}$-Termin bringen die Landwinde die höchste Temperatur, ausgenommen im Februar und Dezember, wo keine E-Winde wehen, der S-Wind; da in diesen Monaten eine Depression im Innern lagert, wie wir bereits gesehen haben, so dürfte auch der S-Wind auf dem Lande seinen Ursprung haben.

Im 9p-Termin besitzen im Januar bis Februar der S-, März bis Juli E-, August bis Oktober S-, November bis Dezember der N-Wind die höchste und im Januar bis Juli W- bis N-, im August E- und W-, Oktober bis Dezember S- bis E-Wind die niedrigste Temperatur.

Eine thermische Anomalie der Seewinde, auf welche v. Danckelman ${ }^{1}$ ) bereits aufmerksam gemacht hat, möge noch erwähnt werden.

Wenn in der kühlen Jahreszeit die warmen, trocknen Landwinde wehen, kommt es häufig vor, $\mathrm{daB} 7 \mathrm{a}$ ein $\mathrm{E}$-Wind mit hoher Temperatur und abnorm geringer, relativer Feuchtigkeit herrscht, gegen Mittag tritt der Seewind ein, ohne jedoch die Temperatur und Feuchtigkeit zu beeinflußen, ja manchmal tritt infolge der kräftigeren Insolation - da die Ostwinde die Wolken und Nebel auflösen - eine Steigerung dieser Erscheinungen auf.

Z. B.:

\begin{tabular}{|c|c|c|c|c|}
\hline & $\begin{array}{l}\text { Mai } \\
\text { I } 899\end{array}$ & $\begin{array}{c}\text { Temperatur } \\
0\end{array}$ & $\begin{array}{c}\text { Relative } \\
\text { Feuchtigkeit } \\
\text { v. H. }\end{array}$ & Wind \\
\hline \multirow{4}{*}{ I. } & $7 a$ & $24 \cdot 3$ & 49 & $\mathrm{SE}_{2}$ \\
\hline & $2 \mathrm{p}$ & $27 \cdot 5$ & 48 & $\mathrm{SSW}_{2}$ \\
\hline & $9 p$ & 20.2 & 57 & $\mathrm{~S}_{1}$ \\
\hline & $7 \mathrm{a}$ & $24 \cdot 3$ & 28 & $\mathrm{ENE}_{3}$ \\
\hline \multirow[t]{3}{*}{20.} & $2 \mathrm{p}$ & 30.2 & 23 & $\mathrm{SW}_{1}$ \\
\hline & $9 p$ & 22.4 & 34 & $\mathrm{ESE}_{0}$ \\
\hline & $7 a$ & 23.2 & $\mathrm{I} 7$ & $\mathrm{E}_{4}$ \\
\hline \multirow{2}{*}{27.} & $2 \mathrm{p}$ & 30.5 & I 4 & $\mathrm{NW}_{2}$ \\
\hline & $9 \mathrm{p}$ & 20.4 & 38 & C. \\
\hline
\end{tabular}

Derartigen Erscheinungen ist es mit zuzuschreiben, daß z. B. im 7 a-Termin im Monat August der SW-Wind die höchste Temperatur besitzt, und wenn die Gegensätze zwischen den Land- und Seewinden in der thermischen Windrose nicht schärfer hervortreten.

1) Mitteilungen aus den deutschen Schutzgebieten XIII, I goo, S, III, 
Im allgemeinen kamn man sagen, daß das ganze Jahr hindurch die Landwinde die wärmsten sind, und zwar in der warmen Jahreszeit infolge der enormen Erhitzung des Sandbodens im Innern, in der kalten infolge dynamischer Erwärmung, und daß die kältesten die Seewinde sind; ab und zu kommen auch kalte Landwinde vor, besonders abends und morgens in der kïhlen Jahreszeit.

Die Berechnung der Windrose für die mittlere Stärke der einzelnen Windrichtungen lieferte folgende Resultate:

Die größte Windstärke besaßen im:

7a: Januar S-, Februar bis Juni Landwinde, und zwar Februar N-, März E-, April S-, Mai bis Juni N-, Juli bis August S-, September bis Dezenber $\mathrm{N}^{-}$, mithin 7 Monate $\mathrm{N}$-, 4 Monate S-, I Monat E-lVind;

2p: Januar bis April $S$, Mai bis Juni $N$, Juli bis September S, Oktober N, November bis Dezember S, mithin S: 9 Monate und N: 3 Monate.

9p: Januar bis April S, Mai bis Juli $N$, August $\mathrm{S}$, September N, Oktober bis Dezember $\mathrm{S}$, also $\mathrm{S}$ 8 Monate, N 4 Monate.

Die größte Windstärke besitzen die $\mathrm{N}$ - und $\mathrm{S}$ Winde, nur 7 a machen sich im Februar bis Juni die Landwinde bemerkbar, sie drehen von $N$ über $\mathrm{E}$ nach $\mathrm{S}$ und wieder zurück nach $\mathrm{N}$.

Mittlere Maxima der VVindstärke sind:

7a: Januar $\mathrm{S}_{4}$, März $\mathrm{E}_{6}$ (I899 Temperatur I9.6, Monatsmittel $\mathrm{I} 8.4^{\circ}$ ), sonst kommen morgens geringe Schwankungen vor;

2p: Oktober $\mathrm{S}_{5}$ und $\mathrm{E}_{7}$ (I9O2 Föhntag $30.5^{\circ}$ Monatsmittel $\mathrm{I}_{6.6^{\circ}}$, tags vorher $\mathrm{SW}_{7}$, I $\left.5^{\circ} \mathrm{I}^{\circ}\right)$; mittags herrscht zumeist eine kräftigere Luftbewegung, hervorgerufen durch stärkere Insolation und infolgedessen größererTempcraturunterschied zwischen L and und Meer. Im juni und Oktober haben die E-IVinde die Führung.

In jährlichen Gange zeigt die Windstärke keine ausgesprochene Periode. In täglichen Gange zcigen größte Werte 7a: Landwinde, 2p und 9p: S- und E-Winde, letztere nur sporadisch auftretend; die S. Winde wehen am stärksten in der warmen Jahreszeit, sie dominieren im Jahr an 7 Monaten: Januar bis April, August, November bis Dezember, die N Vinde an 5 Monaten: Mai bis Juli, September, Oktober.

Die stärkste Bewölkung zeigten folgende Windrichtungen:

$7 \mathrm{a}:$

Januar bis Juni: $\mathrm{N}$ und SE.

Juli bis November: $W$ und $\mathrm{NE}$.

Dezember: $\mathrm{E}$ und $\mathrm{S}$.

$2 \mathrm{p}$ :

Januar bis März: $\mathrm{S}$ und $\mathrm{N}$.
April bis September: $\mathrm{N}$ bis $\mathrm{IV}$.

Oktober bis November: SE und NIV (sekundär).

Dezember: IV.

9p:

Januar bis März: $\mathrm{N}$ bis $\mathrm{IV}^{\top}$.

April: SE.

Mai bis Juli: $\mathrm{N}$

August: SIV und SE.

September bis Oktober: E.

November bis Dezember: $\mathrm{N}$ bis $\mathrm{IV}$.

Den geringsten Grad der Bewölkung wiesen folgende Winde auf:

$7 \mathrm{a}:$

Januar bis April: S.

Mai bis Olitober: E.

November bis Dezember: S.

2p:

Januar bis April: $\mathrm{S}$.

Mai bis August: E.

September bis Dezember: E mit Drehung nach S. $9 \mathrm{p}$ :

Januar bis März: E dreht nach NE.

Mai bis Juli: E.

August: NE und $\mathrm{S}$ (sckundär).

September bis Dezember: E und S (sekundär).

Weitaus am größten ist die Bewölkung bei N-Winden, dann folgen W, S und E; der Grad der Himmelsbedeckung verhält sich bei diesen Winden wie $5: 3: 2: 2$. Die starke Bewölkung in den Monaten März bis Mai im $7 \mathrm{a}$ - und 9p-Termin bei SE-Winden dïrfte auf die Winterregen an der südlich von Swakopmund gelegenen Küste zurückzuführen sein; dieselben reichen nach Dove' ${ }^{1}$ ) bis Port Nolloth, um dann siner Übergangszone mit Regen zu allen Jahreszeiten Platz zu machen«.

Über die zunehmende Bewölkung bei NW-Winden berichtet Schenk ${ }^{2}$ ) folgendes: „Es wehen konstante SIV-Winde, von ro Uhr an heftiger, nachmittags oft bis Sturm, seltener NIV-Winde. Das Meer bedeckt sich alsdann mit dichtem Nebel, der sich allmählich dem Lande nähert, auf demselben eine Zeitlang die Berge einhüllt und dann als Wolken in die Höhe steigt.

Da die Winde aus dem N-Quadranten besonders in der kühlen Jahreszeit aus bedeutend wärmeren Gebieten konmen, so ist ihre Neigung zur Nebelund Wolkenbildung leicht erklärlich.

Heiterer Himmel herrscht am meisten bei $\mathrm{S}$ und $\mathrm{E}$-Winden, erstere dominieren in der warmen, letztere in der kalten Jahreszeit; da der S-Wind in der warmen Jahreszeit dem zylilonalen Windgebiete über Süclafrika angehört, so bringt er die wolken-

1) Dove, Südafrika, S. 133

2) Petermanns Mitteil. I 885 , S. 34 . 
auflösenden Eigenschaften aus den südöstlichen Gegenden mit, er ist also in dieser Jahreszeit Landwind. Von den E-Winden sind es hauptsächlich die heißen, trockenen, föhnartigen Winde, welche infolge dieser Eigenschaften Nebel und Wolken schnell auflösen; sie übertreffen daher an Intensität bei weitem die S-Winde, letztere sind dagegen häufiger, und zwar beherrschen im Jahre die S-Winde 7 Monate lang das Minimum der Bewölkung, dagegen die EWinde nur 5 Monate lang.

Bei der Erörterung der Temperaturverhältnisse wurde bereits wiederholt auf den Einfluß der heißen, trockenen $\mathrm{E}$-Winde hingewiesen, insbesondere mußten die großen Temperaturschwankungen und die hohen Temperaturmaxima in den Monaten Mai bis Juli ihrem Einflusse zugeschrieben werden; auch v. Danckelman hat regelmäßig bei der Veröffentlichung der meteorologischen Beobachtungen von Swakopmund in den "Mitteilungen aus den deutschen Schutzgebieten« auf die enorme Lufttrockenheit und die Störungen im jährlichen Temperaturgange durch die heißen, »föhnartigen « E-Winde hingewiesen.

Auch von Reisenden wie Schenk, 1) Stapff, ${ }^{2}$ ) Gü rich ${ }^{3}$ ) und Dove ${ }^{4}$ ) sind die lästigen Eigenschaften der heißen, trockenen Ostwinde und der sie begleitenden heftigen Sandstürme erwähnt worden. Es blieb jedoch unentschieden, 5 ) ob diese heißen Ostwinde Föhne oder Wüstenwinde waren; erst nachdem mehrjährige Beobachtungen von Walfischbai und Port Nolloth vorlagen, gelangte v. Danckel$\operatorname{man}^{6}$ ) durch Vergleichen der Temperaturmittel für Juli I 890 bis I893 zwischen diesen beiden Orten zu dem Resultat, daß die früher erwähnten warmen Ostwinde einen föhnartigen Charakter haben, indem er nachwies, daß die hohe Temperatur 11icht aus dem Inneren stammen kann, sondern daß sie auf dynamischen Ursachen beruht. Auch die Ostseite Südafrikas hat ihren Föhnwind, so berichtet Man n ${ }^{7}$ ) bereits I866 über heiße NW-Winde in Natal.

Bei einer Erörterung der Föhnwinde in Swakopmund muß man zunächst festsetzen, welche Winde man mit diesem Namen bezeichnen will; denn es kommen Ostwinde mit sehr niederen - z. B. Juni IgOI $5.5^{\circ}$ und $5.6^{\circ}$ - und auch sehr hohen Temperaturen vor, z. B. Mai IgOI: $37.4^{\circ}$; da die unperiodische tägliche Temperaturschwankung im Mittel

1) Petermanns Mitteil. I 885 , S. I 34 .

2) Deutsche Kolonialzeitung I 887 .

3) Gürich, Deutsch-Südwestafrika. Mitteil. d. Geogr. Ges. zu Hamburg 1891/92, S. 54.

$\left.{ }^{4}\right)$ Petermanns Mitteil., Ergänzungsband I2O, I898, S, 39.

5) Meteor. Zeitschr. I 888, S. 312.

$\left.{ }^{6}\right)$ Meteor. Zeitschr. I 895, S. 21.

$\left.{ }^{7}\right)$ Leading Features of the Climate of Natal, South Africa. Proceedings of the Meteorolical Society, Vol. III, I 866, S. 207. $8^{\circ}$ beträgt, wollen wir denjenigen Wind mit Föhn bezeichnen, dessen positive thermische Anomalie vom Monatsmittel den Betrag von $4^{\circ}$ überschreitet.

Hierbei muß aber bemerkt werden, daß der Föhnwind meistens mittags und abends von dem Seewind unterbrochen wird; die hohe Temperatur und enorme Lufttrockenheit vermag aber selbst der kühle, feuchte Seewind nicht sonderliclı zu beeinflussen, ein Zeichen, daB der Föhn oben weiter weht und dem Seewind seine Charaktereigenschaften, hohe Temperatur und große Lufttrockenheit, verleiht; in solchen Fällen ist auch der Seewind mit $\mathrm{zu}$ den Föhnwinden gezählt worden, weil sonst die $2 \mathrm{p}$-Beobachtungen, in denen der Föhn gerade seine größte Häufigkeit und Intensität erreicht, unberücksichtigt bleiben müßten und dadurch die Beeinflussung der übrigen meteorologischen Elemente unklar würde.

Unter dieser Voraussetzung sind während der siebenjährigen Beobachtungsperiode in den drei Beobachtungsterminen zusammen 285 Föhne beobachtet worden, also im Jahr durchschnittlich 4I; am häufigsten waren sie im Jahre I899, nämlich $57 \mathrm{mal}$, am seltensten I903, nämlich nur 24 mal. Von den einzelnen Monaten haben Februar, November und Dezember überhaupt keinen Föhn, der Januàr nur einen, seine Häufigkeit erreicht im Mai ihr Maximum, ein sekundäres Minimum findet im August statt. Mai, Juni und Juli dominieren von allen Monaten bei weitem. An den einzelnen Terminen erscheint:

\begin{tabular}{|c|c|c|c|c|c|}
\hline & & & Föhn & $\begin{array}{c}\text { E-Wind } \\
\text { NNE-SSE }\end{array}$ & $\begin{array}{l}\text { Föhn in Proz. } \\
\text { der E-Winde }\end{array}$ \\
\hline $7 \mathrm{a}$ & . & . & 100 & IOI 5 & IO v. $\mathrm{H}$. \\
\hline $2 \mathrm{p}$ & $\cdot$ & . & I I $\left.2^{1}\right)$ & 90 & 5.0, \\
\hline $9 p$ & . & . & 73 & 323 & 4.4, \\
\hline $\mathrm{ml}$ & & & 285 & I 428 & $5 \mathrm{v} . \mathrm{H}$ \\
\hline
\end{tabular}

Der Föhn erreicht also $2 \mathrm{p}$ sein Maximum im Gegensatz zu den E-IVinden, welche 7 a am häufigsten sind, er erweist sich daher zugleich nicht als Landwind, durch ungleiche Erwärmung zwischen Land und Wasser vercnlaßt, sondern er durchbricht die Periode der Land- und Seewinde und zeigt dadurch auf seinen dynamischen Ursprung hin. Allerdings wehen mittags meist Seewinde, aber die hohe Temperatur und auffallende Lufttrockenheit lassen erkennen, daß der Seewind nur eine geringe Höhe haben kann, und daß über ihn der Föhn weiter weht; als ein weiteres Zeichen, daf3 der Föhn oben auch am Abend weiter weht, muß ich anführen, daß an der Küste oft, wenn am Tage E-Wind geherrscht hat und mittags und abends vom Seewind verdrängt wird, in der Nacht astronomische Messungen selbst mit steilen Visuren, wie sie die Methode HorrebowTalcott erfordert, wegen Zittern der Luft nicht

1) $=$ I 8 Land- und 94 Seewinde. 
möglich sind; vielleicht ist es derselbe Zustand, den Stapff1) schildert mit den Worten: "Und selbst der Zenith pflegt sich nach Mitternacht zu verschleiern, an der Kïste durch Nebel, landeinwärts durch Dünste, welche den Glanz der Sterne sehr abschwächen.

Es ist sehr wahrscheinlich, daß diese Trubung durch eine Mischung der warmen E- mit den relativ feuchten und kalten Seewinden veranlaßt wird.

Eine merkwürdige Erscheinung möge hier noch Erwähnung finden. Der langjährige meteorologische Beobachter in Walfischbai, Missionar Boehm,2) berichtet von einer Menge kleiner Fliegen, welche mit den starken SW-Winden kämen und mit diesen auch wieder verschwänden; auch diese Erscheinung läßt sich mit obiger Annahme, daB die E-Winde über den Seewinden weiter wehen und so die Fliegen vom Lande bringen und in den Seewind hineinblasen, zwanglos erklären.

Daß uberhaupt die föhnartigen E-Winde eine viel häufigere Erscheinung sind als die aus den Beobachtungsterminen ermittelte Zahl, zeigen die großen Temperaturdifferenzen zwischen $2 \mathrm{p}$-Termin und der Angabe des Maximumthermometers:

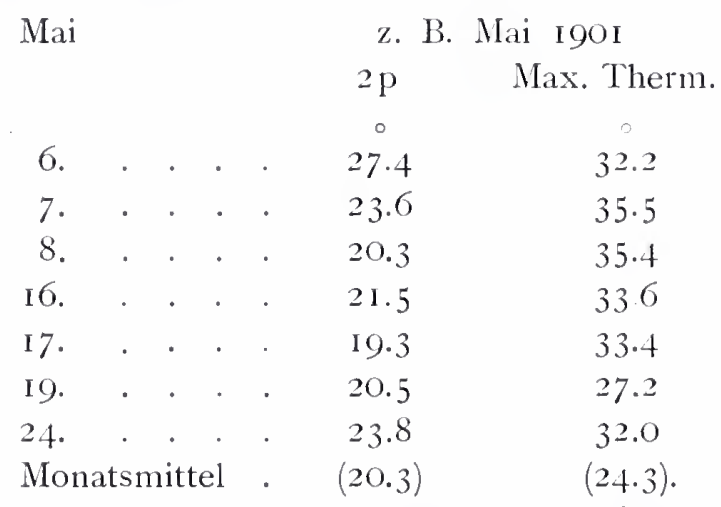

Die hohen Temperaturangaben des Maximumthermometers lassen darauf schließen, daß sehr oft Föhnwinde zwischen den Beobachtungsterminen auftreten. Diese großen Differenzen gaben bereits dem Kaiserlichen Gouvernement in Windhuk Veranlassung, in den Temperaturangaben zwischen 2 pund Maximumthermometer einen $\mathrm{IO}^{\circ}$-Fehler $\mathrm{zu}$ vermuten und die Beobachter in Swakopmund zur Rechenschaft $\mathrm{zu}$ ziehen.

Wenn man nun den Zusammenhang zwischen der Häufigkeit der Föhnwinde und den Gang der übrigen meteorologischen Elemente näher untersuchen will, so muß man berücksichtigen, daß im vorliegenden Falle nicht alle Föhnwinde in Betracht gezogen sind; für eine derartige Untersuchung müßte man zunächst für sämtliche Temperaturangaben die relative Feuchtigkeit berechnen, da bei den geringeren

1) Deutsche Kolonialzeitung 1887, S. 649 .

2) Deutsche überseeische Ineteor. Beobacht. I. S. 74.
Temperaturabweichungen nicht ohne weiteres ersichtlich ist, ob die Erhöhung durch stärkere Insolation infolge geringerer Bewölkung oder tatsächlich dynamischen Ursprungs ist; hier kann allein der Feuchtigkeitsgrad entscheiden, aber auch hierbei bietet sich insofern eine Schwierigkeit, als die relative Feuchtigkeit im Inneren des Landes nach europäischem Begriff bereits einen föhnartigen Charaliter besitzt. So betrug in Windhuk die Luftfeuchtigkeit z. B. im Jahre igo3:

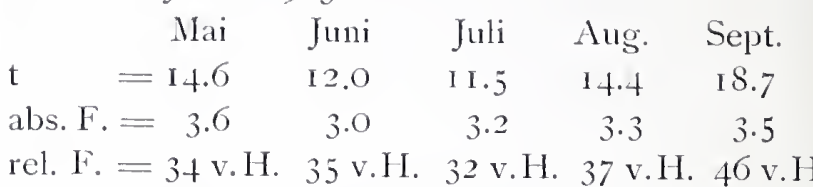

So würde z. B. ein Wind im Inneren mit einer Temperatur von $12.0^{\circ}$ und $3.0 \mathrm{~mm}$ absoluter Feuchtigkeit bei seiner Ankunft an der Küste und einer Temperatur von 32 bereits eine relative Feuchtigkeit von nur I I v. H. haben; es kommen allerdings noch größere Extreme vor, z. B. am 2r. Mai 1901 $2 \mathrm{p}$ war die relative Feuchtigkeit knapp ${ }^{1}$ ) I v. H., aber im allgemeinen ist die relative Feuchtigkeit eine größere, da je nach der Stärke des E-Windes eine größere oder kleinere Mischung mit der feuchten Seeluft eintritt. Es ist daher nicht leicht, eine sichere Grenze zwischen Föhn- und E-Winden festzustellen.

In den folgenden Untersuchungen haben wir es daher nicht mit allen vorkommenden, sondern nur mit den markantesten Föhnwinden zu tun.

Tafel IX zeigt uns die Häufigkeit der Föhne und den Gang der übrigen meteorologischen Elemente.

Zunächst sehen wir, wie die Anzahl der Föhne und die mittlere Jahrestemperatur im Jahre 1899 ihren höchsten Wert erreichen, beide fallen dann bis zum Jahre 1903, wo sie ihren kleinsten Wert aufweisen, und steigen dann wieder bis 1905; nur das Jahr I90 I zeigt eine Störung, aber ein gewisser Parallelismus zwischen der Häufigkeit der Föhne und dem Gang der mittleren Jahrestemperatur ist unverkennbar.

Auch die Meerestemperatur steigt mit der Häu= figkeit der Föhne von 1903 bis I905, wenn auch hier der Zusammenhang wegen der geringen Anzahl von Jahren weniger sicher ist. Ferner zeigen in Tafel IX das absolute und mittlere Maximum sowie die mittlere absolute Jahresschwankung der Lufttemperatur in den einzelnen Jahrgängen einen der Anzahl der Föhne analogen Gang, dagegen weisen absolute Luftfeuchtigkeit geringe, Luftdruck, relative Feuchtigkeit und Bewölkung gar keine Beeinflussung durch Föhnwinde auf. Auffallenderweise zeigt auch die Häufigkeit der Nebel und Föhne einen parallelen Verlauf, während

1) Mitteil. I902, S. 92. 
man nach den charakteristischen Eigenschaften des Föhn gerade das Gegenteil erwarten -sollte; hiermit stimmen auch die tatsächlichen Beobachtungen überein, da unter der Herrschaft des Föhn Bewölkung und Nebel verschwinden, wie Tafel IX und X zeigen. Während der Nebel im April seine größte Häufigkeit erreicht, erlangt der Föhn dieselbe erst im Mai und Juni; in diesen Monaten zeigt der Nebel eine deutliche Abnahme, die aus folgender Zusammenstellung hervorgeht:

\begin{tabular}{lrrrr}
\multicolumn{2}{r}{ April } & Mai & Juni & Juli \\
Nebel: & I 35 & I05 & IO4 & I 2 I \\
Föhne: & I 5 & 96 & 8 I & 49
\end{tabular}

Auch in den einzelnen Beobachtungsterminen zeigt der Gang beider Erscheinungen keinen Parallelismus:

\begin{tabular}{|c|c|c|c|c|c|c|c|}
\hline & I 899 & 1900 & I9OI & 1902 & 1903 & 1904 & I9 \\
\hline Nebel: & 一 & $8 \mathrm{I}$ & 97 & 65 & $5^{2}$ & 80 & I 2 \\
\hline Föhn & 19 & I I & 23 & I I & 9 & I I & \\
\hline Nebel: & 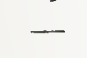 & 49 & 43 & 24 & I6 & 25 & \\
\hline Föht & 23 & I 5 & 19 & I 3 & IO & 17 & \\
\hline $\mathrm{Neb}$ & - & 29 & 34 & 20 & 26 & 36 & \\
\hline Föhn & IS & I I & I 3 & 9 & 5 & IO & \\
\hline
\end{tabular}

Der analoge Gang von Föhn und Nebel in den einzelnen Jahren scheint also ein zufälliger zu sein.

Undie Größe dermittleren Temperaturabweichung von den Normalmitteln festzustellen, wurden von den zu den einzelnen Föhnwinden gehörigen Temperaturen die betreffenden Monatsmittel abgezogen und die Resultate in Tafel II erhalten. Die Temperaturabweichungen waren am größten:

$$
\begin{aligned}
& \text { 7a: Juli I } 899 \cdot=+\mathrm{I} 2.8^{\circ} \\
& \text { 2p: Okt. I902. }=+\mathrm{I} 4.5^{\circ} \\
& \text { 9p: April I905. }=+\mathrm{I} 3.8^{\circ}
\end{aligned}
$$

Die durchschnittlich größten Werte zeigten die Jahre 1899 , 1902 und 1905, die kleinsten 1903 und 1904; im allgemeinen ist die Größe der Abweichung der Häufigkeit der Föhne nicht proportional.

Wenn wir nun die Häufigkeit der Föhne und die Lufttemperatur in ihrem jährlichen Gange betrachten, so finden wir jetzt auch eine Erklärung für das sekundäre Maximum der Temperatur im Mai; in den Jahren 1899 bis I9OI war der Föhn am häu-

\begin{tabular}{|c|c|c|}
\hline & $\begin{array}{l}\text { Zahl der } \\
\text { Föhne }\end{array}$ & $\begin{array}{c}\text { Temperaturdifferenz } \\
\text { Mai-April }\end{array}$ \\
\hline I899. & I9 & $+\mathrm{I}^{\circ} \mathrm{I}^{\circ}$ \\
\hline 1900. & 16 & +0.7 \\
\hline I90I. & 20 & +3.0 \\
\hline 1902. & I 2 & +2.3 \\
\hline 1903. & I 2 & -0.3 \\
\hline 1904. & I 4 & - O.I \\
\hline 1905. & 3 & -3.7 \\
\hline
\end{tabular}
figsten, und in diesen Jahren war die Störung auch am größten, wie folgende Zahlen zeigen:
In den Jahren 1902 und 1903 war die Häufigkeit der Föhne gleich groß $=12$, aber die Temperaturdifferenz $1902=+2.3^{\circ}$, dagegen $1903=-0.3^{\circ}$; diese Abweichung klärt sich auf, wenn man die mittleren Abweichungen der Föhntemperatur von den Monatsmitteln betrachtet; sie betrug:

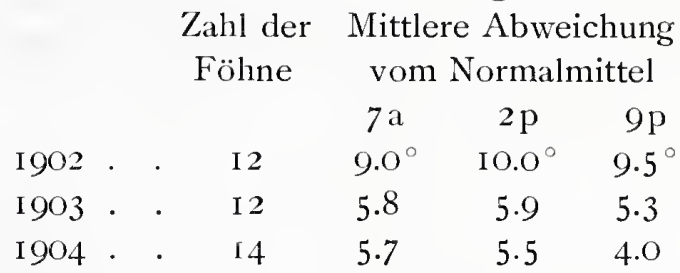

Die größere Temperaturdifferenz des Jahres 1902 ist eine Folge der großen Intensität des Föhn in diesem Jahre.

Wir sehen also, daß das sekundäre Maximum der Temperatur im Mai durch den Föhn verursacht wird.

Ein Vergleich der Föhnhäufigkeit im Juli während der Jahre I 899 bis 1905 mit den übrigen meteorologischen Elementen in Tafel IX führt zu folgendem Resultat:

Die Monatsmittel, die absoluten und mittleren Temperaturmaxima, die tägliche unperiodische Wärmeschwankung und die Abweichungen vom Monatsmittel zeigen einen deutlichen Parallelismus mit dem Gang des Föhn, nämlich 2 Minima: 1900 und 1902, und I Maximum: I905; die relative Feuchtigkeit zeigt dem Charakter des Föhn entsprechend einen umgekehrten Gang; nur die absolute Luftfeuchtigkeit, Luftdruck und Häufigkeit der Nebel zeigen sich nicht beeinflußt.

Nachdem wir nun die Einwirkung des Föhn auf die meteorologischen Elemente in den einzelnen Jahren kennen gelernt haben, bleibt uns noch übrig, den Einfluß des Föhn im jährlichen Gange zu betrachten.

Vergleicht man die Anzahl der Föhne in den Monaten Mai - Oktober 1905 mit dem Gang der übrigen Erscheinungen, so zeigt sich folgendes:

Die große Anzahl der Föhne im Juli 1905 bildet die Ursache, daß die Lufttemperatur in diesem Monat ein zweites sekundäres Maximum erreicht; dasselbe zeigt, wenn auch in geringerem Maße, die Meerestemperatur.

Bereits bei den Jahresmitteln sahen wir ein gleichzeitiges Zunehmen derselben mit der Anzahl der Föhne von 1903 bis 1905 , hier war jedoch der $\mathrm{Zu}$ sammenhang zwischen Ursache und Wirkung noch unklar, ob z. B. die wärmere Meerestemperatur durch Verstärkung des Gradienten die Ursache des Föhn ist oder umgekehrt; wenn man jedoch den regelmäßigen Verlauf der Meerestemperatur in den Jahren 1903 und 1904 mit der Störung Juli 1905 vergleicht, 
so muB diese Frage dahin entschieden werden, da $B$ der Föhn aueh die Meerestemperatur beeinfluBt; dieses ist um so erklärlieher, da naeh v. Danekelman ${ }^{1}$ ) die Föhnerseheinungen zugleieh an der ausgedehnten Küiste auftreten und das Meerwasser in einer Ausdehnung von etwa $700 \mathrm{~km}$ (Swakopmund - Port Nolloth) von Winden mit einer Temperaturabweiehung von $>+\mathrm{IO}^{\circ}$ (Juli 1905 $2 \mathrm{p}=+\mathrm{I} \mathrm{I.2}$ ) vom Normalmittel der Luftemperatur bestriehen wird; daß hierbei die mitgefuhhrten zahllosen, heißen Sandteilehen aueh eine Rolle spielen, ist sehr wahrseheinlieh.

AuBer den Monatsmitteln der Luft- und Meeres temperatur zeigen aueh absolute und mittlere Maxima im Juli I 905 sieh stark beeinflußt, ja diese erreiehen hier sogar ihren absolut größten W'ert während der sanzen Beobaehtungsperiode; die relative Feuehtigkeit, die Zahl der Nebel und die Bewölkung weisen im Juli ein deutliehes Minimum auf.

Bei der Betraehtung der interdiurnen Veränderlichkeit fanden wir die größten WVerte in den Monaten Mai bis Juli; wenn man nun die Ioo größten Erwärmungen und Erkaltungen von $\mathrm{I} 5.5^{\circ}$ bis $5.8^{\circ}$ zwisehen den 7 a-Terminen auf die sie begleitenden Winde untersucht, so findet man:

$$
\begin{gathered}
96 \times \text { E-Winde, } \\
I \times \text { NW-Winde, } \\
I \times \text { W-Winde, } \\
2 \times \text { C-Winde. }
\end{gathered}
$$

Man kann also sagen, daß im 7 a-Termin alle Temperatursprünge von mehr als $6^{\circ}$ dureh E-Winde veranlaßt werden, und zwar die Erwärmungen dureh das Auftreten, die Erkaltungen dureh das Aufhören des Föhn.

In gleieher Weise erreichten die absoluten Temperaturmaxima in den Monaten Mai bis Juli ihre größten Werte und zeigten dadureh, daß sie nieht der Insolation ihre Entstehung verdanken; denn diese erreieht gerade in diesen Monaten ihren kleinsten Wert. Untersueht man die Temperaturmaxima auf die sie begleitenden Winde, so findet man in den Jahren I 899 bis 1905 folgende Zahlen von Föhnwinden als Ursache.

März April Mai Juni Juli Aug. Sept. Okt.

$\begin{array}{llllllll}2 & 5 & 6 & 7 & 6 & 5 & 6 & 4\end{array}$

Die absoluten Temperaturmaxima werden also in der kalten Jahreszeit dureh den Föhn verursaeht; auffallenderweise zeigt die höehste Temperatur von $40.6^{\circ}$ (Juli I905) keinen E-Wind, da dieselbe nicht dureh Insolation hervorgerufen sein kann, so muB man annehmen, daß der Föhn, der tags zuvor 7 a und $2 \mathrm{p}$ geherrseht hat, während der Naeht sieh wieder eingestellt hat; allerdings kann auch die Temperatur-

1) Met, Z, I895 S. 2 I. messung selbst fehlerhaft sein, da dieselben nach v. Danekelman ${ }^{1}$ ) von Februar bis Oktober 1905 weniger zuverlässig sind, zumal anel das feuchte Thermometer 7 a eine um $0.4^{\circ}$ höhere Temperatur zeigt als das troekene; ein Beweis, daß die Behandlung des Psyehrometers wenig saehgemäß gewesen ist.

Vergleieht man die mittlere Häufigkeit des Föhn

\begin{tabular}{|c|c|c|c|c|c|c|}
\hline & I & II & III & IV & V & VI \\
\hline Maritzburg ${ }^{2}$ ) & .1 .5 & I. 2 & 0.7 & 0.9 & 1.2 & 0.9 \\
\hline Bludenz $z^{3}$ ) & .3 .6 & 2.6 & $3 \cdot 3$ & 2.6 & 2.3 & 0.6 \\
\hline \multirow[t]{2}{*}{ Swakopmund } & 0.0 & 0.0 & 1.0 & 0.9 & 6.3 & 6.4 \\
\hline & III & IX & X & XI & XII & $\begin{array}{r}\text { Cahl } \\
\text { Jah }\end{array}$ \\
\hline laritzburg & $\cdot 3.2$ & 5.1 & 4.2 & 3.0 & 1.7 & 8 \\
\hline Bludenz . & . $\mathrm{I} .2$ & $3 \cdot 5$ & 2.9 & 3.6 & 4.4 & ro \\
\hline wakopmund & .2 .1 & 2.0 & O.I & 0.0 & 0.0 & 7 \\
\hline
\end{tabular}
zu Swakopmund mit derjenigen an anderen Orten, z. B. Maritzburg und Bludenz, so erhalten wir folgende Zahlen:

Aus dieser 'Zusammenstellung geht hervor, daf die Häufigkeit der Föhne am gröBten in der kühleren und am geringsten in der wärmeren Jahreszeit ist; eine Erklärung hierfür ist darin zu suehen, daß die Verteilung von Luftdruek und Temperatur im Sommer eine gleiehmäßigere ist, daß im Winter dagegen diese Elemente stärkere dureh das relativ warme Meer und durch das erkaltete Land hervorgerufene Differenzen aufweisen, aueh zeigen die Depressionen naeh Hellmann4) im Winter eine größere Tiefe.

Der Föhn kommt in Swakopmund in der warmen Jahreszeit so gut wie gar nicht vor; als Ursaele hiervon müssen wir die konstante tiefe Depression im Innern und den hohen Luftdruck über dem Meere in dieser Jahreszeit bezeiehnen. Die Umkehrung des Gradienten während der kalten und warmen Jahreszeit zeigen folgendeLuftdruckdifferenzen des Jahres I903:

Windhuk $8 \mathrm{a}$ - Sivakopmund $7 \mathrm{a}$ : (reduziert auf Meeresniveau)

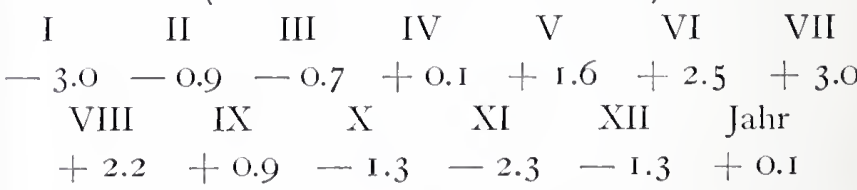

Es herrseht also in der warmen Jahreszeit ein Luftdruelggefälle vom Meere zum Lande und in der kühleren Jahreszeit umgekehrt vom Lande zum Meere.

Die durehsehnittliehe Dauer einer Föhnperiode variiert in den Alpen rwischen wenigen Stunden und mehreren Tagen; sie beträgt im Durehsehnitt

1) Mitteil. 1906, 2. Heft S. 149.

2) Proceedings of the Met. Society Vol III I867. Atmospheric Pressure in Natal. S. 345.

3) Hann. Föhn in Bludenz. Sitzungsber. d. k. k. Akad. d. Wiss. Bd. LXXXV, I 882 S. 24

4) Zeitschr. d. österr. Ges. f. Met. I876 S. 97. 
als Sturm1) zwei bis drei Tage; ungefähr dieselben Zahlen gelten auch fur Swakopmund; es kommen jedoch auch längere Perioden vor, z. B.:

\begin{tabular}{|c|c|c|c|c|c|c|}
\hline & April & Mai & Juni & Juli & Aug. & Sep \\
\hline 1899 & - & 9 & I 2 & - & - & - \\
\hline 1900 & 一 & - & 5 & - & - & - \\
\hline 1901 & - & 10 & $2 \times 4$ & 一 & 一 & - \\
\hline 1902 & - & 6 & 7 & 一 & - & - \\
\hline 1903 & 一 & 5 & - & 4 & - & - \\
\hline 1904 & - & 5 & $\ldots$ & - & - & 0 \\
\hline 1905 & 4 & - & - & 9 & - & - \\
\hline
\end{tabular}

Doch sind hier die Erscheinungen oft abgeschwächt, analog dem Auftreten in den Alpen, wo auch im Winter wochenlang ein schwacher Föhn herrscht und als zahmer oder Heiterföhn ${ }^{1}$ ) von dem wilden Föhn unterschieden wird.

Sehr verschieden ist die Neigung des Weges gegen die Horizontale, den der Föhn beim Herabsinken zurückzulegen hat, so beträgt dieselbe in den Alpen nach Wettstein:2)

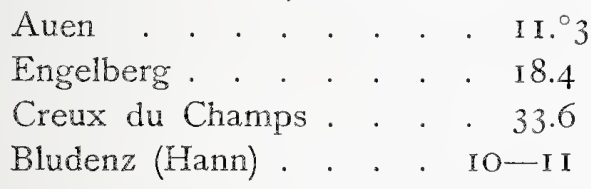

in Swakopmund dagegen $=\frac{1050}{120000}=1 / 2^{\circ}$, wenn man den Anstieg vom Meer zur Namibwüste nach Ortloffi) zugrunde legt; nimmt man die Strecke Swakopmund-Windhuk (höchstgelegener Ort), so beträgt die Neigung noch weniger $=\frac{1662}{260000}=1 / 3^{\circ}$.

Die Neigung dieses Geländes dürfte wohl die kleinste der bis jetzt bekannten Föhngebiete sein.

Als ein weiterer Unterschied zwischen dem Auftreten des Föhn zu Swakopmund und in den Alpen sind die starken Niederschläge zu nennen, welche den Föhn in letzter Gegend teils begleiten (Süseite), teils ihm folgen (Nordseite der Alpen).

Die synoptischen Karten des »Bulletin international « ergeben nach Wettstein, ${ }^{4}$ ) daß der Föhnsturm der Schweiz stets mit einem niederen Luftdruck im Nordwesten und einem höheren südwärts der Alpen zusammenfällt, eine andere Lagerung der Depression im Norden oder Nordosten ergeben keinen, eine solche im Nordwesten und Südwesten zugleich erzeugen nur einen schwachen Föhn.

Wenn wir nun nach einer Erklärung der Föhnerscheinungen in Swakopmund suchen, so kann die Beantwortung dieser Frage bei dem Mangel an ge-

1) Berndt, Der Föhn. Göttingen 1886. S. 46.

2) Wettstein, Strömungen, S. 336 .

3) Zeitschrift für Bauwesen, I904. S 354.

4) Wettstein, Strömungen, S. 344 . eigneten Karten über den Gang des Luftdrucks und der Zyklonen im Südatlantischen Ozean keine vollständige sein.

Zunächst ist es unmöglich, daß die hohe Lufttemperatur in Swakopmund eine Folge adiabatischer Druckänderung ist; denn die absolute jährliche Luftdruckschwankung beträgt nur I6.8 $\mathrm{mm}$, sie würde also einer Erwärmung der Luft um $1 .^{\circ} 7$ entsprechen; ferner können die hohen Temperaturen auch nicht aus dem Innern stammen, da die absoluten Temperaturmaxima in der kalten Jahreszeit in Swakopmund höher sind als in Windhuk, wie folgende Zahlen zeigen werden:

Jährlicher Gang der absoluten Temperaturmaxima in Swakopmund und Windhuk.

$\begin{array}{ccccccc}\text { IgO2 } & \text { I. } & \text { II. } & \text { III. } & \text { IV. } & \text { V. } & \text { VI. } \\ \text { Swakopmund . } & 25.7 & 25.6 & 37.8 & 22.4 & 38.2 & 34.0 \\ \text { Windhuk . . } & 33.2 & 34.5 & 30.4 & 29.2 & 28.3 & 23.4 \\ & \text { VII. } & \text { VIII. } & \text { IX. } & \text { X. } & \text { XI. } & \text { XII. } \\ \text { Swakopmund . } & 20.9 & 35.8 & 20.0 & 37.4 & 22.6 & 23.5 \\ \text { Windhuk . . } & 24.3 & 25.7 & 30.2 & 3 I .7 & 33.3 & 34.3 \\ \text { I903 } & \text { I. } & \text { II. } & \text { III. } & \text { IV. } & \text { V. } & \text { VI. } \\ \text { Swakopmund. } & 22.9 & 2 \text { I.8 } & 27.7 & 23.3 & 33.2 & 34.5 \\ \text { Windhuk . . } & 34.8 & 32.3 & 3 I .5 & 29.5 & 26.8 & 23.7 \\ & \text { VII. } & \text { VIII. } & \text { IX. } & \text { X. } & \text { XI. } & \text { XII. } \\ \text { Swakopmund. } & 33.7 & 23.3 & 32 . I & \text { I9.4 } & \text { I } 8.3 & 24.6 \\ \text { Windhuk . . } & 23.3 & 25.3 & 29.8 & 32.5 & 33.5 & 33.0\end{array}$

Noch deutlicher ersieht man aus der Tafel IX und XI, wie die Temperaturen von Swakopmund mit Auftreten des Föhn plötzlich über diejenigen von Windhuk steigen.

Die hohe Lufttemperatur zu Swakopmund bei dem Auftreten starker Ostwinde kann daher nur dynamischen Ursprungs sein.

Wie wir bereits erwähnt haben, wandert in der kühlen Jahreszeit das Luftdruckmaximum der RoBbreiten mit der Sonne nach Norden, daher zeigt der Luftdruck zu Windhuk und Swakopmund in den Monaten Mai bis August eine erhebliche Zunahme (s. Tafel XI); diese ausgedehnte antizyklonale Luftbewegung erzeugt im Innern des Landes einen wolkenlosen Himmel, starke Insolation bei Tage und eine große nächtliche Wärmeausstrahlung und Erkaltung der untersten Luftschichten; eine Temperaturumkehrung während der Nacht und am Morgen muß daher im Innern des Landes eine häufige Erscheinung sein. Über dem relativ warmen Meere wird die Luft in die Höhe steigen und sich hierbei abkühlen, wir haben daher hier in vertikaler Richtung eine dem Innern entgegengesetzte Temperaturverteilung, und als Folge hiervon eine Luftströmung in der Höhe vom Meere zum Innern und in den unteren Luftschichten die Landwinde als entgegengesetzte Strömung; gegen Mittag wird mit zunehmender Er- 
wärmung der untersten Luftschichten im Innern der Kreislauf ein umgekehrter, daher am Morgen die Land- und am Mittag die Seewinde. Da nun die Landwinde aus einer Höhe von rund $1600 \mathrm{~m} \mathrm{zur}$ Küste hinabwehen, gelangen sie unter einen um etwa $135 \mathrm{~mm}$ höheren Luftdruck und müssen sich daher erheblich erwärmen. Diese Erscheinung tritt jedoch nicht immer ein, denn nach den Beobachtungen lommen 7 a auf IOI 5 E-WVinde IOO warme E-Winde, die übrigen besitzen zum Teil eine reeht niedrige Temperatur.

Wie ist diese Erscheinung zu erklären?

Dem während der Nacht entstehenden Gradienten zwisehen Land und Meer folgt zunächst die Luft an der Küste auf die See hinaus, im weiteren Verlauf werden auch die mehr landeinwärts lagernden Luftschichten mit in diese Bewegung hineingezogen; es ist aber unwahrscheinlich, $\mathrm{daB}$ der Landwind aus den höchstgelegenen Gebieten, z. B. der Umgegend von Windhuk, bis zur Kuiste gelangt; denn erstens weht der Landwind verhältnismäBig nur kurze Zeit, gegen Mittag wird er fast ausnahmslos vom Seewind verdrängt, dann braueht selbst ein starker E-Wind, z. B. mit Stärke 6, von Windhuk bis Swakopmund etwa 7 Stunden; ferner sind die untersten Luftschichten im Innern durch ihre Erkaltung schwer und träge geworden und werden daher durch das vertikal stark gegliederte Innere des Landes zuí Stagnation gezwungen.

Der Landwind wird sich mithin nur auf den Küstenstreifen beschränken, und da dieser nur eine geringe Neigung $=1 / 3^{\circ}$ besitzt, so wird durch den langen Weg über den erkalteten Sandboden die dynamisehe Erwärmung der Luft abgeschwächt oder sogar aufgehoben; daher sind die Landwinde gewöhnlich kalt.

Eine Begleiterscheinung der heiBen Ostwinde sind meist heftige Luftbewegungen und Sandstiurme; leider sind die letzteren nur in den Jahren I 899 bis 1902 mit in das Beobachtungsjournal aufgenommen worden; es kamen während dieser Zeit 27 Sandtreiben vor, das Temperaturmaximum schwankte zwischen 29. 4 (24. Juni I900) und $36 .^{\circ} 5$ (28. Juli 1899). Auch bei den heftigen E-Winden findet man hohe Temperaturen, doch kommen dieselben auch bei schwachen Winden vor, \%. B.:

$$
\begin{array}{ccc}
\mathrm{E}_{9} & 33 .{ }^{\circ} 4 & \text { 6. Juni I } 904, \\
\mathrm{E}_{8} & 29.4 & \text { 24. Juni I } 900, \\
\mathrm{E}_{7} & 37.4 & \text { 3. Oktober I } 902, \\
\mathrm{SE}_{1} & 37.8 & \text { 30. März I902, } \\
\mathrm{SE}_{1} & 34.3 & \text { I 4. Mai I } 902 ;
\end{array}
$$$$
\text { aber auch } \mathrm{SE}_{1} \quad 37.8 \text { 30. März I902, }
$$

ein Zusammenhang zwischen Windstärke und Lufttemperatur ist nicht $\mathrm{zu}$ erkennen.

Auffallend ist die stets hohe Luftemperatur bei
Sandtreiben, ob hier eine Temperaturerhöhung durch den aufgewirbelten erhitzten Sand vorliegt, wie sie beim echten Wüstenwind eintritt, ist zweifelhaft; zwar ist die Insolation auch in der kühleren Jahreszeit an heiteren Tagen, wie sie den Föhn gewöhnlich begleiten, noch beträchtlich, aber solange keine korrespondierenden Temperaturmessungen von Lufttemperatur und Sandboden vorliegen, läBt sich kein Urteil fällen.

Die Windgeschwindigkeit ist bei dem Sandtreiben sehr verschieden, dies führt zu der Vermutung, daB der Wind aus der Antizyklone, welche ständig von Mai bis Juli im Innern lagert, mit einer zum Boden schräggerichteten Komponente herabsteigt und das Sandtreiben erzeugt; nur so kann man auch die kalten Ostwinde erklären, welche im Innern nach Ortloff ${ }^{1}$ ) gleichzeitis mit dem Föhn in Swakopmund herrschen.

Will man nun wissen, um wieviel sich die Luft auf dem Wege von Windhuk bis Swakopmund erwärmt, so findet man diese Größe nach der Formel:

$$
\mathrm{t}_{2}=\left(\frac{\mathrm{p}_{2}}{\mathrm{p}_{1}}\right)^{\frac{\mathrm{K}-\mathrm{I}}{\mathrm{K}}} \cdot\left(273+\mathrm{t}_{1}\right)-273
$$

hier bedeutet:

$$
\left.\begin{array}{rl}
\mathrm{p}_{1} & =\text { Luftdruck } \\
\mathrm{t}_{1} & =\text { Luftemperatur }
\end{array}\right\} \text { in Windhuk }
$$

$\mathrm{P}_{2}$ und $\mathrm{t}_{2}$ dieselben Größen für Swakopmund, $\mathrm{K}=\mathrm{I}, 4 \mathrm{I}$ (Konstante), $273=$ der absolute Nullpunkt der Temperatur.

Da der Luftdruck in Windhuk geringe Schwankungen aufweist, und eine Änderung von $5 \mathrm{~mm}$ das Resultat nur um $1 / 2^{\circ}$ beeinflußt, so kann man einen mittleren Luftdruck zugrunde legen; nimmt man das Monatsmittel des Luftdrucks und der Temperatur von Mai I903

$$
\mathrm{b}_{1}=628 . \mathrm{I} \text { und } \mathrm{t}_{1}=\mathrm{I} 4.6 \text {, }
$$

so beträgt die Temperatur in Swakopmund 3I. 3 ; die Temperaturerhöhung beträgt $160^{\circ} 7$ oder rund $17^{\circ}$.

Vergleicht man hiermit die Temperaturdifferenz zwischen Windhuk und Swakopmund für $7 \mathrm{a}$ in Tafel IX, so finclet man meist kleinere, aber auch einzelne größere Werte, z. B. 2 I. $8^{\circ}$ an I I. Juni I 899. Wenn man nun bedenkt, dab der Föhn sich bei seiner Ankunft an der Küste stets mit kalter, feuchter Luft mischt, und daß er selbst den Seewinden sein Gepräge aufzudrücken vermag, so muissen hier die charakteristischen Eigenschaften des Föhn, große Lufttrockenheit und hohe Temperatur, in ganz außerordentlichem Maße vorhanden sein, und das führt weiter zu der Vermutung, daß wir es hier mit einem Zweig des in den Roßbreiten herabsinkenden Äquatorialstromes zu tun haben, denn einmal läßt die

1) Mitteil., 1902, S. 92 . 
außergewöhnlicheIntensität des Föhn darauf schließen, daß die Luft bereits vor dem Ansteigen auch außerordentlich warm und feucht und die Expansion im Regenstadium ebenfalls außerordentlich bedeutend gewesen sein muß, wie aus der graphischen Darstellung der thermodynamischen Vorgänge in der Atmosphäre beim Föhn von v. Bezoldi) leicht zu entnehmen ist, kurz, wir haben den aufsteigenden Ast des Föhn nicht wie in den Alpen an nahe benachbarten Orten, sondern weit entfernt in den äquatorialen Kalmen zu suchen; dann würde durch die Annahme, daß der Föhn dem Äquatorialstrom entstammt, auch die Erscheinung sich erklären, daß derselbe in Swakopmund nur in der kühlen Jahreszeit, in Pieter-Maritzburg dagegen das ganze Jahr hindurch vorkommt; letzterer Ort liegt eben ständig im Bereiche der Roßbreiten und der auf dem Meere sich bildenden Zyklonen, ersterer dagegen nur in der kühlen Jahreszeit.

Vergleicht man den Luitdruck von Windhuk und Swakopmund miteinander, so findet man nach Tafel XI an ersterem Orte eine Erhöhung desselben vor dem Auftreten des Föhn und an letzterem Orte ein geringes Sinken; die Wetterlage schcint also dieselbe zu sein wie in den Alpen, der Föhn erschcint auch hier als ein Teil des Luftaustausches zwischen Antizyklone und Zyklone. Über die Lage der letzteren läßt sich leider wegen Mangel an synoptischen Karten nichts feststellen.

Wahrscheinlich ist der Vorgang beim Auftreten des Föhn folgender:

Der in der kühlen Jahreszeit durch die Erkaltung des Landes ständig vorhandene Gradient vom Innern zum Meere wird verstärkt, einmal durch das Sinken des Luftdrucks zu Swakopmund - wahrscheinlich infolge zyklonaler Luftbewegung über dem Meere und dann durch Erhöhung desselben im Innern durch eine temporäre Antizyklone; da nun die am Boden erkaltete Luft schwer und träge ist und überdies durch das vertikal starkgegliederte Gelände gehindert wird, den Gradienten zu folgen, so tritt, ähnlich wie durch den Alpenkamm, eine Verhinderung des Luftaustausches und infolgedessen eine Spannung ein, die bewirkt, daß die höheren, wärmeren Luftschichten über den kälteren unten am Boden zur Küste hinabgleiten. Die oft mehrere Tage anhaltende Luftströmung vom Innern nach der Küste mit bisweilen heftigen Stürmen läßt auch auf einen starken Zufluß von Luft im Innern schließen, und dieser entstammt wahrscheinlich der Äquatorialströmung.

$\mathrm{Hann}^{2}$ ) hat zuerst auf die föhnartigen Er-

1) v. Bezold, Zur Thermodynamik der Atmosphäre (Erste Mitteil.). Sitzungsber. d. Berl. Akad. für I 888, S. 5 15.

2) Meteor. Zeitschr. 1876, S. 135, ferner Meteor. Zeitschr. I 883 S. 49, I 889 S. I9, I 890 S. 329.

Mitt. a. d. D. Schutzgebieten, XX. Band. III. scheinungen im Gebiete einer Antizyklone mit den Worten hingewiesen:

»Die hohe Wärme und die Trockenhcit der Luft auf Bergstationen während eines Barometermaximums erklären sich an natürlichsten durch Herabsinken der Luft aus der Höhe, wobei Erscheinungen auftreten müssen denen des Föhn analog.

Auch Billwiller ${ }^{1}$ ) macht auf Föhnerscheinungen namentlich aus dem Randgebiet von Antizyklonen aufmerksam und unterscheidet direkt »Bergföhn « und »antizyklonalen Föhn «; ferner wird diese Erscheinung noch von v. Bebber ${ }^{2}$ ) und Pohlis'3) erwähnt.

Solange keine Föhnbeobachtungen von einem Orte zwischen der Küste und dem Innern vorliegen, muß man annehmen, daß wir es in Swakopmund bzw. an der Küste von Deutsch-Südwestafrika mit einem antizyklonalen Föhn zu tun haben.

Wir können daher unsere Untersuchungen über den Föhn dahin zusammenfassen:

I. Der Föhn in Swakopmund scheint ein sogenannter antizyklonaler Föhn zu scin; denn

I. tritt er nach den bisher vorliegenden Beobachtungen nur an der Küste, also am Rande der Antizyklone auf, während im Innern gleichzeitig sehr kalte E-Winde herrschen; 2. wird er im Gegensatz zu dem Auftreten an anderen Orten nur in der kühlen Jahreszcit beobachtet, wo das Innere des Landes von einer ausgedehnten Antizyklone eingenommen wird.

II. Die Ursache des Föhn dürftc zu suchen sein in einer temporären Verstärkung der antizyklonalen Luftbewegung im Innern und einer gleichzeitig aufsteigenden, aspirierenden über dem Meere, die Neigung des Geländes $\left(1 / 2\right.$ bis $\left.1 / 3^{\circ}\right)$ bildet lediglich einen die Föhnbildung begünstigenden Moment.

III. Die außergewönliche Intensität der Föhnerscheinungen lassen darauf schließen, daß

I. die Luft aus großer Höhe herabstürzt,

2. ihr Wasserdampf fast vollständig ausgeschieden ist,

3. der vertikale Temperaturgradient infolge Temperaturumkehr erheblich kleiner als I auf IOO $\mathrm{m}$ ist,

4. die Luft vor ihrem Aufsteigen außerordentlich warm und feucht gewesen sein muß,

5. die Expansion derselben im Regenstadium sehr bedeutend gewesen sein muB.

1) Meteor. Zeitschr. I899 S. 2 [3.

2) v. Bebber, Meteor. Zeitschr, I887 S. 3 Io

3) Pohlis, Meteor. Zeitschr. I90o S. 282 
Aus 4. und 5. folgt, daß die Luft vor ihrem Aufsteigen eine hohe potentielle Temperatur besessen haben muß, und daß dieselbe durch das lange Verweilen im Kondensationsstadium noch erheblich vermehrt worden ist; da diese Bedingungen während der in Frage kommenden Jahreszeit nur in den Tropen gegeben sind, so haben wir den aufsteigenden Ast der Föhnerscheinung an der Küste von Deutsch-Südwestafrika in den äquatorialen Kalmen zu suchen.

Überblicken wir nun das Gesamtbild, welches wir bisher von dem Klima Swakopmunds gewonnen haben, so finden wir eine Reihe auffallender Erscheinungen.

Zwei Falitoren sind es, die wir für diese Anomalien verantwortlich machen müssen: die kühle Meeresströmung und die heißen, föhnartigen Ostwinde.

Die höhere spezifische Wärme des Wassers, der bedeutende Wärmeverbrauch durch Dampfbildung, seine größ̉ere Wärmedurchlässigkeit und die leichtere Wärmeverteilung infolge seiner Beweglichleit bringen es mit sich, dall das Wasser sich gegenüber der Insolation und Wärmestrahlung wesentlich anders verhält als das Land; es erwärmt sich langsamer als dieses und gibt die einmal empfangene Wärme auch langsamer $\mathrm{ab}$, daher treten Temperaturänderungen nur allmählich ein und halten sich innerhalb enger Grenzen. Kühle Sommer, milde Winter, geringe Temperaturschwankungen und hohe Luftfeuchtigkeit sind mithin die Haupteigenschaften des Seeklimas. Wo jedoch das Meer durch konstante Winde in Bewegung gesetzt wird, da ist der Einfluß dieser Winclund Mecresströme ein sehr verschiedener: je nachdem sie aus höheren oder niederen Breiten stammen, erniedrigen oder erhöhen sie die Temperatur und Niederschlagsbildung der benachbarten Küsten. Diese Unterschiede zeigen sich recht deutlich zwischen den West- und Ostküsten der Kontinente besonders in den niederen Breiten, wie aus folgender Tafel zu ersehen ist:

Temperatur und Regenhöhe der Ost- und Westkïiste.

\begin{tabular}{|c|c|c|c|c|c|c|c|}
\hline $\begin{aligned} \mathrm{E} & =\text { Ostkitste } \\
\mathrm{W} & =\text { Westkiiste }\end{aligned}$ & S-Br. & $\begin{array}{c}\text { Höhe } \\
\text { m }\end{array}$ & $\begin{array}{c}\text { Wärm- } \\
\text { ster } \\
\text { Mo }\end{array}$ & $\begin{array}{l}\text { Käl- } \\
\text { tester } \\
\text { aat }\end{array}$ & Diff. & Jahr & $\begin{array}{c}\text { Regen- } \\
\text { menge } \\
\mathrm{cm}\end{array}$ \\
\hline \multicolumn{8}{|c|}{ Sïdamerika. } \\
\hline E Pelotas ') & $\begin{array}{c}\circ \\
31.8\end{array}$ & 一 & 24.2 & I 2.0 & I 2.2 & I7.8 & I 33 \\
\hline W Serena. & 29.9 & 20 & I 8.4 & I I.7 & 6.7 & I 5. I & 4 \\
\hline E Merced Orient & 33.2 & 30 & 24.2 & IO.I & I $4 . \mathrm{I}$ & 17.1 & 85 \\
\hline W Valparaiso. . & 33.0 & 50 & $17 \cdot 3$ & I I.4 & $5 \cdot 9$ & $14 \cdot 3$ & 35 \\
\hline \multicolumn{8}{|c|}{ Südafrika. } \\
\hline E Durban ${ }^{2}$ ) & 29.8 & 45 & 23.8 & 17.3 & 6.5 & 20.6 & IO4 \\
\hline W Port Nolloth ${ }^{3}$ ) & 29.2 & 78 & I 5.7 & I 2.1 & 3.6 & 14.2 & 6 \\
\hline
\end{tabular}

1) Hann, Klimatologie, Bd. III, S. 424/26.

2) Dove, Klima des außertrop. Südafrika, S. 94.

3) Hann, Meteor. Zeitschr., S. 232.
Die kalte Meeresströmung an der Westküste von Südamerika und Südafrika erniedrigt bedeutend die Luftemperatur, verkleinert die Jahresschwankung und verhindert stärkere Niederschläge.

Wenn man die Temperaturverhältnisse des Oberflächenwassers an der Küste von Deutsch-Südwestafrika an der Hand einer Karte, \%. B. des Atlanten zum Segrelhandbuch für den Atlantischen Ozean I902, betrachtet, so findet man die auffallende Erscheinung; daß das Meer unmittelbar an der Küste am kältesten ist und mit der Entfernung von derselben bedeutend an Wärme zunimmt. So fand Stapffly auf einer Fahrt von Walfischbai nach Kapstadt nördlich vom Pelikan Point 14.4",

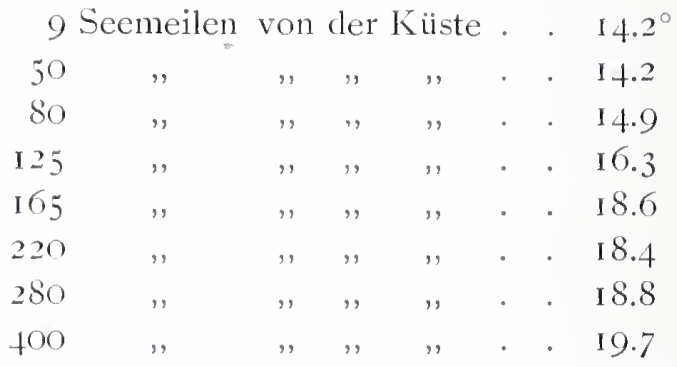

also mit seiner Entfernung von der Küste stetig wachsende Temperaturen, trotzdem er dabei in immer höhere Breiten gelangtc. Auch andere Reisencle, wie Dinklage, ${ }^{2}$ ) v. Danckelman ${ }^{3}$ ) und Pechuël-Loesche, $\left.{ }^{4}\right)$ haben ähnliche Resultate gefunden. Diese Erscheinung erklärt man damit, daß der Südostpassat das Oberflächenwasser in nordwestlicher Richtung wegtreibt und daB kaltes Auftriebwasser an dessen Stelle tritt. Ortloff fand bei seinen Untersuchungen der Meeresströmung, daß die Schwimmer bis zu einer Entfernung von $300 \mathrm{~m}$ vom Ufer durch Brandungswellen fast senkrecht auf das Ufer, in 500, 700 und $1000 \mathrm{~m}$ Entfernung aber mit einer durchschnittlichen Geschwindigkeit von $0.1 \mathrm{~m}$ in der Seliunde paraliel zum Ufer von Süden nach Norden getrieben wurden; leider liegen Temperaturmessungen nicht vor. Auch die Gestalt der Küste spielt eine Rolle; da dieselbe nach dem Äquator zu nach Westen vorspringt, so legt sich die kühle Strömung hart an die Küste und gewinnt an Tiefe.

Über die Wirkung des kalten Auftriebwassers auf das Klima der Küste äußert sich $\operatorname{Hann}^{5}$ ) folgendermalien:

Dieses kalte, aus der Tiefe stammende Küstenwasser, welches durch scine grüne Färbung schon dem Auge auffällt, hat einen sehr bemerkenswerten Einfluß auf das Klima der anliegenden Küste. Es

1) Annalen der Hydrogr., I887, S. 354.

2) Nach Sandmann, S. 29, befindet sich der Bericht im Archiv der Seewarte.

3) Verhandl. der Gesellsch. für Erdkunde zu Berlin, Bd. XIII, I 886 , S. 4I7/I8.

4) Das Ansland. 59. Jahrg., I 886, S. 85 I.

5) Mann, Klimatologie, Bd. I, S. I87. 
erniedrigt in hohem Maße die Lufttemperatur, bedingt häufige, dichte Nebel und dabei Mangel an stärkeren Niederschlägen und Fehlen von Gewittern."

Diese Eigenschaften finden wir durch die Beobachtungen in Swakopmund vollkommen bestätigt, denn:

I. ist die Lufttemperatur im Januar um $7.0^{\circ}$, im Juli um $3.2^{\circ}$ und im Jahr um $3.5^{\circ} \mathrm{zu}$ kalt,

2. kommen im Jahre durchschnittlich $7 \mathrm{a}: 83 \mathrm{mal}$, 2p und 9p: 33 mal Nebel vor,

3. betrug die jährliche Regenmenge im Mittel nur $18.5 \mathrm{~mm}$,

4. hat Swakopmund im Jahrc durchschnittlich 2.3 Gewitter.

Wenn man auch den wüstenähnlichen, öden Charakter der Küstenlandschaft infolge Regenmangels der Einwirkung der kalten Seewinde und der Meeresströmung zuschreiben muß, so ist doch ihr EinfluB ein konstanter und gleichmäßiger, daher zcigen auch die meteorologischen Elemente in ihrem jährlichen und täglichen Gange einen analogen Verlauf. Diesem Umstande ist es neben der relativ kühlen Lufttemperatur zu verdanken, daß das Klima von Swakopmund im ganzen als ein gesundes und dem Euroropäer zuträgliches bezeichnet werden kann.

Anders verhält es sich mit dem Einfluß der heißen, föhnartigen Ostwinde; dieselben treten zwvar nur selten und sporadisch in der kiihlen Jahreszeit auf, aber sie bringen selbst dort Temperaturen, welche diejenigen der warmen Jahreszeit noch ïbersteigen; mit dem Aufhören dieser Winde sinkt ebenso rasch die Temperatur wieder herab, hierdurch entstehen erhebliche Temperaturschwankungen. Sehr lästige Begleiterscheinungen der Föhnwinde sind die Sandstürme, welche große Mengen feinen Flugsandes aufwirbeln und gegen die keine Türen und Fenster dicht genug sind, um ihnen das Eindringen in die Wohnung zu verhindern; verbunden sind diese Stuirme mit einer großen Lufttrockenheit, hierin gleicht der Föhn dem echten Wüstenwinde, und Hann $\left.{ }^{1}\right)$ läßt es daher bei der Erörterung des Klimas von Walfischbai unentschieden, ob es Wüstenwinde oder Föhne sind.

Als eine Folge der Föhnwinde müssen wir bezeichnen:

I. daß die höchsten Temperaturen in die kalte Zeit fallen,

2. das sekundäre Maximum der Temperatur im Monat Mai in den Jahren I 899 bis I9O2,

3. das sekundäre Maximum der Luft- und Mcerestemperatur im Juli I9O5,

4. die große interdiurne Veränderlichkeit der Temperatur in den Monaten Mai bis Juli,

1) Meteor. Zeitschr. 1888, S. 3I 2.
5. die hohe unperiodische Monatsschwankung in denselben Monaten,

6. daß das Minimum der relativen Feuchtigkeit in die Monate Mai bis Juli fällt.

Die konstanten Seewinde und die Meeresströmung wie die Föhne sind ihrerseits wieder bedingt durch die Luftdruckverteilung.

Das Luftdruckmaximum der Roßbreiten müssen wir als die primäre Ursache der eigentümlichen klimatischen Erscheinungen an der Küste DcutschSüdwestafrikas ansehen.

Das ständige Hochdruckgebiet im südatlantischen Ozean ruft auf seiner Ostseite den ständigen SWWind und die Mceresströmung hervor, das ausgedehntc Depressionsgebiet im Inneren Südafrikas während der warmen Jahreszeit untcrstützt diese Tätigkeit; in gleicher Weise wirken in der kühlcn Jahreszeit das Hochdruckgebiet im Innerin und wahrscheinlich Dcpressionen im südatlantischen Ozean zusammen und erzeugcn so die Föhnwinde an der südwestafrikanischen Küste.

Den Ursprung des Benguelastromes hat man in der Vercinigung von dem warmen brasilianischen Strome mit der kalten Kap Horn-Trift zu suchen, beide wcrden als sogenannter Verbindungsstrom durch die starken IVestwinde nach Osten geführt, bis sie in den Bereich des ständigen Hochdruckgebietes der Roßbrciten gclangen, hier wird ein Teil des Verbindungsstromes von den SW-Winden erfaßt und als Benguelastrom gegen die afrikanische Kïste getrieben. Die Temperatur dieser Strömung ist nun abhängig einmal von dem Grad der Miscluung zwischen dem brasilianischen und lem Kap Hornstrom und dann von der Geschwindigkeit, mit welcher sie aus den höheren Breiten in die niederen gelangt. Eine höhere Meerestemperatur wird auch eine höhere Lufttemperatur zur Folge haben und wahrscheinlich auch, indem sie die Bildung von temporären Depressionen im südatlantischen Ozean begünstigt, der Entstehung der Föhnwinde günstig scin; auf diese Weise könnte man den Parallelismus, welchen wir zwischen der Jahrestemperatur der Luft, des Meeres und der Häufigkeit der Föhnwinde gefunden haben, erklären.

Es ist nicht unmöglich, daß man durch Luftdruckuntersuchungen, wie sic Meinardusi) für den nordatlantischen Ozean angestellt hat, ähnliche Beziehungen zwischen der südatlantischen Zirkulation und der Temperatur des Benguelastromes und vielleicht auch den Brandungsverhältnissen an der Küste aufdecken könnte.

1) Meinardus, Über Schwankungen der nordatlantischen Zirkulation und ihre Folgen. Annalen d. Hydrogr., I904, S. 353. 


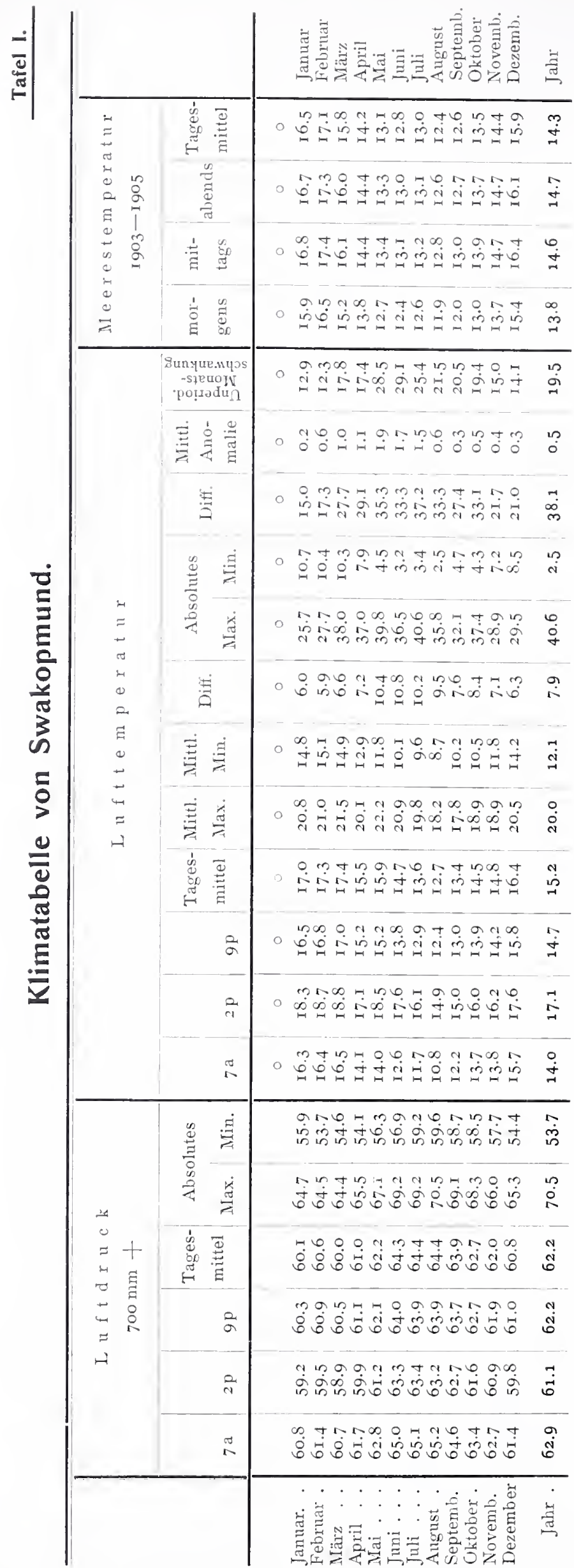

\begin{tabular}{|c|c|c|c|c|}
\hline & & & 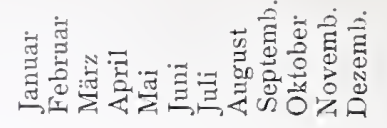 & 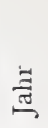 \\
\hline \multirow{2}{*}{ 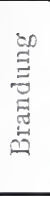 } & 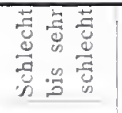 & \multirow{2}{*}{ 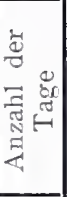 } & 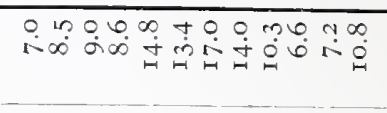 & $\underset{\substack{N \\
N}}{\stackrel{N}{N}}$ \\
\hline & 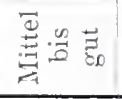 & & 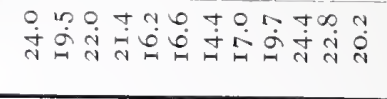 & $\underset{\infty}{\infty}$ \\
\hline \multirow{5}{*}{ 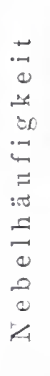 } & \multicolumn{2}{|c|}{ 茪 } & 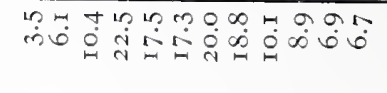 & $\stackrel{\substack{\infty \\
+}}{+}$ \\
\hline & \multirow{2}{*}{\multicolumn{2}{|c|}{$\stackrel{2}{a}$}} & 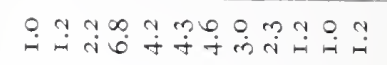 & $\stackrel{\circ}{m}$ \\
\hline & & & & \\
\hline & \multicolumn{2}{|c|}{$\frac{\pi}{4}$} & 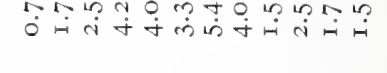 & $\stackrel{\ddot{m}}{\ddot{m}}$ \\
\hline & \multicolumn{2}{|c|}{$\stackrel{\mathbb{E}}{N}$} & 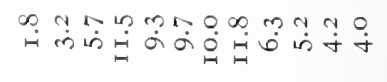 & $\widehat{i}$ \\
\hline \multirow{4}{*}{ 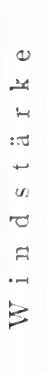 } & \multicolumn{2}{|c|}{ 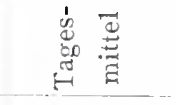 } & 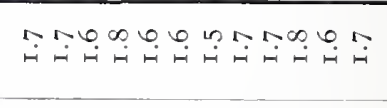 & $\tilde{i}$ \\
\hline & \multirow{2}{*}{\multicolumn{2}{|c|}{$i_{i=1}^{\infty} \quad n^{2}$}} & 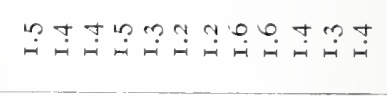 & $\stackrel{4}{i}$ \\
\hline & & & 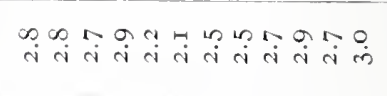 & $\stackrel{\varphi}{\dot{v}}$ \\
\hline & & $\pi$ & 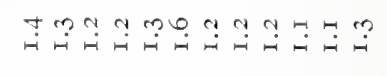 & $\stackrel{-1}{+}$ \\
\hline \multirow{4}{*}{$\begin{array}{l}80 \\
7 \\
= \\
= \\
: 0 \\
= \\
0 \\
0\end{array}$} & 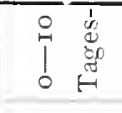 & $\stackrel{\Phi}{.}$ & 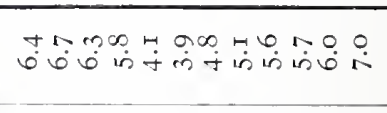 & $\begin{array}{l}0 \\
\text { in }\end{array}$ \\
\hline & \multicolumn{2}{|c|}{2} & 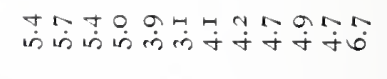 & $\stackrel{\infty}{+}$ \\
\hline & \multicolumn{2}{|c|}{$\stackrel{4}{s}$} & 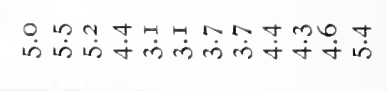 & $\stackrel{\dot{j}}{\dot{j}}$ \\
\hline & \multicolumn{2}{|c|}{$\stackrel{\pi}{n}$} & ஸे & $\stackrel{\circ}{\pi}$ \\
\hline \multirow{8}{*}{ 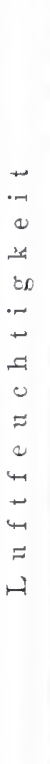 } & \multicolumn{2}{|c|}{ 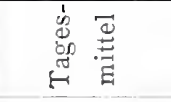 } & 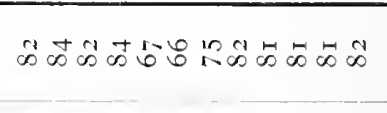 & 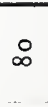 \\
\hline & \multirow{3}{*}{\multicolumn{2}{|c|}{ 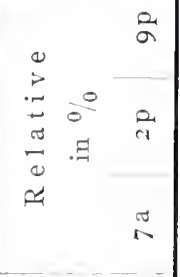 }} & 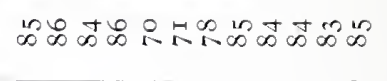 & N \\
\hline & & & 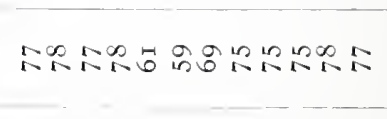 & 兵 \\
\hline & & & 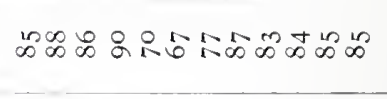 & $\infty$ \\
\hline & \multicolumn{2}{|c|}{ 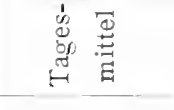 } & 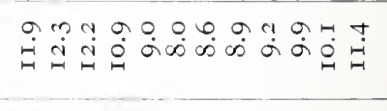 & $\overrightarrow{0}$ \\
\hline & \multirow{3}{*}{\multicolumn{2}{|c|}{ 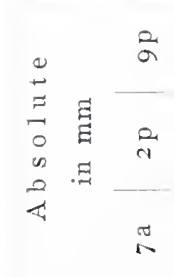 }} & 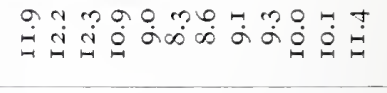 & $\stackrel{-}{\circ}$ \\
\hline & & & 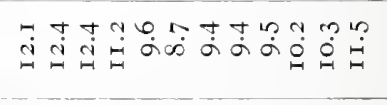 & $\underset{n}{n}$ \\
\hline & & & 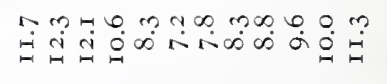 & $\hat{\sigma}$ \\
\hline & & & 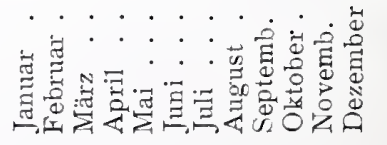 & $\stackrel{\dot{\pi}}{\stackrel{\pi}{\leftrightarrows}}$ \\
\hline
\end{tabular}


Die interdiurne Veränderlichkeit der Temperatur zu Swakopmund.

Tafel II.

7 a-7 a.

\begin{tabular}{|c|c|c|c|c|c|c|c|c|c|c|c|c|c|}
\hline & Januar & Februar & März & April & Mai & Juni & Juli & August & Sept. & Oktober & Nov. & Dez. & Jahr \\
\hline \multicolumn{14}{|c|}{ I. Die mittlere monatliche Veränderlichkeit. } \\
\hline Swakopmund & $0.9 \mathrm{I}$ & 0.87 & I. 16 & I.09 & 2.66 & 2.49 & 2.68 & I.72 & I.49 & I.I4 & 0.93 & 0.72 & I.49 \\
\hline $\begin{array}{l}\text { Klausen } 6 a-6 a \\
\text { Schneekoppe }\end{array}$ & 3.4 & $4 \cdot 4$ & 2.5 & 2.5 & 2.4 & $2 . I$ & I .8 & 2.0 & 2.8 & 2.9 & 2.4 & 3.6 & \\
\hline $7 a-7 a$ & 3.2 & 2.5 & $3 \cdot 3$ & 2.7 & 2.6 & 2.4 & 2.9 & 2.6 & 2.1 & 2.0 & 2.6 & 2.9 & \\
\hline Emden $6 a-6 a$ & 2.0 & 2.4 & 1.8 & I. 7 & I. 4 & 1.8 & $\mathrm{I} .5$ & I.4 & ฯ.8 & 2.0 & $2 . I$ & 2.2 & \\
\hline Kapstadt & & & & & & & & & & & & & \\
\hline $\begin{array}{l}\text { Tagesmittel } \\
\text { Maritzburg }\end{array}$ & 1.2 & I. 3 & 1.3 & I. 4 & I. 2 & I.5 & 1.4 & I.4 & I. I & 1.3 & I.I & I. 2 & $\mathbf{I} \cdot 3$ \\
\hline Tagesmittel & 2.5 & 2.5 & $2 . I$ & I. 6 & I. 3 & 1.9 & I.6 & 2.3 & 2.4 & 2.9 & 2.5 & 2.5 & 2.2 \\
\hline
\end{tabular}

2. Mittlere Mäufigkeit der Erwärmungen und Erkaltungen.

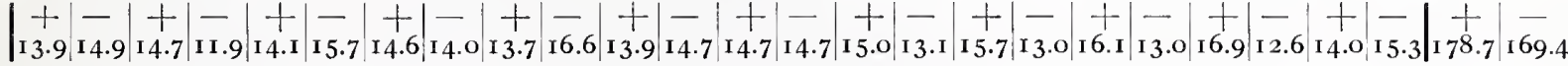

3. Verhältnis der Erwärmungen zu den Erkaltungen.

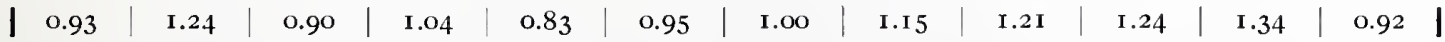

4. Die mittlere Häufigkeit der Erwärmungen (+) und Erkaltungen (-) in den einzelnen Temperaturgruppen.

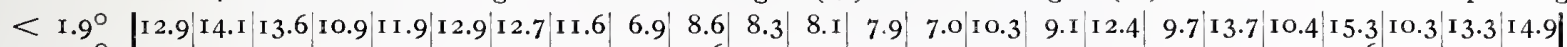

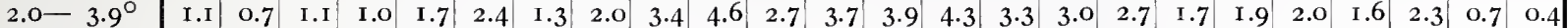

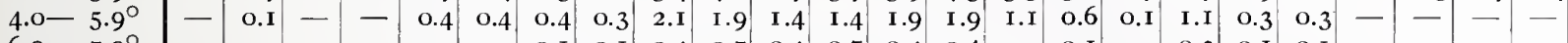

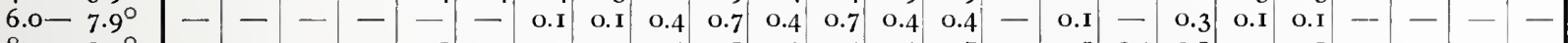

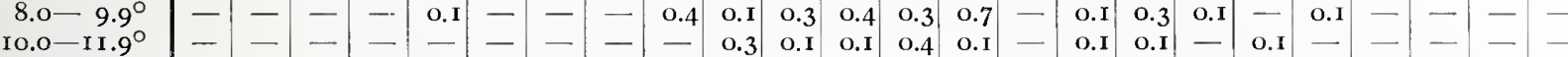

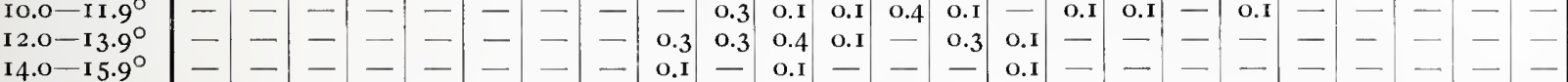

5. Mittlere Größe einer Erwärmung und Erkaltung.

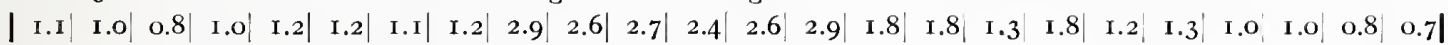

6. Absolute monatliche Extreme der Erwärmungen und Erkaltungen.

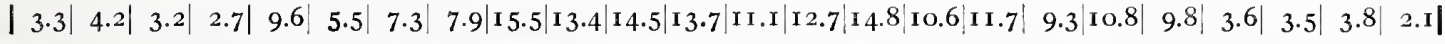

\begin{tabular}{|c|c|c|c|c|c|c|c|c|c|c|c|c|c|c|c|}
\hline & & & & & & & & & & & Der & wind $\left(4^{\circ}\right.$ üb & $\begin{array}{l}\text { Mittel) } \\
\text { Durchso }\end{array}$ & $\begin{array}{l}\text { Ten } \\
\text { Nort }\end{array}$ & höluung \\
\hline & & & & & & & & & $7 \mathrm{a}$ & $2 \mathrm{p}$ & $9 \mathrm{p}$ & Tagesmittel & $7 \mathrm{a}$ & $2 \mathrm{p}$ & $9 \mathrm{p}$ \\
\hline & & & & & & & & & & & & & $\stackrel{\circ}{-}$ & $\circ$ & 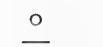 \\
\hline $\begin{array}{l}\text { Januar } \\
\text { Februar }\end{array}$ & $\cdot$ & $\cdot$ & - & $\cdot$ & $\cdot$ & $\cdot$ & $\cdot$ & $\cdot$ & $\overrightarrow{-}$ & $\underline{I}$ & - & $\begin{array}{c}\mathrm{I} \\
\end{array}$ & - & I.9 & - \\
\hline März . & . & . & $\cdot$ & . & . & . & $\cdot$ &. & 4 & 6 & 2 & I 2 & $\overline{6.7}$ & 5.5 & $\overline{9.1}$ \\
\hline April . . & . & . & . & . & . & . & . & . . & 5 & 7 & 3 & I 5 & $5 \cdot 3$ & 9.8 & I 2.2 \\
\hline Mai & . & . & . & . & . & . & . & . & 36 & $3 I$ & 29 & 96 & 8.0 & 8.5 & $6.8^{\circ}$ \\
\hline Juni & • & . & . & . & . & . & . & . . & 27 & 34 & 20 & $8 I$ & $9 \cdot 3$ & 10.2 & 7.0 \\
\hline Juli. & . & . & . & - & . & . & - & . & I 8 & 20 & I I & 49 & 8.1 & 9.6 & 7.0 \\
\hline August & & . & . & . & . & . & . & . & 3 & 3 & - & 6 & 9.4 & 7.0 & - \\
\hline September & & . & . & . & . & . & . & . & 5 & 8 & 6 & I9 & $7 \cdot 3$ & 8.0 & 5.6 \\
\hline Oktober. & & . & . & . & . & . & . & . & 2 & 2 & 2 & 6 & 8.0 & I0.8 & 5.2 \\
\hline November & & . & . & . & . & . & . & . . & - & - & - & - & - & 一 & - \\
\hline Dezember & & . & . & . & . & . & . & . & - & - & - & - & - & - & 一 \\
\hline
\end{tabular}

Regentabelle von Swakopmund.

Tafel III.

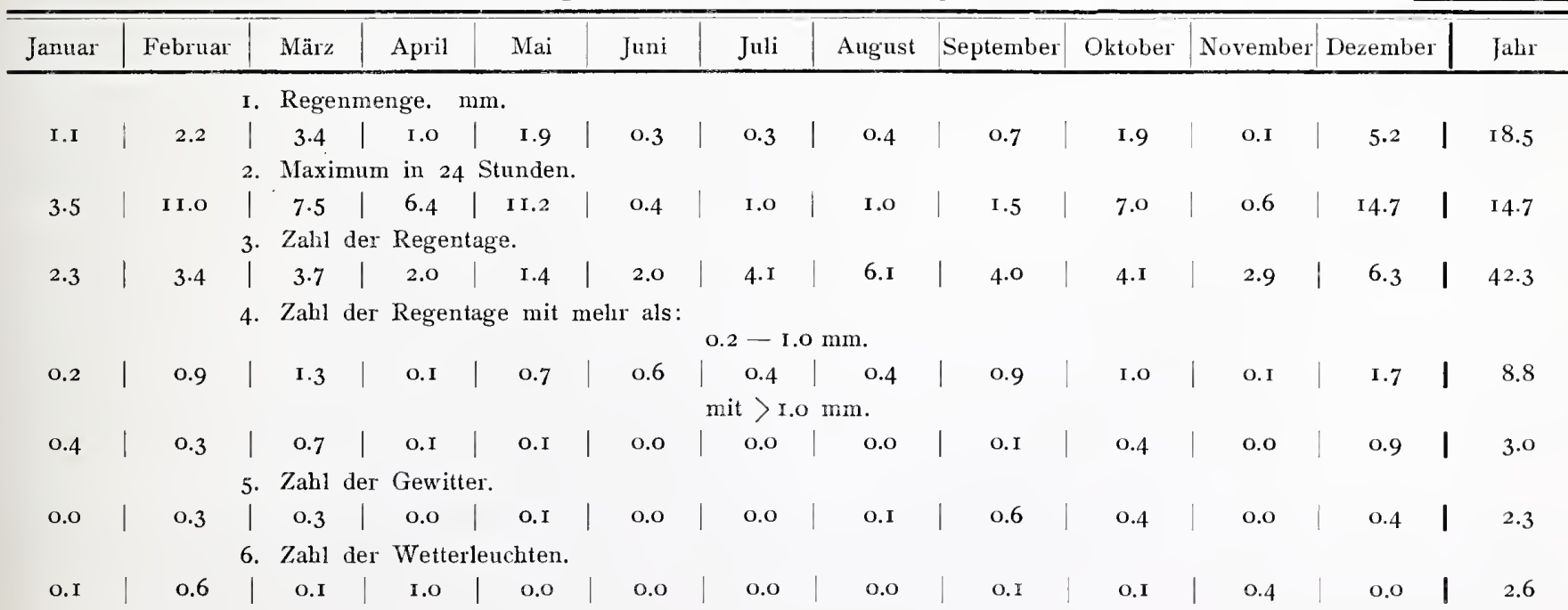


Tafel IV. Die Häufigkeit der Winde zu Swakopmund von 1899 bis 1905 in Prozenten.

\begin{tabular}{|c|c|c|c|c|c|c|c|c|c|c|c|c|c|c|c|}
\hline & & & Jannar & Februar & März & April & Mai & Juni & Juli & Angust & Septbr. & Oktober & Novbr. & Dezbr. & Jalır \\
\hline $7 \mathrm{a} \mathrm{ml}$ & $\begin{array}{l}N \\
N E \\
E \\
S E \\
S E \\
S \\
S W \\
W \\
N W \\
C W \\
C .\end{array}$ & $\begin{array}{lll}\cdot & \cdot & \\
\cdot & \cdot & \\
\cdot & \cdot & \\
\cdot & \cdot & \\
\cdot & \cdot & \\
\cdot & \cdot & \\
. & \cdot & \\
. & \cdot & \\
. & . & \end{array}$ & $\begin{array}{r}23.9 \\
6.6 \\
0.7 \\
1.6 \\
4.2 \\
8.1 \\
17.4 \\
30.8 \\
6.6\end{array}$ & $\begin{array}{r}23.1 \\
6.1 \\
1.2 \\
1.5 \\
4.8 \\
\text { II. } 6 \\
14.0 \\
27.4 \\
10.2\end{array}$ & $\begin{array}{r}\text { I } 9.3 \\
\text { I } 2.2 \\
3.5 \\
2.9 \\
6.0 \\
\text { I0.4 } \\
\text { I } 5.9 \\
\text { I } 9.1 \\
\text { I0.6 }\end{array}$ & $\begin{array}{r}23.8 \\
17.3 \\
6.2 \\
3.8 \\
5.1 \\
8.0 \\
9.2 \\
12.8 \\
13.9\end{array}$ & $\begin{array}{r}\text { I } 7 . I \\
26 . I \\
21.5 \\
9.2 \\
4.0 \\
4.3 \\
4.0 \\
6.3 \\
7.4\end{array}$ & $\begin{array}{r}\text { II.5 } \\
31.0 \\
27.3 \\
8.3 \\
4.6 \\
5.5 \\
4.3 \\
3.1 \\
4.3\end{array}$ & $\begin{array}{r}20.3 \\
24.4 \\
18.2 \\
9.6 \\
3.5 \\
3.7 \\
4.7 \\
8.4 \\
7.4\end{array}$ & $\begin{array}{r}7.2 \\
24.8 \\
\text { I I.8 } \\
\text { I0.0 } \\
5.7 \\
7.6 \\
8.6 \\
7.4 \\
6.5\end{array}$ & $\begin{array}{r}24.0 \\
12.0 \\
6.9 \\
9.8 \\
7.6 \\
7.3 \\
7.6 \\
14.2 \\
10.5\end{array}$ & $\begin{array}{r}22.5 \\
9.8 \\
3.3 \\
4.2 \\
9.2 \\
10.2 \\
9.1 \\
\text { I } 5.3 \\
16.6\end{array}$ & $\begin{array}{r}21.2 \\
7.0 \\
2.8 \\
6.4 \\
9.0 \\
10.0 \\
14.5 \\
22.9 \\
6.2\end{array}$ & $\begin{array}{r}7.6 \\
2.8 \\
0.7 \\
3.4 \\
6.0 \\
10.7 \\
18.8 \\
31.5 \\
8.3\end{array}$ & $\begin{array}{r}20 . \mathrm{I} \\
\text { I } 5 . \mathrm{I} \\
8.7 \\
6.0 \\
5.8 \\
8.2 \\
10.7 \\
\text { I } 6.6 \\
9.0\end{array}$ \\
\hline $2 \mathrm{p} \mathrm{m}$ & $\begin{array}{l}N \\
N E \\
E \\
S E \\
S \\
S W \\
W W \\
N W \\
C . \\
\end{array}$ & $\begin{array}{lll}\cdot & \cdot & \\
. & \cdot & \\
. & \cdot & \\
. & \cdot & \\
. & \cdot & \\
. & . & \\
. & \cdot & \\
. & \cdot & \\
. & . & \\
\end{array}$ & $\begin{array}{r}2 . I \\
0.2 \\
\cdot \\
\dot{1} 4.8 \\
44 . \mathrm{I} \\
30.3 \\
7.5 \\
0.9 \\
\end{array}$ & $\begin{array}{c}0.5 \\
\cdot \\
\cdot \\
\text { II. } \\
47.7 \\
34.6 \\
5.6\end{array}$ & $\begin{array}{c}\mathrm{r} .0 \\
\cdot \\
0.7 \\
20.3 \\
47.5 \\
25.9 \\
4.2\end{array}$ & $\begin{array}{c}0.5 \\
\cdot \\
0.4 \\
25.0 \\
51.8 \\
18.2 \\
4.1 \\
\end{array}$ & $\begin{array}{r}0.9 \\
1.2 \\
0.2 \\
1.4 \\
32.4 \\
46.7 \\
14.1 \\
2.1 \\
0.9 \\
\end{array}$ & $\begin{array}{r}1.2 \\
3.2 \\
1.0 \\
1.7 \\
29.0 \\
43.3 \\
16.3 \\
4.5 \\
.\end{array}$ & $\begin{array}{r}3.0 \\
1.9 \\
1.5 \\
0.2 \\
23.9 \\
42.6 \\
19.5 \\
7.4 \\
\end{array}$ & \begin{tabular}{r}
\multicolumn{1}{c}{0.4} \\
1.0 \\
3.5 \\
23.6 \\
48.3 \\
$I 8.6$ \\
3.9 \\
0.5
\end{tabular} & $\begin{array}{c}1.0 \\
0.2 \\
0 . \\
0.7 \\
19.6 \\
49.3 \\
23.0 \\
6.2\end{array}$ & $\begin{array}{r}\text { I.0 } \\
0.9 \\
0.4 \\
1.8 \\
22.5 \\
43.4 \\
22.5 \\
7.6 \\
\end{array}$ & $\begin{array}{r}2.1 \\
6.0 \\
\mathbf{I} .6 \\
\mathbf{I} .2 \\
\mathbf{I} 5.5 \\
45.5 \\
24.0 \\
3.8 \\
\end{array}$ & $\begin{array}{r}0.2 \\
\cdot \\
\cdot \\
1 \\
11.6 \\
44.1 \\
35.6 \\
7.4 \\
0.9\end{array}$ & $\begin{array}{r}1.2 \\
1 . I \\
0.5 \\
0.9 \\
20.8 \\
46.1 \\
23.5 \\
5.4 \\
0.3 \\
\end{array}$ \\
\hline $9 \mathrm{p} \mathrm{m}$ & $\begin{array}{l}\mathrm{N} . \\
N E \\
\mathrm{E} \\
\mathrm{SE} . \\
\mathrm{S} \\
\mathrm{SW} \\
W \\
\mathrm{~N} W \\
\mathrm{C} . \\
\end{array}$ & $\begin{array}{ll}\cdot & \cdot \\
\cdot & . \\
. & . \\
. & . \\
. & . \\
. & . \\
. & . \\
. & . \\
. & . \\
\end{array}$ & $\begin{array}{r}8.2 \\
0.2 \\
. \\
2.2 \\
21.8 \\
26.2 \\
16.7 \\
16.3 \\
8.3 \\
\end{array}$ & $\begin{array}{r}9.9 \\
1.0 \\
0.5 \\
1.3 \\
19.3 \\
29.8 \\
13.0 \\
13.5 \\
10.4 \\
\end{array}$ & $\begin{array}{r}8.8 \\
1.6 \\
0.2 \\
0.6 \\
27.2 \\
31.5 \\
12.7 \\
11.3 \\
6.0 \\
\end{array}$ & $\begin{array}{r}9.6 \\
1.5 \\
0.8 \\
2.0 \\
25.4 \\
31.9 \\
10.7 \\
13.1 \\
5.0 \\
\end{array}$ & $\begin{array}{r}\text { II } 1.6 \\
5.0 \\
4.2 \\
5.6 \\
22.7 \\
21.8 \\
10.6 \\
\text { IO.I } \\
8.5 \\
\end{array}$ & $\begin{array}{r}12.6 \\
7.2 \\
4.8 \\
6.4 \\
23.8 \\
20.9 \\
8.1 \\
9.5 \\
6.7 \\
\end{array}$ & $\begin{array}{r}\text { II.2 } \\
5.4 \\
2.3 \\
4.7 \\
27.5 \\
26.0 \\
8.1 \\
9.4 \\
5.2 \\
\end{array}$ & $\begin{array}{r}14.1 \\
5.9 \\
2 . I \\
4.7 \\
27.7 \\
23.5 \\
\text { II. } 5 \\
\text { IO.I } \\
0.4 \\
\end{array}$ & $\begin{array}{r}\text { I I.6 } \\
1.9 \\
1.2 \\
5.0 \\
28.9 \\
22.6 \\
9.0 \\
\text { I } 8.1 \\
1.5 \\
\end{array}$ & $\begin{array}{r}9.8 \\
1.9 \\
0.4 \\
4.9 \\
24.1 \\
21.4 \\
12.5 \\
18.0 \\
7.0 \\
\end{array}$ & $\begin{array}{r}8.9 \\
1.0 \\
0.2 \\
5.3 \\
25.9 \\
26.9 \\
\mathrm{I} 2.0 \\
\mathrm{I} 3.3 \\
7.6\end{array}$ & $\begin{array}{r}9.7 \\
0.8 \\
0.2 \\
2.6 \\
17.2 \\
28.3 \\
18.4 \\
17.2 \\
5.6\end{array}$ & $\begin{array}{r}10.5 \\
2.8 \\
1.4 \\
3.8 \\
24.4 \\
25.8 \\
11.9 \\
13.4 \\
6.0\end{array}$ \\
\hline 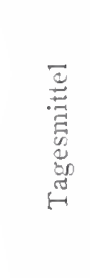 & $\begin{array}{l}N \\
N E \\
E \\
S E \\
S \\
S W \\
S W \\
W \\
N W \\
C .\end{array}$ & $\begin{array}{ll}\cdot & \cdot \\
\cdot & . \\
\cdot & . \\
\cdot & . \\
. & . \\
. & . \\
. & . \\
. & . \\
. & .\end{array}$ & $\begin{array}{r}\text { I I.4 } \\
2.4 \\
0.2 \\
1.3 \\
13.7 \\
26.1 \\
21.5 \\
18.2 \\
5.3\end{array}$ & $\begin{array}{r}\text { Y I.I } \\
2.4 \\
0.6 \\
0.9 \\
12.4 \\
29.6 \\
20.5 \\
\text { I } 5.5 \\
6.9\end{array}$ & $\begin{array}{r}9.8 \\
4.6 \\
1.2 \\
1.4 \\
17.8 \\
29.8 \\
18.2 \\
11.6 \\
5.5\end{array}$ & $\begin{array}{r}\mathrm{I} I .3 \\
6.3 \\
2.3 \\
2.0 \\
\mathrm{I} 8.6 \\
30.5 \\
\mathrm{I} 2.7 \\
9.9 \\
6.3\end{array}$ & $\begin{array}{r}9.9 \\
10.7 \\
8.6 \\
5.5 \\
19.7 \\
24.2 \\
9.6 \\
7.1 \\
5.6\end{array}$ & $\begin{array}{r}8.5 \\
13.7 \\
11.0 \\
5.4 \\
\text { I } 9.1 \\
23.2 \\
9.5 \\
5.6 \\
3.7\end{array}$ & $\begin{array}{r}\text { II } .5 \\
\text { IO.4 } \\
7.1 \\
5.2 \\
\text { I } 8.3 \\
24.2 \\
10.7 \\
8.4 \\
4.2\end{array}$ & $\begin{array}{r}\text { I0.6 } \\
10.3 \\
5.0 \\
6.0 \\
\text { I } 9.1 \\
26.5 \\
12.9 \\
7.2 \\
2.5\end{array}$ & $\begin{array}{r}12.3 \\
4.7 \\
2.7 \\
5.2 \\
18.7 \\
26.4 \\
13.2 \\
12.9 \\
4.0\end{array}$ & $\begin{array}{r}\text { I I.I } \\
4.2 \\
\text { I. } \\
3.6 \\
\text { I } 8.6 \\
24.9 \\
\text { I } 4.7 \\
\text { I3.6 } \\
7.9\end{array}$ & $\begin{array}{r}10.5 \\
4.6 \\
1.6 \\
4.3 \\
16.8 \\
27.4 \\
16.8 \\
13.3 \\
4.6\end{array}$ & $\begin{array}{r}9.2 \\
\text { I.2 } \\
0.3 \\
2.1 \\
\text { II. } 6 \\
27.8 \\
24.3 \\
\text { I } 8.7 \\
4.9\end{array}$ & $\begin{array}{r}\text { I0.6 } \\
6.3 \\
3.6 \\
3.6 \\
17.0 \\
26.8 \\
\text { I } 5.4 \\
\text { II.8 } \\
5.1\end{array}$ \\
\hline
\end{tabular}

\section{Tafel V.}

$\mathrm{N}=$ Komponente
$\dot{\mathrm{S}}=\quad$,
$\mathrm{E}=\quad$,

Mittlere Windrichtung

Azimut von $\mathrm{N}$

Resultierende

$\mathrm{N}=$ Komponente

$\mathrm{S}=$

IV $=$

Mittlere Windrichtung

Azimut von N

Resultierende

$\mathrm{N}=$ Komponente

$\mathrm{s}=$

$\mathrm{E}=$

Mittlere Windrichtung

Azimut von $\mathrm{N}$

Resultierende

Nach Lambert $7 \mathrm{a}$.

$\begin{gathered}\text { Differenz zwischen } \\ \text { beiden Rechenmethoden }\end{gathered}\left|-5.7^{\circ}\right|-\mathbf{I} 4.5^{\circ}\left|-8.2^{\circ}\right|-9.9^{\circ}\left|+7.9^{\circ}\right|-0.2^{\circ}\left|+4.3^{\circ}\right|+7.7^{\circ}\left|-9.8^{\circ}\right|-\mathbf{I} \mathbf{1} .7^{\circ}-7.6^{\circ}\left|-\mathbf{I} 6.5^{\circ}\right|-\mathbf{I 0 . 8 ^ { \circ }}$

\section{Mittlere Wincirichtung nacl Lambert.}

\section{$7 \mathrm{a}$}

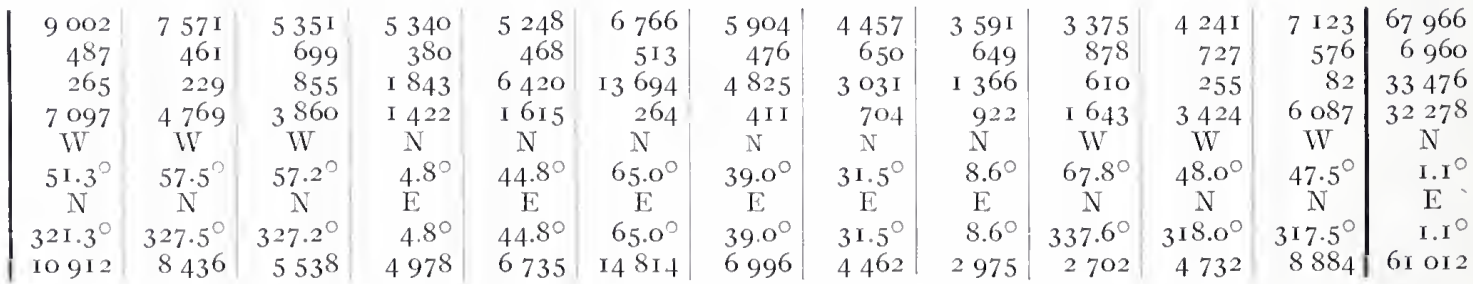
$2 p$

\begin{tabular}{|r|r|r|r|r|r|r|r|r|r|r|r|r|r|r|}
406 & $25 \mathrm{I}$ & 222 & 104 & 39 & $\mathrm{I} 25$ & 356 & 60 & 237 & 310 & 265 & 495 & 2866
\end{tabular}

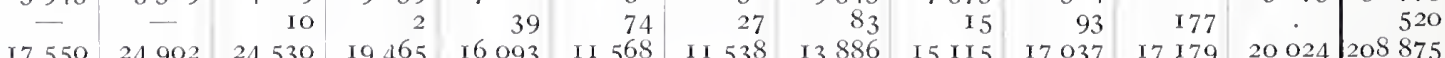

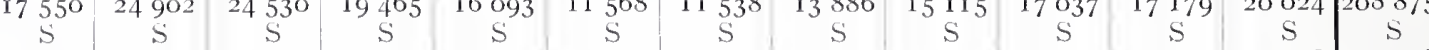

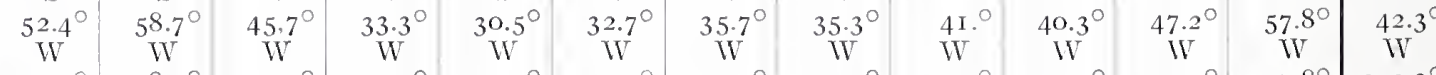
\begin{tabular}{|l|l|l|l|l|l|l|l|l|l|l|l|l}
$232.4^{\circ}$ & $238.7^{\circ}$ & $225.7^{\circ}$ & $213.3^{\circ}$ & $210.5^{\circ}$ & $212.7^{\circ}$ & $215.2^{\circ}$ & $215.3^{\circ}$ & $221.0^{\circ}$ & $220.3^{\circ}$ & $227.2^{\circ}$ & $237.8^{\circ}$ & $222.3^{\circ}$ \\
$2217^{2}$ & 29132 & 34288 & 11238 & 31570 & 21294 & 19940 & 23877 & 20700 & 26223 & 23177 & 23647 & 30953
\end{tabular} $9 \mathrm{p}$

\begin{tabular}{|c|c|c|c|c|c|c|c|c|c|c|c|c|}
\hline 1725 & 696 & I 29 I & $72 \mathrm{I}$ & & & I I & 267 & & & & & \\
\hline 64 & 761 & I $230 \mathrm{I}$ & 92 & & & 78 & $04^{\mathrm{r}}$ & IO & & 87 & & \\
\hline & & & & & & & & & - & & & \\
\hline & $\begin{array}{c}5094 \\
\mathrm{~S}\end{array}$ & $\begin{array}{c}69^{2} \\
\mathrm{~S}\end{array}$ & $\begin{array}{c}5657 \\
S\end{array}$ & $\mathrm{~S}$ & $\mathrm{~s}$ & $\begin{array}{c}388_{3} \\
\mathrm{~S}\end{array}$ & . & $\begin{array}{c}5063 \\
\mathrm{~S}\end{array}$ & $\begin{array}{c}428 \\
\mathrm{~S}\end{array}$ & $\begin{array}{c}4845 \\
\mathrm{~S}_{\mathrm{S}}\end{array}$ & $\begin{array}{c}5774 \\
\mathrm{~S}\end{array}$ & \\
\hline $\begin{array}{l}46.3 \\
\text { IV }\end{array}$ & $40.8^{\circ}$ & $32.2^{\circ}$ & $36.8^{\circ}$ & 36.5 & $36.2^{\circ}$ & $30.2^{\circ}$ & 0 & $30.2^{\circ}$ & $39.8^{\circ}$ & $31.4^{\circ}$ & $54.7^{\circ}$ & \\
\hline & 220.8 & $212.2^{\circ}$ & $2 \mathrm{I} 6.8^{\circ}$ & 216. & $216.2^{\circ}$ & $210.2^{\circ}$ & 08 & 210.2 & 219 & $11.4^{\circ}$ & 34. & \\
\hline & & & 92 & & & & & & & & & \\
\hline
\end{tabular}

\section{Die mittlere Windrichtung 7 a berechnet aus der Windhäufigkeit}

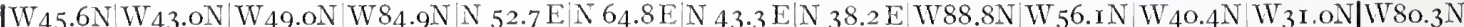

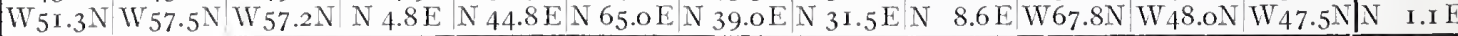


1899 bis 1904 .

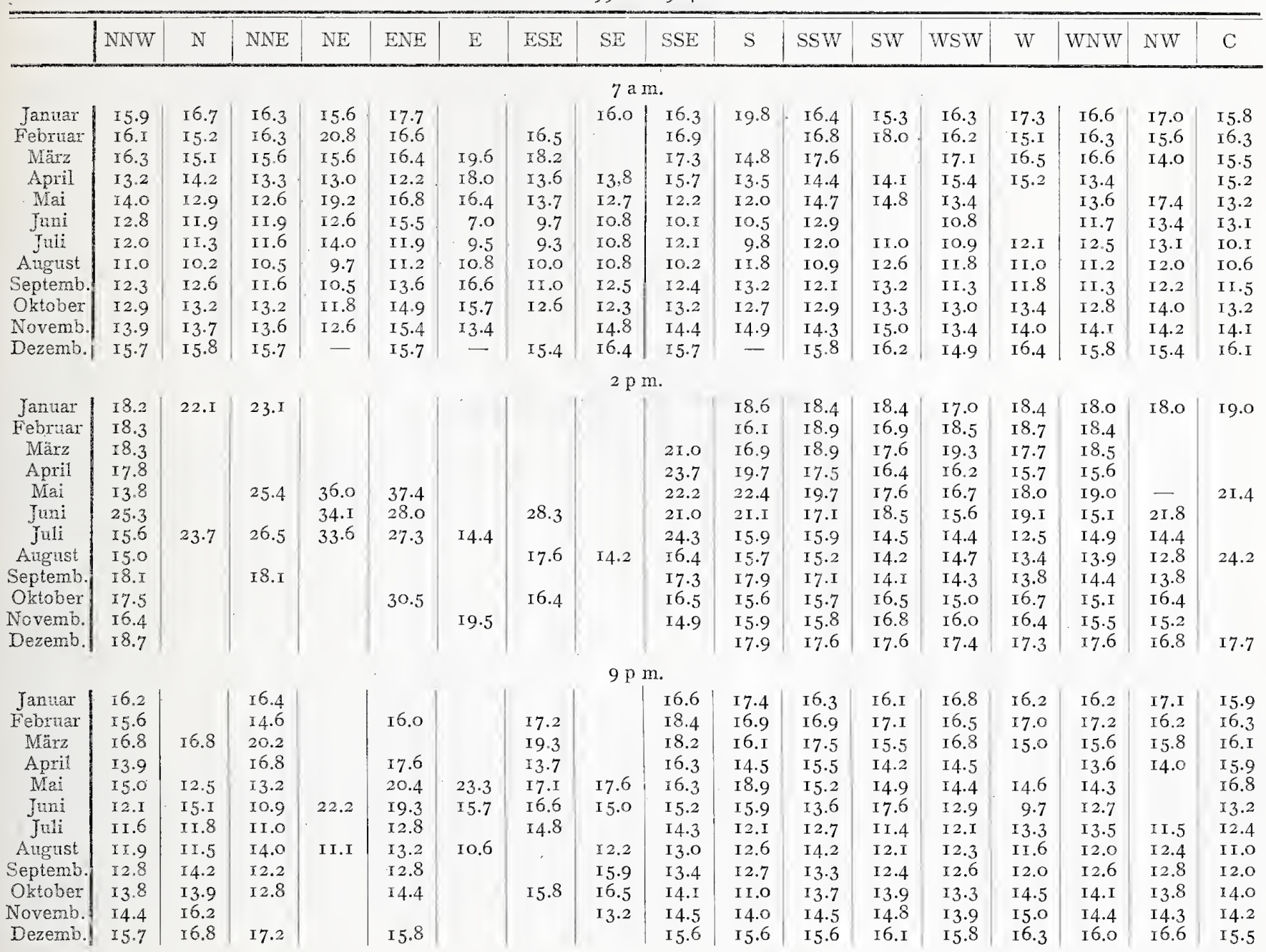

Mittlere Windstärke für $7 \mathrm{a} \mathrm{m}, 2 \mathrm{p} \mathrm{m}, 9 \mathrm{p} \mathrm{m}$.

Tafel VII.

\begin{tabular}{|l|l|l|l|l|l|l|l|l|l|l|l|l|l|l|l|}
\hline NNW & N & NNE & NE & ENE & E & ESE & SE & SSE & S & SSW & SW & WSW & W & WNW & NW \\
\hline
\end{tabular}

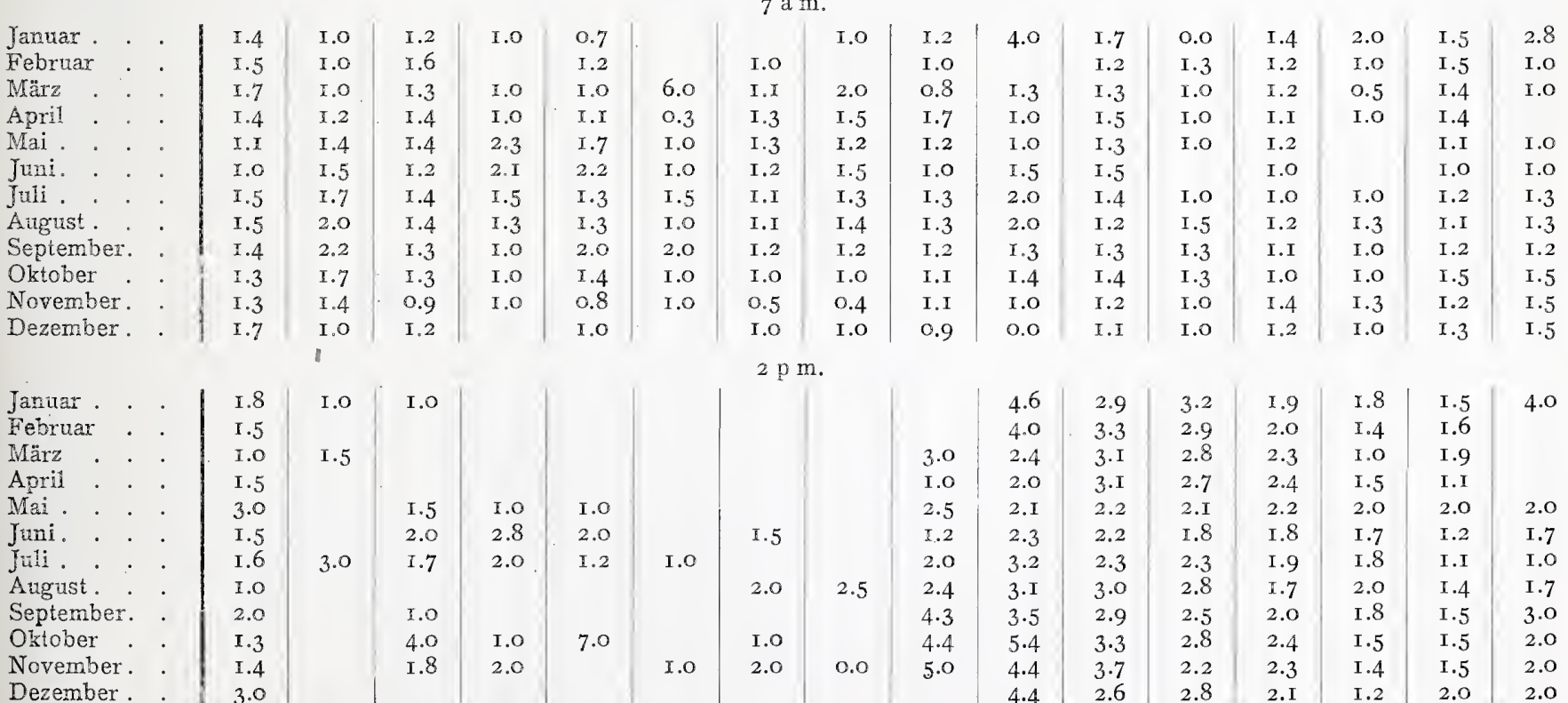




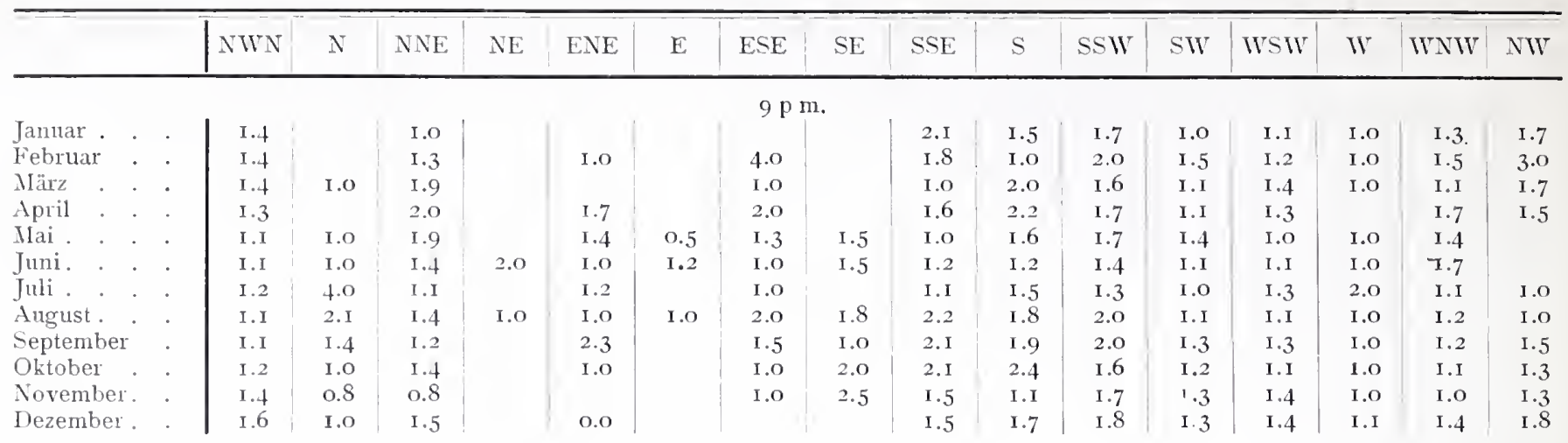

Tafel VIII.

Windrose der Bewölkung.

\begin{tabular}{l|ll|l|lll|l|l|l|l|l|l|l|l|l|l|l|l|l|l|l|l|l|l|l|l}
\hline NNW & $\mathrm{N}$ & $\mathrm{NNE}$ & $\mathrm{NE}$ & $\mathrm{ENE}$ & $\mathrm{E}$ & $\mathrm{ESE}$ & $\mathrm{SE}$ & $\mathrm{SSE}$ & $\mathrm{S}$ & $\mathrm{SSW}$ & $\mathrm{SW}$ & WSW & W & WNW & NW & $\mathrm{C}$ \\
\hline
\end{tabular}

7 a m.

\begin{tabular}{|c|c|c|c|c|c|c|c|c|c|c|c|c|c|c|c|c|c|}
\hline Januar . . & 8.7 & IO.O & $9 \cdot 5$ & 9.0 & 6.0 & & & IO.O & 7.0 & 3.0 & 8.9 & 7.0 & $9 \cdot I$ & 9.0 & 8.8 & $7 \cdot 5$ & 8.4 \\
\hline Februar. & 9.1 & 10.0 & $9 . I$ & 3.0 & 9.8 & & IO.O & & 3.6 & & 9.9 & $7 \cdot 3$ & 9.2 & I0.0 & 9.0 & 8.0 & 8.6 \\
\hline Mårz . & 8.9 & IO.O & 8.2 & IO.O & 6.5 & I0.0 & 5.4 & I0.0 & 9.8 & $7 \cdot 3$ & 5.8 & I .O & S.I & 3.0 & 9.0 & IO.0 & $8 . \mathrm{I}$ \\
\hline April. & 9.1 & 7.0 & $7 \cdot 3$ & 5.0 & 6.2 & 6.0 & $5 \cdot 3$ & 7.0 & 9.7 & 4.0 & 8.8 & 8.6 & 8. I & IO.O & 8.5 & & $8 . \mathrm{I}$ \\
\hline Má... & 8.2 & IO.O & 6.7 & 6.3 & 2.9 & 2.1 & $4 \cdot 1$ & 6.2 & 5.8 & IO.O & 6.7 & 9.0 & 7.2 & & 7.8 & 3.0 & $5 \cdot 2$ \\
\hline Juni $\cdots$ & $7 \cdot 4$ & 6.5 & 7.6 & $5 \cdot 4$ & 3.5 & 6.7 & 4.2 & IO.O & $5 \cdot 6$ & IO.O & $5 \cdot 7$ & & 8.3 & & IO.O & IO.O & 3.0 \\
\hline Juli . . & $9 . I$ & 5.9 & 7.9 & $7 \cdot 5$ & 4.3 & 3.8 & 4.7 & 9.0 & 7.2 & I0.0 & $7 \cdot 1$ & IO.O & 8.4 & 10.0 & 8.8 & I0.0 & 5.6 \\
\hline Aligust. . & 10.0 & 6.4 & 8. I & 7.9 & 6.4 & 6.5 & 4.9 & $5 \cdot 9$ & 6.0 & $4 \cdot 5$ & 8.4 & 6.0 & 8.4 & IO.0 & 8.1 & IO.O & 5.0 \\
\hline September & 9.0 & 8.9 & 8.2 & I0.0 & 4.2 & 0.0 & 4.4 & 6.4 & 7.2 & $5 \cdot 3$ & 6.7 & $9 \cdot 3$ & 8.5 & 10.0 & 8.6 & 9.0 & 9.2 \\
\hline Oktober. & 9.0 & 8.3 & 8.7 & 6.0 & 3.7 & 0.0 & 4.8 & 6.0 & 6.7 & 3.8 & 6.7 & 10.0 & 9.0 & 10.0 & 9.9 & 8.0 & 6.7 \\
\hline November & 6.3 & 7.2 & 7.2 & IO.O & 7.8 & 9.0 & 8.5 & 6.8 & 7.6 & 8.0 & 9.0 & 2.2 & 8.6 & I 0.0 & 9.5 & 7.0 & 9.4 \\
\hline Dezember & 9. I & I 0.0 & $9 . \mathbf{I}$ & & I0.0 & & IO.O & 9.0 & 6.6 & IO.O & 8.5 & IO.O & 8.8 & 8.7 & 8.8 & $9 \cdot 3$ & $7 \cdot 9$ \\
\hline
\end{tabular}

\section{$2 \mathrm{p}$.}

\begin{tabular}{|c|c|c|c|c|c|c|c|c|c|c|c|c|c|c|c|c|c|}
\hline Januar . . & 3.7 & 0.0 & 4.0 & & & & & & & 2.4 & $5 \cdot 3$ & 3.8 & 5.2 & $5 \cdot 7$ & 6.3 & 2.0 & 5.0 \\
\hline Februar. & 9.5 & & & & & & & & & I0.0 & 4.9 & $5 \cdot 3$ & $5 \cdot 2$ & 7.2 & 6.6 & & \\
\hline März . . & 10.0 & 2.0 & & & & & & & 4.7 & 5.6 & $4 \cdot 3$ & 8.2 & 5.2 & 5.0 & 6.1 & & \\
\hline April . . & I.O & & & & & & & & I.O & 4.2 & 3.7 & 6.4 & 4.4 & 10.0 & 6.9 & & \\
\hline Mai . . & I 0.0 & & $3 \cdot 5$ & 0.0 & 0.0 & & & & 3.8 & 2.2 & 3.2 & 2.9 & $3 \cdot 3$ & I. 5 & $4 \cdot 4$ & 2.0 & 2.5 \\
\hline Juni . . & 7.0 & & 10.0 & 0.0 & 0.0 & & 0.5 & & 0.0 & I. 5 & 3.0 & 4.0 & 2.9 & 5.0 & 6.9 & 4.7 & \\
\hline puli... & 8.0 & $3 \cdot \hat{3}$ & 0.0 & 0.0 & 0.2 & 2.0 & & & 0.0 & 3. I & 2.9 & 4.2 & 3.2 & 8.2 & 6.3 & I0.0 & \\
\hline August. . & 5.0 & & & & & & 0.0 & 1.0 & I. 4 & 3.0 & 2.3 & $4 \cdot 7$ & $4 \cdot 3$ & $9 \cdot 9$ & 4.2 & $9 \cdot 3$ & 0.0 \\
\hline September & 3.0 & & 0.0 & & & & & & 0.0 & I.7 & 3.4 & 4.8 & 4.8 & 4.6 & 6.5 & IO.O & \\
\hline Oktober. & $4 \cdot 3$ & & 3.0 & 5.0 & 0.0 & & 10.0 & & 3.1 & 2.8 & 2.6 & 5.2 & 5.0 & $4 \cdot 3$ & $5 \cdot 7$ & 3.8 & \\
\hline November & 8.8 & & 3.8 & 5.9 & & 3.0 & 0.0 & 9.0 & 2.0 & 4.8 & 2.8 & 6.4 & 4. I & 7.2 & 7.2 & IO.O & \\
\hline Dezember & I.O & & & & & & & & & 3.0 & $3 \cdot 3$ & $5 \cdot 3$ & 6.1 & 6.9 & $5 \cdot 7$ & 6.0 & $5 \cdot 5$ \\
\hline
\end{tabular}

$9 \mathrm{p} \mathrm{m.}$

\begin{tabular}{|c|c|c|c|c|c|c|c|c|c|c|c|c|c|c|c|c|c|}
\hline Januar . . & 7.0 & & 10.0 & & & & & & 0.9 & $5 \cdot 5$ & 3.6 & 3.8 & 6.5 & $7 \cdot 5$ & $7 \cdot 9$ & IO.O & 6.6 \\
\hline Februar & 6.8 & & 3.3 & & 0.0 & & 0.0 & & I.O & 2.4 & 4.9 & 5.0 & 6.7 & 10.0 & 7.7 & $7 \cdot 5$ & 6.4 \\
\hline März . . . & 6.7 & IO.O & 4.9 & & & & I.O & & 7.0 & $6 . I$ & 4.9 & 6.0 & 5.0 & IO.O & 7.9 & 5.7 & 3.1 \\
\hline April . . . & $5 \cdot 9$ & & $3 \cdot 5$ & & I.O & & IO.O & & 2.3 & 4.7 & 5.4 & 7.7 & 3.9 & & 6.6 & 5.0 & I.O \\
\hline Mai ... & 3.8 & 6.5 & 6.4 & & 0.0 & 3.0 & 0.6 & 2.0 & I. 5 & 4.4 & $4 \cdot 3$ & 2.5 & 4.2 & 0.0 & 4.7 & & 3.6 \\
\hline Juni ... & 3.9 & IO.O & 3.0 & 0.0 & 0.0 & 3.8 & 0.5 & 5.0 & I. 8 & 2.0 & 3.1 & 3.0 & 2.8 & 0.0 & 4.9 & & 4.0 \\
\hline Juli ... & 5.0 & I 0.0 & 3.5 & & 4.0 & & O.I & & $2 . I$ & 4.2 & 3.3 & $5 \cdot 0$ & $5 . \mathrm{I}$ & IO.O & 5.6 & 0.0 & 7.0 \\
\hline August. . & 6.5 & I.9 & 5.4 & 0.0 & 2.5 & 0.0 & 9.0 & 2.5 & 2.7 & I.I & 2.8 & 9.0 & $4 \cdot 7$ & 8.3 & 6.9 & o.o & 0.0 \\
\hline September & 4.6 & 5.0 & 6.8 & & 10.0 & & IO.O & 5.0 & 0.9 & $5 . \mathrm{I}$ & 4.2 & 3.1 & 6.7 & 0.0 & 4.9 & 9.0 & 0.0 \\
\hline Oktober . & 5.0 & 6.7 & $5 \cdot 7$ & & IO.O & & 0.0 & 8.0 & 3.7 & I.6 & 3.9 & 6.2 & 6.0 & IO.0 & 6.6 & 6.5 & 4.2 \\
\hline November & 5.8 & $7 \cdot 5$ & 2.8 & & & & 0.0 & 0.0 & 4.8 & $3 . \mathrm{I}$ & $4 . I$ & 3.9 & 2.9 & 5.0 & $7 \cdot 4$ & 7.1 & $5 \mathrm{I}$ \\
\hline Dezember & 8.0 & 0.0 & 5.0 & & 0.0 & & & & 5.4 & 0.0 & $5 \cdot 4$ & 7.0 & $5 \cdot 9$ & 7.6 & 9.0 & 9.0 & $6 . \cdot 7$ \\
\hline
\end{tabular}


Die Häufigkeit des Fölnn und der Gang der übrigen meteorologischen Elemente.

Tafel IX.

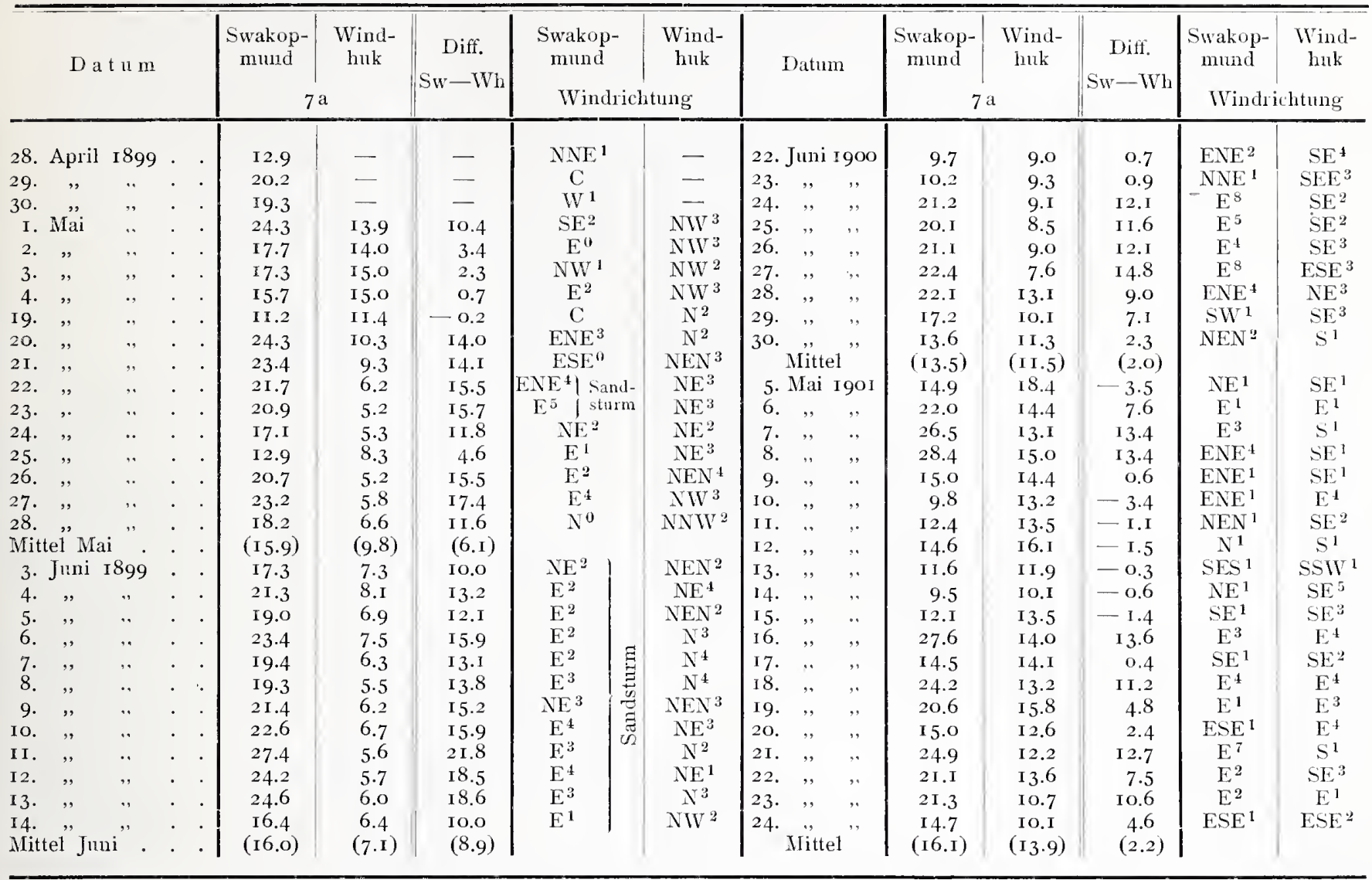

\begin{tabular}{|c|c|c|c|c|c|c|c|c|c|c|c|}
\hline \multirow[b]{2}{*}{ J a h $\mathrm{r}$} & \multirow[b]{2}{*}{$\begin{array}{c}\text { Föhn- } \\
\text { häıfigkeit }\end{array}$} & \multicolumn{5}{|c|}{ Temperatur } & \multirow[b]{2}{*}{$\begin{array}{l}\text { Luft- } \\
\text { druck }\end{array}$} & \multicolumn{2}{|c|}{ Luffteuchtigkeit } & \multirow[b]{2}{*}{$\begin{array}{c}\text { Be- } \\
\text { wölkung }\end{array}$} & \multirow[b]{2}{*}{ Nebel } \\
\hline & & $\begin{array}{c}\text { des } \\
\text { Jahres }\end{array}$ & $\begin{array}{c}\text { des } \\
\text { Meeres }\end{array}$ & $\begin{array}{c}\text { absolutes } \\
\text { Maxim. }\end{array}$ & $\begin{array}{c}\text { mittleres } \\
\text { Maxim. }\end{array}$ & $\begin{array}{c}\text { mittlere abso- } \\
\text { lute Jahres- } \\
\text { schwankung }\end{array}$ & & absolute & relative & & \\
\hline
\end{tabular}

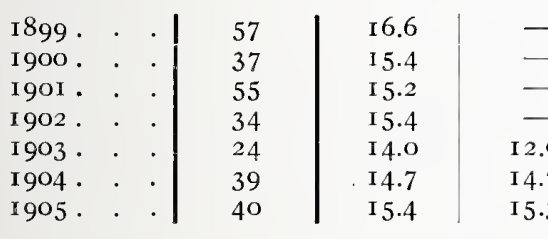

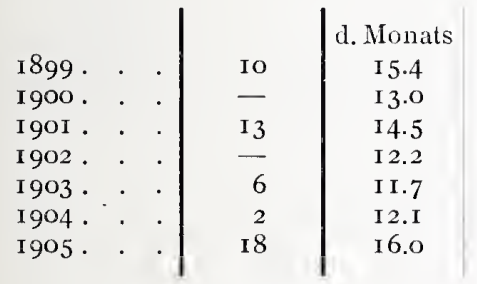

a) für das Jahr.

\begin{tabular}{r|r|r|r|r|r|r|r|r}
- & 38.0 & 22.4 & 35.5 & 76 I.8 & - & - & 4.7 & - \\
- & 34.5 & I 9.0 & 30.6 & 6 I.9 & - & - & 6.6 & I 57 \\
- & 39.8 & I 9.8 & $35 . I$ & $62 . I$ & 10.0 & 78 & 6.3 & I 74 \\
- & 38.2 & I 9.6 & 34.9 & $62 . \mathrm{I}$ & IO.4 & 80 & 5.2 & I I I \\
I 2.9 & 34.5 & I 7.8 & $3 I .3$ & 62.6 & 9.6 & 80 & 5.5 & 94 \\
I 4.7 & 37.5 & I 8.6 & 33.9 & 62.5 & IO.I & 8 I & $5 . I$ & I I I \\
I 5.3 & 40.6 & $23 . I$ & 37.6 & 62.5 & IO.4 & 80 & 5.8 & 2 I 5
\end{tabular}

b) für deu Monat Juli.

\begin{tabular}{|c|c|c|c|c|c|c|c|c|}
\hline - & 36.6 & 23.9 & $\begin{array}{c}\text { Abweichung } \\
\text { v. Mittel } \\
+\quad \text { I.8 }\end{array}$ & 763.1 & 9.8 & 71 & $3 . I$ & 7 \\
\hline - & I 8.6 & I6.2 & -0.6 & $64 . I$ & 8.4 & 84 & 7.5 & I I \\
\hline- & 35.5 & $22 . \mathrm{I}$ & +0.9 & 63.8 & 8.2 & $6 i$ & 3.5 & I I \\
\hline- & 20.9 & I 5.4 & $-\mathrm{I} .4$ & 64.7 & 9.6 & 86 & 5.6 & I I \\
\hline I I. 4 & 33.7 & I 6.8 & $-\mathrm{I} .9$ & 64.9 & $8 . \mathrm{I}$ & 75 & 3.7 & I I \\
\hline I 3.4 & $24 . \mathrm{I}$ & I 5.9 & $-\mathrm{I} .5$ & 64.7 & 9.7 & 84 & 5.6 & $2 I$ \\
\hline I $4 . I$ & 40.6 & 28.2 & +2.4 & 64.8 & 9.0 & 63 & 4.7 & 40 \\
\hline
\end{tabular}

c) fï das Jahr roo5.

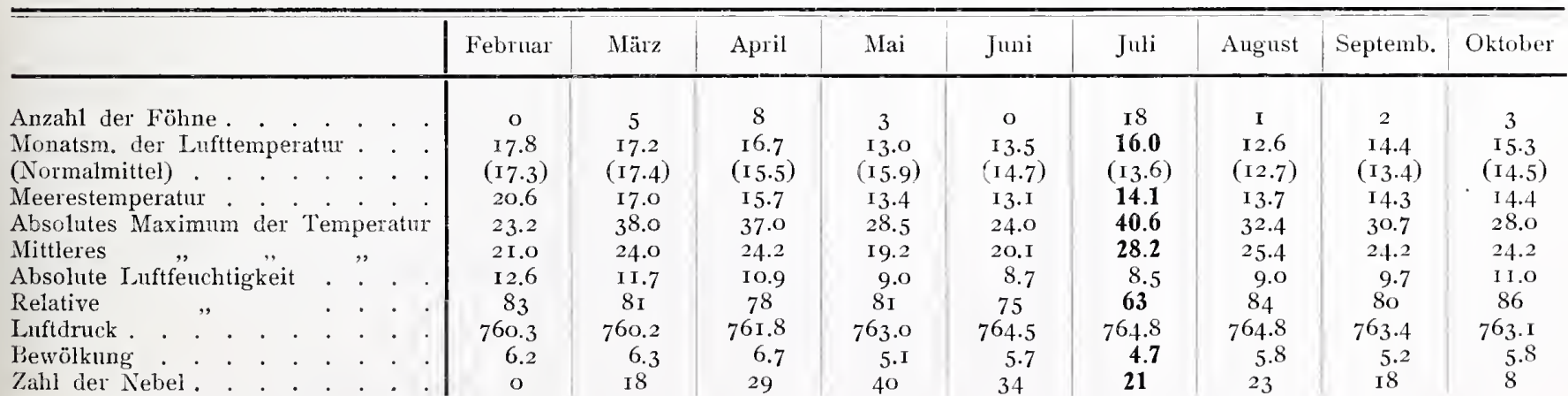
Mitteilungen a. d. D. Schutzgebieten, XX. Band. III. 

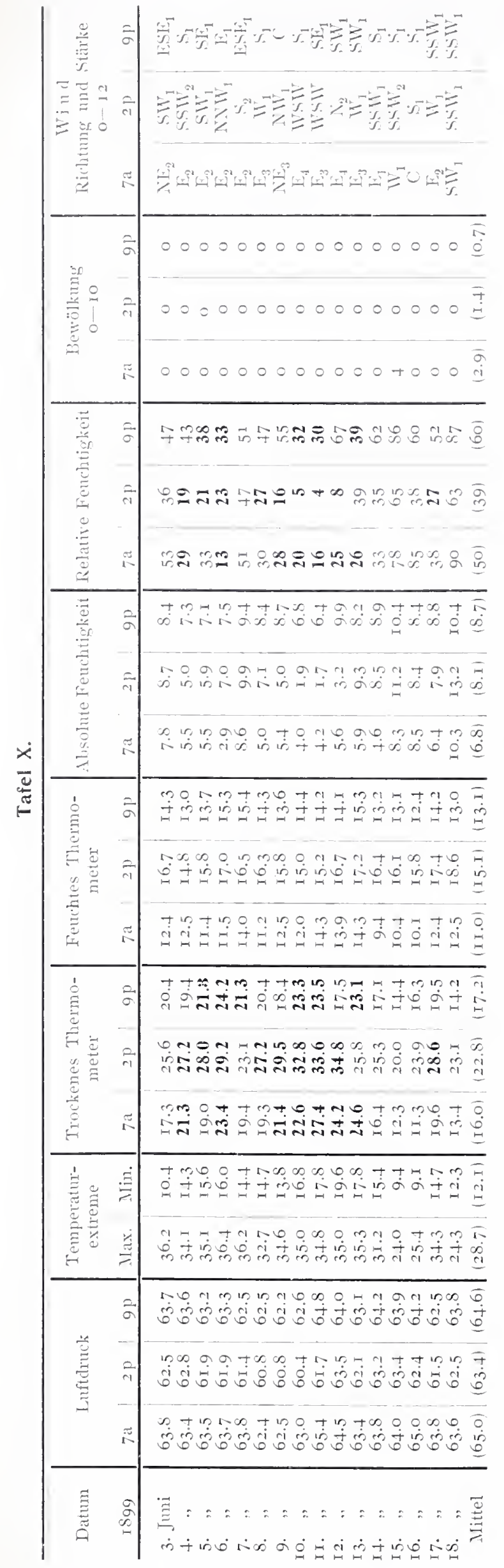

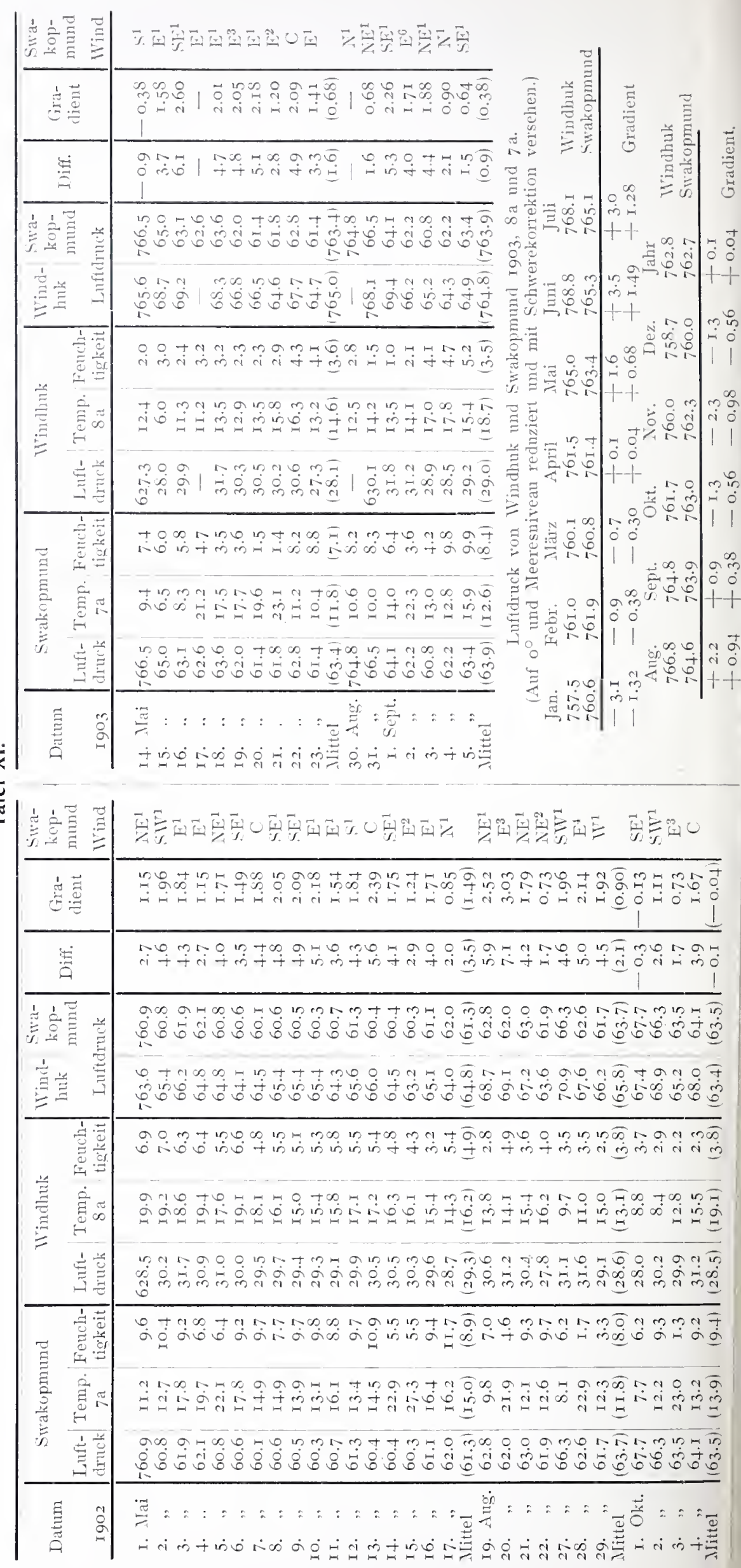




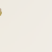

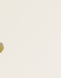




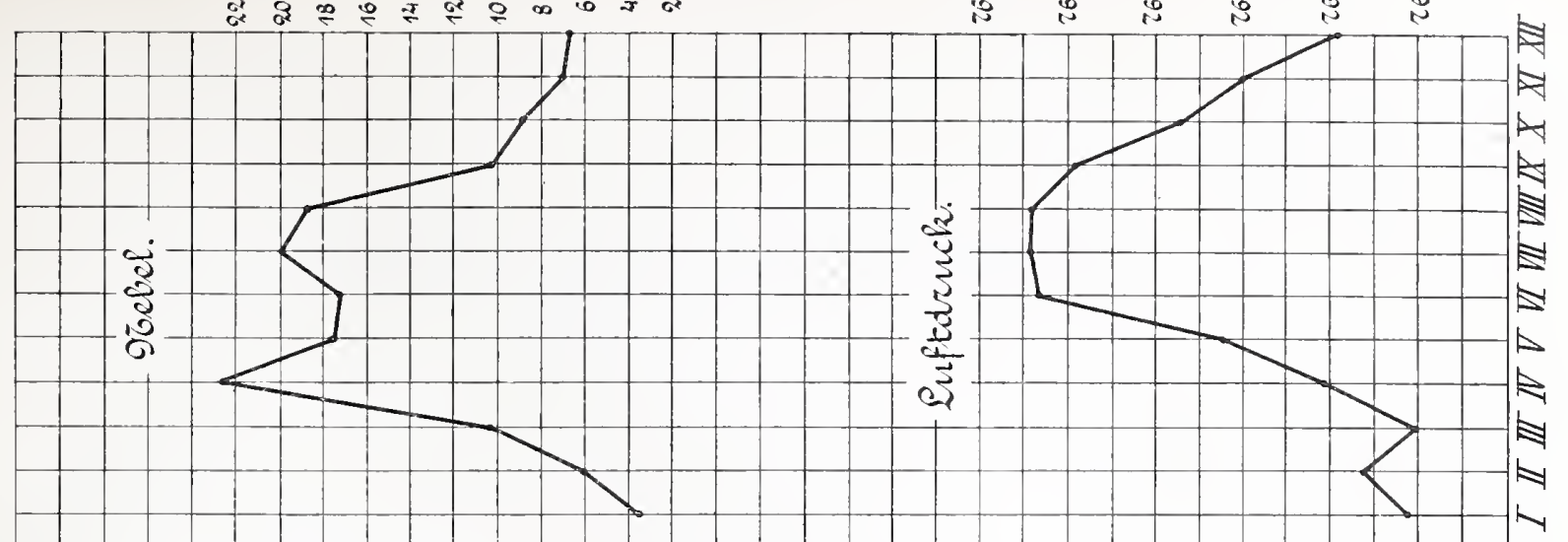

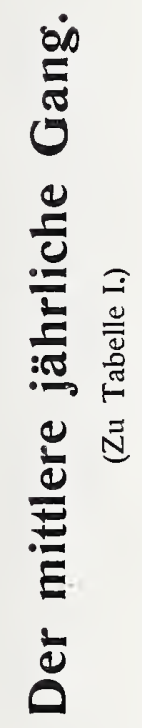
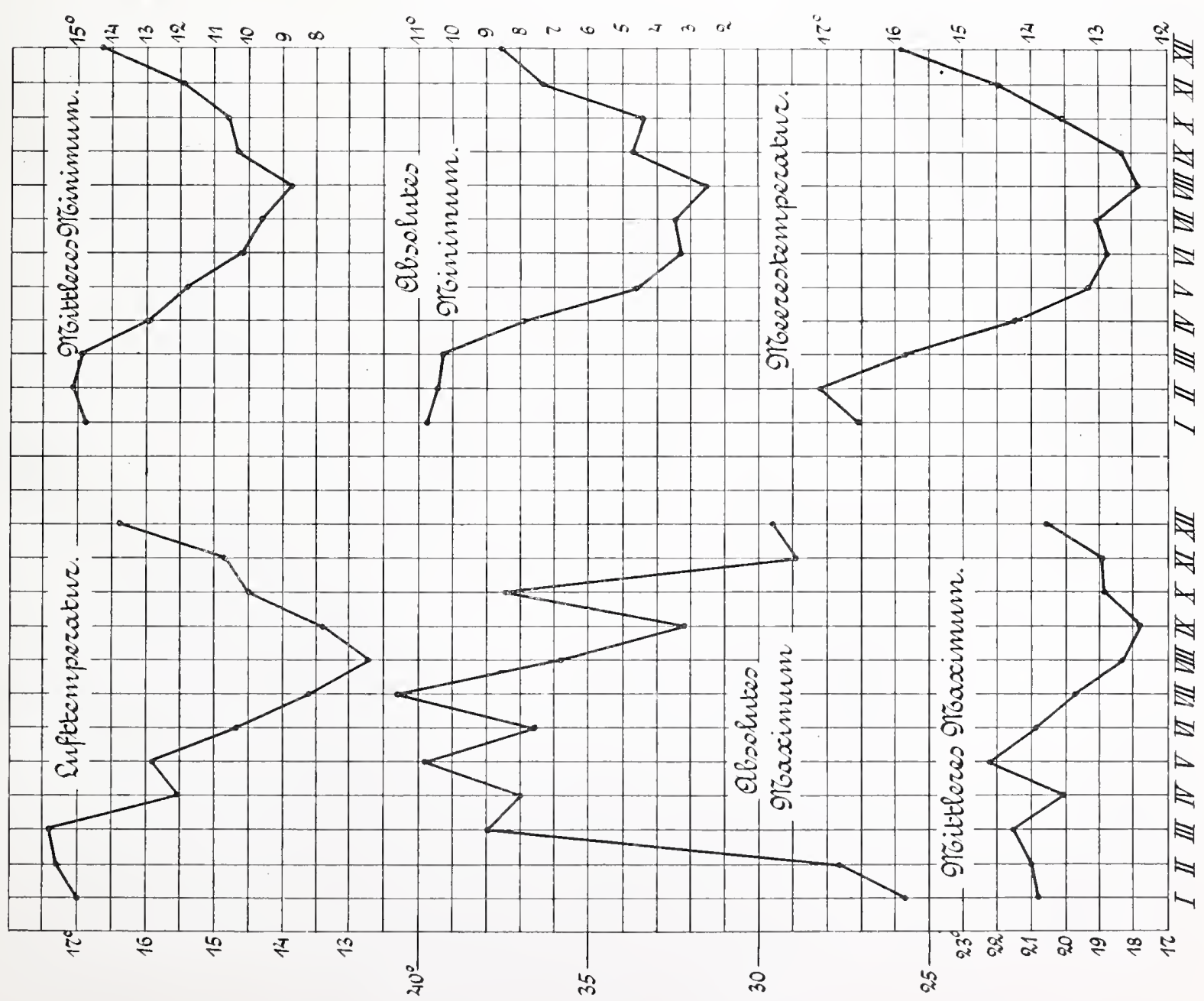

Zu: Gülland, Das Klima von Swakopmund. (Tafel II.) Mitteilungen aus den Deutschen Schutzgebieten, Band XX, rgo7, Tafel IX.

\section{Die Häufigkeit der Winde in Prozenten.}

(Zu Tabelle IV.)
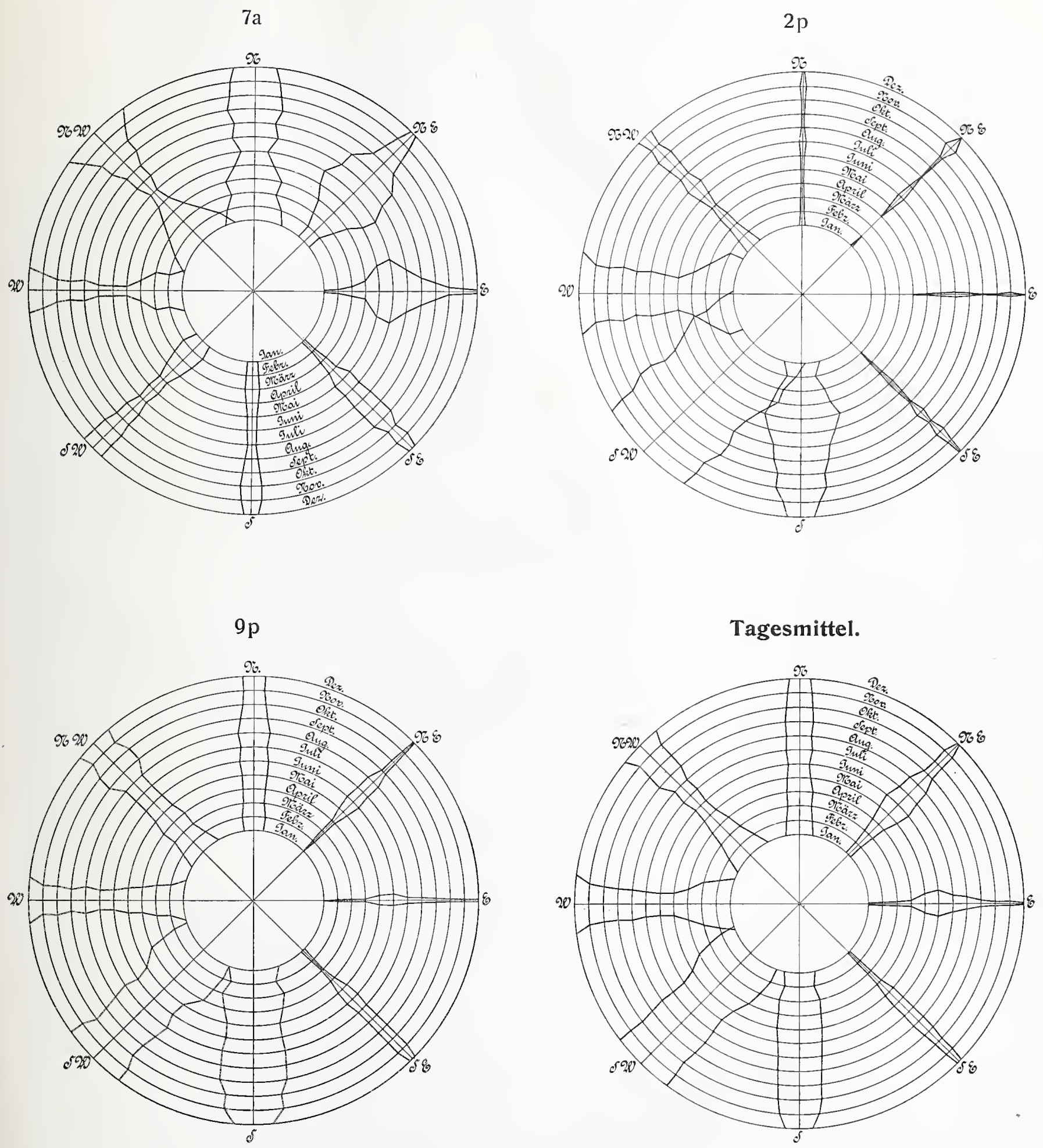

Tagesmittel.

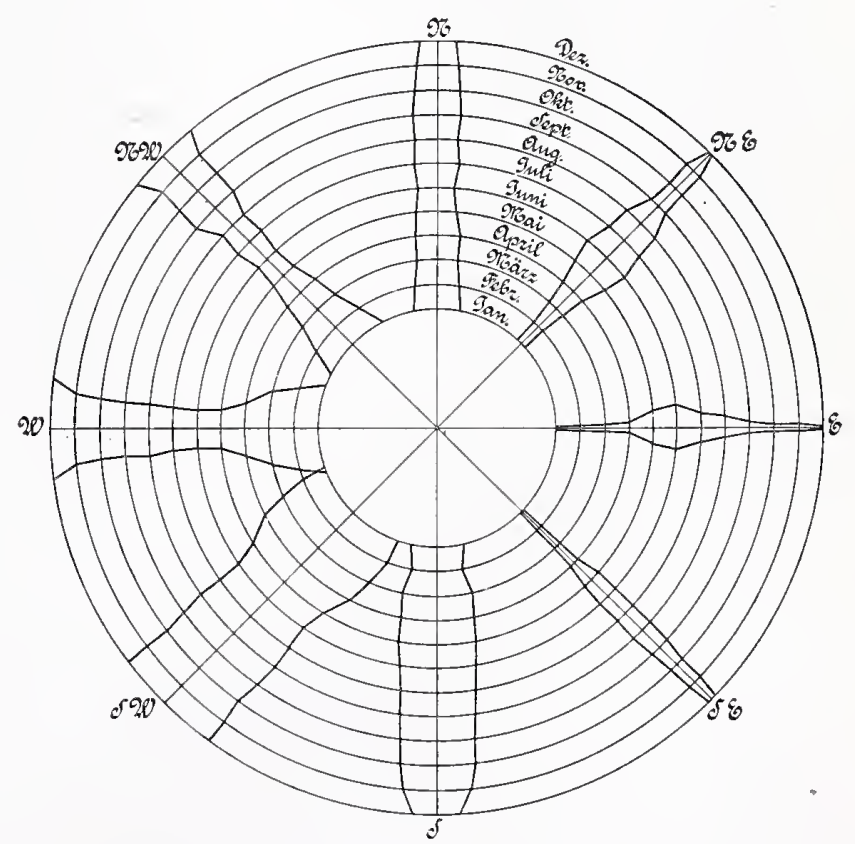

Verlag der Königlichen Hofbuchhandlung von E.S. Mittler \& Sohn, Berlin SW68. 

Die Häufigkeit der Winde in Prozenten. Täglicher Gang.

( $\mathrm{Zu}$ Tabelle IV.)

Die Häufigkeit des Föhn und der Gang der übrigen meteorologischen Elemente.

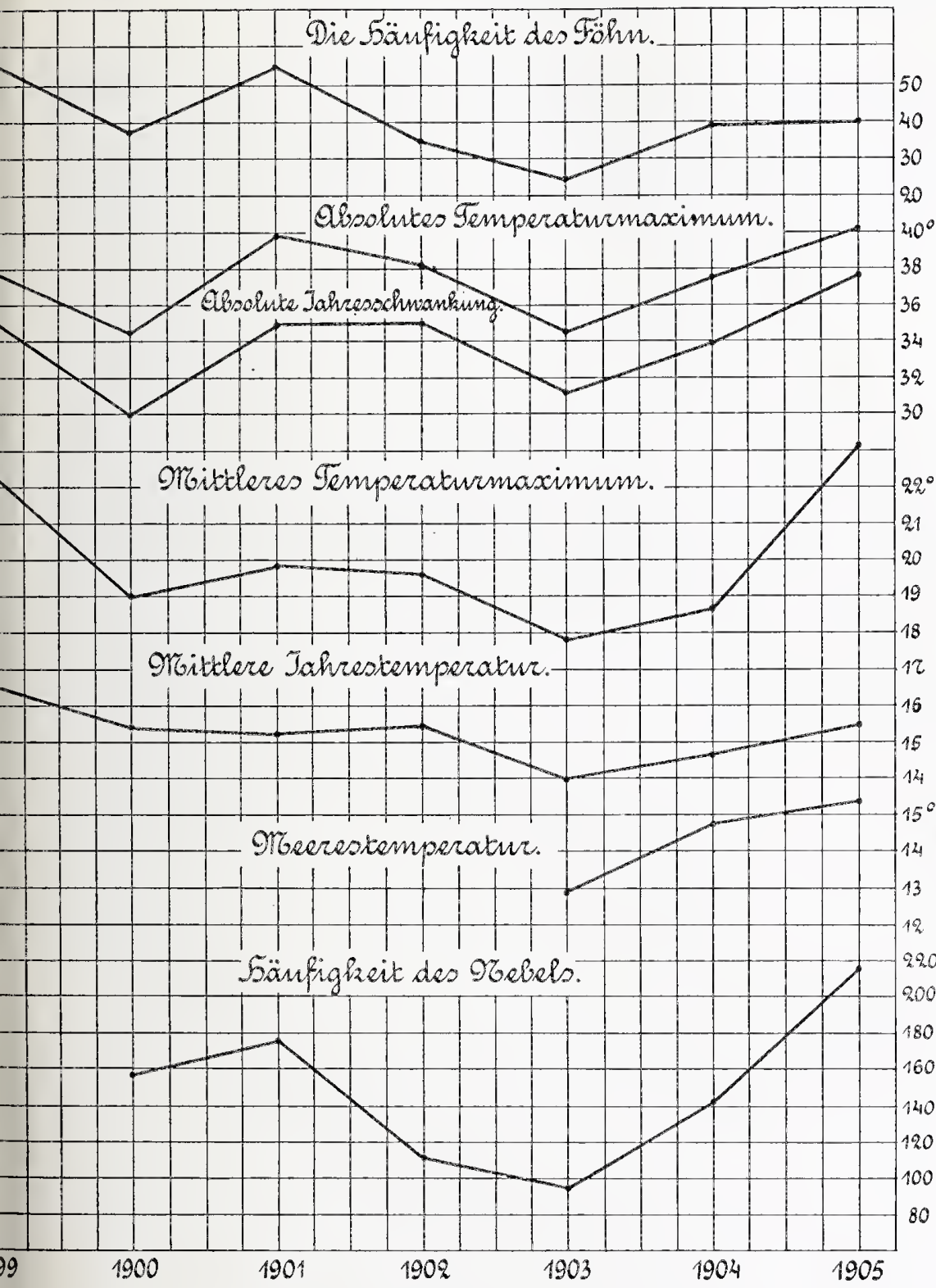

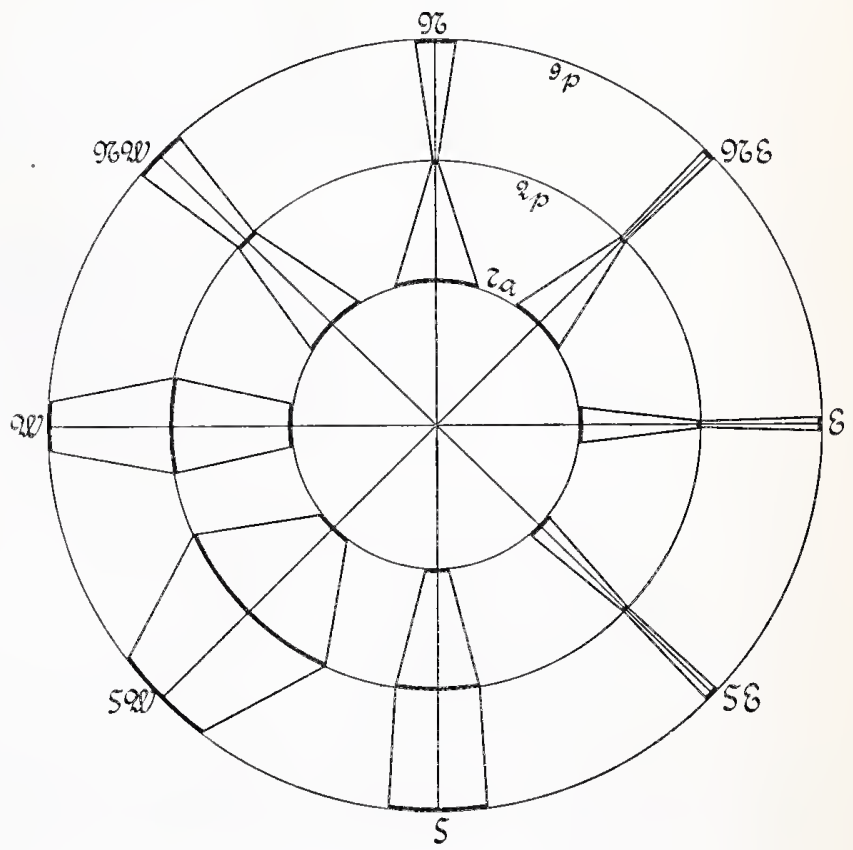

Die mittlere Windrichtung. Extreme.

(Zu Tabelle V.)

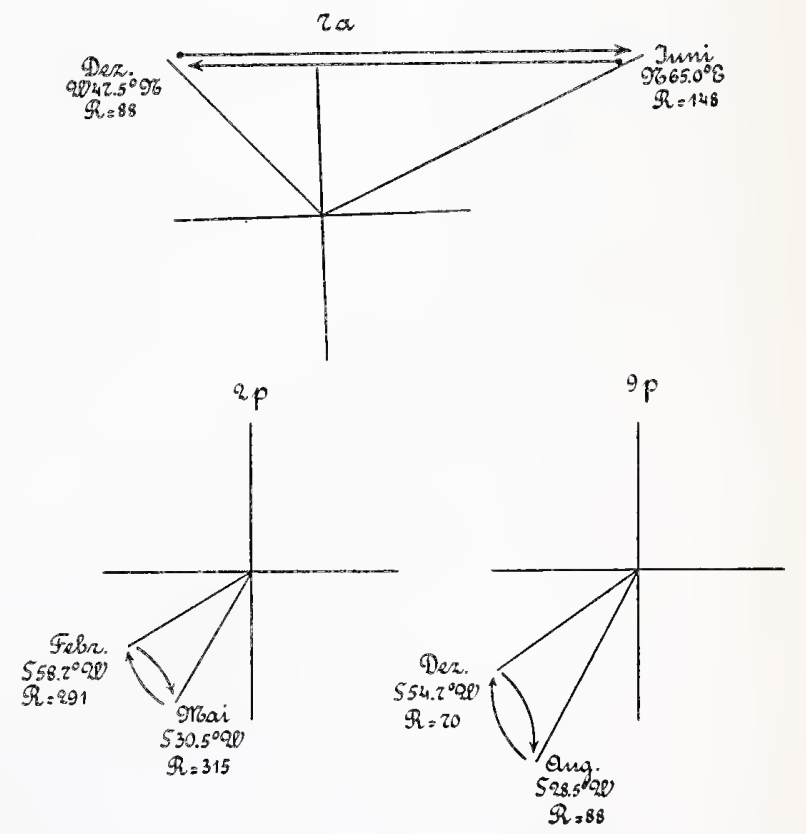





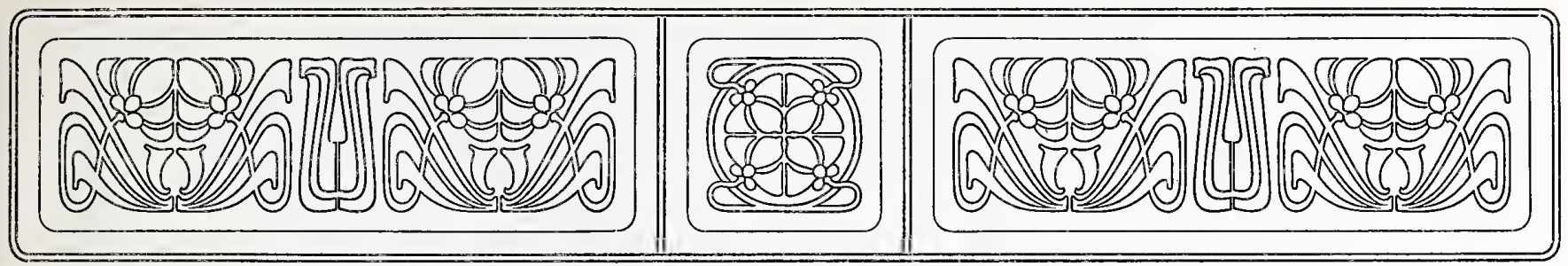

\section{Aus dem deutsch-ostafrikanischen Schutzgebiete.}

\section{Bericht über die astronomischen und geodätischen Arbeiten, welche zur Festlegung der Grenze Deutsch-Ostafrikas gegenüber dem Kongostaat und Britisch-0stafrika von seiten der deutschen Kommissare in den Jahren 1902 bis 1905 ausgeführt worden sind.}

Bearbeitet und zusammengestellt nach den Berichten der Expeditionsführer von Professor Dr. L. Ambronn.

Selten werden Grenzfestlegungen von solcher Ausdehnung durchgeführt worden sein, wie es diejenigen sind, über welche ich hier $\mathrm{zu}$ berichten habe. Ein Gebiet von nahezu 90 ooo qkm, 1) welches die Grenze zwischen Deutsch-Ostafrika und dem Kongostaat im Nordwesten unserer Kolonie und zwischen dieser und Britisch-Ostafrika im Norden derselben bildet, war seiner geographischen Lage nach durch grundlegende astronomische Beobachtungen $\mathrm{zu}$ fixieren und durch genaue geodätische und topographische Aufnahmen in die astronomisch gewonnenen Anhaltspunkte einzufügen, zu erkunden und kartographisch zur Darstellung zu bringen. Alle diese Arbeiten zerfallen sowohl den politischen Grenzen gemäß, als auch den Arbeitsperioden nach in drei wesentlich getrennte Abschnitte, die auch zum Teil von verschiedenen Beobachtern durchgeführt wurden, soweit ein Wechsel derselben durch persönliche Verhältnisse bedingt war.

Teil I. Arbeiten der Kiwu-See-Expedition unter Hauptmann Herrmanns Führung und Professor Lamp als Astronom. An Stelle des letzteren trat nach dessen Tode Oberleutnant Schwartz.

Teil II. Verbindung des Durchschnittspunktes des $30^{\circ}$ östlicher Länge und des $\mathrm{I}^{\circ}$ südlicher Breite mit Port Florence am Nordufer des Victoria-Seés; Fortsetzung dieser Arbeiten bis Schirati am Ostufer des Sees sowie Längenübertragung von Mombasa nach Port Florence.

1) Soviel wie die Königreiche Bayern und Sachsen ztisammengenommen.

Mitteilungen a. d. D. Schutzgebieten, XX. Band. IV.
Teil III. Festlegung der Grenze gegen BritischUganda zwischen Schirati und dem Kilimandscharo sowie die trigonometrische Verbindung zwischen dem östlichen Endpunkte dieser Aufnahmen mit der Insel Zanzibar iiber die Usambara-Landschaft.

Die beiden letzten Arbeiten wurden durch Hauptmann Schlobach, dem Oberleutnant Schwartz und Oberleutnant Weiß zur Seite standen, ausgeführt.

\section{Teil: Arbeiten der Kiwu-See-Expedition unter Hauptmann Hermann.}

A. Beobachtungen auf der Reise zum Tanganjika-See.

Die astronomischen Beobachtungen dieser Expedition wurden von Professor Lamp ausgeführt, und zwar hat derselbe auch schon während der Reise von der Küste nach dem Nordostufer des TanganjikaSees einige Ortsbestimmungen gemacht. Dieselben haben nur bezüglich der Breitenbestimmungen ein Interesse, da die Länge nur in Tabora aus je einer Mondhöhe am I 5. und I 6 . November I 900 bestimmt wurde, deren Resultate aber in sich keine besondere Übereinstimmung zeigen. Sie liefern für diesen Ort die respektiven Werte $32^{\circ} 57 .^{\prime} \mathrm{O}$ und $33^{\circ} 6 .^{\prime} 5$, welche sich wegen der noch anzubringenden Tafelkorrektionen der Mondorte um nahe I.'5 erhöhen, so daß man schließlich aus beiden Beobachtungen hat:

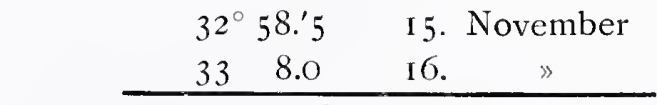

im Mittel $33^{\circ} 3^{\prime} 25$

Das ist ein Wert für die Länge von Tabora, der von den viel sicherer bestimmten Kohlschüitter schen Angaben um nicht weniger als I 4.'5 abweicht. 
Es kann also der von Prof. Lamp aus Mondhöhen ermittelte Längenwert hier unberüicksichtigt bleiben. Dagegen hat die Berechnung der Sonnenfinsternis, welche Prof. Lamp noch am 2I. November gelang, für die Länge die Werte:

$$
\begin{array}{lll}
\text { I. Berührung: } & 32^{\circ} 48^{\prime} 29^{\prime \prime} & \text { Nittel: } \\
\text { IV. } & 325^{\circ} 57 & 3249^{\prime} 43^{\prime \prime}+25^{\prime \prime}
\end{array}
$$

geliefert, wenn auf die Tafelfehler Rücksicht genommen wird. Dieser Vert stimmt mit den Kohlschütterschen aber recht gut, so weit es die Unsicherheit der Daten zuläßt. Aus den Breitenbeobachtungen wurden abgeleitet:

$$
\begin{array}{lrl}
\text { Kilimatinde } & \varphi=-5^{\circ} & 24 .^{\prime} 5 \\
\text { Kiwa Wamba } & -5 & 55.0 \\
\text { Tura } & -5 & 24.2 \\
\text { Tabora } & -5 & 0.5^{1}
\end{array}
$$

B. Astronomische Arbeiten in Usumbura.

Auf der Hauptstation Usumbura hat Professor Lamp für das Heydesche Durchgangsinstrument einen guten, tieffundierten Pfeiler aus Ziegeln und Zement erbaut. Um denselben herum war ein Fußboden aus Brettern gelegt, die ihrerseits auf Balken ruhten, die ziemlich weit von dem Pfeiler selbst entfernt auf den Erdboden gelegt waren. Der Pfeiler ging frei durch diesen FuBboden hindurch. Über demselben war ein Zelt errichtet, dessen Dach beim Beobachten zurïckgeschlagen werden konnte. Diese Einrichtung scheint sich sehr gut bewälrt zu haben, da Prof. Lamp selbst in seinen Tagebüchern mehrfach die Konstanz der Aufstellung seines Instruments erwähnt und auch die Bearbeitung der Resultate dieses bestätigt hat.

Die geographische Breite des Beobachtungspfeilers (die Lage desselben zu den übrigen Fixpunkten auf der Station Usumbura erläutert die beifolgende Skizze I) wurde im ganzen an sechs Abenden mittels des Universalinstruments aus Zirkum-Meridianhöhen von zwölf nördlich und südlich des Zenits kulminierenden Sternen bestimmt; davon sind fünf im Norden und sieben im Süden des Zenits beobachtet.

Die Einzelresultate dieser Beobachtungen sind die folgenden:

1) Kohlschütter gibt für einen Punkt, der nur un wenige Bruchteile einer Bogensekunde südlich liegt (vgl. Mitt. a. d. Deutsch. Schutzgeb. 1902, S. 23 u. 25), $\varphi=-5^{\circ} \mathbf{r}^{\prime} 5^{\prime \prime}$, welcher Wert auf etwa I bis 2 Sekunden sicher ist. Auf dem Wege von Tabora nach Usumbura, wo Professor Lamp Ende Januar IgoI anlangte, sind weitere astronomische Beobachtungen nicht mehr angestellt worden, wenigstens finden sich in den mir vorliegenden Büchern keine solche mehr vor. Die Länge von Tabora würde sich mittels der jetzt bestehenden Telegraphenlinie durch wenige Signalwechsel sebr genau bestimmen lassen, so daß alle anderen Werte dafür nicht mehr in Betracht kommen.
I90I I $\$$. Febr. $\quad a^{2}$ Centauri $q=-3^{\circ} 22^{\prime} 66^{\prime \prime} 4$

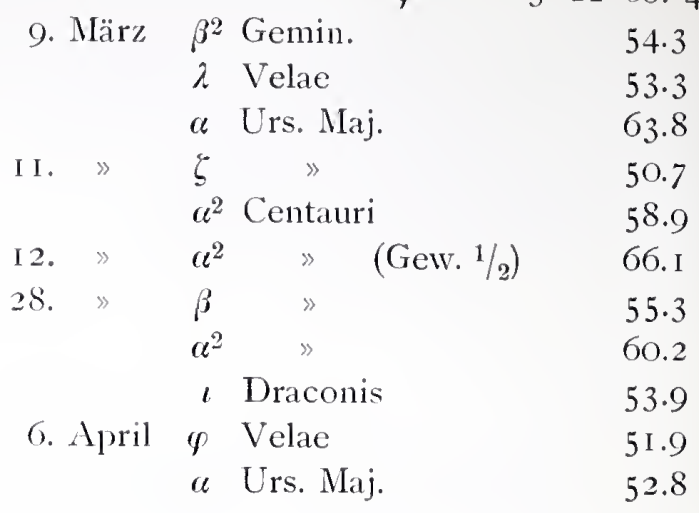

Bildet man aus den Nord- und Sülsternen gesondert die Mittel und gibt ihnen gleiche Gewichte, so erhält man als Resultat für die geographische Breite des deutschen Usumbura-Pfeilers:

$$
\begin{aligned}
& \text { aus Nordsternen (5) } \varphi=-3^{\circ} 22^{\prime} 54^{\prime \prime 2} 2 \\
& \begin{array}{rrrr}
\text { Südsternen } & (7) \quad 3 \quad 22 \quad 58.6 \\
\hline \text { Mittel } & \text { (I } 2) \varphi=-3^{\circ} 22^{\prime} 56 . " 4
\end{array}
\end{aligned}
$$

Diese Mittelbildung mag hier erlaubt sein, da die Anzahl der Sterne im Norden und Süden sich nur um zwei unterscheidet, außerdem die Verteilung auf die Beobachtungsabende zweckmäßig gewählt ist, und besonders die Mittel der Zenitdistanzen nahe gleich sind; denn man hat für die Zenitdistanz der Nordsterne nahe $56 .^{\circ} 7$ und für die Südsterne sehr nahe $53 .{ }^{\circ} \sigma$, so daß das obige Resultat vom Einfluß einer etwaigen Biegung befreit erscheint und als definitiver Wert angesehen werden kann. ${ }^{1}$ )

Der mittlere Fehler dieses Resultats berechnet sich zu 士 I."5; der verhältnismäßig hohe Betrag dieses mittleren Fehlers wird namentlich bedingt durch die starke Abweichung der beiden Werte aus $a^{2}$ Centauri. Es liegt aber liein plausibler Grund vor, deren Zuverlässigkeit noch geringer anzusetzen. ${ }^{2}$ )

Zur Bestimmung der geographischen Länge wurden ausschlieBlich Mondkulminationen beobachtet, und diese haben auch bei der guten Aufstellung des Instruments zu einem recht zuverlässigen Resultate geführt, obgleich die Witterungsverhältnisse der zweckmäßigen Verteilung und der Auswahl der mit dem Mond gleichzeitig beobachteten Sterne nicht immer guinstig waren. Besonders ist es mehrfach vorgekommen, daß entweder vor oder nach dem Monde keine Sterne oder diese nur in großen Ab-

1) Aus den Einzelbeobachtungen wurde die Biegungskonstante zu 4.03 Sekunden abgeleitet. Wenn man diese einzeln anbringt so erleidet der oben gegebene Mittelwert keinerlei Veränderung.

2) Wird der Wert von $\varphi$ vom Dez. 12 gan $z$ weggelassen, so erhält man aus den Südsternen allein - $3^{\circ} 22^{\prime} 57^{\prime \prime} .7$ und damit als Mittel - $3^{\circ} 22^{\prime} 56^{\prime \prime}$.o. Der Unterschied liegt ganz innerhalb der Unsicherheit des Resultates und ich habe es daher vorgezogen, bei dem Wert des Textes zu bleiben. 
ständen davon beobachtet werden konnten. Diese Verhältnisse hatten zunächst Veranlassung gegeben, für die einzelnen Tagesresultate, welche in der nachstehenden Tabelle I gegeben sind, Gewichte abzuleiten, aber es zeigte sich, daß diese nur nach recht vagen Gesichtspunkten gebildet werden konnten, und so habe ich es vorgezogen, den einzelnen Tagesresultaten gleichen Wert beizulegen und dieselben nur nach den beobachteten Mondrändern zu trennen. Die einzelnen Kolumnen der beigegebenen Tabelle enthalten der Reihe nach:

I. Laufende Nr.

2. Datum des Beobachtungstages.

3. Beobachteter Mondrand.

4. Abgeleitete RA des Mondzentrums für die Kulmination in Usumbura.

5. RA des Mondzentrums nach der Con. d. Tps. + Newb. Korrektion.

6. Korrektion der Mond-RA nach der Göttinger Ausgleichung.

7. Korrektion der Mond-RA auf Grund gleichzeitiger Beobachtungen in Göttingen, Paris und Greenwich.

8. Veränderung der Mond-RA in einer Minute der Länge für den Mittelmeridian.

9., I0. u. II. Die nach den Mond-RA.-en in 5., 6. und 7. abgeleitete westliche Längendifferenz gegen Paris.
Die mit alleiniger Benutzung der Newb. Korrektionen abgeleiteten Längenwerte $\left(\lambda_{1}\right)$ sind bekanntermaßen unrichtig und die Realität der Tafelkorrektion nach meiner Ausgleichung wird durch die direkten Beobachtungsresultate durchaus bestätigt. Es besteht nur noch die Frage, in welcher Weise die Resultate $\lambda_{2}$ und $\lambda_{3}$ miteinander $\mathrm{zu}$ vereinigen sein dürften. Die tabulierten Korrektionen sind von zufälligen Fehlern gewiß weit mehr frei, als die einzelnen direkt beobachteten Abendwerte, dagegen sind die auf Grund nahezu gleichzeitiger Mondbeobachtungen gebildeten RA-Differenzen viel weniger abhängig von Unsicherheiten der Randbeschaffenheit und ganz kurz periodischer Störungen. Da es solcher gleichzeitiger Beobachtungen aber nur halb so viele sind, als Längen überhaupt bestimmt werden konnten, so halte ich es für berechtigt, wenn das Mittel aus dem $\lambda_{2}$ mit einem größeren Gewichte zum Resultate herangezogen wird, als der Mittelwert aus dem $\lambda_{3}$.

Die allerdings nur rechnerische Bedeutung besitzenden mittleren Fehler beider Werte sprechen im gleichen Sinne und es dürfte daher als definitives Resultat der westlichen Länge Usumburas gegen Paris

$$
\lambda=22^{\mathrm{h}}+1^{\mathrm{m}} 57^{\mathrm{s}} \cdot 5 \pm \mathrm{I}^{\mathrm{s}}
$$

anzunehmen sein. Das gibt weiterhin

$$
\begin{aligned}
& \lambda=\mathrm{I}^{\mathrm{h}} 48^{\mathrm{m}} 2^{\mathrm{s}} \cdot 5 \text { östlich von Paris } \\
& \lambda=27^{\circ} \quad \mathrm{O}^{\prime} 37^{\prime \prime} .5 \quad, \quad, \quad, \\
& \left.\lambda=29 \quad 20 \quad 5 \text { I.O } \quad, \quad, \quad \text { Greenwich. }{ }^{1}\right)
\end{aligned}
$$

1) Die von Prof. Lamp noch selbst durchgeführte Berech. nung lieferte den Wert $29^{\circ} \mathbf{I}^{\prime} \mathbf{I}^{\prime \prime}$, während die Angabe de

Länge von Usumbura, bestimmt durch Beobachtungen von Mondkulminationen.

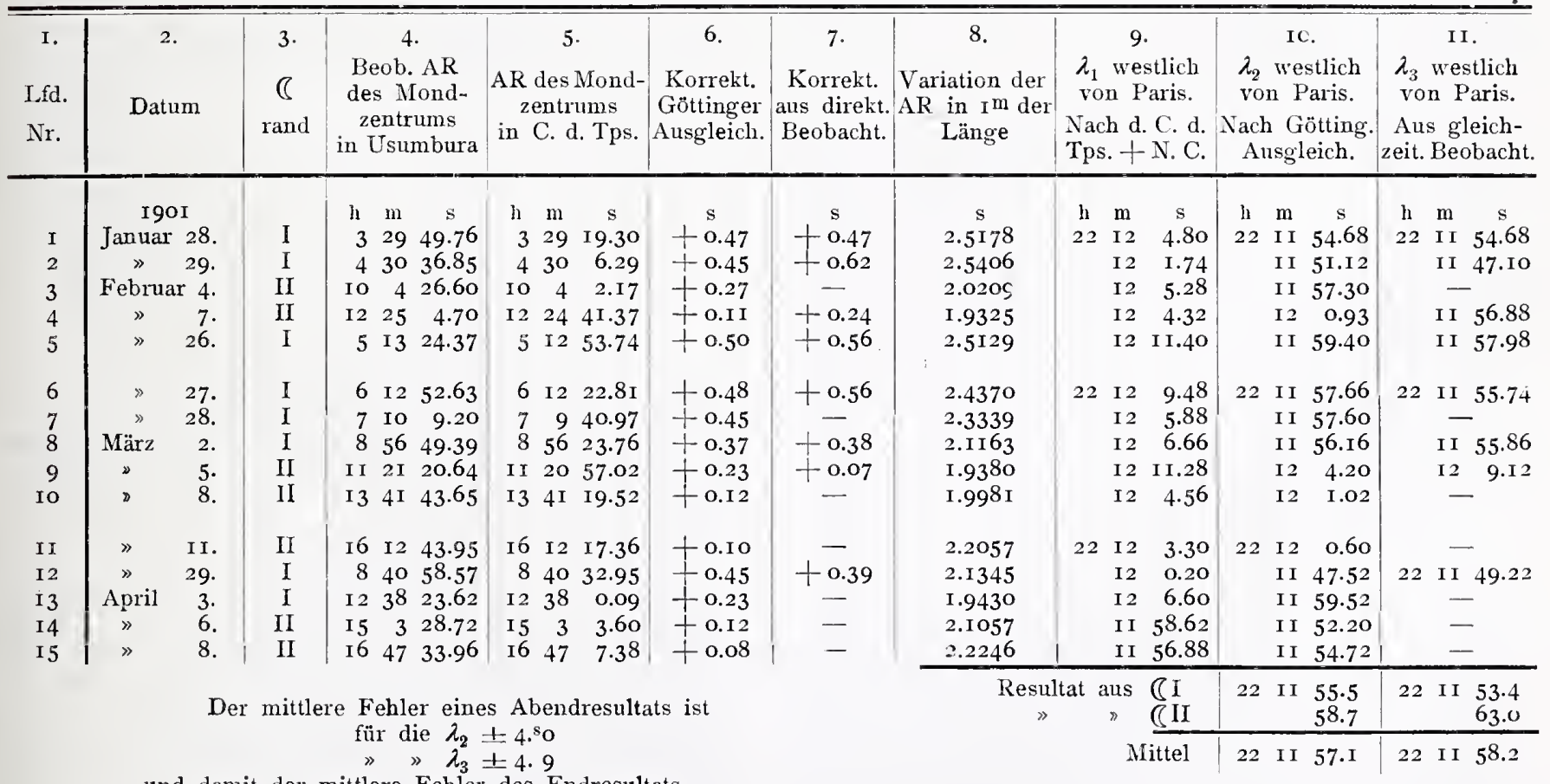

und damit der mittlere Fehler des Endresultats

$$
\begin{gathered}
\text { für } \lambda_{2} \pm 1.80 \\
\quad \lambda_{3} \pm 1.7
\end{gathered}
$$


Als Zentrum der Station ist der durch eine dauernde Vermarkung festgelegtePunkt anzusehen, auf welchem das Durchgangsinstrument aufgestellt war. Der Beobachtungspunkt der Kongolesischen Beobachter befand sich nach Nitteilung des Hauptmanns Herrman n nahezu im gleichen Meridian mit dem deutschen, aber $305 \mathrm{~m}$ nördlicher. Die Redulition beider Längenbeobachtungen aufeinander beträgt nur 5" oder $\mathrm{O}^{\mathrm{s}} .33$ Die Abweichung des Wertes der Kongolesischen Beobachter von dem der deutschen kann wohl nur daran liegen, daß die ersteren entweder an anderen Tagen beobachtet, oder ihren Rechnungen andereReduktionskonstanten zugrunde legten. Es liegt für die gegenwärtige Bearbeitung keine Möglichkeit vor, die Tafelkorrektionen für den Kongolesischen Wert der Längen zu berechnen, so daß von einem Anschlub des oben gegebenen definitiven deutschen Wertes für die Länge an den Kongolesischen Wert abgesehen werden muß und dem Koordinatenverzeichnis allein der deutsche Wert zugrunde gelegt wird. Anders verhält es sich bei der Verbindung beider Verte für die geographische Breite, dort ist eine Redulition von - IO" an dem Kongolesischen Wert anzubringen. Da jedoch die Einzeldaten der Kongolesischen Beobachtungen nicht vorliegen, so muß der von Hauptmann Herrmann angegebene Betrag von - $322^{\prime} 56^{\prime \prime}$.o benutzt werden, und dieser ist schon auf len Ort des deutschen Pfeilers reduziert. Das Mittel aus beiden Werten für die Breite findet sich sonach zu $3^{\circ} 22^{\prime} 56^{\prime \prime} .2$, (len nachher zu gebenden Koordinaten ist aber der von der deutschen Expedition gefundene Wert allein zugrunde selegt worden. Sein mittlerer Fehler wird liaum eine Bogensekunde iiberschreiten.

Zur Orientierung des Dreiecknetzes, welches von der Station Usumbura als Ausgangspunkt nach Norden bis zum Kiwu-See und an dessen Ostufer entlang bis zum I. Grade südl. Breite gelegt wurde, ist am Hauptpfeiler eine Reihe von Azimuten nach dem fast genau im Süden gelegenen Dreieckspunkt (5) Sanhuma (vgl. Skizze I) gemessen worden, und zwar geschah dieses mittels des Durchgangsinstrumentes, in dessen Gesichtsfeld clas betreffende Signal zwischen den Fäden gesehen werden konnte. Aus den Zeitbestimmungen wurde die Azimut-Korrektion des Instrumentes abgeleitet, und mittels dieser und

Kongolesischen Beobachter $29^{\circ} 2 \mathrm{O}^{\prime} \mathrm{I} 4^{\prime \prime}$ latutete. Der daraus gebildete Mittelwert ist $29^{\circ} 19^{\prime} 43^{\prime \prime}$. Es besteht also zwischen dem Iängenwert von Prof. I, amp und dem definitiv abgeleiteten ein

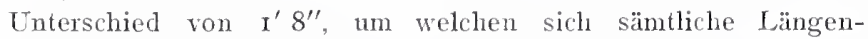
angaben der Kiwn-Expedition nach Osten verschieben, was, wie sich später zeigen wird, zu einer vorzüglichen Übereinstimmung zwischen den Längenangaben der Kiwu-Expedition und denen der Uganda-Grenz-Expedition für den Durchschnitspunkt des 30. Grades östlicher Länge mit dem I. Grad südı. Broite fülurt. der Abweichung des Signalbildes vom Mittelfaden ist dann eine offenbar sehr genaue Bestimmung des Azimutes der Linie: Hauptpfeiler-Sanhuma (5) möglich gewesen. Leider sind die Originale dieser Messungen nicht mehr vorhanden und offenbar nach dem Tode ron Prof. Lamp rerloren gegangen.

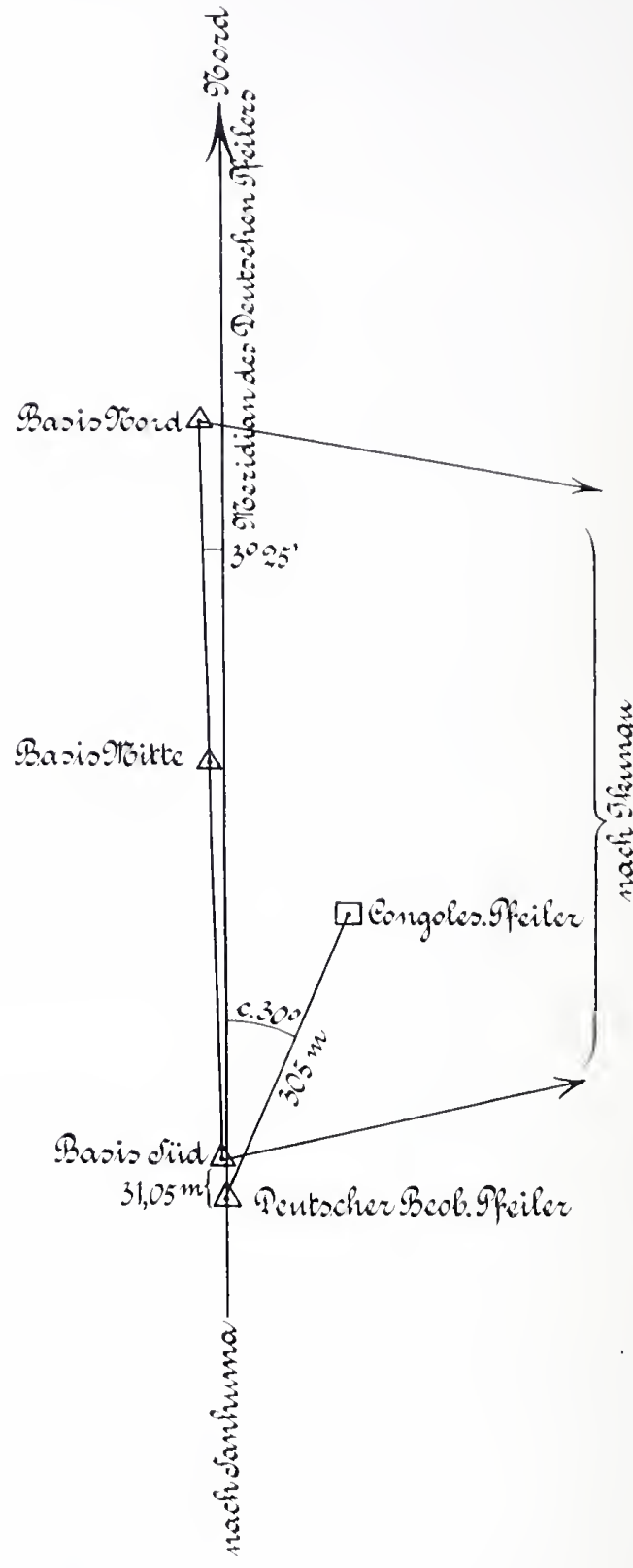

Skizze I. Situation der Tasis bei Usumbura.

Aber clas Resultat aus diesen Bestimmungen wird von Hauptmann Herrmann in seinem bezüglichen Bericht zu

$$
\begin{array}{rrr}
79^{\circ} & 57^{\prime} \quad 37^{\prime \prime} .8 \\
\hline
\end{array}
$$

angegeben. Der mittlere Fehler dieser Zahl wird wohl laum mehr als \pm I" betragen, so dab die Orientierung des Netzes als sehr gut gesichert erscheint. Damit sind die astronomischen Beobachtungen, welche sich auf das Standlager Usumbura beziehen, erledigt. Bevor ich aber zur Erörterung der hieran angeschlossenen seodätischen Arbeiten 
übergehe, sollen zunächst noch die astronomischen Beobachtungen gegeben werden, welche Herr Oberleutnant Schwart $z$ an $z$ wei anderen Punkten des Dreiecknetzes und an der Missionsstation St. Antonius ausgeführt hat. Die ersteren beiden Beobachtungen liefern eine vorzügliche Kontrolle für den Anschlub der Triangulation, da sie gute astronomische Breitenbestimmungen geben, die mit den geodätisch errechneten Breiten in Vergleich gesetzt werden können.

An dem nahe dem Punkt (26) Nkama gelegenen Orte Kissenji wurde ein Standlager bezogen und dort im Januar 1902 eine Reihe von Beobachtungen ausgeführt. Dieselben lieferten, da die Witterung sich sehr ungünstig gestaltete, nur an zwei Abenden Breitenbestimmungen, nämlich am 5. und 7. Januar. Die hier in Betracht kommenden Beobachtungsresultate sind die folgenden:

$$
\begin{aligned}
& \text { I902 Jan. 5. Sirius, Osten } \quad+5^{\mathrm{m}} 3^{8} 8_{\mathrm{s} \cdot 2} \\
& \text { "6. a Aurigae, Nord }+5{ }^{3.6}-\mathrm{I}^{\circ} 42^{\prime} \mathrm{I} 5^{\prime \prime} \text { gut. } \\
& \text { "7. } \gamma \text { Pegasi, West }+540.4 \text { - } \\
& \text { a Aurigae, Nord - - I } 42 \text { I9 gut. }
\end{aligned}
$$

Aus obigen Daten folgt: Die Breite von Kissenji $\varphi=-\mathrm{I}^{\circ} 42^{\prime} \mathrm{I} 6^{\prime \prime} .5$, und zwar für eine Zenitdistanz der beobachteten Sterne von sehr nahe $48^{\circ}$ im Norden. Wird von dem oben bestimmten Wert der Biegung hier Anwendung gemacht, so erhält man als korrigierten Wert für die Breite

$$
\begin{aligned}
\varphi & =-\mathrm{I}^{\circ} 42^{\prime} \mathrm{I}^{\prime \prime} .5-4^{\prime \prime} .03 \times \sin Z \\
& =-\mathrm{I} 42 \text { I6. } 5-3^{\prime \prime} . \mathrm{o} \\
& =-\mathrm{I} 42 \text { I9. } 5 .
\end{aligned}
$$

Eine weitere astronomische Bestimmung ist von Oberleutnant Schwartz auf seiner Rückreise zwecks Teilnahme an der Uganda-Grenz-Expedition in der Nähe des I. Grades südl. Breite auf dem Hunga-Berge ausgeführt worden. Er hat dort am 2. März zwei Zeit- und zwei Breitenbestimmungen erhalten, und zwar mittels desselben Instrumentes, mit dem in Usumbura und Kissenji beobachtet wurde:

a Leonis $\triangle u=+13^{m}$ I9s.5 (im Westen)

$\alpha$ Aquilae $\triangle \mathrm{u}=+\mathrm{I}_{3} \quad \mathrm{i} 9.6$ (im Osten)

$\beta$ Ursae min. $\varphi-0^{\circ} 59^{\prime} 48\left(Z 75^{\circ} .5\right)$ im Norden

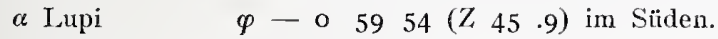

Werden diese Beobachtungsresultate mit Hilfe des oben gefundenen Biegungskoeffizienten reduziert, so erhält man für den Nordstern eine Korrektion von $3^{\prime \prime} .9$ und für den Südstern $2^{\prime \prime} .9$, also die reduzierten Werte:

$$
\begin{aligned}
& \varphi=-0^{\circ} 59^{\prime} 5 \mathrm{I}^{\prime \prime} \cdot 9 \\
& \text { - O } 59 \text { 5I .I } \\
& \text { Mittel }-0^{\circ} 59^{\prime} 5 \mathrm{I}^{\prime \prime} .5 \text {. }
\end{aligned}
$$

Eine Vergleichung dieses Resultates mit den Werten aus der geodätischen Übertragung und denjenigen, welche die Beobachter der Uganda-GrenzExpedition für Punkte in derselben Gegend gefunden haben, wird später ausgeführt werden.
Weiterhin hat Oberleutnant Schwartz auf seiner Reise von Usumbura nach dem" "Schnittpunkt " auf der Missionsstation St. Antonius am I8. Mai eine Breitenbestimmung ausgeführt, welche zwar nicht zu den direkten Arbeiten der Grenz-Expedition gehört, aber ihrer Zuverlässigkeit wegen noch mitgeteilt werden soll. Es gelangen ihm dort zwei Zeitbestimmungen und je eine Breitenbestimmung im Norden und im Süden des Zenits. Die Resultate sind die folgenden:

$$
\begin{aligned}
& \text { Sirius im Westen } \triangle u=+I^{m^{m}} \text { I IS.I }_{\text {I }} \\
& \text { a Scorpii im Osten } \triangle u=+I_{4} \quad 7.2 \\
& \alpha \text { Crucis } \varphi=-3^{\circ} \mathrm{I}^{\prime} \mathrm{I} 7^{\prime \prime} \cdot 3 \mathrm{im} \text { Süden } \\
& \zeta \text { Urs. Maj. } \quad \varphi=-3 \text { I9 I6.I im Norden. }
\end{aligned}
$$

Man hat also im Mittel für die geographișche Breite dieser Missionsstation den Wert

$$
\underline{p}=-3^{\circ} \mathrm{I9^{ \prime }} \times 7^{\prime \prime} \text {. }
$$

\section{Geodätische Arbeiten der Kiwu-See-} Expedition.

Die Station Usumbura bildete den Stuitzpunkt der weiteren Vermessung, und es wurde daher in ihrer Nähe eine Basis gemessen, die wegen des ungünstigen Geländes leider nur eine verhältnismäßig geringe Länge erhalten konnte, aber die Sorgfalt, mit welcher sie gemessen wurde, hat ein recht günstiges Resultat ergeben, so daß sich sowohl bei dem Anschluß an eine dem Nordufer des Kiwu-Sees gemessene kurze Kontrollbasis, als auch die Verbindung mit dem trigonometrischen Punkte der Uganda-Expedition eine Übereinstimmung ergab, wie sie unter den gegebenen Verhältnissen nicht besser erlangt werden kann und wie sie vor allem den Aufgaben solcher Expeditionen vollständig genügt. Es geht daraus hervor, daß nicht nur hier, sonderr auch bei den noch weiterhin anzuführenden Messungen von Basislinien, welche zum Zwecke solcher Triangulationen gemessen werden, eine völlig ausreichende Genauigkeit durch die Benutzung einfacher Stahlbandmaße oder Drahtkabel erzielt wird, und daß dadurch eine große Ersparnis an Zeit und Geldmitteln erlangt werden kann. Alle künstlichen Einrichtungen und Anordnungen sind durchaus unnötig; vielmehr sollte man bei allen diesen Arbeiten weitaus das Hauptaugenmerk auf gute Signalisierung und Festlegung der Dreieckspunkte und vor allen auf scharfe Winkelmessungen legen. Ist die Form der Dreiecke sicher bestimmt, so kann zu jeder Zeit durch Nachmessung der Basislinien mit höheren Anforderungen entsprechenden Vorkehrungen dem ganzen Netze jede gewünschte Genauigkeit gegeben werden. Für die Zwecke der Grenzaufnahme genügt aber zunächst immer eine solche Messung, wie sie hier am Tanganjika, am Kiwu-See, an den Nordufern des Victoria-Sees und am Kilimandscharo von den Herren Hauptmann Herrmann und Hauptmann Schlobach ausgeführt 
worden ist. ${ }^{1)}$ Nach diesen allgemeinen Bemerkungen mögen hier die Einzelheiten der Basismessungen nach dem Berichte des Hauptmann Herrmann etwas ausfülırlicher Platz finden, während bezüglich der später ausgeführten Messungen nur die wesentlichen Resultate angegeben werden sollen.

Es wurde nördlich des deutschen Beobachtungspfeilers in einer Entiernung von $31.03 \mathrm{~m}$ der südliche Endpunkt der Basis durch einen Pfeiler aus Ziegelsteinen mit Kalliverputz bezeichnet und etwa $1550 \mathrm{~m}$ weiter nördlich der andere Endpunkt in gleicher Weise festgelegt. Die Messung dieser Strecke, die nicht ganz horizontal und auch nicht überall gleich geneigt war, wurde in vier Selitionen ausgeführt, deren Endpunkte wieder durch Steinpfeiler festgelegt waren. Dic Neigung der einzelnen Sektionen gegen den Horizont wurde mittels des Universalinstrumentes auf trigonometrischem Wege ermittelt und die gefundenen Winkel zur Redulition auf den Horizont benutzt. ${ }^{2}$ ) Die Strecken zwischen den Steinpfeilern wurden durch eingerammte breite Pfähle bezeichnet. Auf ihren möglichst glatten unct horizontalen Endflächen wurden Nägel eingeschlagen, welche zwischen den Endpunkten in genau gerader Linie eingerichtet waren. Auf dem Kopf der Nägel wurde ein feiner Bleistiftstrich senkrecht zur Basisrichtung gezogen. Zur Messung der Basis standen zwei Meßbänder zur Verfügung, welche scitens der Normal-Eichungskommission mit dem Normalmaß verglichen worden waren, und welche folgende Gleichungen besalien:

Bandmaß Nr. I: $20 \mathrm{~m}-3 . \mathrm{rmm}+0.238 \times \mathrm{T} \mathrm{mm}$, , 2: $20 \mathrm{~m}-\mathrm{I} .3 \mathrm{~mm}+0.238 \times \mathrm{T}^{\mathrm{c}} \mathrm{mm}$.

Das Messen fand morgens vor Sonnenaufgang in der Art statt, daß das Meßband, welches die Nacht über im Freien gelegen hatte, um möglichst die Lufttemperatur anzunehmen, zwischen zwei Pfählen dermaßen durch zwei dazu angelernte Farbige gespannt wurde, daß die an jedem Ende angehängten Federwagen $6 \mathrm{~kg}$ Zug anzeigten. Ein Europäer paßte auf, wenn der Nullstrich der Teilung mit dem Bleistiftstrich auf dem ersten Pfahle koinzidierte und rief dann: „Topl«, worauf der andere Europäer am anderen Ende ablas, welcher Strich der mm-Teilung am anderen Ende des Meßbandes mit dem Bleistift-

1) Herr Hauptmann Herrman hat bei Gelegenheit der Führung der Grenzregulierungs-Expedition zwischen Tanganjikaund Njassa-See mit Prof. Kollschütter sich reiche Erfahrungeu in dieser Art der trigonometrischen Messungen erworben, welche ihm bei der Kiwu-See-Expedition sehr zustatten kamen.

2) Bei den anderen Basislinien ist zur Bestimmung der Neigungen der Einzelstrecken auch vielfach ein einfacher Gefälimesser benutzt worden; nur ausnahmsweise wurde wirkliches Nivellement angewendet (z. B. in der Basis des Übertragungsnetzes bei Entebbe [siehe Uganda-Expedition]). strich des anderen Pfahles koinzidierte, dabei wurden noch zehntel Millimeter geschätzt. Die Messungen, während welcher von Zeit zu Zeit die Lufttemperatur mit einem Schleuderthermometer bestimmt wurde, geschahen mit dem einen Meßband hin und mit dem anderen zurïck, und zwar an je einem Tage von Hauptmann Herrmann, Prof. Lamp und Oberleutnant Fonck, so daß die ganze Basis, da täglich nur eine Sektion gemessen wurde, zwölf Tage, aber immer nur morgens von etwa $5 \frac{1}{2}$ bis 7 Uhr, in Anspruch nahm.

Irrtümlicherweise war bei der Vergleichung aber nur ein Zug von I $\mathrm{kg}$ angewendet worden, während hier ein solcher von $6 \mathrm{~kg}$ benutzt wurde. Auferdem war in Potsdam das Band unterstützt worden, hier icdoch wurde es freihängend benutzt. Eine Vergleichung der beiden Meßbänder nach Rückkehr der Expedition unter Bedingungen, wie sie bei der Messung der Basis herrschten, ergab, daß eine Veränderung der Gleichungen nicht angebracht erscheint, da dic Abweichungen der Bandlänge für beide Gebrauchsarten völlig innerhalb der Genauigkeitsgrenze liegen und außerdem den nachträglich ausgeführten Vergleichungen kein allzu großes Gewicht beigelegt werden kann, weil außer den Basismessungen noch eine größere Anzahl anderweitiger Benutzungen erfolgt war.

Dic gemessene Länge der Sektionen wurde mit ihren Neigungen auf den Horizont des südlichen Endpunktes reduziert und die so erhaltene Länge der Basis wiederum mit der mittleren Höhe derselben ïber dem Meere auf den Meereshorizont zurückgeführt. Für diese Redulition wurde die Höhe der Oberfläche des Tanganjika-Sees zu $780 \mathrm{~m}$ angenommen. Aus den trigonometrischen Messungen der Expedition fand sich, daß der südliche Endpunkt der Basis noch $30 \mathrm{~m}$ höher lag und somit die Reduktion der Basislänge auf den Meereshorizont mit 8 IO m auszuführen war. Die Einzelheiten der Basismessungen sollen zur Erläuterung der Methode hier ausführlich gegeben werden:

\section{Selition I}

Beobachter: Bandmaf I BandmaB 2 Mittel Herrmann $\quad 379.5658 \mathrm{~m} \quad 379.5769 \mathrm{~m} \quad 379.57 \mathrm{r} 4 \mathrm{~m}$ $\begin{array}{llll}\text { Lamp } & 5625 & 5737 & 568 I\end{array}$ Fonck $\quad 5692$ $565 \mathrm{I}$ 5672

Mittel: $379.5689 \mathrm{~m}$

Sektion 2.

Hermann $\quad 367.4752 \mathrm{~m} \quad 367.4764 \mathrm{~m} \quad 367.4758 \mathrm{~m}$

Lamp $\quad 4774 \quad 4780 \quad 4777$ Fonck $\quad 4736$ 472 I

Mittel: $367.4752 \mathrm{~m}$ 
Sektion 3.

\begin{tabular}{lccc} 
Hermann & 3I3.IO66 & 3I3.0974 m & 3I3.IO4O m \\
Lamp & I I 50 & IOI 5 & IO82 \\
Fonck & IOI9 & IO84 & IO52 \\
\cline { 2 - 4 } & & Mittel: 3 I3.IO58 m
\end{tabular}

Sektion 4 .

\begin{tabular}{lccc} 
Herrmann & $488.8280 \mathrm{~m}$ & $488.8200 \mathrm{~m}$ & $488.8240 \mathrm{~m}$ \\
Lamp & 7959 & 8273 & $8 \mathrm{I} \mathrm{I6}$ \\
Fonck & 8023 & 7976 & 8000 \\
\cline { 2 - 3 }
\end{tabular}

Mittel: 488.8 I I9 m

Werden aus diesen Zahlen die mittleren Fehler für jeden einzelnen Beobachter abgeleitet, so erhält man zunächst für die Länge der einzeln gegebenen Sektionen (für welche ich hier rund eine Länge von $400 \mathrm{~m}$ annehmen will) die folgenden Daten:

Herrmann . $\pm \frac{ \pm}{ \pm} 6.7 \mathrm{~mm}$,
Lamp.. $\pm 2.7 \mathrm{~mm}$,
Fonck. .. $\pm 3.4 \mathrm{~mm}$,

das gibt für rund $1550 \mathrm{~m}$

Herrmann . $\quad \pm 13.2 \mathrm{~mm}$,
Lamp . .
Fonck . . $25.0 \mathrm{~mm}$, $6.7 \mathrm{~mm}$.

Werden demgemäß die obigen einzelnen Resultate für jede Strecke miteinander verbunden, indem die Verhältniszahlen auf 3: I : I I als Gewichte abgerundet werden, so erhält man:

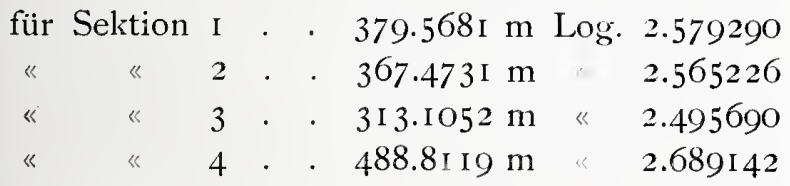

die vorläufigen Res. waren:

$\begin{array}{ccccccc}\text { für Sektion } & \mathrm{I} & . & . & . & 379.5689 \mathrm{~m} \\ \ll & \ll & 2 & \cdot & . & . & 367.4752 \mathrm{~m} \\ \ll & \ll & 3 & . & - & . & 3 \mathrm{I} 3 . \mathrm{I} 058 \mathrm{~m} \\ \ll & \ll & 4 & . & . & . & 488.8 \mathrm{I} 9 \mathrm{~m}\end{array}$

Die Neigungswinkel der einzelnen Selitionen ergaben sich zu resp. $0^{\circ} 37^{\prime} 42^{\prime \prime}, O^{\circ} 37^{\prime} 42^{\prime \prime}, O^{\circ}$ I $2^{\prime} 54^{\prime \prime}$ und $0^{\circ} 4^{\prime} 55^{\prime \prime}$, so daß die Log. obiger Mittel übergehen in:

$\begin{array}{cccccc}\text { Sektion } & \text { I } & \cdot & . & . & 2.579264 \\ \ll & 2 & . & . & . & 2.565200 \\ \ll & 3 & \cdot & . & . & 2.495687 \\ \ll & 4 & . & . & . & 2.689 \text { I } 42\end{array}$

die Reduktion auf den Meereshorizont beträgt für eine mittlere Meereshöhe von 810 m 55 Einh. d. 6. Dez. Damit hat man

$\begin{array}{cccccc}\text { Sektion } & \text { I } & \cdot & \cdot & . & 2.579209 \\ \ll & 2 & . & . & \cdot & 2.565 \text { I } 45 \\ \ll & 3 & . & . & . & 2.495632 \\ \ll & 4 & . & . & . & 2.689087\end{array}$

Das gibt numerisch: I. $379.4974 \mathrm{~m}$

2. $367.4047 \mathrm{~m}$

3. $3 \mathrm{I} 3.063 \mathrm{I} \mathrm{m}$

4. $488.7500 \mathrm{~m}$

Mittel I 548.7 I $52 \mathrm{~m}$

Log. 3. I 89970

Nach den oben gegebenen Einzelwerten der mittleren Fehler für die resp. Beobachter würde sich der mittlere Fehler der Basislänge nahe $\pm 9.2 \mathrm{~mm}$ oder noch nicht ganz $1 / 160000$ der Gesamtlänge finden.

Eine zweite Basis wurde, wie oben mitgeteilt, am Nordufer des Kiwu-Sees gemessen, da das Gelände nur sehr beschränkte Ausdehnung gestattete, so ist diese nur etwa $816 \mathrm{~m}$ lang. Sie wurde in ganz gleicher Weise wie die Hauptbasis, aber nur in zwei Sektionen gemessen. Die Beobachter waren:

Hauptmann Herrmann,

Oberleutnant Fonck,

Landmessergehülfe Dannert.

Die einzelnen Resultate stellen sich, wie folgt:

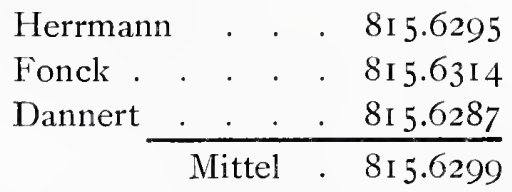

Als mittlerer Neigungswinkel ist angegeben o I $5^{\prime}$ 6". Damit erhält man aus den Log. für 8 I $5.6299=2.9$ I I 493, damit den Log. der auf denselben Horizont red. Basislänge 2.9 I 489 und, da die mittlere Meereshöhe zu I $470 \mathrm{~m}$ angenommen werden kann, so wird daraus auf den Meereshorizont reduziert:

der Log. d. Basis 2.9 I 389 oder die Basis 8I $5.434 \mathrm{~m}$.

Den mittleren Fehler gibt Hauptmann Herrmann offenbar auf Grund der obigen drei Einzelresultate $\mathrm{zu}+\mathrm{I} . \mathrm{I} \mathrm{mm}$ an, nach den früheren Messungsresultaten für die Hauptbasis würde derselbe aber etwas höher zu veranschlagen sein, man wird wohl nahe richtig gehen, wenn man hier die Genauigkeit auf etwa $1 / 500000$ ansetzt. Über die Anlage und Messung des Dreiecksnetzes berichtet H. Herrmann eingehend; im folgenden mag dieser Bericht auszugsweise hier wiedergegeben werden, weil er gleichzeitig für alle späteren Messungen dieser Art, auf die sich unser Bericht erstreckt, charakteristisch ist:

"Die Basis bei Usumbura erlaubte wegen ihrer Lage zum Seeufer nur eine einseitige Entwicklung, die aber zum Anschluß und zur Orientierung der sich im wesentlichen nach Norden erstreckenden Dreieckskette völlig ausreichte. Diese Kette sollte dazu dienen, eine Reihe von Fixpunkten zu beschaffen, zwischen die die topographische Aufnahme des Gebietes eingehängt wurde. Die Ausdehnung 
(ler Dreieckskette von Süd nach Nord beträgt etwa $300 \mathrm{~km}$. Zeit und Personal erlaubten es nicht, die ganze Strecke zuvor zu rekognoszieren oder gar mit Signalen zu besetzen. Da ferner größere $A b$ holzungen bewaldeter Berggipfel, die sich vielleicht gerade gut zu trigonometrischen Punkten geeignet hätten, und der Bau erhöhter Signale mit Beobachtungsständen, wenn das Terrain die Sicht unmöglich machte, aus densclben Gründen ausgeschlossen waren, und schließlich Rücksicht darauf genommen werden mulste, daßs nicht zu weit von jedem Signal, wo doch gelagert werden mußte, Trinkwasser, Brennholz und Verpflegung vorhanden war, so hat das Dreiecksnetz nicht diejenigen günstigcn Formen, die man für europäische Verhältnisse verlangen würde. Wo angängig, wurde in folgender Weise, die sich für solche fliegenden Triangulationen am besten eignet, gearbeitet: Wir beobachteten zu dreien an den drei Ecken eines Dreiecks gleicluzcitiy, jeder mit zwei Helios den beiden anderen Beobachtern zuspiegelnd. Es wurden also lauter einzelne Winkel und lieine Richtungen gemessen. Ich ging immer voran und suchte innerhalb einer gegcbenen Anzahl von Tagen die anderen Punktc aus; nach einem vorher vereinbarten Programm wurde dann gleichzeitig gemessen und geleuchtct. Die Verbindung der drei Kolonnen wurde durch Boten, am Kiwu auch durch Kanus aufrecht erhalten, was sehr nötig war, da infolge ungünstiger Witterung das Programm vielfach nicht klappte und geändert werden nußte. Nach jc einem Drittel der Arbeit, am Südencle des Kiwu bei Ischangi und am Nordende bei Kissenji wurden Standlager gebaut und die ganze Expedition gesammelt, um das Material $z u$ sichten und $z u$ prüfen. Hier und da war es dann noch nötig, einzelne Winkel nachəumessen. Grundsätzlich sollte nur nach Heliolicht gemessen werden, auf kleinen Strecken wurde gelegentlich aber auch nach Sicht gemessen, dann aber vorher die Spitze des Signals nochmals genau zentriert. Die exzentrisch stehenden Helios wurden naturlich jedesmal genau eingerichtet, oder, wenn dies nicht möglich war, die Zentrierungselemente gemessen. Der Theodolit stand nur in zwei Fällen, wo die geraden Stämme großer Bäume das Signal bildeten, exzentrisch. Bei den beiden Spitzen des Karissimbi- und Muhawura-Vulkanes, welche zum Schlub in das Netz, mit aufgenommen werden mußte, da in dem Urwalddistrikt andere Punkte nicht zu finden waren und die Zeit drängte, wurden diese Spitzen direkt ohne künstliche Signalisierung angeschnitten. Hier sind auch die einzigen Dreiecke, in denen ein Winkel nicht gemessen ist.

Die ursprüngliche Absicht, das Dreiecksnetz so zu gestalten, daß sich einc Reihe langgestreckter
Rhomben aneinander fügte, ließ sich leider des ıngünstigen Terrains wegen nicht überall durchführen. So kam es, daß am Ostufer des Kiwu-Sees die Kette eine Einschnürung erhielt und dort nur Dreiecke aneinandergefügt werden konnten. Im Norden des Sees konnte aber in der früheren IVcise weiter gearbeitet werden.

Die Mitglieder der kongolesischen Kommission umfaßten den See auf der Westseite und stießen mit ihrer Kette im Norden in der Nähe des Punktes 25 (Ngoma) wieder mit cler deutschen Vermessung zusammen. Es zcigtc sich, daß selbst die ungünstige Form der Kette keinerlei Einfluß auf die Genauigkeit der Messungen gehabt hattc. Denn dic Übercinstimmung der beiderseits gewonnenen Koordinaten des Punlites (25) war eine vorıügliche, in Längc weichen dieselben nur um etwa $7 \mathrm{~m}$ und in Breite etwa $\mathrm{I} 2 \mathrm{~m}$ voneinander ab. Wenn man bedenkt, daf vielfach unter schwierigen Witterungsverhältnissen gearbeitet werden muBte, und daß für die häıfig dunstige Luft die Spiegel der benutzten Heliotropen verhältnismäßig klein waren, so daß häufig während mehrerer Stunden nur wenige Lichtblitze gesehen werden konnten, so muk man die oben gegebene Übereinstimmung als eine sehr gute bezeichnen. Die Winkelmessungen für dic ganze Kette bis zum Nordufer des Sees gingen in der Weise vor sich, dał mit vier ganzen Sätzen gemessen wurde, für welche der jeweilige Ausgangspunkt um $90^{\circ}$ verändert wurde. Nur in denjenigen Dreiecken, welche zur Entwicklung der Basisnetze dienten und in solchen, welche sehr spitze Winkel enthielten, wurden auch sechs Sätze gemessen, für welche dann jeweils der Limbus um $60^{\circ}$ gedreht wurde."

Der durchschnittliche Dreiccksschlubfehler blieb auf Grund der bei der Ausgleichung gewonnenen Resultate in fast allen Fällen unterhalb 5". Für die Dreiecke bis zum Punkt (3I) ist er etwas geringer. Die Widerspriiche in den Dreiecken sowohl, als auch in den Rhomben wurden mit Berücksichtigung des sphärischen Exzesses gleichmäfig auf die Winkel verteilt. Eine Ausgleichung der ganzen Kette nach den strengen Regeln der Methode der kleinsten Quadrate ist nicht durchgeführt worden und dürfte insofern auch unzwcckmäßig sein, weil die nördlich der Kontrollbasis bei Kissenji gelegenen Dreiecke die bis dahin erzielte Vergröłjerung der Genauigkeit doch wieder illusorisch machen würden. Der Vergleich der durch die trigonometrischen Rechnungen erhaltenen Längen der Kontrollbasis bei Kissenji mit dem direkt erhaltenen Messungsresultat zeigt, da der sich herausstellende Unterschied zwischen $\mathrm{M}-\mathrm{R}=-4.5 \mathrm{~cm}$ völlig innerhalb der Genauigkeitsgrenze liegt, daß die einfache Ausgleichung 
in Rhomben oder Dreiecken und die zugrunde gelegte Basislänge allen Anforderungen entsprochen haben. $\left.{ }^{1}\right)$ Unter Berücksichtigung der Genauigkeit der Messung der Hauptbasis und derjenigen der Kontrollbasis dürften die Seitenlängen dcr die beiden Basen verbindenden Kette auf etwa I : 50000 ihrer Länge richtig sein. Die Unsicherheit, welche damit im Maximum an den Seitenlängen, nach gleichmäßiger Verteilung der Abweichung übrig bliebe, wird den Betrag von $\pm 3 \mathrm{~m}$ nicht überschreiten, und da die scharfe Durchrechnung der Basismessung bei Usumbura ein nur wenig abweichendes Resultat von der vorläufigen Rechnung ergeben hat (der Unterschicd beträgt nur eine Einheit der 6.Dez. des Log.) so sind in den Abrissen nur die Seitenlängen demgemäß verbcssert worden. Auf die im Anschluß bcigefügte Tabellc der geographischen Koordinaten hat diese Verbesserung aber keinerlei Einfluß gehabt, da sie kaum den zehnten Teil einer Bogensekunde für die entferntesten Punkte erreicht.

Nachdem die Arbeiten bis zu der oben gegebenen Breite $-\mathrm{I}^{\circ} 2 \mathrm{O}^{\prime}$ südlich durchgeführt waren, und die Expedition in das Standlager Kissenji zurückgekehrt war, erhielt sie den Befehl, auch das Stück längs des 30. Grades östlicher Länge bis zum I. Grad südlicher Breite zu vermessen. Dazu wurde Oberleutnant Schwartz, der gerade als Ersatz für Professor Lamp eingetroffen war, ausersehen. Er sollte unter Zugrundelegung vorläufig berechneter Koordinaten der letzten Punkte sich nach diesen öfters einschneiden, an den jeweiligen Stationspunkten Pfeiler bauen und event. am I. Grad südlicher Breite noch Breitenbeobachtungen machen. Die Kürze der Zeit, das ungünstige Wetter und die feindliche Haltung der Bevölkerung vereitelten jedoch das meiste. Der erste Stationspunkt wurde mit Meßtischgenauigkeit bestimmt und auf $\mathrm{I}^{\circ} \mathrm{IO}^{\prime}$ gelang ein Rückwärtseinschnitt, das übrige Terrain wurde nur mit Meßtisch und Routen festgelegt. Da jedoch die deutsch-englische Uganda-Grenzexpcdition, welche sich an die Arbeiten der Kiwu-Expedition anschloB, auch am "Schnittpunkt « $\left(30^{\circ} \mathrm{Lg}\right.$. $\mathrm{I}^{\circ} \mathrm{Br}$. $)$ endet, so ist durch Hereinziehen der Punkte 33, 34 und 37, welche sichtbar waren, Anschluß an das Kiwu-Netz gefunden, was um so wichtiger ist, als ihre Anfangslänge durch telegraphische Zeitübertragung gewonnen wurde und so eine sehr gute Kontrolle für die aus Mondkulminationen gefundene Lage von Usumbura bildet. Wie sich zeigen wird, ist tatsächlich einc gute Übereinstimmung der Positionen der Kiwu-Expedition mit denen der Uganda-Grenzexpedition erzielt worden.

1) Dazu ist zu vergleichen die Tabelle der Winkel und Seitenlängen für die Kiwu-See-Triang.

Mitteilungen a. d. D. Schntzgebieten, XX. Band. IV.
Die Berechnung der geographischen Koordinaten der am Schlusse gegebenen Tabelle ist nach den Schreiberschen Formeln und Tafeln, wie sie für eine Triangulation dritter Ordnung genügen, gerechnet worden. Es sei dabei bemerkt, daß diese Formeln in der Nähe des Äquators bis zu wesentlich höherer Ordnung, d. h. bis zu Dreiecksseiten mit einer Länge von 50 bis $60 \mathrm{~km}$, genügen, um noch die $1 / 100$ Bogensekunde durch die Formeln scharf zu geben. Daraus geht hervor, dal die benutzten Formeln in Anbetracht der Genauigkeit der ganzen Messungen und namentlich derjenigen der Basislinien eine weit höherc Genauigkeit verbürgen, als es direkt notwendig gcwescn wäre. Dieser Umstand ist aber insofern von Vorteil, als das Rechnungsverfahren kciner Verändcrung bedarf, wenn man später in der Lage sein sollte, die Dimensionen des Netzes genauer zu bestimmen.

Um die Vergleichung der astronomischen Breitenbestimmungen mit denjenigen Werten durchzuführen, wie sie die geodätische Übertragung für Kissenji und den Hunga-Berg geliefert hat, sind die örtlichen Situationsskizzen und die bezüglich dieser vorhandenen Angaben zu verwenden. Bezüglich Kissenji ist nach Angaben desOberleutnants Schwart $\mathrm{z}$ die Situation etwa die in Skizze 2 angegebene:

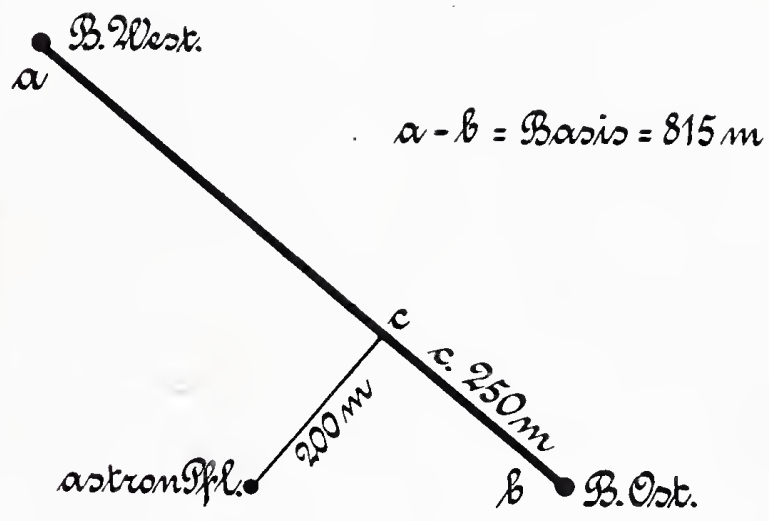

Skizze 2.

Lage der astronomischen und geodätischen Punkte bei Kissenji.

Die Punkte a und b sind der westliche bzw. östliche Endpunkt der Kontrollbasis, die Streckc b-c beträgt nahe $250 \mathrm{~m}$, und der Beobachtungspfeiler stand in senkrechter Entfernung von der Basis ctwa $200 \mathrm{~m} \mathrm{ab}$. Nimmt man für a und b die bctreffenden Werte

$$
\begin{aligned}
\varphi_{\mathrm{a}} & =-\mathrm{I}^{\circ} 4 \mathrm{I}^{\prime} 59.5^{\prime \prime} \\
\text { für } \varphi_{\mathrm{b}} & =-\mathrm{I}^{\circ} 42^{\prime} \mathrm{I} 7.3^{\prime \prime}
\end{aligned}
$$

so erhält man für

$$
\varphi_{\mathrm{c}}=-\mathrm{I}^{\circ} 42^{\prime} \mathrm{II} \cdot 7^{\prime \prime}
$$

und damit für den Punkt

$$
\varphi_{\circ}=-\mathrm{I}^{\circ} 42^{\prime} \mathrm{I} 7 \cdot 7^{\prime \prime} \text {. }
$$


Die astronomische Bestimmung $\varphi$, liefert, wie oben mitgeteilt, den WTert

$$
\text { (astr.) } \varphi_{0}=-I^{\circ} 42^{\prime} \text { I } 9.5^{\prime \prime} \text {. }
$$

Der Unterschied beträgt also im Sinne astron.geodätischer Breite nur

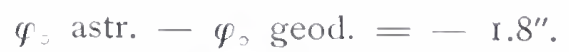

Der geodätische Wert ist recht gut verbürgt, während der astronomische höchstens eine Genauigkeit von $+\mathrm{I}^{\prime \prime}$ besitzt; es ist daher die erhaltene Abweichung durchaus nicht ïberraschend, zumal wenn man beclenkt, daß eine Lotstörung, wie sie an dem Ufer des südlich gelegenen Sees, in dessen nächster Nähe sich im Norden hohe Berge erheben, erwartet werden kann, im gleichen Sinne wirken würde.

An der Station Hungaberg ist ein Vergleich der greodätisch errechneten Breite mit dem früher durch astronomische Beobachtungen gefundenen nicht ganz einwandfrei durchzuführen, da dort wohl ein belgisches Signal aufgestellt war und dessen geodätische Koordinaten von Kapitän Bastien, dem Leiter der kongolesischen Expectition angegeben wurden, aber die astronomische Bestimmung der Brcite ist nicht sehr sicher. Da jedoch auch die Triangulation der Uganda-Expedition bis hierher reicht, so wird später auf diese Frage näher einzugehen sein. Es findet sich aus den bisher gegebenen Daten:

$$
\begin{array}{rr}
\text { "Hungaberg } \varphi \text { astr. } & 0^{\circ} 59^{\prime} 51.5^{\prime \prime} \\
& \varphi \text { geod. }-0^{\circ} 59^{\prime} 44.3^{\prime \prime} \\
\text { Differenz } \varphi \text { astr.-geod. } & 7.2^{\prime \prime} .
\end{array}
$$

Die Abweichung licgt in demselben Sinne, wie sie schon bei Kissenji aufgetreten ist. Die Vergleichung der auf Grund der Kiwu-See-Triangulation und der Messungen der Uganda-Expedition gefundenen Werte für die Längren der betreffenden Übertragungspunkte kann auch erst später nach Erläuterung der letzteren Arbeiten durchgefuihrt werden.

Zum Schlub der Besprechung der Arbeiten der Kiwu-See-Expedition füge ich noch die Koordinatenverzeichnisse und dic Abrisse der cinzelnen Stationen bei, so weit sie weiteres Interesse besitzen und zur Berechnung der vorstehenden Daten gedicnt habcn. Die Breiten und Längen sind hier so gegeben, wie sie die deutschen Beobachtungen liefern.

\section{Verzeichnis der Punkte I. Ordnung und der Stand- lager für astronomische Beobachtungen sowie der Koordinaten und Abrisse für diese Punkte der Kiwu- See-Expedition.}

Liste der trigonometrischen Punkte I. Oidnung.

Die numerierten Punkte bilden die eigentliche Dreieckskette.

Deutscher Beobachtungspfeiler. Pfeiler aus Ziegeln und $\varphi=-3^{\circ} 22^{\prime} 57 .^{\prime \prime} 4$ |Deutsches Zement. Zentrum: Nagel$\lambda=2925 \mathrm{I} \mid$ Resultat kopt. Pfeiler ist stehen geblieben; zum Schutze wurde eine Hütte đdrüber gebaut.

I. Basis Süd

Pfeiler ans Ziegehn mud Kalk; wurde beim Abmarsch weggenommen; Zentrum: Zündhütchen der Granathülse im Fundament im Bodennivean.
2. Basis Nord
3. Ikungu .
4. Mbossa
5. Sanhuma
6. Rubenga

Nördlichster Punkt des Tanganjika .

Nördlichster Punkt der Ostbucht 7. Tschamate

8. MItarischwa

9. Ssolia

Iо. Kiwuburu

I I, Murja

12. Tschandonga

13. Niakabuje

I4. Tscliati

I5. Tschangugu

16. Mgatschutschu

I 7. Iwindsche

Bergfrieden

I8. Gangamanda

I9. Krwidschwi-Süd

20. Wugangoma .

2I. Kwidschwi-Ost

22. Wulemu

23. Wana

24. Wikono.

25. Ngoma

26. Nkama

Kontrollbasis-Ost

$$
- \text { West }
$$

Entwicklungspunkt .

27. Buschwaga

28. Ruschaschu

29. Rwagara

30. Tabarwe

3I. Karissimbi

Magahinga .

32. Jongojongo
Wie Basis Süd.

Zentrum: Pfahlmitte.

in die Felsplatte, auf der das Signal steht, eingehátuenes Krreuz.

Zentrum: Pfahlmitte; der

\begin{tabular}{|c|c|}
\hline & 》 \\
\hline , & 》 \\
\hline 》 & 》 \\
\hline "y & 》 \\
\hline 》 & 》 \\
\hline » & " \\
\hline » & » \\
\hline " & " \\
\hline 》 & " \\
\hline 》 & " \\
\hline
\end{tabular}
Pfahl ist durch einen dicken Baumstamm inmitteı eines hohen Steinhaufens ersetzt. Zentrum: Pfahlmitte.

Stammesmitte des Baumes, der als Signal dient.

Zentrum: Pfahlmitte; der Pfahl steht westlich des Hauses des Dr. Kandt unweit des Zaunes.

Zentrum: Pfahlmitte.

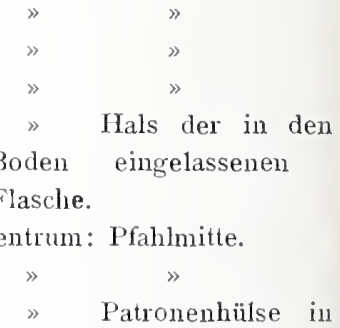
einem in den Boden eingelassenen 'Zementblock. Zentrum: Pfahlmitte.

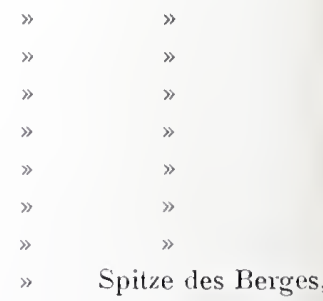
die ohne künstliche Signalisierung angeschnitten wurde.

Zentrum: Höchste Zacke des Kraterrandes, ohne künstliche Signalisierung angeschnitten.

Zentrum: Pfahlmitte. 
33. Muhawura . . . . . Zentrum: Spitze des Berges, die ohne künstliche Signalisierung angeschnitten wurde.

34. Nianganga. . . . . . Zentrum: Pfahlmitte

35. Kahira

Zündhütchen, $\mathrm{Pa}-$ tronenhülse, die mit Blei in einen Steinblock eingegossen wurde; hoher Steinwall darum.

36. Gikole Zentrum: Pfahlmitte.

37. Kijogajoga

38. Irangeri

M Mitte des Baumstamms, der als Signal dient.

\section{Koordinatenverzeichnis.}

Kiwu-See-Triangulation, wie sie auf Grund der deutschen Beobachtungen sich darstellt. ${ }^{1}$ )

Die Breiten » $\varphi$ « sind südliche, die Längen östliche in bezug auf Greenwich.

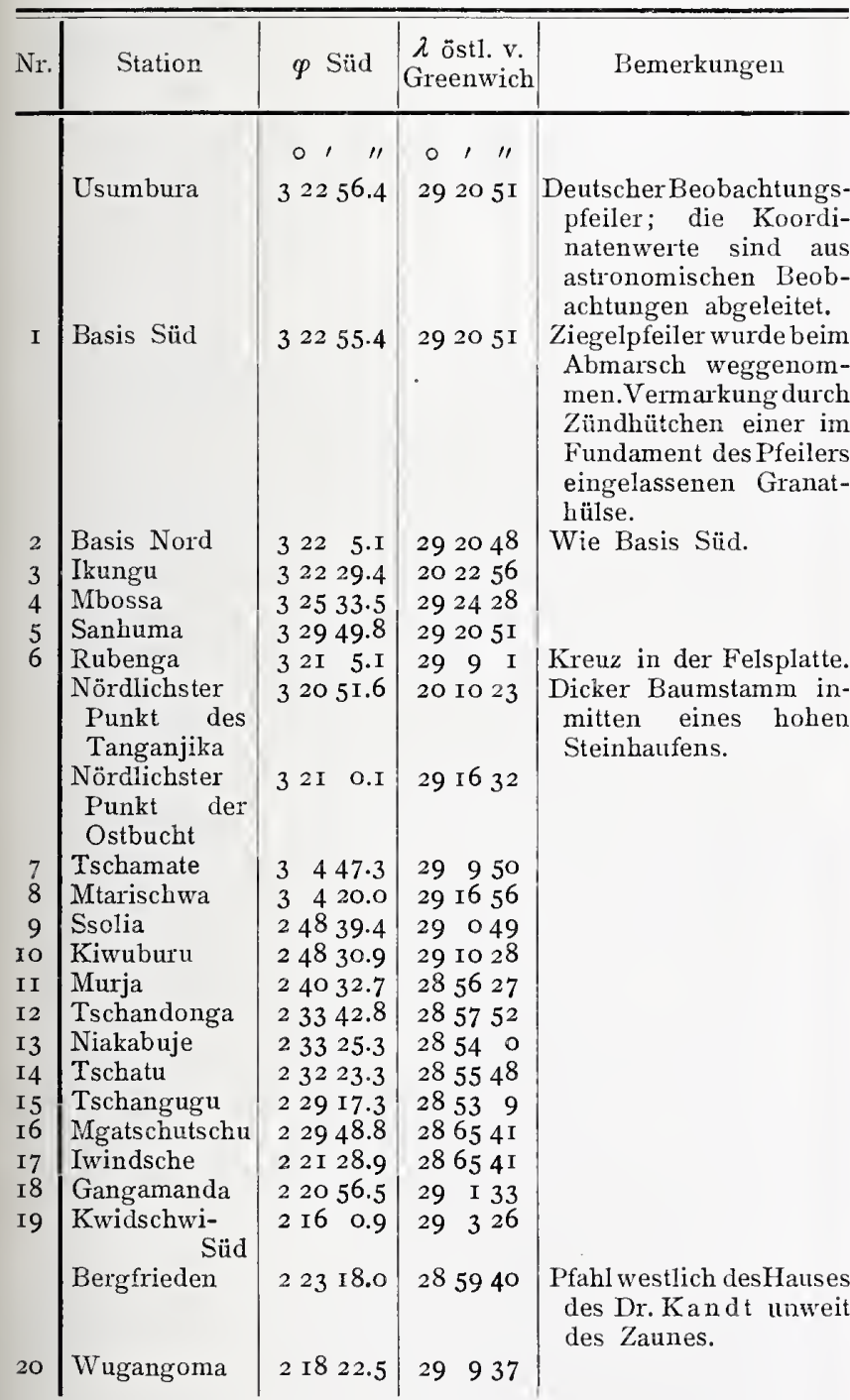

1) Werden die beiden Resultate für die Breite, wie sie die deutschen Beobachtungen geben und wie sie von den belgischen Expeditionen gefunden wurden, zum Mittel vereinigt, so erhält man für den Beobachtungspfeiler der deutschen Expedition $\varphi=-3^{\circ} 22^{\prime} 56 .^{\prime \prime} 2$; für die Länge ist ein solcher Mittelwert in Strenge nicht angebbar.

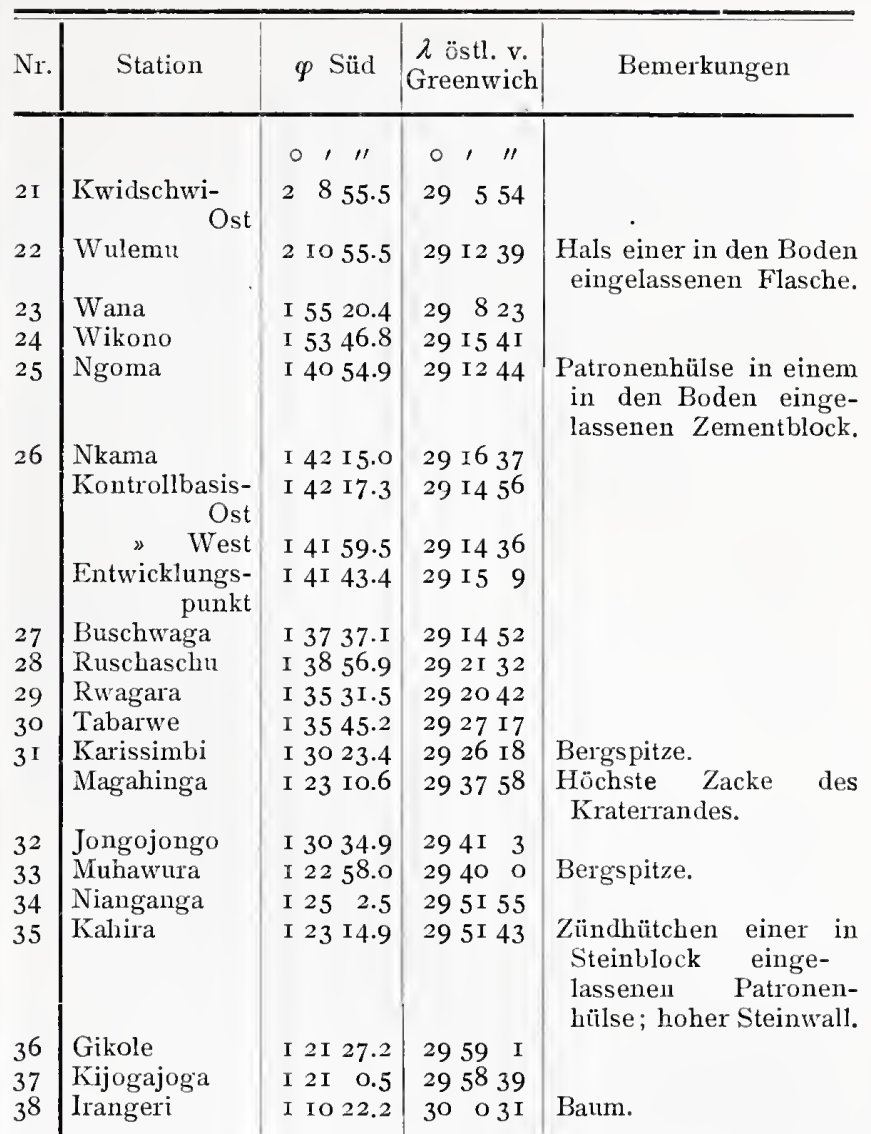

Die nicht bezifferten Stationen sind Nebenpunkte.

Abrisse.

\begin{tabular}{l|l|c|c|c}
\hline \multirow{3}{*}{ Richtung nach } & Azimut & $\begin{array}{c}\text { Loga- } \\
\text { rithmen } \\
\text { der Ent- } \\
\text { fernungen } \\
\text { in m }\end{array}$ & $\begin{array}{c}\text { Ent- } \\
\text { fernumgen } \\
\text { in m }\end{array}$ & $\begin{array}{c}\text { Be- } \\
\text { mer- } \\
\text { kun- } \\
\text { gen }\end{array}$ \\
\hline
\end{tabular}

1. Basis Süd.

2 Basis Nord . $356^{\circ} 35^{\prime} 27^{\prime \prime} .6 \quad 3.189970 \mid$ I 548.71

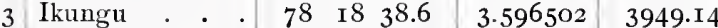

4 Mbossa . . . I25 54 21.0 $3.918080 \quad 8280.94$

5 Sanhuma . . . I \begin{tabular}{llll|l|l|l|}
579 & 57 & 37.8 & 4.104709 & I 2726.50
\end{tabular}

$\begin{array}{lllllll} & \text { Rubenga } .278 & 47 & \text { I } 2.7 & 4.345807 & 22 \text { I } 72.10\end{array}$

7 Tschamate . . \begin{tabular}{llll|l|l|l}
328 & 34 & 26.8 & 4.592884 & 39163.73
\end{tabular}

8 Mtarischwa . . $348 \quad 2 \quad 40.6 \quad 4.544273 \quad 35016.50$

nördlichst. Punkt

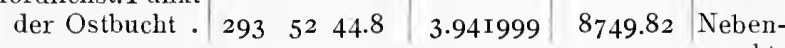

2. Basis Nord.

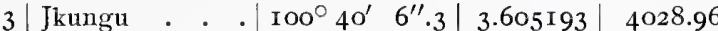

4 Mbossa . . . \begin{tabular}{llll|l|l|l|l|l} 
& I33 & I6 & 34.2 & 3.970319 & 9339.40
\end{tabular}

I Basis Süd . . \begin{tabular}{llll|l|l|l|l}
176 & 35 & 27.7 & 3.189970 & I 548.7 I
\end{tabular}

nördlichst. Punkt

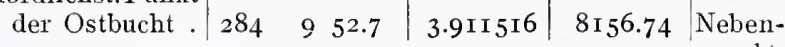

3. Jkungu.

\begin{tabular}{l|l|l|l|l|l|l|l}
4 & Mbossa .. . & $\mathrm{I}^{\circ} \mathrm{20}^{\prime} \mathrm{IO}^{\prime \prime} .7$ & $3.80 \mathrm{I} 37 \mathrm{I}$ & 6329.52
\end{tabular}

I Basis Süd . . \begin{tabular}{llll|l|l|}
258 & I 8 & $3 \mathrm{I} .2$ & 3.596502 & $3949 . \mathrm{I} 4$
\end{tabular}

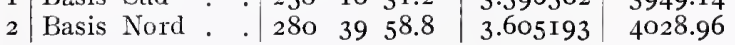

\section{Mbossa.}

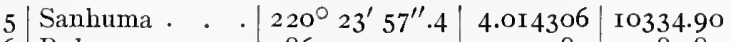

\begin{tabular}{lll|lll|l|l|l|}
6 & Rubenga . . . . & 286 & 3 & 53.0 & 4.473982 & 29783.87
\end{tabular}

I Basis Süd . . \begin{tabular}{lll|l|l}
305 & 54 & 8.0 & 3.9 r8o8o & 8280.94
\end{tabular}

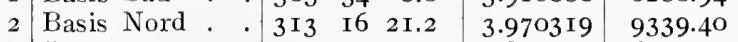

3 Jkungu . . . \begin{tabular}{llll|l|l|l}
333 & 20 & 5.2 & 3.80137 I & 6329.52
\end{tabular}

\begin{tabular}{|r|rrr|r|r|r}
$\begin{array}{r}\text { nördlichst. Punkt } \\
\text { des Tanganjika }\end{array}$ & 288 & 2 I & $27 . I$ & 4.439074 & 27483.62 & $\begin{array}{c}\text { Neben- } \\
\text { punkt }\end{array}$
\end{tabular} 


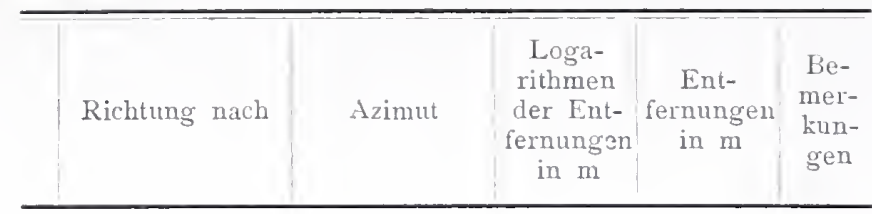

5. Sanhuma.

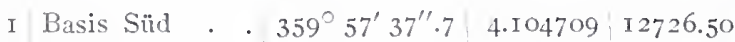

4 MIbossa . . . 40 24 240.5 4.0I4306 10334.90

\begin{tabular}{lll|lll|l|l|l}
6 & Rubenga . . . 306 & 19 & 7.8 & 4.434671 & 27206.37
\end{tabular} nördlichst. Punkt

\begin{tabular}{l|lll|l|l|l} 
des Tanganjika & 3 Io 26 & 58.4 & 4.406II 2 & 25474.86 & Neben-
\end{tabular}

Nördlichster Punkt des Tanganjika. Neben-

4 Mrbossa . . . $\operatorname{Io8}^{\circ} 22^{\prime}$ I $^{\prime \prime} .0 \quad 4.439074|27483.62|$ punkt

\begin{tabular}{|l|l|lll|l|l|l|l}
5 & Sanhuma. . I30 & 27 & 35.9 & 4.406 I I 2 & 25474.86
\end{tabular}

Nördlichster Punkt der Ostbucht. Neben-

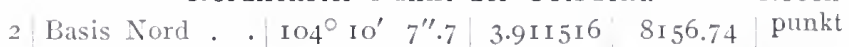

I Basis süd . . II3 53 0.0 $3.941999 \quad 8749.82$

\section{Rubenga.}

7 'Tschamate

8 Mtarischwa

I Basis Süd

4 Mbossit

5 Sanhuma

\begin{tabular}{l|l|l|l|l}
$2^{\circ} 5 \mathrm{II}^{\prime} 2 \mathrm{O}^{\prime \prime} . \mathrm{I}$ & $4.478 \mathrm{II} 7$ & 30068.86
\end{tabular} \begin{tabular}{lll|l|l|l}
25 & 24 & 44.1 & 4.533687 & $34 \mathrm{I} 73.31$
\end{tabular}

\begin{tabular}{lll|l|l|l|l}
98 & 47 & 54.3 & 4.345807 & 22172.10
\end{tabular}

\begin{tabular}{lll|l|l|l} 
I06 & 4 & 47.9 & 4.473982 & 29783.87
\end{tabular}

\begin{tabular}{lll|lll} 
I 26 & I 9 & 50.3 & 4.43467 & 27206.37
\end{tabular}

\section{Tschamate.}

Io Kiwuburu

8 MItarischwa

I Basis Sïd

6 Rubenga .

9 Ssolia

I Basis Süd

6 Rubenga .

7 Tschamate

9 Ssolia.

Io Kiwuburu

Io ' Kiwuburu

8 Mitarischwa

7 Tschamate

I I Murja

I2 Tschandonga

\begin{tabular}{ll|l|l|l|}
2 & I $3^{\prime} 4 I^{\prime \prime} .9$ & 4.477273 & 30010.50
\end{tabular} \begin{tabular}{lll|l|l|l|l|}
86 & 22 & 13.2 & 4.120343 & I 3193.00
\end{tabular} \begin{tabular}{lll|l|l} 
I48 & 35 & 4.0 & 4.592884 & 39163.73
\end{tabular} \begin{tabular}{lll|l|l|l|l}
182 & $5 \mathrm{I}$ & 17.4 & 4.478117 & 30068.86
\end{tabular} \begin{tabular}{ll|l|l|l|l}
330 & 40 & 25.6 & 4.532666 & 34093.08
\end{tabular}

\section{Mtarischwa.}

\begin{tabular}{lll|l|l|l|l} 
I $68^{\circ}$ & $2^{\prime}$ & $53^{\prime \prime} .8$ & 4.544273 & $35016.5 \mathrm{I}$
\end{tabular}

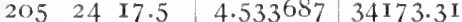
\begin{tabular}{lll|l|l|l|l}
266 & 21 & 50.3 & 4.120344 & I 3193.00
\end{tabular}

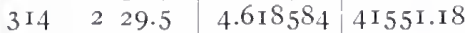
$\begin{array}{llllll}337 & 37 & 21.0 & 4.498659 & 31525.28\end{array}$

\section{Ssolia.}

\begin{tabular}{lll|l|l|l}
$89^{\circ}$ & $9^{\prime}$ & $45^{\prime \prime} \cdot 3$ & 4.252072 & I7 867.87
\end{tabular} \begin{tabular}{lll|l|l|l}
\hline I34 & 3 & I 9.2 & 4.6 I 8584 & 4I I55I.28
\end{tabular} \begin{tabular}{lll|lll|l} 
I 50 & 40 & 53.4 & 4.532666 & 34093.08
\end{tabular} \begin{tabular}{lll|l|l|l|l|l}
$33 I$ & 32 & 20.3 & 4.230575 & I 7004.93
\end{tabular} \begin{tabular}{ll|l|l|l|l}
348 & 47 & 59.7 & 4.448301 & 28073.80
\end{tabular}

\section{Kiwuburu}

8 | Mtarischwa

7 Tschamate

9 Ssolia.

I I Nurja.

I2 Tschandonga

\begin{tabular}{ll|l|l|l|l} 
& $\mathrm{I}^{\circ} 37^{\prime} 37^{\prime} 4 \mathrm{I}^{\prime \prime} . \mathrm{O}$ & 4.498659 & $3 \mathrm{I} 525.28$
\end{tabular} \begin{tabular}{llll|l|l|l}
\hline 182 & I 3 & 40.0 & 4.477273 & 300 I0.50
\end{tabular} \begin{tabular}{lll|l|l|l|l|l}
269 & 9 & I 6.0 & 4.252073 & I 7867.87
\end{tabular}

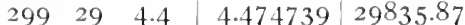
\begin{tabular}{lll|l|l|l}
319 & 28 & 3.1 & 4.554942 & 35887.42
\end{tabular}

\section{Murja.}

I2 'Tschandonga

Io Kiwuburu

9 Ssolia .

I 3 Niakabuje

I4 Tschatu

Io Kiwubur

$9 \mid$ Ssolia.

I I Murja .

I3 Niakabuje

I 4 'Tschatu

\begin{tabular}{|c|c|c|c|}
\hline $\mathrm{II}^{\circ} 5$ & $42^{\prime \prime} .2$ & 4. I $0942 \mathrm{I}$ & \\
\hline II 2 & 44 & & \\
\hline 1 & 32 & & \\
\hline 10 & 22. & 4.14 & \\
\hline 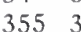 & 0.7 & 4.I78323 & \\
\hline
\end{tabular}

\section{Tschandonga.}

\begin{tabular}{ll|l|l|l}
$\mathrm{I} 39^{\circ} 28^{\prime} 38^{\prime \prime} .5$ & 4.554942 & $35887.4 \mathrm{I}$
\end{tabular} $\begin{array}{llllll}\text { I } 68 & 48 & 8.0 & 4.44830 I & 28073.77\end{array}$ \begin{tabular}{lll|l|l|l} 
I 9 I & 53 & 38.3 & 4.10942 I & I 2865.33
\end{tabular} \begin{tabular}{lllll|l}
274 & 15 & 44.2 & 3.858253 & 7215.27
\end{tabular} \begin{tabular}{lll|l|l|l}
302 & $3 \mathrm{I}$ & 4.7 & 3.657301 & 4542.59
\end{tabular}

\section{Niakabuje.}

I6 Mgatschutschu I4 Tschatu

I 2 'Tschindonga

I I Murja.

\begin{tabular}{lll|l|l|}
$31^{\circ}$ & $6^{\prime}$ & $32^{\prime \prime} .6$ & 3.890266 & 7767.23
\end{tabular} \begin{tabular}{|lll|l|l|}
\hline 60 & 28 & 40.7 & 3.587387 & 3867.12 \\
\hline
\end{tabular}

$\begin{array}{lll}94 & \text { I } 5 & 54.6\end{array}$

$\begin{array}{lll}\text { I } 60 & 54 & 28.8\end{array}$

$3.858253 \quad 7215.29$

I 5 | Tschangugu

4.I 42690 I 3889.6 I

$\begin{array}{ll}3.890841 & 7777.52\end{array}$

\begin{tabular}{|c|c|c|c|c|}
\hline Richtung nach & Azimut & $\begin{array}{l}\text { Loga- } \\
\text { xithmen } \\
\text { der Ent- } \\
\text { fernungen } \\
\text { in m }\end{array}$ & $\begin{array}{c}\text { Ent- } \\
\text { feruungen } \\
\text { in } m\end{array}$ & $\begin{array}{l}\text { Be- } \\
\text { mer- } \\
\text { kun- } \\
\text { gen }\end{array}$ \\
\hline
\end{tabular}

14. Tschatu.

\begin{tabular}{|c|c|c|c|c|}
\hline Mgatschu & $7^{\circ} 4$ & $46^{\prime} 43^{\prime \prime} \cdot 3$ & $3.6802 \mathrm{I} 3$ & 4788.64 \\
\hline Tse & 1223 & $\begin{array}{ll}31 & 10.2\end{array}$ & 3.657303 & \\
\hline Murja & 1753 & $\begin{array}{ll}3 \mathrm{I} & 2.4\end{array}$ & 4.178 & 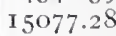 \\
\hline Niakabnje & $240 \quad 2$ & $28 \quad 35.9$ & 3.587387 & \\
\hline Tschangugu & $319 \mathrm{I}$ & 1246.0 & 3.877687 & \\
\hline
\end{tabular}

\begin{tabular}{ll|lll|l|l|}
\hline I5 & Tschangugu . & 319 & I 2 & 46.0 & 3.877687 & 75.45 .49
\end{tabular}

\section{Tschangugu.}

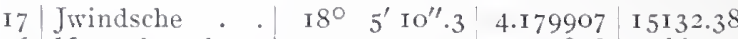
\begin{tabular}{ll|lll|l|l|} 
I6 Mgatschutschu . & 99 & $5 \mathrm{I}$ & I 2.7 & 3.752858 & 5660.54
\end{tabular} \begin{tabular}{l|l|lll|l|l|l|} 
I4 & Tschatu & I . . . & I 39 & I 2 & 53.0 & 3.877687 & 7545.49
\end{tabular} \begin{tabular}{l|l|lrl|l|l|l|l}
\hline 3 & Niakabuje & I68 & 24 & I.O & $3.89084 I$ & 7777.52
\end{tabular}

I 7 Jwindsche . $356^{\circ} 43^{\prime}$ I $2^{\prime \prime} .0 \mid$ 4.I $^{\prime} 699$ I6 I 5378.58 \begin{tabular}{ll|c|c|c|c|c|} 
& I 8 Gangamanda \\
I & 27 & 35.3 & 4.282530 & 19165.95
\end{tabular} \begin{tabular}{l|llllllll} 
& I4 & Tschatu & . . . & I 87 & 46 & 42.4 & 3.680213 & 4788.64
\end{tabular} \begin{tabular}{l|l|l|l|l|l|l|l|} 
I3 Niakabuje & 2 I I & 6 & 26.8 & 3.890266 & 7767.24
\end{tabular} \begin{tabular}{lll|l|l|l|l|l|}
\hline I5 Tschangugu & 279 & 5 I & 4.8 & 3.752858 & 5660.54
\end{tabular} \begin{tabular}{l|lll|l|l|l} 
Bergfrieden . & 28 & 26 & 48.8 & 4.I35I99 & I 3652.09
\end{tabular}

17. Jwindsche.

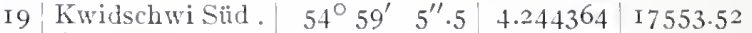

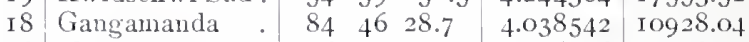
I6 Mgatschutschu 。 I76 $43 \quad 13.2 \quad 4.1869$ I 6 I 5378.58 \begin{tabular}{l|l|lrl|l|l|l|} 
I5 & Tschangugn . & I 98 & 5 & 3.8 & 4.179907 & I5132.38
\end{tabular} \begin{tabular}{|l|lll|l|l|l|}
\hline Bergfrieden . IIt 24 & $\mathbf{1} 4.4$ & 3.908877 & 8107.32
\end{tabular}

\section{Bergfrieden.}

I6 Mgatschutschu . $208^{\circ} 26^{\prime} 39^{\prime \prime} .8 \mid 4$ 4.I35I99 $\mid$ I 3652.09 17 Jwindsche . $\mid$\begin{tabular}{|llc|l|l|}
294 & 24 & 4.5 & 3.908877 & 8107.32
\end{tabular}

\section{Gangamanda.}

I9 $\mid$ Kwidschwi Siid . $\mid$\begin{tabular}{lll|l|l|l} 
& I $^{\circ}$ & $2^{\prime}$ & $53^{\prime \prime} .3$ & 3.987934 & 9726.00
\end{tabular} 20 Wugangoma • \begin{tabular}{llll|l|l|l|}
72 & 27 & 36.8 & 4.195630 & I 5690.25
\end{tabular} I6 \begin{tabular}{ll|lll|l|l|l} 
Igatschutschu & II & 27 & 2 I.6 & 4.282530 & I9I65.95
\end{tabular} \begin{tabular}{l|l|lll|l|l|}
\hline 7 & Jwindsche.$~$ & 264 & 46 & 14.3 & 4.038542 & I0928.03
\end{tabular}

\section{Kwidschwi Süd.}

\section{Wulemu \\ 20 Wugangoma \\ 18 Gangamanda \\ I 7 Jwindsche}

\begin{tabular}{ll|l|l|l|}
$6 \mathrm{I}^{\circ}$ & $13^{\prime} 56^{\prime \prime} .7$ & 4.289822 & 19490.46
\end{tabular} \begin{tabular}{|lll|l|l|l} 
I IO & 45 & 55.6 & 4.0886 .8 & I 2264.45
\end{tabular} \begin{tabular}{|lrr|r|r|r|}
\hline 201 & 2 & 48.8 & 3.987934 & 9726.00
\end{tabular} \begin{tabular}{lll|l|l|l}
234 & 58 & 46.9 & 4.244364 & I 7553.52
\end{tabular}

\section{2o. Wugangoma.}

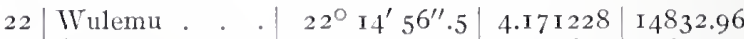
I 8 Gangamanda . \begin{tabular}{llllll|l}
252 & 27 & I 7.2 & 4.195630 & I 5690.25
\end{tabular} \begin{tabular}{l|l|l|l|l|l|l|}
19 & Kwidschwi Süd. 290 & 45 & 40.8 & 4.088648 & I 2264.44
\end{tabular} \begin{tabular}{ll|lll|l|l|}
2 I & Kwidschwi Ost . & 338 & 2 I & I 5.0 & 4.272623 & I 8733.67
\end{tabular}

\section{Kwidschwi Ost.}

$24 \mid$ Wikono

22 Wulemu

20 Wugangoma

\begin{tabular}{lll|l|l|l|l}
$33^{\circ}$ & $2^{\prime}$ & $3^{\prime \prime} . \mathrm{I}$ & $4.5223 \mathrm{I} 2$ & 33289.85
\end{tabular} \begin{tabular}{|lll|l|l|l}
106 & 23 & 27.3 & 4.1 & I 5843 & I 3057.00
\end{tabular} \begin{tabular}{lll|l|l|l}
\hline 8 & 21 & 23.6 & 4.272623 & 18733.67
\end{tabular}

\section{Wulemu.}

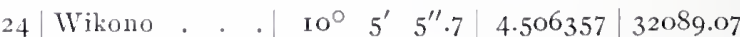
20 Wugangoma. 2 \begin{tabular}{llll|l|l|}
202 & I4 & 49.5 & 4.17 I 228 & I 4832.96
\end{tabular} \begin{tabular}{l|l|lll|ll|l} 
I9 Kwidschwi Süd & 24 I & I3 & 35.4 & 4.289822 & I9490.46
\end{tabular}

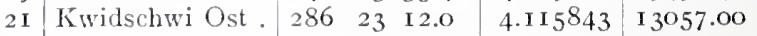
\begin{tabular}{l|l|lll|l|l|l|}
23 & Wana . . . & 344 & 36 & I.3 & 4.474048 & 29788.47
\end{tabular}

\section{Wana.}

$25 \mid$ Ngoma . . . $\left|{ }^{1} 6^{\circ} 53^{\prime} 20^{\prime \prime} \cdot 3\right| 4^{\prime} 4443684 \mid 27776.93$ \begin{tabular}{l|l|cc|c|c|c|}
24 & Wikono. . . 78 & o 29.2 & 4.I 40862 & I 383 I.26
\end{tabular} \begin{tabular}{l|l|lll|l|l|l}
22 & Wulemu : : & I64 & 36 & I0.5 & 4.474048 & 29788.47
\end{tabular}

24. Wikono.

\begin{tabular}{l|l|l|l|l|l|l|l|}
26 & Nkama . . . & $4^{\circ}$ & $4 I^{\prime}$ & $4^{\prime \prime} .8$ & 4.328777 & 2 I 3 I9.50
\end{tabular} \begin{tabular}{l|l|l|l|l|l|l|l}
22 & Wulemu . . . I 90 & 4 & 59.2 & 4.506357 & 32089.07
\end{tabular} \begin{tabular}{l|l|lll|l|l|l}
2 I & Kwidschwi Ost . 2 I3 & I & 42.4 & 4.5223 I 2 & 33289.85
\end{tabular} 23 Wana . . . . $25^{8}$ o I 4.6 4.I 40862 I 383 I.26 \begin{tabular}{lllllll|l}
25 & Ngoma & 0 & 347 & I 32.6 & 4.386065 & 24325.67
\end{tabular}
Nebenpunkt nicht gem.

Nebenpunkt Nebenpunkit 


\begin{tabular}{|l|l|c|c|c}
\hline \multirow{3}{*}{ Richtung nach } & Azimut & $\begin{array}{c}\text { Loga- } \\
\text { rithmen } \\
\text { der Ent- } \\
\text { fernungen } \\
\text { in m }\end{array}$ & $\begin{array}{c}\text { Ent- } \\
\text { fernungen }\end{array}$ & $\begin{array}{c}\text { Be- } \\
\text { mer- } \\
\text { kun- } \\
\text { gen }\end{array}$ \\
\hline
\end{tabular}

25. Ngoma.

\begin{tabular}{l|ll|lll|l|l|}
27 & Buschwaga . . & $33^{\circ}$ & $2^{\prime}$ & $19^{\prime \prime} \cdot 3$ & 3.860394 & 7250.94
\end{tabular} 26 Nkama . . . . \begin{tabular}{llll|l} 
I08 & 49 & 58.4 & 3.88 I 384 & 7609.99
\end{tabular}

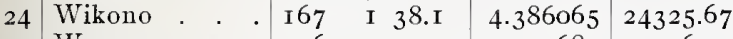
\begin{tabular}{lll|lll|l|l|l|}
23 & Wana... . & I 96 & 53 & I 2.I & 4.443684 & 27776.93 \\
\hline
\end{tabular}

Kontrollbasis-

\begin{tabular}{|l|lll|l|l|} 
Entwickl.Punkt & I08 & 23 & 55.7 & 3.672887 & 4708.54
\end{tabular}

Kontrollbasis

\begin{tabular}{llllll|l} 
Ost . . . . I I & 57 & 7.4 & 3.679195 & 4777.43
\end{tabular}

\section{Nkama.}

$29 \mid$\begin{tabular}{l|l|l|l|l|} 
Rwagara . . . & $3 \mathrm{I}^{\circ} 20^{\prime} 36^{\prime \prime} .9$ & $4 . \mathrm{I} 6 \mathrm{I} 654$ & $\mathbf{I} 4509.5^{6}$
\end{tabular}

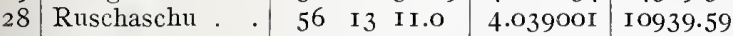

$\begin{array}{lllllll} & \text { Wikono I84 } & 4 \mathrm{I} & 3.0 & 4.328777 & \text { 2I3I9.50 }\end{array}$

\begin{tabular}{|l|l|lll|l|l|l|}
25 & Ngoma . . . & 288 & 49 & 51.5 & 3.88 & I 384 & 7609.99
\end{tabular}

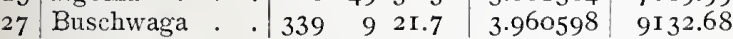

\section{Kontrollbasis Ost.}

Kontrollbasis-

\begin{tabular}{l|l|l|l} 
Entwickl. Punkt & $2 \mathrm{I}^{\circ} 4 \mathrm{o}^{\prime} 37^{\prime \prime} .8$ & 3.049770 & I I 2 I.42
\end{tabular}

\begin{tabular}{l|l|lll|l|l|l}
25 & Ngoma & . & 301 & 57 & 3.5 & 3.679195 & 4777.43
\end{tabular}

Kontrollbasis

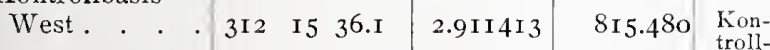

basis

direkt

gem.

Kontrollbasis West.

\begin{tabular}{|c|rcc|c|c|}
$\begin{array}{c}\text { Kontrollbasis- } \\
\text { Entwickl.Punkt } \\
\text { Kontrollbasis }\end{array}$ & $64^{\circ}$ & $7^{\prime}$ & $22^{\prime \prime} .0$ & 3.053536 & I I3 I.I9 \\
Ost . . . . . & I32 & I5 & 36.7 & 2.9 I I4 I 3 & 8 I 5.480
\end{tabular}

Kontrollbasis-Entwicklungspunkt.

\begin{tabular}{|c|c|c|c|}
\hline Os & $201^{\circ} 40^{\prime} 37^{\prime}$ & $3.04977^{\circ}$ & I I 2 I. 4 \\
\hline & & & \\
\hline ma. & $\begin{array}{rrr}288 & 23 & 5 \text { I. } \\
356 & 6 & 24.6\end{array}$ & $\begin{array}{l}3.672887 \\
3.870700\end{array}$ & $\begin{array}{l}4708.54 \\
758.10\end{array}$ \\
\hline
\end{tabular}

27. Buschwaga.

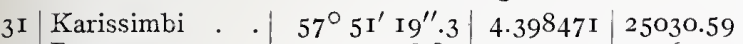

29 Rwagara . . . $702038.8 \quad 4.059390$ I I 465.42

28 Ruschaschu . . IOI I4 2 I.6 4.099807 I 2583.66

\begin{tabular}{l|l|l|lr|r|r|r|}
26 & Nkama * . . . & I 59 & 9 & 24.8 & 3.960598 & 91 32.68
\end{tabular}

Kontrollbasis-

\begin{tabular}{|l|lll|l|l|} 
Entwickl.Punkt & I 76 & 6 & 25.1 & 3.879790 & 7582.10 \\
\hline
\end{tabular}

\begin{tabular}{l|l|lll|l|l|}
25 & Ngoma. . . . & 213 & 2 & 15.5 & 3.860394 & 7250.94
\end{tabular}

28. Ruschaschu.

3I $\mid$ Karissimbi . . $\mid$\begin{tabular}{lll|l|l|}
$29^{\circ}$ & I $8^{\prime}$ & $\mathrm{o}^{\prime \prime} .3$ & 4.257308 & I 8084.56
\end{tabular}

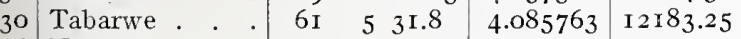
26 Nkama $\quad . \quad . \quad . \quad$\begin{tabular}{rrrr|r}
236 & I 3 & 2.4 & 4.03900 I & I 0939.59
\end{tabular}

\begin{tabular}{l|ll|lll|l|l|l|}
27 & Buschwaga . . 28I & I 4 & I 0.2 & 4.099807 & I 2583.66
\end{tabular}

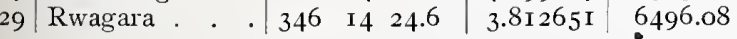

29. Rwagara.

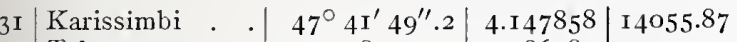

\begin{tabular}{|l|lll|ll|l|l|l}
30 & Tabarwe . . . & 9 I & 58 & 17.3 & 4.086984 & I 221 7.54
\end{tabular}

$\begin{array}{lllllllll}28 & \text { Ruschaschu . . } & \text { I66 } & \text { I } 4 & 26.0 & 3.8 \text { I 265 I } & 6496.08\end{array}$

\begin{tabular}{l|lllllllll}
26 & Nkama . . . & 2I I & 20 & 29.9 & 4.161654 & I 4509.56
\end{tabular}

\begin{tabular}{|l|l|l|l|l|l|l|}
27 & Buschwagd . . 250 & 20 & 29.0 & 4.059390 & I I 465.42
\end{tabular}

\begin{tabular}{l|l|c|c|c}
\hline \multirow{3}{*}{ Richtung nach } & Azimut & $\begin{array}{c}\text { Loga- } \\
\text { rithmen } \\
\text { der Ent- fernungen } \\
\text { fernungen } \\
\text { in m }\end{array}$ & in m & knt- \\
kun- & & gen \\
\hline
\end{tabular}

30. Tabarwe.

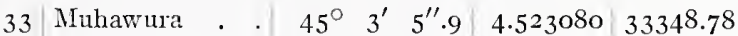

\begin{tabular}{l|llllllll}
35 & Kahira . . . & 63 & 3 & 32.4 & 4.706316 & 50852.90
\end{tabular}

$\begin{array}{lllllllll}34 & \text { Nianganga . . } & 66 & 38 & 46.4 & 4.697046 & 49779.01\end{array}$

\begin{tabular}{llllll|l}
32 & Jongojongo . . & 69 & 32 & 2.5 & 4.435326 & 27247.43
\end{tabular}

\begin{tabular}{l|l|r|r|r|r|r|}
28 & Ruschaschu . . $24 \mathrm{I}$ & 5 & 22.0 & 4.085763 & I 2183.25
\end{tabular}

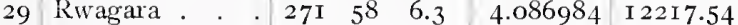

\begin{tabular}{lll|ll|l|l|l|l}
3 I & Karissimbi . . 349 & 35 & 54.2 & 4.002067 & I 0047.70
\end{tabular}

\begin{tabular}{rl|rrr|r|r|r|r} 
Magahinga : & 40 & 33 & 0.9 & 4.484283 & 30498.8 & Neben-
\end{tabular}

31. Karissimbi.

\begin{tabular}{l|l|l|l|l|l|} 
32. Jongojongo . . & $90^{\circ} 44^{\prime} 43^{\prime \prime} .0$ & 4.436862 & 27344.06
\end{tabular} \begin{tabular}{l|llll|l|l|l|l|}
30 & Tabarwe . . . & I69 & 35 & 55.7 & 4.002067 & I 0047.70
\end{tabular} 28 Ruschaschu . . 209 I 7 \begin{tabular}{ll|l|l}
52.4 & 4.257308 & I 8084.56
\end{tabular}

\begin{tabular}{l|l|lll|l|l|}
29 & Rwagara . . 227 & $4 \mathrm{I}$ & 4 & O.I & $4 . \mathrm{I} 47858$ & I 4055.87
\end{tabular}

\begin{tabular}{|l|l|lll|l|l|l|}
27 & Buschwaga . . & 237 & $5 \mathrm{I}$ & 0.6 & $4.39847 \mathrm{I}$ & 25030.59
\end{tabular}

32. Jongojongo.

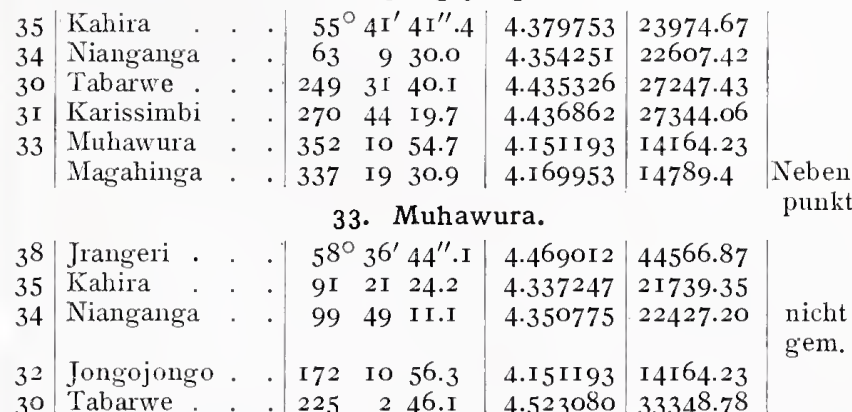

30 Tabarwe $\quad 2252246 . \mathrm{I} \quad 4.523080 \quad 33348.78$

34. Nianganga.

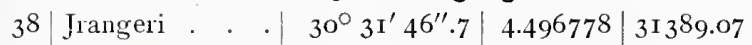

\begin{tabular}{l|l|lll|l|l}
37 & Kijogajoga . . & 59 & I 2 & 50.7 & 4.162063 & I 4523.23
\end{tabular}

36 Gikole. . . 63 I $856.9 \quad 4.168$ I 500 I 4726.5 I

\begin{tabular}{llllll|l|l|l}
32 & Jongojongo & 243 & 9 & $\mathrm{I} 3.4$ & $4.35425 \mathrm{I}$ & $\mathbf{2 2 6 0 7 . 4 2}$
\end{tabular}

30 'Tabarwe . . . $\quad$\begin{tabular}{llll|l|l}
246 & 38 & 7.5 & 4.697046 & 49779.01
\end{tabular}

\begin{tabular}{l|lllllll|l|l|}
33 & Muhawura &. & 279 & 48 & 53.6 & 4.350775 & $\mathbf{2 2 4 2 7 . 2 0}$
\end{tabular}

35 Kahira . . . $353 \quad 3448.4 \quad 3.52$ I 708 3324.36

35. Kahira.

\begin{tabular}{l|l|l|l|l|l|}
36 & Gikole . . . & $76^{\circ}$ I $5^{\prime}$ I $6^{\prime \prime} .2$ & 4.I 439 I I & I 3928.7 I
\end{tabular}

\begin{tabular}{l|ll|lll|l|l|}
34 & Nianganga & I & . . & 34 & 48.7 & 3.52 I 708 & 3324.36
\end{tabular}

\begin{tabular}{lll|lll|l|l|}
32 & Jongojongo . . 235 & 4 I & 25.2 & 4.379753 & 23974.67
\end{tabular}

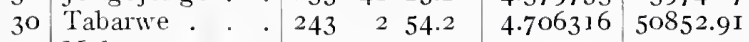

33 Muhawura . . 27 I 2I $37.2 \quad 4.337247$ 2I 739.35

36. Gikole.

\begin{tabular}{l|l|l|l|l|l|}
34 & Nianganga . . & $243^{\circ}$ I $8^{\prime} 46^{\prime \prime} .6$ & 4.168 Ioo & I 4726.5 I
\end{tabular}

35 Kahira . . . 256 I 5 5.7 4. 4 439 I I I 3928.7 I

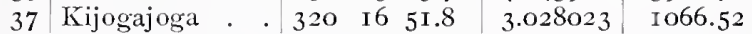

37. Kijogajoga.

\begin{tabular}{l|l|lll|l|l|}
38 & Jrangeri . . IO & $2^{\prime}$ & $8^{\prime \prime} .0$ & 4.299072 & I 9910.05
\end{tabular}

\begin{tabular}{|l|l|lll|l|l|}
36 & Gikole. . . . I 40 & I6 & 51.3 & 3.028024 & I 066.52
\end{tabular}

\begin{tabular}{l|l|l|l|l|l|}
34 & Nianganga . . 239 & I 2 & 41.0 & 4.162063 & I 4523.23
\end{tabular}

38. Jrangeri.

Rück

wärts-

$37 \mid$ Kijogajoga

34 Nianganga

\begin{tabular}{lll|l|l|l|l} 
& $190^{\circ}$ & $2^{\prime}$ & $5^{\prime \prime} .5$ & 4.299072 & I 9910.05 & $\begin{array}{c}\text { ein- } \\
\text { schnitt }\end{array}$
\end{tabular}

\begin{tabular}{lll|l|l}
238 & 36 & I 6.6 & 4.649012 & 44566.87
\end{tabular} nicht gem.

nich gem.

nicht gem. 


\section{Deutsche Uganda-Grenz-Expedition unter Hauptmann Schlobach.}

\section{Teil II. Längendifferenz Mombasa-Port Florence und astronomische und geodätische Arbeiten im Westen und am Nordufer des Victoria-Sees.}

Die Aufgabe der gemischten deutsch-englischen Kommission bestand in einer Feststellung und Vermarkung der vertragsmäßigen Grenzlinien im Norden und Nordwesten Deutsch-Ostafrikas. Diese Grenzen waren gegeben auf dem Westufer des Victoria-Sees durch den Schnittpunlit des I. Grad siidlicher Breite mit dem 30. Grad östlicher Länge von Greenwich. Von diesem Punlite aus bildet der I. Grad südlicher Breite bis zum Westufer des Sees die Grenze. Diese Linie durchschneidet den See bis zum Ostufer, wo sie dasselbe in der Nähe des Ortes Schirati trifft. Von hier aus bildet die Grenze eine schicfe Linie bis zu einem Punkt in der Landschaft Leitokitok am Nordabhang des Kilimandscharo. Dieser Punkt sollte zunächst als Endpunlit der Arbeiten angesehen werden, später kam noch der Befehl, daß dieselben bis zum Siidufer des Djipe-Sees weitergeführt werden sollten. Schließlich aber wurde auch noch durch die Landschaft Usambara eine Reihe von Dreiecken gelegt, die den Anschluß der gesamten Vermessung an Zanzibar crmöglichten. Es ist auf diese Weise eine Verbindung der Längenbestimmung, welche Prof. Lamp in Usumbura ausfuilhrte, mit der Länge von Zanzibar, welche von Sir David Gill bei Gelegenheit der Verbindung der Cap-Sternwarte mit Aden und Greenwich erhalten worden war, hergestellt. Ebenso ist aber auch die Längenbestimmung, welche, wie gleich zu erwähnen ist, auf telegraphischem Wege von Mombasa nach Port-Florence ausgeführt wurde, durch das Dreiecksnetz zwischen Port-Florence, Schirati und Zanzibar kontrolliert. Die Gesamtarbeiten, welche die Uganda-Grenz-Expcdition ausführte, erstrecken sich also von dem mehrfach erwähnten Schnittpunkte um das Nordufer des Victoria-Sees herum bis nach Zanzibar, eine Ausdehnung der Dreiecksnetze von nahezu $\mathrm{I} 800 \mathrm{~km}$. Die eigentlichen Arbeiten zerfallen demnach in folgende Abteilungen: Triangulierung vom Schnittpunkte" bis zur Mündung des Kagera-Flusses am Westufer des Sees. Darauf Verbindung dieses Punktes mit Entebbe am Nordufer des Sees durch eine Dreieckskette; Verbindung von Entebbe mit Port-Florence einmal durch eine Dreieckskette, welche die Engländer vermaßen, und zweitens durch Zeitubcrtragung vernittelst Chronometerreisen zwischen beiden Punkten (deutsche Kommission).
Weiterhin Verbindung von Port-Florence nit Schirati durch eine Dreieckskette und Verbindung von Schirati mit Zanzibar durch Dreieckskette und Verbindung von Port-Florence mit Mombasa durch telegraphische Übertragung. DieLängendifferenzzwischen Mombasa und Zanzibar ist früher schon durch Arbeiten der englischen Marine mittels Zeituibertragung durch Chronometer bestimmt worden. Außer den zu dicsen Arbeiten erforderlichen ausgedehnten trigonometrischen Aufnahmen, die später ausführlich zur Darstellung gelangen sollen, wurden an einer größeren Anzahl von Punliten astronomische Beobachtungen sowohl zur Breitenbestimmung als auch zur Beschaffung der Grundlage für die Bestimmung der Längendifferenz ausgeführt. Es ist somit eine Reilhe von Kontrollen für die Dimensionen des Dreiecknetzes und die dadurch geodätisch errechneten geographischen Positionen dureh astronomische Beobachtungen geliefert worden, welche ihrerseits nicht nur eine Beurteilung der Genauigkeit der ausgeführten Arbeiten, sondern bis zu einem gewissen Grade auch einen Anhalt fuir etwa in dem Arbeitsgebiet vorhandenen Lotstörungen gestatten. Die Arbeitsleistung der Expedition ist eine ganz außergewöhnliche, wenn man die Größe des Gebictes beachtet und die verhältnismäßig geringe Anzahl der Beobachter in Betracht zieht. Die Expedition setzte sich zusammen auf deutscher Scite aus:

I. Kommissar und Leiter Hauptmann Schlobaeh,

II. Kommissar Oberleutnant Schwartz,

III. Konmissar Oberleutnant WeiB,

Feldwebel Buchner, Sergeant Müneh, Vermessungstechniker Dannert, 40 Askaris und etwa 250 Träger,

auf englischer Seite aus:

Leiter Leutnant Colonel Radeliffe,

Major Bright,

Captain Harman,

Leutnant Behrens,

Sergeant Major Rehm, Arzt, Naturkundiger als Sammler (Dogget), Eskorte-Offiziere, I 20 Askari (meist Sudanesen), mehrere indische Heliographisten (Shiks) und etwa 400 Träger.

An Instrumenten standen der deutschen Expedition im Laufe ihrer Arbeiten zur Verfügung: 
3 Universalinstrumente von Wanschaff,

I von Bamberg,

2 Theodolite von Sprenger,

I kl. Universalinstrument von Hildebrand und

I Durchgangs-Instrument von G. Heyde, welches aber nicht zur Verwendung kam.

Chronometer Delolme 843, Sternzeit gebend,

\begin{tabular}{|c|c|c|c|c|}
\hline , & Molyneux I948 & " & & ", \\
\hline & Hohwü 426 & ," & & , \\
\hline & Bröcking $\mathrm{I} 37 \mathrm{I}$, & Mittl. & Zeit & rebend \\
\hline , & Ehrlich 830 & ", & , & 8 \\
\hline & Knoblich 2346 &, & ", & $"$ \\
\hline , & Reid u.Sons 4 I 75 & ," & " & ", \\
\hline & 1213 & ," &, & ," \\
\hline
\end{tabular}

Taschenchron. Schlesiky I $3962 \quad, \quad, \quad$,

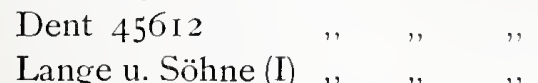

, (II) , , , , ,

" (III) Sternzeit gebend,

" iiblichen meteorologischen "Instrumente.

und die ïblichen meteoren Instrumente.
Dazu kamen die nötigen Meßtische mit Zubehör.

\section{A. Verbindung des Punktes Port Florence mit Mombasa durch telegraphische Längenübertragung.}

Während Hauptmann Herrmann von der KiwuExpedition auf der Rückreise sich befand, waren die Verhandlungen mit der britischen Regierung soweit gediehen, daß die Grenzmessungen zwischen BritischUganda und den nordöstlichen Gebieten DeutschOstafrikas begonnen werden konnten. Demgemäß wurde deutscherseits der Hauptmann Schlobach beauftragt, sich nach dem Schnittpunkte des I. Grads südlicher Breite mit dem 30. Grad östlicher Länge zu begeben, dort mit dem Oberleutnant Schwartz zusammenzutreffen und die nötigen Anschlußbeobachtungen in der Nähe des erwähnten Punktes vorzunehmen. Bevor noch diese Arbeiten von der Expedition begonnen werden konnten, wurde der Arbeitsplan geändert und zunächst die Bestimmung der Längendifferenz zwischen einem geeigneten Punkte am Victoria-See und dem Küstenplatz Mombasa, dem Ausgangspunkt der Uganda-Bahn, in Angriff genommen. Als Ort am Victoria-See wurde Port Florence, der Endpunkt der UgandaBahn, gewählt. Es war somit die erste Arbeit der Uganda-Grenz-Expedition die Ausführung der für eine solche Längenbestimmung nötigen astronomischen Beobachtungen. Diejenigen Beobachtungen zur Längenübertragung, welche später zur Verwendung kamen, fanden an vier Abenden im September und Oktober I902 statt. Im September beobachtete die deutsche Kommission in Mombasa und die englische in Port Florence, im Oktober fand ein Wechsel der Beobachter statt, um dieGenauigkeit der Bestimmungen zu erhöhen, und es beobachtete dann die englische Kommission in Mombasa und die deutsche in Port Elorence. Der Vorgang bei dieser Bestimmung war der folgende:

Da auf der Uganda-Bahn die telegraphischen Übermittlungen nicht mit Benutzung von Morseapparaten erfolgten, so mußten die gegebenen Signale, welche zur Vergleichung der Uhren in Mombasa gegeben wurden, mittels des Gehörs aufgenommen werden. Dieser Umstand hat viel dazu beigetragen, daß die erzielte Genauigkeit nicht ganz so groß gewesen ist, als es eine telegraphische Zeitübertragung erwarten ließ. Weiterhin kommt dabei in Betracht, daß die erforderlichen Zeitbestimmungen von den beiderseitigen Kommissaren nicht in gleicher Weise ausgeführt werden konnten, da die Ausrüstung mit Instrumenten eine ungleiche war. Die deutschen Kommissare hatten zwar ein Durchgangsinstrument zur Verfügung, doch wurde dasselbe auf Wunsch der Engländer zur Zeitbestimmung nicht benutzt, sondern es wurden die Uhrstände aus Messungen von Zenithdistanzen in der Nähe des Ost- und Westvertikals bestimmt. Die englischen Kommissare benutzten dazu das Verfahren der Beobachtung gleicher Höhen zweier Sterne im Osten und Westen. Wenn so auch die Methode der Zeitbestimmung der beiden Beobachtungsabteilungen nahezu identisch war, so konnte selbst bei der Sorgfalt, mit welcher die betreffenden Beobachtungen jeden Abend, an welchem ein Zeichenwechsel möglich war, ausgeführt wurden, doch nicht dieselbe Genauigkeit erlangt werden, welche die genaueren Beobachtungen im Meridian mit Leichtigkeit ergeben hätten. Wenn es bei diesemStand der Dinge auch nicht erforderlich gewesen wärc, daß zur Eliminierung der persönlichen Auffassungsfehler der Beobachter ein Wechsel dersclben stattgefunden hätte, so hat dieser doch insofern zur Genauigkeit des Resultates beigetragen, als sich bei scharfer Durchrechnung der Beobachtungen ein gewisser systematischer Unterschied zwischen den beiden Beobachtungssystemen nicht ganz verkennen läßt.

Die deutschen Kommissare haben sich in die Ausführung der Arbeiten an einem Beobachtungsabend in der Weise geteilt, daß regelmäßig Hauptmann Schlobach die vor und nach dem Signalwechsel notwendigen Zeitbestimmungen ausführte und Oberleutnant Schwartz das Geben und den Empfang der Signale besorgte. Über die Arbeitsweise, welche die eng]ischen Kommissare anwandten, ist mir nichts Näheres bekannt geworden. Zur Erläuterung des Verfahrens mögen hicr die Arbeiten an dem ersten 
vollgültigen Beobachtungsabend, am 2O. September 1902, angegeben werden:

Nachdem Hauptmann Schlobach sowohl im Osten als im Westen Sterne zur Zeitbestimmung erhalten hatte, wurden etwa eine halbe Stunde danach, nachdem das sichere Funlitionieren der Telegraphenlinie festgestellt war, durch Oberleutnant Schwartz Signale in der Weise gegeben, daB von einer ganzen Minute beginnend 5 Minuten lang jede zehnte Sekunde ein Signal nach Port Florence gesandt wurde. Zur Identifizierung der einzelnen signale wurde die 50. Sekunde jeder Minute übersprungen, so daB im ganzen 26 Signale ïbermittelt wurden. Davon sind schlieblich die beiden ersten jedesmal nicht benutzt worden, da sie noch als unsicher erschienen. Das Geben der Signale erfolgte nach dem Chronometer wolyneux. Nach etwa Io Minsiten wurle von Port Florence aus ein gleicher Satz von Signalen nach dem dortigen Standchronometer Dent I 212" nach Mombasa gegeben. Oberleutnant Schwartz empfing diese Signale mittels des Taschenchronometers: Schlesiky Nr. 808I", nachdem dieses mit dem Standchronometer Molyneux genau verglichen war. Einige Zeit darauf gab wiederum Oberleutnant Schwartz 5 Minuten lang (26) Signale nach dem Chronometer Molyneux an Port Florence. Darauf erfolgte wiederum eine Signalabgrabe von Port Florence nach
Mombasa, die mit dem deutschen Taschenchronometer Schlesily aufgenommen wurde. Nach Schluß eines solchen viermaligen Signalwechsels hat Hauptmann Schlobach wiederum eine Zeitbestimmung ausgeführt. Diese Zeitbestimmungen bestehen meist aus je zwei oder vier vollen Sätzen vor und nach dem Signalwechsel. Die Genauiglieiten, welche die Zeitbestimmungen geben, dürften $\mathrm{zu}$ etwa \pm 0.05 Zeitselunden anzunehmen sein. An den drei anderen Abenden wurde in gleicher Weise verfahren, nur wurden an den beiden Abenden im Olitober die Signale in Port Florence direkt am ChronometerDent beobachtet. An einigen dazwischen liegenden Abenden wurden wohl noch Beobachtungen ausgefüilnt und Signale ausgetauscht, doch sind diese Daten zur Ableitung der Endresultate nicht benutzt worden, da die Beobachter selbst mitteilen, daß durch ungünstige Witterung nur unvollständige Zeitbestimmungen erhalten wurden und wegen häufiger Störungen auf der Telegraphenlinie den Signalen kein Zutrauen ge. schenkt werden darf. Es bleiben danach nur die vollständigen Beobachtungsabende 2O. und 2I. September und I8. und 28. Oktober übrig. Die genauen Rechnungen, welche auf Grund des vorliegenden Materials durchgefüht wurden, finden sich auf den nachfolgenden Seiten.
1902 September 20.

Ableitung des Uhrstandes und Uhrganges.

Chron. Molineux I948. Sept. 20.

\begin{tabular}{cccccc} 
& \multicolumn{4}{c}{ Ulirzeit } & \multicolumn{3}{c}{$\Delta \mathrm{ul}$} \\
& $\mathrm{h}$ & $\mathrm{m}$ & $\mathrm{h}$ & $\mathrm{m}$ \\
& $2 \mathrm{I}$ & $22.8+2$ & 32 & $24.52 \mathrm{~W}$ \\
& 22 & $\mathrm{I} .4+2$ & 32 & $23.82 \mathrm{O}$ \\
\hline Mittel & $2 \mathrm{I}$ & $42 . \mathrm{I}+2$ & 32 & $24 . \mathrm{I} 7$
\end{tabular}

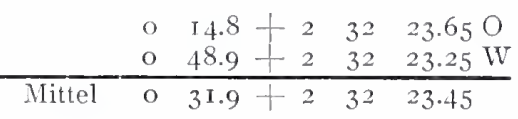

Also zur Ableitung des Ganges:

In $2^{\text {h }} 50^{\mathrm{m}}$ Diff. $\Delta u=-0.72$ daraus $\delta \mathrm{u}$ fü $\mathrm{I}^{\mathrm{m}}=-\mathbf{0 . 0 0 5}$

Differenz der Uhrangaben Molineux ind Schlesiky:

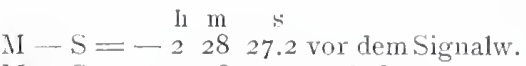
$\mathrm{M}-\mathrm{S}=-\begin{array}{lll}2 & 28 & 27.0 \text { nach dem }\end{array}$

Mittel $=-228$ 27.I

*) Reduktion der Sternzeit im Mittl. Mittag Greenwich anf Sternzeit im M. M. Mombasa: - 26s.o8.

\section{Daten des Signalwechsels.}

Mombasa (deutsclie Beob)

Mittel der Signale, Uhrzeit Schl.

- $22827.10-280$

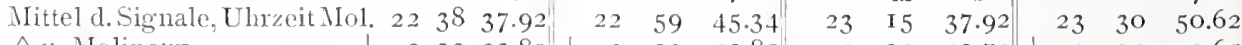
\begin{tabular}{lr}
$\Delta u$ Molineux & $+\quad 3223.89+2 \quad 32 \quad 23.80$ \\
\hline
\end{tabular}

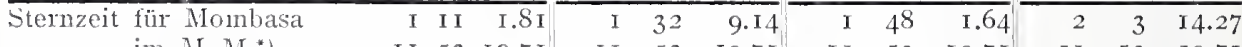

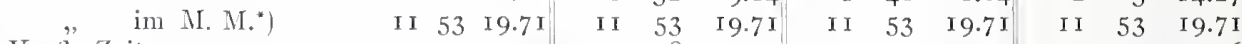

$\begin{array}{lllllllllllll}\text { Verfl. Zeit } & \text { I3 } & \text { I } 7 & 42.10 & \text { I3 } & 38 & 49.43 & \text { I3 } & 54 & 4 \text { I.93 } & \text { I4 } & 9 & 54.56\end{array}$ \begin{tabular}{lllll} 
Reduktion auf mittl. Zeit - $\quad 2$ & 10.69 & 2 & I 4.I5 \\
\hline
\end{tabular}

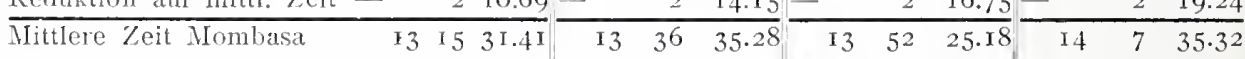

Pt. Florence (engl. Beob.).

\begin{tabular}{|l|ll|lll|llllll} 
Mittel der Signale nach Dent & IO 50 & 34.28 & I I & I I & 37.92 & I I & 27 & 28 . I 5 & I I & 42 & 37.92
\end{tabular}

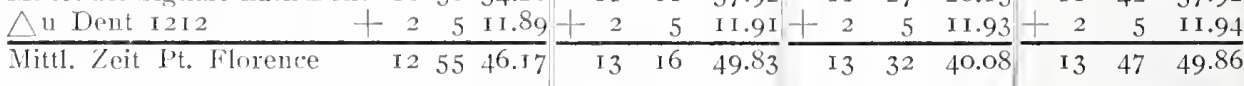
Diff. d. mittl.Zeiten $=\triangle \lambda=\begin{array}{lllllllllllll}\text { o } & \text { I9 } 45.24 & \text { o } & \text { I9 } & 45.45 & \text { o } & \text { I9 } & 45 . \text { IO } & \text { o } & \text { I9 } & 45.46\end{array}$

Beobachtung der Koinzidenzen.

Mombasa, Uhrzeit Sch1.

Reduktion anf Mol.

Ulirzeit $\mathrm{Mol}$

\begin{tabular}{rrr|rrrrrrrr}
36 & 10.0 & 23 & I & 57.9 & 23 & I 7 & 20.0 & 23 & 32 & 27.9
\end{tabular}

\begin{tabular}{|c|c|c|c|c|c|c|c|c|c|c|c|c|}
\hline$\triangle$ u Mol. & 2 & 32 & 23.90 & 2 & 32 & 23.80 & $\begin{array}{l}3 \\
2\end{array}$ & 32 & $23.7 \mathrm{I}$ & 0 & 32 & 23.66 \\
\hline Sternzeit Mombasa & I & 8 & 33.90 & I & 34 & $21.7 \mathrm{O}^{\prime}$ & I & 49 & $43.7 \mathrm{I}$ & 2 & 4 & I. 56 \\
\hline.$\quad$ im mittl. M. & II & 53 & I $9.7 \mathrm{I}$ & I I & 53 & $19.7 \mathrm{I}$ & I I & 53 & I $9.7 \mathrm{I}$ & I I & 53 & $9.7 \mathrm{I}$ \\
\hline Verfl. Zeit & I3 & 15 & 14. 19 & I 3 & $4 \mathrm{I}$ & I.99 & I 3 & 56 & 24.00 & 14 & I I & . \\
\hline Reduktion auf mittl. Zeit - & & 2 & I0.28 & - & 2 & I. $4.5 \mathrm{I}$ & - & 2 & 17.02 & & 2 & 19.50 \\
\hline Mittl. Zeit Mombasa & I3 & I3 & $\overline{3.91}$ & I3 & 38 & $47 \cdot 48$ & I3 & 54 & 6.98 & I4 & 9 & 2.3 \\
\hline Pt.Florence, Uhrzeit Dent & IO & 48 & 7.0 & I I & 13 & & I I & 29 & & II & 44 & \\
\hline$\triangle u$ Dent & 2 & 5 & II.89 & + & 5 & II.9I & $+\quad 2$ & 5 & I I .93 & 2 & 5 & 1.9 \\
\hline Mittl. Zeit Pt. Florence & 12 & 53 & 18.89 & I3 & I9 & $\overline{I .9 I}$ & I3 & 34 & 21.93 & I3 & 49 & 26 \\
\hline Diff. d. mittl. Zeiten $=\Delta \lambda=$ & $\mathrm{O}$ & 19 & 75.02 & o & I9 & .57 & o & 19 & 45.05 & o & 19 & \\
\hline
\end{tabular}




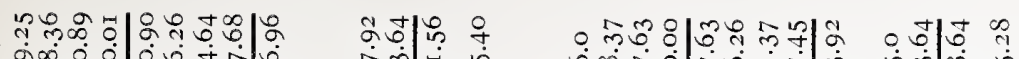

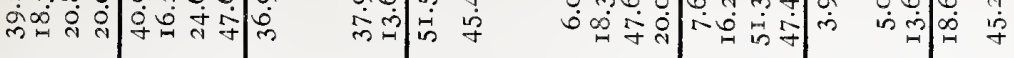

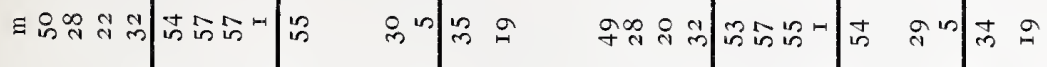

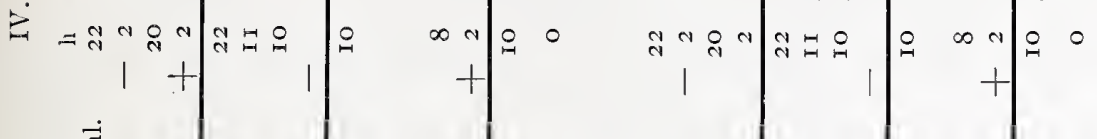
द्यु

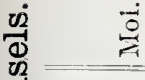

is

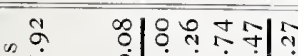

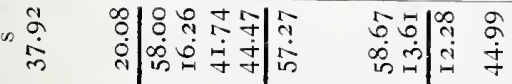

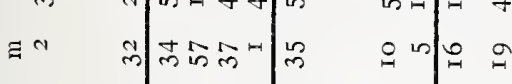

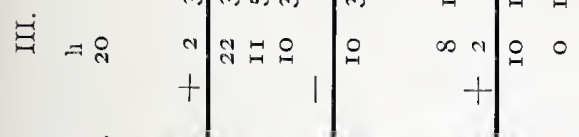

कि कि

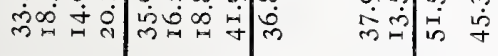

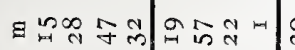

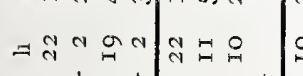

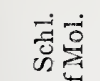
可

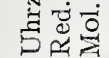
in - 190

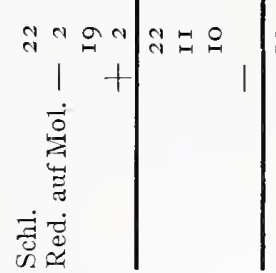

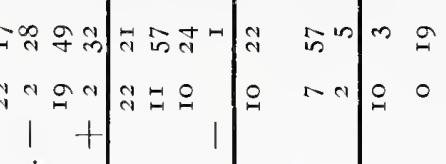
थ

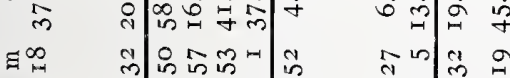
$=9$ तो $=0$ व $\mathrm{Na} / \mathrm{O} O$ 횽 $\rightarrow \infty$ 总

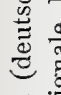

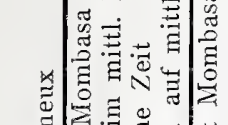
等

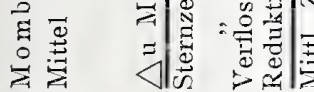

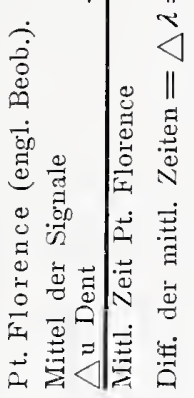

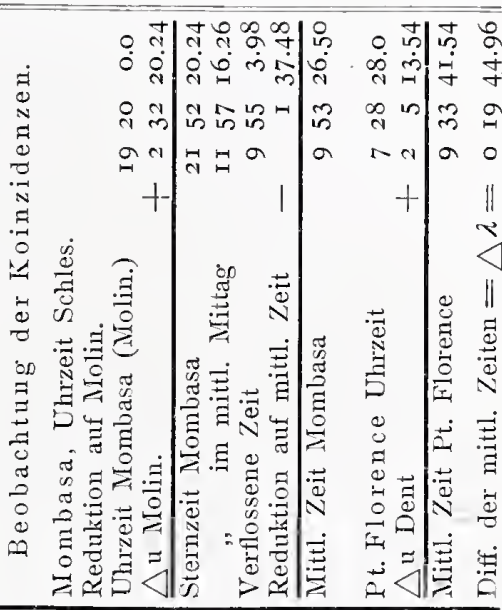

\section{(1)}

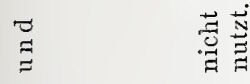

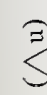

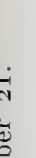
م-1

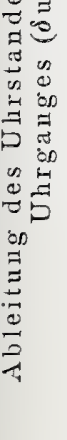

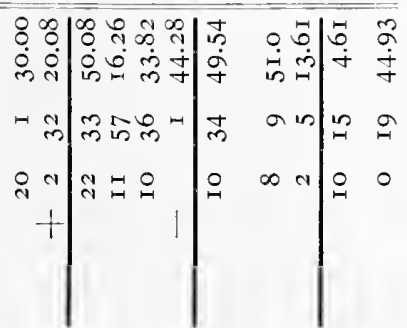

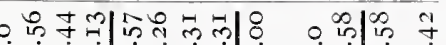

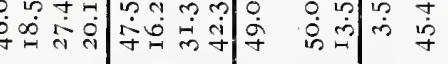
$+$
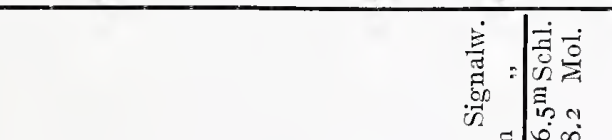

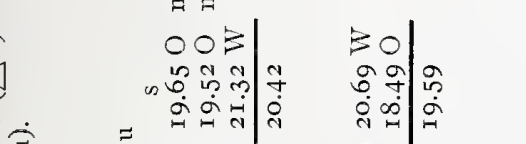

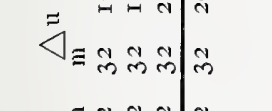

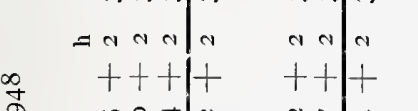

空

青

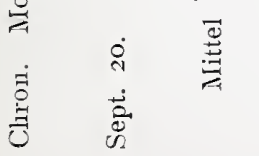

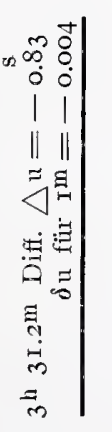

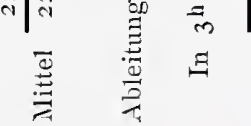

$\stackrel{\Xi}{v}$

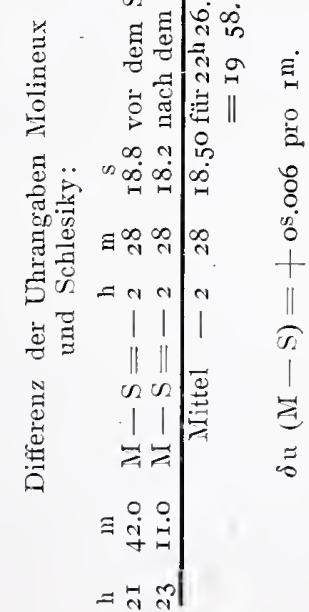

Mitteilungen a. d. D. Schutzgebieten, XX. Band. IV.
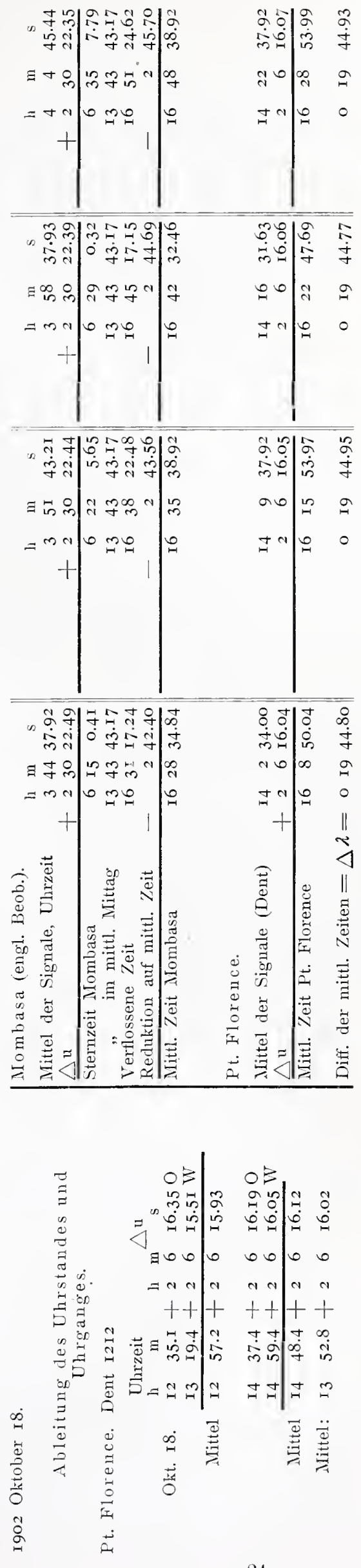


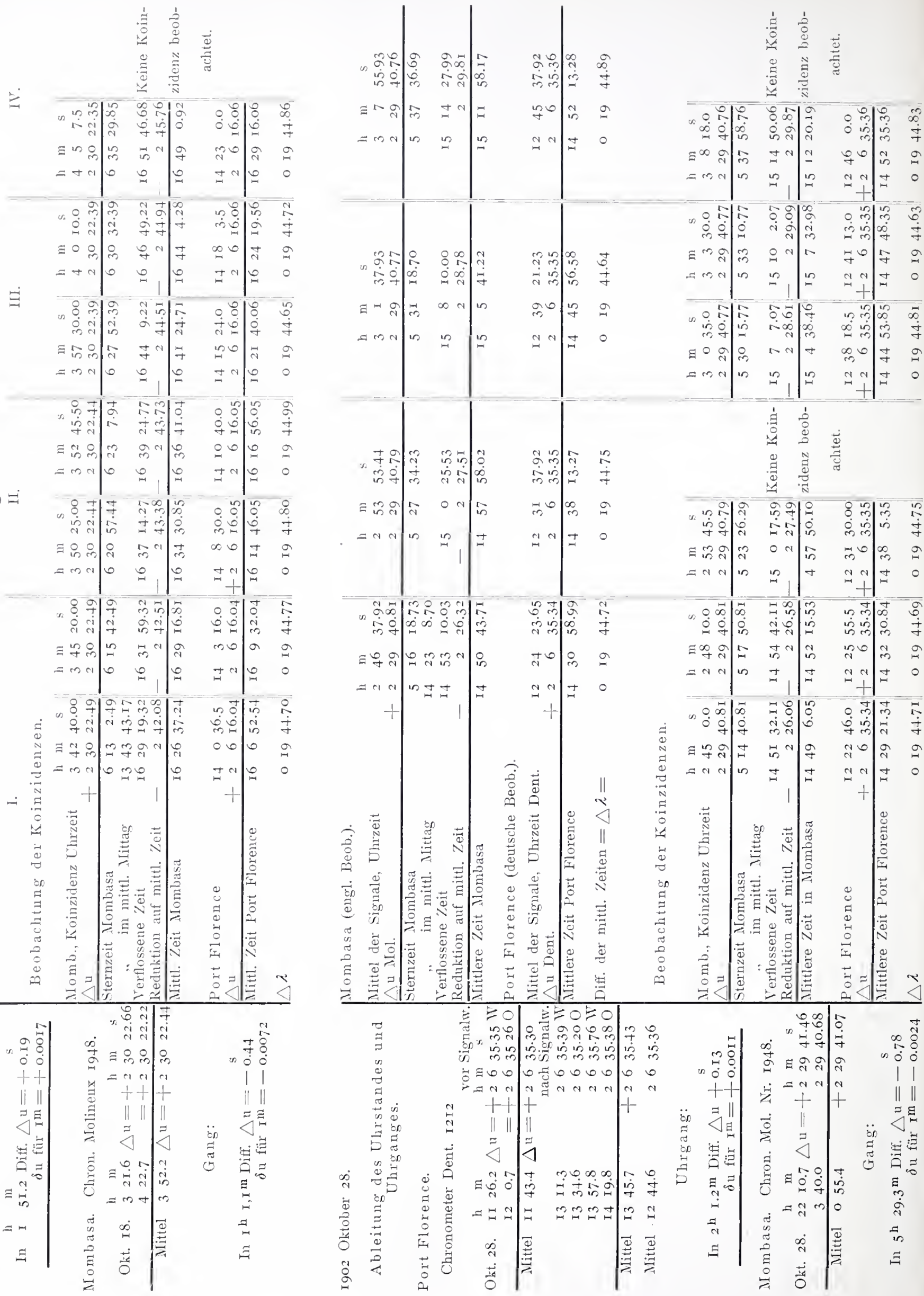


Längendifferenz Mombasa-Port Florence: Zusammenstellung der Resultate der einzelnen Tage.

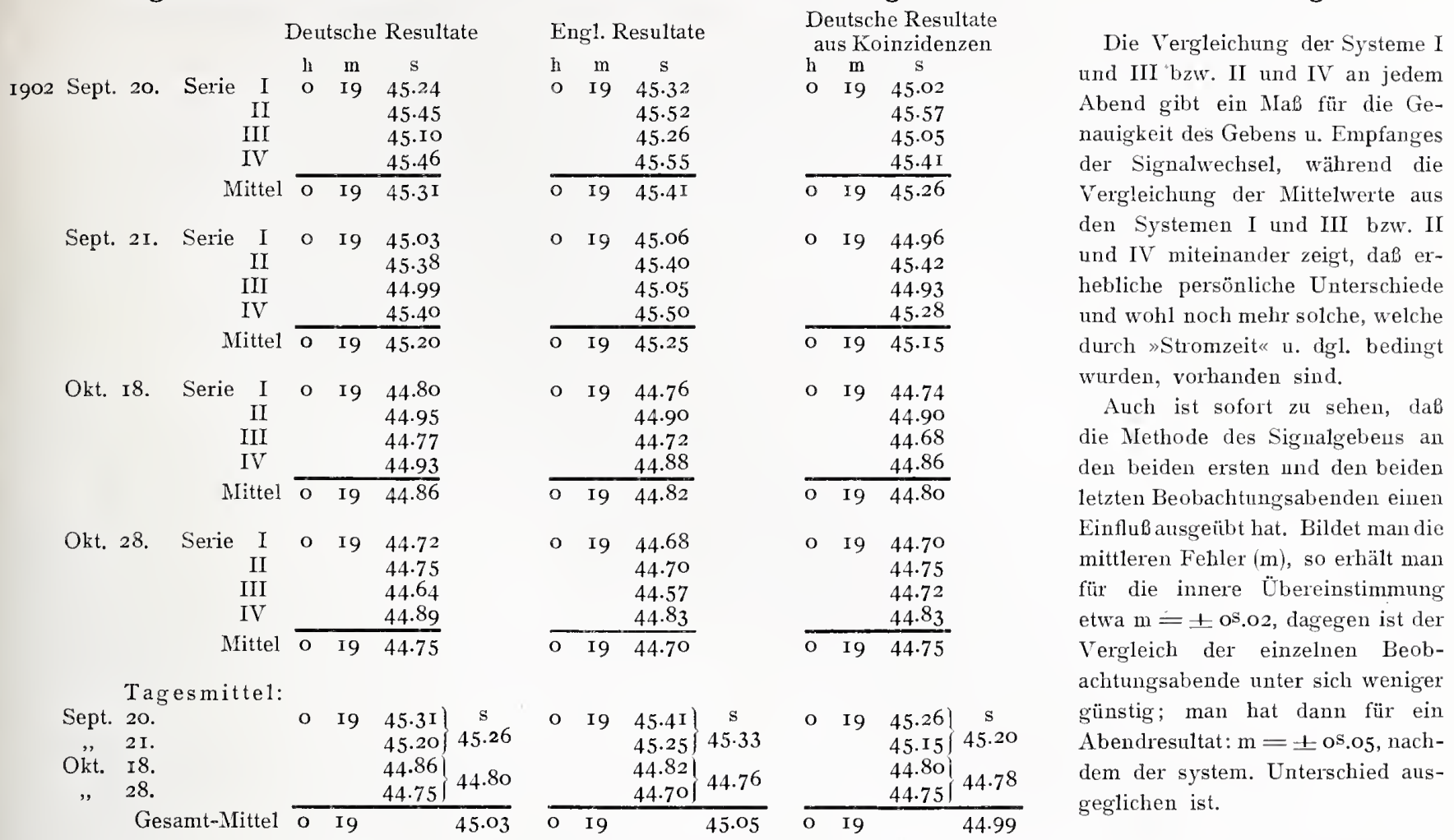

Wird die aus dem telegraphischen Signalwechsel abgeleitete Längendifferen $z$ im Betrage von

$$
\left.\mathrm{O}^{\mathrm{h}} 19^{\mathrm{m}} 45^{\mathrm{s}} .03=4^{\circ} 56^{\prime} 15^{\prime \prime} .45^{1}\right)
$$

an die den neuesten Bestimmungen entsprechende Länge von Mombasa angebracht, ${ }^{2}$ ) so erhält man

$$
\begin{aligned}
& \lambda \text { Mombasa: } \quad 2^{\mathrm{h}} 3^{8 \mathrm{~m}} 44^{\mathrm{s}} .74=39^{\circ} 4 \mathrm{I}^{\prime} 4^{\prime \prime} .9 \\
& \triangle \lambda \text { Mombasa- } \\
& \quad \text { Port Florence: } \mathrm{O}^{\mathrm{h}} 19^{\mathrm{m}} 45^{\mathrm{s}} .03=4^{\circ} 56^{\prime} 15^{\prime \prime} .45
\end{aligned}
$$
somit $\lambda$ Port Florence: $2^{\mathrm{h}} \mathrm{I} 8^{\mathrm{m}} 59^{\mathrm{s}} \cdot 7 \mathrm{I}=34^{\circ} 44^{\prime} 49^{\prime \prime} \cdot 45$.

Aus der Gesamtheit sämtlicher Beobachtungsresultate läßt sich sowohl mit Rücksicht auf den Wechsel der Beobachter als auch für die eine oder

1) Dieser Wert ist den beigegebenen Tabellen entnommen, welche die Einzelheiten der Berechnungen der Längendifferenz enthalten. Es sind in denselben auch die englischen Daten, welche mir durch die Güte des Herrn Cpt. Behrens zugänglich gemacht wurden, einer nochmaligen Durchrechnung unterzogen worden, nachdem im einzelnen von den richtigen Werten der Reduktion der Sternzeiten im Mittl. Mittag Gebrauch gemacht wurde. Aufserdem sind auch die Resultate aus den während der Signalwechsel beobachteten "Koinzidenzen" der Uhren mit berechnet worden, was bisher unterlassen worden war. Die Genauigkeit der letzteren scheint geringer zu sein, und ich habe daher die drei Resultate, von denen die beiden ersteren nur dadurch einen kleinen Unterschied aufweisen, dafs bei meiner Berechnung die Uhrgänge etwas anders abgeleitet wurden, in der Weise miteinander verbunden, dafs ich dem Koinzidenzwert nur das Gewicht $1 / 3$ beilegte. So entstand das oben angefiihrte Resultat.

$\left.{ }^{2}\right)$ Länge von Mombasa nach Angabe des englischen Kommissars. die andere Periode ein mittlerer Fehler ableiten, und wenn man annimmt, daß durch den Beobachterwechsel selbst systematische Verschiedenheiten aus dem Resultat eliminiert worden sind, so kann man die Genauigkeit des erlangten Resultates für dieLängendifferenz unter Berücksichtigung aller Umstände auf etwa \pm 0.2 bis \pm 0.3 Zeitsekunden einschätzen. Diese Unsicherheit ist in Anbetracht der gesamten Verhältnisse, unter welchen diese Beobachtungen ausgeführt wurden, eine recht geringe, und es ist mit Ausnahme der Längenbestimmungen am Njassa, wie sie mit Hilfe der Astronomen der Kapsternwarte von Prof. Kohlschütter ausgeführt wurden, wohl eine der sichersten astronomischen Längenbestimmungen, die wir in Zentralafrika besitzen.

\section{B. Chronometer-Reisen Port Florence-Entebbe und Triangulation am Nordufer des Sees.}

Um das Resultat der Längenbestimmung von PortFlorence mit demjenigen der Kiwu-See-Expedition in Verbindung $z u$ bringen und damit eine sichere Kontrolle für den mehrfach erwähnten Schnittpunkt des I. Grades südlicher Breite mit dem 30. Grade östlicher Länge zu erhalten, wurde von Port Florence aus eine weitere Längenübcrtragung nach Entebbe unternommen. Dieses geschah auf zwei verschiedenen Wegen. Zunächst dadurch, daß einc Zeitübertragung vermittels Chronomcter-Reisen von Port Florence nach Entebbe und zurück ausgeführt wurde, zweitens 
aber auch durch eine un das ganze Nordufer des Victoria-Sees herum geführte Dreieckskette. Die Chronometer-Reisen wurden in den Tagen November ro. bis I2., 20, bis 22, und 24. bis 26. von dem deutschen Kommissar Oberleutnant Schwartz und dem englischen Leutnant Behrens ausgeführt. Es stand den Kommissaren eine größere Anzahl von Chronometern und Taschenuhren zur T'erfügung. Leider war für die Zwecke der Reisen kein besonderer Dampfer verwendbar, und die Offiziere mußten den regelmäßig verkehrenden Gouvernementsdampfer Mackinon benutzen, dessen Fahrten aber an bestimmte Zeiten gebunden waren. Es war deshalb nicht immer möglich, die Reisen dann anzu stellen, wann gerade zuverlässige Zeitbestimmungen erhalten waren. Dieser Umstand bedingte es, daß die Gänge der Chronometer einen etwas größeren Einfluß auf das Resultat hatten, als es sonst der Fall gewesen wäre. Der Vorgang bei dieser Zeitübertragung war der folgende:

Sowohl in Port Florence als auch in Entebbe wurden während der ganzen Arbeiten dieselben Chronometer als Stand-Chronometer benutzt, und zwar in Port Florence das Mittlere Zeitchronometer Arnold \& Dent I2r2 und in Entebbe das Sternzeitchronometer. Hohwü +26\%. Auf diese beiden Uhren wurden die Zeitbestimmungen bezogen, und ihre Stände wurden durch die auf dem Schiffe hin und her geführten Uhren miteinander verglichen. Die Gänge der Standchronometer haben sich im allgemeinen zur Zufriedenheit gehalten, nur bei dem Chronometer Hohwü 426 in Entebbe zeigte sich am 20. November ein plötzlicher Sprung. Die Ursache dieser Erscheinung dürfte die sein, dab an jenem Tage in Entebbe das Observatorium umgebaut wurde und auBerdem am selben Tage in nächster Nähe des Chronometers ein Blitz einschlug. Die Uhrvergleichungen zwischen den Reisechronometern und den Standchronometern fanden in der Weise statt, dab alle Io Sekunden zuerst mach dem Standchronometer und später nach dem Reisechronometer Klopfsignale gegeben wurden, deren Momente von einer zweiten Person am anderen Chronometer entsprechend abgelesen wurden. Aus diesen Signalen sind die Mittelwerte abgeleitet und sodann die Uhrstände in solche gegen mittlere Zeiten oder Sternzeiten, je nach Bedarf, umgerechnet worden. Wie oben bemerkt, sind im ganzen drei solcher Reisen ausgefuhrt worden. Die Einzelheiten der Uhrvergleichungen sowohl, wie die weiteren Daten über diese Arbeiten werden in den nachfolgenden Tabellen gegeben, soweit das zum Verständnis des Ganges der Rechnungen nötig erscheint.
Als Schlubresultat der vorstehenden Berechnungen erhält man den $\mathrm{IV}^{\top} \mathrm{crt}$

$\therefore \lambda$ Port Florence-Entebbe zu $9^{\mathrm{m}} 6^{\mathrm{s}} .7$

für den Fall, daB man sämtliche Uhren in Betracht zieht. Nun sind aber die Taschenuhren Lange I bis + nur auf der zweiten und dritten Reise benutzt worden, es dürfte deshalb zweckmäbig sein, den aus ihnen erhaltenen Werten geringeres Gewicht beizulegen. Geschieht das, so erhält man aus den Chronometern und den Lange-Uhren den Wert

$\Delta \lambda$ Port Florence-Entebbe $9^{\mathrm{m}} 6^{\mathrm{s}} .8$.

Werden die Taschenuhren ganz ausgeschlossen, so ergibt sich für die gesuchte Längendifferenz

$\Delta \lambda$ Port Florence-Entebbe $9^{\mathrm{m}} 6^{\mathrm{s}} .9 \mathrm{~S}$

mit einem mittleren Fehler von etwa +0.4 ZeitSekunden.

Man wird also nicht um mehr als höchstens os.2 bis os.3 fehl gehen, wenn man in runder Zahl für die Länğendifferenz

Port Florence-Entebbe (Observatorium) ansetzt

$\Delta \lambda=9^{\mathrm{m}} 6^{\mathrm{s}} .9 \pm 0^{\mathrm{s}} .2=2^{\circ} \mathrm{I}^{\prime}+3^{\prime \prime} .5 \pm 6^{\prime \prime}$.

Diese Längendifferenz bezieht sich für Entebbe auf den Ort des Observatoriums.

Die von seiten der englischen Kommissare ausgeführte Triangulation um das Nordufer des VictoriaSees lieferte eine Kontrolle der Chronometerlänge. Diese Triangulation beginnt in Port Florence an dem auch für die Chronometerübertragung gültigen Endpunkt. Auf der Station Entebbe fallen der astronomische und der trigonometrische Stationspunkt aber nicht zusammen. Zu ihrer Verbindung wurde cine kleine Triangulation ausgefüht, die auf einer in der Nähe des astronomischen Observatoriums gemessenen Basis beruht. (Vergleiche Skizze 3.)

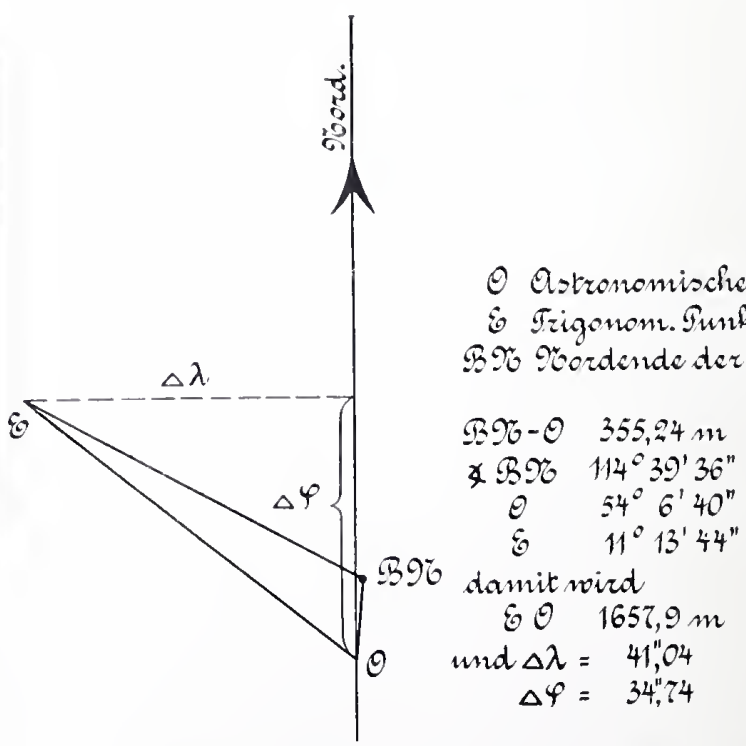

Skizze 3. Übertragung der Koordinaten in Entebbe. 


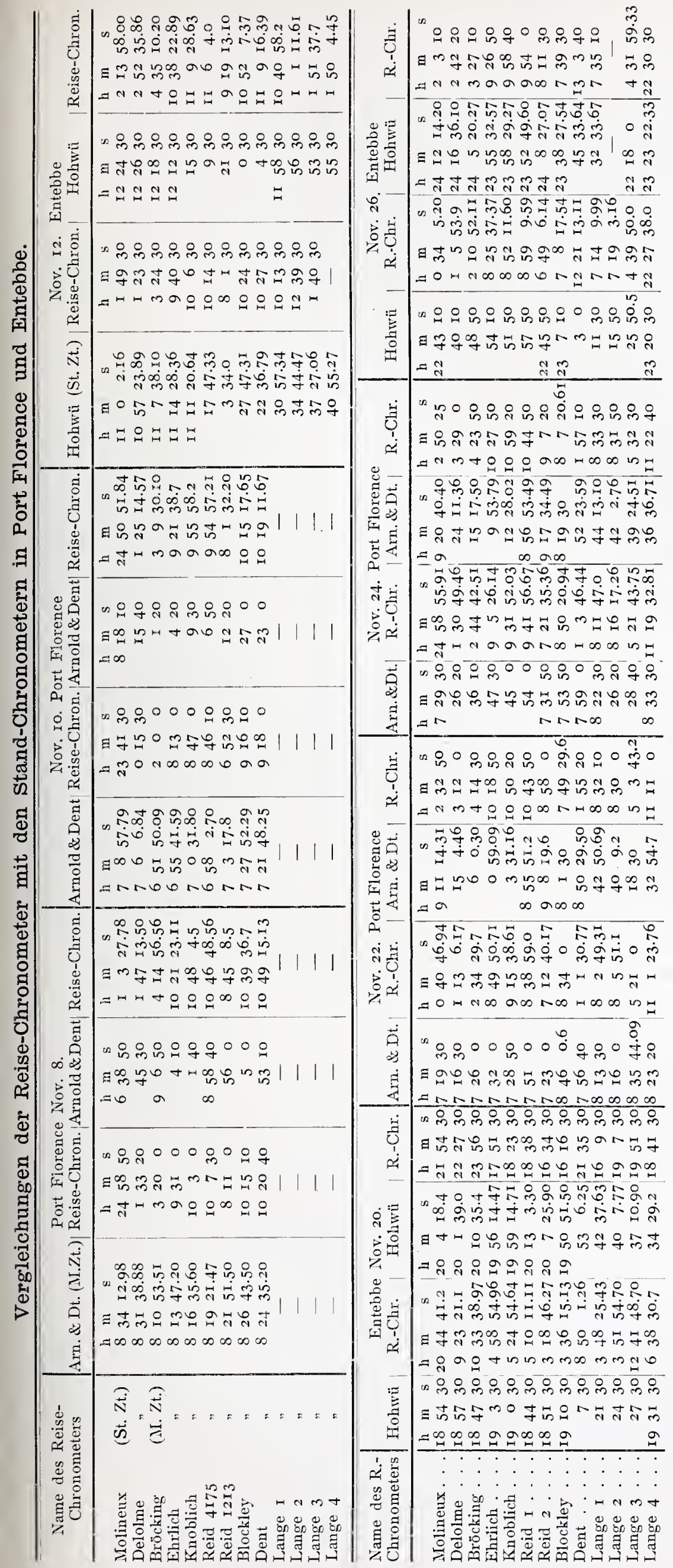

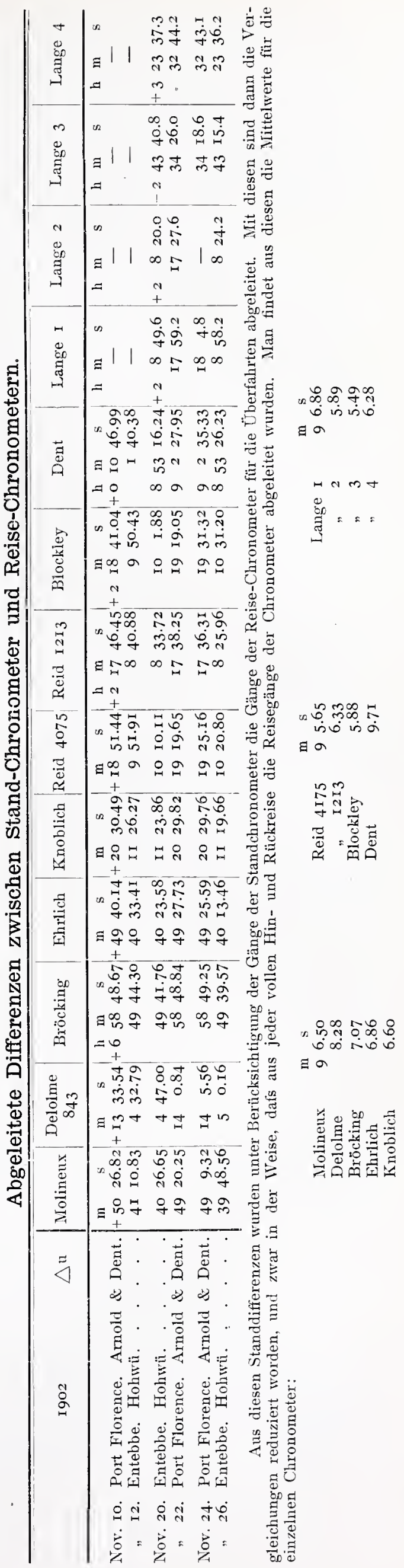


Auf Grund dieser Triangulation ergaben sich die Übertragungselemente zu nachstehenden Beträgen : Differenz $\triangle \varphi=\varphi$ Observ. - $\varphi$ Trig.Pkt. $=-34^{\prime \prime} .74$

$$
\lambda \text { (in gleichem Sinne) }=-4{ }^{\prime \prime} .04 \text {. }
$$

Sollen daher die Resultate der beiden Bestimmungen für die Länge des Observatoriums in Entebbe miteinander verglichen werden, so müssen die aus der kleinen Triangulation erhaltenen KoordinatenDifferenzen berücksichtigt werden. Auf Grund der für Port Florence angenommenen Koordinaten, die zunächst als Ausgangsdaten sowohl für den Anschluß nach Westen als auch später für den nach Osten hin gelten sollen, findet sich das Folgende:

Wenn man mit $E_{\varepsilon}$ den trigonometrischen Punkt und mit $E_{o}$ (len astronomischen Punkt bezeichnet, hat man

Anschluß in Länge:

$\lambda$ Port Florence $=34^{\circ}+4^{\prime}+9^{\prime \prime} .+$ (telegr.)

$\lambda$ Chronometer-Reise $=2$ I $64+3.5$

$$
\begin{aligned}
& \lambda E_{0}=32 \quad 28 \quad 5.9 \\
& \lambda \lambda\left(E_{\varepsilon}-E_{0}\right)=\quad+1.0 \\
& \lambda E_{\varepsilon}=32^{\prime 2} 27^{\prime} 24^{\prime \prime} .9 \\
& \lambda \text { Pt. Florence }=34^{\circ}+t^{\prime} 49^{\prime \prime} \cdot 4
\end{aligned}
$$

$\triangle \lambda$ (Pt. Fl.-Ent.) trigon. $=2^{\circ} 17^{\prime} \mathrm{O}^{\prime \prime} \cdot 3$

Also lurch trig. Ubertr. $\lambda E_{\varepsilon}=3227^{\prime}+9^{\prime \prime}$. I

Differenz (Chron.-Triag.) $=-2 t^{\prime \prime} .2$

oder - Is.6I

Anschluf in Breite:

$q=-0^{\circ} \sigma^{\prime} \mathrm{IO}^{\prime \prime} .4$ astr.

$\Delta \varphi+0$ IO $3.2\left(\phi P\right.$ t.Florence- $\left.\phi F_{\varepsilon}\right)$

$\varphi E_{\varepsilon}=+0^{\circ} 3^{\prime} 52^{\prime \prime} .8 \operatorname{geod}$.

aus der astronomischen Beobachtung in Entebbe (E.) findet sich:

$$
\begin{aligned}
\varphi & =+0^{\circ} 3^{\prime} 24^{\prime \prime} .0 \\
\Delta \varphi & =-\quad 34.7\left(\varphi E_{0}-\varphi E_{\varepsilon}\right) \\
\varphi E_{\varepsilon} & =+0^{\circ} 3^{\prime} 58^{\prime \prime} .7 \text { astr. }
\end{aligned}
$$

Differenz (astr.-geod.) $=+5^{\prime \prime} .9$.

Nun ist die Chronometerubcrtragung auf etwa $\pm \mathrm{O}^{5} .4= \pm 6^{\prime \prime}$ sicher. Die Triangulationsübertragung ist aber erheblich genauer, wic sich aus der Ubercinstimmung der Längen für die Seite $S_{1}$ - Entebbe ergibt, die bis auf rund 6 bis $7 \mathrm{~m}$ aus der Trangulation Port Florence-Entebbe und derjenigen von der Kagera-Mündung nach Norden übereinstimmend gefunclen wird. Es lürfte daher als sicher anzunehmen sein, daß sich die astronomische östliche Länge für Entebbe um etwa I5 bis 20 Bogensekunden kleiner ergibt als diejenige, welche durch geodätische Übertragung von Port Florence aus erhalten wurde. Das wüirde also eine relat. Lot. störung zwischen Entebbe und Port Florence von diesem Betrage anzeigen, was bei der Lage der Stationen an den Ufern des Vcitoria-Sccs nicht überraschen kann. Die Einzelheiten der englischen Triangulation sind aus den beigegebenen Abrissen ersichtlich.

Bezüglich der greographischen Breite lassen sich noch weitere Vergleichungen anstellen. Es ist an der Kagera-Mündung eine Reihe von Breitenbestimmungen gemacht worden, die sich auf die Orte des Basisnetzes bei Nyangoma bezichen und die mittels der sicheren Koordinaten-Differenzen sich alle auf len Punkt 4 (in Bugera) iibertragen lassen, wodurch für diesen Ort eine astron. Breite erhalten wird, welche auf mindestens eine Bogensekunde sicher ist. Es sind in diesem Basisnetze (vgl. Skizze 4) Breiten-

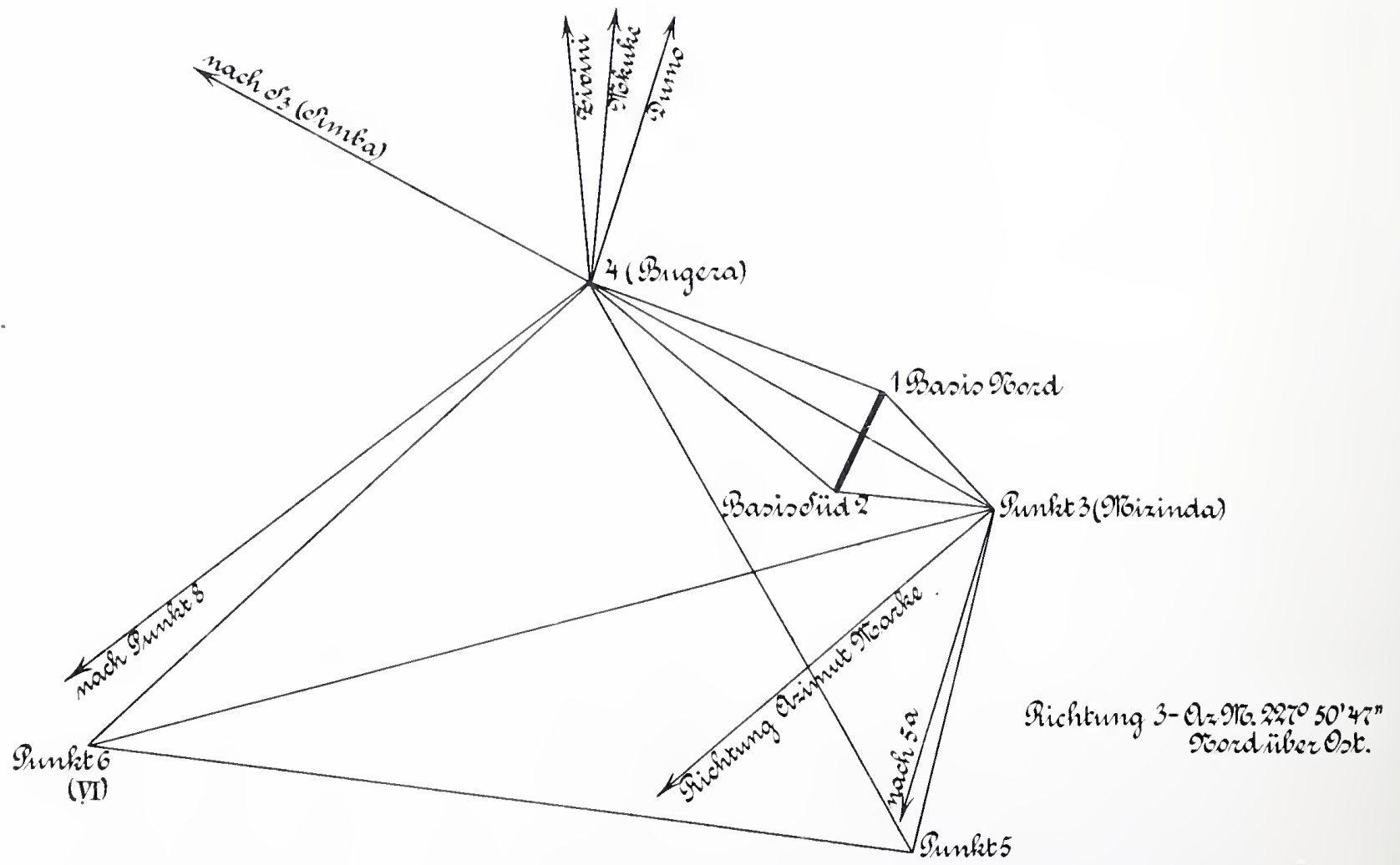

Skizze 4. Basis-Netz bei Njangoma. 
bestimınungen vorhanden für: die Orte Mizinda (Punkt 3), für die Station Bugera selbst (Punkt 4) und außerdem für einen südlich gelegenen Ort Minsiro (Punkt 5). Es ist der Reihe nach:

Mizinda $\varphi_{3}=-0^{\circ} 58^{\prime} 28^{\prime \prime} .0 \pm \mathbf{I}^{\prime \prime}$.

aus einer großen Anzahl von Beobachtungen. $\left.{ }^{1}\right)$ Weiterhin wurde beobachtet:

$$
\begin{aligned}
& \text { Bugera } \varphi_{4}=-\mathrm{O}^{\circ} \quad 56^{\prime} \quad \mathrm{I}^{\prime \prime} .8 \pm 2^{\prime \prime} .5 \text { und }
\end{aligned}
$$

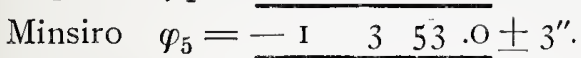

Die Übertragungen aus den Basisnetze ergeben sich für

$\begin{array}{lllll} & \varphi_{3} \text { auf } \varphi_{4} \text { zu } 2^{\prime} 22^{\prime \prime} . \mathrm{I} \\ \text { für } & \varphi_{5} \text { auf } \varphi_{4} \mathrm{zu} 7^{\prime} 5 \mathrm{O}^{\prime \prime} .7 .\end{array}$

Bringt man diese Reduktion an $\varphi_{3}$ und $\varphi_{5}$ an, so erhält man für $\varphi_{4}$ die beiden Werte

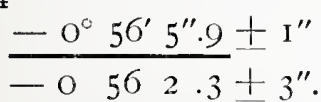

Da die geodätisch gefundene Korrektion den astronomischen Werten gegenüber als fehlerfrei angesehen werden kann, so bleibt die Zuverlässigkeit der drei Werte unverändert. Werden dieselben ihrem mittleren Fehler gemäß miteinander verbunden, so erhält man

$$
\text { (Bugera) } \underline{\varphi_{4}}=-0^{\circ} 56^{\prime} 5^{\prime \prime} .0
$$

mit einer Unsicherheit von etwas mehr als einer Bogensekunde. Wird an den Wert $\varphi_{4}$ der Betrag der Breitendifferenz zwischen Entebbe (trigonometrischer Punkt) und Bugera im Betrage von

$$
\triangle \varphi=+\mathrm{I}^{\circ} \mathrm{O}^{\prime} 5^{\prime \prime} \cdot 4
$$

angebracht, so erhält man für $\varphi$ trigonometrischer Punkt Entebbe

$$
\varphi_{E_{\varepsilon}}= \pm 0^{\circ} 4^{\prime} \mathrm{O}^{\prime \prime} .4
$$

ein Wert, der mit den direkten Beobachtungen in sehr naher Übereinstimmung steht, denn die astronomischen Beobachtungen in Entebbe selbst lieferten, wie oben mitgeteilt:

$$
{ }^{\varphi} E_{\varepsilon} \text { zu } \underline{0^{\circ} 3^{\prime} 58^{\prime \prime} \cdot 7}
$$

Es scheint danach auf dieser Strecke von etwa $I^{\circ}$ Breitendifferenz eine erhebliche Verschiedenheit zwischen dem Geoid und der ellipsoidischen Erdoberfläche nicht zu bestehen.

\section{Triangulation zwischen Kagera-Mündung und dem "Schnittpunkt .}

Führt man die Vergleichungen sowohl bezüglich der geographischen Länge als auch dergeographischen Breite bis zu dem Endpunkte der Kiwu-See-Expedition, so erhält man die folgenden Daten:

Aus der Chronometerreise folgt

$$
{ }^{\lambda} E_{\varepsilon}=\underline{32^{\circ} 27^{\prime} 25^{\prime \prime}},
$$

1) Vgl. Gesamtïbersicht der astronomischen Beobachtungen. aus der Triangulation

$$
\lambda_{E_{\varepsilon}}=\underline{32^{\circ} 27^{\prime} 49^{\prime \prime}} .
$$

Die Triangulation von der Kagera-Mündung nach Entebbe liefert für die Länge des Punktes 4 (Bugera) die Differenz

$\Delta \lambda$ (Punkt $4-$ Entebbe, trig. Punkt $)=0^{\circ} 45^{\prime}$ I $5^{\prime \prime}$, damit wird also

$$
\lambda \text { Punkt } 4=\underline{3 \mathrm{I}^{\circ} 42^{\prime} \mathrm{IO}^{\prime \prime}}
$$

auf Grund der Chronometerreise oder

$$
\underline{31^{\circ} 42^{\prime} 34^{\prime \prime}}
$$

nach den Ergebnissen der engl. Triangulation.

Die Triangulation von Bugera nach dem »Schnittpunkt « liefert Längendifferenzen, welche es gestatten, die Punkte $U_{e}$ und das Signal »Wina « mit Bugera in Verbindung zu bringen, anderseits sind aber diese beiden Punkte wiederum Signale der Kiwu-See-Expedition gewesen. Es findet sich aus der Triangulation $\delta \lambda$ (Punkt $\left.4-\mathrm{U}_{\mathrm{e}}\right)=\mathrm{I}^{\circ} 4 \mathrm{O}^{\prime} \mathrm{O}^{\prime \prime}$.

Damit hat man an Punkt 4 angeschlossen

$$
\lambda \mathrm{U}_{\mathrm{e}}=\underline{30^{\circ} 2^{\prime} 10^{\prime \prime}} \text { auf Grund der }
$$

chronometrischen Länge von Entebbe und

$$
\lambda \mathrm{U}_{\varepsilon}=30^{\circ} 2^{\prime} 34^{\prime \prime}
$$

(trig. Länge von Entebbe) östlich von Greenwich.

Wie in dem Bericht über die Kiwu-See-Expedition erwähnt, findet man für dasselbe Signal nach den Angaben des Kapitäns Bastien in Verbindung mit der wegen der Tafelfehler korrigierten Länge von Usumbura

$$
\lambda \mathrm{U}_{\mathrm{e}}=3 \mathrm{O}^{\circ} 2^{\prime} \mathrm{1}^{\prime \prime} .
$$

Es würden somit die beiden Werte für $\mathrm{U}_{\mathrm{e}}$ sehr gut miteinander übereinstimmen, wenn man das Resultat der Chronometerreise in die Rechnung einführt. Im Falle der geodätischen Übertragung ist diese Ubereinstimmung nicht in gleichem Maße vorhanden.") Die zweite Vergleichung mittels des Signals »Wina", welches nahezu identisch mit dem Signal »Irangeri« der Kiwu-Expedition ist, gestaltet sich folgendermaßen:

Seitens der Uganda-Expedition wurde das Baumsignal "Wina an die Seite 19/2 I der Kagera-Triangulation angeschlossen. Wie die beigegebene Skizze 5 zeigt, ist dieser Anschluß durch das Dreieck I 8/19/2 I ermöglicht worden. Aus der Kagera-Triangulation wurde der Log. für die Seite I9/2 I zu 4,224294 abgeleitet. Die hiermit auf zwei verschiedenen Wegen gefundenen Koordinaten des Punktes »Wina" finden sich $\mathrm{zu}$

*) Nach Mitteilung des Oberleutnants Schwartz war das hier in Betracht kommende Signal $U_{e}$ nicht genau identisch mit dem Signal $U_{e}$ der Kiwu-Expedition, doch ist der Unterschied so gering gewesen, daß er für die obigen Betrachtungen nicht von Belang sein dürfte. 
Wina $\varphi=-\mathrm{I}^{\circ} \mathrm{IO}^{\prime} 25^{\prime \prime} .8$ und

Wina $\lambda=30^{\circ} \mathrm{o}^{\prime} 38^{\prime \prime}$.

Dabei ist vorausgesetzt die Breite von Punkt $+z u$ und die Länge $\frac{\varphi_{4}=-0^{\circ} 56^{\prime} 5^{\prime \prime}}{2 u}$
Aus den Koordinaten der Kiwu-See-Expedition, für welche der Punkt , Wina" nahezu identisch ist mit dem durch Rückwärtseinschneiden gefundenen Punkte :Irangeri« findet sich für letzteren die Breite von $\varphi$ Irang. $=-\mathrm{I}^{\circ} \mathrm{IO}^{\prime} 23^{\prime \prime}$ und die Länge $z u$

$\lambda$ Irang. $=3 \mathrm{O}^{\circ} \mathrm{O}^{\prime} 3 \mathrm{I}^{\prime \prime}$.

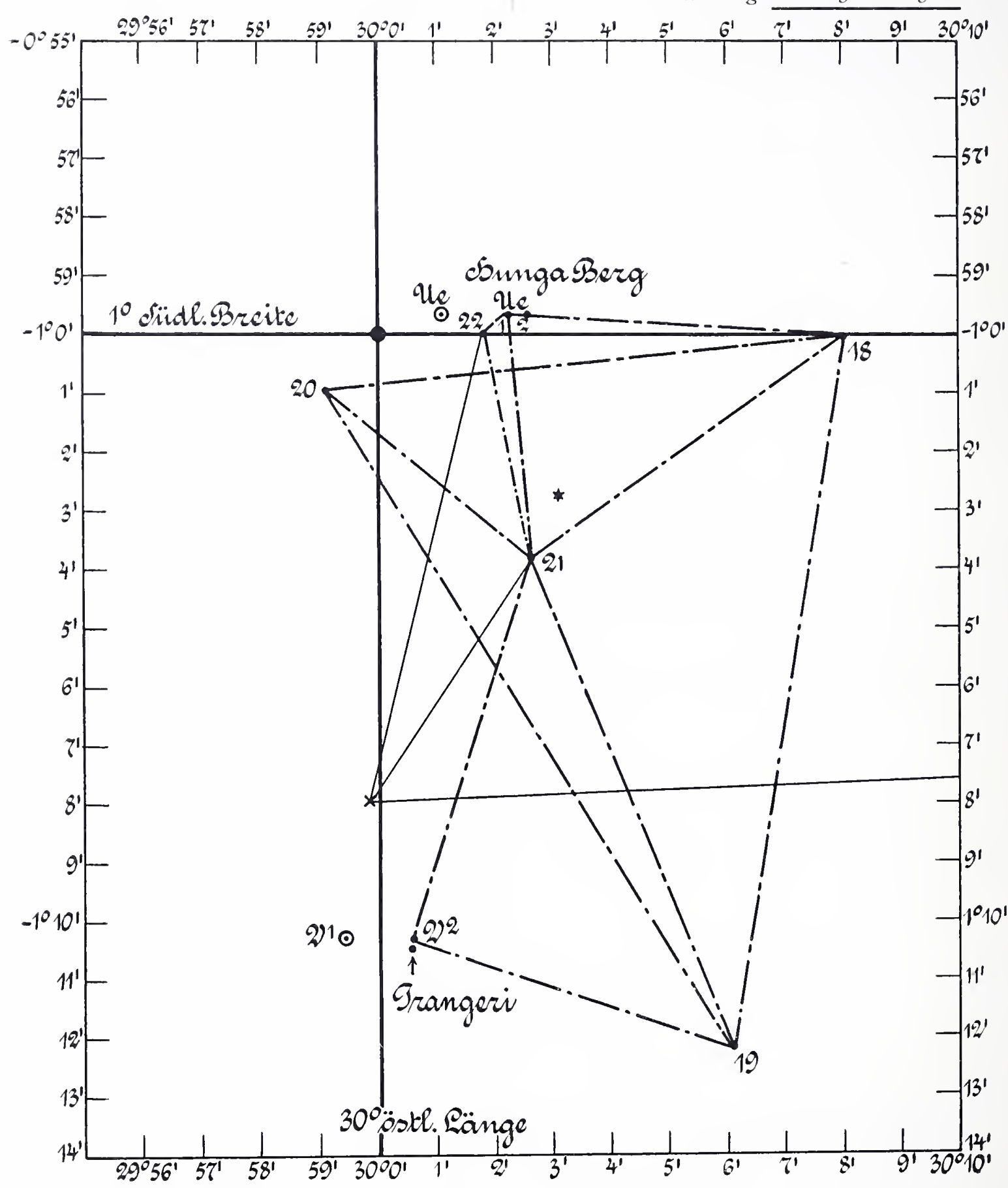

-.-. Schlobachsche Dreiecke. —_ Richtungen von dem Belgischen Signal aus.

* Beobachtungspunkt „Chamutera“. × Belgisches Signal.

Skizze 5. Lage der Punkte am Schnitt des I. Grades südl. Br. und des 3o. Grades östl. Lg.

○ Ue Lage des Signals Hunga-Berg nach der Länge von Usumbura nach Lamp.

$\mathrm{U}_{\mathrm{e} 1}$ und $\mathrm{U}_{\mathrm{e} 2}$ Lage der Punkte nach der Kageratriangulation (I trig., 2 Chronometer-Reisen).

$\mathrm{U}_{\mathrm{e} 1}=\mathrm{U}_{\mathrm{e}}$ nath Anbringung der Tafelkorrektion der Md. $\mathbb{R}$.

$\mathrm{V}_{1}$ Lage des Signals Wina nach Lamp, Usumbura-Länge.

$V$, nach Schlobach und Lamp + Korr.

$\varphi$ Wina $-\varphi$ Irengeri $=\mathbf{I} .5$. 
Die vorstehend errechneten Koordinaten für Wina (Kagera-Triangulation) gelten noch nicht direkt für das Signal der Kiwu-See-Expedition, vielmehr hat das letztere nach den Angaben des Oberieutnants Schwartz genau $45 \mathrm{~m}$ südlich des ersteren gestanden, es würde also der Wert für die geographische Breite für »Wina " noch um I".5 zu verringern sein, um ihn mit dem Resultat der Kiwu-Expedition zu vergleichen. Wird für die Übertragung der Länge nicht das Resultat der Chronometerreise, sondern das der Triangulation benutzt, so würde damit die Länge, welche aus den Beobachtungen der Uganda-Expedition für den Punkt Wina folgt, um $23^{\prime \prime}$ östlich vergrößert werden. Man hätte dann

$$
\lambda \text { Wina }=30^{\circ} \underline{1}^{\prime} 2^{\prime \prime}
$$

Unter Berücksichtigung des Umstandes, daß die Position des Kiwu-Signales Irangeri nur durch Rückwärtseinschneiden gefunden ist, kann dieVergleichung nur eine beiläufige sein, doch scheint so viel sicher aus derselben hervorzugehen, daß die Übertragungen der Längendifferenz von Usumbura nach Nordosten und derjenigen von Port Florence nach Westen in bessere Übereinstimmung kommen, wenn an Stelle der Triangulationsverbindung Port Florence-Entebbc diejenige der Chronometerreise gesetzt wird. Dieses Resultat kann auch durchaus nicht überraschen, wenn man beachtet, daß die erstere nur die süd-nördlich verlaufende Triangulation Usumbura-Wina, die letztere aber auch noch die ostwestliche Triangulation Kagera-Mündung-Wina umfaßt.

Zur Feststellung des wirklichen "Schnittpunktes《 wurde von der Uganda-Expedition eine Anzahl von Punkten mit dem Meßtisch festgelegt, wie sie aus der beigegebenen Skizze erkennbar sind. Für die astronomischen Berechnungen, welche sich an die beiden Vermessungen anschlossen, haben diese Übertragungen aber keine weitere Bedeutung. Es sind an Ort und Stelle verschiedene Pfeiler errichtet, deren Lage aus den topographischen Aufnahmen sich genau ermitteln läßt. Für die Festlegung einer Grenzlinie zwischen den betreffenden Schutzgebieten dürfte in der Praxis doch wohl nur das Hauptsignal $\left(\mathrm{U}_{\mathrm{e}}\right)$ auf dem Hungaberge in Betracht kommen, dessen geographische Position aus den oben gegebenen Daten hervorgeht. Aus Vorstehendem ist der Anschluß der Arbeiten der Kiwu-See-Expedition an diejenige der UgandaExpedition ersichtlich, und es mag nun zu dem zweiten Hauptteil der Uganda-Expedition, nämlich der Verbindung zwischen Kisumu (Port-Florence) und Schirati, sowie auch zu den Resultaten der Vermessung der schiefen Linie Schirati-Kilimandscharo -Djipe-See bzw. Zanzibar übergegangen werden, zuvor aber soll noch die Grundlage der KageraMitteilungen a. d. D. Schutzgebieten, XX. Band. IV,
Triangulation, nämlich die Messung der Basislinien bei Nyangoma, Bukira und Entebbe, mitgcteilt werden.

\section{Erläuterung zu den Basismessungen bei Nyangoma sowie Bukira und bei Entebbe.}

Auf die Länge dieser Basis ist im wesentlichen sowohl die Triangulation nach dem Schnittpunkte des 30. Grads östlicher Länge und I. Grads südlicher Breite als auch diejenige von der Kagera-Mündung nach Entebbe gegründet, welch letztere den Anschluß an die Triangulation Port Florence-Entebbe vermittelt. Die Vorarbeiten für die Absteckung dieser Basis, die Einrichtung der Zwischenpunkte in Alignements der Endpunkte und die Horizontierung dieser Zwischenpunkte wurde von Feldwebel Buchner ausgeführt, während Hauptmann Schlobach und Oberleutnant Schwartz die telegraphische Längenübertragung Mombasa-Port Florence durchführten. Es fand sich in der Nähe des obengenannten Ortes ein sehr günstiges Terrain, insofern der Basislinie dadurch eine vollständig horizontale Lage gegeben werden konnte. Der Vorgang bei den Messungen selbst, die in der Zeit vom I8. bis 25. September I902, und in den Tagen vom 27. bis 30. Dezember 1902 vom Feldwebel Buchner bzw. vom Hauptmann Schlobach ausgeführt wurden, war im wesentlichen genau derselbe, wie er schon früher in dem Bericht über die Basismessung bei Usumbura dargestellt worden ist. Zwischen den gut fundierten und sicher bezeichneten Endpunkten wurden in einem Abstande von etwa $20 \mathrm{~m}$ Holzpfähle eingeschlagen, die auf ihrer oberen geglätteten Fläche senkrecht zur Basisrichtung gezogene Bleistiftstriche trugen. Die beiden zur Verfügung stehenden Meßbänder wurden dann so zwischen je zwei solcher Pfähle eingehängt, daß an jedem Ende desselben ein Europäer und ein Farbiger das Meßband mit einem Zuge von $8 \mathrm{~kg}$ spannten. Die Temperatur der Meßbänder wurde vermittelst Beobachtung am Schleuderthermometer in der Mitte einer jeden Strecke bestimmt. Zur genauen Einschätzung der Millimeterteilung und der Bleistiftstriche waren ein Transversalmaßstab und ein Zirkel benutzt. Diese Einschätzung fand auf jeder Meß. strecke zweimal statt. Das für die Messungen der deutschen Kommission benutzte Meßband hatte Oberleutnant Schwartz von der Kiwu-See-Expedition mitgebracht. Die Berechnung der Länge ist aber nicht auf die dort benutzte Gleichung des Meßbandes begründet, sondern es wurden an Ort und Stelle Vergleichungen des Meßbandes mit zwei Normalmetern von Bamberg 511/94, 512/94 vorgenommen. Diese Normalmeter waren durch die Normaleichungskommission geprïft und bis auf $1 / 10 \mathrm{~mm}$ für richtig befunden. Diese Ver- 
gleichungen wurden von Meter zu Meter auf einer $j \mathrm{~cm}$ breiten Latte vorgenommen, die sich zum Schutz gegen Regen und Sonne unter einem Grasdach befand. Da die Basis auch von den Engländern als Grundlage für die Triangulation benutzt werden mußte, so wurde dieselbe auch durch die englischen Kommissare gemessen. Diese verwendeten dazu zunächst ein Meßband von $++\mathrm{Fuß}$ Länge. Da sich jedoch dessen Handhabung Schwierigkeiten entgegenstellteu, so haben sie später ebenfalls von dem deutschen Mebbande Gebrauch gemacht. Der Ausdehnungskoeffizient des Meßbandes wurde von den englischen Kommissaren so angenommen, wie er bei den indischen Vermessungen für Stahlmeßbänder im Gebrauch ist, nämlich zu 0,0000063 für I Fahrenheit bei einer Mitteltemperatur von $62^{\circ}$. Aus den Vergleichungen des Meßbandes mit dem Normalmeter und der Benutzung des angegebenen Ausdehnungskoeffizienten fand sich für die Länge les Mebbandes bei 80.25 Fahrenheit und bei freiem Durchlhang und $8 \mathrm{~kg}$ Zug der Betrag von $20.00103 \mathrm{~m}$. Ohne hier auf die näheren Einzelheiten der Messung einzugehen, will ich nur die Schlußwerte der einzelnen Abteilungen (dic ganze Basis war in fünf solcher Abteilungen geteilt) der vier Messungen im September und im Dezember anführen, um ein Urteil über die erlangte Genauigkeit zu beschaffen.

Die beiden Resultate für September und Dezember sind danach bzw.

$2120.016 \mathrm{~m}$ und $2119.992 \mathrm{~m}$.
Der Mittelwert ist also $2120.004 \mathrm{~m}$ mit einem mittleren Fehler von etwa $10 \mathrm{~mm}$ oder $\frac{1}{200000}$ der Länge. Zur Redultion dieser Basislänge auf den Meereshorizont ist die Höhe derselben über dem Meere zu IIfI $m$ angenommen. Damit ergibt sich die Reduktion zu 78 Einheiten der 6. Decimalstelle des Logarithmus, und man erhält als Länge der Basis im Meereshorizont

$$
2 \text { I } 19.625 \mathrm{~m}
$$

als Resultat der deutschen Messungen. Das Resultat der englischen Messungen war, nachdem es in gleicher Weise reduziert worden ist,

$$
2119.574 \mathrm{~m} .
$$

Das Mittel beider Werte ergibt lemnach

$$
2119.600 \mathrm{~m} \text {. }
$$

Dieser Wert für die Basislänge ist den Dreieclisberechnungen zugrunde gelegt worden. Berücksichtigt man also den Unterschied der beiderseitigen Messungsresultate, so erscheint es wahrscheinlich, daB noch eine systematische Verschiedenheit bei den Messungen stattgefunden hatte, weiche dem Schlubresultat eine größere Unsicherheit gibt, als es die innere Übereinstimmung der Einzelmessungen vermuten läßt, da es aber nicht möglich ist, auf Grund der vorliegenden Daten eine genauere Untersuchung anzustellen, so mußte vorläufig von dem Mittelwerte Gebrauch gemacht werden. Es ist das umsomehr gestattet, als die auf diesen Wert ge-

\begin{tabular}{|c|c|c|c|c|c|c|c|c|c|}
\hline Abschnitt & $\begin{array}{l}\mathrm{Nr} \text {. } \\
\text { der } \\
\text { Mes- } \\
\text { Sung }\end{array}$ & $\begin{array}{l}\text { Summe der } \\
\text { Differenzen } \\
\text { Band minus } \\
\text { Teilstrecke }\end{array}$ & $\begin{array}{l}\text { Mittlere } \\
\text { Tempe- } \\
\text { ratur }\end{array}$ & $\begin{array}{c}\text { Lünge des } \\
\text { Baudes mit Riuck- } \\
\text { sicht auf seine } \\
\text { Temperatur }\end{array}$ & $\begin{array}{l}\text { Anzalil } \\
\text { der 'Teil- } \\
\text { strecken }\end{array}$ & $\begin{array}{l}\text { Anzahl der } \\
\text { Teilstrecken } \\
\text { multipliziert in } \\
\text { d. Bandlänge }\end{array}$ & $\begin{array}{l}\text { Länge des } \\
\text { Abschnittes }\end{array}$ & $\begin{array}{l}\text { Mittel } \\
\text { der Einzel- } \\
\text { messungen }\end{array}$ & $\begin{array}{c}\text { Differenz } \\
\text { zwischen } \\
\text { den Mitteln }\end{array}$ \\
\hline $\begin{array}{c}\mathrm{I} \\
\mathrm{I}+\mathrm{II}\end{array}$ & $\begin{array}{l}1 \\
2 \\
3 \\
4\end{array}$ & $\begin{array}{c}\mathrm{m} \\
-0.10435 \\
-0.11415 \\
-0.15730 \\
-0.16889\end{array}$ & $\begin{array}{l}0 \\
17.5 \\
15.8 \\
19.1 \\
17.4\end{array}$ & $\begin{array}{c}\mathrm{m} \\
\mathrm{I} 9.9989 \mathrm{I} \\
99853 \\
99929 \\
99890\end{array}$ & $\left\{\begin{array}{c}\mathrm{I} \\
3 \mathrm{II} \\
(\mathrm{I}+\mathrm{II})\end{array}\right.$ & $\begin{array}{r}111 \\
279.9847 \\
9794 \\
619.9781 \\
9659\end{array}$ & $\begin{array}{c}\mathrm{m} \\
280.089 \mathrm{I} \\
0936 \\
620,1354 \\
\mathrm{I} 348\end{array}$ & $\begin{array}{c}\mathrm{m} \\
280.09 \mathrm{I} 3 \\
620 . \mathrm{I}_{35} \mathrm{I}\end{array}$ & Dez.-Sept. \\
\hline JI & $\begin{array}{l}I \\
2 \\
3 \\
4\end{array}$ & $\begin{array}{c}-0.08760 \\
--0.08065 \\
-\end{array}$ & $\begin{array}{l}15.6 \\
\text { I } 6.8 \\
- \\
-\end{array}$ & $\begin{array}{c}99849 \\
99876 \\
- \\
-\end{array}$ & $\begin{array}{l}17 \\
- \\
-\end{array}$ & $\begin{array}{c}339.9743 \\
9979 \\
-\end{array}$ & $\begin{array}{r}340.0619 \\
0785 \\
-\end{array}$ & $\begin{array}{c}340.0702 \\
-\end{array}$ & \\
\hline III & $\begin{array}{l}\text { I } \\
2 \\
3 \\
4\end{array}$ & $\begin{array}{r}-0.03410 \\
-0.03890 \\
-0.05590 \\
-0.04165\end{array}$ & $\begin{array}{l}16.9 \\
16.0 \\
16.8 \\
18.0\end{array}$ & $\begin{array}{l}99879 \\
99859 \\
99853 \\
99904\end{array}$ & 27 & $\begin{array}{r}539.9673 \\
9619 \\
9603 \\
9741\end{array}$ & $\begin{array}{r}540.0014 \\
\text { OOO } 8 \\
\text { OI } 62 \\
\text { OI } 57\end{array}$ & $\begin{array}{l}540.0011 \\
540.0160\end{array}$ & +0.0149 \\
\hline IV & $\begin{array}{l}\text { I } \\
2 \\
3 \\
4\end{array}$ & $\begin{array}{r}+0.08793 \\
+0.08270 \\
+0.09355 \\
+0.08610\end{array}$ & $\begin{array}{l}17.4 \\
15.9 \\
17.0 \\
17.0\end{array}$ & $\begin{array}{l}99889 \\
99855 \\
99881 \\
99879\end{array}$ & 26 & $\begin{array}{r}5 \text { I } 9.97 \text { I I } \\
9623 \\
969 \text { I } \\
9688\end{array}$ & $\begin{array}{r}519.8832 \\
8796 \\
8755 \\
8827\end{array}$ & $\begin{array}{l}519.8814 \\
519.8791\end{array}$ & -0.0023 \\
\hline$V$ & $\begin{array}{l}\mathrm{I} \\
2 \\
3 \\
4 \\
\end{array}$ & $\begin{array}{r}-0,018 \mathrm{I} 5 \\
-0.02080 \\
+0.00915 \\
+0,00273 \\
\end{array}$ & $\begin{array}{l}\text { I } 3.0 \\
\text { I } 2.4 \\
\text { I } 6.4 \\
\text { I } 5.3 \\
\end{array}$ & $\begin{array}{l}99789 \\
99777 \\
99867 \\
99843 \\
\end{array}$ & 22 & $\begin{array}{r}439.9536 \\
9509 \\
9707 \\
9655 \\
\end{array}$ & $\begin{array}{r}439.9717 \\
9717 \\
9615 \\
9627 \\
\end{array}$ & $\begin{array}{l}439 \cdot 97 \text { I } 7 \\
439 \cdot 962 \text { I }\end{array}$ & -0.0096 \\
\hline
\end{tabular}
gründeten Dreiccksberechnungen sich nicht über

Tabelle der Einzelmessungen für die Basis bei Nyangoma (als Beispiel).

Die Messungen $\mathbf{I}$ und 2 sind im Septenber, die unter 3 and 4 im Dezember r 902 gemacht.
Mittel September: 2 I 20.0157

Dezember : 2 I 9.9923

Gesauntmittel : 2120.0040 
ein allzugroßes Gebiet erstrecken und ihrerseits wieder eine Kontrolle erhalten durch eine am Westende der Kagera-Triangulation gemessene Kontrollbasis und außerdem durch den Anschluß der nördlichen Dreiecke an den Punkt Entebbe.

Die am Westende der Kagera-Triangulation in der Nähe des Hungaberges gemessene Basislinie ist im wesentlichen genau in derselben Weise erhalten worden, wie es eben geschildert wurde. Das Gelände der sich nahezu von Südwesten nach Nordosten erstreckenden Linie war weniger günstig, da es erhebliche Höhenunterschiede zeigte. Der Ausbau der Linie wurde von der deutschen und englischen Kommission gemeinsam gemacht. Die Messungen erfolgten in der Zeit vom I8. bis 24. Juli 1903 meist in den späten Abendstunden unter Benutzung desselben MeBbandes wie bei Nyangoma. Die Messungen erfolgten nur zweimal und lieferten die nachstehend aufgeführten Resultate.

Einzelwerte für die 7 Abschnitte der Kontrollbasis bei Bukira (Schnittpunkt).

\begin{tabular}{|c|c|c|c|c|c|}
\hline \multicolumn{2}{|c|}{ Abschnitt } & $\begin{array}{l}\text { Anzahl } \\
\text { der Teil- } \\
\text { strecken }\end{array}$ & $\begin{array}{l}\text { Länge des } \\
\text { Abschnittes }\end{array}$ & $\begin{array}{l}\text { Mittel beider } \\
\text { Messungen }\end{array}$ & $\left\{\begin{array}{c}\text { Mittel auf } \\
\text { den Horizont } \\
\text { reduziert }\end{array}\right.$ \\
\hline$I$ & $\begin{array}{l}\mathrm{I} \\
2\end{array}$ & I 3 & $\begin{array}{r}\mathrm{m} \\
259 \cdot 9 \mathrm{I} 35 \\
903 \mathrm{I}\end{array}$ & $\begin{array}{c}\mathrm{m} \\
259.9083\end{array}$ & $\begin{array}{c}m \\
259.7562\end{array}$ \\
\hline II & $\begin{array}{l}\text { I } \\
2\end{array}$ & 18 & $\begin{array}{r}359.9696 \\
9746\end{array}$ & $359.972 \mathrm{I}$ & 359.9545 \\
\hline III & $\begin{array}{l}\text { I } \\
2\end{array}$ & 20 & $\begin{array}{r}399.8093 \\
8036\end{array}$ & 399.8065 & 399.7767 \\
\hline IV & $\begin{array}{l}\text { I } \\
2\end{array}$ & $3 I$ & $\begin{array}{r}619.9317 \\
9316\end{array}$ & 619.9316 & 6I9.8806 \\
\hline V & $\begin{array}{l}\text { I } \\
2\end{array}$ & 22 & $\begin{array}{r}439.985 \mathrm{I} \\
978 \mathrm{o}\end{array}$ & 439.98 I 5 & 439.9754 \\
\hline VI & $\begin{array}{l}\text { I } \\
2\end{array}$ & 7 & $\begin{array}{r}\text { I } 40.0537 \\
0525\end{array}$ & $\mathrm{I} 40.053 \mathrm{I}$ & I 40.0448 \\
\hline VII & $\begin{array}{l}\mathrm{I} \\
2 \\
\end{array}$ & $2 \mathrm{I}$ & $\begin{array}{r}420.0546 \\
0527 \\
\end{array}$ & 420.0537 & $4 I 9.9$ I 75 \\
\hline & & & & 2639.7068 & 2639.3057 \\
\hline
\end{tabular}

Die Neigungen der einzelnen Teilstrecken wurden mittels des Theodoliten gemessen und bei der Reduktion in Rechnung gebracht. Werden dieselben berücksichtigt, so wird die Gesamtlänge der Basis in mittlerer Höhe der Endpunkte zu 2639.306 m gefunden.

Die Unsicherheit dieser Messung kann auf Grund der inneren Übereinstimmung der einzelnen Teilstrecken zu etwa $3 \mathrm{~cm}$ angenommen werden. Nach den trigonometrischen Höhenmessungen betrug die Höhe des südlichen Endpunktes I $534 \mathrm{~m}$, die des nördlichen Endpunktes 1520 m ïber dem Meere. Die mittlere Höhe der Basis beträgt aber nach der topographischen Aufnahme nur etwa $1518 \mathrm{~m}$. Dafür ergibt sich eine Reduktion auf dem Meereshorizont von
IO2 Einheiten der 6. Decimalstelle des Logarithmus oder der numerische Wert von - $0.631 \mathrm{~m}$, so daß man für die Länge der auf dem Meereshorizont reduzierten Basis bei Bukira den Betrag von $2658.675 \mathrm{~m}$ erhält.

Da an dem Orte Entebbe der astronomische Punkt $\left(\mathrm{E}_{\mathrm{o}}\right)$ mit dem trigonometrischen Punkte $\mathrm{E}_{\varepsilon}$ nicht zusammenfällt, war es erforderlich, daß auch dort noch eine kleine Übertragungstriangulation vorgenommen wurde. Es wurde zu diesem Zweck ebenfalls eine Basis gemessen, und zwar in derselben Weise, wie oben geschildert, da es sich aber dabei nur um den angegebenen Zweck handelte, so ist dieser Messung nur eine geringere Genauigkeit beizulegen. Es wurde dazu das englische 200 FuB lange Mebband benutzt und nur bei bedecktem Himmel gemessen. Die Entfernung der beiden End punkte, welche in Höhe um etwa $33 \mathrm{~m}$ verschieden waren (diese Höhendifferenz wurde durch Nivellement gefunden), ergab sich aus einer zweimaligen Messung zu I I65.49 engl. FuB $=355.238 \mathrm{~m}$ mit einer Unsicherheit von etwa $10 \mathrm{~cm}$.

\section{Teil III. Astronomische und geodätische Ar- beiten im Osten des Victoria-Sees.}

Triangulation Port Florence-Schirati, Festlegung der Grenze zwischen Schirati und Leitokitok am Kilimandscharo bzw. dem Südufer des Djipe-Sees mit der sich daran anschließenden Verbindung bis Zanzibar.

A. Triangulation und astronomische Beobachtungen auf der Strecke Schirati-Port Florence.

Auf dem Ostufer des Victori -Sees begannen die Grenzvermessungen mit der Triangulation zwischen Port Florence (Kisumu) und Schirati auf der Mohuru-Halbinsel, nachdem dort die astronomischen Beobachtungen beendigt waren. Diese letzteren bestanden in einer größeren Anzahl von Breitenbestimmungen an beiden Orten und aus der Festlegung des Azimutes der Linie Schirati-Kilimandscharo. Die Resultate dieser Beobachtungen sind nachstehend aufgeführt, während sich die Einzelbeobachtungen in der am Schluß angefügten $\mathrm{Zu}$ sammenstellung aller astronomischen Beobachtungen verzeichnet finden. An diesen sowie an den späteren Arbeiten waren beteiligt:

auf deutscher Seite:

Hauptmann Schlobach als Leiter, Toposraph und Astronom,

Oberleutnant Schwartz,

$$
\text { Weib, }
$$

Feldwebel Münch, Sanitätsunteroffizier Groha, Vermessungstechniker Dannert, 40 Askari, 200 bis 
350 Träger, 5 schwarze Heliographenschüler aus Daressalam;

auf englischer Seite:

Leiter Colonel Smith

Major Bright,

Leutnant Behrens,

I Eskorteoffizier, später 2 und 3 .

Arzt (Dr. Chevallier), I Sergeant-Major, einige Unteroffiziere vom Survey-Department als Topographen, 60 später I 20 Askari, eine Anzahl Küstenleute als Träger usw.

Die Arbeiten in Gelände begannen, sobald der Schnittpunkt des 1 . Grades mit dem Seeufer und die Länge dieses Punktes ermittelt waren. Aus diesen Daten und den Koordinaten des Endpunktes der Grenze am Kilimandscharo wurde das Azimut der schrägen (geodätischen) Linie berechnet und mittels des aus den astronomischen Beobachtungen gewomnenen Azimutes festgelegt. Es galt nun diese gerade schräge Linic in einer Länge von rund t to lim durch völlig unbekannte Gebiete fortzuführen. Die Vermessungsarbeiten gestalteten sich hierbei in geodätischer Hinsicht naturgemäß liomplizierter als am Westufer, wo der I. Grad südlicher Breite die Grenzlinic bildete.

Die beiden Expéditionen arbeiteten in der Weise miteinander, dalj die deutschen Beobachter sich im wesentlichen südlich der schrägen Linie und die englischen nördlich derselben hielten. Dem zum Teil steppenartigen Gebiete, zum Teil aber auch durch schroffe Gebirgszüge kupierten Gelände muBte dic Form der Dreiecke angepalst werden. AIs Ausgangsstrecken wurden für die Berechnung der Dreiecke benutzt eine bei Schirati und eine nördlich des Kilimandscharo gemessene Basis. Die Messung dieser Basislinien geschah im allgemeinen in gleicher Veise, wie dies bei den früheren Triangulationen geschildert worden ist. Es wurden dazu Stalılmeßbänder benutzt, die von der englischen Expedition in einer Iänge von $400 \mathrm{~m}$ mitgeführt wurden. Dadurch war es möglich, daß diese Basismessungen sehr schnell und doch mit genuigender Genauigkeit ausgeführt werden konnten. Auf die Einzelheiten der Triangulationen und die durch die örtlichen Verhältnisse bedingte Form der Dreiecke näher einzugehen, dürfte sich hier eribrigen, zumal aus der beigegebenen ïbersichtlichen Karte über sämtliche Dreiecksketten die Form, die Anzahl und die Lage der einzelnen Teile derselben genau ersichtlich ist. Es wird hier nur von Interesse sein, zu erwähnen, daß die Genauigkeit, welche bei den einzelnen Winkelmessungen erzielt werden konnte, sich auf Grund einer ausgedehnten Vergleichung auf etwa 3-5 Bogenseliunden als einzelnen Winkelfehler angeben läBt. Die Dreiecks- oder Polygonschlüsse zeigen demmach einen mittleren Fehler von etwa 5 bis 8 Bogensekunden. Die verhältnismäBige Größe dieser Schlußfehler wird durch die zum Teil sehr wenig günstigen Sichtbarkeitsverhältnisse bedingt sein. Die Vinlielmessungen selbst wurden fast stets in vier Sätzen in beiden Fernrohrlagen durchgeführt. Im allgemeinen wurden auch hier nicht Richtungs-, sondern Winkelmessungen angestellt, weil es nicht möglich gewesen wäre, in jedem Satz eine größere Anzahl von Richtungen gleichzeitig zu vereinen, da meist nicht mehr als 2 bis 3 Signale gleichzeitig sichtbar waren.

Zur Verbindung des Schnittpunktes des I. Grades südlicher Breite mit dem Ostufer des Victoria-Sees einerseits und dem Ausgangspunkte der Messungen bei Port Florence diente cin Dreieclisnetz, welches sich am Ufer des Sees entlang zieht. Es wurde eine Basislinie gemessen in der oben ausführlich geschilderten Wreise, es soll deshalb hier nicht des weiteren auf die Einzelheiten der Messungen eingegangen werden, nur soviel mag erwähnt werden, dab dieselbe aus sechs Einzelabteilungen besteht, für die die nachstehenden Längen gemessen wurden:

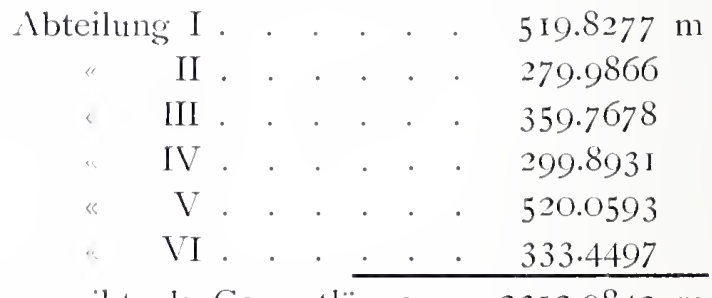

Das ergibt als Gesamtlänge . $2312.9842 \mathrm{~m}$ und auf das Meeresniveau reduziert mit einer mittleren Höhe von I I $57 \mathrm{~m}$

die Länge von 2312.56+ m (log. 3.3640938).

Nach den Vergleichungen der aus je zwei Einzelmessungen bestehenden Resultate ist der mittlere Fehler $= \pm \mathrm{IO} \mathrm{cm}$. An diese Basis schliebt sich durch Vermittelung des Erweiterungsnetzes die Seite Mohuru-Nundowat an. Da die zuverlässigsten astronomischen Beobachtungen auf dem Beobachtungspfeiler in Mohuru ausgeführt worden sind, so war es berechtigt, die wesentliche Orientierung nicht an eine Seite des Erweiterungsnetzes selbst zu knüpfen, sondern an die Seiten MohuruNundowat. AuBerdem bildet der Mohuru-Pfeiler auch wieder den Anknüpfungspunkt für die Dreieckskette nach dem Kilimandscharo. Die astronomischen Daten für den Beobachtungspunlit in Mohuru sind: $\varphi=-\mathrm{I}^{\circ} \mathrm{O}^{\prime} 24^{\prime \prime} .2$ und $\lambda=34^{\circ} 3^{\prime} 55^{\prime \prime}$.

Beide Werte sind als Mittel aus den englischen und deutschen Beobachtungen gebildet. Zunächst war für die Länge des Dreieckspunktes der Näherungswert

$$
(\lambda)=34^{\circ} 3^{\prime} 30^{\prime \prime}
$$


eingeführt worden. Durch den Anschluß des Dreiecksnetzes an die aus der telegraphischen Bestimmung für Port Florence gefundene Länge zeigte sich aber, daß diese Annahme um 25".3 Bogensekunden zu klein war und demgemäß der Näherungswert des Zwischenpunktes Mohuru verbessert werden mußte. Die Azimutmessungen an dem Pfeiler in Mohuru lieferten, wie aus der Zusammenstellung der Einzelbeobachtungen hervorgeht, für eine dort aufgestellte Marke ein Azimut von

$$
90^{\circ} \quad 0^{\prime} 33^{\prime \prime} \cdot 9 \text {. }
$$

Der Winkel zwischen Nundowat und der Marke am Beobachtungspfeiler wurde zu

$$
45^{\circ} 5^{\prime} 9^{\prime \prime} .6
$$

bestimmit. Danach erlält man für das Azimut Mohuru-Nundowat (siehe Skizze auf Karte Nr. 7).

$44^{\circ} 55^{\prime} 24^{\prime \prime} \cdot 3$ von Norden über Osten oder $244^{\circ} 55^{\prime} 24^{\prime \prime} \cdot 3$.von Süden über Westen.

Die englischen Beobachtungen ergaben für dasselbe Azimut

$$
44^{\circ} 55^{\prime} 22^{\prime \prime} .5 \text {. }
$$

Daraus wurde nach Übereinkunft der beiden Kommissare das Mittel gebildet und somit für die Gesamtorientierung der beiden sich anschließenden Dreiecksketten für das Azimut Mohuru-Nundowat

$$
\begin{array}{lll}
44^{\circ} \quad 55^{\prime} \quad 23^{\prime \prime} \cdot 4 \\
\hline
\end{array}
$$

angenommen. Auf Grund des Basis-Erweiterungsnetzes und des sich daran anschließenden Polygons Mohuru - Ugingo - Uganju - Nundowat wurde der Logarithmus der Seite Mohuru-Nundowat

deutscherseits $\mathrm{zu} 4.364729 \mathrm{I}$

und englischerseits « 4.3647 I4 I

also im Mittel zu 4.36472I7 bestimmt.

Auf Grund dieser Annahme ist zunächst die Kette Schirati-Port Florence (Bungalow) durchgerechnet worden, bis zu dem Anschluß an die Triangulation Port Florence-Entebbe. Die Beziehung läBt sich in folgender Weise herstellen:

Als Hauptpunkte, welche beiden Triangulationen gemeinsam sind, können angenommen werden Punkt Ndere und Port Florence selbst. (Vgl. Dreiecksnetz auf beigegebener Karte.) Wird die geographische Breite von Port Florence auf Grund der englischen Messungen zu

und die Länge zu

$$
\varphi=-0^{\circ} \quad 6^{\prime} \mathrm{IO}^{\prime \prime} .4
$$

$$
\lambda=34^{\circ} 44^{\prime} 49^{\prime \prime} \cdot 4
$$

auf Grund der telegraphischen Längenbestimmung angesetzt, so hätte man für den Punkt Ndere

$$
\varphi=-\mathrm{O}^{\circ} \mathrm{I} 2^{\prime} 33^{\prime \prime} .5
$$$$
\text { und } \lambda=34 \quad 3028.9 \text {. }
$$

Nimmt man für Mohuru

$$
\begin{array}{rlll}
\varphi & =-\mathrm{I}^{\circ} & \mathrm{O}^{\prime} & 24^{\prime \prime} .2 \\
\text { und } \lambda & = & 3 & 55.2
\end{array}
$$

an, so erhält man durch die Triangulation für Ndere

$$
\varphi=-\mathrm{O}^{\circ} \mathrm{I} 2^{\prime} 23^{\prime \prime} \cdot 7
$$

und $\lambda=3430^{\circ} 3$ I.I.

Die Länge muß allerdings noch wegen des hier eingeführten Wertes der Länge von PortFlorence gegenüber dem Mittelwert, wie er zunächst benutzt worden, um 2".3 korrigiert werden, damit sie wieder in Übereinstimmung mit der Länge von Port Florence kommt. Für den Log. der Länge der Seite Port Florence-Maragul folgt aus derEntebbe-Triangulation

$$
\text { 4. } 154 \text { I } 88
$$

und aus der Triangulation Schirati-Port Florence

$$
\text { 4. } 154196 .
$$

Das macht in der Länge selbst nur einen Unterschied von

$$
0.25 \mathrm{~m} \text {. }
$$

Weiterhin erhält man für den Log. der Seite Ndere-Maragul auf dem ersten Wege

auf dem zweiten Wege

$$
4.448095
$$

$$
4.448 \text { I06, }
$$

welches seinerseits nur eine Verschiedenheit von

$$
0.68 \mathrm{~m}
$$

ausmacht, also etwa $1 / 30000$ der Länge. Die Dimensionen der Anschlußseite finden sich soweit übereinstimmend, als man es nach der Ausführung der Messungen und speziell der Genauigkeit der Winkelmessungen verlangen kann. Dagegen weichen in Breite die beiden Resultate um den nicht unerheblichen Betrag von fast $\mathrm{IO}^{\prime \prime}$ voneinander ab. . Ich habe beide Resultate nebeneinander bestehen lassen und sie nicht zur Mittelbildung für weitere Rechnungen benutzt, da die geodätische Übertragung von Schirati (bzw. Mohuru) auf alle Fälle bis auf I" genau sein dürfte. Anderseits ist auch die Bestimmung der astronomischen Breite für den MohuruPfeiler eine so gute, daß, falls die englische Angabe der Breite von Port Florence richtig ist, bzw. sich auf denselben Punkt bezieht, eine Lotabweichung nachgewiesen wäre. Die direkte astronomische Breite von Entebbe (trigonometrischer Punkt) wurde $\mathrm{zu}$

$$
\varphi \boldsymbol{E}_{\varepsilon}=+0^{\circ} 3^{\prime} 59^{\prime \prime}
$$

gefunden, die von Port Florence übertragene Breite zu

$$
\varphi \boldsymbol{E}_{\varepsilon}=+\mathrm{O}^{\circ} 3^{\prime} 53^{\prime \prime} \text {. }
$$

Wird der Ausgangspunkt für Port Florence um nahezu $\mathrm{IO}^{\prime \prime}$ verringert, d. h. so angenommen, wie er sich aus der Triangulation Schirati-Port Florence findet, nämlich $\mathrm{zu}$

$$
\varphi \text { Pt.Fl. }=-\mathrm{o}^{\circ} \sigma^{\prime} \mathrm{o}^{\prime \prime} .6
$$

(ob die Orte ganz identisch sind, konnte ich nicht entscheiden), so erhält man für Ndere

$$
\varphi=-0^{\circ} \text { I } 2^{\prime} 23^{\prime \prime} \cdot 7
$$

wie oben angegeben und damit für Entebbe

$$
\varphi E_{\varepsilon}=+0^{\circ} 4^{\prime} 3^{\prime \prime}
$$


einen Wert, der von dem direkt astronomiseh bestimmten im ungeliehrten Sinne abweicht. Die Triangulation Kagera-Entebbe hat auf Grund des astronomisch sehr sicher bestimmten Punktes 4 für Entebbe (Triangulationssignal) geliefert

$$
\varphi E_{\varepsilon}=+0^{\circ} 4^{\prime} \mathrm{O}^{\prime \prime} .4
$$

Die Breitendifferenz Entebbe Port Florence betrug

$$
\lrcorner \varphi=\quad \mathrm{O}^{\circ} \mathrm{IO}^{\prime} 3^{\prime \prime} .2
$$

somit wird auf diesem II'ege

$\varphi$ Port Florence $=-0^{\circ} 6^{\prime} 2^{\prime \prime} .8$

und mit der Breitendifferenz Port Florence-Ndere

$$
\Delta f=-0^{\circ} \quad 6^{\prime} 23^{\prime \prime} .1
$$$$
\varphi \text { Nidere }=-\begin{array}{llll}
0 & \text { I } 2 & 25 & 2.9
\end{array}
$$

Man hat also für den Punkt Ndere

$$
\varphi=-\mathrm{O} \mathrm{I}^{\prime} 23^{\prime \prime} .5
$$

nach Angaben der englischen Triangulation,

$$
\varphi=-\mathrm{O}^{-} 12^{\prime} 23^{\prime \prime} .7
$$

als Resultat der Triangulation Mohuru-Port Florence mit dem astronomischen Wert der Breite von Mohuru und $\varphi=-0^{\circ}$ I $2^{\prime} 25^{\prime \prime} \cdot 9$

nach der Übertragung von Punkt 4 (Bugera).

\section{B. Arbeiten an der Linie Schirati--} Kilimandscharo.

Nachdem das Azimut Mohuru nach dem vertragsmäßigen Grenzpunkte am Kilimandscharo, dessen Position zu

$$
\begin{aligned}
& \varphi=-2^{\circ} 57^{\prime} 36^{\prime \prime} . \mathrm{O} \text { und } \\
& \lambda=37 \text { 3 I } 12.0
\end{aligned}
$$

berechnet worden war und zwar unter Annahme, daß die Länge des Schnittpunktes des I. Grades südlicher Breite mit dem Seeufer

$$
\lambda=34 \quad 2^{\prime} \quad 29^{\prime \prime} .6
$$

(Naeh Ubereinkunft der Kommissare.)

sei, fand sich als Mittelwert dieses Azimutes am Ausgangspunkt der Wert

$$
119 \text { I } 8^{\prime} 9^{\prime \prime} .5
$$

von Norden über Osten gezählt. Mittels dieses Azimutes wurden Durchschnittspunkte der geodätischen Linie für eine Reihe von Längengraden in Breite berechnet. Ebenso die Azimute, unter welchen die geodätische Linie die betreffenden Längengrade schneidet. Die Resultate dieser Berechnungen sind die folgenden:

$$
\text { Länge Breite Azimut }
$$

$$
\text { für }
$$
a) $342^{\prime} 29^{\prime \prime} .6$ Seeufer - $\mathrm{I}^{\circ} \mathrm{O}^{\prime} \mathrm{O}^{\prime \prime}$
$119^{\circ} 18^{\prime} 9^{\prime \prime} .48$
b) 3430
c) $35 \mathrm{O}$
- I I 532.13
d) 3530
- I 3228.2 I
e) 36
-I 4923.57
f) 3630
- 26 I8.I3
$\begin{array}{lll}\text { I I9 } & \text { I } 7 & 36.95\end{array}$
I I9 $16 \quad 52.97$
I I9 I6 O.I3
II9 I $4 \quad 58.44$
g) 37
-223 II.73
I I9 $13 \quad 47.90$
h) $37 \quad 31 \quad 12$
-2404.25
-24736
$-25736$
I I9 I 228.53
I I9 IO 56.63

Demgemäß wurden nunmehr die Dreiecksketten angeordnet. Als Ausgangswerte wurden, wie schon erwähnt, die Länge der Seite Mohuru-Nundowat und deren Azimut angewandt. Eine große Anzahl von Dreiecken wurde von den beiden Kommissionen an der Grenzlinie entlang gelegt, wie sie die Übersichtskarte am Schlusse erkennen läßt. Die Resultate der Berechnumgen dieser Triangulation sind in den beigegebenen Abrissen, so weit sie von geographischem Interesse sind, aufgeführt. Außerdem wurden aber noch sehr viel mehr Punkte topographisch bestimmt. Diese können ihre V'erwendung aber nur in den betreffenden Kartenblättern finden, da sie auch meist nur mit MeBtischgenauigkeit festgelegt wurden. Nur soviel mag bemerkt werden, dab die trigonometrischen Messungen mit Hilfe der Kippregel auf dem Meßtisch selbst ausgeführt wurden und demgemäß eine ziemliche Genauigkeit beanspruchen können. (Durchschnittlich \pm I $m$ auf d. Kil. Entfernung.) Die barometrischen Höhenmessungen sind so ausgefuihrt worden, daB mittels eines Aneroidbarometers zwischen zwei Stationsablesungen die zu bestimmenden Höhen eingesehaltet wurden. $\left.{ }^{1}\right)$ Die errechmeten Koordinaten sind zwischen den beiden Expeditionsleitern von Zeit zu Zeit gegenseitig mitgeteilt und verglichen worden, wo solche Vergleiche stattfanden, habe ich sie in den Abrissen mit angegeben. Es geht aus ihnen hervor, daß die beiderseitigen Messungen und Rechnungen stets in guter Übereinstimmung geblieben sind. Für die vorliegenden Berichte ist es aber besonders von Interesse, die Resultate der geodätisch berechneten Koordinaten und Azimute mit den an einigen Punkten astronomisch beobachteten $\mathrm{zu}$ vergleichen. Wenn es auch solcher Punkte nur wenige sind, so dienen sie doch dazu, ein Urteil über die Übertragungsgenauigkeit zu gewinnen. Der erste Punkt, von welchem eine solche astronomische Beobachtung vorliegt, ist die Station Kilibe. Dort wurde von Hauptmann Schlobach eine Anzahl Azimutbeobachtungen einer Marke angestellt. Durch Anschluß der Marke an den Punkt Luanje ist das Azimut der Seite Kilibe-Luanje astronomisch ermittelt. Es fand sich das Azimut der Marke im Mittel aus 4 Beobaehtungen $\mathrm{zu}$

I $59^{\circ} 48^{\prime} \quad 40^{\prime \prime}$
der Winkel Marke-Kilibe-Luanje zu
$239^{\circ} \quad 26^{\prime} \quad$ I I" $^{\prime \prime}$
und damit das Azimut der Seite Kilibe-Luanje
$39^{\circ} \quad$ I $^{\prime} \quad 5 I^{\prime \prime}$

1) Ein Darmersches Quecksilber-Barometer hatte die Expedition anfänglich zur Verfügung, es ist mit demselben eine Reihe von Beobachtumgen ausgeführt worden, dann aber zerbrach das Glasrohr. 
Die geodätische Übertragung liefert für dasselbe Azimut aus den

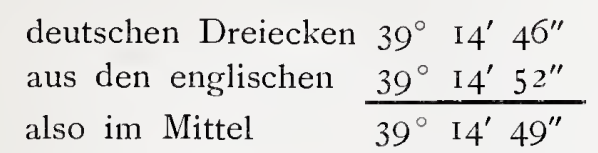

Die Übereinstimmung des astronomischen und des geodätischen Resultates für das Azimut KilibeLuanje ist eine so gute, daß von einer Korrektion der Azimute auf Grund dieser Vergleichungen abgesehen worden ist. Eine Breitenbestimmung liegt leider für den Ort Kilibe nicht vor. Der nächste Vergleichspunkt ist das Standlager nördlich des Kilimandscharo in der Landschaft Leitokitok. Für diesen Punkt liegt eine große Anzahl von astronomischen Breitenbestimmungen vor. Der Mittelwert derselben ergibt für den Beobachtungsplatz

$$
\left.-2^{\circ} 57^{\prime} \quad 23^{\prime \prime} .2 \pm 0^{\prime \prime} .5^{1}\right)
$$

Die geodätische Übertragung liefert für diesen Punkt die Breite von

$$
\begin{aligned}
& -2 \quad 57 \quad 34.45 \\
& \hline
\end{aligned}
$$

Das bedeutet einen Unterschied zwischen astronomischem und geodätischem Wert der Breite von

$$
\varphi \text { astron. }-\varphi \text { geod. }=+\mathrm{II}^{\prime \prime}, 2
$$

Diese ziemlich starke Verschiedenheit findet eine genügende Erklärung in dem südlich gelegenen Gebirge des Kilimandscharo, dessen Entfernung vom Beobachtungsort nur etwa Io bis $15 \mathrm{~km}$ beträgt. Eine Azimutmessung, welche von Hauptmann Schlobach mit Hilfe einer Marke ausgeführt wurde, lieferte das astronomische Azimut der Seite Leitokitok-Longaria $\mathrm{zu} \quad 7 \mathrm{I}^{\circ} \quad 3^{8^{\prime}} 54^{\prime \prime}$

während das Dreieck Leitokitok-Longaria-Loosoito für die Seite Leitokitok--Longaria das Azimut von

$$
7 \mathrm{I}^{\circ} \quad 38^{\prime} \quad 59^{\prime \prime} \cdot 34
$$

finden ließ. Auch hier zeigt sich nur eine Abweichung von $5^{\prime \prime} .3$, welche bei der immerhin vorhandenen Unsicherheit des astronomischen Azimutes von $3^{\prime \prime}$ bis $4^{\prime \prime}$ vollständig vernachlässigt werden kann.

Nach Ausmessung und Berechnung des genannten Dreiecks wurde von den beiderseitigen Kommissaren eine Mittelung für die Seite LongariaLoosoito sowohl bezüglich des Azimutes, wie der Länge vorgenommen. Die betreffenden Einzelwerte sind die folgenden

Log. der Seite in Fußen $=4,9258034$ englischer Wert , " " , , $=4,9258837$ deutscher ," in engl. Fußen Mittel $=4.9258436=4.4098552 \mathrm{~m}$

Der Unterschied beträgt nur etwas mehr als $5 \mathrm{~m}$, das ist rund $\frac{\mathrm{I}}{50000}$ der Länge.

$\left.{ }^{1}\right)$ Vgl. Zusammenstellung in der Liste der Einzelbeobachtungen.
Das Azimut Longaria--Loosoito I $86^{\circ} 39^{\prime} 56^{\prime \prime} .6$ englischer Wert $\begin{array}{r}186^{\circ} 39 \quad 40.9 \text { deutscher Wert } \\ \hline 186^{\circ} 39^{\prime} 488^{\prime \prime}\end{array}$

Mittel $186^{\circ} 39^{\prime} 48^{\prime \prime} 8$

und für die Koordinaten von Longaria

$$
\begin{aligned}
& \varphi=-2^{\circ} 56^{\prime} 2^{\prime \prime} .0 \quad \lambda=37^{\circ} 35^{\prime} 4 \mathrm{O}^{\prime \prime} .83 \text { (engl.) } \\
& \frac{2.74}{\varphi=-2^{\circ}} \frac{5^{\prime} 2^{\prime \prime} .38 \lambda}{}=37^{\circ} 35^{\prime} \frac{4^{\mathrm{I}} .3 \mathrm{O} \text { (deutsch) }}{4 \mathrm{I}^{\prime \prime} .07 \text { Mittel. }}
\end{aligned}
$$

Mit diesen Mittelwerten sind die Koordinaten von Loosoito auf Grund der geodätischen Koordinaten von Leitokitok neu berechnet worden, ebenso auch das Azimut und die Seitenlänge, welche nun ihrerseits wieder die Ausgangsdaten für die weiter nach Südosten fortgesetzte Triangulation bilden. Es ist dadurch eine Korrektion der Kette vorgenommen worden, welche für die Beurteilung des gleich noch zu besprechenden Anschlusses an Zanzibar ohne Bedeutung bleibt.

Es sind zur Kontrolle der Dimensionen der Dreieckskette noch zwei Basislinien gemessen worden, nämlich in der Nähe von Leitokitok und bei Taveta am Südende der offiziellen Grenzarbeiten. Über erstere Basis sind mir Einzelheiten nicht bekannt geworden, aber bezüglich der zweiten Linie finden sich in den Büchern von Hauptmann Schlobach mehrere Angaben. Wenn sich daraus auch genaue Einzeldaten nicht ableiten ließen, so konnte doch die Gesamtlänge der Basis bestimmt und ihre Länge auf den Horizont reduziert werden. Die Messung wurde von Hauptmann Schlobach und Major Bright mit dem englischen 400 FuB-Band ausgeführt bei einer Belastung mit 12 englischen Pfund. Man hatte aus je vier Messungen:

\begin{tabular}{rrr} 
I. & 8402.1477 Fup (wegen & Temp. \\
II. & $.0590 \%$ & Korr.) \\
III. & $.1488 »$ & \\
IV. & $.1339 »$ & \\
\hline Mittel & 8402.1224 Fuß &
\end{tabular}

Korr. w. Durchh. - I.37 IO »

Red. auf Meereshor. - I.0520 "

Länge der Basis im

M. Hpt. $\left.8399.7000 \pm 0.021^{1}\right)$

Die Unsicherheit wird auf $\frac{1}{60000}$ von Hauptmann Schlobach angegeben; aus den vier Einzelmessungen findet sich nur $\frac{1}{400000}$.

Die Länge der Seite Chala_Latema läßt sich nun sowohl direkt aus der Basis mittels des Dreiecks: BS-BN--Latema und des Dreiecks: BS-LatemaChala berechnen, und außerdem ist sie eine Seite

1) I.g. in engl. FuBen 3.9242638 .

, "Netern 3.4082754. 
der Hauptdreiecksliette. Die beiden Resultate sind: Direlite Rechnung $1 \mathrm{~g} . \mathrm{S}=4.061 \mathrm{I} 26 ; \mathrm{S}=\mathrm{I}$ I $5 \mathrm{II} .3 \mathrm{~m}$ Aus d.Dreiecksnetz $1 \mathrm{~g} . \mathrm{S}=4.06 \mathrm{I} 180 ; \mathrm{S}=\mathrm{I} 15 \mathrm{I} 2.7 \mathrm{~m}$

Der Unterschied beträgt also nur $\mathrm{I}+\mathrm{m}$ m zwischen beiden Werten oder etwa $\frac{1}{800} \overline{\text { der Länge. }}$

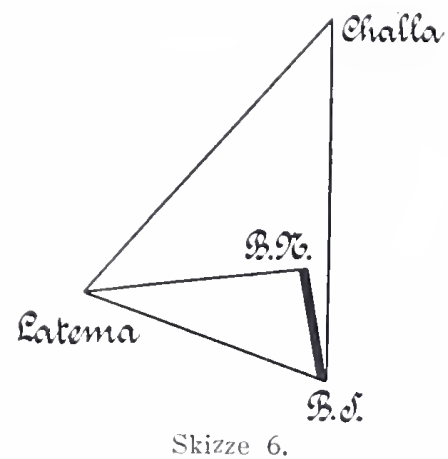

Eine Veränderung der Dimensionen der Kette ist nicht vorgenommen worden, da die Unsicherheit für den vorliegenden Zweck ohne Belang und die Übertragung nach Zanzibar wieder durch die Dreiecke der Usambara-Landesvermessung kontrolliert wird.

C. Anschlub der Dreieclisketten der UgandaGrenz-Expedition an Zanzibar.

Die weitere Fortsetzung der Vermessung hatte noch den Zweck, das Südende des Djipe-Sees festzulegen. Für die Dreiecke, welche sich bis dorthin zichen, ist eine astronomische Kontrolle nicht mehr vorhanden, dagegen ist später die Triangulation bis nach dem astronomisch sowohl bezüglich seiner Breite als seiner Länge sicher bestimmten Fixpunkte auf dem englischen Konsulatsgebäude in Zanzibar weiter geführt worden. Es sincl nur verhältnismäßig wenig Dreiecke, welche diesen Anschluß durch die Landschaft Usambara vermitteln. Die Dreiecke, welche vom Kilimandscharo nach Südosten gelegt wurden, schließen sich dort an einige Punkte der Usambara-Landesvermessung an, deren Koordinaten ihrerseits aus den Angaben jener Vermessung berechnet werden konnten. Die Vermessung der Grenztriangulation schliebt sich an die Usambara-Punlite Funta-Tusa-Schageiu an. Für die beiden letzten Orte sind die geographischen Koordinaten sowohl auf Grund der Grenztriangulation als auch auf Grund der Usambara-Landesvermessung nach den Angaben des Landmessers Techmer berechnet worden ${ }^{1}$ ), so daß in Länge und Breite die Redultion beider Systeme aufeinander ausgeführt werden kann. Mit den letzten

1) Die Grundlagen dex Usambaratriangulation sind mir nur insoweit bekannt als deren Ursprungspunkt $z \mathrm{u} \varphi=-5^{\circ} \mathrm{o}^{\prime} \mathrm{u} . \lambda$ $2 u 38^{\circ} 30^{\prime}$ angenommen wird; auf welchen Bestimmungen diese Koordinaten beruhen, wird nirgends mitgeteilt. beiden Punkten stehen durch eine Dreieckskette der Usambara-Triangulation die Punlite Segera und Tongwe in Verbindung, und diese remitteln durch ein großes Fünfeck mit dem zentralen Punlite Gendagenda an Zanzibar. (Vgl. Skizze.) In dem Fünfeck Koft-Segera-Tongwe-Zanzibar-Kondussi sind alle Winkel gemessen, und es ist eine Ausgleichung durch Teilung in zwei Vierecke vorgenommen worden, so daß man auf zwei vollständig unabhängigen Wegen zu den Koordinaten ron Zanzibar gelangt. Diese Berechnung lieferte ein so gut übereinstimmendes Resultat für die Koordinaten von Zanzibar, daß eine vollständige Ausgleichung des Zentralsystems um Gendagenda nicht erforderlich wurde. Die einzelnen Daten, wie sie sich für Tusa und Schageiu aus der Grenz-Triangulation und weiterhin für diese Orte und die übrigen Punkte des Systems um Gendagenda ergeben, zeigt nachstehende Tabelle. Der Unterschied, welcher zwischen den Koordinaten für Tusa und Schageiu aus beiden Systemen sich ergibt, diurfte in den verschiedenen Grundlagen beider Systeme im wesentlichen seinen Grund haben. Derselbe kommt hicr aber nicht in Betracht, da er lediglich zur Übertragung des Uganda-Grenzsystems auf die Koordinaten von Zanzibar dienen soll. Bringt man diesen Unterschied an die auf Grund der Landesvermessung berechneten Koordinaten von Zanzibar an, so werden diese dadurch auf das System der Uganda-Grenzexpedition bezogen.

Man erhält dann für die Breite des Beobachtungspunktes in Zanzibar $\varphi=-6^{\circ} 9^{\prime} 49^{\prime \prime} .42$ und dessen Länge $39^{\circ}$ I I' I $5^{\prime \prime} .86$ östlich von Greenwich.

Nun sind nach den Angaben des Kapitän Behrens die Koordinaten des Pfeilers auf dem englischen Konsulat

$$
\varphi=-6^{\circ} 9^{\prime} 45^{\prime \prime} .8 \pm 0^{\prime \prime} .3 \text { Länge }=39^{\circ} \text { I I }^{\prime \prime} 4^{\prime \prime} .7 \pm 7^{\prime \prime} .5 \text {. }
$$

Es befand sich die Beobachtungsstation aber nicht auf diesem Pfeiler selbst, sondern sie lag um $0^{\prime \prime} .25$ südlicher, und um $O^{\prime \prime} .2$ westlicher, so daß man damit die Koordinaten des Dreieckspunkites Zanzibar erhält:

$$
\varphi=-6^{\prime \prime} 9^{\prime} 46^{\prime \prime} .05 \text { und Länge } 39^{\circ} \mathrm{II}^{\prime} 4^{\prime \prime} .5 \text {. }
$$

Aus der Vergleichung der Koordinaten von Zanzibar, wie sie aus der Übertragung der Ugandaexpedition folgen, mit den direkten Werten aus astronomischen Beobachtungen, für welche die Länge aus der Übertragung Kapstadt-Zanzibar-Aden gefolgert ist, findet man die Differenzen (astron.-geod.)

$$
\Delta \varphi=+3^{\prime} \cdot 37 \text { und } \Delta \lambda=-\mathrm{II}^{\prime \prime} . \mathrm{IO} \text { östl. Lge. }
$$




\section{Ubersicht über den Anschluß der Triangulation der Uganda-Expedition an Zanzibar.}

Ort Koordinaten aus der Grenzexpedition

\begin{tabular}{|c|c|c|c|c|c|}
\hline & & $\varphi$ & & & $\lambda$ \\
\hline Tusa & $-4^{\circ}$ & $9^{\prime}$ & $24 . " 29$ & $38^{\circ} \quad 5$ & $5^{\prime}$ I $7 .^{\prime \prime} 2$ \\
\hline Schagein & -4 & 30 & 57.59 & $38 \quad 17$ & $\begin{array}{ll}7 \quad 43.24 \\
\end{array}$ \\
\hline Funta & & & & & \\
\hline Segera & & & & & \\
\hline Tongure & & & & & \\
\hline Gendagenda & & & & & \\
\hline Kofi & & & & & \\
\hline Kondussi & & & & & \\
\hline Zanzibar & & & & & \\
\hline
\end{tabular}

Koordinaten aus der Usambara-Landesvermessung und Difterenzen Grenzexp. - Ldsverm.

$\begin{array}{rrrr} & \varphi & & \Delta \varphi \\ -4 & 9^{\prime} & 33^{\prime \prime} 5^{2} & +9 .^{\prime \prime 23} \\ -4 & 31 & 6.43 & +8.84 \\ -4 & 29 & 0.45 & \\ -5 & 18 & 47.40 & \\ -5 & 18 & 30.74 & \\ -5 & 34 & 25.86 & \\ -5 & 28 & 49.20 & \\ -5 & 48 & 18.04 & \\ -6 & 9 & 58.46\end{array}$

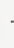

Es sind also an die Koordinaten von Zanzibar (Usambara-Laudesvermessıng + Grenzvermessung) die Beträge von $+9 .{ }^{\prime \prime} 04$ bzw. - 9."9o anzubringen, 1 m sie auf das System der Uganda-Grenzexpedition zu beziehen, damit exhält man für Zanzibar (geod.) . . . . . . . Diese letzten Werte, verglichen mit den aus astronomischen Beobachtungen gefolgerten Koordinaten voll Zanzibar ${ }^{1}$ ) .

und verbessert wegen anderen Pfeilers.

Beobachtungspfeiler (Helio)

\begin{tabular}{|c|c|c|c|c|}
\hline$-6^{\circ}$ & $9^{\prime} 49 . .^{\prime \prime} 42$ & $39^{\circ}$ & $\mathrm{II}^{\prime}$ & I5." 86 \\
\hline$-6^{\circ}$ & $\begin{array}{ll}9^{\prime} & 45 .^{\prime \prime} 80 \pm 0 .{ }^{\prime \prime} 30 \\
- & 0.25\end{array}$ & $39^{\circ}$ & $\underline{\mathbf{I}^{\prime}}$ & $\begin{array}{l}4 \cdot{ }^{\prime \prime} 70 \pm 7 \cdot^{\prime \prime} 50 \\
0.20\end{array}$ \\
\hline$-6^{\circ}$ & $9^{\prime} 46 . " 05 \pm 0 .{ }^{\prime \prime} 30$ & $39^{\circ}$ & $I^{\prime}$ & $4.5^{\circ} \pm 7 .^{\prime \prime} 5^{\circ}$ \\
\hline
\end{tabular}

\section{Schlußwort. .}

Die Übereinstimmung der trigonometrisch übertragenen Koordinaten für Zanzibar mit den direkten astronomischen ist eine sehr gute zumal in Rücksicht auf die mittleren Fehler der Breite Mohuru, auf welche die Übertragung gegründet ist, und auf die sehr große Unsicherheit der Länge von Zanzibar. Es geht aus dieser Übereinstimmung offenbar hervor, daß auch die Länge von Mombasa, welche doch für diejenige von Port Florence als Ausgangswert diente, ziemlich sicher bestimmt zu sein scheint. Man könnte daran denken, den Unterschied in der Länge von $9^{\prime \prime} .4$ (der aber eine Unsicherheit von mindestens $\pm \mathrm{IO}^{\prime \prime}$ hat), etwa proportional der Entfernung von Zanzibar auf die Länge der Zwischenpunkte zu verteilen, aber ich möchte hier davon absehen, denn die telegraphische Übertragung Mombasa-Port Florence dürfte ihrerseits doch auf nicht mehr als auf etwa \pm 0.3 Zeitsekunden sicher sein, und diese Unsicherheit in Verbindung mit derjenigen der Zanzibarlänge ist schon vollständig imstande, die ganze Differenz zu erklären, und aufserdem ist die kontinentale Lage von Mohuru gegenüber derjenigen von Zanzibar im Osten eines ausgedehnten Erdteiles gerade in bezug auf Länge stark durch Lotabweichung beeinfurst, so dafs eine solche Verteilung direkt widersinnig wäre. Es ist durch die Zeitübertragung von Mombasa nach Port Florence und durch die Dreieckskette Zanzibar - Kilimandscharo - Mohuru - Port Florence eine Längenbestimmung für letzteren Punkt erhalten worden, welche sicher bis auf $1 / 2$ Zeitsekunde zuverlässig ist. Die Verbindung von Port Florence mit Entebbe auf zweifachem Wege und die Dreieckskette zwischen letzterem Punkt, dem Kiwu-See und Usumbura mit dem Tanganjika geben wiederum eine sehr sichere Kontrolle für die Längenbestimmung, welche Professor Lamp in Usumbura durch Mondkulminationen erhalten hat. Wenn man in diesem Sinne die Gesamtarbeit, welche von der Kiwu-SeeExpedition und von der Uganda-Grenzexpedition in so umfangreichem Maße geleistet worden ist, überblickt, so sieht man, daß durch diese Arbeiten nicht nur bezüglich der geographischen Breitenbestimmungen, welche ja weitere Schwierigkeiten nicht bieten, sondern auch bezüglich derLängenübertragung sehr sichere Resultate erzielt worden sind. Diese Arbeiten würden sich leicht mit denen von Professor Kohlschütter in Verbindung bringen lassen, wenn man an dem Ostufer des Tanganjika-Sees entlang eine Dreiecisskette von Usumbura nach Süden bis zu dem Kohlschütterschen Punkte an der Kalambomündung legen würde, da die geographische Länge, welche Professor Kohlschütter dort bestimmt hat, auf der telegraphischen Übertragung von Kapstadt her und auf dessen Triangulation zwischen dem Njassa und dem Tanganjika beruht. Es würde dann eine vollständige Schlinge Zanzibar-Port Florence-Entebbe-Usumbura-Udjidji-NjassaKapstadt-Zanzibar vorliegen, welche nicht nur die geographischen Koordinaten vieler Punkte

1) Die hier benutzten astronomischen Koordinaten von Zanzibar sind die von Cpt. Behreus angegebenen.

Die Connaissance des Temps gibt für. den Pfeiler auf dem englischen Konsulate: $\varphi=6^{\circ} 9^{\prime} 42^{\prime \prime}$ und $\lambda=39^{\circ} \mathrm{II}^{\prime} 8 .^{\prime \prime} 4$ nach den Vermessungen von I 900.

Mitteilungen a. d. D. Schutzgebieten, XX. Band. IV. 
Zentralafrikas sicher bestimmen wiirde, sondern auch dazu dienen könnte, Störungen der Geoidfläche, wie sie sicherlich durch die beiden großen afrikanischen Grabengebiete besonders in Länge bewirkt werden, aufzufinden. Die verhältnismäBig wenigen Daten, welche in dieser Beziehung die U'ganda-Grenzexpedition liefern kann, gehen aus den obigen Darlegungen hervor. Die Abweichungen zwischen astronomischen und geodätischen Bestimmungen sind im allgemeinen sehr gering, nur an dem Nordufer des Victoria-Sees in Entebbe und nördlich des Kilimandscharo-Gebirges scheinen sie von Belang zu sein.

Wie frïher bemerkt, sind sowohl die Winkelmessungen in den großen 1)reiecksnetzen als auch die Längenbestimnungen der Basislinien zum Teil nicht von der Genauigkeit, wie sie für eine große Triangulation, welche möglicherweise zu Gradmessungszwecken Verwendung finden könnte, bedingt werden. Und es ist deshalb eine vollständige einheitliche Ausgleichung der ausgedehnten Netze nicht durchgeführt, ganz abgesehen davon, daf eine solche einen außerordentlich großen Zeit- und Arbeitsaufwand bedingt hätte, (ler dem IVesen einer solchen Grenzexpeditionsaufnahme nicht entsprochen hätte; denn diese soll doch zunächst nur die Grundlagen für die Topographie der Grenzgebiete schaffen, damit dadurch die Auswahl natürlicher Grenzen zwischen den Schutzgebieten ermöglicht wird. Dic von unseren Expeditionen ausgewählten Dreieckspunkte können aber für kïnftige genauere Messungen, wie sie für eine zusammenhängende Gradmessung zwischen Kairo und Kapstadt geplant wird, als vorzuigliche Rekognoszierung dienen. Anderseits künnen solche Dreiecksketten für die nächstliegenden Bedïrnisse der Landesvermessung ohne Bedenken verwendet werden. Es ist also nicht zu verkennen, daB die Arbeiten der Kiwu- und Uganda-Grenzexpedition auBer dem geographischen Interesse, welches sie bieten, auch für die Landesvermessung Ostafrikas wichtige Anhaltspunke geschaffen haben.

\section{Abrisse der Stationen der Triangulationen der Uganda-Grenz-Expedition.}

Den Abrissen sind zugleich die errechneten geographischen Koordinaten beigefingt.

\section{Abrisse der Kette Hungaberg bis Kagera- Mündung.}

Richtung nach

XIX

XXI.

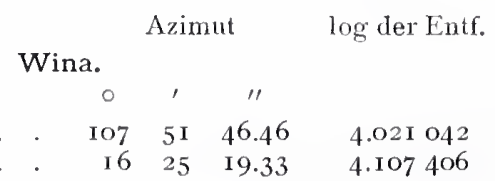

Ue.

$\varphi=-0^{\circ} 59^{\prime}+3 \cdot 4^{\prime \prime} \quad \lambda=30^{\circ} 2^{\prime} \mathrm{Io}^{\prime \prime}$.

I $74 \cdot 2+17.56$

$17+\cdot 2 \quad 47.56 \quad 3.87+1594$ XXII.

XXI. $\begin{array}{lll}95 & 31 & 39.79\end{array}$ $\varphi=-\mathrm{I}^{\circ} \mathrm{o}^{\prime} \mathrm{o}^{\prime \prime} \quad \lambda=30^{\circ} \mathrm{I}^{\prime}+9^{\prime \prime}$.

XVIII. I68 IO II.74 $\begin{array}{lll}92 & 34 & 49.75\end{array}$ XXI. (Kahotora).

Wina

XIX.

XXII.

Ruembogo

Nsassa

Ue

$\mathrm{Xx}$.

XVIII.

XXI.

XIX.

XVIII.

Wint

XXI.

NX.

XVIII.

XVII.

\section{XXI.}

Nsassa

Basis Sür

XXII.

Basis Nord

\section{XXI.}

Ruenbogo

Basis Siid

Basis Nord

$\varphi=-\mathbf{I}$
Nsassa.
Ruembogo

Basis Nord

Basis siid Ruembogo Nsassa .

XXII

Ue

XXI.

XX.

XIX.

XVII.

XVI.

$\mathrm{X} 1 \mathrm{X}$.

XVIII

XVI.

XV. $+.0342609$

3.8492691 4.0589865

$\gamma=-\mathrm{I}^{\circ} 3^{\prime}+6^{\prime \prime} \quad \lambda=30^{\circ} 2^{\prime} 36^{\prime \prime}$.

$\begin{array}{lll}196 & 25 & 17.04\end{array}$

$\begin{array}{lll}157 & 39 & 42.63\end{array}$

$\begin{array}{lll}348 & \text { I0 } & \text { 10. } 89\end{array}$

$\begin{array}{lll}76 & 24 & 2.80\end{array}$

$\begin{array}{lll}32 & 35 & 2.71\end{array}$

$\begin{array}{lll}354 & 2 & 47.11\end{array}$

$\begin{array}{lll}307 & 22 & 12.05\end{array}$

$\begin{array}{lll}57 & 2 \mathrm{I} & 30.98\end{array}$ $\mathrm{XX}$.

$\varphi=-\mathrm{I}^{\circ} \mathrm{I}^{\prime} 4^{\prime \prime} \quad \lambda=29^{\circ} 59^{\prime} 6^{\prime \prime}$.

$\begin{array}{lll}127 & 22 & 15.86\end{array}$

I $47 \quad 5 \mathrm{I} \quad \mathrm{I} 7.27$

$\begin{array}{lll}84 & 58 & 21.06\end{array}$

XIX.

$\varphi=-\mathrm{I}^{\circ} \mathrm{I}_{2^{\prime}} \mathrm{IO}^{\prime \prime} \quad \lambda=30^{\circ} 6^{\prime} 2^{\prime \prime}$,

$\begin{array}{lll}287 & 5 \mathrm{I} & 34.76\end{array}$

$\begin{array}{lll}337 & 39 & 38.57\end{array}$

$\begin{array}{lll}327 & 5 \mathrm{I} & 9.2 \mathrm{I}\end{array}$

$\begin{array}{lll}9 & 23 & 32.01\end{array}$

$\begin{array}{lll}72 & 21 & 30.27\end{array}$

Ruembogo.

$q=-\mathbf{I}^{\circ} 2^{\prime} 32^{\prime \prime} \quad \lambda=30^{\circ} 7^{\prime} 39^{\prime \prime}$.

$\begin{array}{lll}256 & 23 & 57.25\end{array}$

$\begin{array}{lll}324 & 29 & \mathrm{I} 5.22\end{array}$

$308 \quad 40 \quad 39.44$

$\begin{array}{lll}293 & 18 & 38.21\end{array}$

$\begin{array}{lll}320 & 40 & 6.88\end{array}$

Nsassa.

$\varphi=-0^{\circ} 59^{\prime} 22^{\prime \prime} \quad \lambda=30^{\circ} 5^{\prime} 24^{\prime \prime}$

$\begin{array}{lll}212 & 34 & 59.7 \mathrm{I}\end{array}$

$144 \quad 29 \quad 17.61$

$\begin{array}{lll}164 & 43 \quad 53.28\end{array}$

$\begin{array}{lll}\text { II } 2 & 2 \text { I } & \text { I } 3.32\end{array}$

3.983285

3.856 I 78

3.522232

3.331168

\section{Basis Süd.}

$$
\begin{aligned}
& \mathrm{I}^{\prime} 6^{\prime \prime} \lambda=30^{\circ} 5^{\prime} 52^{\prime \prime} \text { astron. } q=-\mathrm{I}^{\circ} \mathrm{o}^{\prime} 59^{\prime \prime} \text {. } \\
& \begin{array}{lll}
344 & 43 & 52.79
\end{array} \\
& \begin{array}{lll}
\text { I } 28 & 38 & 4 \mathbf{I} .36
\end{array}
\end{aligned}
$$

Basis Nord.

. 204

I $56 \quad 29 \quad 9$

$\begin{array}{lll}292 & 21 & 13\end{array}$

3.421378

3.739209

XVIII.

$\varphi=-\mathrm{I}^{\circ} \mathrm{o}^{\prime} \quad \mathrm{I}^{\prime \prime} \quad \lambda=30^{\circ} 7^{\prime} 59^{\prime \prime}$.

$\begin{array}{lll}272 . & 34 & 43.27\end{array}$

$275 \quad 3 \mathrm{I} \quad 33.7 \mathrm{I}$

$\begin{array}{lll}237 & 21 & 25.14\end{array}$

$\begin{array}{lll}264 & 58 & \text { I I.65 }\end{array}$

$\begin{array}{lll}\text { I } 89 & 23 & 29.75\end{array}$

I $37 \quad 49 \quad$ II.40

XVII.

$\varphi=-\mathrm{I}^{\circ} 9^{\prime} 2^{\prime \prime} \quad \lambda=30^{\circ} \mathrm{I}^{\prime} \quad 5^{\prime \prime}$.

4.0589865

4.0342609

4.0744042

4.2 I 85790

4.3464003

4.3372985

4.4369088

$\begin{array}{rrr}252 & 2 \mathrm{I} & 38.16 \\ 3 \mathrm{I} 7 & 49 & 2.52 \\ 33 & 52 & 17.59 \\ 97 & 29 & 48.40\end{array}$

4.28 I 5032

4.3372985

$4.354787 \mathrm{I}$ 4.4056004 
XVI.

$$
\varphi=-0^{\circ} 58^{\prime} \quad 50^{\prime \prime} \quad \lambda=30^{\circ} \quad 22^{\prime} 39^{\prime \prime} \text {. }
$$

$\begin{array}{lllllll}\text { XVIII. . . . . . . . . } & \cdot & 264 & 22 & 4.48 & 4.436 & 9088 \\ \text { XVII. } & 213 & 52 & \text { IO.OI } & 4.3547871\end{array}$

XVII. . . . . . . . . . $\begin{array}{lllll}213 & 52 & \text { IO.OI } & 4.3547871\end{array}$

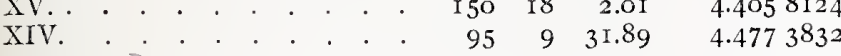
$\mathrm{XV}$.

$\varphi=-\mathrm{I}^{\circ} \mathrm{Io}^{\prime} 5 \mathrm{O}^{\prime \prime} \quad \lambda=30^{\circ} 29^{\prime} 28^{\prime \prime}$.

XVII. . . . . . . . . . $277 \quad 29 \quad 31.80 \quad 4.4056004$

$\begin{array}{lllllll}\text { XVI. . . . . . . } 330 & \text { I } 7 & 54.32 & 4.4058 \mathrm{I} 24\end{array}$

XIV. . . . . . . . . . $\begin{array}{rrrrr}4 \mathrm{I} & 4 \mathrm{O} & 32.86 & 4.4 \mathrm{I} 48_{529}\end{array}$

XIII. . . . . . . . $\quad 89$ 4r $\quad \begin{array}{llll} & 56.77 & 4.347 & 457 \mathrm{I}\end{array}$ XIV.

$\varphi=-\mathrm{r}^{\circ} \mathrm{o}^{\prime} \mathrm{r} 8^{\prime \prime} \quad \lambda=30^{\circ} 38^{\prime} 46^{\prime \prime}$.

XVI. . . . . . . . $275 \quad 9 \quad \mathrm{I} 5.13$

$\mathrm{XV} . \cdot \cdot \cdot \cdot \cdot \cdot \cdot \cdot 22 \mathrm{I} \quad 40 \quad 22.20$

XIII. . . . . . . . . $\quad \begin{array}{rrrr} & 65 & 32 & 44.16\end{array}$

XII. . . . . . . . 87 2I 16.7 I

XIII.

$\varphi=-\mathrm{I}^{\circ} \mathrm{Io}^{\prime} 46^{\prime \prime} \quad \lambda=30^{\circ} 4 \mathrm{I}^{\prime} 27^{\prime \prime}$.

XV.. . . . . . . 269 4I 4 I I.95 4.347457 I

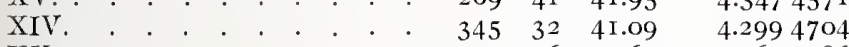

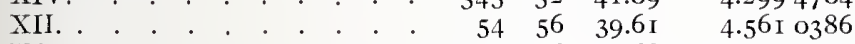

XI. . . . . . . . . . $\quad 9946 \quad 32.68 \quad 4.5723879$

XII.

$\varphi=-0^{\circ} 59^{\prime} 25^{\prime \prime} \quad \lambda=30^{\circ} 57^{\prime} 3 \mathrm{I}^{\prime \prime}$ astron. $\varphi=-\mathrm{O}^{\circ} 59^{\prime} 2 \mathrm{I}^{\prime \prime}$.

XIV. . . . . . . . . $267 \quad 20 \quad 57 . \mathrm{I} 3 \quad 4.54 \mathrm{I} 63 \mathrm{I} 2$

XIII. . . . . . . . $234 \quad \begin{array}{lllll}26 & 21.36 & 4.56 \text { I } 0386\end{array}$

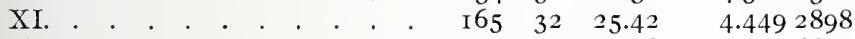

X. . . . . . . . 9 . 9 I $3 \mathrm{I} \quad 57 . \mathrm{I} 8 \quad 4.5456635$

$\mathrm{XI}$.

$\varphi=-\mathrm{I}^{\circ} \mathrm{I}^{\prime} \mathrm{I}^{\prime \prime} \quad \lambda=3 \mathrm{r}^{\circ} \mathrm{r}^{\prime} \mathrm{I}^{\prime \prime}$.

XIII. . . . . . . . . . $279 \quad 46 \quad 7.56$

XII. . . . . . . $\quad 34532$. 31.0

X. . . . . . . . $\quad \begin{array}{rrrr}46 & 52 & 36.64\end{array}$

IX. . . . . . . . . 9 I $47 \quad 57.29$

$\mathrm{X}$.

$\varphi=-0^{\circ} 59^{\prime} 56^{\prime \prime} \quad \lambda=3 \mathrm{I}^{\circ} \mathrm{I}^{\prime} \quad 27^{\prime \prime}$.

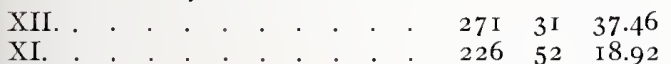

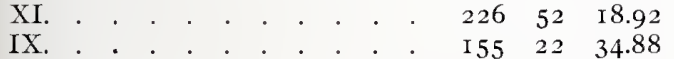

VIII. . . . . 104 3I 16.64

IXX.

$\varphi=-\mathrm{I}^{\circ} \mathrm{I} 4^{\prime} 54^{\prime \prime} \quad \lambda=3 \mathrm{I}^{\circ} 23^{\prime} \mathrm{I}^{\prime \prime}$

XI. . . . . . . . . . . . $27{ }^{2} \quad 274 \quad 28.72 \quad 4.610$ I3 365

$\begin{array}{lllllllllll}\text { X. . . . . . . } & 335 & \mathbf{2 2} & 26.87 & 4.482 & 0859\end{array}$

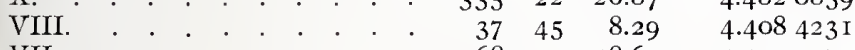

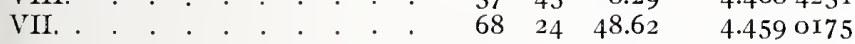

VIII.

$\varphi=-\mathrm{I}^{\circ} 3^{\prime} 55^{\prime \prime} \quad \lambda=3 \mathrm{I}^{\circ} 3 \mathrm{I}^{\prime} 43^{\prime \prime}$.

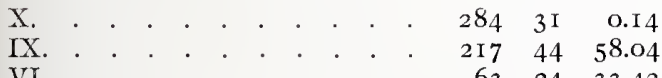

VI. . . . . . . 632433.42

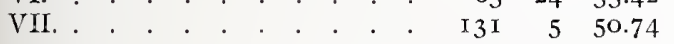

4.4662597 4.4084231 4.0341557 VII.

$\varphi=-\mathrm{I}^{\circ} 9^{\prime} 9^{\prime \prime} \quad \lambda=3 \mathrm{I}^{\circ} 37^{\prime} 42^{\prime \prime}$

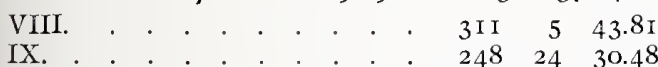

$\begin{array}{llllll}\text { IX. . . . . . . . . } & \cdot & 248 & 24 & 30.48 \\ \text { VI. } & \cdot & 354 & 28 & \text { I } 9.54\end{array}$

$\mathrm{Va} . . \quad . \quad . \quad \begin{array}{rrr}35 & 28 & 19.54 \\ 50.98\end{array}$

4.1672948

\section{Ulembe.}

VIII. . . . . . . . . . $\quad \begin{array}{llll}243 & 24 & 27.72\end{array}$

$\mathrm{Va}$

$\begin{array}{llllll}4 & 24 & 27.7\end{array}$

4.0341557

4.1672948 4.459 OI 75 4.163 5348 4.I 8 I 5047

$$
\text { III. }
$$

$\begin{array}{rrr}174 & 28 & 20.40 \\ 73 & 17 & 49 . \mathrm{II}\end{array}$

$$
\varphi=-\mathrm{I}^{\circ} 3^{\prime} 5^{6^{\prime \prime}} \quad \lambda=3 \mathrm{I}^{\circ} 44^{\prime} 2^{\prime \prime} .
$$

VII. . . . . . . . . . . $\begin{array}{lllllll}230 & 37 & 23.63 & 4.181 & 5047\end{array}$

III. . . . . . . . . . $\quad 22 \quad 53 \quad 56.42$

4.0396894

$$
\mathrm{V} \text {. }
$$$$
\varphi=-\mathrm{I}^{\circ} 2^{\prime} \mathrm{I}^{\prime \prime} \quad \lambda=3 \mathrm{I}^{\circ} 45^{\prime} 4^{\prime \prime} .
$$

III.

I8 $12 \quad 4.70$

3.869804

IV. Bugera (Ausgangspunkt).

astron. $\varphi=-0^{\circ} 56^{\prime} 5.0^{\prime \prime} \quad \lambda=3 \mathrm{I}^{\circ} 42^{\prime} \mathrm{Io}^{\prime \prime}$.

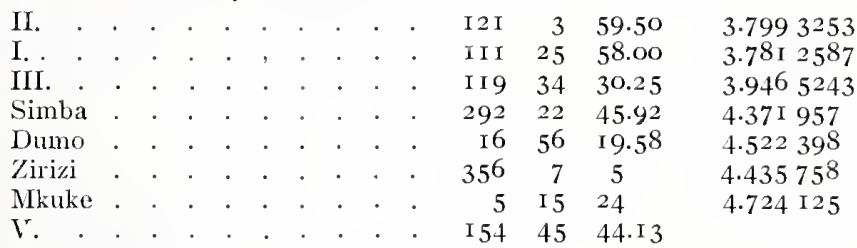

\begin{tabular}{|c|c|c|c|c|c|c|c|}
\hline & $\varphi=$ & $-o^{\circ}$ & $38^{\prime} 48^{\prime \prime}$ & $\lambda=$ & & $47^{\prime} 24^{\prime \prime}$ & \\
\hline$V$ Bugera. & 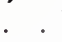 & 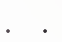 & 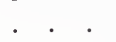 & 196 & $5^{6}$ & I 5.25 & 4.522398 \\
\hline . & . & . & . & 233 & 58 & $4 \mathrm{I}$ & $4.590 \mathrm{I} 25$ \\
\hline . & & . & . & 248 & 6 & I 8.5 & 4.095060 \\
\hline e & . & . & . & 346 & 56 & 42 & 666 \\
\hline umange) & . & . & . & 53 & I 4 & $9.0 \mathrm{I}$ & 4.783904 \\
\hline & & . & . & 9 & 2 & 43 & 59 \\
\hline & $\lambda$ & . & $\cdot$ & 68 & 24 & 52 & 4.62209 \\
\hline
\end{tabular}

III. Mizinda.

$\varphi=-0^{\circ} 58^{\prime} \quad 28^{\prime \prime} \quad \lambda=3 \mathrm{I}^{\circ} 46^{\prime} \quad \mathrm{I}^{\prime \prime}$

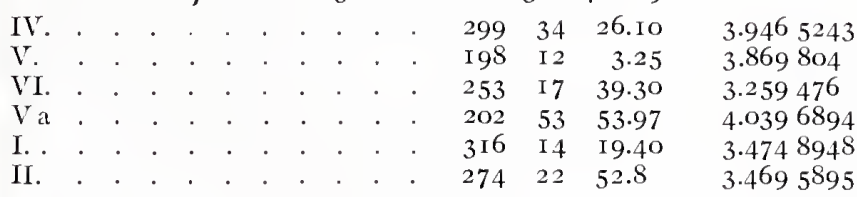

Dumo.

Bumange $\left(\mathrm{S}_{1}\right)$.

$\varphi=-0^{\circ} \mathrm{I}^{\prime} 3^{\prime \prime} \quad \lambda=32^{\circ} \mathrm{I} 3^{\prime} 4 \mathrm{o}^{\prime \prime}$.

$\begin{array}{llllllllll}\text { Dumo . . . . . . . . } & 233 & \text { I } 3 & 55.75 & 4.783 & 839\end{array}$

Eutebbe $\varepsilon .+2 . \quad . \quad . \quad 31 \quad 0 \quad 44.84 \quad 4.695238$

Entebbe $\varepsilon$.

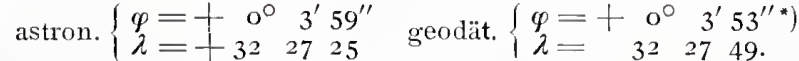

Bumange $\left(\mathrm{S}_{1}\right)$. . . . . . 2 II $\quad$ o $43.03 \quad 4.695238$

\section{Abrisse der Triangulation Port Florence- Entebbe.}

Richtung nach

Azimut log der Entf.

Port Florence.

$\varphi=-0^{\circ} 6^{\prime} \mathrm{Io}^{\prime \prime} \quad \lambda=34^{\circ} 44^{\prime} 49^{\prime \prime}$.

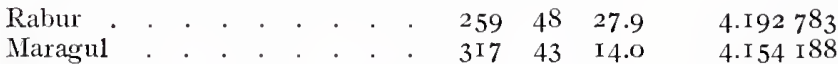

Rabur.

$\varphi=-0^{\circ} 7^{\prime} 40^{\prime \prime} \quad \lambda=34^{\circ} 36^{\prime} 33^{\prime \prime}$.

$\begin{array}{llllll}\text { Port Florence . . . . . . } & 79 & 48 & 28.9\end{array}$

Maragul . . . . . . . 23 2I 22.2

Ndere. $\quad . \quad 23$ I 2 I 18 I 8 . I

Marewa. . . . . . . $31922 \quad 31.2$

4.192783

4.161300

4. 159020

$4.0255^{8} 5$

Rambugu

Maragul.

4.443 I 88

$$
\varphi=-\mathrm{o}^{\circ} \mathrm{o}^{\prime} \quad 27^{\prime \prime} \quad \lambda=34^{\circ} 39^{\prime} 39^{\prime \prime} .
$$

Port Florence . . . . . I $\begin{array}{llll}37 & 43 & \text { I } 4.2\end{array}$

Rabur . . . . . . . . 2032121.9

Ndere . . . . . . . 217 I9 5.0

Marewa. . . . . . . $247 \quad 25 \quad 50.2$

4.154 I 88

4.16 I 300

*) Yol. Text, Seite 184 
Ndere.

Rabu*
Maragul
Marena
Rambugu .
Buga .

$\varphi=-0^{\circ} 2^{\prime} 34^{\prime \prime} \quad \lambda=34^{\circ} 30^{\prime} 29^{\prime \prime}$.

Aburi Hill.

\section{Marewa.}

$\begin{array}{rrrl}5 \text { I } & \text { 2 I } & \text { I } 9.2 & 4.159020 \\ 37 & \text { I } 9 & 6 . I & \\ \text { I } 4 & \text { I } 9 & 47.6 & \\ 306 & \text { I I } & 0.2 & 4.305959 \\ 257 & 56 & 7.4 & 4.15559 \text { I } \\ 276 & 23 & 2 \text { I.4 } & 4.462385\end{array}$

$\varphi=-0^{\circ} 3^{\prime}$ I $8^{\prime \prime} \quad \lambda=34^{\circ} 32^{\prime} 50^{\prime \prime}$.

Rabur
Maragul
Ndere.
Rambugu

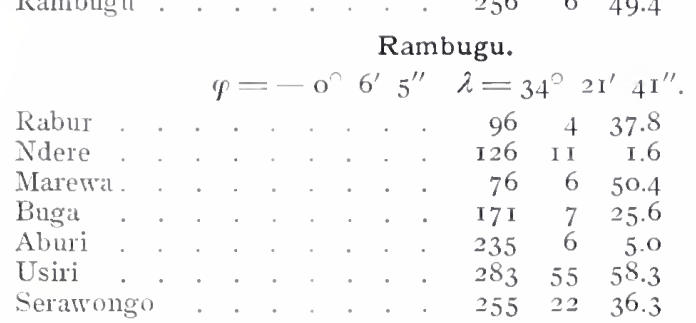

Buga.

$\begin{array}{rrrr}\text { I } 39 & 22 & 31.5 & 4.025585 \\ 67 & 25 & 50.5 & \\ 194 & 19 & 47.3 & \\ 256 & 6 & 49.4 & \end{array}$

$p=-\mathrm{o}^{\circ} \mathrm{I}^{\prime} \mathrm{ri}^{\prime \prime} \lambda=34^{\circ} 22^{\prime} 56^{\prime \prime}$.

Ndere .

Aburi

$$
\begin{array}{rrr}
77 & 56 & 9.2 \\
35 \mathrm{I} & 7 & 25.5 \\
292 & 45 & 28.6
\end{array}
$$

Aburi Hill.

Ndere.
Rambugi
Usiri
Serawongo
Ramogi .
Buga .

$\varphi=-0^{\circ} \mathrm{Io}^{\prime} 48^{\prime \prime} \quad \lambda=34^{\circ} \mathrm{I}^{\prime} 57^{\prime \prime}$.

. . . . . $9 \begin{array}{llll} & 96 & 23 & 24.8\end{array}$

$\begin{array}{lll}55 & 6 & 6.0\end{array}$

346 Iо 23.6

$\begin{array}{lll}279 & 55 & 23.1\end{array}$

$\begin{array}{lll}-310 & 22 & 38.1\end{array}$

Usiri Hill.

Rambugu

Aburi

Serawongo.

Ramogi .

Obambo

Wanga .

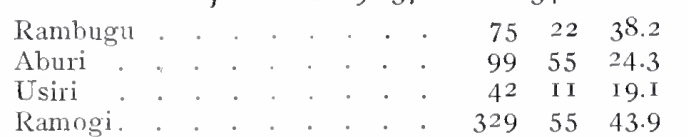

\section{Ramogi.}

$$
p=-0^{\circ} \mathrm{o}^{\prime} 35^{\prime \prime} \quad \lambda=34^{\circ} 3^{\prime} \mathrm{o}^{\prime \prime} .
$$

Aburi . . . . . . I $\begin{array}{llll}30 & 22 & 39.3\end{array}$

Usiri $\quad . \quad \begin{array}{llr}108 & \text { II } & 7.7\end{array}$

Serawongo . . . . . $\begin{array}{rrrr}449 & 55 & 44.3\end{array}$

Obambo

Wanga .

Namenya

Misoma

Usiri.

Ramogi .

Wanga .

$\begin{array}{rrr}67 & 2 & 43.3\end{array}$

$\begin{array}{lll}9 & 8 & 6.0\end{array}$

$\begin{array}{lll}319 & 49 & 7.8\end{array}$

Obambo.

$\varphi=+0^{\circ} 3^{\prime} \mathrm{I}^{\prime \prime} \quad \lambda=34^{\circ}$ I $2^{\prime} 4^{\prime \prime}$.

$\begin{array}{llr}170 & 3 \mathrm{I} & 0.9\end{array}$

$\begin{array}{lll}247 & 2 & 43.7\end{array}$

Wanga. $301 \quad 42 \quad 6.5$

$$
\varphi=+0^{\circ} 8^{\prime} 4^{\prime \prime} \quad \lambda=34^{\circ} 4^{\prime} 23^{\prime \prime} \text {. }
$$

Ramogi . I $89 \quad 8 \quad 6.1$

Obambo

$\begin{array}{lll}\text { I } 2 \text { I } & 42 & \text { I } 2.3\end{array}$

Namenya . . . . . 246 40 II.5

Misoma . . . . $\quad 338 \quad 34 \quad$ I 4.0

Usiri
4.443 I 88

4.305959

4. I 82768

4.462385 4. I 82768

4.112535

4.104037

4.463732

Nampongre.

Siavona.

Yumba.

Dagusi .

4. I I 2535

4.302454

Nimpongwe

Bumern.

Dagusi .

Iavia

Nampongwe

Bumeru

Yumba.

4.463732 4.302454

4.261840 4.207976

4'I 53233

4.386 497

4.261840

4.207976

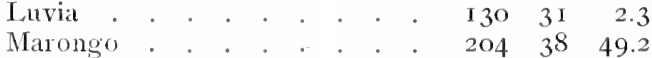

Namenya.

$$
\varphi=+\circ^{\circ} 5^{\prime} \mathrm{I}^{\prime \prime} \quad \lambda=33^{\circ} 5^{8^{\prime}} 3^{\prime \prime} .
$$

I $39 \quad 49 \quad 7.6$

$6640 \quad 10.9$

$\begin{array}{lll}32 & 6 & 0.3\end{array}$

$\begin{array}{lll}273 & \text { I } 7 & \text { I } 8.9\end{array}$

$\begin{array}{rrr}323 & 7 & 7.1\end{array}$

Misoma.

$p=+0^{\prime} \mathbf{1 2}^{\prime} 38^{\prime \prime} \lambda 34^{\circ} 2^{\prime} 36^{\prime \prime}$. $\begin{array}{lll}\text { I } 78 & \text { I } 6 & \text { I } 8.0\end{array}$ $\begin{array}{lll}158 & 34 & 14.7\end{array}$

$212 \quad 6 \quad$ I.I

$248 \quad$ I $6 \quad$ I 3.2

$\begin{array}{rrr}278 & 50 & 3.9\end{array}$

Nampongwe.

$\varphi=+0^{\circ} 6^{\prime} \mathrm{I}^{\prime \prime} \quad \lambda=33^{\circ} 46^{\prime} 7^{\prime \prime}$

$$
\begin{array}{rrr}
93 & 17 & 17.7 \\
68 & 16 & 10.4 \\
31 & 49 & 50.3 \\
329 & 35 & 4.9 \\
240 & 50 & 41.4 \\
278 & 52 & 33.9
\end{array}
$$

4. I 53233

4.201302

4.346040

4.320474

4.476696

\section{Siavona.}

$\varphi=+\mathrm{o}^{\circ} 14^{\prime} 24^{\prime \prime} \quad \lambda=33^{\circ} 5 \mathrm{I}^{\prime} \mathrm{I}^{\prime \prime}$.

$\begin{array}{lrr}143 & 7 & 5.9\end{array}$

$\begin{array}{lll}98 & 50 & \text { I.5 }\end{array}$

$\begin{array}{lll}2 \text { II } & 49 & 5 \mathrm{I} .2\end{array}$

$\begin{array}{lll}249 & 33 & 19.7\end{array}$

$4 \cdot 386497$

4.201302

\section{Bumeru.}

$\varphi=+0^{\circ} \mathrm{II}^{\prime} \mathrm{I}^{\prime \prime} \quad \lambda=33^{\circ} 43^{\prime} 2^{\prime \prime}$.

$\begin{array}{lll}\text { I I I } 34 & 20.3\end{array}$

4.476696

$\begin{array}{lll}149 & 35 & 4.6\end{array}$

$\begin{array}{lll}69 & 33 & \text { I } 8.0\end{array}$

204 I6 6.I

$\begin{array}{lll}246 & 44 & 0.4\end{array}$

Yumba.

$\varphi=+0^{\circ} \mathrm{I}^{\prime} 55^{\prime \prime} \quad \lambda=33^{\circ} 38^{\prime} 5 \mathrm{o}^{\prime \prime}$.

43137

4.189658

4.323813

4.320474

4.053 I 37

$$
\begin{array}{rrr}
60 & 50 & 40.9 \\
24 & 16 & 10.6 \\
325 & 53 & 18.5 \\
273 & 16 & 35.8
\end{array}
$$

Dagusi.

$p=+0^{\circ} 7^{\prime} 4^{\prime \prime} \quad \lambda=33^{\circ} 34^{\prime} 53^{\prime \prime}$.

$\begin{array}{lll}98 & 5^{2} & 32.6\end{array}$

$\begin{array}{lll}66 & 43 & 58.9\end{array}$

$\begin{array}{lll}\text { I } 45 & 53 & \text { I } 8.4\end{array}$

Luvia.

$\tau=+0^{\circ} 2^{\prime} 31^{\prime \prime} \quad \lambda=33^{\circ} 28^{\prime} \quad 32^{\prime \prime}$.

Yumba. . . . . . . $93 \begin{array}{llll}96 & 16 & 35.5\end{array}$

Dagusi . . . . . . $\begin{array}{rrr}50 & 3 \mathrm{I} & \mathrm{I} .6 \\ 352 & 20 & 44.0\end{array}$

Marongo . . . . . 3522044.0

Bugala . . . . . . . . $266 \quad 54 \quad 55.5$

Bagete . . . . . . 299729.8

4.28 I 355

4. 183381

4.297496

4.366478

Marongo.

$\varphi=+0^{\circ}$ г $3^{\prime}$ I $^{\prime \prime} \quad \lambda=33^{\circ} 27^{\prime} 7^{\prime \prime}$.

Dagusi . . . . . . . $\quad \begin{array}{llll}224 & 38 & 47.7\end{array}$

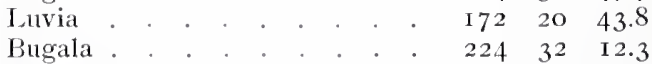

Bagete . . . . $\quad 247 \begin{array}{lll}27 & 8.3\end{array}$

\section{Bugala.}

$r=+0^{\circ} \mathrm{I}^{\prime} 5 \mathrm{o}^{\prime \prime} \quad \lambda=33^{\circ} \mathrm{I} 6^{\prime} 36^{\prime \prime}$.

Luvia . . . . . . . $86 \quad 54 \quad 55.0$

Marongo - . . . . . $44 \quad 32$ II.5

Bagete . . . . . . $8 \begin{array}{rrrr} & 8 & 57.8\end{array}$

Mwama. . . . . $\quad \begin{array}{lllll}287 & 34 & 26.2\end{array}$

Woma . . . . 235 I8 12.1
4.388072

4.297496

4.3664 I 8

4.123 I 4 I

4.299520

4.242543 
Richtung nach Azimut

Bagete.

geod. $\varphi=+0^{\circ} 8^{\prime} 5^{8^{\prime \prime}} \quad \lambda=33^{\circ} \mathrm{I}^{\prime} 2^{\prime \prime}$, astr. $\varphi=+0^{\circ} 9^{\prime} 5^{\prime \prime}$.

Luvia

Marongo

Bugala .

Mwama

Woma

Mwama.

$\varphi=-0^{\circ} 3^{\prime} 34^{\prime \prime} \quad \lambda=33^{\circ} 8^{\prime} \mathrm{I} 7^{\prime \prime}$

$\begin{array}{llllrr}\text { Bugala . . . . . . . . . } & 55 & \text { I } 8 & \text { I } 2.2 \\ \text { Bagete . . . . } & \text {. . } & 35 & 7 & \text { I. } 8\end{array}$

Woma . . . . . . $343 \quad 504.4$

Munda . . . . . . . . 303 I 328.2

Kome . . . . . . . . $\quad 264 \quad 52 r$

Woma.

$\varphi=+0^{\circ} 5^{\prime} 6^{\prime \prime} \quad \lambda=33^{\circ} 5^{\prime} 47^{\prime \prime}$,

Bugala . . . . . . . $\quad$ I07 $34 \quad 25.6$

Bagete . . . . . . . . . $\quad \begin{array}{llll}7 \text { I } & 8 & 36.5\end{array}$

Mwama. . . . . . . . . $\quad{ }_{16} 6300$

Munda . . . . . . . . . 269450

Kome . . . . . . . . . $23920 \quad 29.6$

Munda.

$\varphi=+0^{\circ} 5^{\prime} 4^{\prime \prime} \quad \lambda=32^{\circ} 55^{\prime} \mathrm{I}^{\prime \prime}$.

Mwama . . . . . . . I23 I3 28.0

Woma . . . . . . . $\quad 8947 \quad 57.0$

Kome . . . . . . . 2 I3 3454

$\begin{array}{llllll}\text { Mbazi . . . . . . . . . } & 275 & 42 & 38.5\end{array}$

Nsadzi . . . . . . $240 \quad 24 \quad 24.7$

Kome.

$\varphi=-0^{\circ} 5^{\prime} 23^{\prime \prime} \quad \lambda=32^{\circ} 48^{\prime} \quad 4^{\prime \prime}$

Mwama . . . . . . . . . $\quad \begin{array}{llll}84 & 52 & 3.9\end{array}$

$\begin{array}{llllll}\text { Woma . . . . . . . . . } & 59 & 20 & 48.9\end{array}$

Munda . . . . . . . . . $\quad 33 \quad 54 \quad 39.9$

Mbazi . . . . . . . 328 30 51.7

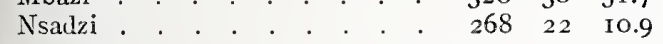

Mbazi.

$\varphi=+0^{\circ} 6^{\prime} \quad 29^{\prime \prime} \quad \lambda=32^{\circ} 4 \mathrm{I}^{\prime} \mathrm{o}^{\prime \prime}$.

Munda . . . . . . . $95 \quad 42 \quad 38.1$

Kome . . . . . . . 148 30 5 I.7

Nsadzi . . . . . . . $201 \quad 200$

Bumange . . . . . $226 \quad 35$ 4I.2

Entebbe . . . . . . . $\quad 258 \quad 53 \quad 26.0$

4.409006 4.382 IOI

4.396754

\section{Nsadzi.}

$\varphi=-0^{\circ} 5^{\prime} 43^{\prime \prime} \quad \lambda=32^{\circ} 36^{\prime} 20^{\prime \prime}$.

Munda . . . . . . . . $60 \begin{array}{lllll}60 & 24 & 48.3\end{array}$

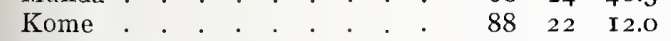

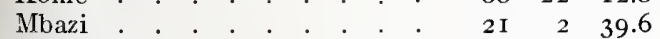

Bumange, $S_{1}$. . . . . . 239 I3 16.5

Entebbe . . . . . . 3 II 23 4.0

Bumange, Sesse ${ }_{1}$.

$\varphi=-0^{\circ} \mathrm{I}^{\prime} \mathrm{Io}^{\prime \prime} \lambda=3^{\circ} \mathrm{I}^{\prime} 3^{\prime \prime}$.

Mbazi . . . . . . . . $\quad 46 \begin{array}{llll}46 & \text { I } 1.4\end{array}$

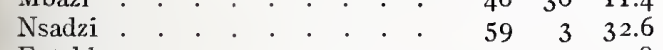

Entebbe . . . . . . . 3 3I 0

4.683070

Entebbe.

Triang. $p=+0^{\circ} 3^{\prime} 53^{\prime \prime} \quad \lambda=32^{\circ} 27^{\prime} 49^{\prime \prime}$.

Nsadzi . . . . . . . . . . $\begin{array}{llll}\text { I } 38 & \text { I } 3 & 25.4\end{array}$

Mbazi . . . . . . . . $\quad \begin{array}{llll}78 & 53 & 46.1\end{array}$

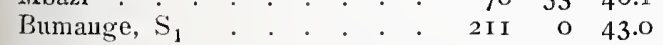

4.396754 $4.695 \mathrm{I} 70$

20769

4.462655
4.572290

4.299520

4.220769

4.462655

4.365105

4.572290

4.365 I05

4.409006

4.343580

4.343580 4.382 IOI

$4.683 \circ 70$

4.695 I 70 $\log$ der Entf.

III. Abrisse der astronomischen und geodätischen Stationen zwischen Port Florence und Zanzibar.*)

Den Abrissen sind zugleich die errechneten geographischen Koordinaten beigefügt.

Richtung nach:

Azimut

$\log$ der Entf.

Maragul.

$$
\varphi=-\mathrm{o}^{\circ} \mathrm{o}^{\prime} \mathrm{I} 8.3^{\prime \prime} \quad \lambda=34^{\circ} 39^{\prime} 4 \mathrm{I}^{\prime \prime} \text {. }
$$

Ndere . . . . . . . . 2 I 7 I8 47.40 I 4.448 I055

Bungalow . . . . . . . $13742 \quad$ 57.IOI 4.I54 I 962

Kibuye . . . . . . . . I $5 \mathrm{I}^{5} 55$ 5I.102 4.235 256I

Bungalow.

Maragul . . . . . . 3 I $744^{2} 54^{6.8} 5^{\prime \prime}$.

Kibuye.

$\varphi=-0^{\circ} 8^{\prime} 3^{2 . I^{\prime \prime}} \quad \lambda=34^{\circ} 44^{\prime} 3^{\prime \prime}$.

Maragul _. . . . . $33 \mathrm{I} \quad 55 \quad 50.767-4.235$ 256 I

Ndere . . . . . . . . . $\begin{array}{rrrrr}254 & 5 & 49.777 & 4.416 & 5862\end{array}$

Wire . . . . . . . . $\quad \begin{array}{lllll}\text { I } 83 & 56 & 48.864 & 4.559 & 5095\end{array}$

Ndere.

$\varphi=-0^{\circ} \mathrm{I}^{\prime} 24^{\prime \prime} \quad \lambda=34^{\circ} 3 \mathrm{O}^{\prime} 3 \mathrm{I}^{\prime \prime}$.

Bungalow . . . . . . . . $\quad \begin{array}{llllll}66 & 8 & 35.236 & 4.4637657\end{array}$

Maragul . . . . . . . 37 I $8 \quad 48.4$ I6 4.448 I055

Kibuye . . . . . . . . . $\quad \begin{array}{lllll}74 & 5 & 52.246 & 4.416 & 5862\end{array}$

Homa . . . . . . $\begin{array}{lllll}\text { I83 } & 23 & \text { II } 864 & 4.301 & 3570\end{array}$

Wire . . . . . . $142 \quad 5 \quad 53.446 \quad 4.5657415$

Mbala.

$$
p=-0^{\circ} 47^{\prime} \quad 58.2^{\prime \prime} \quad \lambda=34^{\circ} 26^{\prime} \quad 20^{\prime \prime} .
$$

Gwasi . . . . . . . . . $304 \quad 48 \quad$ I $9.733 \quad 4.526294 \mathrm{I}$

Nundowat . . . . . . . . $\begin{array}{lllll}225 & 26 & 26.205 & 4.416 & 1000\end{array}$

Gem. . . . . . . . . $\begin{array}{lllll}29 & 14 & 11.903 & 4.3208027\end{array}$

Ruri . . . . . . . . . $\quad$ - 4.4492726

Wire.

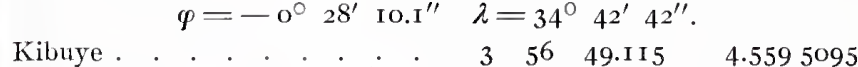

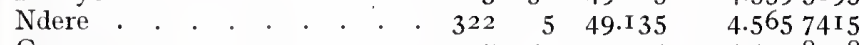

Gem. . . . . . . . 227 5I $1.404 \quad 4.4338 \mathrm{I} 38$

Homa . . . . . . . . . $\begin{array}{lllll} & 290 & 49 & 55.665 & 4.405 \\ 6397\end{array}$

Homa.

$\varphi=-0^{\circ}{ }_{2} 8^{\prime}$ I $5.5^{\prime \prime} \quad \lambda=34^{\circ} 2 \sigma^{\prime} 53^{\prime \prime}$.

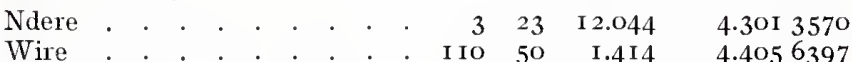

Gem. . . . . . . . . . $\begin{array}{lllll}172 & 22 & 22.964 & 4.439 & 5640\end{array}$

Ruri . . . . . . . . . 2 I $8 \quad 44 \quad 42.063 \quad 4.3795^{845}$

Gem.

$\varphi=-0^{\circ} 38^{\prime} 3 \cdot 5^{\prime \prime} \quad \lambda=34^{\circ} 3 \mathrm{I}^{\prime} 5 \mathrm{I}^{\prime \prime}$.

Mbala . . . . . . . . . . 209 I $4 \quad 7.767 \quad 4.3208027$

Wire .. . . . . . . $47 \begin{array}{llll}5 \mathrm{I} & 7.672 & 4.4338 \mathrm{I} 38\end{array}$

Homa . . . . . . . . . 40454564

Ruri . . . . . . . . . . $294 \quad 42 \quad 10.602 \quad 4.3123769$

Ruri,

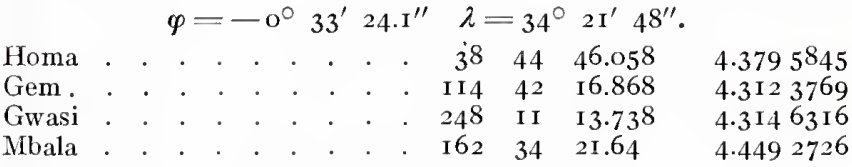

*) Betreffs der hier angeführten Daten für die geographischen Koordinateu ist im Text Seite 193 zu vergleichen. Die Koordinaten sind hier mit Bezug auf den deutscherseits astronomisch bestimmten Wert der Breite für den »Mohuru-Pfeiler《 und das Mittel der gecdätischen Übertragungen der Länge vou Port Florence ausgeführt, während die Koordinaten unter II. (Seite I99) auf dem englischen Wert für $\psi$ und dem Längenwert der telegraphischen Übertragungen von Mombasa beruhen. Daraus resultiert der Unterschied in den Koordinaten der gleichen Punkte unter II. und III. 
Gwasi.

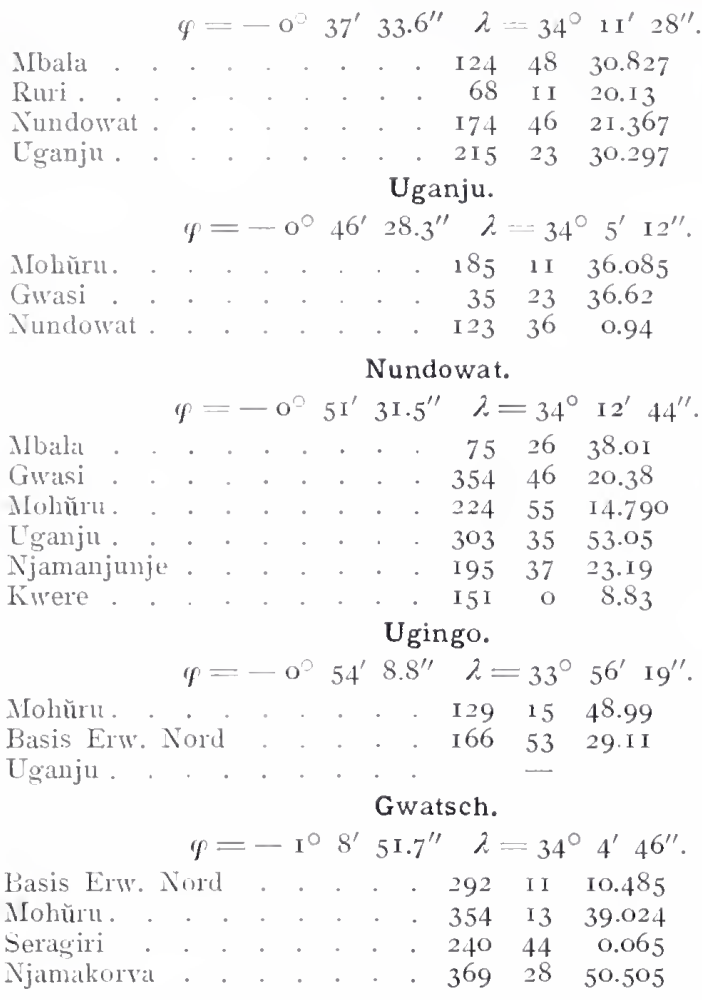

Seragiri (Basis Erweiterung Süd). $\varphi=-\mathrm{I}^{\circ}$ I I $^{\prime} 48.8^{\prime \prime} \quad \lambda=33^{\circ} 59^{\prime} 32^{\prime \prime}$.
Gwatsch

Basis Erw. Nord

Pasis Schirati West

Basis Schirati Ost
$4.526294 \mathrm{I}$

4.3146316

$4.4 I 22436$

4.3040248

4.4 I I 9050

4.3040248

4.2260560

4.4161000

$4.4 I 22436$

$4 \cdot 36+7217$

4.2260560

4.5665709

4.3896194

4.2619533

4.3708597

4.2369372

4.0502974

4.193 8908

4.0464280

-

0464280 $3.986980 \mathrm{I}$ 3.9276698

3.9230290

Basis Erweiterung Nord.

Mohйчu . . . . . . . . $37 \quad \begin{array}{llll}38 & 9.25\end{array}$

Ugingo. . . . . . . . $346 \quad 53 \quad 26.09$

Gwatsch . I I 2 II 17.106

Seragiri

$\begin{array}{lll}\text { I I } 2 & \text { II } & 17.106 \\ \text { I } 75 & 55 & 55.026\end{array}$

Busis Schinati Ost

Basis Schirati West

\section{Basis Schirati: West.}

$\varphi=-I^{\prime \prime} 7^{\prime} 17.9^{\prime \prime} \quad \lambda=-33^{\circ} 58^{\prime} 42^{\prime \prime}$.

Seragiri . . . . . . . $\begin{array}{lllll} & 69 & 24 & 49.660 & 3.927669\end{array}$

Basis Erw. Nord

Basis Schirati Ost

\section{Basis Schirati: Ost.}

$$
\varphi=-\mathrm{I}^{\circ} 7^{\prime} \mathrm{I} 7.4^{\prime \prime} \lambda=33^{\circ} 59^{\prime} 56^{\prime \prime} .
$$

Seragiri Fis 185 I I 9.425

Basis Schirati West

\section{Mohŭru (Pfeiler)}

$$
r=-\mathrm{I}^{\prime} \mathrm{o}^{\prime} 24.4^{\prime \prime} \quad \lambda=34^{\circ} 3^{\prime} 55^{\prime \prime} \text {. }
$$

Nundowat . . . . . . . $44 \quad 55 \quad 23.43$

Basis Erw. Nord . . . . $217 \quad 58 \quad 3.98$

Ugingo .

Gwatsch

Uganju

Njamanjunje

Njamakorva

Kivere

Kŭribe Pfeiler

309 I $5 \quad 42.20$

174 I $3 \quad 40.15$

$\begin{array}{lll}5 & 11 & 35.83\end{array}$

$\begin{array}{lll}\text { I } & 24 & 34.72\end{array}$

163242.16

$\begin{array}{lll}100 & 8 & 42.99\end{array}$

I $20 \quad 40 \quad$ II.I 2

Njamanjunje.

$\varphi=-\mathrm{I}^{\circ} \mathrm{IO}^{\prime} 47.4^{\prime \prime} \quad \lambda==34^{\circ} 7^{\prime} 23^{\prime \prime}$

Mohŭru .

$$
\varphi=-\mathbf{I}^{\circ} \operatorname{IO}^{\prime} 47 \cdot 4^{\prime \prime} \quad \lambda==34^{\circ} 7^{\prime} 23^{\prime \prime} \text {. }
$$

4.3708597

4.0502974

3.9869801

3.2945088

3.2072259

3.2072259

3.3640856

3.9230290

3.2945088

3.3640856

4.3647217

4.1566765

4.2619533

4.1938908

4.4 I I 9050

4.3044083

4.4577450

4.4323645

5709 4.3044083
Kwere

$\begin{array}{lll}57 & \text { I2 } & 57.576\end{array}$

Kŭribe Pfeiler

Kuigĕg*o

$\begin{array}{lll}72 & 32 & \text { I 9. I }\end{array}$

4.414 I3II

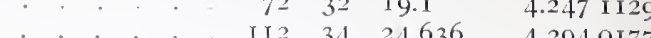

Kwere (Goddi-Kwaer).

$\varphi=-\mathbf{I}^{\circ} \quad 3^{\prime} \quad 9.9^{\prime \prime} \quad \lambda=34^{\circ} \mathbf{1 9}^{\prime} 9^{\prime \prime}$.

$\begin{array}{lllll}. \quad 280 & 8 & 26.573\end{array}$

$2.42 \quad 4.3896$ I 94

$\begin{array}{rrrr}189 & 34 & 13.57 & 4.3406539\end{array}$

$4.452795^{8}$

Kŭribe (Pfeiler).

$$
\varphi=-\mathrm{I}^{\circ} 7^{\prime} 54 \cdot 9^{\prime \prime} \quad \lambda=34^{\circ} 16^{\prime} 2 S^{\prime \prime} \text {. }
$$

MIohŭıчu : . . . . . . $300 \quad 39 \quad 56.97 \quad 4.4323645$

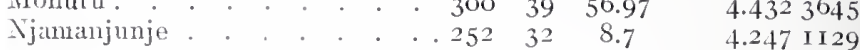

\section{Kuigĕgo.}

$\varphi=-\mathrm{I}^{\circ} \mathrm{I}_{4^{\prime}} 53 \cdot 4^{\prime \prime} \quad \lambda=34^{\circ} \mathrm{I}^{\prime} \mathrm{II}^{\prime \prime}$.

Njamanjunje . . . . . . $292 \quad 34 \quad \mathbf{1 2 . 1} 84$

Kwere . . . . . . . $9 \begin{array}{rrrr} & 9 & 34 & 15.94\end{array}$

Schirari. . . . . . 924324.53

\begin{tabular}{|c|c|c|c|c|c|c|c|c|c|c|c|}
\hline Kuigergo & • & & . & . & . & . & - & 272 & 43 & 9.829 & 4.3 I 83988 \\
\hline Kwere. & - & . & - & - & - & . & . & 322 & 47 & 50.705 & 4.4527958 \\
\hline Uirěge . & - & . & - & . & - & - & . & 180 & I I & 22.512 & 4.0893818 \\
\hline Tagari & - & . & . & . & - & • & . & 131 & 56 & 51.812 & 4.3505743 \\
\hline Muiwari & . & . & . & . & . & & . & $2 \mathrm{I} 4$ & 24 & 50.432 & 4.2799253 \\
\hline Миёma. & . & - & . & - & & - & - & 276 & 36 & $\mathrm{I} 2.2 \mathrm{I} 2$ & 3.9483765 \\
\hline Kiora & - & - & . & . & - & & - & 224 & 10 & 53.I 29 & $4.357835^{\circ}$ \\
\hline Njamuaga & - & . & . & - & - & . & . & 142 & 37 & 13.012 & 4.325 IOI I \\
\hline Njanejeng & & . & . & - & . & . & 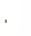 & 120 & 32 & 10.7 & - \\
\hline gaa & & . & . & . & . & & & 66 & 20 & 42.5 & 5.0230699 \\
\hline
\end{tabular}

Uirěge . . . . . I $122 \quad 3624.05$

Kiora

Schirari.

Uirĕge.

$f=-I^{\prime} 22^{\prime} \quad 5 \cdot 7^{\prime \prime} \quad \lambda=34^{\circ} 28^{\prime} 22^{\prime \prime}$

$\begin{array}{llll}O & \text { II } & 22.542\end{array}$

$\begin{array}{llllll}\text { Kuigěgo . . . . . . . . 302 } & 36 & 8.72\end{array}$

$\begin{array}{lll}29.812 & 4.2286539\end{array}$
Tagari.

Njamuaga

$\begin{array}{rrr}99 & 10 & 29.81 \\ 109 & \text { I } 9 & 6.04\end{array}$

4.1348999

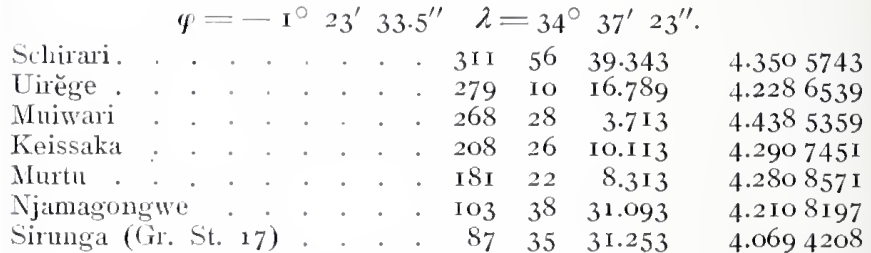

Muiwari.

$\begin{array}{rrrrr}34 & 24 & 58.505 & 4.2799253\end{array}$

$\therefore$ I32 II 43.I35 4.3888383

Muëma.

$\varphi=-\mathrm{I}^{\circ} 14^{\prime} 52.4^{\prime \prime} \quad \lambda=34^{\circ} 23^{\prime} 38^{\prime \prime}$

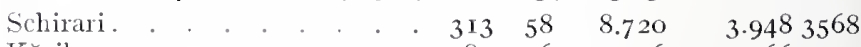

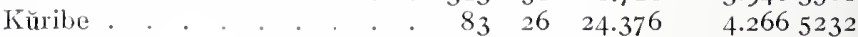

Murtu.

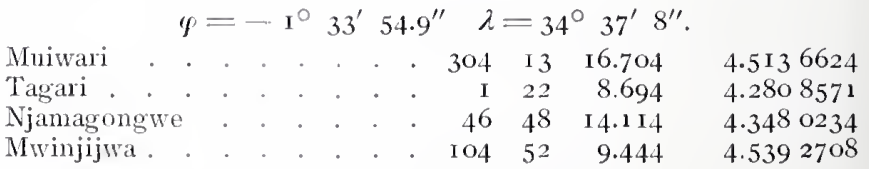

Sigaa (Englisch-).

$\varphi=-\mathrm{I}^{\circ} 8^{\prime} 25 \cdot 7^{\prime \prime} \quad \lambda=34^{\circ} 44^{\prime} \mathrm{I}^{\prime \prime}$.

Sclirari. . . . . . . 246 $240 \begin{array}{lll}248.7 & 5.0230699\end{array}$

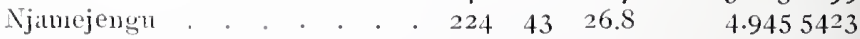


Njamejengu.

$$
\varphi=-\mathrm{I}^{\circ} \mathrm{I}^{\prime} \quad 47 \cdot 7^{\prime \prime} \quad \lambda=34^{\circ} 34^{\prime} 4^{\prime \prime} \text {. }
$$

Schirari. . . . . . . . $300 \quad 32 \quad 3.1$

Sigaa

$\begin{array}{lll}44 & 43 & 40.2\end{array}$

4.9455423

\section{Njamagongwe.}

$$
\varphi=-\mathrm{I}^{\circ} 25^{\prime} 38.2^{\prime \prime} \quad \lambda=34^{\circ} 45^{\prime} 54^{\prime \prime} \text {. }
$$

Tagari. . . . . . . . . . $28 \begin{array}{llll}28 & 38 & \text { 1 } 8.526\end{array}$

4.3480234

Mwinjijwa. . . . . . . . $\quad \begin{array}{llllll} & \text { I } 44 & 30 & 25.282 & 4.47 \text { I } 9408\end{array}$

Sirunga (Gr. St. 17) . . . . $\begin{array}{lllll}316 & 45 & 24.276 & 3.7735910\end{array}$

Olbitgoi . . . . . . . . . $\begin{array}{lllll}\text { IO } 7 & 54 & 34.862 & 4.301 & 8595\end{array}$

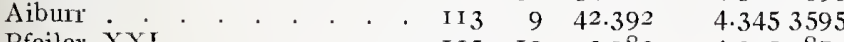

Pfeiler XXI . . . . . . I I5 Io $\begin{array}{rlr}3.982 & 4.395 & 0870\end{array}$

Mwinjijwa.

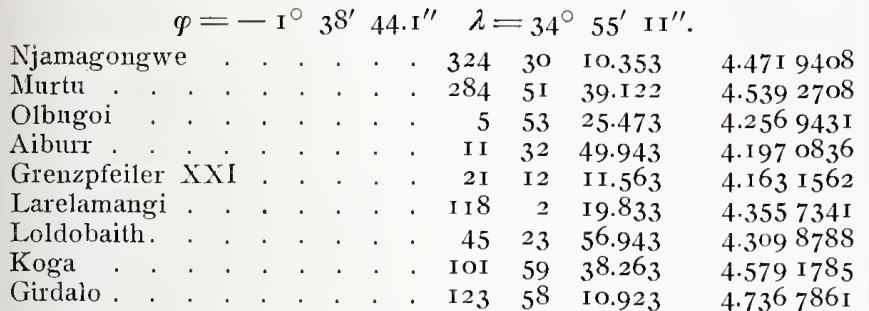

Sirunga (Grenzstein Nr. 17).

$\varphi=-\mathrm{I}^{\circ} 23^{\prime} \mathrm{I} 7.5^{\prime \prime} \quad \lambda=34^{\circ} 43^{\prime} 42^{\prime \prime}$.

Tagari . . . . . . . . . . $\begin{array}{llllll} & 267 & 35 & 22.052 & 4.069 & 4208\end{array}$

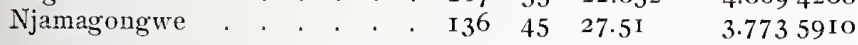

Olbugoi (Deutsch-).

$\varphi=-\mathrm{I}^{\circ} 28^{\prime} 5^{8.9^{\prime \prime}} \quad \lambda=34^{\circ} 5^{6^{\prime}} \mathrm{I}^{\prime \prime}$.

Njamagongiwe . . . . . . $\begin{array}{lllll} & 287 & 54 & 19.200\end{array}$

$\begin{array}{lllllllllll}\text { Njamagong } & . & . & . & . & . & . & 287 & 54 & \text { 19.200 } & 4.3018595 \\ \text { Mwinjijwa. . . . . } & . & . & . & . & \mathbf{1} 85 & 53 & 23.836 & 4.2569431\end{array}$

Isuria (Grenzpfeiler XVIII.).

$\varphi=-\mathrm{I}^{\circ} 24^{\prime} 52.2^{\prime \prime} \quad \lambda=34^{\circ} 46^{\prime} 30^{\prime \prime}$.

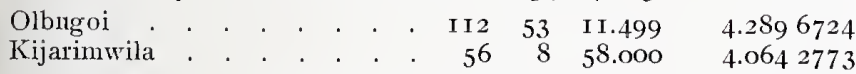

Kijarimwila (Englisch-).

$\varphi=-\mathrm{I}^{\circ} 2 \mathrm{I}^{\prime} 20.9^{\prime \prime} \quad \lambda=34^{\circ} 5 \mathrm{I}^{\prime} 42^{\prime \prime}$.

$\begin{array}{llllllllllrr}\text { Olbugoi } & . & . & . & . & . & . & . & . & \text { I } 49 & 20 & 23.08 \\ \text { Isuria } & . & . & . & . & . & . & . & . & 236 & 8 & 50.47\end{array}$

Aiburr (engl. Olbugoi).

$\varphi=-\mathrm{I}^{\circ} 3 \mathrm{o}^{\prime} 2 \mathrm{I} \cdot 9^{\prime \prime} \quad \lambda=34^{\circ} 56^{\prime} 53^{\prime \prime}$.

Njamagongwe . . . . . . $\begin{array}{cccc} & 293 & 9 & 25.532\end{array}$

Mwinjijwa. . . . . . . 19 I 32 47.140

Larelamangi . . . . . . . I $47 \begin{array}{rrr} & 69.95\end{array}$

Lòloemŭli . . . . . . . 116.36 3I.00

Loldobaith. . . . . . . $95 \quad \begin{array}{rrr}28 & 43.460\end{array}$

\section{Grenzpfeiler XXI.}

$$
\varphi=-\mathrm{I}^{\circ} 3 \mathrm{I}^{\prime} 22.2^{\prime \prime} \quad \lambda=34^{\circ} 5^{8^{\prime}} \mathrm{I}^{\prime \prime} .
$$

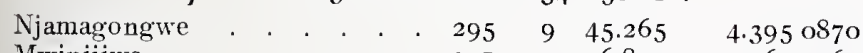

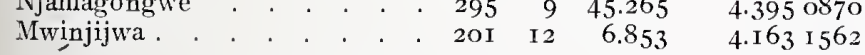

Larelamangi.

$\varphi=-\mathrm{I}^{\circ} 44^{\prime} 3 \mathrm{I} \cdot 3^{\prime \prime} \quad \lambda=35^{\circ} 5^{\prime} 59^{\prime \prime}$.

Mwinjijwa. . . . . . . . . $298 \quad 200.686$

$\begin{array}{rlrrrr}\text { Lóloemŭli . . . . . . . . . . . . } & . & 327 & 6 & 14.480 \\ 50 & 36 & 58.930\end{array}$

\section{Lŏloemŭli.}

$\varphi=-\mathrm{I}^{\circ} 38^{\prime} 34 \cdot 7^{\prime \prime} \quad \lambda=35^{\circ} \mathrm{I}^{\prime} \mathrm{Io}^{\prime \prime}$.

Aiburr . . . . . . . . . $\begin{array}{ccccc}296 & 36 & 4.143 & 4.528 & 8262\end{array}$

$\begin{array}{llllll}\text { Larelamangi . . . . . . . . } & . & 230 & 36 & 46.182 & 4.237 \\ \end{array}$

\section{Loldobaith.}

Mwinjijwa . . . . . . . . . $225 \quad 23 \quad 43.974$

Aiburr . . . . . . . . . $\begin{array}{llll}275 & 28 & 33.752\end{array}$

Koga . . . . 134 3 I 35.564
4.3453595

4.1970836

4.4923067

4.5288262

4.0582114

$4.355734 \mathrm{I}$

4.4923067

4.2370798

4.3098788

$4.0582 \mathrm{II} 4$

4.5008091
Koga.

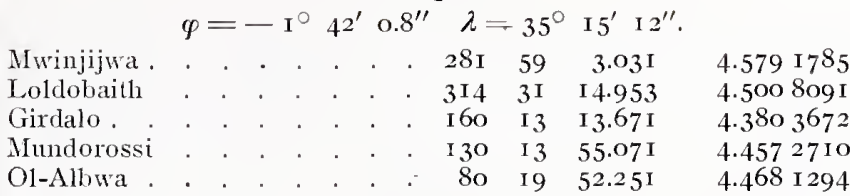

Girdalo.

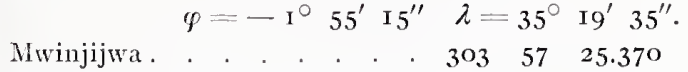

$\begin{array}{rrrr}340 & 13 & 5.327 & 4.380 \\ 7672\end{array}$

Mundorossi.

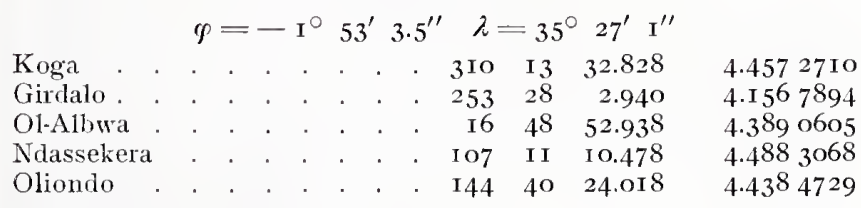

O1.Albwa.

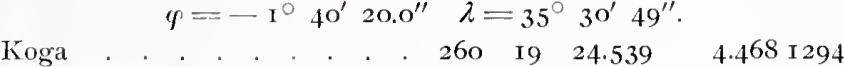

Mundorossi . . . . . . $196 \quad \begin{array}{llll}48 & 45.825 & 4.389 & 0605\end{array}$

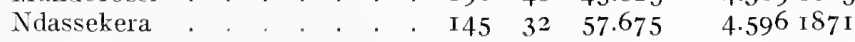

Ndassekera.

Mundorossi . . . . . . . . 287 10 $38.507 \quad 4.4883068$

Ol-Albwa . . . . $\quad \begin{array}{lllll}325 & 32 & 34.743 & 4.596 \text { I } 87 \text { I }\end{array}$

Oliondo . . . . . . . . $\begin{array}{lllll}225 & 30 & 25.967 & 4.278 & 1955\end{array}$

Sambu (engl.) . . . . . . . $\begin{array}{lllll}226 & 26 & 36.947 & 4.5136726\end{array}$

Gr. Pfeiler (Sambu) . . . . . II4 $24 \quad 33.797 \quad 4.4129090$

Sambu (Deutsch-) . . . . . . I30 I7 $\quad$ I $8.517 \quad 4.5280200$

Oliondo.

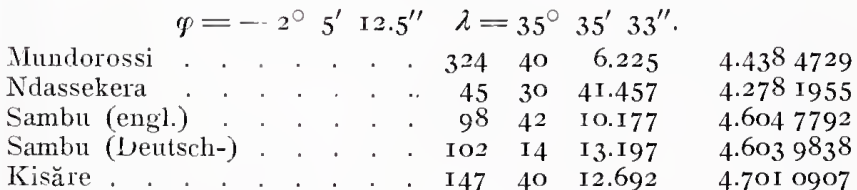

H. S. Sambu (engl.).

$\varphi=-2^{\circ} 8^{\prime} 30.7^{\prime \prime} \quad \lambda=35^{\circ} 57^{\prime} \mathbf{I}^{\prime \prime}$.

Ndassekera . . . . . . . . $\begin{array}{lllll}206 & 26 & 6.495 & 4.5136726\end{array}$

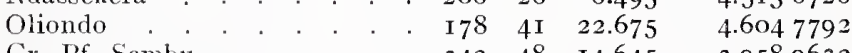

Gr. Pf. Sambu. . . . . . $342 \quad 48$ 14.645 3.9589632

Gr. Pf. Schombole. . . . . 93 50 $\quad 35.245 \quad 9.1607734$

Grenzpfeiler Sambu.

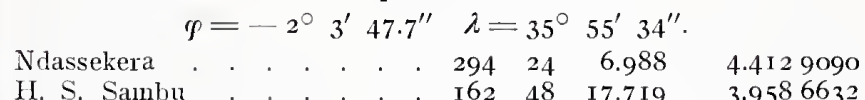

H. S. Sambu . . . $162 \quad 48$ I 7.7 I9 3.9586632

4.2938834

Sambu (Deutsch-).

$\varphi=-2^{\circ} 9^{\prime} 49 \cdot 7^{\prime \prime} \quad \lambda=35^{\circ} 56^{\prime} 44^{\prime \prime}$

Ndassekera . . . . . . . 3I0 $16 \quad 48.5$ I3

Oliondo . . . . . . 282 I3 26.075

Kisăre . . . . . . . . . $200 \quad 2050.745$

, mit nenen Werten der

$\begin{array}{lllll}\text { Basismessung am Natronsee. } 200 \quad 2 & 50.745 & 4.5578936\end{array}$

Gelei . . . . . . I46 48 Io.I3I 4.6 I4 3653

Kilibe . . . . . . . II 2 40 $21.844 \quad 4.7777760$

Basis Erw. S. (Natronsee) . . II9 36 Io.58 4.3696793

4.I 757523

\section{Kisăre.}

$\begin{array}{lllllll}\text { Sambu (Deutsch-) . . . . . . } & 20 & 3 & 6.957 & 4.5579499\end{array}$

$\begin{array}{lllllll}\text { Oliondo . . . . . . . . } & 327 & 39 & 38.109 & 4.701 & 0907\end{array}$

$\begin{array}{llrrr}\text { Sambu(D.) mit nenen Basiswerten } \quad 20 & 3 & 6.954 & 4.5578936\end{array}$

$\begin{array}{lllllll}\text { Gelei . . . . . . . . } & 90 & 48 & 36.668 & 4.543 & 0693\end{array}$

Basis Erw. S. (Natronsee) . . 55 40 $\begin{array}{lll}35.02 & 4.598 & 3984\end{array}$

\section{Grenzpfeiler Schombole.}

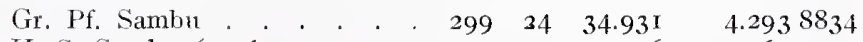

H. S. Sambu (engl.) . . . . 273 50 $17.736 \quad 4.1607734$ 
Richtung nach:

Azimut

$\log$ der Entf.

Gelei.

$\varphi=-2^{\circ} \quad 28^{\prime} \quad 30.8^{\prime \prime} \quad \lambda=36^{\circ} S^{\prime} 54^{\prime \prime}$.

Sambu (Deutsch-)

Kisăre

Kilibe

Naroka

Ngorika-Fels

$32647 \quad 40.6 I_{5}$

$\begin{array}{lll}270 & 47 & 47.902\end{array}$

$\begin{array}{lll}70 & 56 & 6.802\end{array}$

IO5 $42 \quad 30.353$

Kilibe.

$q=-2^{\circ} 22^{\prime} 2 \times .8^{\prime \prime} \quad \lambda=36^{\circ} 26^{\prime} 36^{\prime \prime}$.

Gelei imbu (Deutsch-)

Litanje

Nitroka

Nororika-Fels

Erok

$\begin{array}{rlll}250 & 55 & 21.925 & 4.540 \text { I } 546 \\ 292 & 39 & 10.984 & 4.7777760 \\ 39 & \text { I } 4 & 48.5 & 4.3327046 \\ \text { I } 83 & 44 & 47.4 \text { IO } & 4.305695 \text { I } \\ 273 & 22 & 54.6 & 4.6379047 \\ \text { III } & 22 & 27.01 & 4.5660048\end{array}$

Naroka.

\begin{tabular}{|c|c|c|c|c|c|c|c|c|c|c|c|c|}
\hline Kilibe & . & . & . & • & - & . & - & • & 3 & 44 & 49.248 & $4.305695 \mathrm{I}$ \\
\hline Gelei & . & - & & & • & . & - & - & 285 & $4 \mathrm{I}$ & $45.65^{8}$ & 4.5142873 \\
\hline Erok & . & . & . & - & . & - & • & . & 79 & I 5 & 21.848 & 4.559 I 586 \\
\hline Longido & & . . & & - & . & 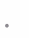 & . & . & I I 5 & 9 & I 8.658 & $4.528528 \mathrm{I}$ \\
\hline Erok-Gi & rell: & zsigna & & . & . & . & . & . & 85 & 19 & $25 \cdot 338$ & 4.5575800 \\
\hline
\end{tabular}

\section{Ngorika-Fels.}

$\varphi=-22^{\circ} 0^{\prime} 58.9^{\prime \prime} \quad \lambda=36^{\circ} 3^{\prime}$ I I I $^{\prime \prime}$.

Basis Erweiterung Süd (Natronsee).

$\varphi=-2^{2}$ I $6^{\prime} 6.4^{\prime \prime} \quad \lambda=36^{\circ} 7^{\prime} 44^{\prime \prime}$.

Sumbu (Deutsch-) * * . . . $\quad 2993545.09$

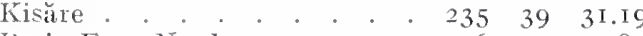

Basis Erw. Nord" . . . . 336 49 \begin{tabular}{lll}
59.83 \\
\hline
\end{tabular}

Basis Erweiterung Nord (Natronsee).

$\varphi=-2^{\circ} 9^{\prime} 13.9^{\prime \prime} \quad \lambda=36^{\circ} 4^{\prime} 4^{\prime \prime \prime}$.

Basis Erw. Sïd

Sambu (Deutsch-)

Erok.

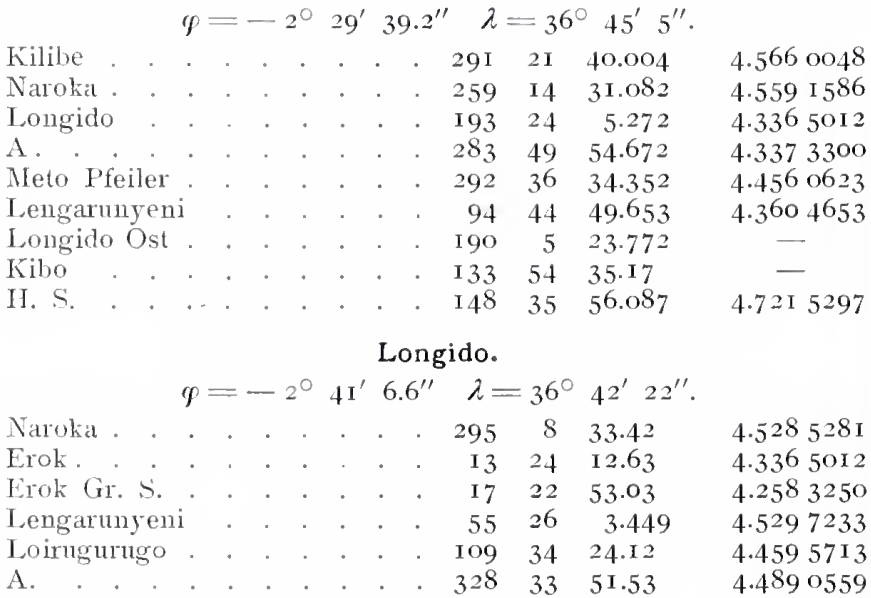

Erok - Grenz - Signal.

$\varphi=-2^{\circ} 3 \mathrm{I}^{\prime} 43 \cdot 3^{\prime \prime} \lambda=36^{\circ} 45^{\prime} \mathrm{I} 7^{\prime \prime}$

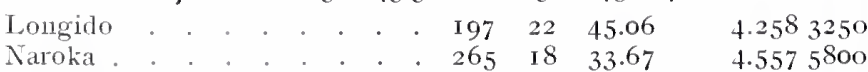

Meto-Pfeiler.

$\varphi=-2^{\circ} 23^{\prime} 4 \mathrm{I} \cdot 4^{\prime \prime} \quad \lambda=36^{\circ} 30^{\prime} 5 \mathrm{I}^{\prime \prime}$

Erok . . . . . . . . II2 $37 \quad$ I0.7 8

A. . . . . . I 374 I 43.56

4.4560623

3.8937086

\section{Lengarunyeni.}

Meshanai . . . . . . . 964448.23

$\begin{array}{llll}\text { Nenkereri Gr. P. I } 46 & 2 & 32.46\end{array}$

Loirugurugo . . . . . . I8I $27 \quad$\begin{tabular}{lll}
$\mathbf{1} 3.05$ \\
\hline
\end{tabular}

Longido . . . . . . $235 \quad 25 \quad 22.53$

Erok . . . $274 \quad 44 \quad$ I 7.35

4.5297233

4.3604653
Richtung nach:

Azimut

$\log$ der Enth.

Loirugurugo.

$p=-2^{\circ} 4^{6^{\prime}} \quad 20.8^{\prime \prime} \quad \lambda=36^{\circ} 57^{\prime} \mathrm{I}^{\prime \prime}$

$\begin{array}{llllll}\text { garunyeni . . . . I } 27 & \text { I } 4.14 & 4.4605044\end{array}$

Meshanai . . . . . . 45 Io $48.27 \quad 4.5647807$

Nenkereri Gr. P. . . . . $70 \quad 28 \quad 38.14 \quad 4.2374430$

Nairadad . . . . . . . $96 \quad 92 \quad 6.22 \quad 4.4268395$

H. S. . . . . . I $15925 \quad 42.70$

Lougido . . . . . . $289 \quad 33 \quad 42.27$

$4.459778_{3}$

Nenkereri Grenzpunkt.

$\varphi=-2^{\circ} 43^{\prime} \mathbf{1} 2.8^{\prime \prime} \quad \lambda=37^{\circ} 5^{\prime} 48^{\prime \prime}$.

I. oirugurugo . . . . . . . $\begin{array}{llll}250 & 28 & 12.88\end{array}$

4.2374430

Lengarunyeni . . . . $326 \quad 2 \quad 9.49 \quad 4.4446520$

Meshanai.

$\varphi=-2^{\circ} 32^{\prime} \mathbf{I} 8.2^{\prime \prime} \quad \lambda=37^{\circ} \mathbf{I I}^{\prime} 4^{\prime \prime}$

Naduyatui . . . . . II8 5 I 42.12

Nairadad . . . . . . 179 I 28.86

Loirugurngo . . . . . . 225 Io 9.22

Lengarunyeni

$\begin{array}{lll}276 & 43 & 28.14\end{array}$

H. S.

$\varphi=-2^{\circ} 54^{\prime} 2.8^{\prime \prime} \quad \lambda=36^{\circ} 59^{\prime} 53^{\prime \prime}$.

Kibo. . . . . . . . II6 I3 $\quad$ I $53.33 \quad 4.6435003$

Erok. . . . . . . $328 \quad 35 \quad$ I $4.27 \quad 4.7215298$

Loirugurugo

Nairadad.

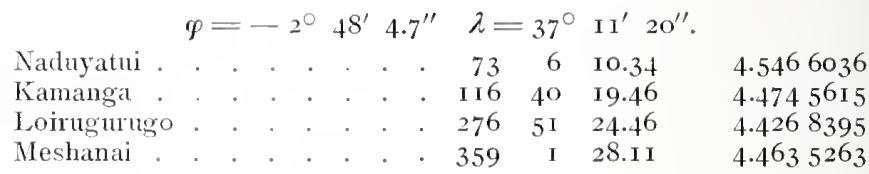

Endpunkt der Grenze.

$\varphi=-2 \quad 57^{\prime} 27.6^{\prime \prime} \quad \lambda=37^{\circ} 3 \mathrm{I}^{\prime} 34^{\prime \prime}$.

Kiknmbuliı . . . . . . . 54 I 4.1 . 4.709070

Nogunda Io . . . . . $6936 \quad 46.4$

$\begin{array}{lllllll}\text { Longaria . . . . . . . } 73 & 79 & 35.87\end{array}$

Mogunda I 5 . . . . . . $94 \quad 46 \quad 47.7$

Lesako. . . $96 \quad 96 \quad 53.87$

Nogunda 12 . . . . . . III 59 . 32. I

$\begin{array}{llllllll}\text { Kasigao } & \text {. . . . . . } 27 & 28 & 33.7\end{array}$

Teita-ya-Bura . . . . . I I $20 \quad 56 \quad 29.7$

Mogunda 9 . . . . . $129 \quad 38 \quad 55.0$

Mawensi . . . . $205 \quad 52 \quad 13.7$

$\mathrm{T}_{2}$

$240 \quad 52 \quad 12$

4.5913742

4635263

4.5647807

4.4062382

4.718346

3.9149829

4.84754

$3.98755^{83}$

4.784175

5.202355

4.998049

4.71954

$4.24137 \mathrm{I}$

2.819048

Mogunda 15 .

$q=-3 \mathrm{o}^{\prime} 3 \mathrm{I}^{\prime \prime} \lambda=38^{\circ} 9^{\prime} 2 \mathrm{I}^{\prime \prime}$.

$\begin{array}{lllll}\text { Kasigao } & \text { I } 48 \quad 4 & \text { I8.I } & 5.029562\end{array}$

Teita-ya-Bura

Mogunda I 2

Endpunkt d. Gr.

$\begin{array}{rrr}148 & 4 & 18.1 \\ \text { I } 61 & 7 & 6 . I\end{array}$

$219 \quad 16 \quad 19$

$274 \quad 53 \quad 51$

Kikumbulin

$\begin{array}{lll}32 \mathrm{I} & 28 & 49.2\end{array}$

4.679264

$4.3365 \mathrm{I}$

4.84754

4.663894

Mogunda 12

$-39^{\prime} 3^{\prime \prime} \quad \lambda=38^{\circ} \mathrm{I}^{\prime} 5^{6}$

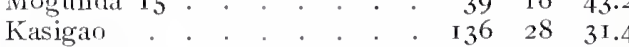

Mogunda 9 . . . . . . . $23624 \quad 54.3$

Endpunkt d. Gr. . . . . . 29I 34 I.4

Kikumbuliu . . . . . . 344 I I 10.03

Mogunda Io . . . . $34948 \quad 9.83$

$4.3365 \mathrm{I}$

5.009 I 872

4.28484

$4.784 \quad 75$

4.7401032

4.620041

Mogunda 9 (Muruguti).

$\varphi=-3^{\circ}$ I $^{\prime} 25^{\prime \prime} \quad \lambda=37^{\circ} 53^{\prime}$ I $^{\prime \prime}$.

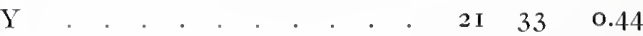

Mogunda I 2 . . . . . . $\quad \begin{array}{llll}56 & 25 & 23.5\end{array}$

$\begin{array}{llllllll}\mathrm{X} & . & 213 & 57 & 37.99\end{array}$

Tschăla . . . . $248 \quad 4248.73$

Liumi Gr. P. . . . . . 282 I4 36.96

Lumi-camp. . . . . . . $\quad \begin{array}{llll}283 & \text { I } 3 & 9.93\end{array}$

Endpunkt d. Gi. $\because 309$ 4I 30.2

Usseri G1. P. . 31 I 27 10.98

Usseri-camp. . . . . . . 313 5I 36.12

Nagavai .... . . 32743 I4.50
4.4898997

4.28484

4.37 I 9656

$4 \cdot 3275131$

4.2937753

4.71954

4.4930264

4.4765678

4.484409
4.2796564 
Kikumbuliu.

$$
\varphi=-2^{\circ} 40^{\prime} 56^{\prime \prime} \quad \lambda=37^{\circ} 53^{\prime} 5 \mathrm{I}^{\prime \prime} .
$$

Endpunkt d. Gr. . . . . . $2333336.7 \mathrm{I}$

Mogunda IO . . . . . . I47 $20 \quad 52.6 \mathrm{I}$

Mogunda I5 . . . . . . . . I4I 29 35.4I

Mogunda I2 . . . . . . . I64 II 34.75

4.712979

4.148622

4.663894

4.7401032

Mogunda 10.

$$
\varphi=-3^{\circ} 9^{\prime} 37^{\prime \prime} \quad \lambda=3^{\circ} \mathbf{I}^{\prime} 56^{\prime \prime} .
$$

Endpunkt d. Gr.

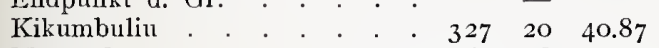

Mogunda I2 . . . . . . . . $16948 \%$

Teita-ya-Bura.

$$
\varphi=-3^{\circ} \quad 25^{\prime} 3^{\prime \prime} \quad \lambda=38^{\circ} \text { I } 7^{\prime} \quad 42^{\prime \prime} .
$$

$\begin{array}{llllllllll}\text { Mogunda I5 . . . . . . } & \text {. } & 34 \mathrm{I} & 6 & 38.02 & 4.679 & 264\end{array}$ Endpunkt d. Gr. . . . . . $\begin{array}{lllcl}300 & 33 & 2.8 & 4.998 & 049\end{array}$

\section{Langaugas.}

$\varphi=-2^{\circ} 48^{\prime} 34.6^{\prime \prime} \quad \lambda=37^{\circ}{\text { I } 2^{\prime} 44^{\prime \prime}}^{\prime}$

Kitenden . . . . . . . . I 30 Io I6.60 3.772435

20-Meilenpunkt . . . . . . $\quad \begin{array}{lllll}96 & 4 & \text { I6.28 } & 3.785 & \text { I98 }\end{array}$ 20-Meilenpunkt.

$\varphi=-2^{\circ} 48^{\prime} 55.6^{\prime \prime} \quad \lambda=37^{\circ} \mathrm{I}^{\prime} \mathrm{o}^{\prime \prime}$.

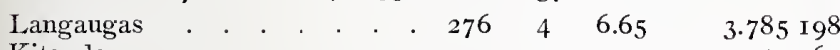

Kitenden . . . . . . $\quad 3.547565$

Kasigao.

$\varphi=-3^{\circ} 49^{\prime} 48 \cdot 7^{\prime \prime} \quad \lambda=38^{\circ} 29^{\prime} 5^{6^{\prime \prime}}$.

Mogunda I 2 . . . . . . . 3 I6 26 I2.4

Endpunkt d. Gr. . . . . $307 \quad$ I4 57.8

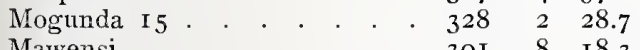

Mawensi

Mawensi.

$\varphi=-3^{\circ} 5^{\prime} \quad 53^{\prime \prime} \quad \lambda=37^{\circ} 27^{\prime} \quad 4 \mathrm{I}^{\prime \prime}$.

Kasigao . . . . . . . . I I I I2 $40.3 \quad$ 5.I94 I5I9

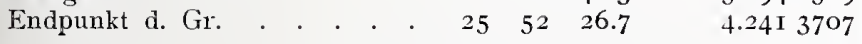

Naduyatui.

Meshanai $\varphi=-2^{\circ} 42^{\prime} 3 \mathrm{I} \cdot 4^{\prime \prime} \quad \lambda=37^{\circ} 29^{\prime} 3 \mathrm{I}^{\prime \prime}$

. . . . $\cdot 298 \quad 50 \quad 51.468$

Kamanga . . . . . . . . $\begin{array}{llll}196 & 34 & 14.907\end{array}$

Loosoito

$\begin{array}{lll}87 & 44 & 32 . \mathrm{II} 7\end{array}$

Kamanga (Endoinet).

$\varphi=-2^{\circ} 55^{\prime} 20.5^{\prime \prime} \quad \lambda=37^{\circ} 25^{\prime} 43^{\prime \prime}$.

Naduyatui . . . . . . . . $16 \quad \begin{array}{lll}6 & 34 & 26.087\end{array}$

Nairadad . . . . . . . . $\begin{array}{lllll}296 & 39 & 36.378\end{array}$

Loosoito . . . . . . . . 4 I $34 \quad 34.937$

Longaria . . . . . . . . $94 \quad \begin{array}{llll} & 9 & 57.497\end{array}$

Grenzsignal 50 . . . . . $\begin{array}{cccc}307 & 57 & 36\end{array}$

Engero. . . . . . . . 353 I 736

Grenzsignal 5I . . . . . . $\quad \begin{array}{llll}34 & 32 & \text { I3 }\end{array}$

Grenzsignal 52 . . . . . $9 \mathrm{I}$ I 46

Loosoito.

5.009 I 873

5.2023552

5.0295623

5.194 I 519

4.5913742

4.5466036

4.3917309

4.I 594905

4.3917309

4.47456 I 5

4.5096598

4.2675725

3.9225743

4.09529 I I

3.1239534

$3.523548 I$

$$
\varphi=-2^{\circ} 42^{\prime} \text { I } 2.6^{\prime \prime} \quad \lambda=37^{\circ} 37^{\prime} \quad \text { 1 } 8^{\prime \prime} .
$$

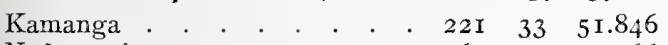

Naduyatui . . . . . . . . $267 \quad 44 \quad$ I0.066

Longaria . . . . . . . . I $86 \quad 39 \quad 44.003$

Leitokitok (Deutsch-) . . . . $202 \quad 2 \quad 36.14$

Soiti Sambu , . . . . . . . $\quad$ IO2 3334.593

\section{Longaria.}

$$
\varphi=-2^{\circ} 56^{\prime} 3.6^{\prime \prime} \quad \lambda=37^{\circ} 35^{\prime} 4 \mathrm{I}^{\prime \prime} \text {. }
$$

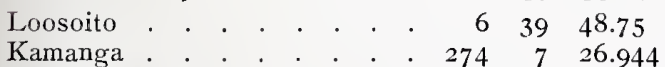

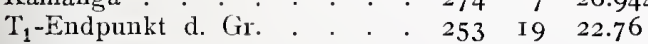

Leitokitok . . . . . . . . $25 \mathrm{I} \quad 38 \quad 59.337$

H. $\mathrm{S}_{2}$, . . . . . . . 204 I6 32.48

H. $\mathrm{S}_{1}$ Lesako . . . . . .

H. $\mathrm{S}_{3}$. . . . . . .

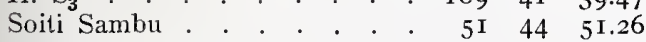

Nagavai . . . . I I8 47 21.50

Kimangelia-camp. . . . . . . $167 \quad 2 \quad 35.29$

Kimangelija Gr. P. . . . . . 173 I 8 I6.6I Mitteilungen a. d. D. Schntzgebieten, XX. Band. IV.

4.5096598

4.I 594905

4.4098552

4.4853827

4.3706202

4.4098552

4.2675725

3.9149829

3.9516927

4.0189536

3.5893585

4.0020703

4.5181956

4.2589763

3.9098269

3.954 3 I I 3

$$
\varphi=-2^{\circ} 57^{\prime} 3{ }^{\mathrm{T}_{2} \cdot 2^{\prime \prime}} \quad \lambda=37^{\circ} 3 \mathrm{I}^{\prime} 8^{\prime \prime} .
$$

$\begin{array}{lllllll}\text { Endpunkt d. Gr. . . . . . } & 60 & 52 & \text { I } 2.96 & 2.8190480\end{array}$ \begin{tabular}{llllllllllll}
$\mathrm{T}_{5}$ &. &. &. &. &. &. & & 287 & $\mathrm{I} 6$ & $\mathrm{I} .27$ & $\mathrm{I} .805$ \\
\hline
\end{tabular} $\mathrm{T}_{5}$

$$
\varphi=-2^{\circ} 37^{\prime} 3 \circ .7^{\prime \prime} \quad \lambda=37^{\circ} 3 \mathrm{I}^{\prime} 5^{\prime \prime} \text {. }
$$

$\mathrm{T}_{2}$. . . . . . . . . $\mathrm{IO} 7 \mathrm{I} 6 \quad \mathrm{I} .47 \quad \mathrm{I} .8053649$ Grenzsignal $5 \circ$.

$$
\varphi=-2^{\circ} 52^{\prime} 3 \mathrm{I} .8^{\prime \prime} \quad \lambda=37^{\circ} 22^{\prime} \mathrm{Io}^{\prime \prime} \text {. }
$$

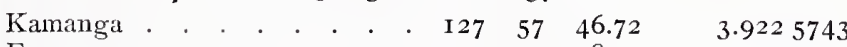

$\begin{array}{lllllll}\text { Engero. . . . . . . . } & 35 & 27 & 28.72 & 3.947 & 7033\end{array}$

Grenzsignal 51.

$$
\varphi=-2^{\circ} 54^{\prime} 40.9^{\prime \prime} \quad \lambda=37^{\circ} 26^{\prime} \mathbf{I}^{\prime \prime} \text {. }
$$

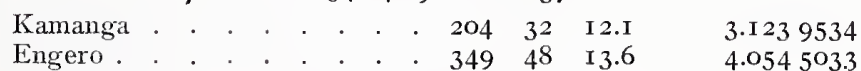

\section{Grenzsignal 52.}

$\varphi=-2^{\circ} 55^{\prime} 22.3^{\prime \prime} \quad \lambda=37^{\circ} 27^{\prime} 3 \mathrm{I}^{\prime \prime}$.

Kamanga . . . . . . . 27 I I $40.49 \quad 3.523548 \mathrm{I}$

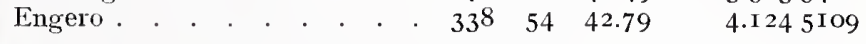

\section{Engero.}

$\varphi=-2^{\circ} 48^{\prime} \quad 37.7^{\prime \prime} \quad \lambda=37^{\circ} 24^{\prime} \quad 56^{\prime \prime}$

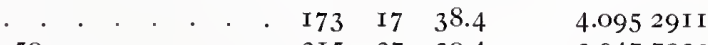

$\begin{array}{lll}215 & 27 & 30.4\end{array}$

$\begin{array}{lll}169 & 48 & 16.9\end{array}$

$\begin{array}{lll}5^{8} & 54 & 50.4\end{array}$

3.9477033

4.0545033

Lesako.

$\varphi=-2^{\circ} 57^{\prime} 56.3^{\prime \prime} \quad \lambda=37^{\circ} 36^{\prime} 39^{\prime \prime}$

Endpunkt d. Gr

4.1245109

Longaria

3.9875583 3.5890932

Deutsches Lager-Signal, Leitokitok.

Longaria . . . $\cdot \cdot \cdot \begin{array}{rrrr}22 & 2 & 54.50 & 4.4853827\end{array}$

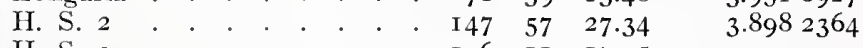

H. S. 3 . . . . . . I 36 II I $7.55 \quad 3.992$ 2I 30

H. S. 2 .

$\varphi=-3^{\circ} \mathbf{I}^{\prime}$ I $4.0^{\prime \prime} \quad \lambda=37^{\circ} 33^{\prime} 22^{\prime \prime}$.

H. S. 3 .

$\varphi=-3^{\circ}$ I $^{\prime} 26 \cdot 4^{\prime \prime} \quad \lambda=37^{\circ} 34^{\prime} 46^{\prime \prime}$.

Soiti Sambu.

$\varphi=-2^{\circ} \quad 44^{\prime} \quad 58.8^{\prime \prime} \quad \lambda=37^{\circ} 49^{\prime \prime} 40^{\prime \prime}$

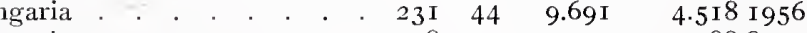

Nagavai . . . . . . . $198 \quad 53$ 30.35 I 4.488852 I

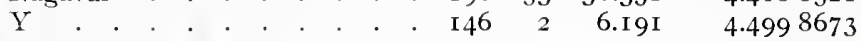

Nagavai. $\begin{array}{lll}298 & 46 & 54.769\end{array}$

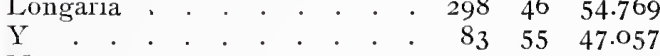

$\begin{array}{llllllllll}\text { Mogunda } 9 & . & . & . & . & . & \text { I } 47 & 43 & 43.307\end{array}$

$\begin{array}{lllll}\text { Tschăla. } \quad . \quad & \text { I } 89 & 21 & 0.867\end{array}$

Kinnangelia-camp. . . . . . $\quad \begin{array}{llll}273 & 20 & 33.179\end{array}$

Kimangelija Gr. P. . . . . 269 I3 56.659

Usseri-camp. . . . . . . . $\begin{array}{llll}226 & 33 & 3.297\end{array}$

Usseri Gr. P.

$\begin{array}{lll}233 & 33 & 56.437\end{array}$

$\mathrm{Y}$.

$\varphi=-2^{\circ} 59^{\prime} \mathrm{I} 2.4^{\prime \prime} \quad \lambda=37^{\circ} 59^{\prime} \quad$ I $2^{\prime \prime}$

Soiti Sambu . . . . . . . . 326 I $37.572 \quad 4.4998673$

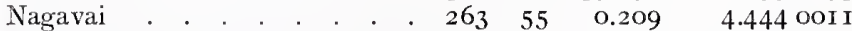

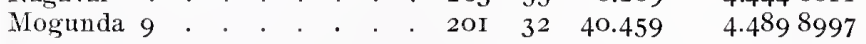

Tschăla.

$\varphi=-3^{\circ} \mathrm{I}^{\prime} 26.3^{\prime \prime} \quad \lambda=37^{\circ} 4 \mathrm{I}^{\prime} \mathrm{I}^{\prime \prime}$.

Nagavai . . . . . . . . . 92 2I $10.992 \quad 4.5416202$

$\begin{array}{lllllllllll}\text { Mogunda } 9 & \text {. . . . . . . } & 68 & 43 & 29.462 & 4.371 & 9656\end{array}$

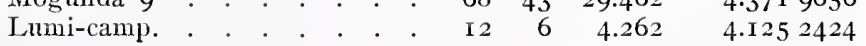

4888521

2589763

$4.484409 \mathrm{I}$

4.5416202

4.1496064

720793

3.8643009

3.9415235
I8 $53 \quad 46.597$ 
Richtung nach:

\begin{tabular}{rrl}
\multicolumn{4}{c}{ Azimut } \\
\multicolumn{1}{c}{,} & \multicolumn{1}{c}{} \\
5 & 7 & 23.222 \\
I 30 & 47 & 41.25 \\
122 & 39 & 20.622 \\
219 & 58 & 20.252 \\
$21 \mathrm{I}$ & 26 & 21.022 \\
I 55 & 51 & 25.557 \\
I 80 & 8 & 21.141
\end{tabular}

$\log$ der Entf.

Lumi Gr. P.

Ndui

Latemia

VIalogogoi

Tilima - Yiwili

Ugweno-Ost

Kimangelia - camp.

Longaria
Nagavai $\varphi=-3^{\circ} \mathrm{o}^{\prime} 2 \mathrm{I} \cdot 4^{\prime \prime} \quad \lambda=37^{\circ} 36^{\prime} 40^{\prime \prime}$ $\begin{array}{llll}347 & 2 & 32.24\end{array}$ $9320 \quad 57.14$

3.9098269 4.1496064

Kimangelija-Grenzpunkt.

Longaria
Nagavai $\varphi=-3^{\circ} \mathrm{o}^{\prime} 54.7^{\prime \prime} \quad \lambda=37^{\circ} 36^{\prime} \mathrm{I} 5^{\prime \prime}$.

353 I 8 I 4.84

89 I4 21.96

3. 9543 I I 3

4.1720793

Usseri-camp.

$\varphi=-3^{\circ} 3^{\prime} 32.0^{\prime \prime} \quad \lambda=37^{\circ} 4 \mathrm{I}^{\prime} 24^{\prime \prime}$.

Nagavai. $.4 \begin{array}{lllll}4 & 33 & \text { I } 2.4 \mathrm{I}\end{array}$

MIogunda 9 $\begin{array}{rrr}46 & 33 & 12.41 \\ 133 & 52 & 14.60\end{array}$

3.8643009 4.4765678

Usseri Grenzpunkt.

$\varphi=-3^{\circ} 3^{\prime} 37 \cdot 2^{\prime \prime} \quad \lambda=37^{\circ} 40^{\prime} 29^{\prime \prime}$.

Nagavai . . . . . $\begin{array}{cccc}53 & 34 & 8.5 \mathrm{I}\end{array}$

Mogunda 9 $\begin{array}{lll}131 & 27 & 52.54\end{array}$

3.9415235

Lumi-camp.

$\varphi=-3^{\circ} \mathrm{I}^{\prime} 20.4^{\prime \prime} \quad \lambda=37^{\circ} 42^{\prime} 44^{\prime \prime}$.

$\begin{array}{rrrr}103 & \text { I } 3 & 44.90 & 4.2937753\end{array}$

Tschăla.

$192 \quad 5 \quad 59.10$

4.1252424

\section{Lumi Grenzpunkt.}

Tschăla. $\varphi=-3^{\circ} \mathrm{I}^{\prime} 2 \mathrm{I} .2^{\prime \prime} \lambda=37^{\circ} 4 \mathrm{I}^{\prime} 5 \mathrm{I}^{\prime \prime}$.

Mogunda 9

$\begin{array}{lll}102 & \text { I } 5 & \mathbf{1} 4.82\end{array}$

$\mathrm{X}$.

4.I I 757 I4

$4.3275 \mathrm{I} 3 \mathrm{I}$

$$
\varphi=-3^{\circ} 23^{\prime} 22.2^{\prime \prime} \quad \lambda=37^{\circ} 47^{\prime} \quad 19^{\prime \prime} .
$$

Mogunda $9 \quad$. . . . . $33 \quad 57 \quad 57.931$

Tschăla. . . . . . $302 \quad 38 \quad 59.178$

Latema . . . . . . . 265 Io 18.348

Nlokimni . . . . . . 234 I9 38.888

Vil.-Yiwili . . . . . 176 I8 17.478

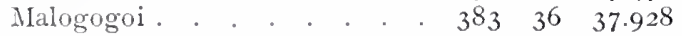

\section{Latema.}

$$
\varphi=-3^{\circ} 24^{\prime} \mathrm{I} 3 \cdot 6^{\prime \prime} \quad \lambda=37^{\circ} 37^{\prime} 4^{\prime \prime} \text {. }
$$

Tschăla. . . . $39 \quad 58 \quad 34.3$ I I

Mokinni 169 I 53.6 I 2

Kilewo Gr. F. . . . . . $201 \quad 5929.61$

Lemrika . . . . . . 2 2I $59 \quad 42.01$

Mokinni.

$\varphi=-3^{\circ} 29^{\prime} 52.1^{\prime \prime} \quad \lambda=37^{\circ} 38^{\prime} 19^{\prime \prime}$.
$\mathrm{X}$.

I.atema .

Vil.-Viwili

Kilewo Gr. P.

Lemrika

Usange .
4.2796564

4. I 279845

4.2733968

4.3125402

4.3230439

4.1492457

4.06 I I 768

4.2733968

4.0249155

3.870 I 152

\begin{tabular}{|c|c|c|c|c|c|c|c|}
\hline & & & & ilima & a-Viwi & & \\
\hline & $\varphi=$ & $=-5^{\circ}$ & C $34^{\prime}$ & 45 & $s^{\prime \prime}$ & $=37$ & ${ }^{\circ} 48^{\prime} 3^{\prime \prime}$ \\
\hline x. & . & . . . & . . & & . $35^{6}$ & 18 & I 4.808 \\
\hline Mokinni & & . & . & . & 296 & 33 & $5 \mathrm{I} .89 \mathrm{I}$ \\
\hline Tschăla (ber. & & . & . & . & 335 & $5 \mathrm{I}$ & $0.86 \mathrm{x}$ \\
\hline Ugweno-Ost & & . & & . & . 279 & 3 & I 2.077 \\
\hline Djipe-Süd . & & . & . & . & . 189 & 18 & $33.15^{8}$ \\
\hline Usange. & . & & & . & . 236 & 23 & 19.165 \\
\hline Ndea & & . & & - & . I6I & II & 48.165 \\
\hline
\end{tabular}

3.75 I 1844

Malogogoi.

$\varphi=-3^{\circ} 2 \mathrm{I}^{\prime} 34 \cdot \mathrm{I}^{\prime \prime} \quad \lambda=37^{\circ} 39^{\prime} 55^{\prime \prime}$.

Tschăla

$\begin{array}{rrr}54 & 20 & \text { II } .357 \\ 349 & \text { I } & 49.683\end{array}$

$\begin{array}{lll}\text { II6 } & 34 & 27.967\end{array}$

$\begin{array}{lll}306 & 18 & 40.183\end{array}$

$\begin{array}{lll}316 & 59 & 50.2\end{array}$

$\begin{array}{lll}80 & 34 & 38.794\end{array}$

4.3125402

4.0249155

4.3046822

3.7742662

3.9287133

4.3253208

4.3230439

4.3046822

4.4906428

4.I IO OII 8

$4.0345 \mathrm{I} 86$

4.340695 I

4.5225259

$\mathrm{X}$.

3.6628480

4.1492457
Richtung nach:

Azimut

$\log$ der Eutf

Ugweno-Ost.

$\varphi=-3^{\circ} 33^{\prime} 39.8^{\prime \prime} \quad \lambda=37^{\circ} 4 \mathrm{I}^{\prime} \quad 1 \mathrm{I}^{\prime \prime}$

$\begin{array}{lllll}0 & 8 & 21.265 & 4.4185159\end{array}$

Djipe-Süd . $99 \begin{array}{rrr}9 & 37.747 & 4.1100118\end{array}$

Djipe-Süd.

$$
\varphi=-3^{\circ} 40^{\prime} 33 \cdot 7^{\prime \prime} \quad \lambda=37^{\circ} 47^{\prime} 7^{\prime \prime} .
$$

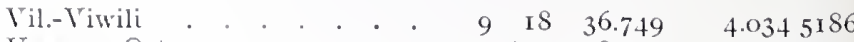
Ugweno Ost . . . . . 3I9 I2 I8.730 4.225 O871

\section{Kilewo Grenzpunkt.}

$\varphi=-3^{\circ} 27^{\prime} 57 \cdot 5^{\prime \prime} \quad \lambda=37^{\circ} 35^{\prime} 44^{\prime \prime}$.

Lemrika.

$\varphi=-3^{\circ} 26^{\prime} 30.0^{\prime \prime} \quad \lambda=37^{\circ} 35^{\prime} \mathrm{II}^{\prime \prime}$.

Usange.

$\varphi=-3^{\circ} 4 \mathrm{I}^{\prime} 20.7^{\prime \prime} \quad \lambda=37^{\circ} 38^{\prime} \mathrm{I} 2^{\prime \prime}$

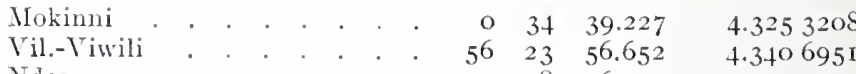

$\begin{array}{lllllll}\text { Ndea . . . . . . . } & 123 & 48 & 16.352 & 4.542 & 5393\end{array}$

Kwisu . . . . . . $150 \quad 12 \quad 30.058 \quad 4.7286530$

Ndea.

$\varphi=-3^{\circ} 5 \mathrm{I}^{\prime} 52.4^{\prime \prime} \quad \lambda=37^{\circ} 53^{\prime} 5 \mathrm{I}^{\prime \prime}$

… .34 I I I $25.577-4.5225259$

$\begin{array}{rrrr}303 & 47 & \text { I } 4.476 & 4.5425393\end{array}$

Kwisu . . . . . . . 185 o 4 I.169 4.4339547

Tusa. . . . . . . . I I6 $4923.479 \quad 4.587$ I529

Kwisu.

$\varphi=-4^{\circ} 6^{\prime} 33 \cdot 3^{\prime \prime} \quad \lambda=37^{\circ} 52^{\prime} 34^{\prime \prime}$.

Usange . . . . . . . 330 II 3 I. $397 \quad 4.7286530$

Ndea . . . . . . . $\begin{array}{rrrrr} & 5 & 0 & 46.518 & 4.4339547\end{array}$

Tusa. . . . . . . . 102 $40 \quad 50.398 \quad 4.3822$ I 42

Schageiu . . . . . . $\mathrm{I}_{34} 4 \mathrm{I} 4.288 \quad 4.8 \mathrm{II} 0970$

Tusa.

$\varphi=-4^{\circ} 9^{\prime} 25.6^{\prime \prime} \quad \lambda=3^{\circ} 5^{\prime} \mathrm{I}^{\prime \prime}$.

Ndea . . . . . $326 \quad 48 \quad 35.510$

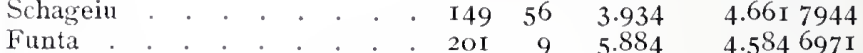

Schageiu.

$\varphi=-4^{\circ} 30^{\prime} 58.8^{\prime \prime} \quad \lambda=3^{\circ}$ i $7^{\prime} 43^{\prime \prime}$

Kwisu . . . . . . . $314 \quad 2 \quad 20.830 \quad 4.8$ II 0970

Tusa. . . . . . . . $329 \quad 55 \quad 7.526 \quad 4.66$ I 7944

Funta . . . . . . . . $\quad \begin{array}{lllll}275 & 58 & 48.368 & 4.568 & 8992\end{array}$

Funta.

$\varphi=-4^{\circ} 28^{\prime} \quad 51.4^{\prime \prime} \quad \lambda=37^{\circ} 57^{\prime} 4^{\prime \prime}$

\section{Segera.}

$\varphi=-5^{\circ}$ I $^{\prime} \quad 3^{8.5^{\prime \prime}} \quad \lambda=3^{\circ} \quad 33^{\prime} 23^{\prime \prime}$

Tongwe $\quad . \quad . \quad . \quad \begin{array}{ccccc}88 & 28 & 56.22 & 4.2838201\end{array}$

Genda Genda . . . . . I60 4I $38.94 \quad 4.4849118$

Kofi . . . . . . . 229 I5 $28.66 \quad 4.4521963$

Tongwe.

$\varphi=-5^{\circ} \mathrm{I}^{\prime} \quad 2 \mathrm{I} \cdot 7^{\prime \prime} \quad \lambda=3^{\circ} 43^{\prime} 47^{\prime \prime}$.

Zanzibar … . . 15 I 53 I $5.65 \quad 5.03$ I 59 II

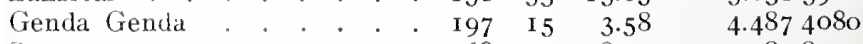

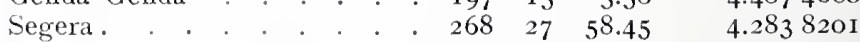

\section{Kofi.}

$\varphi=-5^{\circ} 28^{\prime} \quad 40.2^{\prime \prime} \quad \lambda=3^{\circ} 2 \mathrm{I}^{\prime} \quad 4^{\prime \prime}$.

Segera $\quad . \quad \begin{array}{lllll}49 & 16 & 34.24 & 4.452 & 1963\end{array}$

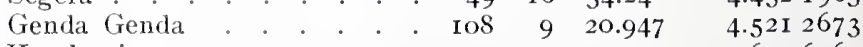

Kondussi. . . . I45 244.39 4.64I 6163

Genda Genda.

$$
\varphi=-5^{\circ} 34^{\prime} \mathrm{I} 6.8^{\prime \prime} \quad \lambda=38^{\circ} 38^{\prime} 5 \mathrm{I}^{\prime \prime} \text {. }
$$

Segera . . . . . . . . $340 \quad 4^{\mathrm{I}} \quad 7.82 \quad 4.4849 \mathrm{II} 8$

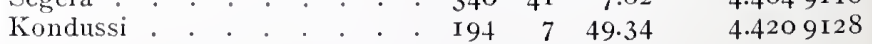


Richtung nach:

Kofi

Tongwe

Zanzibar

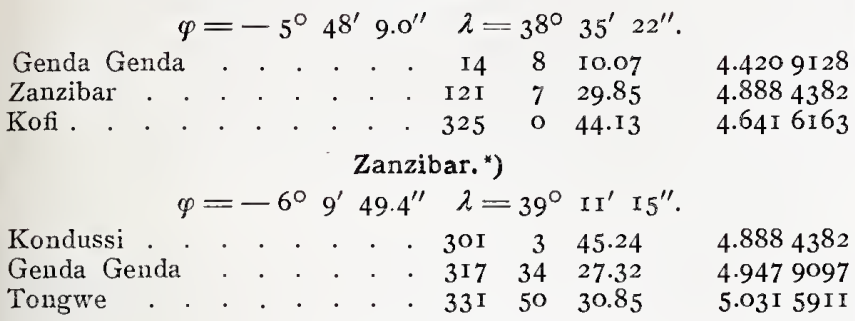

\section{Höhenmessungen.}

\section{Hauptmann Herrmanns Bericht über die Höhen- messungen der Kiwusee-Expedition.}

Zur Verfügung standen: Hypsometer Fueß Nr. 366 Ind 588, später auch noch Nr. 583 und 584; außerdem drei Aneroide: Bohne Nr. 3286 und 28IO, und Casella Nr. 5532. Dr. Kandt hatte Hypsometer Nr. 4 I2 und 4I3, mit denen unsere verglichen wurden.

Während des Aufenthaltes in Usumbura hatte Professor Lamp eine meteorologische Station eingerichtet und das aus Udjidji mitgebrachte Quecksilberbarometer regelmäßig abgelesen; nach unserem $\mathrm{Ab}$ marsch wurde das von seiten der Station weiter fortgesetzt. Die Aufzeichnungen, während wir am Kiwu arbeiteten, habe ich noch nicht bekommen und daher zu meinen Berechnungen nicht verwerten können. Die Aufzeichnungen des Professor Lamp sind, wie schon erwähnt, leider verloren gegangen. Für unsere Höhen liegen die des Tanganjika und Kiwu zugrunde; erstere ist jetzt von Dr. Kohl. schütter unter Benutzung alles Materials der Njassa-Tanganjika Grenzexpedition, der Pendelexpedition und der unsrigen, sowie der für Kwai und Tanga vorliegenden Beobachtungen mit $780 \mathrm{~m}$ berechnet, was für die nächste Zeit als definitiv zu gelten haben dürfte. Die aus den Jahren I 898, I 899 und I9OI stammenden Beobachtungen für den Tanganjika ergeben völlig übereinstimmende Resultate. Dr. Kohlschütter bat dabei auch alles ältere Material kritisch gesichtet und als jedenfalls mit Fehlern behaftet, ausgeschlossen. Manche der vorliegenden belgischen Beobachtungen verdienen überhaupt nicht ernst genommen zu werden.

Alle von uns aufgenommenen Routen sind gleichzeitig Aneroidzüge in Schleifenform mit Kontrollen

*) Betreffend die Koordinaten von Zanzibar ist zu vergleichen die Erläuterung auf Seite 197. durch Siedepunktsbestimmungen. Auch geht längs der Dreieckskette eine Linie trigonometrischer Höhenmessungen. Diese werden bei größeren Entfernungen, etwa über $20 \mathrm{~km}$, insofern ungenau, als die Elemente zur Bestimmung der Refraktionskoeffizienten fehlten, und solche daher unter der etwas willkürlichen Annahme, daß die Temperatur mit jedem Meter Höhe um $\mathrm{O}^{\circ}$.OI C. fiele, berechnet werden mußten; auch konnte nicht immer hin und her gemessen werden, und niemals zu gleicher Zeit, da nur das Universal, das ich bei der Triangulation benutzte, einen Höhenkreis hatte. Zur Ermittlung der Hölen von Bergen aber, die man aus Mangel an Zeit nicht alle besteigen kann, deren Kenntnis aber für die Karte wünschenswert ist, ist trigonometrischeHöhennessung das einzige Mittel; und für dortige Verhältnisse genügend genau, selbst wenn die Entfernung nicht gerechnet, sondern nur auf dem Meßtisch abgestochen war. $\mathrm{Da}$ wo barometrische und trigonometrische Messungen zusammenfallen, ist die Übereinstimmung immer bis auf wenige Meter. Die Höhe des Kiwu über dem Tanganjika wurde trigonometrisch mit $672 \mathrm{~m}$ bestimmt, nach Siedepunktsbestimmungen mit $677 \mathrm{~m}$, woraus übereinstimmend eine Meereshöhe von $1455 \mathrm{~m}$ (rund $1460 \mathrm{~m}$ ) resultiert.

Die Aneroidablesungen wurden zunächst nach denen der Hypsometer, die eigentlich alle 4 bis 5 Tage stattfinden sollten, aber leider viel zu wenig stattfanden, korrigiert, mit einfacher Interpolation der Korrektur auf die einzelnen Tage, was natürlich auch willkürlich ist; dann wurden alle Ablesungen auf das Tagesmittel reduziert, und schließlich die Höhen nach den Jordanschen Tabellen für rohe Meereshöhen berechnet. Die Kurve für die Tagesbewegung entnahm ich den Veröffentlichungen des Dr. Maurer für die Station Tabora, was ich unbedenklich tun konnte, da die Kurve für die ganze Kolonie beinahe dieselbe Form hat. Die Gesamtschwankung nahm ich mit $2 \mathrm{~mm}$ an, was ich als ungefähres Mittel aller Differenzen zwischen Morgenund Nachmittagablesungen fand. Eine Reduktion auf das Jahresmittel konnte ich nicht vornehmen, da mir dazu das Material fehlte; da die Aneroidschleifen jedoch nie über einen Monat dauerten, kommt die Jahresschwankung kaum in Betracht. Übrigens ist sie nach Dr. Maurer im Innern auch viel geringer als an der Küste. Auch die Aneroidablesungen, welche nicht durch Siedepunktskontrollen gestützt sind, konnten Verwendung finden, da unsere Märsche Schleifen waren, die Punkte, deren. Höhen bereits festlagen, passierten und immer wieder zum Ausgangspunkt, meist einem Standlager an Kiwu oder dem Niveau desselben, zurüçkkehrten, so daß auch hierbei durch eine, wenn auch manchmal recht 
willkürliche Verteilung des Schlubfehlers auf die ganze Reise Höhenzahlen resultieren, die für die vorläufige Kenntnis jener Länder genuigen. Natürlich könnten sämtliche Höhenzahlen, unbeschadet ihrer Genauigkeit, auf 5 und IO abgerundet werden, womöglich noch mehr; wenn dies bei der Eintragung in die Karte nicht geschah, so ist das nur einer eventuell späteren Vergleichung mit anderen Resultaten wegen geschehen. Geschätzte Höhen sind nur da mit aufgeführt (besonders bezeichnet), wo dieses bei einzelnen Bergzügen für die Beurteilung des Geländes wïnschenswert erschien. Die Höhen der Inseln im Kiwu sind Relativhöhen ïber den See, da dies für das Kartenlesen bequemer ist; die kleineren sind nur geschätzt. (Die hier behandelten Resultate sind nicht in besonderer Tabelle zusammengestellt, da mir das Originalmaterial nicht vorlag, sondern direkt in die betreffende Manuskript-Karte eingetragen. A.)

\section{Trigonometrische Höhenmessungen, ausgeführt während der Uganda-Grenz-Expedition.}

\begin{tabular}{c|c||c|c|c|c}
\hline Eingemessener Punkt & Ausgangspunkt & $\begin{array}{c}\text { Distanz } \\
\text { oder deren }\end{array}$ & $\begin{array}{c}\text { Elevations- } \\
\text { oder } \\
\text { Depressions- } \\
\text { werte }\end{array}$ & Lögarithm. \\
Name & Höhe & Name & Höhe & Bemerkungen \\
\hline
\end{tabular}

\section{Messungen von Hauptmann Schlobach.}

\begin{tabular}{|c|c|c|c|c|c|c|c|c|}
\hline \multirow{2}{*}{\multicolumn{2}{|c|}{$\begin{array}{c}\text { Basis Ost . } \\
\text { West }\end{array}$}} & & & & & & & \\
\hline & & & & . & & & . & \\
\hline hйru-Pf & fei & & & . & & & & \\
\hline kt dich & at & & & & & & & \\
\hline kt am & de & 11 & & & & 1 & & \\
\hline P. 8 & ${ }^{\circ}$ & $\cdot$ & - & . & . & . & . & \\
\hline o. Nr. I & & . & . & . & . & . & . & \\
\hline . P. 9 & . & - & - & . & . & . & . & \\
\hline IO & & $\cdot$ & - & . & . & · & - & \\
\hline I 2 & & & & & & & 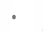 & \\
\hline 13 & (i) & & & & & It & & \\
\hline I 5 & & 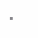 & . & - & . & & & \\
\hline I 6 & $\cdot$ & . & . & . & 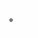 & & & \\
\hline ", & . & . & . & . & . & . & · & \\
\hline I 8 & & - & . & . & . & . & • & \\
\hline I9 & $?$ & . & . & - & . & . & & \\
\hline 25 & . & . & . & . & & . & & \\
\hline , & . & - & . & . & . & . & • & \\
\hline 28 & . & $\theta^{\circ}$ & . & . & . & . & . & \\
\hline 29 & . & 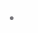 & . & 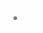 & & . & & \\
\hline $3 I$ & . & . & . & 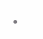 & & . & . & \\
\hline$\Rightarrow \quad 32$ & $\cdot$ & - & . & . & & . & . & \\
\hline feiler IV & . & . & $\cdot$ & . & . & . & . & \\
\hline " $\quad V$ & . & . & . & . & . & - & . & \\
\hline$V^{r}$ & . & . & . & . & . & . & - & • \\
\hline I. P. 33 & . & . & . & . & . & . & . & \\
\hline$" \quad 34$ & . & . & . & . & . & 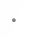 & . & \\
\hline$\because \quad 35$ & . & . & . & . & & $\cdot$ & . & \\
\hline Ugiseru & 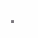 & . & . & . & . & . & $\cdot$ & . \\
\hline M. P. 36 & . & . & $\cdot$ & . & . & . & . & . \\
\hline 37 & & 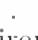 & . & • & & . & 1) & \\
\hline$"$ & & 111 & & & & & & \\
\hline Njamak & arv & va & . & - & . & . & . & \\
\hline watsch & . & . & $\cdot$ & . & . & . & . & \\
\hline I. I’. 39 & $\cdot$ & . & 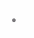 & . & & . & . & \\
\hline Grobe Fel & $\operatorname{spa}$ & artic & & - & . & • & . & \\
\hline M. P. 40 & . & . & . & . & . & . & . & . \\
\hline $4 \mathrm{I}$ & . & . & $\cdot$ & . & . & . & $\cdot$ & \\
\hline 42 & & & & $\dot{x}$ & . & $\therefore$ & ${ }^{\circ}$ & \\
\hline 43 & (K & the & & & & 1) & . & \\
\hline " 44 & . & 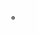 & & 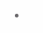 & & . & . & \\
\hline - Kuboke & & . & 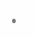 & . & ${ }^{\circ}$ & . & . & \\
\hline amjanju & $\cdot$ & $\cdot$ & 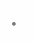 & . & · & $\cdot$ & . & . \\
\hline M. P. 49 & . & & . & . & . & . & ${ }^{\circ}$ & · \\
\hline Canjiri-Ka & $\mathrm{mr}$ & & & & & - & . & . \\
\hline 1. P. 52 & (B) & the & ro & & & - & $\cdot$ & \\
\hline ŭribe-Pf & eile & & & $\mathrm{Hal}$ & & . & . & . \\
\hline & om & & bis & & & - & . & \\
\hline . P. $5^{8}$ & . & . & - & 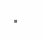 & - & - & . & . \\
\hline 59 & $\cdot$ & $\cdot$ & $\cdot$ & . & . & . & $\cdot$ & . \\
\hline 60 & . & . & . & . & . & · & . & . \\
\hline
\end{tabular}

\begin{tabular}{|c|}
\hline $\mathrm{m}_{\mathrm{I}} \mathrm{f} 6.03$ \\
\hline I I 77.34 \\
\hline I 227.16 \\
\hline I I 86.4 \\
\hline I I 77.3 \\
\hline I I 97.7 \\
\hline I 250.6 \\
\hline I I92.I \\
\hline I I 85.4 \\
\hline I I 57.7 \\
\hline I I 56.6 \\
\hline I I 63.6 \\
\hline I I 6I. 4 \\
\hline I I 55.9 \\
\hline I I 65.4 \\
\hline I $20 \mathrm{I} .4$ \\
\hline I 168.7 \\
\hline I 197.3 \\
\hline 1198.4 \\
\hline 1167.6 \\
\hline I I 7 I. 7 \\
\hline I I 69.8 \\
\hline I I 88.5 \\
\hline I 204.4 \\
\hline 1205.1 j \\
\hline I 198.5 \\
\hline I I 77.8 \\
\hline 1203.7 \\
\hline I 208.8 \\
\hline I I 64.7 \\
\hline I I 68.2 \\
\hline I I 71.8 \\
\hline I 245.6 \\
\hline 1327.9 \\
\hline I 239 \\
\hline $126: .5$ \\
\hline I I $83 . \mathrm{I}$ \\
\hline I I 80.9 \\
\hline I I 79. I \\
\hline I 233 \\
\hline I 183 \\
\hline I 300 \\
\hline 1236 \\
\hline I I 99 \\
\hline I 363 \\
\hline I 168 \\
\hline I 5 I 8 \\
\hline I 557 \\
\hline I 482 \\
\hline I $45^{\circ}$ \\
\hline I 399 \\
\hline
\end{tabular}

Vict. Njansa
Pfeiler Lasis W.
Mohurru-I'feiler
".
Gurekeri

Runder Stein!

$$
\text { Njansa }
$$

Mohŭru-Pfeiler

Runder Stein Gurekeri Punkt I 8

Mohŭru-Pfeiler

Gurekeri

Mohŭru-Pfeiler Gurekeri

Mohŭru-Pfeiler Gurekeri

Mohŭru-Pfeiler

",

Nohŭı-Pfeiler

Sigu. Njamakar"wa

Mohŭru-Pfeiler

S. Njamakarwa

Mohuัru-Pfeiler

S. Njamakarwa

Basis West

S. Njamakarwa

S. Kuboke

Mohñru-Pfeiler

M. P. 49

Mohŭru-Pfeiler

Kŭribe

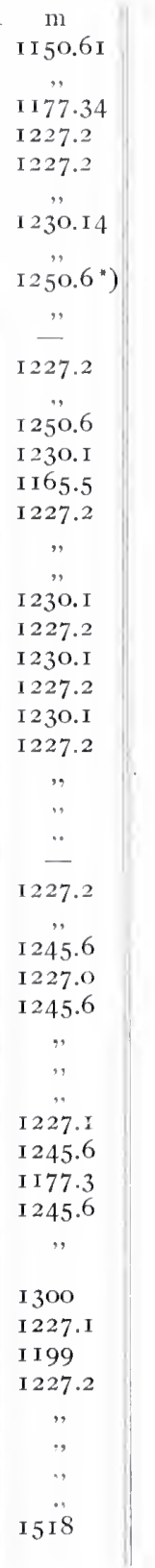

$\mathrm{m}$

I 5935

600

530

I 50

260

2740

I $\mathrm{OO}_{3}$

-

2420
2060

I 860
I 004

900

3630

5280

7420

5 I90

4700

4340

$495^{\circ}$

4840

5300

5840

7880

8300

6870

5430

5130

9235

6808

1 002

I $73^{\circ}$

I I 80

8030

5620

7960

7860

7930

3380

I 3520

9900

I 2280

27000

27500

26780

26440

3260

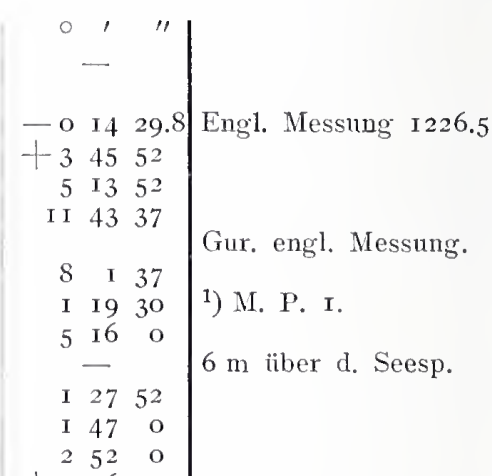

$+33637$

-2 I I 37

- -053 I5

$\begin{array}{lll}\circ & 1722\end{array}$

O I I O

o 3922

o 3830

o 4545

o 2445

o I 6 I 5

O I 2 I 5

o 1445

$\begin{array}{lll}0 & 19 & 15\end{array}$

O 7 I 5

० 29

- $35 \quad$ I 5

$+04722$

- o 953.3

+039 I 8.7

o 4 I 30

$\begin{array}{lll}\text { O } & 28 & 37\end{array}$

2580

O I7 22

+ 04245

- o 26 I 5

+o 250

- $0255^{8}$

$+130$

+ 0345

- 054 I 5

+o I3 I 5

- 03028.7

- o 4748.5

- o 39 I 5

- o 35 I 5

-2337
-235

*) Kŭribe-Stat. I557 nach Oberleutnant WeiB. 


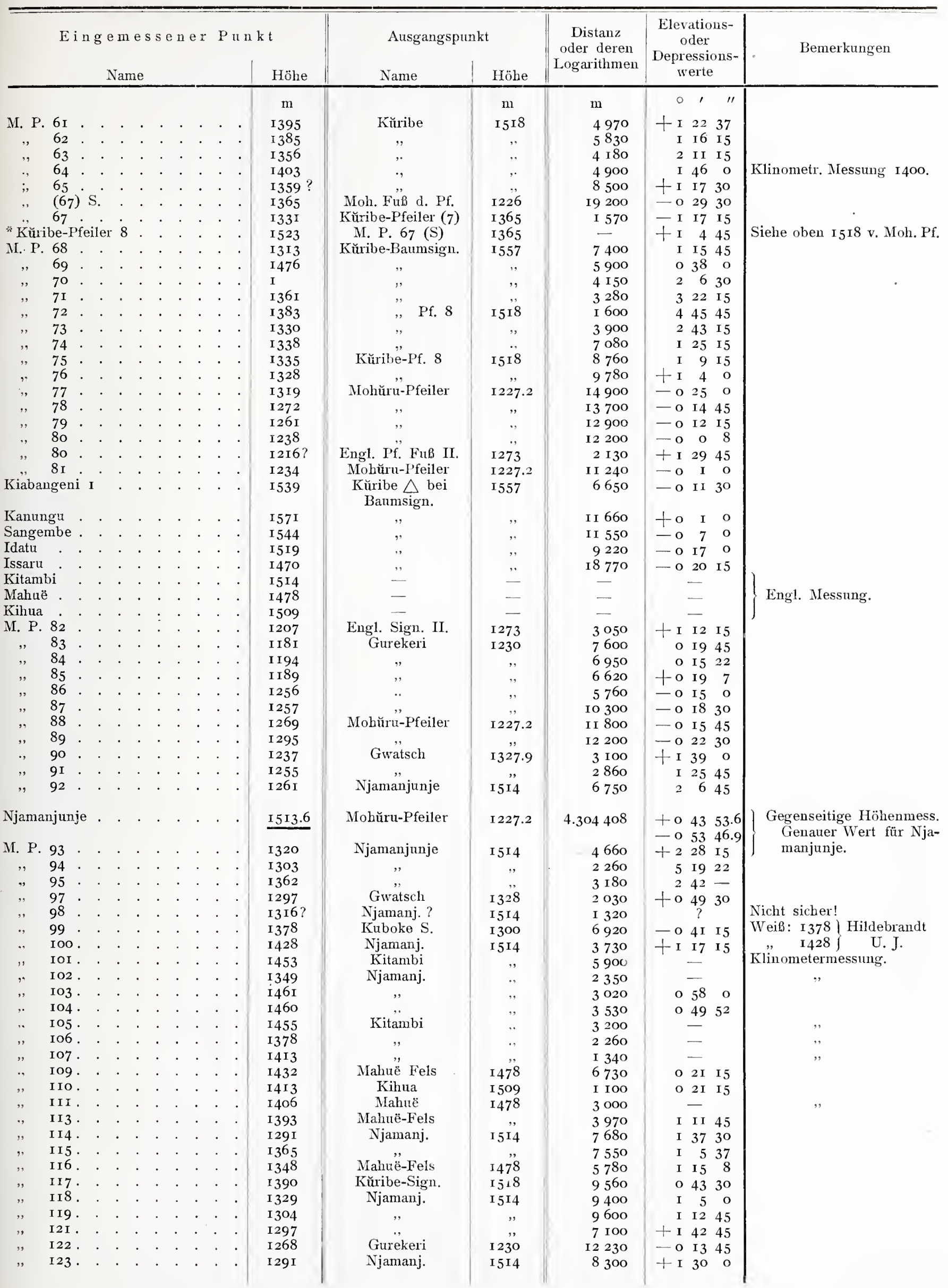




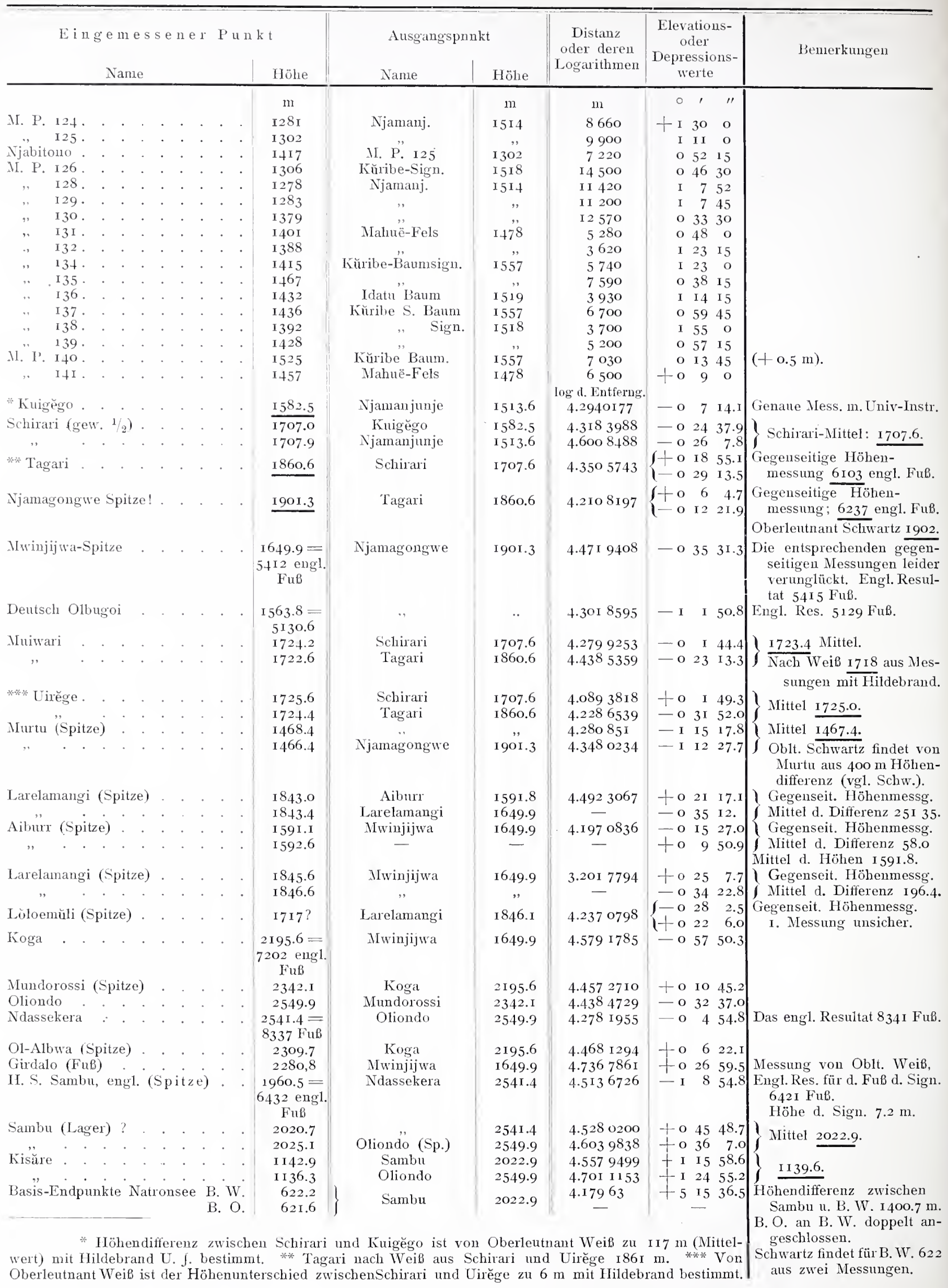




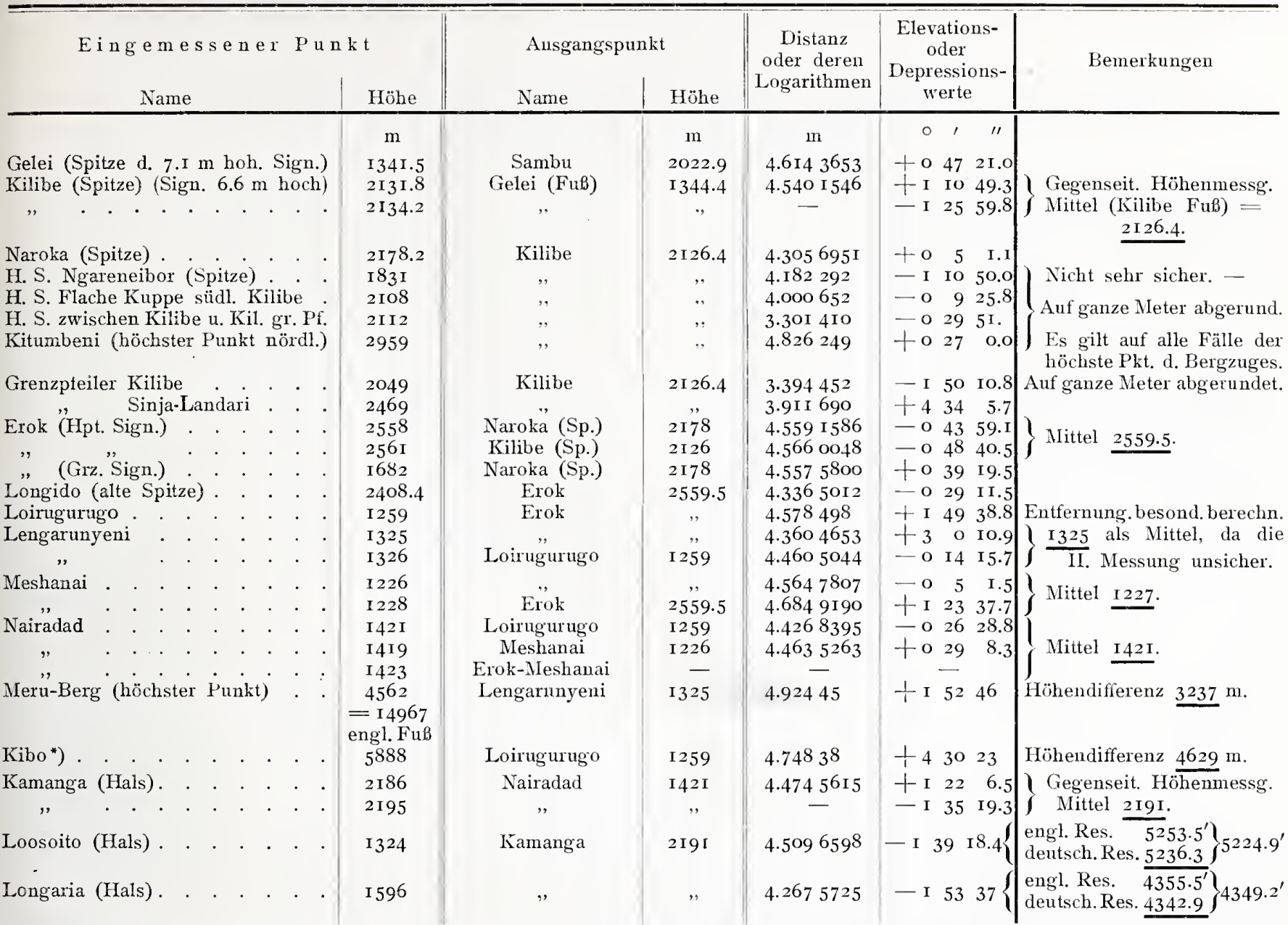

Nach Übereinkommen zwischen dentsch. nnd engl. Kommissar ist danach für die weiteren Messungen als Ausgangswert angenommen:

Loosoito . $=\mathrm{I} 325.6 \mathrm{~m}$

Longaria . . . . . $=\mathrm{I} 598.6$,,

Sign. T, (P) .

Lesako (P) . . . . . . . 1799

Mawensi (höchster Punkt)

5160

$=\mathrm{I} 69 \mathrm{I} 8$

engl. FuB

Sambu (FuB) .

I 304
I 299

1299
I 302

Nagavai (FuB) . . . . . . . .

1229

I 229

I 229

Stat. Y . . . . . . . . 830

830

828

830

I 234

I 234

I I 33

I I 24

I060

Longaria
,,
Loosoito
Longaria
Loosoito
Sambu
",
Longaria
,"
Nagavai
Sambu
Stat. Y
Nagavai
Tschăla
,"

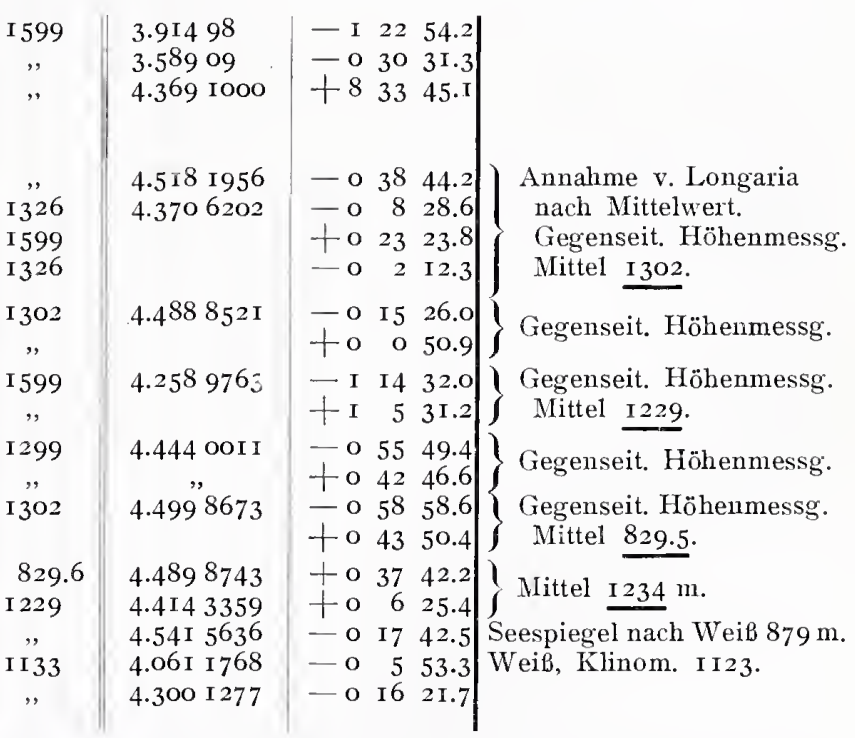

*) Herr Professor Dr. H. Meyer macht darauf aufmerksam, daß diese Messung sich nicht auf den höchsten Punkt des Kibo, die Kaiser Wilhelmspitze, beziehen kann, da diese am Innenrand der Südseite des Kraters aufragende höchste Erhebung des Berges von seinem Fuß aus gar nicht gesehen werden kann, sondern durch den äußeren Kraterrand von dort aus verdeckt wird. 


\begin{tabular}{|c|c|c|c|c|c|c|}
\hline \multicolumn{2}{|c|}{ Eing enuessener Punkt } & \multicolumn{2}{|c|}{ Ausgangspunkt } & \multirow{2}{*}{$\begin{array}{c}\text { Distanz } \\
\text { oder deren } \\
\text { Logarithmen }\end{array}$} & \multirow{2}{*}{$\begin{array}{c}\text { Elevations- } \\
\text { oder } \\
\text { Depressions- } \\
\text { werte }\end{array}$} & \multirow{2}{*}{ Bemerkungen } \\
\hline Name & Höhe & Name & Höhe & & & \\
\hline
\end{tabular}

\section{Messungen von Oberleutnant Schwartz.}

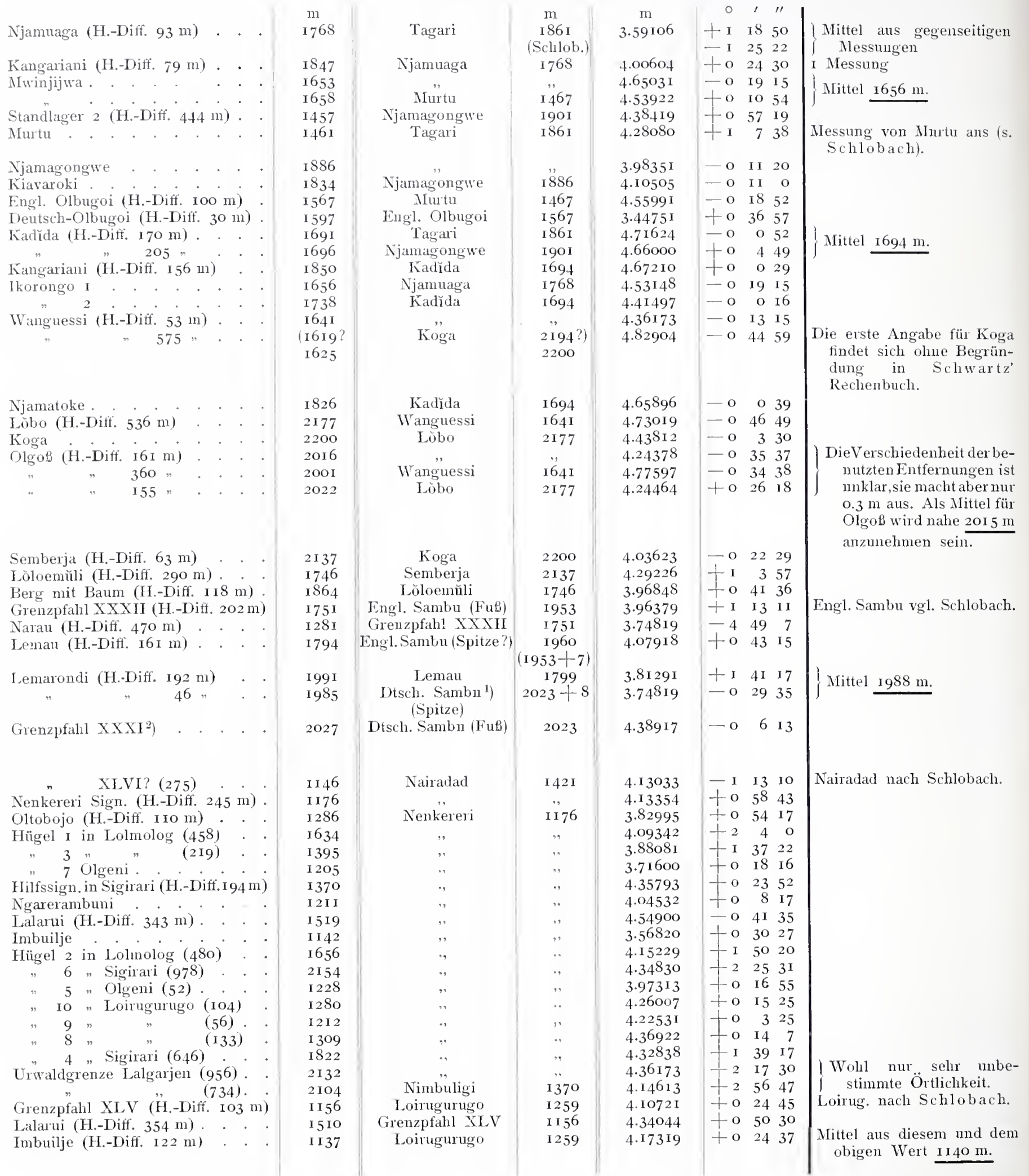

1) Den Unterschied zwischen Dtsch. und Engl. Sambu findet Schwartz zu $62 \mathrm{~m}$ (es sclıeint die Höhe des Sign. auf einer Station nicht in Rechnung zu stehen).

2) Die gegenseitige Lage von Ngorika und Sinja ist $2 n 757 \mathrm{~m}$ Höhendiff. bestimmt. 


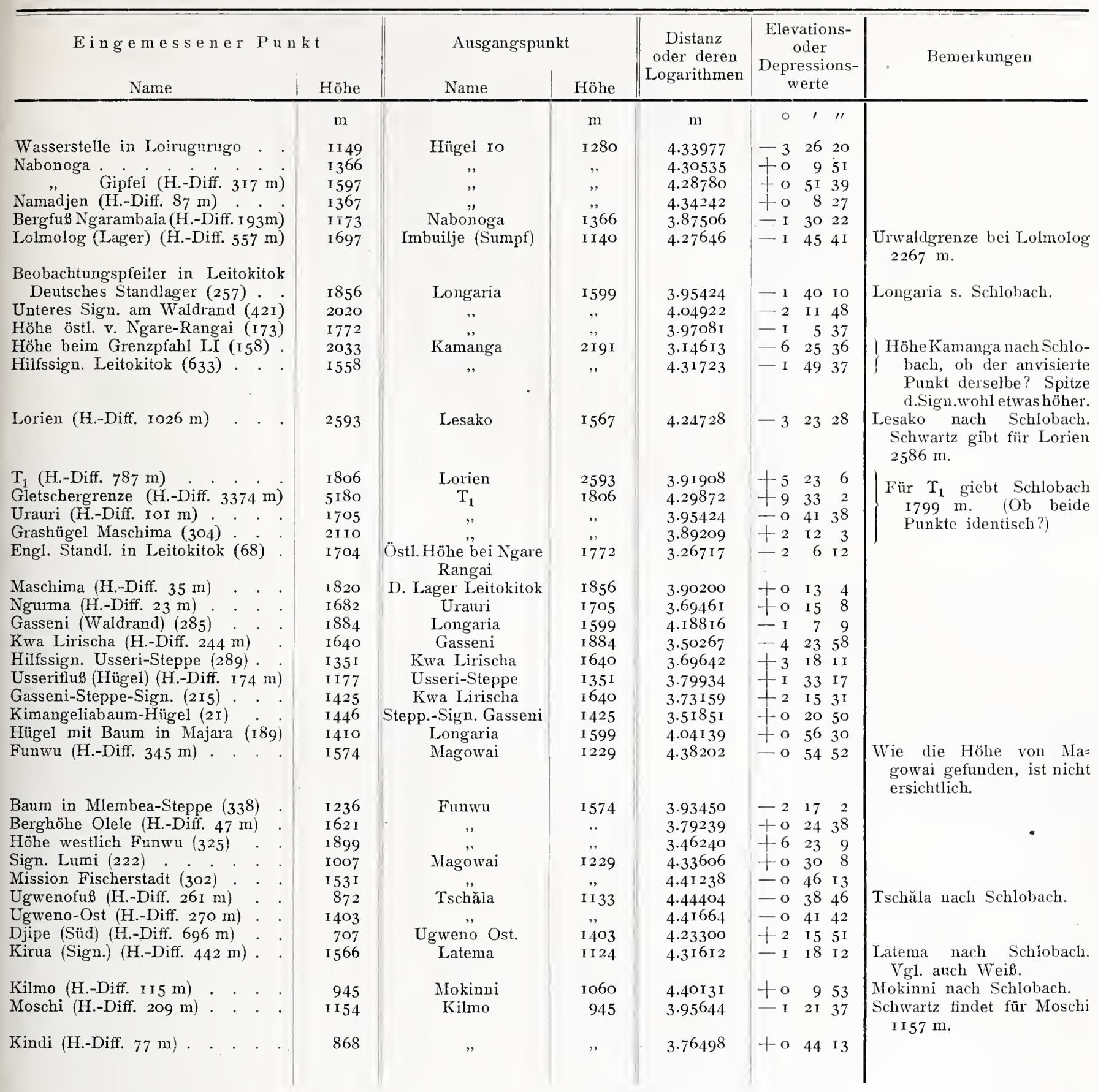

\section{Messungen von Oberleutnant Weiß.}

\begin{tabular}{|c|c|c|c|c|c|c|c|c|c|c|c|}
\hline Njamuaga . & . & $\cdot \cdot$ & . & $\cdot \cdot$. & 1770 & Uirĕge & 1725 & 13630 & - o 13 & I 5 & Höhendiff. $45 \mathrm{~m}$. (Nach \\
\hline Muëma . . & . & $\cdot$. & . & $\cdot$. & $\begin{array}{l}\text { I } 647 \\
\text { I } 648\end{array}$ & $\begin{array}{l}\text { Muiwari } \\
\text { Schirari }\end{array}$ & $\begin{array}{l}1723 \\
1707\end{array}$ & $\begin{array}{r}16900 \\
8900\end{array}$ & $\begin{array}{l}-019 \\
+020\end{array}$ & $\begin{array}{r}39 \\
0\end{array}$ & $\begin{array}{ll}" & 76 \% \text { Schlobach) }\end{array}$ \\
\hline K & & 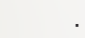 & & & 1633 & Kuigěgo & I 582 & 18200 & - o 14 & 6 & $5 \mathrm{I}$ \\
\hline Nora & $\cdot$ & · & • & • & I 638 & Schirari & 1707 & 22000 & to 5 & 32 & $69 "$ \\
\hline $\begin{array}{l}\text { Pemba } \text { Pemba } \text { I } \\
\text { Per. }\end{array}$ & . & . & . & . . . & I 699 & Uiřờo & ", & 6170 & - o $\quad 2.5$ & $5-$ & $8 \%$ \\
\hline Pemba III . & . & . & . &. & $\begin{array}{l}1035 \\
1687\end{array}$ & Schirari & $\begin{array}{l}1725 \\
1707\end{array}$ & $\begin{array}{l}6800 \\
5750\end{array}$ & $\begin{array}{r}\text { to } 43 \\
\text { to } 10\end{array}$ & $\longrightarrow$ & \\
\hline Kitenga (nahe & e d. & Boma & v. & Ndera) & I 742 & , & , & 8760 & - o I 6 & I 5 & \\
\hline Jabihengu . & . & . . & . & . . & 1830 & & ," & I 2 I 80 & - o 38 & - & $123 "$ \\
\hline Jabussende & . & . . & . & . . & 1687 & Uirĕge & 1725 & 8 o70 & - o I I & & Mit Univ. Iustr. Hildebrand. \\
\hline Ndera & . & . . & . & . . & $\begin{array}{l}1795 \\
1790\end{array}$ & , & $1 / 07$ & I0 300 & $\begin{array}{rr}\text { To } & 3 \\
\text { - } & 29.5\end{array}$ & & $"$ \\
\hline
\end{tabular}




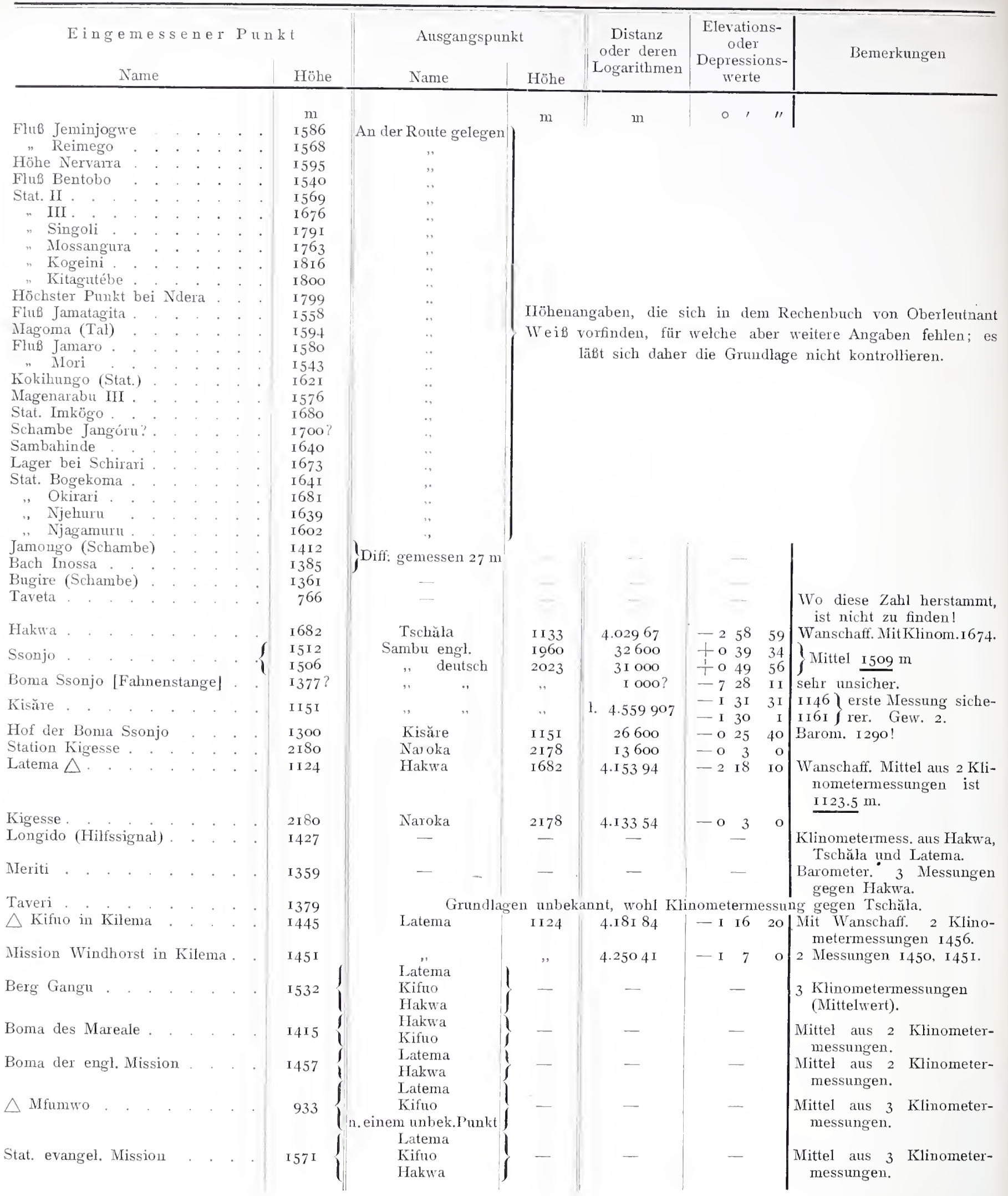

In dem Rechenbuch von Oberlentnant WeiB finren sich noch eine Reihe von weiteren Höhenangaben, die nur Bezug auf Punkte der Meßtischblätter haben, die spezielle Bezeichnungen tragen und sich ohne diese Blätter nicht identifizieren lassen, sie scheinen meist aus englischen Messungen übernommen zu sein. 


\section{Verzeichnis aller astronomischen Beobachtungen und der Resultate,}

welche während der Kiwu- und deutsch-englischen Grenz-Expeditionen ausgeführt worden sind.

Berechnet und bearbeitet von L. Ambronn, W. Wagemann und Dr. Mainka.

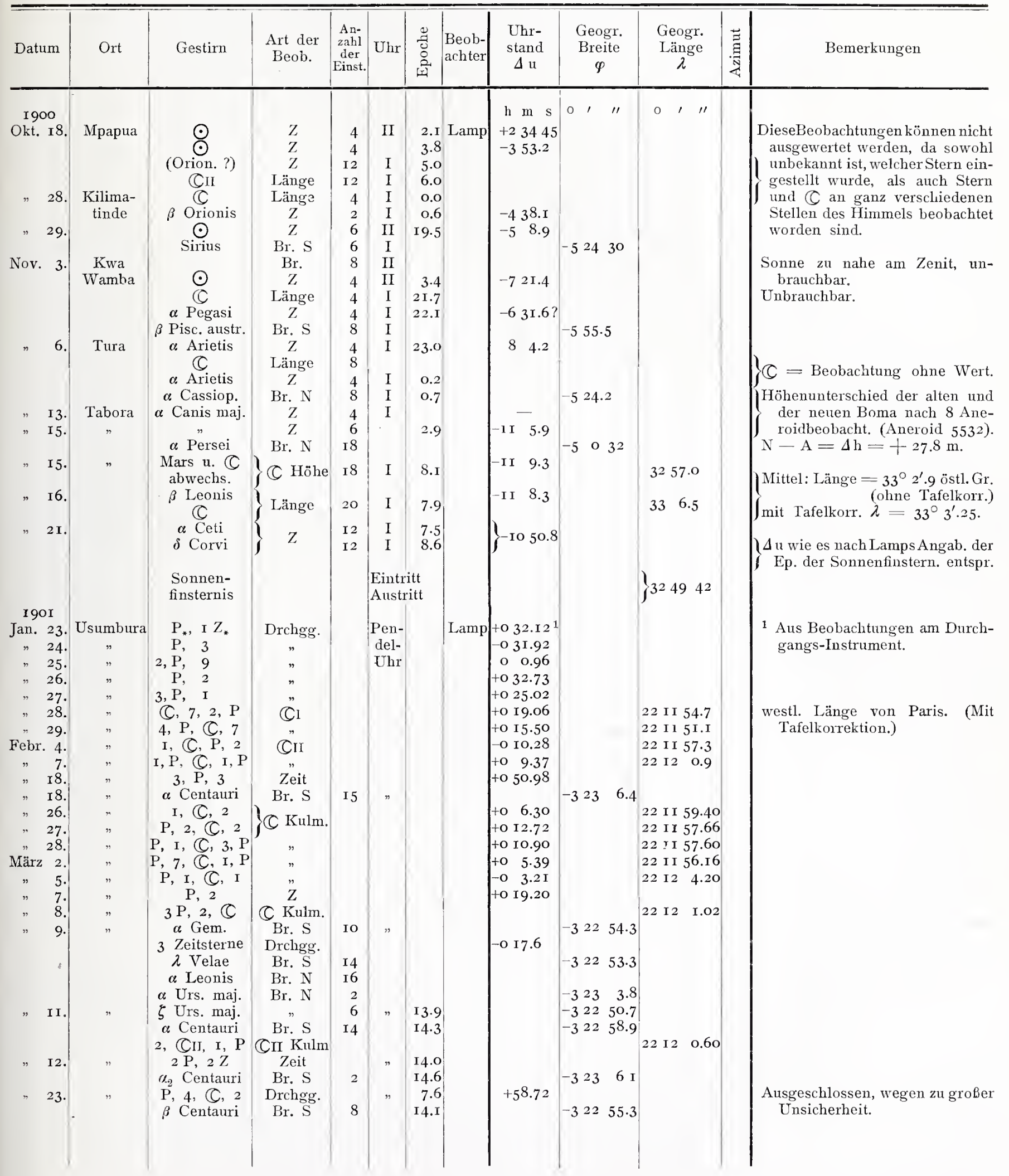




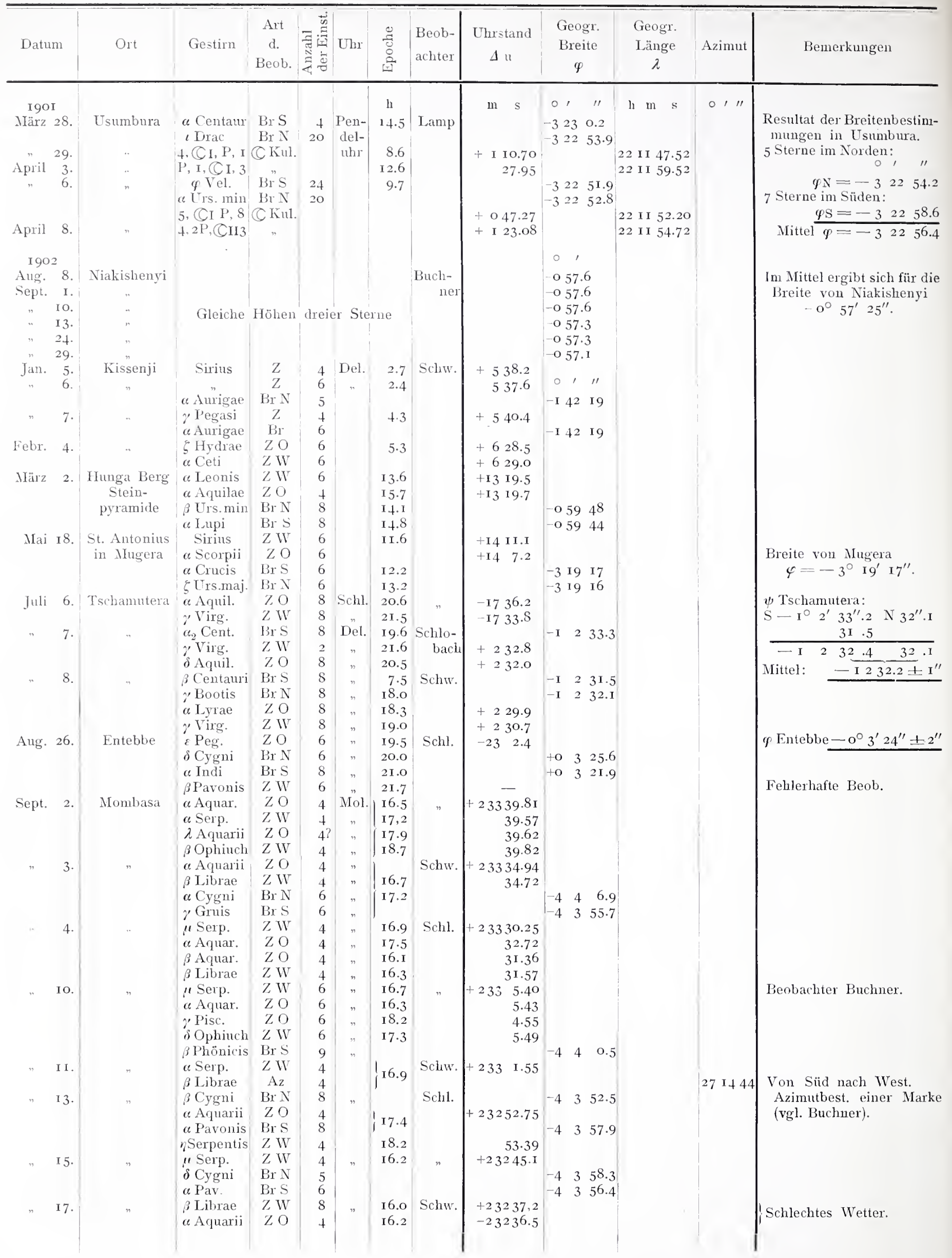




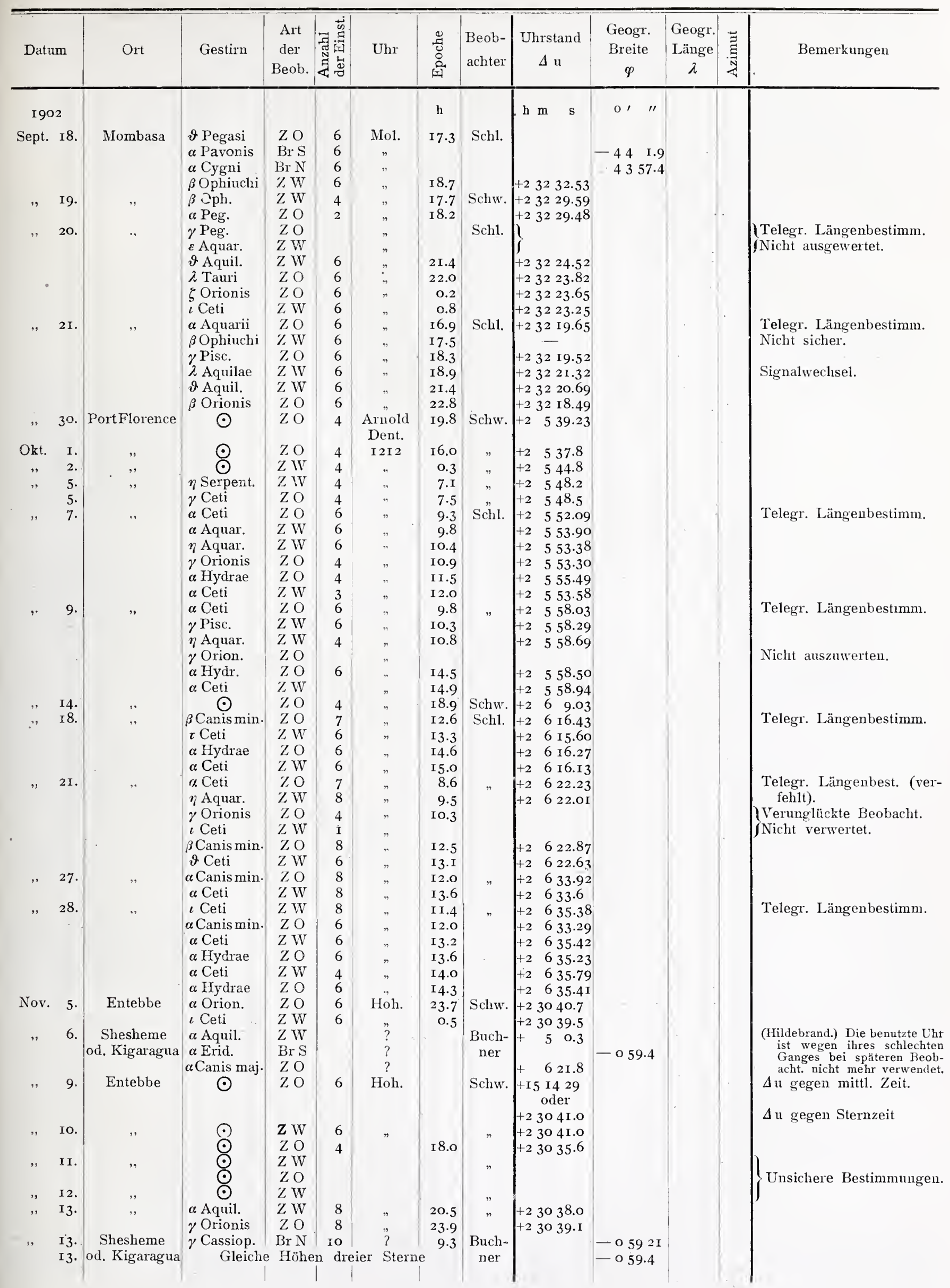




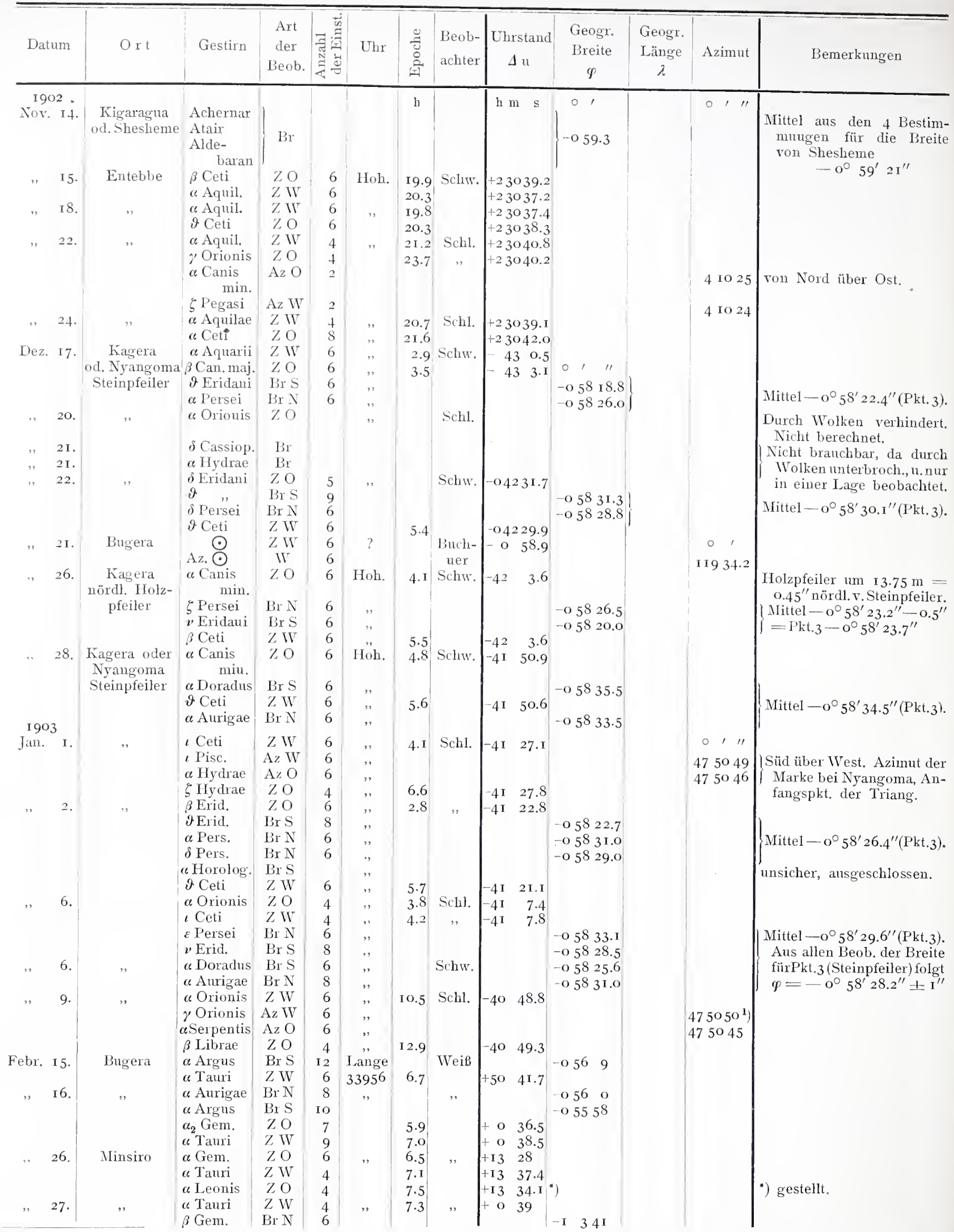

1) Azimut der Marke bei Nyangoma, Anfangspunkt der Triangulation. Als Mittelwert für das Azimut Steinpfeiler $\rightarrow$ Azimutmarke Nyangoma wurde angenommen: $47^{\circ} 50^{\prime} 47 \cdot 5^{\prime \prime}$. Das euglische Resultat beträgt: $47^{\circ} 50^{\prime} 47 \cdot 3^{\prime \prime}$. Nach Übereinkunft mit dem englischen Kommissar wurde $47^{\circ} 50^{\prime} 47 \cdot 4^{\prime \prime}$ als Ausgangsazimut sowohl für die Triangulation nach Entebbe als ancl für diejenige nach dem Schnittpunkt von $30^{\circ}$ östl. Länge und $\mathrm{I}^{\circ}$ südl. Breite angenommen. 


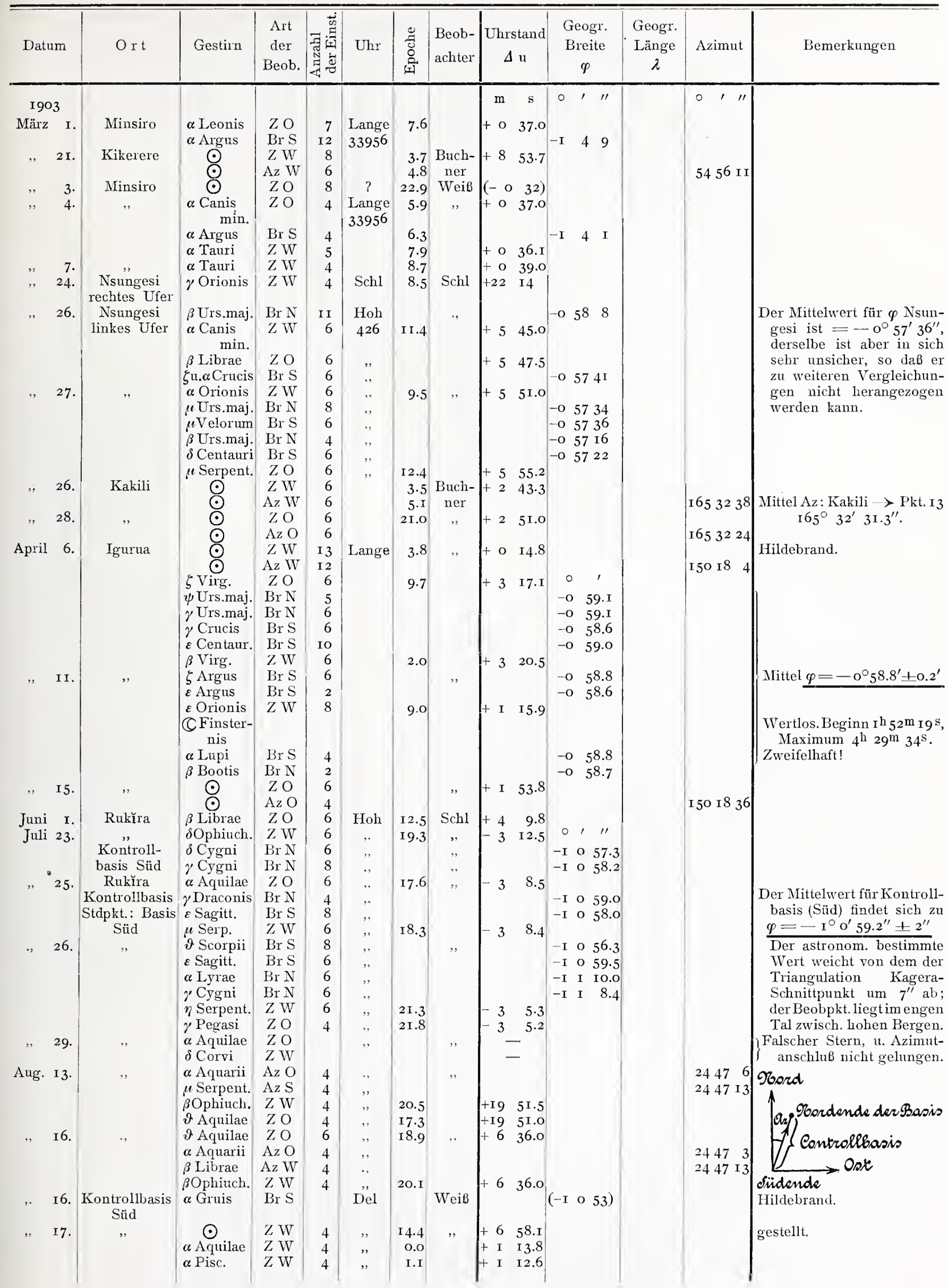




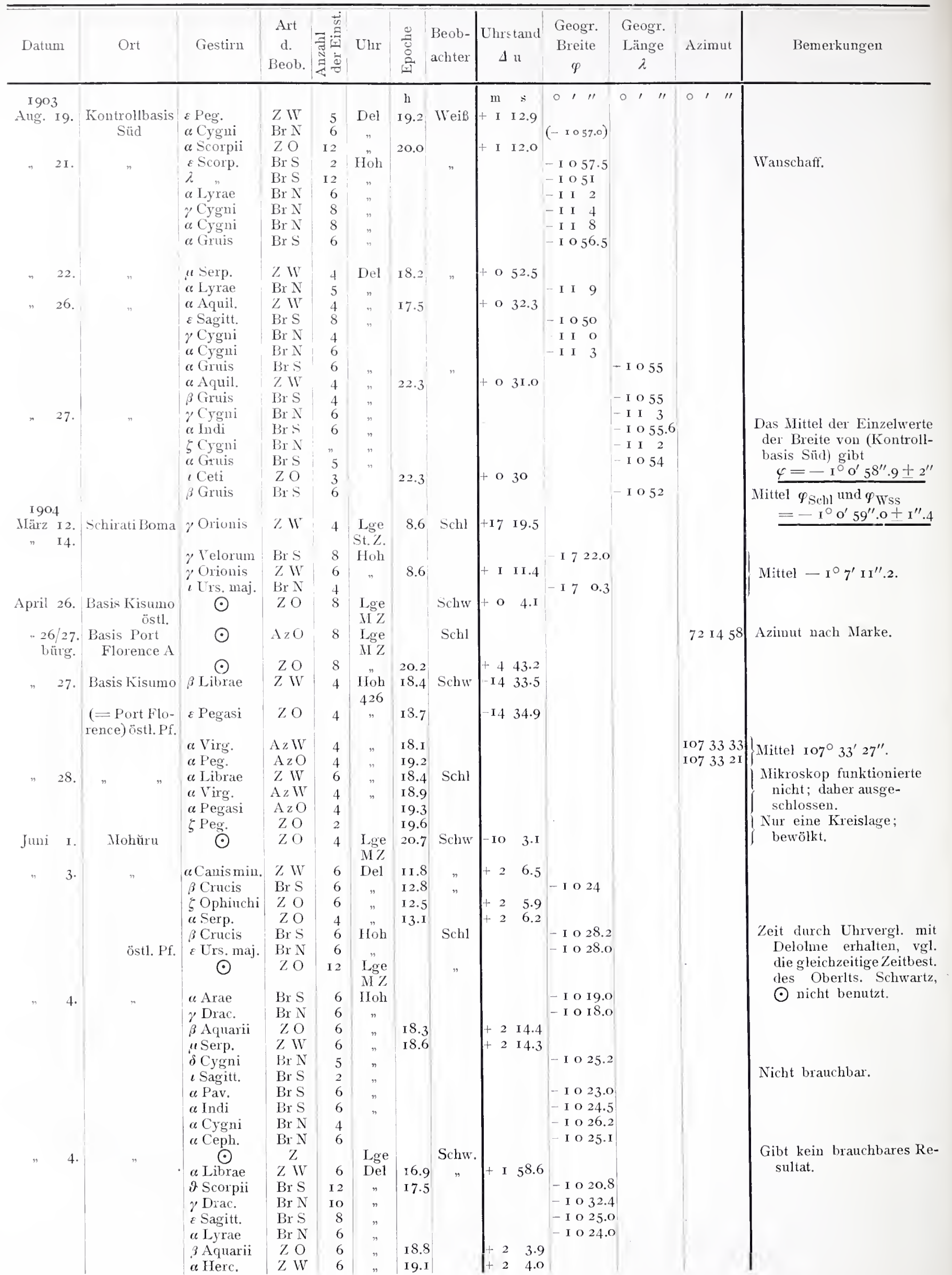




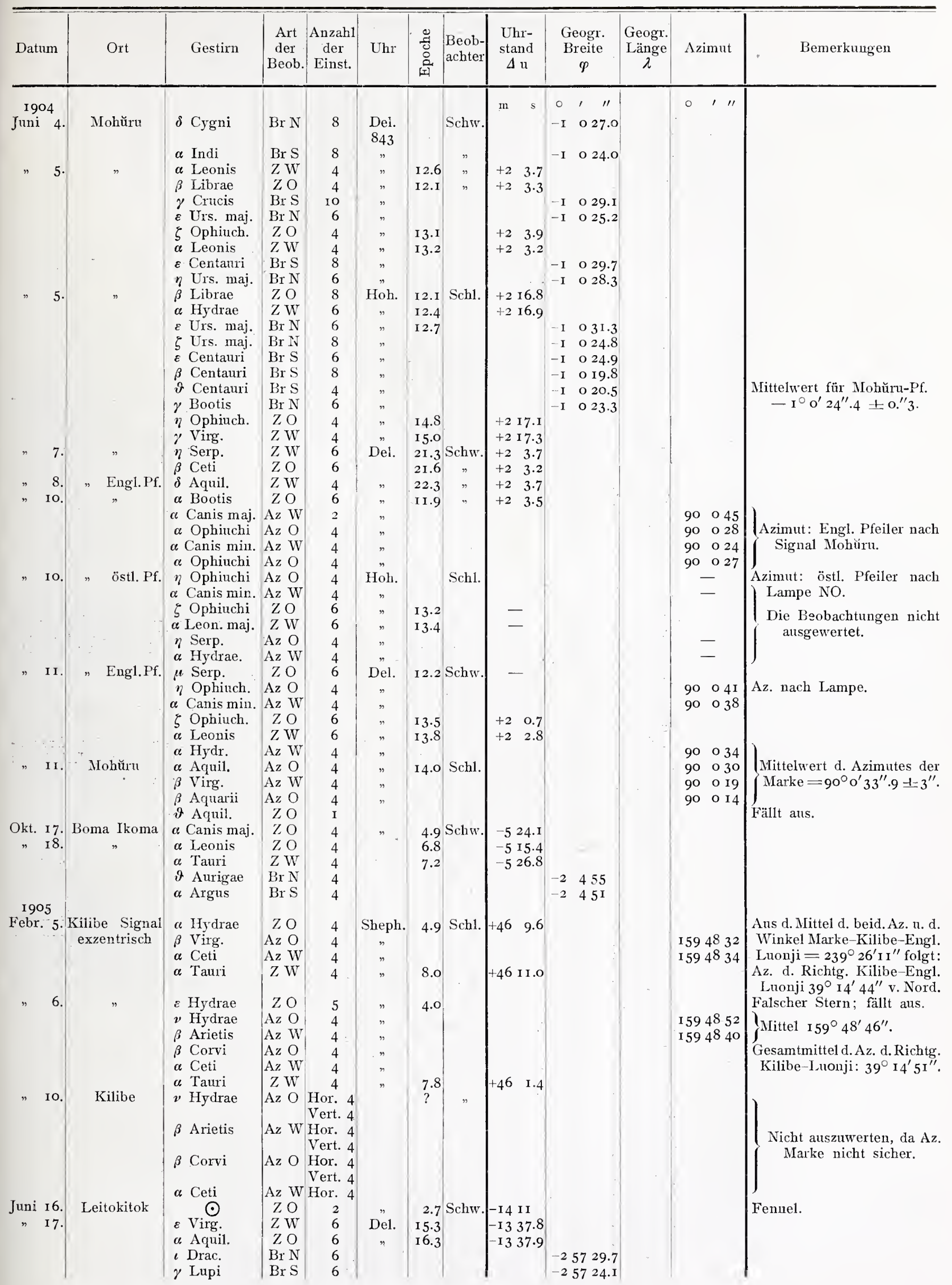




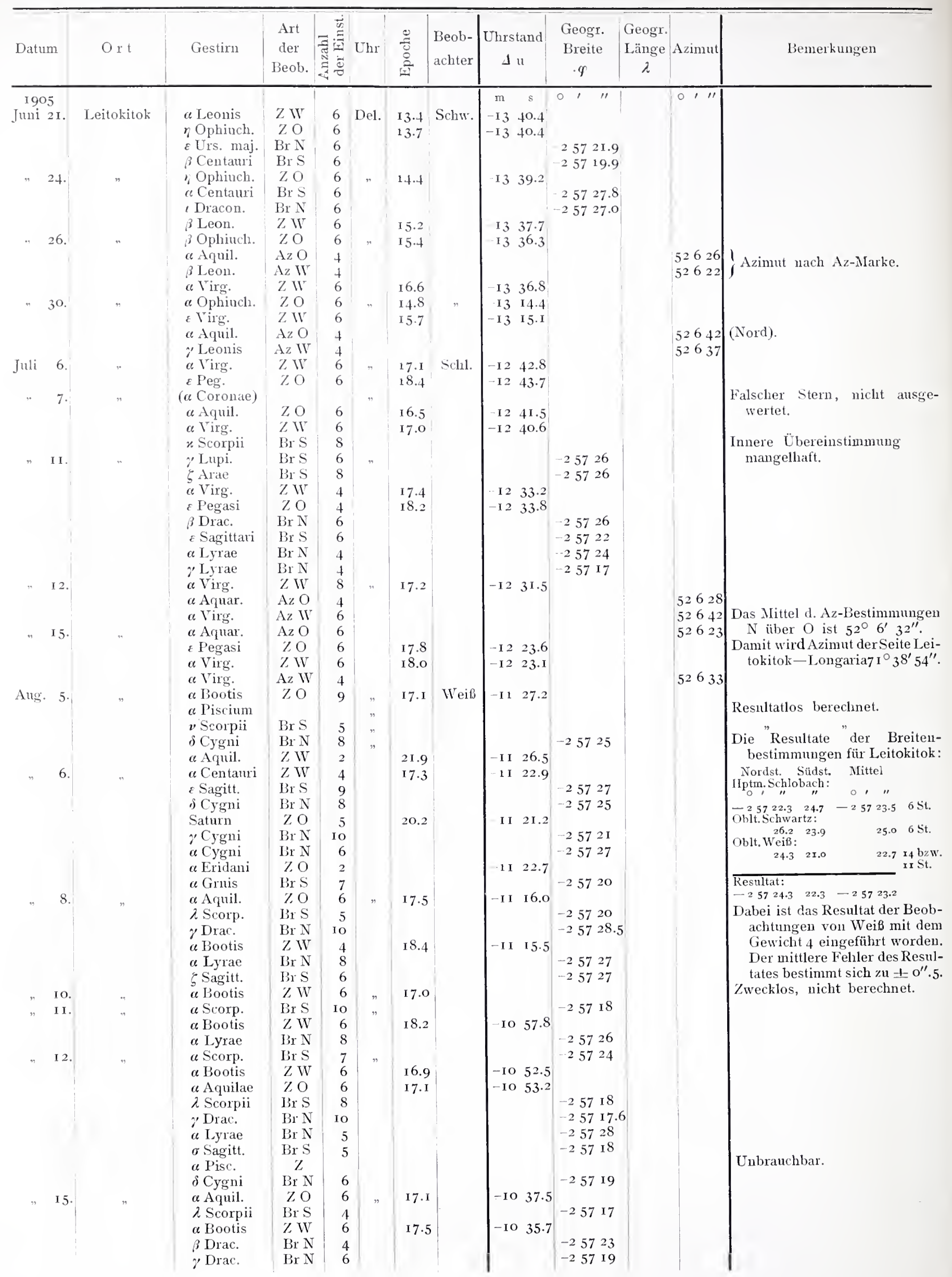




\begin{tabular}{|c|c|c|c|c|c|c|c|c|c|c|c|c|}
\hline Datum & Ort & Gestirn & $\begin{array}{c}\text { Art } \\
\text { der } \\
\text { Beob. }\end{array}$ & 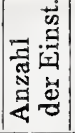 & Uhr & $\begin{array}{c}\stackrel{0}{8} \\
0 \\
0 \\
\text { 되 }\end{array}$ & $\begin{array}{l}\text { Beob- } \\
\text { achter }\end{array}$ & $\begin{array}{c}\text { Uhrstand } \\
\Delta \mathrm{u}\end{array}$ & $\begin{array}{c}\text { Geogr: } \\
\text { Breite } \\
\varphi\end{array}$ & $\mid \begin{array}{c}\text { Geogr. } \\
\text { Länge } \\
\lambda\end{array}$ & Azimut & Bemerkungen \\
\hline $\begin{array}{c}1905 \\
\text { Ang. I7. }\end{array}$ & Leitokitok & $\begin{array}{c}\alpha \text { Scorpii } \\
\varepsilon \text { Scorpii } \\
\alpha \text { Aquil. } \\
\alpha \text { Bootis } \\
\beta \text { Dracon. } \\
\alpha \text { Lyrae }\end{array}$ & $\begin{array}{l}\mathrm{BrS} \\
\mathrm{BrS} \\
\mathrm{ZO} \\
\mathrm{ZW} \\
\mathrm{BrN} \\
\mathrm{Br} \mathrm{N}\end{array}$ & $\begin{array}{r}6 \\
5 \\
6 \\
6 \\
10 \\
5\end{array}$ & Del. & $\begin{array}{l}17.2 \\
17.3\end{array}$ & Weif & $\left|\begin{array}{cc|}m & s \\
- \text { Io } & 27.0 \\
\text { - I0 } & 26.6\end{array}\right|$ & $\left|\begin{array}{rcc}0 & \prime & \prime \prime \\
-2 & 57 & 24 \\
-2 & 57 & 18 \\
& & \\
-2 & 57 & 27 \\
-2 & 57 & 26\end{array}\right|$ & & & - \\
\hline
\end{tabular}

बतिक

\title{
Aus den Schutzgebieten der Südsee.
}

\section{Wanderungen im Gebiete der Kai (Deutsch-Neuguinea).}

\author{
Von Dr. Rudolf Pöch. \\ (Hierzn Karte Nr. 8 und Tafel XI.)
}

Während einer zweijährigen anthropologischen Studienreise in Neuguinea besuchte ich in der Zeit vom Dezember 1904 bis zum Februar 1905 das Gebiet der Kai, landeinwärts von Finschhafen in Deutsch-Neuguinea.

Nachrichten über dieses Gebiet liegen bisher von verschiedenen Seiten vor. Die wissenschaftliche Expedition unter Schrader und Hellwig hat den Sattelberg erstiegen, die Neuendettelsauer Missionare haben auf dem Sattelberg eine Station errichtet, die Mitglieder dieser Gesellschaft, namentlich Flie rl und KeyBer, haben wiederholt die Kaidörfer in der weiteren Umgebung des Sattelberges besucht. B. Geisle r hat in der Umgebung des Sattelberges zoologisch gesammelt. Seinem Berichte*) ist eine Karte des nördlichen Huongolfes beigegeben, auf dem seine Tour nach und vom Sattelberg verzeichnet ist, mit allen den Ortschaften, die er besucht hat. Auch E. Wahnes hat längere Zeit auf dem Sattelberge zoologisch gesammelt. Über eine größere Expedition der Neu-Guinea-Kompagnie unter der Leitung Heppners sind leider keine ausführlichen Nachrichten publiziert, da Heppner auf der Heimreise starb. Man erzählte mir im Lande, er sei vom Sattelberg westlich zum Oberlaufe des Bubui gekommen und habe dann dessen vielgewundenen Lauf flußabwärts verfolgt.

Die Höhe des Sattelberges ist heute leicht zu erreichen, da von Bussim aus, welches etwa eine

*) Abhandlungen und Berichte des Königlich zoologischen Museums in Dresden I892-1893 (publiziert durch A. B. Meyer).
Stunde Bootsfahrt an der Küste nördlich von Finschhafen liegt, ein gut angelegter Weg hinaufführt, der auch für Fuhrwerk (Ochsenkarre) passierbar ist. Der Weg, der von der Neuendettels. auer Missionsgesellschaft gebaut ist, fuilırt zuerst an »Heldsbach« vorbei, das auf einer kleinen Anhöhe nahe der Küste liegt. Dort sind die Vorratslager für den Sattelberg und eine Viehstation. Die eingeführten australischen Rinder gedeihen auf die Dauer auf der Höhe des Sattelberges nicht, trotzdem es dort kühler ist, wahrscheinlich wegen der $z u$ großen Feuchtigkeit. Die Tiere werden jetzt. zu zeitweisem Aufenthalt nach der Küste zu heruntergetrieben.

Hinter Heldsbach führt der Weg noch über Grasfelder, dann aber kommt man in dichten Busch. Die Täler sind tief eingeschnitten. Der Weg umgeht eine Schlucht, in der ein Bach flieBt, welcher aus einer Höhle entspringt. Der nackte Fels besteht aus Korallenkalk.

Diese Wälder sind bis zu einer Meereshöhe von etwa $500 \mathrm{~m}$ von einer besonders zahl- und artenreichen, laut schreienden und kreischenden Vogelwelt bevölkert. Weiter oben fehlen viele Vertreter der Küstenfauna, und die Zahl der Vögel nimmt überhaupt ab. Dafür leben hier die schönsten Vertreter aus der Gattung der Paradiesvögel. Auch der Wald ändert seinen Charakter. Dic Dichte des Unterholzes nimmt ab, die hochstämmigen Bäume bilden ein undurchdringliches Blätterdach, von den Ästen sieht man hier häufig eine weiße Bartflechte herabhängen. 
Der Weg folgt größtenteils nicht mehr den früheren Eingeborenenpfaden, sondern ist nach der günstigsten Steigung angelegt. Er fülırt nur zweimal an Dörfern vorbei. Die Häuser der Kai sind im allgemeinen kleiner als die der Küustenbewohner, der Jabim, und stehen auf hohen Pfählen. Die Leute aus diesen Dörfern haben alle Beziehungen zu der Mission, viele haben auch beim Gouvernement, der Neu-GuineaKompagnie oder privat bei Europäern gedient. Sie sind daher leicht zu verschiedenen Hilfeleistungen, z. B. zum Tragen, gegen eine kleine Belohnung zu haben. Nicht so im Beginn der Kolonisation. Da wurden den Europäern oft die Kisten von den Trägern abseits geschafft und ausgeplündert; um sich in den Besitz der Tauschwaren zu setzen, lag den Kai auch der Gedanke an cinen Überfall nicht ferne.

Nach etwa vierstündigem Marsch ist die Höhe des »Plateaus" mit etwa $930 \mathrm{~m}$ Meereshöhe") erreicht. Die Fläche war früher auch mit Urwald bedeckt, ist aber jetzt in weiter Ausdehnung gerodet. Einen einzelnen Baumriesen wollte man als Landmarke erhalten, er ist in seiner isolierten Lage aber nach kurzem abgestorben, offenbar infolge der Austrocknung des Bodens. Die Niederlassung der Neuendettelsauer Missionsgesellschaft auf dem Sattelberg zählt heute, alles mitgerechnet, sechs größere Baulichkeiten; dancben ziemlich ausgedehnte Felder, auf denen Süßkartoffeln und andere Feldfrüchte gezogen werden. Es wohnt immer eine größere Anzahl Kinder monatweise auf dem Sattelberg, um hier die Schule zu besuchen; diese Kinder müssen auch mit von dem Ertrage der Felder verköstigt werden. Auf eine andere Weise ist der Schulunterricht nicht möglich, da die Dörfer viel zu verstreut liegen. Es gibt in der Nähe der Häuser zwei Steinbrüche, in denen ein wcißer leichter Kalkstein (reiner kohlensaurer Kalk) gebrochen wird. Ansehnliche Stuicke davon sind für die Pfeiler der Häuser verwendet.

Der Höhenunterschied gegen die Meereskiiste, über $900 \mathrm{~m}$, macht sich durch einen namentlich des Nachts sehr bedeutenden Temperaturunterschied fühlbar. Hat der von der Küste Heraufgekommene die erste Zeit der Ermattung, die eine Folge des jähen Wechsels ist, überwunden, so wirken die Frische der Luft und die kühlende Nacht (oft bis $15^{\circ}$ C. herab) belebend und stärkend. Bei längerem Aufenthalt leidet man unter der Feuchtigkeit. In der Regenzeit muß sogar ein Ofen in Tätigkeit kommen, um die Kleider wenigstens einigermaßen zu trocknen. Der meiste Regen fällt übrigens hier während der

*) Mittel aus vier wenig differierenden Bestimmungen mit einem Aneroid-Barometer.
Herrschaft des Südost-Monsuns. Während des Nordwest-Monsuns sind Regen seltener, da der Sattelberg bekanntlich im Regenschatten des Finisterre-Gebirges liegt.

Wasserläufe und Quellen gibt es auf dem Sattelberg nicht; man muß, um Wasser zu holen, ein ziemliches Stiick zu einem Wildbach herabsteigen. Infolge der häufigen Niederschläge dccken aber die Regenfässer meistens den Bedarf.

Vom Sattelberg genießt man eine reiche und sehr schöne Fernsicht. Der Ausblick auf das Mcer ist frei, da die Hänge bis dahin stetig abfallen. In einer Luftlinie von kaum $10 \mathrm{~km}$ liegt das Mcer mchr als $900 \mathrm{~m}$ tiefer da. Über den Huongolf kann man an klarem Morgen die Zentralkette an der Grenze zwischen Deutsch- und Britisch-Neuguinea sehen. Die Klarheit des Bildes wird jedoch meist schon in den Vormittagsstunden durch aufsteigende Nebel getribt. Am Nachmittag ist der Sattelberg meist ganz in Nebel.

Gegen das Inland zu ist der Blick nicht vom Plateau aus, sondern erst vom Kamm der Bergspitze frei, die etwa $975 \mathrm{~m}$ hoch ist, also I $45 \mathrm{~m}$ höher als der Sattel liegt. Von dort sieht man gegen Nordwesten einen hohen Berg, den Nanson, rein westlich eine tiefe Einsenkung, den Oberlauf des Bubui, Mape genannt. Gegen Südwest fällt cine entfernte, blaue Kette auf, in der Richtung der Berge, die auf der Karte als »Rowlinson-Kette « bezeichnet sind, aber noch sehr der genaueren Bestimmung bedürfen. Diese Stclle mit dem freien Ausblick wird jetzt von den Europäern "Schöne Aussicht " genannt, im Kai heißt sie zanga fifi, d. h. »mach die Augen auf . So heißen mehrere Stellen mit einem steilen Abfall, und der Name mahnt offenbar zur Achtsamkeit beim Gehen; denn dem Ästhetischen in der Landschaft gibt der primitive Mensch nur selten bewußt Ausdruck.

Schon auf dem kurzen Wege bis zur schönén Aussicht wird man mit einer großen Plage dieser Gegend bekannt, den Landblutegeln. Diesen Tieren war ich in den Küstengegenden von Potsdamhafen und Friedrich Wilhelmshafen nicht begegnet; meine beiden Diener, die aus Mochlon in Neu-Pommern stammten, waren ïber die Angriffe "der kleinen Blutsauger sehr entsetzt, sie kannten diese Tiere aus ihrer Gegend auch nicht, auch litten sie sehr unter der Kälte. Ich war froh, daß sich bald Gelegenheit bot, sie zurückzuschicken, und von da an ging ich nur immer in Begleitung der an die verschiedenen Unannehmlichkeiten ihres Landes vollständig adaptierten Kaileute. In landblutegelreichen Gegenden muß man die Träger immer wieder in kurzen Zwischenräumen etwas stille stehen lassen, 
damit sie die Tiere von ihren Beinen entfernen können. Sie gehen dann mit blutenden Wunden weiter; andere Folgen als den Blutverlust habe ich bei Eingeborenen nicht gesehen. Dagegen vereitern die Wunden beim Europäer sehr leicht, heilen schlecht und lassen dunkel pigmentierte Narben zurück. Der Europäer tut gut, sich durch undurchlässige Gamaschen oder Wadenstutzen zu schützen. Am sichersten und auch am kühlsten zu tragen sind die von den Vettern Sarasin empfohlenen Leinenstrümpfe. Es ist ein sehr merkwürdiger Anblick, auf ganz verlassenen Buschpfaden sofort ganze Mengen dieser Tiere gegen sich heranschlängeln $\mathrm{zu}$ sehen. Man muß ihren guten Geruchssinn bewundern, durch den ihnen die Beute offenbar schon aus großer Ferne verraten wird, ebenso, wie ihre Kunst, lange zu hungern. An Vögeln sah ich die Tiere niemals, ich glaube sie sind an den feuchten Boden gebunden, und die auf dem Boden lebenden Säugetiere sind sehr spärlich.

Buschmucker fand ich in diesen höhergelegenen Regionen niemals.

Eine ernstere Gefahr droht dem Wanderer im Kailande durch die zahlreichen Schweinegruben. In diesen Wäldern gibt es viel verwilderte Schweine, und die Eingeborenen suchen sie in diesen Fallen zu fangen. Da die Schweine erfahrungsgemäß oft längs der Eingeborenenpfade wandern, so sind die Fallen dann auch mitunter mitten am Wege gemacht. Die Gruben sind gewöhnlich ungefähr I m lang, $3 / 4 \mathrm{~m}$ breit und $\mathrm{I} 1 / 2 \mathrm{~m}$ tief und mit $\ddot{A}$ sten und Laub wohl verdeckt. Natürlich kann der vorübergehende Mensch ebenso getäuscht werden und in die Falle hineinfallen, was um so verhängnisvoller werden kann, als am Grunde der Falle oft Speerspitzen eingerammt sind. Es verunglücken tatsächlich mitunter Menschen in solchen Schweinegruben. Das hindert aber die Leute nicht daran, wieder Fallen in derselben Weise anzulegen; die Leute der Dorfschaft, der die Grube gehört, wissen, wo sie ist, das andere berührt die Leute weniger. Eine ganz ähnliche Erscheinung soll bei den Jagden auf Schweine mit Netzen zu beobachten sein: jede Dorfschaft hat ihr Netz, und die Leute von verschiedenen Dorfschaften kommen einander in der Regel nicht $z u$ Hilfe, wenn die eine Gruppe von dem gefangenen Wildschwein bedroht wird.

In der ersten Zeit hielt ich mich vorwiegend auf dem Sattelberg selbst auf und beobachtete und maß die zahlreich auf der Missionsstation verkehrenden Kai. Ich lernte in ihnen einen von den früher besuchten Küstenvölkern recht verschiedenen Bergstamm kennen. Als Durchschnittsgröße fand ich bei 50 Männern $152.5 \mathrm{~cm}$, die Schädel sind in der Regel mesocephal bis brachycephal. Gegen die Küste zu (Jabim) wird Dolichocephalie häufiger, auch der Typus ändert sich. Nicht zu selten begegnet man unter den Kai ganz klein gewachsenen Menschen. Über diese auffallende Erscheinung habe ich schon an anderem Orte ausführlich berichtet, ${ }^{*}$ ) so $\mathrm{da} \beta$ ich hier, um mich nicht zu wiederholen, nur kurz die Zahlen mitteilen will: Unter 300 erwachsenen Männern fand ich unter $146 \mathrm{~cm}$ hoch 9 Individuen, das ist $3 \mathrm{vH}$. Die gemessenen Körperhöhen waren: I 33, I35, I 38.2, I39, I39. I, I40, I43, I43.I, I43.2, I 45.4, I 45.5, I 45.6. Die beigegebene Abbildung 1 zeigt drei solche kleine Kaileute, die I 43.2, I5I.7 und $139 \mathrm{~cm}$ hoch sind.

$\mathrm{Ob}$ es sich hier um eine bloße Variation der Körperhöhe handelt oder ob wir nicht hier vielmehr die Reste einer älteren, in die Kai selbst noch nicht ganz aufgegangenen kleineren Rasse zu sehen haben, läßt sich vorläufig noch nicht entscheiden.

Gegenüber den Jabim erscheinen die Kai als die älteren Besitzer des Landes. Sie mögen ursprünglich überall bis an die Küste gewohnt haben, gegenwärtig sind sie durch die Jabim fast überall von der Küste zurückgedrängt, nur an der Mündung des Bussim ist ein Kaidorf bestehen geblieben, ebenso ein schmales Gebiet südlich von Finschhafen. Im Norden und Nordwesten wird das Kailand begrenzt von dem Gebiete der Poum, nach dem Südwesten und Westen ist die Ausdelinung ihrer Wohnsitze noch nicht festgestellt, es scheint aber sehr weit westlich $\mathrm{zu}$ reichen. In dem Gebiete, das nördlich vom Flusse Bussim, südlich vom Bubui, östlich von den an der Küste wohnenden Jabim und westlich von den Poum begrenzt wird, wohnen schätzungsweise I 500 Kaileute.

Das Land ist in Bezirke geteilt, in jedem Bezirke gibt es eine Anzahl einzelner Dörfer, die aber häufig, bisweilen jedes Jahr verlegt werden, aber niemals aus den Bezirksgrenzen hinaus. Die Bezirke in dem oben begrenzten Gebiete heißen, von Nordost am Bussim angefangen, im Halbkreis herum bis wieder gegen die Küste am Bubui:

Bússim, Sạmbąlắbu, Gnạ́bung, Dạ́gi, Démbang, Massángo, Qáta (es gibt zwei Bezirke dieses Namens; dies ist der nördliche), Silílio, Åtezíne, Sahang, Qáta (das südliche), Bónine (jetzt ausgerottet), Náka, Wána, Sạ́meng, Wạ́sa, Laókube, Gaítama, Fóndeng, Wạ́ne, Bógaseng.

*) Sitzungsbericht der anthropologischen Gesellschaft in Wien, 1905 S. [40] ff.

**) Die Namen sind nach dem G. von dem Gabelentzschen Alphabet geschrieben. Das dumpfe a wird von den Missionaren à bezeichnet, das $\mathrm{q}$ mit $\mathrm{gb}$, was sehr gut andeutet, dab das $\mathrm{q}$ eigentümltch weich lautet. Die Namen der Bezirke gab mir Herr Keyber an. 
Der Bezirk Bónine hat jetzt aufgehört zu sein; sechs Leute wurden erschlagen, der Rest zog nach Dági.

Die Pflanzungen werden von den Angehörigen einer Dorfschaft gemeinsam angelegt. Jede Pflanzung ist von einem Bambuszaun umgeben, um das Einbrechen der wilden Schweine zu verhindern. Die wichtigsten Feldfrüchte sind Taros, die im Gebirge besonders gut gedeihen, und nach ihnen die Yams. Sehr oft sieht man im Kailande Mais, der den Namen jágong führt und damit seinen malaiischen Ursprung verrät. Bananen sind nicht mehr häufig, Zuckerrohr erinnere ich mich nicht im Kailand gesehen zu haben. Die Kokospalmen fehlen hier vollständig. Auf dem Sattelberg hat man versucht, noch einige zu pflanzen, sie kommen aber nur kümmerlich fort. In Britisch Neu-Guinea habe ich erfahren, daß es in Höhen über $2000 \mathrm{~m}$ keine Niederlassungen mehr gibt. Der Grund ist darin zu suchen, daß die Feldfruichte der Papuas, Taro und Yams in diesen Höhen nicht mehr gepflanzt werden können.

Zur Anlage der Pflanzung wird jedes Jahr ein frisches Stiick Boden benutzt, der durch Roden des Waldes gewonnen wird. Diese Gepflogenheit ist vielen Papuastämmen eigen und erklärt sich daraus, daß sie weder plügen noch düngen. Nach der Ernte wird die Pflanzung ganz aufgegeben und das betreffende Stück Land seinem Schicksal überlassen. Entweder wächst wieder Wald oder es beginnt der Bambus des elemaligen Bambuszaunes zu grünen und auszuwachsen und verwandelt so die Stelle in ein undurchdringliches Bambusgestrüpp, in dem kein Raum und kein Licht für andere Vegetation bleibt; der in der Küstenregion häufige Ausgang, daß sich nämlich Alanggras etabliert, kommt im Kailand nicht so oft vor.

Während nun bei den von mir besuchten Küstenpapuas (Monumbo und Jabim) bloß die Pflanzungen ihre Stelle wechseln, die Dörfer aber stehen bleiben, lösen die Kai oft mit der Pflanzung auch ihre Dörfer auf, wenn auch nicht immer alle Jahre, so doch in vielen Gegenden alle zwei bis drei Jahre. Immer bleiben aber die Dorfleute mit der neuen Anlage innerhalb ihres Bezirkes.

Dieses Herumziehen erinnert an die Art des Ortswechsels bei nomadisierenden Jagd-oder Hirtenvölkern, diejenigen Kai, welchen diese Sitte eigen ist, wären also als halbnomadische Ackerbauer zu bezeichnen.

Das Dorf scheint keinen besonderen neuen Namen zu erhalten, sondern nur den Namen des Platzes, auf dem es erbaut ist, zu führen. Natürlicherweise hat dann das neue Dorf, von denselben Leuten bewohnt, wie das alte, einen ganz anderen
Namen. Es scheinen alle markanten Punkte, Bergspitzen, Rücken, Schluchten usw. schon seit uralten Zeiten von den Eingeborenen mit Namen belegt zu sein.

Wenn man die Leute nach dem Grunde des Aufgebens ihres alten Platzes fragt, sagen sie, er wäre schon zu schmutzig, und die Häuser wären schon schlecht. Aber auch Krankheit, Unglück und Totschlag können zum sofortigen Verlassen des Dorfes Veranlassung geben.

Es wurde mir in einen Falle der Hergang der Dinge genau bekannt, die zum augenblicklichen Aufgeben einer Niederlassung führten. Ich schalte diese Mitteilnug am besten hier ausführlicl ein, da sie auch ein Licht auf die Rechtsvorstellungen der Eingeborenen wirft.

Das erste Dorf nach Bussim auf dem Wege zum Sattelberge wird Sake's Dorf genannt, naclı einem angesehenen Maune.

Sake's Frai war durch einen jüngeren Dorfgenossen, Sorong, verführt worden. Zur Strafe band Sake die Frau mit Lianen an einen Holzprügel an und hing sie iiber ein offenes Feuer. Dies ist die Art, wie man Schweine brät. Die mit furchtbaren Brandwunden bedeckte Frau wurde losgemacht und ihrem Schicksal überlassen. Sie konnte sich noch in iln Heimatdorf im Bezirke Wasa schleppen. Die Wunden heilten, hinterließen aber furchtbare Narben, die ich selbst an der Frau sah. Der Zorn der Verwandten kehrte sich merkwürdigerweise nicht gegeu Sake, sondern gegen den Verführer Sorong. Sake schickte zudem zwei große Eberhaner als Geschenk in das Dorf, ohne ausdrïcklichen Auftrag, aber das begleitende Schweigen war auch verständlich. Als Sorong das nächste Mal in das betreffende Dorf kam, um Taro zu kaufen, hatte man schon beschlossen, ihn aus dem Wege zu räumeı. Sorong hatte sich gerade anf der Veranda eines Hauses niedergelassen, ein alter Mann näherte sïch ihm vorsichtig, um ihn zu warnen, da trat ein anderer Mann, namens Allumbang mit einer Axt in der Hand aus dem Hanse, ohne daß Sorong ihn sehen kounte und versetzte dem Sitzenden von rückwärts einen Axthieb in die linke Seite - die Eingeweide quollen hervor und der $z$ Tode Verwundete sank sterbend um. Die Leiche wurde sofort unterhalb der Veranda von einem jungen Mamne, namens Kaze, begraben. Nach wenigen Stunden hatten die Leute das Dorf geräumt, denn das mub geschehen, noch bevor die Sonne nutergegangen ist. Sie erbauten ungefähr eine Stunde weit südwestlich ein neues Dorf, das heute noch steht.

Als die Kunde von der Ermordung Sorongs in Sakes Dorf gelangte, unternahm dieser, da ja Sorong sein Dorfgenosse gewesen war, einen Kriegszug nach dem Dorfe im Wasa-Bezirk, wo die Mordtat geschehen war; der Platz war natürlich schon verlassen, und das durften Sakes Lente auch voraussetzen, man speerte einige zurückgebliebene Schweine und zerschlug einige Töpfe. Damit war dem Rechtsgefülıl Genüge getan und die Pflicht der Blutrache erfüllt.

Diese Mitteihung verdanke ich Hernı Keyßer; den verlassenen Dorfplatz habe ich besucht und das Skelett Sorongs ansgegraben. Kaze, der den Erschlagenen begraben hatte, gab mix den Ort an, Alumbang hatte sich aus Furcht geweigert mitzugehen.

Meine erste Wanderung im Kailande, die sich auf zwei Tage erstreckte, machte ich mit Herrn Keyßer; wir hatten vor, einige nordwestlich vom Sattelberg gelegene Kaidörfer zu besuchen. Zunächst 
gingen wir bergauf, den Weg nach der Spitze des Sattelbergs, ungefähr nach einer halben Stunde stiegen wir steil bergab, nach Nordosten, ins Flußgebiet des Bussimflusses. Wir gingen anfangs in dichtem Wald, einen schmalen steilen Eingeborenenpfad herab, wie über Stufen. Diese waren teils von quer verlaufenden Wurzeln gebildet, teils waren sie in den Boden eingetreten. Der Grund war ungemein schlüpfrig, ohne genagelte Bergschuhe hätte der Europäer hier keinen sicheren Tritt. Der barfüßige Eingeborene ist natürlich noch immer weit überlegen. Weiter unten führt der Weg eben fort und durch sumpfiges Terrain; da sind Baumstämme den Weg entlang gelegt, ebenfalls sehr glatt und schlüpfrig und für europäische Beschuhung jeder Art sehr unangenehm. Die Dörfer sind auf Hügeln oder an den Hängen erbaut. Der Distrikt heißt Massango. Wir waren bis ungefähr $600 \mathrm{~m}$ herabgestiegen. Von Massango ging es westlich einen steilen Hang hinauf, bis wir wieder auf den Rücken kamen, der vom Sattelberg in ungefähr nördlicher Richtung streicht. Wir gingen ihn eine Strecke entlang und stiegen dann wieder gegen den Bussim hinab. Wir waren nun im Bezirk Quáta." Einen verlassenen Dorfplatz gingen wir durch und blieben dann weiter unten in einem neu aufgebauten Dorfe über Nacht. Wir schliefen in einer Eingeborenenhütte. Das Innere besteht nur aus einem einzigen Raum, der keine Fenster, sondern nur eine Öffnung zum Hineinkriechen hat. Des Nachts wird sie durch eine vorgeschobene Tür geschlossen. In der Hütte findet man die Eingeborenen meist nur des Abends und in der Nacht. Sind die Leute tagsüber zu Hause, so halten sie sich auf einer kleinen Plattform vor dem Hause auf. Abbildung 2 zeigt einen solchen Vorbau bei einem Kaihause im Wasa-Distrikt.

Die Kai unterhalten des Nachts in der Hütte ein offenes Feuer. Infolgedessen ist der Innenraum ganz rauchig, und der Neuling fühlt sich so belästigt, daß er die Augen kaum offen halten kann. Man gewöhnt sich aber bald daran und fühlt die Wärme des Feuers als etwas sehr Angenehmes bei der nächtlichen Kühle, die durch die kolossale Luftfeuchtigkeit um so empfindlicher wird.

Am nächsten Morgen stiegen wir einen steilen Hang durch ein Bambusgestrüpp hinab zum Bussim. An einer scharfen Biegung des hier sehr reißenden Flusses ist eine tiefe Auswaschung, eine Art Höhle. Die Kai glauben, daß in dieser Hönle der Geist der Erdbeben wohne. Die Gegend ist sehr reich an Erdbeben, da die Kette tätiger Vulkane sehr nahe im Norden der Küste vorbeizieht. Erinnerlich ist

*) Auf der Karte ist die Schreibweise Gbata der Neuendettelsauer Missionare beibehalten. noch die große Flutwelle, bei welcher Hunstein und Below den Tod fanden.

Die Leute trugen Bedenken, uns bis hinab zu begleiten, schließlich folgte außer einigen Knaben nur ein erwachsener Mann. Vor einiger Zeit mußten die Leute von Quáta bei einem Kriegszug den Bussim dort überschreiten. Sie stiegen recht rasch herunter, übersetzten den Fluß unterhalb der Höhle, ohne Lärm zu machen und ohne auch nur hinzusehen, und stiegen ebenso rasch das gegenüberliegende Ufer wieder hinauf. Die Bambusrohre aus dem Dickicht, welches wir eben verlassen hatten, sind auch verwunschen, und Bambusrohr zum Aufbewahren von Zaubermedizin muß von diesem Orte geholt werden.

Dann kehrten wir nach dem Dorfe zurück. Wie sonst auch oft, fragte ich auch hier nach menschlichen Schädeln oder Skeletten. Diese Frage tat ich immer mit Vorsicht, um die Leute nicht zu verletzen, da sie ihre Toten verehren. Heute dagegen trug man kein Bedenken, mir zu eröffnen, daß im Walde ein wegen Zauberei Erschlagener begraben sei und daß ich die Gebeine ausgraben könnte.

Wir wurden von den Leuten zuerst etwa eine Stunde in der Richtung gegen den Sattelberg geführt, dann abseits vom Wege, wo der Erschlagene begraben lag. Der Totschlag war vor 4 Jahren geschehen. Es war ein junger Kai, namens Bạsing, ungefähr I 8 Jahre alt, aus Sililio, genau westlich vom Sattelberg. Er war verdächtigt, auf Anstiften älterer Leute gezaubert zu haben. Er floh dann nach dem Bezirke Gbata. Die Gbataleute fürchteten Streit mit ihren Nachbarn, wenn sie ihn verheimlichten, und so töteten sie ihn in Walde durch Speerstiche in die Schultergegend. Die Leiche wurde dann in eine alte Schweinegrube geworfen. Man konnte heute noch den festen Rand der Schweinegrube von dem lockeren Inneren abgrenzen. Die Skeletteile und der Schädel, alles noch wenig morsch, konnten mit den Händen leicht ausgegraben werden. Die Männer aus dem Dorfe wollten nicht zugreifen, um zu helfen, sondern schoben eine junge Frau vor. Mir schien, daß die Männer am Morde beteiligt waren und nun eine gewisse Furcht empfanden.

Später besuchte ich den südöstlich gegen die Küste zu gelegenen Wasadistrikt. Die Hausplanken in den Dörfern dort zeigen ähnliche bemalte Schnitzereien wie in den Jabim-Dörfern.

Dann erstieg ich den nördlich vom Sattelberg in westöstlicher Richtung streichenden Wamororücken. Ich stieg von der Küste von „Heldsbach" aus dahin auf, bis zur neuen Missionsstation Wareo (auf der Karte noch als Wamoro bezeichnet), die 
gegenüber dem Sattelberg und ungefähr in gleicher Höhe liegt. Zwischen beiden ist das Tal des Bussim. Ich ging diesen Weg zurïck und fand in dem Marsch ein typisches Beispiel für die unenvarteten Terrainschwierigkeiten im Gebirge NeuGuineas. Man sieht von oben nur dic eine Schlucht des Bussim, während des Marsches erfährt man aber, daB man in vier tiefe Schluchten hinabsteigen muB, ehe man den Sattelbergrïicken erreicht. Man braucht einen halben Tag, um diese in der Luftlinie ganz unbedeutende Entfernung zuriickzulegen, so zerrissen ist das Terrain.

Zum Schlusse meines Aufenthaltes im Kaigebicte machte ich eine viertägige Tour in die Gegend westlich vom Sattelberg und dabei auch in noch ganz unbekanntes Gebiet. Ich ging allein und war nur von sieben jungen Kaileuten aus der Nähe des Sattelbergs begleitet.

Am Morgen des 30. Januar brachen wir vom Sattelberg auf. Wir gingen zuerst in nordwestlicher Richtung, an der "schönen Aussicht" vorbei. Von da sahen wir unser nächstes Ziel im Westen, einen mit großen Bäumen bestandenen Kamm. Die Stelle heißt Sililio. Der Weg führte den westlichen Abhang des Sattelberges hinunter, über rote, offenbar stark eisenhaltige Erde. Dann ging es durch eine Pflanzung und eine Ortschaft, Kiombea, die aus 5 Häusern besteht, fünf Minuten weiter stehen noch 3 Häuser. Die Bergdörfer der Kai haben in der Regel keine größere Ausdehnung.

Wir stiegen nun über eine frisch gerodete Stelle bergab zu einem Bache, namens Bạngi, auf der anderen Seite ging es wieder steil bergauf. Erst um etwa I Uhr erreichten wir die Höhe Sililio. Dort steht jetzt kein Dorf, es war aber früher eines dort, das natürlich auch Sililio genannt wurde. Etwa 5 Minuten weiter liegt das neue Dorf Midschali (auf der Karte irrtümlich Nidschaki). Da einer meiner Begleiter hier seine Verwandten hatte, versuchte man es, mich hier schon zurückzuhalten, der guten Tarofrüchte wegen. Wir marschierten aber weiter, eine frisch gerodete Stelle hinab; man sah viele Gabelweihen herumkreisen und auf den Bäumen sitzen, die auf die zahlreichen kleinen Tiere lauern, die durch die Rodung des Waldes ihr schützendes Obdach verloren haben.

Es hatte geregnet, der Himmel blieb bedeckt, und das Thermometer zeigte nur $25^{\circ} \mathrm{C}$, was ich als angenehme Kühle empfand. Wir stiegen weiter bergab in ein mit dichtem Busch bestandenes Bachbett. Der Bach hieß Mạngalang und war jetzt unmittelbar nach dem Regen wasserreich und reißend.

Am anderen Ufer ging es ebenso steil wieder bergauf. Wir passierten ein Dorf, Simáo, das aus vier Hütten bestand. Gleich darauf hatten wir nocls weiter zu steigen, es war sehr feucht und kühl, ich und meine Begleiter waren müde und hungrig und wir waren sehr froh, als wir bald wieder zu zwei Hütten gelangten. Es war ein Mann anwesend mit einem Hunde, der von dem gewöhnlichen Papuahund im Aussehen abwich, mehr einem Spitz ähnlich sah*) und eine Schelle trug. Der Mann war sehr einsilbig und scheu und schien keine Neigung zu haben, uns uiber Nacht dort zu behalten. Sonst zeigte sich niemand.

Ich drängte nicht weiter, weil es oft komplizierte Vorstellungen sind, die gegen die Aufnahme von Fremden sprechen. So fand ich z. B. die Ansicht weit verbreitet, der Gast müßte, wenn er im Hause eines Kranken aufgenommen wird, dann solange dort bleiben, bis der Betreffende genesen ist, da sonst Gefahr für das Leben des Kranken besteht. Setzt man sich ïber solche Dinge einfach hinweg, so kann man leicht ein sonst gastfreundliches Volk gegen sich haben.

Ich zog es also vor, weiter zu gehen. Der Pfad führt durch hohen WVald, dreimal in tiefe Rinnen hinab und wieder hinauf. Nach einer Stunde kamen wir zu fünf Hütten, die aber unbewohnt waren. Hier änderten wir die Wegrichtung, die schon von Midschali bis hierher eine im wesentlichen südliche war, und gingen nun rein westlich. Nach Io Uhr hatten wir leicht steigend eine Höhe erreicht und sahen von da herab in das Tal des Bubui, der hier in seinem Oberlauf Mape heißt. Mein Aneroid zeigte auf diesem Ruicken $530 \mathrm{~m}$ Meereshöhe an, wir waren also von dem höheren Zuge des Sattelberges herabgestiegen. Trotzdem waren wir jetzt in eine großartigere Berglandschaft gekommen, als es die unmittelbare Umgebung des Sattelberges ist. Wir sahen ein tiet eingeschnittenes, scheinbar auch viel gewundenes Tal mit steilen Ufern vor uns, als Abschluß des Tales den Berg Nanson, zu dem rechts von uns ein mächtiger, nach der Aussage des Herrn Keyßer über $1000 \mathrm{~m}$ hoher Rücken hinzieht.

Nach weiteren fünf Minuten hatten wir ein kleines Dorf mit nur zwei Hütten erreicht. Es hieß Sulukong und lag ganz in Buschwerk und Farnbäumen versteckt; unten hörten wir den Mape rauschen. Man nahm uns freundlich auf, und wir bekamen in einem der beiden Häuser Unterkunft.

*) Bei der Besteigung des König Albert Eduard-Berges in Britisch-Neuguinea sah C. G. W. Mouckton Dorfhunde, »die von denen anderswo abwichen. Es sind gedrungene, kleine Tiere - schwarz, mit weißer Brust, weißem Bauch, buschigem Schweife nnd recht dichtem I'elz." Annual Report on British New Guinea for the year ending 3oth June I 906. 

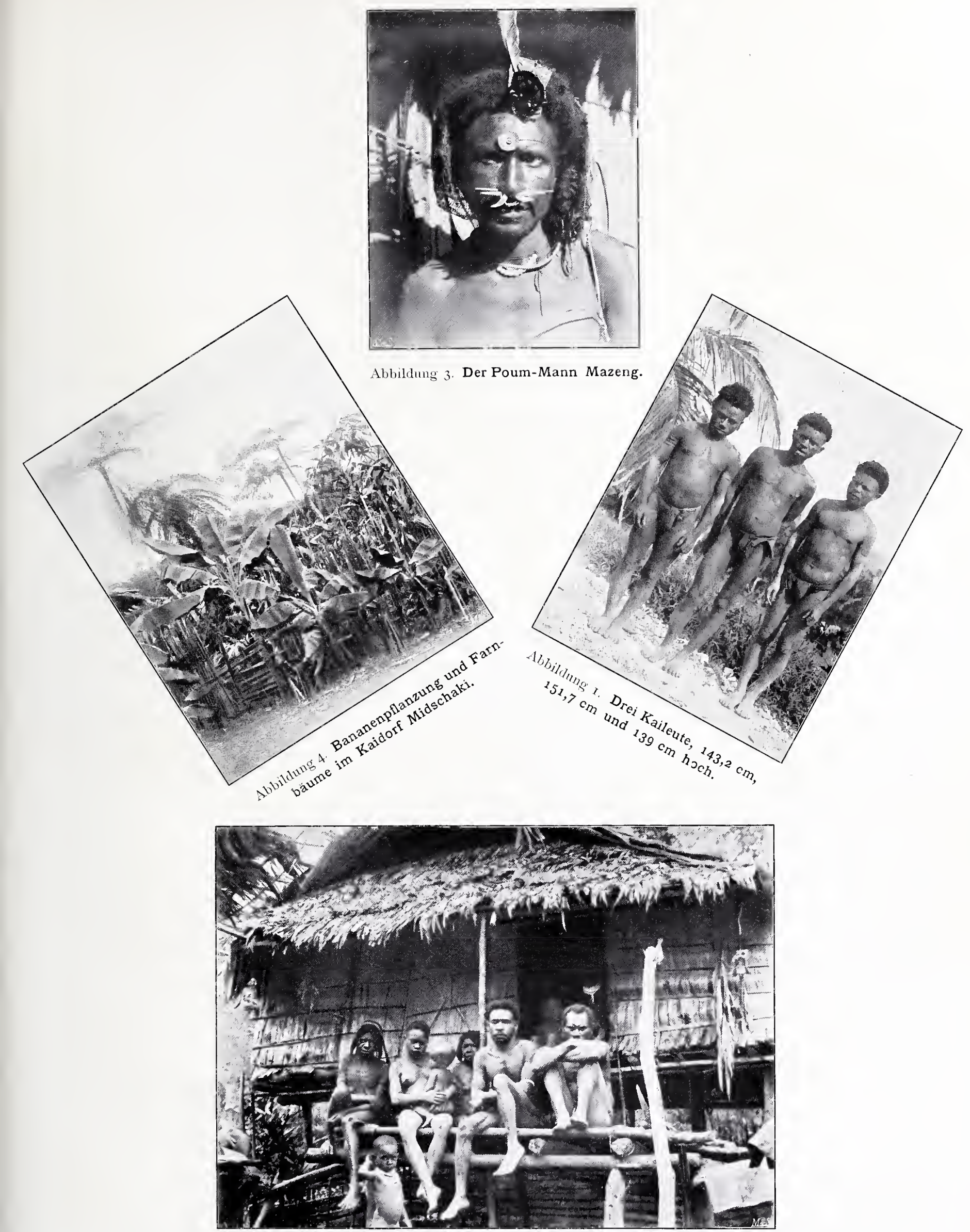

Abbildung 2. Haus im Kaidorf Marignoko im Wasa-Distrikt.

Verlag der Küniglichen Ilof luchhandlung von L. S. Mittler \& Sohn, Berlin SW68. 

Es war schon nahe an 6 Uhr und begann zu dunkeln.

Nur wenige Männer waren da; einer derselben trug die Ballonmütze der Poum. Man erzählte mir, der Mann hätte in seinem Stamme »eine Frau gestohlen«, was nur bedeutet, daß er sie verführt hat, und wäre nun, aus Furcht vor Strafe, in das nahegelegene Grenzdorf der Kai geflohen. Mazeng, so hieß der Poum, hatte noch nie zuvor einen Europäer gesehen und war anfangs sehr scheu, auch noch am nächsten Morgen, als ich ihn photographierte. Abbildung 3 gibt dieses Bild wieder. Mazeng hat die den Poum des Hinterlandes eigentümliche Mütze aus Baumbast auf, welche mit einem fadengeflochtenen Netz geschmückt ist. Durch die durchbohrte Nasenscheidewand ist ein geschliffener Stab vom Schlosse der Tridacnamuschel gesteckt, auf der Stirne trägt er ein Stück Perlmuschel, beides Dinge, die er durch Tausch von der Küste beziehen muß. An dem Tridacnastift sind zwei Hundezähne angehängt. Der Blick weicht scheu zur Seite aus, er wagt es aus Furcht noch nicht, gerade ins Gesicht zu sehen. Später schien Mazeng es sich aber doch überlegt zu haben, daß ihm meine Gesellschaft noch mehr Schutz vor den Verfolgungen seiner Stammesgenossen gewährt als sein Verwandter in Sulukong, und so schloß er sich mir an, und ich erfreute mich eines Trägers mehr. Er hatte seinen Bogen, ein Bündel Pfeile und einen eigentümlichen Pfeilscluutz aus Baumbast mit, den er um die Achsel trug. Seine Situation war also gewiß ernst gewesen.

Die Hütte in Sulukong hatte, wie gewöhnlich, nur einen Raum, von dem aber durch ein etwa einen halben Meter hohes Brett ein kleines Stück abgetrennt war, für die Weiber bestimmt. In der Mitte der Hütte war auf einem Untersatz aus Lehm und Sand ein Feuer gemacht. Es gab zu meinem mitgebrachten Proviant etwas Taro; wir verbrachten eine gute Nacht und brachen am nächsten Morgen bei Sonnenaufgang auf. Die Bezahlung für solche Nachtquartiere geschah natürlich in Tauschwaren. Die Hauptrolle spielt dabei der importierte gepreßte virginische Kautabak, der in gedrehten Stangen in den Handel kommt. Ich ließ in der Regel vier solche Stangen als Gegengeschenk für die Gastfreundschaft zurück, was dem Werte nach ungefähr einer halben Mark entsprach, außerdem zahlte ich die von mir und meinen Begleitern verzehrten Lebensmittel in anderen Tauschwaren: Messern, Zündhölzchen usw.

Wir stiegen den steilen Hang zum Mape hinab. Er war mit Gras und niederem Busch bewachsen, der Boden hatte also wahrscheinlich früher schon als Pflanzung gedient. Ganz unten waren die Ufer Mitteilungen a. d. D. Schutzgebieten, XX. Band. IV. felsig und von dichtem Urwald bedeckt. Das Wasser ging beim Durchwaten bis über die Hüfte, die Strömung war sehr reißend. In solchen Flußtälern entwickelt sich die tropische Laubvegetation zu großer Fülle und Mannigfaltigkeit.

Der Aufstieg am gegenüberliegenden Ufer war wieder sehr steil. Nach einer Viertelstunde kamen wir auf einen Kamm und sahen, daß der Bubui hier eine enge Schlinge macht. Wir gelangten in ein Dorf mit drei Hütten, das Sululao hieß und auf einer luftigen Höhe lag. Von hier sahen wir vor uns den Nanson, im Rücken den Sattelberg. Wir kamen nun etwas ab von dem Haupttale des Mape und gelangten in ein sehr schwieriges, dicht bewaldetes und fast unbewohntes Gebiet. Der Pfad führte quer durch zwei tiefe, wasserlose Einschnitte, die offenbar in der Regenzeit große Wassermengen zum Bubui hinabführen.

Auf einer Blöße stand wieder ein einzelnes Haus, von hier sah man den Nanson und auch zurück nach dem Sattelberg. Eine Viertelstunde weiter bergauf gelangten wir nochmals an ein einzelnes Haus, das noch im Bau war. Wir kamen gerade zurecht, denn mit starkem Sturm brach ein Gewitter herein. Wir warteten den Regen ab, litten aber alle sehr unter der plötzlichen Kälte. Dann ging es weiter auf einem durch die Nässe sehr schlüpfrigen Pfade, teils durch Busch, teils durch Bambusgestrüpp. Ich ging oft vom Wege ab, um das nötige Fleisch für das Nachtessen in Form von Tauben zu erbeuten. Um $3 / 46$ Uhr abends kamen wir wieder an den Hang hinaus, der das rechte Ufer des Mape bildet und blieben in einem großen Dorfe namens Salungo. Wir sind höher als tags vorher, mein Aneroid zeigt $650 \mathrm{~m}$. Steile Hänge gehen hinab zum Mape, gegenüber sieht man wieder den hohen bewaldeten Rücken, der gegen den Nanson zieht.

Am folgenden Morgen, den I. Februar, wurde ich vor Sonnenaufgang geweckt und meine Leute eröffneten mir, daß die Dorfbewohner ein Schwein zum Verkaufe gebracht hätten. Natürlich hatten sie die Sache tags vorher bestellt gehabt; ich ging aber darauf ein, da für das Schwein Tauschwaren im Werte von nur 5 Mark gefordert wurden. Das Schwein wurde sofort geschlachtet, gekocht und verspeist. Ich hatte inzwischen photographiert und alle meine Sachen revidiert. Punkt I 2 Uhr brachen wir auf. Meine Leute machten mir nun eristlich den Vorschlag, über den Mape hinüber nach einem Dorfe zu gehen, wo es gute Tarofrüchte gäbe. Natürlich erfüllte ich diesen Wunsch nicht, sondern verfolgte meinen Plan weiter, das Land jenseits des Mape näher kennen zu lernen. 
Wir gingen bergauf und lamen auf eine Blöße, wo wieder nur ein einzelnes Haus stand. Die Stelle hieB Hambong. Der Weg stieg nun durch einen Wald und wendete sich dann südlich, in ein dichtes Bambusgestrüpp. Dann ging es wieder durch Wald die Hänge einer Schlucht hinab, die schließlich auf einem darüberliegenden Baumstamm übersetzt wurde. Der Pfad führte immer höher, wir kamen abermals an ein einzelnes Haus; in einer halben Stunde auf einer Blöße trafen wir wieder auf ein Haus.

Dann wendete sich der Weg nach Osten. Wir marschierten durch einen hochstämmigen Wald, einen schrägen Hang entlang. Es war ein schweres Gehen auf dem feuchten Boden, besonders, da zahlzeiche Wurzeln offenbar durch Regengüsse freigelegt waren und num in der Richtung des Gefälles herabliefen. Die Eingeborenen mit iluren bloßen Füßen kamen über alle diese Schwierigkeiten leicht hinweg. Es wurde hier sehr einsam, man hörte sehr lange keine Vogelstimme. Dies begegnet einem in diesen Höhen bisweilen; wahrscheinlich fehlen die Fruchtbäume oder es waren gerade zur Zeit keine Früchte angesetzt. Der Wald war so dicht, daß man kieinen Ausblick bekam; aber man hörte tief unten das Rauschen eines Flusses.

Der Weg wurde besser, als man links den Grat betrat. Nach + Uhr kamen wir auf einen freien Platz mit weiter Aussicht. Nun sah man, daß der Hang, welchen entlang wir gewandert waren, unmittelbar zu dem Flusse abfiel, deir man in der Tiefe rauschen gehört hatte. Die Leute nannten ihn Hu und sagten, er sei ein Nebenfluß des Mape. Er selbst hatte rechts wieder ein Seitental, durch das sich ein Nebenfluß namens Hopi in ihn ergießt. Links sah man ein Tal, das sich auch gegen den $\mathrm{Hu}$ eröffnete, und in dem ein Bach, Bąbatu (Babatu auf der Karte), fließt. Nach Westen zu sah man eine zusammenhängende Bergkette, gewiß über $1000 \mathrm{~m}$ hoch.

Leute aus dem Tal waren heraufgestiegen und begegneten uns auf dieser Lichtung. Man zeigte uns den Weg zum nächsten Dorf. Wir mußten durch Bambusdickicht hinabkriechen. Es war diesmal besonders unangenehm, weil die Bambusstöcke sich tief unten zusammenschlossen und man nur gebückt durchkommen konnte.

Das Dorf, wo wir zu übernachten beschlossen, lag etwa auf halber Höhe des Hanges und hieß Beufun. Es war 5 Uhr vorbei und wir sahen an vielen Stellen des gegenüberliegenden Hanges Rauch aufsteigen, zum Zeichen, daß viele Niederlassungen da sind und das Tal dicht bevölkert ist, ebenso, wie das Mapetal selbst. Dagregen ist das Bergland zwischen den Flüssen weniger dicht bewohnt. Den ganzen Marsch von Salungo bis Beufun, der fünf Stunden gedauert hatte, war nicht eine Niederlassung, sondern nur einzelne Häuser getroffen worden.

Nachdem ich mit meinen Leuten in ein uns angebotenes Haus geklettert war, stellten sich am Abend viele Besucher aus Nachbardörfern ein. So ein überfülltes, auf Ptählen stehendes Haus gerät dann durch einen jeden neuen Ankömmling in ein eigentümliches Wanken. Dieses Haus hatte eine Art Dachfenster, d. h. Dachklappen, die von innen aus geöffnet werden konnten.

Am folgenden Morgen, den 2. Februar, stiegen wir den Hang des Tales hinauf und erreichten etwas östlicher die Fortsetzung des gestern begangenen Ruickens. Wir kamen wieder in dichte Wälder und sehr zerrissenes Gebiet. Wir überschritten kleinere Gewässer und kamen später an den oben erwähnten Bạbątu, einen sehr großen, reißenden Bach.

Nun ging es steil aufwärts, dann einen Abhang entlang, und wir umgingen, immer im dichten Walde, im Bogen eine Bergspitze. Diesen ganzen Marsch, vom Morgen bis Mittag, sahen wir keine Spur einer menschlichen Niederlassung. Erst jetzt kamen wir in ein Bambusgestrüpp, in dieser Gegend immer ein Beweis früherer Pflanzungen. Dann gelangten wir auch zu einer neuen Pflanzung, auf eine Blöße, und sahen von dort den Sattelberg. Wir hatten die Höhe des Abhanges erreicht, der am rechten Ufer des Mape abfällt.

Kurze Zeit nachdem wir die Pflanzung passiert hatten, kamen wir zu einem ungewöhnlich großen und hohen alleinstehenden Baum. Meine Leute machten mich darauf aufmerksam, daß auf dem Baume, in der Krone versteckt, ein Haus erbaut sei. Es war tatsächlich so von den Blättern verhüllt, daß ich es nicht bemerkt hätte. Auf Leitern, die aus Bambus und Rotang hergestellt waren, kamen die Bewohner des ziemlich umfangreichen Hanses, das einer ganzen Dorfschaft als Unterkunft dienen mochte, herabgeklettert. Ich erfuhr, daß die Leute sich auf diesen Baum zurückgezogen hätten aus Furcht vor einem Überfalle. Es waren im Nachbardorf einige Todesfälle vorgekommen. Der Papua sucht dann immer den "Zauberer", der das verursacht hat, und übt dann, wenn er den Betreffenden gefunden zu haben glaubt, an dem unschuldigen Opfer Blutrache.

Der Weg senkte sich von hier weiter gegen den Mape. Wir kamen zu 3 Häusern.

Dann ging es weiter durch Wald und schließlich sehr steil bergab zum Fluß. Der Mape ist hier sehr reißend. Es ist quer über den Fluß ein starker 
Rotang gespannt (Stiel einer Kletterpalme, Calamus), an dem man sich beim Überschreiten anhalten muß, um nicht von der Strömung fortgerissen $\mathrm{zu}$ werden.

Ebenso steil geht es am linken Ufer wieder aufwärts. Die Wegrichtung war eine fast nördliche; nach etwa $3 / 4$ Stunden kamen wir $z u$ fünf unbewohnten Hütten. Das war dieselbe Stelle, welche wir beim Ausmarsch am ersten Tage der Wanderung berührt hatten. Damals waren wir von da rein westlich marschiert und hatten den Mape etwas weiter flutaufwärts überschritten.

Von hier ab nahmen wir dieselben Pfade, auf denen wir gekommen waren. Es hatte zu regnen begonnen und es war recht unangenehm, hier durch das zerrissene Terrain mit den drei tiefen Rinnen hindurchzukommen.

Trotzdem blieb ich nicht in dem kleinen Dorf mit 2 Hütten, wo man schon beim Hinmarsch Bedenken getragen hatte uns aufzunehmen, sondern ging noch weiter bis zum größeren Dorfe Simao. Dort verbrachten wir die vierte Nacht auf diesem Marsche. Meine Leute allerdings wären trotz des Regens noch sehr gerne weiter gegangen bis Midschaki, der Tarofrüchte wegen.

Am nächsten Morgen, den 3. Februar, stiegen wir zum Mangalang hinab. Er war durch die Regengüsse stark geschwollen. Ich und meine Kaileute nahmen ein Bad und schwammen, während unser Begleiter, der Poum-Mann Mazeng, am Ufer hin- und herlief und über den ihm offenbar ganz neuen Anblick des Schwimmens erstaunt und erfreut in die Hände klatschte. Ich sah daraus, daß den Inland-Poum, in deren Lande es nur wilde Gebirgsbäche gibt, das Schwimmen ganz fremd und wohl auch das Baden schon ungewohnt ist. Schon bei den Kai ist die Reinlichkcit viel geringer als bei den am Meere wohnenden Jabim. Infolgedessen ist die Hautkrankheit der Südsee, die Tinea imbricata, bei den Kai viel häufiger. Eine eigentümliche Art der Hautpflege besteht darin, daß sich die Kai oft den ganzen Körper mit Asche einreiben.
Gegen Mittag kamen wir nach Midschaki, und da wir nicht mehr viel vor uns hatten, gestattete ich das langersehnte Taromahl. Auch ich muß die besondere Güte dieser Früchte an dem Orte anerkennen. In der Regel gewöhnt sich der Europäer an die Taros schwerer als an die Yams, wegen ihres eigentümlichen Geschmackes und ihrer Konsistenz, die an einen sitzengebliebenen Teig erinnert. Man lernt sie aber später schätzen, besonders die feineren Sorten aus dem Gebirge. Gewiß verlohnt es sich, solche anfänglichen Vorurteile zu überwinden. Die frische Kost, welche das Land bietet, ist gewiß gesünder als der fortwährende Genuß von Konserven.

Abbildung 4 zeigt die Pflanzung des Dorfes Midschaki. Sie ist umgeben von einem Bambuszaun, vorne stehen einige Bananen. Im Hintergrunde sieht man Farnbäume, die man bei der Ausrodung des Waldes hat stehen lassen.

Ohne weiteren Zwischenfall legten wir dann den Heimweg zum Sattelberg zurück. Zwischen Midschaki und der Sattelberghöhe schoß ich noch Paradiesvögel und zwar Exemplare des Kaiser Wilhelm- und des Kaiserin Augusta Paradiesvogels, von welchen aber nur der letztere zur Zeit vollen Schmuck hatte. Wälırend es hier in den Wäldern Mengen dieser Vögel gab und ihre Rufe fortwährend ertönten, erinnere ich mich nicht, jenseits des Mape einen gesehen oder gehört zu haben.

Wenige Tage nach Beendigung dieses Marsches verließ ich das Gebiet der Kai. Der gegenwärtige Gouverneur, Dr. A. Hahl, hat selbst auch schon den Sattelberg besucht, und es ist eine Durchwanderung des Kaigebietes behufs Aufstellung einer Bevölkerungsstatistik beabsichtigt, da die Kai sich, wie erwähnt, bisher im Dienst des Gouvernements sehr bewährt haben. Von Herrn KeyBer liegt mir eine briefliche Mitteilung vor, nach der er im Jahre 1906 in westlicher Richtung bis zum Bulesom gekommen sei, einem Flusse, der bei Kap Arkona den Huongolf erreicht. So ist zu hoffen, daß unsere Kenntnis über dieses Gebirgsland und seine Bewohner in nächster Zeit wesentlich erweitert wird.

\section{Resultate der Regenmessungen im Jahre 1906.}

Bei den vielfach unregelmäßigen und mangelhaften Verbindungen vieler Südsee-Stationen mit der Heimat treffen die Beobachtungsergebnisse nicht selten verspätet ein oder gehen unterwegs zuweilen verloren. Da die Erledigung diesbezüglicher Nach- forschungen ebenfalls viele Monate erfordert, ist es erst jetzt möglich, einige Lücken in den Veröffentlichungen der Ergebnisse des Jahres 1905 (s. d. Z. Jahrgang I 906 S. 339 ff.) auszufüllen. 


$$
\begin{aligned}
& \text { Regentage in } \mathrm{mm}
\end{aligned}
$$

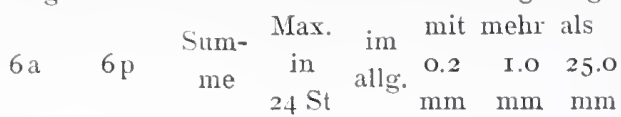

$$
\mathrm{J} \text { a } \mathrm{p} \text {. }
$$

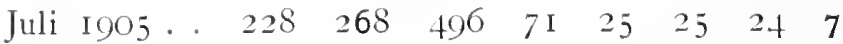
August . . $222 \quad 222 \quad 444$ II3 $26 \quad 26 \quad 25 \quad 6$

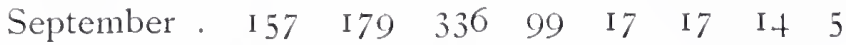
mithin Jahr I $496 \quad 1446 \quad 2942 \quad 166 \quad 2$ I6 2 I6 $184 \quad 33$

$$
\text { Ponape. }
$$

März 1905 . 228 IO3 33 I $179 \begin{array}{lllll}27 & 20 & \text { I } 4 & 2\end{array}$

Die im Taifun vom 20. April 1905 verloren gegangenen Regenmessungen für März I 905 sind nach-

\begin{tabular}{|c|c|c|c|c|c|c|c|}
\hline Nov. I905 & I 50 & 52 & 202 & 71 & 9 & 9 & 9 \\
\hline Dezember & 54 & 38 & $9^{2}$ & 30 & 6 & 6 & 6 \\
\hline mithin Jahr & 一 & - & 1963 & - & - & - & \\
\hline
\end{tabular}
träglich wieder aufgefunden worden.

\section{Lamotrek West-Karolinen.}

März I905. 68 23I 499 I 49 IO $\quad 9 \quad 8 \quad 3$ mithin Jahr II 34 I963 3297 I 49 I 79 I $53 \quad$ I +3 39

Der Raumersparnis halber mögen hier zunächst noch die Ergebnisse von einigen Stationen für das Jahr 1906 folgen, von denen nur vereinzelte Beobachtungen vorliegen.

Tobera.

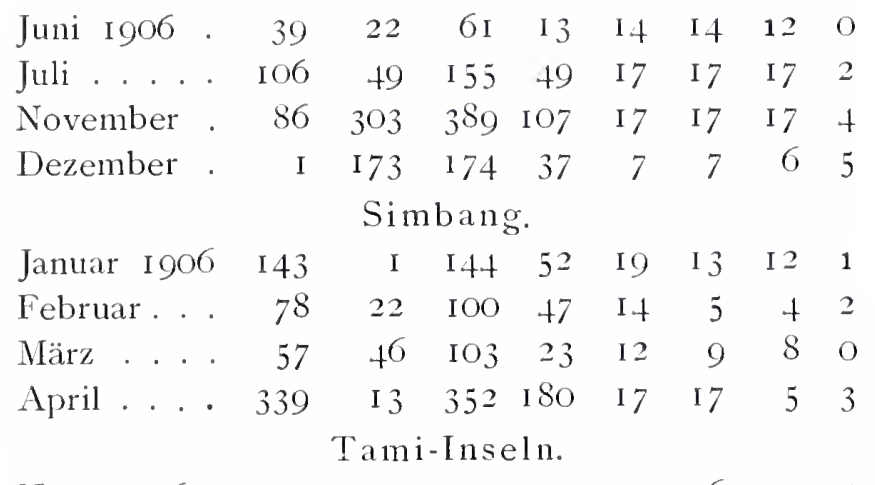

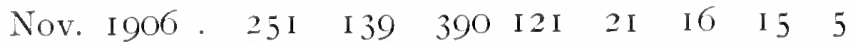

Der Regenfall in Kaiser Wilhelmsland war 1906 wesentlich ergiebiger als in dem trockenen Jahr I905; es fielen etwa 40 bis 80 v. H. mehr Regen. Besonders starke Niederschläge wurden im Oktober I906 an den Stationen der Neuendettelsauer Mission am Huongolf beobachtet. Hier fielen, nachdem im ganzen Monat südliche Winde gewelit hatten und nachdem am 28. Oktober heftiger Nordwind eingesetzt hatte, z. B. in Finschhafen auf Salankaua

$$
\begin{array}{cc}
\text { am 29. Oktober von } 2 \mathrm{p} \text { bis } 6 \mathrm{p} & \text { I } 26 \mathrm{~mm} \\
\text { bis } 30 . \text { Oktober } 6 \mathrm{a} & 397 ", \\
\text { bis 30. Oktober } 2 \mathrm{p} & \mathrm{IO2} \\
\cline { 2 - 2 } & \text { zusammen } 625 \mathrm{~mm},
\end{array}
$$

bei einem wolkenbruchartigen Regen, der 27 Stunden anhielt. Eine derartige große Regenmenge ist in diesem Gebiet bisher, solange dort beobachtet wird, noch nicht gemessen worden.
In dem benachbarten WVareo fielen in diesem Zeitraum nur $363 \mathrm{~mm}$, in Deinzerhöhe dagegen $559 \mathrm{~mm}$ (vom 29. 6a bis 30. 6p wurden hier indessen $732 \mathrm{~mm}$ gemessen), in Heldsbach $509 \mathrm{~mm}$, auf dem Sattelberg nur $348 \mathrm{~mm}$.

Besonders reich war das Jahr 1906 an Erdbeben, namentlich im Gebiet des Huongolfes. Sehr bemerkenswert ist es, daB auch in diesem Fall, wie schon früher beobachtet, die starken seismischen Erscheinungen in Kaiser Wilhelmsland sich im Bismarck-Archipel nicht bemerkbar machten, wodurch wiederum der Beweis erbracht wurde, daß die Erdbebenerscheinungen beider Gebiete von völlig unabhängigen seismischen Herden ausgehen.

Herr Missionar J. G. Pfalzer von der Neuendettelsauer Mission hat ïber das Erdbeben vom 15. September I 906 in der Umgebung von Finschhafen sowie über die sich an dasselbe bis zum Jahresschluß anreihenden Beben einen Bericht eingesandt, dem wir folgendes entnelmmen:

Nachdem im ganzen Jahre sehr wenig Erdbeben zu verzeichnen gewesen waren, erschreckte uns am I 5. September 1906 früh gegen 2 Uhr ein solch außerordentlich heftiges Beben, wie es seit Besetzung dieses Landes durch die Weißen - also seit Ende 1885 noch nie beobachtet worden ist. Es war ein sehr heftiger, drehender Stoß direkt senkrecht von unten und dann schüttelte es, wie wenn ein Sieb geschuittelt wird. Dem ersten StoB folgten bis Tagesanbruch noch etwa Io bis I 2 weitere starke Stöße, wenn auch lieiner mehr die Heftigkeit des ersten erreichte. Dazwischen gab es aber noch unzählige kleinere.

Zu gleicher Zeit mit dem Erdbeben setzte eine Flutwelle ein, die etwa $1 / 1 / 2 \mathrm{~m}$ über Normal-Fluthöhe stieg und die sich am 17 . abends 7 Uhr wieder holte. Am I7. abends gegen 7 Uhr wechselten Flut und Ebbe dreimal rasch hintereinander; doch stieg die Flut nicht über gewöhnliche Fluthöhe.

Das Hauptgebiet dieses Erdbebens war in hiesiger Gegend der Gebirgsstock des Sattelberges und des Wamoro, auch noch Logaueng - da gab's allenthalben gewaltige Erdrutsche und Abstürze, dazu Risse und Spalten ïberall.

Die ganze Katastrophe scheint sich aber nur auf unsere Halbinsel ${ }^{1}$ ) und zwar nur auf den östlichsten Teil erstreckt zu haben, denn schon jenseit des Bulesom in Deinzerhöhe war das Erdbeben nur schwach. In Kap Arkona wurde es auch noch bemerkt, aber nur ganz leicht. Weit im Innern sieht man nur vereinzelte Bergstürze an besonders steilen Stellen, während an der Küste hier herum, besonders

\footnotetext{
1) i. e. das Land östlich des $147^{\circ}$.
} 
um Sattelberg und Wareo (auf dem Wamorohöhenrücken), die Gegend eine ganz andere Physiognomie erhalten hat infolge der vielen Bergstürze; ganz besonders schlimm war's im Busimtal. Im Bubuital ist's lange nicht so arg; da sind größere Bergrutsche schon vereinzelt.

Dementsprechend hat das Erdbeben auch auf unseren Stationen Sattelberg und Wareo den meisten Schaden angerichtet. Auf Sattelberg hat es das älteste Wohnhaus von den Pfosten geschleudert um etwa $2 \mathrm{~m}$ weit; doch war bei diesem Haus der Unterbau schon ziemlich schlecht, so daß diese Wirkung nicht allzu verwunderlich scheint. Dagegen hat es aber auf Wareo ein eben fertiggestelltes neues Wohnhaus gleichfalls von den Pfosten gerissen, doch nicht hinuntergeworfen, sondern das Haus fiel auf die Pfosten zurück, nur nicht mehr genau auf den richtigen Platz, sondern etwa I m nach einer anderen Richtung, so daß die vorderste Reihe Pfosten nun neben statt unterm Haus stand.

Sonst hat es auf diesen beiden Stationen noch mehrere Wassertanks demoliert; es hat die vollen Tanks von den Fundamenten geschleudert, trotzdem dieselben nicht hoch, sondern auf dem Boden standen, und zusammengedrückt wie einen Zylinderhut.

Im übrigen war der Schaden nicht groß. Hier an der Küste hat es die Häuser ja etwas schief gedrückt, hin und wieder eine Kleinigkeit zerbrochen, aber das ist kaum der Rede wert. Nur Schränke, Büchergestelle hat es hier wie auf den Bergen umgeworfen und Lampen und Geschirr zerschlagen.

Verunglückt ist auf unseren Stationen niemand, weder Weiß noch Schwarz, nur ein paar Weiße erlitten leichte Verletzungen. Auf dem Sattelberg wohnte in dem eingestürzten Haus Frau Miss. Flirl mit ihren Kindern allein (Miss. Flirl war abwesend in Heldsbach). Sie entkamen, aber erst nachdem das Haus von den Fundamenten geschleudert worden war, aus demselben durch die Fenster.

Dagegen sind im Inland von Wareo eine ganze Anzahl Eingeborene durch Erdrutsche verschüttet worden, soviel wir zu hören bekamen bis jetzt, sicher etliche Dutzend. Ein kleiner Häuptling verlor seine ganze Dorfschaft. Auch an der Küste beim Festungshuk sind einige Leute verschüttet worden.

Hier in Finschhafen hat es auf Madang 2 Häuser der N. G. Co. eingeworfen. Auch diese Häuser sind in der Richtung von Nordwest nach Südost um I bis $2 \mathrm{~m}$ weggeschleudert, ebenso wie auf dem Sattelberg. Danach und nach manchen anderen Umständen ist anzunehmen, daß die Hauptstöße in dieser Richtung Nordwest bis Südost oder umgekehrt erfolgten - doch, wie schon oben bemerkt, der erste Stoß erfolgte fast senkrecht direkt von unten wie auch später noch mehrere der heftigeren Stöße.
Erdbeben und Flutwelle haben auch den Verbindungsdamm zwischen der. Insel Madang und dem Land zerstört. Sonst hat die Flutwelle uns noch Schaden getan durch Wegspülen diverser Sachen, die im Freien auf Madang lagerten, doch im Verhältnis zur Stärke der Erderschütterungen ist der ganze Schaden nur geringfügig.

Die Flutwelle war an der Küste entlang nur bis Busega - Schollenbruchspitze - im Huongolf bemerkbar, in Deinzerhöhe wurde nichts mehr bemerkt.

Auf den Tami-Inseln sind Flut und Beben auch bemerkt worden. Das Beben war auch kräftig, doch hat es keinen Schaden angerichtet.

Eingeborenenhäuser sindan der ganzen Küste hier herum zahlreich eingestürzt, aber auch nur die schlechteren, älteren, viele sind nur schief gedrückt und blieben stehen und bewohnbar.

Auf der Siassi-Insel Tu war unser Missionar Hansche vom Mai bis November, er spürte das Beben in jener Nacht, auch ebenso die Flutwelle, aber beides war nicht außergewöhnlich. Auch dauerten die Beben bloß bis zum I8. September. Dagegen bemerkte er noch, daß am I4. September die TupinierInsel, bei den Eingeborenen Ginges genannt, rauchte.

Herr Pfalzer berichtet dann weiter, daß in PolaFinschhafen im September vom I5. abends an in diesem Monat täglich nocl weitere Erdstöße beobachtet wurden, darunter 88 starke, schwächere mindestens 200; im Olitober wurden 85 an 22 Tagen, im November I9 an I4 Tagen und im Dezember I 5 an I2 Tagen gezählt. Besonders häufig waren die Stöße am 2. und 3. Oktober, an welchen beiden Tagen 24 bzw. 27 gezählt wurden; sehr heftig war darunter ein Stoß, der am 2. um II,3O abends eintrat und der nach den Angaben der Regentabellen auch in Jomba an der Astrolabebai und in Peterhafen auf den French-Inseln beobachtet ist. In Finschhafen trat zu dieser Zeit abermals eine starke Flutwelle ein, die eine erheblich stärkere Bewegung des Meeres veranlaßte als an I 5 . September, es lief fast der ganze Finschhafen aus, doch stieg die Flut nur etwa I $m$ über gewöhnliche Fluthöhe.

Das Beben am 15. September ist zwischen I.30 und 2 Uhr morgens an der ganzen Küste von Kaiser Wilhelmsland, in Potsdamhafen, Friedrich-Wilhelmshafen, Jomba, Erima, Stephansort wie auch am Huongolf beobachtet worden. Eine ähnliche Verbreitung hatte ein am 20. Februar I 906 zwischen 8,30 bis $9 \mathrm{p}$ vorgekommenes Beben. Im übrigen sind die Ausführungen der verschiedenen Regenmeßstationen des Schutzgebietes über die vorgekommenen Beben zu lückenhaft, als daß es sich lohnte, die in früheren Jahrgängen dieser Zeitschrift im einzelnen veröffentlichten diesbezüglichen Zusammenstellungen hier in der früheren Form zum Abdruck gelangen zu lassen. 
Jaluit. Beobachter: Kr ïm ling.

Potsdamhafen.

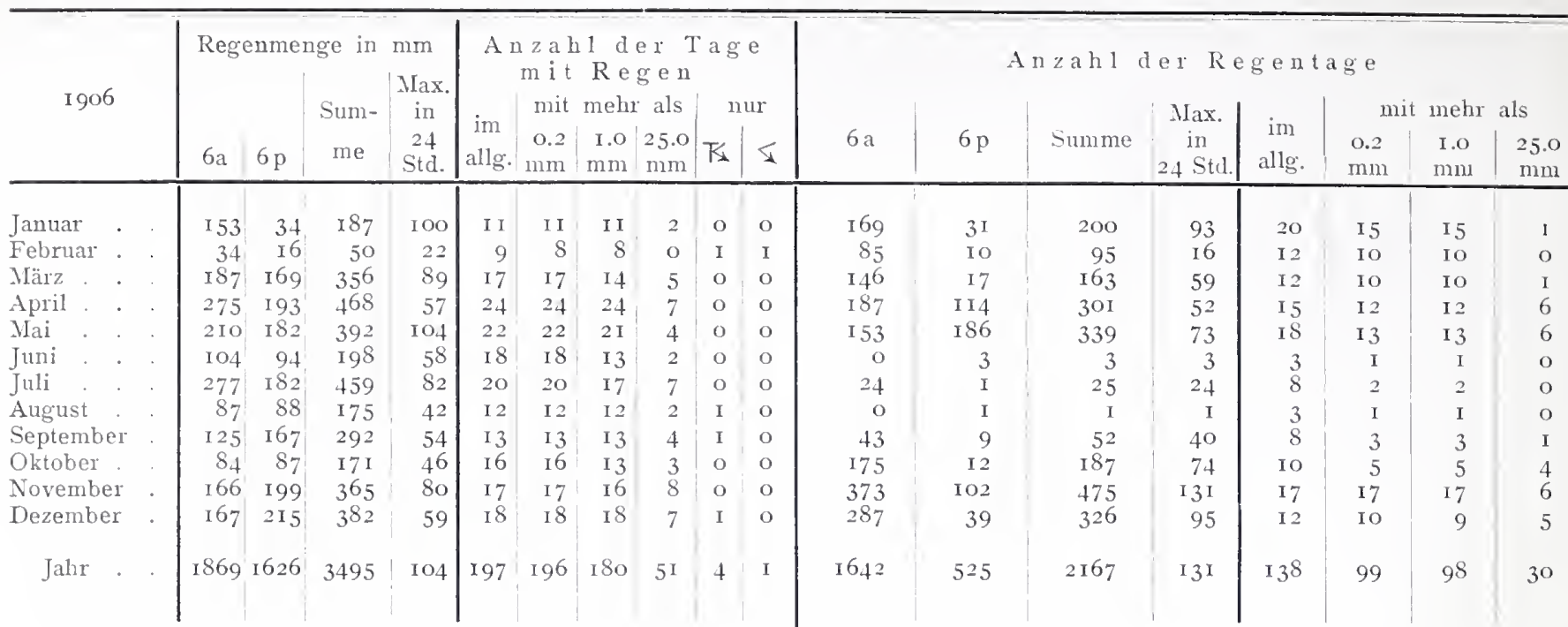

Friedrich Wilhelmshafen.

\begin{tabular}{|c|c|c|c|c|c|c|c|c|c|}
\hline \multirow{3}{*}{1906} & & \multirow{3}{*}{$6 \mathrm{a}$} & \multirow[t]{3}{*}{ enme } & \multirow{3}{*}{$\begin{array}{c}\text { Sum- } \\
\text { me }\end{array}$} & \multirow{3}{*}{$\begin{array}{c}\text { Max. } \\
\text { in } \\
24 \text { Std. }\end{array}$} & \multicolumn{4}{|c|}{ Anzahl der Regentage } \\
\hline & & & & & & 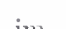 & mit & melir & als \\
\hline & & & & & & allg. & $\begin{array}{l}0.2 \\
\mathrm{~mm}\end{array}$ & $\begin{array}{l}1.0 \\
\mathrm{~mm}\end{array}$ & $\begin{array}{l}25.0 \\
\mathrm{mim}\end{array}$ \\
\hline Januar & & 204 & o & 204 & 32 & I6 & I6 & I 6 & 2 \\
\hline Februar & . & I 53 & 4 & 157 & 36 & I 8 & 15 & 14 & 2 \\
\hline März . . & . & 216 & $2 \mathrm{I}$ & 237 & 55 & 23 & 19 & 17 & 4 \\
\hline April . . & . & I 59 & 28 & 187 & 37 & 22 & 15 & I 5 & 2 \\
\hline . . & . & I 54 & $2 \mathrm{I}$ & I 75 & 35 & 20 & 19 & 19 & 2 \\
\hline Juni . . & . & 23 & 2 & 25 & 5 & I 5 & 8 & 7 & o \\
\hline Juli . & . & 40 & 4 & 44 & I I & I 5 & $1 \mathrm{I}$ & 7 & o \\
\hline August & $\cdot$ & I & I & 2 & $I$ & I I & 3 & I & o \\
\hline September & . & $5 I$ & I 3 & 64 & 17 & I 8 & I 2 & 9 & o \\
\hline Oktober. & . & 199 & $6 I$ & 260 & 52 & 27 & 22 & I 8 & 3 \\
\hline November & . & I 55 & I 8 & 173 & 54 & 20 & I 8 & I 2 & 2 \\
\hline Dezember & & 192 & 34 & 226 & 46 & 17 & 9 & 8 & 4 \\
\hline Jahr & - & I 547 & 207 & I 754 & 55 & 222 & 167 & I 43 & 22 \\
\hline
\end{tabular}

\section{Stephansort.}

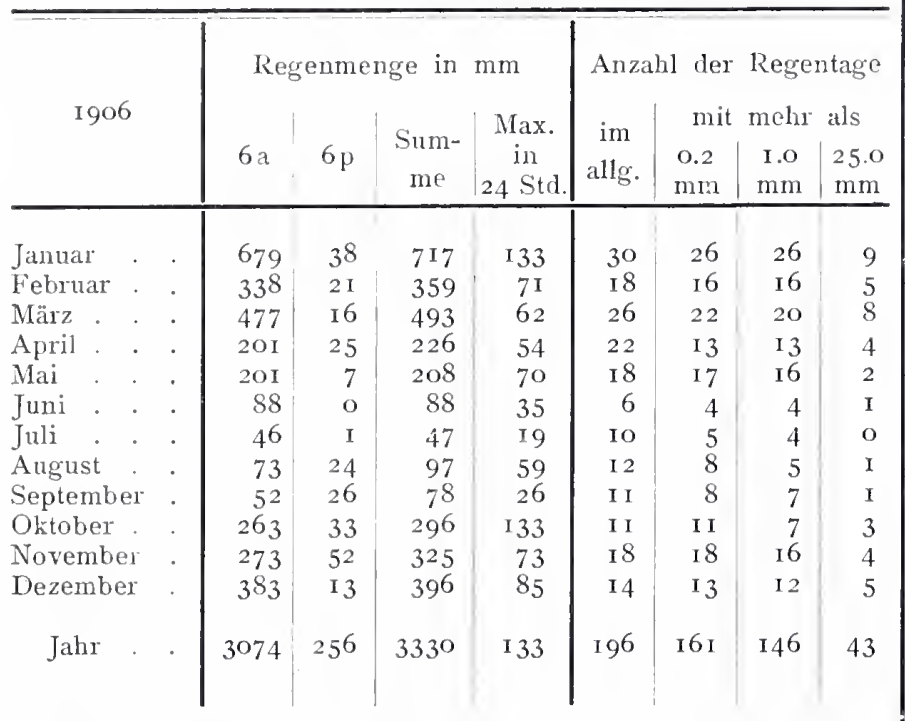

\section{Jomba.}

Alzabl der Regentage

\begin{tabular}{|c|c|c|c|c|c|c|c|}
\hline \multirow[b]{2}{*}{$6 \mathrm{a}$} & \multirow[b]{2}{*}{$6 p$} & \multirow[b]{2}{*}{ Summe } & \multirow{2}{*}{$\begin{array}{c}\text { Max. } \\
\text { in } \\
24 \text { Std. }\end{array}$} & \multirow[b]{2}{*}{$\begin{array}{l}\text { in } \\
\text { allg. }\end{array}$} & \multicolumn{3}{|c|}{ mit mehr als } \\
\hline & & & & & $\begin{array}{c}0.2 \\
\mathrm{~mm}\end{array}$ & $\begin{array}{l}\text { I.o } \\
\text { mmm }\end{array}$ & $\begin{array}{c}25.0 \\
\mathrm{~mm}\end{array}$ \\
\hline 278 & 6 & 284 & 50 & 28 & 22 & 19 & 4 \\
\hline I 12 & I 3 & I 25 & 38 & I 5 & I 5 & I 5 & I \\
\hline I 73 & 27 & 200 & 56 & 2 I & I9 & 17 & 3 \\
\hline I 52 & 37 & 189 & 43 & I 9 & I9 & I 7 & 3 \\
\hline IO3 & 14 & I I 7 & $3 I$ & 17 & I 4 & I 4 & I \\
\hline 17 & o & 17 & 5 & 8 & 5 & 5 & o \\
\hline 69 & 8 & 77 & 46 & I 8 & I 4 & 9 & I \\
\hline I & 2 & 3 & 2 & 9 & 2 & 2 & 0 \\
\hline $3 \mathrm{I}$ & 9 & 40 & I 2 & 8 & 6 & 6 & O \\
\hline 205 & 27 & 232 & $5^{8}$ & 24 & 24 & $2 I$ & 3 \\
\hline 167 & I 3 & I 80 & 57 & I 8 & 17 & I 5 & 3 \\
\hline IOO & 29 & I 29 & $3^{8}$ & I 6 & I 3 & I 3 & 2 \\
\hline 1408 & I 85 & I 593 & 58 & $20 I$ & 170 & I 53 & 21 \\
\hline
\end{tabular}

Alt-Erima.

An\%ah 1 der Regentage

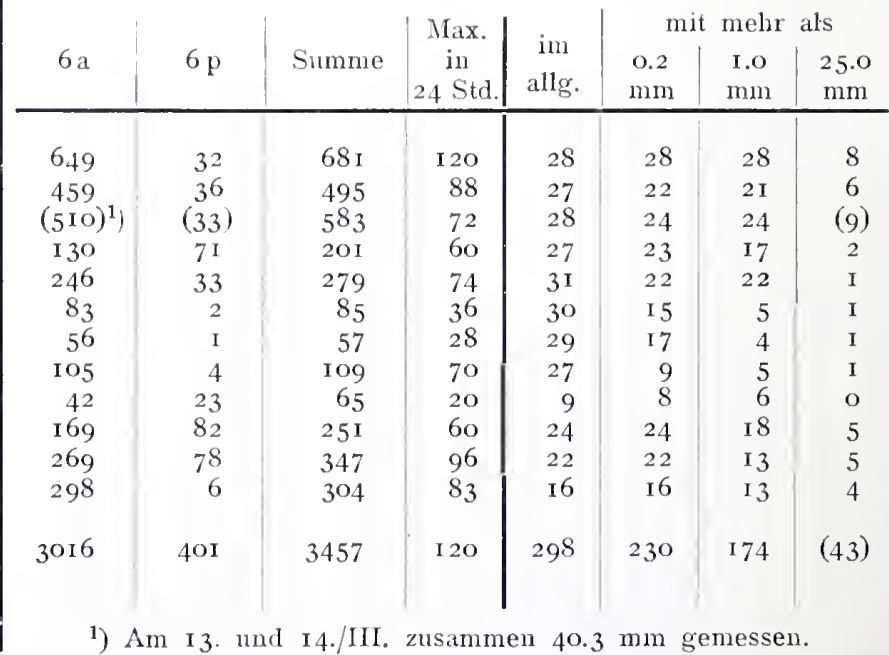


Heldsbach. Beobachter: Miss. K. Wacke.

Peterhafen French-Inseln.

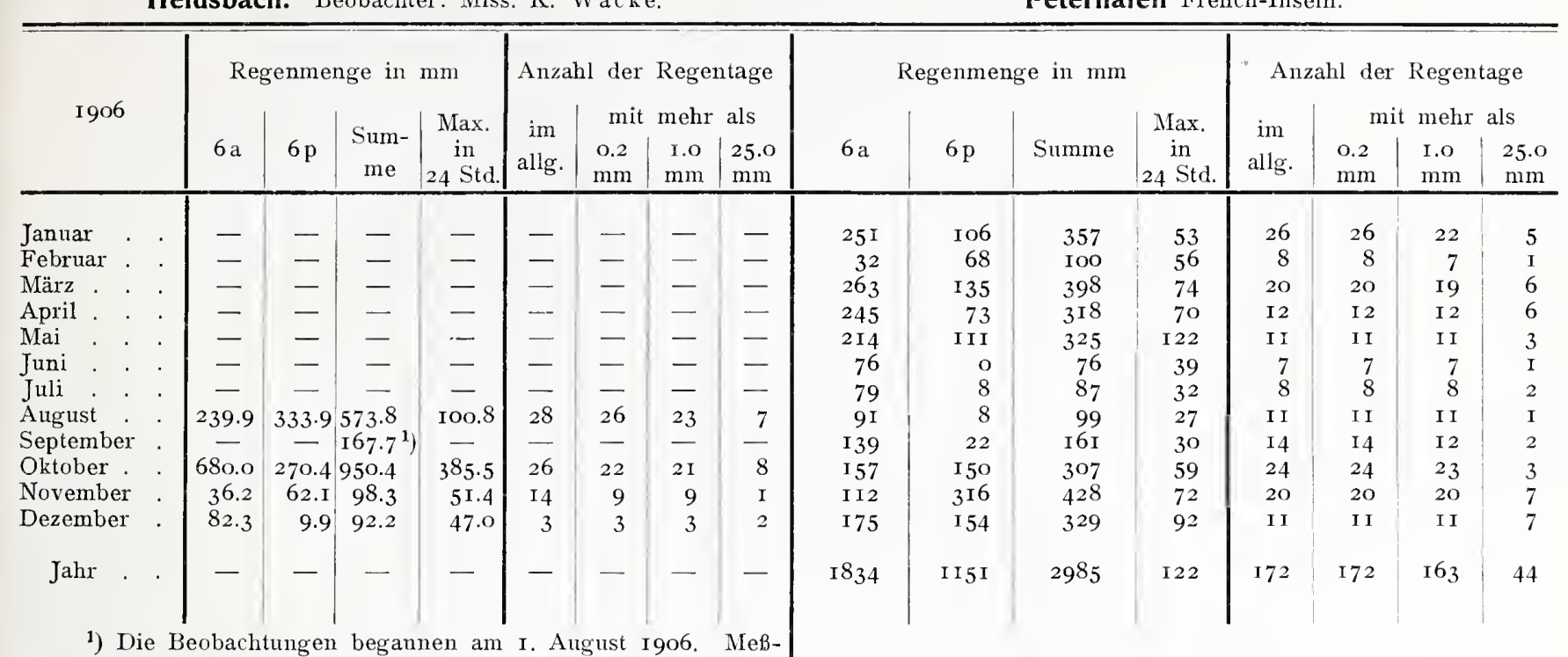

glas beobachtungen begannen am I. August i 906. Me des Monats fielen zusammen $92.2 \mathrm{~mm}$.

Herbertshöhe (Raniolo).

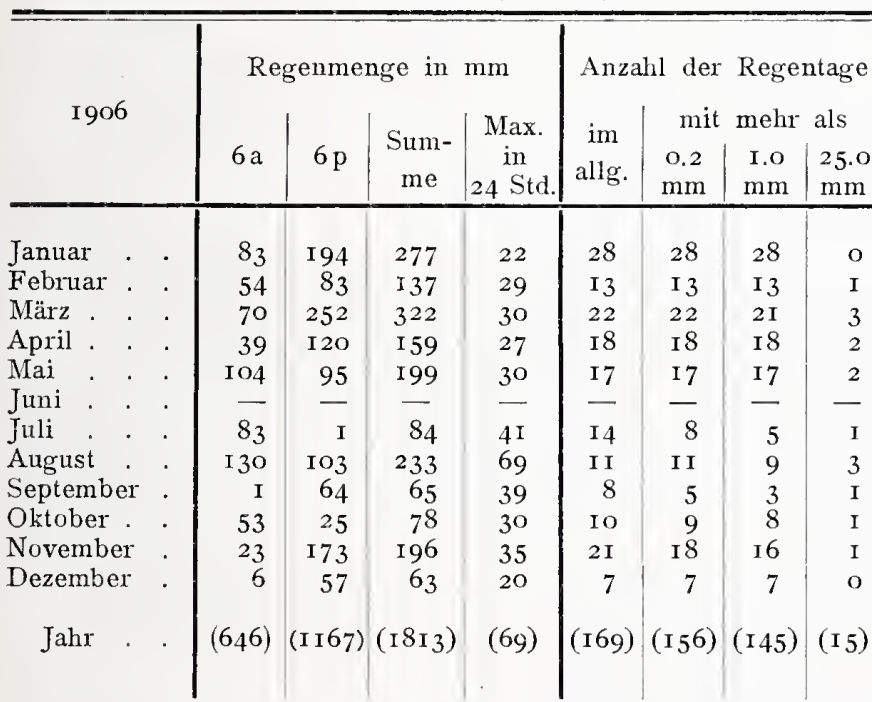

Toma. Beobachter: Fitsch.

\begin{tabular}{|c|c|c|c|c|c|c|}
\hline \multirow[t]{2}{*}{ I906 } & \multirow[t]{2}{*}{ Summe } & \multirow[t]{2}{*}{$\begin{array}{l}\text { Max. in } \\
24 \text { Std. }\end{array}$} & \multicolumn{4}{|c|}{ Anzahl der Regentage } \\
\hline & & & allg. & $\begin{array}{l}0.2 \\
\mathrm{~mm}\end{array}$ & $\begin{array}{l}\mathrm{I} . \mathrm{O} \\
\mathrm{mm}\end{array}$ & $\begin{array}{l}25.0 \\
\mathrm{~mm}\end{array}$ \\
\hline Januar & 336.3 & 53.7 & $>$ I 8 & - & - & - \\
\hline Februar & 302.6 & 75.4 & IO & - & - & - \\
\hline März . & 475.5 & - & $>20$ & 一 & - & - \\
\hline April . . & 289.7 & $54 \cdot 3$ & 20 & I 5 & I 5 & 5 \\
\hline Mai . . & 298.5 & 56.2 & $>\mathrm{I}_{5}$ & - & - & - \\
\hline Juni . & 50.8 & I I. 2 & I 4 & I 4 & I I & 0 \\
\hline Juli . & I I 4.6 & 56.2 & I 4 & 9 & 9 & I \\
\hline August . & 282.2 & - & $>\mathrm{II}$ & - & - & - \\
\hline September & 93. I & - & $>5$ & - & - & - \\
\hline Oktober . & IO3.8 & 43.2 & IO & 8 & 8 & I \\
\hline November & 330.8 & 62.4 & I 8 & I 5 & I 5 & 6 \\
\hline Dezember & 264.6 & - & - & - & - & - \\
\hline Jahr & 2942.5 & 一 & - & - & - & - \\
\hline
\end{tabular}

Wegen öfterer Abwesenheit des Beobachters von der Station konnten nur die während dieser Zeit im Regenmesser angesammelten Regenmengen nachträglich gemessen werden.
Herbertshöhe (Gouvernement). Beobachter: Dr. Wendland.

\begin{tabular}{|c|c|c|c|c|c|}
\hline \multirow[t]{2}{*}{ Summe } & \multirow[t]{2}{*}{$\begin{array}{l}\text { Max. in } \\
24 \mathrm{St} .\end{array}$} & \multirow{2}{*}{ im allg. } & \multicolumn{3}{|c|}{$\begin{array}{l}\text { er Regentage } \\
\text { mit mehr als }\end{array}$} \\
\hline & & & $0.2 \mathrm{~mm}$ & $1.0 \mathrm{~mm}$ & $25.0 \mathrm{~mm}$ \\
\hline - & - & - & . & - & $\longrightarrow$ \\
\hline - & - & - & - & - & - \\
\hline- & - & - & - & - & - \\
\hline - & - & - & - & - & .. \\
\hline$\left.(\mathrm{I} 86.3)^{\mathrm{t}}\right)$ & $(56.6)$ & (I4) & (I4) & (I 2$)$ & (2) \\
\hline 65.0 & 39.9 & I I & 7 & 6 & I \\
\hline I 48.7 & 47.5 & I 8 & I I & IO & I \\
\hline 319.9 & I 66.7 & I 8 & I 7 & I 4 & 3 \\
\hline 86.8 & $4 \mathrm{I} \cdot 4$ & I 3 & 7 & 5 & 2 \\
\hline 70.2 & I 7.7 & I 8 & I 4 & I I & o \\
\hline I 74.4 & 54.6 & I9 & I 5 & I 4 & I \\
\hline 79.7 & 27.8 & I 4 & I I & 7 & I \\
\hline- & - & - & - & - & - \\
\hline
\end{tabular}

1) Vom 6. Mai ab beobachtet.

Paparatawa. Beobachter: R. Wolff.

\begin{tabular}{|c|c|c|c|c|c|}
\hline \multirow[t]{2}{*}{ Sunime } & \multirow[t]{2}{*}{$\begin{array}{l}\text { Max. in } \\
24 \text { St. }\end{array}$} & \multicolumn{4}{|c|}{$\begin{array}{c}\text { Anzahl der } \text { Regentage } \\
\text { mit melur als }\end{array}$} \\
\hline & & im allg. & $0.2 \mathrm{~mm}$ & I.O $\mathrm{mm}$ & $25.0 \mathrm{~mm}$ \\
\hline $\left.340.7^{1}\right)$ & 一 & $>25$ & - & - & - \\
\hline 212.4 & 69.8 & I 3 & I I & IO & 4 \\
\hline 417.8 & 48.6 & 23 & 22 & 20 & 8 \\
\hline 285.2 & 8o. I & $>16$ & - & - & - \\
\hline 383.0 & - & $>17$ & - & - & 一 \\
\hline 42.9 & I 3.2 & I5 & 8 & 7 & o \\
\hline 176.7 & 56.0 & $>\mathrm{I} 4$ & - & 一 & - \\
\hline 325.0 & I 58.9 & $>18$ & - & - & 一 \\
\hline 79.0 & 26.9 & I3 & 9 & 8 & I \\
\hline $8 \mathrm{I} . \mathrm{I}$ & $2 \mathrm{I} \cdot 5$ & I 3 & I I & I I & o \\
\hline 310.9 & $5^{8.4}$ & $>\mathbf{I} 8$ & 一 & - & - \\
\hline I 82.7 & - & $>\mathrm{IO}$ & - & - & - \\
\hline 2837.4 & - & - & - & - & - \\
\hline
\end{tabular}

1) Siehe Bemerkungen zu Toma. 
Ponape. Beobachter: Dr. Girschner.

Palau. Beobachter: Winkler.

\begin{tabular}{|c|c|c|c|c|c|c|c|c|c|c|c|c|c|c|c|c|}
\hline \multirow[t]{2}{*}{ I 906} & Rege & enmer & Sum- & $\begin{array}{l}\mathrm{mm} \\
\text { Max. } \\
\text { in } \\
2\end{array}$ & \multicolumn{6}{|c|}{$\begin{array}{c}\text { Anzahl der Tage } \\
\text { mit Regen }\end{array}$} & \multicolumn{6}{|c|}{ Anzalul der Regentage } \\
\hline & $7 \mathrm{a}$ & $7 \mathrm{p}$ & & St. & allg. & $\mathrm{mm}$ & $\mathrm{mm}$ & $\mathrm{mm}$ & Ks & 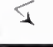 & Derintise & 24 Std. & $110 \mathrm{tang}$ & $0.2 \mathrm{~mm}$ & I.o $\mathrm{mm}$ & $25.0 \mathrm{~mm}$ \\
\hline Jantrar . & 247 & I I 3 & 360 & 70 & 27 & 23 & 19 & 6 & I & o & I95 & $4 \mathrm{I}$ & 23 & 23 & 20 & 2 \\
\hline Februar. & 56 & 24 & 80 & 27 & I4 & I3 & 9 & I & o & o & 209 & 91 & I6 & I 3 & I 2 & 2 \\
\hline März · · & $9^{8}$ & 83 & I 81 & $5^{6}$ & 17 & I6 & I3 & 2 & I & I & 80 & I 8 & I6 & I 2 & 9 & o \\
\hline April . . & I69 & 220 & 389 & 73 & 26 & 25 & 25 & 5 & o & o & I 57 & 23 & Is & I 5 & I 5 & o \\
\hline Mai . & 227 & 207 & 434 & $8 I$ & 23 & 22 & $2 \mathrm{I}$ & 7 & I & I & 572 & I 20 & $2 \mathrm{I}$ & I9 & I9 & 8 \\
\hline Juni . . & 73 & 214 & 287 & 50 & 24 & 24 & 23 & 3 & I & o & 282 & $5 \mathrm{I}$ & $2 \mathrm{I}$ & 20 & 20 & 3 \\
\hline Juli . & 3 I 3 & 59 & 372 & I 2 I & I 6 & I6 & I3 & 4 & 2 & o & 664 & I 66 & 20 & I 8 & I 7 & 9 \\
\hline August & 88 & 272 & 360 & 90 & 23 & $2 \mathrm{I}$ & 20 & 3 & I & 4 & 393 & 74 & 20 & I 8 & I 5 & 8 \\
\hline September & 212 & 226 & 438 & I I I & 24 & 24 & 24 & 4 & 4 & o & 379 & 63 & 19 & 19 & I9 & 5 \\
\hline Oktober. & 93 & I09 & 202 & 36 & I9 & I6 & I 5 & 2 & 3 & I & I 94 & $3 \mathrm{I}$ & I 4 & I 3 & 12 & 3 \\
\hline November & I 31 & 285 & 416 & 36 & 30 & 30 & 29 & 5 & 3 & 3 & 275 & IO4 & 19 & I6 & $I_{4}$ & 4 \\
\hline Dezember & I 95 & 278 & 473 & 65 & 23 & 23 & 22 & 7 & 2 & o & 406 & 77 & 22 & $2 I$ & I 8 & 6 \\
\hline Jahr . & 1902 & 2090 & 3992 & I 2 I & 266 & 253 & 233 & 49 & I9 & IO & 3806 & I 66 & 229 & 207 & I 90 & 50 \\
\hline
\end{tabular}

Gárapan auf Saipan. Beobachter: Kirn.

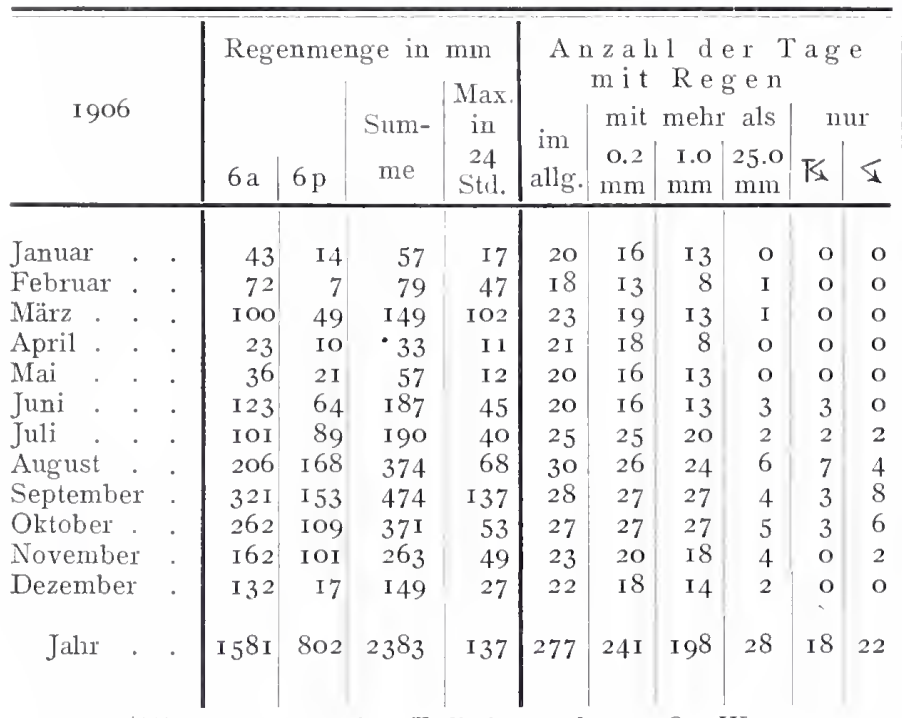

Io./III. II - 30p starker Erdbebenstob von O-W.

Truk-Insel, Eten. Beobachter: E. Petersen u. T. Janssen,

\begin{tabular}{|c|c|c|c|c|c|c|c|c|}
\hline \multirow{3}{*}{1906} & \multicolumn{4}{|c|}{ Regenmenge in mm } & \multicolumn{2}{|c|}{ Anzah1 der } & \multicolumn{2}{|c|}{ Regentage } \\
\hline & & & & Mar & im & mit & mehr & als \\
\hline & $7 \mathrm{a}$ & $7 \mathrm{p}$ & me & 24 Std. & allg. & $\mathrm{mm}$ & $\begin{array}{l}1.0 \\
\mathrm{~mm}\end{array}$ & $\begin{array}{l}25.0 \\
\mathrm{~mm}\end{array}$ \\
\hline Januar & 40 & $3^{2}$ & 72 & Io & 25 & I 8 & I 6 & o \\
\hline Februar. & 37 & 55 & 92 & 38 & I 9 & I 2 & 9 & I \\
\hline März & 92 & 88 & 180 & 39 & $2 \mathrm{I}$ & I 5 & 12 & 3 \\
\hline April & (I 44 ) & (3OI) & 445 & 92 & $>25$ & & $\pi$ & \\
\hline Mai & $(247)$ & (90) & 337 & 108 & 28 & 26 & 22 & 3 \\
\hline Juni & I 13 & 50 & 163 & 30 & 26 & 25 & I6 & 2 \\
\hline Juli & (I5I) & (I I 8 ) & 269 & 70 & $>20$ & $>19$ & 14 & 3 \\
\hline August & $15^{8}$ & 56 & $2 \mathrm{I} 4$ & 43 & 24 & 22 & I8 & I \\
\hline September & - & - & - & 一 & - & - & 一 & - \\
\hline Oktober & 一 & - & 一 & - & - & - & - & - \\
\hline November & - & 一 & - & - & 一 & - & - & - \\
\hline Dezember & 一 & - & - & - & - & - & - & - \\
\hline Jahn & - & - & - & - & - & 一 & $一$ & - \\
\hline
\end{tabular}

Im April, Mai, Juli fieten einzelue Messungen aus, so daß die Verteilung der Niederschläge auf die Tages- und Nachtstunden nicht genau ist, besonders im April, wo 6 Beobachtungen hintereinander mit $163.0 \mathrm{~mm}$ Ertrag ausfielen.
Jap. Beobachter: v. Heynitz.

\begin{tabular}{|c|c|c|c|c|c|c|c|c|}
\hline \multicolumn{4}{|c|}{ Regenmenge in $\mathrm{mm}$} & \multicolumn{5}{|c|}{$\begin{array}{c}\text { Anzahlder Tage } \\
\text { mit Regen }\end{array}$} \\
\hline \multirow[b]{2}{*}{$6 a$} & \multirow[b]{2}{*}{$6 \mathrm{p}$} & \multirow[b]{2}{*}{ Summe } & \multirow{2}{*}{$\underset{24 \text { Std. }}{\operatorname{llax}}$} & \multirow[b]{2}{*}{$\begin{array}{l}\text { im } \\
\text { allg. }\end{array}$} & \multicolumn{2}{|c|}{ mit mehr als } & \multicolumn{2}{|c|}{ nur } \\
\hline & & & & & $\begin{array}{r}0.2 \\
\mathrm{~nm}\end{array}$ & $\begin{array}{l}\mathrm{I.O} \\
\mathrm{mm}\end{array}$ & $\mathrm{K} /$ & 5 \\
\hline 75 & $2 \mathrm{I}$ & 96 & 24 & I 8 & I 8 & I6 & $\mathrm{o}$ & o \\
\hline
\end{tabular}

Beobachtungen fehlen.

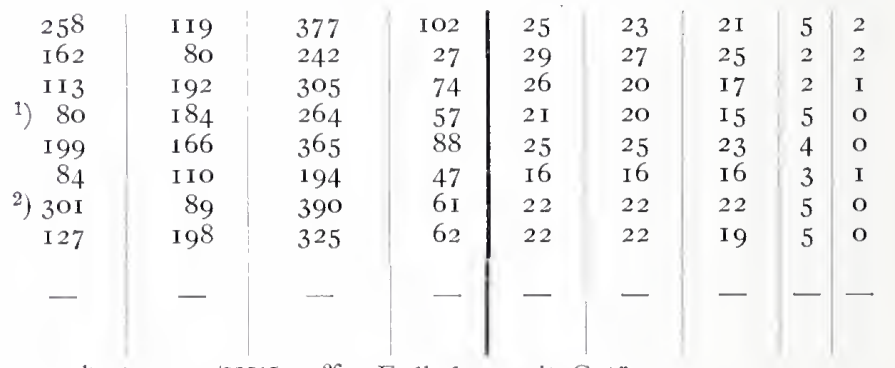

1) Am 23./VI1I. $2{ }^{26} \mathrm{p}$ Erdbeben mit Getöse.

2) Am 4./XI. $7^{10}$ a starker ErdstoB von W-O.

Kusaie, Lelahafen. Beobachter: J. V. Melander.

\begin{tabular}{|c|c|c|c|c|c|c|c|}
\hline \multirow[b]{3}{*}{$6 a$} & \multicolumn{6}{|c|}{ Anzahl der Regentage } & \multirow[b]{2}{*}{ als } \\
\hline & & & Max. & & & mehr & \\
\hline & $6 \mathrm{p}$ & Summe & $\begin{array}{c}\text { int } \\
24 \text { Std. }\end{array}$ & $\begin{array}{l}\text { 1m } \\
\text { allg. }\end{array}$ & $\begin{array}{l}0.2 \\
\mathrm{~mm}\end{array}$ & $\begin{array}{l}\text { I.o } \\
\text { mm }\end{array}$ & $\begin{array}{l}25.0 \\
\mathrm{~mm} \\
\end{array}$ \\
\hline$(\mathrm{IO} 7)$ & $(85)$ & $\left.(192)^{1}\right)$ & (69) & (8) & (8) & (8) & (3) \\
\hline 100 & 76 & 176 & 48 & I3 & I3 & I 2 & 3 \\
\hline I 74 & I 40 & $3 \mathrm{I} 4$ & 48 & 19 & I9 & I 8 & 6 \\
\hline 394 & 217 & 6II & 174 & 19 & 19 & I 8 & 6 \\
\hline 267 & 126 & 393 & 86 & 22 & 22 & 22 & 3 \\
\hline 2 I I & 255 & 466 & I 5 I & 21 & $2 \mathbf{I}$ & 19 & 6 \\
\hline 200 & I 44 & 344 & 54 & $2 \mathrm{I}$ & $2 \mathrm{I}$ & $2 I$ & 4 \\
\hline IO4 & $8 I$ & 185 & 37 & 19 & I9 & I8 & 2 \\
\hline 243 & 69 & 312 & $6 \mathrm{I}$ & 23 & 23 & 22 & 2 \\
\hline I 57 & I 16 & 273 & 76 & 19 & I9 & I 6 & 3 \\
\hline 255 & 3 IO & 565 & 97 & 24 & 23 & 23 & 8 \\
\hline 344 & 217 & 561 & 69 & 27 & 27 & 26 & 9 \\
\hline$(2556)$ & $(1836)$ & $(4392)$ & (I5I) & (235) & $(234)$ & $(223)$ & (55) \\
\hline
\end{tabular}
gangenen Regenmesser erst am I8. Januar 1906 Ersatz geliefert werden. 
Erimahafen.

Constantinhafen.

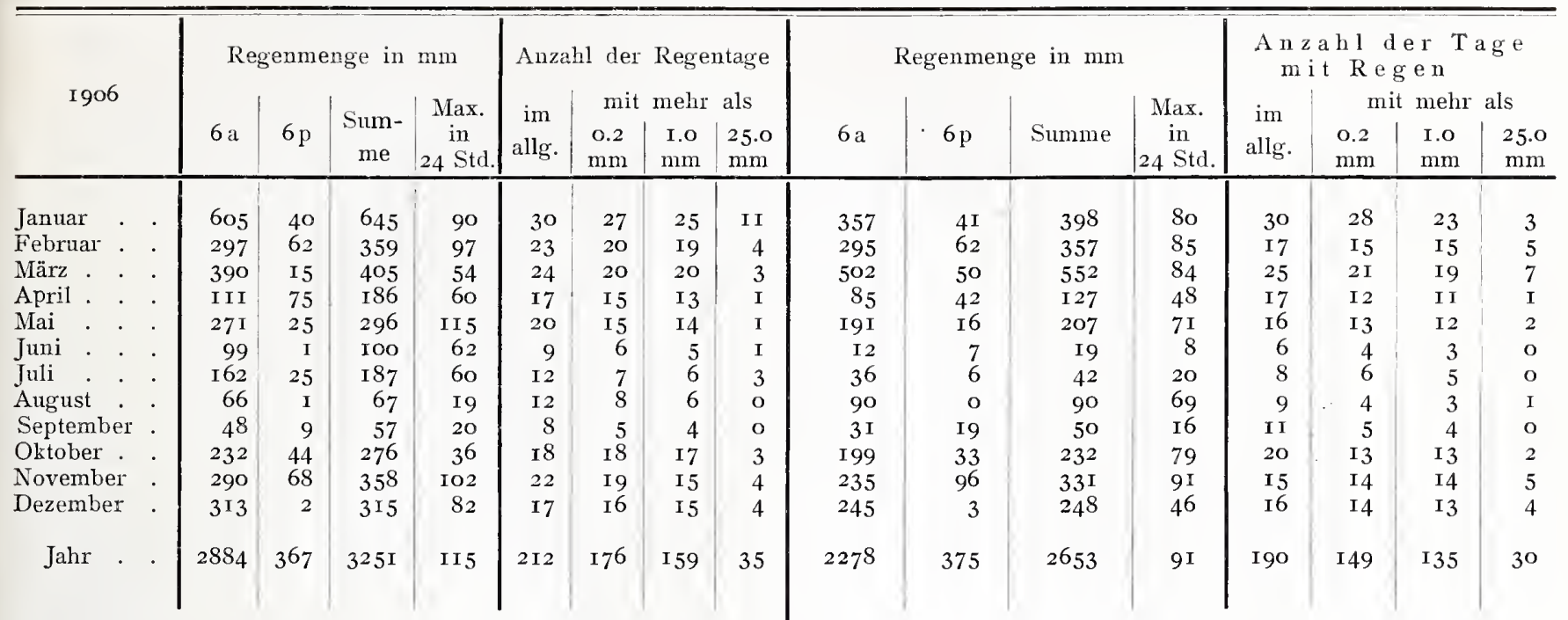

Finschhafen. Beobachter: Oldörp.

\begin{tabular}{|c|c|c|c|c|c|c|c|c|c|}
\hline I906 & & $6 a$ & $6 \mathrm{p}$ & $\begin{array}{c}\text { Sum- } \\
\text { me }\end{array}$ & $\begin{array}{l}\mathrm{mm} \\
\begin{array}{c}\text { Max. } \\
\text { in } \\
24 \text { Std. }\end{array}\end{array}$ & \multicolumn{4}{|c|}{$\begin{array}{l}\text { Anzahl der Regentage } \\
\mathrm{im} \mid \text { mit mehr als }\end{array}$} \\
\hline Januar & . & 97 & 4 & IOI & $3 I$ & 13 & I3 & 9 & I \\
\hline Februar . & & 40 & I & $4 \mathrm{I}$ & I6 & 8 & 7 & 6 & o \\
\hline März . . & . & 40 & 39 & 79 & 22 & Io & IO & 9 & o \\
\hline April . & 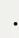 & 404 & 25 & 429 & 224 & $2 \mathrm{I}$ & I 5 & I4 & 3 \\
\hline Mai . & . & 212 & 217 & 429 & 129 & 23 & I 7 & I 5 & 7 \\
\hline Juni . & . & 434 & 305 & 739 & I I 8 & 25 & $2 \mathrm{I}$ & 19 & 9 \\
\hline Juli & 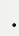 & $43^{2}$ & 320 & $75^{2}$ & $9 I$ & 27 & 23 & 19 & I 2 \\
\hline August & . & 244 & 344 & 588 & 88 & 29 & 27 & 23 & 9 \\
\hline September & . & I 47 & 59 & 206 & 48 & I8 & I 7 & I3 & 4 \\
\hline Oktober. & . & $75 \mathrm{I}$ & 306 & 1057 & 499 & 25 & 23 & 22 & 8 \\
\hline November & & 34 & 59 & 93 & 56 & I5 & 12 & 8 & I \\
\hline Dezember & & 34 & 55 & 89 & 33 & IO & 8 & 7 & I \\
\hline Jahr & & 2869 & I734 & 4603 & 499 & 224 & I93 & I 64 & 55 \\
\hline
\end{tabular}

Sattelberg. Beobachter: Miss. C. Keysser.

\begin{tabular}{|c|c|c|c|c|c|c|c|c|}
\hline \multirow[t]{2}{*}{1906} & \multicolumn{4}{|c|}{ Regenmenge in $\mathrm{mm}$} & \multicolumn{4}{|c|}{ Anzalıl der Regentage } \\
\hline & $6 a$ & $6 \mathrm{p}$ & $\begin{array}{c}\text { Sum- } \\
\text { me }\end{array}$ & in & allg. & $\begin{array}{l}0.2 \\
\mathrm{~mm}\end{array}$ & $\begin{array}{l}\mathrm{I} . \mathrm{O} \\
\mathrm{mm}\end{array}$ & $\begin{array}{l}25.0 \\
\mathrm{~mm}\end{array}$ \\
\hline Januar & I I I 4 & 62.5 & I 73.9 & 70.1 & 22 & I9 & I 5 & I \\
\hline Februar & 69.I & $5 \mathrm{I} .7$ & I 20.8 & 52.1 & I6 & I 2 & I I & I \\
\hline März & 53.9 & 70.4 & I 24.3 & 38.1 & 26 & 22 & I4 & I \\
\hline April & 326.7 & 9.7 & 336.4 & I 59.5 & 22 & I 5 & $x_{5}$ & 2 \\
\hline Mai & I 27.9 & 226.9 & 354.8 & 48.8 & 25 & 23 & 22 & 5 \\
\hline Juni & $44 \mathrm{I} .8$ & 301.6 & 743.4 & $\mathrm{I}_{5} 6.2$ & 26 & 22 & 20 & Io \\
\hline Juli & 374.3 & 259.7 & 634.0 & 98.9 & 25 & $2 \mathrm{I}$ & 20 & IO \\
\hline August & 427.0 & 452.3 & $879 \cdot 3$ & I I 4.5 & 28 & 25 & 25 & I I \\
\hline September & I30.4 & 105.2 & 235.6 & 59.2 & I9 & 16 & I 3 & 4 \\
\hline Oktober & 367.3 & 522.6 & 889.9 & 202.3 & 29 & 26 & 23 & Io \\
\hline November & 28.9 & I 28.7 & I 57.6 & $4 \mathrm{I} .2$ & 20 & 12 & ro & 2 \\
\hline Dezember & I I. 8 & 67.2 & 79.0 & 25.0 & I 5 & 9 & 5 & o \\
\hline Jahr & 2470.5 & 2258.5 & 4729.0 & 202.3 & 273 & 222 & I93 & 57 \\
\hline
\end{tabular}

Mitteilungen a. d. D. Schutzgebieten, XX. Band. IV.
Wareo. Beobachter: Miss. A. Z wanzger.

\begin{tabular}{|c|c|c|c|c|c|c|c|}
\hline \multirow[b]{3}{*}{$6 a$} & \multicolumn{3}{|c|}{ Regenmenge in $\mathrm{mm}$} & \multicolumn{4}{|c|}{ Anzahl der Regentage } \\
\hline & & & & im & & meh & \\
\hline & $6 \mathrm{p}$ & Summe & ${ }_{24}$ in Std. & allg. & $\begin{array}{l}0.2 \\
\mathrm{~mm}\end{array}$ & $\begin{array}{l}\text { I.O } \\
\mathrm{mm}\end{array}$ & $\begin{array}{l}25.0 \\
\mathrm{~mm}\end{array}$ \\
\hline I I 9.8 & 70.0 & I 89.8 & 46.0 & 22 & 22 & I8 & 2 \\
\hline 99.0 & 5.4 & I04.4 & 72.6 & IO & Io & 9 & I \\
\hline 51.9 & I I9.9 & I 7 I.8 & 49.8 & I 5 & I 5 & I4 & 2 \\
\hline 243.7 & 9.2 & 252.9 & 94.5 & I6 & I 5 & I 2 & 2 \\
\hline 91.7 & 208.4 & 300.1 & 38.6 & 20 & I 8 & I 7 & 4 \\
\hline $444 \cdot 3$ & 234.3 & 678.6 & 103.7 & I9 & I8 & 17 & 9 \\
\hline 344.5 & $3 \mathrm{I} 3.4$ & 657.9 & I I 3.0 & I9 & I 8 & I 8 & IO \\
\hline 376.5 & 396.1 & 772.6 & $87 \cdot 7$ & 27 & 25 & 23 & I I \\
\hline I $4 \mathrm{I} .2$ & 48.9 & I90.I & 62.8 & I4 & 14 & I I & 3 \\
\hline 399.9 & 394.6 & 794.5 & $24 I .5$ & 22 & $2 \mathrm{I}$ & $2 \mathrm{I}$ & 9 \\
\hline $2 \mathrm{I} .7$ & $54 . \mathrm{I}$ & 75.8 & 39.2 & I 2 & I I & IO & I \\
\hline 29.8 & 90.4 & I 20.2 & 50.0 & 6 & 6 & 6 & $\mathbf{I}$ \\
\hline 2364.0 & I 944.7 & 4308.7 & 241.5 & 202 & I93 & 176 & 55 \\
\hline
\end{tabular}

Deinzerhöhe. Beobachter: Miss. Bamler, Decker, Raum.

\begin{tabular}{|c|c|c|c|c|c|c|c|}
\hline \multirow[b]{3}{*}{$6 a$} & \multicolumn{3}{|c|}{ Regenmenge in min } & \multicolumn{4}{|c|}{ Anzahl der Regentage } \\
\hline & & & Max. & $\operatorname{im}$ & & mehr & ls \\
\hline & $6 \mathrm{p}$ & Summe & ${ }_{24}^{\text {in }}$ Std. & allg. & $\begin{array}{l}0.2 \\
\mathrm{~mm}\end{array}$ & $\begin{array}{l}\mathrm{I} . \mathrm{O} \\
\mathrm{mm}\end{array}$ & $\begin{array}{l}25.0 \\
\mathrm{~mm}\end{array}$ \\
\hline $415 \cdot 3$ & 2.0 & $417 \cdot 3$ & IOO.O & I 5 & I4 & I3 & 7 \\
\hline 290.0 & 9.5 & 299.5 & 78.2 & I3 & I 2 & 9 & 6 \\
\hline 420.4 & I6.4 & 436.8 & $\mathrm{I} 6 \mathrm{I} .4$ & I6 & I3 & I 2 & 5 \\
\hline I97.I & 17.0 & $2 \mathrm{I} 4 . \mathrm{I}$ & 92.0 & I6 & I6 & I6 & I \\
\hline 385.6 & 272.9 & $65^{8.5}$ & $\mathrm{I} 45.0$ & 22 & 22 & 22 & 6 \\
\hline 628.9 & I98.7 & 827.6 & I 44.0 & 22 & $2 I$ & $2 \mathrm{I}$ & I I \\
\hline 626.9 & 327.1 & 954.0 & I 44.2 & 24 & 23 & $2 \mathrm{I}$ & I I \\
\hline 389.9 & 333.9 & 723.8 & 93.6 & 25 & 24 & 24 & I I \\
\hline I83.9 & 70.1 & 254.0 & 72.9 & I6 & I6 & I $5_{5}$ & 3 \\
\hline I IO 4.0 & I $78 . \mathrm{I}$ & I 282. I & 545.5 & 20 & I 7 & I6 & 9 \\
\hline 1) (I IO.3) & $(\mathrm{I}$ 6.0) & $(226.3)$ & $(\mathrm{I} 4 \mathrm{I}, 0)$ & - & - & - & - \\
\hline I 42.7 & 0.0 & I 42.7 & 85.8 & Io & 6 & 6 & o \\
\hline$(4895.0)$ & (I54I.7) & $(6436.7)$ & 545.5 & ( I99) & (I84) & $(\mathrm{I} 75)$ & (7o) \\
\hline
\end{tabular}

1) Nur vom I. bis í $7 /$ XI. beobachtet. 
Lassulbai. Beobachter: Wr. Bolten.

Massawa.

\begin{tabular}{|c|c|c|c|c|c|c|c|c|c|c|c|c|c|c|c|c|c|}
\hline \multirow{2}{*}{\multicolumn{2}{|c|}{ I906 }} & \multirow[t]{2}{*}{ Summe } & \multirow[t]{2}{*}{$\begin{array}{l}\text { Max. in } \\
24 \text { Std. }\end{array}$} & \multicolumn{4}{|c|}{ Anzahl der Regentage } & \multicolumn{4}{|c|}{ Regenmenge in $\mathrm{mm}$} & \multicolumn{6}{|c|}{ Anzahl der Regentage } \\
\hline & & & & allg. & $\begin{array}{l}0.2 \\
\mathrm{~mm}\end{array}$ & $\begin{array}{l}\mathrm{I} . \mathrm{O} \\
\mathrm{mm}\end{array}$ & $\begin{array}{l}25.0 \\
\mathrm{~mm}\end{array}$ & $6 a$ & $6 \mathrm{p}$ & Summe & in & allg. & $\begin{array}{l}0.2 \\
\mathrm{~mm}\end{array}$ & $\begin{array}{l}\text { I.O } \\
\mathrm{mm}\end{array}$ & $\left|\begin{array}{l}25.0 \\
\mathrm{~mm}\end{array}\right|$ & $K$ & 5 \\
\hline Januar . & & 527.3 & $8_{7.5}$ & 20 & 20 & I 8 & IO & 323 & $29 I$ & 614 & 70 & $2 \mathrm{I}$ & 19 & 19 & I I & 2 & 7 \\
\hline Februar. & . & I 24.4 & $45 \cdot I$ & I 4 & IO & 7 & 2 & 85 & 34 & I I9 & 48 & 10 & 9 & 9 & I & 3 & IO \\
\hline März . . & . & 494.4 & 138.2 & $2 \mathrm{I}$ & I 8 & I 7 & 4 & 446 & 314 & 760 & I 83 & I9 & I 8 & 16 & 7 & 4 & 6 \\
\hline April . & . & 195.8 & 41.0 & I 3 & 12 & I 2 & 3 & I 12 & 68 & I 80 & $3 \mathbf{I}$ & 14 & 13 & I 2 & 2 & 2 & I 2 \\
\hline Mai . & . & $249 \cdot 3$ & 50.4 & I 7 & I 4 & 13 & 5 & 100 & 247 & 347 & I 33 & 17 & I6 & I 4 & 4 & I & I 2 \\
\hline Juni . & • & I I 2.6 & 59.7 & IO & 8 & 7 & I & 48 & 9 & 57 & 29 & 9 & 7 & 6 & I & I & 7 \\
\hline Juli . & . & 106.5 & $35 \cdot 3$ & I 2 & 9 & 6 & 3 & $5^{6}$ & 100 & I 56 & 34 & 19 & I9 & I 8 & I & 2 & IO \\
\hline August & . & 43.1 & 29.4 & 7 & 5 & 4 & I & 77 & 93 & 170 & 40 & I 8 & $x 6$ & 14 & 2 & 3 & 3 \\
\hline Septembe & & 43.8 & 28.0 & 7 & 4 & 4 & I & 0 & $5^{\circ}$ & 50 & 23 & 9 & 7 & 7 & o & I & 8 \\
\hline Oktober & & 103.5 & 22.4 & 13 & IO & IO & o & 6 & 137 & 143 & 37 & I6 & I 4 & I 4 & 2 & I & I 7 \\
\hline Norembes & & 336.6 & 105.3 & $2 I$ & I 8 & I 7 & 4 & 92 & I 86 & 278 & 64 & $2 \mathrm{I}$ & I 8 & 16 & 3 & 2 & 20 \\
\hline Dezembex & & 38.8 & I 8.6 & I 2 & 5 & 5 & o & I I & 20 & $3 \mathbf{I}$ & 9 & 9 & 6 & 5 & $\mathrm{O}$ & I & 4 \\
\hline Jahx & - & 2376.1 & $\mathrm{I} 38.2$ & 167 & I 33 & I 20 & 34 & I 356 & I 549 & 2905 & 183 & I 83 & 162 & I 50 & 34 & 23 & I I 6 \\
\hline
\end{tabular}

Namane bei Nusalıafen (Neu-Mecklenburg).

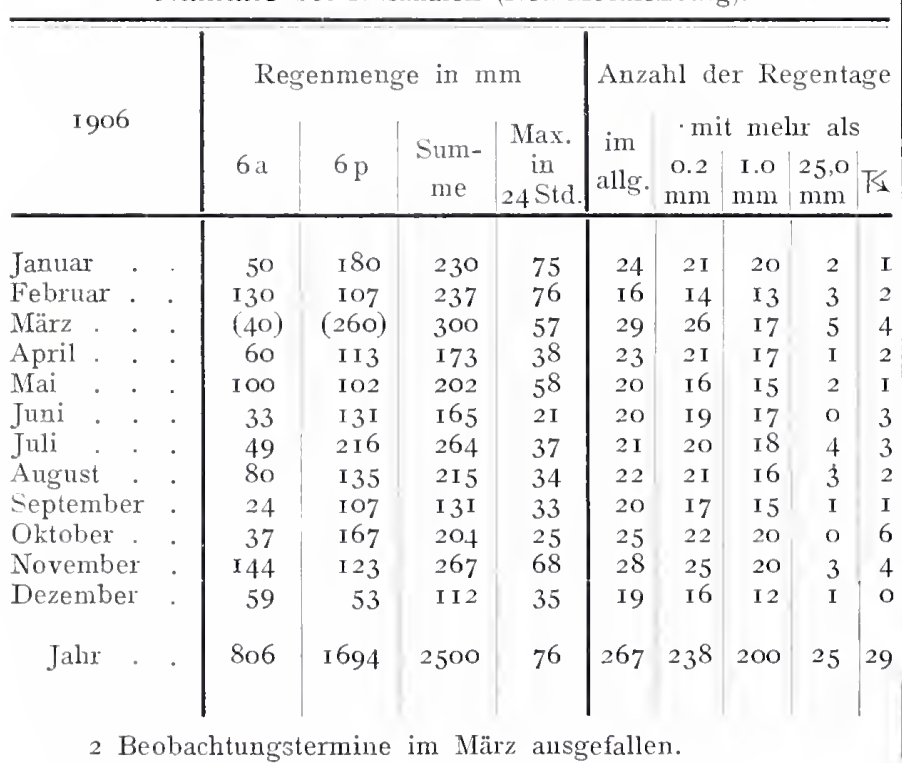

Namatanai (Neu-Mecklenburg). Beobachter: Wostrack.

\begin{tabular}{|c|c|c|c|c|c|c|c|}
\hline \multirow[b]{3}{*}{$6 a$} & \multicolumn{3}{|c|}{ Regenmenge in $\mathrm{mm}$} & \multicolumn{4}{|c|}{ Anzahl der Regentage } \\
\hline & & & & im & & mehx & \\
\hline & $6 \mathrm{p}$ & Summe & $\begin{array}{c}\text { in } \\
24 \\
\text { Std. }\end{array}$ & allg. & $\begin{array}{l}0.2 \\
\mathrm{~mm}\end{array}$ & $\begin{array}{l}\text { I.o } \\
\mathrm{mm}\end{array}$ & $\begin{array}{l}25.0 \\
\mathrm{~mm}\end{array}$ \\
\hline - & - & - & - & - & - & - & - \\
\hline - & - & - & - & - & - & - & - \\
\hline - & - & - & - & - & - & - & - \\
\hline - & - & - & - & - & - & - & - \\
\hline - & - & - & - & - & - & - & -- \\
\hline - & - & - & - & - & - & - & - \\
\hline (43.I) & $(4 \mathbf{I} .5)$ & $\left.(84.6)^{1}\right)$ & $(35.4)$ & (9) & (8) & (5) & (I) \\
\hline 70.4 & 40.8 & II 1.2 & 34.0 & 20 & 16 & II & I \\
\hline 26.0 & 166.2 & 192.2 & 38.3 & $2 \mathrm{I}$ & I 4 & I I & 5 \\
\hline$\times 55.7$ & 95.8 & $25^{x} \cdot 5$ & $55 \cdot 3$ & 22 & I 8 & 16 & 4 \\
\hline 256.6 & I 24.4 & 381.0 & $79 \cdot 5$ & 26 & 22 & 20 & 7 \\
\hline 107.5 & I9.I & I 26.6 & $63 \cdot 7$ & 22 & I6 & IO & I \\
\hline - & - & - & - & - & - & - & - \\
\hline
\end{tabular}

1) Vom i6. Juli an beobachtet. 


\section{Die Regenverhältnisse Samoas im Jahre 1906.*)}

Bericht des Samoa-Observatoriums, erstattet von Dr. F. Linke.

Die im Jahre 1905 durch das Samoa-Observatorium ins Ieben gerufene Organisation meteorologischer Beobachtungen in den deutschen SamoaInseln hat sich auch im zweiten Jahre durchaus bewährt. Veränderungen sind insofern vor sich gegangen, als im Juni die Aanastation von Lesea (Faleasiu) nach Tuvao (Fasitootai) verlegt wurde, wo Herr E. Langen die Beobachtungen übernommen hat und die Lealatelestation der Katholischen Mission infolge des Vordringens der Lava eingegangen ist. Neu hinzugekommen sind an Regenstationen: Alisa (Herr A. Spemann), Falealupo (P. Ginsbach) und Moamoa (Maristenbrüder).

Die Regenverhältnisse des Jahres 1906 waren, obgleich die Jahresmenge nur 82 v. H. der durchschnittlichen ausmacht, nach allgemeinem Urteile recht günstige, weil die Verteilung des Regens auf die Jahreszeiten eine so außergewöhnlich gleichmäßige war, wie sie nur im Jahre I 892 und I 897 beobachtet wurde. Das Verhältnis des Regens in der Regenzeit zur Trockenzeit (die jährliche Ungleichheit) ist in Apia im Mittel 2,8. Im verflossenen Jahre war es jedoch nur I,9. Das Mittel aller Stationen war I,6, im Vorjahre 2,0. Dabei ist die Trockenzeit von Mai bis Oktober einschl. gerechnet, die übrigen sechs Monate bilden die Regenzeit. Unnormal trocken war die Regenzeit I905/06, ganz besonders die Monate Januar und Februar, während der März recht regenreich war. Die ganze Trockenzeit hatte auf der Nordseite der Inseln übernormalen Regenreichtum, hauptsächlich fällt's ins Auge, daß in ihr die Anzahl der Regentage sehr hoch ist.

Die Verteilung der Niederschlagsmenge auf die einzelnen Gegenden zeigt diesmal nicht die großen Unterschiede des Vorjahres. Im Jahr I905 hatten die Stationen an der Küste im Mittel $760 \mathrm{~mm}$ weniger Regen als die dazu gehörigen Inlandstationen. In diesem Jahre sind es nur $500 \mathrm{~mm}$. Die Vertei- lung auf die Jahreszeit ist fast die gleiche an der Küste und im Inlande. Die Südküste hatte im Vorjahre I750 mm Regen mehr als die Nordküste, I 906 sind es nur $660 \mathrm{~mm}$. Interessant ist, daB an einigen Stationen der Südküste in der Trockenzeit mehr Regen als in der Regenzeit gefallen ist.

Eine wesentliche Ergänzung in der Diskussion der Regenverhältnisse bildet die Betrachtung der Anzahl der Regentage. Naturgemäß kommt die Gesamtregenmenge weit besser zur Wirkung, wenn sie sich auf möglichst viele Regentage verteilt. In Apia und Umgegend regnet es durchschnittlich 2 I9 Tage im Jahre, also etwa 4 Tage in der Woche; I906 war es etwas mehr, überhaupt ist die Anzahl der Regentage weit größer als im Vorjahre. Besonders auffällig ist, daß sie in Trocken- und Regenzeit fast die gleiche ist, und wenn schon im Vorjahre der Unterschied von Küste und Inland, Nord- und Südseite bei den Regentagen geringer war als bei den Regenmengen, so ist er in diesem Jahre fast nicht zu erkennen.

Die letzte Spalte der folgenden Zusammenstellung ist nach den I6jährigen Beobachtungen des Herrn Dr. Funk berechnet und gibt die im Mittel vieler Jahre zu erwartende jährliche Regenmenge an für den Fall, daß die Regenmenge in Apia ein Maß für ganz Samoa ist. Natürlich trifft das nicht ganz zu, aber dennoch zeigt sich aus der Übereinstimmung der Zahlen aus den letzten beiden grundverschiedenen Jahren, daß an der Küste von ganz Tuamasaga-Nord bis Mulifanua hin ziemlich gleiche Verhältnisse herrschen. Für den Osten, Süden und Westen hingegen kann man aus den Beobachtungen in Apia keinerlei Schlüsse ziehen. Ferner lassen die Zahlen dieser letzten Kolumne erkennen, daß sich in der Gegend von Matautu (Sawaii) die Regenverhältnisse während cier Dauer der Vulkantätigkeit, was Menge und Verbreitung anbetrifft, erheblich verbessert haben.

*) Dieser Bericht ist unter Zustimmung des Herrn Verfassers mit einigen Abkürzungen der Samoanischen Zeitung entnommen. Die Red. 
Die Regenverhältnisse Samoas im Jahre 1906.

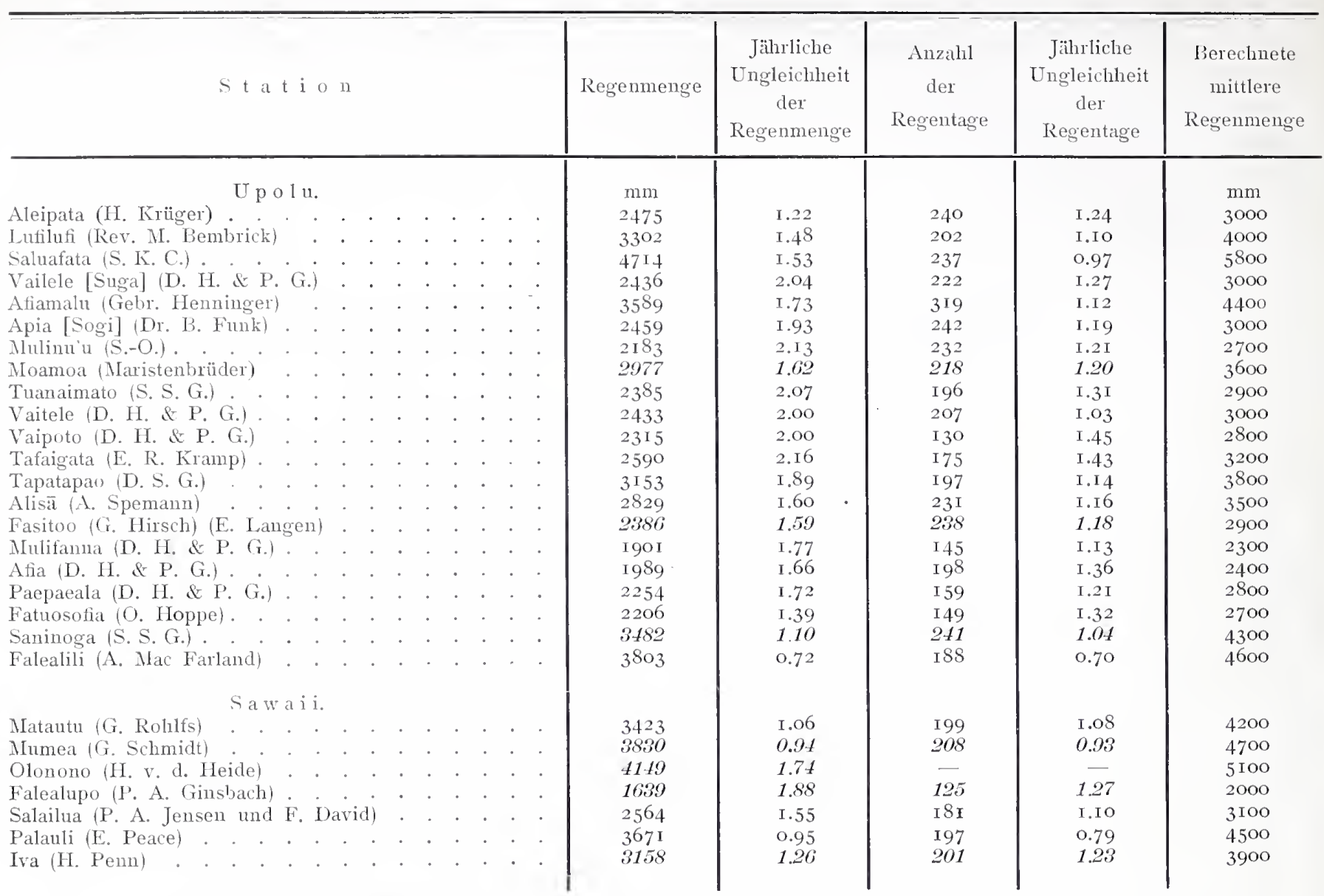

B emerkung: Bei den kursiv gedruckten Zahlen sind einige Lücken auszufüllen gewesen.

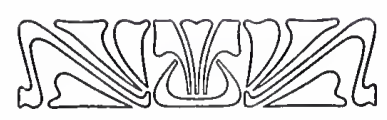


GETTY CENTER LIBRARY

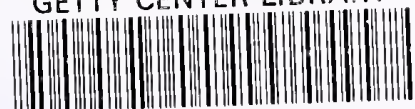

33125006842245 

Schematisches Profil des Reliefs und der Regenhöhen von Walfischbay-Strakropmund über Gr-Windhuk zur Ostorrenze Deutsch-Südwestafrika's.

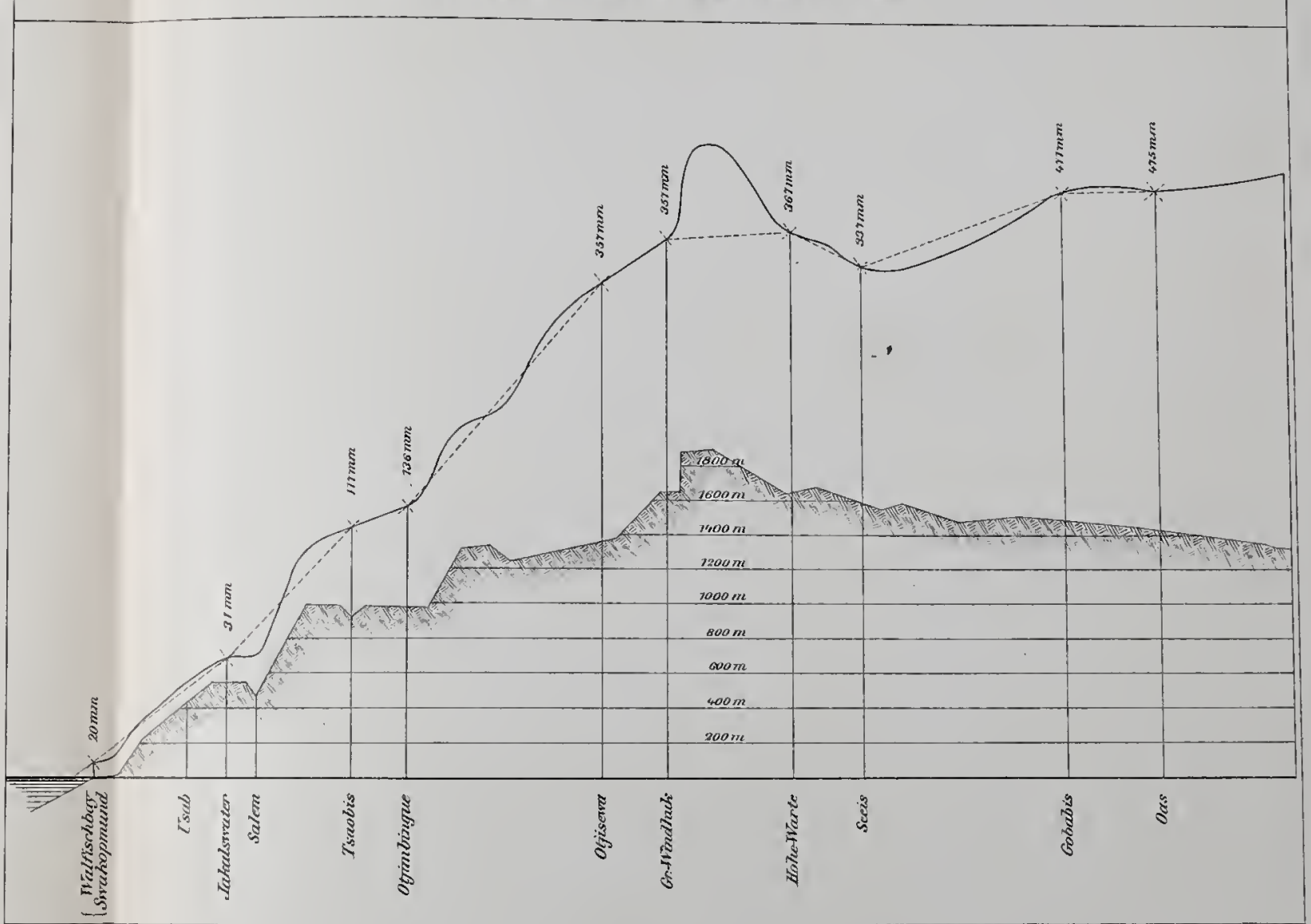

Ber den Angaben der Regenhöhen bedeutet $/ \mathrm{m} / \mathrm{m}$. Höht" $10 \mathrm{~m} / \mathrm{nn}$ Niederschlag. 
Jăhrliche Niederschlagshöhen in Prozenten des Normalmittels. Norm. Mittol $100 \%=\mathrm{N}$.

Diagramm

Diagramm I.

Diagranm 2.

Diagrasmm 3.

Diagramen t.

Diagramm 5.

Diagramm 6 .

Diagramm 7.

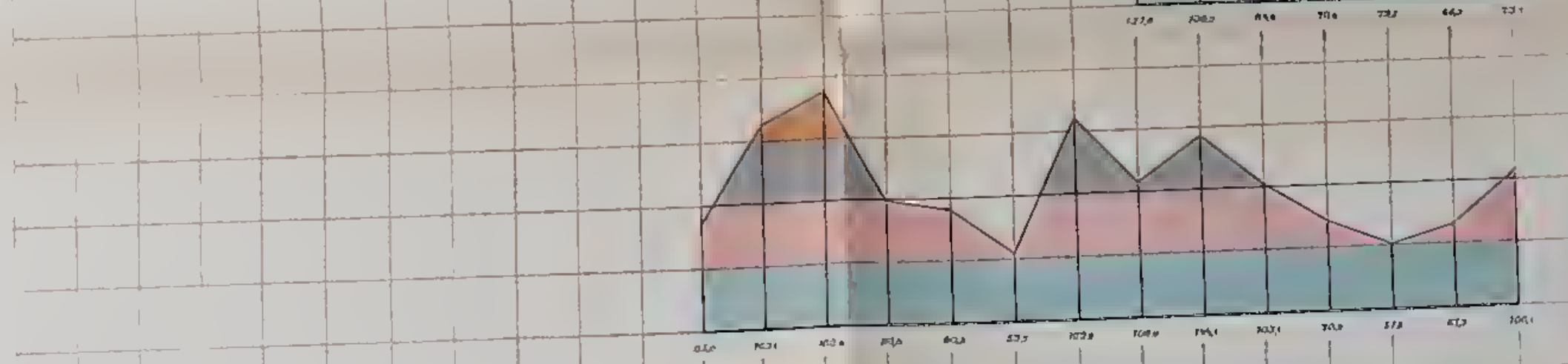

Gr. Wirdlizuk [35] $\mathrm{N}=357.8 \mathrm{sutn}$

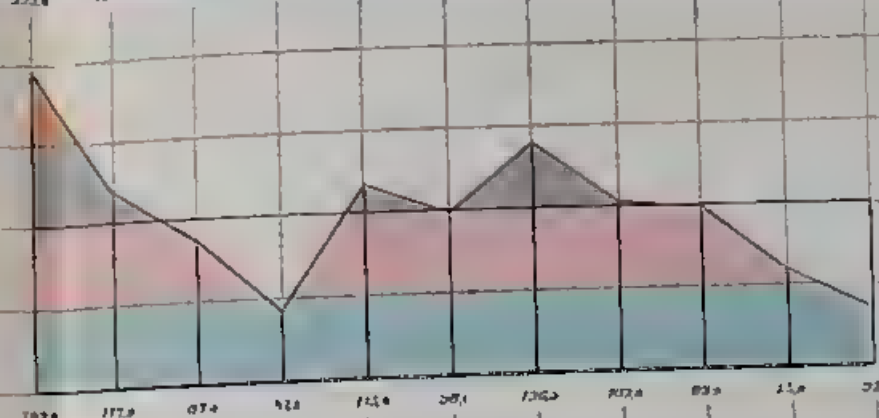

$\mathrm{N}=470.6$ stm

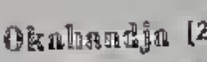
$\mathrm{N}=377.4 \mathrm{~mm}$

Omonemand [19] $\mathrm{N}=275.7 \mathrm{nam}$
Diagramm 8

Diagramm 10

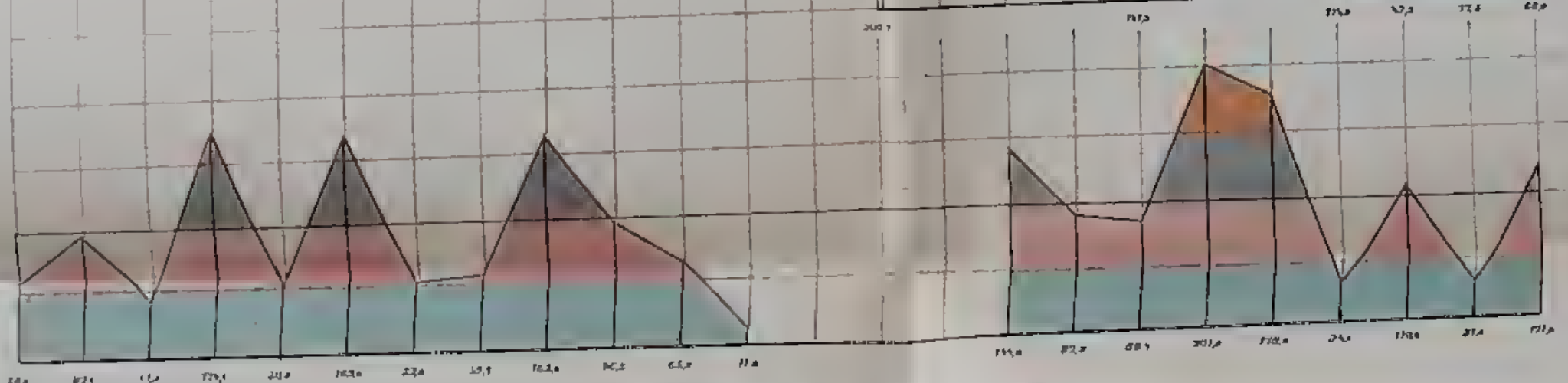

Anmerifung zu Dlagramm 1-10

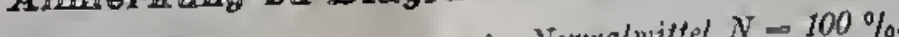

Vertikalima $\beta_{3 l a b}: 1 \mathrm{~cm}=60 \%$ des Normalwiftels; Normalmittel $N=100 \%$.

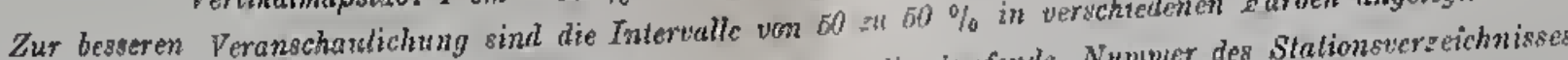

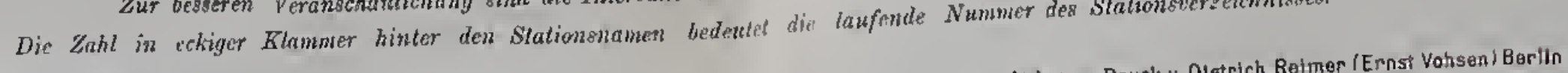


Diagramm 11-39.

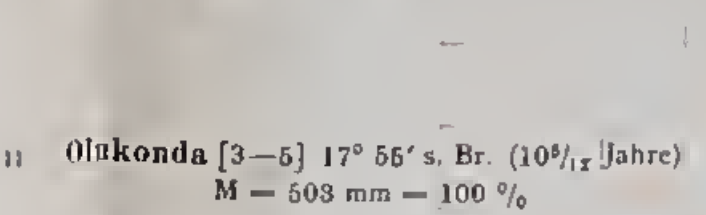

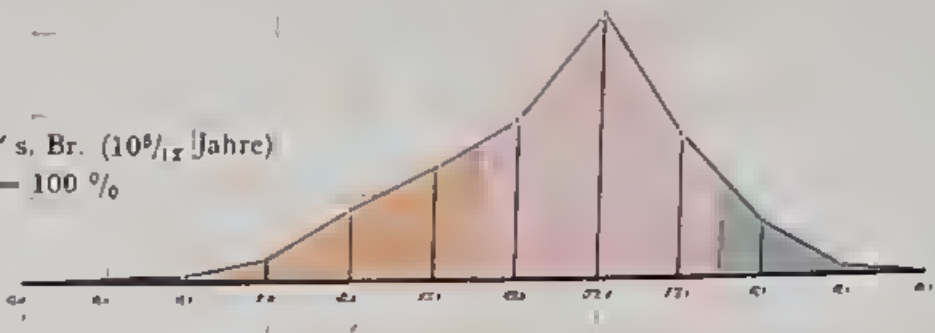

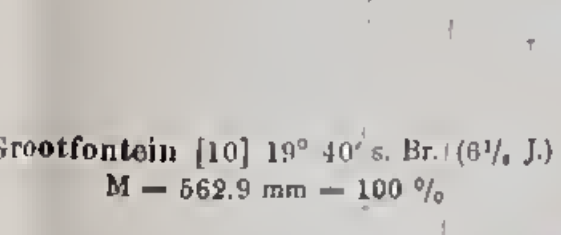
$+1 /$

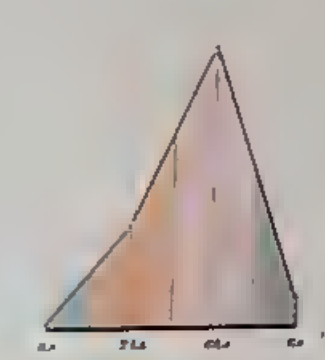
$\triangle$

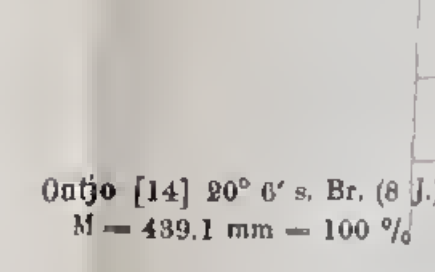
$\Lambda \triangle$

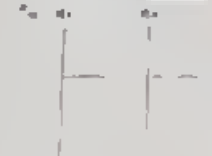
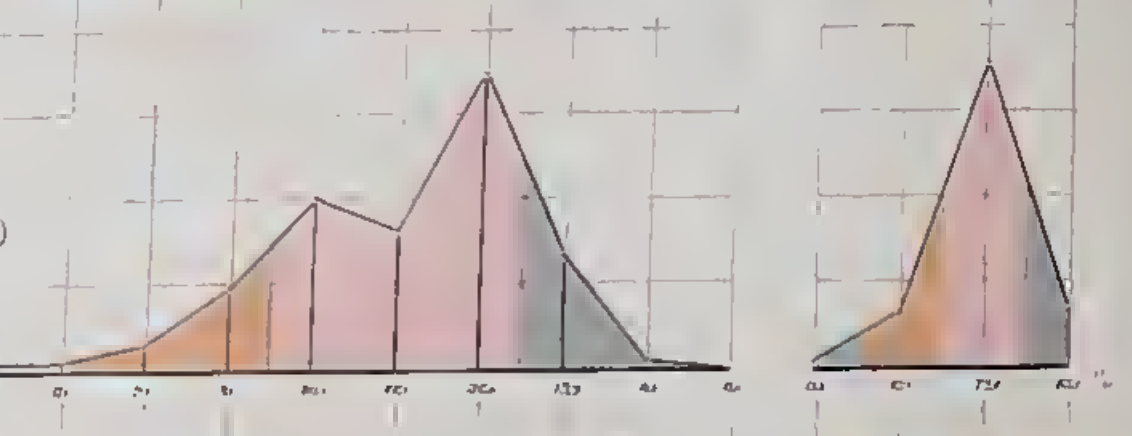

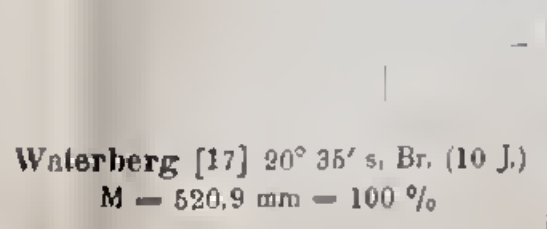

,
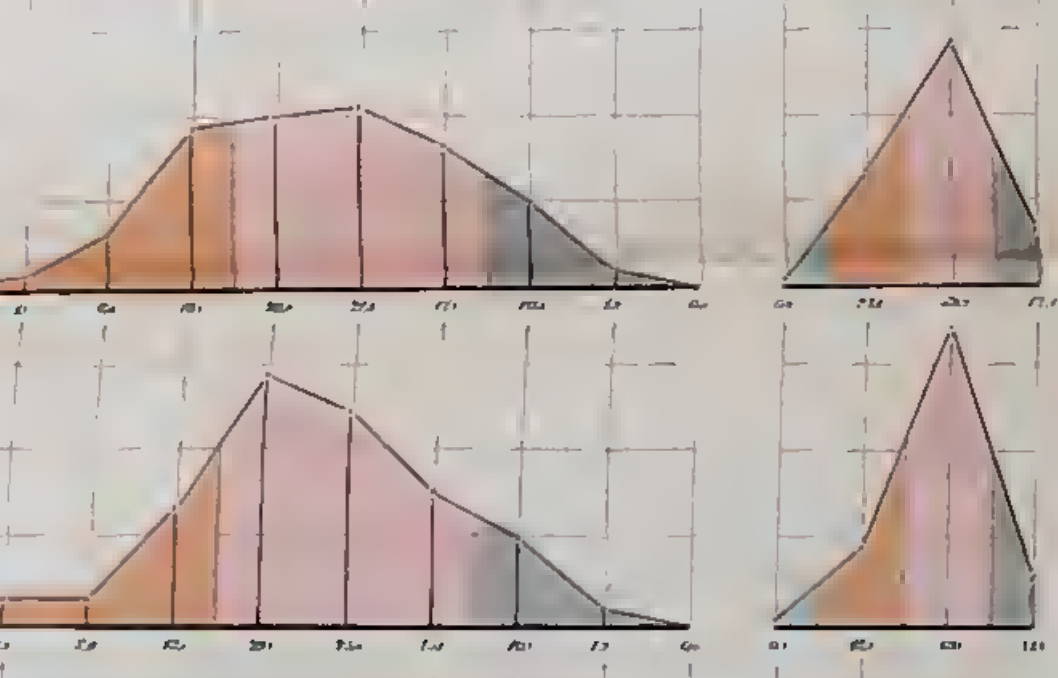

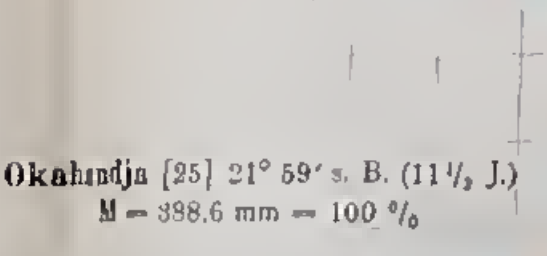
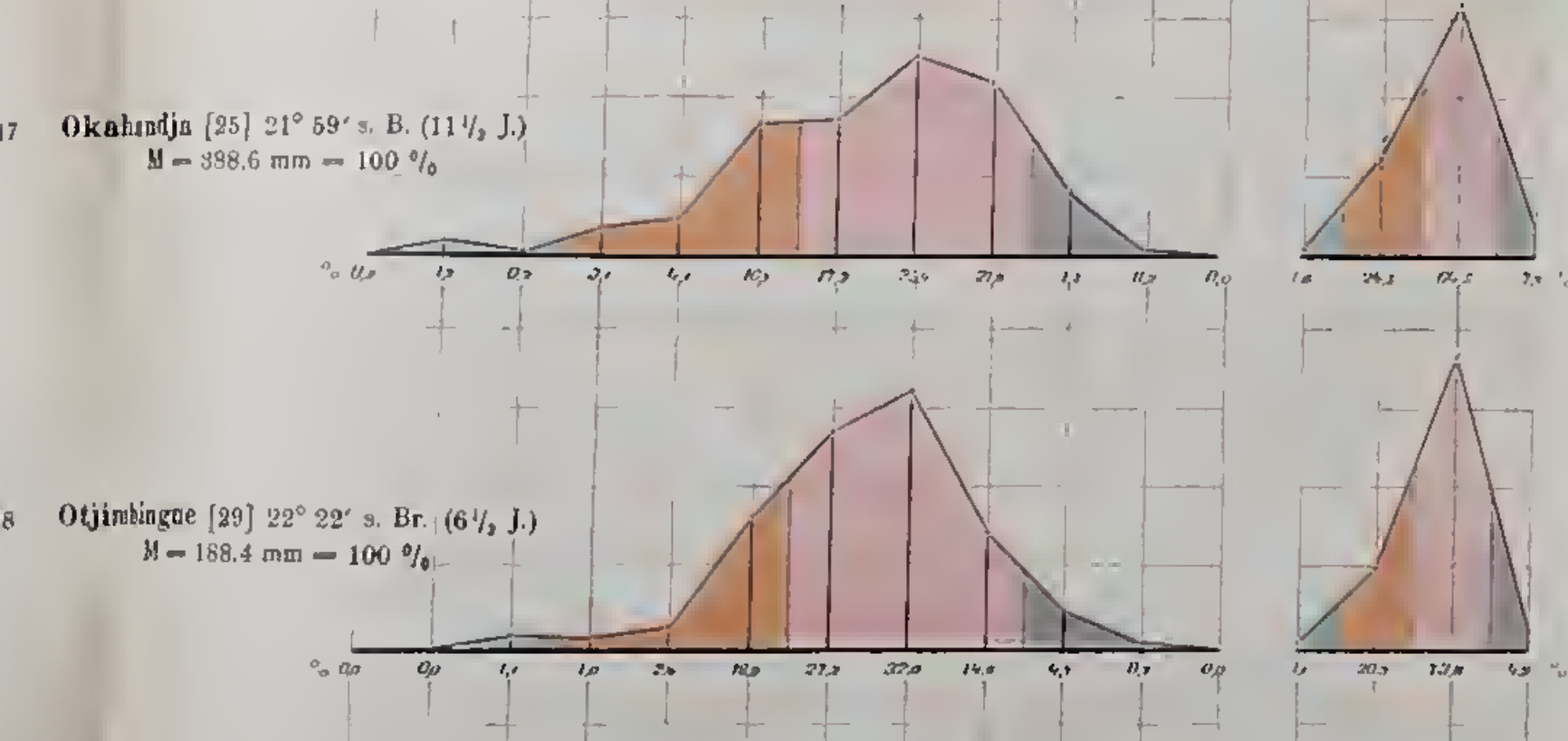

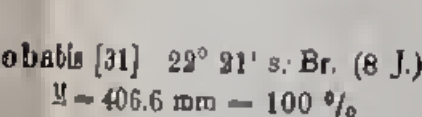
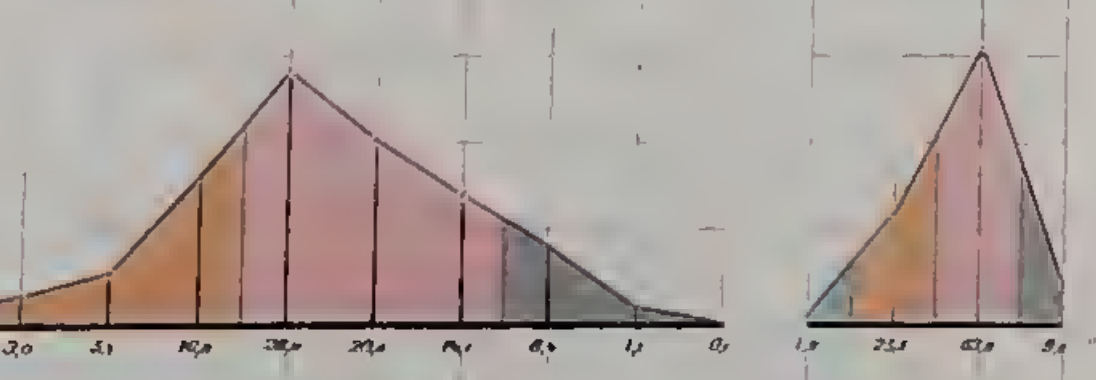

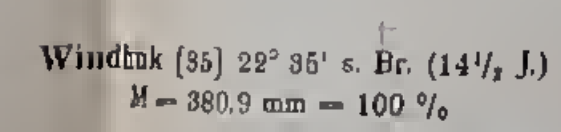

$$
\text { . }
$$

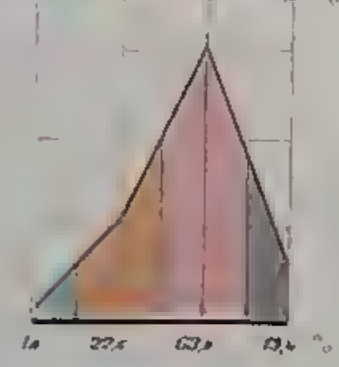

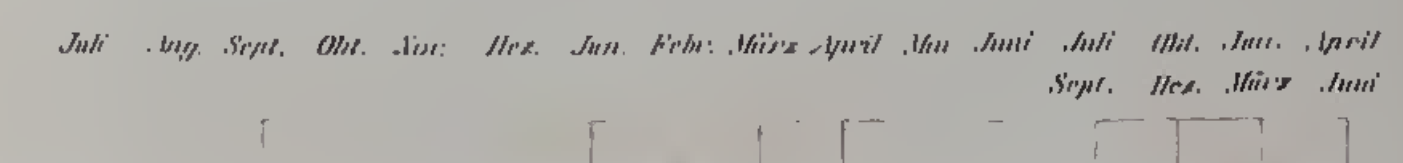

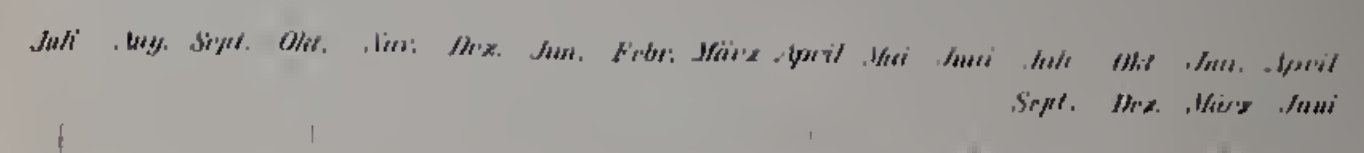
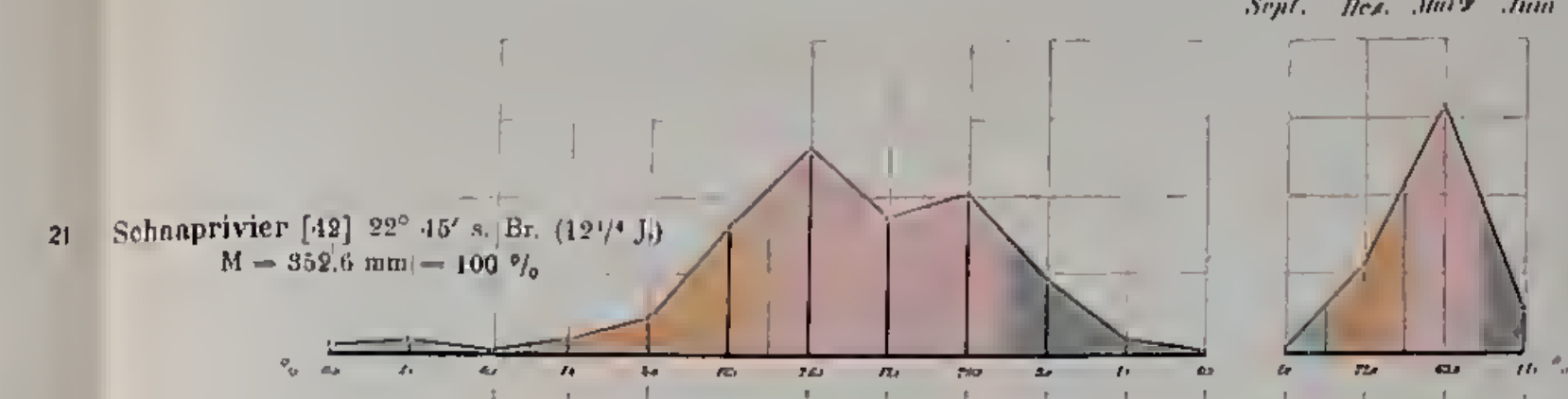

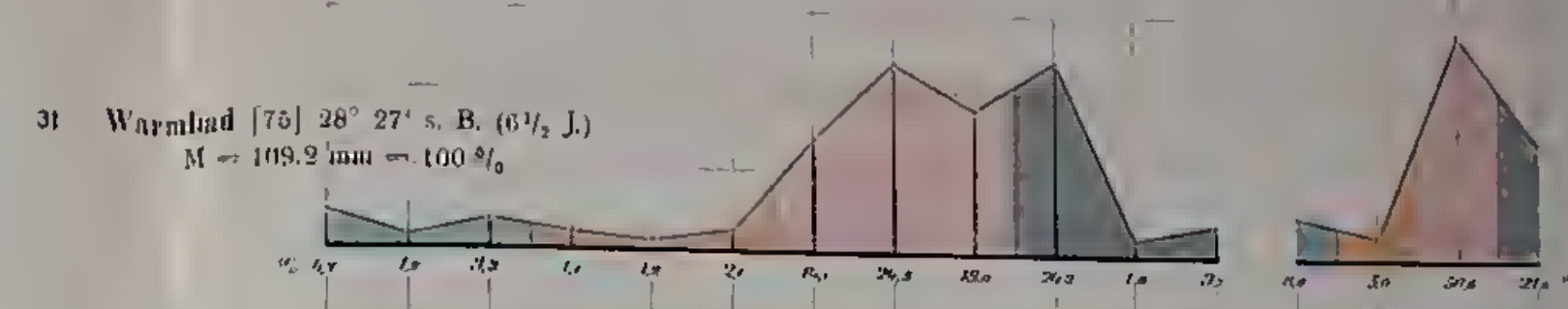

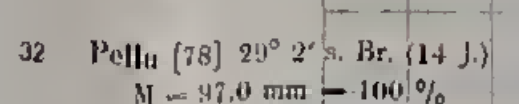
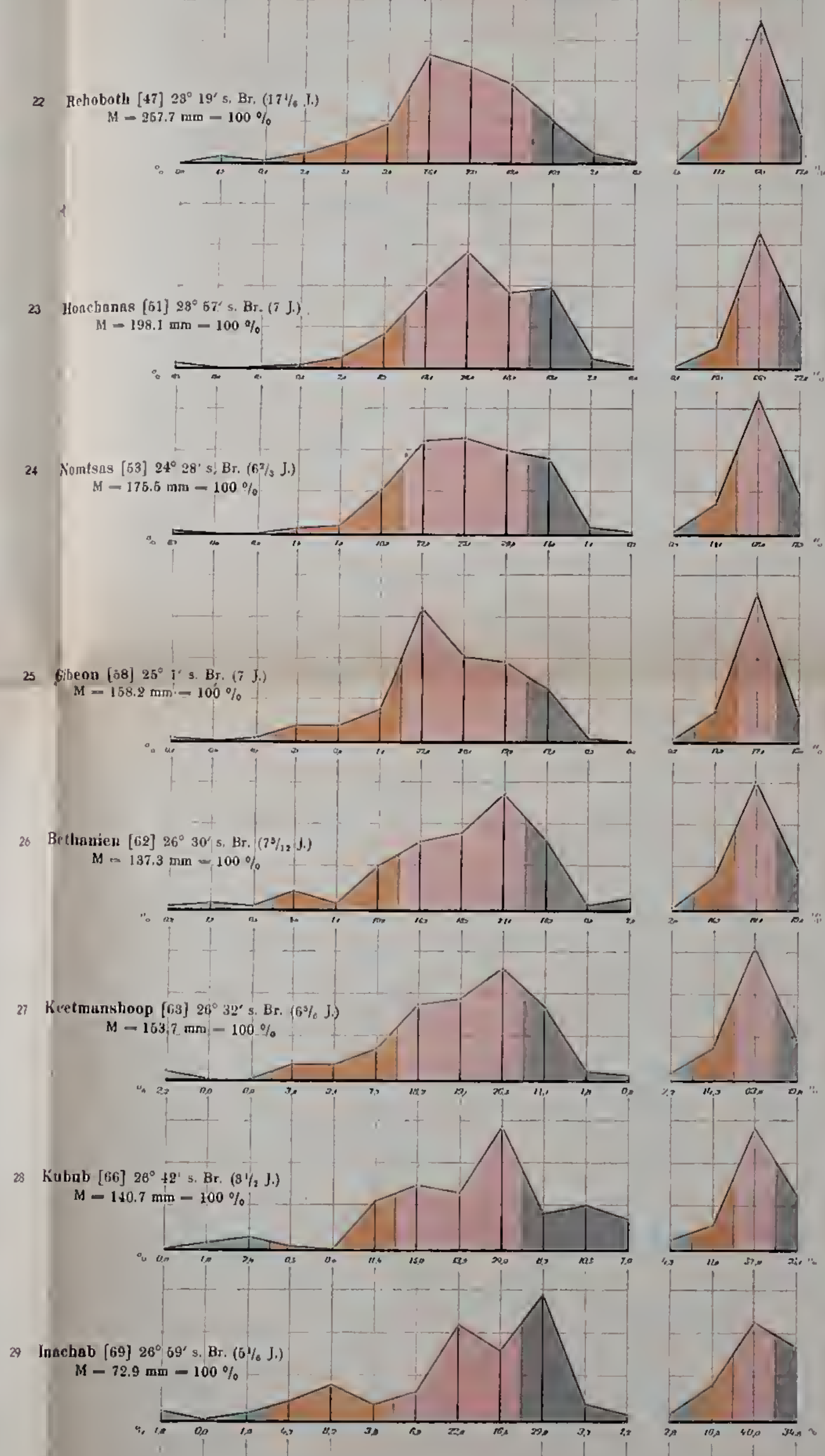

3. Zeeffontein $[6] 18^{\circ} 35^{\circ}$ s. Br. $\left(33^{2} / . J\right)$

$\sum_{30}^{2}$
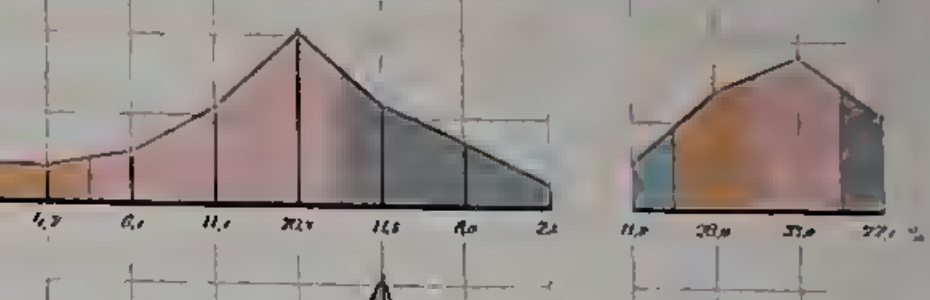

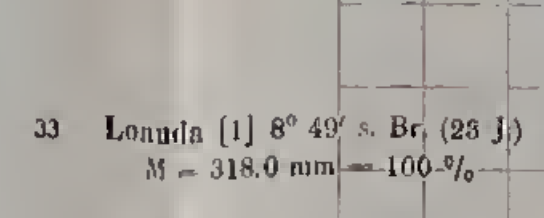

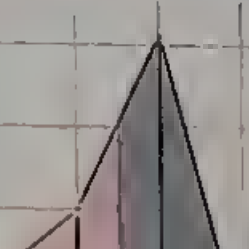

(1)

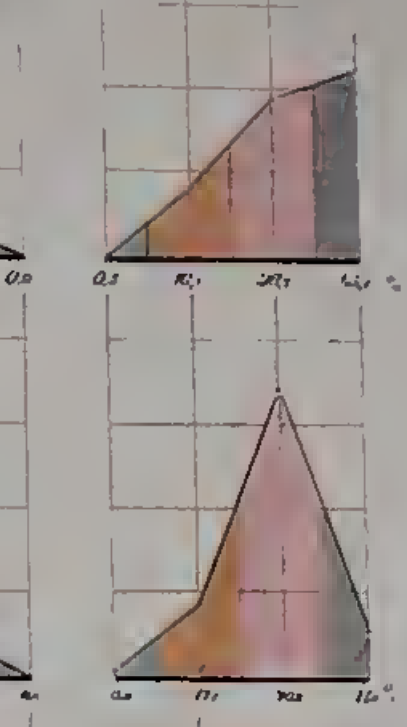

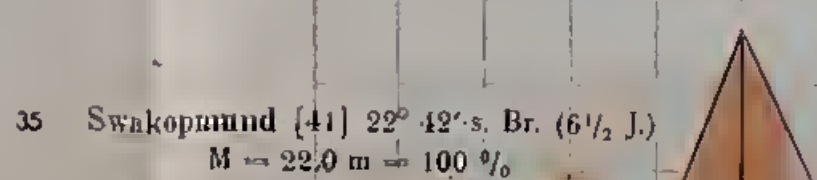

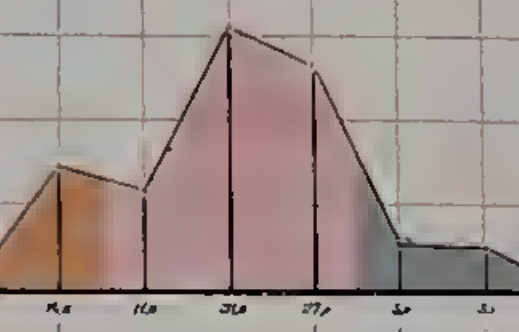

$=\frac{1}{21}$

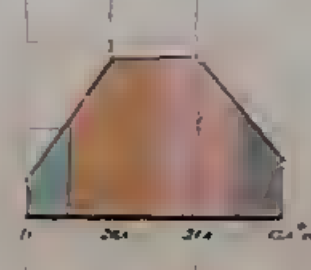

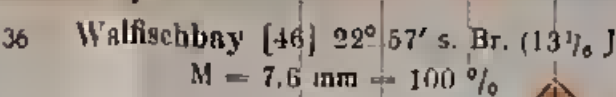
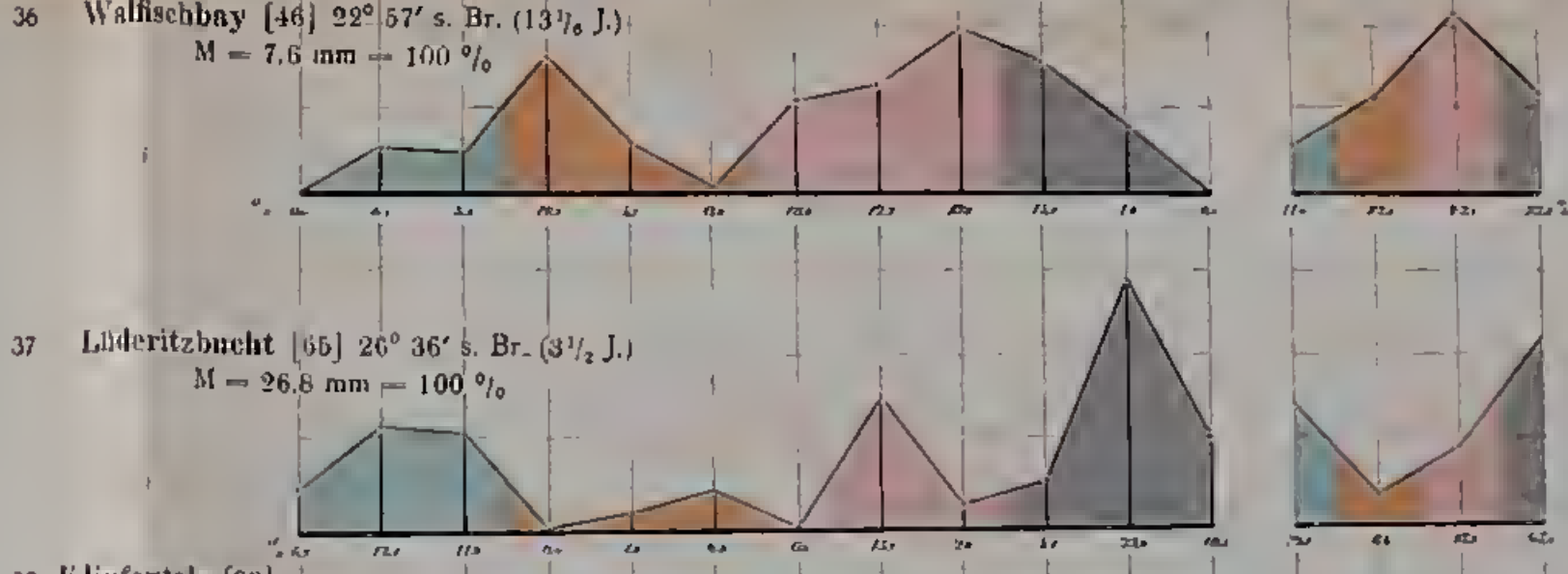

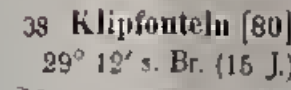
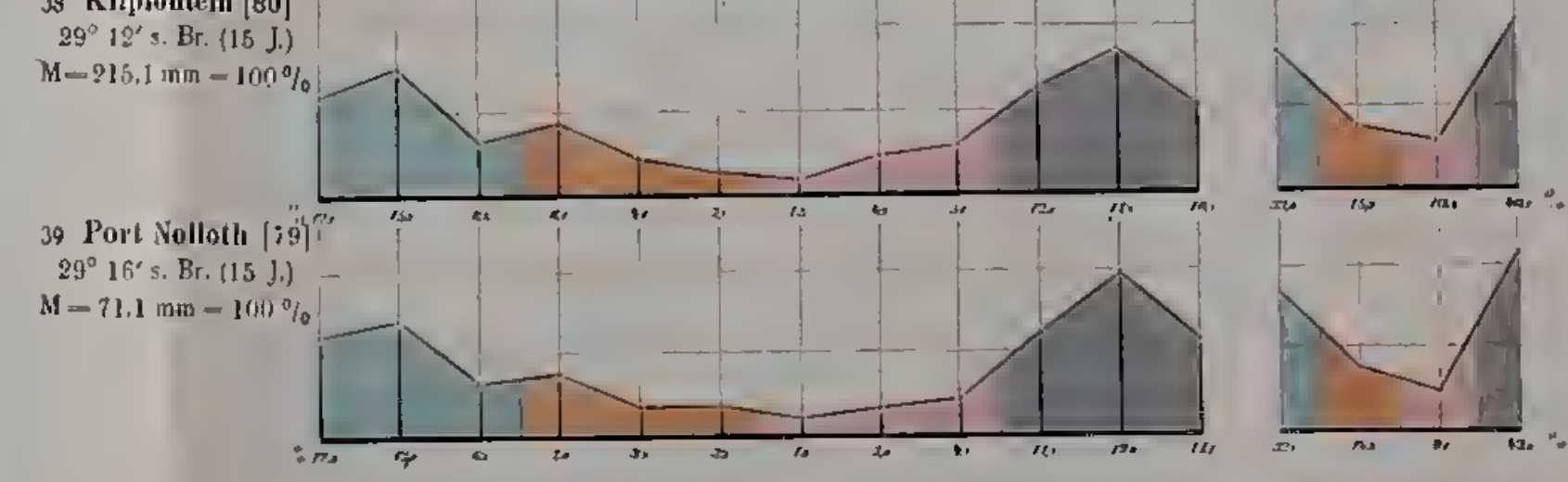

Anmerkung:

('raphische Darstelling in Prosenten der rohen Jahreasmittel eineelner Stationen.

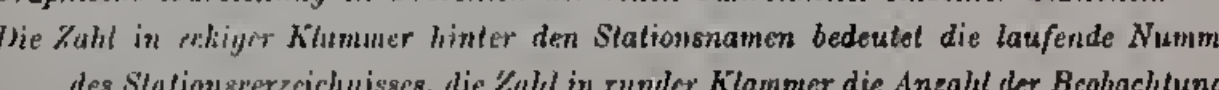
Jithe

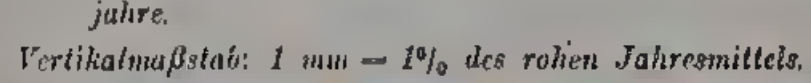

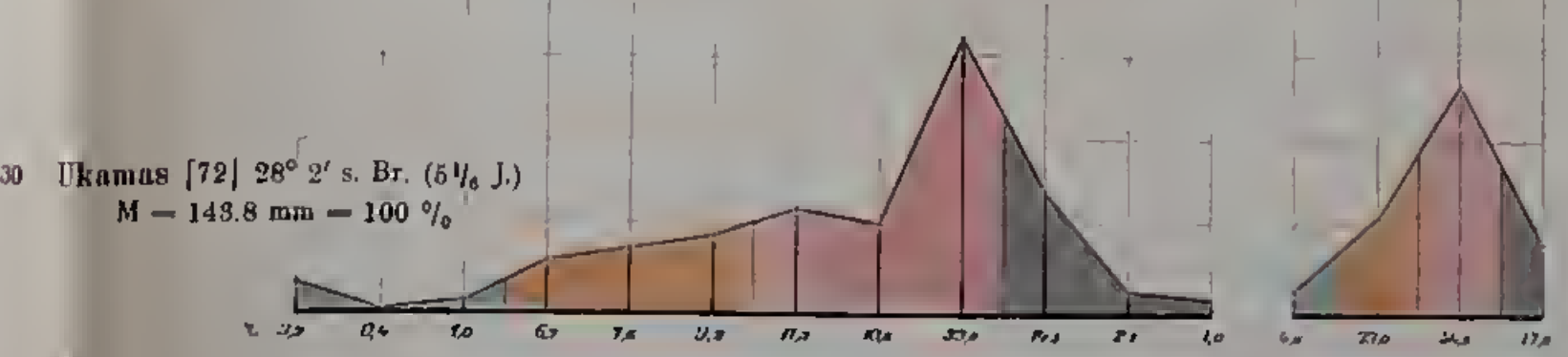


Die jahrichen Mengen des Niederschlages in S.-W.-Afrika in Prozentralwerten der jedesmaligen Normalmittel nach geographischen Breitenzonen

(Normalmittel $\mathrm{N}=100 \%$ )

Diagramm $40-46$.

VertikalmaBstab: 1 man $=6 \%$.

1. Zone: $17 \frac{1}{2}-20^{\circ}$ s. Br. Ausboland

41

1i. Zone: $20^{\circ}-22^{3} \mathrm{~s}$. Br. Nöril. Damaraland (12 Stationen)

1II. Zone: $22^{\circ}-24^{\circ} \mathrm{s}, \mathrm{Br}$. +2 Sưll, Damara- und nürdl. Gr. Namaland (21 Stationen)

IV. Zone: $24^{\circ}-26^{\circ}$ s. $\mathrm{Br}$. Mittleres $\mathrm{Gr}$, Naraaland (8 Stationen)

V., Zone: $26^{\circ}-28^{\circ} \mathrm{s}, \mathrm{B}$,
Sǘdl, Gr. Namaland (7) Stationen)

VI. Zone: $28^{\circ}-30^{\circ} \mathrm{s}, \mathrm{Br}$, 15. Das Gelict des Orangefiusses nach Osten bis ca, $211_{2}^{\circ}$ ostl. L. v, Gr. (8 Stationen)

VII. Zone: $27^{\circ}-90^{1} / 2^{\circ}$ s. Br. 13b Das Gebiet des Ornngefimsses von $c a_{,} 21^{\circ}-241 / 2^{\circ}$ astl. L, v, Gr. (7 Stationen)

VIII, Zоле: $29^{\circ}-31 \% \%^{\circ} \mathrm{s}, \mathrm{Br}$ 46 Dis Kustergebiet des and westl. Kaplandes.
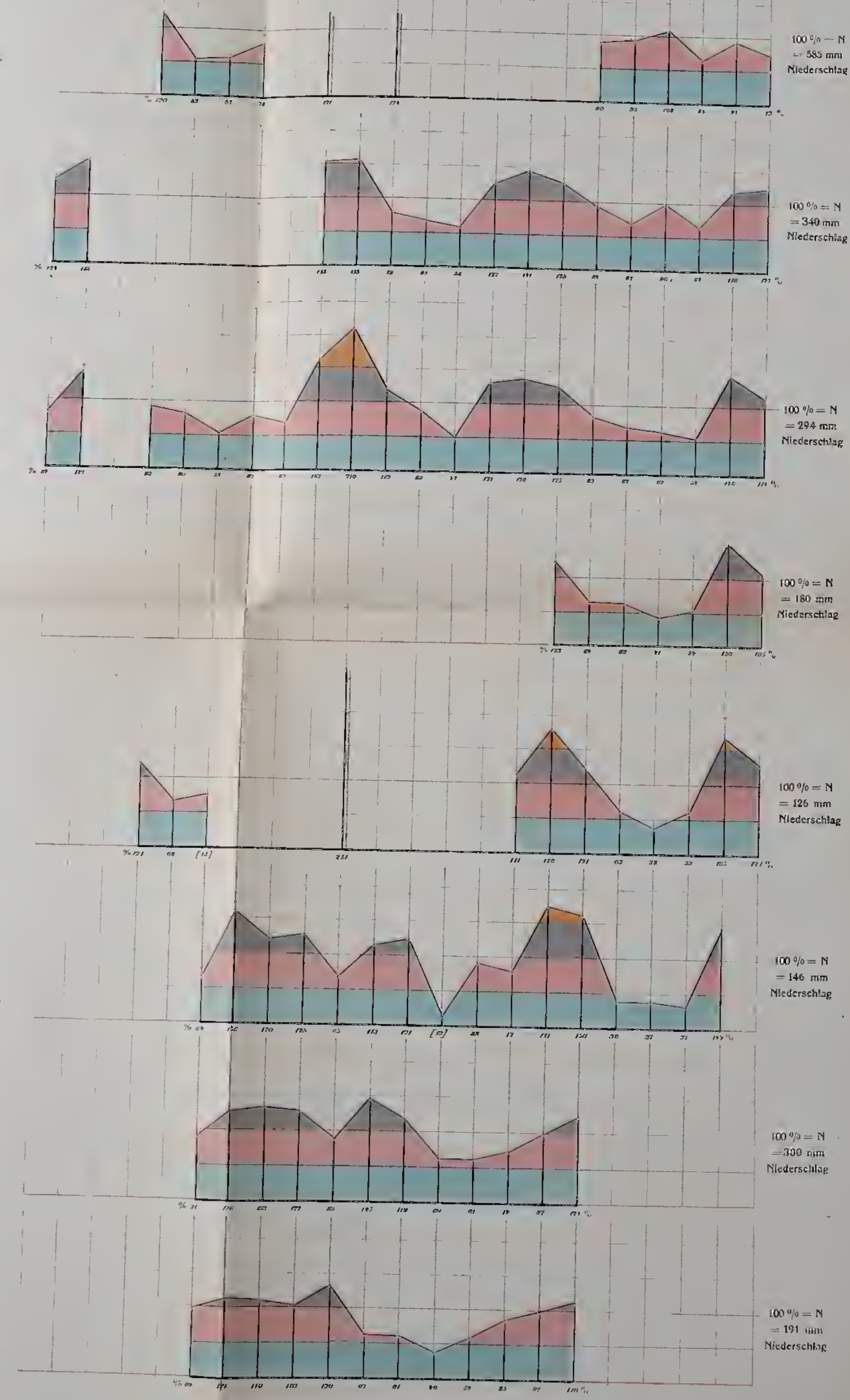
Liagramm $47-53$,

\section{a) monatliche Verteilung}

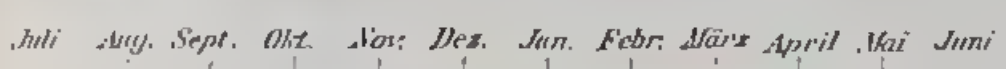

47 Oidkonda [5] N $-4.9 \mathrm{~mm} ; N=570 \mathrm{~mm}$
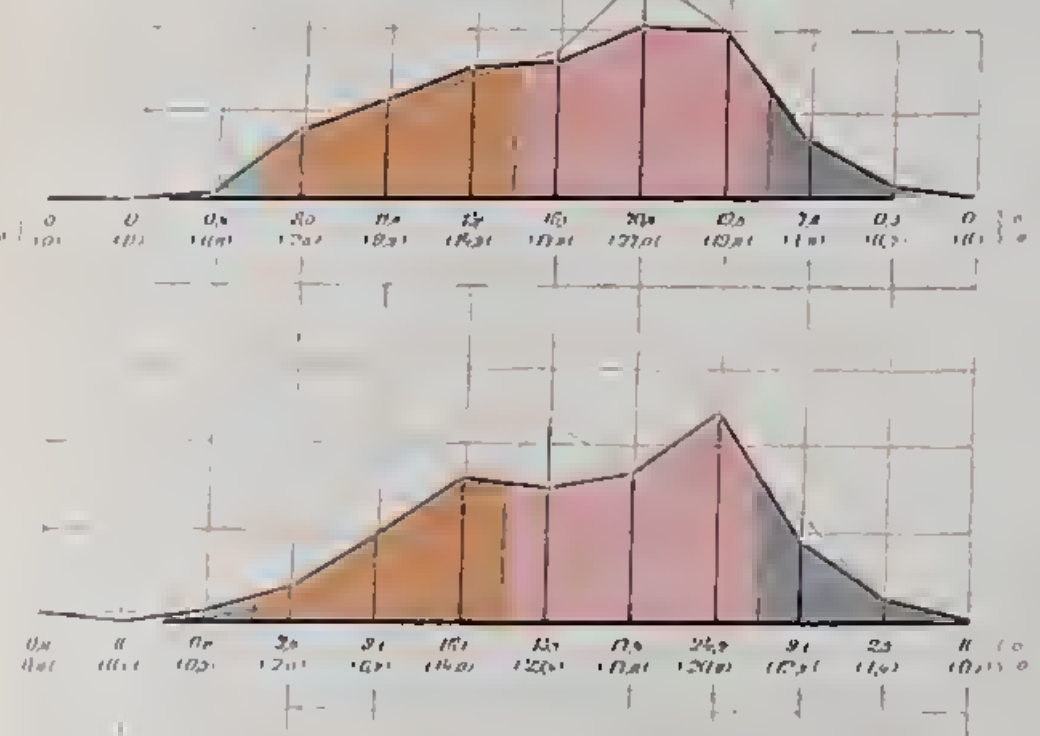

18 (ir. Windhuk $[36]$
$\mathrm{Tr}=52 ; \mathrm{Tn}-5]$ $M=38: 2 \mathrm{~nm} ; \mathrm{N}=357 \mathrm{~m}$

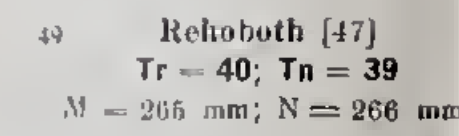

50 Port Nolloth [7.97 $\operatorname{Tr}=22$

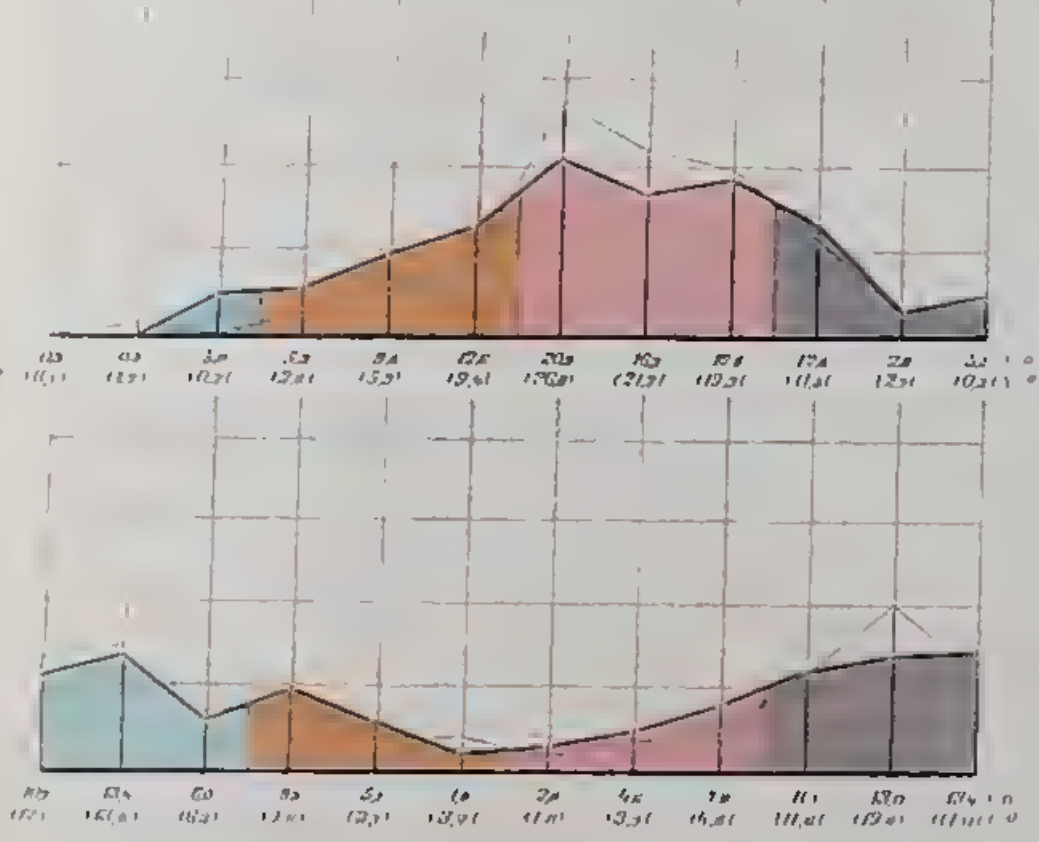

s)

Olukoula $[5]$

\section{b) jährliche Verteilıng}

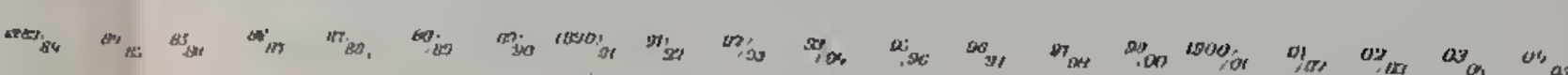

5? Gr. Windhnk $[35]$

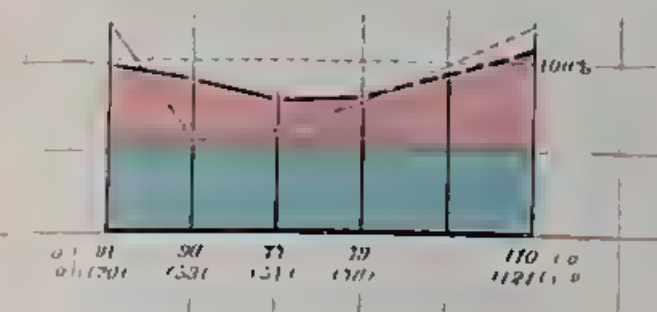

53 Reloboth [\$7]

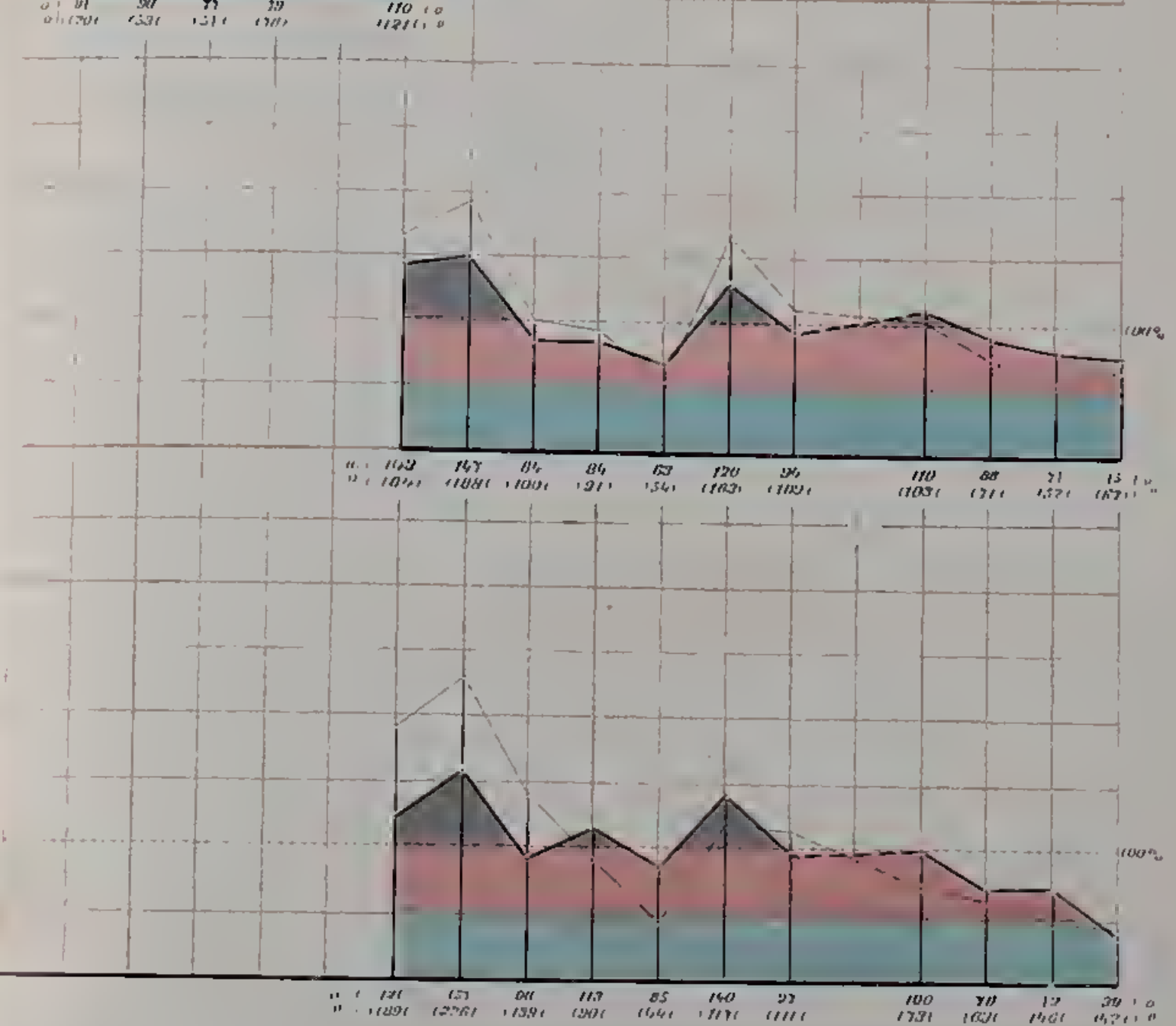

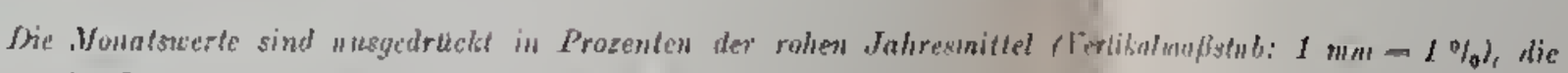

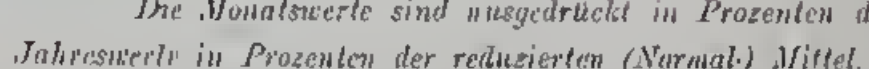

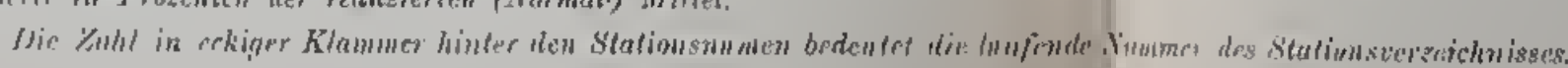

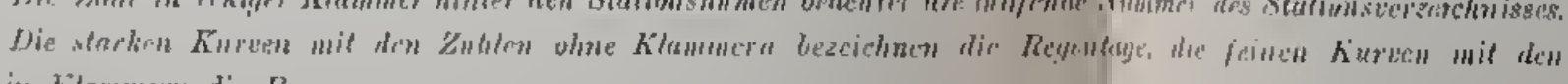
Zahlen in Klanmorn die Rrgenuengten.

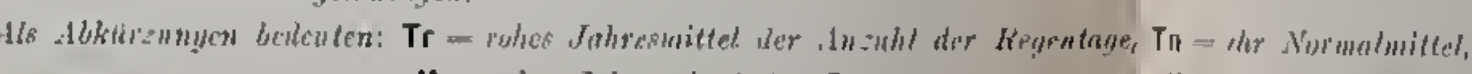

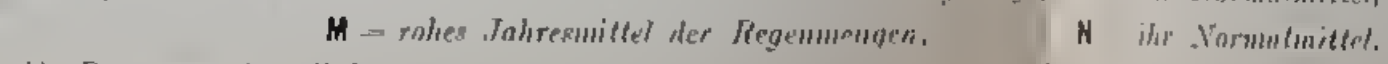




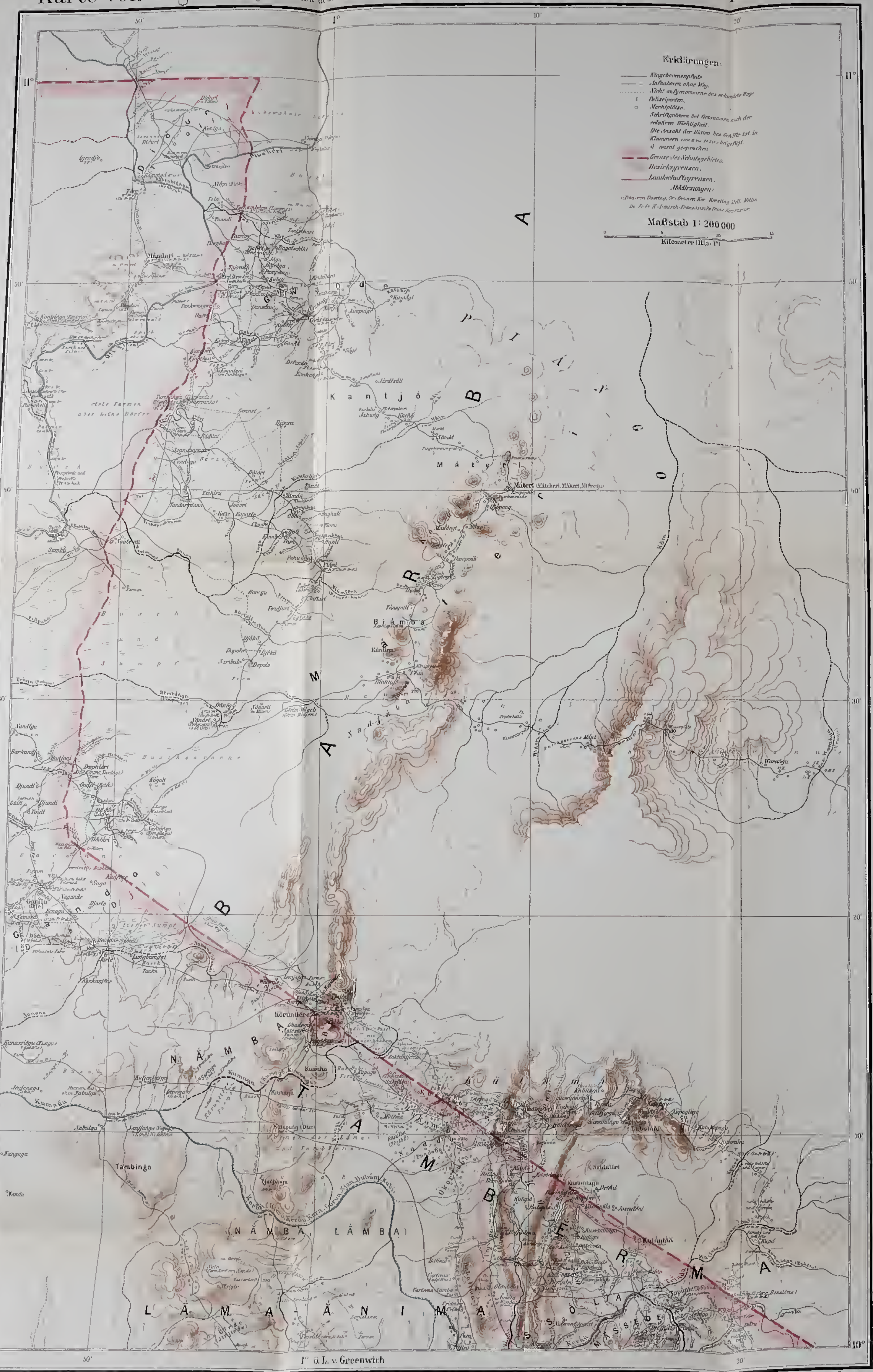




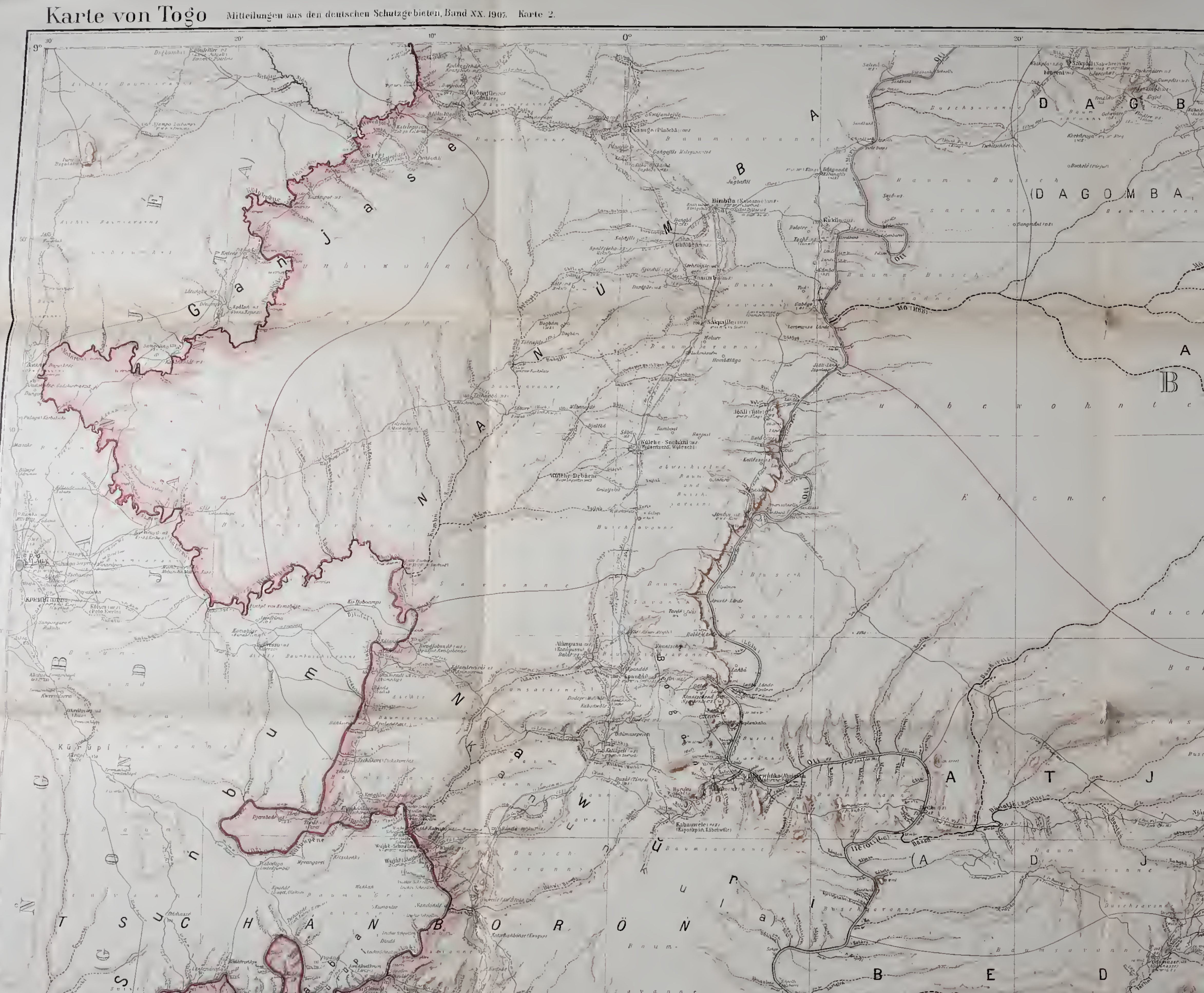


Die a) monatiche und b) jährliche Verteilung der Regentage und Rogenmengen in Südwestafrika.

Wingramm $4 \tau-53$.

8) monatliche Verteilung

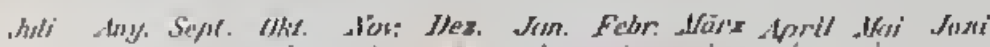

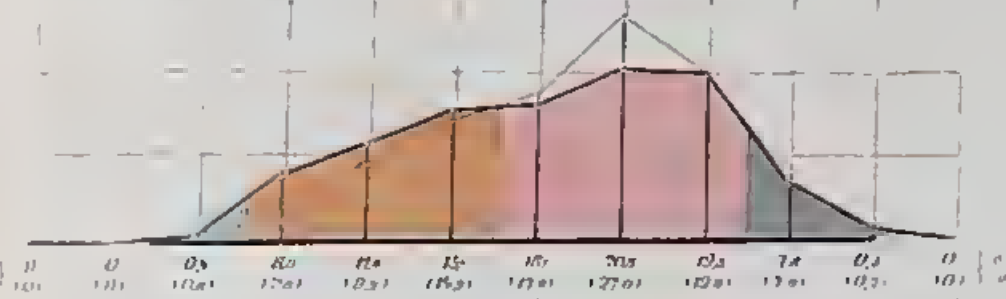

$T r=58 ; T_{n}=6$ (5) $M=4.4 \mathrm{~mm} ; \mathrm{N}=570 \mathrm{~mm}$

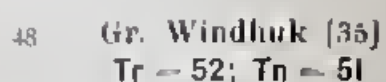

50 Port Nolioth [79] $\operatorname{Tr}=22$

Irchoboth [47] $\operatorname{Tr}=40 ; T_{n}=39$ B. $=205 \mathrm{~mm} ; \mathrm{N}=200 \mathrm{~mm}$ (1)

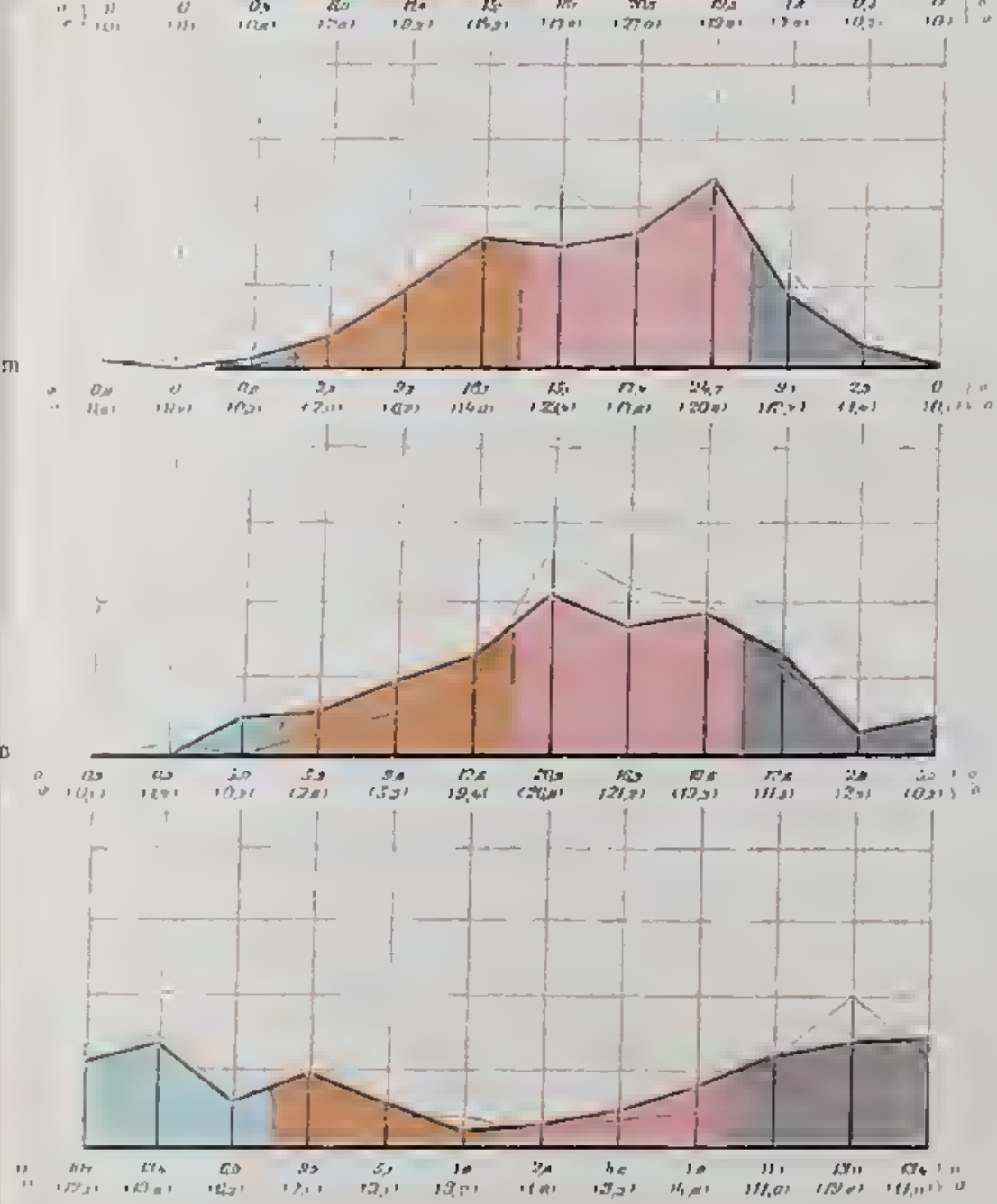

b) jährliche Verteilung

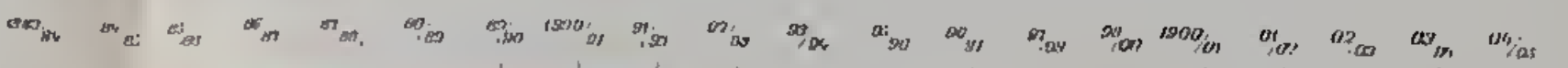

5) Olukonda [6]

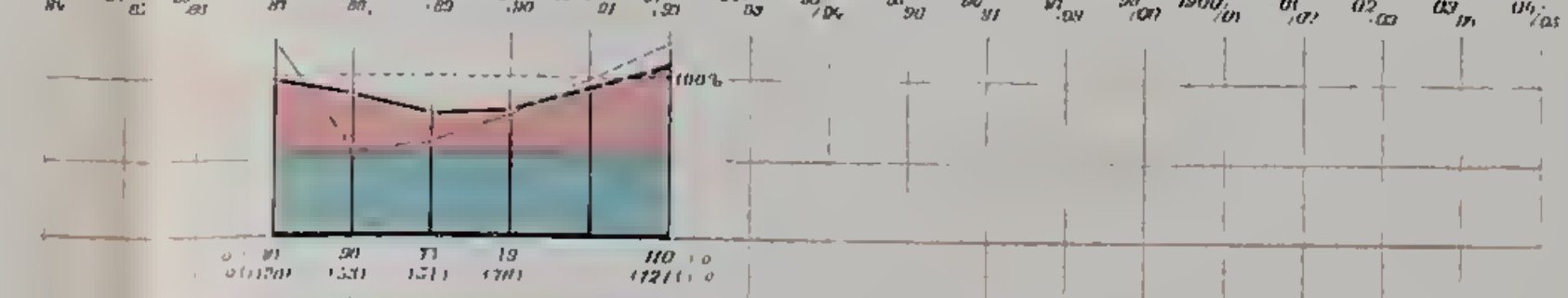

32 Gr. Windhuk $[35]$

3 Rehoboth [47]

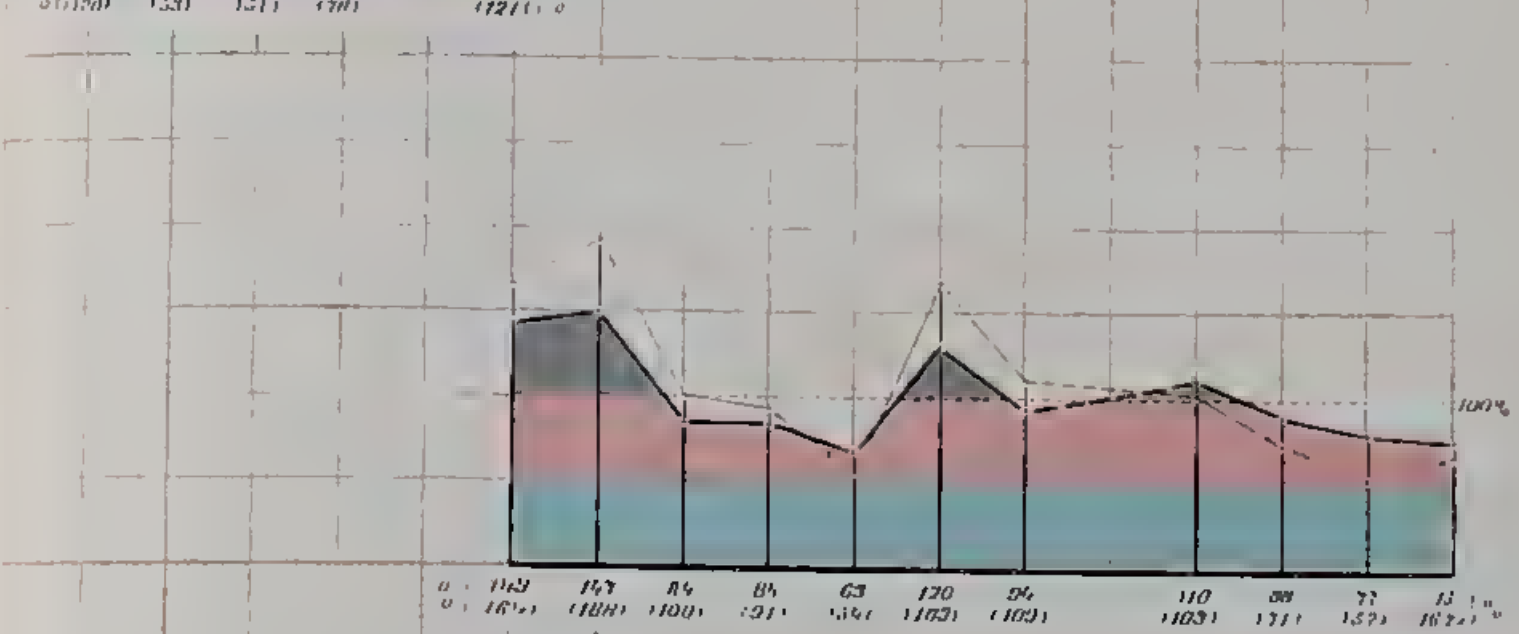

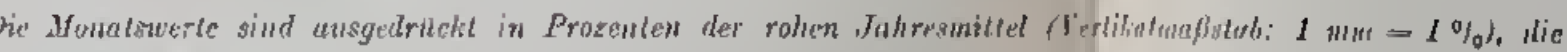

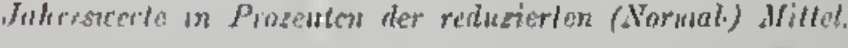

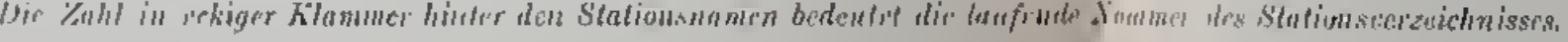

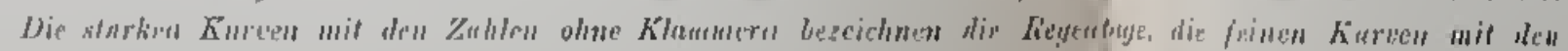

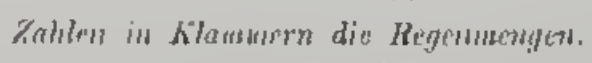

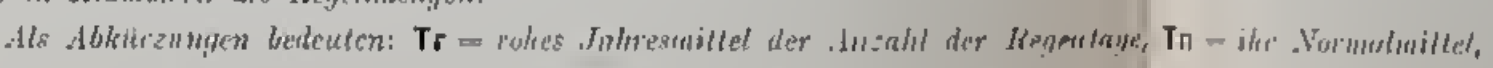

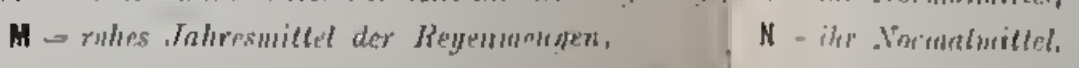




\section{NIEDERSCHLAGS - KARTE}

\section{DEUTSCH = SÜDWESTAFRIKA}

auf der topogr. Grundlage der von P.SPRIGADE u. M. MOISEL

bearbeiteten Kriegskara in 1:800000

entworfen von

E.OTTWEILER.

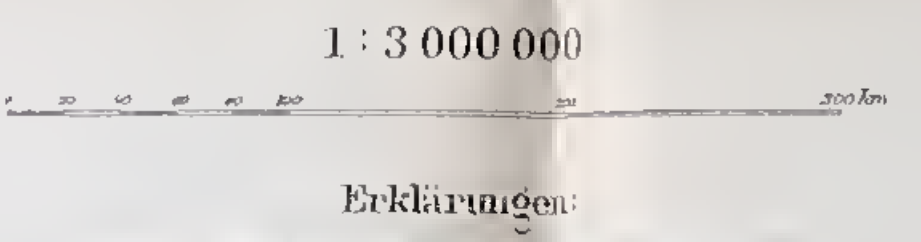

Mittlere jährliche Niederschlagsmengen in $\mathrm{mm}$

$\square$.

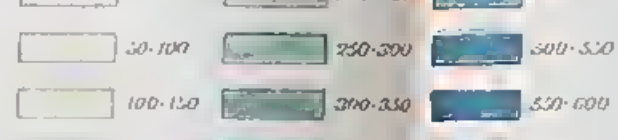

$\square_{1-1}^{150: 50200}$

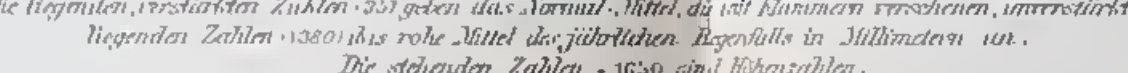

Durchschnittliche Anzahl der jährl. Regentage mil meßbarem Niederschlag in D.S.W.Afrika
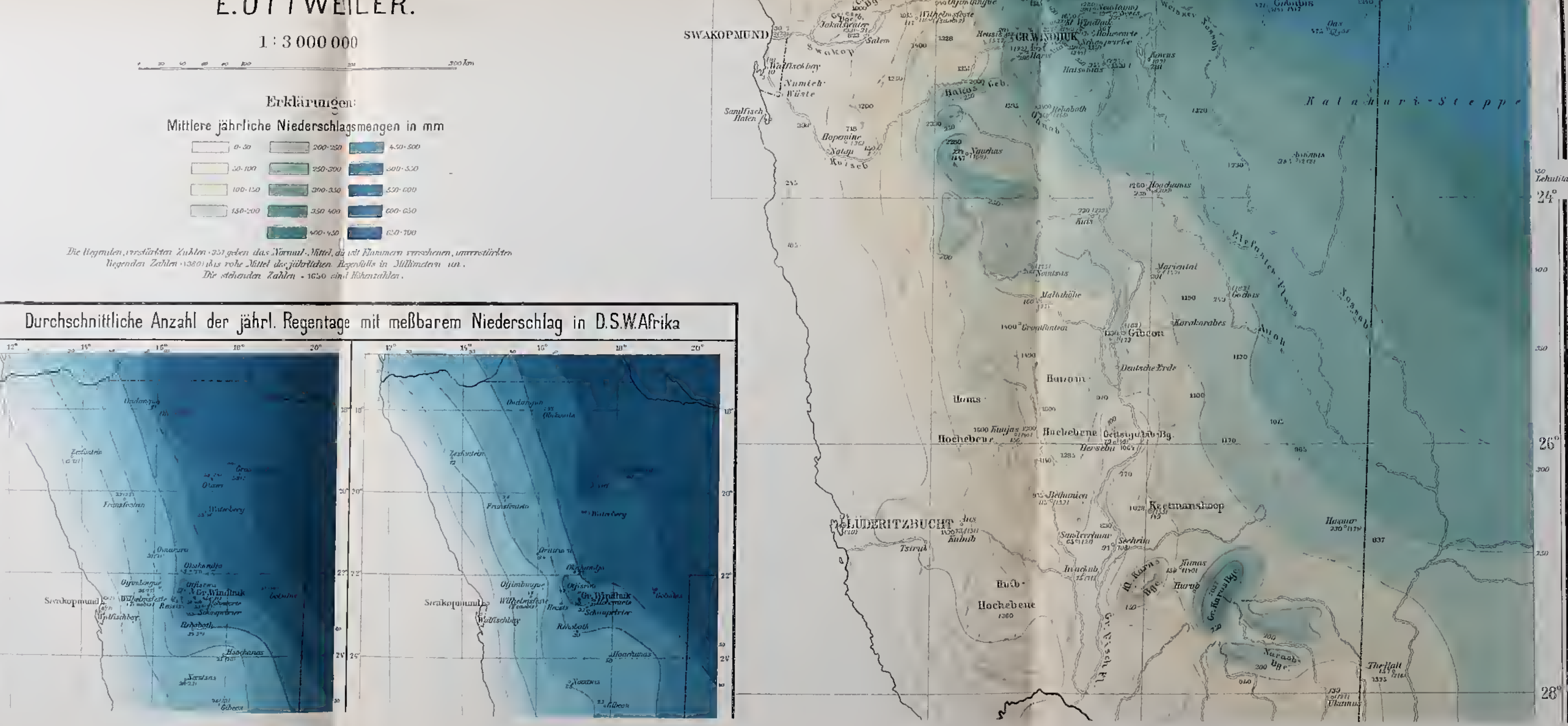


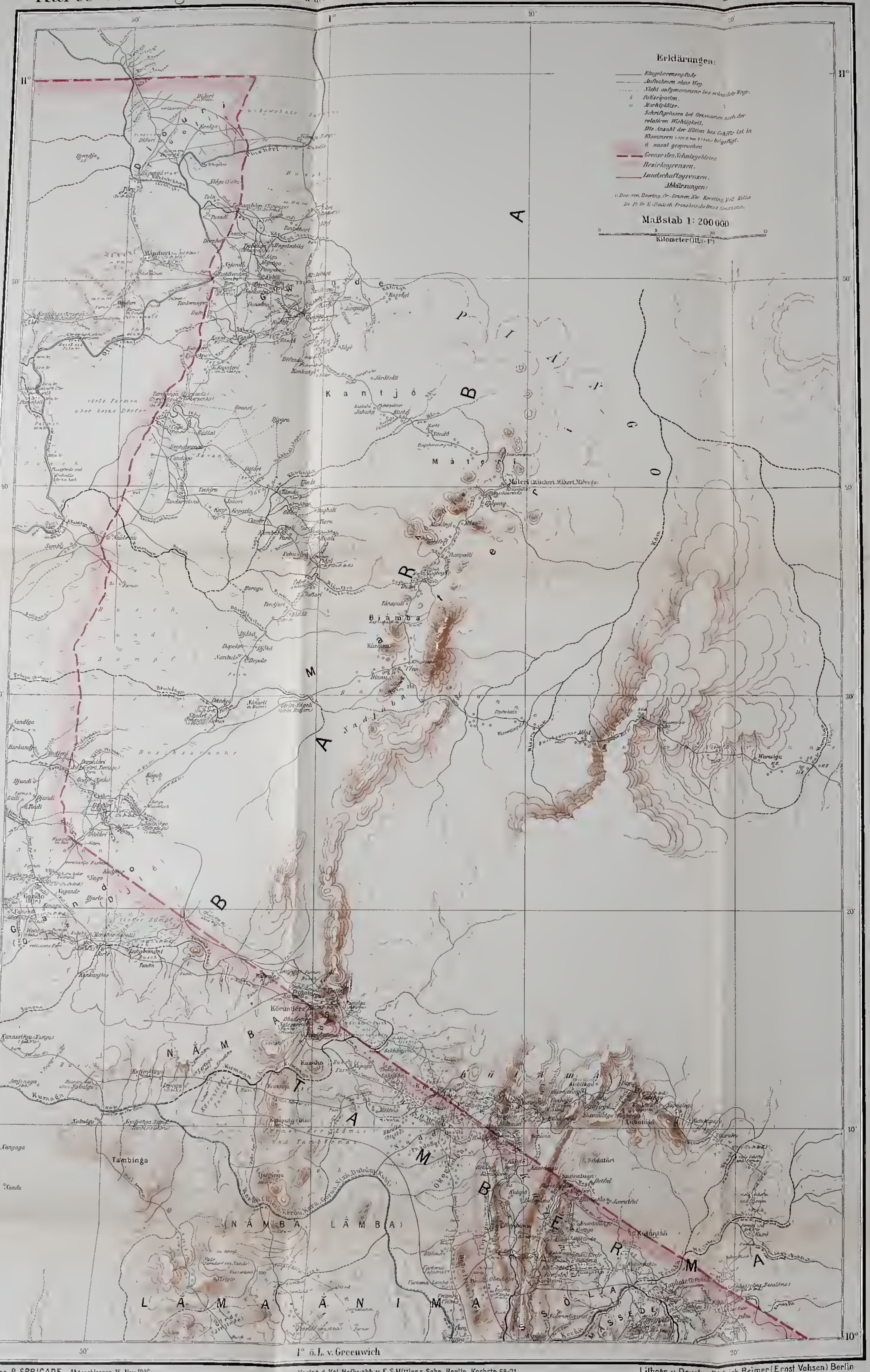




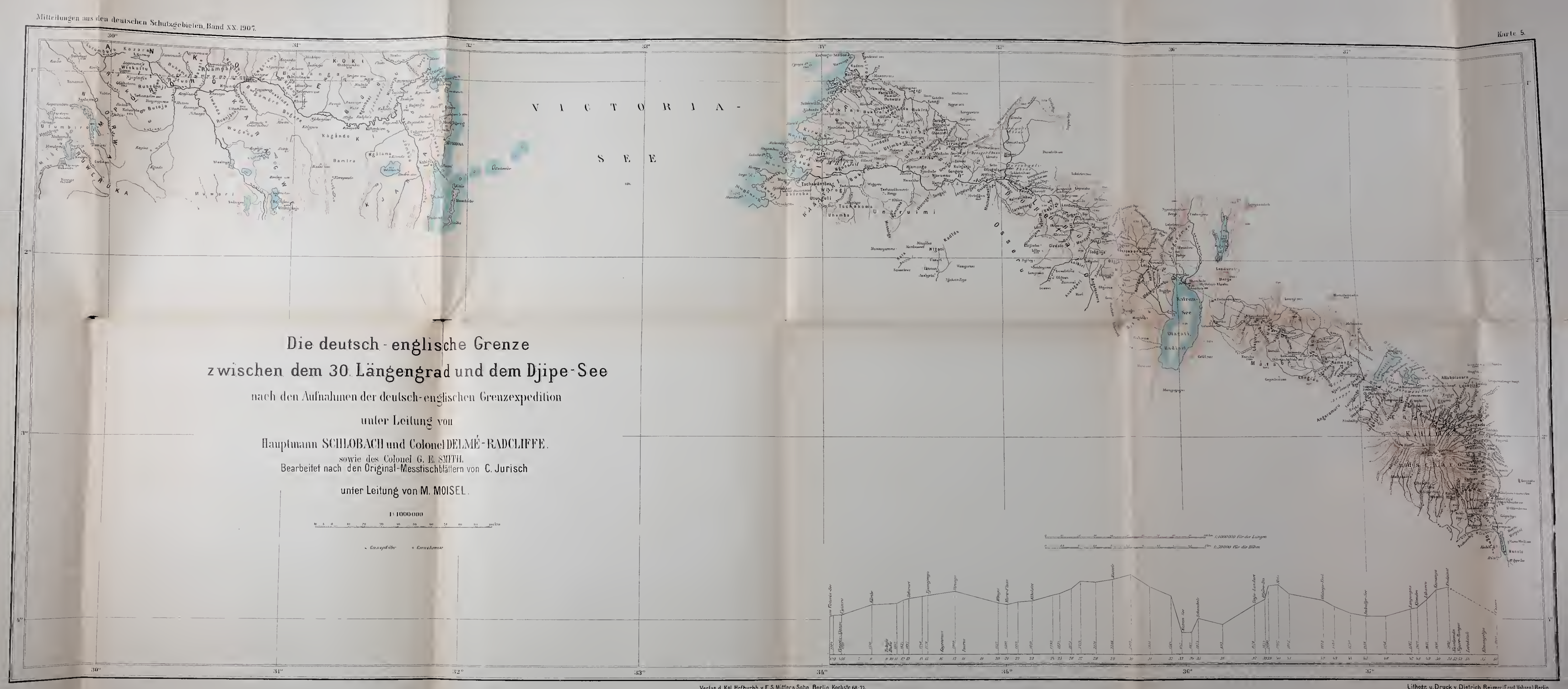


Mitteilungegen aus den deutschen Schutzegerbieten. Baand XX. 1907.

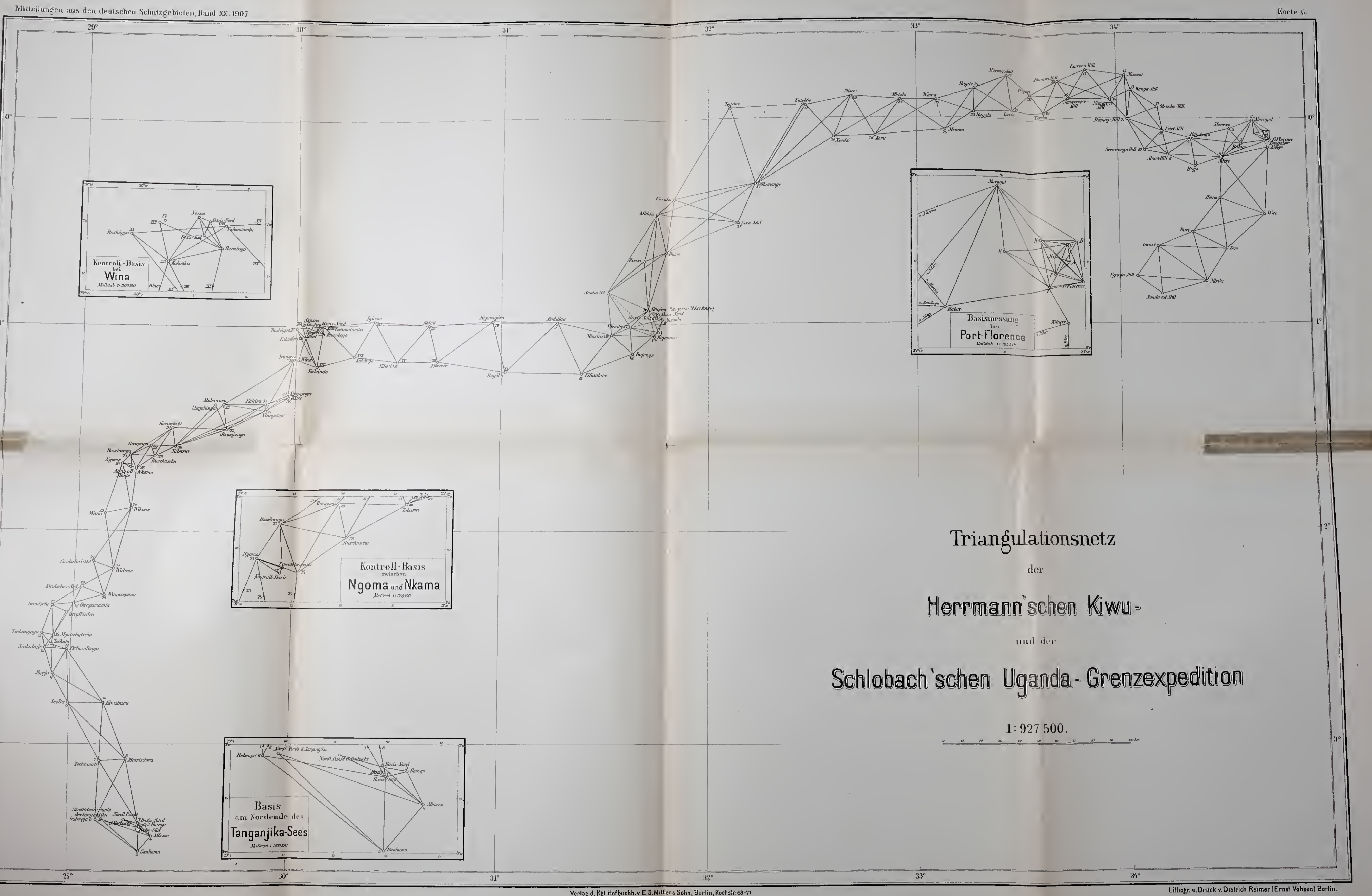




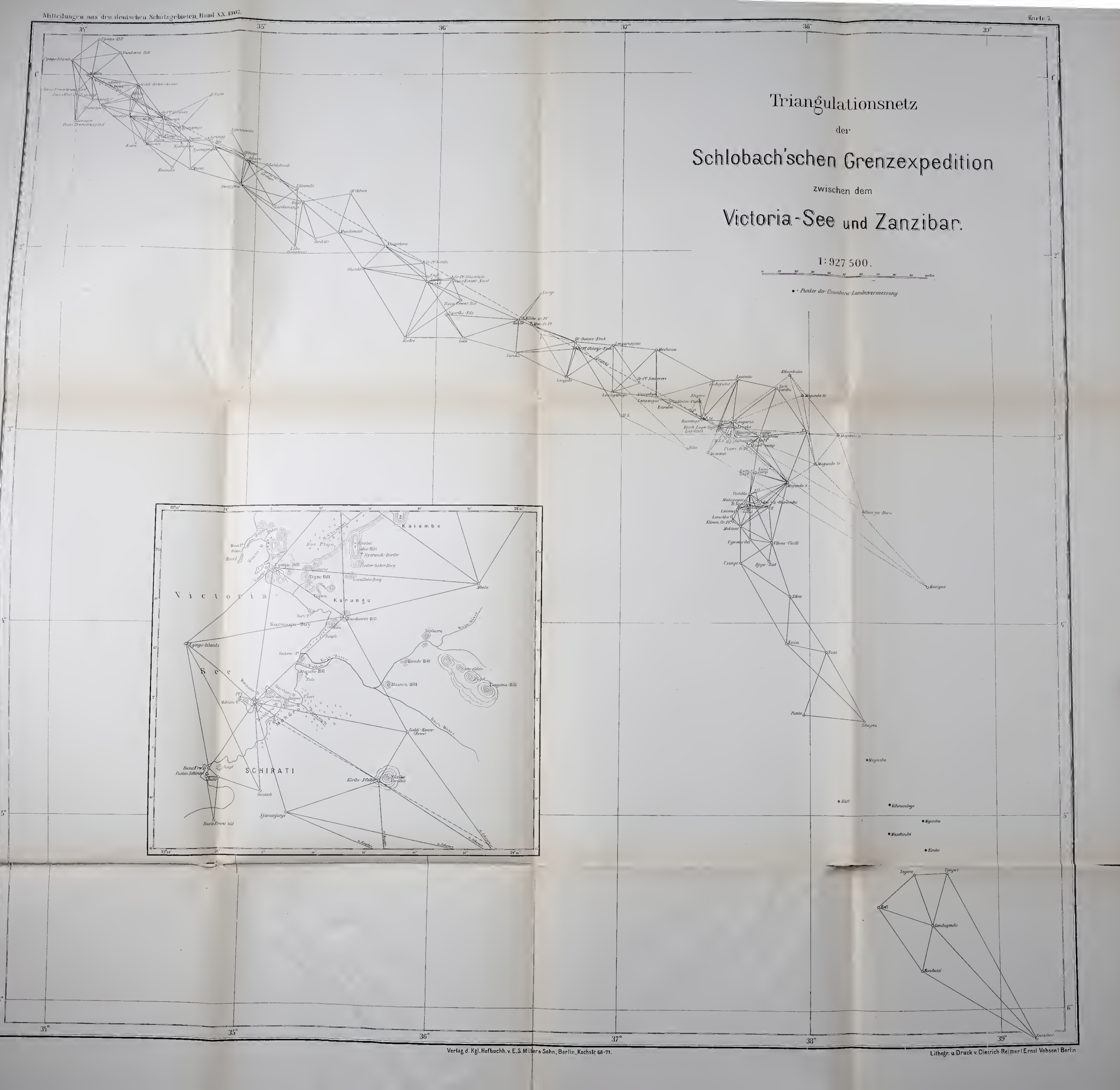




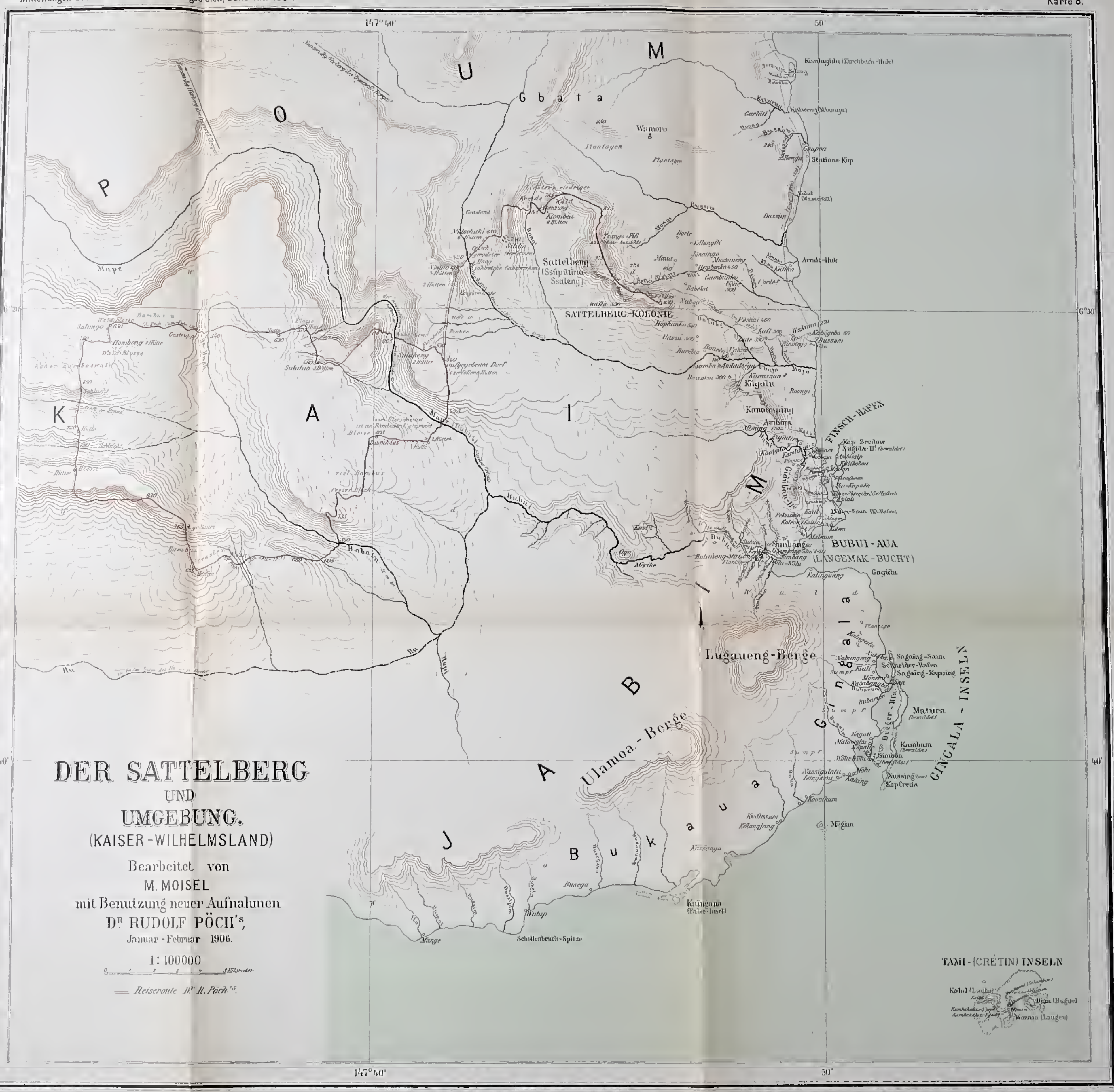




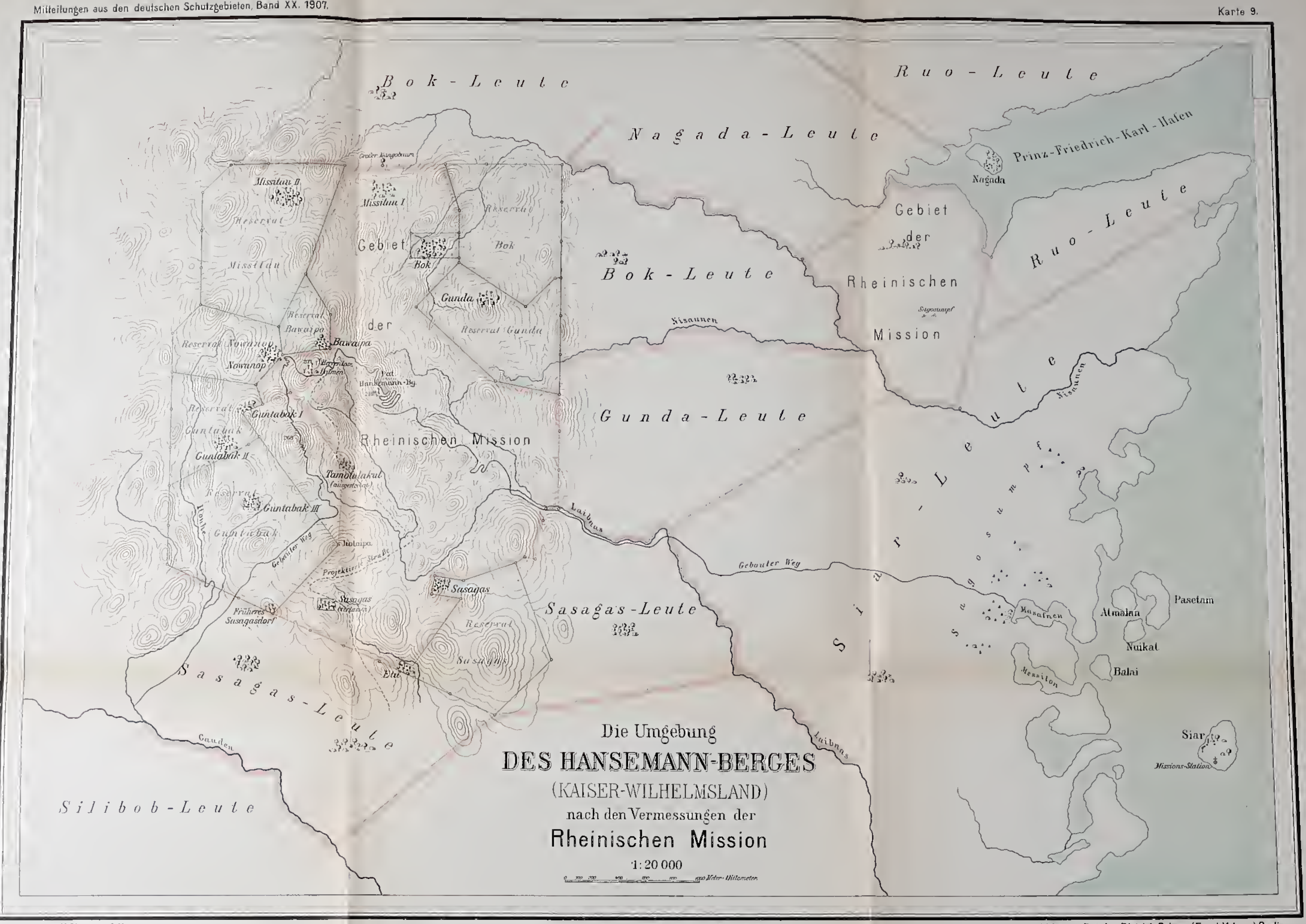




\section{PROVISORISCHE KARTE}

von Teilen der Bezirke

\section{OSSIDINGE, BAMENDA UND DSCHANG.}

Konstruirt u gezeichnet auf Grundlage der Aufnahumen

HAUPTMANN GLAUNING

u umit Bemutzung noreröffentlichter Aufnalmen

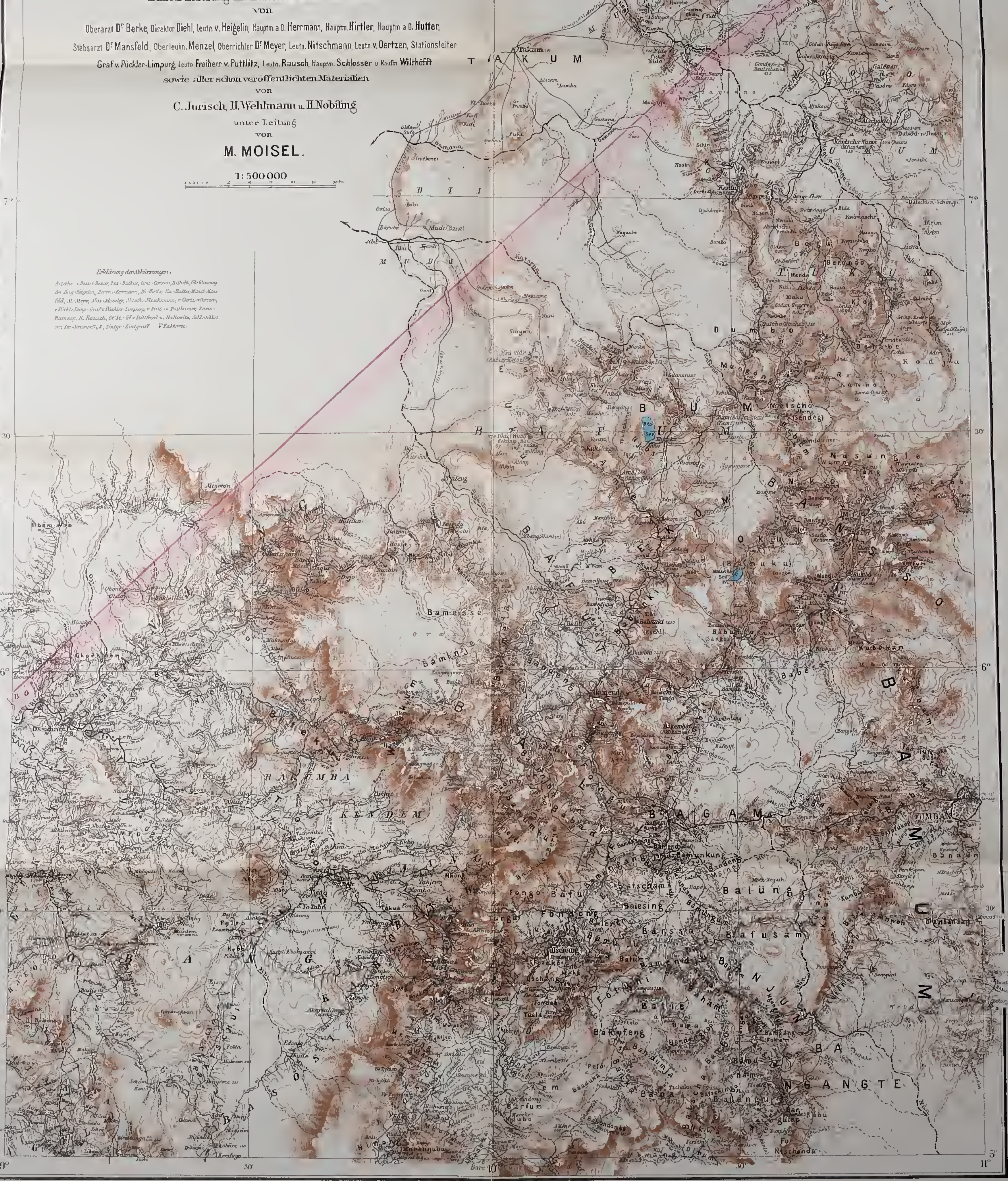


